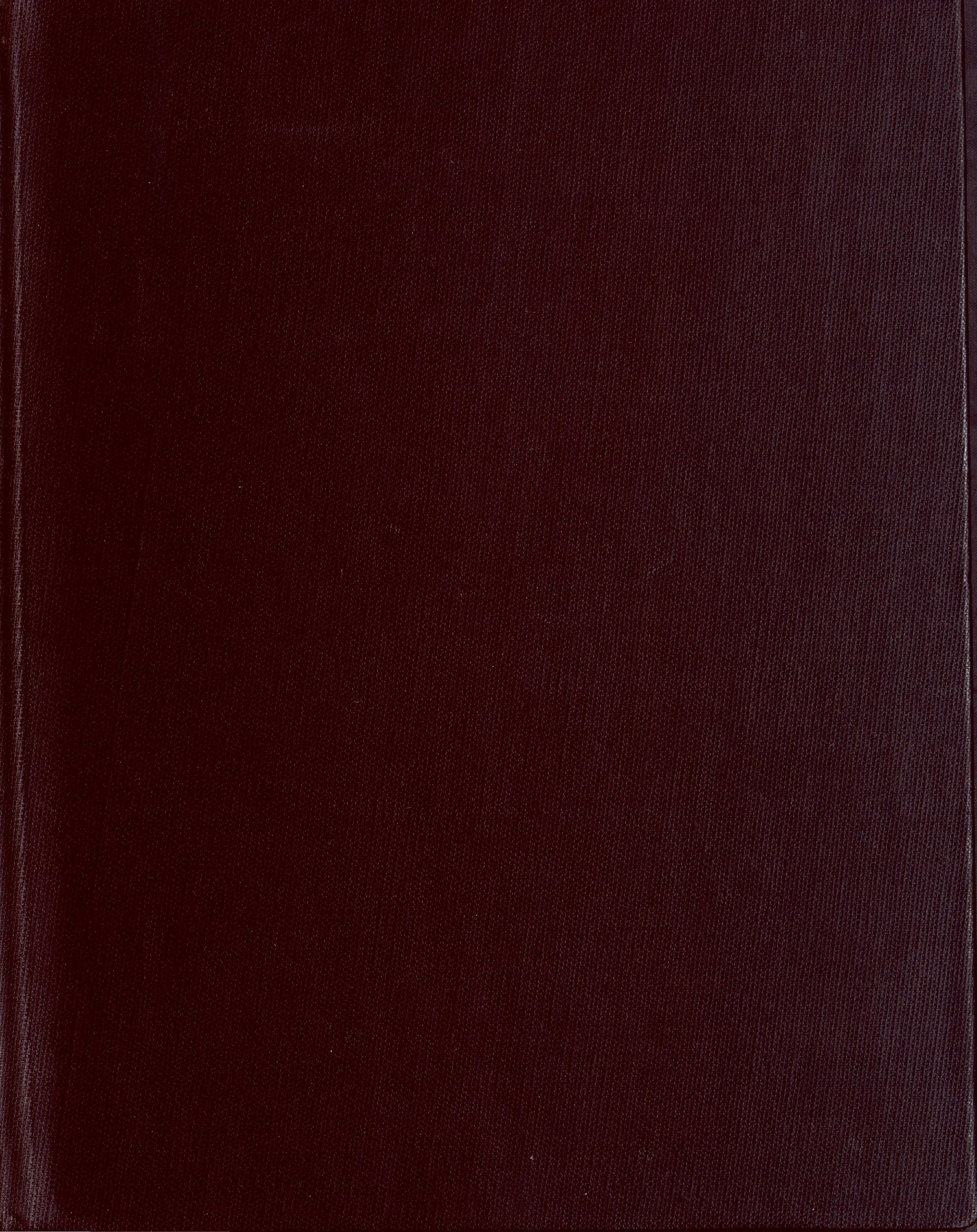




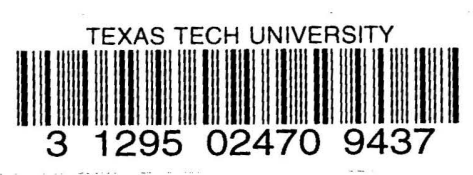




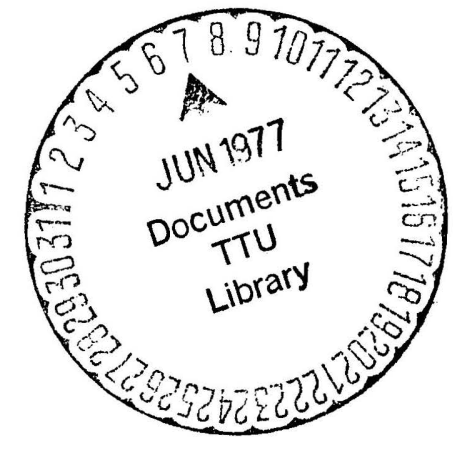







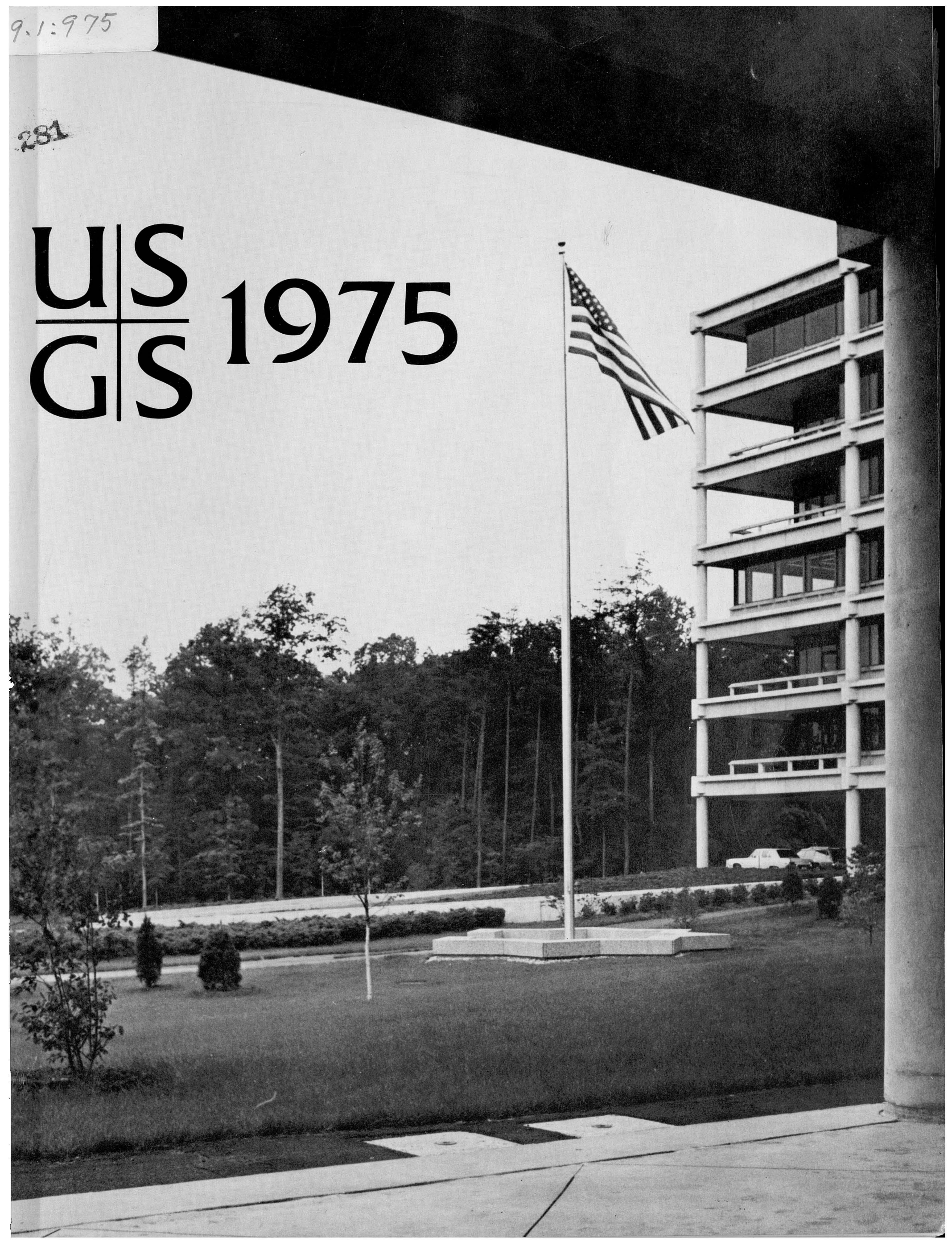





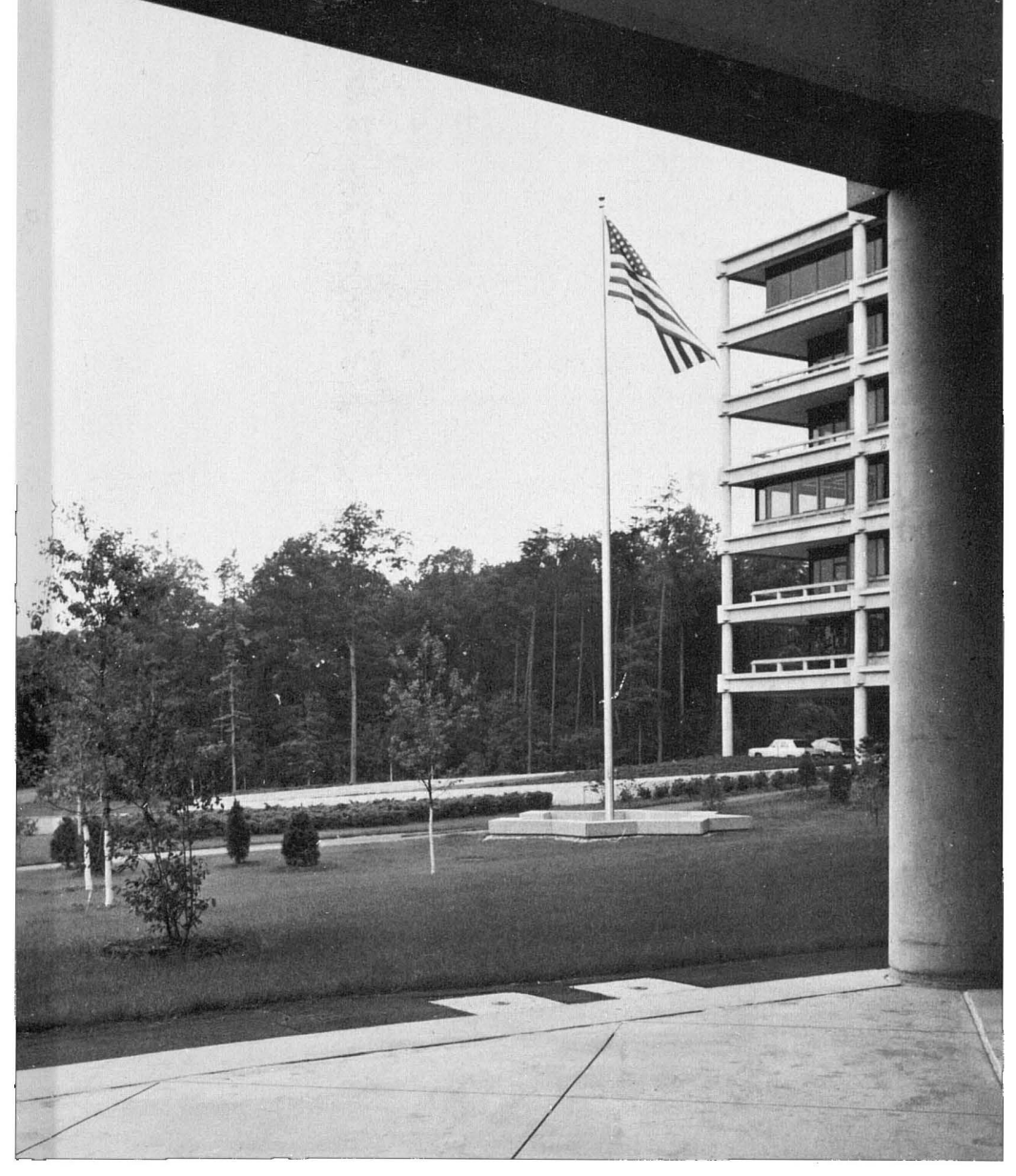

\section{United States Geolozical Survey Annual Report, Fiscal Year 1975}

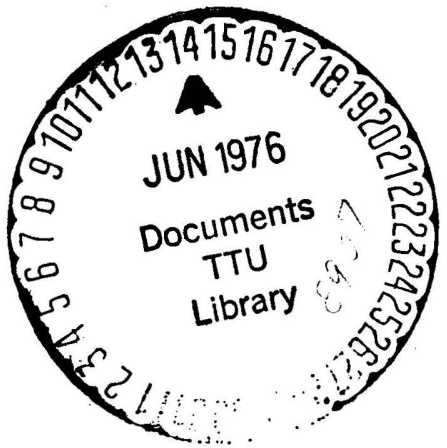


UNITED STATES DEPARTMENT OF THE INTERIOR

Thomas S. Kleppe, Secretary

\section{GEOLOGICAL SURVEY}

V. E. McKelvey, Director

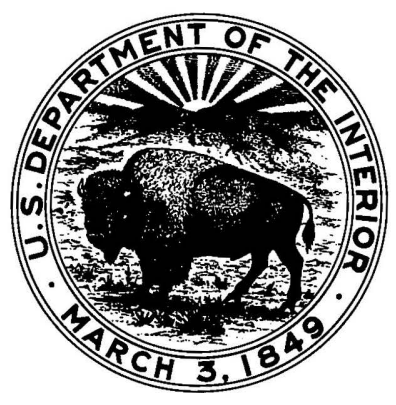

For sale by the Superintendent of Documents

U.S. Government Printing Office

Washington, D.C. 20402

STOCK NUMBER 024-001-02818-2 


\section{Preface}

In 1880, Director Clarence King submitted the First Annual Report of the United States Geological Survey to the Secretary of the Interior for transmittal to the Congress. The Geological Survey continued to publish an annual report through 1932, after which time the Survey's report was included as part of the Annual Report of the Secretary of the Interior. The format of the latter was changed to the current U.S. Department of the Interior Conservation Yearbook series in 1965. The last Annual Report of the Director, Geological Survey, to the Secretary of the Interior was for fiscal year 1963.

With the publication of United States Geological Survey Annual Report, Fiscal Year 1975, the Survey resumes the practice of annually summarizing the progress it has made in identifying the Nation's land, water, energy, and mineral resources, classifying federally owned mineral lands and waterpower sites, and in supervising the exploration and development of energy and mineral resources on Federal and Indian lands. The Annual Report for 1975 consists of five parts:

- The Year in Review-a review of the issues and events which affected Survey programs and highlights of program accomplishments.

- Perspectives-several short papers which address major resource issues and summarize recent advances in the earth sciences.

- A description of the Survey's budget, programs, and accomplishments.

- A set of statistical tables and related information which documents program trends, workloads, and accomplishments.

- A compendium of Survey publications and information services available to the public.

One purpose of this report is to increase public awareness and understanding of the Geological Survey's programs and, more generally, of the role of earth sciences information in helping to resolve many of the natural resource conflicts that face our society now and in the years ahead. To be useful, however, information must be available and readily accessible to those responsible for natural resource policy at the time that the decisions are made. This report emphasizes the types of information products and services provided by the Survey and tells how to obtain additional information.

Supplemented by Professional Paper 975, Geological Survey Research 1975, the latest in a series of annual reviews of technical results of the Geological Survey's research programs, the Annual Report provides a comprehensive description of the activities of the Federal Government's largest earth science agency.

The Geological Survey welcomes comments and suggestions for improving the content and format of this report. 


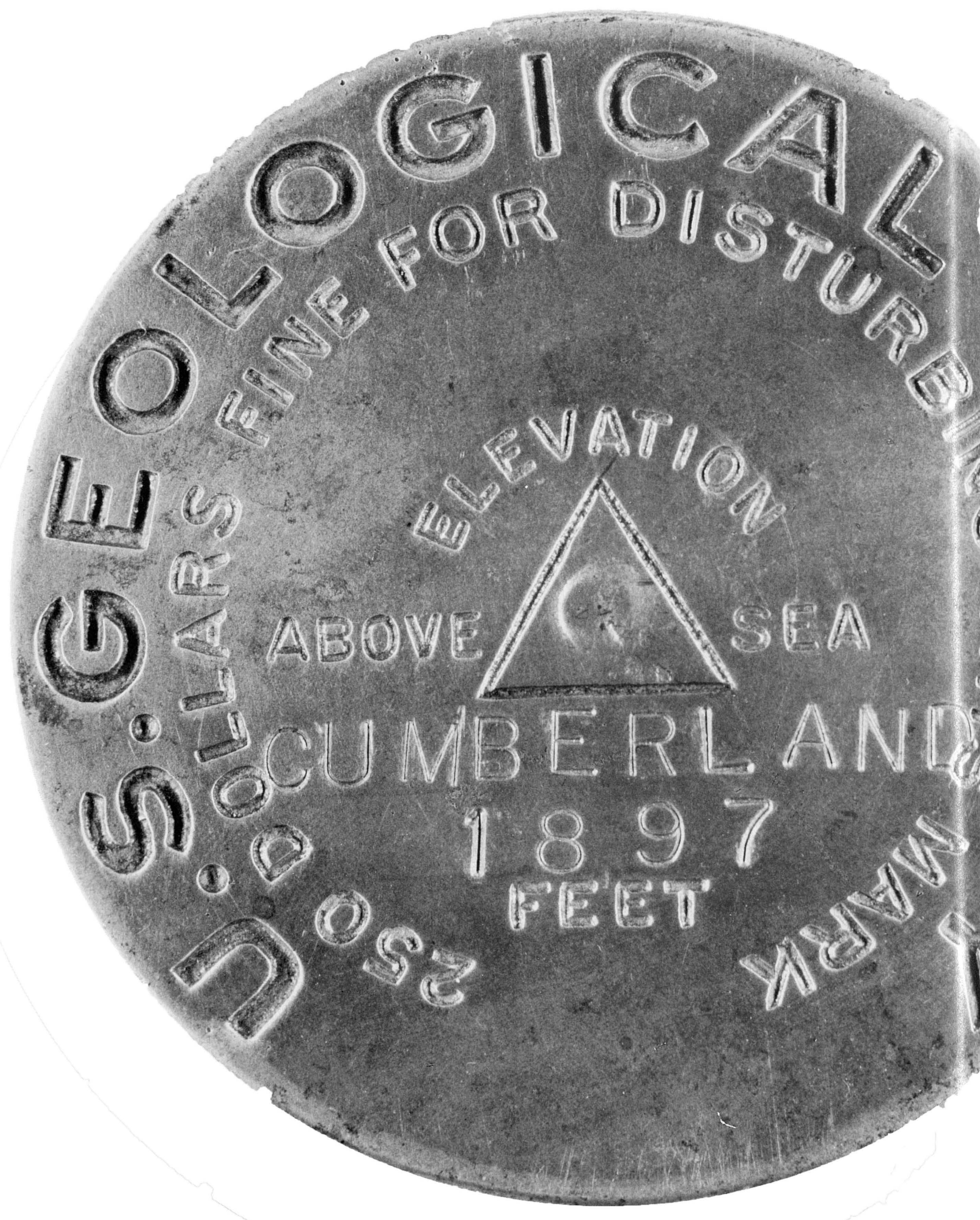


III -Preface

1 -The Year in Review

7 - Perspectives

The Future of Earthquake Prediction

Estimates of Undiscovered Petroleum Resources -A Perspective

Earth Sciences and the Urban Environment

31 - Missions, Organization, and Budget

39 - Topographic Surveys and Mapping

53 - Geologic and Mineral Resource Surveys and Mapping

79 - Water Resources Investigations

99 - Conservation of Lands and Minerals

$119 \cdot$ Land Information and Analysis

135 - Program Support Activities

141 - Organizational and Statistical Data Tables 25 through 57

181 - Guide to Publications and Information Services 

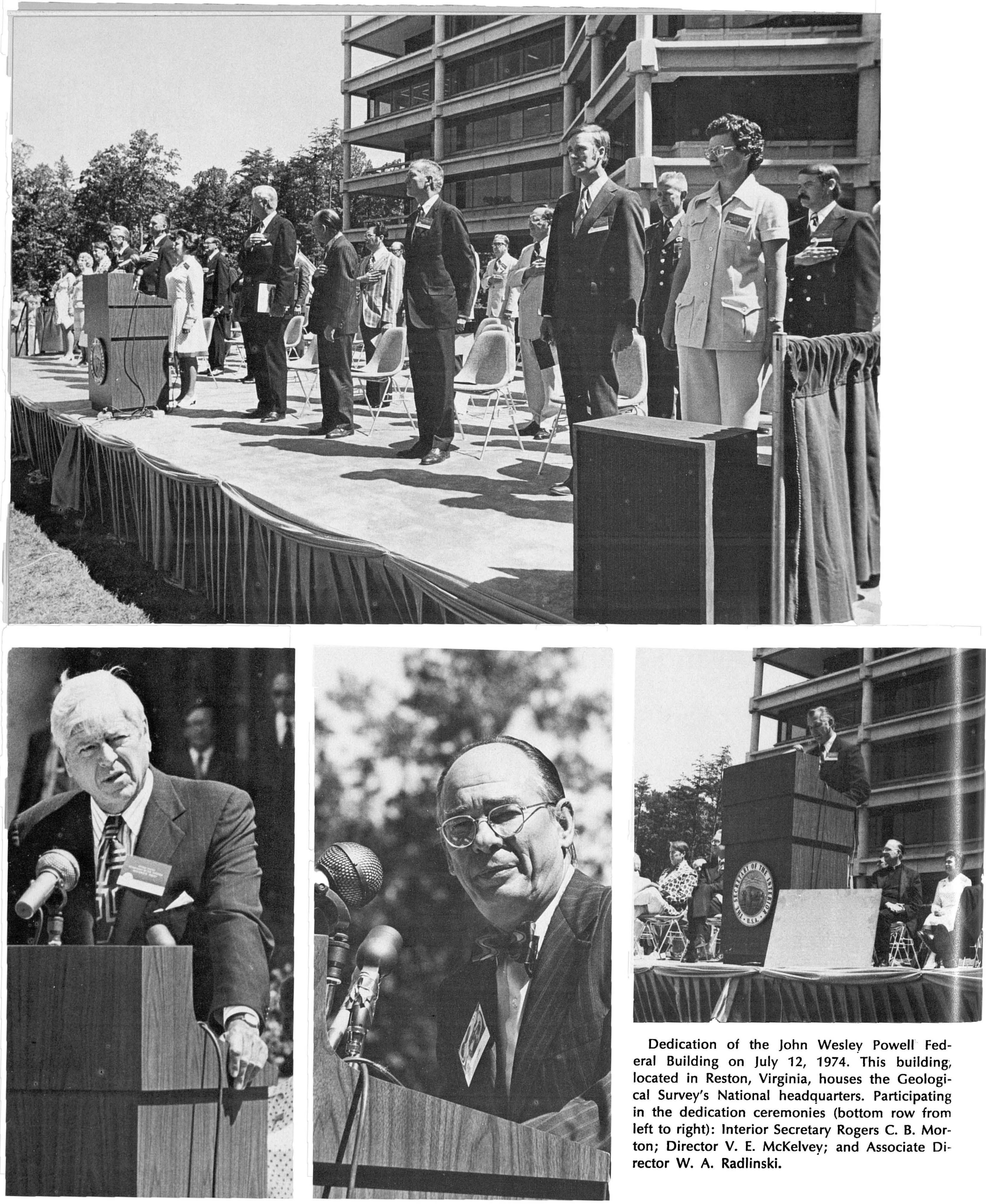

Dedication of the John Wesley Powell Federal Building on July 12, 1974. This building located in Reston, Virginia, houses the Geological Survey's National headquarters. Participating in the dedication ceremonies (bottom row from left to right): Interior Secretary Rogers C. B. Morton; Director V. E. McKelvey; and Associate Director W. A. Radlinski. 


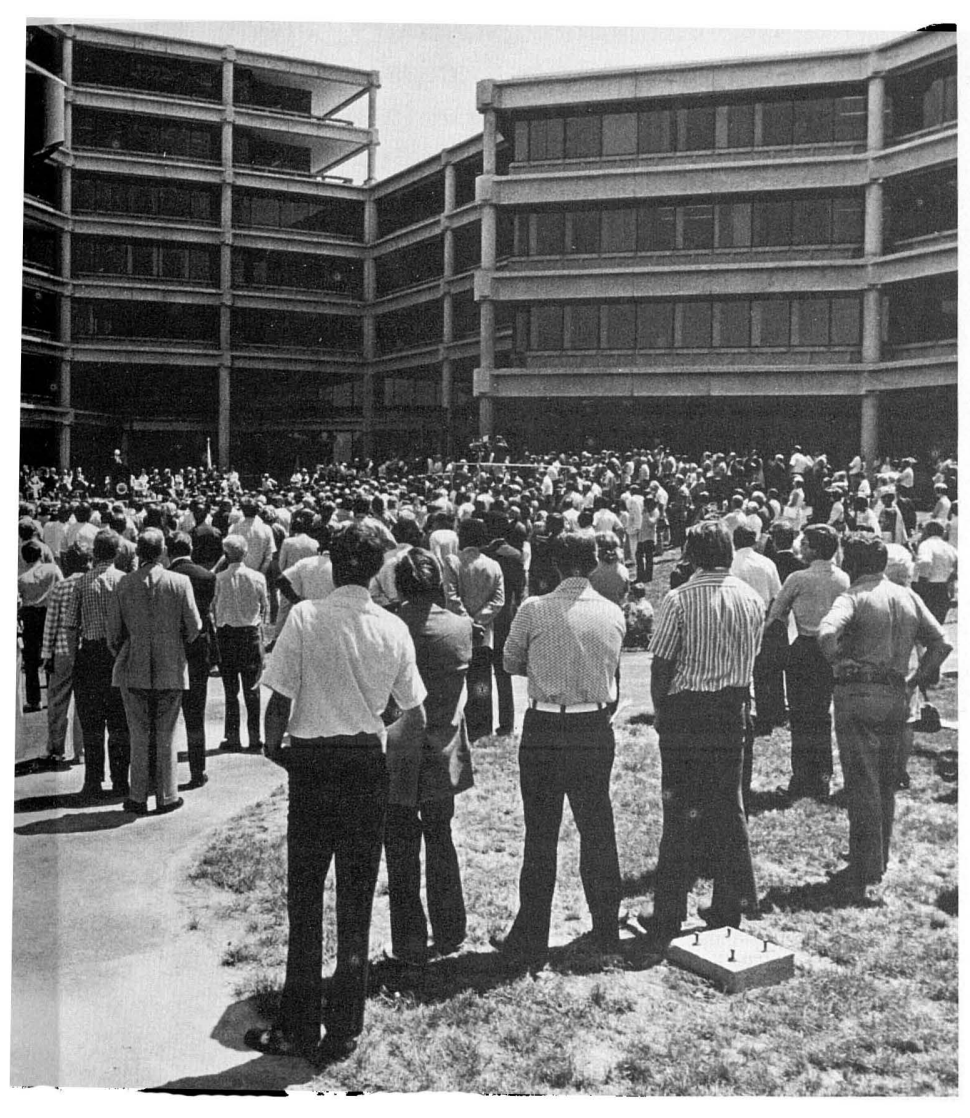

During fiscal year 1975, programs of the U.S. Geological Survey continued to grow in response to the increasingly complex demands for scientific information of a Nation faced with current and potential shortages of energy and minerals, conflicts between competing users of land and water resources, wellfounded public concern about the environmental consequences of resource development, and the needs of a population growing in both numbers and in expectations for an improved standard of living and a better quality of life.

Perhaps at no other time in the Geological Survey's 96-year history have national interest and concern about natural resources been as great and intense as they have been during the past several years. This interest and concern affected virtually every activity and program and placed the Geological Survey in the unaccustomed spotlight of public attention. During fiscal year 1975, for example, the Geological Survey answered nearly a quarter of a million public inquiries about its programs, and Survey witnesses participated in some 30 Congressional hearings on subjects such as oil and gas reserve estimates, Federal coal leasing policy, Outer Continental Shelf oil and gas activities, and strip-mining legislation.

Historically, the Geological Survey has had two missions: to provide information about the Earth and its physical resources, and to regulate the activities of

\section{The Year in Review}

lessees engaged in extracting minerals from the public lands. In practical terms the discharge of these responsibilities has required extensive and continuing investigations of the location, character, and extent of the Nation's mineral, land, and water resources; a continuing program of topographic mapping; and the classification of the mineral and water potential of Federal lands to assure that private parties developing mineral leases meet appropriate standards of safety, environmental protection, and resource conservation, and that the public receives a fair return from the development of its resources.

The budget of the Geological Survey for fiscal year 1975 reflects the strong influence that current resource problems have had on the Survey's traditional missions. Major emphasis has been placed on developing a full range of mineral and energy resource assessments, defining the actual and potential environmental impacts of energy development, and strengthening capabilities to supervise the exploration and development activities implicit in a substantially enlarged oil and gas leasing program for the Outer Continental Shelf. Other programs selected for emphasis are aimed at improving identification of natural hazards, including earthquakes, floods, and volcanic activity, and developing land resource planning tools such as orthophotoquads and land use maps. Especially significant has been the effort to 
make the products of the Geological Survey more meaningful to decisionmakers and to the public by collecting, interpreting, and displaying land resource information in forms that are easily understandable to a wide range of users. Public access to map and water-resources information was further enhanced by the establishment of information centers to serve as focal points for users who wish to obtain specific and timely data. These and other highlights of fiscal year 1975 are described below.

\section{ENERGY}

No demand for resource assessment is currently more compelling than that for oil and gas, not only as a guide to policy decisions such as timing, location, and extent of offshore lease sales, but also for what the assessments may disclose about the potential location and size of critically needed domestic oil and gas supplies. In fiscal year 1975 the Geological Survey launched a major effort, at the request of the Federal Energy Administration, to estimate the undiscovered recoverable petroleum resources of the United States. The talents of 70 petroleum specialists were used to develop estimates for 102 different petroleum provinces in the United States and its Continental Shelf to a water depth of about 200 metres (660 feet). Their findings, based on the assumption that technology, prices, and other economic conditions prevailing in 1974 remain unchanged, indicated that undiscovered recoverable resources range between 50 and 127 billion barrels of oil; 9.12 and 18.6 trillion cubic metres (322 and 655 trillion cubic feet) of natural gas; and 11 to 22 billion barrels of natural gas liquids. The significance of these estimates and their relation to other estimates are described in "Estimates of Undiscovered Petroleum Resources-A Perspective" in the next chapter.

The accelerated Outer Continental Shelf Leasing Program-a major action program in the Nation's effort to reduce its dependence upon foreign oilplaced heavy strains upon the Geological Survey as the amount of Outer Continental Shelf land offered in lease sales during calendar year 1974. increased by 230 percent over the amount offered in 1973. This was followed by another increase of 45 percent in calendar year 1975. More than 1,370 lease tracts covering 29,330 square kilometres $(11,325$ square miles) were evaluated in connection with offshore lease sales conducted during calendar year 1975 . The amount of land under the Survey's supervision also increased during calendar years 1974 and 1975 by 29 and 15 percent, respectively. In preparation for future lease sales in Outer Continental Shelf frontier areas, million square kilometres $(540,000$ square miles) located in 17 Continental Shelf areas.

With new petroleum resources increasingly difficult to find, coal has become a very attractive alternative energy source. During fiscal year 1975, geologists mapped 1,900 square kilometres (733 square miles) of coal-bearing lands in Wyoming, Montana, West Virginia, Kentucky, and Pennsylvania to locate coal deposits in these areas. The results of this work, much of it done on Federal lands, will assist planners in both the public and private sectors to determine what areas are most promising for future leasing when resumed.

Geological mapping was also completed on 4,800 square kilometres $(1,850$ square miles) of oil shale lands to support the Survey's land classification and tract evaluation activities and to provide the basis for appraising the engineering and environmental problems associated with oil shale mining. During 1975, four companies submitted their initial exploration plans under the Department of the Interior's Prototype Oil Shale Leasing program. Since little is known about the environmental effects of commercial oil shale mining and processing technology, the Bureau of Land Management, the Geological Survey, and the lessees are carefully monitoring air and water quality and collecting baseline environmental data upon which to base guidelines for future operations.

During the year, the first national assessment of geothermal resources was prepared in cooperation with the Energy Research and Development Administration. The assessment concluded that geothermal energy could be a very significant factor in the regional energy supply of those areas where it occurs. By the end of calendar year 1975, 552 leases had been awarded. Although none of these are yet in a producing status, the first commercially producible geothermal well on Federal lands was completed in May 1975, near the Castle Rock Springs area in California, and a potentially producible well was completed in June 1975, at Roosevelt Hot Springs in Utah.

Assessing the environmental aspects of energy cievelopment is also an important part of the Geological Survey's energy program. The extraction and use of energy resources and the planning, siting, and construction of energy conversion and distribution facilities lead to many environmental problems. Survey activities are directed towards providing geologic, hydrologic, geophysical, and geochemical data that will be of use in the analysis and solution of these problems.

Work continued during the year on national environmental overview maps which show the extent and frequency of occurrence of geologic processes and events which may pose constraints to land use and to energy and mineral resource development. 
During fiscal year $1975,90,000$ square kilometres $(34,750$ square miles) in the Rocky Mountains and the northern Great Plains were thus mapped. Activities also included the collection of environmental baseline data, studies of landslide incidence and susceptibility in the Appalachian bituminous coal region, and studies of erosion and weathering rates.

The drive to develop the Nation's energy resources, particularly in the arid West, also focused attention on the availability of water required to mine, transport, and convert energy resources, and, of equal importance, the effects of such use upon regional water sources, water quality, and upon present users. During 1975, efforts were started in 22 States to answer such questions. Most of the initial effort concentrated on establishing data collection sites to determine baseline conditions prior to development, arranging for exploratory drilling, and making aquifer tests.

Environmental investigations on the Outer Continental Shelf were directed towards identifying faults, slumps, sand waves, and other bottom features which might pose a hazard to offshore energy development.

\section{MINERALS}

The need for comprehensive resource assessments of minerals continues. Not only is the Nation's dependence upon foreign sources increasing, but millions of hectares of public lands remain to be classified as to mineral potential. Work completed in the Nabesna quadrangle in Alaska identified significant potential for copper, molybdenum, gold, silver, and several nonmetallic commodities. Studies of 12 additional Alaskan quadrangles are in progress or scheduled. Commodity studies are also in progress for critical minerals and for minerals required to develop, produce, and distribute energy.

Geologic and geophysical mapping to support future mineral resource appraisal work was conducted in many parts of the country during the year and included aeromagnetic surveys of 117,000 square kilometres $(45,170$ square miles).

During the year, 11 wilderness area appraisals were published. Parts of five of the areas were found to contain significant mineral resources resulting in modification of the wilderness area boundaries. Equally important, the mineral potential of the other six areas studied appears to be insignificant and will not prejudice their consideration for withdrawal as wilderness areas.

\section{GEOLOGIC HAZARDS}

In addition to programs concerned with the environmental impacts of energy development, the
Geological Survey is engaged in major efforts to delineate the hazards associated with earthquakes, volcanic eruptions, landslides and mudflows, ground subsidence, and floods.

Encouraging progress was made during the year in earthquake prediction. The Thanksgiving Day 1974 earthquake near Hollister, Calif., was anticipated from marked changes in deformation of the Earth's surface and local changes in the Earth's magnetic field which occurred during the weeks preceding the earthquake. During 1974, 12 other earthquakes in California were preceded by significant changes in the tilt of the Earth's surface. Those observations suggest that some earthquakes can be predicted by presently available geophysical instrumentation and analytical techniques. Before prediction systems can be deployed to provide warnings to urban areas, however, additional research on a wide variety of earthquake precursors is required. During fiscal year 1975, 35 earthquake hazards maps were published. These maps are designed to minimize future hazards and damages by providing information useful for land use zoning measures.

Two events of 1975 heightened interest in premonitory volcanic activity and the possibility of predicting volcanic eruptions. Mauna Loa in Hawaii was carefully monitored as it inflated and then erupted on July 5-6, 1975, for the first time in 25 years. Increased thermal activity on Mount Baker in Washington raised the possibility that accelerated melting of ice and snow on the volcano's flanks might lead to a large mudflow.

Survey geologists also studied the mechanisms of mudflows and landslides and the physical properties of rocks and soils that affect urban development and land use. A method was developed during the year to show the tendency of unconsolidated sediments to liquefy when shaken by an earthquake.

In its work for the Department of Housing and Urban Development's Flood Insurance Administration, the Geological Survey published 1,140 floodprone area maps (including 202 maps prepared for publication by the Soil Conservation Service). Each map shows the boundaries of areas that would be under water from a major flood. These maps are designed to provide a basis for minimizing future flood hazards and damages through land use planning, improvements in structural design, and insurance.

\section{WATER RESOURCES}

The National Water Data System has the objective of appraising the Nation's water resources and providing water data and information needed to develop and manage surface and underground water. Waterdata collection is the first step in determining how 
much and what kind of water is available. Water data are commonly used to evaluate the adequacy of water supplies, to design culverts, bridges, dams, and other public works, and to prevent or lessen the impacts of floods and droughts. During 1975, the Geological Survey collected continuous stream-discharge records at 7,700 sites, measured water quality at 5,000 sites, and made water-level observations and water-quality analyses of 8,000 wells.

The National Stream Quality Accounting Network, which measures chemical, physical, and biological characteristics of the Nation's surface waters, was expanded by the addition of 245 stations. About 60 percent of the planned network to provide baseline water-quality information for national and regional water-quality evaluation and management is now in place.

Regional ground-water appraisals were completed during the year for 3 river basins out of a total of 21, and progress was made in 10 of the other basin studies. These assessments describe the quantity and quality of ground-water resources, including availability, and the existing and potential problems associated with ground-water development. In many parts of the country, ground water is a large, important, and manageable resource that can play a significant role in regional water supply and warrants full consideration as an alternative or supplemental source of water.

The first of several pilot studies of intensive riverquality assessment-the Willamette River basin in Oregon-was nearly completed during the year, and two others were begun near the end of the yearthe Chattahoochee River basin in Georgia and the Yampa River basin in Colorado and Wyoming. The objective of these studies is to develop and demonstrate a technical methodology for analyzing riverquality problems and management alternatives.

In 1975, the Survey published the first 14 maps in the new series of Hydrologic Unit Maps of States. The new four-color maps use the Survey's State base map series at a scale of $1: 500,000$ to show hydrologic boundaries with numerical codes identifying each subdivision and counties or county equivalents. The maps, developed in cooperation with water-oriented Federal and State agencies, including the U.S. Water Resources Council, are designed for use in planning activities and in organizing and disseminating data on both a civil-unit and a hydrologic-unit basis.

\section{SURVEYING AND MAPPING}

The topographic mapping program has become a classic example of productivity growth through careful management and the introduction of new tech- than ever before as productivity continued to improve at an average rate of almost 6 percent per year.

A major highlight of the year was the formal adoption of the National Mapping program (a modification of the National Topographic Mapping program) that provides for gathering, processing, and distributing basic cartographic data in a variety of forms, including several series of multipurpose line maps, aerial photographs, photoimage maps, and digital map data.

During the year a new series of topographic base maps, the intermediate-scale map series, was designed, and production was started to support energy, land management, and soils programs. Agreements were consummated with the Bureau of Land Management (BLM) and the Soil Conservation Service (SCS) to use these new base maps as the standard map data for the BLM Minerals Management Mapping program and the SCS Prime and Unique Farmland program.

The preparation and revision of 1:24,000-scaie topographic maps are being assisted by the use of high-altitude photography and the application of recent advances in mapping technology. A byproduct of this process is a new kind of map-an orthophotoquad-consisting of nearly distortion-free aerial photography in the 7.5-minute quadrangle format and with a grid and a few names added. These maps are produced in less than a year as a first step in preparing conventional standard topographic maps. In fiscal year 1975, 2,869 orthophotoquads, 2,016 standard topographic maps, about 1,000 revised standard maps, and 1,359 reprinted maps were completed. At the year's end, 64 percent of the conterminous States, Hawaii, and outlying areas was covered by 1:24,000scale maps, and 83 percent of Alaska was covered by $1: 63,360$-scale maps.

\section{PROGRAM TRENDS}

A significant trend in current Geological Survey programs is the increasing use of computers to in i- $^{-}$ prove productivity in such diverse areas as royalty accounting, lease-tract evaluation, enhancing the quality of satellite images of the Earth, decoding water data transmitted from field sites to a central receivirig station by satellite, checking chemical analyses from laboratories, and speeding the analysis of resource and scientific data. Research and development programs, which rely heavily on computer techniques to develop new exploration tools and resource asses;ment methods and to apply new technology, such as the Landsat satellite images, represent the foundation upon which future programs will be built.

Advanced mapping technology permits cartographic data to be digitized during the map compilation process and thus avoids the necessity of a 
separate operation as is now done digitizing existing maps. Since many agencies already use or plan to use digital map data in connection with geographic based data storage and retrieval systems, this development should result in substantial savings in data preparation costs to the user.

Decisions often must be made with insufficient time to allow detailed examination and analysis of available data. Data must be available in forms which can be directly used by the planner in the decisionmaking process. During fiscal year 1975, a program was instituted to provide orthophotoquads for all areas of the conterminous United States presently unmapped at $1: 24,000$ scale by 1978 ; a land use data and analysis program was established to collect a comprehensive national baseline set of land use and land cover data that would alleviate or remedy many of the shortcomings of various types of existing data; methods of strengthening the impact of earth sciences on land use and environmental planning decisions were tested and evaluated; and major efforts were directed toward development of energy and mineral data systems as tools in resource decisionmaking.

Still another trend found in many Geological Survey programs during fiscal year 1975 was the improvement of accessibility to information. Map users, for example, have long suffered the problem of not knowing where to go for particular maps. More than 30 Federal agencies actively collect or prepare and distribute aerial photographs, maps, and survey data in support of their missions. These agencies have spent over $\$ 1$ billion on these activities during the past 10 years. To make this information readily available from a single source, the Geological Survey established the National Cartographic Information Center as a focal point for obtaining information on U.S. maps and charts, aerial photographs and space images, geodetic control data, and related cartographic data. A similar service to provide better and faster access to water data collected by Federal and State agencies, the National Water Data Exchange, was nearly ready to begin operation at the end of the fiscal year.

Fiscal year 1975 was one of change and challenge for the U.S. Geological Survey. Domestic supplies of oil and gas continued to decline, while the development of coal resources was delayed by unsolved environmental and political problems related to its extraction and conversion to energy. Attempts to open the frontier areas of the Continental Shelf to development were strongly contested, often on the grounds that not enough was known about the geology of the areas. Dependence on foreign sources for certain nonfuel minerals continued to increase. The future development of energy sources in the Western States depends upon the availability of land and water resources. None of these issues had been resolved by the end of fiscal year 1975, and they remain high priority areas of study for 1976 .

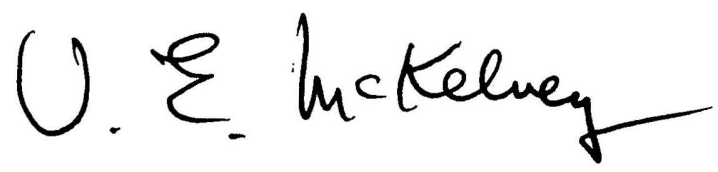

V. E. McKelvey,

Director, U.S. Geological Survey 


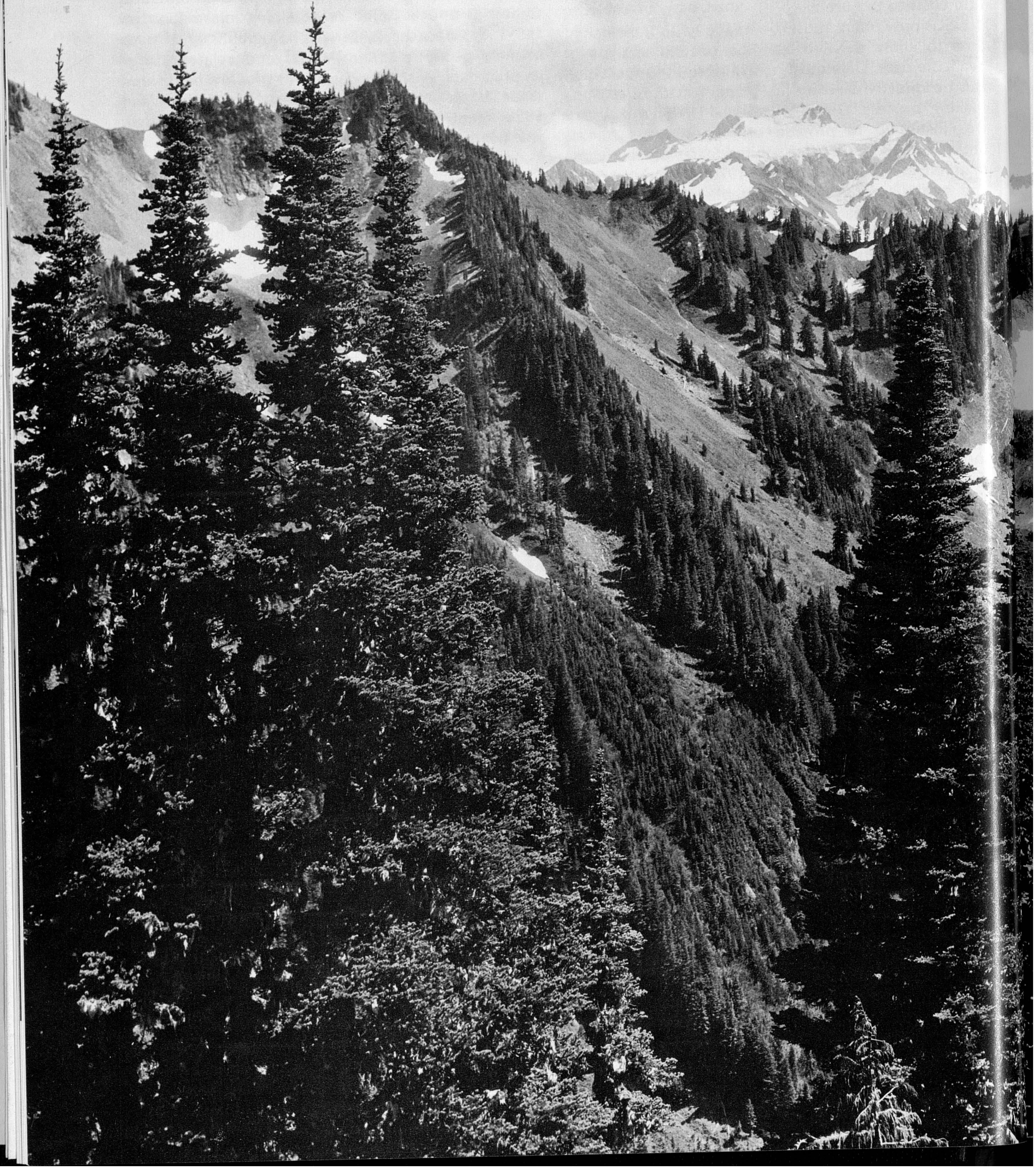




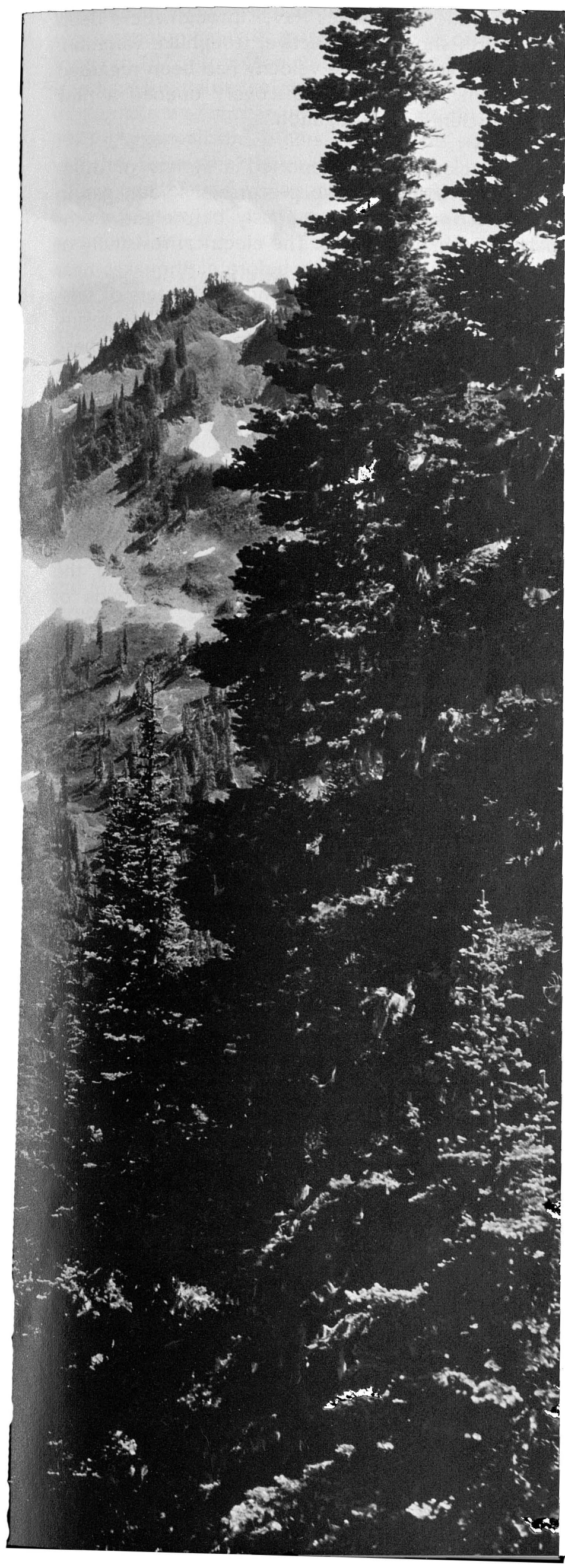

\title{
Perspectives
}

\section{The Future of Earthquake Prediction}

\author{
BY ROBERT M. HAMILTON
}

The scientists first concluded in 1970 from anomalies in the earthquake pattern that an earthquake might be coming. In June 1974, observations of further changes in the earthquake pattern, tilting of the land surface, changes in water level in wells, changes in electric current in the ground, and strange animal behavior confirmed this conclusion. More seismographs and tiltmeters were moved into the area. On December 20, 1974, local government was warned to expect a large earthquake soon, and, in mid-January 1975 , warning was given that the quake was imminent. On January 28, villages were warned to be prepared. Extra seismographs were set up.

Observations in the threatened area continued until February 1, when indications of an impending earthquake began to mount. A minor tremor was detected in an area that had not recently experienced one. The next day, there were seven more. On February 3, the minor tremors increased further, and more shocks were felt.

These events led the scientists to call an emergency conference at 7 p.m. on February 3 to report to authorities their prediction that a strong earthquake would probably occur in the very near future. By the afternoon of February 4, the seismic activity had leveled off, but this was judged to be the calm before the storm. At 2 p.m., people were told to expect a major quake within 2 days. Shops were shut, and general evacuation of buildings was ordered in two counties. At 6 p.m. that night in one village, the people were warned," A strong earthquake will probably occur tonight. We insist that all people leave their homes and all animals leave their stables. The people from the cinema team will show four feature films outside for us tonight."

One and one-half hours later, the earthquake, measured at 7.3 on the Richter scale, struck. 
The scenario in the prologue sounds like a sciencefiction writer's fantasy. Yet the events reportedly preceded an earthquake that struck Liaoning Province in the People's Republic of China on February 4, 1975. Extensive damage resulted from the shock, but loss of life was relatively light owing to the warning. This apparently successful prediction, with its life-saving benefit, represents a milestone in studies to predict the time of earthquake occurrence.

Earthquake prediction has long been a lively topic of after-dinner conversation, a proclaimed but unsubstantiated capability of mystics and soothsayers, and a controversial and elusive goal of scientists. The fascination with earthquakes derives mainly from their mysterious nature and awesome power and their capability of striking without warning to wreak disaster.

Earthquakes threaten the United States with a potential average annual loss estimated at about $\$ 630$ million. True, the losses to date have not been at this rate, but the potential for disasters is rapidly increasing with the growth of population and development in earthquake-prone areas.

Historical accounts are rich with reports of strange events before earthquakes: dogs howling, strange lights in the night sky, wierd sounds, withdrawal of the sea from a harbor, and so on. In hindsight, the significance of strange animal behavior has generally been discounted, and the reports of lights and sounds have been difficult to document. But many of the other observed phenomena have been sufficiently impressive to hold out the hope to scientists that earthquakes can be predicted (see, for example, Kisslinger, 1974, and Press, 1975).

Many of the reports of earthquake precursors have come from Japan. A particularly impressive anomaly was observed for the magnitude 7.5 earthquake that caused heavy damage in the city of Niigata in 1964, when level surveys and a tide-gage station revealed anomalous land uplift beginning 10 years before the shock. Reports such as this one proved sufficiently encouraging to lead Japan in 1965 to establish a formal program to predict earthquakes. In recent years, however, that effort has been crippled by a strike of technicians at the Earthquake Research Institute in Tokyo.

A serious attempt to predict earthquakes has also been underway for some time in the Soviet Union. Near the village of Garm in the seismically active Republic of Tadzhikistan, scientists have been working for over 25 years. The fruits of these labors were revealed in the late 1960 's, when Soviet scientists re8 ported that, prior to some earthquakes, the speed with which vibrations or waves travel through rocks deep in the Earth shows a distinctive, troughlike variation. Up to then, seismic-wave velocity had been regarded as constant. This startling discovery opened a new realm of scientific investigation.

Soviet scientists also reported a variety of other phenomena as earthquake precursors. Radon gas in well water increased anomalously before the earthquake at Tashkent in 1966. The electrical resistivity of the Earth behaved unusually before earthquakes near Garm and in Kamchatka. Migration of centers of seismic activity and reorientation of earthquake-causing rock stress were also observed. Taken together, these findings presented an impressive case that earthquakes indeed have precursors.

These observations have an explanation. Earthquakes are caused by a gradual buildup of stress in rock to the point at which the rock can no longer withstand the forces and fails suddenly along a preexisting zone of weakness, or fault. This failure, of course, takes place on a large scale in the Earth, the larger earthquakes affecting areas of hundreds of square kilometres. The stresses are created when large plates of the Earth's crust scrape past each other; this process is variously termed continental drift, sea-floc:r spreading, or plate tectonics.

The failure process can be simulated in the laboratory by squeezing a rock specimen only centimetres across. As the stress builds up and the rock nears fracture, tiny cracks develop that actually cause the rock to expand in volume-a phenomenon called dilatancy. Laboratory measurements show variations in seismic-wave velocity, electrical resistivity, and other properties of a rock experiencing dilatancy that are similar to the anomalies observed before earthquakes. American scientists have played a key role in establishing this association.

A serious effort to predict earthquakes in the United States got underway in the aftermath of the great Alaskan earthquake of 1964, which, at magnitude 8.5, is the largest U.S. shock ever observed. The magnitude 6.5 earthquake at San Fernando, Calif., in 1971 further drew attention to the prediction challenge. Soon fo: lowing the shock, the Geological Survey's Earthquake Hazards program, which supports most of the American research on earthquake prediction, was expanded.

American scientists have reported earthquake precursors similar to those reported by foreign scientists. In hindsight, it appears that the magnitude 6.5 earthquake near San Fernando in 1971 was preceded by a 
velocity anomaly (Whitcomb and others, 1973), as was a smaller shock of magnitude 5.0 in central California in 1972 (Robinson and others, 1974). In the Adirondak Mountains region of New York State, a small earthquake was successfully forecast on this basis in 1973 (Aggarwal and others, 1973). The size of the velocity anomalies, however, has not been much above background variations in velocity, and some earthquakes in well-instrumented regions have shown no anomalies.

Anomalies in other phenomena have proved more encouraging. A resistivity anomaly was observed before a magnitude 3.9 earthquake in central California in 1973 (Mazzella and Morrison, 1973). The most exciting new results, however, came in November 1974, when a magnitude 5.2 earthquake struck near Hollister, Calif., in an area where the Geological Survey operates a dense network of instrumentation as part of an experimental earthquake prediction system. Strong precursors to the shock were observed in the Earth's magnetic field, the first such anomaly recorded anywhere, and in the tilting of the land surface (Johnston and Mortenson, 1974). Weak anomalies were also observed in the length of survey lines. Such a variety of precursory phenomena had not been previously observed to be associated with a single earthquake.

Thus, by 1974, the Soviet Union, Japan, and the United States had taken on earthquake prediction as a national goal and had found evidence that earthquakes have precursors. At that time, the Chinese effort in earthquake prediction was virtually unknown in other countries. The troubles of the Cultural Revolution made it difficult to follow Chinese science, but, as the turmoil began to wind down, word reached the West that a major prediction program was underway. The opportunity to learn of it came when former President Nixon's visit to China led to an exchange of earthquake specialists. The Chinese came to the United States in the spring of 1974, and, although they gave little substantive information on their program, they dropped enough hints to alert American scientists that they had some surprises in store when the U.S. delegation visited China in October of 1974.

What the delegation found was a well-organized, large-scale research effort specifically aimed at earthquake prediction. This program began soon after two very destructive earthquakes hit China's Hopeh Province in 1966. China's leaders, including Premier Chou en-lai, visited the stricken area and launched a serious effort to reduce the dreadful impact that earthquakes have had on the Chinese people. Over 800,000 people were killed in 1556 by a shock near Sian in central China, and about 180,000 were killed in 1920 near Kansu.
The cessation of publication and the lack of outside contact with Chinese scientists during the Cultural Revolution obscured from outside view the progress of the new program. The surprise awaiting the American delegation was that roughly 10,000 people, including several hundred scientists, are working to predict earthquakes by means of a wide variety of instrument systems, including some of the best in use anywhere in the world today. These specialists are joined by uncounted thousands of amateur workers who contribute to the prediction effort. Almost every technique that has ever been suggested as a basis for prediction is being studied to some degree. Numerous precursors have been observed, ranging from reports of unusual animal behavior to well-documented geophysical anomalies. About 10 earthquakes have been successfully predicted, and warnings have been issued. It is readily acknowledged that many predictions have not been followed by earthquakes.

The Chinese success in saving lives during the Liaoning earthquake signals that the age of earthquake prediction is upon us. Laboratory studies show that earthquake precursors should exist, and numerous field observations seem to confirm that they are observable. But we confront two important scientific questions. Do all earthquakes have precursors? And are precursors sufficiently regular or uniform in nature to be reliable? These questions can be answered only through careful observations and continued research.

As is the case with most new technological developments, progress can be a mixed blessing. There is no doubt that earthquake predictions can save lives, as has already been demonstrated in China. But, in the finely balanced socioeconomic structure of the United States, a prediction can also cause serious problems (Panel on the Public Policy Implications of Earthquake Prediction, 1975). One can imagine that prediction of a shock near a major city could lead to, among other things, a drop in tourism, nonrenewal of earthquake insurance policies, fleeing of the area by the panic stricken, and convergence on the area by the thrill seekers. Failure of the earthquake to occur could result in recriminations, law suits, and loss of faith in the scientists who made the prediction. Convincing people they had just experienced a near miss with an earthquake would not be as simple as convincing them that they had barely avoided a hurricane that had veered offshore.

It is nearly certain that some incorrect predictions will be made while scientists gain experience. With adequate preparation, however, adverse public response can be minimized. The time span over which predictions are most susceptible to error could be reduced by intensifying research efforts. 


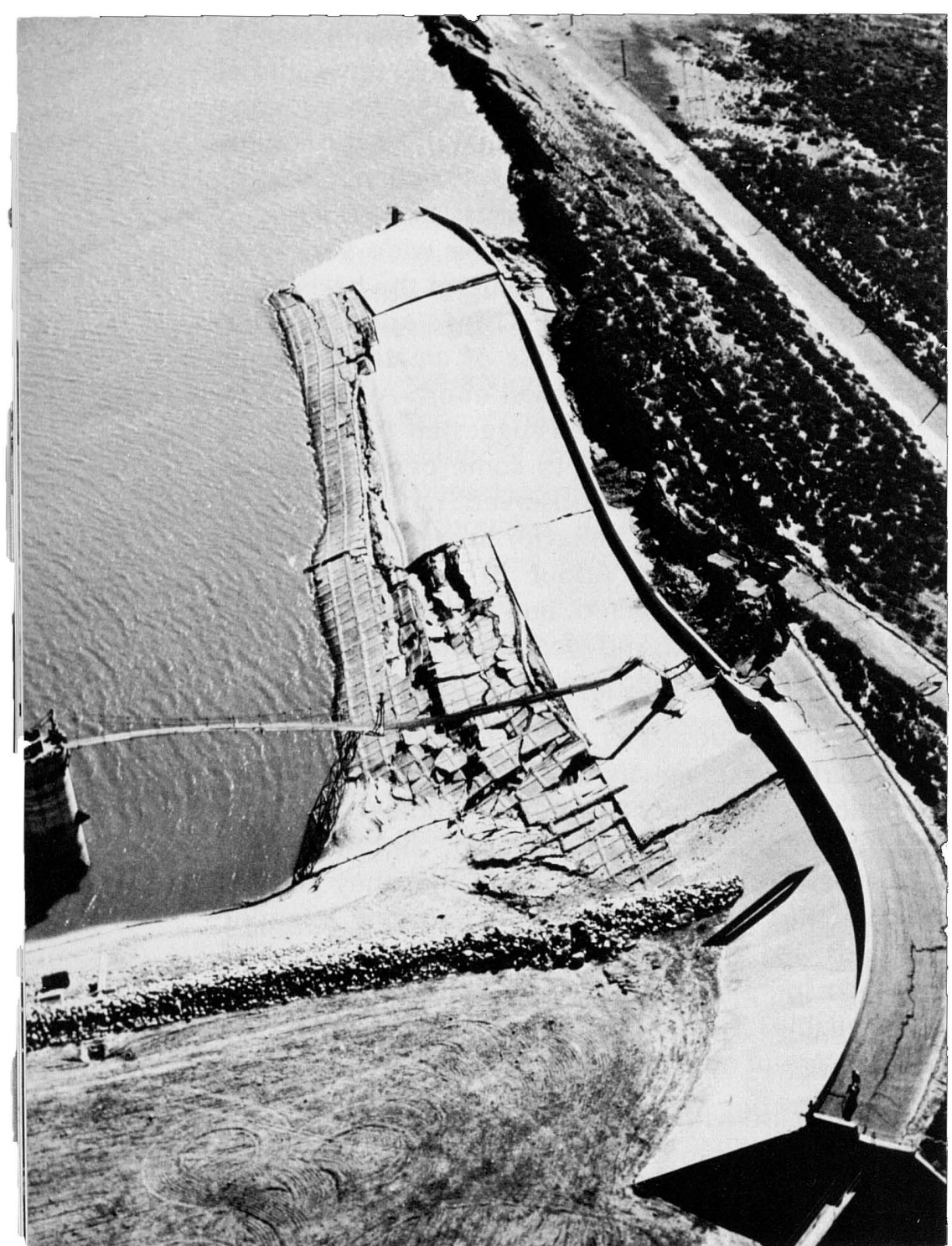

Damage to Lower Van Norman Reservoir caused by the February 9, 1971, San Fernando Valley earthquake.

Handled in the proper way, predictions can provide enormous benefits. Tens of thousands of lives were saved in 1971 because the level of the Lower Van Norman Reservoir had been lowered before the earthquake that struck at San Fernando, Calif., caused near collapse of the dam. Although the action was based on general concern for the dam rather than on an earthquake prediction, the lesson is clear. Many critical facilities are of necessity located in regions that will experience strong earthquakes. A warning could avert serious consequences resulting from damage to pipelines, storage tanks, and nuclear reactors. Many substandard buildings in use today would have a good chance of collapsing in an earthquake; these could be converted for warehouse use, reinforced, or evacuated.

Evacuation of cities, though often mentioned as a wise course in the United States under almost any circumstances. In California, where prediction may first become a reality, most residences are of woodenframe construction and stand up well in earthquakes. Therefore, most people would be relatively safe in their homes during a tremor. Certain hazardous buildings should be evacuated, but these could be specifically identified. Thus, the vision of a mass of people streaming out of an earthquake-threatened city need not become a reality. Dissemination of information and advice to the populace can avert panic situations.

Much remains to be accomplished before a solid basis for earthquake prediction can be established and before such prediction becomes as useful as weather forecasting. Instruments are deployed in only a few areas, the consistency of precursors has not been established, and a physical model to explain precursors remains to be confirmed. The transition to a reliable prediction capability will not be sudden. Even in the areas that are now under study, the development phase may stretch over the next decade. In the meantime, we can expect to see numerous scientific predictions based on fragmentary data. Procedures have been established to assure that these data receive thoughtful and responsible consideration.

In the quest for earthquake prediction, scientists are learning much about the nature of earthquake generation. The success with which earthquakes can be predicted remains to be determined, and many problems in the use of predictions remain to be solved. Progress toward prediction has been rapid in recent years, and the future is bright.

\section{REFERENCES}

Aggarwal, Y. P., Sykes, L. R., Armbruster, John, and Sbar, M. L., 1973, Premonitory changes in seismic velocities ard prediction of earthquakes: Nature, v. 241, p. 101-104.

Johnston, M. J. S., and Mortenson, C. F., 1974, Tilt precurso s before earthquakes on the San Andreas fault, Californic: Science, v. 186, p. 1031-1034.

Kisslinger, Carl, 1974, Earthquake prediction: Physics Today, \%. 27 , no. 3, p. 36-42.

Mazzella, Aldo, and Morrison, H. F., 1974, Electric resistivily variations associated with earthquakes on the San Andreas fault: Science, v. 185, p. 855-857.

Panel on the Public Policy Implications of Earthquake Prediction, 1975, Earthquake prediction and public policy: Wast:ington, D.C., Natl. Acad. Sci., 142 p.

Press, Frank, 1975, Earthquake prediction: Sci. American, ॠ. 232 , no. 5 , p. $14-23$.

Robinson, R., Wesson, R. L., and Ellsworth, W. L., 1974, Variation of $P$-wave velocity before the Bear Valley, California, earth quake of 24 February 1972: Science, v. 184, p. 1281-1283.

Whitcomb, J. H., Garmany, J. D., and Anderson, D. L., 1973, Earthquake prediction: Variation of seismic velocities before the San Fernando earthquake: Science, v. 180, p. 632635. 


\section{Estimates of Undiscovered Petroleum Resources-A Perspective}

\section{BY RICHARD P. SHELDON}

Present and impending energy shortages clearly call for reliable estimates of the magnitude of the Nation's petroleum resources. Planners and policymakers must have an idea of petroleum production potential in terms of magnitude, life, and cost in order to define the actions needed to achieve this potential and also those required for the timely development of alternative sources of energy supply.

One part of the Nation's petroleum resources is the oil and gas remaining in fields that have been discovered and tested and partially produced. Estimates of the magnitude of the remaining producible oil and gas in these fields can be made with some assurance, even though they may be subject to some dispute on both engineering and economic grounds. These oil and gas field estimates can be added up to give an inventory of the amount of petroleum reserves available to the country.

The other part of the Nation's petroleum resources consists of the oil and gas that has yet to be discovered. This presents a different problem. How can the magnitude of undiscovered oil and gas fields be estimated? Perhaps it is better to ask: Can their magnitude be estimated at all when it is not even certain that they exist in the first place? Several approaches to this problem have been devised, but all have one thing in common. They are predictions or projections into the future, based on one theory or another, using a number of assumptions and some set of data. About the only thing that any estimator can say with certainty about his estimate is that it is wrong. There is simply too much uncertainty in all the approaches to allow the kind of accuracy of estimation that can be achieved for the already discovered petroleum resources.

Perhaps the next question to be asked is: Should such unpredictable resources be predicted? The answer clearly is yes, because essential national planning depends on our ideas about our future resources. The Nation at its inception had an expansionist policy based on faith in resource abundance, because not too much financial investment was at stake. The Louisiana Purchase cost only $\$ 15$ million, and Alaska cost only $\$ 7.2$ million. Now we must decide on multibillion-dollar investments in energy research and development to achieve national expansion. The stakes are too high to proceed on faith alone, and so an objective assessment of national resources is neces- sary. The assessments must be as reliable as we can reasonably make them.

How reliable are the present estimates of undiscovered petroleum resources? The different approaches or methodologies give different numbers. Is one more reliable than the others? The central controversy so far has begun with this question. This point of departure is valid only if the methodologies yield different estimates of the oil and gas that will be available to the Nation in the future. The contention of this paper is that this point of departure is not valid, because the estimates from the different methodologies are different partly, if not largely, because they are not all estimating the amount of oil and gas that will be available in the future. One method yields estimates of the amount of petroleum resources that there is to look for. Another yields estimates of the amount that there is to look for, as in the first case, but reduces the estimate by the amount that would be left in the ground if it were produced by using only the recovery technology available today. Both of these estimates are of the geologic availability and do not try to take into account the even more difficult problem of economic availability, which is what the national planner or policymaker is really interested in. The last method estimates economic availability in a limited way by analyzing the past results of our petroleum supply system with all of its economic, technologic, and political complexity and, using historic trends of discovery and production, by projecting into the future. This estimate would be equal to the first estimate of undiscovered resources only if our petroleum supply system were effective enough to find and recover what geologists think is there to find and what petroleum engineers think can be recovered in the long run. In fact, this estimate is lower, which indicates one of two things: Either the geologists and engineers are too optimistic and their estimates are too high, or our petroleum supply system has room for improvement in the future, given the proper economic stimulus, government policy, and scientific and technologic research.

If this line of reasoning is followed, the three estimates may not be incompatible but reinforcing. This does not put aside the question of how close one or all are to the unknowable "truth." That remains to be studied and is the substance of the question of reliability. The difference between estimates, then, includes both the substantial differences of reliability and the insubstantial differences of terminology. This perspective is presented in this paper. 


\section{DIMENSIONS OF PETROLEUM RESOURCE ESTIMATES}

Petroleum resource estimates have many dimensions. To begin with, there are the several commodities: crude oil, natural gas liquids (NGL), and natural gas. Crude oil and NGL are commonly combined and reported as petroleum liquids. Additional potential sources of hydrocarbons that are usually not included in conventional resource estimates of petroleum are synthetic oils and gases from tar sands, oil shale and black shale, and natural gas in tight reservoirs, occluded in coal beds, and dissolved in geopressured subsurface water. Petroleum occurs in many provinces, some maturely explored, some virgin, some partly explored, some onshore, some in deep water offshore, and some in shallow water offshore. Resources within these provinces include the presently known deposits as well as the deposits that will be discovered in the future by using present exploration techniques. They also include the petroleum that will remain undiscovered by using present techniques but that could be found if better techniques were developed. Petroleum resources also include the petroleum that is left in the ground by past and present extraction technology and prices but that could be produced at higher prices or by technology yet to be developed.

If two petroleum estimates are to be compared, it is necessary to make sure that the estimates cover the same things. The dimensions of the estimates must be the same in relation to:

1. Commodity (crude oil, NGL, natural gas).

2. Time of the estimate relative to the stage of technology and economics as well as to the data source.

3. Coverage of petroleum provinces.

4. Resource category (identified, undiscovered, economic, subeconomic).

The first three dimensions are relatively easy to deal with theoretically, even though in practice the complexities that they introduce make it difficult to keep estimates consistently comparable. The fourth dimension, resource category, is more difficult to deal with theoretically because of a lack of a generally accepted resource terminology.

\section{RESOURCE TERMINOLOGY}

"As Mark Twain is reported to have remarked, most disputes arise because people use the same word to refer to different things or different terms to refer to the same thing. The report that follows is an attempt to help confine disputes over the size of resources and reserves of energy resources to substance," wrote standing review of mineral resource terminology ("Resource terminology: An examination of concepts and terms and recommendations for improvement," unpublished report to Electric Power Research Institute, 1975). Uniform resource terminology is critical to lucid discussion and analysis of petroleum resource problems.

Petroleum accumulations in the ground are both known and unknown and range in size from a trace to billions of barrels of oil or to trillions of cubic feet of natural gas. These accumulations occur at various depths beneath the surface from a few hundred feet to as much as about 30,000 feet and in various parts of the country from the flat midcontinent area, to the mountainous regions of both the East and the West, to the continental margins offshore, and to the remote and hostile regions of Alaska. Many of the accumulations are too remote, too deep in the Earth or too far underwater, too obscure, or too small to make them worthwhile to search out, or to produce if discovered, and are not classed as resources.

The total petroleum resources of the country consist of that part of the petroleum in the ground that has been or can be discovered and can be recovered either now at present prices and technology or in the future at whatever prices and technology then exist.

McKelvey (1972) classified resources according to the geologic certainty of occurrence and the economic feasibility of recovery (fig. 1). This classification is described in other places and need not be redescribed here except to say that the "reserves" category in the upper left corner of the diagram includes petroleum that has been found and is now economic to produce, whereas the remainder of the resource field includes petroleum that has not yet been found or has been found but is not economic to recover at present prices and technology. Undiscovered resources were divided into hypothetical and speculative resource categories by Brobst and Pratt (1973) and defined as follows: "Hypothetical resources here are defined as undiscovered resources that we may still reasonably expect to find in known districts; speculative resources are defined as undiscovered resources that may exist elsewhere-either conventional types of deposits in broad geologic terrains in which as yet there are no discoleries, or else unconventional types of resources that have only recently been recognized (or are yet to be recognized) as having some potential."

These categories were created to allow the resource specialist the opportunity to separate undiscovered resources, which he feels fairly sure could be predicted by using well-established geologic theory in areas where known deposits exist, from undiscovered resources, which he feels might not exist at all and 


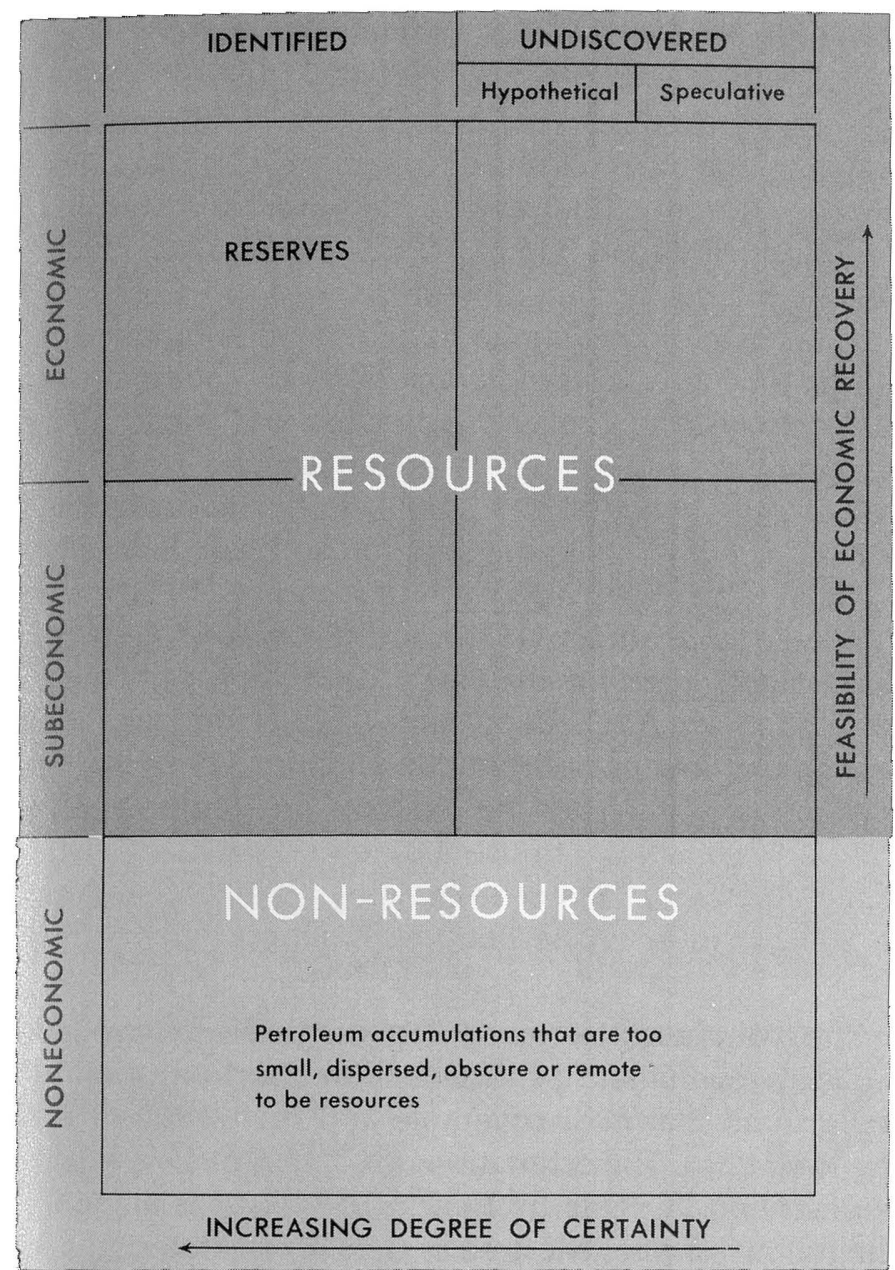

FIGURE 1.-General classification of petroleum resources (McKelvey, 1972).

whose magnitudes, if they did exist, could be estimated only very crudely within several orders of magnitude. The problem does not really stop there, because every resource geologist recognizes that resources probably exist that he has no basis to speculate on and that he would not include even in his speculative resource estimates. These resources could be set up as a category, but it would be mere sophistry. It is worthwhile to remember, however, that estimates of undiscovered resources tend to grow as knowledge increases.

It has been difficult to fit undiscovered resource estimates of petroleum into these hypothetical and speculative categories, and so far the categories have not been used by Geological Survey petroleum specialists. Most recently, the concept of probability of occurrence has been used (Miller and others, 1975). One can report these estimates in the McKelvey classification in one of two ways. The estimates can simply be shown as a range and placed in the undiscovered economic category (Miller and others, 1975, fig. 13), or the probability definitions can be adopted as part of the terminology and substituted for the hypothetical and speculative categories (fig. 2). Perhaps an acceptable correlation between the two systems would be to equate hypothetical resources with the mean estimates of resources, and speculative resources with the higher estimates at lower probabilities. In the rest of this paper, this procedure is adopted.

It is important to realize that the estimation of these resources does not imply that they will, in fact, be found or will, in fact, be produced. It is implied, however, that material classified as a resource has some chance of existing, being found, and being used in the future and is a target for exploration and technologic development.

\section{DYNAMICS OF PETROLEUM SUPPLY SYSTEM}

The movement of petroleum resources from one category to another over time transforms the McKelvey diagram from a simple static report of resources at one time into a dynamic model of the petroleum

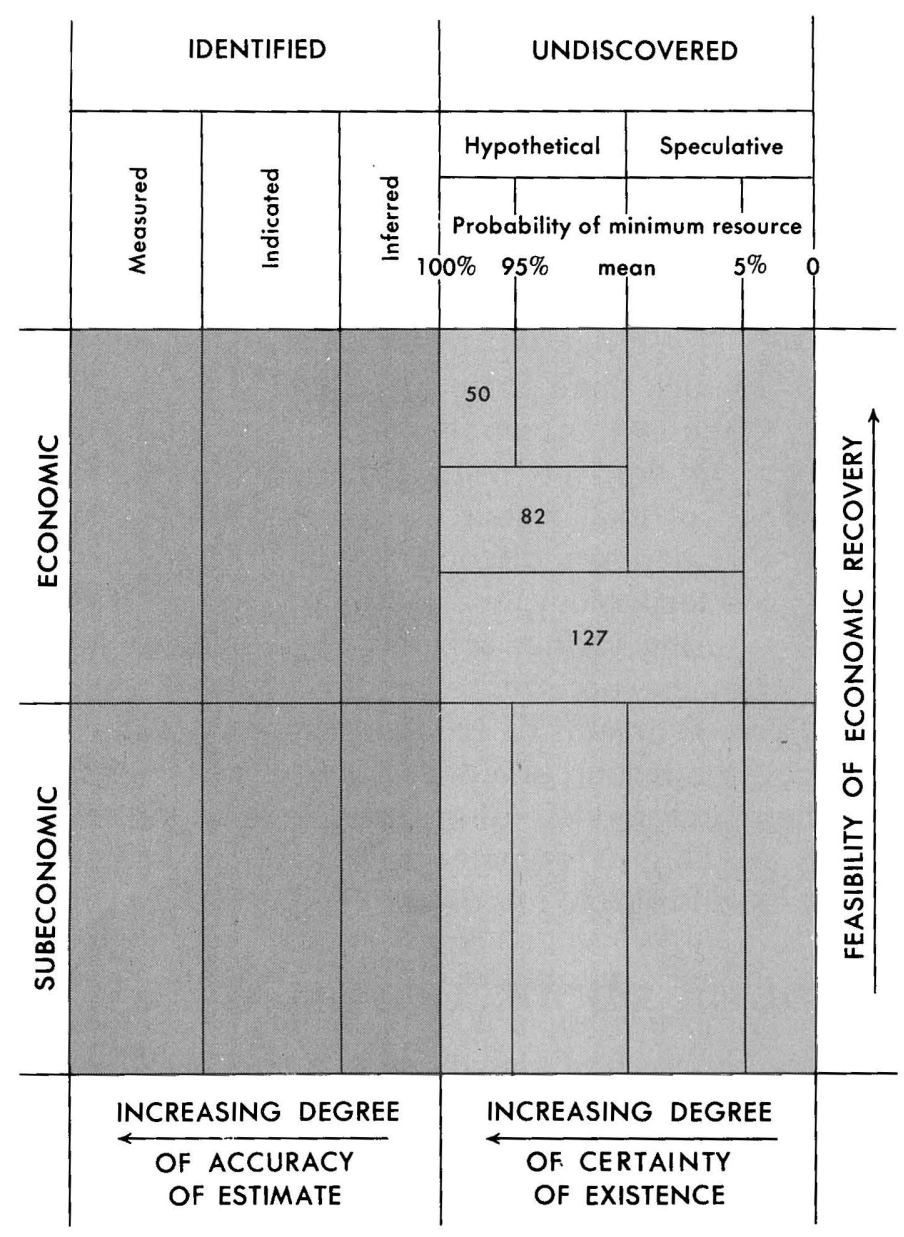

FIGURE 2.- Resource Appraisal Group (RAG) estimates of undiscovered recoverable crude-oil resources (in billions of barrels) as categorized for this discussion. 
supply system if production is added as an outlet from the reserve box (fig. 3). The movement of material is to the left in the McKelvey diagram as deposits are identified through exploration and upward as more costly or lower grade deposits are developed with higher price-cost ratios or technologic advances.

A more sophisticated model of the dynamics of the complete petroleum supply system has been conceived and is being developed by Allen Clark and Lawrence Drew of the Geological Survey (fig. 4). Their

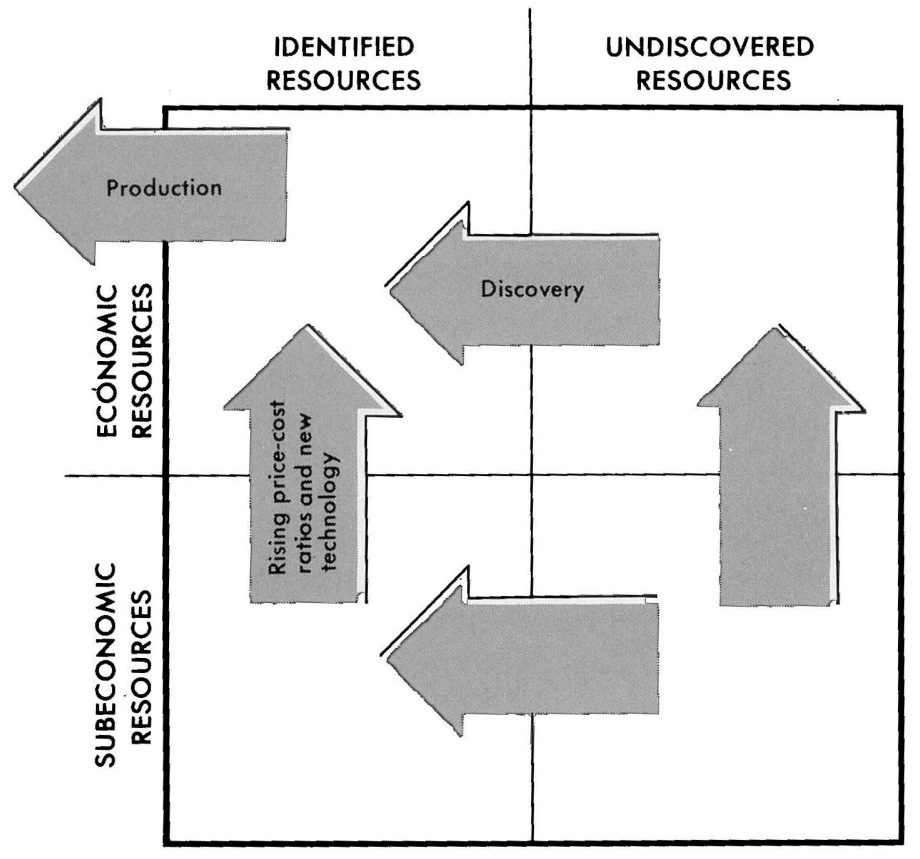

FIGURE 3.-Simplified model of petroleum supply system.

model includes three basic parts: (1) An occurrence model, (2) a search model, and (3) a production model, which describe, respectively, (1) the field size distribution of total resources, (2) the field size distribution of deposits discoverable at different levels of cost and technology, and (3) the production curves over time using various socioeconomic assumptions. Thus, when the occurrence model is operational, it would give estimates of economic and subeconomic undiscovered resources of the McKelvey classification, and the search model, using current prices and technology, would give estimates of the undiscovered economically producible resources.

\section{CRUDE-OIL RESOURCE ESTIMATES}

These concepts of classification can be applied to the many crude-oil resource estimates that have been made by scientists of various organizations, which will be discussed later, and a summary (table 1) shows the classificatory relationship of most of the modern estimates from various sources. This paper, however, will cently by members of the Geological Survey to illustrate the principal effects of confusion of terminology.

Three series of estimates of undiscovered crude-oil resources have been initiated by Survey scientists. The discovery-production trend series of six estimates was begun by Hubbert (1956, 1962, 1966, 1967, 1969, 1974) while he was employed by Shell Oil Company but was extended when he joined the Geological Survey in 1964 as a senior scientist. The volumetric series of five genetically related estimates was made by a number of authors, including Duncan and McKelvey (1963, table 9), Hendricks (1965), T. A. Hendricks and S. P. Schweinfurth (written commun., 1966), Schweinfurth in works by McKelvey and others (1973), and Theobald and others (1972) and the U.S. Geological Survey (1974), using the basic estimation technique developed by A. D. Zapp and T. A. Hendricks. The geologic estimates published in Circular 725 by Miller and others (1975) are the first of the Resource Appraisal Group (RAG) to use a different, more sophisticated approach. Each of these series is an estimate of a different level of the petroleum supply system (fig. 5).

The volumetric series is a geologically controlled subjective volumetric estimate of the portion of oil in the ground that is discoverable and recoverable over the long term. The estimation, the technique of which is described in detail by Hendricks (1965), is made in the following way. The area of the United States that is favorable for the occurrence of petroleum is estimated on the basis of geologic concepts. The success of past exploration is used as a yardstick to predict the success of future exploration in the unexplored area. A number of assumptions are involved: (1) the number of wells required to totally explore an area, (2) the average depth of an exhaustive exploratory well, (3) the thickness of the petroleum-bearing rocks, (4) the comparative incidence of petroleum in the unexplored area relative to that in the explored area, (5) the extent of the unexplored area that probably will be explored, and (6) the percentage of the oil found that will be recovered.

The volumetric series of estimates has never been broken down, but it covers both the hypothetical and the speculative parts of the undiscovered economic resource field of the McKelvey diagram (fig. 6), because the analog methodology used assumes that past exploration has discovered accumulations from both the hypothetical and the speculative resource categories and thus should serve as an estimation device for both categories in the unexplored areas. The speculative resources may have been underestimated, however, because most wildcat wells have been drilled on hypothetical resource targets. It is impossible for any analog methodology to estimate the spec- 


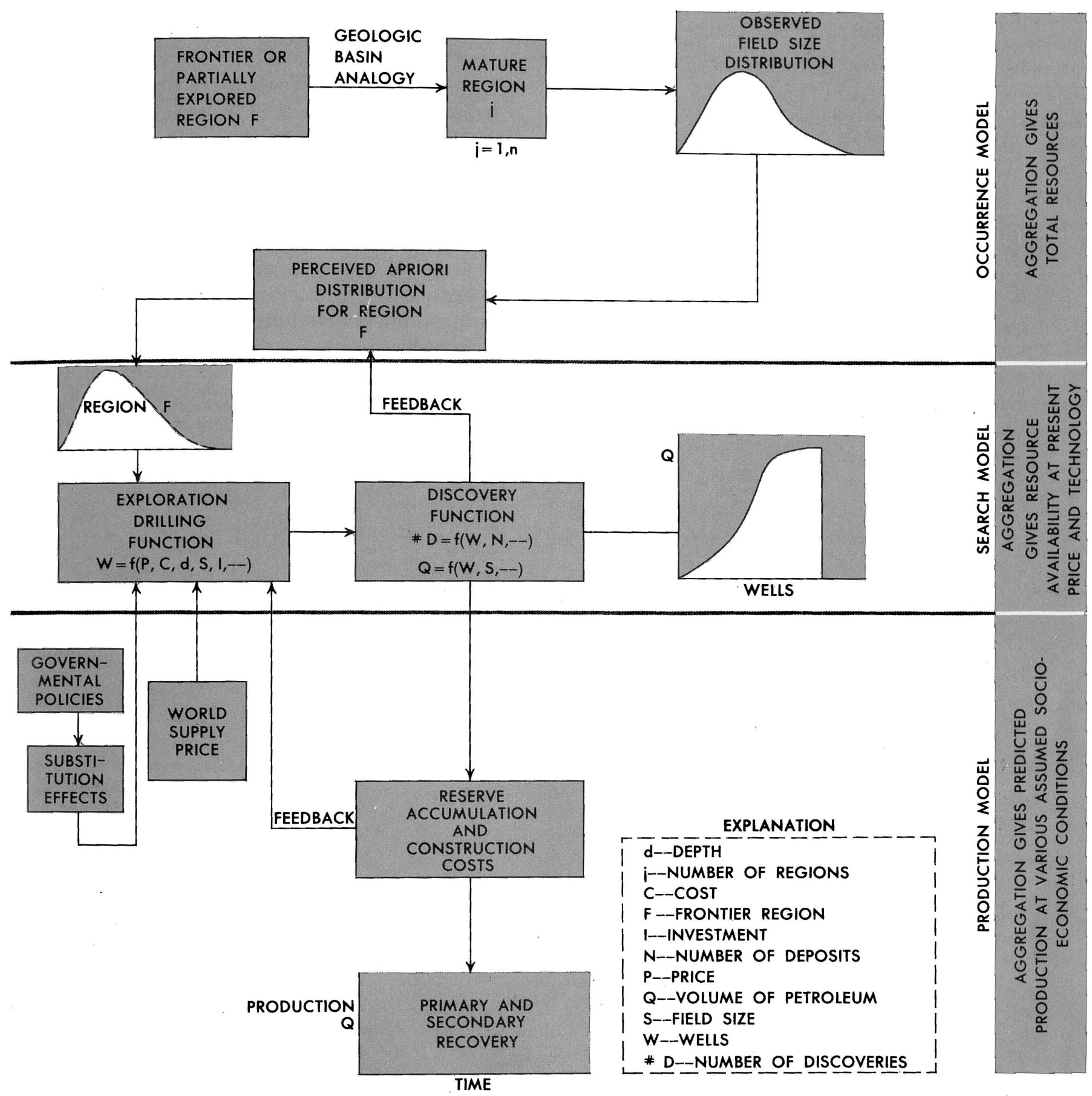

FIGURE 4.-Clark-Drew conceptual model of petroleum supply system.

ulative resources that are not analogous to known resources, since these fall into what might be termed an unconceived category, or resources that the estimator will not speculate about. Thus, the volumetric series covers as much of the undiscovered economic field as it is possible to cover. The Geological Survey volumetric estimates cover, in addition, the portion of the undiscovered subeconomic resource field that lies between the historical average of 32-percent recovery and the recovery rate of 40 percent assumed in the estimates.
The geologic estimates are of an entirely different character than those in the volumetric series. The first major difference is the magnitude of scientific effort going into the estimate. The volumetric estimates used about one scientist-year of effort and relied for their validity on the experienced judgment of the estimator, who used relatively small amounts of geologic data. The geologic estimates, on the other hand, used tens of scientist-years of effort from 70 areal-geology specialists and 8 experienced petroleum resource geologists, who used large amounts of geologic data. The 
methodology is described in detail in Circular 725 (Miller and others, 1975) and consists of making estimates by assuming then-present technologic and pre1974 economic conditions of the occurrence of undiscovered economic petroleum resources at several subjective probability levels for over 100 different petroleum provinces by means of several appraisal techniques. These geologically controlled results were then aggregated according to statistical theory. The results are explicitly reported at the 95-percent and the 5-percent probability levels of occurrence, with the idea that a 19-in-20 chance of the occurrence of a given quantity of oil is a fairly sure estimate, and a 1 -in-20 chance of the occurrence of a larger quantity of oil is as unsure an estimate of the occurrence of additional petroleum as it is prudent to make. How- ever, the technique estimates additional undiscovered recoverable oil at still lower probabilities, even though these estimates are reported only graphically. The 95and 5-percent probability estimates do not cover all the undiscovered economic field of the McKelvey diagram. What is lacking is undiscovered economic resource estimates from the 5-percent level down to very small probability levels. The reported RAG estimates, when they are arrayed in vertical columns as they are in figure 2, therefore cover a smaller part of the undiscovered economic field than the volumetric series, particularly the later ones. Because the geologic estimates of undiscovered economic resources use the presently economic recovery factors most appropriate to the potential reservoir rocks in the basins being appraised, they did not incorrectly include any sub-

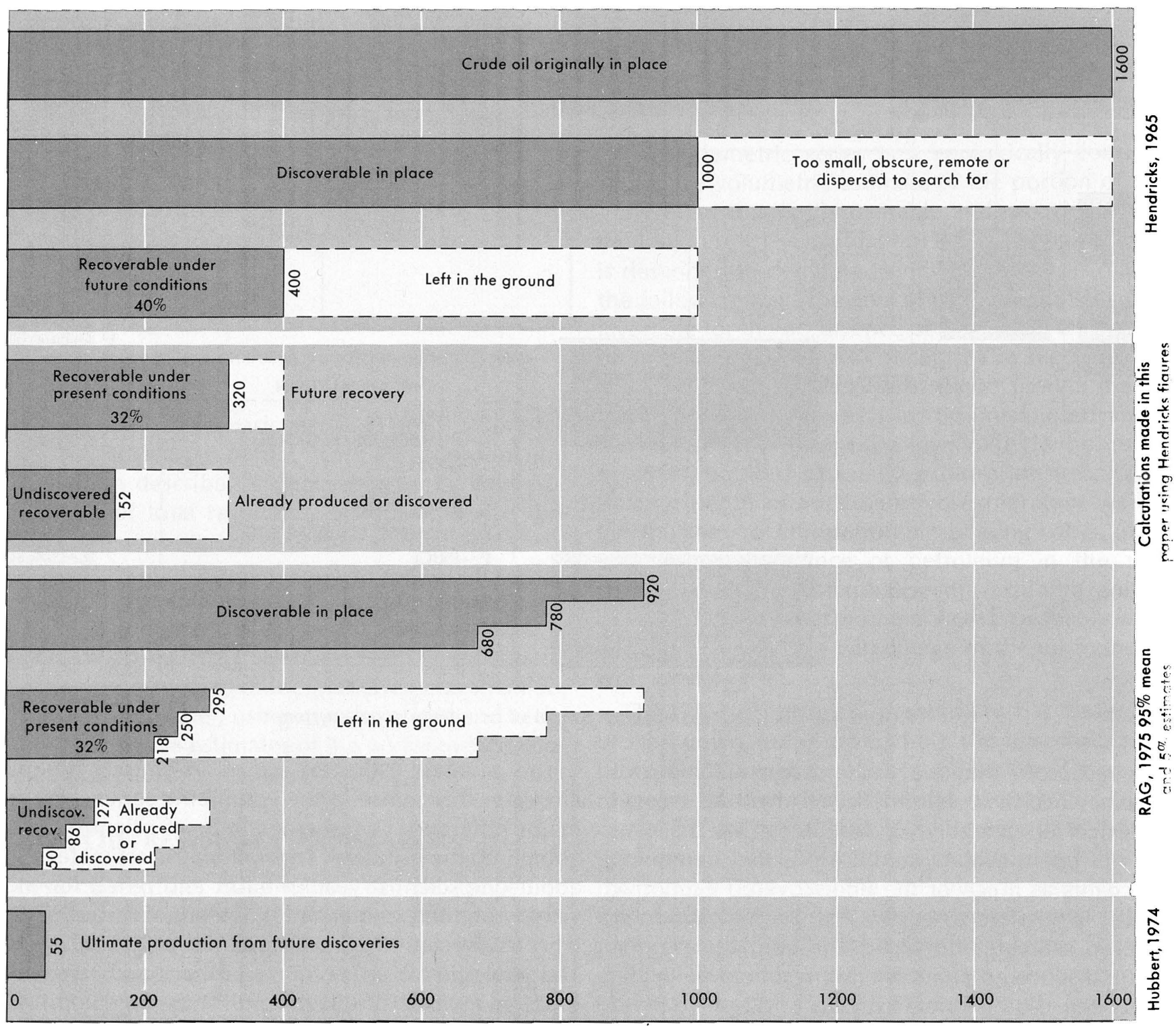

CRUDE OIL IN BILLIONS OF BARRELS

FIGURE 5.-Relationship between the crude-oil estimates of Hendricks (1965), Miller and others (1975), and Hubbert (1974). 
TABLE 1.-Comparison of crude-oil resource estimates (in billions of barrels) for the entire United States onshore and offshore to 200-metre water depth [If an original estimate was revised for this paper in order to express it in comparable dimensions and if the change involved implicit assumptions,

\begin{tabular}{|c|c|c|c|c|c|}
\hline Estimator & $\begin{array}{l}\text { Original } \\
\text { estimate }\end{array}$ & $\begin{array}{l}\text { Undiscovered } \\
\text { economic and } \\
\text { subeconomic crude- } \\
\text { oil resources } \\
\text { (60-percent } \\
\text { recovery) }\end{array}$ & $\begin{array}{l}\text { Undiscovered } \\
\text { economic } \\
\text { crude-oil resources } \\
\text { (using present } \\
\text { technology) }\end{array}$ & $\begin{array}{l}\text { Ultimate crude-oil } \\
\text { production from } \\
\text { future } \\
\text { discoveries }\end{array}$ & $\begin{array}{l}\text { Original crude-oil } \\
\text { resources (60-percent } \\
\text { recovery of discovered } \\
\text { and undiscovered } \\
\text { crude oil in place) }\end{array}$ \\
\hline $\begin{array}{l}\text { Hendricks (1965) } \\
\text { Theobald and others (1972) } \\
\text { U.S. Geological Survey (1974) } \\
\text { National Petroleum Council (1970) } \\
\text { Resource Appraisal Group (Miller and } \\
\text { others, 1975) } \\
\text { Oil Co. A (Weeks, 1960) } \\
\text { Oil Co. D (National Academy } \\
\text { of Sciences, 1975) } \\
\text { Oil Co. E (National Academy } \\
\text { of Sciences 1975) } \\
\text { Shell Oil Co. } \\
\text { (R. H. Nanz, oral commun., 1975). } \\
\text { M. K. Hubbert (1974) } \\
\text { C. L. Moore } \\
\text { (written commun., 1975) }\end{array}$ & $\begin{array}{c}400^{1} \\
459^{4} \\
200-400^{4} \\
107 \\
50-127 \text { (82 mean) } \\
-\quad 8\end{array}$ & $\begin{array}{c}285^{2} \\
\text { ca } 585^{5,6} \\
\text { ca } 255-510^{5,6} \\
199 \\
\geqslant 94 \text { to } \leq 238^{8} \\
-\end{array}$ & $\begin{array}{c}\text { ca } 152^{3} \\
\text { ca } 312^{3} \\
\text { ca } 136-272^{3} \\
107^{3} \\
50-127(82 \text { mean }) \\
\text { ca } 62^{\circ} \\
76^{5} \\
77^{5} \\
65-155 \\
-\end{array}$ & $\begin{array}{l}--- \\
--- \\
---- \\
-\cdots- \\
---\end{array}$ & $\begin{array}{c}600 \\
\text { ca } 900^{5,7} \\
570-825 \\
514 \\
408-553 \text { (468 mean) } \\
-\end{array}$ \\
\hline
\end{tabular}

1 Includes past production and identified resources.

2 Corrected for past production and all categories of reserves at 60-percent recovery. Hendricks gives 1,000 billion barrels of discoverable in-place crude oil.

3 32-percent recovery.

4 Includes NGL.

5 The original estimate includes NGL and is here reduced by 15 -percent in order to subtract NGL.

- Estimate was classified as an undiscovered economic resource at the time of release and is reciassified here as an undiscovered resource.

7 Estimates of crude oil on continental slope is subtracted from original estimate.

8 The 95- and 5-percent probability levels of estimates of economic and subeconomic resources are not arithmetically additive. The proper aggregated 95- and 5-percent probability estimates would be greater than or equal to the sum of the 95-percent estimates and less than or equal to the sum of the 5-percent estimates. Estimates at 60-percent recovery.

${ }^{\circ}$ Weeks (1960) reported a figure of 270 billion barrels of ultimate resources of crude oil and NGL for the United States. This figure is adjusted by assuming crude oil is 85 percent of this and subtracting past production and all categories of reserves as of the end of 1974 .

${ }_{10} \mathrm{Nanz}, \mathrm{R} . \mathrm{H}_{\text {. }}$ 1975, The offshore imperative-the need for a potential of offshore exploration: talk presented at colloquium on Conventional Energy Sources and the Énvironment, University of Delaware.

II Assumes continuation of pre-1974 socioeconomic conditions.

${ }_{12}$ Calculated by subtracting from C. L. Moore's 471 billion barrels ultimate recovery the 168 billion barrels of past production and present reserves plus an additional 147 billion barrels from identified resources at a 60 -percent recovery.

economic resources and thus did not lap into the subeconomic field at all (fig. 6).

The discovery-production trend series of resource estimates is of still a different character. Hubbert analyzed the yearly trends of production and the additions to reserves through exploration by year and by exploratory drilling footage. He pointed out the dependence of the former on the latter and then projected their historic trends into the future by using logistics or growth curves. These estimates are predictions of ultimate discovery and ultimate production assuming no significant changes of exploration incentive or access to prospective land or no significant change in the rate of technological development.

\section{RELATIONSHIP BETWEEN ESTIMATE SERIES}

It was contended at the outset of this paper that part of the disagreement about estimating resources stems from using the same words for different things. This contention applies to the differences between the volumetric series and the geologic series. Both the
1972 volumetric estimate (Theobald and others, 1972, fig. 5) and the geologic estimates (Miller and others, 1975, fig. 13) are shown filling diagrammatically the complete undiscovered economic resource field (fig. 6). But, as discussed above, the volumetric series, particularly the later estimates, fills more than the undiscovered economic resource field, whereas the geologic estimate fills less, so that each series uses the term undiscovered economic resource in a different way. The true relationship between the two series, using the estimates of Hendricks (1965) and Miller and others (1975), are shown in figures 5 and 6.

The validity of the idea that differences between undiscovered economic estimates are partly due to a difference in assumptions of recoverability rates can be tested by comparing the estimated original crudeoil resources-that is, 60-percent recovery of original oil in place, estimated by each series (table 1). Hendricks' (1965) estimate at a 60-percent recovery would be 600 billion barrels, and the RAG 5-percent probability estimate is 553 billion barrels. Thus, both Hendricks and Miller and others were estimating similar amounts of undiscovered crude oil but drew different 


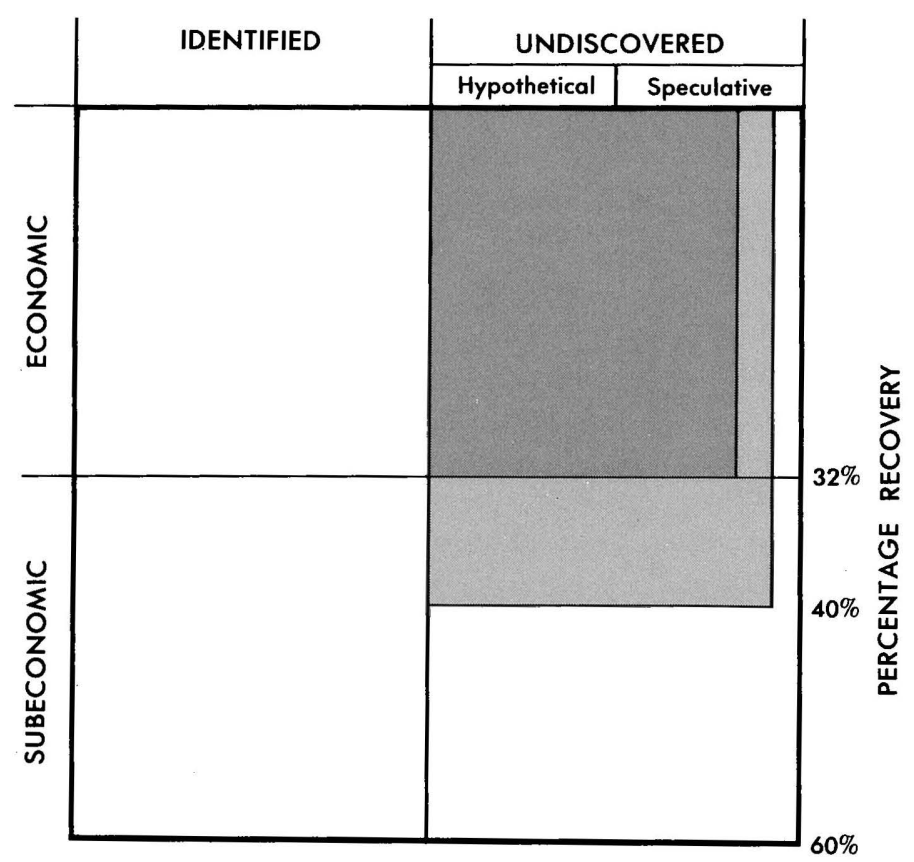

Volumetric Series

Geologic estimates (Miller and others, 1975) at 5 percent probability level of discoverable recoverable

FIGURE 6.-Comparison of crude-oil resource estimates of the volumetric series with those of the geologic series.

boundaries between economic and subeconomic resources. On the other hand, Schweinfurth's (Theobald and others, 1972) estimate is about 900 billion barrels, almost twice the RAG 5-percent probability estimate. It can be assumed that the additional amount would be classed as speculative undiscovered and should be compared with the additional amount of crude oil estimated by RAG to occur at less than 5percent probabilities, in both the economic and the subeconomic categories.

McKelvey developed and published his classification in 1972, after the first volumetric estimates had been made. However, the volumetric estimates of 1972 and 1974 were categorized as undiscovered economic resources rather than undiscovered resources. In hindsight, the assumptions of the volumetric methodology should have been adjusted to better fit the McKelvey classification. The geologic estimates, on the other hand, have followed the McKelvey classification as closely as possible. This difference has been a major source of confusion and controversy.

How do these estimates relate to the petroleum supply system model of Clark and Drew (fig. 4)? As a first approximation, the volumetric series is analogous to the resource estimates of the occurrence model. The geologic estimates are most closely analogous to search model. The discovery-production trend estimates are most similar to a production model prediction based on the assumption that the socioeconomic conditions prevailing over the last several decades will continue.

Thus, one can compare the estimates by saying that the volumetric estimates are the total undiscovered resource (to a 40-percent recovery level) and the geologic estimates are that part of the volumetric estimate that could be discovered and recovered under pre1974 economic and technologic conditions, whereas the discovery-production trend estimates are that part of the geologic estimates that would be discovered and produced under the socioeconomic conditions of the last several decades.

\section{UNCERTAINTY OF ESTIMATES}

The above analysis asserts the relationship between these three petroleum resource estimates but does not deal with the uncertainty inherent in the estimates. The relationship requires that the volumetric estimates must be larger than the geologic estimates, which in turn must be larger than Hubbert's discovery-production trend estimates. But are the existing differences larger or smaller than they should be? Or, stated another way, is the accuracy of the estimates satisfactory?

The degree of certainty of the existence of resources decreases to the right of the McKelvey diagram. The feasibility of economic recovery decreases downward and implies a decreasing certainty of technological development and increasing economic incentive necessary to recover the resources. Thus, the volumetric estimates, which include resources that ire either less well known or subeconomic, are by their nature less certain than the resources that were associated with the 5-percent probability estimated in the geologic estimates. Each series used a different technique to handle its inherent uncertainty.

Hendricks (1965, p. 3) gave a single resource figt re but stated that "The statistical data from drilling in the United States are utilized to estimate the minimum total quantities originally underlying the United States and its adjoining continental shelves. As will be seen, none of the factors that enter into such a computation can be actually determined; many are purely matters of opinion. However, the analysis is given in such a manner that any reader who disagrees with any of the values assigned, or assumptions made, may substitt te other values or other assumptions and derive his oivn estimates." In effect, he said: Here are my judgments; if you disagree, l've given you a formula into which you can substitute your own judgments. This caveat also applied to the 1966, 1969, and 1972 estimates of 
the series, in which other judgments were made with the purpose of estimating not the "minimum" but the more likely (in the minds of the estimators) larger quantities of crude oil underlying the United States. As a result, estimates increased to finally the largest estimate of about 390 billion barrels of crude oil in 1972. Thus, the inherent uncertainty of the estimates was not dealt with directly until 1974 (U.S. Geological Survey, 1974) when a range of estimates was introduced that almost covered the span of estimates from 1965 through 1972. It is likely that, if additional petroleum geologists would make petroleum resource estimates by means of the Hendricks technique, the range of estimates would increase still more. For example, a number of petroleum geologists, including Halbouty (1975, p. 10), past president of the American Association of Petroleum Geologists (AAPG) and a leading analyst of petroleum resources as well as a highly successful explorationist, feel that the volumetric series estimate of 1974 is reasonable and acceptable and, if anything (Michel Halbouty, oral commun., 1975), is too low. The Panel on the Estimation of Mineral Reserves and Resources of the Committee on Mineral Resources and the Environment of the $\mathrm{Na}$ tional Academy of Sciences (1975, p. 90), which included John Moody, the incoming president of AAPG and retired Senior Vice President for Exploration and Production for Mobil Oil Company, felt that even the lowest of the volumetric series estimates is too high. It is likely that some of this difference of opinion reflects a misunderstanding of what is being estimated, but, even so, it is probable that the full range of uncertainty inherent in the Hendricks estimation technique has not been established.

The uncertainty of the RAG estimates, as discussed above, was handled by presenting the estimates at several probability levels and by showing the probability of any estimate by a curve. It is possible that broadening the number of resource specialists beyond the eight in the Resource Appraisal Group would increase the range of resources estimated at the 95and 5-percent probability levels, because it is unlikely that the RAG specialists represent the full possible range of experienced resource judgments. In addition to this, although the Resource Appraisal Group was concerned about the effect on the estimates of using a group discussion to arrive at a consensus estimate for each province, the members felt that the benefits of group discussion to the quality of the estimate outweighed any possible bias introduced. It has been suggested that the effect of group behavior might tend to reduce the range of estimates, and the generalization pointed out by Myers and Lamm (1975, p. 297)that "group discussion tends to enhance the average pregroup inclination of the group members" - supports this suggestion. An alternative procedure for avoiding this pitfall would be to have the resource specialists make their province estimates independently and then aggregate them for each province according to statistical theory. It appears then that, even though the full range of uncertainty inherent in the geologic estimates has not been established, it is certainly better established than the range of the volumetric estimates, because probabilities were dealt with directly, more views were represented in its preparation, and statistical theory rather than intuition was used to aggregate probabilities of the occurrence of oil by province.

The inherent uncertainty of the discovery-production trend estimates is more difficult to assess. The internal precision of the projection technique-that is, the goodness of fit of the points to the curve-has been estimated by Hubbert (1975) at about \pm 20 percent. However, the effect of significant changes in the socioeconomic factors which would influence Hubbert's prediction of ultimate production have not been analyzed. For example, if the OPEC cartel were to break up and the world oil price return to a level more closely related to the cost of finding and producing petroleum, the effect on the American domestic petroleum industry, which has already lost the depletion allowance, would be extremely depressing, and it is possible that Hubbert's predicted ultimate production would be too large, at least within the time range of his projections. Similar effects in the opposite direction are conceivable. Thus, it is apparent that a part of the uncertainty of Hubbert's estimate is inherently tied to the uncertainties of future political events. Also, if other types of curves are adopted, the same data give widely different results. Hubbert uses a symmetrical curve to predict 170 billion barrels of ultimate crude-oil production, ${ }^{1}$ whereas C. L. Moore (written commun., 1975), using an asymmetrical curve with the same data plus Alaskan data, predicts an ultimate crude-oil production of 471 billion barrels. I can see no evidence produced by either Hubbert or Moore that makes one curve or one manner of curve fitting preferable to the other, much less requires the use of one curve or the other. Furthermore, these particular curves are useful, mainly because they are mathematically simple. This simplicity facilitates the analysis of the data, but does it mean that other mathematically more complex curves, which would give still different results, are more or less valid? Finally, it is difficult to say, even though past frontiers are included in the historic discovery and production data, whether future frontier petroleum provinces are

1 He adds an additional 43 billion barrels derived from a geologic estimate to account for Alaska, giving an ultimate U.S. production of 213
billion barrels. 
adequately handled in the projections, and, thus, additional uncertainly is introduced into the estimates. Thus, there is a large amount of inherent uncertainty introduced into Hubbert's estimates from these three sources-that is, (1) uncertainty of future socioeconomic events, (2) choice of alternative curves and method of fitting used for prediction, and (3) the geographic extent of the prediction. However, it must be recognized that Hubbert's predictions, made 13 years ago, accurately predicted the peaking of domestic production in 1972, a significant achievement.

To repeat the question asked at the outset of this section, are the existing differences between series estimates larger or smaller than they should be? The question cannot be answered now because the full range of uncertainties inherent in the production, search, and occurrence models has not been assessed. It is too early to judge.

\section{Other recent estimates}

A number of other estimates of undiscovered petroleum resources have been made. Some of these have been described and analyzed by Theobald and others (1972), McCulloh (1973), and Miller and others (1975), and six of them are shown in table 1 along with estimates of Geological Survey scientists. One difficulty in comparing these estimates is caused by the combination of their aggregated nature and their dimensional differences.

The industry estimates given in the report of the Committee on Mineral Resources and the Environment of the National Research Council of the National Academy of Sciences (1975, p. 89) and the Shell Oil estimate apparently are estimates of undiscovered recoverable resources under pre-1974 economic conditions and technology. The estimates of the National Petroleum Council and the AAPG are very difficult to categorize owing to the varying methodologies and resource terminologies used by scientists for different regions. Still, we can be confident that the overall methodology of deriving these estimates was similar to that used by RAG. The resource is reported as undiscovered oil in the ground, and several recovery factors are reported. The resulting estimates are comparable in magnitude at a 32-percent recovery factor with the RAG estimate. The ultimate production estimates of C. L. Moore (written commun., 1975) are analogous to Hubbert's estimates as discussed earlier.

All these estimates are listed in table 1 according to the resource categories that correspond to the crudeoil supply model as proposed by Clark and Drewthat is, undiscovered crude oil (equaling the occurrence model estimates), undiscovered economic crude oil (equaling the search model estimates), and pro- duction from future discoveries (equaling part of the production model estimates). These non-Survey estimates fall within the ranges of Survey estimates, except for Moore's estimate, which is more than twice that of Hubbert's.

\section{SUMMARY AND CONCLUSIONS}

A full analysis of the Nation's petroleum supply system requires knowledge of (1) the total petroleum resources discoverable and recoverable under future technologic and economic conditions, (2) the portions of those resources that are discoverable and recoverable under present technologic and economic conditions, and (3) the ultimate production possible under a range of socioeconomic conditions. As an approximate characterization, the volumetric series of estimates was an attempt to estimate the first category, the first geologic estimate was an attempt to estimate the second category, and the discovery-production trend series of estimates was an attempt at the third category, but only under the assumption of continuing socioeconomic conditions prevailing over the last several decades. Thus, even though these estimates have inherent uncertainties that can and should be narrowed with additional work and even though they are only first approximations of their categories, they are not necessarily incompatible with one another.

It is important for policymakers to recognize these relationships so they can address substantive resource problems.

Agreement exists on all sides on the magnitude of the fairly well assured undiscovered economic resources under pre-1974 technologic and economic conditions, that is, the geologic estimates. The estimates should be improved, but little change in their magnitude is expected until substantial exploration is carried out in the frontier areas. Better estimates of undiscovered resources-that is, the occurrence model estimates-are badly needed, because the present volumetric estimates are too uncertain and too general to allow full development of the search model estimates or, in turn, the production mcidel estimates. Finally, although the discovery-producion trend estimate is valuable for the assessment of the petroleum supply system operating in 1973, the effects of a range of differing socioeconomic factors on ultimate production badly need to be evaluated in order to demonstrate the options available for policy considerations.

\section{PLANS FOR FURTHER RESOURCE STUDIES}

The Geological Survey has the responsibility to continue to improve resource estimates. The critical needs have been discussed in this paper, and plans to meet 
some of these needs have been made and partially implemented.

\section{Occurrence modeling}

The Resource Appraisal Group and the Office of Resource Analysis of the Geological Survey are developing the computerized analytical techniques required for occurrence modeling. This process involves the development of field size distributions in the petroleum provinces of the country and the application of mature geologic basin analogs to each of the frontier basins and the partially explored basins. The data required to implement these studies are being developed cooperatively by the Geological Survey, various State geological surveys, the AAPG, the International Oil Scouts Association, the U.S. Bureau of Mines, and the University of Oklahoma or are being purchased through Petroleum Information, Inc.

A novel geophysical technique for helping to estimate petroleum resource potential is being developed by T. H. McCulloh of the Geological Survey. It consists of applying to the partially explored or frontier basins the relationship between the average lightness of a petroleum basin (that is, the average difference between the gravity of the rocks in the basin and the gravity of the surrounding area) and the average petroleum richness of the basin that McCulloh established for the well-developed basins. This technique shows promise in sharpening the analog methodology for appraising the total petroleum resources of the Nation, both onshore and offshore, thus providing the improved reliability of resource estimates necessary for the search model.

\section{Search modeling}

The Office of Resource Analysis is developing the techniques for a computerized analytical search model to generate the field size distributions, by basin, of petroleum discoverable and recoverable under present as well as alternative economic and technologic conditions. The geologic information necessary to implement this modeling is being generated by the Resource Appraisal Group and the Oil and Gas Resources Branch of the Geological Survey. This estimate will be the next in the RAG series.

In 1975, the AAPG was asked by Acting Secretary of the Interior Kent Frizzell, with the strong endorsement of the Director of the Geological Survey, to undertake a petroleum resource appraisal of the country. This effort will allow a major input to petroleum resource estimation by the petroleum explorers of the Nation.

The Resource Appraisal Group, in addition to providing input to the above modeling, will continue its ongoing resource studies on a province-by-province basis for the entire Nation. This effort will include the updating and revision of earlier appraisals, the development and improvement of appraisal methodology, Outer Continental Shelf area evaluations, wilderness area appraisals, finding-rate studies, and a series of maps showing the petroleum basins of the world.

\section{Production modeling}

The Geological Survey does not normally engage in production modeling, which gives long-range supply curves. Occurrence and search modeling are, however, necessary inputs to production modeling, and the Survey is undertaking research in the application of its occurrence and search models to production modeling in order to facilitate cooperation with these organizations that are engaging in production modeling.

These plans constitute the next steps in appraising the Nation's petroleum resources. When these steps have been taken and when an appropriate organization undertakes production modeling studies, a resource information system will have been set up to allow for continuing monitoring and assessment of the Nation's petroleum resources. Only then will a firm base have been laid for making energy policy in relation to petroleum resources. Such steps will, however, require several years to complete. In the meantime, necessary policy decisions on offshore leasing, petroleum pricing, and alternate energy source development must be made on the basis of the incomplete and uncertain petroleum resource estimates that we now have.

\section{REFERENCES}

Brobst, D. A., and Pratt, W. P., eds., 1973, Introduction, in United States mineral resources: U.S. Geol. Survey Prof. Paper 820, p.1-8.

Duncan, D. C., and McKelvey, V. E., 1963, U.S. resources of fossil fuels, radioactive minerals, and geothermal energy, in Federal Council for Science and Technology, Research and development of natural resources: Washington, D.C., Office of Science and Technology, Executive Office of the President, p. 43-45.

Halbouty, Michel, 1975, Methods of estimating the volume of undiscovered oil and gas resources-Introductory remarks: Am. Assoc. Petroleum Geologists Studies in Geology, no. 1, p. 8-10.

Hendricks, T. A., 1965, Resources of oil, gas and natural-gas liquids in the United States and the world: U.S. Geol. Survey Circ. 522, $20 \mathrm{p}$.

Hubbert, M. K., 1956, Nuclear energy and fossil fuels, in Drilling and production practice: Dallas, Am. Petroleum Inst., p. 7-25.

- 1962, Energy resources: Natl. Acad. Sci.-Natl. Research Council Pub. 1000-D, 141 p. 
1966, M. King Hubbert's reply to J. M. Ryan: Jour. Petroleum Technology, v. 18, p. 284-286.

1967, Degree of advancement of petroleum exploration in United States: Am. Assoc. Petroleum Geologists Bull., v. 51 , no. 11 , p. 2207-2227.

1969, Energy resources, in Resources and man: Washingtion, D.C., Natl. Acad. Sci.-Natl. Research Council Comm. on Resources and Man, p. 157-242.

1974, U.S. energy resources, a review as of 1972, pt. 1, in A national fuels and energy policy study: Senate Comm. Interior and Insular Affairs, U.S. 93d Cong., 2d sess., serial no. 39-40 (92-75), 267 p.

1975, Statement before House Committee on Ways and Means, first session on the energy crisis and proposed solutions, pt. 3, in Petroleum supply: Washington, D.C., Govt. Printing Office, p. 1158.

McCulloh, T. H., 1973, Oil and gas, in Brobst, D. A., and Pratt, W. P., eds., United States mineral resources: U.S. Geol. Survey Prof. Paper 820, p. 477-496.

McKelvey, V. E., 1972, Mineral resource estimates and public policy: Am. Scientist, v. 60 , no. 1, p. 32-40; reprinted in Brobst, D. A., and Pratt, W. P., eds., 1973, United States mineral resources: U.S. Geol. Survey Prof. Paper 820, p. 9-19.

McKelvey, V. E., Wang, F. H., Schweinfurth, S. P., and Overstreet, W. C., 1973, Potential mineral resources of the United States Continental Shelf, in Public Land Law Review Commission study of Outer Continental Shelf lands of the
United States, v. 4 (appendices): Springfield, Va., U.S. Dept. Commerce, Natl. Tech. Inf. Service PB 188717, p. 5A15 A117.

Miller, B. M., Thomsen, H. L., Dolton, G. L., Coury, A. B., Hendricks, T. A., Lennartz, F. E., Powers, R. B., Sable, E. G., and Varnes, K. L., 1975, Geological estimates of undiscovered recoverable oil and gas resources in the United States: U.S. Geol. Survey Circ. 725, 78 p.

Myers, D. G., and Lamm, Helmut, 1975, The polarizing effect of group discussion: Am. Scientist, v. 63, no. 3, p. 297303.

National Academy of Sciences, 1975, Mineral resources and the environment: Washington, D.C., 348 p.

National Petroleum Council, 1970, Future petroleum provinces of the United States-a summary: Washington, D.C., Committee on Possible Future Petroleum Provinces of the U.S., $138 \mathrm{p}$.

Theobald, P. K., Schweinfurth, S. P., and Duncan, D. C., 1972, Energy resources of the United States: U.S. Geol. Survey Circ. 650, 27 p.

U.S. Department of the Interior, 1974, New mineral resource terminology adopted: U.S. Dept. Interior news release, April 15, 1974.

U.S. Geological Survey, 1974, U.S. oil and gas resource estimates: U.S. Dept. Interior news release, March 26, 1974.

Weeks, L. G., 1960, The next hundred years energy demand and sources of supply: Geotimes, v. 5 , no. 1, p. 18-21, 51-55.

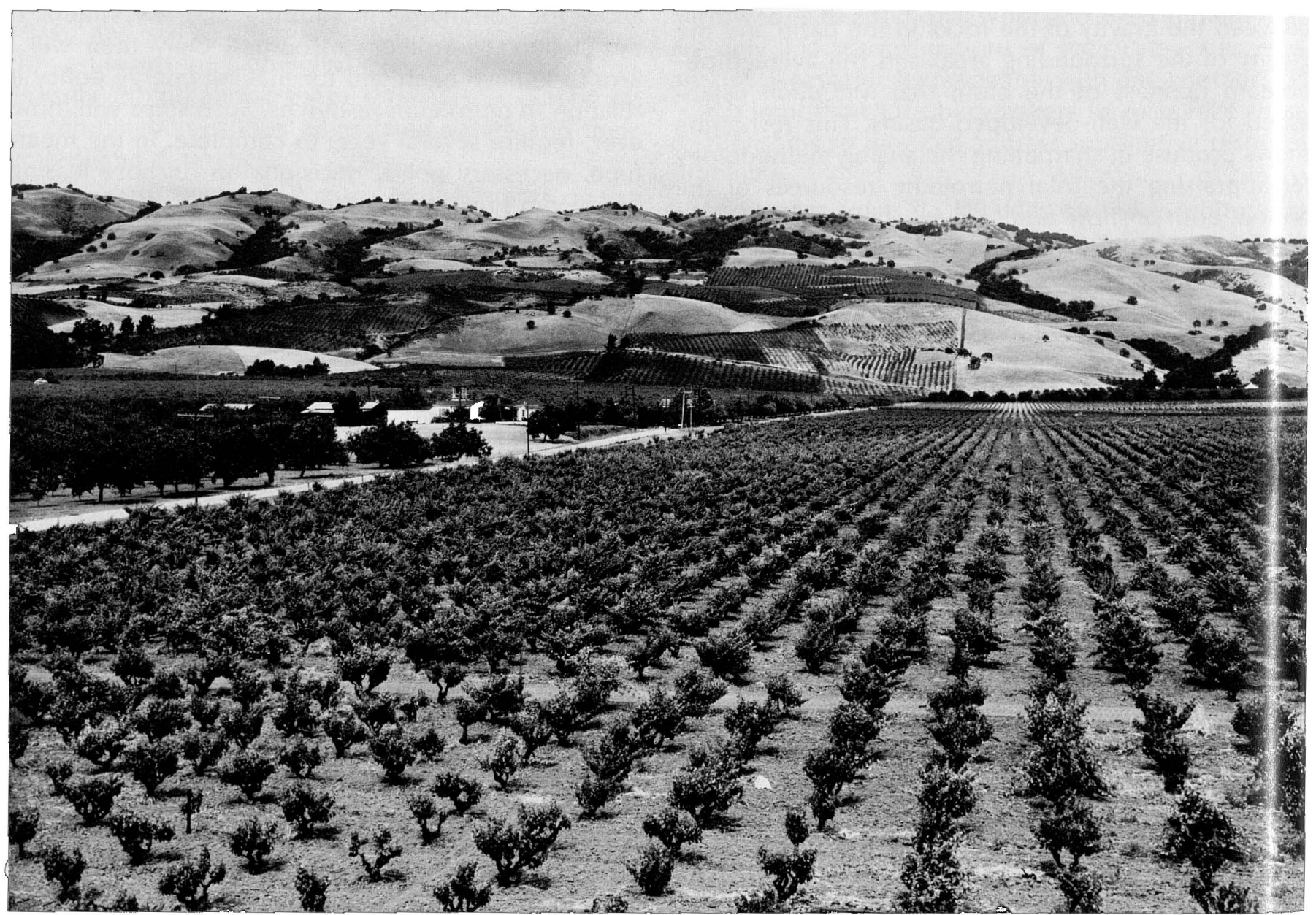

Fundamental to an increasing global population is the expansion of food production, which requires preservation of good agricultural land. (Photograph courtesy of Wine Institute, San Francisco, Calif.) 


\section{Earth Sciences and the Urban Environment}

\section{By DONALD R. NICHOLS}

Cities have been built and have either prospered or declined and died because of the natural attributes of their locations. Only recently has there been much awareness of the role that earth sciences can play in defining the urban environment and in offering alternatives for its development and enjoyment.

Commerce traditionally has been regarded as the basis of urbanization. Commerce itself, however, is governed by the availability of resources, such as construction materials, land, water, and minerals, and by the ease of transportation, which in turn is governed by energy, topography, or the presence of navigable waterways. Where these resources have combined favorably to support large populations, cities have prospered and grown; where they have not, cities have gradually declined or even been obliterated overnight by the forces of nature. For example, the depletion of mineral resources created many ghost towns in the West; many ancient and even some relatively modern cities have disappeared because of catastrophes such as drought, duststorms, earthquakes, and volcanic eruptions.

Modern technology can overcome some resource problems by transporting water, by transmitting energy and fuel, and by moving minerals to factories, but the direct and indirect costs to the Nation's economy and environment are skyrocketing; also, opposition is growing in many areas to the export of critical resources. In addition, byproducts of modern technology produce air and water pollution that make many cities ugly, uncomfortable, and even hazardous to the health and life of their inhabitants.

\section{NATURAL RESOURCES}

Natural resources are the basis for urbanization. Without construction materials, cities could not be built; without minerals, industry could not develop and expand and most urban jobs would not exist; without fuel, factories would close and houses would be cold and unlit; without a potable water supply, society could not function; without prime agricultural land, vast concentrations of people could not be fed. Because these resources are severely limited in many areas, it is important that they be identified and judiciously developed if urban amenities are to be preserved.

Construction materials are essential to urban growth. Sand, gravel, and crushed stone are rapidly becoming scarce commodities in some urban areas because nearby sources are exhausted or are being built over or because their development is opposed as a nuisance. Such materials have a low unit value; thus, transporting them is a major factor in their cost, which roughly doubles for every 32 kilometres $(20$ miles) of transport.

Although the development of most mineral commodities does not conflict with urbanization, some jurisdictions have recognized the need to divert urbanization from potential resource areas. For example, Pima County in Arizona has adopted an ordinance prohibiting surface development over potentially mineable copper deposits. The ubiquitous oil-well pumps in commercial, industrial, and even residential districts of Los Angeles, Calif., and Oklahoma City, Okla., are striking testimony to the priority that society has placed on fuel resources.

As oil and gas become more scarce, other sources of fossil fuels become more important. It remains to be seen, however, whether the development of coal and oil shale, where it conflicts with urbanization and the quest for environmental quality, will be pursued. In any event, the rapid depletion of fossil fuels requires development of alternative energy sources if our present form of society is to be maintained. Even more fundamental to an increasing global population

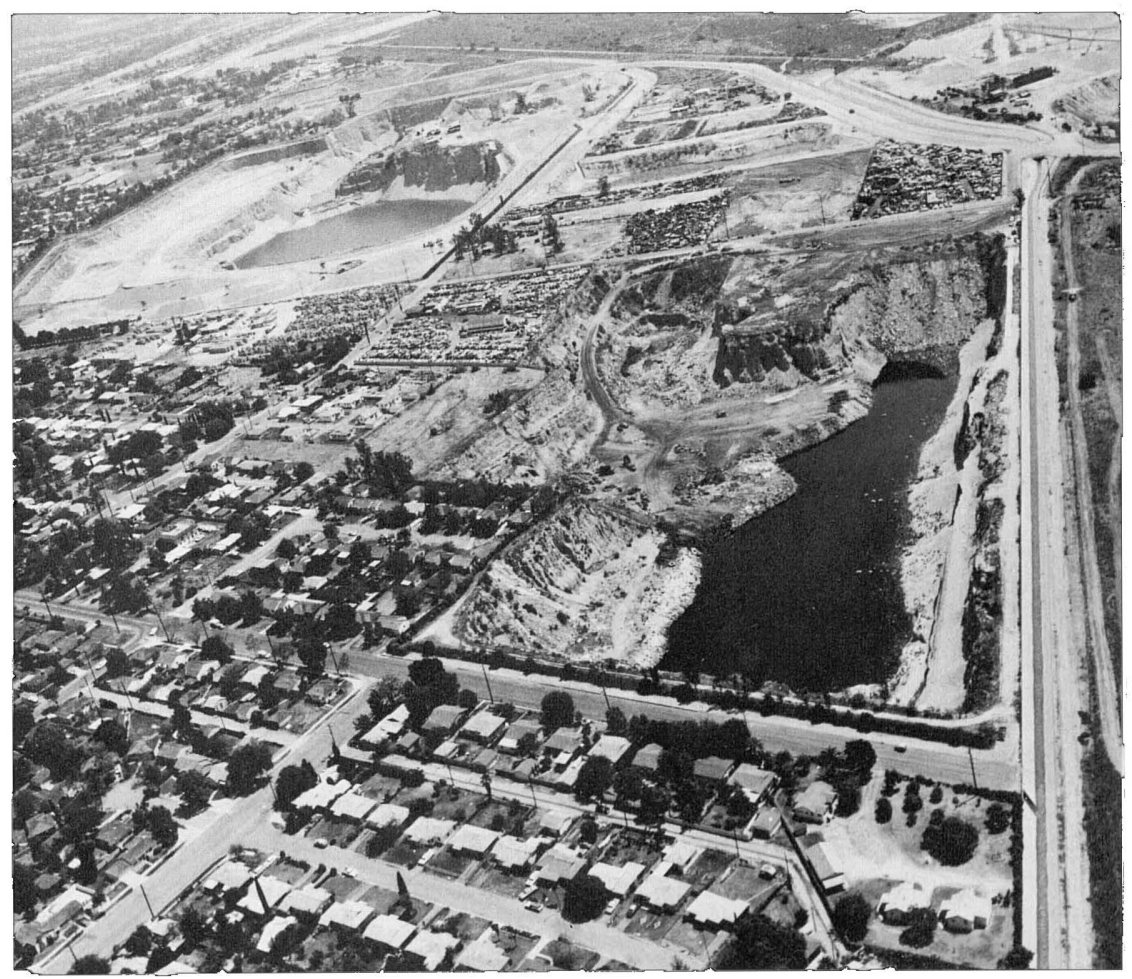

Sand and gravel are becoming scarce because many sources are being exhausted or built over or because their development is opposed as a nuisance. (Photograph courtesy of Los Angeles City Department of Building and Safety.) 
is the expansion of food production, which requires preservation of good agricultural land and water supplies and the production of fertilizers. These prerequisites are being threatened, however. For example, prime agricultural land is being converted to housing tracts, and the mining of phosphate, a critical fertilizer ingredient, is in conflict with other land use values in some areas.

Although water is usually not considered a depletable commodity, as are minerals and fuels, adequate good-quality water supplies are of special concern in most urban areas. This concern arises from the increasing demands placed on locally limited water supplies and the effects of urbanization on water quality. Urban areas compete for existing surface-water supplies from streams and reservoirs; suitable reservoir sites are few and often are in conflict with other land uses. Only by regional or, in some cases, statewide or interstate water-resource planning can serious shortages be averted.

Continuous heavy withdrawal of ground water, coupled with urbanization that paves recharge areas and that greatly increases storm runoff, has severely depleted supplies in many areas. Additionally, industrial and residential wastes have polluted both surfaceand ground-water sources. In the case of ground water, the effects of existing waste-disposal practices (for example, poorly designed landfills, leaky sewer systems, and septic tank systems) may not become evident for decades; where serious ground-water pollution has occurred, as it has in some areas of acid mine-water drainage, water supplies may not become potable for tens of years, if ever. It is essential, therefore, that critical ground-water supplies be identified and wisely managed.

Just as conflicts over the use of the land surface grow, so has competition for the use of the subsurface. The shallow subsurface has long been used to store and filter effluents from septic tank systems and industrial and urban wastes. In recent decades, deeper zones have been used to store industrial wastes and toxic fluids. Existing underground openings in mines and new, specially designed excavations are used increasingly, particularly in urban areas; stormwater runoff is stored temporarily in tunnels in the Chicago, III., area; natural gas is stored for peak urban use in manmade caverns in many areas; factories and warehouses occupy excavations beneath Kansas City, Mo.; tunnels are being designed, built, or expanded for utilities and rapid transit systems in many larger cities. Development of all underground resources requires extensive and detailed subsurface geologic and hydrologic data to determine their capacity for development.

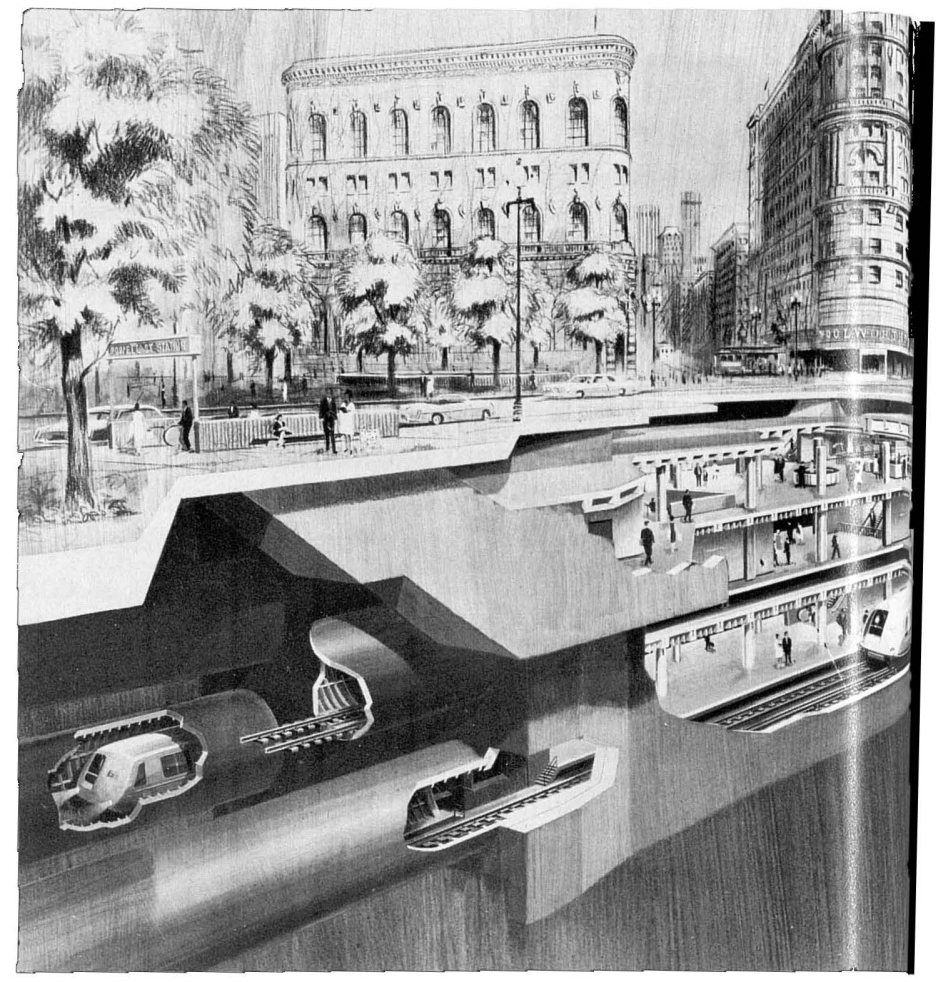

Development of all underground space requires extensive and detailed subsurface geologic and hydrologic data. (Photograph courtesy of San Francisco Bay Area Rapid Transit District.)

\section{HAZARDS}

Natural hazards are taking an increasing toll of life and property. Catastrophic landslides that have claimed large numbers of lives include earthquakegenerated avalanches that killed 30,000 Peruvians in 1970 and 830,000 Chinese in 1556 . Not all destructive landslides are triggered by earthquakes, however. Almost 3,000 people were killed in 1963 when a large earth mass, lubricated by a rising water table, slid ir to the Vaiont Reservoir in Italy. The resulting overflow destroyed several towns (fig. 7). We court similar disasters in the United States by building reservoirs in valleys underlain by active faults or on the flanks of volcanoes that have produced debris avalanches.

Aside from such infrequent catastrophic events, thousands of landslides occur annually throughout the United States, especially in urban areas where residential development, seeking new ground for expansion, has moved into "view" sites on hillslopes, many of which are already unstable. Cutting into these slopes, adding water to lawns, concentrating runoff from roofs and streets, and other acts of man catise landslides estimated to cost over $\$ 200$ million annually. Typical damage during a single winter has been documented for only a few areas; damages of more than $\$ 25$ million occurred in the nine-county San Francisco Bay region (Taylor and Brabb, 1972), 
$\$ 6.25$ million in the Los Angeles area (Yelverton, 1971), and $\$ 250,000$ in the vicinity of Seattle, Wash. (Tubbs, 1974).

Most losses from flooding and erosion are predictable and can be avoided. Despite that, flooding is the most widespread natural hazard in the United States and accounts for the largest average annual property losses (White and Haas, 1975, p. 255). Nearly all cities were founded beside rivers and along coasts to be close to both the water supply and a convenient means of transportation and to enjoy the scenic views. When man encroaches on river flood plains or coastal plains, he is subject to havoc from rapid runoff of melting snow, intense rainfall, hurricanes, tsunamistidal surges caused by submarine landslides-and accelerated erosion and sedimentation (table 2). Erosion along shorelines of rivers, along Lakes Michigan and Erie, in coastal California, along the Gulf Coast, and along the Atlantic is both costly and hazardous to owners of waterfront property. Major engineering works to prevent flooding and erosion in many cases succeeded only in postponing the hazard or in diverting it and intensifying it in another area.

Earthquakes pose the greatest potential hazard to many urban areas of the United States. A great earthquake today in Los Angeles or San Francisco, Calif., or a repeat of the Charleston, S.C., earthquake of 1886 would probably result in the loss of tens of thousands of lives and many billions of dollars in property damage. Most of these losses would be caused by building collapse owing to vibration or to failures in the ground beneath them (landslides and liquefaction). Losses also would result from surface ruptures along active faults that underlie many urban towns along the $\mathrm{Pa}$ cific coast and in other parts of the West.

Subsidence of the land surface owing to groundwater withdrawal occurs in many densely populated areas in Alabama, Florida, Missouri, Texas, Louisiana, Arizona, and California. Individual houses and even entire cities have suffered major property damage; losses are likely to continue for several years, even after the causes are identified and eliminated. Land subsidence of as much as 2.5 metres (8 feet) in the Houston-Galveston area of Texas has been estimated to cost $\$ 110$ million. Even greater amounts of subsidence have occurred in San Jose (4 metres, 13 feet) and Long Beach (8 metres, 26 feet), Calif., the latter being due to oil withdrawal. The Baldwin Hills Reservoir failure in Los Angeles that killed five people in 1954 is generally attributed to subsidence resulting from oil-well operations. Subsidence also occurs in other States over formerly mined areas, natural cavities and caverns, and heavily pumped oilfields.

Volcanic activity during historic time in the United States fortunately has been infrequent and restricted to remote areas. Elsewhere, however, the complete burial of Pompeii, Italy, in 79 A.D. and of St. Pierre on the island of Martinique in 1902 and the rapid growth to a height of 366 metres $(1,200$ feet) of the Parícutin Volcano on farmland in Mexico in the mid-1940's serve

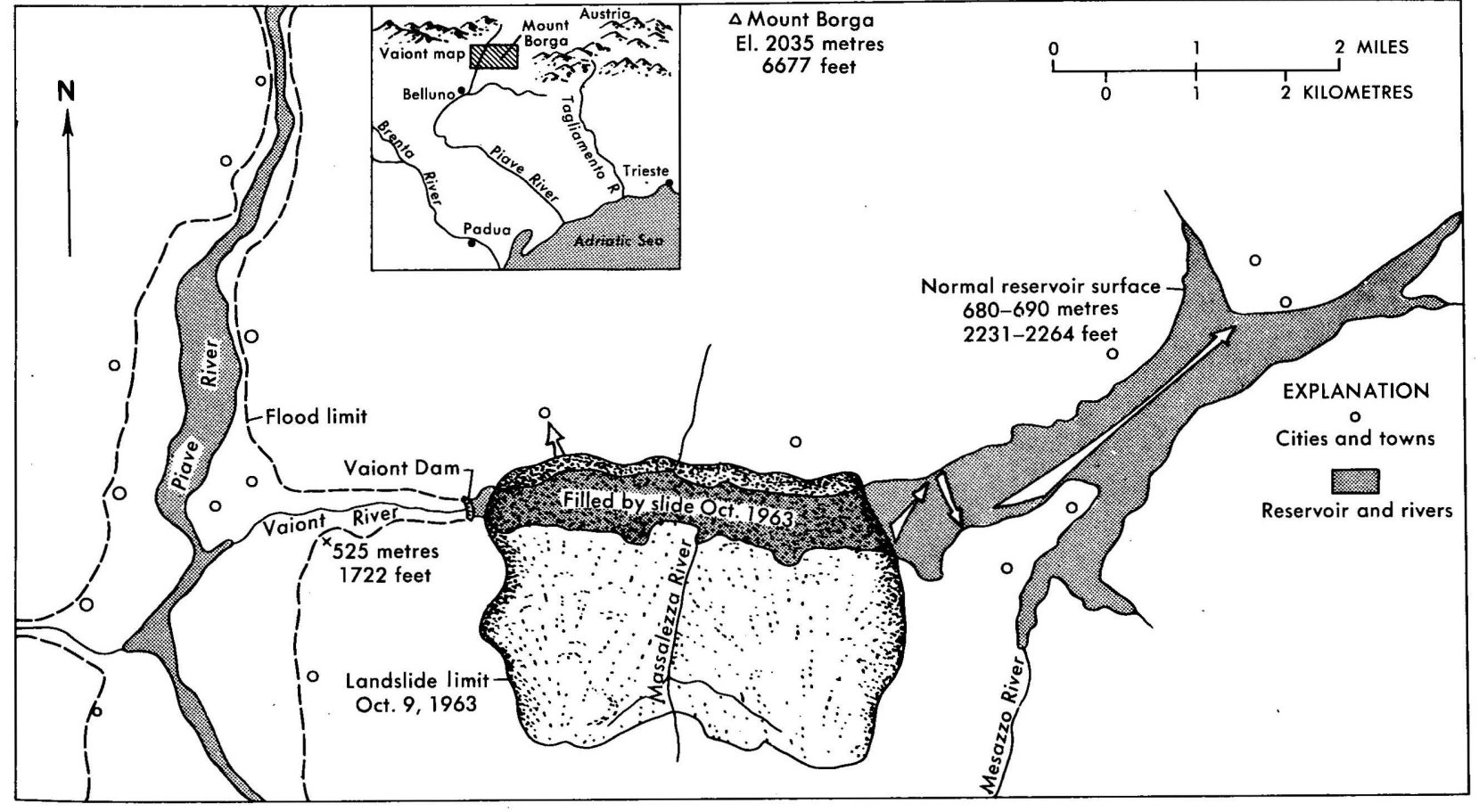

FIGURE 7.- Sketch map of Vaiont Reservoir in Italy showing the 1963 landslide which created waves that overtopped the dam and caused flooding and destruction over large areas downstream (modified from Kiersch, 1964, fig. 1). 


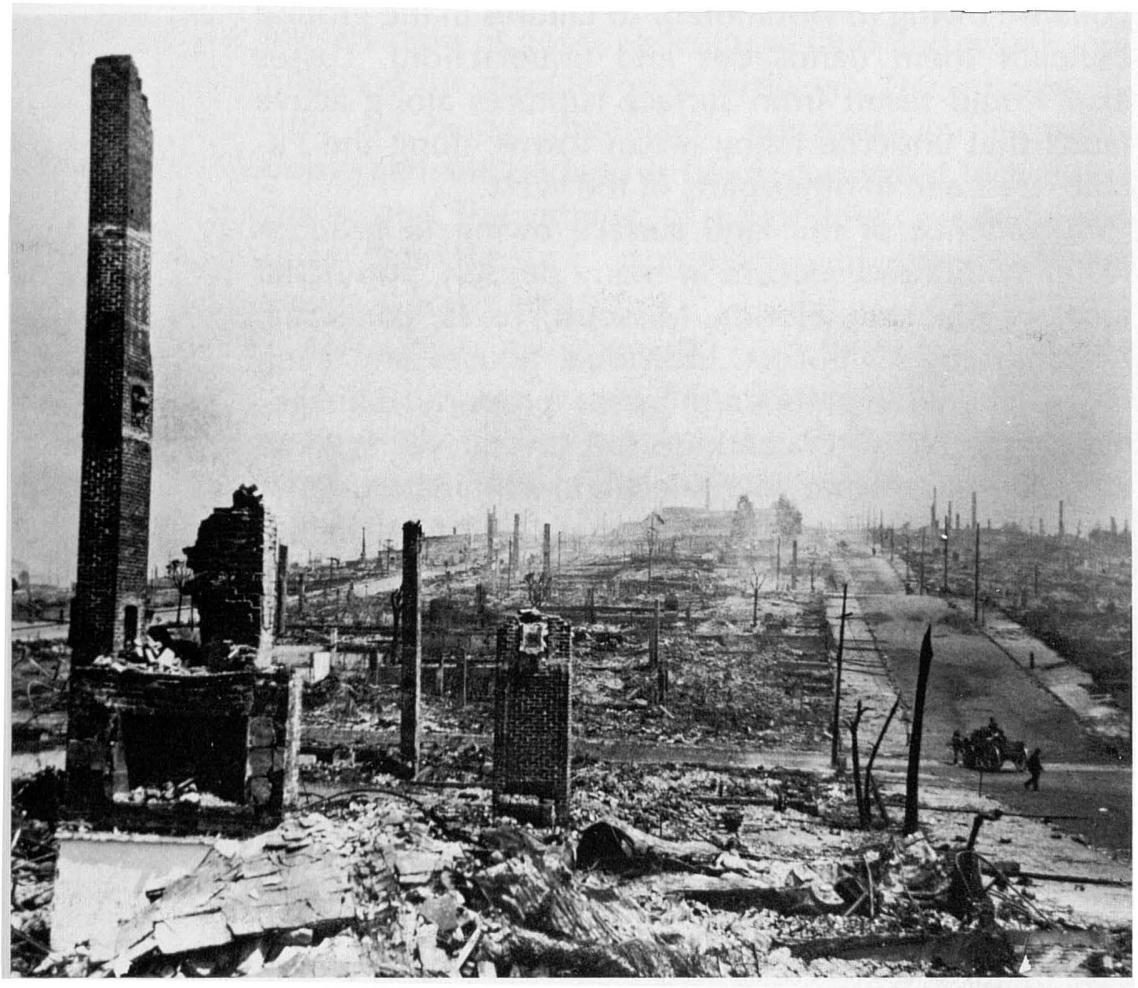

A great earthquake today in Los Angeles or San Francisco would probably result in the loss of tens of thousands of lives and many billions of dollars in property damage.

as reminders that we live on a dynamic planet. Large areas in the Western United States, including many urban areas (Hilo, Hawaii; Portland, Oreg.; and Seattle, Wash.) are adjacent to major volcanic eruptive centers. A residential subdivision near Hilo is located on a series of lava flows, the most recent of which erupted from Kilauea in 1955. The renewal of volcanic activity in 1975 on Mount Baker, east of Bellingham, Wash., is a cause for concern in the Puget Sound area. The location and frequency of future volcanic activity are unknown, but the consequences are predictable in some areas.

The safe disposal of wastes is closely interrelated with geologic and hydrologic phenomena and conditions. Certainly, a better understanding of geologic processes and environments, combined with the application of established engineering practices, could have averted the Buffalo Creek, W. Va., disaster, where failure of coal-mine waste piles claimed 118 lives in 1972. The potential hazards from nuclear waste disposal; many types of industrial and mining operations; overconcentrations of fertilizers, herbicides, and insecticides; livestock feedlots; and municipal sewage and trash disposal have long been recognized. For example, a recent newspaper article (Washington Post, September 29, 1975) cited authorities in Tampa, Fla., as saying "High levels of radiation, which could
TABLE 2.-Examples 'of catastrophic losses to property and lives from single hydrologic events affecting low-lying land

\begin{tabular}{|c|c|c|}
\hline Event & $\begin{array}{l}\text { Property } \\
\text { losses } \\
\text { (millions } \\
\text { of } \\
\text { dollars) }\end{array}$ & $\begin{array}{l}\text { Fatali- } \\
\text { ties }\end{array}$ \\
\hline $\begin{array}{l}\text { Rapid runoff from melting snow } \\
\text { (Vanport, Oreg., flood, 1948)_-- } \\
\text { Intense rainfall }\end{array}$ & $\$ 103$ & 51 \\
\hline $\begin{array}{l}\text { (Rapid City, S. Dak., 1972) } \\
\text { Hurricane Agnes (1972) } \\
\text { Hurricane Camille (1969) } \\
\text { Tsunami }\end{array}$ & $\begin{array}{r}128 \\
3,100 \\
1,400\end{array}$ & $\begin{array}{l}238 \\
117 \\
258\end{array}$ \\
\hline (Hawaii, 1946) & 25 & 159 \\
\hline $\begin{array}{l}\text { Tsunami } \\
\quad \text { (Crescent City, Calif., 1964) } \\
\text { Submarine landslides }\end{array}$ & 11 & 10 \\
\hline $\begin{array}{l}\text { (Valdez and Seward, Alaska, } \\
\text { 1964) }\end{array}$ & 27 & 42 \\
\hline
\end{tabular}

in houses built on reclaimed phosphate mining lands in southwest Florida." Similar accounts have come from Colorado, Missouri, and other States.

\section{CONSTRAINTS AND OPPORTUNITIES IN LAND USE MANAGEMENT AFFORDED BY EARTH SCIENCES}

Man has lived with and surmounted natural hazard and finite resource problems without much serious consequence throughout his history. Why should there suddenly be such strong concern for earthscience problems? Some reasons are obvious. The total dependency of urbanization and technology on natural resources and on a stable and conducive urban environment was no problem as long as (1) resources were plentiful, (2) population growth did not exceed the capability of the land and water 0 absorb the resultant wastes, and (3) complex ecanomic and industrial centers did not concentrate in hazard areas. Recognition of the constraints that the Earth places on its exploitation is a first step in developing opportunities for continued growth through effective land and water management.

Natural resources can be harvested in such a way that the land surface and subsurface can still be put to other vital uses. Planning and development to tale advantage of these uses, however, rest upon (1) recognition of resource areas, (2) definition of geologic ard hydrologic controls, (3) ultimate potential uses of the land, (4) environmental consequences of development, (5) imaginative management, and (6) an enlightened public that has the will and patience to conserve resources and guide sequential use of the land.

After resource extraction, open-pit mines can be used for recreational lakes, for flood storage and desilting basins, for buried underground structures, and for disposal of solid wastes and subsequent reclamation and development of the surface. Ground-water recharge areas can be used for nonintensive agriculture and grazing or as parkland. Treated sewage can 
be injected into aquifers to form barriers against saltwater intrusion. Underground mines sometimes can be reclaimed for solid-waste disposal, storage, or even for industrial sites.

Future development can minimize natural hazards by avoiding high risk areas and, at the same time, provide for such environmental amenities as open-space and recreational areas. Applying earth-science information can avert most hazard losses in new construction and reduce them in existing structures. Where hazards to structures cannot be mitigated, alternative land uses are possible. Golf courses, nurseries, agriculture, parks, and many other land uses are compatible with active faulting, landsliding, flooding, and volcanic hazards. Existing mechanisms that can be used to encourage future development and redevelopment in low-risk areas include public education, land use planning, zoning, public acquisition, and tax incentives, when they are properly based on a knowledge of natural conditions and processes.

Less catastrophic but equally or more costly problems, such as subsidence, swelling soils, erosion, and weak foundation conditions, can be overcome by knowing where and why they occur, how severe they are, and how to engineer for them. For example, corrective construction design and practice, stimulated by building codes, allow development on swelling or compressible soils without serious consequences.

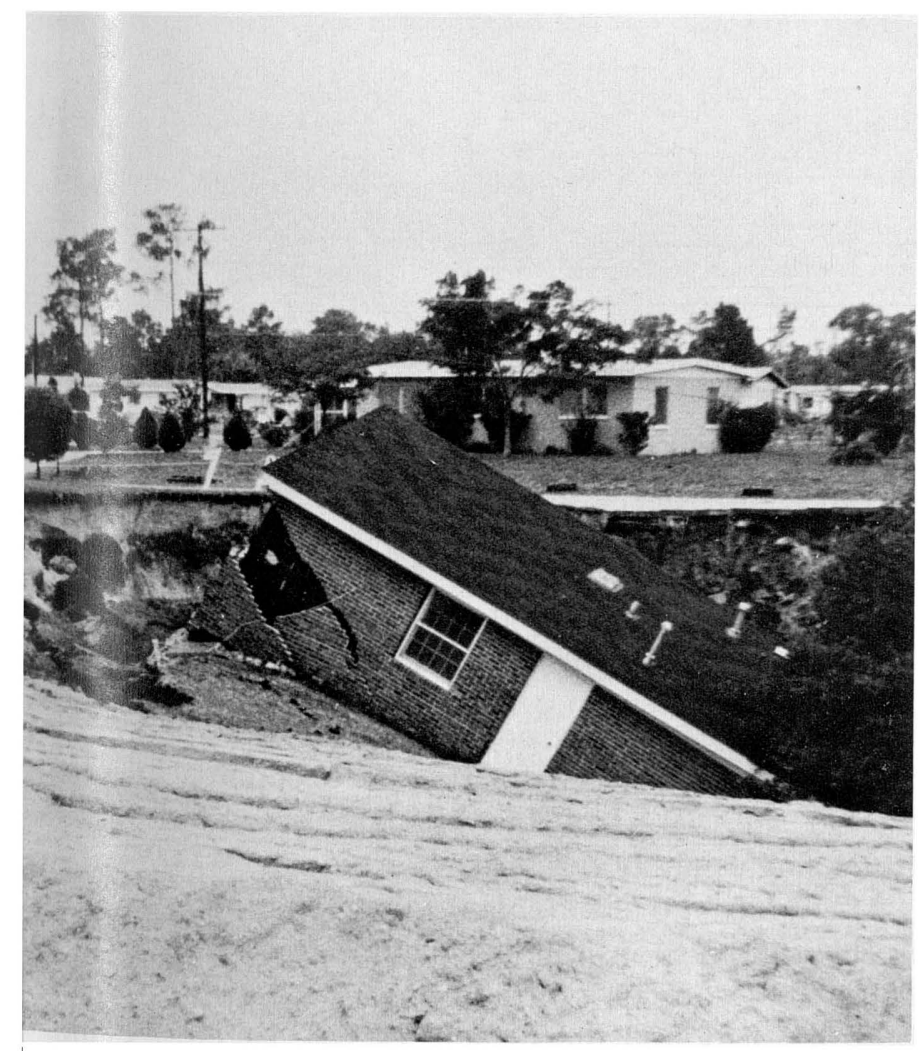

Individual houses and even entire cities have suffered major property damage owing to subsidence.

\section{STATUS OF EARTH SCIENCES IN THE URBAN ENVIRONMENT}

The U.S. Geological Survey, its sister State surveys, and the earth-science professions have a long and proud history of service to society. Geologists, hydrologists, and topographers, through nationwide mapping programs that have identified mineral, water, and energy resources, have provided the basis for current urban and technological development.

Today, earth scientists are becoming more active in relating their work directly to urban problems. More scientists, at all levels of government and in the private sector, are working in urban areas, making their studies more easily understandable to nonscientists, and participating in public forums. Consequently, many people now have a much greater awareness of the role that the earth sciences play in governing the quality of life in the urban environment.

This awareness is reflected in recent legislation such as the National Environmental Policy Act (Public Law 90-190) of 1969, the Flood Insurance Program of 1968, which was amended in 1973 to include mudslide insurance, and the Federal Water Pollution Control Act (Public Law 92-500) of 1972, and the act establishing the Environmental Protection Agency. In addition, several Federal agencies are actively seeking a greater application of earth science in their programs. For example, the Department of Housing and Urban Development joined with the Geological Survey in sponsoring a program to develop and apply earth-science information in support of land use planning and decisionmaking in the San Francisco Bay region. Similarly, the Department of Transportation and the Appalachian Regional Commission have provided funds for the Geological Survey to conduct geologic, geographic, hydrologic, and topographic studies in urban areas and to relate them to urban and regional planning needs. Leading this effort was a new program initiated by the Survey in 1971 to conduct a series of interdisciplinary earth-science studies in representative urban areas across the country. Many new and innovative products and techniques are outgrowths of the program, including regional topographic maps at scales of 1:100,000 and 1:125,000; orthophoto quadrangles at a variety of scales and with overprinted contours; slope maps; maps delineating potential hazards such as floods, active faults, landslides, and mine subsidence; maps delineating the availability of ground water, the potential for copper deposits, and other mineral and construction resource maps; and land capability studies.

At the same time, many States have undertaken earth-science studies in urban areas and have adopted legislation for their application to land use problems. 


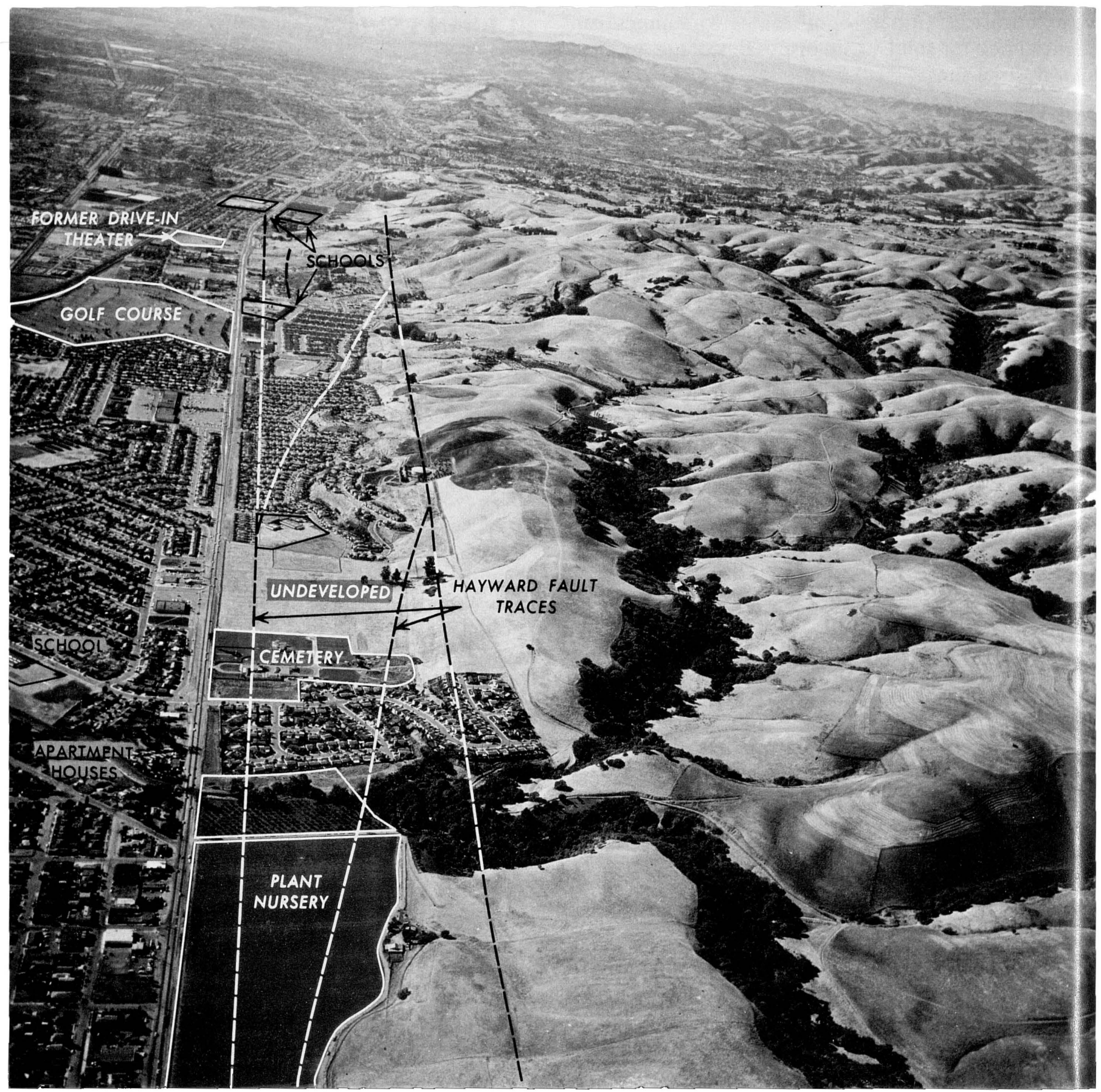

A plant nursery, undeveloped open space, a freeway, and a cemetery are land uses most compatible with the hazards posed by this active fault. Other uses might include a drive-in theater, a golf course, a riding stable, and other recreational activities.

Alabama, California, Florida, Illinois, and Texas are among the States that have provided leadership in collecting, interpreting, and applying geologic, hydrologic, and soils data to urban decisionmaking. Two noteworthy examples of a State's concern for geologic hazards are California Senate Bills 351 (1971) and 520 (1972). Senate Bill 351 requires that all community general plans include a seismic safety element which assesses hazards from earthquake faulting, ground shaking, ground failure, and seismic sea waves.
Senate Bill 520 initially prohibited the construction of any structure intended for human occupancy on tie trace of an active fault but was later amended to exclude single-family residences.

Many local governments have independently faced up to their responsibilities to minimize hazards and conserve resources in urban areas. As early as 1952, both the City and the County of Los Angeles, Calif., required geologic studies to be made before construction was allowed in hazard areas. Since 19\%2, 
four counties and a major city in the San Francisco area have employed geologists on their staffs to review development plans, assist in general planning, and guide public-works construction. Geologists are now similarly employed in Tucson, Ariz., Boulder and Lakewood, Colo., King County in Washington, and other areas. Long Island, N.Y., Orange County in California, and Houston, Tex., are among the many urban areas that have adopted controls to limit the withdrawal and degradation of ground-water resources.

Private industry, which had employed geologists, hydrologists, and geotechnical engineers largely to correct costly foundation failures, now is employing an increasing number of private consultants in advance of site selection and development. Earth scientists contribute not only to the siting and construction of major urban-related structures such as dams, powerplants, highways, and office and apartment buildings, but also to the planning and designing of new communities.

\section{THE FUTURE}

As people continue to concentrate in cities, earth science becomes increasingly important in maintaining an acceptable environment. Urbanization, already so dependent on limited mineral, water, energy, and agricultural resources, will stagnate and wither unless critical resources are conserved, new resources are found, and the effects of potential catastrophic natural disasters are minimized. The future also affords many new opportunities to correct past mistakes and avoid new ones. As cities age, redevelopment should not concentrate populations in previously developed areas of potential hazards and costly foundation conditions. In the past, development generally proceeded first in areas of flat ground having good foundation conditions, but often on flood plains, sand and gravel deposits, ground-water recharge areas, and prime agricultural land, and avoided land more costly to develop (often unstable hillslopes and other hazard areas). When land was plentiful and cheap, earth science was not critical to development. More recently, development has tended to "fill in" the still open hazard areas. With less land available, increasing development costs, and major potential hazards, earth science becomes more critical in guiding urban development.
As the use of earth science grows, so will the ability of the science to devise means of collecting and applying knowledge. Computer-assisted mapping and display techniques are evolving that combine a variety of earth-science and related data and will allow legislators to rapidly assess planning solutions and the consequences of alternative courses of actions (Stewart and Van Driel, in press). Opportunities also are in sight to use Landsat and other Earth satellites more fully in monitoring environmental and land use changes. New geophysical techniques, remote sensing tools, and the data collection and relay capacities of satellites can greatly reduce the cost of data collection and the speed with which data can be interpreted and synthesized.

Earth-science information is useless, however, without effective communication and application. Earth, natural, and social scientists must work diligently to communicate with one another, with decisionmakers, and with the public. Where earth-science expertise exists in support of the planning process, opportunities are enhanced for partnerships between local, State, and Federal agencies to effectively address urban problems. A start has been made under the Geological Survey's pilot Urban Area Studies program. However, a much greater effort is necessary if the earth sciences are to assume their full responsibilities in helping to guide future urbanization.

\section{REFERENCES}

Kiersch, G. A., 1964, Vaiont Reservoir disaster: Civil Eng., v. 34, no. 3, p. 32-39.

Stewart, J. C., and Van Driel, J. N., in press, The role of computer mapping in the decisionmaking process for Montgomery County, Maryland: Am. Inst. Planners Ann. Conf., 57th, San Antonio, Tex., Oct. 25-29, 1975, Proc.

Taylor, F. A., and Brabb, E. E., 1972, Map showing distribution and cost by counties of structurally damaging landslides in the San Francisco Bay region, California, winter of 196869: U.S. Geol. Survey Misc. Field Studies Map MF-327, scale 1:500,000.

Tubbs, D. W., 1974, Landslides and associated damage during early 1972 in part of west-central King County, Wash.: U.S. Geol. Survey Misc. Inv. Series Map I-852-B, scale 1:48,000.

White, G. F., and Haas, J. E., 1975, Assessment of research on natural hazards: Cambridge, Mass., MIT Press $487 \mathrm{p}$.

Yelverton, C. A., 1971, The role of local governments in urban geology, in Nichols, D. R., and Campbell, C. C., eds., Environmental planning and geology: Washington, D.C., U.S. Geol. Survey and U.S. Dept. Housing Urban Devel., p. 76-81. 


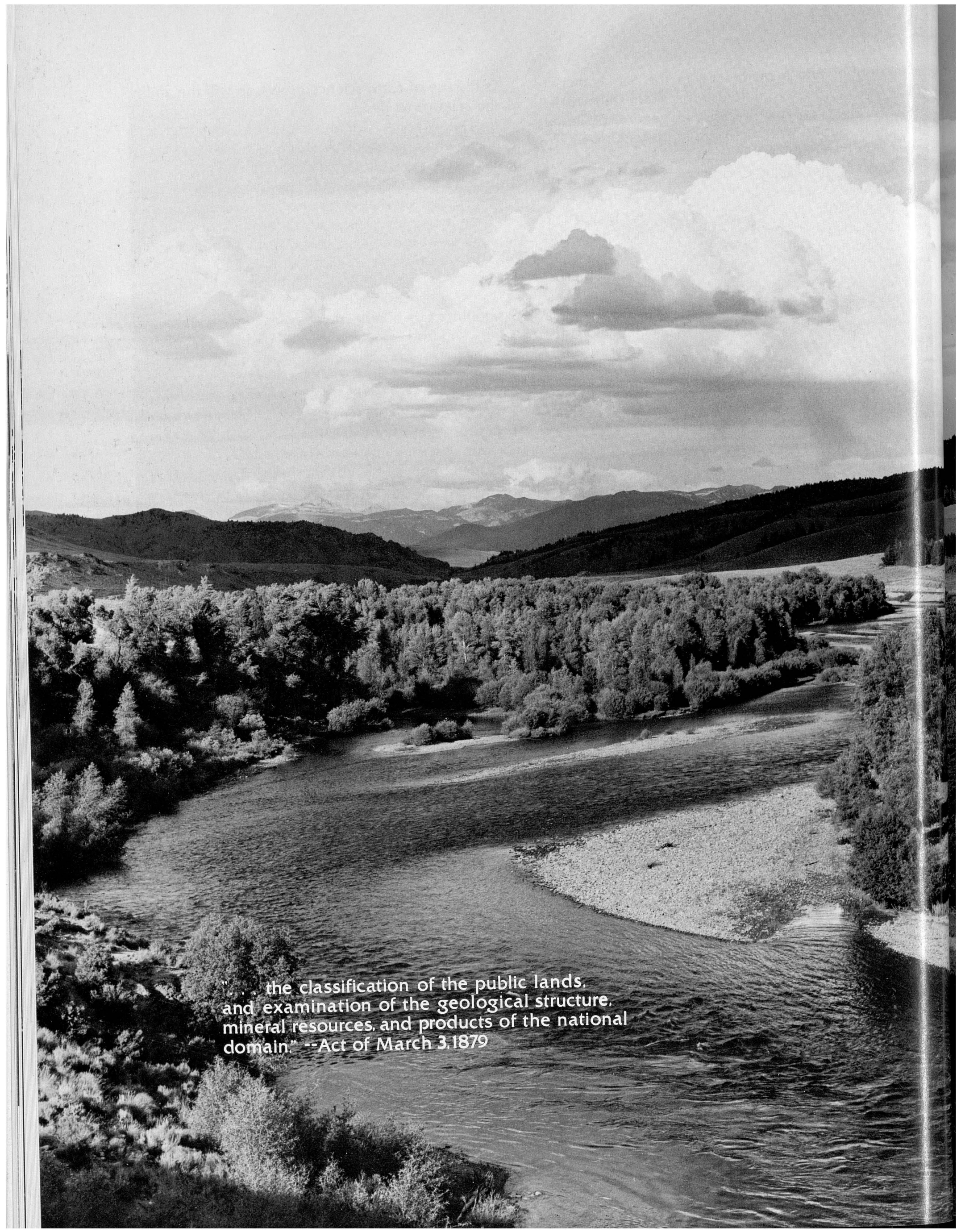




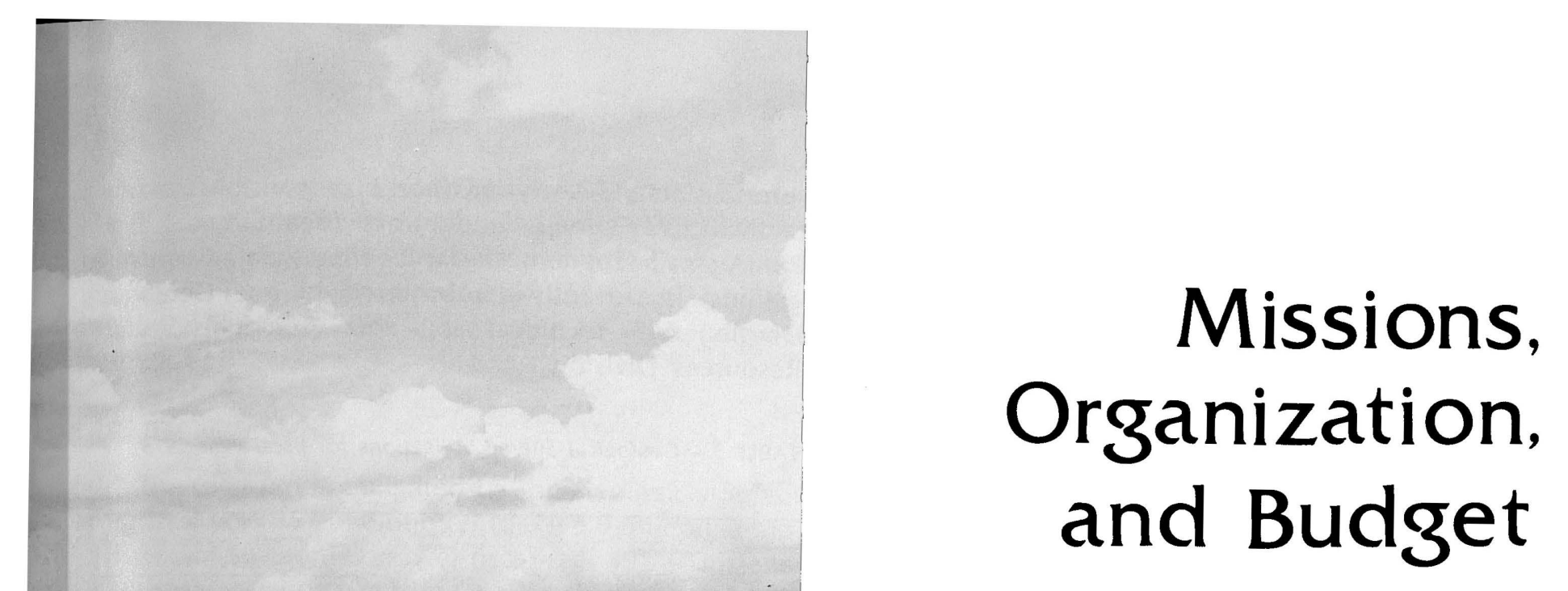

For more than 96 years, the U.S. Geological Survey has served Federal, State, and local governments and the public by collecting, analyzing, and publishing detailed information about the Nation's mineral, land, and water resources. The Geological Survey was originally created in 1879 to study the geologic structure and mineral resources of the public domain and to provide information to support development of the West. Congress and the Secretary of the Interior later expanded the Survey's responsibilities to include: topographic mapping, chemical and physical research, stream gaging and water-supply assessments, supervision of mineral exploration and development activities on Federal and Indian lands, administration of a minerals exploration program, and engineering supervision of waterpower permits.

Although the emphasis and balance of the Survey's programs have changed over the years, these programs still retain the fact-finding mission described in the brief enabling legislation of 1879. Today the Survey's broad mission is to enlarge the knowledge of the extent, distribution, character, and origins of the Nation's natural resources and of the geologic processes that affect the use of the land so that man may intelligently adjust his activities to the constraints imposed by the environment and may wisely manage the Earth's resources. The Survey's regulatory responsibilities-classifying Federal lands and supervising mineral lease development on Federal and Indian lands-are no less important. By working closely with the Bureau of Land Management and other land management agencies, the Survey seeks to identify, conserve, and supervise development of the Nation's public resources so that the public receives its fair share for leased resources and so that damage to other resource, environmental, and social values are minimized during exploration and development.

Both missions call for objective and impartial reporting of investigations, identification of natural constraints on land use and resource development, and analyses of the consequences of alternative policies or actions related to resource development, conservation, or environmental protection. 


\section{ORGANIZATION}

The scientific and regulatory missions of the Geological Survey are carried on by five organizational units, each of which has responsibilities for one of the Survey's major programs or budget activities (see the organization chart and table 25 in the section "Organizational and Statistical Data."

- The Topographic Division produces maps delineating the physical features of land areas in the United States, its outlying areas, and Antarctica. The Division also collects and distributes information on the availability of aerial photographs and space images, maps and charts, geodetic data, and related cartographic information through its National Cartographic Information Center.

- The Geologic Division, through research on geologic processes and Earth history, provides information that permits intelligent adjustment to the national environment and wise use of the Earth's resources. The Geologic Division determines the composition and structure of the rocks and materials that lie at and beneath the Earth's surface, identifies potential energy and mineral resources including those of the Outer Continental Shelf, and develops and distributes knowledge about natural hazards such as earthquakes, volcanic eruptions, and land subsidence.

- The Water Resources Division assesses the quantity and quality of the Nation's water supply, develops the knowledge necessary to predict the environmental consequences of alternative plans for developing water resources, coordinates Federal waterdata acquisition activities, collects and distributes information about the availability of water data through the National Water Data Exchange, and develops and distributes information about natural hazards such as floods and land subsidence.

- The Conservation Division classifies the public lands with respect to leasable minerals and waterpower sites, and supervises exploration and development authorized under leases and permits on Federal and Indian lands.

- The Land Information and Analysis Office coordinates and administers interrelated interdisciplinary programs of both the Department of the Interior and the Geological Survey with the objective of interpreting and displaying resource information in ways that are readily accessible and understandable to a wide range of potential users, particularly land use planners and decisionmakers.

The structure of the Geological Survey's budget closely parallels the structure of the organization. Each program division (Topographic, Geologic, Water Re-
Information and Analysis Office) is responsible for one of the Survey's major budget activities (tables 3 and 25). A small program, Alaska Pipeline Related Investigations, is currently administered by the Geologic Division with technical assistance from the Water Resources Division.

TABLE 3.-Geological Survey obligations for fiscal year 1975, by activity

\begin{tabular}{|c|c|c|c|}
\hline \multirow{2}{*}{ Activity } & \multirow{2}{*}{$\begin{array}{c}\text { Fiscal } \\
\text { year } \\
\text { 1975 } \\
\text { (Dollars } \\
\text { in } \\
\text { millions) } \\
\end{array}$} & \multicolumn{2}{|c|}{$\begin{array}{l}\text { Percent change relative } \\
\text { to fiscal year } 1974\end{array}$} \\
\hline & & $\begin{array}{l}\text { Current } \\
\text { dollars }\end{array}$ & $\begin{array}{l}\text { Constant } \\
\text { dollars }\end{array}$ \\
\hline Total & $\$ 338.76$ & +36 & +22 \\
\hline $\begin{array}{l}\text { Direct program } \\
\text { Reimbursable program -- }\end{array}$ & $\begin{array}{r}253.60 \\
85.16 \\
\end{array}$ & $\begin{array}{l}+48 \\
+10\end{array}$ & $\begin{array}{r}+33 \\
-1\end{array}$ \\
\hline $\begin{array}{l}\text { Alaska Pipeline Related } \\
\text { Investigations }{ }^{1}\end{array}$ & .34 & -61 & -65 \\
\hline $\begin{array}{l}\text { Topographic Surveys and } \\
\text { Mapping }\end{array}$ & 52.60 & +21 & +9 \\
\hline $\begin{array}{l}\text { Direct program } \\
\text { Reimbursable program }\end{array}$ & $\begin{array}{r}45.35 \\
7.25\end{array}$ & $\begin{array}{l}+22 \\
+11\end{array}$ & $\begin{array}{r}+10 \\
+1\end{array}$ \\
\hline $\begin{array}{l}\text { Geologic and Mineral } \\
\text { Resource Surveys and } \\
\text { Mapping }\end{array}$ & 114.48 & +56 & +40 \\
\hline $\begin{array}{l}\text { Direct program } \\
\text { Reimbursable program }\end{array}$ & $\begin{array}{l}89.02 \\
25.46\end{array}$ & $\begin{array}{r}+78 \\
+8\end{array}$ & $\begin{array}{r}+61 \\
-3\end{array}$ \\
\hline $\begin{array}{l}\text { Water Resources Investi- } \\
\text { gations }\end{array}$ & 101.44 & +15 & +4 \\
\hline $\begin{array}{l}\text { Direct program } \\
\text { Reimbursable program -- }\end{array}$ & $\begin{array}{l}53.42 \\
48.02\end{array}$ & $\begin{array}{l}+18 \\
+12\end{array}$ & $\begin{array}{l}+6 \\
+1\end{array}$ \\
\hline $\begin{array}{l}\text { Conservation of Lands and } \\
\text { Minerals }\end{array}$ & 36.08 & +98 & +79 \\
\hline $\begin{array}{l}\text { Direct program } \\
\text { Reimbursable program }\end{array}$ & $\begin{array}{r}36.03 \\
.05 \\
\end{array}$ & $\begin{array}{l}+98 \\
+22\end{array}$ & $\begin{array}{l}+79 \\
+10\end{array}$ \\
\hline $\begin{array}{l}\text { Land Information and } \\
\text { Analysis }\end{array}$ & 16.99 & +31 & +18 \\
\hline $\begin{array}{l}\text { Direct program } \\
\text { Reimbursable program }\end{array}$ & $\begin{array}{r}15.46 \\
1.53\end{array}$ & $\begin{array}{r}+35 \\
-1\end{array}$ & $\begin{array}{l}+22 \\
-10\end{array}$ \\
\hline General Administration $^{1}$-- & 3.67 & +4 & -6 \\
\hline Facilities $^{1}$ & 10.31 & +88 & +70 \\
\hline $\begin{array}{l}\text { Miscellaneous services to } \\
\text { other accounts }{ }^{2}\end{array}$ & 2.85 & +3 & -7 \\
\hline
\end{tabular}

1 Direct program.

2 Reimbursable program.

These research, fact-finding, and regulatory programs receive executive direction from the Office of the Director and technical and administrative support from the Administrative, Computer Center, and Publications Divisions. The General Administration and Facilities budget activities fund the Office of the Director, the Administrative Division, and the opera ion of the Survey's National Center facilities located in Reston, Va. Other administrative and management services provided by the Administrative Division and technical services provided by the Computer Center and Publications Divisions are financed through as- 
sessments of the program Divisions. While not a budget activity, the entry Miscellaneous services to other accounts represents reimbursements received from other Federal agencies for data-processing and publication services and for the sale of material from stock.

\section{BUDGET}

The total funds obligated by the Geological Survey in fiscal year 1975 amounted to $\$ 338.8$ million, an increase of $\$ 89.3$ million over fiscal year 1974 . This oneyear increase, much of which was aimed at strengthening the Survey's regulatory programs and at expanding energy-related resource assessments and environmental studies, represented 40 percent of the total increases received by the Survey during the past 10 years (fig. 8). While the budget has increased 197 percent since fiscal year 1966, rising prices have taken their toll. The purchasing power of the Survey's budget (in terms of constant 1967 dollars) has only increased 87 percent during this 10 -year period.

The mix of funding sources for the Survey's programs has changed markedly during the past year

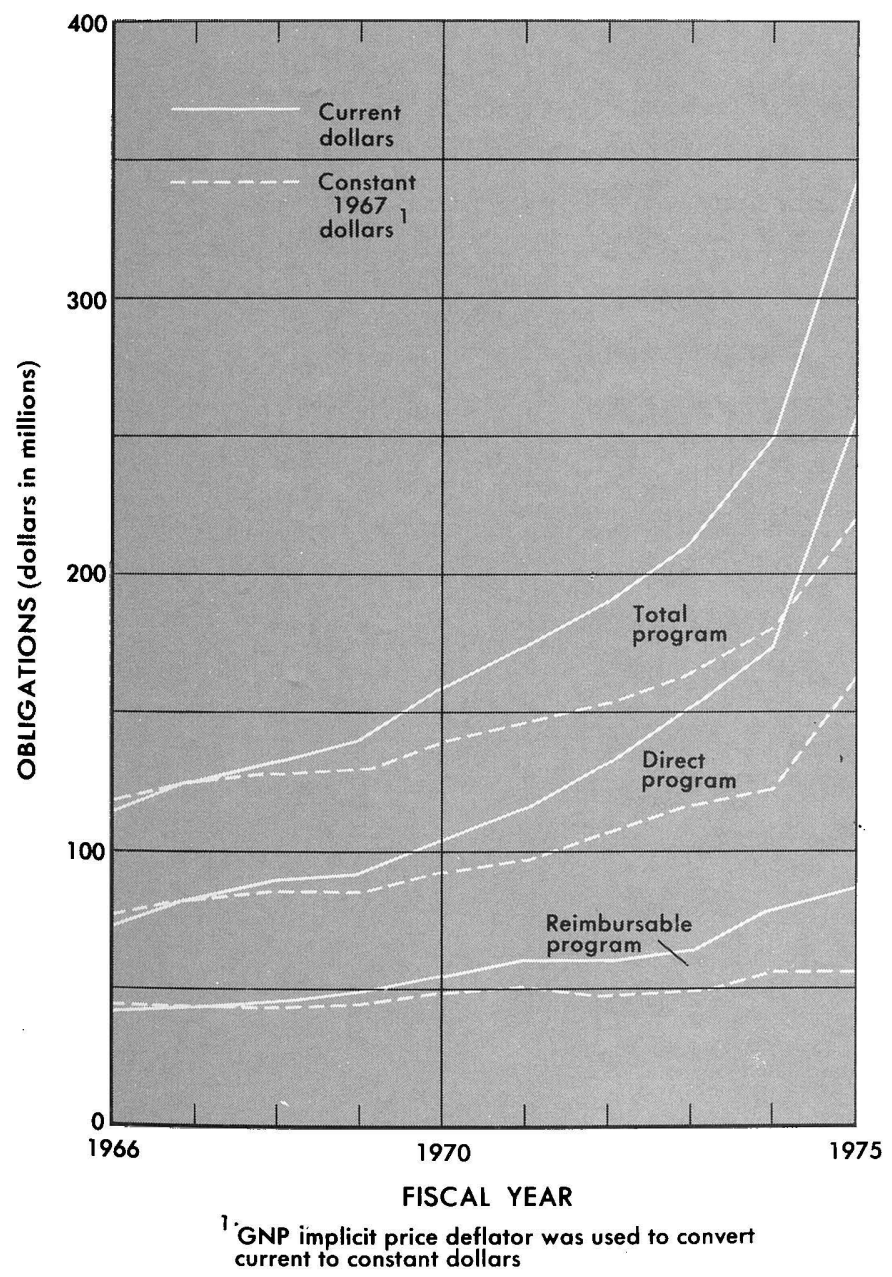

FIGURE 8.-Geological Survey budget, by source of funds, fiscal years 1966-75. because the growth rate of direct programs (funds appropriated by Congress) continued to exceed the growth rate of reimbursable programs (funds transferred to the Survey by Federal, State, and local agencies, and by miscellaneous non-Federal sources). In fiscal year 1975, about 75 percent of the total funds available to the Survey were appropriated directly to the Survey by Congress as opposed to 69 percent in fiscal year 1974 (fig. 9). While the purchasing power of the direct program increased about 33 percent, the purchasing power of the reimbursable program remained about the same as in fiscal year 1974 (table 3 and fig. 8).

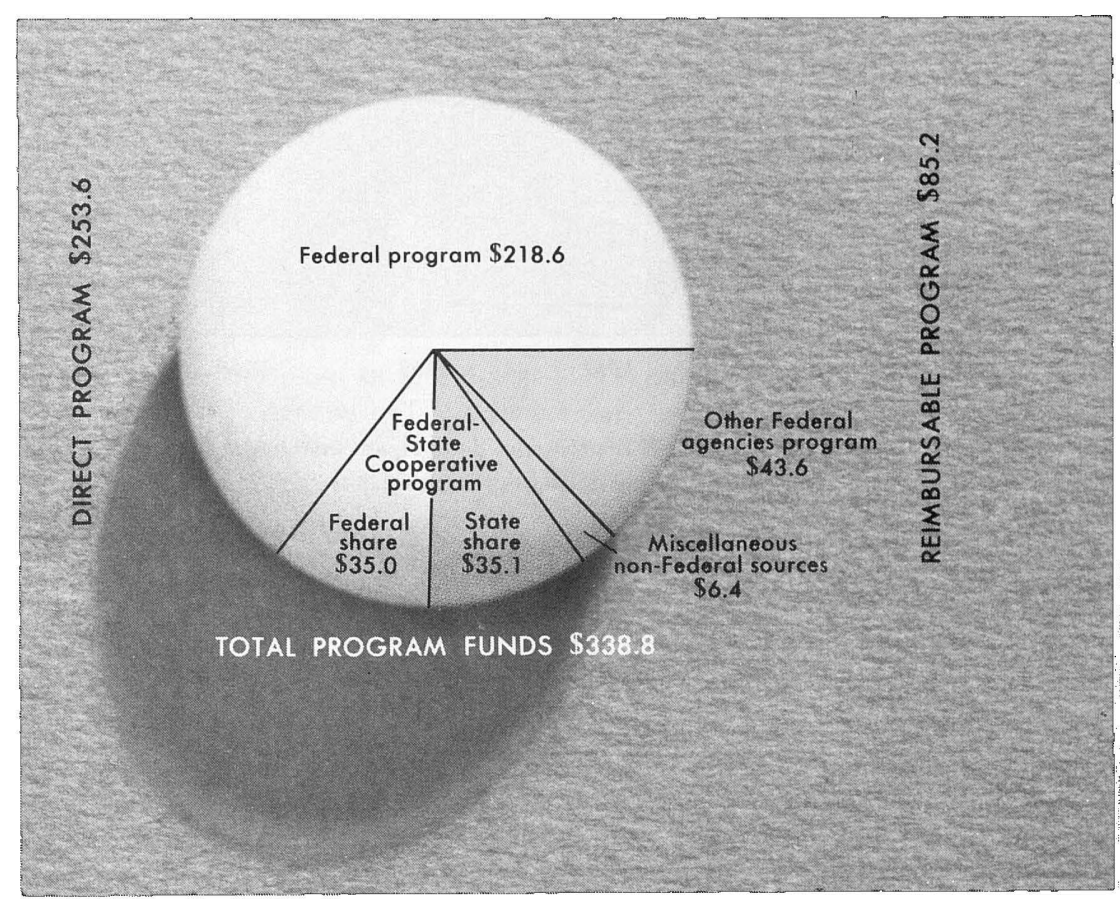

FIGURE 9.-Sources of Geological Survey funds in fiscal year 1975 (dollars in millions).

The allocation of funds to the Geological Survey's five principal budget activities (Topographic Surveys and Mapping, Geologic and Mineral Resource Surveys and Mapping, Water Resources Investigations, Conservation of Lands and Minerals, and Land Information and Analysis) has also changed rather dramatically over the last several years reflecting the increased emphasis the Survey is placing on its regulatory programs and energy-related resource appraisals and environmental studies (fig. 10). Both the Geologic and Mineral Resource Surveys and Mapping and the Conservation of Lands and Minerals budget activities underwent rapid growth in fiscal years 1974 and 1975 (fig. 10). In fiscal year 1975, the Geologic and Mineral Resource Surveys and Mapping activity comprised 34 percent and the Conservation of Lands and Minerals comprised 11 percent of the Survey's total budget (fig. 11). 


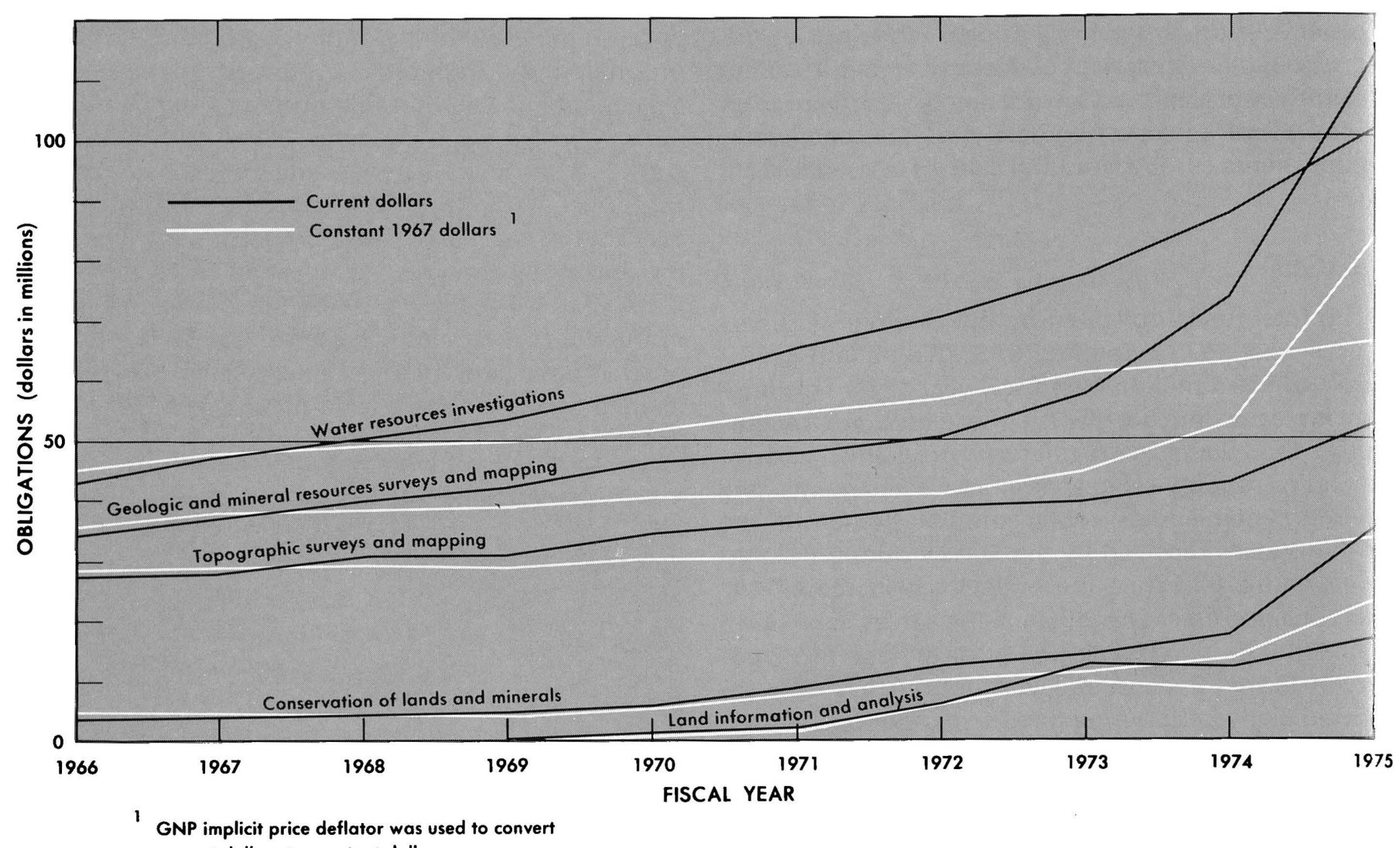

current dollars to constant dollars

FIGURE 10.-Geological Survey budget by activity, fiscal years 1966-75.

TABLE 4.-Participation of Survey organizational units in areas of study included in the fiscal year 1975 budget

\begin{tabular}{|c|c|c|c|c|c|c|}
\hline Area of study & $\begin{array}{l}\text { Topo- } \\
\text { graphic } \\
\text { Divi- } \\
\text { sion }\end{array}$ & $\begin{array}{l}\text { Geologic } \\
\text { Divi- } \\
\text { sion }\end{array}$ & $\begin{array}{l}\text { Woter } \\
\text { Resources } \\
\text { Divi- } \\
\text { sion }\end{array}$ & $\begin{array}{l}\text { Conserva- } \\
\text { tion } \\
\text { Divi- } \\
\text { sion }\end{array}$ & $\begin{array}{l}\text { Land } \\
\text { Intorma- } \\
\text { tion } \\
\text { Analysis } \\
\text { Office }\end{array}$ & $\begin{array}{l}\text { Office } \\
\text { ott the } \\
\text { Director } \\
\text { and } \\
\text { Administra- } \\
\text { tive } \\
\text { Divi- } \\
\text { sion } \\
\end{array}$ \\
\hline $\begin{array}{l}\text { Energy: } \\
\text { OCS oil and gas } \\
\text { Onshore oil and gas } \\
\text { Oil shale }- \\
\text { Coal } \\
\text { Uranium and thorium } \\
\text { Geothermal }\end{array}$ & $\begin{array}{l}-- \\
-- \\
-- \\
-- \\
--\end{array}$ & $\begin{array}{l}\times \\
\times \\
\times \\
x \\
x \\
\times \\
x\end{array}$ & $\begin{array}{l}- \\
\bar{x} \\
x \\
\times \\
x \\
x\end{array}$ & $\begin{array}{l}\stackrel{\times}{\times} \\
\times \\
\times \\
\times \\
\times \\
\times\end{array}$ & $\begin{array}{l}-- \\
-- \\
-- \\
-- \\
--\end{array}$ & $\begin{array}{l}-- \\
-- \\
-- \\
-- \\
--\end{array}$ \\
\hline $\begin{array}{l}\text { Minerals: } \\
\text { Metallic and nonmetallic minerals } \\
\text { Mineral and fuels information system }\end{array}$ & $=$ & $\begin{array}{l}\times \\
x\end{array}$ & -- & $\begin{array}{l}x \\
--\end{array}$ & $=$ & -- \\
\hline $\begin{array}{l}\text { Hazards: } \\
\text { Earthquakes } \\
\text { Volcanoes } \\
\text { Floods } \\
\text { Water quality }-1,0\end{array}$ & $\begin{array}{l}-- \\
-- \\
--\end{array}$ & $\begin{array}{l}\stackrel{x}{\times} \\
-- \\
--\end{array}$ & $\begin{array}{l}-- \\
\bar{x} \\
x\end{array}$ & $\begin{array}{l}-- \\
-- \\
--\end{array}$ & $\begin{array}{l}-- \\
-- \\
--\end{array}$ & $\begin{array}{l}-- \\
-- \\
--\end{array}$ \\
\hline General hydrology - & -- & -- & $\times$ & -- & -- & -- \\
\hline General geology - & -- & $x$ & -- & -- & -- & -- \\
\hline Standard topographic mapping & $x$ & -- & -- & -- & -- & -- \\
\hline Products for land-resources decisions & $\times$ & -- & -- & -- & $\times$ & -- \\
\hline Environmental impact statements & -- & $x$ & $x$ & $\times$ & $x$ & -- \\
\hline Earth Resources Observation System & -- & -- & -- & -- & $\times$ & -- \\
\hline General administration and facilities & -- & -- & -- & -- & -- & $\times$ \\
\hline
\end{tabular}


An alternative way of looking at the Survey's budget is by area of study (fig. 12). For example, energyrelated investigations include the regulatory and resource-evaluation activities of the Conservation Division, the resource assessments and related mineral research of the Geologic Division, and hydrologic investigations of the Water Resources Division (table 4). In fiscal year 1975, energy-related investigations constituted 27 percent of the Survey's budget; mineral investigations, 8 percent; natural hazards, 15 percent; and general hydrology, general geology, and standard quadrangle mapping, 39 percent. The remaining 11 percent involved operation of the Earth Resources Observation System programs; preparation of products to aid in making land-resources decisions, preparation of environmental impact statements, and general administration and operation of facilities.

\section{PERSONNEL}

Unlike the budget, which has increased 197 percent since 1966, the number of permanent full-time employees involved in the Survey's programs remained more or less constant through fiscal year 1973 (fig. 13

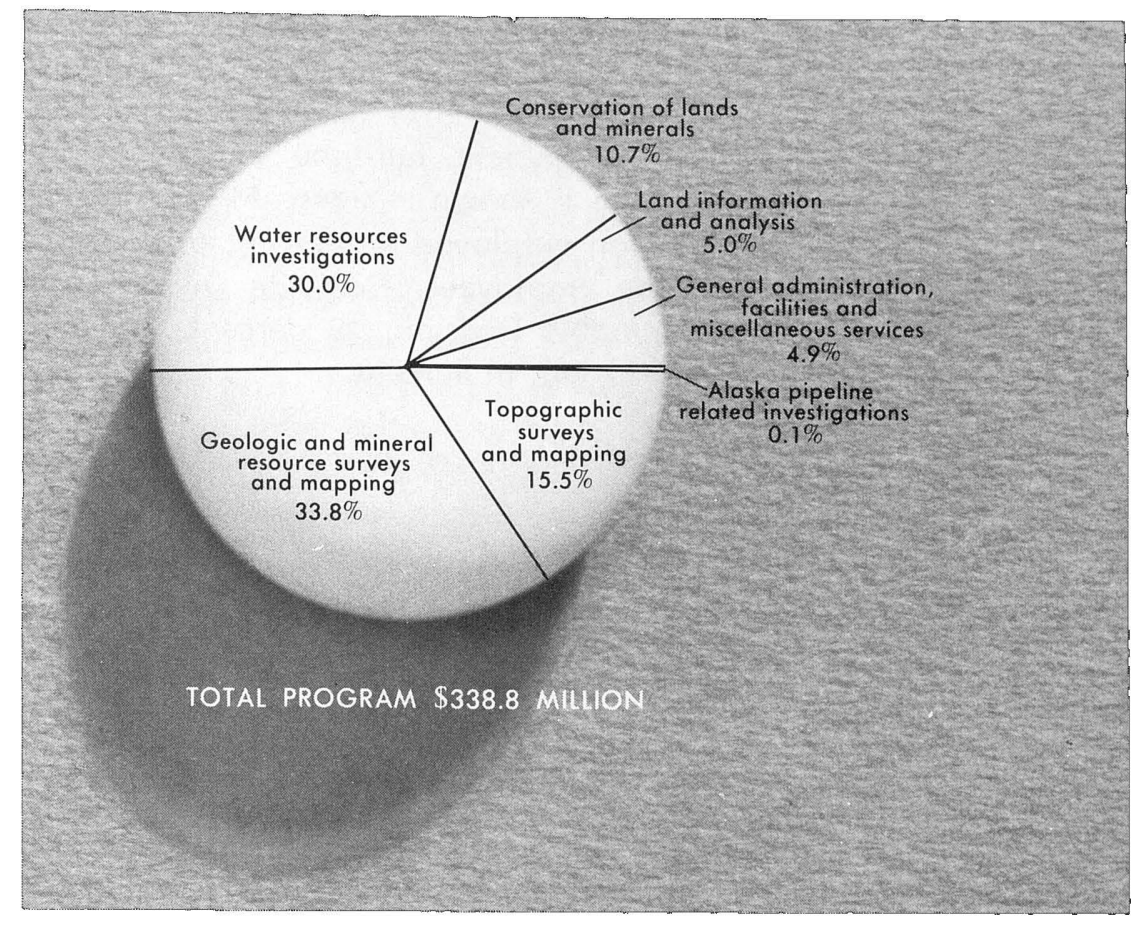

FIGURE 11.-Distribution of Geological Survey funds by budget activity in fiscal year 1975 .

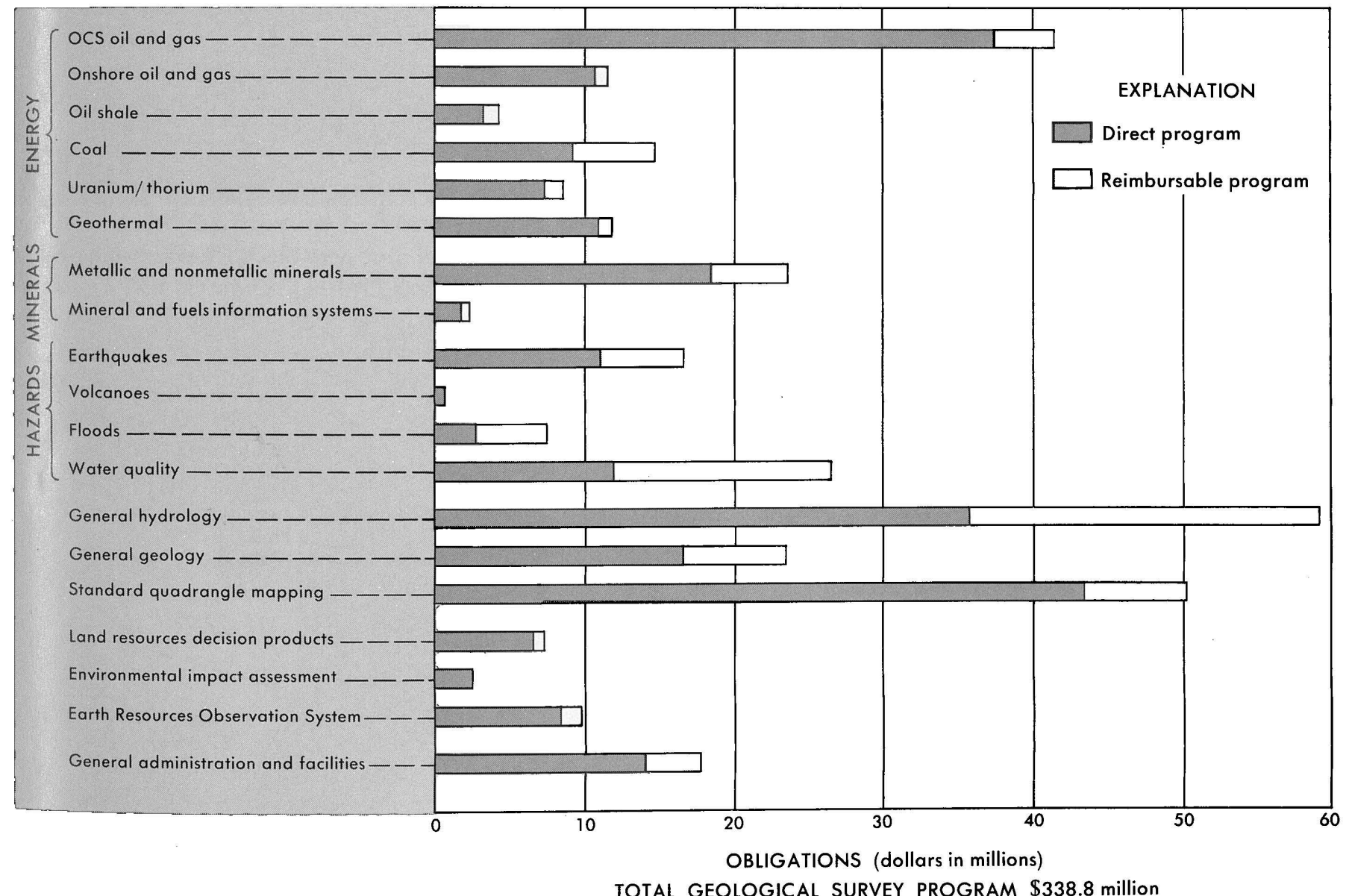

FIGURE 12.-Distribution of Geological Survey obligations for fiscal year 1975, by areas of study. 
and table 44). In fiscal years 1974 and 1975, 910 additional permanent full-time positions were filled, an increase of 11 percent over fiscal year 1973. The distribution of permanent full-time employees by organizational unit is shown in figure 14 . The Water Resources Division employed 33 percent of the permanent full-time employees, Geologic Division, 24 percent, Topographic Division, 19 percent, and the Conservation Division, 10 percent.

FIGURE 13.-Geological Survey end-of-year employment, fiscal years $1966-75 . \nabla$

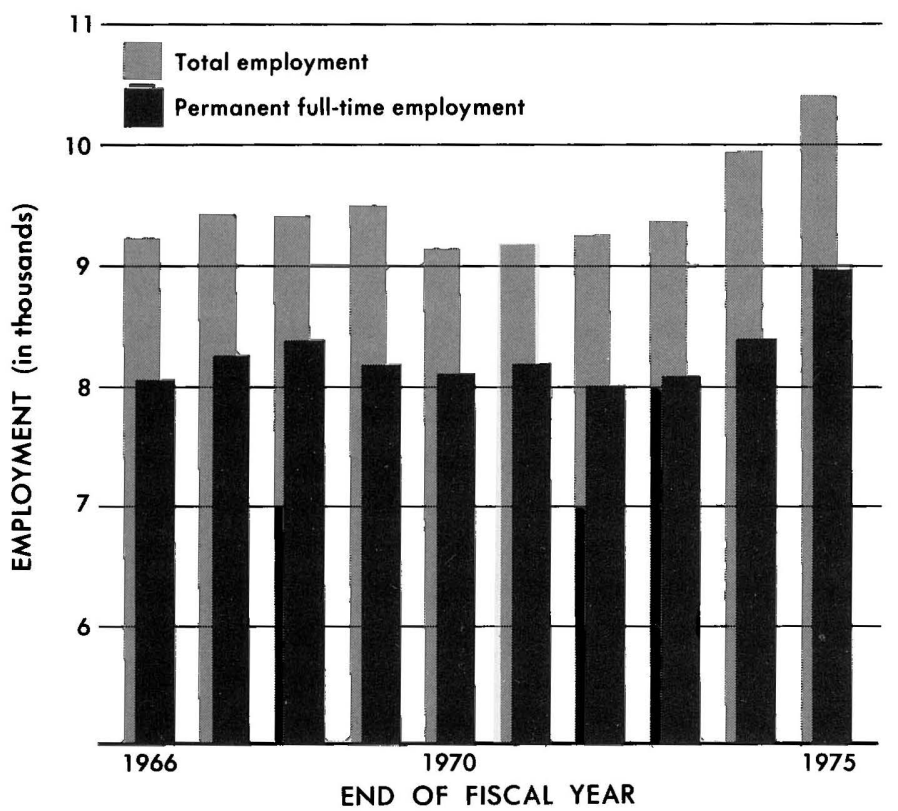

FIGURE 15.-Geological Survey permanent full-time employees by type. $\boldsymbol{V}$
The technical nature of the Geological Survey's programs is reflected in the composition of the work force. At the end of fiscal year 1975, the Survey employed 8,999 people on a permanent full-time basis of which 76 percent held professional or technical positions (figure 15). The high level of training and diversity of specialized skills present in this work force provides the Federal Government with an important resource of scientific expertise in the earth sciences.

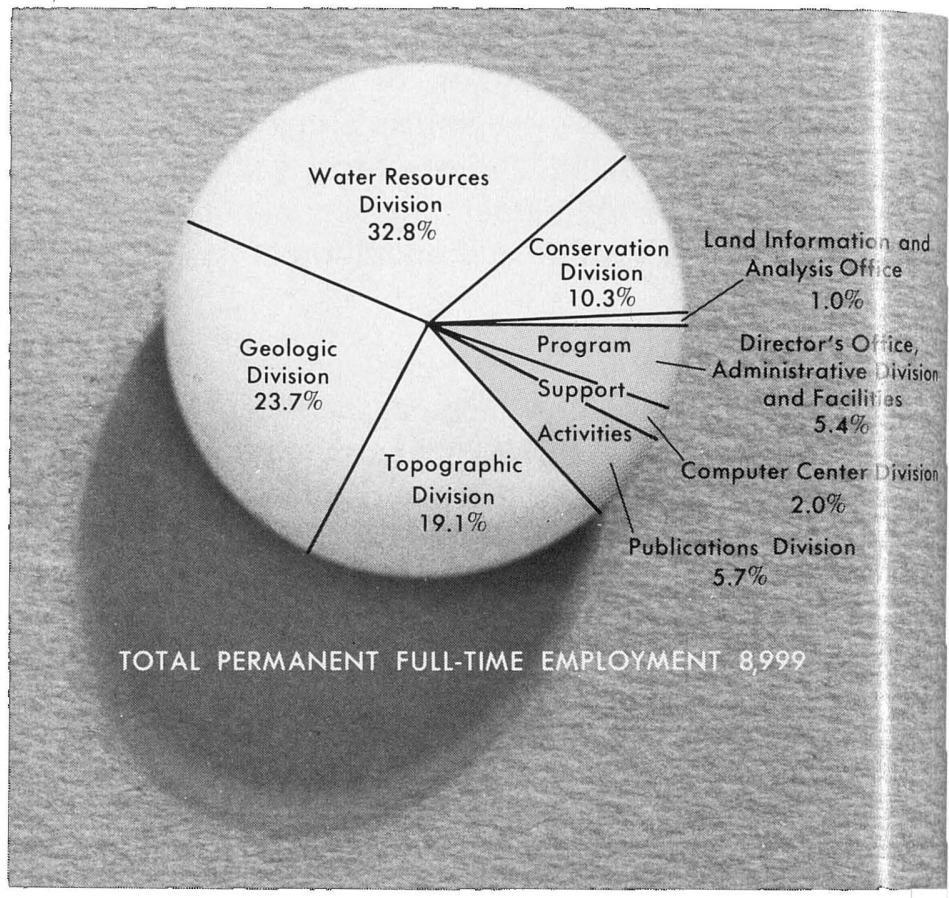

$\Delta$

FIGURE 14.-Distribution of permanent full-time employees by organizational unit as of the end of fiscal year 1975 .

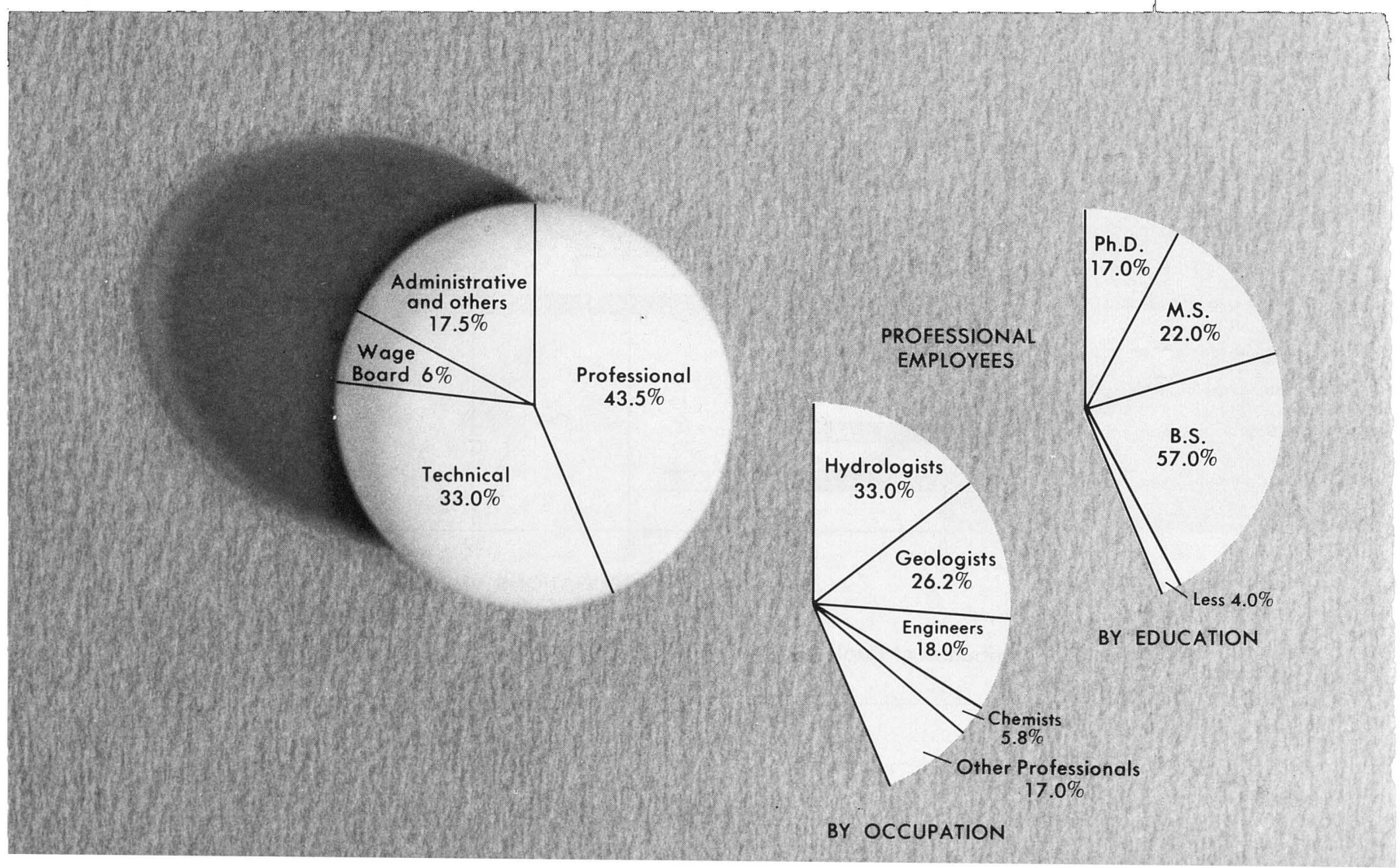




\section{DEFINITIONS}

A few of the terms used to describe the budget are defined here, as they will be frequently used throughout the next few chapters. The budget appropriation of the Geological Survey consists of a number of budget activities or broad functional areas such as Topographic Surveys and Mapping and Water Resources Investigations. Budget activities are further subdivided into subactivities, programs, and program elements, depending upon the size and complexity of the activity. However, the term "program" may refer to the entire budget, a budget activity, a subactivity, or may denote work supported by funds from a particular source.

Funds to support Geological Survey programs come from two sources: (1) an annual Congressional appropriation and (2) reimbursements from Federal and non-Federal agencies. Federal funds, appropriated by Congress under the title "Surveys, Investigations, and Research" support the Survey's direct programs under each budget activity. Other funds from State and local agencies, Federal agencies, permittees and licensees of the Federal Power Commission, foreign countries, and international organizations pay for various information products and services provided by the Survey's reimbursable programs.

Whereas direct programs are aimed at resource investigations and research on problems of nationwide concern, the reimbursable programs enable the Survey to expand earth-science support to the specific problems of Federal, State, and local agencies. The results of these investigations contribute in a very substantial way to the solution of urgent national resource problems and directly respond to the changing mutual needs of Federal, State, and local governments for earth-science information. Agencies and organizations with which the Survey had written agreements for fiscal cooperation in fiscal year 1975 are listed in the "Organizational and Statistical Data" section.

To carry out its nationwide missions and programs, the Geological Survey has established over 160 offices throughout the United States (see map in "Organizational and Statistical Data" section). The Survey's National Headquarters is located in Reston, Va. Regional research and administrative centers are located at Menlo Park, Calif.; and Denver, Colo.; and Rolla, Mo.
Work done for State, county, or municipal agencies may be performed on a cost-sharing basis. The funding arrangements vary depending on the type of investigation. For example, the Survey's annual appropriation bill restricts the use of Federal funds to finance not more than one-half the cost of any topographic mapping or water-resources investigation carried on in cooperation with a State or municipality. Within this general 50-percent limitation, the bill also specifies the dollar amount of Federal funds that shall be available for cooperative water-resources investigations. On the other hand, appropriated funds may be used to pay for more than 50 percent of the cost of cooperative geologic investigations. The activities jointly funded by State and local reimbursable program funds (State share) and direct program funds (Federal share) are collectively referred to as the Federal-State Cooperative program. Other work done by the Survey for specific Federal agencies and nonFederal organizations is usually performed on a fully reimbursable basis.

Finally, mention should be made of the use of current dollars and constant dollars in the various budget tables in this report. Financial resources are one measure of the level of program activity and are often used to show the expansion or contraction of an agency's program over a period of years. To be used in this way, however, the current dollars (the dollar amount received in a particular year) must be adjusted to reflect changes in the purchasing power of the dollar. The adjusted dollars, referred to as constant dollars, represent the purchasing power of any year's budget in terms of a base year; fiscal year 1967 is the base year in this report. In the absence of an index with which to measure the impact of rising prices on the Survey's activities, the implicit price deflator for the total gross national product has been used to convert current dollars to constant dollars following the practice of the National Science Board in analyzing trends in research and development funding (National Science Board, 1975).

A directory of principal Survey offices appears in the section, "Organizational and Statistical Data."

\section{REFERENCE}

National Science Board, 1975, Science Indicators 1974, report of the National Science Board 1975: Washington, D.C., Natl. Sci. Found., Natl. Sci. Board, 242 p. 


\section{Topozraphic Surveys and Mapping}

\section{OVERVIEW}

A basic mission of the Geological Survey is to produce and distribute topographic maps of the United States. While topographic mapping was begun to support the Survey's resource investigations and landclassification activities, many other Federal, State, and local agencies throughout the country have come to depend upon the topographic map for detailed and precisely referenced information about the natural and manmade features on the Earth's surface. Whether the task is coal resource assessment, land reclamation, flood and erosion control, or industrial site selection, there is a common need for accurate and up-to-date cartographic data.

Fiscal year 1975 marked the transition from the National Topographic Mapping Program to the National Mapping Program-no mere change of name. The action was largely the result of recommendations made by the Federal Mapping Task Force after a thorough examination of all Federal domestic mapping and geodesy programs (Office of Management and Budget, 1973). The mapping program has been expanded and strengthened in several important ways:

- Basic cartographic data (such as roads, structures, topography, and watercourses) will be gathered, processed, and distributed in formats tailored to users' specifications in addition to the well-known topographic map series. Cartographic data collected by other agencies may also be incorporated into the program.

- Public access to cartographic data will be simplified through the newly formed National Cartographic Information Center-a clearinghouse for the exchange of information on maps and charts, aerial photographs and satellite imagery, and geodetic data.

- Clearly defined Federal standards for urban mapping and for coastal wetlands mapping will be formulated to meet the need for common mapping methodologies affirmed by the Department of Housing and Urban Development and by States affected by the Coastal Zone Management Act of 1972.

- A digital cartographic base will be produced to aid the construction of computerized, geographicbased information systems by Federal and State agencies. Some of the developmental work on this data base will be a jointly funded interagency effort.

\section{Programs}

The National Mapping Program makes graphic or digital cartographic data and services readily available for a multiplicity of uses. Cartographic products include:

- Aerial photographs-low- to high-altitude photographs which provide basic information on the character of the land surface for mapping and other purposes.

- Geodetic data-positions, elevations, and descriptions of control points which are used in the preparation of the map base.

- Standard topographic maps in the $1: 24,000,7.5-$ minute quadrangle series (or in the $1: 62,500,15-$ minute quadrangle series until replaced)-the basic map series from which smaller scale and special maps are usually derived.

- Orthophotoquads-rectified aerial photographs in standard quadrangle format and with map information superimposed.

- Smaller scale and special maps-standard series at scales ranging from $1: 50,000$ to $1: 1,000,000$ and National Park maps and special products such as slope maps at various scales.

- Digital map data-a numerical representation of the information normally shown on multipurpose topographic maps, to be used in planning and management activities as well as in map production and revision.

- The National Atlas.

The National Cartographic Information Center is an important link between the cartographic data and the user. The Center collects and organizes descriptions of the form and whereabouts of data, such as maps and photographs, so that a user need only query the Center to find out what information is available to meet his cartographic needs. Other major repositories of cartographic data, such as the National Oceanic and Atmospheric Administration's National Geodetic Survey Information Center and the Survey's Earth Resources Observation System Data Center, will be linked with the National Cartographic Information Center.

The Survey provides technical assistance and training in surveying and mapping to other countries through an international activities program. The Survey is also a major participant in the U.S. Antarctic 
Research Program by administering field mapping programs and supporting ongoing multidisciplinary studies with Doppler satellite observations.

\section{Coordination of mapping with other agencies}

Federal surveying and mapping activities are coordinated by the Geological Survey for the Department of the Interior. Following the procedures set forth in the Office of Management and Budget Circular A-16 (Bureau of the Budget, 1967), the Survey annually requests and assists other Federal agencies to identify their mapping requirements. In fiscal year 1975, the Survey received specific mapping requests from 26 Federal agencies and bureaus. A total of 43,519 requests for 27,630 quadrangles were received for 1:24,000-scale mapping: 32 percent of these requests were for new mapping, 48 percent for revision, and the balance for mapping already in progress. At present funding levels, about 1,800 new 7.5-minute quadrangles are started each year, only about 20 percent of the requests for new mapping.

The Survey also receives requests for mapping from State and local governments. State mapping advisory committees in 13 States (Alaska, Colorado, Idaho, lowa, Maine, Michigan, Minnesota, Montana, Nebraska, Nevada, New Mexico, Texas, and Utah) make requests for cartographic data and in some cases guide the use of State funds to support cooperative mapping programs. Mapping needs of States, counties, and municipalities are also established and met through the medium of cooperative programs with costs being equally shared; there were cooperative programs with 38 States and the Commonwealth of Puerto Rico in fiscal year 1975 (table 31). Requests from private individuals are also considered in setting priorities for the National Mapping Program. In this manner, new areas to be mapped and revised are selected on the basis of demand insofar as practical from the standpoint of mapping operations. The Survey reports back to all concerned agencies once the selections are made and supplies details on the entire mapping program.

In addition to other agencies and individuals, the Geological Survey itself is a principal user of cartographic data, for mapping the location and determining the extent of the Nation's natural resources, for helping develop new sources of energy, and for solving a wide range of environmental problems through various technical assistance programs.

\section{Budget}

The Topographic Surveys and Mapping activity comprises three budgetary subactivities (table 5): (1)

40 Quadrangle Mapping and Revision, (2) Small-scale and Special Mapping, and (3) the National Cartographic Information Center. Quadrangle Mapping and Revision is carried out in four regional mapping centers located in Reston, Va., Rolla, Mo., Denver, Colo., and Menlo Park, Calif. Most Small-scale and Special Mapping is the responsibility of a fifth mapping center in Reston. The National Cartographic Information Center is also located in Reston.

Obligations of the Topographic Surveys and Mapping activity in 1975 amounted to $\$ 52.6$ million, an increase of 20.5 percent over fiscal year 1974 (table 5). Of this total (fig. 16), $\$ 5.0$ million from 38 States and Puerto Rico was matched by Federal funds, and $\$ 2.2$ million was from other Federal and non-Federal sources (table 26). Such cooperative mapping projects must benefit the national program to be accepted. Currently the largest cooperative project is a 6-year, \$9-million program for complete coverage of Georgia with standard quadrangle maps (either line maps or orthophotomaps) and a variety of special maps$1: 100,000$-scale, slope, and land use maps-of the Greater Atlanta metropolitan area.

TABLE 5.-Topographic Surveys and Mapping activity obligations for fiscal year 1975, by program

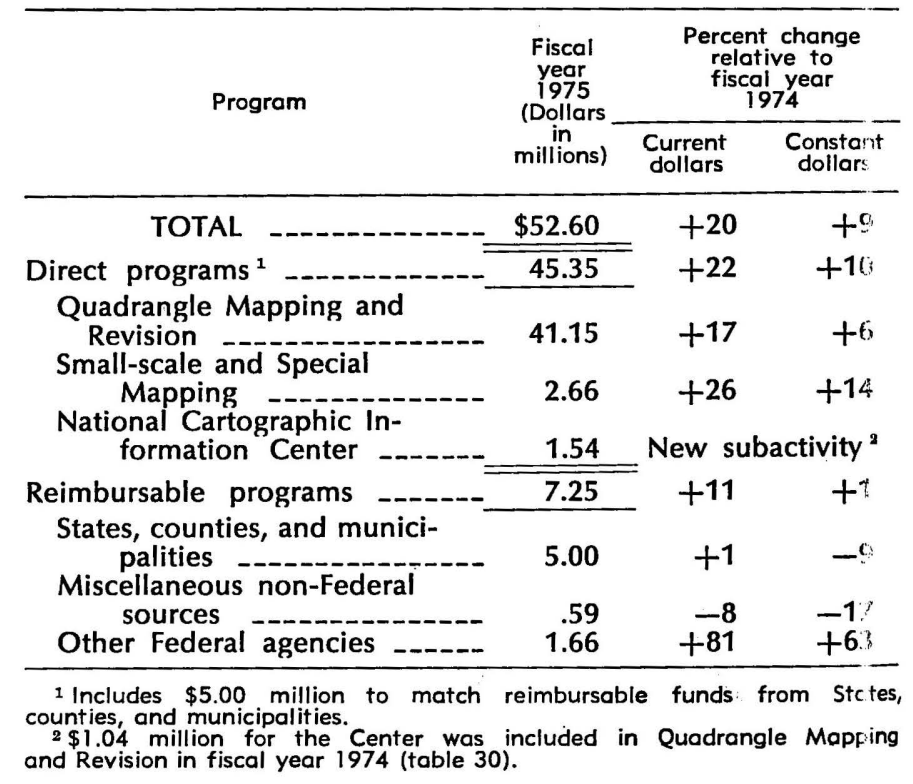

Though total obligations for the mapping program increased from $\$ 28.7$ million in 1966 to $\$ 52.6$ million in 1975 (fig. 10), the increases were largely absorbed by higher operating costs. In fiscal year 1975, additic nal funds were approved to undertake a national orth ophotoquad program and to exploit advances in mapping technology. The growth and decline of the reinbursable funds during this period resulted from the absorption of cost-sharing programs into the National Mapping Program and the replacement of completed basic mapping programs by less costly map revision. 


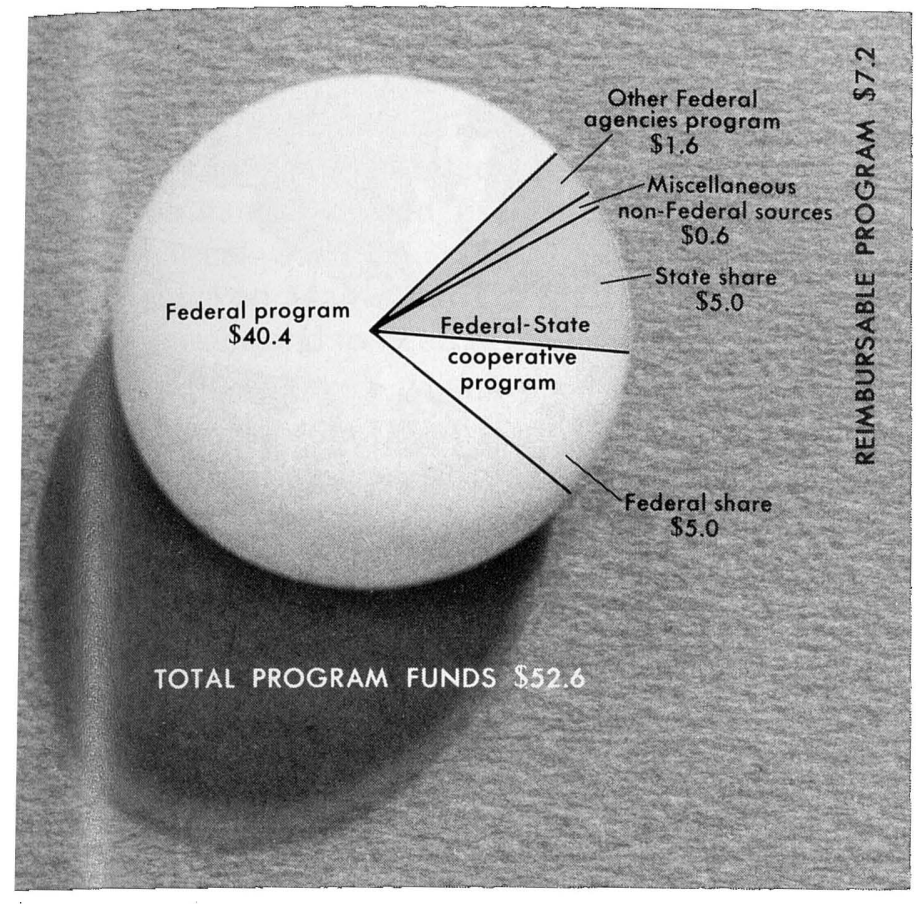

FIGURE 16.-Sources of fiscal year 1975 funds for Topographic Surveys and Mapping (dollars in millions).

\section{Personnel and productivity}

In fiscal year 1975, the National Mapping Program was carried out by 1,719 career employees-largely photographic technologists, cartographers, physical scientists, engineers, engravers, computer specialists, and clerical workers (table 44). An additional 158 temporary employees, many on work-study programs, served as aids, technicians, and professional consultants.

Despite decreasing personnel and rising costs, productivity has improved on the average about 6 percent per year (fig. 17). Although operating costs have increased 124 percent since 1966, improvements in the efficiency of operations have kept the actual unit cost of standard quadrangle mapping from increasing more than 34 percent.

\section{Highlights}

Noteworthy achievements and events of fiscal year 1975 include:

- Establishment of the National Mapping Program to meet the increasing demand for basic cartographic data in all forms.

- Bureau of Land Management agreement to provide intermediate-scale base maps of public lands, with priority given to areas of known coal and geothermal energy potential.

- National Ocean Survey agreement to coordinate topographic and bathymetric mapping in the coastal zone.
- Opening of the National Cartographic Information Center to begin building a central file that will link U.S. repositories of cartographic data.

- Organization of Mapping Requirements Staff to analyze nationwide map use on a continuous, fulltime basis.

- Record map production of about 4,900 new and 923 revised standard maps to meet the goal of covering unmapped areas of the U.S. by 1978 with either standard quadrangles or orthophotoquads.

- Design of the Digital Cartographic Data Base to serve as the structure for future map production.

\section{QUADRANGLE MAPPING AND REVISION}

\section{Aerial photography}

Although taking aerial photographs of areas to be mapped is essential to the mapping process, there is also great demand for aerial photographs for other purposes. In fiscal year 1975, Survey contracts for precision aerial photography covered about 1.22 million square kilometres $(473,000$ square miles). More than half of the photographs were taken from altitudes higher than 7,900 metres $(26,000$ feet) for use in orthophotoquad mapping and map revision projects. Virginia and Ohio have cooperative programs with the Survey to obtain high-altitude photographs of their entire States on a 5- and 6-year cycle, respectively, as part of their map revision programs. Several other States are considering similar programs.

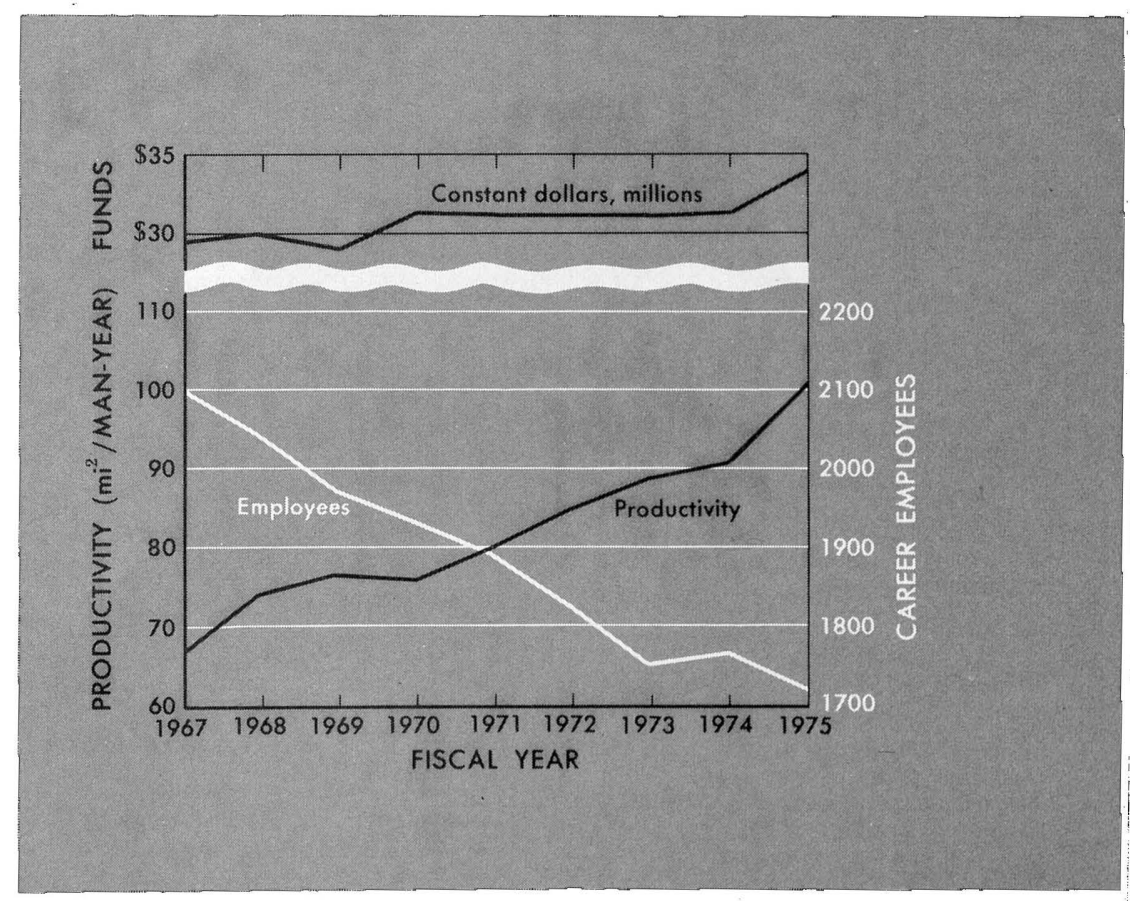

FIGURE 17.-Productivity of $1: 24,000$-scale mapping, fiscal years 1967-75. 


\section{Revision mapping}

As maps become outdated, revision is necessary to show changes in terrain and manmade features, especially changes associated with the development of metropolitan areas and expansion of their suburbs. During fiscal year 1975, 1,569 7.5-minute quadrangles were checked against current photographs, and 1,044 maps were found to need revision.

More than 900 1:24,000-scale maps were revised in 1975 (table 46). The majority of these maps were updated from new aerial photographs and without a field check. Generally, photorevised maps can be produced within a year by overprinting revisions in purple on the original map. If more extensive revision is warranted, the changes are field verified, and occasionally a completely new map must be prepared.

During the year, about 1,280 quadrangle maps were reprinted to replenish shelf stocks of published maps. Nearly 10 million copies of maps were distributed.

\section{Orthophotoquads}

The Survey has introduced a new series of photomaps which can be produced quickly, economically, and accurately. The standard 1:24,000 orthophotoquad consists of a nearly distortion-free, black-andwhite aerial photograph in 7.5-minute-quadrangle format with a geographic grid and a few place names added. Orthophotoquads are in demand as interim maps for unmapped areas or as up-to-date companions to published line maps. The imagery provides a wealth of detail that cannot be portrayed on a conventional line map (fig.' 19).

The objective of the program is to produce orthophotoquads for all areas of the conterminous United States presently unmapped at 1:24,000 scale by 1978 . In fiscal year 1975, the Survey produced 2,869 orthophotoquads (fig. 20 and table 46).

\section{Orthophotomaps}

An image-enhanced version of the topographic map is called an orthophotomap. To date, 291 orthophotomaps have been produced for areas of the United States where conventional line maps cannot adequately portray relatively featureless terrain. The orthophotomap represents approximately the same production effort and cost as the line map, but the colored imagery accentuates such detail as types of vegetation, marshland limits, and the physical character of prominent geologic features. During fiscal year 1975, 66 orthophotomaps were published; about 300 are in various stages of production.

\section{SMALL-SCALE AND SPECIAL MAPPING}

\section{Intermediate-scale maps}

The new intermediate-scale mapping series includes base maps at scales of $1: 50,000$ in county format and $1: 100,000$ in quadrangle, county, or regional format. These maps are normally derivative products of standard 1:24,000 maps. The 1:100,000 30×60-minute series will be in metric units.

Intermediate-scale mapping is designed to provide, in either graphic or digital form, basic map data at various levels of detail and scales, and will enable Federal, State, regional, county, and other map users to select the combinations of content, scale, and format that will best suit their general or special needs.

During fiscal year 1975, the Geological Survey and Federal and State agencies developed technical specifications for these maps. In this developmental process, two 1:100,000 maps in 30×60-minute format and seven 1:50,000 county maps were produced. Intermediate-scale mapping scheduled for fiscal year 1976 includes 134 1:100,000 quadrangle base maps for the Bureau of Land Management, 116 1:100,000 county maps for the Soil Conservation Service, and 39 1:100,000 quadrangle maps and 68 1:50,000 county maps for State cooperators (fig. 21).

\section{$1: 250,000$-scale topographic maps}

The conterminous States and Hawaii are completely covered by 473 topographic maps at $1: 250,000$ scale. Alaska is covered by 153 maps of which 141 are topographic maps and 12 are older reconnaissance maps. During fiscal year 1975, 52 maps in this series were revised (fig. 22 and table 46).

The 1:250,000-scale maps are used by the Survey as a base for the preparation of the State base map series, the International Map of the World series, various geologic maps, and special-purpose maps such as those produced for the Land Use Data and Analysis program. The series has also been designated by the Board on Geographic Names as the standard reference for geographic nomenclature in Government publications. Elevation data, digitized from the contours on the $1: 250,000$-scale maps, are available on magnetic tape from the National Cartographic Information Center (fig. 22).

The Geological Survey and the National Oceanic and Atmospheric Administration have agreed on a program to produce topographic-bathymetric editions of the 1:250,000-scale maps for the coastal zones of the conterminous States (including the Great Lakes), Hawaii, and Alaska. The Beaufort, N.C., quadrangle is the first topographic-bathymetric map published in this program, and five more joint editions are in production. 


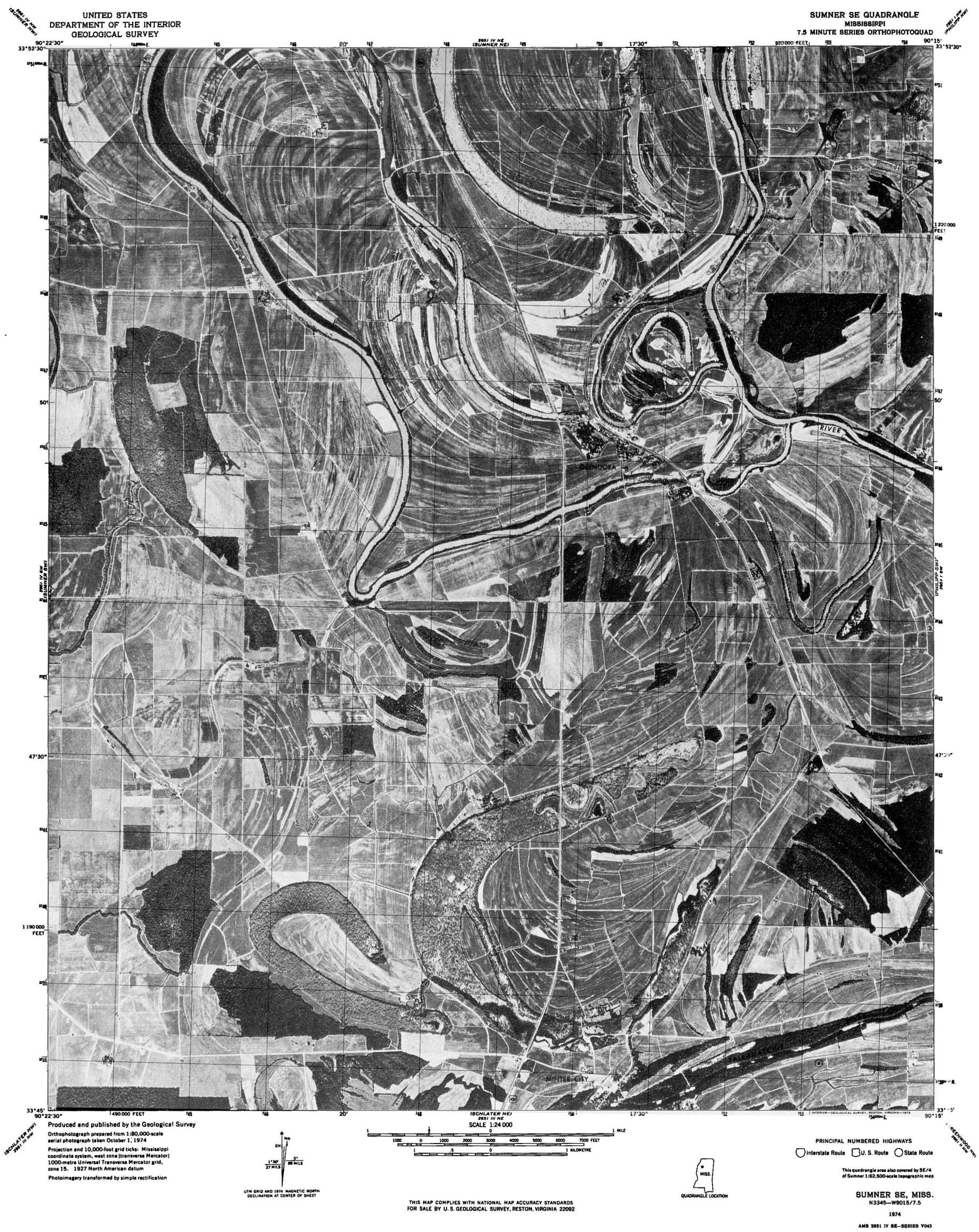




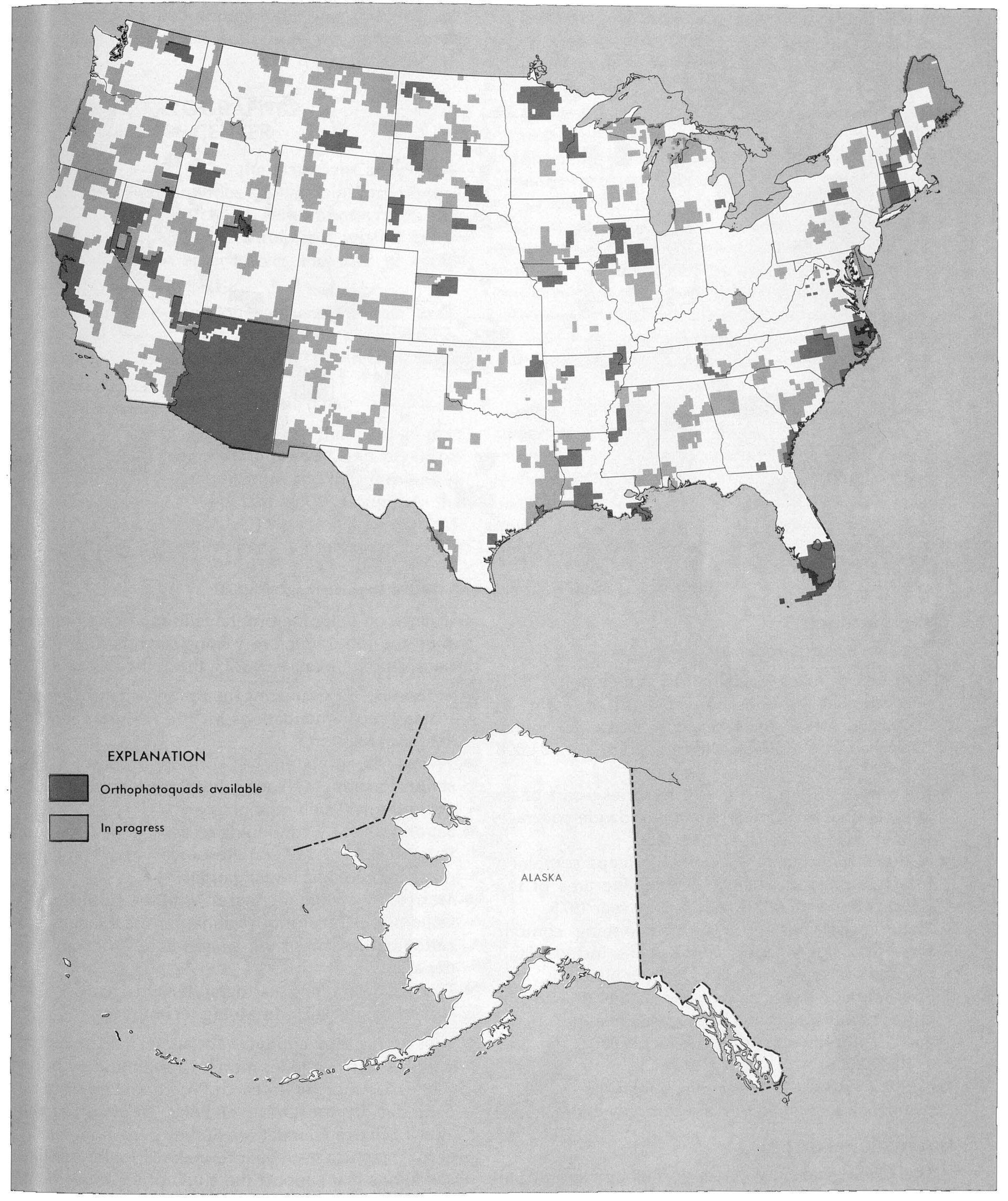

FIGURE 20.-Status of orthophotoquad production. 


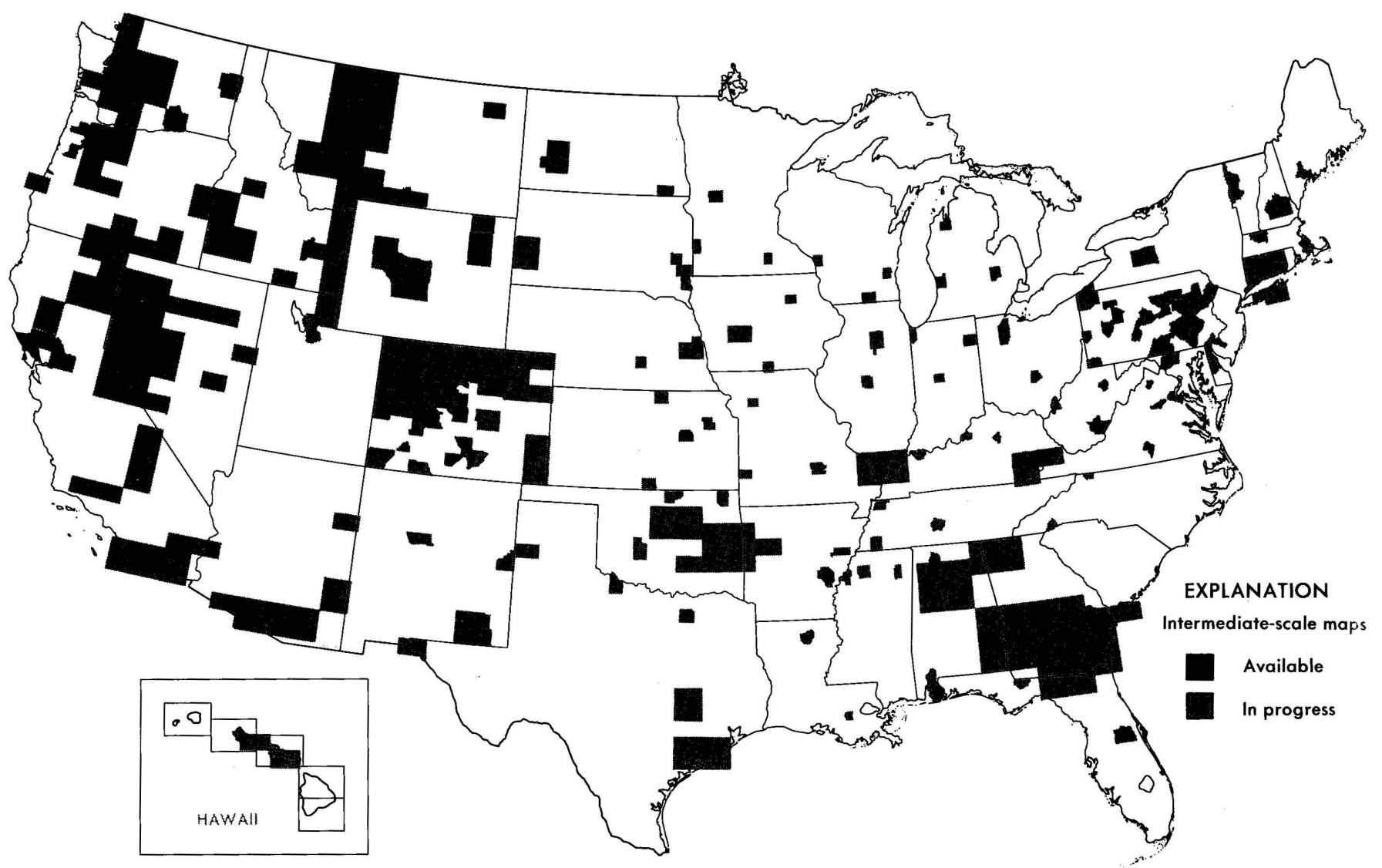

FIGURE 21.-Status of the Intermediate-scale Mapping program.

\section{Other products}

The Survey also produces:

- State base maps-planimetric, topographic, and shaded-relief editions available at a scale of 1:500,000 for all States except Alaska, for which base maps are available at scales from 1:1,584,000 to $1: 12,000,000$.

- International Map of the World series-part of an international program to attain worldwide coverage with maps at a scale of $1: 1,000,000$.

- National park maps-topographic maps combined into one or more sheets covering the area of the park; seven were published in fiscal year 1975.

- Slope maps-the result of transforming contour lines into slope zones; applications include land use and soil studies and construction planning.

- Special maps-such as the map of the 50 States in correct proportion, position, and relationship to each other; available at $1: 6,000,000$ and $1: 10,000,000$.

- National Atlas-first edition published in 1971; plans for a second edition are currently under study.

\section{International mapping}

The Geological Survey, supported by funds from the Agency for International Development, the United Nations, International Development Association, and assistance on mapping programs in the host countries and on-the-job training to visiting scientists and technicians. During fiscal year 1975, the Survey assisted:

- Indonesia, by evaluating mapping capabilities and making recommendations for the new National Institute of Mapping.

- Yemen, by preparing 11 orthophotobase maniscripts to support an agricultural development project in the Tihāmah region.

- Saudi Arabia, by continuing to assist the Ministry of Petroleum and Mineral Resources and compiling maps for geologic investigations.

- Mexico, by continuing liaison with the Comisión de Estudios del Territorio Nacional for the exchange of cartographic data of the United States-Mexico border area.

- Turkey, by training cartographers in shaded-relief and other specialized scribing techniques.

The Survey also conducts Antarctic field mapping operations and provides other cartographic support for the U.S. Antarctic Research Program, administered and funded by the Office of Polar Programs of the National Science Foundation. Survey personnel winter over in Antarctica each year to make Doppler satellite observations that support the study of ice movement, scintillation, and polar motion, and to operate seismological equipment for the Survey's Earthquake Hazards program. The Survey publishes a variety of maps of 
Antarctica-1:250,000 topographic maps, 1:500,000 sketch maps, and small-scale satellite image maps (fig. 23).

\section{NATIONAL CARTOGRAPHIC INFORMATION CENTER}

Established in July 1974, the National Cartographic Information Center provides a focal point for information on U.S. maps and charts, aerial photographs and space imagery, geodetic control, and related cartographic data. The Center serves the user of cartographic data in three ways:

- Furnishes information on cartographic data available from Federal, State, and private organizations.

- Furnishes information on the data-collection plans of these organizations.

- Processes orders for cartographic data.

The Center does not duplicate the cartographic holdings of other agencies but collects and organizes information describing their form and location in such major repositories as the Library of Congress, the National Ocean Survey, the Department of Agriculture, and the Earth Resources Observation System
Data Center. In fiscal year 1975, the Center's staff began to negotiate interagency agreements, develop information systems, and acquire information on Federal holdings of aerial photographs.

Representatives from 27 Federal organizations and 4 professional societies met in August 1974 at the invitation of the National Cartographic Information Center to discuss the coordination of the collection and distribution of cartographic data and ways in which to carry out the Center's mission. Formal management agreements were reached by the end of fiscal year 1975 with the Agricultural Stabilization and Conservation Service and the Soil Conservation Service to acquire information on their aerial photographs and soils maps and with the National Oceanic and Atmospheric Administration concerning geodetic control data.

During the year, the Defense Mapping Agency Topographic Center also began transferring digital terrain data of the conterminous States to the Center for distribution. Magnetic tapes contain a grid of elevations interpolated from the 1:250,000-scale topographic maps and are useful in computer analyses of difficult terrain and land-management problems.

FIGURE 22.-Status of 1:250,000-scale map revision and digital terrain data.

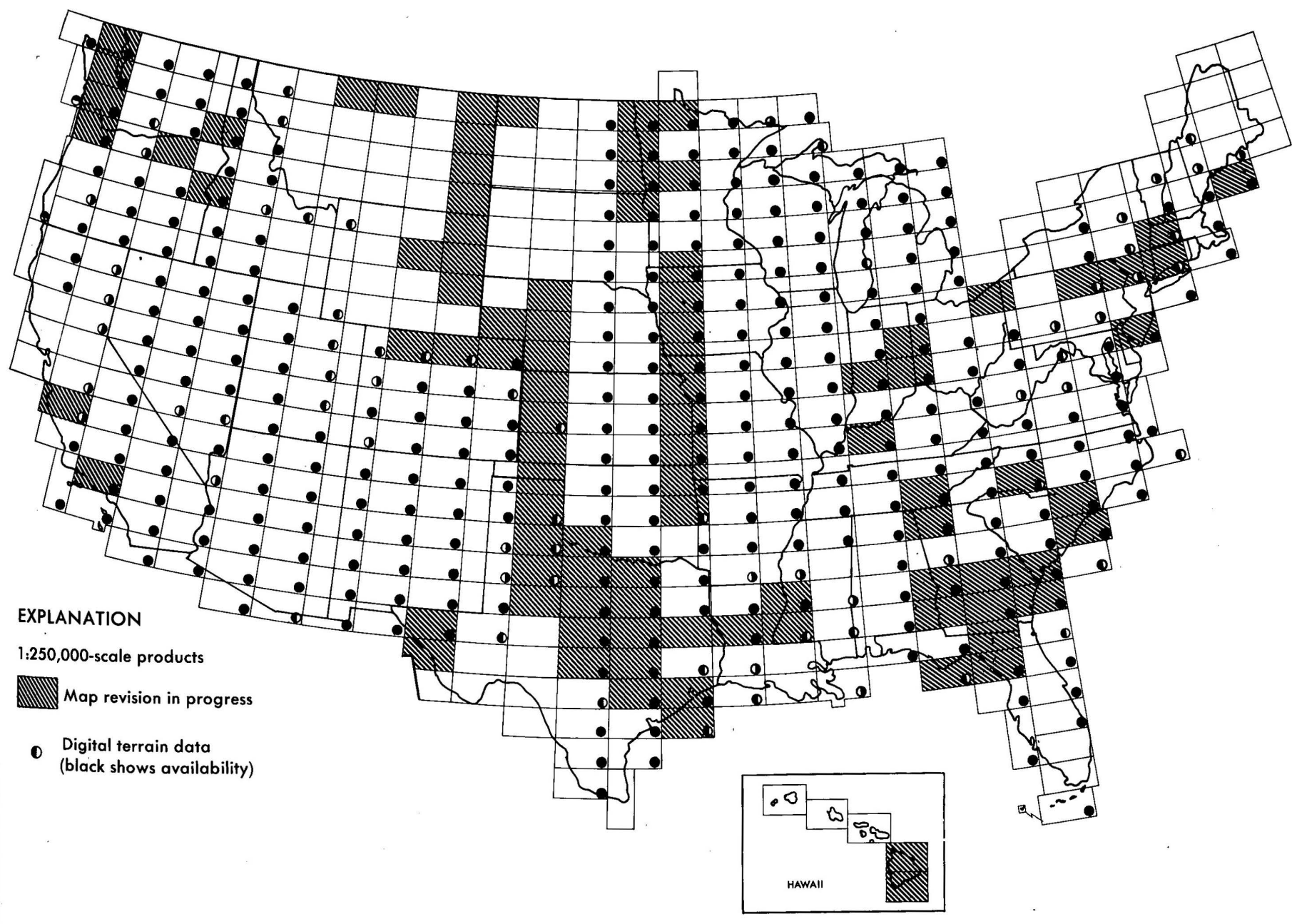




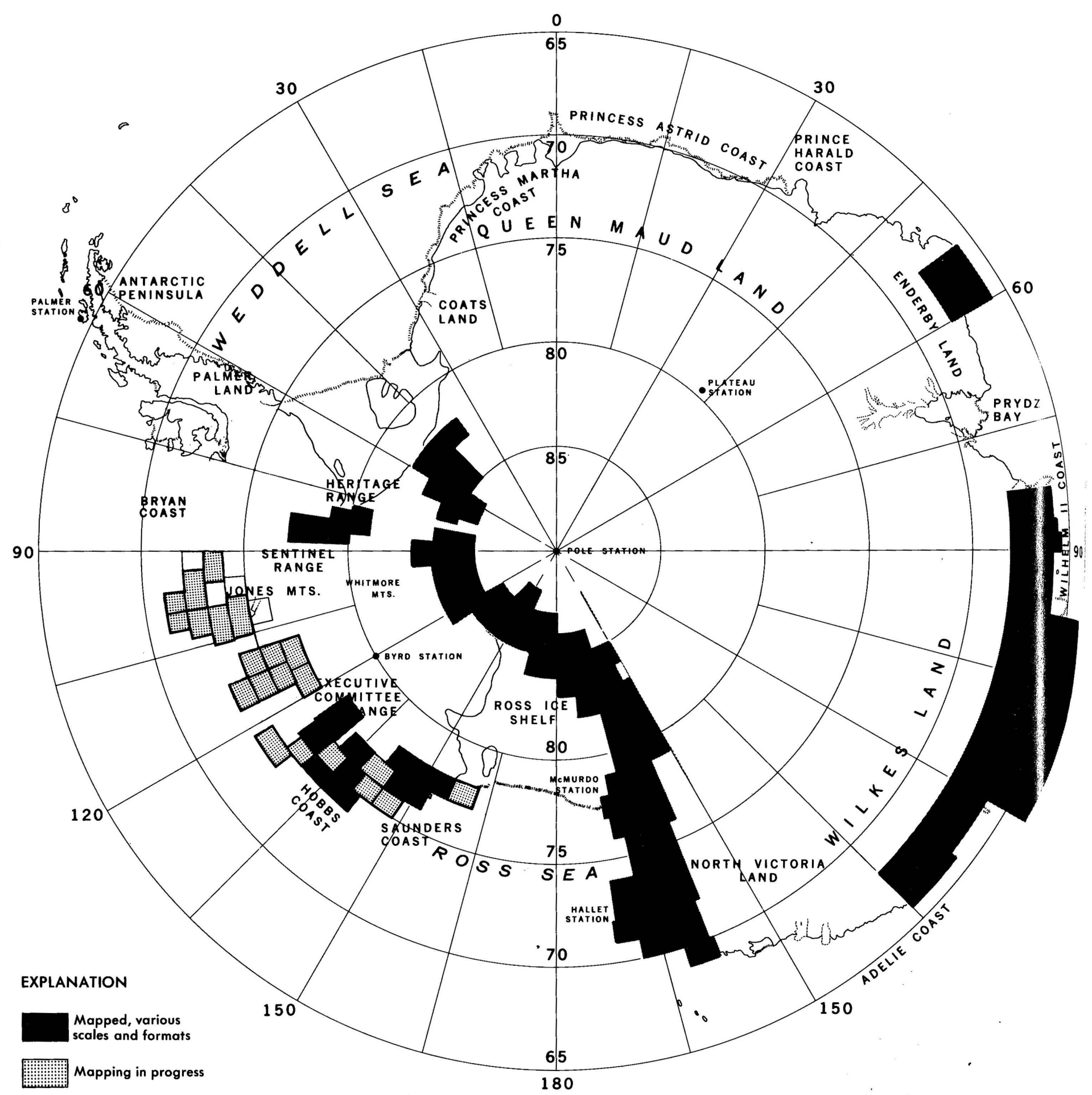

FIGURE 23.-Status of mapping in Antarctica.

The Center began developing computer information systems for cartographic data. In this period, the design of an aerial photography information system was completed; the data base contains information on the coverage and general characteristics of available collections and on plans for the acquisition of photographs. Participating agencies provide the Center with the essential data in digital form for direct input to the system. To date, the system has information on the photo collections and mapping plans of ministration, and the Defense Mapping Agency. Other Federal agencies will be involved in building this data base, as will State and private organizations.

The demand for out-of-print Survey maps and need for a more compact and convenient research file led the Center to build a microfilm map file. About 20,000 of the 100,000 current and historic topographic maps have been microfilmed on 35-mm black-a idwhite film to complete a New England and NidAtlantic States file; all maps are expected to be microfilmed by the end of 1976 . 


\section{RESEARCH AND DEVELOPMENT}

A primary objective of Survey cartographic research is to automate and link together as many of the mapping phases as possible. Automatic data-processing equipment is an integral part of the mapping system -automatic data acquisition, analytical aerotriangulation, computation and adjustment of geodetic control data, and automatic plotting. The Survey's library of computer programs for geodesy, photogrammetry, and cartography represents a major developmental effort and a valuable tool available to the mapping community.

\section{Mapping systems}

In the last decade, the trend in mapping techniques has been towards greater precision and speed. The mechanical and optical techniques of 1965 have given way to the computerized, digital, remote sensor, space technology techniques of 1975. The Survey's effort to advance mapping instrumentation and technology concentrates on improving productivity and the quality and diversity of cartographic products by replacing obsolete mapping equipment, procuring high-resolution orthophoto instrumentation also capable of producing digital terrain data, obtaining the hardware and software to extract digital information from stereoimages and available graphics, and developing automatic theme extraction techniques (U.S. Geological Survey, 1975). Examples of systems examined during fiscal year 1975 are described below:

- Inertial navigation systems were investigated for possible application as map-control surveying instruments. The Position and Azimuth Determining System, developed by the U.S. Army Engineer Topographic Laboratories, is an inertial platform mounted on a Jeep; field trials showed that mapcontrol accuracies can be met over a distance of several kilometres, but elevation accuracy is marginal. In December 1974, the Survey and the Bureau of Land Management tested the Auto-Surveyor, a civilian helicopter-borne version of the military system. Preliminary analyses of the test data indicate an acceptable average accuracy of \pm 0.6 metres ( 2 feet) in latitude, longitude, and elevation over a 38kilometre (24-mile) course on flat terrain. In this field test, data were obtained in 30 minutes which would normally take a field party 2 days to collect.

- The engineering analysis of the Aerial Profiling of Terrain System was completed by the Charles Stark Draper Laboratory (Cambridge, Mass.) under contract to the Survey. This inertial navigation system is being developed as a means of providing ground profiles and cross sections by measurement from an aircraft. When the system is applied to map-control surveys, substantial savings of field time may be realized.

- The Survey acquired new orthophoto instrumentation that produces higher quality orthophotos; digital coordinate data precisely control the exposure of the film to produce an accurate and esthetically pleasing orthophoto (fig. 19). In addition, a digital orthophoto system was designed that will produce digital profile data from a stereoimage, store the data on magnetic tape, and use the data off line to control the photographic unit that produces the orthophoto; construction started on prototypes of the three subsystems.

- Analytical plotters and associated techniques developed by the Department of Defense were adapted to standard topographic mapping in an effort to increase mapping capability and reduce production time.

\section{Product research}

Cartographic products will be tailored to the user's needs; however, an equally important objective is to promote simplicity and economy in the design and reproduction of future products, both analog and digital. For ease in digitizing and flexibility in format, data will be separated by color and by map feature.

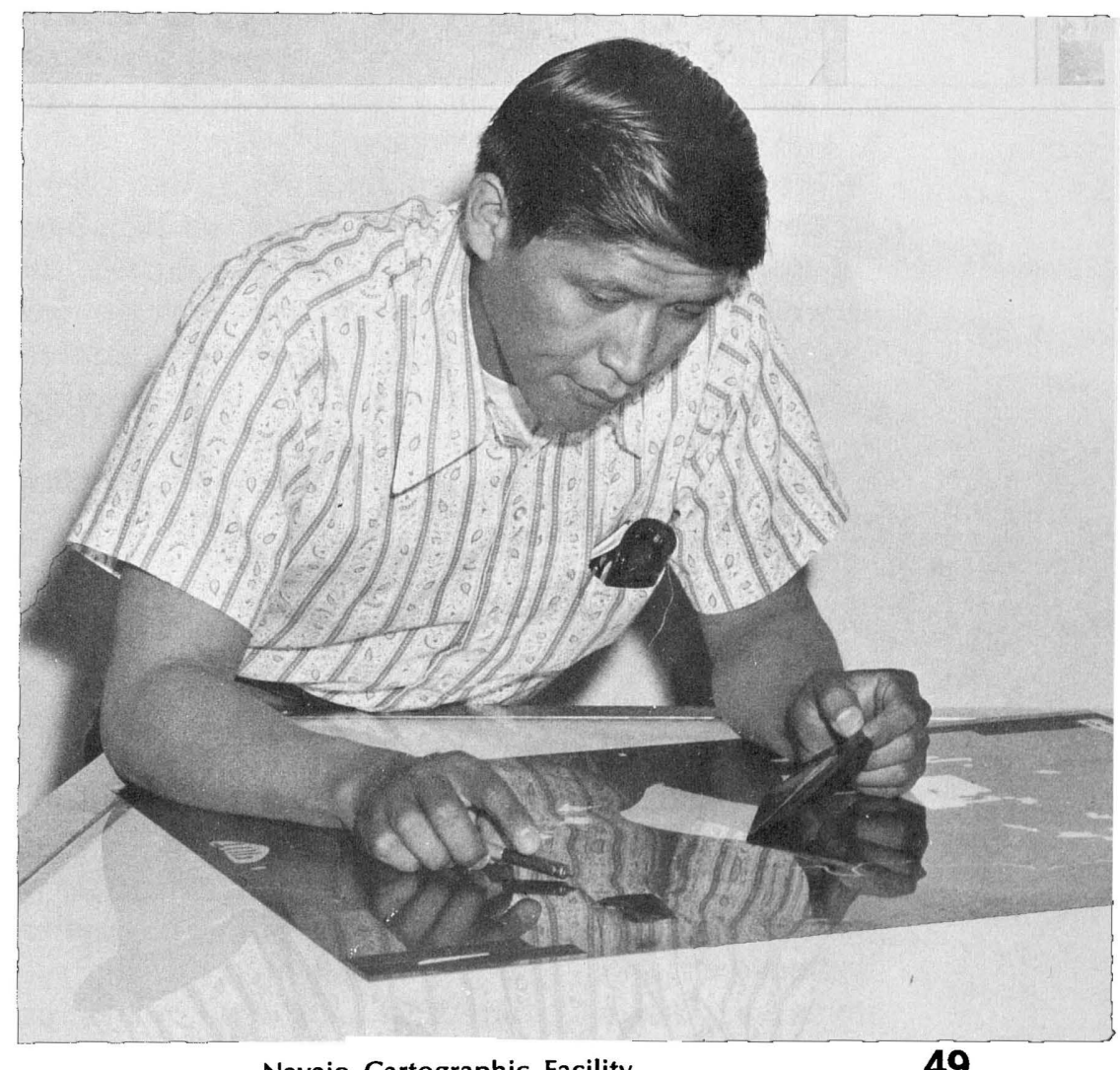

Navajo Cartographic Facility
49 
The ultimate in flexibility is the digital map for which most map parameters may be specified by the user before the map is automatically plotted.

During the year, considerable progress was made toward these objectives:

- Experimental maps have been produced that incorporate a metric format, computer-compatible symbology, feature-separation flexibility, and economy in printing. Specifications for the new intermediatescale maps are being drawn from this research.

- Maps reproduced by standard color printing on scale-stable clear plastic resulted in good transparency and register. Such color printings are being considered for thematic overlays displaying land use and terrain slope.

- To optimize use of the new Survey 5-color press, experiments were conducted in combining map colors for printing 6-color interim-revision maps in a single press run. The 5 -color scheme could save from $\$ 65$ to $\$ 245$ per quadrangle in printing preparation costs and could reduce printing time 2.5 times.

- Research in analog approaches to slope mapping resulted in the development of photomechanical techniques and equipment for semiautomatically deriving slope zones from map contours. A patent is pending for the Survey's orbital-lens slope mapping device.

- A research contract for the production of maps for the visually handicapped was awarded to the University of Washington. The maps will cover the Capitol Mall area in the District of Columbia and will be ready for the Bicentennial.

- The core of future cartographic production will be the Digital Cartographic Data Base. A data-base structure was proposed and is being evaluated that would enable users to interactively extract data from the base and produce the desired graphic, whether a television image or hard copy. In some applications, the map may not be displayed but will serve as a computer model for conducting analyses.

\section{Automated cartography}

In recent years, great strides have been made in the field of automated cartography, both in the development of hardware and software. The Survey is investigating possible applications of: (1) digital data-collection systems, from hand-operated digitizers to computer-controlled line followers; (2) interactive systems for identifying and correcting data errors; (3) output systems, especially precision automated drafting systems such as the Gerber $1232{ }^{1}$ purchased by the Sur- vey (fig. 24); and (4) cartographic software packages which offer the user an impressive array of programs.

\section{Orthophoto applications}

The widespread acceptance of the Survey's orthophoto products is reflected in their applications to forest management, soil surveys, geological studies, land use inventories, urban mapping, and coastal wetlands management. Continued orthophoto product refinement represents a major research and development effort utilizing several new technologies. A special laboratory was designed to support image technology research, and construction is scheduled to begin in 1976 .

Developments in orthophotomapping during the year included:

- Improved image quality-Orthophotomapping projects are now subject to stringent quality controls in every phase of production, from aerial photography through generation of the orthophoto negative to lithographic printing. Masking techniques were used to alleviate the problem of scan lines showing on orthophotos, and the Survey's orthophotoscopes were modified to improve conditions during exposure of the film.

- Large-scale urban mapping-Four urban areasFort Wayne, Ind., Charleston, S.C., San Francisco, Calif., and Frederick, Md.-were mapped by contractors at large scale to determine what type of orthophoto product would be most useful to urban

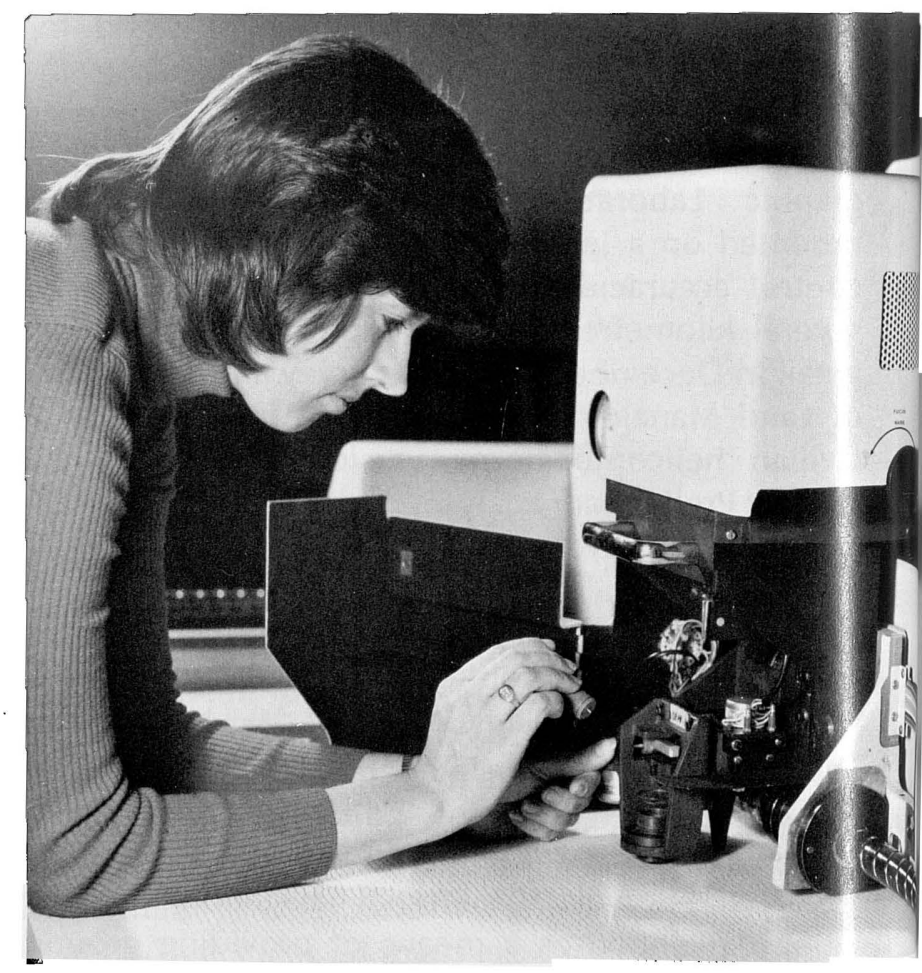

FIGURE 24.-Automated drafting system. 
decisionmakers and to develop standards for urban mapping. To date the maps have been used by the cities to derive line maps and to digitize land use information.

- Wetlands mapping-The Survey prepared six 1:10,000-scale orthophotoquads of Sapelo Island, Ga., as a first step in an effort to formulate and recommend a coastal mapping policy for coastal States. At this experimental scale, major plant species could be delineated from color infrared photographs, but considerable field checking was required.

\section{Cartographic applications of satellite imagery}

With Landsat-1 and Landsat-2 in orbit and LandsatC scheduled for launch in late 1977, mapmakers have a new source of data from which to produce smallscale image maps. Experiments have shown that several cartographic applications (Williams and Carter, 1976) are feasible from Landsat-type imagery:

- Photomapping at 1:250,000 and smaller scales.

- Aeronautical charting-line-chart revision of gross features or as an image base.

- Mapping shallow-water areas.

- Extending geodetic positions from mapped into unmapped areas.

- Mapping selected features, such as water areas, infrared-reflective vegetation, snow and ice, massed works of man, and spatial changes in these over time.

- Mapping Antarctica-revising small-scale maps, detecting and monitoring gross changes in coastal glaciological features, and discovering geographic features.

Future investigations will concentrate on the development of a variety of Landsat cartographic products and applications of various scales, waveband treatments, formats, and processing techniques in conjunction with the Earth Resources Observation System program. The continuing development and improvement of sensor and spacecraft technologies point the way toward automated mapping of the Earth.

\section{FUTURE PROGRAM OPPORTUNITIES}

New demands and uses are not only forcing a reshaping of the mapping program but suggest a redefinition of mapping. Historically, mapping activities have been directed almost exclusively to the production of maps. Today, the data gathered about the Earth's surface are analyzed and distributed in many ways, some bearing little resemblance to what has been customarily known as mapping.

The nature and scope of Federal mapping will be fundamentally affected by the actions of the Government during the next few years:

- Since gathering and processing the data are major costs in mapping and require advanced programs and technologies, the responsibilities and systems for gathering data need to be carefully planned and integrated to avoid costly duplication of programs and systems. For example, nearly every Government agency collecting cartographic data is now in the process of developing at least one digital map- or image-processing system.

- The rapid rate at which our world is changing has increased the demand for cartographic data that are accurate and current and that meet the user's format requirements. This means that more flexible and economical mapping methods need to be devised that will make the data available more quickly. Additionally, data distribution systems need to be coordinated to realize the full value of the data.

- Advances in computer technology over the past decade have made many new applications of cartographic data technically feasible, such as projecting the advance of forest fires, conducting resource inventories, predicting the effects of floods and pollution, or automating aerial-navigation warning systems. Digital cartographic data need to be structured to anticipate applications beyond mapping; this means future user requirements need to be identified as quickly as possible.

The key problem of the future is how to collect, store, and retrieve land use and resource data in a way that is accurate and understandable and within the price range of planners and decisionmakers.

\section{REFERENCES}

Bureau of the Budget, 1967, Coordination of surveying and mapping activities: Bureau of the Budget Circular A-16 (revised), May 6, 1967, 3 p.

Office of Management and Budget, 1973, Report of the Federal Mapping Task Force on mapping, charting, geodesy, and surveying: Washington, U.S. Govt. Printing Office, 198 p.

U.S. Geological Survey, 1975, Research and development in topographic mapping-the annual report: National Technical Information Service, Springfield, Va., No. PB243596/ AS.

Williams, R. S., Jr., and Carter, W. D., eds., 1976, ERTS-1, A new window on our planet: U.S. Geol. Survey Prof. Paper 929, 362 p. [In press.] 

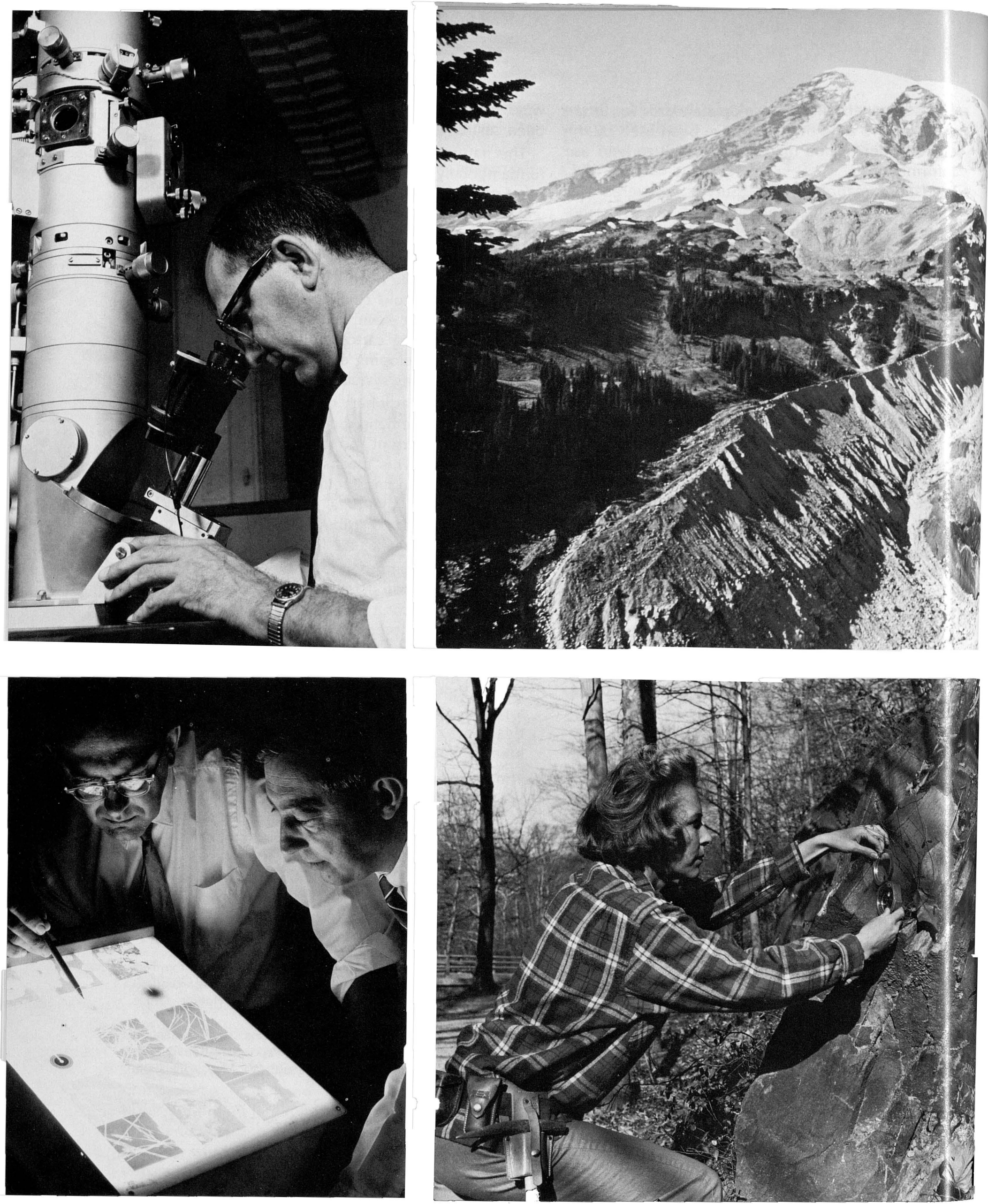

Clockwise from lower right: Geologist measures the attitude of a rock outcrop; scientists examine electron micrographs of mineral grains; a valuable research tool is the electron micro- scope which can magnify particles up to 120,000 times; Mt. Rainier, Washington; RV Don J. Miller supports mineral assessment work in Alaska. 

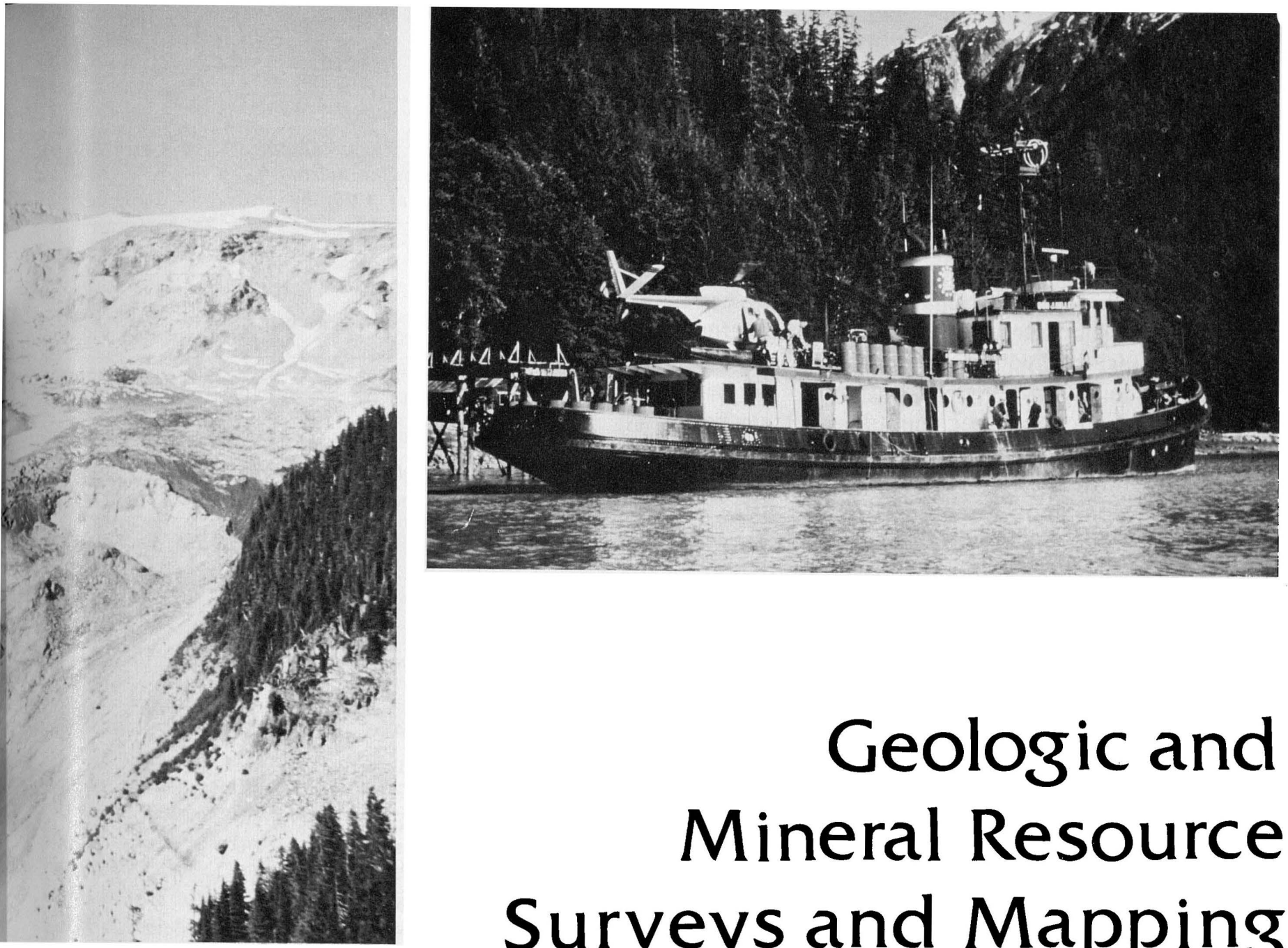

\section{Geologic and Mineral Resource Surveys and Mapping}

\section{OVERVIEW}

Geologic processes and events that led to the composition and structure of the Earth affect every facet of our lives in one way or another by controlling the distribution and amount of energy, mineral, and land resources needed to support modern societies. Improving our understanding of the Earth, its composition, its structure, and the geologic processes that effect it, can lead to wiser, more intelligent use of our Nation's natural resources.

The basic mission of the Geologic and Mineral Resource Surveys and Mapping activity, under the direction of the Geologic Division, is to provide geologic, geochemical and geophysical information for other Governmental agencies and for the general public on land resources, on mineral and energy resources, and on geologic hazards of the Nation and its territories. The activity is divided into four subactivities: Land Resource Surveys, Mineral Resource Surveys, Energy Resource Surveys, and Offshore Geologic Surveys.

Land Resource Surveys provide the basic interpretive geological, geophysical, and geochemical maps and data that support the resource and missionoriented activities of the Geological Survey. Other programs of this subactivity aim at identifying the effects of geologic hazards, including earthquake and volcanic hazards, the environmental aspects of developing energy resources, and investigations of the geologic processes and historical events that led to the present physical and chemical composition and structure of the Earth.

Mineral Resource Surveys provide knowledge of the availability of metallic and nonmetallic mineral resources by studying the geology of known mineral occurrences and potentially mineralized areas, developing and improving exploration techniques, and assessing the Nation's mineral resources. Mineral resource assessment work responds to the requirements of legislative actions such as the Survey's Organic Act (1879), the Strategic Raw Materials Act (1938), the Wilderness Act (1964), the Mining and Minerals Policy Act (1970), and the Alaska Native Claims Settlement Act (1971).

Energy Resources Surveys update our knowledge of the location, quantity, and quality of the Nation's energy resources through resource studies of coal, oil and gas, oil-shale, uranium and thorium, and geothermal energy. 
Offshore Geologic Surveys assess the potential mineral resources on the continental margins of the United States and determine the nature of geological environmental hazards related to offshore siting of energy facilities.

Two programs-International Activities and Astrogeology-are supported primarily by outside funds and are not included within the four budget subactivities. The International Activities program provides technical assistance to other countries utilizing funds provided by other Governments or international organizations through the Department of State. The Astrogeology program, established on behalf of $\mathrm{Na}$ tional Aeronautics and Space Administration, provides geological research in support of space exploration.

In addition to the Geologic and Mineral Resources Surveys and Mapping activity, this chapter also describes the Alaska Pipeline Related Investigations activity. The Alaska Pipeline Related Investigations activity monitors the construction of the TransAlaskan Pipeline from Prudhoe Bay to Valdez, Alaska. The hydrologic, geologic, and topographic data collected by the Survey's Water Resources, Geologic, and Topographic Divisions are used by the Alaska Pipeline Office of the Department of the Interior to establish engineering design criteria and to assure that the pipeline contractor conforms to the technical and environmental stipulations of the construction permits.

\section{Budget and personnel}

In fiscal year 1975, obligations of the Geologic and Mineral Resources Mapping and Surveys activity were $\$ 114.5$ million (table 6), an increase of 56 percent over 1974. About $\$ 1.5$ million came from 20 States and the

TABLE 6.-Geologic and Mineral Resource Surveys and Mapping activity and Alaska Pipeline Related Investigations activity obligations for fiscal year 1975, by programs

[Figures may not add to totals because of rounding]

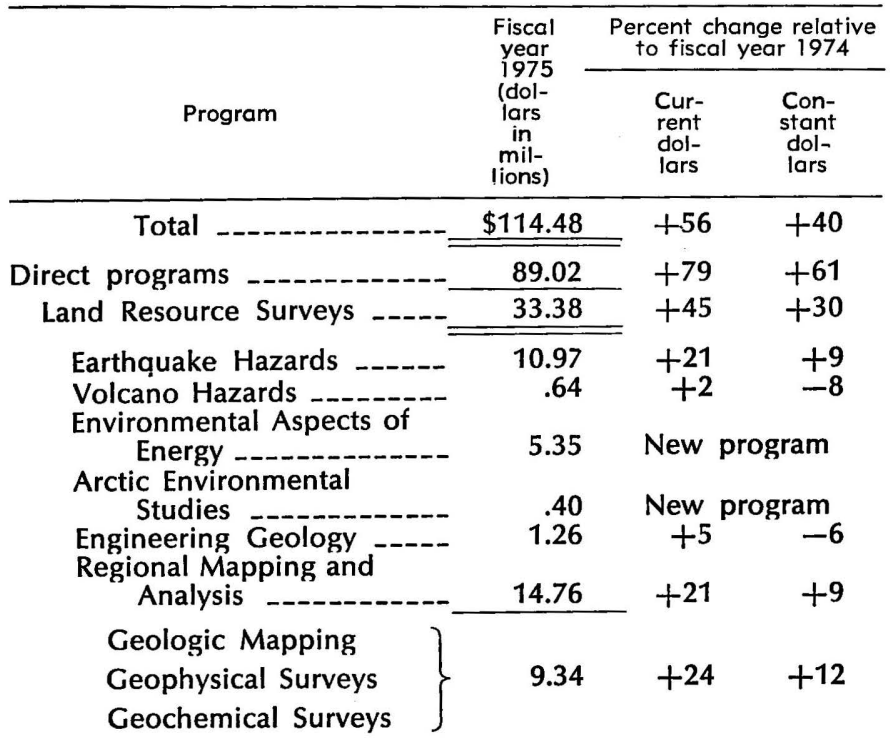

TABLE 6.-Geologic and Mineral Resource Surveys and Mapping activity and Alaska Pipeline Related Investigations activity ob. ligations for fiscal year 1975, by programs-Continued

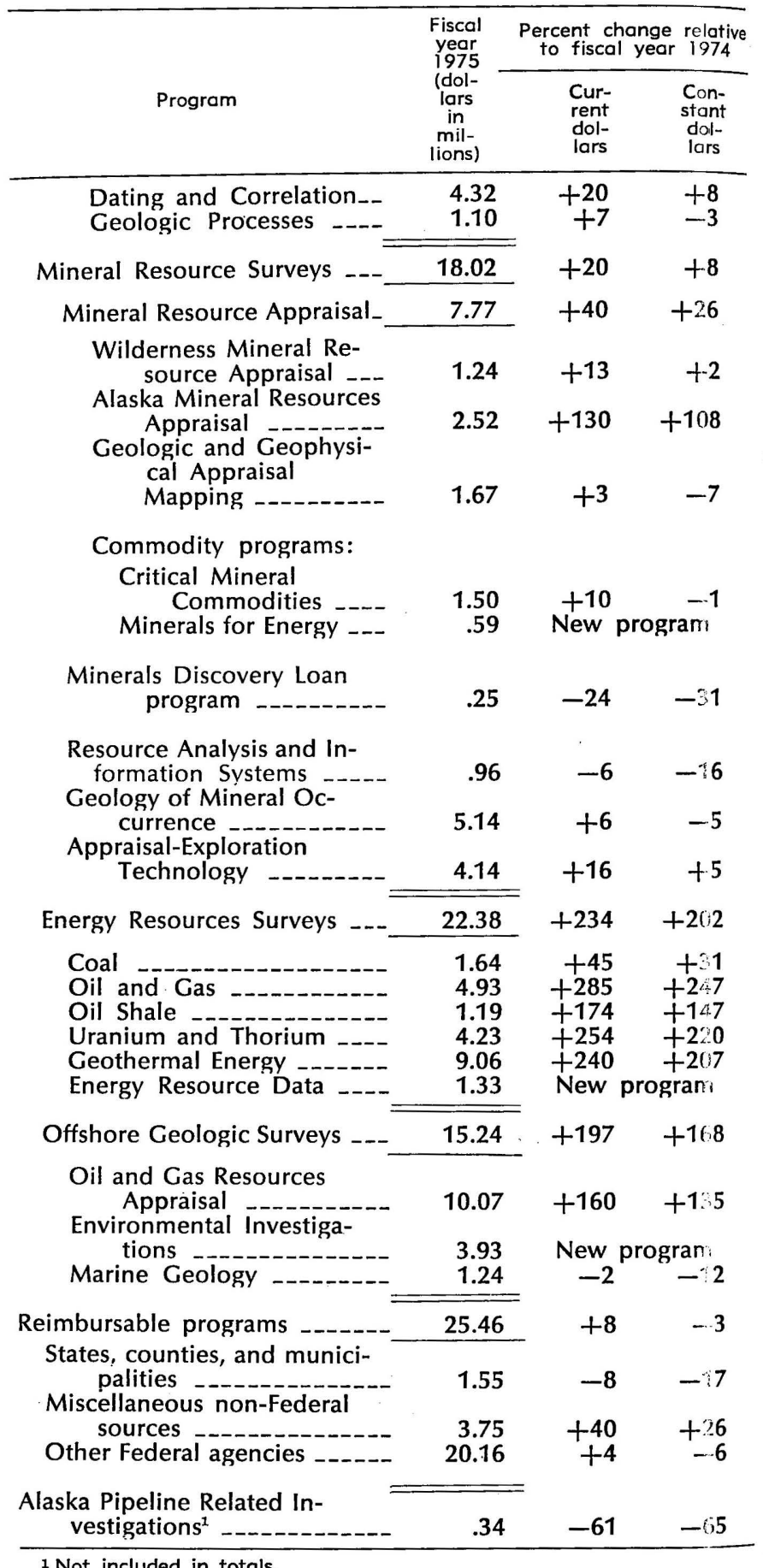

1 Not included in totals.

Virgin Islands and $\$ 24$ million came from other Federal and non-Federal sources (fig. 25 and table 26). The largest cooperative project was with the State of Kentucky for quadrangle geologic mapping at a scale of $1: 24,000$. Although budget obligations increased from $\$ 33.1$ million in 1966 to $\$ 51.5$ million in 1972 (fig. 10), the increase was largely absorbed by higher operating costs. Since fiscal year 1973, however, the 


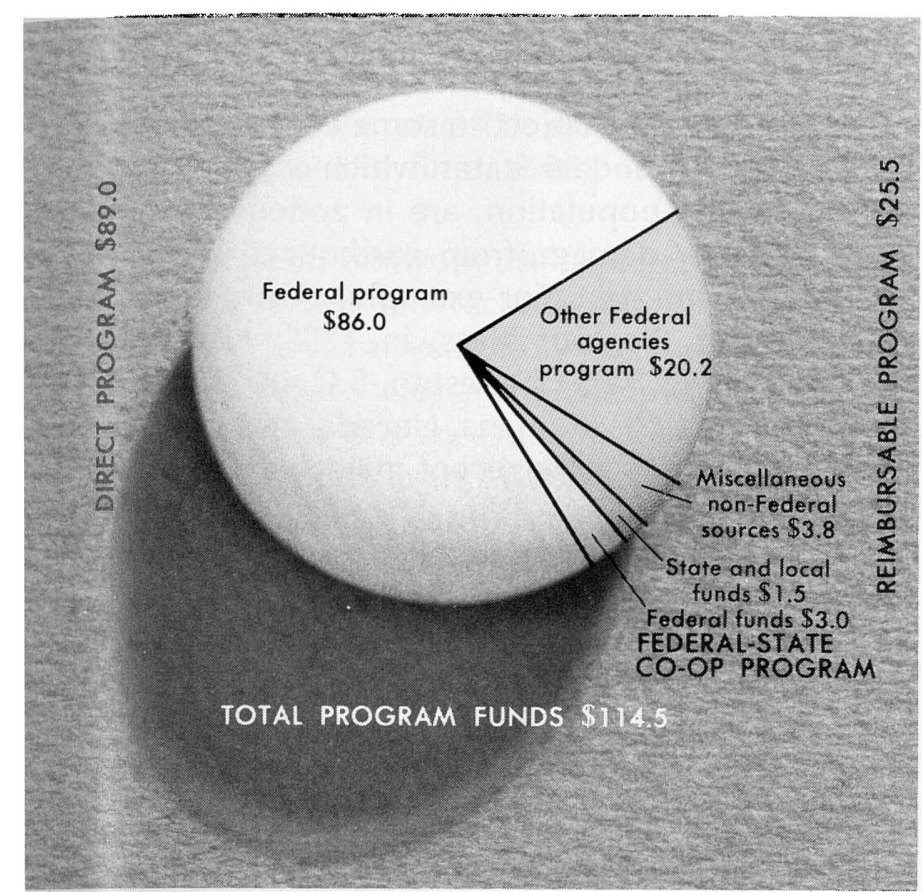

FIGURE 25.-Sources of fiscal year 1975 funds for Geologic and Mineral Resource Surveys and Mapping (dollars in millions).

activity's budget has been doubled by substantial increases in Energy Resource Surveys, Offshore Geologic Surveys, and the Earthquake Hazards and Environmental Aspects of Energy programs of Land Resources Surveys (table 33), together with large increases in support from other Federal agencies.

At the end of fiscal year 1975 the Geologic Division had 2,135 permanent fulltime employees, an increase of 13.1 percent over 1974. In addition 437 temporary employees served as scientific aides, laboratory technicians, and field assistants.

\section{Highlights}

Major highlights of 1975 included the following events and developments:

- The Thanksgiving Day, 1974, earthquake near Hollister, Calif., was anticipated from a variety of precursory geophysical signals. These and other observations indicate there is a possibility that some earthquakes can be predicted.

- The July 5-6, 1975, eruption of the Hawaiian volcano Mauna Loa was predicted from measurements of the volcano's inflation.

- Mount Baker, Wash., was monitored because increased thermal emissions accelerate the melting of snow and ice which could cause massive landslides.

- Regional and detailed geologic mapping of 145,000 square kilometres (55,970 square miles) was accomplished to support land, mineral, and energy resource assessments.
- A new method of dating rocks 35,000 to a million years old was developed, based on certain changes in the amino acids in fossil mollusks.

- Environmental impact statements were prepared for the Alaska Trans-Arctic pipeline, potassium mining in New Mexico, coal mining in Montana, Wyoming, and Colorado, phosphate mining in Idaho, copper-nickel mining in Minnesota, and recreational development in the Glen Canyon National Recreation Area, Utah.

- Geologic studies of 11 Wilderness areas found that portions of 5 areas contained significant mineral resources.

- Resource appraisals in Alaska identified copper, molybdenum, gold, silver, chromium, and tin as potential mineral occurrences.

- Aeromagnetic mapping of 116,550 square kilometres (45,000 square miles) was completed in parts of Alabama, Georgia, Maryland, New Mexico, New York, North Carolina, South Carolina, Washington, and West Virginia. These maps show the distribution of rocks potentially related to mineral deposits.

- New geochemical methods were developed to locate buried sulfur-rich and radioactive minerals by measuring the amounts of sulfur gases, carbon dioxide, mercury, and helium in soil gas.

- Estimates of recoverable oil and gas resources of the United States were revised (Miller and others, 1975).

- The geothermal resources of the United States were assessed (White and Williams, 1975).

- Potential oil and gas resources were estimated on 17 Outer Continental Shelf areas covering approximately 1.4 million square kilometres $(540,400$ square miles).

\section{LAND RESOURCE SURVEYS}

The reservoir of knowledge and expertise that the Geological Survey develops in the land resource investigations assists the Government and the general public to analyze and to solve geologic problems related to the use of the land and the protection of man's environment. It also makes possible quick and effective response to requests for geologic information and advice from other Federal agencies, and, where practical and appropriate, from State and local agencies. The research carried out under the Land Resource Surveys subactivity consists of six major programs: Earthquake Hazards, Volcano Hazards, Environmental Aspects of Energy, Arctic Environmental Studies, Engineering Geology, and Regional Mapping and Analysis. 


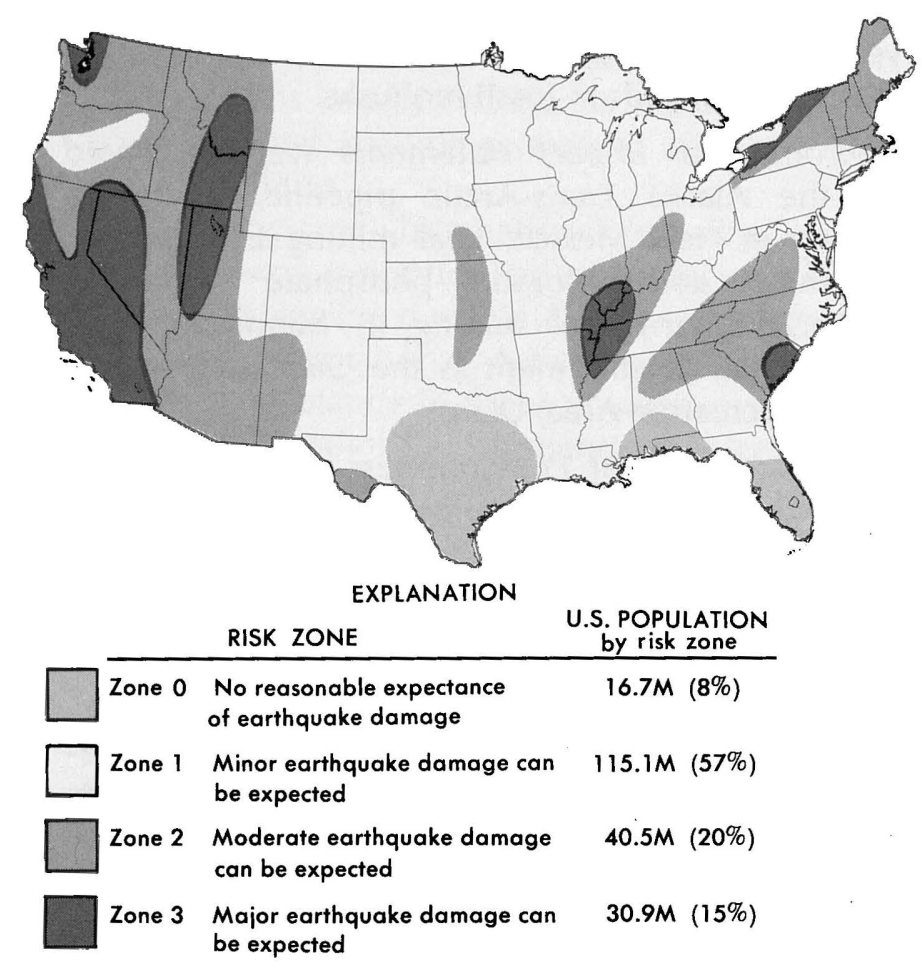

\section{Earthquake Hazards}

All 50 States are subject to some earthquake-related hazard (fig. 26), and 39 States, which contain nearly 35 percent of the population, are in zones where moderate to major damage from earthquake shaking has occurred in the past. For example, destructive earthquakes struck Boston, Mass. in 1755, New Madrid, Mo. in 1811-12, and Charleston, S.C. in 1886. Alaska, California (fig. 27), Montana, Nevada, and Washington have experienced more recent major damaging earthquakes.

Losses from earthquakes can be greatly reduced by proper engineering design, by wise use of the land, and by emergency preparedness actions. The National Earthquake Information Service locates and rapidly evaluates important earthquakes worldwide, provides data support for the Tsunami Warning System, and notifies appropriate disaster authorities and the public within 2 hours of the earthquake's occurrence. For several days after the occurrence of a destructive earthquake, the alerting service also acts as an information center. Major program objectives include: (1)

FIGURE 26.-Earthquake risk zones in the United States.

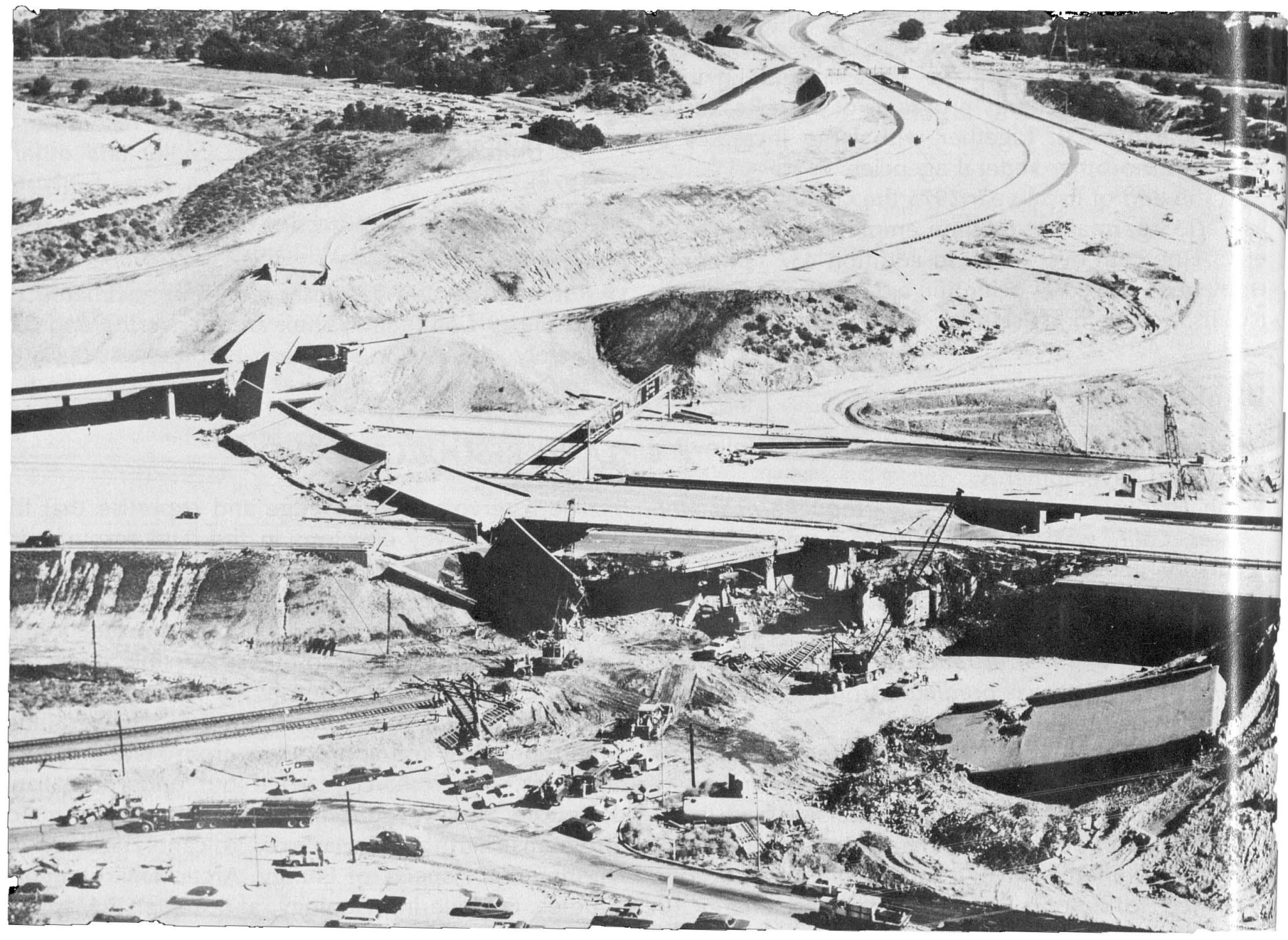


acquisition and dissemination of information on earthquake occurrences; (2) mapping and evaluation of earthquake hazards; and (3) development of techniques to predict the time, place, and magnitude of earthquakes.

The Worldwide Network of Standard Seismographs (WWNSS) observes and records distant earthquakes. The network in fiscal year 1975 consisted of 31 stations in the United States and 85 stations located in 68 foreign countries. It is an essential source of data for locating earthquakes worldwide, determining the internal structure of the Earth, identifying and delineating earthquake-prone regions, and estimating seismic risk. The Geological Survey operates the WWNSS in cooperation with the National Science Foundation.

The Geological Survey also operates a strongmotion engineering seismology program for the $\mathrm{Na}$ tional Science Foundation. The accelerograph records obtained indicate the nature and magnitude of ground motion associated with earthquakes and are used by the engineering community to develop and improve earthquake-resistant designs for structures. Approximately 130 accelerograph records were obtained during fiscal year 1975 (U.S. Geological Survey, 1975a).

The Earthquake Hazards program conducts a variety of studies to assess the expected size and frequency of earthquakes, and to identify and to delineate areas affected by earthquake hazards such as surface faulting, strong shaking, ground failure, tectonic elevation changes, landslides, and flooding from tsunamis (seismic sea waves) or dam failure (Wallace, 1974). Activities in fiscal year 1975 included:

- Geologic studies to determine the relation between regional structure and earthquakes, the distribution of potentially active faults, and the nature and rates of movement along these faults. Studies are underway for the San Andreas and related fault systems, California; southern Alaska; Nevada seismic zone; the Intermountain seismic zone of Utah, Idaho, Montana, and Wyoming; the Rio Grande rift; and the central Mississippi Valley. Most of these investigations are concentrated in or near major urban areas of high seismic risk in the Western United States (fig. 28).

- Operation of local seismometer networks in earthquake-prone regions for detection and accurate location of small-magnitude earthquakes (fig. 28). These networks, dense arrays of sensitive instruments that permit the detection and accurate location of small-magnitude earthquakes, are used to map seismically active fault segments in three dimensions and to identify major active faults. Part

\FIGURE 27.-Damage to highways in San Fernando, Calif., caused by an earthquake on February 9, 1971. of this effort is conducted by State geological surveys, universities, and the private sector under Geological Survey research grants and contracts.

- Investigations of the factors and processes that determined the behavior of rocks and soils when shaken by earthquakes and that cause ground failure. For example, the mechanics of liquefaction -the sudden weakening of soils because of high fluid pressure-are being explored in detail because liquefaction is the basic cause of ground-failure during an earthquake.

Accurate forecasting of the time, place, and size of destructive earthquakes could substantially reduce the potential loss of life and the number of injuries. Prediction research includes monitoring and analysis of crustal strain and local earthquake activity, the study of the behavior of rocks under conditions like those within the Earth, and investigation of the basic causes and mechanisms of earthquakes. Field measurements, iaboratory experiments, and theoretical studies of geophysical precursors of earthquakes are being carried out in order to establish a firm physical basis for prediction. Permanent seismograph networks of roughly 400 stations in California and Nevada are important components of the earthquake-prediction effort.

The Geological Survey has been conducting an earthquake-prediction experiment astride a highly seismic part of the San Andreas fault near Hollister, Calif. A dense network of seismometers, tiltmeters, magnetometers, and devices for recording horizontal strain, fault creep, and water-level changes in wells at 150 different locations in that region is monitored to establish the physical characteristics of the fault zone and to develop efficient methods for recording and interpreting the changes that occur within the Earth prior to earthquakes. A long-term goal of the experiment is to test hypotheses that can explain the time of occurrence of earthquakes. Part of this earthquakeprediction research is supported by approximately 55 contracts that utilize the capabilities of university scientists to develop techniques for identifying geophysical anomalies that might signal impending earthquakes. In addition to seismic techniques for earthquake prediction, both Survey and university scientists are investigating possible earthquake precursors such as variations in electrical and magnetic properties, changes in the flow of ground water and in water geochemistry, and anomalous tilts and uplifts of the Earth's surface.

Fiscal year 1975 accomplishments of the Earthquake Hazards program included:

- Prediction of the Thanksgiving Day 1974 earthquake (5.2 magnitude) between the San Andreas and Calaveras faults near Hollister, Calif., from marked 


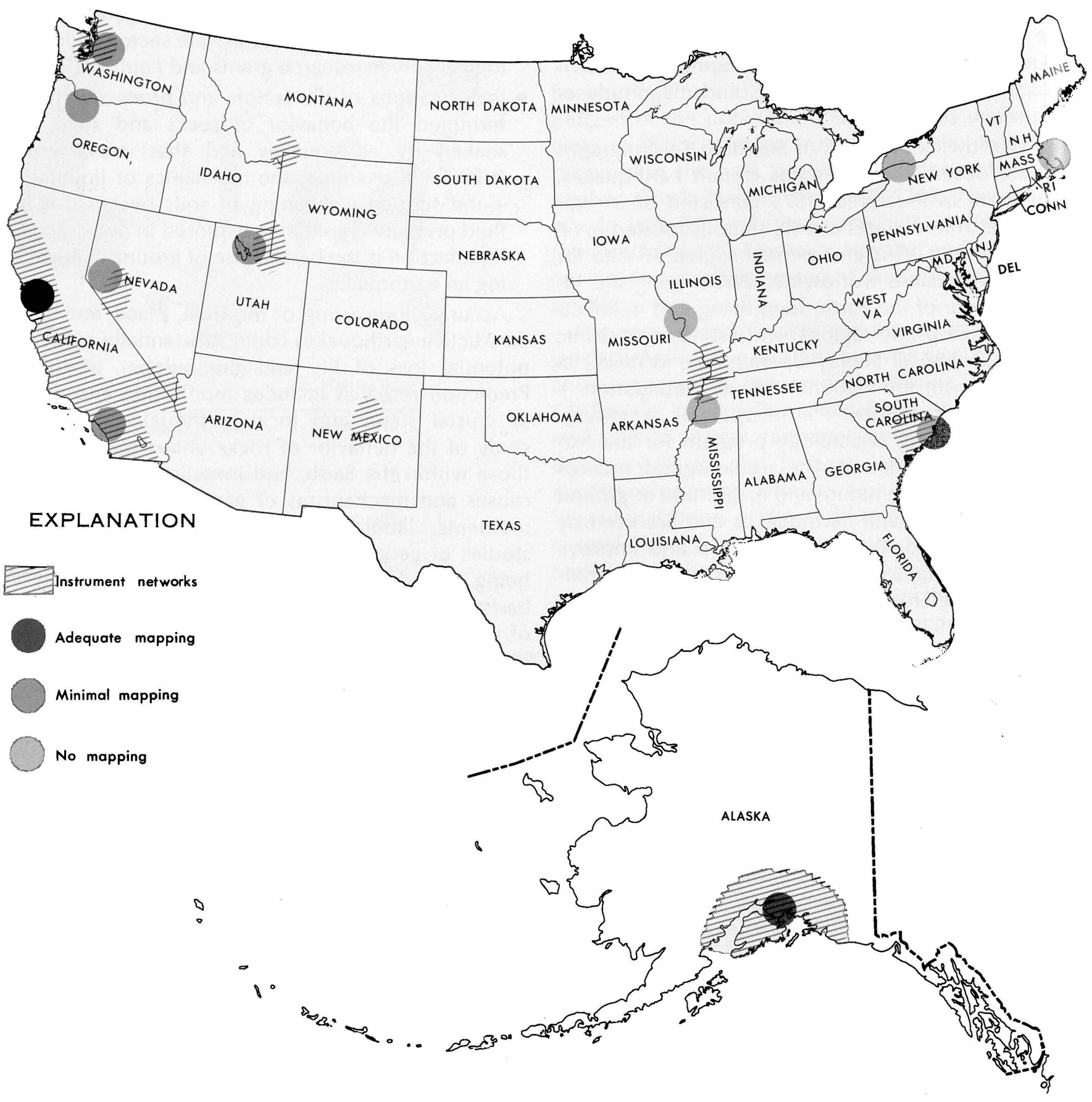

FIGURE 28.-Earthquake hazards mapping and instrument networks in fiscal year 1975.

changes observed during the preceeding weeks in deformation of the Earth's surface and in the magnetic field. Retrospective analysis of seismic data suggested an anomaly that coincided in time with changes in other geophysical signals. This was the first time that such a variety of precursory signals had been observed for a single earthquake in the United States. During 1974, 12 other earthquakes in the test area were preceded by significant changes in tilt of the Earth's surface. These observations con- presently available geophysical instrumentation and analytical techniques.

- Publication of 35 earthquake geologic hazard maps and evaluations which are useful in establishing new building and zoning requirements in earthquake-prone areas.

- Identification of active faults by estimating regional attenuation of strong shaking, and the qualitative delineation of the relative shaking response of geologic units in the San Francisco Bay area (Gibbs and Borcherdt, 1974). 
- Determination of liquefaction potential and landslide susceptibility in the San Francisco Bay area.

These analytical methods for the assessment of seismic hazards have application to other earthquakeprone regions and can be used as a basis for land use planning and engineering actions that will substantially reduce hazards caused by earthquakes.

Reliable forecasting of destructive earthquakes appears to be an attainable goal in the light of recent advances in understanding earthquake mechanisms and the geophysical anomalies that precede earthquakes. However, before prediction systems can be deployed to provide warnings to urban areas, additional research into a wide variety of earthquake precursors is required, together with development of sophisticated techniques for rapidly analyzing large quantities of geophysical data. Prediction systems will probably be deployed first for areas in California, because that is where the knowledge of earthquake mechanics is most highly developed. Prediction methods and sensors presently being used in the central California experiment need to be tested in other geologic settings. The Geological Survey plans to place a dense array of seismometers and tiltmeters astride the highly active San Jacinto fault about 96 kilometres (60 miles) southeast of Los Angeles. Gradual expansion of instrumentation to cover the highly populated San Francisco and Los Angeles areas would be the next step as prediction methods are validated from the experimental system.

\section{Volcano Hazards}

The Volcano Hazards program seeks to mitigate the hazards posed by the active volcanoes in Hawaii and the Cascade Range in the Western United States. These volcanoes have been intermittently active throughout historic time, and the possibility of eruptions and other hazardous situations will continue in the future.

Work at the Hawaiian Volcano Observatory is directed toward anticipating the time and location of future outbreaks of the active volcanoes, Kilauea and Mauna Loa, which are of concern to more than 35,000 people who live downslope. Volcano hazards maps for the Island of Hawaii, prepared in cooperation with the Department of Housing and Urban Development, outline areas exposed to varying types and degrees of hazards. In the Pacific Northwest, geologic and geophysical studies are directed toward understanding the types of hazards posed by eight Cascade Range volcanoes.

Several volcanoes in Alaska are also being investigated to study the relationships between volcanism and geothermal energy. These projects are funded through the Geothermal Energy program.
In fiscal year 1975, two events underscored the importance of the Volcano Hazards program:

- Mauna Loa inflated in preparation for an eruption that eventually took place on July 5-6, 1975 (fig. 29). This was the first eruption from Mauna Loa in 25 years, and it increases the probability that this volcano will erupt again in the near future. Monitoring efforts on Mauna Loa have been increased. At present, the volcano is reinflating in advance of its next eruption.

- Thermal emissions on Mount Baker, Wash., increased (fig. 30) in March 1975. By May, the emissions had increased to about 100 times normal. This thermal activity accelerated the melting of snow and ice on the volcano's flank. In June, the Geological Survey estimated that the likelihood of a large mudflow originating on Mount Baker was about 10 times normal. Subsequently, the Forest Service and the Puget Sound Power and Light Company restricted public access to nearby recreational areas. The Geological Survey, State agencies, and university groups have increased geophysical monitoring of the volcano.

\section{Environmental Aspects of Energy}

The Environmental Aspects of Energy program, which began in fiscal year 1975, is an integral part of the Geological Survey's energy-resource research, exploration, and evaluation effort. The program acquires, interprets, and distributes geologic, hydrologic, geophysical, geochemical, and related information that will assist in analyzing and solving environmental problems associated with energy-resource extraction and utilization and the planning, siting, and construction of facilities for energy conversion and distribution.

Much of the information and expertise developed by this program is used by the Survey to prepare and review environmental impact statements and to guide environmental monitoring required during the supervision of resource development on Federal and Indian lands.

\section{National environmental overview maps}

National environmental overview maps are being prepared to show the extent and frequency of occurrence of certain geologic processes and events that may pose constraints to safe land utilization and to mineral- and energy-resource development. This broad-scale assessment is no substitute for more detailed information and analysis, but for many areas of the country, it is a useful beginning to the complex problem of land use planning and its implementation.

Maps of the United States scheduled for preparation at a scale of $1: 7,500,000$ will cover the following topics: landslides, active faults, surficial materials, vol- 

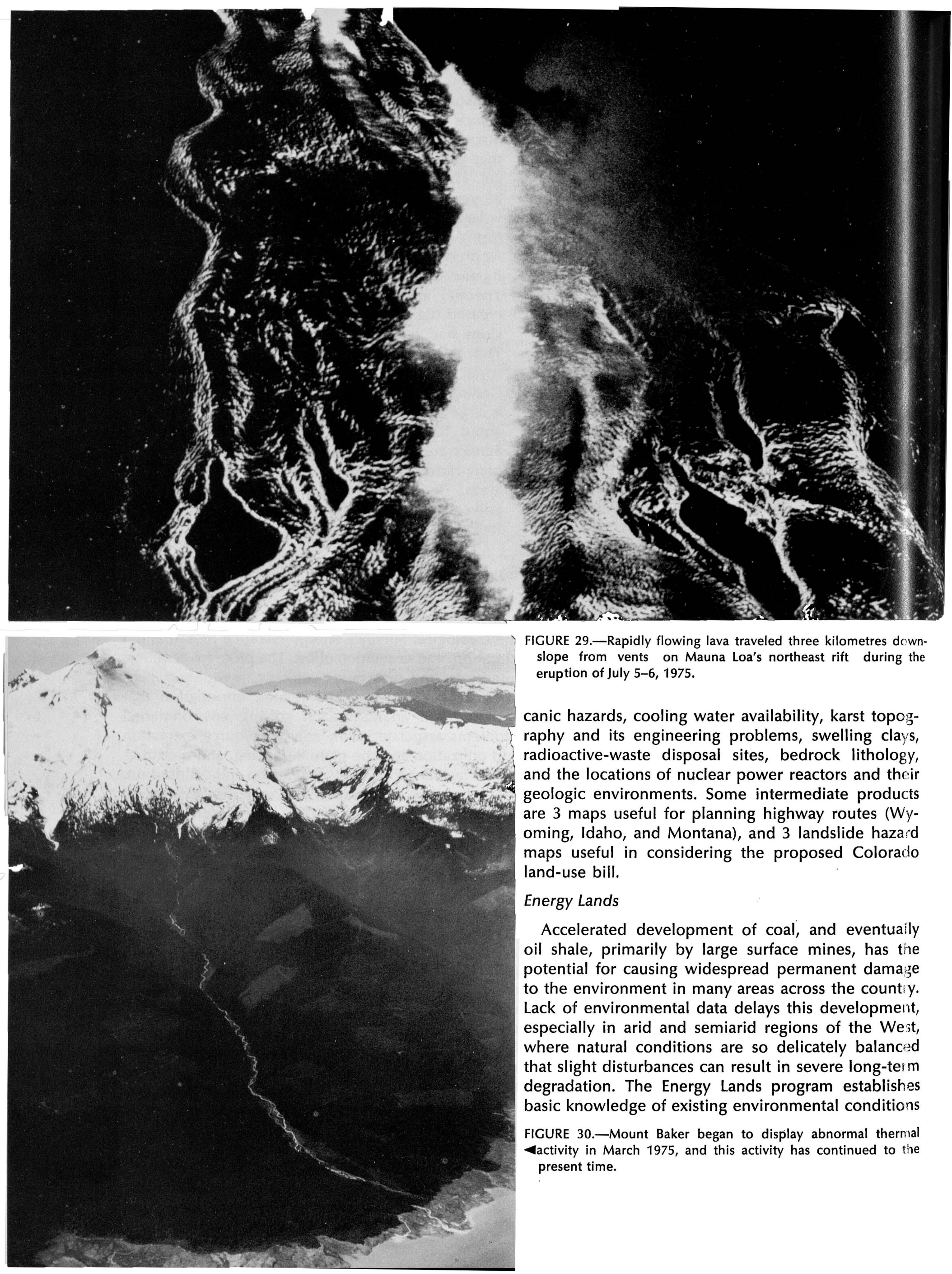

FIGURE 29.-Rapidly flowing lava traveled three kilometres downslope from vents on Mauna Loa's northeast rift during the eruption of July 5-6, 1975.

canic hazards, cooling water availability, karst topography and its engineering problems, swelling clays, radioactive-waste disposal sites, bedrock lithology, and the locations of nuclear power reactors and their geologic environments. Some intermediate products are 3 maps useful for planning highway routes (Wyoming, Idaho, and Montana), and 3 landslide hazard maps useful in considering the proposed Colorado land-use bill.

\section{Energy Lands}

Accelerated development of coal, and eventuaily oil shale, primarily by large surface mines, has the potential for causing widespread permanent damage to the environment in many areas across the count $y$. Lack of environmental data delays this development, especially in arid and semiarid regions of the West, where natural conditions are so delicately balanced that slight disturbances can result in severe long-term degradation. The Energy Lands program establishes basic knowledge of existing environmental conditions

FIGURE 30.-Mount Baker began to display abnormal thermal $\checkmark$ activity in March 1975, and this activity has continued to the present time. 
in each of the principal coal and oil-shale resource areas in order to predict possible changes before mining and related industrial activity start, and then to monitor changes by means of quantitative measurements as the development takes place. The preparation of a comprehensive environmental data base includes the integration of large amounts of information on bedrock geology, surficial geology, geomorphology, quality and quantity of coal and overburden, ground- and surface-water conditions, and erosional and weathering patterns. Efforts are being concentrated in the basins of the Rocky Mountains and northern Great Plains where the greatest coal and oil-shale development is expected to take place in coming years. Seven grants to universities and State agencies for studies in their particular areas of experience and knowledge form an important part of the program.

During fiscal year 1975, 90,600 square kilometres $(35,000$ square miles) were geologically mapped by reconnaissance or in detail around the energy resource areas. Investigations included studies of landslide incidence and susceptibility in the Appalachian hituminous coal regions, studies of active geologic processes and rates of weathering and erosion in the coal-rich eastern Powder River Basin, Wyo., and engineering and geologic studies in the western Powder River Basin of Wyoming and Montana where underground mining operations have caused pronounced ground subsidence.

\section{Reactor hazards}

About 100 nuclear power reactors are now built or under construction (fig. 31), but several times that number may be constructed in the next two decades. This program focuses on identifying geologic hazards such as fault movement, earthquakes, volcanic eruptions, ground subsidence due to ground water and petroleum withdrawal, and failure of foundation materials that deny the use of otherwise suitable sites for reactors or that can greatly increase reactor design and construction costs. During fiscal year 1975, geologic mapping was underway in various parts of California, Oregon, and Washington to delineate these hazards. In the eastern part of the country, which contains 85 percent of the population and more than three-quarters of the power reactors now built or under construction, the nature and regional distribution of hazards are less obvious. For example, no clear basis exists for predicting the distribution of future earthquakes. Studies of earthquakes, deformation, geologic structure, and recency of faulting were conducted in New York, New England, and the Atlantic Coastal Plain from Maryland to Alabama. A study was also underway in the Texas Coastal Plain to understand better the relation of surface faulting to withdrawal of fluid from the ground. These investigations are closely coordinated with and depend upon information obtained by the Earthquake Hazards, Volcanic Hazards, Engineering Geology, and other related Survey programs.

Program accomplishments during the year included:

- Recognition of many faults in southeast United States including several structural zones 16 kilometres (10 miles) or more long which are young enough to suggest that active faults may be present in the region.

- Development of a new method of dating rocks based on certain changes in the amino acids in fossil mollusks. The method is applicable to dating rocks in the age range from 35,000 to a million years for which other methods are largely inapplicable.

\section{Arctic Environmental Studies}

The Arctic Environmental Studies program began during fiscal year 1975 as an outgrowth of the Alaska Pipeline Related Investigations activity, to take advantage of the unique opportunity to collect scientific and engineering data made available during construction of the Alaska pipeline. During the year, special attention was given to the collection of data on permanently frozen soils, glacial features, surficial deposits, and geologic processes to assess whether engineering designs for pipelines, ancillary construction, and maintenance facilities are adequate to preserve the Arctic environment. A network of 12 seismometer stations was established in northeast Alaska to collect data needed for evaluating earthquake risks along the Arctic coast and in the eastern Brooks Range. Future studies will concentrate on proposed gas pipeline routes from Fairbanks to the Canadian border and from Fairbanks to Anchorage.

\section{Engineering Geology}

The Engineering Geology program advances engineering geologic knowledge by mapping the distribution of geologic materials and by measuring and describing the properties of the materials that predict their engineering behavior. The program also provides engineering-geologic advice and assistance to local, State, and other Federal agencies. The program includes studies of: (1) rock deformation hazards in coal mines, rock-mechanics research, and other investigations that provide information for the safe and environmentally efficient extraction of energy and mineral resources from the ground; (2) landslides and mudflows, drainage characteristics, foundation condi- 


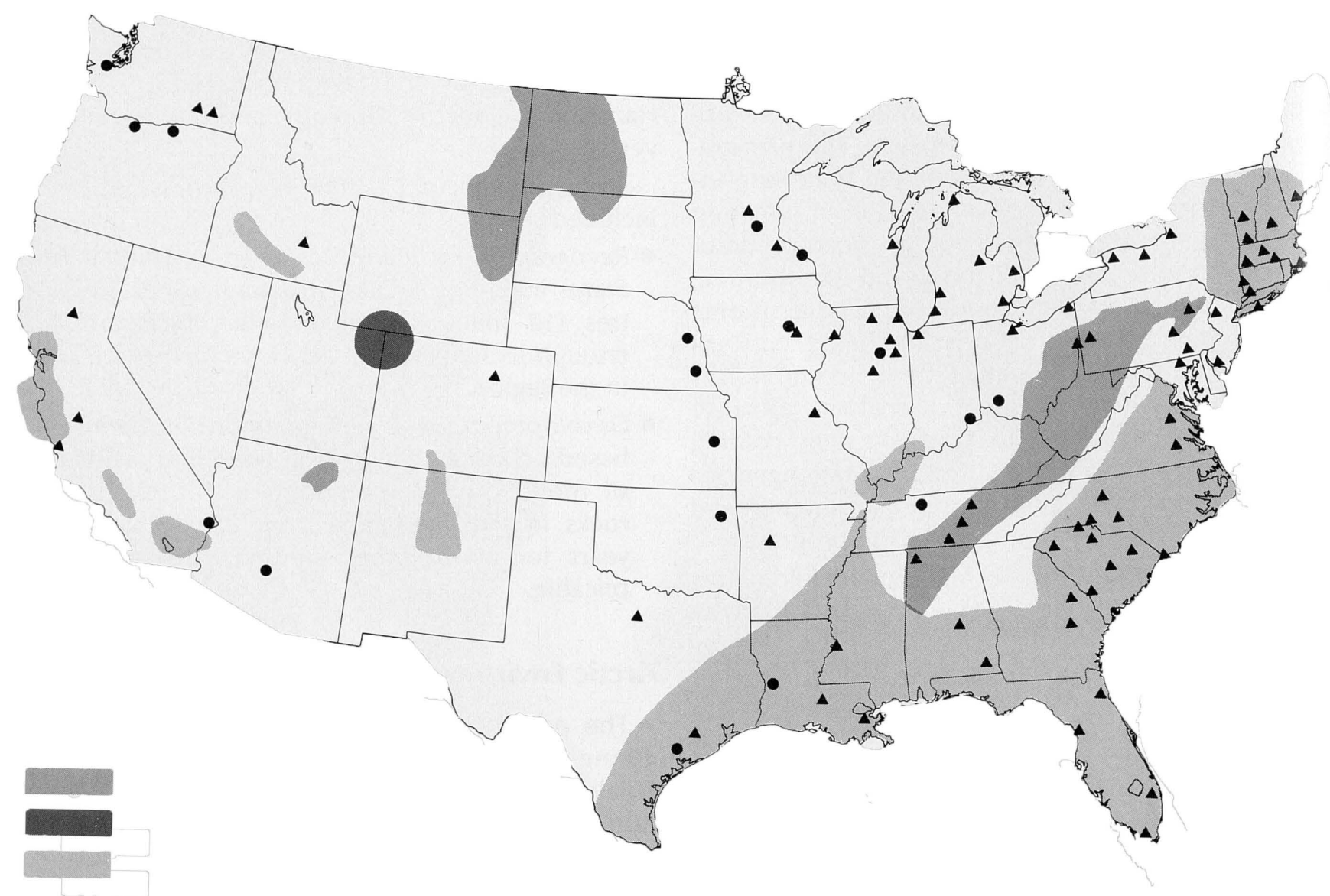

FIGURE 31.-Geologic studies relating to environmental aspects of energy development.

tions, and properties of rocks and soils that affect urban development and land use; and (3) geologic processes governing the stability of slopes, surface subsidence, and volcanic eruptions in order to understand these processes more fully and to reduce the impacts of these natural hazards. These studies focus on the engineering-geology aspects of natural hazards and thus provide technical support to other Survey programs which seek to characterize the type and extent of natural hazards. The program also conducts engineering-geology studies related to underground nuclear weapons tests at the Nevada Test Site with funds from the Department of Defense and the Energy Research and Development Administration.

Major accomplishments in fiscal year 1975 included:

- Development of a mapping technique to portray liquefaction potential of unconsolidated sediments under seismic loading developed for mapping techniques.

- Provision of information on subsurface geology of underground explosions to the Soviet Union under the terms of the proposed Threshold Test Ban Treaty.

\section{Regional Mapping and Analysis}

The Regional Mapping and Analysis program provides the earth-science programs throughout the Geological Survey with basic geologic, geophysical, and geochemical data and services such as fossil identification and age determinations. Supporting research leads to improved understanding of geologic processes and development of new instruments and analytical methods.

\section{Geologic mapping}

Geologic maps are invaluable tools in the search for water, mineral, and energy resources; evaluation of geologic hazards; assessment of environmental impacts; and planning for prudent use of land resources. These maps show the distribution of rocks and urficial material by age, and their physical and structural relationships with one another. Inferences can be drawn from these maps about an area's geologic history, the geologic processes, the orientation of rock layers, and of faults and fractures, and the shape of rock bodies beneath the surface. 
The Survey maps the geology at scales ranging from $1: 24,000$ to $1: 2,500,000$ depending upon the type of information to be portrayed and the purpose of the mapping (tables 7 and 8). By the end of fiscal year 1975 , geologic maps at 1:250,000 or larger scales were available for 38 percent of the United States. The Survey is increasing the amount of geologic mapping at $1: 250,000$ (fig. 32 ) in order to increase coverage more rapidly and at relatively lower cost. Greater emphasis is also being placed on cooperative arrangements by which Federal and State personnel work together to produce geologic maps.

In fiscal year 1975, the mapping program:

- Mapped geologically about 73,000 square kilometres $(28,200$ square miles) at various scales (table 7$)$.

- Identified resources of sand, gravel, clay, coal, and phosphate rock.
TABLE 7.-Distribution of geologic mapping in the Regional Mapping and Analysis program by State in fiscal year 1975

\begin{tabular}{|c|c|c|c|c|}
\hline \multirow[b]{2}{*}{ State } & \multicolumn{3}{|c|}{ Scale of mapping } & \multirow[b]{2}{*}{$\begin{array}{l}\text { Man } \\
\text { years }\end{array}$} \\
\hline & $\begin{array}{l}1: 12,000- \\
1: 24,000\end{array}$ & $\begin{array}{l}1: 48,000- \\
1: 63,360\end{array}$ & $1: 250,000$ & \\
\hline TOTAL _ & $7,703 \mathrm{~km}^{2}$ & $6,207 \mathrm{~km}^{2}$ & $59,438 \mathrm{~km}^{2}$ & 88 \\
\hline Alaska & $\begin{array}{lll}-- & \end{array}$ & $2,978 \mathrm{~km}^{2}$ & $9,324 \mathrm{~km}^{2}$ & 3 \\
\hline Arizona & - & & $10,360 \mathrm{~km}^{2}$ & 1 \\
\hline California & & $78 \mathrm{~km}^{2}$ & & 1 \\
\hline Colorado & $65 \mathrm{~km}=$ & $388 \mathrm{~km}^{2}$ & $4,920 \mathrm{~km}^{2}$ & 5.5 \\
\hline $\begin{array}{l}\text { Connecticut } \\
\text { Idaho }\end{array}$ & $337 \mathrm{~km}^{2}$ & & & 7.5 \\
\hline $\begin{array}{l}\text { Idaho } \\
\text { Kentucky }\end{array}$ & 100 & $2,072 \mathrm{~km}^{2}$ & $27,972 \mathrm{~km}^{2}$ & 7 \\
\hline $\begin{array}{l}\text { Kentucky } \\
\text { Maryland }\end{array}$ & $5,180 \mathrm{~km}^{2}$ & -- & -- & 31 \\
\hline Massachusetts & $1,217 \mathrm{~km}^{2}$ & & & 14 \\
\hline Montana & - & $3 \overrightarrow{03} \mathrm{~km}^{2}$ & $2.979 \mathrm{~km}^{2}$ & 2.5 \\
\hline Nebraska & - & - & $906 \mathrm{~km}^{2}$ & 1 \\
\hline Nevada & $103 \mathrm{~km}^{2}$ & -- & esen. & 1 \\
\hline New Hampshire & $78 \mathrm{~km}^{2}$ & & & 1 \\
\hline New Mexico _...- & & - & $2,330 \mathrm{~km}^{2}$ & 1.5 \\
\hline Pennsylvania & $10 \mathrm{~km}^{2}$ & -- & - & .04 \\
\hline Puerto Rico _-_-_- & $362 \mathrm{~km}^{2}$ & - & - & 4 \\
\hline Utah & $28 \mathrm{~km}^{2}$ & & $\ldots$ & .5 \\
\hline Virginia & $129 \mathrm{~km}^{2}$ & $259 \mathrm{~km}^{2}$ &.- & 3 \\
\hline Washington & -- & $129 \mathrm{~km}^{2}$ & & 1 \\
\hline Wyoming _- & -- & -- & $647 \mathrm{~km}^{2}$ & 1 \\
\hline
\end{tabular}

TABLE 8.-Scales of geologic maps commonly used by the Geological Survey

\begin{tabular}{|c|c|c|c|}
\hline Scale & $\begin{array}{l}\text { Percentage } \\
\text { of U.S. } \\
\text { covered at } \\
\text { this or } \\
\text { larger scale }\end{array}$ & Type of information & Purpose \\
\hline $\begin{array}{l}1: 2,500,000 \\
\quad(1 \mathrm{~cm}=25 \mathrm{~km})\end{array}$ & 100 & $\begin{array}{l}\text { Very general distribution of limited num- } \\
\text { ber of very large and heterogeneous } \\
\text { rock units. }\end{array}$ & $\begin{array}{l}\text { General planning and resource evaluation } \\
\text { over very large regions (Federal regions, } \\
\text { very large States). }\end{array}$ \\
\hline $\begin{array}{l}1: 500,000 \\
\quad(1 \mathrm{~cm}=5 \mathrm{~km})\end{array}$ & 73 & $\begin{array}{l}\text { General distribution of a larger number } \\
\text { of somewhat less heterogeneous rock } \\
\text { units. Little information on depth. }\end{array}$ & $\begin{array}{l}\text { General planning and resource evaluation } \\
\text { over large regions (large States, river } \\
\text { basins). Common scale for older State } \\
\text { maps. }\end{array}$ \\
\hline $\begin{array}{l}1: 250,000 \\
1 \mathrm{~cm}=2 . \overline{\mathrm{km}})\end{array}$ & 38 & $\begin{array}{l}\text { Semidetailed distribution of large numbers } \\
\text { of fairly homogeneous rock units. Some } \\
\text { information on depth. Often has topo- } \\
\text { graphic base. }\end{array}$ & $\begin{array}{l}\text { More detailed planning and resource } \\
\text { evaluation in medium-sized areas } \\
\text { (small States, large counties, national } \\
\text { forests, mineralized belts). }\end{array}$ \\
\hline $\begin{array}{l}1: 100,000 \\
(1 \mathrm{~cm}=1 \mathrm{~km}) \\
1: 63,360 \text { (Alaska) } \\
(1 \mathrm{~cm}=6.33 \mathrm{~km}) \\
1: 62,500 \\
(1 \mathrm{~cm}=6.25 \mathrm{~km})\end{array}$ & 24 & $\begin{array}{l}\text { Detailed distribution of large number of } \\
\text { homogeneous rock and surficial units } \\
\text { and considerable information on thick- } \\
\text { ness and depth. Generally has topo- } \\
\text { graphic base. }\end{array}$ & $\begin{array}{l}\text { Detailed planning, land-management and } \\
\text { resource studies (mining districts, urban } \\
\text { areas, many counties). }\end{array}$ \\
\hline $\begin{array}{l}1: 24,000 \\
(1 \mathrm{~cm}=240 \mathrm{~m}) \\
1: 20,000 \text { (Puerto Rico) } \\
(1 \mathrm{~cm}=200 \mathrm{~m})\end{array}$ & 15 & $\begin{array}{l}\text { Very detailed distribution of large number } \\
\text { of quite homogeneous rock units. Sur- } \\
\text { ficial deposits may be shown on } \\
\text { separate map. Much information on } \\
\text { thickness and vertical extent of rock } \\
\text { units. Has topographic base. }\end{array}$ & $\begin{array}{l}\text { Detailed planning, zoning, site selection, } \\
\text { resource evaluation and exploration } \\
\text { (cities and towns, subdivisions, mining } \\
\text { districts, mine sites, large construction } \\
\text { projects). }\end{array}$ \\
\hline
\end{tabular}

- Discovered occurrences of nickel, chromium, gold, copper, zinc, lead, and uranium.

- Increased knowledge of geothermal energy in Idaho and New Mexico, oil and gas in Washington, and oil shale and coal in Wyoming, Utah, Colorado, and Alaska.

- Located landslide areas, areas with unstable slopes, and areas of potential earthquakes.

- Indicated areas suitable for radioactive-waste disposal.

\section{Geophysical Surveys}

The Geophysical Surveys program assists the other programs by providing information on the structure, composition, and dynamics of the Earth's crust. The geophysical force fields associated with distinctive types of rocks and structures are interpreted by analyzing the behavior of the Earth's present and past magnetic field. Examples of research activities in 1975 include: studies of gravity anci magnetic fields; electrical and electromagnetic studies; seismic studies; heat flow studies; laboratory studies of the physical properties of rocks at high temperatures and pressures; 


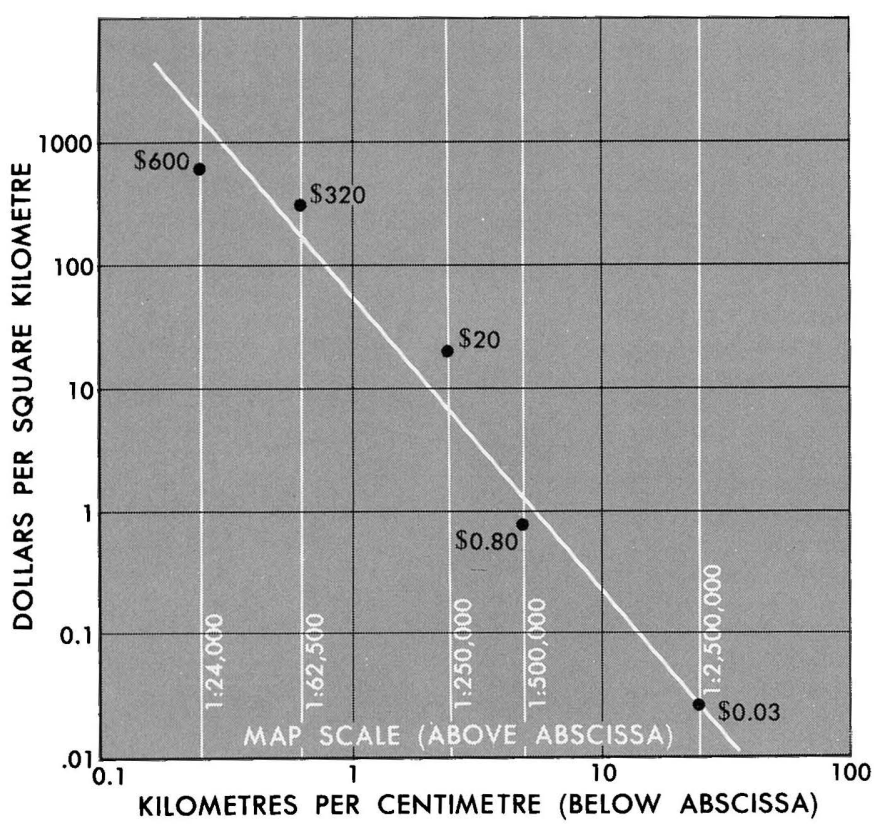

FIGURE 32.-Cost of geologic mapping at different scales.

constructing instruments for measurement of the effects of temperature, pressure, and chemical alterations on the magnetic properties of rocks; developing techniques for determining polarity reversals of the Earth's magnetic field in the geologic past; compiling charts showing components of the Earth's magnetic field; and compiling a world magnetic chart from satellite-magnetometer data. Some fiscal year 1975 findings were:

- Recent faulting in the Rio Grande graben, N. Mex., was found to be influenced by Precambrian structural features of deeply buried rocks.

- Electrical measurements in Hawaii indicated that occurrences of molten magma are associated with recently formed lava tubes.

- Seismic studies in California indicated that the changes preceeding earthquakes occur at great depth.

- Heat flow studies in the Long Valley, Calif., thermal area indicated that magma has been confirmed at considerable depth.

- Reversed paleomagnetic fields in Precambrian-age rocks of Arizona and Montana may be a useful tool in correlating rocks between the two areas.

- Oxidation of lava influenced the magnetic anomalies associated with sea-floor spreading.

- Magnetic impulses detected by geomagnetic observatories around the world may be explained by sunspot phenomena rather than by processes in the Earth's core.

\section{Geochemical Surveys}

Geochemical Surveys provide data on variations of information establishes baselines against which to compare future observations and provides data for pollution control and environmental health research. Activities in 1975 included development of analytical methods, compilation of rock analysis data, operation of a geochemical data system, investigation of trace elements in the human food chain, and studies of urban area geochemistry. Accomplishments during the year included:

- Completion of geochemical surveys of trace elements in soils and plants in Denver, Colo., and Pittsburgh, Pa. urban areas.

- Preparation of a major treatise on the statistical treatment of geochemical data.

\section{Dating and correlation-isotope geology}

The Isotope Geology program investigates, develops, and utilizes methods for determining ages of rocks and minerals, geochemical methods for studying geologic processes, and neutron activation methods of field chemical analysis for mineral exploration. This provides the basic data necessary for understanding Earth history and the geologic processes that have been active in shaping the Earth for the last 4.5 billion years and for solving a great variety of problems, ranging from mineral exploration to nuclear-plant site evaluation in which knowledge of the age of rocks or geologic events is essential. In fiscal year 1975, the Isotope Geology program:

- Dated volcanic activity in Long Valley, Calif., which began 700,000 years ago and continued intermittently until 50,000 years ago.

- Dated mineral deposits in the San Juan Mounains, Colo., which were formed 5 million to 15 million years after the main volcanic episode.

- Dated two massive sulfide deposits in norhern Wisconsin which were formed about 1,900 million years ago. This discovery may change the direction of future prospecting for mineral deposits.

\section{Dating and correlation-paleontology and stratigraphy}

The Paleontology and Stratigraphy program ac quires basic data on the distribution of fossils vithin the stratigraphic column and applies them to cetermine the age and correlation of sedimentary rocks. Accomplishments in fiscal year 1975 included:

- Identification of 3,040 fossils for other scientists.

- Stratigraphic reconnaissance studies of the Caballo Mountains area just east of Truth or Consequences, N. Mex., revealed a much greater sequence of marine Upper Cretaceous rocks than had been formerly recognized, increasing the oil potential of the area. 
- Synthesis of Ordovician history of the Western United States showed varying climatic belts and depths of water produced four contrasting depositional terranes: dolomite and evaporites, limestone, windblown sand, and peripheral siliceous rocks.

\section{Geologic processes}

The Geologic Processes program studies the fundamental properties of rocks and minerals. Past studies of the chemical analysis of rocks, optical properties of minerals, volcanic structures, and the nature of hot springs have provided the basis for methods now used by the mission-oriented programs. Current studies of the relationship of volcanic activity to plate tectonics, the details of chemical differentiation in volcanoes and in ground water, and the mechanism of mineral crystallization to form rocks will contribute to future resource evaluations of many types of mineral deposits.

- Studies of the structural and chemical variations within the Sierra Nevada batholith gave a better understanding of active plate tectonic motions that occurred during the last 200 million years.
- Studies in the rift areas of Oman that are associated with the Arabian Shield resulted in finding important copper deposits that are associated with midplate spreading rather than a subduction boundary where continental crust overrides oceanic crust.

- Geologic studies in Hawaii provided a good model for the interpretation of the geology of seamounts in the northern Pacific, which in turn provided information on the motions of the Pacific plate through geologic time.

\section{MINERAL RESOURCE SURVEYS}

The major emphasis of the Geological Survey's Mineral Resource Surveys programs is on the identification and assessment of hitherto unknown and unsuspected sources of mineral materials, primarily on Federal lands (figs. 33 and 34). Because the assessment of minerals and the identification of new resource occurrences are complex, time consuming, and expensive tasks, the development of new, more rapid, and more effective methods to accomplish these tasks is an important element of the program.

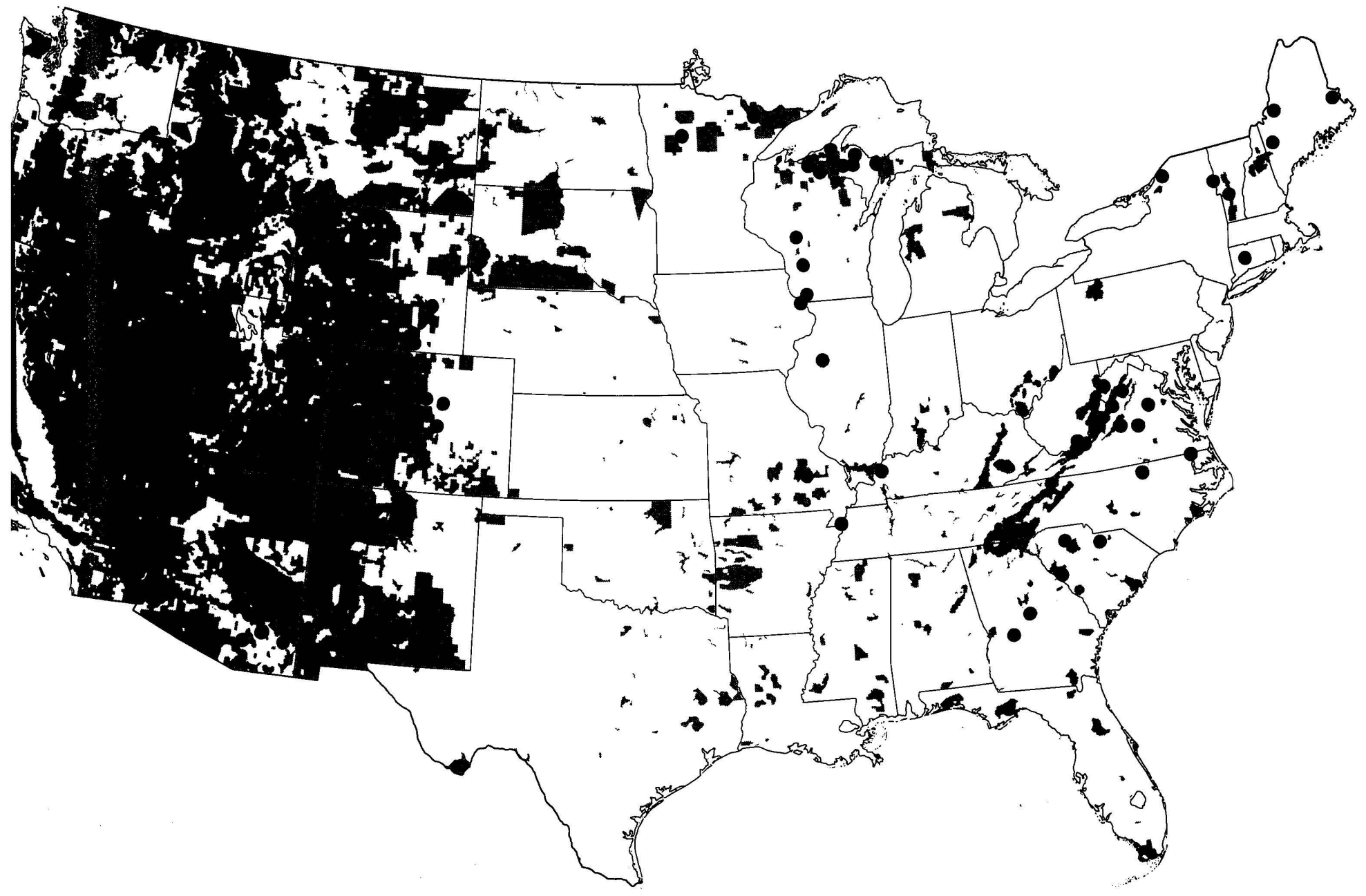

FIGURE 33.- Map of the conterminous States showing Federal lands and Indian reservations (shaded) and the location of current Mineral Resource Surveys project areas (dots). 


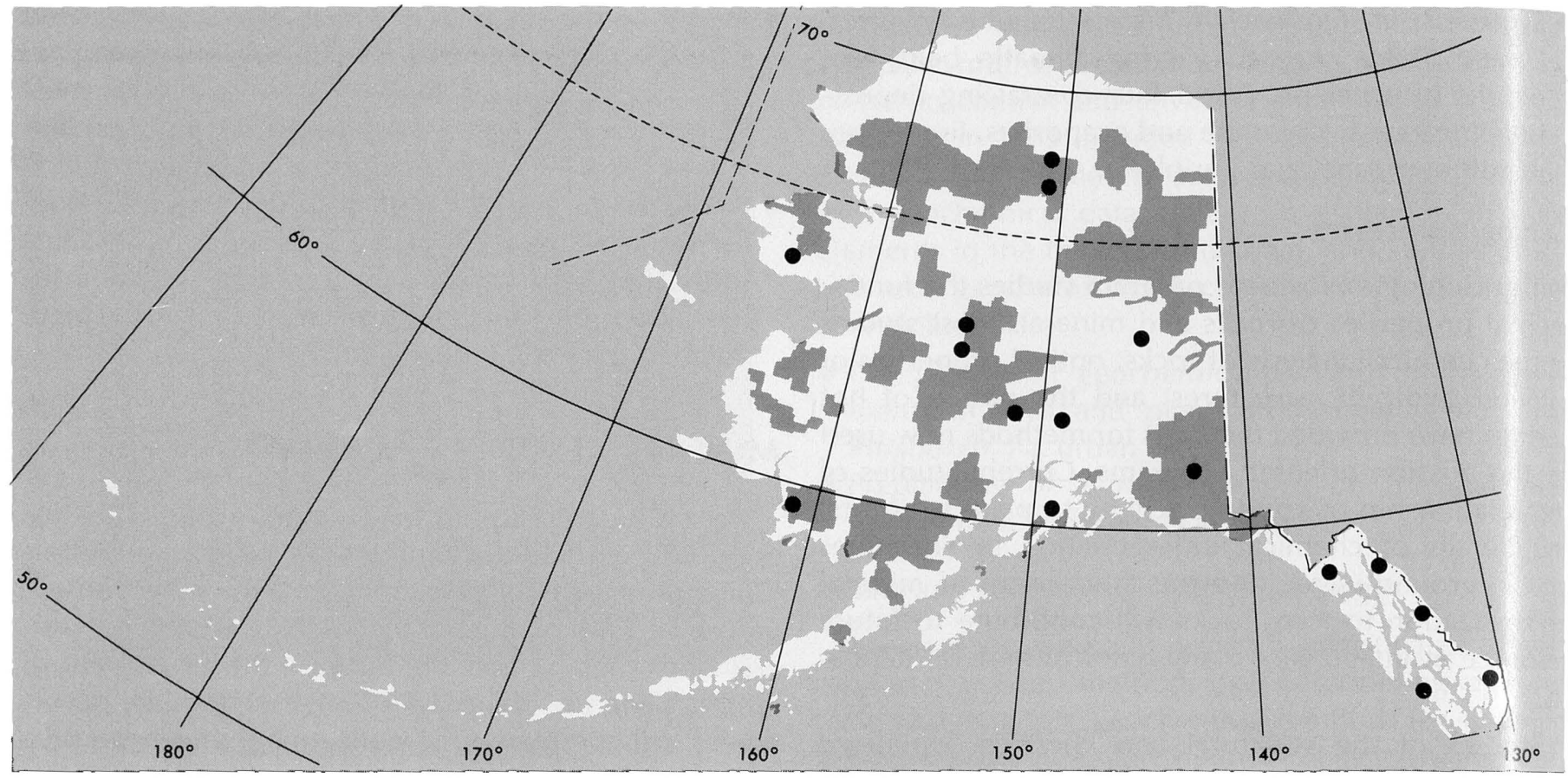

FIGURE 34.-Map of Alaska showing D-2 lands (shaded) and location of current Mineral Resource Surveys projects (dots).

\section{Mineral Resource Appraisal}

To obtain up-to-date information on mineral potential, Congress has directed the Geological Survey and Bureau of Mines to conduct mineral resource assessment programs for some of the Federal lands of immediate legislative concern and to provide reports of these programs for public use. The Survey uses three levels of resource assessment, each designed to meet specific information needs (table 9). In 1975, assessments were underway on lands proposed for designation as wilderness areas, on D-2 lands under jurisdiction of the Alaska Native Claims Settlement Act, and on lands administered by the Department of the
Interior and other Federal agencies. Studies were also conducted on non-Federal lands that are believed to have substantial potential for the discovery of buried, low-grade, or new speculative resources.

\section{Wilderness Mineral Resource Appraisal}

The Nation has recognized the need to preserve fragile wilderness values for future generations. Since passage of the Wilderness Act in 1964, more than 31 million acres have been proposed for wilderness status by agencies of the Federal Government. The Congress requires an assessment of the resource possibilities before making its final dispositions, because min-

TABLE 9.-Three levels of resource assessment used by the Geological Survey

\begin{tabular}{|c|c|c|c|c|}
\hline Level & Objective & Method of study & Advantage & Limitations \\
\hline $1 \ldots$ & $\begin{array}{l}\text { General inventory of past } \\
\text { production and resource } \\
\text { activity. Identify areas } \\
\text { needing more detailed } \\
\text { study. }\end{array}$ & $\begin{array}{l}\text { Library and records survey; } \\
\text { search of all sources for } \\
\text { unpublished data on } \\
\text { known districts; computer } \\
\text { storage of data. }\end{array}$ & $\begin{array}{l}\text { Status report: assessment of } \\
\text { all known resource infor- } \\
\text { mation. Important first step } \\
\text { for any assessment. }\end{array}$ & $\begin{array}{l}\text { Superficial; most data will } \\
\text { be spotty; inadequate for } \\
\text { determination of to al re- } \\
\text { source; often biased; un- } \\
\text { developed areas will be } \\
\text { overlooked. }\end{array}$ \\
\hline II -- & $\begin{array}{l}\text {-Uniform reconnaissance- } \\
\text { level appraisal to } \\
\text { establish base for total } \\
\text { resource estimate. }\end{array}$ & $\begin{array}{l}\text { Level I plus reconnaissance } \\
\text { geologic, geochemical, and } \\
\text { geophysical mapping; re- } \\
\text { mote sensing; sampling } \\
\text { of broad areas that are } \\
\text { promising. Computer stor- } \\
\text { age, retrieval, and inter- } \\
\text { pretation of data. }\end{array}$ & $\begin{array}{l}\text { Sufficient detail to present } \\
\text { resource evaluation for use } \\
\text { of decisionmakers. New } \\
\text { areas identified for classi- } \\
\text { fication and development. }\end{array}$ & $\begin{array}{l}\text { Not sufficient to define re- } \\
\text { serves or to be usec by } \\
\text { management. Deep y } \\
\text { buried deposits missed. }\end{array}$ \\
\hline III - & $\begin{array}{l}\text { Sufficiently detailed geo- } \\
\text { science data to deter- } \\
\text { mine reserves and to } \\
\text { make management de- } \\
\text { cisions regarding leases } \\
\text { and environmental con- } \\
\text { sequences. }\end{array}$ & $\begin{array}{l}\text { Detailed geologic mapping, } \\
\text { geochemical sampling and } \\
\text { assaying, and geophysical } \\
\text { surveys in small areas of } \\
\text { known potential. Com- } \\
\text { puter storage, retrieval, } \\
\text { and interpretation of data. }\end{array}$ & $\begin{array}{l}\text { Development of geologic } \\
\text { theory leading to identifi- } \\
\text { cation of new types of de- } \\
\text { posits; basis for stockpile } \\
\text { decisions. }\end{array}$ & Time consuming, expensive. \\
\hline
\end{tabular}


ing of such potential materials is banned once an area is designated a wilderness. To date, the Geological Survey and the Bureau of Mines have completed mineral surveys of 17 million acres of land proposed for wilderness status.

\section{Alaska Mineral Resource Appraisal}

The Survey started the Alaska Mineral Resource Appraisal program in 1975 to supply basic resource information on the State of Alaska. The program (Yount, 1975) involves rapid evaluations of the mineral potential of the State by preparation of a resource map folio series consisting of geologic geochemical, and geophysical maps, and interpretive maps based on Landsat satellite imagery, and a resource-potential map based on geostatistical and mineral economic models. The first $1^{\circ} \times 3^{\circ}(1: 250,000)$ quadrangle folios (Nabesna quadrangle) to be completed under the program consists of a text and 12 maps. Studies of 12 additional quadrangles are in progress or scheduled, and 18 others are planned but not yet scheduled. This area totals about 440,300 square kilometres $(170,000$ square miles) and contains about half the regions of exposed bedrock now considered to have significant potential for mineral resources in Alaska.

\section{Geologic and Geophysical Appraisal Mapping}

Resource assessments are conducted on the Federal domain and on State and private lands where there is a high probability that mineral resources may be found or for which special but longer term needs for resource information have been recognized. Such studies provide the Geological Survey with evaluations of the resource potential of large areas as well as with a basis for planning future, more detailed surveys. Geologic mapping is being done at many map scales and in many types of areas in support of resource assessments ranging from urban impacted areas, in order to assist in local zoning and planning, to surveys of mineral belts in desert, swamp, and mountainous regions in Arizona, Colorado, Michigan, New Mexico, Oregon, Utah, and Wisconsin. Geophysical mapping is being done by using gravity, magnetic, electrical, and seismic surveys to outline distinctive rocks and structures below the Earth's surface.

\section{Commodity programs}

The Commodity programs (U.S. Geological Survey, 1975b) obtain specific knowledge about the geologic availability and location, distribution, quantity, and quality of specific mineral commodities. Some mineral commodities are not now commercially mined in the United States and must be imported to meet demands. Other minerals are known to occur in domestic deposits but cannot economically compete with foreign sources. These mineral commodities are "critical" because their supply is vulnerable to potential economic and political actions by foreign governments. A second group of mineral commodities, yet to be fully evaluated, may become critical as a result of greatly increased demand to support increased production from new energy sources. A third mineral group of more abundant mineral commodities requires low-level investigation. During the past few years the Survey has reviewed the current knowledge of domestic, and, to a lesser degree, world mineral resources for nearly 100 commodities (Brobst and Pratt, 1973) and summarized the domestic resource position in 1974 with respect to 27 major energy and mineral commodities used by industry (Pratt and Brobst, 1974).

The Commodity programs consist of, the Critical Mineral Commodities program element and the Minerals for Energy program element. Primary emphasis is on the critical mineral commodities (aluminum, chromium, platinum, iron, nickel, manganese, zinc, tin, titanium, cobalt, mercury, tungsten, columbium, vanadium, fluorspar, and copper) for which there is present or potential national dependence on imports. The program will be expanded to include other critical materials as they are identified. Commodity specialists maintain and analyze the world commodity resource files and make periodic estimates of mineral availability. They develop and apply new concepts for the assessment and identification of new domestic and overseas sources of these materials and provide analyzed data for the Resource Analysis and Information System.

Greater self-sufficiency in energy production within the next few decades will increase the demand for minerals required to develop, produce, and distribute energy. Minerals required include: iron to produce steel for drill rigs, pipelines, and refineries for oil and gas, and rails and trains to transport coal; copper and aluminum for the electric industry; and exotic minerals for many uses in the nuclear industry. Aluminum and nickel were recognized early as vulnerable imported materials and studies of substitute domestic sources have been started such as high-alumina clays in southeastern Georgia and low-grade nickel resources in northern Minnesota, Michigan, and Wisconsin.

Highlights of the Mineral Resource Appraisal programs in fiscal year 1975 included:

- Publication of 11 wilderness area assessments (Scapegoat Wilderness and Absaroka Primitive Area, Mont.; Clear Creek-Upper Big Deer Creek Study Area, Idaho; Salmon-Trinity Alps additions, 
Calif.; DuNoir Study Area, Wyo.; Conger LakesMt. Aix Study Area and Alpine Lakes additions, Wash.; Lone Peak, Utah; San Pedro Parks Wilderness and White Mountains Wilderness, N. Mex.; and Indian Peaks Study Area, Colo.). Parts of five of the areas were found to contain significant mineral resources resulting in modification of wilderness area boundaries. Equally important, the mineral potential of the other six areas studied last year appears to be insignificant and will not prejudice their consideration for withdrawal for wilderness preservation status.

- Mineral resource evaluation of the Nabesna quadrangle in Alaska identified significant potential for copper, molybdenum, gold, silver, and several nonmetallic commodities.

- Discovery in Alaska of chromite, tin, and copper in geologic terrane not previously suspected to contain these elements. This discovery suggests that these elements should be looked for in similar geologic environments elsewhere.

- Publication of maps that outline the potential for copper mineralization in part of the PhoenixTucson, Ariz. urban corridor. These maps contribute to a broader study of the region by the Survey's Land Information and Analysis Office and are being used by State and local agencies to plan zoning legislation.

- Discovery of gold, tin, and beryllium in unusual concentrations in areas of South Carolina where no previous mining of these commodities has taken place and in areas where exploration has not been conducted for many years.

- Completion of geologic maps of Nevada and eastern Oregon; the compilation of a new geologic map of Colorado is well advanced.

- Completion of aeromagnetic surveys of 117,000 square kilometres $(45,162$ square miles) for parts of Alabama, Georgia, Maryland, Nevada, New Mexico, New York, North Carolina, South Carolina, Washington, and West Virginia that show the distribution of rocks potentially related to mineral deposits.

- Compilation of a Bouguer gravity anomaly map of Alaska that shows a marked series of linear anomalies that appear to be closely related to zones of mineralization.

- Location of fine-grained fluorspar deposits of potential commercial value in zedite-bearing western lakebeds about 10 to 14 million years old (Miocene age). Detailed study of some of these unusual deposits near Rome, Oreg., suggests that as much as
Similar deposits of fluorspar have been found near Eastgate, Churchill County, Nev., and may become prime sources for new domestic resources of fluorine chemicals and flux for the steel industry.

- Determination that large amounts of zeolite minerals are available in tuffaceous lake sediments. These minerals are potentially useful in the treatment of sewage-disposal and other wastes, as soil conditioners, and to remove undesirable components such as carbon dioxide, water, and hydrogen sulfide from natural gas.

- Demonstration that there is no direct relationship between grade and tonnage in porphyry copper deposits, and that the estimated large energy requirements necessary to utilize ores of lower grade than are now being used limit the availability of critical materials like copper, nickel, cobalt, and platinum.

\section{Minerals Discovery Loan program}

Under Public Law 85-701, a total of $\$ 4.8$ million in financial assistance has been loaned to private industry to explore for 36 strategic minerals. The value of ore produced by mines that have received assistance totals $\$ 8.1$ million, and royalties totalling about $\$ 430,000$ have been paid to the Government. As an indirect benefit to the Nation, the loan program provided limited employment in small economically depressed mining communities, helped to maintain a reserve of skilled manpower in an essential industry, contributed to the collection of valuable geologic information on the Nation's mineral resources, and aided the small-mine sector of the mining industry. This program started phasing out in fiscal year 1975 .

\section{Resource Analysis and Information Systems}

The Resource Analysis and Information Systems program assists in mineral-policy decisions by using automatic data processing techniques to store, retrieve, and process large amounts of resource information and to model the complex interactions of geology and economics and their impacts on mineral supply and demand. Activities during 1975 included:

- Continued building of the Computerized Resource Information Bank (Calkins, Kays, and Keefer, 1973). Some 31,000 records which describe the geologic occurrence of mineral commodities are now in the system.

- Development in cooperation with the Bureau of Mines of a file on the world's 1,000 largest mines which produce 90 percent of the world's suppiy of 22 major minerals. 
- Development of a Decision Oriented Resource Information System which consists of various mathematical models and analyses, the exploration processes, the economics of resource convertibility, and long-term resource supply and demand. This system will be used in conjunction with the resource data bases to investigate the implications of various mineral policy options and to estimate the occurrence, size, and grade of as-yet-undiscovered mineral deposits.

\section{Geology of Mineral Occurrence}

Research on the geology of mineral occurrence is essential to continue successful exploration of minerals in the United States as the search to find deposits becomes more difficult. Present mineral assessment and discovery depends upon concepts resulting from past research on the geology of mineral occurrences; future assessment and discovery will be based on the continuance of these research efforts. For example, most minerals are more soluble at high temperatures than at low temperatures. Recent research, however, has revealed that molybdenite (the most important source of molybdenum) and chalcopyrite (an important copper mineral) may show the opposite behavior under certain conditions. If this is the case, then we may expect copper and molybdenum deposits to form earlier and deeper than ores of other metals such as lead and silver. On the other hand, occurrence of the latter metals at the surface may indicate deep underlying deposits of copper and molybdenum. This and other such information is useful in constructing models of ore deposits and greatly expedites assessment of regions for new deposits by limiting the search to a few well-defined geologic targets.

Significant results in 1975 included:

- Identification of regional controls of porphyry copper mineralization through geologic mapping at Bingham, Utah and Ray, Ariz. The temperature and composition of ore-forming fluids in these copper deposits and others in New England and Puerto Rico have been determined from examination of fluid inclusions-tiny bubbles of gas and liquid inside crystals. Potassium-argon and fission-track ages of a half-dozen different kinds of minerals at Ray, Ariz., show that the copper deposit was formed after intrusion, solidification, and cooling of molten rock over a span of some 16 million years. Electronmicroprobe analyses for fluorine, copper, and other elements locked in the crystal structure of minerals are being used to decipher the composition of the ore-forming fluids and the molten rock from which they came. These facts are providing the basis for new and revised models of the formation of copper deposits, and these models will suggest new places to look for copper.

- Defined the composition, distribution, and origin of gold at Carlin, Nev. The data produced by these studies of gold mineralization provide valuable clues for discovery and appraisal of gold resources in other similar areas.

- Research on beryllium in rock of Spor Mountain, Utah, which occurs in submicroscopic form-invisible to the unaided eye of the exploration geologist as well as the oldtime prospector. Recent studies illustrate how research can provide guides to finding these difficult-to-locate resources. The Utah beryllium deposits are restricted to fluorine-bearing igneous rocks formed relatively recently in the Earth's history, suggesting that similar beryllium deposits likely will be found elsewhere in the Western United States where such rocks occur. Fission tracks - the microscopic paths made in a crystal when uranium atoms split spontaneously-were used to establish the young age of rocks related to beryllium mineralization. Computerized statistical analysis of more than 5,000 separate mineral and chemical measurements was used to discover and measure the intensity of subtle halos of trace elements in rocks surrounding the beryllium deposits. Discovery of these halos will provide a means of rapidly appraising the beryllium resource potential of other regions.

- Discovery of small diamonds (fig. 35) in the State Line diatreme group of the northern Front Range, Colo.-Wyo. It is estimated that these diamonds formed at a temperature and pressure of $1050^{\circ} \mathrm{C}$ and 42 kilobars suggesting that they originated at a depth of about 135 kilometres (84 miles).

\section{Appraisal-Exploration Technology}

The Appraisal and Exploration Technology program supports mineral resource assessments by developing geochemical and geophysical techniques that offer the best hope for locating buried or low-grade mineral deposits. Geologic processes such as volcanic activity, earth movements, ground-water circulation, and weathering can move metals such as copper, zinc, gold, and silver from mineral deposits to the surface and disperse them in the environment. Geochemical surveys provide information on the distribution of elements in rocks, soils, vegetation, volatile gases, and water. Anomalous areas of high metal concentrations may be due to mineral-bearing rocks that crop out at the surface or to the migration of metals from deeply buried deposits. Geophysical surveys provide infor- 


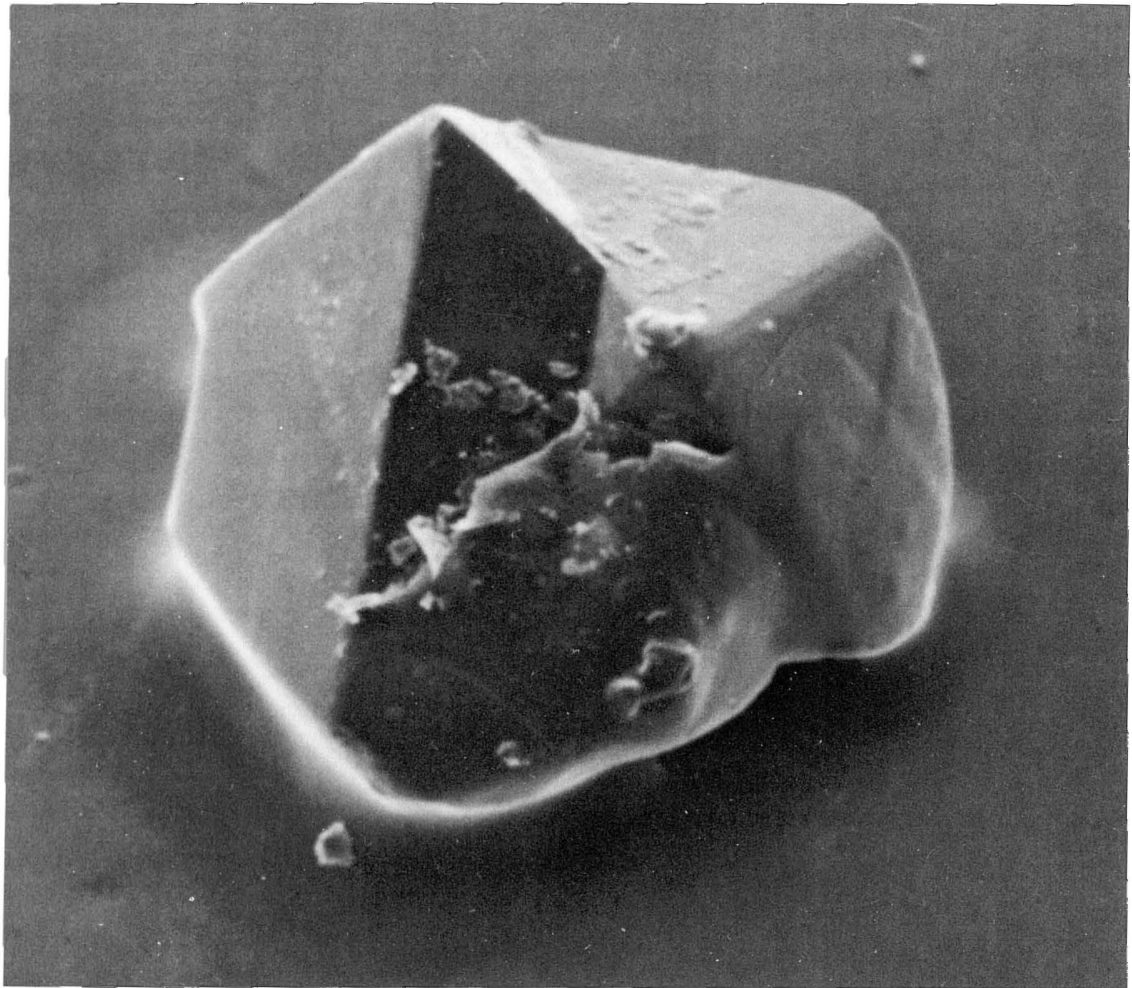

FIGURE 35.-Diamond, a crystal of two intergrown octahedrons, found in the northern Front Range, Colo.

mation on the magnetic and gravity properties of rocks that often correlate with geochemical anomalies of elements such as copper, molybdenum, silver, gold, and uranium. Landsat imagery, which is computer enhanced, has been used successfully to detect and map hydrothermally-altered areas that are spatially related to ore districts in south-central Nevada. Thermal infrared images of the Colorado Front Range near Denver have revealed anomalous textural patterns that correspond to known mining districts. Determination of the character of buried or low-grade mineral deposits depends on exploration drilling by industry.

Fiscal year 1975 program highlights included:

- Development of new geochemical techniques to detect anomalous concentrations of metallic oxides released into the environment by weathering processes. The technique involves chemical separation and analysis of the manganese and iron-rich fractions of stream sediments and soils. The manganese and iron oxides are very sensitive scavangers and concentrate metals such as copper, zinc, and silver, allowing the detection of subtle geochemical anomalies that may indicate deeply buried mineral deposits. This method has been successfully applied to outline metal anomalies in regions of thick rock cover in New Mexico. Here, minute amounts of metallic oxides have migrated through hundreds tors of mineral deposits cannot be detected by the usual geochemical surveys.

- Development of methods to detect volatiles given off by buried mineral deposits. Volatile elements and compounds such as helium, sulfur gases, carbon dioxide and mercury in soil gas-the air trapped between particles of soil-can be measured by new methods. Soil moisture conditions may complicate exploration of soil gas, but the anomalous concentrations of gases in soil can point to sulfur-rich minerals beneath the surface.

- Development of electrical and seismic measurements to locate mineral deposits up to 300 metres from a borehole. This is a vast improvement over the method of measuring the geophysical properties of rocks a few metres from a borehole currently applicable to most well-logging techniques. Results of field tests and computer-model studies indicate that these techniques can improve exploration efficiency by reducing the number of drill holes needed for locating buried ore bodies.

\section{ENERGY RESOURCES SURVEYS}

The Energy Resources Surveys subactivity provides Congress, other Federal agencies, and the public with current, systematic, and thorough assessments o: the Nation's energy resources. Resource assessment; are inherently uncertain and reflect the available datc and state of knowledge at the time the assessment are made. Resource estimates have to be refined as more geologic information is collected and compiled and as new theories of origin and new exploration echniques discover hitherto unknown and unsuspected sources of energy commodities. Thus, resource assessments must be periodically reevaluated in the light of new knowledge and they may be expected to change over time. The resource assessments, that are the goal of the Energy Resources Surveys subactivity, are supported by research on the origin, occurrence, magnitude, and quality of energy resources, the development and evaluation of geophysical and geochemical techniques of exploration, and the implementation of computerized data systems.

\section{Coal}

The purposes of the Coal Resource Investigations program are to: increase research on the physical and chemical characteristics of coal, collect geologic data to aid in selecting future mine sites, develop geophysical techniques to provide data on buried coal beds, and establish a computerized National Coal Resource Data System.

The physical and chemical characterization effort is designed to acquire basic coal data through geologic 
mapping, sedimentologic investigations, stratigraphic studies, petrologic determinations, and geochemical analyses of coal samples. Geologic, geochemical, and resource data and guidelines are needed by planners for use in regional development and siting of future coal mines. The geophysical techniques in coal exploration include borehole neutron-activation methods to provide accurate onsite chemical data on trace elements without the expense of laboratory analyses; and sonic, magnetic, and seismic methods of tracing coal beds in the subsurface. The National Coal Resources Data System consists of a series of computerized data files which contain information on the location and characteristics of the Nation's coal resources.

Fiscal year 1975 accomplishments included:

- Geologically mapping approximately 1,900 square kilometres (733 square miles) in coal-bearing areas of Wyoming, Montana, West Virginia, Kentucky, and Pennsylvania. Mapping was confined to areas of low-sulfur coal, including bituminous and subbituminous coal and anthracite.

- Investigation of six potential coal mine sites on Federal land in cooperation with the Bureau of Land Management, Bureau of Mines, Bureau of Indian Affairs, and Bureau of Reclamation.

- Delineating previously unknown low-sulfur coal resources in West Virginia, Virginia, and Kentucky which will aid in insuring an adequate supply of metallurgical coal.

- Core drilling in West Virginia, Kentucky, Wyoming, and Montana, thereby increasing the knowledge of the quantity and quality of low-sulfur coal deposits in these States.

\section{Oil and Gas}

The purposes of the Oil and Gas Resources Investigation program are to advise the Nation as to remaining oil and gas potential, emphasizing public lands onshore and offshore, and to conduct research that encourages and improves petroleum exploration. Petroleum exploration utilizes capabilities in geology, geophysics, geochemistry, remote sensing, and computer technology. In the exploration research and technology area, the objectives are to: (1) develop and apply operational laboratory methods capable of identifying and evaluating source rocks that could generate petroleum; (2) work out practical geophysical procedures that will use seismic data to indicate subtle stratigraphic traps that may contain oil or gas; (3) predict commercial reservoir porosity in ancient carbonate rocks through study of their modern counterparts; (4) predict accurately, prior to exploratory drilling, the porosity and permeability of potential sandstone reservoirs; (5) evaluate new geochemical procedures by which hidden petroleum accumulations may be identified at the surface through detection of trace-element anomalies produced by upward microseepage of oil or natural gas; and (6) develop borehole geophysical tools and methods capable of measuring reservoir porosity directly and accurately and of detecting the presence of previously overlooked and (or) cased-off oil and gas horizons.

Accomplishments in 1975 included:

- Publication of new oil and gas resource estimates for undiscovered recoverable oil and gas resources in the United States (Miller and others, 1975). The estimates, which involved more than 70 specialists who analyzed 102 possible petroleum provinces, indicate that undiscovered recoverable resources onshore and offshore amount to 50-127 billion barrels of crude oil, 322-655 trillion cubic feet of gas, and 11-22 billion barrels of natural-gas liquids. The ranges represent estimates at the 95- and 5-percent probability levels, respectively.

- Identification of two geochemical anomalies in Colorado and Oklahoma as promising oil and gas exploration targets.

\section{Oil Shale}

The purpose of the Oil-Shale Resource Investigations program is to determine the distribution and grade of oil shale deposits of the Green River Formation, Colo., Wyo., and Utah. The program also evaluates trace elements and the sodium and aluminum minerals associated with the oil shale. The oil-shale resource studies provide information pertaining to lease tract selections, equitable exchanges of private and public lands, shale-oil extraction methods, legal ownership of unpatented claims, and national energy policy. The resulting information supports the land classification and lease management activities of the Conservation Division. During 1975 the program mapped nearly 4,800 square kilometres $(1,853$ square miles) of land underlain by oil shale. These maps have been used by government and industry to establish the value of many parcels of land, and to appraise engineering and environmental problems related to oil-shale exploration and development.

\section{Uranium and Thorium}

The Geological Survey has been investigating the nuclear raw materials, uranium and thorium, since 1939. A large program was carried out from 1947 to 1958 in cooperation with the Atomic Energy Commission, and, in fiscal year 1975, the effort was again increased in cooperation with the Energy Research and Development Administration. 
The Uranium and Thorium investigations improve the understanding of the nature and distribution of our nuclear fuel resources. These investigations call for resource assessments to aid Government planning and policy development, and exploration research to help industry obtain new supplies of uranium needed in the near future.

The program, which is closely coordinated with the Energy Research and Development Administration, includes studies in theories of origin of uranium in highgrade sandstone-type and vein deposits and the identification of new geologic environments of uranium occurrence, research in geophysical and geochemical exploration techniques and instrumentation, field studies of structural and sedimentological basin analyses, and detailed field and laboratory studies of selected uranium and thorium mining districts. Guides to new mining districts resulting from these various studies will be applied to delineate favorable areas for resource assessment and exploration by private industry. A National Uranium Resource Data Bank has been assembled to serve as a base for resource estimation and to permit evaluation of deposits and geologic environments.

Fiscal year 1975 accomplishments included:

- Location of a geological discontinuity closely associated with important known uranium ore-bearing strata in the San Juan Basin, N. Mex. This feature provides a key to future exploration of the region.

- Location of an area favorable for uranium exploration in the Wind River Basin, Wyo.

- Demonstration that uranium can be detected by a hole-to-hole electrical survey technique.

- Location by remote sensing techniques of altered ground associated with uranium in Wyoming and channels filled with potential conglomerate host rocks for uranium in Texas. A new fission-track method for determining the uranium in water and a new truck-mounted helium detector for field use have advanced the geochemical techniques.

- Initiation of a nationwide survey of uranium concentrations in stream water and sediments in cooperation with the Water Resources Division and the Energy Research and Development Administration

- Investigations of various theories of uranium origin have led to important new discoveries, such as the Shirley Basin and Powder River Basin districts.

- Indication that uranium resources in Alaska may be much greater than previously suspected as

\section{Geothermal Energy}

The Geothermal Energy Investigations program appraises the magnitude of regional and national geothermal resources, identifies promising target areas and regions for further exploration and development by industry, develops a scientific basis for improving appraisal and exploration methodology, and assists the Energy Research and Development Administration (ERDA) in locating sites for demonstration facilities. Current studies include: identifying areas of young silicic volcanic rocks; delineating areas of high heat flow; locating hot waters; mapping areas of geopressured aquifers; and developing mathematical methods and computer programs for calculating geothermal resources and reserves. Many of the exploration techniques used in the search for oil, uranium, and other minerals are of limited value in finding geothermal reservoirs. Therefore, new geological, geophysical, geochemical, and hydrological techniques must be found to explore and evaluate geothermal reservoirs and to evaluate individual Known Geothermal Resource Areas before leasing Federal lands.

Use of geothermal energy, unlike oil or gas, requires that conversion plants be within or near the producing fields. Before a specific geothermal reservoir can be developed, a method for predicting the energy potential of various types of geothermal systems must be available. Prediction of the energy potential of geothermal systems, however, is dependent on knowledge of the physical and chemical conditions in the systems at various depths.

Drilling will provide data on the lower boundary conditions of reservoirs and provide an understanding of how geologic and hydrologic hazards, such as land subsidence, induced microearthquakes, groundand surface-water pollution, and ground-water depletion, might be created by withdrawal and reinjection of geothermal fluids. The changes in the temperature and pressure resulting from extraction of geothe rmal energy results in the solution and deposition of minerals that impede the energy-extraction process. In order to establish the basic thermodynamic properties of geothermal fluids essential for maintaining reservoir permeability and productivity, studies are being made to: evaluate existing data on thermodynamic properties of solutions and associated minerals, determine the thermodynamic properties of minerals and fluids where existing data are poor or lacling; determine the viscosity and volumetric properties of brines; and develop computer models to predict chemical reactions when geothermal fluids are withdrawn or waste fluids reinjected. 
The accomplisments in fiscal year 1975 included:

- Completion of an evaluation of the geothermal resources of the United States in cooperation with ERDA (White and Williams, 1975). The geothermal resources are extensive in the United States, and that geothermal energy could indeed supply a significant part of the country's energy needs. In particular, the evaluation highlighted the huge amounts of energy stored in the geopressured resources of the Gulf Coast and concluded that these resources might well become economic within the next few years (fig. 36).

- Development of a method of locating subsurface magma by using the relative delays of seismic waves from distant earthquakes.

- Demonstration of advanced electromagnetic and audio-frequency magnetotelluric techniques to be rapid, inexpensive, and reliable for reconnaissance work in many geothermal areas.

- Refinement of exploration models for geothermal systems related to intrusive activity on the basis of investigations at the Geysers, Long Valley, and Coso Range, Calif., and Yellowstone Park, Wyo.

\section{Energy Resource Data}

An integral part of each of the energy resources surveys described above is the maintenance of a com-

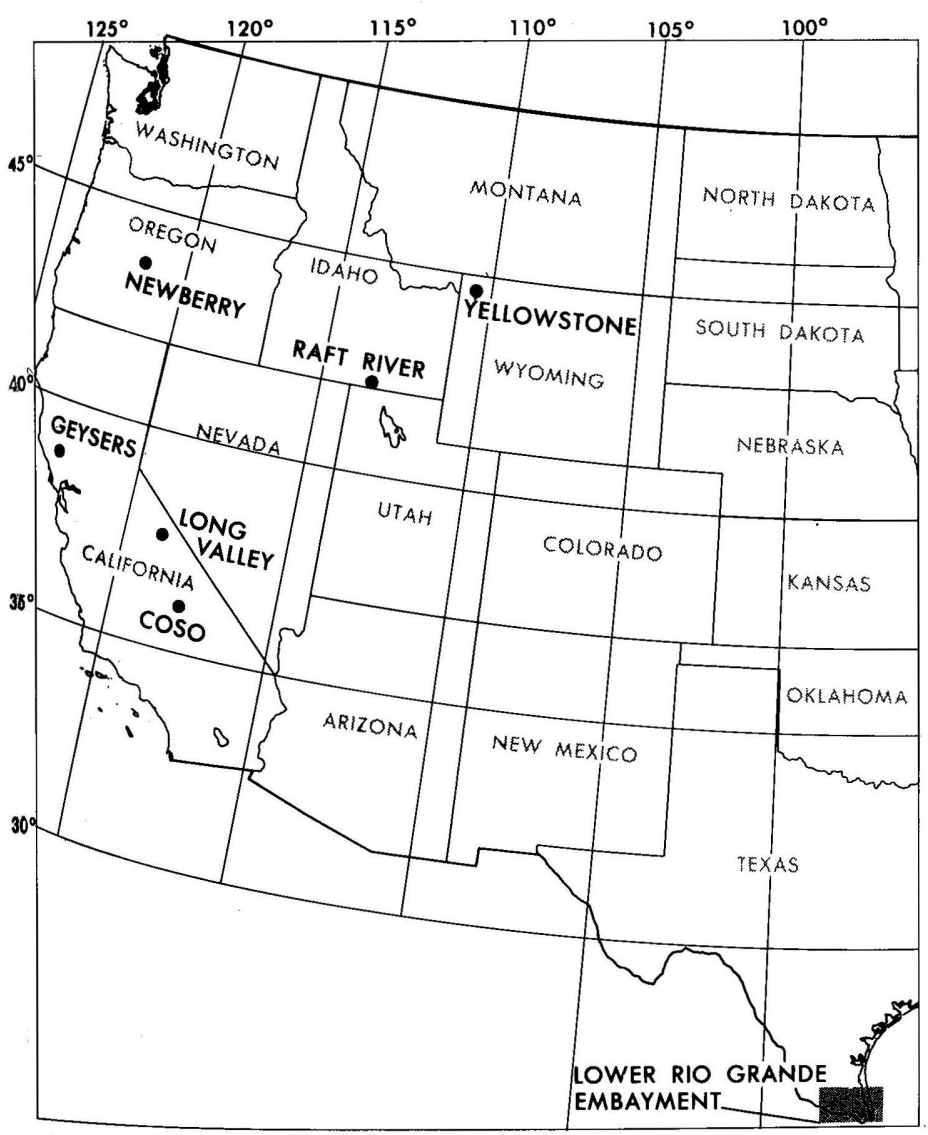

FIGURE 36.-Areas where geothermal investigations were conducted in fiscal year 1975 . puterized data system. The Energy Resource Data program provides timely, accurate energy-resource data in useful form at minimal cost for Government planners, the exploration and scientific community, and the concerned public; builds and maintains computerbased energy-data files containing information from Government, both Federal and State, industry, and the universities; makes the files responsive to user needs in readily accessible format; and has the capability for graphic display of the data by digitized maps of resource occurrence and machine-processed charts and histograms.

The National Coal Data System consists of information on the major coal beds in the United States. The information contains type of coal, location, formation name and age, thickness of coal, thickness of overburden, and the source and reliability of the data. A separate file contains physical and chemical analyses for each coal bed sampled.

The Oil and Gas Data System contains information on the location, production, history, reservoir characteristics, and oil, gas, and water chemical analyses of oil and gas pools in the United States and Canada. At the end of fiscal year 1975, the system contained over 68,000 records of individual oil and gas pools.

The Oil Shale Data Storage contains information on Fischer Assay Analyses, saline analyses, chemical analyses, lithology, stratigraphy, thickness, and geophysical data of oil shale. Maps showing oil-shale thickness, content of volatiles, and overburden are prepared from the data for use in estimating the amount of shale-oil yield.

The National Resource Uranium Data Bank is being assembled from data on the location, physiographic province, rock type, mineralogy, and other information collected by the Geological Survey and the Atomic Energy Commission (now the Energy Research and Development Administration) during the 1950's. When completed the data will be entered in the Computerized Resources Information Bank. Thorium deposits will be added to the file at a future date.

The Geothermal Resources Data System contains information on location, surface-temperature data, well or drill-hole data, chemical analyses of steam vapor and water samples, heat-flow data and other information that characterize the resource and its energy potential. At present the file contains information on $\mathbf{1 5 5}$ locations throughout the United States.

\section{OFFSHORE GEOLOGIC SURVEYS}

The continental margins of the United States are the sites of sediment-filled basins which contain accumulations of petroleum and other mineral resources. Geographically, the margins consist of a continental shelf, slope, and rise (fig. 37). The Outer Continental 


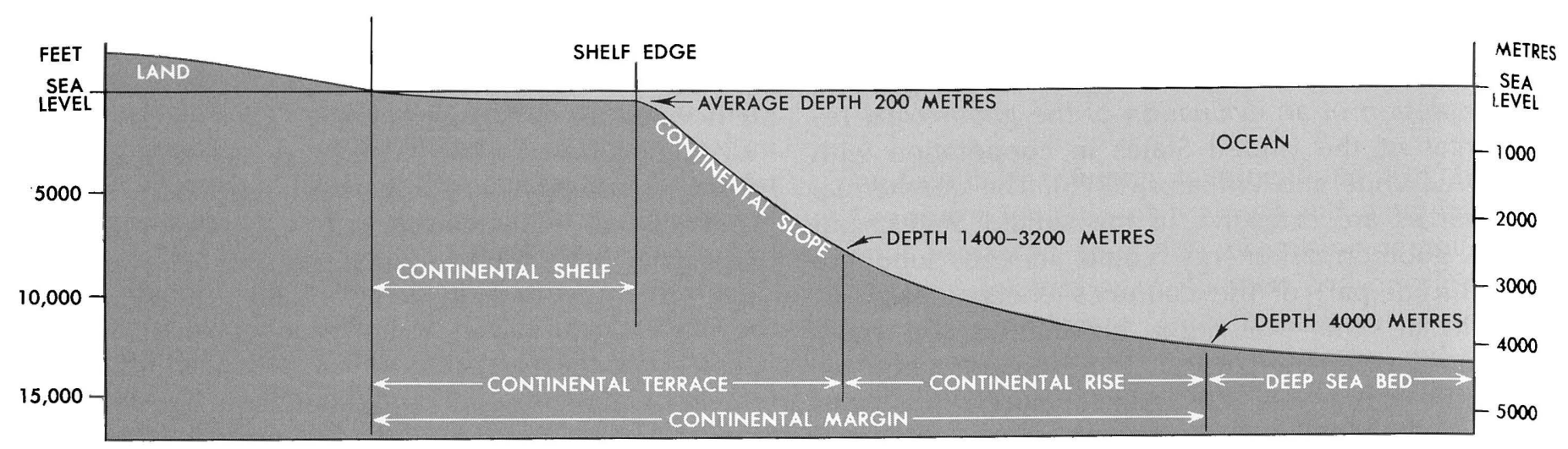

FIGURE 37.-Diagrammatic profile of the continental margin.

Shelf is the submerged land lying seaward of a State's jurisdiction-commonly 4.8 kilometres (3 miles). The continental shelf includes lands out to 200 metres (656 feet) water depth, and the continental slope, which is peripheral to the shelf, is in water depths ranging from 200 metres (656 feet) to about 2,500 metres $(8,200$ feet). The relationship of the continental shelf, slope, and rise to the landmass of the conterminous 48 States and Alaska is shown on figure 38.

The Offshore Geological Surveys subactivity assesses the potential mineral wealth of subsea areas and determines the nature of the geological and environmental hazards that might affect the siting of offshore energy facilities such as drilling rigs, production platforms, and pipelines. Because there is little information available about some of the offshore areas, a substantial amount of data needs to be collected and integrated in order to make reliable resource assessments. The assessments and support data are used by the Department of the Interior and the Bureau of Land Management to identify offshore areas for possible leasing and for preparation of environmental impact statements. Later on in the leasing process, the data supplement that data acquired by the Conservation of Lands and Minerals activity's Outer Continental Shelf Lands program. The combined data and interpretations assist the Bureau of Land Management in selecting tracts for inclusion in proposed lease sales.

The Department of the Interior's accelerated Outer Continental Shelf leasing program calls for about six oil and gas lease sales per year through calendar year 1978. This proposed schedule defines for the most part the timing of the Survey's data collection activities in the various sale areas. In frontier areas such as the Alaskan Outer Continental Shelf, substantial lead time is necessary because weather conditions limit data collection to only a few months each year.

\section{Oil and Gas Resources Appraisal}

The Offshore Oil and Gas Resource Appraisal pro74 gram delineates sedimentary basins favorable for the occurrence of hydrocarbons, assesses the existence of geologic conditions conducive to the accumulation of oil and gas in giant fields, estimates the oil and gas resource potential of particular basins, determines specific areas within basins which have significant petroleum potential for Outer Continental Shelf lease sales, and provides geological and resource data and analyses to the Government, to coastal States, and to the public.

The Resource data are used to interpret basin configuration in three dimensions, generalized basin geologic framework, basin history (age of sedimentary rocks and structure), structural type and distribution of hydrocarbon traps, sediment thickness and quality, potential source beds and reservoir rocks (quality, quantity, and distribution), and analogy with known producing basins.

The estimates released by the Geological Survey in 1975, (Miller and others, 1975) are that the undiscovered recoverable resources for the offshore areas (including State water) to a depth of 200 metres $(656$ feet) total 10 billion to 49 billion barrels of oil, 1 billion to 6 billion barrels of natural gas liquids, and 42 trillion to 181 trillion cubic feet of natural gas. Petroleum resource estimates were not prepared for the continental slope and rise areas because the geological and geophysical data were insufficient to determine the amounts that could be discovered and recovered economically. However, recent discoveries in deep waters of the Gulf of Mexico and in the Santa Barbara Channel of California indicate that future production may extend down the continental slope.

Activities during 1975 included refinement of resource estimates released on the 17 continental shelf areas (1.4 million square kilometres or 540,400 sq uare miles), development of preliminary estimates or the continental slope areas (1.2 million square kilometres or 463,200 square miles), and initiation of studies of the continental rise (2.8 million square kilometres or 1.08 million square miles). 
Results of 1975 geological and geophysical investigations and interpretations suggests that:

- North, Middle, and South Atlantic Shelf areas have promising potential for oil and gas production.

- Substantial petroleum resources could be present in the Gulf of Alaska.

- Large accumulations of petroleum may exist in the area between the Aleutian Arc and the Beaufort Sea.

\section{Environmental Investigations}

The Environmental Investigations program identifies faults, slumps, sand waves, and other features which may pose a hazard to offshore energy development, investigates the manner in which oil and gas exploration and development might be a hazard to the onshore and offshore environments, and collects information for use in preparing environmental impact statements prior to Outer Continental Shelf lease sales. Examples of activities during the year include studies of potential geologic hazards in the Baltimore Canyon and Georges Bank areas (Atlantic Coast); studies of recent faulting in and around Monterey Bay, Calif.; studies of sea-floor sediments and faults off the southern California coast; and studies of environmental assessment of the Gulf of Alaska and in the Gulf of Mexico.
Highlights of fiscal year 1975 investigations included:

- Identification of the sediment sources, transport mechanisms, circulation patterns, and depositional environments of San Francisco Bay.

- Identification of potential hazards related to sedimentary instability of bottom sediments and to tectonic activity in the Mississippi delta area, where oil platforms have failed in the past.

\section{Marine Geology}

The Marine Geology program reinforces the other two programs of the Offshore Geologic Surveys subactivity. It develops better techniques for data collection and better analytical methods for data interpretation in order to increase the understanding of geologic history, existing conditions, and processes operating in marine areas. The current program includes: on the Atlantic Continental Margin, studies of the nature, extent, and type of nonpetroleum deposits, such as sand and gravel and the geologic history associated with them; on the coastal areas of Massachusetts, studies of the engineering properties of bottom sediments; in the Gulf of Mexico, studies of sediment instabilities and associated engineering properties of

FIGURE 38.-Outer Continental Shelf areas showing depth of water and areas leased or soon to be leased.

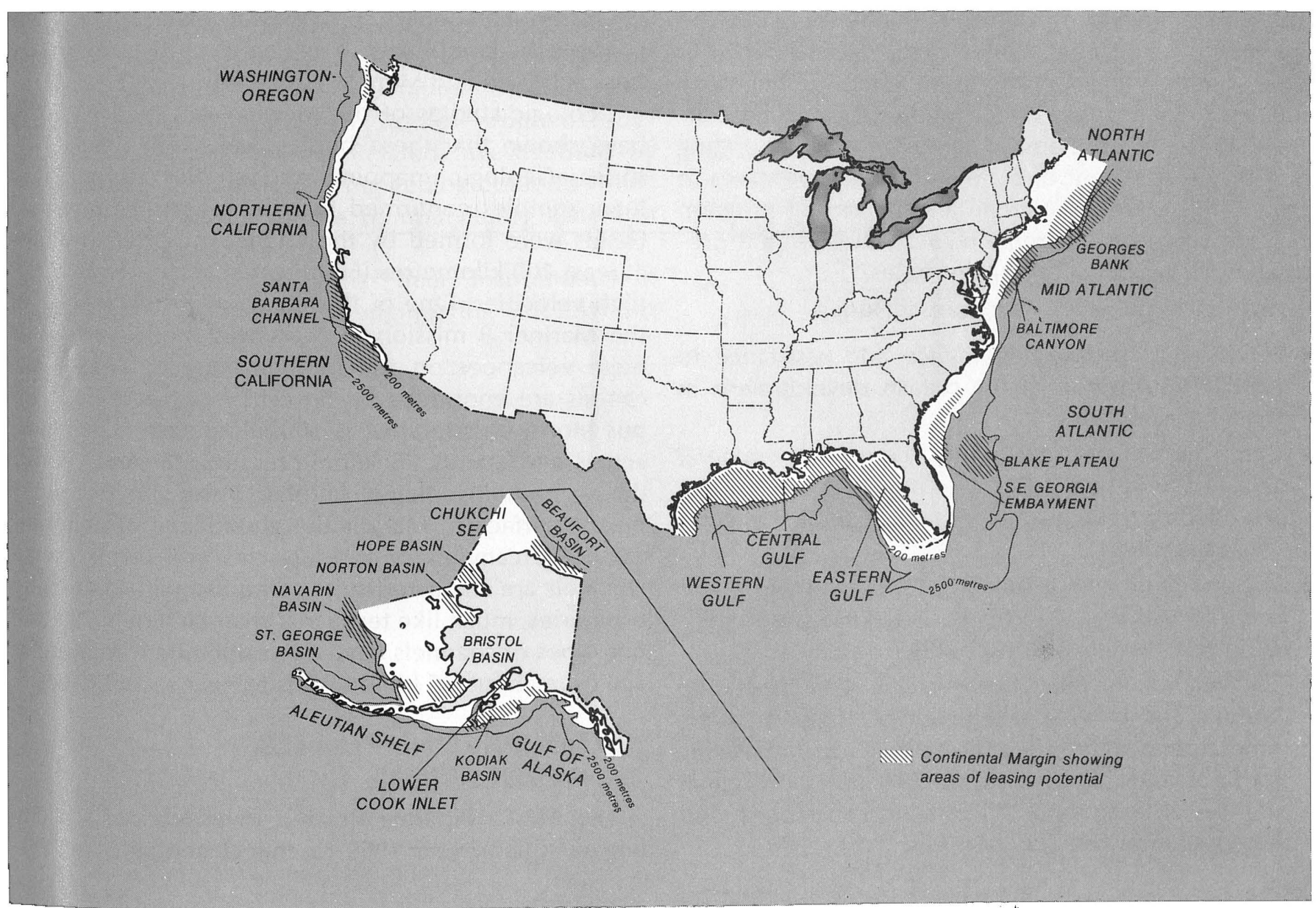


the sea floor; studies of coastal processes along the Texas shoreline and diagenesis in clays adjacent to diapirs; studies of tectonic hazards for nuclear reactor siting along the southern California coastline; and in the Alaska region, studies of gold placer deposits deep-sea clays. Interdisciplinary geologic and hydrologic studies with the Water Resources Division and the Land Information and Analysis Office are in progress in San Francisco Bay and Monterey Bay, Calif. and Willapa Bay, Oreg. in order to anticipate potential problems related to offshore energy development.

\section{INTERNATIONAL ACTIVITIES}

Geological Survey international activities during World War II responded to needs for strategic minerals. After the war, these activities evolved into longrange technical assistance programs under the United States Foreign Assistance Act, sponsored mostly by the Agency for International Development and its predecessors in the Department of State. In the last few years, however, a major part of the technical assistance program has been funded by reimbursable agreements with foreign governments and international organizations through the Department of State.

Since 1970, the Geological Survey has also participated in an expanded program of scientific cooperation and assistance with other countries, partly on behalf of other United States agencies and partly to gain a better understanding of geological phenomena and resources that are under investigation in the Survey's domestic program. The Survey is collaborating with the Department of State and Bureau of Mines to expand the Minerals Attaché and Reporting program to improve and standardize resource assessment procedures for the benefit of all countries.

Highlights of the 1975 program included:

- Provision of technical guidance and assistance to evaluate the potential for potash development in Thailand and Laos.

- Identification of structurally controlled mineral belts in Saudi Arabia. Detailed mapping and drilling extended several mineral districts containing gold, silver, and copper.

- Documentation of a rapid decline of water levels in the Sanaa Basin as a result of ground-water studies in the Yemen Arab Republic.

- Continuation of the Circum-Pacific map project to compile and publish a series of geologic, tectonic, mineral, and energy resources maps of the Pacific sea floor and adjacent continental areas on behalf of three international scientific organizations and

\section{ASTROGEOLOGY}

The Survey established the Astrogeology program in 1960 on behalf of the National Aeronautics and Space Administration to support lunar and planetary exploration. The program seeks to understand better the origin and evolution of the Earth, Moon, and planets, to map the geology of the Moon and planets, to formulate theories on planetary geologic phenomena that can be applied to terrestrial geologic problems, and to develop procedures and techniques to facilitate geologic investigations of the Earth, Moon, and planets. Current activities of the Astrogeology program include: systematic mapping of the stratigraphy and structure of the Moon, Mars, and Mercury; terrestrial analog studies, including field studies of natural and man-made impact craters and craters created by chemical and nuclear explosions; and laboratory studies of terrestrial rocks and minerals subjected to shock.

The most important result of planetary exploration will be an improved understanding of the early history of the Earth. The more that is known about each planet, the more that will be known about fundamental processes affecting the Earth. Little evidence remains of the events and processes that took place during the first 2 billion years of Earth's history. However, the early histories of the Moon and Mercury have been remarkably well preserved, and Mars, naving a thin atmosphere, provides an experiment irtermediate in complexity between primitive planetary bodies (Moon and Mercury) and Earth.

Geologic studies of the Moon, Mars, and Mer ury have shown that these bodies had similar early histories. Geologic mapping and studies of returned lunar samples confirmed that the large circular lunar basins were formed by the impact of large moonlets at least 100 kilometres (60 miles) in diameter at uitrahigh velocities. One of the most surprising resulis of the Mariner 9 mission to Mars was the discovery of huge volcanoes on the Martian surface. These volcanoes are enormous by terrestrial standards. Oympus Mons, for example, is 600 kilometres (370 miles) across and stands 25 kilometres $(82,000$ feet) atove the surrounding plains. Another intriguing discovery on the surface of Mars is the abundance of channels and large canyons of various sizes and forms. Small channels are characteristically sinuous, with branching tributaries, much like terrestrial river channels. At least five types of channels have been delimited, ranging in age from about 2.5 billion years to near recent times.

\section{ALASKA PIPELINE RELATED INVESTIGATIONS}

The Alaska Pipeline Related Investigations activity began in fiscal year 1969 to collect geologic and hy- 
drologic information upon which to base safeguards against possible pollution and environmental damage that might result from the construction and use of the Trans-Alaska Pipeline from Prudhoe Bay across predominantly Federal lands to Valdez. To date personnel from the Topographic, Geologic, and Water Resources Division have collaborated to publish more than 50 reports describing the terrain, geology, location of sand and gravel deposits, flood, ice, and waterquality characteristics of streams, ground water, earthquake hazards, the distribution and characteristics of permafrost (perennially frozen ground), and the environmental characteristics that control permafrost along the 15,500 square kilometres $(6,000$ square miles) of pipeline corridor. In addition, the Survey published 118 topographic and 14 engineering-geologic maps covering the pipeline route and, as lead agency, prepared the Department of the Interior's six-volume pipeline environmental impact statement (U.S. Federal Task Force on Alaskan Oil Development, 1972). These data are used by the Department's Alaska Pipeline Office to establish engineering design criteria and to assure that the pipeline contractor conforms to the technical and environmental stipulations of the construction permits.

With a staff of 12 and a budget of $\$ 344,000$ in fiscal year 1975, the program continued geologic, hydrologic, and seismic investigations needed to support the construction and initial operating and monitoring phases of the pipeline project. Upon completion of the pipeline, the contractor will reimburse the Federal Government for this work ( $\$ 6.0$ million to date).

The Arctic Environmental Studies programs augments the Alaska Pipeline Related Investigations by conducting certain engineering geologic studies which are not covered under the reimbursibility clause of the pipeline program.

The Geological Survey has been instrumental in solving many of the serious engineering and environ- mental problems that were posed by the construction and operation of the 1,290-kilometre (800-mile) largediameter hot-oil pipeline.

Highlights of fiscal year 1975 included:

- Publication of ground motion values for use in the seismic design of the pipeline.

- Continuation of streamflow and water-quality montoring at 35 locations along the pipeline route to collect baseline data.

- Continuation of earthquake monitoring at several locations along the pipeline corridor.

\section{REFERENCES}

Brobst, D. A., and Pratt, W. P., eds., 1973, United States mineral resources: U.S. Geol. Survey Prof. Paper 820, 722p.

Calkins, J. A., Kays, Olaf, and Keefer, E. K., 1973, CRIB-The mineral resources data bank of the U.S. Geological Survey: U.S. Geol. Survey Circ. 681, 39p.

Gibbs, H. G. and Borcherdt, R. D., 1974, Effects of local geology on ground motion in the San Francisco Bay region, California-a continuing study: U.S. Geol. Survey open-file report, $57 \mathrm{p}$.

Miller, B. M. and others, 1975, Geological estimates of undiscovered recoverable oil and gas resources in the United States: U.S. Geol. Survey Circ. 725, 78p.

Pratt, W. P. and Brobst, D. A., 1974, Mineral resources-potentials and problems: U.S. Geol. Survey Circ. 698, 20p.

U.S. Federal Task Force on Alaskan Oil Development, 1972, Final environmental impact statement, proposed transAlaska pipeline (6 volumes): U.S. Dept. of Interior interagency rept.; available from U.S. Dept. Commerce, Natl. Tech. Inf. Service, Springfield, Va. 22151, NTIS PB-206921.

U.S. Geological Survey, 1975a, Seismic engineering program report January-March 1975: U.S. Geol. Survey Circ. 717A, 17p.

U.S. Geological Survey, 1975b, Mineral resource perspectives 1975: U.S. Geol. Survey Prof. Paper 940, 24p.

Wallace, R. E., 1974, Goals, strategy, and tasks of the earthquake hazard reduction program: U.S. Geol. Survey Circ. 701, 26p.

White, D. E., and Williams D. L., eds., 1975, Assessment of geothermal resources of the United States: U.S. Geol. Survey Circ. 726, 155p.

Yount, M. E., 1975, United States Geological Survey Alaska program: U.S. Geol. Survey Circ. 722, 58p. 


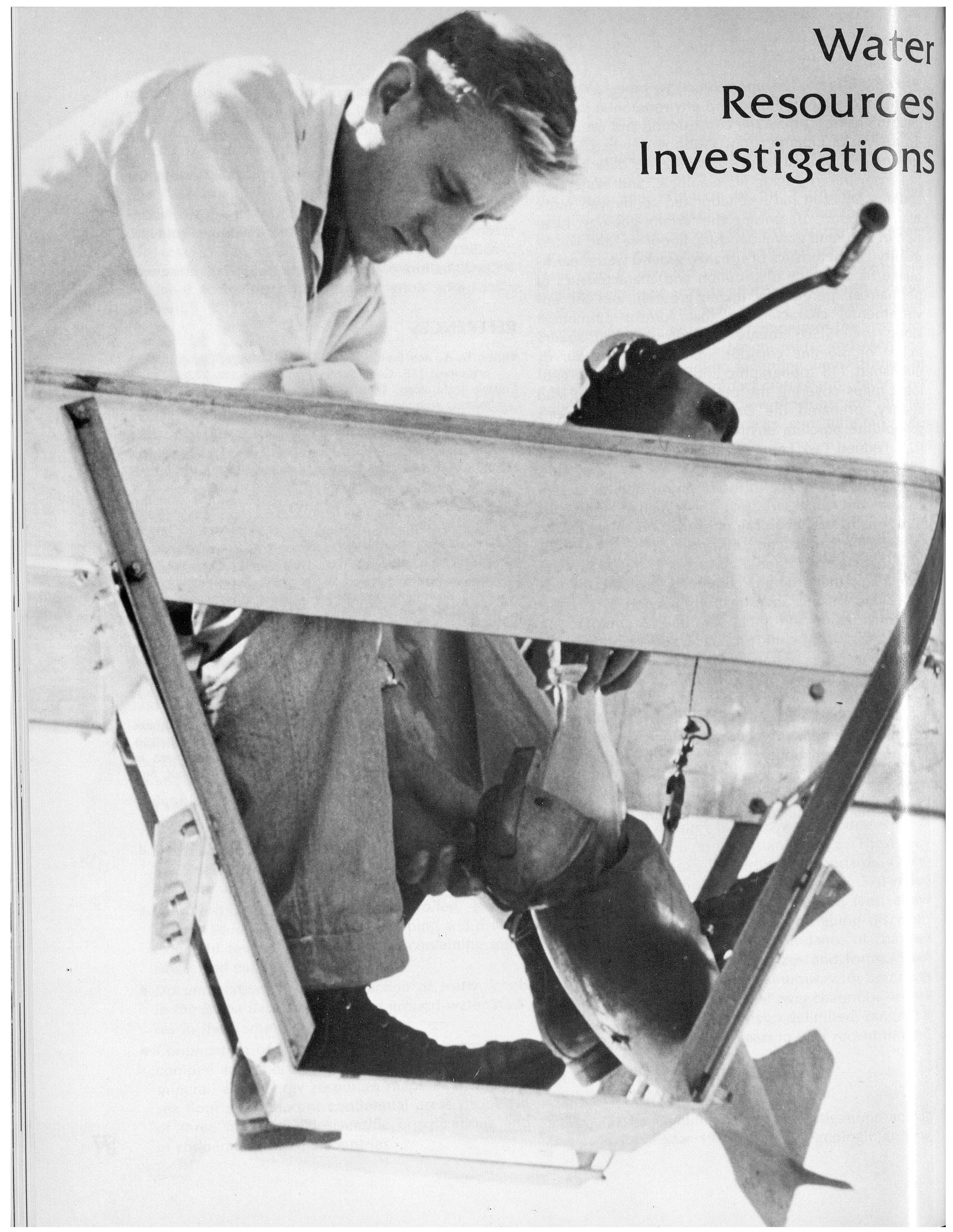




\section{OVERVIEW}

Many people take water for granted because it is as close as the nearest faucet, is safe to use, and is usually plentiful and inexpensive. To the farmer, industrialist, waterworks superintendent, home developer, and others, however, an adequate and safe supply of water in the right place at the right time is a matter for serious concern.

A number of local, State, and Federal agencies are involved in the investigation, management, and conservation of this vital national resource. The Geological Survey is the Federal agency that has principal responsibility for the continuing appraisal of the source, quantity, quality, and movement of the Nation's water resources; analytical and interpretive resource and environmental studies, including the hazardous aspects of water; and supportive basic and problemoriented research.

At the direction of the President's Office of Management and Budget (U.S. Bureau of the Budget, 1964) and as further delegated by the Department of the Interior, the Survey's responsibilities were broadened in 1964 when it was designated the lead agency for coordinating the activities of all Federal agencies in the acquisition of certain water data from streams, lakes, reservoirs, estuaries, and ground water.

The Survey is in the unique position of being charged with gathering and publishing water facts without having the responsibility for managing or developing water resources. Through the years, the organization has established a reputation for maintaining high standards in scientific and engineering studies and for substantial and widely distributed reporting of the results of water-resources investigations. For example, during fiscal year 1975 alone, more than 900 different water reports and 1,198 maps authored by Survey personnel were made available to the public in Federal, State, and local publications, in technical journals, or in depositories for public inspection (tables 45 and 46).

Another important characteristic of the Geological Survey's water program is the large and widespread financial support given to it by State and local agencies. The Federal-State Cooperative program of water investigations comprises more than one half of the entire water effort and is funded by equal amounts of Federal and State and local appropriations. Such an arrangement of many years' standing has helped assure consideration of and program responsiveness to the mutual water-information needs at Federal, State, and local levels. To carry out this work, the Survey's Water Resources Division has one or more offices in all 50 States, Puerto Rico, and Guam (fig. 39).
In addition to their responsibilities for waterresources investigations, the Water Resources Division's district offices also serve as points of contact for those wishing to obtain information about the status of other Geological Survey programs in each State. The addresses and telephone numbers of these offices are listed on page 145.

\section{Programs}

The Water-Resources Investigations activity consists of two subactivities: the National Water Data System and Critical National Water Problems.

The National Water Data System programs comprise 95 percent of the water-resources studies carried out by the Geological Survey and constitute a large part of governmentwide water-data collection activities. For example, in 1972, the Geological Survey operated more than 70 percent of all surface-water stations (streamflow, lake level, and water stage) reported by 17 Federal and 193 non-Federal agencies. The Survey also was responsible for 35 percent of all sites at which the quality of ground and surface water was measured. The objectives of the National Water Data System are to appraise the Nation's water resources and to provide the water data and information needed to develop and manage these resources efficiently. Investigations include collecting basic information at hydrologic-data stations, making areal studies, and conducting supportive research.

The Critical National Water Problems subactivity focuses on data collection, problem-oriented studies, and research to aid in solving water problems of national concern. In fiscal year 1975, for example, critical water problems included studies of water availability for energy development, studies of groundwater recharge in the High Plains of Texas and on Long Island, N.Y., delineation of geologic formations suitable for waste storage, mapping of flood-prone areas, and investigations of estuaries and water resources of coastal areas.

\section{Budget and personnel}

In fiscal year 1975, $\$ 101.4$ million obligated by the Water-Resources Investigations activity came from three sources (fig. 40 and table 26):

- Direct Congressional appropriations for the Federal program.

- Joint Congressional and State and local appropriations for the Federal-State Cooperative program.

- Funds transferred from other Federal agencies and State and local agencies for reimbursable programs. 


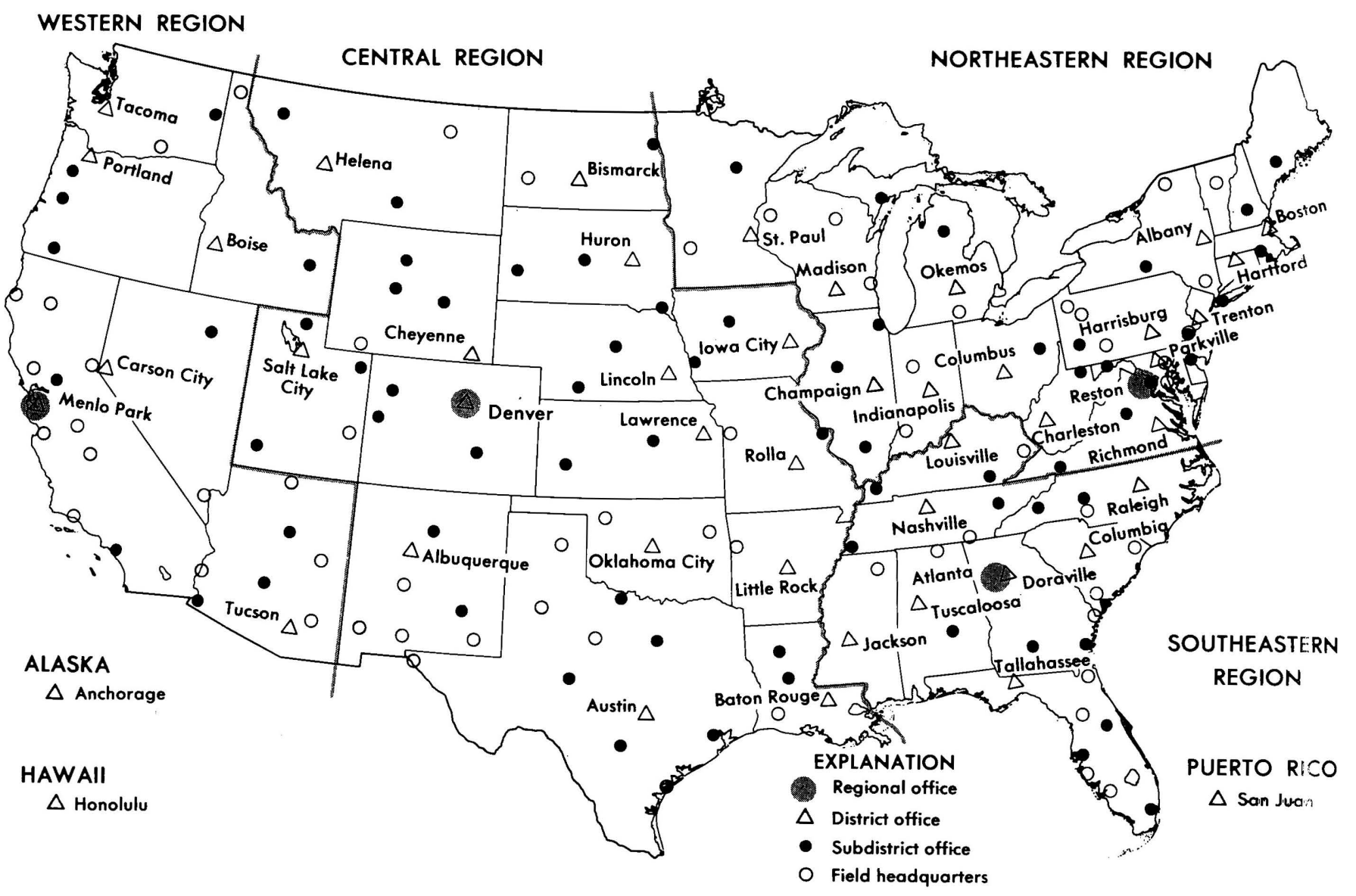

FIGURE 39.-Location of principal offices of the Geological Survey's Water Resources Division in the conterminous Lnited States. Cities named are those where regional and district offices are located. In addition to the subdistrict offices inoted on the map, there are two subdistrict offices in Alaska, three in Hawaii, and one on Guam, all in the western region.

The work funded by these three sources is subdivided into a number of subactivities and programs listed in table 10.

The teamwork and expertise of almost 3,000 fulltime personnel are essential to carry out the many water-resources studies and data-collection activities of the Water Resources Division. In 1975, the Division employed 1,280 hydrologists, 202 other professional engineers and scientists, 1,205 technical specialists and aids, and about 270 persons who provided administrative, secretarial, and clerical services. An additional 653 persons were temporarily employed as field assistants and technicians.

\section{Federal program}

The Federal program, amounting to $\$ 26.4$ million $^{1}$ in fiscal year 1975 (26 percent of the Geological Survey's total water program), is designed to provide the nationwide base level of resource data for planning and management and to improve the scientific basis

1 In fiscal year 1975, $\$ 53.4$ million was appropriated for the WaterResources Investigations activity, $\$ 27.0$ million of which was used to
match State and local agency funds (tab!e 36). The balance, $\$ 26.4$ million, is referred to here as the Federal program. of hydrologic investigations and techniques. Waterdata collection, resources investigations, and research activities support that segment of the National V/ater Data System in which the Federal interest is paramount, including the public domain, interstate river basins and aquifers, and other areas of internat onal or interstate concern.

The Federal program supports the operation of more than 700 surface-water measurement-stage and (or) discharge-stations throughout the Nation, including nearly 650 sites where stream discharge is gaged continuously. The program also includes the operation of the National Stream Quality Accounting Network (fig. 41), hydrologic research, and the publication of water reports.

\section{Federal-State program}

The Federal-State Cooperative program consists of projects funded on an equal matching basis by the Geological Survey and State and local agencies-some 550 in fiscal year 1975 (table 11). These projects contribute to the solution of urgent National and state problems and complement the federally funded part 
of the National Water Data System. Once the existence of a Federal interest in a proposed project is identified, cooperative projects are jointly planned at grassroots levels by State (or local) and Federal representatives, and thus optimum melding of Federal and State priorities is assured. The Cooperative program totaled $\$ 54$ million, $^{2} 53$ percent of the total water program, in fiscal year 1975 .

Efficient and effective conservation, development, and utilization of the Nation's water resources are dependent upon an adequate data base. The Cooperative program provides more than half of that base and is a continuing program which directly responds to the changing mutual needs of Federal, State, and local governments for data.

Ongoing activities in the Cooperative program in 1975 were distributed as follows:

- Data collection, analysis, and dissemination, including nearly 5,000 continuous-record and 7,700 partial-record (high and (or) low flow) streamflow sta2Includes $\$ 27.0$ million specifically appropriated for the Federal-State
Cooperative program (table 36 ) and $\$ 27.0$ miltion of matching State and local agency funds.

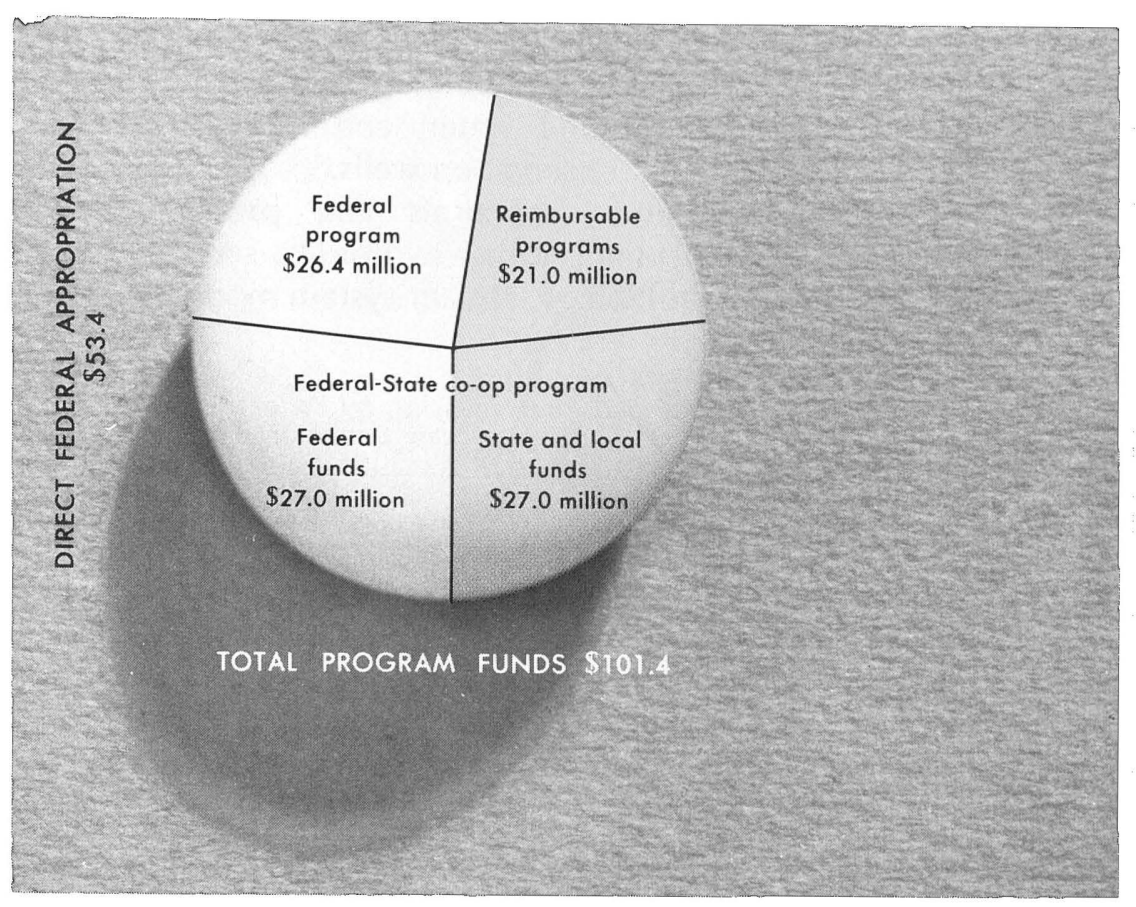

FIGURE 40.- Sources of fiscal year 1975 funds for Water-Resources Investigations (dollars in millions).

TABLE 10.-Water-Resources Investigations activity obligations for fiscal year 1975, by program [Dollars in millions]

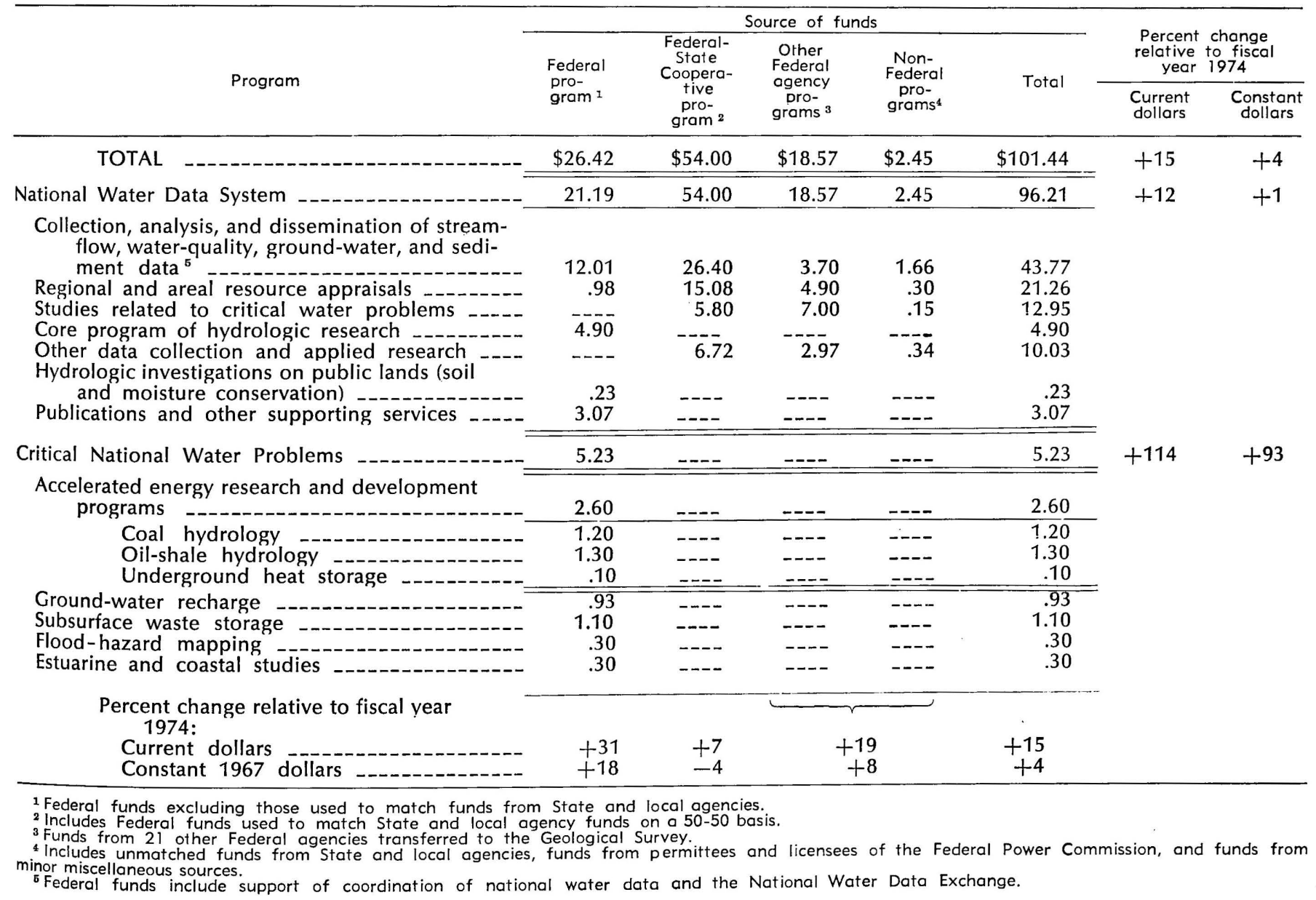


tions, more than 4,000 stations for measuring the chemical, physical, and biological quality of streams, lakes, and ground water, and more than 8,000 ground-water observation wells.

- Areal resource appraisals and problem-related studies, including urban hydrology, sedimentation, lakes, hydrobiology, stream-system modeling, aqui- fer modeling, water-quality modeling, saline waters, flood frequency and magnitude, floods and droughts, waste disposal, and others, for a total of 576 areal resource projects.

- Studies related to critical problems, including 15 projects on burial of wastes, 13 projects on estua-

TABLE 11.-State and local agencies, by State, with which the Geological Survey had a written agreement for fiscal cooperation (Federal-State Cooperative program) in Water-Resources Investigations in fiscal year 1975

\begin{tabular}{|c|c|c|c|c|c|}
\hline \multirow{2}{*}{ State } & \multicolumn{5}{|c|}{ Number of agencies } \\
\hline & State & County & City & Other & Total \\
\hline TOTAL & 197 & 118 & 122 & 113 & 550 \\
\hline $\begin{array}{l}\text { Alabama } \\
\text { Alaska } \\
\text { Arizona } \\
\text { Arkansas } \\
\text { California } \\
\text { Colorado } \\
\text { Connecticut }\end{array}$ & $\begin{array}{l}2 \\
5 \\
4 \\
4 \\
5 \\
5 \\
1\end{array}$ & $\begin{array}{r}1 \\
--\overline{3} \\
--\overline{36} \\
4 \\
--\end{array}$ & $\begin{array}{r}1 \\
6 \\
3 \\
-7 \\
7 \\
3\end{array}$ & $\begin{array}{r}--\overline{3} \\
6 \\
-\overline{26} \\
10 \\
1\end{array}$ & $\begin{array}{r}4 \\
14 \\
16 \\
4 \\
74 \\
26 \\
5\end{array}$ \\
\hline $\begin{array}{l}\text { Delaware } \\
\text { District of Columbia } \\
\text { Florida } \\
\text { Georgia } \\
\text { Hawaii } \\
\text { Idaho } \\
\text { Illinois }\end{array}$ & $\begin{array}{l}2 \\
1 \\
8 \\
4 \\
3 \\
2 \\
6\end{array}$ & $\frac{---}{22}$ & $\begin{array}{r}--- \\
-\overline{25} \\
-- \\
-1\end{array}$ & $\begin{array}{c}--- \\
-\overline{11} \\
--- \\
--\overline{4}\end{array}$ & $\begin{array}{r}2 \\
1 \\
66 \\
7 \\
5 \\
2 \\
17\end{array}$ \\
\hline $\begin{array}{l}\text { Indiana } \\
\text { lowa } \\
\text { Kansas } \\
\text { Kentucky } \\
\text { Louisiana } \\
\text { Maine } \\
\text { Maryland }\end{array}$ & $\begin{array}{l}3 \\
6 \\
4 \\
1 \\
3 \\
3\end{array}$ & $\begin{array}{c}--\overline{1} \\
--- \\
--- \\
--\overline{1}\end{array}$ & $\begin{array}{r}2 \\
3 \\
1 \\
-- \\
-- \\
-1\end{array}$ & $\begin{array}{r}-\overline{1} \\
--\overline{1} \\
--\overline{2}\end{array}$ & $\begin{array}{r}6 \\
10 \\
6 \\
1 \\
4 \\
3 \\
8\end{array}$ \\
\hline $\begin{array}{l}\text { Massachusetts } \\
\text { Michigan } \\
\text { Minnesota } \\
\text { Mississippi } \\
\text { Missouri } \\
\text { Montana } \\
\text { Nebraska }\end{array}$ & $\begin{array}{l}4 \\
2 \\
4 \\
5 \\
3 \\
7\end{array}$ & $\begin{array}{r}-- \\
--- \\
1 \\
1 \\
5\end{array}$ & $\begin{array}{r}-- \\
-1 \\
1 \\
--\end{array}$ & $\begin{array}{r}--- \\
--\overline{1} \\
--\overline{4}\end{array}$ & $\begin{array}{r}4 \\
2 \\
6 \\
1 \\
5 \\
8 \\
5\end{array}$ \\
\hline $\begin{array}{l}\text { Nevada } \\
\text { New Hampshire Jersey } \\
\text { New Mexico } \\
\text { New York } \\
\text { North Carolina } \\
\text { North Dakota }\end{array}$ & $\begin{array}{l}3 \\
2 \\
3 \\
6 \\
9 \\
3 \\
2\end{array}$ & $\begin{array}{r}--- \\
-2 \\
-14 \\
1 \\
1\end{array}$ & $\begin{array}{r}--- \\
--- \\
--\overline{2} \\
4 \\
6 \\
---\end{array}$ & $\begin{array}{r}--- \\
--\overline{4} \\
4 \\
8 \\
--- \\
--\end{array}$ & $\begin{array}{r}3 \\
2 \\
9 \\
2 \\
5 \\
0 \\
3\end{array}$ \\
\hline $\begin{array}{l}\text { Ohio } \\
\text { Oklahoma } \\
\text { Oregon } \\
\text { Pennsylvania } \\
\text { Rhode Island } \\
\text { South Carolina } \\
\text { South Dakota }\end{array}$ & $\begin{array}{l}3 \\
4 \\
4 \\
3 \\
3 \\
\mathbf{5} \\
\mathbf{2}\end{array}$ & $\begin{array}{r}--- \\
--- \\
-- \\
---\end{array}$ & $\begin{array}{r}2 \\
1 \\
9 \\
4 \\
-- \\
1 \\
2\end{array}$ & $\begin{array}{r}2 \\
--\overline{4} \\
--- \\
--\overline{2}\end{array}$ & $\begin{array}{r}7 \\
5 \\
2 \\
0 \\
3 \\
6 \\
6\end{array}$ \\
\hline $\begin{array}{l}\text { Tennessee } \\
\text { Texas } \\
\text { Utah } \\
\text { Vermont } \\
\text { Virginia } \\
\text { Nashington } \\
\text { West Virginia }\end{array}$ & $\begin{array}{l}6 \\
2 \\
3 \\
2 \\
4 \\
4 \\
4\end{array}$ & $\begin{array}{r}2 \\
1 \\
-1 \\
-- \\
2 \\
--\end{array}$ & $\begin{array}{r}6 \\
4 \\
-- \\
-5 \\
5 \\
2\end{array}$ & $\begin{array}{r}2 \\
2 \\
1 \\
-- \\
-- \\
--\end{array}$ & $\begin{array}{r}16 \\
9 \\
5 \\
2 \\
11 \\
15 \\
5\end{array}$ \\
\hline $\begin{array}{l}\text { Nisconsin } \\
\text { Nyoming } \\
\text { Jirgin Islands } \\
\text { American Samoa } \\
\text { Juam Tero } \\
\text { rust Territories }\end{array}$ & $\begin{array}{r}4 \\
6 \\
3 \\
1 \\
--- \\
---\end{array}$ & $\begin{array}{r}2 \\
--- \\
--- \\
--- \\
---\end{array}$ & $\begin{array}{r}2 \\
1 \\
--- \\
--- \\
--- \\
---\end{array}$ & $\begin{array}{r}--- \\
--- \\
--- \\
-1 \\
1 \\
1\end{array}$ & $\begin{array}{l}3 \\
7 \\
3 \\
1 \\
1 \\
1 \\
1\end{array}$ \\
\hline
\end{tabular}


rine problems, 19 projects on artificial recharge, and 4 projects on flood-hazard mapping.

- Applied research on hydrologic problems, principles, and techniques.

One of the quickest ways to gain an insight into the nature and wide scope of the effort involved in the Federal-State program is to scan the titles of a few of the more than 600 reports published from Cooperative projects:

Salt-balance study of Pauba Valley, upper Santa Margarita River area, Riverside County, California.

Chemical and biological quality of Lake Dicie at Eustis, Florida, with emphasis on the effects of storm runoff.

Application of statistical techniques to the estimation of groundwater withdrawals (Kansas).

Floods in East Baton Rouge Parish and adjacent areas, Louisiana, for the period 1953-74.

Availability of ground water in the Saco River basin, east-central New Hampshire.

Predictive modeling of effects of the planned Kindred Lake on ground-water levels and discharge, southeastern North Dakota.

Estimating streamflow characteristics for streams in Utah, using selected channel-geometry parameters.

A method for the relative classification of lakes in the State of Washington from reconnaissance data.

\section{Other Federal agency programs}

Other Federal agency programs, amounting to $\$ 18.6$ million in fiscal year 1975, consist of work carried out by the Geological Survey at the request of 21 other Federal agencies to provide them with information for use in support of their missions.

Examples of work performed for 6 of the 21 Federal agencies are:

\section{Department of} Agriculture.

Department of Housing and Urban Development.

Department of Transportation.

Energy Research and Development Administration.

\section{Environmental} Protection Agency.

National Aeronautics and Space Administration.
Stream discharge, quality, and trapefficiency studies; hydrologic studies on small watersheds.

Flood-insurance studies (flood-plain delineation, flood profiles, flood frequency).

Stream discharge and flood-frequency data; hydrologic studies on small watersheds, scour, and bank erosion.

Hydrologic and water-supply exploration studies at test sites; research in field of radiohydrology related to interaction between radioactive materials and the environment, both above and below ground.

Collection of water-quality information; study of relationship of ground water to lakes; national eutrophication survey; waste-disposal site studies.

Applications of remote sensing to hydrologic problems (ground water, estuaries, water temperature, lakes, glaciology, snowcover mapping).
As with the Federal-State program and much of the Federal program of the Geological Survey, the work of other Federal agency programs is classified into four main elements (data collection, resource appraisals, critical problems, and research) for the purposes of budgeting and planning (table 10). Thus, the work of the three major programs that constitute the total effort of the Geological Survey in Water-Resources Investigations-Federal, Cooperative, and other Federal agencies-is mutually supportive in terms of measuring and appraising the Nation's water resources.

\section{Non-Federal program}

Non-Federal reimbursable funds are unmatched funds received by the Geological Survey from State and local agencies (\$1.54 million) in situations where there is both Federal and State interest in investigation of water resources but where matching Federal funds are either unavailable or are not otherwise applicable to cost sharing. A large part of the work in this category during fiscal year 1975 was for energyrelated water studies in Colorado, Utah, and Wyoming. Also included with the non-Federal reimbursable funds are monies $(\$ 901,000)$ received from permittees and licensees of the Federal Power Commission.

\section{Highlights}

Studies that received strong emphasis during fiscal year 1975 included:

\section{Water and energy}

The energy problems of the winter of 1973-74 not only stirred the Nation to reappraise and intensify the development of its fuel resources but also turned the spotlight on water. Would there be enough water for mining, refining, and transportation of fuels at the times and places needed? What would be the effects on existing water sources and uses in those places? A significant start toward finding answers to such questions was made during fiscal year 1975, including the beginning of energy research and development studies in 22 States, principally on oil-shale hydrology, coal hydrology, and nuclear hydrology.

\section{Water quality}

A much strengthened and broadened water-quality measurement network for the Nation's streams was begun during the 1973-75 period. The National Stream Quality Accounting Network is commonly referred to by its acronym, NASQAN. NASQAN measures chemical, physical, and biological characteristics of water to provide baseline water-quality information for national and regional evaluation and planning. 
The network not only shows geographic variations and changes in stream quality but also determines trends and provides baseline data for future assess- the Geological Survey's professional paper series for three river-basin regions: Ohio, Rio Grande, and Upper Colorado. Reports for the Upper Mississippi,

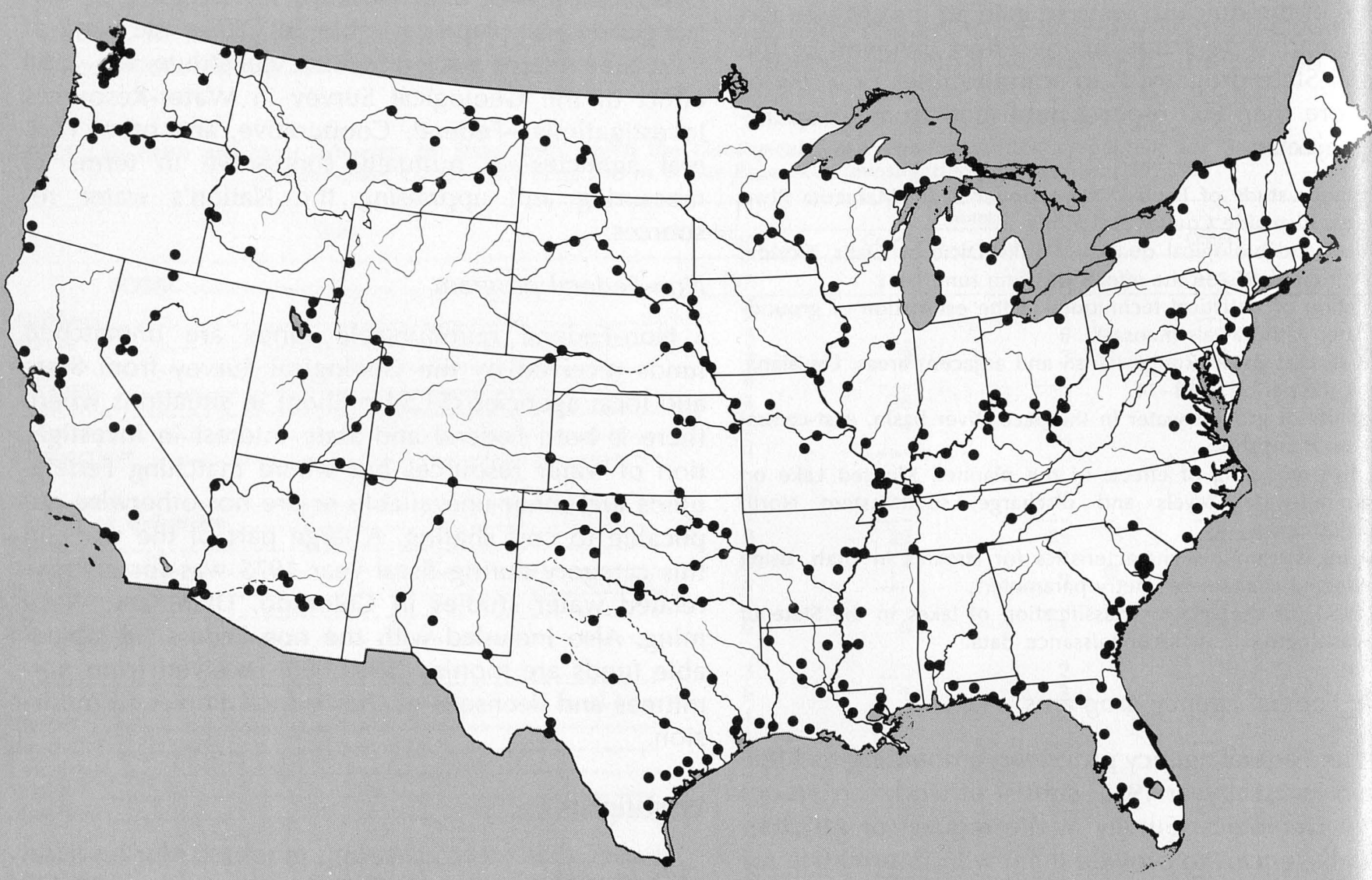

FIGURE 41.-Locations of stations in the National Stream Quality Accounting Network (NASQAN) in operation as of January 1 , 1975, in the conterminous United States (Ficke and Hawkinson, 1975, p. 9). Stations not shown include six in Alaska, six in Hawaii, and three in Puerto Rico.

ments of changes in stream quality. As of January 1, 1975, there were 345 stations, about 60 percent of the total planned network (fig. 41).

\section{Ground water}

Substantial progress was made on the regional appraisals of ground-water resources that began in 1970 . These regional assessments-a series of 21 reports that will describe ground water throughout the $\mathrm{Na}$ tion, including Puerto Rico-will give an overall picture of this somewhat "hidden" segment of the country's water resources. They will also identify groundwater problems and the locations of major present and potential ground-water development. Ground water is a large, important, and manageable resource that, in many parts of the Nation, can play a significant role in regional water supply and warrants full consideration as an alternative or supplemental source of
Texas-Gulf, and California-South Pacific regions were in press; manuscripts completed for four other regions were under review.

\section{National Water Data Exchange (NAWDEX)}

Preparations for the implementation of the National Water Data Exchange were nearly completed by the end of fiscal year 1975. The purpose of the Exchonge is to give all water-data users better and more rapid access to water data by coordinating and linking, via computer terminals, major Federal and non-Fecieral water-data collector and user organizations. During fiscal year 1975, a contract was completed that included (1) designing the structure, formats, and operating procedures for the Master Water Data Index and (2) preparation of initial operations manuals. The first data that will be available directly to NAWIJEX participants from computer storage will be the "caily 


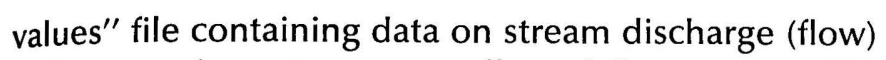
and reservoir contents as well as daily water-quality data such as temperature, specific conductance, and suspended sediment concentration.

\section{Mapping in flood-prone areas}

During 1975, many flood-prone areas in the United States were mapped to provide a basis for minimizing future flood hazards and damages through land use planning, structural design, and insurance. Much of the mapping, begun in fiscal year 1969 and funded by the Department of Housing and Urban Development, carries out a recommendation made in 1966 by the Task Force on Federal Flood Control Policy (White and others, 1966). The Survey published 1,140 maps in 1975 , each showing on a topographic base map the boundaries of areas that would be under water from a major flood (one likely to occur on the average once in 100 years); 938 of the maps were prepared by district offices of the Survey, and 202 were prepared by the Soil Conservation Service. Figure 42 shows the number of maps published each year since 1969.

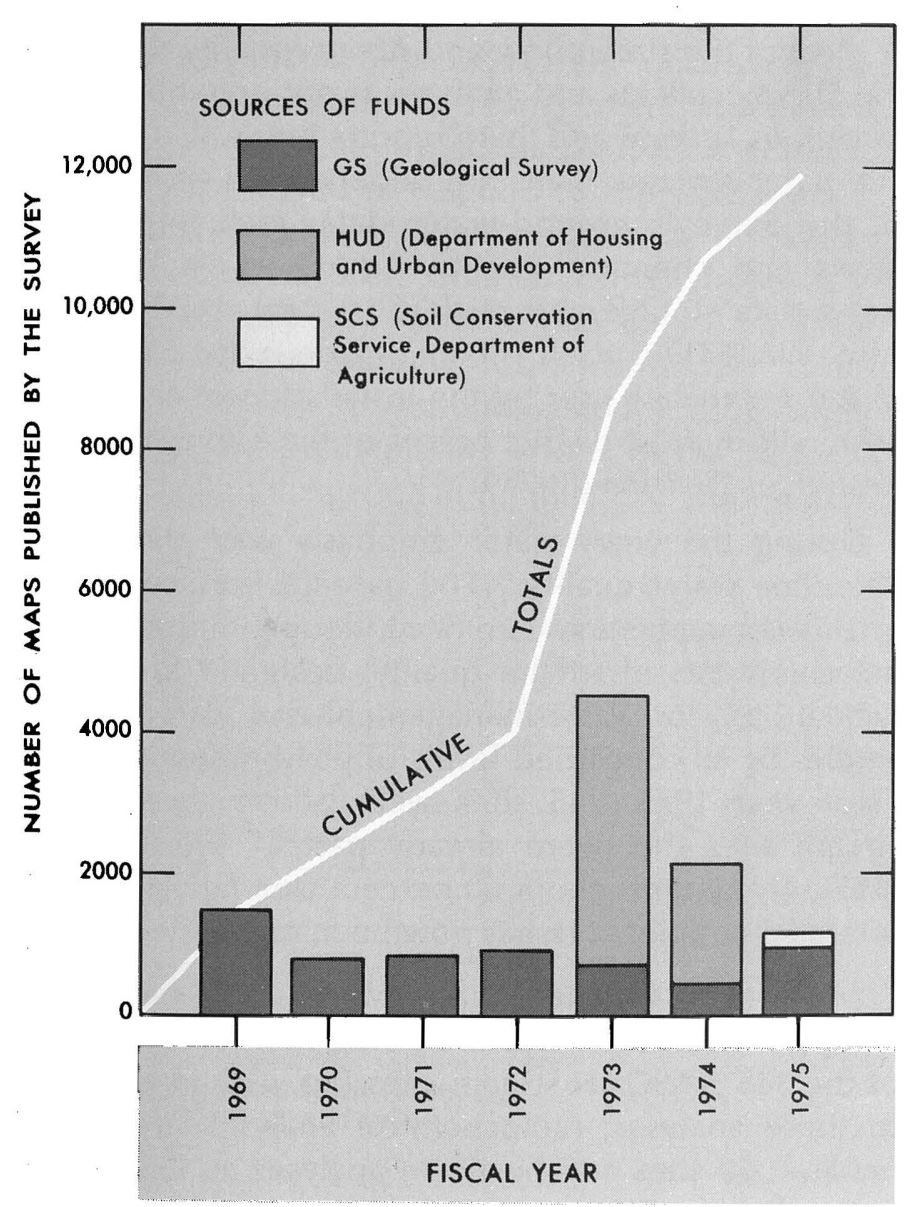

FIGURE 42.-Maps of flood-prone areas published by the Geological Survey, fiscal years 1969-75, and sources of funds. All maps were prepared by Geological Survey except for 202 maps prepared by Soil Conservation Service in 1975.

\section{Other national water problems}

The Survey continued to give strong emphasis during 1975 to research on ground-water recharge and subsurface waste storage. Ground-water-recharge studies are using water-spreading basins and injection wells located in the semiarid High Plains of west Texas and New Mexico and in the glacial deposits on Long Island, N.Y., to investigate the feasibility of artificially augmenting ground-water supplies with surface water that would normally leave the area as streamflow or evaporate into the atmosphere. Subsurface waste-storage investigations are providing planners and managers of waste-storage and disposal activities with information that will be used to prevent or minimize ground-water pollution. Studies conducted in 1975 continued to concentrate on the fundamental principles that control (1) the chemical reactions of wastes and other pollutants with aquifer materials and (2) the subsurface movement, dilution, and dispersion of pollutants in ground water.

\section{New series of hydrologic maps}

In 1975, the Survey published the first 14 maps in the new series of Hydrologic Unit maps of States. The new four-color maps use the Survey's State base map series at a scale of 1:500,000 to show hydrologic boundaries with numerical codes identifying each subdivision and counties or county equivalents. The maps, developed in cooperation with water-oriented Federal and State agencies, including the U.S. Water Resources Council, are designed for use in planning activities and in organizing and disseminating data on both a civil-unit and a hydrological basis. The maps for the remaining States and the Caribbean region are to be published during fiscal year 1976 .

\section{ELEMENTS OF NATIONAL WATER-DATA SYSTEM}

\section{Interagency water-data coordination}

The Survey's Office of Water-Data Coordination continued during fiscal year 1975 to work closely with a large number of governmental agencies and representatives (see table 12) in the planning, design, and documentation of water-data networks and in the planning and development of standards for waterdata acquisition. This closely coordinated effort is especially important because about 19 Federal and at least 200 non-Federal agencies collect water data, and 40 Federal agencies and more than 600 non-Federal agencies use water data. 
TABLE 12.-Activities and participants of interagency water-data coordination committees and groups associated with the Survey's Office of Water Data Coordination

$$
\text { Activity }
$$

Coordination of Federal agency waterdata programs through Interagency Advisory Committee on Water Data.

Consultation with non-Federal community of data users through Advisory Committee on Water Data for Public Use.

Design of national system for handling water data.

Development of recommended methods for collecting water data; includes Coordinating Council for Water Data Acquisition Methods (17 Federal agencies).

Design of small-watershed network. Field coordination and development of 21 regional plans annually for water data.

Assessment of river quality-Ad Hoc Working Group of Advisory Committee on Water Data for Public Use.

Strong emphasis was placed during 1975 on workgroup activities designed to produce a comprehensive "National Handbook of Recommended Methods for Water-Data Acquisition," an update of a preliminary report issued in 1972 (U.S. Geological Survey, 1972). Particularly important was the addition of methods and concepts by non-Federal members of the work groups. Another major activity during the year was preparation and publication of the first 14 maps in the new nationwide series of four-color State Hydrologic Unit maps, scale 1:500,000, covering 18 States (fig. 43).

\section{Collection, analysis, and dissemination of basic water data}

The collection and analysis of basic water records, such as the flow (discharge) of a stream, the level (stage) of a lake, the water level in a well, the chemical quality and sediment load of a stream, and the amount

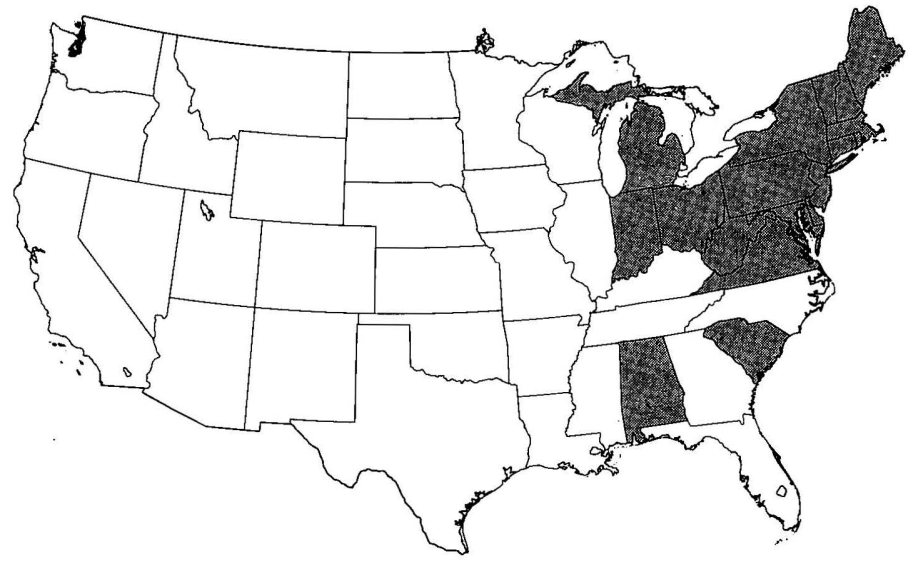

FIGURE 43.- - Location of areas covered by maps published in fiscal year 1975 in the Survey's new series of State Hydrologic Unit maps (scale 1:500,000). of water used by a large industry or public supply, are fundamental building blocks upon which all other aspects of water-resources investigations rest. These kinds of measurements are necessary first steps in determining how much and what kind of water is available when and where and then in comparing these quantities with water used and water needed. Basic water data are essential not only to determine the adequacy of water supplies but also to design culverts, bridges, dams, and other public works, to prevent or lessen the damages and impacts of floods and droughts, to determine the feasibility of water-power and irrigation developments, and to some extent to plan projects for water-pollution control, navigation, and outdoor recreation. About 40 percent of the water funds that the Geological Survey receives from all sources supports basic-data activities-the largest single major element of the National Water Data System.

In 1975, the Survey maintained continuous discharge records at 7,700 stream sites, analyzed water quality at nearly 5,000 stream sites, and measured water levels or other parameters periodically in more than 8,000 wells (table 13).

Most of the streamflow and stream-quality data that the Survey collects and analyzes is not only published in various Federal and State reports but is also filed in computer storage. Plans are underway to have much of the Survey's ground-water data, including water levels and chemical quality, added to its national water-data storage and retrieval system, WATSTORE. Also, WATSTORE itself is being made more accessible to the water-data user by the installation of comp ter terminals in most district offices of the Survey's Water Resources Division (fig. 39).

During the year, major emphasis was placed on "baseline water quality." The baseline surface-waterquality concept is a system of continuing multipurpose measurements of stream quality, designed to be the factual base for waste-management and water-supply studies by all concerned levels of government. During fiscal year 1975, 245 sites were added to the 100 stream sites that were already part of the baseline NASQAN system; about 60 percent (see fig. 41) of the total planned network has now been completed.

More than 40 chemical, physical, and biological characteristics (table 14) are being measured at each of the 345 NASQAN stream sites (fig. 41); in addition to these analyses, radiochemical analyses are being made at 50 sites and pesticide analyses at 153 of the network sites. The NASQAN program will provide a balanced and unbiased basis for evaluating streamquality conditions and changes in the United States for use by Federal, regional, and State agencies in 
TABLE 13.-Number and type of measurement sites (stations) of the Geological Survey and sources of funds for station operation, April 1975

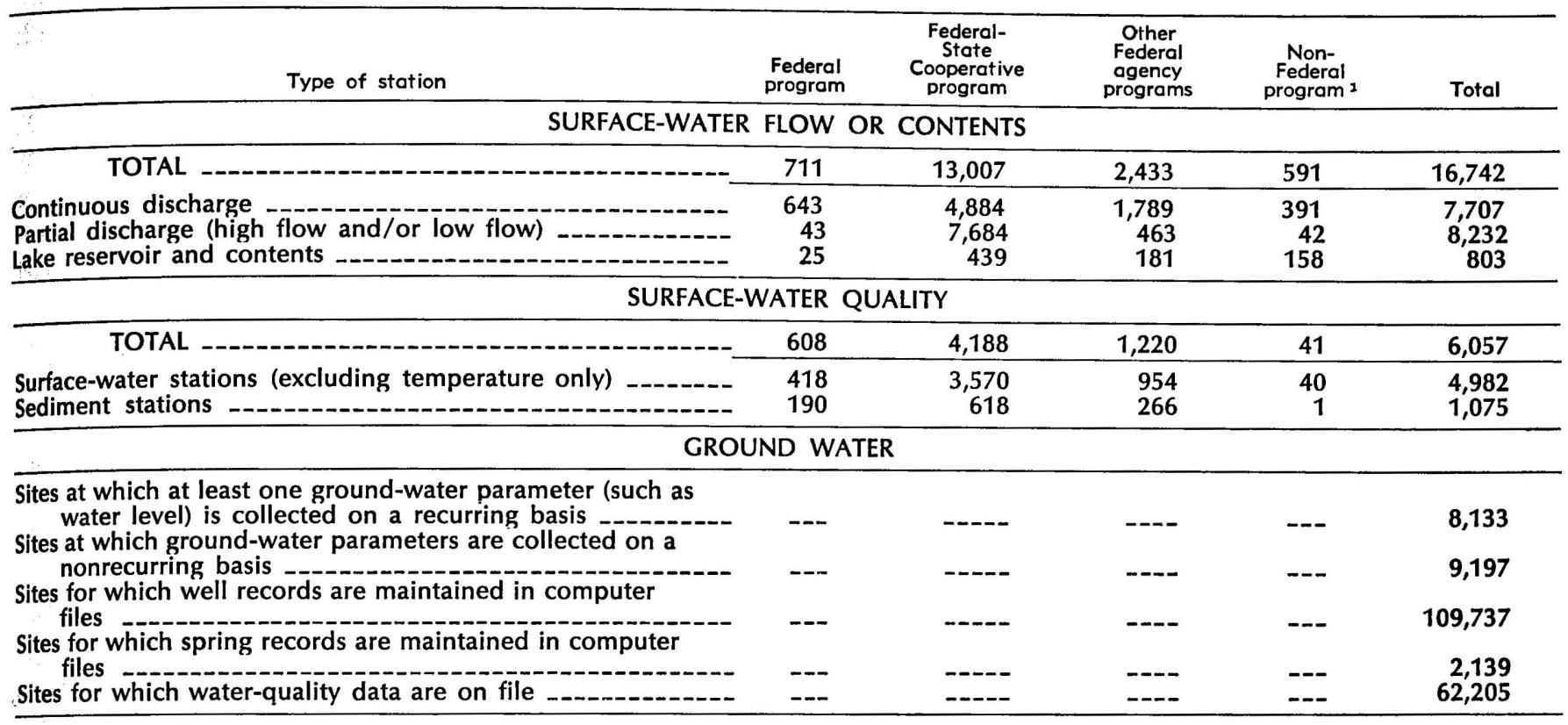

1 Includes permittees and licensees of the Federal Power Commission.

judging the effectiveness of current quality-control programs and in assessing management alternatives on a nationwide scale. In terms of Federal interest, NASQAN is designed to respond to the stream-information requirements of agencies such as the Water Resources Council, the Council on Environmental Quality, the Corps of Engineers, and special commissions such as the National Commission on Water Quality. In addition to responding to these demands, the network complements the efforts of the Environmental Protection Agency in fulfilling the information requirements specified under section 104(a)(5) of the Federal Water Pollution Control Amendments of 1972 (Public Law 92-500), which calls for the establishment of a nationwide water-quality surveillance system.

The Survey is also conducting a pilot program of river-quality assessments. The objective is to develop and demonstrate an approach and a technical methodology by which water-resource planners and managers can use basic water-quality information to assess river-quality problems and evaluate management alternatives.

TABLE 14.-Characteristics measured at NASQAN stations (Ficke and Hawkinson, 1975, p. 8)

[Frequencies: $C$, continuous; $D$, daily; $M$, monthly; $Q$, quarterly]

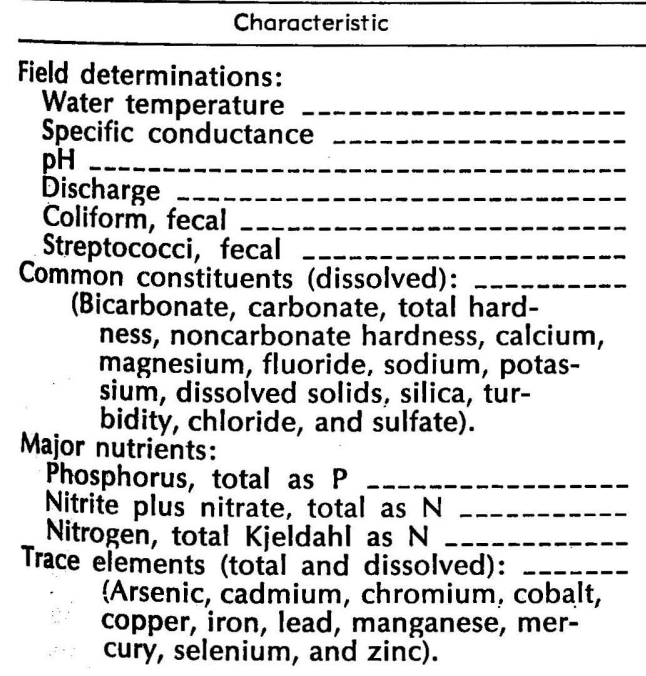

Frequency
${ }^{1} \mathrm{C}, \mathrm{D}$, or $M$
${ }^{1} \mathrm{C}, \mathrm{D}_{\text {, or } M}$
$\mathrm{M}$
$\mathrm{M}$
${ }^{2} \mathrm{M}$ or $\mathrm{Q}$
$\mathrm{M}$
$\mathrm{M}$
$\mathrm{Q}$

Organics and biological:

Organic carbon, total _.

Phytoplankton, total, cells/ml

Phytoplankton, identification of 3 codominants

Phytoplankton, 3 codominants, percent of total

Periphyton, biomass, dry weight $\mathrm{g} / \mathrm{m}^{2}-\cdots \quad \mathrm{Q}$

Periphyton, biomass, ash weight $\mathrm{g} / \mathrm{m}^{2} \ldots$

Periphyton, chlorophyll a
Periphyton, chlorophyll b $b$ -

Suspended sediment:

Suspended sediment concentration -.-.-- M

Percent finer than 0.062-mm sieve diameter_ $\quad M$

1 Continuous or daily depending upon whether the station is equipped with a monitor or whe' her daily observations are made. Monthly measure-

ments made at stations where a long-term record is available.
2 Ouarterly or monthly, depending upon whether relationships have been established between conductance and concentrations of various common constituents. 
The intensive river-quality assessment of the Willamette River basin in Oregon was within a few months of completion by the end of June; several reports on methods and results were being reviewed, and several others were in preparation. Near the end of the year, two new pilot river-quality assessments were begun-one in the Chattahoochee River basin in Georgia and the other in the Yampa River basin of Colorado and Wyoming. The Chattahoochee study will address problems related to thermal loading and heat dissipation, wastes from concentrated urbanindustrial areas, effects of hydropower pulsations on river quality, and sediment movement and deposition. The Yampa assessment will investigate water problems related to development for energy production, especially the impact on river quality of water derived from coal extraction and conversion.

\section{Regional and areal resource appraisals}

The Federal-State Cooperative program is the principal source of funds for areal water-resources investigations. In fiscal year 1975, 576 areal projects were a part of the program. Most such projects are studies of ground or surface water (or both) in a river basin, aquifer, county, metropolitan area, or city. These projects are generally completed in 1 to 3 years with a published report.

An important component of areal water-resources investigations in 1975 was the substantial progress made on a nationwide series of regional appraisals of ground water. During fiscal year 1975, 3 of the regional reports were published, and 11 others moved ahead toward completion (fig. 44).

A few highlights from the first three reports are:

- The Ohio region-Bloyd (1974) reported that:

Nearly 80 percent of the total potable ground water available from natural storage (water-bearing formations) in the region is from the outwash and alluvial aquifers in the Ohio River valley.

Annual regionwide water use is a small fraction of the average annual recharge-only 3 percent in 1965, for example.

Of the region's subbasins, the Wabash and the White probably have the highest potential for additional ground-water development.

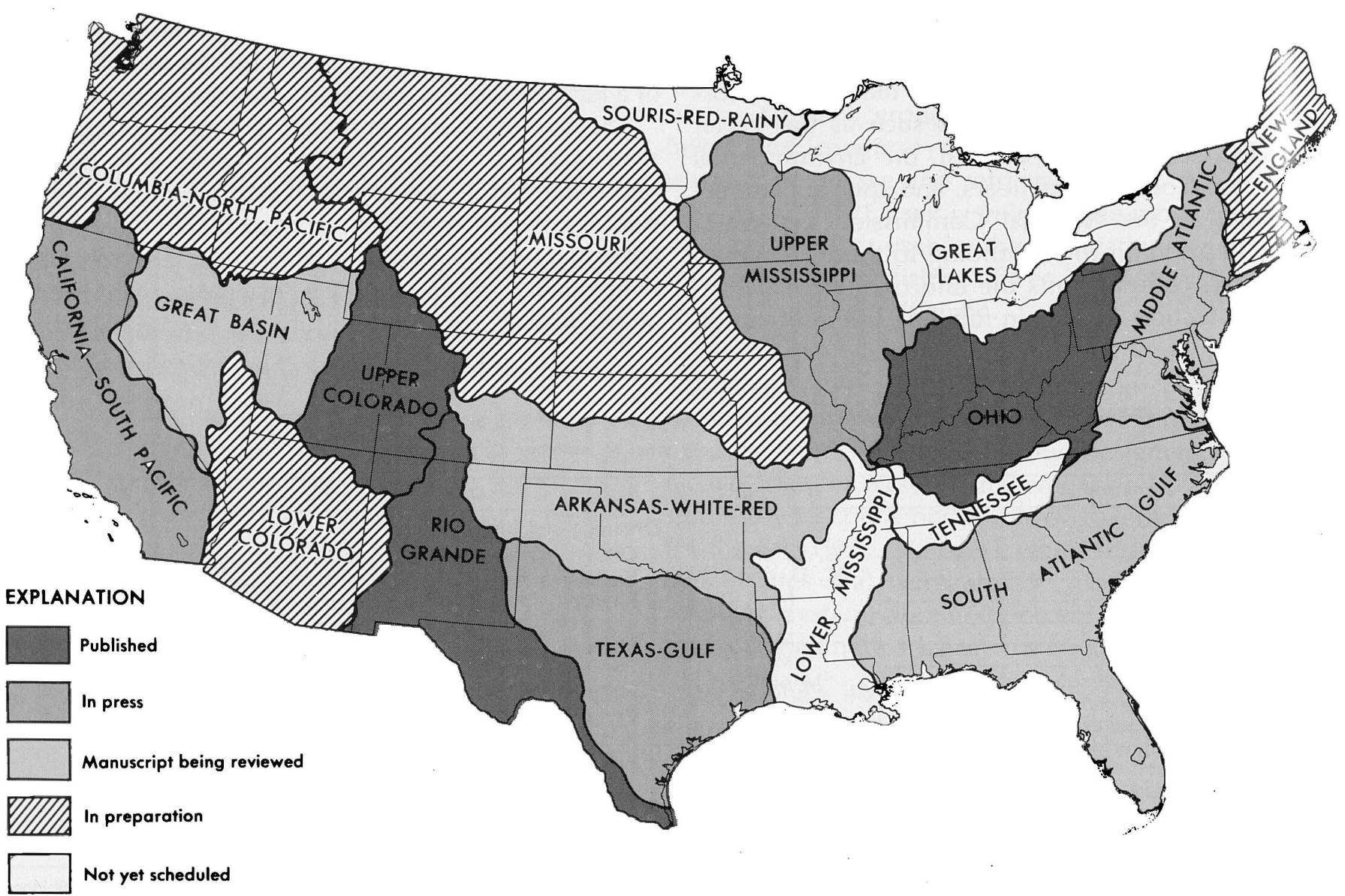

FIGURE 44.-Status of regional ground-water appraisals as of June 30, 1975. (Studies of the remaining seven regions, including Alaska, Hawaii, and Puerto Rico, will begin as other studies are completed.) 
- The Rio Grande region-West and Broadhurst (1975) reported that:

Withdrawal of ground water in 1970 was about 3,300 cubic hectometres (2.7 million acre-feet), of which nearly 90 percent was for irrigation.

The largest ground-water reservoirs are in the San Luis Valley and Albuquerque subregions, each of which contains about 2.5 million cubic hectometres ( 2 billion acre-feet) of fresh and slightly saline water.

Salvage of water lost to noneconomic evapotranspiration in wet phreatophyte-infested areas offers the greatest possibility of improving the effective water supply of the region.

- Upper Colorado region-Price and Arnow (1974) reported that:

The sparsely populated region is used chiefly for grazing, recreation, and mineral development; only about 2 percent of the region's water use in 1970 came from ground-water sources.

Projected consumptive water use from all sources by the year 2020, including water exports to adjacent regions, may total more than 8,000 cubic hectometres (6.5 million acre-feet) per year; ground water could help meet those needs.

Most of the ground water is in consolidated rocks that generally yield water to wells slowly; much of the water is saline and in some places occurs at great depths; compensating advantages are the relatively uniform distributions, both areally and with time.

The Geological Survey began this program of rapid, regional appraisals of the ground-water resources of the United States in 1970 in order to develop and publish as quickly as possible a broad-perspective analysis of the Nation's ground water as one means of alerting planners to its potential value and widespread availability. These reports will include an assessment of the significance of ground water in the regional water supply, quality characteristics and their importance, and present and potential hydrologic and economic problems associated with the use of ground water. As the prospective limits of water availability are approached, it is important to consider conjunctive surface-water-ground-water development, induced infiltration systems, artificial recharge, recycling of waste water, streamflow augmentation, and other innovative plans for improving ground-water development and management.

Another kind of areal investigation made by the Survey is the documentation and analysis of the causeand-effect relationships of an extreme hydrologic event such as a flood or drought. A case in point was
Nevada's Eldorado Canyon disaster of September 14, 1974-a flash flood that took nine lives and caused extensive damage to recreational facilities. The peak flow was estimated to be 2,200 cubic metres per second $(76,000$ cubic feet per second) from the 60 square-kilometre (23-square-mile) drainage area (a flow equivalent in weight to 2,182 tonnes of water per second). A report published in 1975 by the Geological Survey and prepared in cooperation with the National Park Service points out that, although floods of this magnitude would on the average not occur in the same area for many years, a similar flood could occur in any given year. "These types of flash floods, although common in the desert Southwest, are not fully understood and are frequently ignored, and therefore the danger to developed areas is not decreased. With proper understanding and informed planning, the risk of damage from similar floods in the future can be greatly reduced" (Glancy and Harmsen, 1975, p. 1).

\section{Studies related to critical water problems}

New energy-related water projects begun in 1975 dealt with determining the quantity and quality of water available at potential energy-development sites, such as mines, and coal and oil-shale processing centers, and with defining energy-development impacts on water resources. These and other critical national water problems, such as ground-water recharge and subsurface waste storage, received direct Federal funding in situations where the Federal interest was paramount and where an accelerated time schedule for project completion was vital.

The States also gave substantial support to critical water problems in the Federal-State program, including cooperative funding for (1) 15 projects on burial of wastes, (2) 13 projects on estuarine problems, (3) 19 projects on artificial recharge, and (4) 4 projects on flood-hazard mapping. Examples of Cooperative energy-related projects during 1975 are given below for eight States:

Project title or objective
Black Mesa study; to monitor hy-
drologic effects of ground-water
withdrawals and strip mining at
Black Mesa.


North Carolina

Hyco Lake; to relate evaporation
losses to increased powerplant
capacity.
Hydrology of estuaries and sounds
of North Carolina; thermal effects
of powerplants, including nuclear
site at Wilmington.
Wyler resources of western Penn-
sylvania.

In addition to the above-noted projects, several high-priority, energy-related studies were fully supported by funds from three Western States:

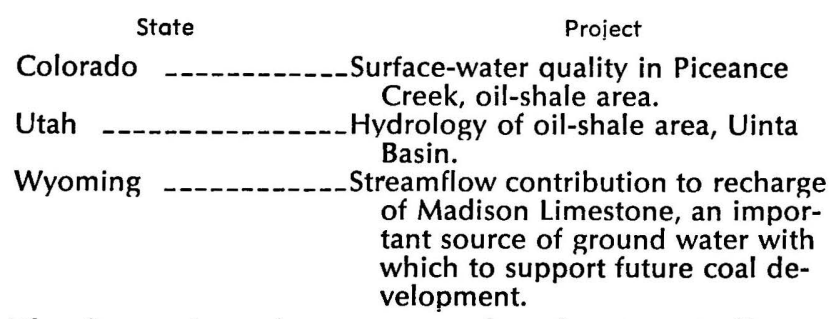

The Survey's major energy-related water studies are discussed under Critical National Water Problems.

\section{Core program of hydrologic research}

During 1975, the Geological Survey carried on 66 major hydrologic research projects. This core program, constituting the federally funded part of the Survey's hydrologic research, is subdivided into seven principal categories:

- Exploration of natural water systems-mathematical and computerized analysis and description of ground-water systems, significant aquifers, and ground-water regions.

- Lakes and reservoirs-investigations of the physical interchange of water between lakes and ground water, methods for minimizing water loss from lakes by evaporation, and the effect of plant growth on lake-water quality.

- Water consumption by phreatophytes-studies to determine the relationships between types of vegetational cover and water loss as a means of predicting loss of water under various types of environmental conditions.

- Flow and diffusion-studies on the development and implementation of models of the flow and movement of water, heat, and dissolved and suspended material in open channels, estuaries, and the unsaturated zone.

- Chemistry-basic research studies on the composition, distribution, and movement of inorganic, or- and surface water. Applied aspects seek to predict the source and fate of pollutants and the effects thereof on the use of the water resource as well as on the confining environment.

- Geomorphology-basic and applied research studies on weathering, erosion, transport and deposition of sediments, and channel morphology, including the role of sediments as pollutants and transporting agents in fluvial and estuarine environments.

- Glaciology-basic and applied research on the extent, movement, and water-supply potential of glaciers, as well as other aspects related to navigation, floods, flow measurements, and bridge construction.

A large part of the Survey's water-research activity is carried on at the Gulf Coast Hydroscience Center of the National Space Technology Laboratories (formerly the Mississippi Test Facility) in Bay St. Louis, Miss. An indoor hydraulics laboratory is used to test and calibrate hydrologic instruments and to obtain experimental data used in research studies on the mechanics of flow and the transport and dispersion of heat, solvents, and solids in rivers and estuaries. An outdoor flood-plain simulator is used for research on factors affecting the mechanics of flow in open natural channels. The Survey's water projects in progress at the Laboratories during 1975 were basic and applied research on (1) open-channel experiments, (2) operational models of surface-water systems, (3) physical modeling of hydrologic systems, (4) the oxygen cycle in streams, lakes, and estuaries, (5) heat transfer and the air-water interface, (6) satellite data relay support, (7) microwave remote sensing, (8) subsurface waste storage, and (9) instrument development.

Additional water-research activities are condtcted as parts of the Federal-State program and other Federal agency programs on projects where there are objectives of mutual Federal and State or local interest (and therefore cooperative funding) or where there is a need for such research by Federal action agericies, but the nature and scope of the research work itself is of a kind normally or most effectively carried out by the Geological Survey.

Accomplishments in research projects during fiscal year 1975 included:

- Development of mathematical models that can simulate the production behavior of geothermal reservoirs and thus contribute to the proper managernent of the Nation's geothermal resources. The energy potential of the geopressured reservoirs of the Gulf Coast is also being evaluated.

- Development and demonstration of a computerautomated scheme for processing randomly col- 
lected estuarine hydrographic data into the initial-condition bathymetry used in two- and threedimensional modeling. This methodology is being applied in Tampa Bay, Fla.

- Demonstration of the practicality and advantages of employing an orthogonal curvilinear coordinate system for developing a mathematical model to predict the steady-state two-dimensional distribution of solute concentration in a meandering nonuniform natural channel. This methodology has direct application for streams experiencing natural or man-induced stresses.

- Development of models for predicting the movement of contaminants from shallow or deep subsurface waste-disposal sites, taking into account simple chemical reactions that may take place along the path of movement.

- Establishment of the absence of significant variation in the deuterium and oxygen-18 isotope content of Coastal Plain ground water over the past 30,000 years. This finding contrasts markedly with oceanographic conditions and thus permits differentiation of recharge sources in regional aquifer systems.

- Development of computer methods for the calculation of $\mathrm{pH}$ and equilibrium distribution of inorganic species as a result of net reaction progress involving the seven principal solute components of natural waters. This methodology will be useful in establishing expected steady-state conditions that are required prior to determining the predictive effects of induced changes.

\section{Hydrologic investigations on public lands}

The public-lands hydrology studies have for several years consisted of the collection and evaluation of data on the hydrologic effects of land use and land treatment practices on the public domain. This program investigates the effects of (1) grazing, (2) changes in vegetative cover, and (3) mechanical treatments of the land to increase the efficiency of onsite use of surface water. More recently, the focus of hydrologic studies on public lands has shifted to energy-resource development, the environmental impacts of surface mining, and the rehabilitation potential of surfacemined lands. These investigations are being done in cooperation with the Bureau of Land Management.

\section{Supporting services}

This program includes primarily the training of personnel and the printing of publications. The waterresources training center is located at Lakewood, Colo., where 1- and 2-week courses are given throughout the year (35 in 1975) to scientific, techni- cal, and administrative personnel, usually in groups of 20 to 30. Participants include not only Survey personnel but also representatives of State cooperating agencies and foreign hydrologic organizations.

During 1975, the Geological Survey prepared about 1,000 water reports and maps (in addition to 1,140 maps of flood-prone areas); 364 of these reports were published in several of the Survey's series of book and map publications (Water-Resources Investigations, Water-Supply Papers, Professional Papers, basic data reports, and Hydrologic Investigations Atlases). Significant progress was made in publishing annual basic data promptly; 43 State reports in the annual series were published within 9 months of the close of the water year (the 12 months ending September 30, 1974).

In addition to the above-noted books and maps, two particularly informative and colorful reports published in the Survey's bulletin series described the geology of two Western park areas-Arches National Monument and Canyonlands National Park, Utahareas in which the hydrologist author had wide knowledge and interest (Lohman, 1974, 1975).

Other supporting services include the three large water-quality laboratories-at Atlanta (Doraville), Ga., Albany, N.Y., and Salt Lake City, Utah-that comprise the Central Laboratory System of the Water Resources Division. During 1975, more than 1.7 million waterquality characteristics were analyzed and funded on a reimbursable basis from the Federal and Cooperative programs and other Federal agency programs. All data are stored in and are available from WATSTORE.

\section{CRITICAL NATIONAL WATER PROBLEMS}

\section{Accelerated energy research and development programs}

"Water-for-energy" studies were begun in 1975 as a result of the energy crisis and the subsequent emphasis on rapid exploration and development of the Nation's energy resources. These studies are of two principal types: (1) investigation and appraisal of the water supplies needed in mining, transportation, refining, and conversion processes and (2) evaluation of environmental impacts on water resources associated with the development of energy resources, including the effects of radioactive waste disposal. Work in 1975 concentrated on defining the hydrology of coal, oil-shale, and geothermal resource areas primarily in the Western States and included arranging for exploratory drilling, making aquifer tests, and establishing 
sites for monitoring water quality and quantity to measure baseline water conditions prior to energy development. Although current efforts have centered on the Western coal and oil-shale areas, several investigations are also in progress in coal-mining regions of the Appalachians, the Midwest, and the Far West. The Survey also began testing the feasibility of using ground water as a means of storing the large amounts of waste heat generated by powerplants during the summer for use during the winter at suitable locations. The locations and types of 100 energyrelated water projects in progress during 1975 are listed in table 15. The list includes projects that were supported by funds from the Federal and FederalState programs (see table 10, "Studies related to critical water problems" ${ }^{\prime \prime}$.

The coal hydrology program consists of three elements: mining-water supply and quality, coal slurryline demands and impacts, and water-supply impacts of waste management in conversion processes. After necessary surface and subsurface hydrologic data have been acquired, they will be used to design predictive models so that the impacts of energy development upon water resources under various planning alternatives can be analyzed.

The oil-shale hydrology program measures (and models as appropriate) the parameters of different water-bearing formations (aquifers), the connection between aquifers, the occurrence of fresh and saline ground water, and the relation between different ground-water zones and surface water. Observation wells and aquifer tests establish initial ground-water conditions and record subsequent changes due to developments. Also, streamflow and quality-of-water stations are being established at key locations to document changes in surface-water and ground-water discharge resulting from oil-shale developments, increased municipal and industrial demands, and changes in the irrigation patterns of farm lands.

Another important component of the water-forenergy program is the development of hydrogeologic criteria for use in selecting and locating sites for future shallow land burial of low-level radioactive waste. The studies will document what has occurred physically and geochemically during the past 10 to 20 years at three currently used waste-burial sites.

Accomplishments during the year included:

- Publication of a report (Weeks and others, 1974), prepared in cooperation with the Colorado Department of Natural Resources, which concluded that development of oil-shale deposits in the 2,330square-kilometre (900 square-mile) Piceance basin in northwestern Colorado will have significant effects on the hydrology of the region. A digital computer simulated the possible effects on the hydrologic system of precipitation changes due to the introduction of (1) atmospheric pollutants from oilshale development or cloud seeding and (2) mine dewatering. The model results showed that, for the hypothetical dewatering scheme simulated, one proposed mine will produce enough water to meet the demands of oil-shale processing and disposal over a 30-year period and that a second hypothetical mine will not produce enough water. Such an

TABLE 15.-Locations and types of energy-related water-resource projects begun or in progress during fiscal year 1975, by State

\begin{tabular}{|c|c|c|c|c|c|}
\hline State & Coal & $\begin{array}{l}\text { Oil- } \\
\text { shale }\end{array}$ & Nuclear & $\begin{array}{c}\text { Geo- } \\
\text { thermal }\end{array}$ & $\begin{array}{c}\text { Heat } \\
\text { sterage }\end{array}$ \\
\hline Totals & 39 & 13 & 20 & 27 & 1 \\
\hline \multicolumn{6}{|l|}{ Eastern United States } \\
\hline Alabama & 1 & -- & -- & -- & 1 \\
\hline Illinois & 1 & - & $\overline{1}$ & -- & $\ldots$ \\
\hline Indiana & 1 & -- & -- & -- & $\ldots-$ \\
\hline Kentucky , & 1 & -- & 1 & -- & $\ldots$ \\
\hline Mississippi & -- & -- & 1 & 1 & - \\
\hline New York & -- & -- & 1 & -- & $\ldots-$ \\
\hline Ohio - - & 1 & -- & -- & -- & $\ldots$ \\
\hline Pennsylvania - & 1 & -- & -- & -- & -- \\
\hline South Carolina & -- & -- & 1 & -- & -.. \\
\hline Tennessee $-1-1$ & 1 & -- & 1 & 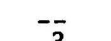 & $\cdots$ \\
\hline Virginia (including regional projects) & 2 & -- & 4 & 3 & $-\cdots$ \\
\hline West Virginia & 1 & -- & -- & -- & - \\
\hline \multicolumn{6}{|l|}{ Central and Western United States } \\
\hline Arizona & 1 & -- & -- & 1 & $-\cdots$ \\
\hline California (including regional projects) & -- & $-\overline{1}$ & 1 & 10 & -- \\
\hline Colorado (including regional projects) & 10 & 11 & 3 & 5 & -- \\
\hline Idaho - & -- & -- & 3 & 2 & $\cdots$ \\
\hline Montana -- & 6 & -- & $-\overline{1}$ & 1 & $\cdots$ \\
\hline Nevada & $-\overline{1}$ & -- & 1 & 1 & $\cdot-$ \\
\hline New Mexico & 1 & -- & 2 & 1 & $\cdots$ \\
\hline North Dakota & 2 & -- & -- & $-\overline{1}$ & -- \\
\hline Oregon & $-\overline{1}$ & $-\overline{1}$ & -- & 1 & -- \\
\hline Utah & 1 & 1 & -- & 1 & -- \\
\hline Washington & 1 & $-\overline{1}$ & -- & -- & -- \\
\hline Wyoming -- & 7 & 1 & -- & -- & -- \\
\hline
\end{tabular}


assessment is particularly important because water is of great value to the region not only for any future oil industry but also for existing ranches and farms in the immediate area as well as in downstream parts of the Colorado River basin.

- Publication of a summary of information on the demands placed on water by different methods of energy production (Davis and Wood, 1974).

- Installation of 99 new stream-gaging stations and 122 new stream-sampling stations (quality of water) in the coal and oil-shale regions in order to determine natural hydrologic conditions and subsequent changes in those conditions. In addition, 510 ground-water observation wells were installed to measure water levels; 272 of these are also being sampled to obtain baseline data on the quality of ground water.

\section{Ground-water recharge}

Ground-water-recharge studies include the use of both spreading basins and injection wells and are conducted mainly in two areas-the semiarid High Plains of Texas and New Mexico and the glacial deposits on Long Island, N.Y. These studies are developing methods to predict the amount of water that can be returned to aquifers by studying the fundamental properties that control movement of water into aquifers, the rock-water interactions that occur during storage, and the diffusion-dispersion phenomena accompanying water movement after emplacement. A report is in preparation on the relative merits of the various techniques as they relate to artificial-recharge pit design on Long Island. In another area, recharge studies have been completed in the fractured carbonate rock at St. Paul, Minn.

Accomplishments to date in these ground-water-recharge studies include:

- Demonstrations under experimental field conditions that recharge is technically feasible for selected locations on the southern High Plains.

- Development of unique instrumentation for extraction of water samples from the unsaturated zone to depths greater than 30.5 metres (100 feet) below land surface. This instrumentation makes it possible for the first time to monitor quality changes in percolating water in the unsaturated zone beneath spreading sites.

- Improvement of core-barrel sampling equipment that has resulted in increased core-sample recovery from unconsolidated or poorly consolidated aquifers.

- Development of geophysical logging techniques that relate logged parameters of gamma radiation, neutron response, resistivity, and natural gamma radiation to the movement of recharge water.
- Development of methodology for visual demonstration of pore space and clogging mechanisms through use of the scanning electron microscope and microanalysis.

\section{Flood-hazard mapping}

The flood-prone-area mapping program was begun in 1969 and consists of locating on 7.5-minute topographic quadrangles the approximate boundaries of areas having a 1 percent chance of being flooded in any given year. These maps alert the public, including local, State, and Federal agencies and others such as builders and insurance companies, to the flood hazards along flood plains and other low-lying areas. A large share of this work and other flood-mapping activities has been supported by funds from the Department of Housing and Urban Development's Federal Insurance Administration.

The flood-prone maps and pamphlets are stocked in field offices of the Water Resources Division for general distribution to the public without charge. At the request of the Soil Conservation Service, the Geological Survey arranged to publish and distribute in 1975 some 200 maps of flood-prone areas prepared in 1974 by the Service under the Department of Housing and Urban Development's accelerated flood-prone-area mapping program. From 1969 through fiscal year 1975, the Geological Survey has produced maps of nearly 12,000 flood-prone areas (figure 45).

The program has progressed in two phases. The first phase, now essentially completed, was directed toward defining flood limits in populated areas where significant flood problems were known and flood information was urgently needed. The second phase, begun during fiscal year 1973, expanded the areal coverage to include areas where future development was anticipated, including areas within the public domain where management or planning decisions were needed. The flood boundaries in about 6,000 quadrangles will be mapped in order to complete the second phase and thereby provide flood boundaries for 50 percent of the 30,000 different 7.5 -minute topographic quadrangles now available for the conterminous United States.

In addition to conducting reconnaissance flood mapping, normally at a scale of $1: 24,000$ (1 centimetre equals 240 metres), the Geological Survey delineates flood boundaries of greater accuracy on city or community maps of equal or larger scale such as $1: 4,800$ ( 1 centimetre equals 48 metres) as part of detailed flood studies sponsored by the Department of Housing and Urban Development. Since.1970, such studies have been undertaken in 299 communities. 


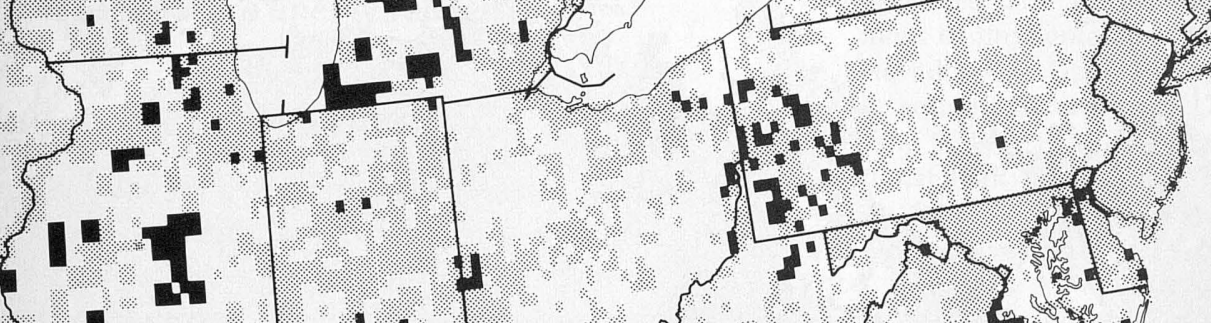

$+1+w^{2}$

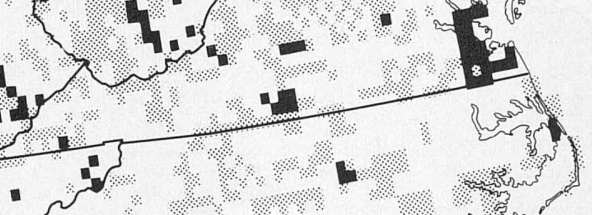

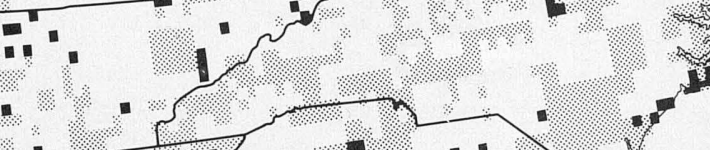

\{.

-

$-1$.

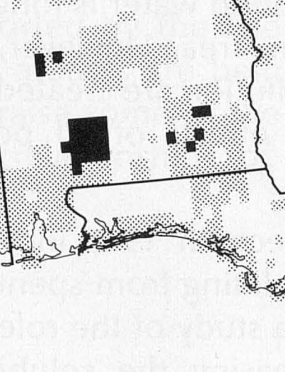




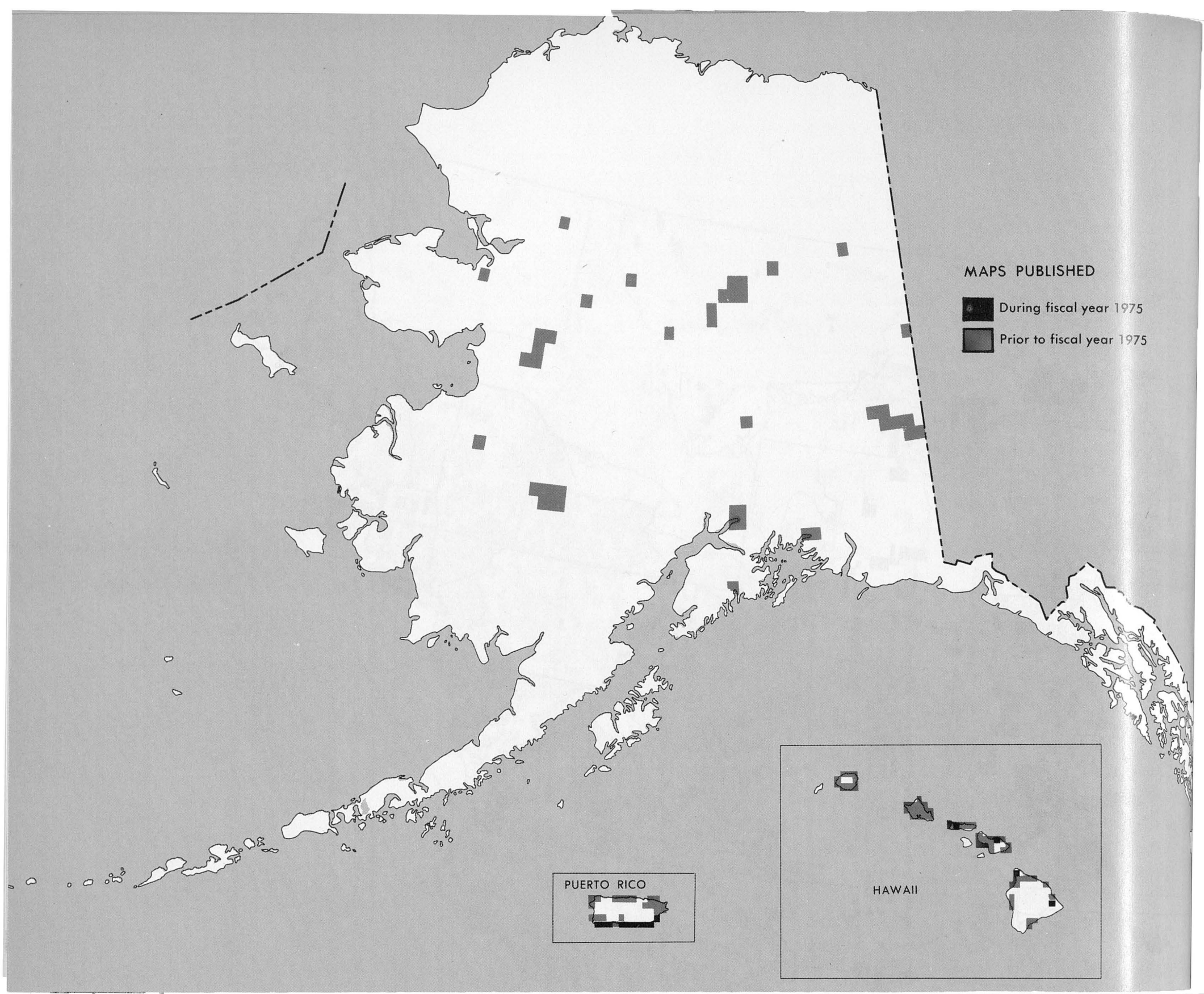

FIGURE 45.-Location of maps of flood-prone areas (quadrangles) published by the Survey prior to fiscal year 1975 and during fiscal year 1975.-Continued

\section{Subsurface waste storage}

The Survey's subsurface waste-storage program consists of regional delineation and description of aquifer systems that contain geologic formations suitable for waste storage, assessment of existing activities that may cause or have caused degradation of groundwater quality, determination of the field values of hydrodynamic dispersion of waste in ground water, and other fundamental studies in geology, hydrology, chemistry, and physics. The purpose of the program is to define hydrologic principles and techniques relevant to the use and management of subsurface waste storage and to prevent endangering usable water resources. Subsurface waste storage is becoming more common because of increasing legal restraints on sur- waste on ground water is long lasting, although usually limited in area.' However, each year, many new points of pollution are created and few are eliminated, so that the effects of all points, old and new, are cumulative.

New projects in 1975 included a study of organic wastes percolating from spent oil-shale and coal-mine wastes and a study of the role of microbes in decreasing or increasing the solubility of minerals in oilshale and coal-mine wastes. Continuing projects include monitoring seismic events near injection wells at Tuscaloosa and Birmingham, Ala.; investigation of the biological effects of landfill leachate on a stream near Albany, N.Y.; and development and use of about 15 municipal and industrial waste injection wells in Florida. Mapping of potential waste-injection aquifers 
continued in the Wilcox Formation in Texas, Triassic grabens in the Atlantic Coastal Plain, and three saline aquifers in the Atlantic Coastal Plain in the southeast.

Only part of the subsurface waste-storage program is directly concerned with energy-related waste disposal such as mine tailings. However, data on industrial waste-injection problems and potential disposal horizons (porous rock formations) or on the percolation from landfills, industrial lagoons, and spray irrigation all find applications to energy developments. Many of the studies that yield data and insights into waste movement involve areas where waste disposal was active for many years before pollution was observed or before the public became concerned. Studies of these sites are likely to show the long-term effects of waste movement, dispersion, dilution, retention, and dimunition and furnish information useful to all kinds of waste-disposal developments, including those that are energy related.

\section{Estuarine and coastal studies}

The objectives of estuarine and coastal studies are to determine the substances entering estuaries and coastal waters, their movement in the waters, their effect on the environment, and their subsequent fate and to determine factors and impacts affecting present and future usability of freshwater supplies in coastal areas. The studies provide knowledge of the processes involved in the movement of water and water-borne materials within the estuaries and coastal areas and the responses of the environment to the introduction of extraneous materials.

During 1975, estuarine and coastal studies continued on the geochemistry and circulation patterns in San Francisco Bay and the effects of quality of water on estuary biota in Chesapeake Bay. Coupled with hydrologic studies and data from Port Royal Sound, Delaware Bay, and Tampa Bay, Fla., and other bays where studies are supported by the Federal and the Federal-State programs, models are being developed that will be able to appraise some of the present and future effects and interrelationships of natural and manmade impacts on estuaries. The first models will be two-dimensional models of water circulation and solute transport in Port Royal Sound and Tampa Bay. Research into the development of three-dimensional models is underway. The 25 estuarine and coastal studies in progress or underway in 1975 are in Florida, Massachusetts, Oregon, Puerto Rico, South Carolina, Texas, Virginia, and Washington.

\section{REFERENCES}

Bloyd, R. M., Jr., 1974, Summary appraisals of the Nation's ground-water resources-Ohio Region: U.S. Geol. Survey Prof. Paper 813-A, 41 p.

Davis, G. H., and Wood, L. A., 1974, Water demands for expanding energy development: U.S. Geol. Survey Circ. 703, $14 \mathrm{p}$.

Ficke, J. F., and Hawkinson, R. O., 1975, The National Stream Quality Accounting Network (NASQAN)-Some questions and answers: U.S. Geol. Survey Circ. 719, 23 p.

Glancy, P. A., and Harmsen, Lynn, 1975, A hydrologic assessment of the September 14, 1974, flood in Eldorado Canyon, Nevada: U.S. Geol. Survey Prof. Paper 930, 28 p. (Prepared in cooperation with the U.S. National Park Service.)

Lohman, S.W., 1974, The geologic story of Canyonlands National Park: U.S. Geol. Survey Bull. 1327, 126 p. 1975, The geologic story of Arches NNational Park: U.S. Geol. Survey Bull. 1393, 113 p.

Price, Don, and Arnow, Ted, 1974, Summary appraisals of the Nation's ground-water resources-Upper Colorado Region: U.S. Geol. Survey Prof. Paper 813-C, 40 p.

U.S. Bureau of the Budget, 1964, Coordination of Federal activities in the acquisition of certain water data: U.S. Bur. Budget Circ. A-67, 4 p.

U.S. Geological Survey, 1972, Recommended methods for waterdata acquisition-Preliminary report of the Federal Interagency Work Group on Designation of Standards for Water Data Acquisition: U.S. Geol. Survey, Office of Water Data Coordination, 411 p.

Weeks, J. B., Leavesley, G. H., Welder, F. A., and Saulnier, G. J., Jr., 1974, Simulated effects of oil-shale development on the hydrology of Piceance Basin, Colorado: U.S. Geol. Survey Prof. Paper 908, 84 p. (Prepared in cooperation with the Colorado Department of Natural Resources.)

West, S. W., and Broadhurst, W. L., 1975, Summary appraisals of the Nation's ground-water resources-Rio Grande Region: U.S. Geol. Survey Prof. Paper 813-D, 39 p.

White, G. F. (chm.), and others, 1966, A unified national program for managing flood losses-A report by the Task Force on Federal Flood Control Policy: U.S. 89th Cong., 2d sess., House Document No. 465, Aug. 1966, 47 p. 

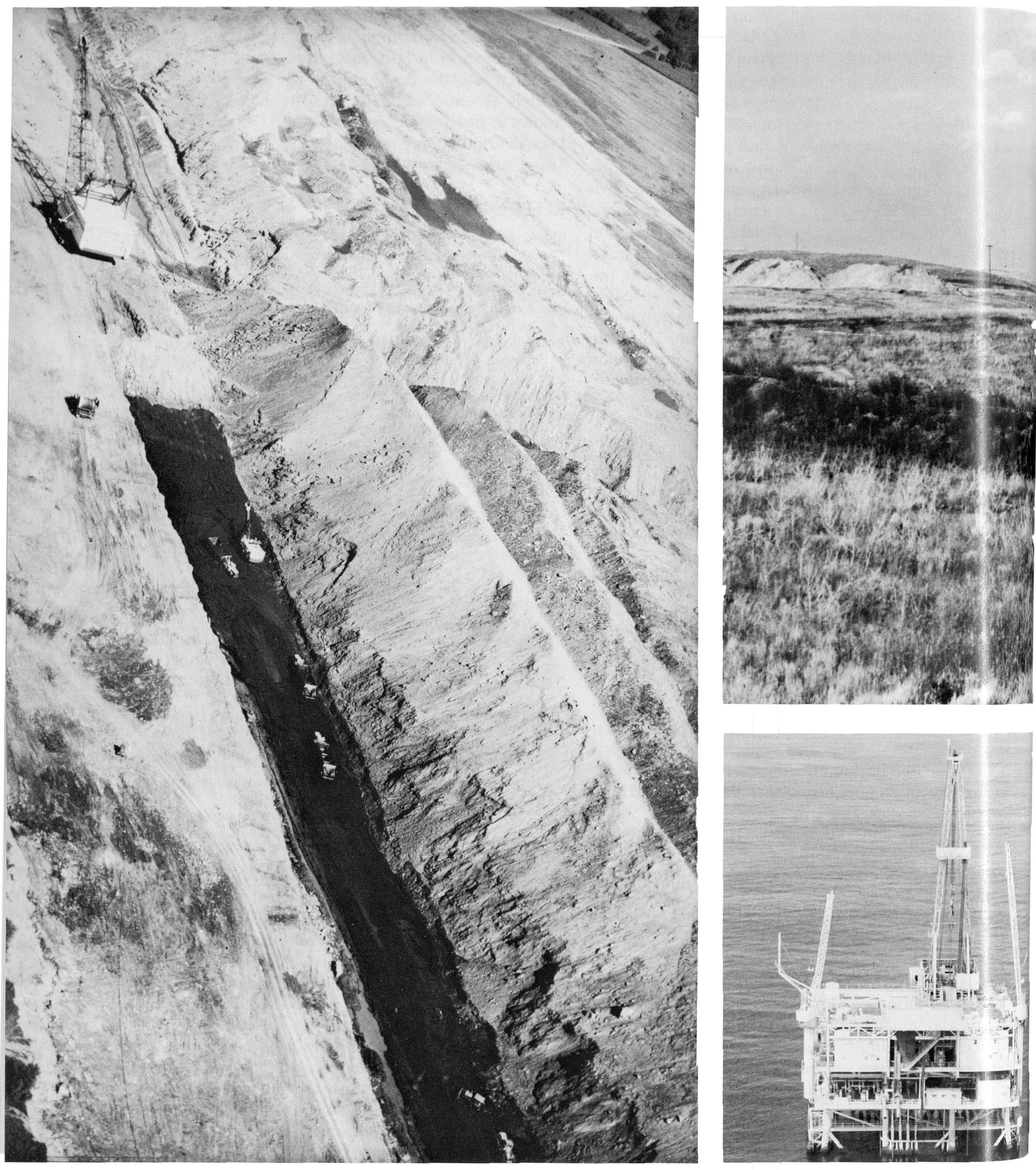


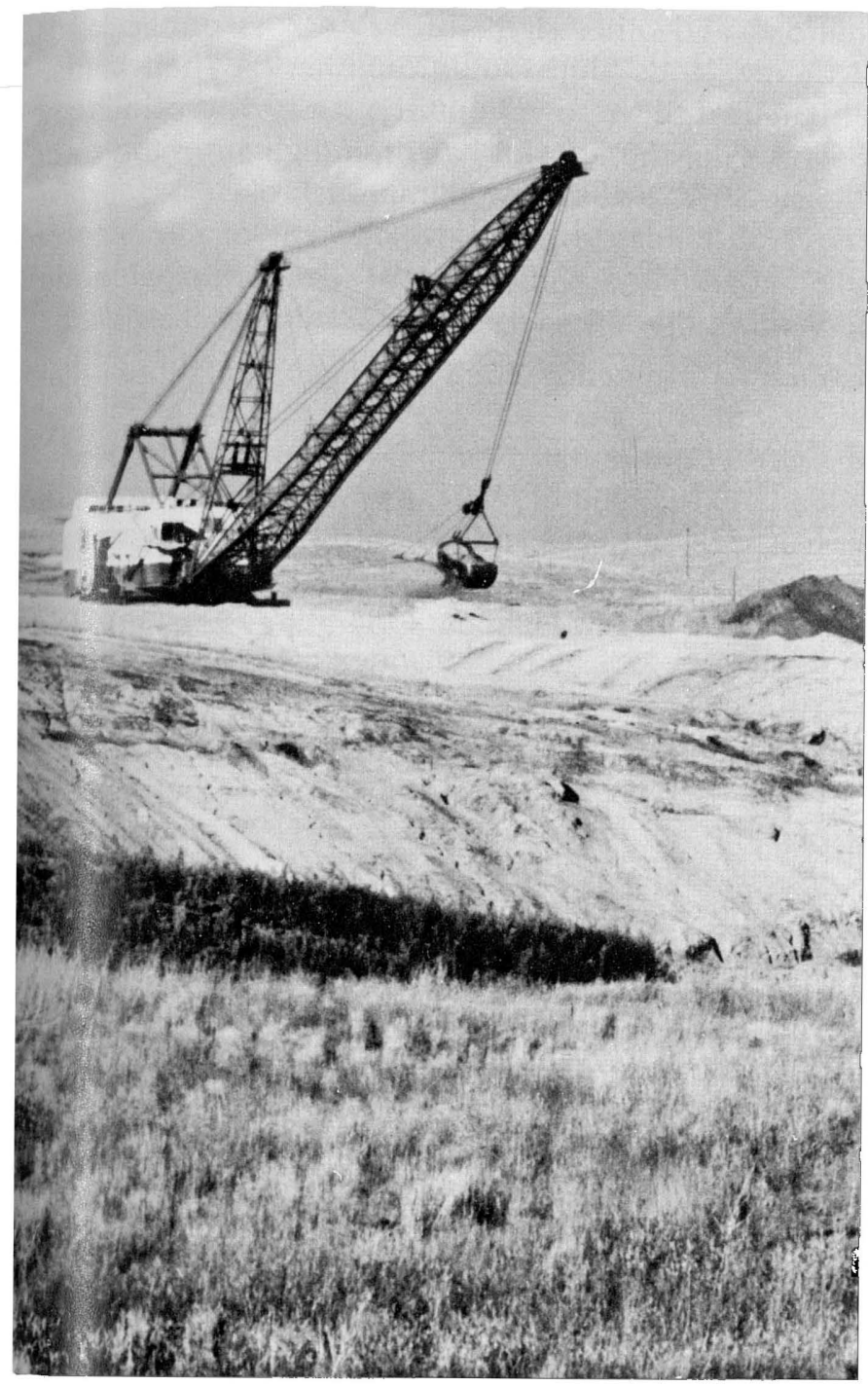

Oil and gas platform in the Gulf of Mexico (lower right). Draglines removed overburden from coal in strip mine operation (left and top right).

\section{Conservation of Lands and Minerals}

\section{OVERVIEW}

The Conservation of Lands and Minerals activity encompasses regulatory responsibilities delegated to the Geological Survey by the Secretary of the Interior under laws governing the leasing, mining, and use of mineral and water resources on Federal and Indian lands. The Conservation Division, the organizational unit within the Survey which executes these responsibilities, has three major missions:

- Classification of public lands as to their mineral character and their value for waterpower and water storage purposes.

- Evaluation of mineral tracts that are subject to competitive leasing.

- Supervision and regulation of operations associated with the exploration, development, and production of minerals on Federal, Indian, Naval Petroleum Reserve, and Outer Continental Shelf lands under lease, license, and prospecting permits, including the collection of royalties and certain rentals which result from those operations.

From data acquired in pursuit of these missions, the Geological Survey provides technical advice and information on the leasing or disposal of mineral rights to land management agencies such as the Bureau of Land Management, the Bureau of Indian Affairs, the Bureau of Reclamation, the Forest Service, the General Services Administration, and the Department of Defense.

The importance of Federal and Indian lands to the Nation's domestic supply of energy and mineral resources is illustrated in figure 46 . In fiscal year 1975, 7 percent of the coal, 17 percent of the uranium, 18 percent of the oil, and 21 percent of the natural gas produced in the United States came from Federal and Indian lands.

The impact of the operations supervised by the Geological Survey on the Nation's economy is substantial. In fiscal year 1975, the product value of all energy and mineral commodities produced from leased Federal and Indian lands amounted to about $\$ 6.2$ billion. Bonuses, royalties, and rentals during the same period totalled more than $\$ 3.0$ billion. 


\section{Authority}

The authority to classify public lands and regulate mineral development on Federal and Indian lands, to protect the environment, and to collect a fair return from extracted resources lies in a complex body of mineral and land laws some of which date back to the 1870 s.

Congress stipulated in the Act of March 3, 1879, which created the U.S. Geological Survey, that the Director of the Survey should classify the public lands to identify features pertaining to land values for many purposes. In 1906, the President directed the Secretary of the Interior to immediately withdraw from entry all valuable coal lands on the public domain. Coal lands in Alabama, Arkansas, and Wyoming were withdrawn and later classified under this directive. Subsequently, Congress passed the Withdrawal Act of 1910 which authorized the President to withdraw public lands from settlement, location, sale, or entry. This Act resulted in the immediate reservation of about 100 million acres of public lands for their potential value for coal. Once withdrawn, the Geological Survey began to examine these lands and classify them; the lands found to be noncoal were restored to entry and those found to contain workable coal beds were appraised and priced at varying amounts per acre.

Since the lands withdrawn included some lands that were valuable for farming, Congress passed the "Separation Acts" of 1909 and 1910 which provided for the separation of the surface estate from the subsurface estate, thus permitting land claimants to obtain patents to the land surface while reserving to the United States the mineral deposits and the right to prospect and mine them.

The Mineral Leasing Act of 1920 ended the practice of disposing of coal lands at appraised values and provided for the leasing of coal and certain other mineral commodities. The leasable minerals on public lands now include oil, gas, coal, potash, sodium, phosphate, oil shale, asphaltic minerals, sulfur (only in New Mexico and Louisiana), and geothermal resources. Under the provisions of the 1920 Act, as amended and supplemented, a permit to explore public land for minerals other than oil, gas, oil shale, and geothermal resources may be obtained; however, if the land is determined by the Geological Survey to contain a known leasable mineral deposit, it is subject to competitive bidding for a lease. All minerals on acquired and Indian lands are leasable. A lessee is required to pay the Federal Government a stipulated royalty on production.

Other laws authorize the leasing and management railroad and other rights-of-way across public lands, acquired lands, and Outer Continental Shelf lands.

Pursuant to these various statuatory authorities, the Secretary of the Interior has promulgated in the Code of Federal Regulations, numerous rules and procedures pertaining to the development of minerals on the Federal and Indian lands. The principal codes governing operations on Federal mineral leases are:

- Outer Continental Shelf Leasing Regulations-Part 3300 of Title 43.

- Outer Continental Shelf Operating RegulationsParts 225a, 250, and 260 (Proposed) of Title 30.

- Onshore Federal Lands Leasing Regulations--.-Parts 3100,3200 , and 3500 of Title 43.

- Onshore Federal Lands Operating RegulationsParts 211, 221, 223, 225, 226, 231, 270, and 271 of Title 30.

- Indian Lands Leasing and Operating RegulationsParts 171, 172, 173, 174, 176, and 177 of Tile 25 and the pertinent onshore Federal operating regulations contained in Title 30 .

Leasing regulations are issued by the Bureau of Land Management and the Bureau of Indian Affairs, but some provisions of leasing regulations and all provisions of operating regulations are implemented and enforced by the Geological Survey.

\section{Programs}

Because of the distinctly different operating environments, logistics, and technologies used to explore and develop the resources offshore as compared with onshore, the Conservation of Lanc's and Minerals activity is divided into an Outer Continental Shelf Lands subactivity and an onshore Federal and Indian Lands subactivity. Both, however, involve prelease responsibilities for evaluation of resource:; the postlease responsibilities for supervision of exploration, development, and production operations: and the computation and collection of royalty and cartain rental payments. The onshore program also includes the classification of Federal lands for minera: and water resource development potential.

\section{Resource classification and evaluation}

- Resource classification-The purpose of res’urce classification actions by the Geological Survey is to retain for the Federal Government the title to leasable minerals which otherwise might be inalvertently lost with disposal of the surface rights Survey geologists classify public domain lands an 1 certain acquired lands at the request of other Federal agencies by considering all available geologic evidence in order to determine which legal subdivisions of land meet the standards for m neral lands. 
- Resource evaluation-Once classified as to their mineral character, resources must be evaluated prior to being offered for lease. On the Outer Continental Shelf, resource evaluation activities are concentrated on identifying target areas for future lease sales, advising the Bureau of Land Management on the selection of tracts to offer for sale, estimating the value of oil and gas on each tract offered, and determining the minimum acceptable bid for each tract.

Onshore leases may be awarded competitively or noncompetitively, depending upon whether or not the area lies within a "known leasing area." The Geological Survey performs a presale evaluation of each parcel of Federal land offered competitively for leasing. Principal responsibilities in this regard are:

1. To make recommendations to the leasing agency about the size of each parcel offered and any special stipulations required.

2. To evaluate each parcel on the basis of current geologic, geophysical, economic, and engineering data, and, prior to the sale, to furnish the leasing agency with the minimum acceptable bid for each parcel and the technical basis by which the minimum bid was derived.

3. To make subsequent recommendations as to whether the high bid submitted for each parcel should be accepted or rejected.

Most Indian lands are leased by competitive bidding methods. The Bureau of Indian Affairs has relied heavily on the Geological Survey to parcel the individual tracts for each sale and to make recommendations as to lease stipulations and as to the acceptance or rejection of high bids offered.

The procedures used for both onshore and offshore mineral evaluation assure the public a fair market value in return for the leasing of their mineral resources.

\section{Supervision of operations}

After leases are issued by the Bureau of Land Management or the Indians, the Geological Survey supervises the exploratory, development, and production operations of the lessee or the lease operator. Supervision is designed to assure that operations are conducted in conformance with Interior Department operating regulations and orders and that royalties paid to the Government or to the Indians are correct and epresent a fair market value for their share of the esources produced. Supervision of lessee operations involves:

FIGURE 46.-Production from Federal and Indian lands as percentage of total U.S. production in 1975.
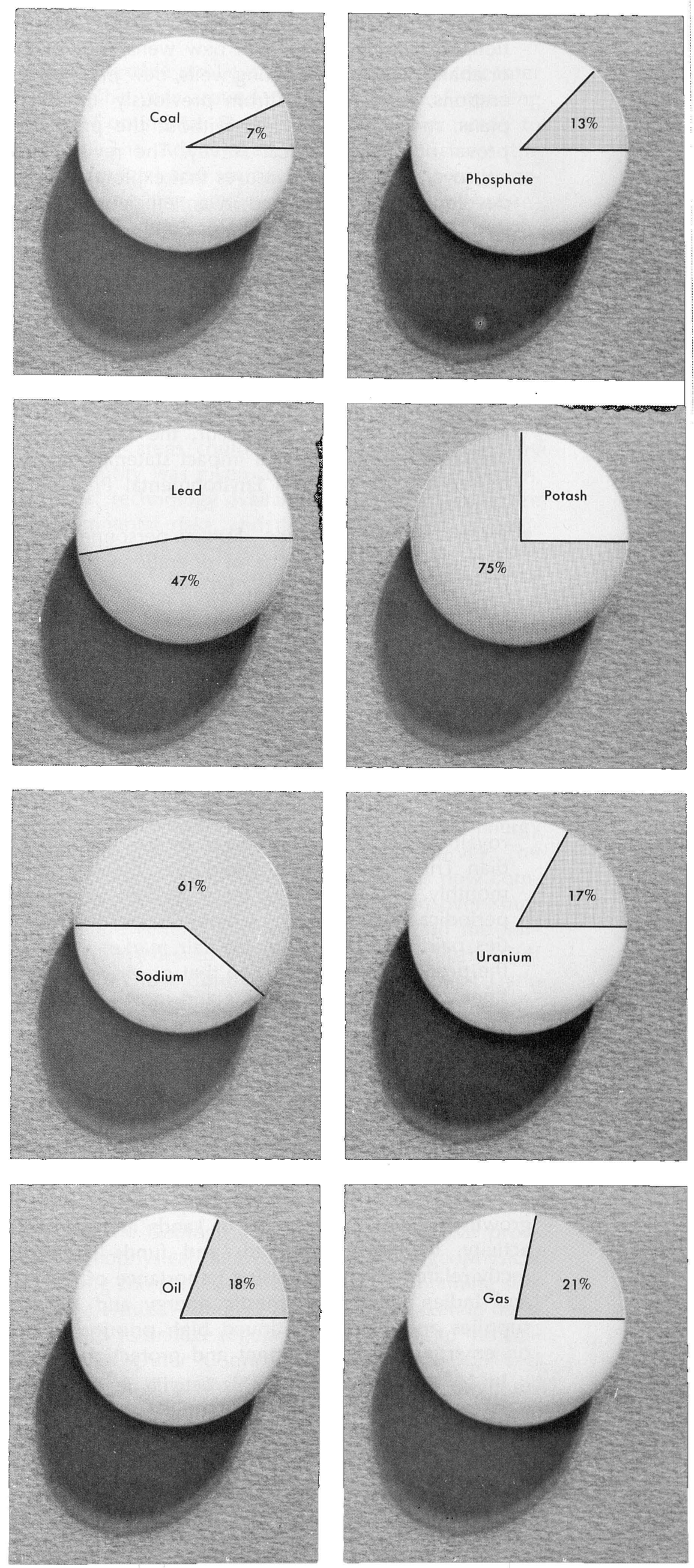
- Review and approval of plans-No industry operation, such as the drilling of new wells, workovers or abandonments of existing wells, new mining operations, or departures from previously approved plans, may be undertaken without the prior approval of the Geological Survey. The review and approval of such plans insures that exploration and development will proceed in an efficient and orderly fashion and that the maximum amount of resources will be recovered. For proposals such as exploratory drilling, prospecting, development, and production of oil and gas fields, mines, or geothermal resources, the Survey is required to prepare an environmental analysis to determine if the proposed operation will have significant impact on the human environment. If it is determined that a significant impact will occur, the Survey must prepare an environmental impact statement as required by the National Environmental Policy Act of 1969.

- Inspection of operations-Survey personnel make periodic field inspections of operations to insure that permittees, licensees, lessees, and operators comply with the approved operating plans, Department of the Interior regulations, lease terms, and environmental stipulations. Periodic reports filed by industry also keep the Survey informed about the progress of operations.

- Computation and collection of rents and royaltiesOn the basis of production sales reports, purchaser statements, field measurements of production, and other pertinent information, the Survey computes royalties due the Government or the various Indian Tribes and Allottees and bills the operators monthly. Each producing lease account is audited periodically to determine whether or not the royalties paid were based on the fair market value of the products sold and to see that previous calculations are correct. Bonus bids and most rental payments on nonproducing leases are collected by the Bureau of Land Management; however, once a lease becomes producible the Survey assumes the responsibility for the collection of advance rentals.

\section{Budget and personnel}

Fiscal Year 1975 marked a period of substantial growth for the Conservation of Lands and Minerals activity. Increased workloads and funds were directly related to the increasing importance of Federal and Indian lands to domestic energy and mineral supplies and to the continued high priority placed on environmental assessment and protection.

In 1975, the budget for this activity increased 98 percent to $\$ 36$ million (table 16), 64 percent of which was expended on the Outer Continental Shelf (fig. 47). Staffing of the activity increased from 612 permanent full-time employees at the end of 1974 to 926 in 1975 (table 44). Most of the increased positions were filled by geophysicists, geologists, and petroleum engineers.

TABLE 16.-Conservation of Land and Minerals activity obligations for fiscal year 1975, by program

\begin{tabular}{|c|c|c|c|}
\hline \multirow{2}{*}{ Program } & \multirow{2}{*}{$\begin{array}{l}\text { Fiscal } \\
\text { Year } \\
1975 \\
\text { (Dollars } \\
\text { in } \\
\text { millions) }\end{array}$} & \multicolumn{2}{|c|}{$\begin{array}{c}\text { Percent change relative to } \\
\text { tiscal year } 1974\end{array}$} \\
\hline & & $\begin{array}{l}\text { Current } \\
\text { dollars }\end{array}$ & $\begin{array}{c}\text { Constant } \\
\text { dollars }\end{array}$ \\
\hline Total $^{1}$ & $\$ 36.03$ & +98 & +78 \\
\hline Outer Continental Shelf Lands_. & 23.20 & +112 & +91 \\
\hline $\begin{array}{l}\text { Regulation OCS oil and gas_ } \\
\text { OCS oil and gas tract } \\
\text { selection and resource } \\
\text { evaluation }\end{array}$ & 10.05 & +58 & +156 \\
\hline Federal and Indian Lands & 12.84 & +78 & +60 \\
\hline Regulation of operations & 8.43 & +51 & +36 \\
\hline $\begin{array}{l}\text { Oil and Gas } \\
\text { Energy Minerals (coal and }\end{array}$ & 5.26 & +33 & +20 \\
\hline $\begin{array}{l}\text { Uranium) } \\
\text { Oil Shale } \\
\text { Geothermal } \\
\text { Nonenergy Minerals }\end{array}$ & $\begin{array}{r}.51 \\
.32 \\
1.01 \\
1.33 \\
\end{array}$ & $\begin{array}{l}+29 \\
\text { New } \\
+583 \\
+24\end{array}$ & $\begin{array}{l}\text { - } 16 \\
\text { gram } \\
+423 \\
-12\end{array}$ \\
\hline 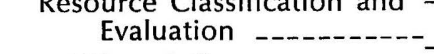 & 4.41 & +165 & +139 \\
\hline $\begin{array}{l}\text { Oil and Gas } \\
\text { Coal } \\
\text { Oil Shale } \\
\text { Geothermal } \\
\text { Nonenergy Minerals } \\
\text { Water-Resource Develop- }\end{array}$ & $\begin{array}{r}.22 \\
2.38 \\
.30 \\
.96 \\
.08\end{array}$ & $\begin{array}{r}+10 \\
+186 \\
\text { New } \\
+596 \\
+14\end{array}$ & $\begin{array}{r}0 \\
+\quad 58 \\
\operatorname{gran} \\
+\quad 28 \\
0\end{array}$ \\
\hline ment & .47 & +11 & 0 \\
\hline
\end{tabular}

1 Total direct program. Reimbursable program amounted to $\$ 50,000$ bringing total program to $\$ 36,082,000$ (table 26).

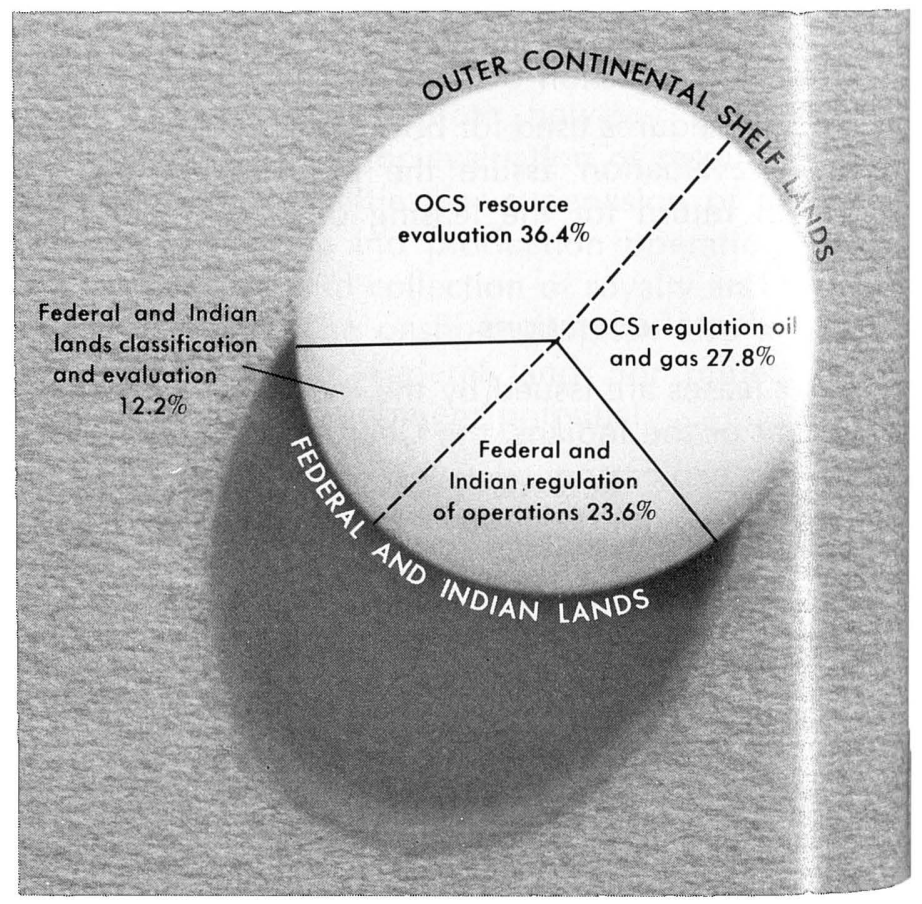

FIGURE 47.-Distribution of Conservation of Land and Minerals funds for fiscal year 1975 by subactivities and programs. 
The Outer Continental Shelf Lands subactivity funding increased $\$ 12.2$ million (112 percent) over fiscal year 1974. The increase was related to the Administration's decision to select and evaluate an increased number of Outer Continental Shelf tracts to support a policy to increase energy production from Federal land and the need to inspect additional drilling and production operations on recently leased tracts and increased activity on older tracts. The increased funds covered additional staff, several large contracts for helicopter services to transport inspectors offshore to monitor operations ( $\$ 1.8$ million), and the acquisition of geophysical data with which to select and evaluate tracts for lease sales (\$7.5 million).

Increased workload in resource classification and evaluation, and supervision of development and production operations also resulted in a budget increase of $\$ 5.6$ million (78 percent) for the Federal and Indian Lands subactivity. In addition, the Survey started two new programs. Two million dollars and 50 positions were allocated to classify and evaluate geothermal resources and to supervise and monitor operations on Federal lands. An Oil-Shale program was also established during fiscal year 1975 with $\$ 610,000$ and 16 new positions to review and approve development plans, and to monitor the collection of environmental baseline data on four prototype oil-shale leases in Colorado and Utah.

\section{Highlights}

Accomplishments of the Conservation of Lands and Minerals activity included:

- Completion of tract evaluations for five Outer Continental Shelf lease sales covering 5.0 million acres in calendar year 1974 and for four sales covering 7.2 million acres in calendar year 1975. During these two calendar years, 1.8 and 1.7 million acres were leased for bonuses of $\$ 5.0$ billion and $\$ 1.1$ billion, respectively.

- Revision and updating Outer Continental Shelf orders for the Gulf of Mexico and Pacific areas.

- Supervision of 1,590 offshore oil and gas leases covering 7.2 million acres in calendar year 1974 and 1,784 leases covering 8.2 million acres in calendar year 1975.

- Supervision of 123,652 onshore oil and gas leases covering 89.8 million acres in calendar year 1974 and 126,718 leases covering 93.6 million acres in calendar year 1975 .

- Supervision of 2,479 mineral leases covering 8.0 million acres in fiscal year 1975 .

- Collection of $\$ 850$ million in royalties and rentals from all sources during fiscal year 1975.

Also during the year a number of issues received much attention.

\section{Outer Continental Shelf leasing}

Considerable public discussion continued to center during the year around the advisability of opening Outer Continental Shelf lands in frontier areas to leasing. The Administration decided to assess the environmental and socioeconomic impacts of an accelerated leasing program in these areas and subsequently a report, "OCS Oil and Gas-An Environmental Assessment," by the Council on Environmental Quality (1974) was completed in April 1974, and the final environmental impact statement, on the proposed increase in oil-and-gas leasing on the Outer Continental Shelf was completed in July 1975 (Bureau of Land Management, 1975).

Authors of these reports concluded that leasing in frontier areas could proceed provided that very high priority was given to environmental protection, the best technology available was used to minimize environmental risks, and that States and local communities had an opportunity to participate in the management and regulation of the Outer Continental Shelf. The most recently proposed planning schedule of lease sales released in June 1975 calls for about six lease sales per year on the average through fiscal year 1978 (table 17).

\section{Oil and gas reserve studies}

Studies of the oil-and-gas reserves in five fields (four in the Gulf of Mexico and one in Santa Barbara Channel) were made for the Federal Energy Administration for their National Energy Survey. The Federal Energy Administration reports are now complete. Also in response to public concern over shutin gas, the Federal Power Commission and the Survey jointly reviewed the shut-in gas fields in the Gulf of Mexico Outer Continental Shelf. The Federal Trade Commission challenged the estimates in the Federal Power Commission report, and the report is now being reviewed by the National Research Council of the National Academy of Sciences at the request of the Director of the Geological Survey.

\section{Geologic and geophysical data}

In November 1974, the Secretary of the Interior instructed the Geological Survey to require that processed geophysical data be submitted by geophysical surveying companies as a condition for obtaining surveying permits. A number of steps were taken in fiscal year 1975 to finalize regulations pertaining to the collection of Outer Continental Shelf geological and geophysical data. Proposed regulations were published in the Federal Register as proposed rulemaking on April 22, 1975. 


\section{Outer Continental Shelf stratigraphic drilling}

During fiscal year 1975, the Department of the Interior authorized deep off-structure stratigraphic testing for the first time. A group of companies drilled two deep test wells off South Texas to provide stratigraphic information in the OCS Sale no. 37 area. The tests showed that the area lacked sandstone or limestone reservoir rocks, thus indicating that there was only limited potential for the accumulation of petroleum deposits. The adverse information obtained in drilling these tests is believed to be responsible for so few bids being received for tracts offered near the two well sites and one reason why there were fewer bids for far lower amounts for the entire sale than had been estimated.

\section{Royalty oil}

The various mineral leasing acts authorize the Secretary of the Interior to sell royalty oil accruing to the United States under oil and gas leases issued under those acts. In order to assist small business enterprise, the Congress has authorized and directed the Secretary, when he determines that sufficient supplies of crude oil are not available in the open market to refineries not having their own source of supply for crude oil, to grant a preference to such refineries in the sale of royalty oil for processing or use in such refineries but not for resale in kind. The Act of July 13,1946 , provides that the sale of royalty oil to such refineries may be at a private sale at not less than the market price and that in selling such oil the Secretary may at his discretion prorate such oil among such refineries in the area in which the oil is produced.

During fiscal year 1975, 27.1 million barrels of royalty oil from operations conducted on the OCS (Gulf of Mexico and Pacific) were taken by oil refineries under 41 separate contracts and 11.0 million barrels of royalty oil from Federal onshore leases were taken by oil refineries under 23 separate contracts. The royalty oil was allocated pursuant to the regulations contained in Title 30, Parts 225 and 225a of the Code of Federal Regulations as they apply to onshore and OCS royalty oil, respectively. It is anticipated that the total volume of royalty oil distributed during fiscal year 1976 will increase substantially.

\section{Geothermal resources leasing}

Leasing of geothermal resources began during 1974. By the end of the calendar year, 552 leases had been awarded. Eight geothermal wells had been drilled on five leases and five additional wells were being drilled on three leases. Although none of these leases is yet in a producing status, the first commercially completed in May 1975, near the Castle Rock Springs area in California, and a potentially producible well was completed in June 1975, at Roosevelt Hot Springs in Utah.

\section{OCS Tract Evaluation Procedures ,}

During fiscal year 1975, the General Accounting Office issued a report on "Outer Continental Shelf Oil and Gas Development-Improvements Possible in Determining Where to Lease and at What Dollar

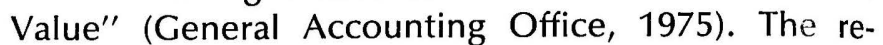
port found that the Survey had difficulty in hiring qualified personnel, particularly experienced geophysicists, to fill the positions authorized for tract evaluation. The shortage of experienced personnel limited the preparation of geophysical structure maps for many tracts to only one seismic horizon, although mapping on two or more horizons would have defined the structures more accurately. The General Accounting Office concluded that the size and timing of lease sales should be based upon the ability of the Survey to evaluate tracts. Since the release of the General Accounting Office report, the tract-evaluation staff has been brought up to authorized strength, and new employees have been trained in OCS - evaluation procedures. The quality of the work ha: improved, and the Survey now has the capacity to map two or more seismic horizons for each tract proposed for leasing in fiscal year 1976.

\section{Onshore Lease Management}

In December 1973, the Geological Survey began an intensive review of the onshore lease maragement program in order to define deficiencies in: the program and to recommend corrective actions. The National Aeronautics and Space Administratior, assisted by the Martin Marietta Corporation, was requested to study the Conservation Division's responsibilities, authority, and procedures for supervising leases on Federal and Indian lands, to define echniques for measuring program performance an $d$ industry compliance, to recommend ways of improving leasehold inspections, and to suggest ge:eral management improvements. The Geological Survey also requested that the Department of the Interior's Office of Audit and Investigation undertake a study of the onshore-royalty accounting system. This second study had two parts: oil-and-gas-royalty acceunting and solid-minerals-royalty accounting.

The National Aeronautics and Space Admin stration's component of the study was completed in December 1974 (National Aeronautics and Space Administration and Martin Marrietta Corporation, 1974). Their report contained 79 numbered recommendations, many of which had subparts. The study recommendations addressed overall program management 
and contained various suggestions for clarifying and interpreting Departmental regulations governing onshore operations. These regulations provide guidelines but do not explicitly define the criteria which lessees or operators must meet in conducting operations on leases. In the past, it has been left to local Survey officials to interpret and enforce these regulations, and, as a result, there has been a lack of uniformity in the application of standards and procedures.

Subsequent to the completion of the National Aeronautics and Space Administration's study, the Survey established a task force to review the onshorelease management report. After extensive review by the managers responsible for the various operations, in May 1975, the Survey adopted nearly all of the recommendations as presented or as slightly modified (U.S. Geological Survey, 1975a). Implementation of the recommendations will proceed as adequate resources are made available.

The Office of Audit and Investigations' report on accounting procedures (Office of Audit and Investigations, 1975a) concluded that improvements were needed in the following areas:

- Lessee reporting procedures-The Survey should require lessees to submit all reports and sales and production data needed to verify royalty computations in a single package, and thereby reduce the time required to sort and rollate reports which are currently submitted individually. Furthermore, standardized royalty forms should be developed for Federal and Indian leases, and greater use should be made of magnetic-tape data by companies which have such capabilities and where the volume of transactions warrants such an approach.

- Royalty accounting procedures-The Survey should establish subaccounts within each lease account to reflect the status of royalty liability to the Federal Government of each entity that holds an interest in the lease and that is responsible for making payments. While increasing the number of accounts from about 14,500 to 23,900 , the change would encourage more rapid payment of delinquent balances. Lessees should also be informed of adjustments and corrections made by the Survey to their royalty reports, so that errors will not recur, and so that the lessees will understand why they are being billed for additional royalties. In addition the Survey should seek timely payment of royalties, quickly follow up on delinquent accounts, and collect penalties for overdue royalty reports and royalty payments. Finally, greater emphasis should be placed on the postaudit review of lease accounts and the preaudit of royalty data should be reduced.
- Value and volume of oil and gas production-The Survey should develop improved guidelines to determine royalty value and to establish the validity of oil-and-gas prices used by lessees to compute royalty payment. Also the Survey should attempt to find ways of verifying production volumes. With respect to independent verification of the production volumes, the Office of Audit and Investigations recognized that it is a complex technical problem and that verification may be costly. They accepted a suggestion by the Survey that a production and analysis team evaluate the internal controls of one major and one large independent producer to determine if such controls are adequate to accumulate and report accurately volumes of oil and gas produced and sold from Federal and Indian lands. - Increase staff-The Office of Audit and Investigation concluded that, "the main reason the RAS [Royalty Accounting Section] has so many operational and procedural problems is because of a chronic understaffing condition. And being realistic, there is no way these problems can be addressed unless the staff is expanded significantly" (Office of Audit and Investigations, 1975a, p. 9).

In its comments on the Office of Audit and Investigations report (U.S. Geological Survey, 1975b), the Geological Survey generally agreed with the findings of the study and immediately took steps to implement them. Although little could be accomplished in the remaining weeks of fiscal year 1975, detailed plans were made to complete nearly all suggested actions in fiscal year 1976. A request for 45 new positions for onshore oil-and-gas-royalty accounting was approved by the Department on August 6, 1975. With these additional people in fiscal year 1976, the Survey will restructure the Chief Accountant's responsibilities to provide for overall systems management and policy development and to streamline accounting operations through such means as requiring uniform reporting, eliminating duplicative reporting, and making more extensive use of automation to handle accounting data and audit reporting. Coupled with those modifications will be an aggressive effort to insure prompt and accurate royalty reporting and payment.

The second part of the Office of Audit and Investigation study of the onshore royalty accounting system relating to solid minerals, was completed in August 1975. The report included: "In our opinion, excepting certain weaknesses in internal control, the EGS [Geological Survey] royalty accounting system is procedurally adequate to account for and collect royalties on leasable solid minerals produced from Federal lands" (Office of Audit and Investigation, 1975b, p. 4). 
The Office of Audit and Investigation noted that the accounting activities are much the same for solid minerals as for oil and gas. However, the accounting activities related to the management of solid minerals are less complex than those related to the management of oil and gas because of the smaller number of leases and the absence of most of the royalty reporting, payment, and accounting problems caused by multiple lease assignments, fragmented royalty reporting and payment practices, and unitization and communitization agreements.

The report made recommendations in four main areas:

- Internal accounting controls-One person in each of the seven Area Mining Offices of the Conservation Division is basically responsible for all accounting operations, that is, the receiving and depositing of royalty payments and the recording of royalties due and paid by lessees. The Survey should separate the duties of collection, accounting, and billing to insure that all royalty payments are properly collected, deposited, and recorded in the lease accounting records.

- Improvement of independent financial audits-Department of the Interior mining regulations provide for periodic independent audits of accounting records of solid-mineral leases to be performed and for copies to be sent to the Survey. The Survey should use these reports to greater advantage by requiring: the lessee and the auditor to include all information needed to verify that correct royalties have been paid as well as the auditors opinion as to the accuracy of the royalties reported and paid on each lease; a statement about the consistency of accounting procedures used to determine royalties with those used in preceding reporting periods; that the lease documents, amendments, and all applicable laws, rules, regulations, and Department of the Interior decisions have been considered in formulating the auditor's stated opinion; and a statement about the condition of the lessee's internal controls over the production and shipment of minerals from the lease and over the accumulation of production, shipment, and gross revenue data used to compute royalties.

- Late royalty payments-The Survey should enforce timely payment of royalties as required by leases. In those cases where the actual value of production cannot be determined within the required time period, arrangements should be made for the lessee to pay estimated royalty payments.

- Accounting responsibilities for Indian leases-The Bureau of Indian Affairs historically has been responsible for the accounting functions related to solid minerals on Indian leases. However, Departmental regulations identify the Geological Survey as the agency responsible for the maintenance of accounting control over revenue derived from Indian leases. Accordingly, the Office of Audit and Investigations' report recommended that the Survey should assume accounting control for these leases.

The Survey accepted all of the Office of Audit and Investigations recommendations and on July 11, 1975, instructed all Area Mining Supervisors to:

- Designate a person other than the Area Mining Accountant to prepare a listing of all rental and royalty checks received prior to the delivery of the checks to the Area Mining Accountant. The monthly listing of checks will be sent directly to the Chief Accountant for later verifications agains the royalty accounts. All mining royalty statements of accounts will be mailed directly to the lessee by the Chief Accountant's Office.

- Send each lessee a formal notice requiring an annual audit report and specifying information and auditor's opinions to be included in the report. All reports must be reviewed and followup action taken if the report does not meet the criteria shown in the notice.

- Review the timeliness of the receipt of all royalty reports and payments and advise all lessees who are not presently paying and reporting in accordance with the lease terms to do so.

- Provide the Chief Accountant's office with a list of producing Indian leases to permit the Survey to initiate action to place producing Indian leasing in the royalty accounting system.

All actions, with the exception of the assumption of accounting control of Indian leases, were completed by September 1975 .

\section{Shut-in wells}

One of the major concerns during fiscal year 1975 was the question of shut-in oil and gas wells. As of June 30, 1975, 172 leases were shut-in and not producing. A Congressional subcommittee contend that some oil companies are deliberately leaving producible wells and reservoirs, particularly gas wells and reservoirs shut-in waiting for better prices before producing them. Industry's response was that reserve figures include behind-the-pipe reserves in wells with multiple sands which could not be produced concurrently. Where multiple horizons occur, the productive sands are produced sequentially. In January 1975, the Survey asked 10 companies that appeared to have the most questionable cases of shut-in wells on leases to start production immediately or submit reasons and data explaining why shut-in status should be per- 
mitted. Subsequently, in March 1975, 3 of these 10 lessees were required to submit additional data supporting the shut-in status of their wells. As a result of these actions, two lessees chose to terminate one lease each. However, in general, the inquiries indicated that the wells and leases were shut-in because transportation facilities did not exist, production equipment was ordered but not yet delivered and installed, or the gas reserves had been depleted to the point where further production was not economic. While investigations continued into fiscal year 1976, the findings so far have not supported the contention that a substantial number of wells had been shut-in for price speculation.

\section{OUTER CONTINENTAL SHELF LANDS}

Outer Continental Shelf leasing regulations are chiefly administered by the Bureau of Land Management, but some sections of these regulations and the operating regulations are implemented and enforced by the Geological Survey.

In practice the Bureau of Land Management and the Geological Survey consult closely on the significant actions that take place before each lease sale (Adams and others, 1975). The Survey provides the Bureau of Land Management with:

- Petroleum-resource assessments and other technical information used to identify areas for leasing and to schedule lease sales.

- Environmental baseline data and geologic hazards information for use in preparing environmental impact statements for each lease sale.

- Resource evaluations for use in jointly selecting tracts for each lease sale and for establishing fair market value for each tract.

After a lease is awarded, the Survey supervises exploration, development, and production operations and collects royalties and rents due to the United States. The workload of these Survey programs is dependent upon the Department of the Interior's leasing schedule for Outer Continental Shelf lands (table 17) and upon lessees' successes in making commerical discoveries.

\section{Outer Continental Shelf resource evaluation}

In 1967, the Geological Survey established a mineral resource evaluation program to improve methods of selecting and evaluating Outer Continental Shelf tracts for leasing. The Survey has since expanded considerably its geological, geophysical, and engineering capability to map, select, and evaluate the potential resource of the Outer Continental Shelf.

For tract selection, geophysical maps are produced which show the structural configuration of the area proposed for leasing. Facies changes are interpreted from geologic data to identify the areas favorable for the occurrence of petroleum. A preliminary estimate of potential resources is derived from known geological and engineering factors. Tracts that have potential geologic hazards may require special stipulations for development or may be deleted from the sale.

For the tract evaluation process, geophysical multihorizon maps are produced and models of expected reservoirs are constructed using geological, geophysical, and engineering data. Wildcat risk, exploration and development costs both for dry structures and commercial fields, the most probable resource value, and annual production are estimated for each tract.

Because the values of many of the geological and engineering variables used in the computation cannot be measured directly before a tract is drilled, and many of the economic variables are also uncertain, a distribution of values is estimated for each variable. Then, using discounted cash-flow analysis, the value of the resources on the tract is repeatedly computed up to 500 times by randomly sampling each of the variable distributions (Monte Carlo simulation) to obtain a range of values for the present worth of the tract.

These resource values, together with recommendations on bid acceptance or rejection and supporting data, are provided to the Bureau of Land Management. The Secretary of the Interior makes the final decision to accept or reject bids received in the competitive lease sales. During calendar year 1974, tract evaluations were completed for five sales in the Gulf of Mexico covering a total of 5.0 million acres offered, and 1.8 million acres were leased for bonuses totaling $\$ 5.0$ billion. During calendar year 1975 , evaluations were completed for four sales covering 7.2 million acres, of which 1.7 million acres were leased for bonuses of nearly $\$ 1.1$ billion.

Tract evaluations were begun in fiscal year 1975 for Sales 38A and 41 in the Gulf of Mexico, Sale 35 off Southern California, and Sale 39 in the Gulf of Alaska. Preliminary work was also in progress for Sale 40 in the Mid-Atlantic Area, Sale 42 in the North Atlantic, Sale 43 in the South Atlantic, Sale 45 in the Bering Sea, and Sale 46 in the western Gulf of Alaska.

The Survey purchased 132,230 kilometres $(82,200$ miles) of common-depth-point seismic data to locate potential hydrocarbon-bearing structures, 74,830 kilometres $(46,500$ miles) of high-resolution seismic data to detect the presence of shallow geological hazards, and 62,440 kilometres $(38,800$ miles $)$ of gravity data and 123,110 kilometres $(76,500$ miles) of magnetic data for specialized studies, at a total cost of $\$ 7.5$ million. 


\section{Regulation of operations}

On January 28, 1969, a well being drilled in the Santa Barbara Channel off southern California blew out. Although the flow of fluids from the well was effectively controlled by closing the blowout preventor, oil and gas continued to flow for 11 days through subsurface fractures to the ocean floor and subsequently to the water surface. The Santa Barbara oil spill focused national attention on the potential damage from offshore oil and gas installations if adequate safety and environmental controls were not maintained. Public concern was further heightened when a fire broke out on an oil and gas platform in the Gulf of Mexico on February 10, 1970. This fire destroyed the platform and damaged equipment to the extent that oil and gas flowed for several weeks after the fire was extinguished. Although no injuries or environmental damage were reported, the potential for such damage existed.

These incidents precipitated a number of major studies of oil and gas operations on the Outer Continental Shelf:

- National Aeronautics and Space Administration (1971) — A study, made at the request of the Geological Survey, to review the applicability of $\mathrm{Na}$ tional Aeronautics and Space Administration contract quality management techniques and failuremode effect analysis procedures to the Outer Continental Shelf oil and gas lease management program.

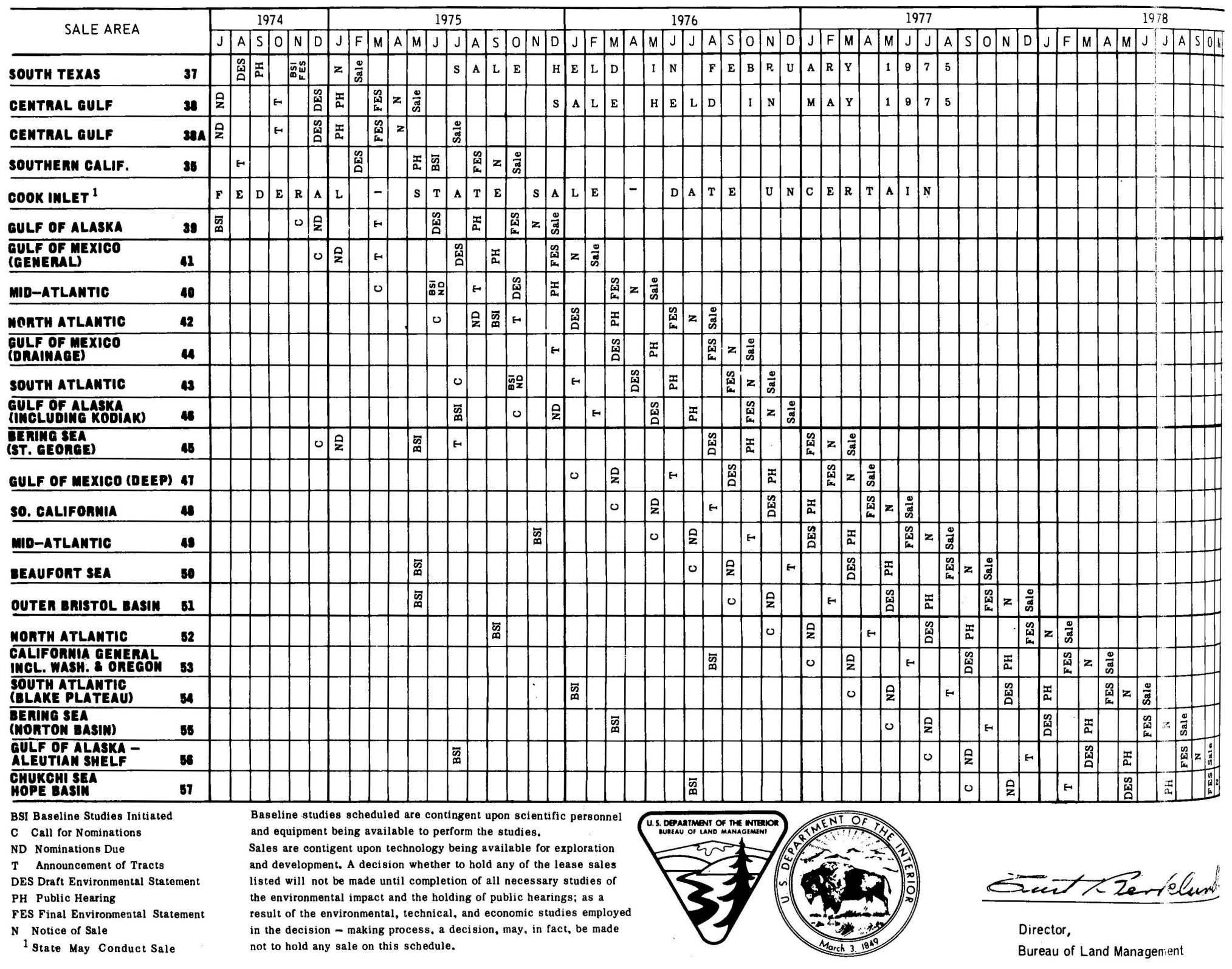


U.S. Geological Survey (1972)-An in-house study of the Survey's inspection program and procedures for enforcement of regulations.

- National Academy of Engineering (1972) —A study done at the request of the Survey, by the Marine Board of the National Academy of Engineering, which reviewed the technology and recommended regulatory practices that would minimize pollution of the Outer Continental Shelf from oil and gas operations.

- Kash and others (1973)-An exhaustive study, conducted under the aegis of the University of Oklahoma's Science and Public Policy program through a grant from the National Science Foundation which resulted in a technological assessment of Outer Continental Shelf oil and gas operations.

- Council on Environmental Quality (1974) —A study which assessed the environmental impact of oil and gas production on the Atlantic Outer Continental Shelf and in the Gulf of Alaska.
Shortly following the Santa Barbara blowout, the Survey began to review and revise its operating procedures and regulations. A set of revised regulations and Outer Continental Shelf orders which implemented the regulations were issued August 28, 1969. Subsequently, the Survey commissioned three of the studies cited above (National Aeronautics and Space Administration, 1971; U.S. Geological Survey, 1972; and National Academy of Engineering, 1972) and established a work group on Outer Continental Shelf safety and pollution control, chaired by the Survey's Associate Director, to review the study's findings and recommendations. This work group issued its first report and recommendations in May 1973 (U.S. Geological Survey, 1973). Two supplemental studies (U.S. Geological Survey, $1974 \mathrm{a}$, b) evaluated the two other reports listed above (Kash and others, 1973; Council on Environmental Quality, 1974).

These recommendations and their status in fiscal year 1975 are listed in table 18.

TABLE 18.-Status of Outer Continental Shelf recommendations

Work group recommendation Implementation in fiscal year 1975

1. Failure reports and A system was established for operators corrective ac- to report quarterly failures of subtions. surface safety valves. The system can be expanded to include other types of equipment failures. Failure reporting forms are being designed.

2. Accident investiga- Accident reporting procedures were retion and report- vised to define better causes and efing. fects of accidents. Geological Survey reports of accidents are available for public inspection.

3. Information ex- Reports on failures of subsurface safety change. valves are distributed quarterly to all operators. A safety alert system has been established to inform operators of the causes of accidents and pollution events.

4. Research and de- American Petroleum Institute sponsored velopment. committees have been formed to encourage industry research on sandprobe development and testing, orifice coefficients, and oil detection and removal. The Survey has contracted with the Harry Diamond Laboratories to assess industry research and development concerning safety and pollution control and development of communications equipment and flow meters.

5. Standards and spe- The American Petroleum Institute is cifications.

6. Systems analysis establishing standards and specifications for: design, installation, and operation of subsurface safety valve svstems; analysis, design, installation and testing of surface safety systems on offshore platforms; wellhead surface safety valves; design and installation of production platform piping systems.

The Survev received agreement from the American National Standards Institute to form committees to review standards.

The Geological Survey has contracted for pilot studies on the analysis of the design of platform facility systems. The Survey has also provided a
Work group recommendation

Implementation in fiscal year 1975

research grant to Rice University to draft standards on platform-systems design analysis.

7. Engineering The revision of OCS Order No. 8 (Platdocumentation. forms and Structures) requires extensive documentation of construction design and safety systems.

8. Wearout prevention.

The revision of OCS Order No. 8 requires the monitoring of sand erosion of valves and lines. Industry is conducting research on sand-erosion detectors.

9. Training and certification.

OCS Order No. 2 (Drilling Procedures) (Pacific Area) requires well-control training for supervisory and drilling personnel. OCS Order No. 8 requires training for all personnel working with safety devices. Procedures have been established to insure that minimum training standards are met. Training of inspectors is to be evaluated on an individual basis. Training sources are (1) on-the-job training, (2) technical schools, and (3) indoctrination sessions.

10. Motivation

As a result of work group recommendations, industry has published a bulletin on ways to motivate employees to be concerned with safety and pollution prevention.

11. Lease Management This program on the OCS has been program. buttressed to provide adequate staff and funds to mount an optimum effort.

12. Inspection proce- Uniform inspection and enforcement dures. procedures have been established. A computerized platform inspection system has been developed.

13. OCS Order development.

Procedures were established for development of OCS Orders and revision of existing Orders.

Public participation in the development of OCS Orders is provided through the placing of notices of proposed rule making in the Federal Register. 
TABLE 18.-Status of Outer Continental Shelf recommendations -Continued

\begin{tabular}{|c|c|c|}
\hline \multicolumn{2}{|c|}{ Work group recommendation } & Implementation in fiscal year 1975 \\
\hline 13. & $\begin{array}{l}\text { OCS Order de- } \\
\text { velopment- } \\
\text { Continued }\end{array}$ & $\begin{array}{l}\text { The technical adequacy of OCS Orders } \\
\text { was assured by providing for review } \\
\text { by the American National Standards } \\
\text { Institute. }\end{array}$ \\
\hline 14. & $\begin{array}{l}\text { Standardization } \\
\text { of forms. }\end{array}$ & $\begin{array}{l}\text { A pollution report form was revised and } \\
\text { is in use. }\end{array}$ \\
\hline 15. & $\begin{array}{l}\text { Safety and ad- } \\
\text { visory com- } \\
\text { mittees. }\end{array}$ & $\begin{array}{l}\text { The Marine Board of the National Acad- } \\
\text { emy of Engineering established a } \\
\text { committee to review OCS operations } \\
\text { (National Academy of Engineering, } \\
\text { 1974a, b; National Research Council, } \\
\text { 1975a, b) The Geological Survey } \\
\text { established safety committees in field } \\
\text { operations offices. Oil companies } \\
\text { have established internal safety and } \\
\text { anti-pollution groups. }\end{array}$ \\
\hline 16. & $\begin{array}{l}\text { Memorandum of } \\
\text { understanding } \\
\text { with the Occupa- } \\
\text { tional Safety and } \\
\text { Health Admin- } \\
\text { istration. }\end{array}$ & $\begin{array}{l}\text { Negotiations failed to produce a pro- } \\
\text { cedural memorandum of understand- } \\
\text { ing. }\end{array}$ \\
\hline \multirow[t]{2}{*}{17.} & $\begin{array}{l}\text { Memorandum of } \\
\text { understanding } \\
\text { on pipelines. }\end{array}$ & $\begin{array}{l}\text { A memorandum of understanding is in } \\
\text { effect with the Bureau of Land Man- } \\
\text { agement. }\end{array}$ \\
\hline & & $\begin{array}{l}\text { Discussion is continuing between the } \\
\text { Department of the Interior and De- } \\
\text { partment of Transportation (Office of } \\
\text { Pipeline Safety). }\end{array}$ \\
\hline 18. & $\begin{array}{l}\text { Memorandum of } \\
\text { understanding, } \\
\text { on standards for } \\
\text { discharge from } \\
\text { platforms and } \\
\text { rigs. }\end{array}$ & $\begin{array}{l}\text { The Environmental Protection Agency } \\
\text { has begun to establish discharge cri- } \\
\text { teria. }\end{array}$ \\
\hline & $\begin{array}{l}\text { Subsea production } \\
\text { systems. }\end{array}$ & $\begin{array}{l}\text { A task force was assembled to assess } \\
\text { the current state of the art, and com- } \\
\text { ments were solicited through Federal } \\
\text { Register notice. }\end{array}$ \\
\hline & & $\begin{array}{l}\text { Two reports on subsea systems have } \\
\text { been prepared. }\end{array}$ \\
\hline
\end{tabular}

Outer Continental Shelf Orders are formal numbered requirements issued by Oil and Gas Supervisor, with the prior approval of the Chief, Conservation Division, that implement the OCS operating regulations by applying them uniformly to a region or a major portion thereof. Considerable activity was directed in fiscal year 1975 to the updating of the following OCS Orders:

\section{Gulf of Mexico Area}

OCS Order No. 2 (Drilling Procedures)

Revised Order effective January 1, 1975

OCS Order No. 6 (Completion of Oil and Gas Wells)

Federal Register Notice of December 11, 1974, solicited comments on a revision to include workover procedures.

Draft revision has been prepared and is being reviewed.

OCS Order No. 7 (Pollution and Waste Disposal)

$A$ request for comments for revision of this order was published in the Federal Register during
Revision of the Order is being prepared and reviewed for publishing in Federal Register during fiscal year 1976.

OCS Order No. 8 (Platforms and Structures)

Proposed revision published in Federal Register January 21, 1975.

Public meeting held to discuss technical aspects of the Order on February 25, 1975.

OCS Order No. 12 (Public Inspection of Records)

Revised Order effective February 1, 1975.

\section{Pacific Area}

OCS Order No. 2 (Drilling Procedures)

Proposed revision published in Federal Register for comment on August 19, 1974.

OCS Order No. 11 (Oil and Gas Production Rates)

Final Order issued effective May 1, 1975.

OCS Order No. 12 (Public Inspection of Records)

Final Order issued effective December 1, 1974.

\section{Gulf of Alaska Area}

OCS Order Nos. 1 through 9, 11, and 12 published in the Federal Register for comment on January 6, 1975

\section{Atlantic Area}

Notice of Intention to Develop OCS Orders published in Federal Register on October 1, 197.

A list of all the Outer Continental Shelf Orders and their status as of the end of fiscal year 1975 is shown in table 19.

The Survey supervised oil and gas operations on 1,590 OCS leases covering 7.2 million acres during calendar year 1974 (table 47). The bulk of these sperations were located in the Gulf of Mexico, altho Igh 68 leases were located offshore of California. Total production from these leases amounted to 361 million barrels of oil, and 3,515 billion cubic feet of natural gas. The total value of all petroleum products produced on Outer Continental Shelf lands was $\$ 3.6$ billion.

During calendar year 1974, Survey personnel for the Gulf of Mexico made 1,300 inspections of $d$ illing rigs, 2,505 inspections of production platforms, and many overflights of other sites, while flying between inspections, in order to check for oil spills. As a result of these inspections the Survey issued 1,690 warnings on individual items found not to be in compliance with regulations, and ordered 1,244 zones and 290 platforms shut-in until violations of orders and regulations were corrected. The number of oil spills and fires and explosions associated with Outer Continental Shelf oil and gas operations during the last 5 years are summarized in tables 20 and 21. 
TABLE 19.-Status of Outer Continental Shelf Orders at the end of fiscal year 1975

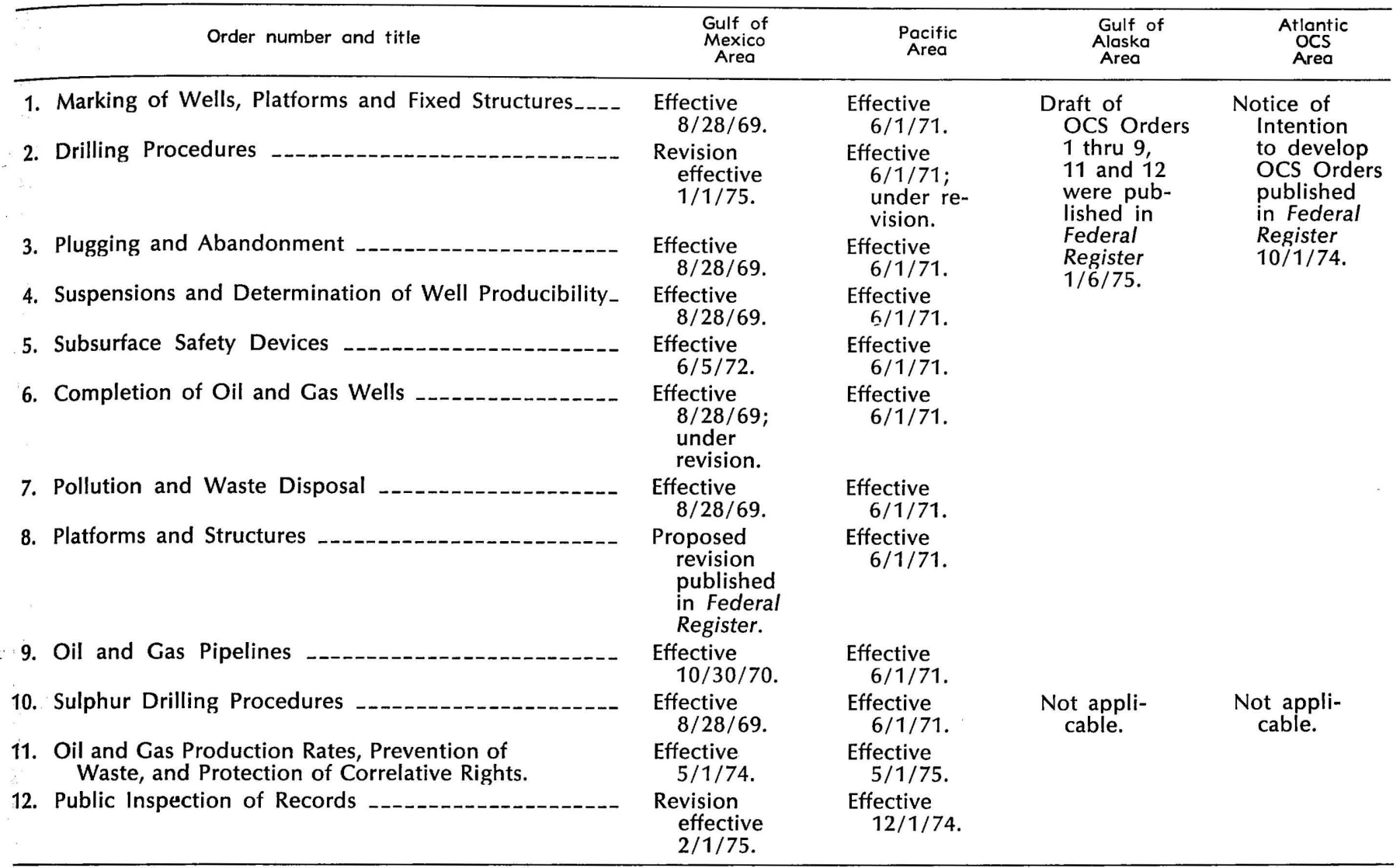

TABLE 20.-Summary of hydrocarbon spills on Outer Continental Shelf, 1971-74

\begin{tabular}{|c|c|c|c|c|}
\hline \multirow{2}{*}{$\begin{array}{c}\text { Calendar } \\
\text { year }\end{array}$} & \multicolumn{2}{|c|}{$\begin{array}{c}\text { Spills of } 50 \text { barrels } \\
\text { or more }\end{array}$} & \multicolumn{2}{|c|}{$\begin{array}{c}\text { Spills of less than } \\
50 \text { barrels }\end{array}$} \\
\hline & Number & $\begin{array}{l}\text { Barrels } \\
\text { spilled }\end{array}$ & Number & $\begin{array}{l}\text { Barrels } \\
\text { spilled }\end{array}$ \\
\hline 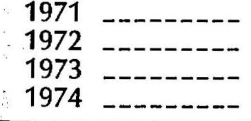 & $\begin{array}{r}11 \\
2 \\
4 \\
8\end{array}$ & $\begin{array}{r}1,285 \\
150 \\
22,175^{1} \\
22,721^{2}\end{array}$ & $\begin{array}{l}1,245 \\
1,159 \\
1,171 \\
1,129\end{array}$ & $\begin{array}{r}1,493 \\
1,032 \\
921 \\
667\end{array}$ \\
\hline
\end{tabular}

19,935 barrels were spilled from a storage tank rupture $(1 / 9 / 73)$ and

7,000 barrels were spilled from a leaking barge $(1 / 26 / 73)$.

${ }_{2} 19,850$ barrels were spilled from a pipeline break caused by a ship's anchor dragging on the seabed $(4 / 17 / 74)$.

TABLE 21.-Summary of fires and explosions on the Outer Continental Shelf, 1970-74

\begin{tabular}{lcccc}
\hline $\begin{array}{c}\text { Calendar } \\
\text { Year }\end{array}$ & $\begin{array}{c}\text { Number } \\
\text { of } \\
\text { events }\end{array}$ & Injuries & Fatalities \\
\hline 1970 & -10 & 31 & 11 \\
1971 & - & 10 & 16 & 1 \\
1972 & -17 & 9 & 0 \\
1973 & - & 9 & 2 \\
1974 & - & 15 & 0 \\
\hline
\end{tabular}

In calendar year 1974 royalty revenue from the sale of petroleum and sulfur products amounted to $\$ 560$ million, an increase of $\$ 159$ million over calendar year 1973, and \$197 million over calendar year 1972.
Oil production from the Outer Continental Shelf has been declining since 1971 (fig. 48) as new discoveries have not kept pace with the decline in production from older fields. A major disappointment during the year was the failure of exploratory drilling on the Destin dome offshore of Florida to locate the substantial oil and gas resources that had been anticipated for this structure.

Since production usually lags behind lease sales by 3 to 10 years, the impact of the accelerated leasing program has not yet been fully experienced; however, requests for approval of exploration plans and notices of intent to drill have increased.

\section{FEDERAL AND INDIAN LANDS}

The Geological Survey classifies and evaluates the mineral resources on Federal lands onshore and supervises exploration, development, and production operations on both Federal and Indian land leases. Specific procedures for leasing and development are governed by a multitude of different laws and regulations which complicate the administration of the onshore program. For example, unlike public land laws which 
provide for the leasing of specific minerals, such as oil and gas, coal, oil shale, asphaltic minerals, sodium, potash, phosphate, geothermal resources, and sulfur (in New Mexico and Louisiana only), Indian land and acquired land laws authorize the leasing of all metalliferous and nonmetalliferous minerals.

The Survey also, by cooperative arrangement with the Department of the Navy, furnishes technical advice with respect to Naval Petroleum Reserve lands and supervises operations for the drilling and production of oil and gas on Naval Petroleum Reserve No. 2 (Buena Vista) in California.

As is the case with the Outer Continental Shelf Lands subactivity, the Federal and Indian Lands subactivity also consists of two programs, Resource Classification and Evaluation and Regulation of Operations.

\section{Resource Classification and Evaluation}

Resource classification involves the collection of basic data needed to (1) classify Federal mineral lands, (2) delineate prospectively valuable mineral areas in order to determine whether or not the mineral rights should be retained by the Government in land disposal and exchange actions, and (3) modify or eliminate outstanding mineral-, waterpower-, and reservoir-site classifications or withdrawals.

Survey geologists classify Federal lands as to their potential for leasable minerals by considering all the available geologic data in order to determine which legal subdivisions of land are mineral lands. The Survey prepares and reviews its standards from time to time in order to make the classification action uniform and objective. Standards have been recently published for coal (Bass, Smith, and Horn, 1970) and geothermal resources (Godwin and others, 1971). Standards for other minerals are being revised.

To identify which lands are underlain by leasable minerals within the limits set by the classification standards, Survey geologists prepare geologic maps, collect drill-core samples, and make laboratory analyses to determine the quality or grade of the mineral commodity. Limits for classification are expressed for coal in terms of depth, thickness, and heat values (Bass, Smith, and Horn, 1970). At the end of fiscal year 1975, 41.9 million acres of withdrawn land had been classified as mineral land, and 45.7 million acres remained to be classified (table 22).

Potential waterpower and water-storage sites on Federal lands are also classified as valuable or not valuable for development in order to retain the Government's right to authorize or license hydroelectric or water-storage development on such lands. Of the 13.9 million acres so withdrawn, 143,000 acres were classified or reclassified in fiscal year 1975. About 9 million acres of the total are withdrawn for possible use at the Ramparts Reservoir site on the Yukon River, Alaska.

As a result of complying with requests for 15,000 mineral reports by other Federal agencies during the year, the Survey designated 1.17 million acres of land as prospectively valuable for leasable minerals.

Once Federal land has been classified as mineral land it must be evaluated to determine whethe or not it is subject to competitive or noncompet tive leasing. Where lands are designated as subject to competitive leasing they must be divided into tracts, and the Survey must determine the value of the resources for each tract in order to establish a minimum acceptable bid. The Survey then provides this information to the agency responsible for leasing the land.

The applicable leasing procedures and regulations differ with each commodity. Lands within the boundaries of Known Leasing Areas are subject to competitive leasing and are not subject to lease by application. For example, when the initial discovery of an oil and gas field is made, the Survey establishes an undefined Known Geologic Structure and informs the Bureau of Land Management. This action pre-

TABLE 22.-Status of Federal land classifications, fiscal year 1975 [Acres in thousands]

\begin{tabular}{|c|c|c|c|c|c|c|}
\hline \multirow{2}{*}{ Commodity } & \multirow{2}{*}{$\begin{array}{c}\text { Mineral } \\
\text { lands } \\
\text { withdrawn }\end{array}$} & \multicolumn{2}{|c|}{ Classified lands } & \multirow{2}{*}{$\begin{array}{l}\text { Prospec- } \\
\text { tively } \\
\text { valuable } \\
\text { Federal } \\
\text { lands }{ }^{1}\end{array}$} & \multicolumn{2}{|c|}{ Known Leasing Areas } \\
\hline & & Nonmineral & Mineral & & Undefined & Defined \\
\hline Total & 45,708 & 38,145 & 41,958 & $2,341,324$ & 5,834 & 24,462 \\
\hline Oil and gas & & ---- & 4 & $1,476,001$ & 5,151 & 11,864 \\
\hline Oil shale - & 14,206 & 75 & ----- & 14,375 & --- & --- \\
\hline $\begin{array}{l}\text { Asphaltic minerals } \\
\text { Coal }\end{array}$ & $\overline{20, \overline{471}}$ & $\overline{33,4 \overline{4}}$ & $\overline{40,939}$ & $\begin{array}{r}17,941 \\
350,349\end{array}$ & ---- & $\overline{9,277}$ \\
\hline Geothermal resources & $\begin{array}{r}20,411 \\
-----\end{array}$ & J3, & $\begin{array}{r}40,305 \\
-----\end{array}$ & 98,180 & --- & 2,684 \\
\hline Phosphate & $\overline{1,620}$ & 4,625 & $-\overline{390}$ & 30,531 & $---\overline{2}$ & 40 \\
\hline Potash & 9,411 & - & ----- & 80,928 & 114 & 309 \\
\hline Sodium & --- & $-\ldots-$ & 625 & 267,426 & 567 & 288 \\
\hline Sulphur & $-\cdots$ & $-\cdots$ & ---- & $\quad 5,593$ & --- & $-\ldots$ \\
\hline
\end{tabular}


vents any further noncompetitive leasing of the area until such time as the boundaries of the Known Geologic Structure can be more accurately determined and published in the Federal Register.

The Survey recommends lands for leasing whenever there is reason to believe that sufficient competitive interest exists or that leasing would be in the best interests of the United States. With regard to Federal lands, the Survey: (1) recommends to the Bureau of Land Management the size of each parcel and special stipulations such as those pertaining to surface use or drilling requirements, (2) determines and recommends to the Bureau of Land Management a minimum acceptable bid for each parcel on the basis of current economic, geologic, and engineering data; and (3) recommends to the Bureau of Land Management whether the high bid submitted for each parcel should be accepted or rejected.

Most Indian lands are leased by competitive bidding methods, and the Bureau of Indian Affairs has usually relied on the Survey to parcel tracts for sale, to recommend stipulation to be included in the leases regarding other surface use and drilling requirements, and to recommend acceptance or rejection of high bids offered. Complete presale evaluations for Indian lease sales are only done when requested.

As noted above, oil and gas lands are leased competitively if they are located on Known Geologic Structures of producing oil and gas fields as defined from analysis of well logs, core sampling data, production records, and maps that are required to be submitted to the Geological Survey by lessees and operators. Lands not located on the Known Geologic Structure of a producing oil or gas field are leased by application to the Bureau of Land Management. During fiscal year 1975, the Survey identified 7,408 acres to be within Known Geologic Structures and classified 228,683 acres in 119 undefined Known Geologic Structures.

Coal is leased by competitive bidding when information available to the Government is adequate to prove existence of coal of workable quality and quantity. Alternatively, where prospecting or exploratory work is necessary to determine the existence or workability of deposits, coal may be leased noncompetitively by approval of a prospecting permit which can lead to a preference-right lease if prospecting discloses coal in commercial quantities.

During fiscal year 1975, field mapping for coal was in progress on 127 7.5-minute and 115 -minute quadrangles and 3 coal-investigations maps were published. To date a total of 1227.5 -minute and 4 15-minute coal quadrangles have been published or released for open file as part of the coal program.

FIGURE 48.-Oil and gas production from Outer Continental Shelf lands, calendar years 1966-75.
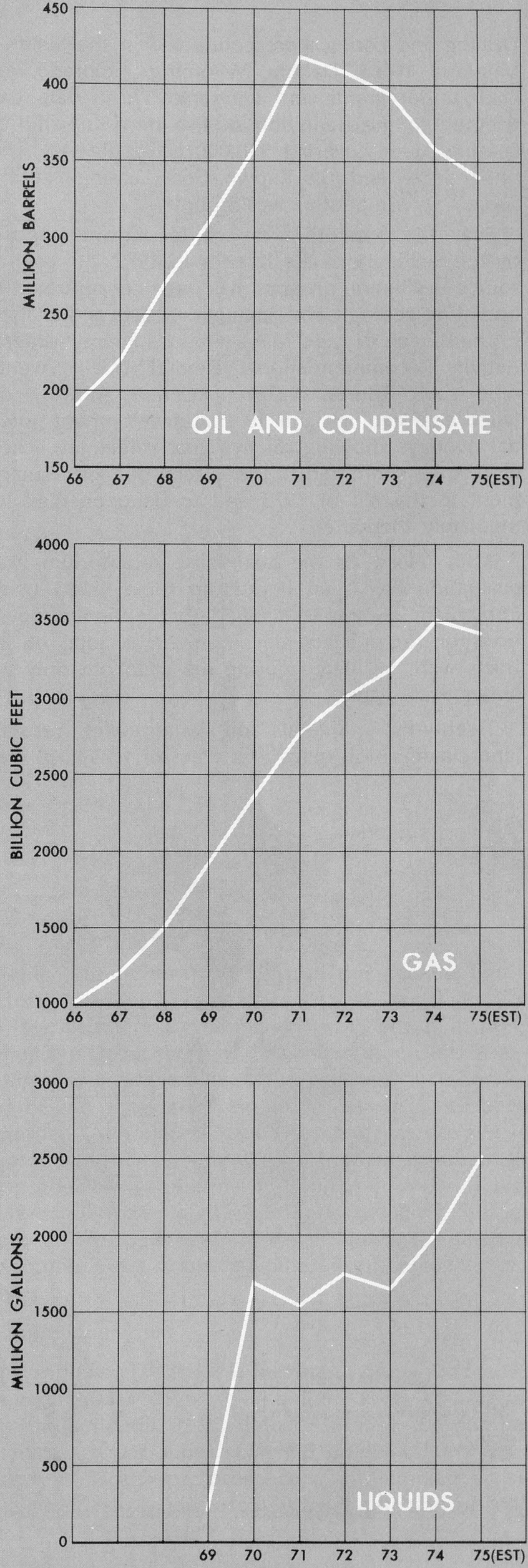
Drilling and coring were conducted in the States of Montana, North Dakota, Wyoming, Colorado, and Utah under grants and contracts. These data contributed to the definition of five new Known Coal Leasing Areas covering 910,000 acres (fig. 49). Coal on Federal lands in Known Coal Leasing Areas is subject to competitive leasing only.

Since the moratorium on coal leasing was imposed by the Secretary of the Interior in 1972, the coal-resource evaluation program has been concentrated on providing geologic and engineering data and analyses to the Bureau of Land Management's Energy Minerals Activity Recommendation System (EMARS). Twentynine coal-resource occurrence maps showing detailed coal geology and 19 coal-development-potential overlays showing relative coal values are scheduled to be submitted to the Bureau of Land Management in the fall of 1975 and to be open filed immediately thereafter.

Also, owing to the coal lease moratorium, tract evaluation has been limited to those tracts where immediate leasing is justified for continued operations or for efficient development. A total of five tracts were evaluated during the year, but only two leases were issued.

Twenty-five mineral and waterpower resource land classification maps at a scale of $1: 250,000$ were

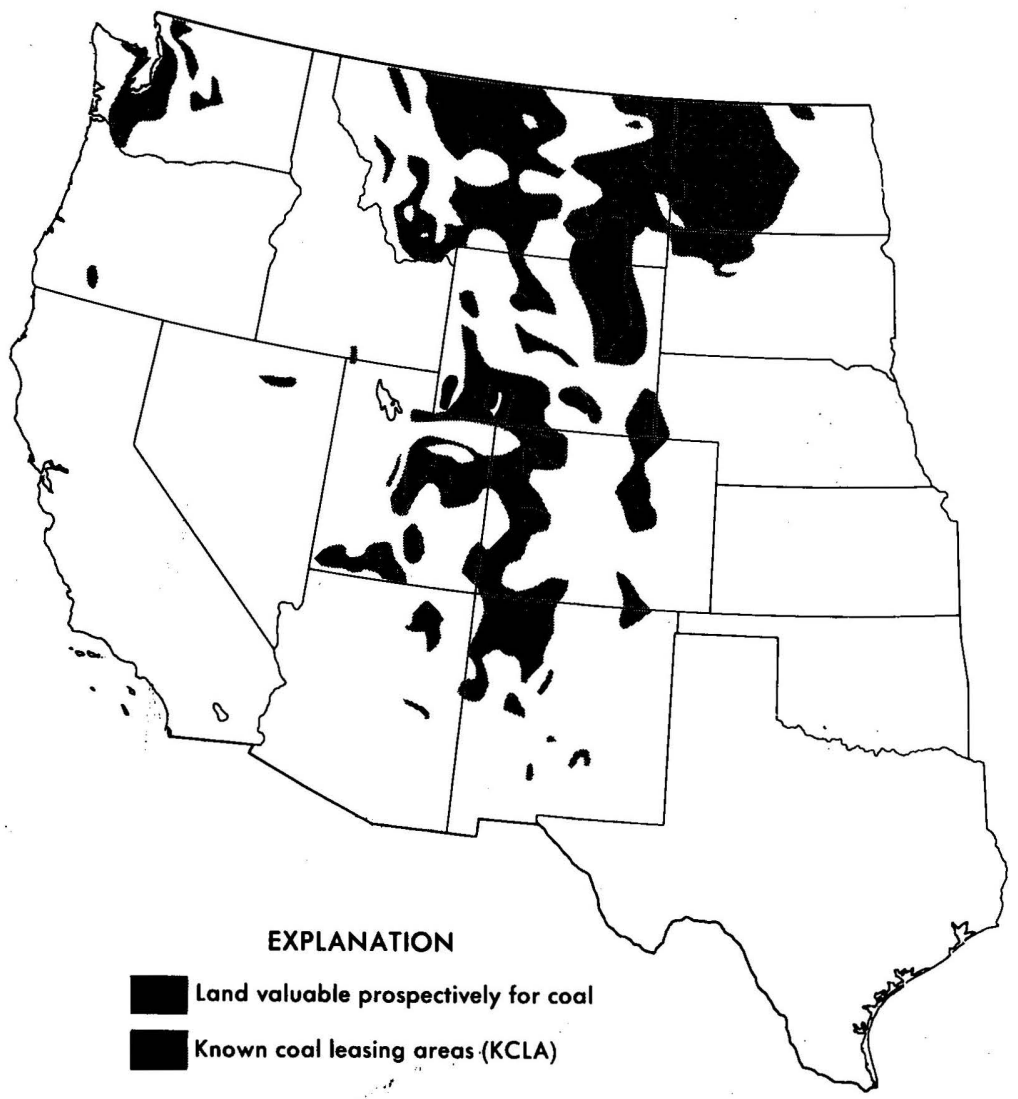

FIGURE 49.--Status of coal classification on Federal and Indian lands. completed and open filed by the end of fiscal year 1975; ten additional maps are complete and will be released in fiscal year 1976; and 25 maps are in progress. All maps cover areas in the Rocky Mountain States (fig. 50). These maps provide an overall picture of land classification by the Geological Survey which is useful in showing resource relationships for land use planning.

Resource-evaluation activities for other leasable minerals during the year included:

- Classification of about 3,120 acres in Known Potash Leasing Areas in New Mexico.

- Completion of seven 7.5-minute quadrangle maps of the geology of phosphate lands.

\section{Regulation of Operations}

The Geological Survey is responsible for supervising oil, gas, and mining operations on Federa and Indian lands and geothermal operations on Federal lands. In this regulatory program, oil, gas, geothermal, and mining operations are treated as separate units because of the different technologies and engineering disciplines used by each type of operation. The major program requirements, however, are basically the same: (1) review and approval of exploration and development plans; (2) supervision of exploration, development, and production operations; (3) computation and collection of royalties and certain rentals.

Other related activities such as unitization, method of production measurement, transportation allowances, commingling of products, off-lease stcrage, and sales contracts also require the prior approval or concurrence of the Survey.

\section{Oil, gas, and geothermal operations}

At the end of calendar year 1975, there were 126,718 oil and gas leases covering 93.6 million acres and 552 geothermal resources leases covering 1.3 million acres in effect (table 49). These leases were located in 33 States. During calendar year 1975, total oil and gas production from these leases amounted to 198 million barrels of oil, a decrease of nearly 5 percent from calendar year 1974, and 1,057 billion cubic feet of natural gas, a decrease of 14 percent from calendar year 1974. Survey personnel made over 18,000 inspections of oil and gas lease operations, prepared 1,078 environmental analyses of proposed new wells, approved 2,321 new wells (both exploratory and development wells), and processed 1,396 other types of applications.

At the end of fiscal year 1975, the Geological Survey was maintaining 15,398 producing oil and gas lease accounts, an increase of 3.3 percent over iscal 


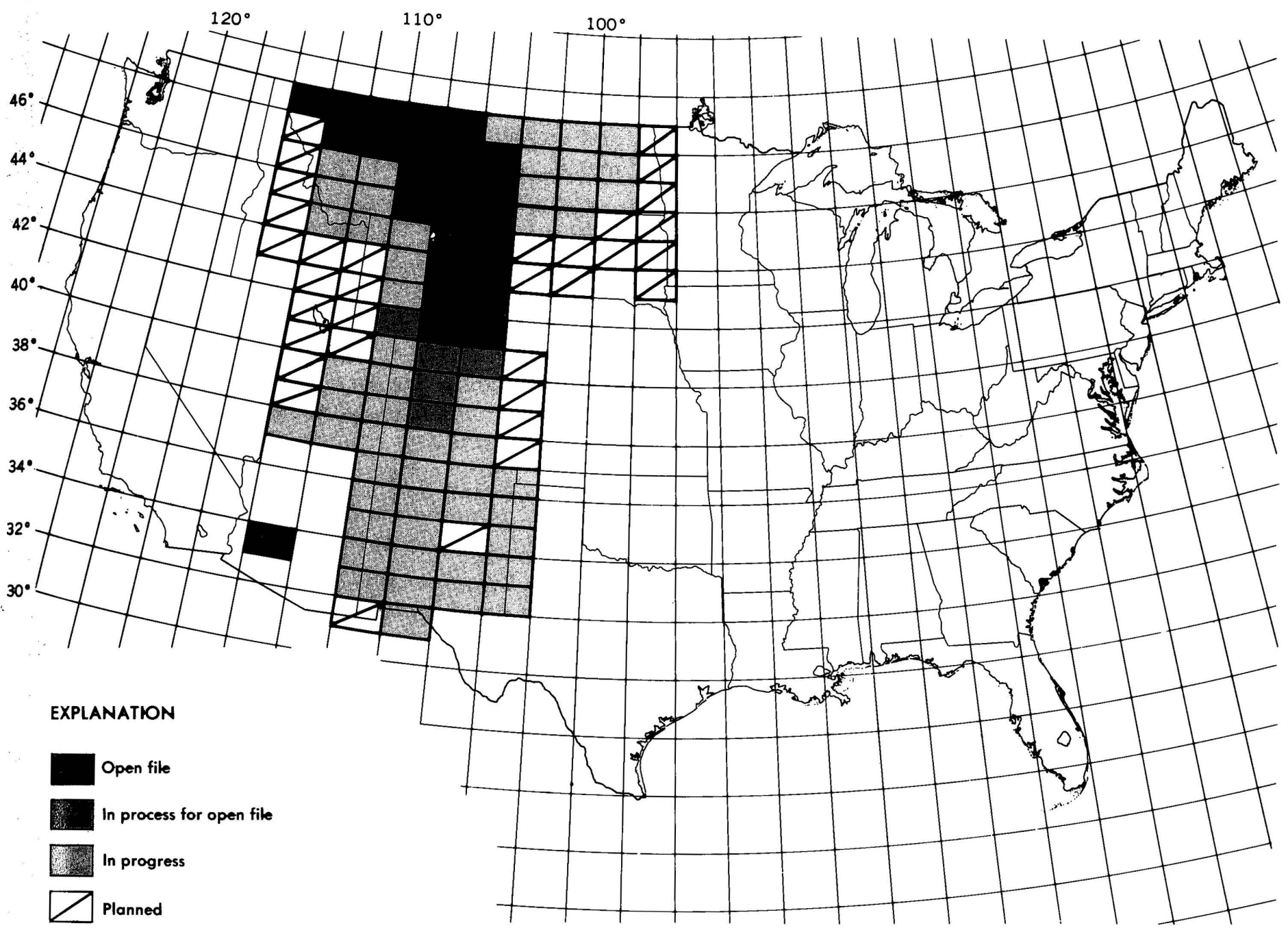

FIGURE 50.-Status of leasable mineral and waterpower resource land classification maps.

year 1974. At that time the Survey also had under its jurisdiction 1,670 rental accounts for Federal land leases. Total royalty revenue from the sale of oil, gas, and liquid products in calendar year 1975, amounted to $\$ 245$ million dollars which was an increase of $\$ 26$ million over calendar year 1974 owing to increased prices for those commodities.

About 6.5 percent of the Nation's domestic production of oil and 5.6 percent of its production of natural gas came from onshore Federal and Indian lands. Oil production from these lands, however, has been declining since 1968 (fig. 51) because new discoveries have not kept pace with the decline in production from older fields. The increasing demand for natural gas, which has caused greater effort to be directed toward finding new gas reserves, may account for some of the decline in oil production as well as the small increase in gas production. Liquid hydrocarbon products, which are extracted from natural gas produced from gas wells and from casinghead gas produced in association with oil, increased slightly during the year despite the decline in oil production.

The Geothermal Leasing program began in 1973 when the Department of the Interior published regulations governing the leasing of geothermal resources. By the end of calendar year 1975, 552 leases had been awarded. Although no geothermal leases are yet in a producing status, in May 1975 the first commercially producible geothermal well on Federal lands was successfully completed near the Castle Rock Springs area of the Geysers-Calistoga Known Geothermal Resources Area about 90 miles north of San Francisco.

\section{Mining operations}

During fiscal year 1975, the Survey supervised 2,479 mineral leases covering 8 million acres of Federal and Indian lands in 32 States. Although the number of leases under supervision has decreased from the previous fiscal year, prospecting and mining activities have sharply increased. Total production of solid 

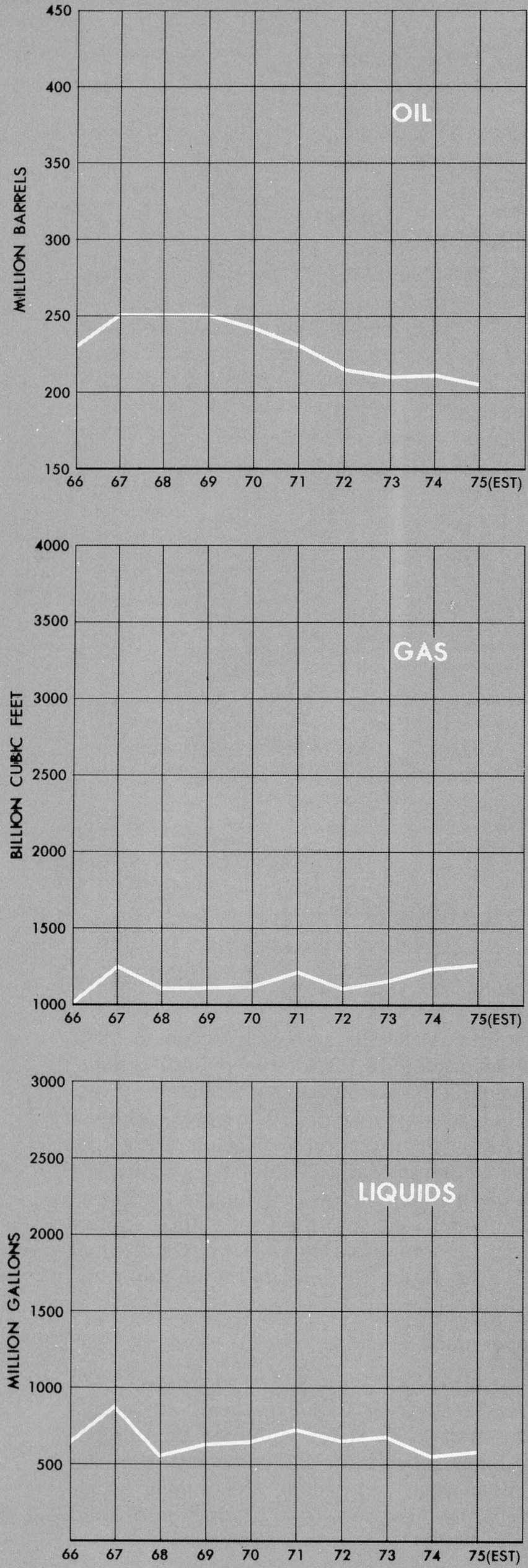

mineral commodities under lease during the year, for example, increased 34 percent to 88.3 million tons valued at $\$ 681$ million as a result of continuing increases in demand for energy minerals, such as coal and uranium, fertilizer minerals, such as potash, and metallic minerals, such as lead, zinc, and copper.

Survey personnel made 2,100 producing lease and permit inspections, reviewed and approved 146 new or modified exploration and mining plans, prepared 146 environmental analyses, and assisted in the preparation of 26 environmental impact statements. Royalties from 180 producing lease accounts totaled \$30.1 million, an increase over 1974 of 41.3 percent. Revenues from 803 rental accounts provided an additional $\$ 750,000$.

The importance of Federal and Indian lands to the Nation's domestic production of solid minerals is illustrated in figure 46.

- Coal-Seven percent of the Nation's coal prociuction in fiscal year 1975 came from leases on Federal and Indian lands in Montana, Wyoming, Colorado, Utah, New Mexico, and Arizona. It is estimated that production from existing leases cculd be increased from 44 million tons in 1975 to 213 million tons in 1980, an increase of nearly 384 percent. At the end of the fiscal year, 191 preferenceright leases covering approximately 492,000 acres were pending a decision by the Secretary of the Interior on future coal leasing policy, and the coal leasing and operating regulations were being revised.

- Oil Shale-In 1971, the Department of the Interior initiated the Prototype Oil Shale Leasing program to encourage private industry to develop oil-shale mining and processing technology on a commercial scale, to insure the environmental integ ity of the affected areas, to develop environmertal safeguards and land-restoration techniques, and to develop management expertise in leasing and $s u-$ pervising oil-shale development. Following the preparation of an environmental impact stateme nt, the Department competitively leased four tracts of land in Utah and Colorado embracing 20,400 ac es for a bonus of $\$ 449$ million. The lease terms require each lessee to file a detailed development plan with the Survey for review and approval on or before the third anniversary date of the lease. Furthermore, the lease terms require the borius payments to be paid in five annual installments and permit the lessee to credit against the fourth and fifth payments any expenditures incurred prior

FIGURE 51.-Oil and gas production from Federal and Indian lands, calendar years 1966-75. 
to the third anniversary of the lease that are directly attributable to operations for the development of the lease. The Survey's mining supervisor is responsible for determining that such expenditures credited by the lessee are properly attributable to development operations.

During 1975, four companies submitted their initial exploration plans for evaluation and approval by the Survey. Initial work also began on projects involving collecting baseline environmental data, monitoring air and water quality, and developing guidelines for future operations.

- Fertilizer minerals-A large increase in the demand for fertilizer minerals has accelerated the production and leasing activities for potash and phosphate during the past few years. Seventy-five percent of the Nation's potash is produced from Federal lands and 13 percent of phosphate comes from Federal and Indian lands. In Idaho, the principal western phosphate-producing State, there are 189 prospecting-permit applications pending.

\section{REFERENCES}

Adams, M. V., John, C. B., Kelly, R. F., LaPointe, A. E., and Meurer, R. W., 1975, Mineral resource management of the Outer Continental Shelf: U.S. Geol. Survey Circ. 720, 32 p.

Bass, N. W., Smith, H. L., and Horn, G. H., 1970, Standards for the classification of public coal lands: U.S. Geological Survey Circ. 633, 10 p.

Bureau of Land Management, 1975, Final environmental impact statement-proposed increase in oil and gas leasing on the outer continental shelf (FES-75-61):Washington,D.C., Bureau of Land Management, July 1975.

Council on Environmental Quality, 1974, OCS oil and gas-an environmental assessment, A report to the President: Council on Environmental Quality, Washington, D.C. (U.S. Government Printing Office), 5 vols., April 1974.

General Accounting Office, 1975, Outer Continental Shelf Oil and Gas Development-improvements possible in determining where to lease and at what dollar value: U.S. General Accounting Office, Rept. no. RED-75-359, June 30, $1975,51 \mathrm{p}$.

Godwin, L. H., and others, 1971, Classification of public lands valuable for geothermal steam and associated geothermal resources: U.S. Geological Survey Circ. 647, 18 p.

Kash, D. E., and others, 1973, Energy under the Oceans: Norman, Oklahoma, University of Oklahoma Press, $378 \mathrm{p}$.

National Academy of Engineering, 1972, Outer Continental Shelf resource development safety-a review of technology and regulations for the systematic minimization of environmental intrusion from petroleum products: National Academy of Engineering, Marine Board, Panel on Operational Safety in Offshore Resource Development, Washington, D.C., December, 1972, 197 p.

1974a, First report of the Review Committee on Safety of Outer Continental Shelf Petroleum Operations to the
United States Geological Survey: National Academy of Engineering, Marine Board, Review Committee on Safety of Outer Continental Shelf Petroleum Operations, Washington, D.C., January 1974, 6 p.

1974b, Second report of the Review Committee on Safety of Outer Continental Shelf Petroleum Operations to the U.S. Geological Survey: National Academy of Engineering, Marine Board, Review Committee on Safety of Outer Continental Shelf Petroleum Operations, Washington, D.C., June 1974, 20 p.

National Aeronautics and Space Administration, 1971, Feasibility study report-applications of NASA contract quality management techniques and failure mode effect analysis procedures to the USGS Outer Continental Shelf oil and gas lease management program: National Aeronautics and Space Administration, George C. Marshall Space Flight Center, Huntsville, Alabama, October 1971, 65 p.

National Aeronautics and Space Administration, and Martin Marietta Corporation, 1974, Onshore lease management program study for the U.S. Geological Survey: National Aeronautics and Space Administration, Washington, D.C., December 1974, 91 p.

National Research Council, 1975a, Third report of the Review Committee on Safety of Outer Continental Shelf Petroleum Operations to the U.S. Geological Survey: National Research Council, Assembly of Engineering, Marine Board, Washington, D.C., March 1975, 12 p.

1975b, Fourth report of the Review Committee on Safety of Outer Continental Shelf Petroleum Operations to the U.S. Geological Survey: National Research Council, Assembly of Engineering, Marine Board, Washington, D.C., August $1975,25 \mathrm{p}$.

Office of Audit and Investigation, 1975a, Review of royalty accounting system for onshore oil and gas leases: U.S. Department of the Interior, Office of Audit and Investigation, Washington, D.C., June 1975, 106 p.

1975b, Royalty accounting system study of solid mineral leasing activities: U.S. Department of the Interior, Office of Audit and Investigation, Washington, D.C., August 11, 1975, 24 p. (Includes U.S. Geological Survey comments on report as exhibit I).

U.S. Geological Survey, 1972, Outer Continental Shelf lease management study-safety and pollution control: U.S. Geological Survey, Washington, D.C., May 1972.

- 1973, Report of the work group on OCS safety and pollution control: U.S. Geological Survey, Reston, Va., May $1973,33 \mathrm{p}$.

- 1974a, Supplement No. 1 to the report of the work group on OCS safety and pollution control, May 1973: U.S. Geological Survey, Reston, Va., May 1974, 17 p.

1974b, Supplement No. 2 to the report of the work group on OCS safety and pollution control, May 1973: U.S. Geological Survey, Reston, Va., November 1974, 12 p.

1975a, Conservation Division Task Force Report on the Onshore lease management study for the U.S. Geological Survey by National Aeronautics and Space Administration and a support team from Martin Marietta Corporation: U.S. Geological Survey, Reston, Va., May 1975, 120 p.

$1975 \mathrm{~b}$, Comments on the findings and recommendations of the OA \& I audit report of June 9, 1975, entitled "Review of royalty accounting system for onshore oil and gas leases, Geological System": U.S. Geological Survey, Reston, Va., June 12, 1975, $34 \mathrm{p}$. 


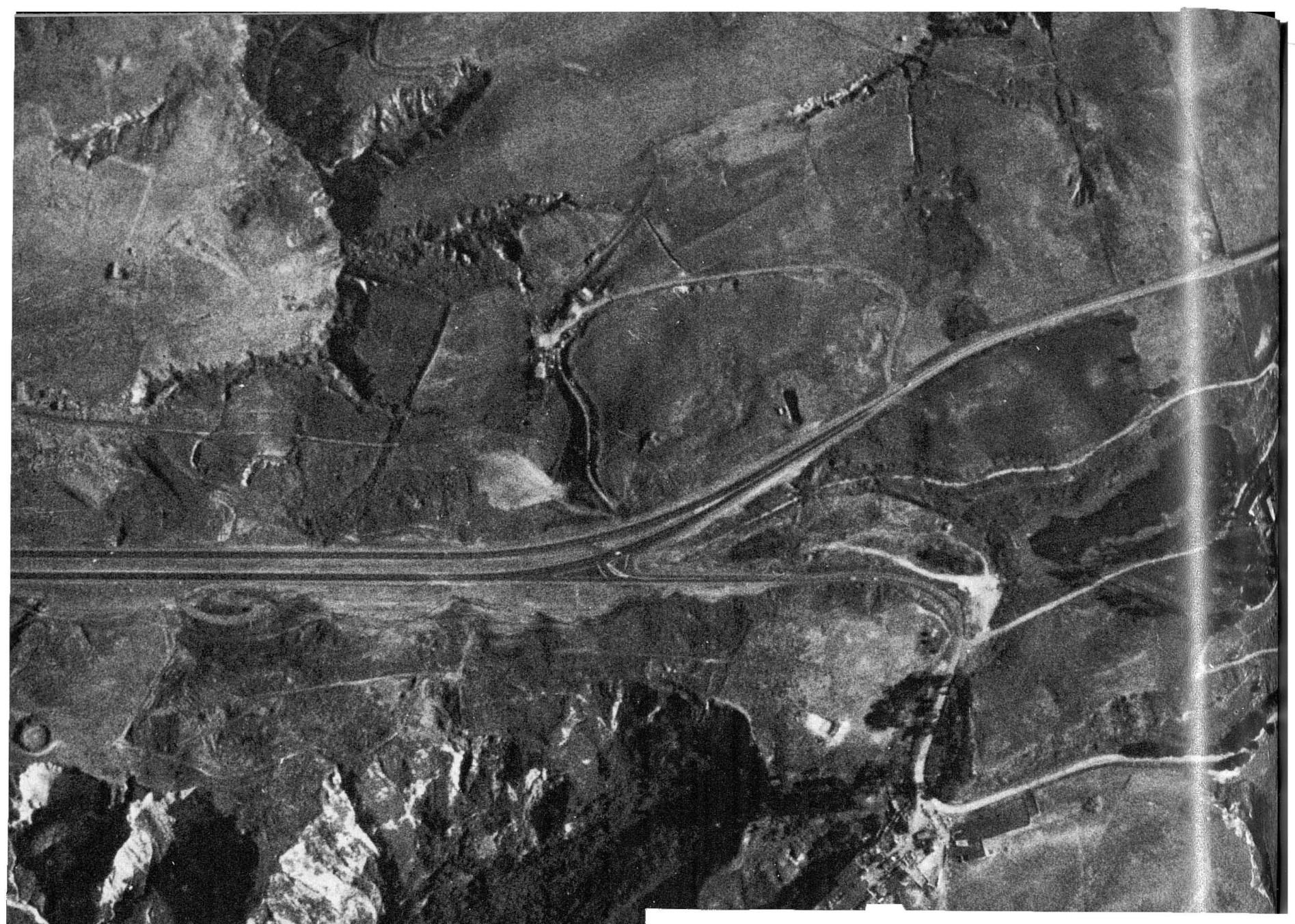




\section{Land Information and Analysis}

\section{OVERVIEW}

In the past decade, conflicting uses of land resources have become one of the Nation's most critical problems. Too often, urbanization has encroached on land ill-suited for such development-houses, offices, and factories are built on or near active fault zones, on floodplains, or in areas prone to subsidence. Valuable mineral deposits, including building materials such as sand and gravel, have been paved or built over when prior planning could have achieved both the development of these resources and the use of the land for other purposes.

Serious concern over the environment is manifest in the enactment of the National Environmental Policy Act of 1969, recent State and local land use legislation, and intensive analyses of the implications of shortages of food, energy, and mineral resources. Consequently, there is an unprecedented need for information about our land for use in planning and decisionmaking. For example, recent moves to accelerate the development of energy resources, particularly the strip mining of Western coal deposits, demand greater knowledge of water supplies and of reclamation techniques to restore mined lands for future use.

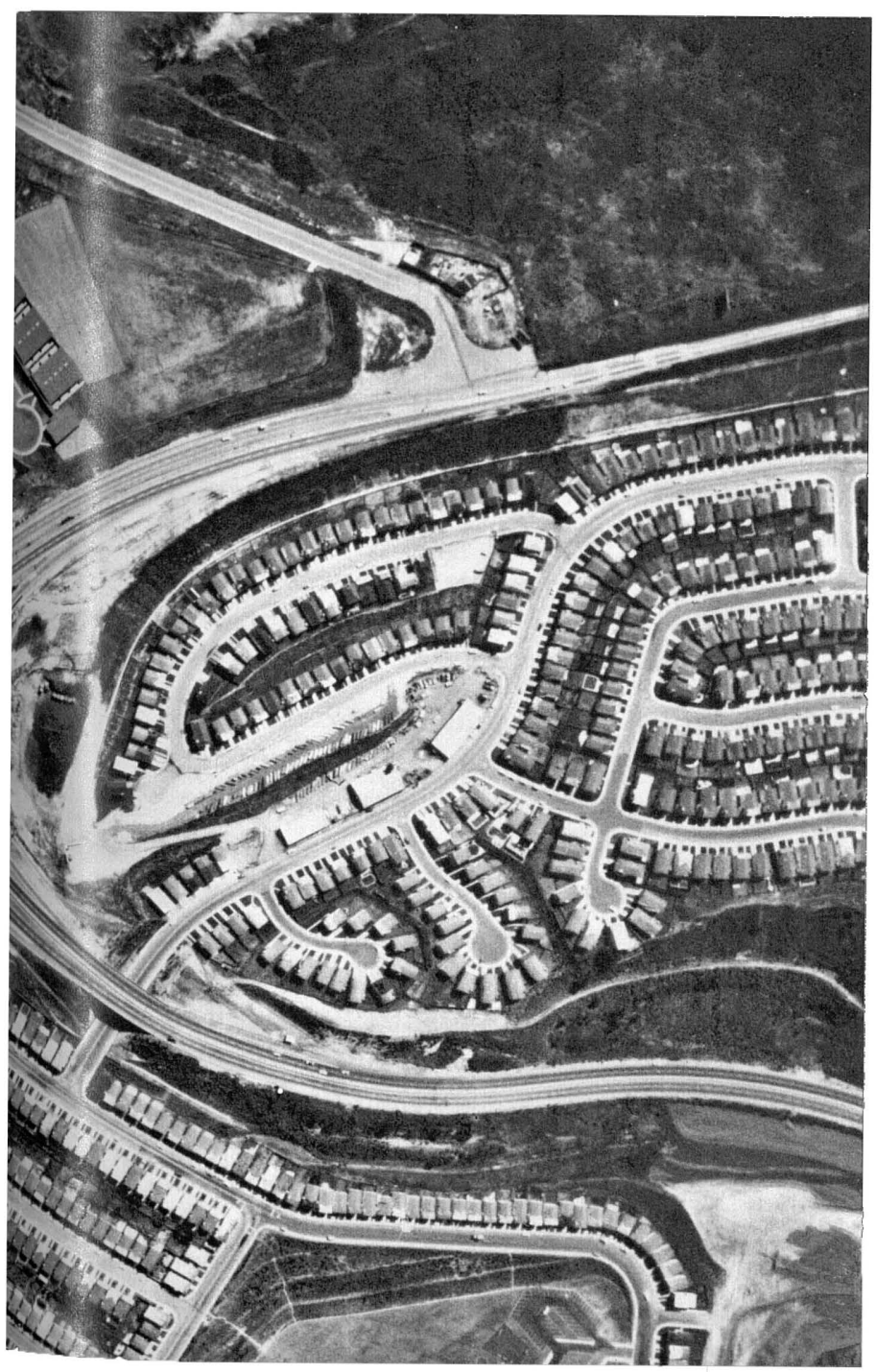

Although the Geological Survey is the Nation's principal source of information about the character of the land surface and underlying resources, few Survey products have synthesized the results of the geologic, hydrologic, and topographic studies. Planners have had to seek the help of specialists to further analyze and interpret the information. The information base needed to resolve many of today's land use conflicts often reaches beyond the Survey's domain and includes the full range of concerns of the Department of the Interior.

In April 1975, the Department established the Land Information and Analysis Office within the Survey to consolidate several multidisciplinary land resource and environmental programs. This new office will interpret and display land resource information collected within the Department in ways that are readily accessible and understandable to a wide range of users, particularly land use planners and decisionmakers.

\section{Programs}

The Land Information and Analysis Office manages five multidisciplinary programs:

- The Earth Sciences Applications program (formerly the Urban Area Studies and the Land Resources and Analysis programs) is responsible for integrating the earth-science information collected by the Survey for use in analyzing land resource problems. The products, mainly thematic maps and reports, provide insight into the environmental consequences of land use decisions. For example, the San Francisco Bay region study has produced more than 70 geologic, hydrologic, and topographic maps and technical reports, plus 15 interpretive reports relating the data to land use planning and management alternatives and possible environmental impacts.

- The Resource and Land Investigations program encompasses the multidisciplinary, multibureau efforts of the Department of the Interior. The national problems addressed include, for example, the delineation of environmentally endangered areas, the development and application of land use inventory systems, and the siting of onshore facilities associated with Outer Continental Shelf energy resource development.

- The Geography program (formerly the Land Use Data and Analysis program) calls for the application of geographic analysis techniques to land and resource problems. Land use data are systematically collected, revised, and analyzed on a nationwide basis, and basic geographic research is conducted. 
- The Earth Resources Observation Systems (EROS) program is the largest Departmental program to be managed by this new office. Since 1966, numerous experiments have been conducted applying remotely sensed data, primarily photographs and telecommunicated images obtained from satellites and high-altitude aircraft, to a wide variety of resource and environmental problems. The key facility of this program is the EROS Data Center in Sioux Falls, S. Dak., where the data are stored, reproduced, and distributed. The program includes research as well as user training in the interpretation and application of remotely sensed data and also includes the development of improved sensor and data processing systems.

- The Environmental Impact Analysis program (formerly the Energy Impact Evaluation program) directs the preparation and review of the environmental impact statements required of the Survey by the National Environmental Policy Act of 1969.

In addition, the Land Information and Analysis Office enters into cooperative projects with State, local, and other Federal agencies.

\section{Budget and personnel}

Obligations of Land Information and Analysis Office activity in 1975 amounted to $\$ 17.0$ million, an increase of 31 percent over 1974 (table 23). The additional funds were used largely to undertake the Geography and Environmental Impact Analysis programs.

The work of the Land Information and Analysis Office is partly accomplished through private contracts and research grants. Of the fiscal year 1975 funds, $\$ 5$ million (29.6 percent) was expended on contracts and

TABLE 23.- - Land Information and Analysis Office activity obligations for fiscal year 1975 , by program

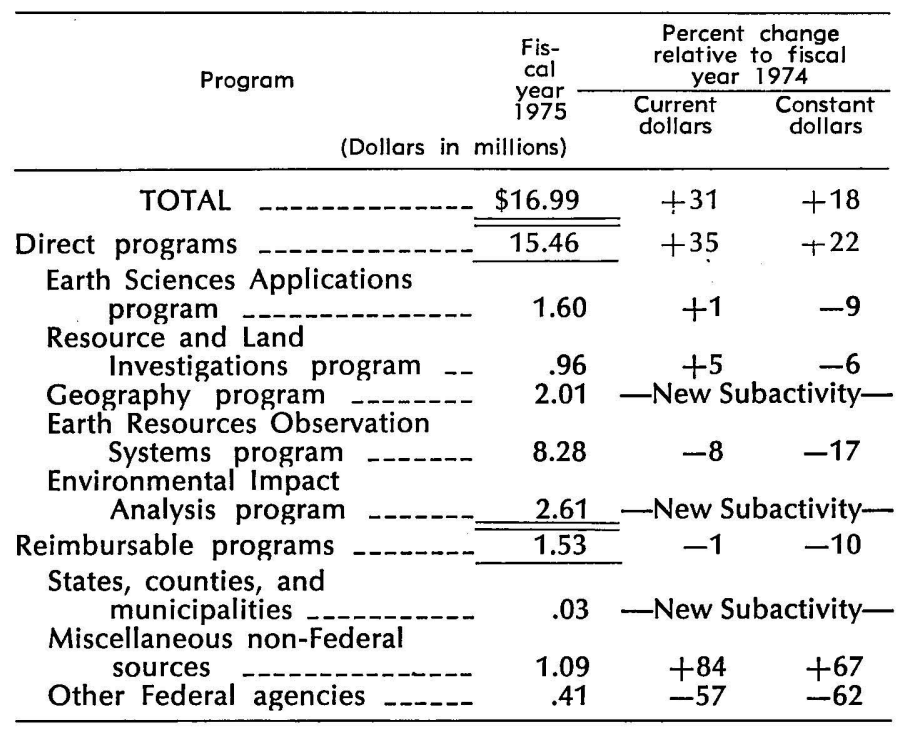

$\$ 231,000$ (1.4 percent) on research grants. This research centered on developing new methods of obtaining, interpreting, and displaying remotely sensed information. Contract services are also used to support the EROS Data Center.

The programs of the Land Information and Analysis Office were carried out by 191 full-time career employees in 1975; at the end of the year, 89 were assigned to the Office's programs (table 44), 10 were in the process of transferring to the Office, and 92 were assigned to other Survey offices to work on specific projects supported by the Land Information and Analysis Office. In addition, contract support services at the EROS Data Center amounted to 238 man-years. Personnel of the Topographic, Computer Center, and Administrative Divisions are also assigned to the Data Center.

\section{Highlights}

The principal issues faced by the Land Information and Analysis Office in fiscal year 1975 concerned:

- Land use implications of energy and mineral resource development.

- Accelerated requests from State and local governments for information to support land use ard resource planning and management (mainly for areas affected by the Coastal Zone Management Act of 1972 and by State and local land use legislation).

- Major Federal actions, especially related to energy resource development, that required environmental impact statements.

Consequently, new studies were undertaken to determine the onshore effects of oil and gas development along the Outer Continental Shelf off New England and the State of Washington, land use mapping of coastal States was accelerated, and environment $\mathrm{im}$ pact analysis task forces were formed. The analytical capability and user services associated with the remote sensing activities of the Office were also expanded.

The major events and accomplishments in fiscal year 1975 were:

- Organization of the Land Information and Aralysis Office to address critical earth-science problems from a multidisciplinary perspective.

- Successful launch of Landsat-2 and Congressional approval of a third Landsat to continue the global collection of valuable resource and environmental data.

- Production of land use maps for all of Louisiana and Arkansas and parts of Missouri, Kansas, Oklahoma, and Arizona to assist State and local plannin $\xi$ and development activities. 


\section{EARTH SCIENCES APPLICATIONS PROGRAM}

The Earth Sciences Applications program was established to provide a unit within the Geological Survey specifically concerned with making earth-science information available to land use planners and decisionmakers in directly usable form. Although the program's emphasis is chiefly upon geology, hydrology, and topography, many of its products eventually serve as Survey input to the Departmentwide Resource and Land Investigations program, which integrates earthscience information with natural-science information from other agencies.

The objectives of the Earth Sciences Applications program are threefold: (1) To interpret, demonstrate, and enccurage the use of earth-science information for land use decisionmaking through demonstration projects, user interaction, technical assistance, publication of specially designed map and book reports, and project evaluations; (2) to stimulate development of multidisciplinary studies in the Survey through coordination and integration of activities; and (3) to serve as the focal point within the Survey for multidisciplinary studies to support the work of other Federal agencies. In accomplishing these objectives, the program has focused mainly on the interpretation and presentation of earth-science data bearing on land use conflicts in selected urban and adjoining areas throughout the United States. The location of these studies is shown in figure 52 . These urban area studies

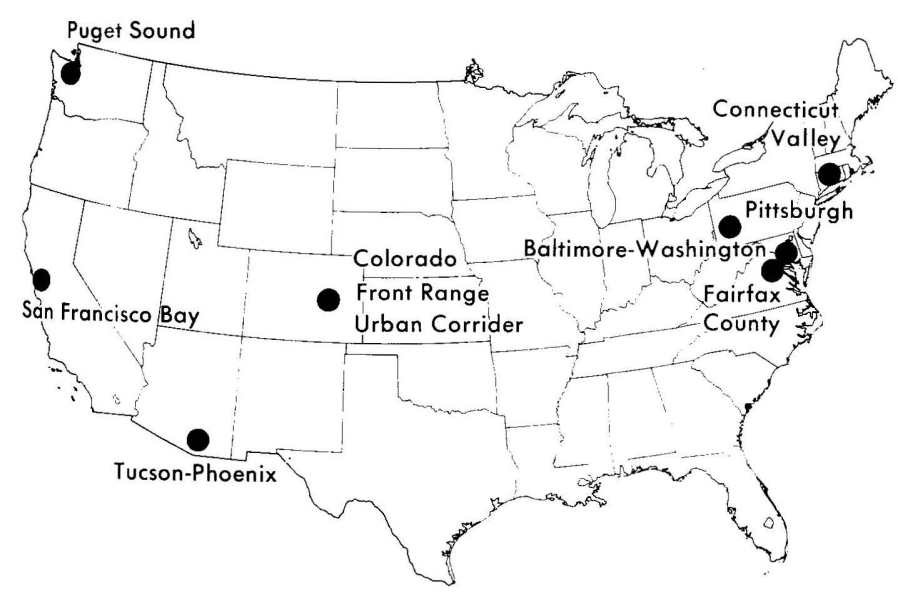

FIGURE 52.-Location of urban area studies in progress during fiscal year 1975.

are conducted by personnel from the Geologic, Water Resources, and Topographic Divisions supported by allocations of personnel and funds from the Earth Sciences Applications program. In fiscal year 1975, about $\$ 1.6$ million was allocated to the urban area studies; however, about $\$ 5$ million of related work coordinated with and ultimately contributing to the urban area studies was also conducted by the Topo- graphic, Geologic, and Water Resources Divisions. An additional $\$ 505,000$ was available to these Divisions from the Appalachian Regional Commission and the Department of Housing and Urban Development for work related to urban area studies.

The urban and adjoining areas under study in 1975 included Baltimore-Washington; Connecticut Valley; Denver, Colo.; Pittsburgh, Pa.; Puget Sound, Wash.; San Francisco, Calif.; Fairfax County, Va.; and TucsonPhoenix, Ariz. (fig. 52). The Kentucky River Area Development District was also studied.

All of the urban areas under study in fiscal year 1975 have rapidly growing populations that impose severe demands on land and water resources. The types of earth-science information collected for land use and resource planners during these studies include character, thickness, and erodibility of soils; quantity and quality of surface water and ground water; definition of hazards associated with floods, earthquakes, landslides, subsidence, and poor foundation materials; and distribution of mineral resources, landforms, slopes, and watercourses. Without earth-science information to define the locations of natural resources and hazardous areas, land use managers run the risk of making decisions that may lead to substantial social and economic costs in future years.

Current urban area study projects were reviewed during fiscal year 1975, in terms of original objectives relative to past and likely future funding. Because of the lower-than-anticipated funding, the original objectives could not be achieved despite strong support from the other Divisions. It was decided to complete short-term goals of five urban area studies in fiscal year 1976, or early fiscal year 1977, and to concentrate funding in the other areas. The Puget Sound urban area study is being reoriented to consider the regional impacts of extensive oil and gas development in Alaska.

The Tucson-Phoenix urban area study, which began in July 1971 and carried through 1975, is an example of an ongoing study. This study area includes about 11,700 square kilometres $(4,500$ square miles) in three counties of Arizona. Reports published through fiscal year 1975 include 25 regional maps (scale 1:250,000) showing land status, distribution and thickness of alluvial deposits, recoverable ground water, vegetation, nonmetallic mineral deposits, chemical quality of ground water, and land subsidence and Earth fissures. An index to maps of flood-prone areas and a largescale slope map were also published, and $901: 24,000$ scale slope maps were released to the open file.

The Arizona State Health and Land Departments use the regional scale maps to make decisions on water supply, sewage disposal, and use of State lands. 
Engineers and supervisors of the Pima County Planning and Sanitation Departments use the various large- and regional-scale maps and reports to identify hazardous areas, plan major sewer lines, deny or alter construction plans in flood-prone or flooderodible areas, and permit or deny real estate development in mineral deposit areas.

Accomplishments of the Earth Sciences Applications program in fiscal year 1975 included:

- Publication of "Seismic Hazard and Land-Use Planning" by Nichols and Buchanan-Banks (1974). An outgrowth of San Francisco Bay regional studies, the report summarizes and demonstrates the need for land use planning in areas of known seismic hazards.

- Publication of maps showing the potential sources of gravel and crushed-rock aggregate in certain areas of the Front Range Urban Corridor, Colo., specifically, (1) the Boulder-Fort Collins-Greeley, (2) Greater Denver, and (3) Colorado Springs-Castle Rock areas (Colton and Fitch, 1974; Trimble and Fitch, 1974a, b). These maps are the basis of local jurisdictions' preliminary evaluation of land development plans in response to State legislation that requires an evaluation of all mineral resources (metallic and nonmetallic) and geologic hazards before a real estate development is approved.

- Publication of "Relative Susceptibility of Lakes to Water-Quality Degradation in the Southern Hood Canal Area, Washington" by Bortleson and Foxworthy (1974). A result of early studies in the Puget Sound urban area, the report presents a method of evaluating future lake quality that has been adopted by State agencies.

- Completion of 23 open-file maps in Allegheny County, Pa., showing landslide susceptibility. An outgrowth of the Greater Pittsburgh region urban area study supported by the Appalachian Regional Commission, the maps are a valuable aid to land use planners, developers, and residents in avoiding the widespread natural hazard of landslides.

- Completion of six open-file, single-topic, earthscience maps of Montgomery County, Md. (Froelich, 1974a, b, c, d, e, f) and maps of the geology, mineral resources, and construction conditions of Prince Georges County, Md. (Hack, 1975a, b, c). The maps of the Baltimore-Washington urban area study are being widely used by regional planners, decisionmakers, and developers for land use management.

- Completion of about 33 single-topic earth-science maps in the Connecticut Valley urban area. These kinds of maps and their uses are explained in a report entitled "Geologic and hydrologic maps for land-use planning in the Connecticut Valley with examples from the folio of the Hartford North quadrangle, Connecticut" by Pessl and others (1972).

\section{Evaluation of study results}

The urban area projects are pilot studies to develop and demonstrate techniques of earth-science data collection and presentation that appear to be most useful to land use planners and decisionmakers. All the urban area studies have focused on regional planning and problems, yet local jurisdictions have been major users, perhaps because of the lack of essential earthscience data at larger map scales. At the urging of project personnel, some local governments have developed their own earth-science expertise to apply existing data to local needs. In the San Francisco Bay region, for example, four of the nine counties and one major city have established full-time geologist positions, and several other communities employ consultants or earth scientists part time, whereas none were employed in 1970 when the study began.

A survey was conducted to assess the extent to which maps and reports from the San Francisco Bay region study have been applied in land use decisions (Kockelman, 1975). The following applications identified during the survey are indicative of the widespread use of the study products at all levels of government:

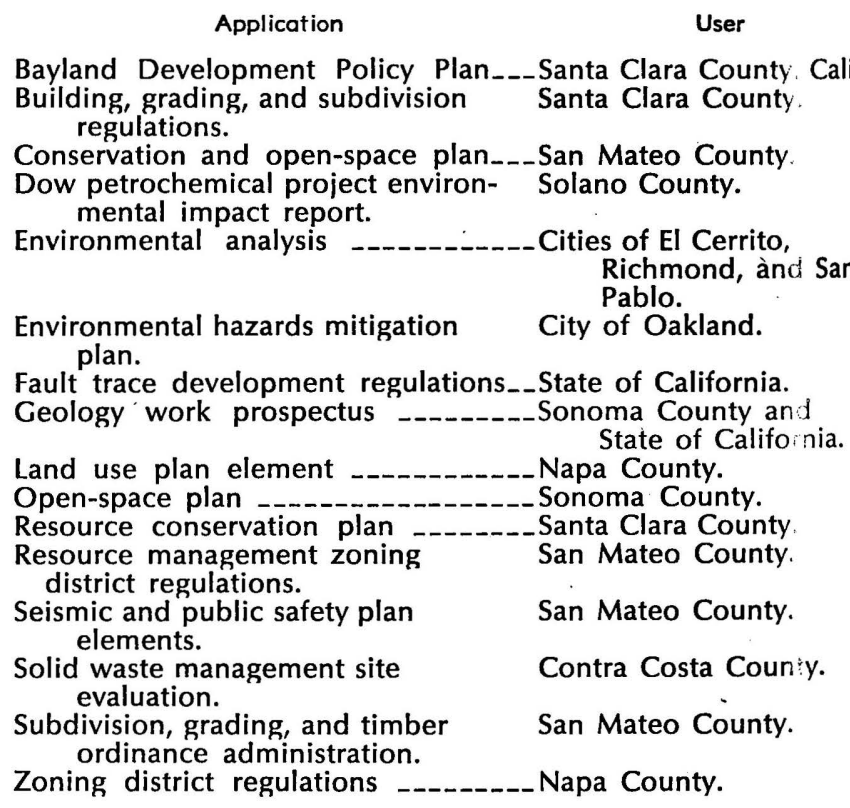

The Department of Housing and Urban Development, a principal cooperator in the San Francisco Bay region study, contracted with Arthur D. Little, Inc., to conduct an evaluation of the study. Although the report (Arthur D. Little, Inc., 1975) was prepared prior to the completion of many of the interpretive reports of the study, the findings were significant: 
"The SFBRS Program has:

A. Raised the level of consciousness about natural hazards in the user community.

B. Begun to bridge the communication gap and improve information transfer among scientists, planners and decisionmakers.

C. Developed new, more detailed earth-science data for a complex geological area larger than Connecticut.

D. Expanded the focus and content of earth-science studies in other urban areas.

E. Strongly influenced the organizational structure of USCS, making it more responsive to data-application needs of others.

F. Strengthened the environmental requirements of and responses to HUD programs in the Bay area.

G. Improved the capability of ABAG (Association of Bay Area Governments) in environmental assessment, regional planning and decisionmaking.

H. Improved the capability of county and local planning agencies to perform environmental assessments and land use planning and to prepare codes and ordinances.

I. Experimented with new methods of data presentation and begun the development of a common language among scientists, planners, and users of resources."

The report also states that "Much still remains to be done to strengthen the fledgling impact of earth sciences in land use and environmental planning decisions." Perhaps the most valuable result of the continuing urban area studies will be the extension of effective communications between earth scientists, land use planners, and decisionmakers throughout the United States. If so, we may one day truly achieve a harmonious balance wherein man makes full use of land resources while he maintains esthetic and environmental values and avoids natural hazards.

\section{RESOURCE AND LAND INVESTIGATIONS PROGRAM}

The Department of the Interior established the Resource and Land Investigations program in September 1972 to mobilize more effectively its technological capacity and scientific competence for making objective analyses of land use alternatives. The Survey was assigned to take the lead in developing a technology and an information base for efficient and safe resource and land development in collaboration with other Interior agencies. The Survey's input to this program comes principally from the multidisciplinary studies conducted under the aegis of the Earth Sciences Applications program.

The purpose of the program is to improve technical communication between the collectors and analysts of resource and land information and the planners, managers, and decisionmakers in Government, industry, and the public sector. This goal is accomplished by coordinating the activities of the several Bureaus in those cases where a multidisciplinary perspective would improve the Department's ability to communi- cate with the planning community and by coordinating the Department's technical response to complex issues relating to land resource analysis. To improve the transfer of technical information in the planning community, directories, catalogs, and bibliographies are compiled and distributed that describe the information products, services, and research. The program also provides for technical assistance to aid planners in the acquisition and interpretation of information and in the development, selection, and application of planning tools.

The Resource and Land Investigations program in fiscal year 1975 included activities to:

- Identify and assess the utility of selected information products, geographic data systems, and data sources to State and local planning communities.

- Develop and distribute directories of data holdings and special information products of the Department of the Interior.

- Identify technical expertise in the Department that is needed by regional, State, and local planning communities and develop administrative procedures to make appropriate personnel available for consultation.

- Support and coordinate the preparation of guidebooks to planning methodologies.

Accomplishments during the year included the completion of guidebooks and other reports on:

- Utility corridor siting-A guidebook to methods for locating power transmission lines and pipelines and evaluating potential environmental impacts (GrafWebster and others, 1974a).

- Powerplant siting-An annotated bibliography on factors influencing the location of thermal power generating facilities (Graf-Webster and others, 1974b).

- State land use programs-A series of background papers on land use planning and program analysis prepared by the Council of State Governments' Task Force on Natural Resources and Land Use Information and Technology (1974a, b, c, d, e; 1975a, b, c) as part of a grant from the Geological Survey.

- Environmental analysis methodology-A review and annotated bibliography of methodologies for evaluating environmental impacts (Bennington and others, 1974).

\section{Evaluation}

The reports, bibliographies, and assistance on planning techniques have been well received, and user responses have identified the need for more coordination between Federal and State data-collection and dissemination programs and for closer cooperation 
within the planning community to provide specific information for land use information systems, critical environmental area planning, and assessment of the utility of information products for planning needs.

\section{GEOGRAPHY PROGRAM}

The Geography program links and integrates social science information and the techniques of geographic analysis with earth-science information collected by the Geological Survey. Activities of the program include:

- Mapping land use and land cover on a nationwide basis.

- Developing and demonstrating techniques of land use mapping using remote sensor data and a geographic information system for handling land use data.

- Conducting field investigations and participating in multidisciplinary studies that contribute to solutions of problems arising from interactions of land use practices and environmental factors.

- Contributing to the National Atlas project.

Planning and implementing programs designed to promote wise use of the land depend in part on a knowledge of the present distribution of and temporal changes in different types of land use and land cover and on a knowledge of where urbanization and other types of development are occurring. The location, area, and percentages of land use and land cover are among the types of statistical data used by Federal and State legislators and local officials to determine land use policy, to project demands for different types of land use, to predict where future development pressures will occur, and to formulate plans for regional development. Current land use and land cover data also support Federal and State planning for developing energy resources, managing public lands, siting public facilities, developing recreational areas, managing water resources, and assessing potential and actual natural disaster damages.

\section{National land use and land cover mapping and data compilation}

In fiscal year 1975, the Geological Survey established a Land Use Data and Analysis program to collect a comprehensive national baseline set of land use and land cover data that would alleviate or remedy many of the shortcomings of various types of existing data. Maps of current land use and land cover for the entire Nation are being prepared at $1: 125,000$ scale $(1.25$ kilometres to the centimetre, or 2 miles to the inch). Additional maps are being prepared in overlay for- to other sets of information such as: (1) resources on and ownership patterns pertaining to Federal lands; (2) certain resource management data, such as drainage-basin management; (3) political subdivisions, for example, counties and States; and (4) various types of census data.

The classification system being employed to map land use and land cover was developed in cooperation with many Federal and State agencies, employs common terminology, and is flexible (Anderson and others, 1976). Applied research has been conducted to assess the accuracy of the maps, as well as that of the data requirements and inventory methods, such as the application of Landsat digital data to land use and land cover mapping needs.

A computerized geographic information system has been developed to store and retrieve the data compiled under the national land use mapping program and other Survey land use and land cover research projects. The system includes: (1) entry of digitized land use and land cover maps and other related data; (2) editing and updating of the data base; and (3) retrieval and manipulation of the data for area measurement, comparative analysis with other dat?, and other analytic applications. Statistical reports are being prepared that present land use and land cover data for counties, watersheds, census county subdivisions, and federally owned land.

Experimental and demonstration land use and land cover maps are produced to test various mepping techniques, remote sensor applications, regional applications, classification variations, computer applications, and combinations of map scale and mirimum area depicted.

Geography program personnel have provided technical assistance to users of Geological Survey land use and land cover data and maps and to those who desire to use the data in conjunction with computer so itware developed by the Geography program or who need the data converted to use with other systems. For example, the Geography program is cooperating with and assisting the U.S. Fish and Wildlife Service, the Bureau of Land Management, and the Soil Cor:servation Service to utilize the Survey's land use and land cover data in their resource management and planning. A cooperative Geological Survey and Forest Service test of the utility of the data in implementing requirements of the Forest and Rangeland Renewable Resource Planning Act of 1974 was started in fiscal year 1975.

Geography program accomplishments durirg the year included:

- Compilation of land use and land cover data for approximately $1,036,000$ square kilometres $(400,000$ 


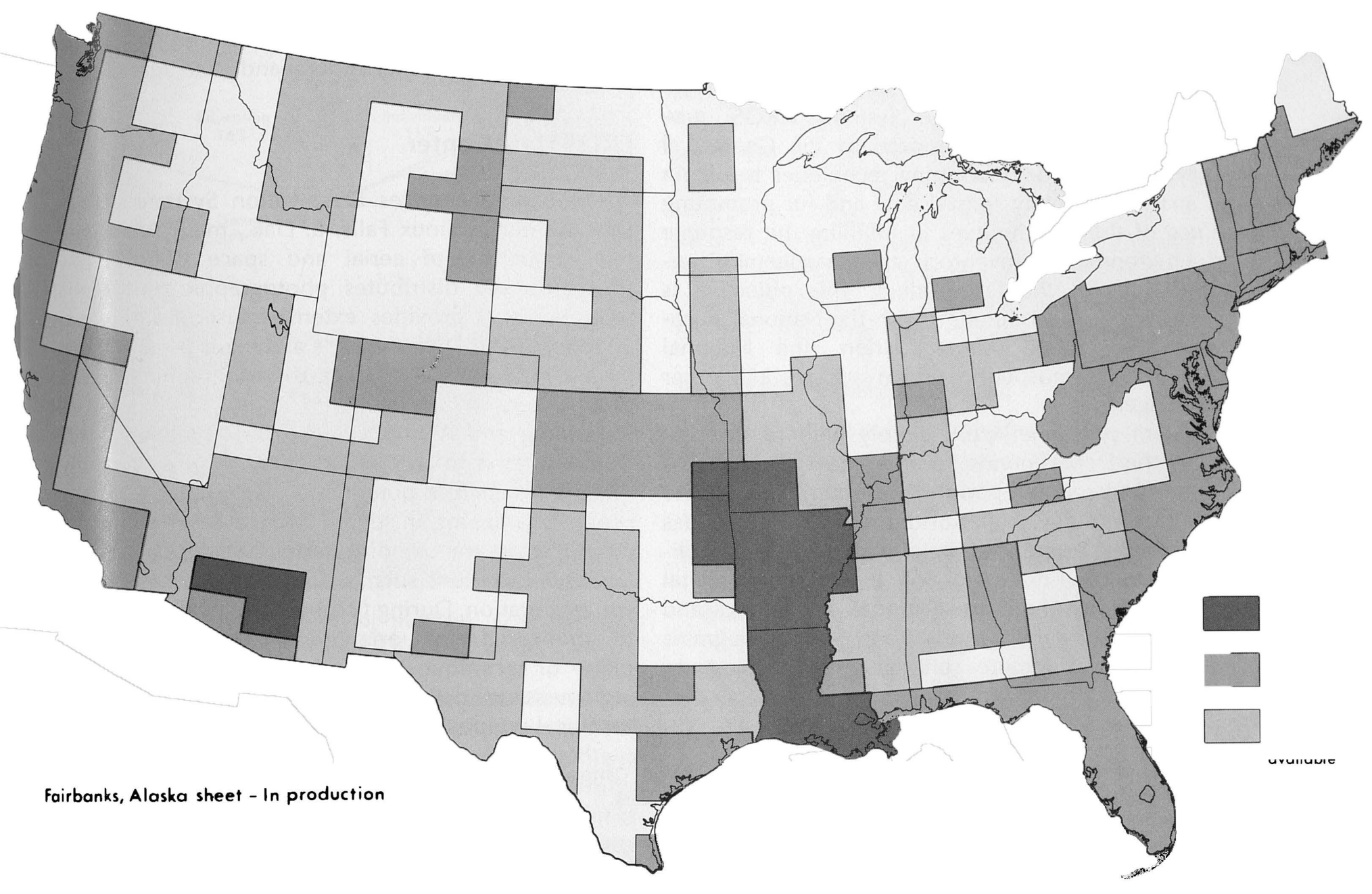

FIGURE 53. - Status of land use and land cover mapping, fiscal year 1975

square miles) during the first year of the national land use mapping effort (fig. 53). Emphasis was placed on mapping coastal areas, energy production areas, and areas covered by other Geological Survey program cooperative agreements such as the Greater Atlanta metropolitan area.

- Compilation of regional and large-scale land use and land cover maps for the phosphate development area in southeastern Idaho for use in the preparation of an environmental impact statement by the Environmental Impact Analysis program.

- Completion of land use maps for the Greater Pittsburgh area, Pa., Lycoming County, Pa., and the Kentucky River Area Development District for the Earth Science Applications program's urban area studies.

- Completion of 85 percent of the Central Atlantic Regional Ecological Test Site (CARETS) Project final reports for the National Aeronautics and Space Administration. These reports describe the results of studies of land use patterns and trends in the Norfolk, Va., area, image interpretation techniques, land use mapping accuracy, land use and air-quality planning, streamflow estimation using remotely sensed data, coastal ecosystems and environmental problems, environmental impact assessment, user evaluation, and geographic information system development.

- Study of limitations on future resource development and urban expansion related to existing patterns of land use in the Little Rock, Ark., area in cooperation with the Ozarks Regional Commission. Land use and land cover data were combined with soils data (such as permeability, structure, and agricultural potential), 100-year flood limits, mineral deposits data, and fish and wildlife information to produce a statistical data base that could be used in assessing limitations on future resource development and urban expansion.

Finally, Geography program personnel started a study of the development of the oil and gas industry on the Louisiana coast in fiscal year 1975 to determine the impact on land use and land cover of canal system expansion, maritime facilities siting, and changes in the labor force since 1947. 


\section{EARTH RESOURCES OBSERVATION SYSTEMS PROGRAM}

In 1966, the Secretary of the Interior established the Earth Resources Observation Systems (EROS) program. The program, administered by the Geological Survey, provides for developing techniques to obtain and analyze remotely sensed data and for promoting the use of these techniques in fulfilling the resource and environmental inventory and management responsibilities of the Department. This objective is accomplished in cooperation with the National Aeronautics and Space Administration, the National Oceanic and Atmospheric Administration, and other Federal agencies.

Program personnel work closely with representatives of the Department's Bureaus and Offices to coordinate and jointly sponsor applications of remote sensing technology. Much of the research, which has resulted in the demonstration of numerous new applications, has been made possible by the experimental data acquired through the National Aeronautics and Space Administration's Landsat and Skylab programs and their aerial remote sensing research program. Other research draws on data collected by other systems, such as the environmental satellites of the $\mathrm{Na}$ - tional Oceanic and Atmospheric Administration and aerial remote sensing activities sponsored by Department Bureaus and other Federal and State agencies.

\section{EROS Data Center}

The Earth Resources Observation Systems (EROS) Data Center in Sioux Falls, S. Dak., maintains an extensive archive of aerial and space photography, processes and distributes photographic and digital products, and provides extensive user training and assistance. The Data Center's archive is a major component of the Survey's National Cartographic Information Center.

Training and Assistance-A major function of the Data Center is to communicate the results of remote sensing research to potential users. Technical training programs, ranging in length from a few days to one month, stress the use of remotely sensed data to particular applications such as forest inventories or mineral exploration. During fiscal year 1975, the Data Center sponsored eight orientation courses, three discipline- or technique-oriented workshops, three training courses for people from other countries, anc three technical symposia.

FIGURE 54.-Earth Resources Observation Systems and National Cartographic Information Center data inquiry and assistance network.

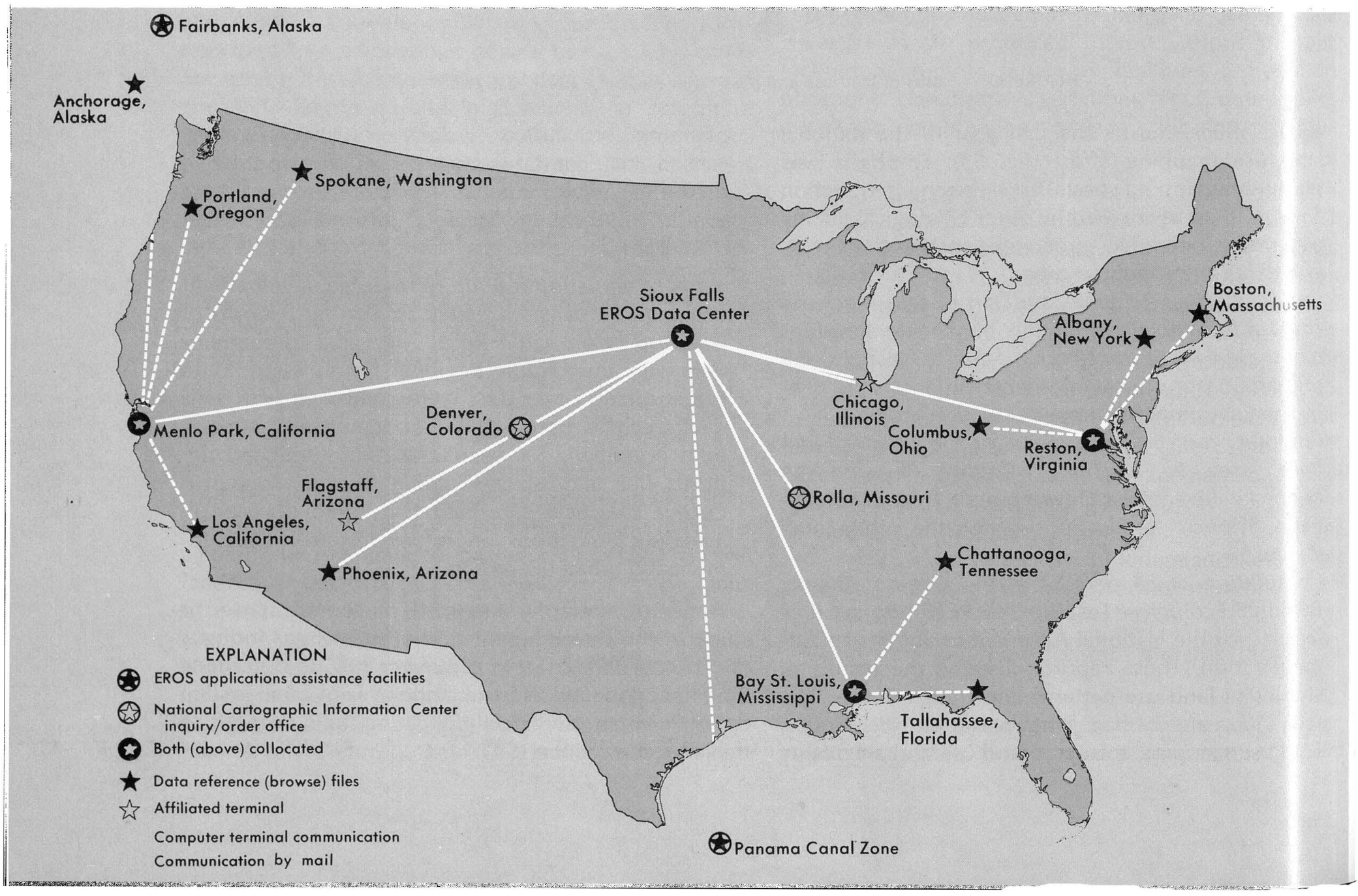




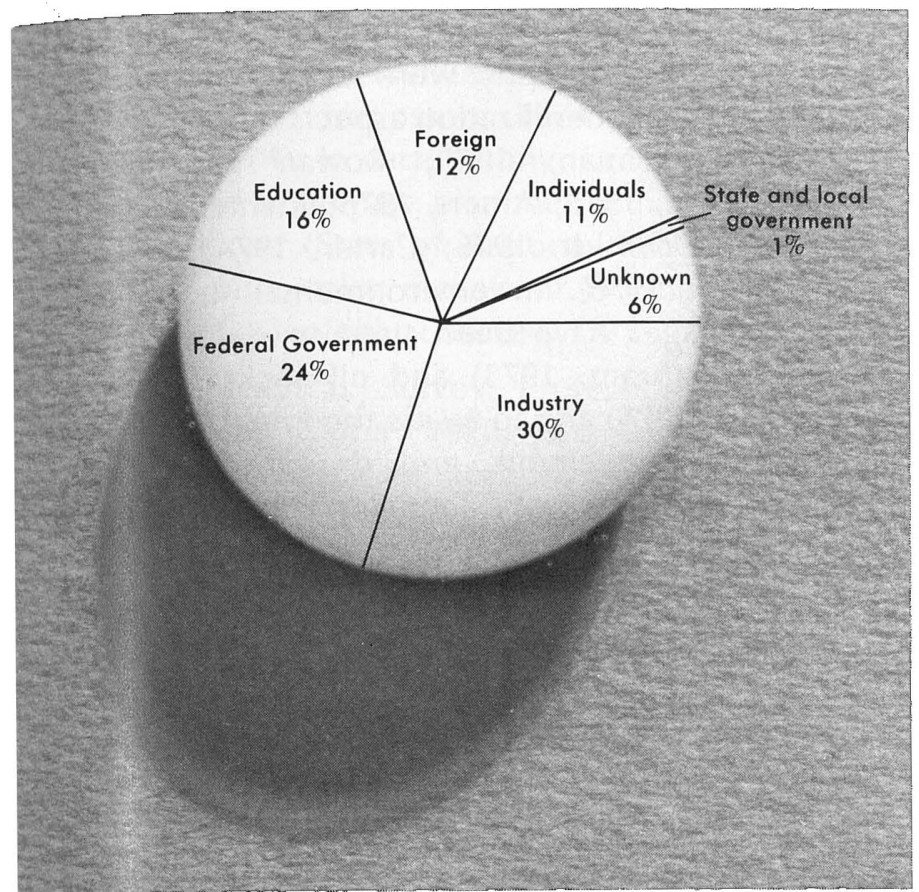

FIGURE 55.-Customer profile for purchase of all data from the EROS Data Center from April 1974 through March 1975.

In addition to formal courses, the Data Center operates a laboratory that provides visiting scientists with access to the latest equipment for processing digital imagery. This equipment is used for research, demonstration projects, and training. Data Center scientists also assist individual Federal, State, and local agencies in applying remotely sensed data to specific problems.

To encourage regional applications, the Earth $\mathrm{Re}$ sources Observation Systems program includes eight applications assistance facilities (fig. 54) where the public can view microfilm copies of imagery available from the Data Center and order data. These facilities also offer assistance in techniques for applying the data to resource problems. In addition to these facilities, 12 Data Reference Files (fig. 54) are maintained for public use in Survey offices throughout the country; these files contain microfilm copies of the most frequently requested data available from the Center.

\section{Data production and dissemination}

The Data Center at Sioux Falls produces and distributes materials from data collected by satellites and aircraft (Watkins, 1975). Data archived at the Center total about 6 million images, including over 500,000 frames of Landsat imagery and Landsat electronic data in the form of computer-compatible tapes; over 40,000 photographs from Skylab, Apollo, and Gemini; more than 1.8 million photographs from the National Aeronautics and Space Administration Research Aircraft program; and almost 4 million aerial mapping photographs from the Department of the Interior.
The demand for reproductions of archival data continues to increase (table 53). In fiscal year 1975, the Data Center filled requests for over 400,000 frames of imagery, an increase of 46 percent over 1974, and the income amounted to $\$ 1.6$ million (about 58 percent from the sale of Landsat data). A customer profile (fig. 55) shows that private industry is the largest single purchaser, accounting for 30 percent of total sales; Federal agencies account for 24 percent. A major application of the data is in mineral and petroleum exploration and related geologic base mapping by major petroleum and mining companies.

\section{Applications and highlights}

Several projects are described below to provide insight into the scope and applications of Landsat and aerial imagery to resource and land use planning and management.

- Petroleum exploration-Representatives from a number of petroleum and petroleum exploration companies have indicated in technical papers that they are routinely using Landsat data to improve their exploration and planning programs.

- Environmental monitoring-In response to the increase in coal mining in the Appalachians, the Geological Survey and other Federal and State agencies are jointly assessing the effect of coal mining on water quality, sedimentation, and streamflow in the Duncan Flats quadrangle of eastern Tennessee. Aerial thermal infrared imagery delinates groundwater outflow, ponding on strip mining benches, storm runoff, surface-water flow, and indications of acid mine drainage. Digitally processed Landsat imagery delineates land cover categories such as forest types, agricultural land, and bare earth caused by strip mining. Both the thermal infrared and the Landsat data provide a base on which to assess the dynamic environmental changes.

- Hydrology-A collaborative study of 1,930 river kilometres (1,200 miles) of a Mississippi River flood during the spring of 1973, conducted by the Survey, the National Oceanic and Atmospheric Administration, the National Aeronautics and Space Administration, and the U.S. Army Corps of Engineers, demonstrated the potential of Landsat imagery for important engineering, economic, disaster-relief, and planning applications and provided the basis for a hydrologic atlas of the flood. Landsat-2 imagery was also used to map the extent of flooding of the lower Mississippi River and the Red, Ouachita, Black, and Atchafalaya Rivers during April 1975 at the request of the State of Louisiana. Analysis of the imagery was performed jointly by personnel of the Louisiana Office of State Planning, the Earth Resources Observation Systems program ap- 
plications assistance facility at Bay St. Louis, Miss. and the Survey's Geography program. By comparing land use maps with Landsat imagery from the time of the flood, State officials determined that flood waters covered approximately 3,200 hectares $(8,000$ acres $)$ of urban and other highly developed regions, 120,000 hectares $(300,000$ acres) of farmland, 44,100 hectares $(109,000$ acres) of upland forest, 282,500 hectares $(698,000$ acres $)$ of wetland forest, and 1,130 hectares (2,800 acres) of sand and silt areas. Both the maps and statistics were used by the State for rapid analysis of flood damage and for immediate documentation of the need for Federal disaster-relief funds.
- Other work-In mineral exploration, Landsat images and aerial photography were used to study the structural and mineralization aspects of a number of regions (Sisselman, 1975; Rowan and others, 1974; Rowan, 1975; Albert, 1975; Richter and others, 1975; Schmidt, 1976; Carter, 1974; Williams and Carter, 1976). In environmental monitoring, Landsat images have been used to detect terrain changes (Lathram, 1973) and oil slicks (Svensson and others, 1975) and to assess the impacts of flood, fire, glacial movement, and drought (Robinove, 1975). Landsat imagery, aerial photography, and thermography have been used in studies of geothermal areas, glaciology, volcanology, cartography,

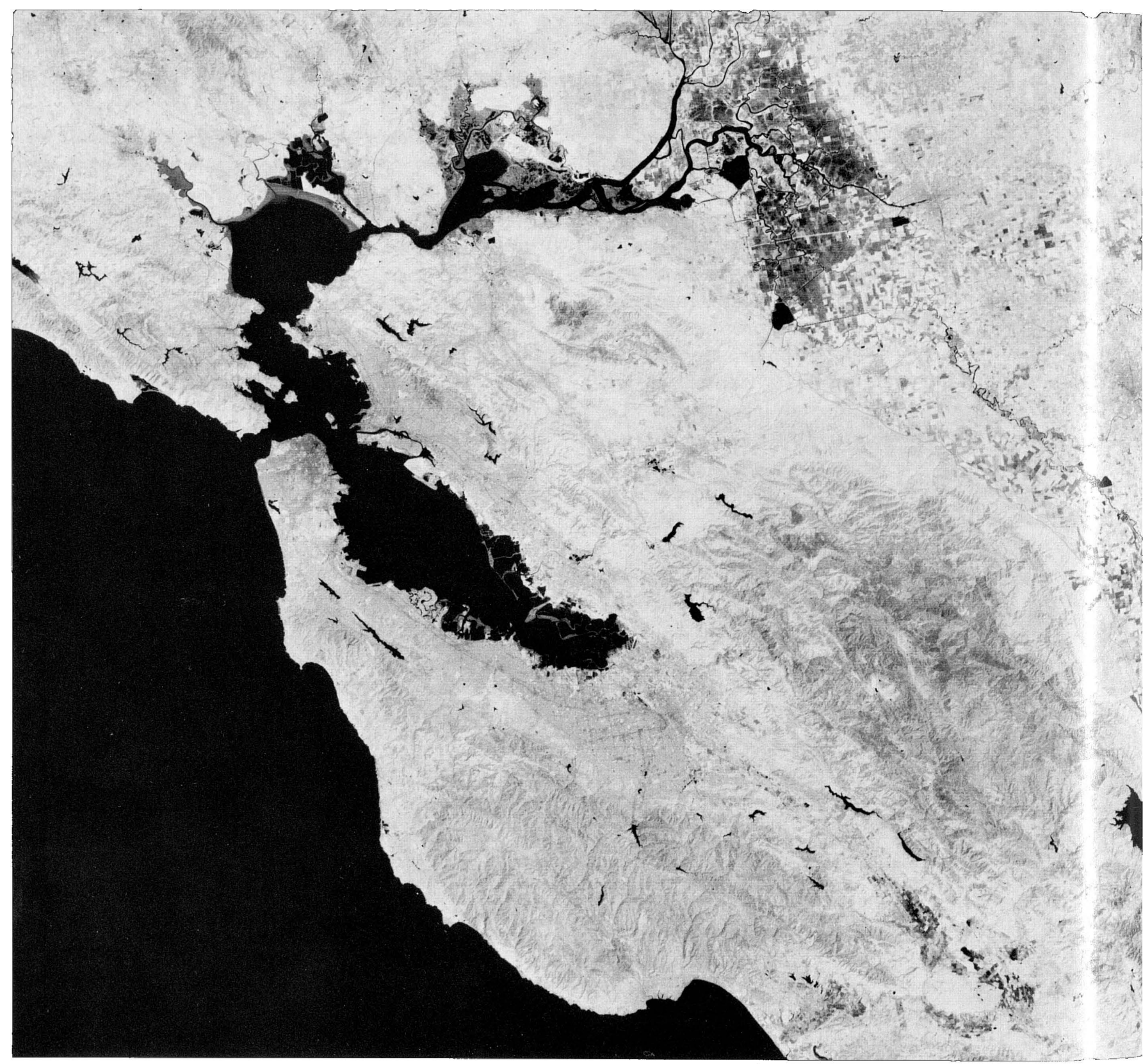

Landsat image of the San Francisco Bay region, California. 
rangeland management, and environmental monitoring in Iceland (Williams and others, 1974; Williams and Thorarinsson, 1974; Thorarinsson and others, 1974). In cartography, Landsat images have been used to prepare planimetric maps of Antarctica and Arizona (State of Arizona, 1975) and to produce a false-color mosaic of Florida at 1:500,000 scale (U.S. Geological Survey, 1975).

U.S. Geological Survey Professional Paper 929 (Williams and Carter, 1976) is a compilation of 85 case histories of the applications of Landsat-1 data to global cartographic, geologic, hydrologic, geographic, and oceanographic problems. This report provides substantive documentation of applications of satellite remote sensing systems for operational programs.

Program highlights of the year included:

- Distribution of over 400,000 frames of imagery valued at over $\$ 1.6$ million.

- Reduction of product delivery time to an average of 12 days by mid- 1975.

- Improvement of data quality by applying recent advances in photographic processing methods and strict quality controls on both incoming reproducible materials and on outgoing data products.

- Training courses and workshops attended by more than 150 scientists. Formal courses on remote sensing techniques had 102 attendees representing 35 countries.

- Successful launch of Landsat-2 by the National Aeronautics and Space Administration and Congressional approval of Landsat-C made possible continued research and demonstration projects on the application of satellite images of the Earth.

- Availability of cloud-free Landsat images for the entire United States.

- Preparation of a mosaic of 24 separate Landsat images of the State of Arizona. This project demonstrated the usefulness of a gridded image as a base map for State and regional planning. A similar mosaic was also prepared for Florida.

\section{Evaluation}

Data production statistics, post card responses from people who purchase data, evaluation forms by participants in training courses, and interaction with Department coordinators provide a basis for evaluating the progress of the Earth Resources Observation Systems program.

The increasing demand for products is one indication of the success of the program. Each improvement in delivery time or data quality has been followed by an increase in demand for products. Another indication of success is the increasing number of requests for workshops and training in how to use the data.
Perhaps the most important measure of success, however, is the increasing applications of the data to resource management, environmental protection, and scientific research.

Some agencies have expressed concern about becoming dependent on Landsat data, for several reasons:

1. Landsat is experimental. There is no assurance of program continuity beyond 1980 , or even 1976 , if a spacecraft or launch vehicle fails.

2. Data are not always available quickly enough to be used in making time-critical decisions.

3. Standard photographic products contain less than the complete data content of the original digital data and thereby preclude their use in some applications.

Continuation of the program beyond 1980 will, of course, depend upon Congressional appraisal of the costs and benefits of the Landsat system. The last two reasons for caution are technical, and their solutions are known. Within the resources available, the $\mathrm{Na}$ tional Aeronautics and Space Administration and the Earth Resources Observation Systems program are augmenting their data processing and distribution systems to make the necessary improvements.

\section{ENVIRONMENTAL IMPACT ANALYSIS PROGRAM}

The Environmental Impact Analysis program provides an integrated Geological Survey response to the requirements of the National Environmental Policy Act with:

- Direction, coordination, and expertise in the preparation of environmental impact statements for which the Survey has lead or joint responsibility.

- Technical information and expertise in support of the preparation of statements for which the Survey has contributing responsibility.

- Technical analyses and review of statements and related documents prepared by other agencies.

- Manuals, guidelines, and training courses on the preparation and review of statements.

- Environmental research.

The National Environmental Policy Act requires that a Federal agency contemplating a major action that could significantly affect the quality of the environment must prepare a detailed statement of the possible environmental impacts. The Act further requires that statements must be reviewed by other Federal agencies having pertinent jurisdiction or expertise. In final form, the statement plays an essential role in an agency's decisionmaking process. 
The Geological Survey becomes involved as a lead agency in the preparation of statements through the Conservation Division's supervision of mineralresource exploration, development, extraction, and reclamation operations on Federal and Indian lands. During fiscal year 1975, approximately 80 percent of the environmental impact analysis involving the Geological Survey as the lead agency concerned the development of coal and oil and gas resources. The remaining 20 percent was mainly concerned with critical minerals, such as copper, nickel, and phosphate.

The Geological Survey becomes involved in the preparation of statements as a participating agency, in a nonlead role, both through its supervisory function, as described above, and through its special expertise in the areas of geology, hydrology, and mining and petroleum engineering. During fiscal year 1975, approximately 70 percent of this effort was energy related, involving principally coal and oil and gas leasing operations and projects involving minemouth electric generating plants, coal gasification plants, and related transmission lines, pipelines, and water supply. The remaining 30 percent was mainly concerned with critical minerals.

In accordance with guidelines set by the Council on Environmental Quality, Federal agencies submit environmental impact statements to the Department of the Interior for review. The statements are assigned by the Department to one or more Bureaus, primarily on the basis of legal jurisdiction or special expertise.

The principal objectives of the Environmental Impact Analysis program are to:

- Provide a core group of multidisciplinary specialists to assure the continuity of quality standards through acquired expertise in the preparation and review of environmental impact statements and through associated research and training.

- To reduce the time required for preparation and review of environmental impact statements.

During fiscal year 1975, the program assumed the direction and coordination of Geological Survey efforts to prepare and contribute to statements required by the Secretary of the Interior as background for decisions on leasing, mineral exploration and development, and powerplant construction; these decisions related directly to national issues of energy and critical minerals. The Survey efforts employed a task-force approach-assembling the expertise needed for an individual project from personnel in the Environmental Impact Analysis program, the operating Divisions of the Geological Survey, other Interior Bureaus, other Federal agencies, and contractors.

During the year, the Survey: ration of 10 environmental impact statements. Eight statements concerned the development of onshore coal, oil and gas, and offshore oil and gas operations. The other two concerned critical minerals (fig. 56 and table 24). These statements are in preparation.

- Participated in a nonlead capacity in the preparation of 15 impact statements for which other Federal agencies had lead responsibility. Approximately 70 percent of these statements were energy-related. The remainder dealt with critical minerals. Two were completed during the year (fig. 56 and table 24).

- Provided technical information, gathered by other Survey programs, to the U.S. Forest Service for three impact statements on geothermal energy resources and to the Bureau of Land Management for seven impact statements on leasing of the Outer Continental Shelf.

- Reviewed and commented on 2,046 impact statements and related documents to assist other agencies in areas of Geological Survey jurisdiction and expertise.

\section{Evaluation}

The task-force approach to preparation of en ironmental impact statements has provided a centralized, effective, and flexible means of furnishing lead rship and technical expertise. Management and review of work in progress are being accomplished more efficiently and with more in-depth probing.

The extensive procedures routinely employed for review and criticism of completed statements povide substantial feedback, which promotes rapid de elopment of preparation expertise. These procedures include (1) internal reviews by the Department of the Interior and by agencies participating in the preparation effort, (2) external reviews by a broad spe trum of other Federal agencies, State and local agencies, and the public, and (3) application of the resilts of adjudications.

By the end of fiscal year 1975, the workload associated with preparing required environmental inpact statements was increasing at a rate of about 30 percent per year. This rate reflects the critical problems that the statements address-problems that irvolve the balance between the environmental quality goals of the National Environmental Policy Act and the rapidly growing needs for development and use of the Nation's resources. The rate of increase is expected to continue or to accelerate owing to national fforts to decrease reliance on foreign sources of energy and critical minerals. Furthermore, the level of effert required to review environmental statements prepared by other agencies is increasing at a rate of ab ut 10 percent per year. 

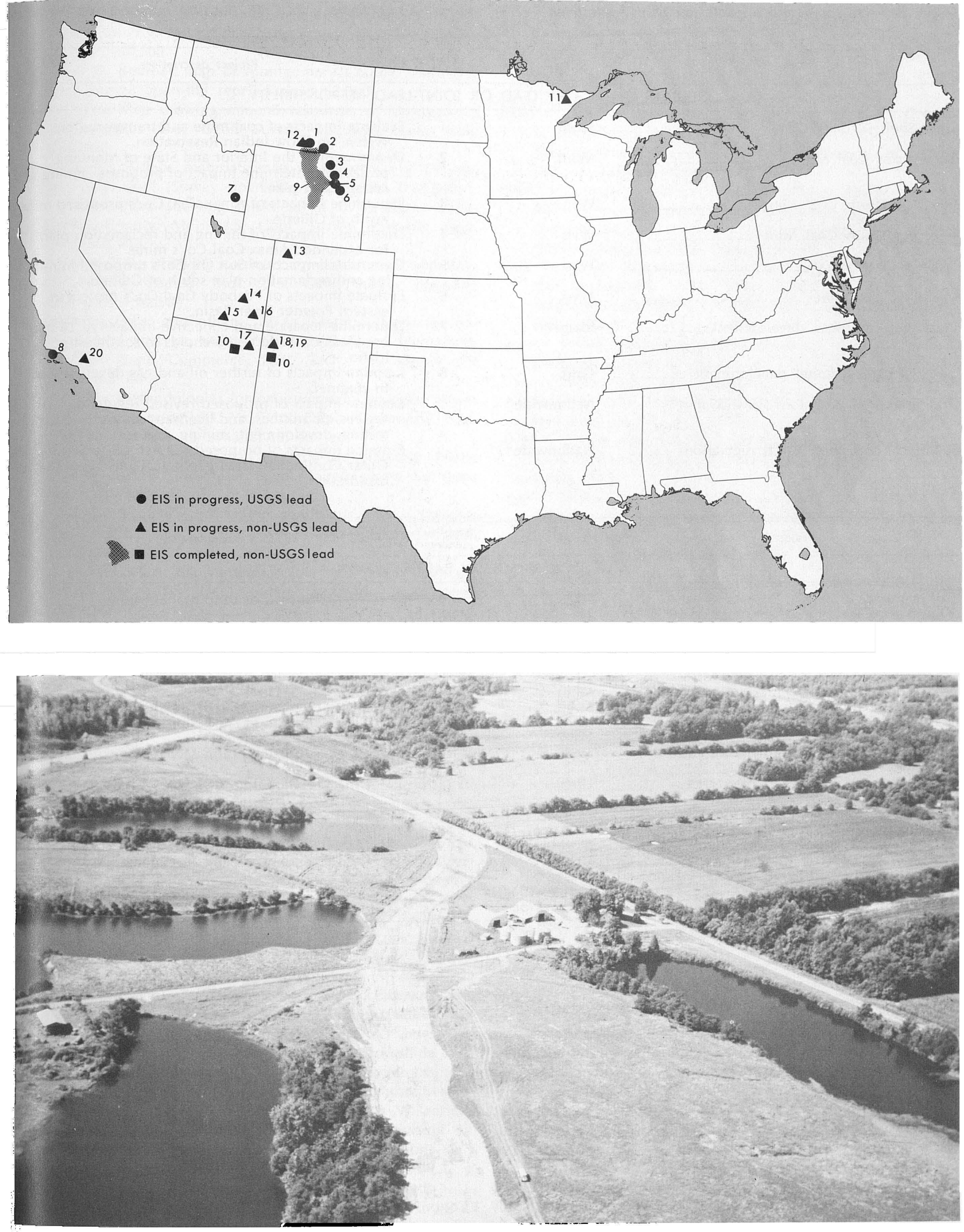

Farmlands and pond created through the reclamation of an area mine in Indiana. Techniques for such reclamation projects were developed during the 1930's. 
TABLE 24.-Environmental impact statements completed or in progress during fiscal year 1975 (locality numbers are keyed to figure 56)

\begin{tabular}{|c|c|c|c|}
\hline Title & State & $\begin{array}{l}\text { Locality } \\
\text { number }\end{array}$ & Project description \\
\hline \multicolumn{4}{|c|}{ GEOLOGICAL SURVEY LEAD OR JOINT-LEAD RESPONSIBILITY } \\
\hline Crow Shell (Youngs Creek) Coal Mine _----- & Mont. & 1 & $\begin{array}{l}\text { Evaluate impacts of coal mine and transportation } \\
\text { system on Crow Indian Reservation. }\end{array}$ \\
\hline East Decker Coal Mine - - & Mont. & 2 & $\begin{array}{l}\text { Department of the Interior and State of Montana } \\
\text { project to determine impact of proposed mining and } \\
\text { reclamation plan. }\end{array}$ \\
\hline Belle Ayr North Coal Mine - & Wyo. & 3 & $\begin{array}{l}\text { Determine impacts of Amax Coal Co.'s proposed mine } \\
\text { north of Gillette. }\end{array}$ \\
\hline Belle Ayr South Coal Mine - & Wyo. & 4 & $\begin{array}{l}\text { Determine impacts of mining and reclamation plan } \\
\text { for expanded Amax Coal Co.'s mine. }\end{array}$ \\
\hline Cordero Coal Mine - & Wyo. & 5 & $\begin{array}{l}\text { Determine impacts of Sun Oil Co.'s proposed min- } \\
\text { ing and reclamation plan south of Gillette. }\end{array}$ \\
\hline Rochelle Coal Mine - & Wyo. & 6 & $\begin{array}{l}\text { Evaluate impacts of Peabody Coal Co.'s project in } \\
\text { eastern Powder River Basin. }\end{array}$ \\
\hline Phosphate resources development _..-_-- & Idaho & 7 & $\begin{array}{l}\text { Determine separate and collective impacts of } 16 \mathrm{~min}- \\
\text { ing plans on Federal leaseholds in southeastern } \\
\text { Idaho. }\end{array}$ \\
\hline Santa Barbara Channel development -------- & Calif. & 8 & $\begin{array}{l}\text { Examine impacts of further oil and gas developmert } \\
\text { in channel. }\end{array}$ \\
\hline $\begin{array}{l}\text { Coal operating regulations ( } 30 \text { CFR, part } \\
\text { 211). }\end{array}$ & Nationwide $^{2}$ & & $\begin{array}{l}\text { Examine impact of proposed revised regulations on } \\
\text { lessees, permittees, and licensees during discovery, } \\
\text { testing, development, mining, and reclamation. }\end{array}$ \\
\hline Geological and geophysical regulations _-...- & Nationwide $^{2}$ & & $\begin{array}{l}\text { Examine impacts of proposed regulations governing } \\
\text { Outer Continental Shelf geological and geophysical } \\
\text { exploration. }\end{array}$ \\
\hline Project & State & $\begin{array}{l}\text { Locality } \\
\text { number }\end{array}$ & Lead agency \\
\hline \multicolumn{4}{|c|}{ GEOLOGICAL SURVEY PARTICIPATION } \\
\hline $\begin{array}{l}\text { Coal resources in eastern Powder River } \\
\text { Basin - surface mines, generating and } \\
\text { gasification plants, and railroad. }\end{array}$ & Wyo. & 9 & Bureau of Land Management \\
\hline $\begin{array}{l}\text { Cholla project-additional power-generating } \\
\text { units and transmission lines in Arizona } \\
\text { and enlarged coal mine in New Mexico. }\end{array}$ & Ariz.- N. Mex. & 10 & Forest Service. \\
\hline INCO copper-nickel open-pit mine & Minn. & 11 & Do. \\
\hline $\begin{array}{l}\text { Crow Reservation coal program } \\
\text { Coal resources }\end{array}$ & $\begin{array}{l}\text { Mont. } \\
\text { NW. Colo. }\end{array}$ & $\begin{array}{l}12 \\
13\end{array}$ & $\begin{array}{l}\text { Bureau of Indian Affairs. } \\
\text { Bureau of Land Management. }\end{array}$ \\
\hline North Emery powerplant and coal mine - - & Utah & 14 & Forest Service. \\
\hline $\begin{array}{l}\text { Kaiparowits power-generating plant and sur- } \\
\text { face coal mine. }\end{array}$ & Utah & 15 & Bureau of Land Management. \\
\hline $\begin{array}{l}\text { Glen Canyon National Recreation Area } \\
\text { master plan. }\end{array}$ & Utah & 16 & National Park Service. \\
\hline $\begin{array}{l}\text { Coronado power station and mine } \\
\text { El Paso gas coal-gasification plant and mine-- } \\
\text { WESCO coal-gasification plants and mine -- } \\
\text { Los Padres phosphate mining leases } \\
\text { Natural gas transportation system } \\
\text { Coal programmatic } \\
\text { Oil and gas programmatic }\end{array}$ & $\begin{array}{l}\text { Ariz. } \\
\text { N. Mex. } \\
\text { N. Mex. } \\
\text { Calif. } \\
\text { Alaska }^{2} \\
\text { Nationwide }^{2} \\
\text { Nationwide }^{2}\end{array}$ & $\begin{array}{l}17 \\
18 \\
19 \\
20\end{array}$ & $\begin{array}{l}\text { Bureau of Reclamation. } \\
\text { Do. } \\
\text { Do. } \\
\text { Bureau of Land Management. } \\
\text { Do. } \\
\text { Do. } \\
\text { Do. }\end{array}$ \\
\hline
\end{tabular}

1 Joint-lead responsibility with Bureau of Land Management.

2 Not shown in figure 56 .

3 Completed.

\section{REFERENCES}

Albert, N. R. D., 1975, Interpretation of Earth Resources Technology Satellite imagery of the Nabesnà quadrangle, Alaska: U.S. Geol. Survey Misc. Field Studies Map MF655-J, 2 sheets, scale 1:250,000.

Anderson, J. R., Hardy, E. E., Roach, J. T., and Witmer, R. E., 1976, A land use and land cover classification system for use with remote sensor data: U.S. Geol. Survey Prof. Paper 964.

Arthur D. Little, Inc., 1975, An evaluation of the San Francisco Bay region environment and resources planning study (draft report to U.S. Dept. Housing Urban Development): San Francisco, Calif., 93 p.

Bennington, Gerald, and others, 1974, Methodologies for environmental analysis, environmental assessment: 'Springfield,

Va., U.S. Dept. Commerce, Natl. Tech. Inf. Service, PB 244600/AS, $160 \mathrm{p}$.

Bortleson, G. C., and Foxworthy, B. L., 1974, Relative susceptibility of lakes to water-quality degradation in the southern Hood Canal area, Washington: U.S. Geol. Survey Misc. Inv. Ser. I-853-B, scale 1:62,500.

Carter, W. D., 1974, Tectolinear interpretation of an ERTS-1 mosaic, La Paz area, southwest Bolivia, southeast Peru and northern Chile: Comm. on Space Research, 17th Plenary Mtg., Workshop for Developing Nations, Sa Jose dos Campos, Brazil 1974, Paper B.4.3.

Colton, R. B., and Fitch, H. R., 1974, Map showing poiential sources of gravel and crushed-rock aggregate in the Boulder-Fort Collins-Greeley area, Front Range urban corridor, Colorado: U.S. Geol. Survey Misc. Inv. Ser. I-855-D, scale $1: 100,000$. 
Froelich, A. J., 1974a, Natural soil assemblages map of Montgomery County, Md.: U.S. Geol. Survey open-file rept., 6 p., scale $1: 62,500$.

1974b, Bedrock map of Montgomery County, Md.: U.S. Geol. Survey open-file rept., scale 1:62,500.

- 1974c, Map showing mineral resources of Montgomery County, Md.: U.S. Geol. Survey open-file rept., scale $1: 62,500$.

1974d, Surface materials map of Montgomery County, Md.: U.S. Geol. Survey open-file rept., scale 1:62,500.

1974e, Map showing thickness of overburden, Montgomery County, Md.: U.S. Geol. Survey open-file rept., scale $1: 62,500$.

1974f, Map showing contours on the base of saprolite, Montgomery County, Md.: U.S. Geol. Survey open-file rept., scale $1: 62,500$.

Graf-Webster, Erika, and others, 1974a, Methodologies for environmental analysis, utility corridor selection: Springfield, Va., U.S. Dept. Commerce, Natl. Tech. Inf. Service, PB 244601/AS, 84 p.

1974b, Methodologies for environmental analysis, power plant siting: Springfield, Va., U.S. Dept. Commerce, Natl. Tech. Inf. Service, PB 244602/AS, 460 p.

Hack, J. T., 1975a, Geologic map for land-use planning, Prince Georges County, Md.: U.S. Geol. Survey open-file rept., scale 1:62,500.

- 1975b, Map of construction conditions, Prince Georges County, Md.: U.S. Geol. Survey open-file rept., scale $1: 62,500$.

- 1975c, Map of mineral resources, Prince Georges County, Md.: U.S. Geol. Survey open-file rept., scale $1: 62,500$.

Kockelman, W. J., 1975, Use of USGS earth science products by city planning agencies in the San Francisco Bay region, California: U.S. Geol. Survey open-file rept., 110 p., 3 figs.

Lathram, E. H., 1973, Analysis of state of vehicular scars on Arctic tundra, Alaska: NASA Goddard Space Flight Center Symposium on Significant Results Obtained from ERTS-1, Greenbelt, Md., Dec. 1973, Proc., NASA SP-351, v. 1, sect. A, p. 633-641.

Nichols, D. R., and Buchanan-Banks, J. M., 1974, Seismic hazards and land-use planning: U.S. Geol. Survey Circ. 690, $33 \mathrm{p}$.

Pessl, Fred, Jr., Langer, W. H., and Ryder, R. B., 1972, Geologic and hydrologic maps for land-use planning in the Connecticut Valley with examples from the folio of the Hartford North quadrangle, Connecticut: U.S. Geol. Survey Circ. 674, $12 \mathrm{p}$.

Richter, D. H., Albert, N. R. D., Barnes, D. F., Griscom, Andrew, Marsh, S. P., and Singer, D. A., 1975, The Alaskan Mineral Resource Assessment Program-Background information to accompany folio of geologic and mineral resource maps of the Nabesna quadrangle Alaska: U.S. Geol. Survey Circ. $718,11 \mathrm{p}$.

Robinove, C. J., 1975, Disaster assessment and warning with LANDSAT [abs.]: Internat. Symposium on Remote Sensing of Environment, 10th, Univ. of Mich., Ann Arbor, Mich., Oct. 6-10, 1975, p. 116.

Rowan, L. C., 1975, Application of satellites to geologic exploration: Amer. Scientist, v. 63, no. 4, p. 393-403.

Rowan, L. C., Wetlaufer, P. H., Goetz, A. F. H., Billingsley, F. C., and Stewart, J. H., 1974, Discrimination of rock types and detection of hydrothermally altered areas in southcentral Nevada by the use of computer-enhanced ERTS images: U.S. Geol. Survey Prof. Paper 833, 35 p.

Schmidt, R. G., 1976, Detection of hydrothermal sulfide deposits, Saindak area, west Pakistan, in Williams, R. S., Jr.,
Carter, W. D., eds., ERTS-1, A new window on our planet, U.S. Geol. Survey Prof. Paper 929, p. 89-91. [In press.]

Sisselman, Robert, 1975, Looking for minerals via satellite-A far-out approach to exploration: Eng. Mining Jour., v. 176, no. 5 , p. 87-94.

State of Arizona, 1975, Climatological map series: Laboratory of Climatology, Arizona State University, Tempe, Ariz., and Arizona Resources Information System, Phoenix, Ariz., Coop. Pub. no. 5, 5 map sheets.

Svensson, Harald, Helldén, Ulf, and Olsson, Hans-Åke, 1975 ERTS-1 data förr markanvädningskartering och vattenundersökning [ERTS-1 data for land-use mapping and water quality studies]: Statens Naturvårdsverk, v. 615,38 p.

Task Force on Natural Resources and Land Use Information and Technology, 1974a, Data needs and resources for State land use planning: Lexington, Ky., Council of State Govts., $35 \mathrm{p}$.

1974b, Intergovernmental relations in State land use planning: Lexington, Ky., Council of State Govts., 40 p. - 1974c, Land use management_-Proceedings of the National Symposium on Resource and Land Information: Lexington, Ky., Council of State Govts., $127 \mathrm{p}$.

- 1974d, Organization, management, and financing of State land use programs: Lexington, Ky., Council of State Govts., 84 p.

$1974 \mathrm{e}$, State of the art for designation of areas of critical environmental concern: Lexington, Ky., Council of State Govts., 52 p.

-1975a, Issues and recommendations-State critical are programs: Lexington, Ky., Council of State Govts., $45 \mathrm{p}$

1975b, Land-State alternatives for planning and management: Lexington, Ky., Council of State Govts., 100 p.

1975c, Manpower needs for State land use planning and public involvement in State land use planning: Lexington, Ky., Council of State Govts., $30 \mathrm{p}$.

Thorarinsson, Sigurdur, Saemundsson, Kristján, and Williams, R. S., Jr., 1974, ERTS-1 image of Vatnäjokull, in Analysis of glaciological, structural, and volcanic features: Jökull, v. 23, p. $7-17$.

Trimble, D. E., and Fitch, H. R., 1974a, Map showing potential sources of gravel and crushed-rock aggregate in the greater Denver area, Front Range urban corridor, Colorado: U.S. Geol. Survey Misc. Inv. Map 1-856-A, scale 1:100,000.

$1974 b$, Map showing potential sources of gravel and crushed-rock aggregate in the Colorado Springs-Castle. Rock area, Front Range urban corridor, Colorado: U.S. Geol. Survey Misc. Inv. Ser. Map 1-857-A, scale 1:100,000.

U.S. Geological Survey, 1975, Florida, ERTS-1 satellite image mosaic-Experimental printing: Reston, Va., scale 1:500,000.

Watkins, A. H., 1975, The role of the EROS Data Center within the Earth resources program [abs.]: NASA L. B. Johnson Space Center Earth Resources Survey Symposium, Houston, Texas, June 8-13, 1975, Abs. Paper U-2, p. 41-42.

Williams, R. S., Jr., Bödvarsson, Augúst, Fridriksson, Sturla, Pálmason, Gudmundur, Rist, Sigurjón, Sigtryggsson, Hlynur, Saemundsson, Kristján, Thorarinsson, Sigurdur, and Thorsteinsson, Ingvi, 1974, Environmental studies of Iceland with ERTS-1 imagery: Internat. Symposium on Remote Sensing of Environment, 9th, Univ. of Mich., Ann Arbor, Mich., April 15-19, 1974, Proc., v. 1, p. 31-81.

Williams, R. S., Jr., and Carter, W. D., eds., 1976, ERTS-1, A new window on our planet: U.S. Geol. Survey Prof. Paper 929, 362 p. [In press.]

Williams, R. S., Jr., and Thorarinsson, Sigurdur, 1974, ERTS-1 image of Vatnajökull area-General comments: Jökull, v: 23, p. $1-6$. 

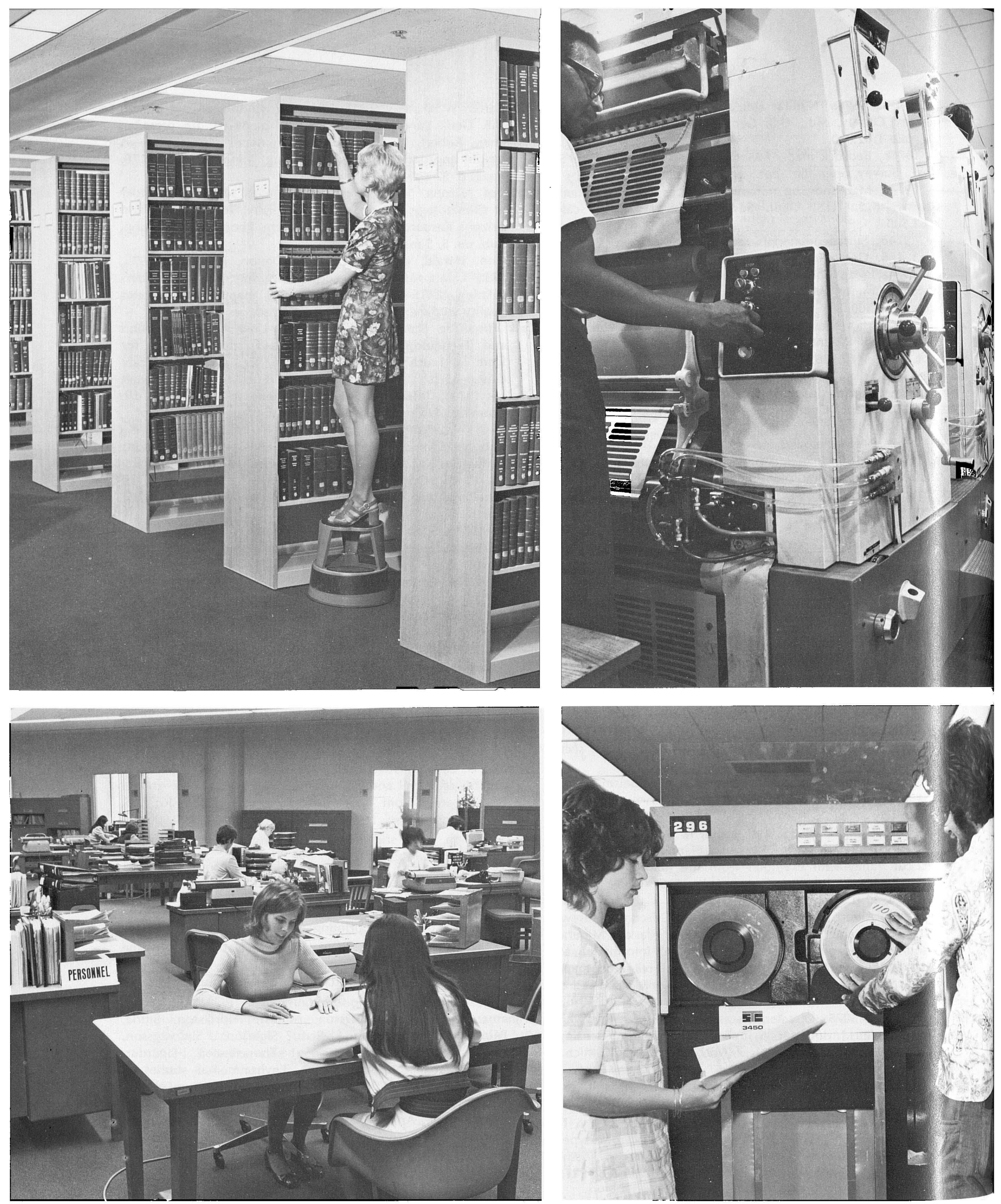

Program support activities at the National Center (clockwise from lower right): Computer Center, Personnel Office; Library; Printing Plant; Public Inquiries Office. 


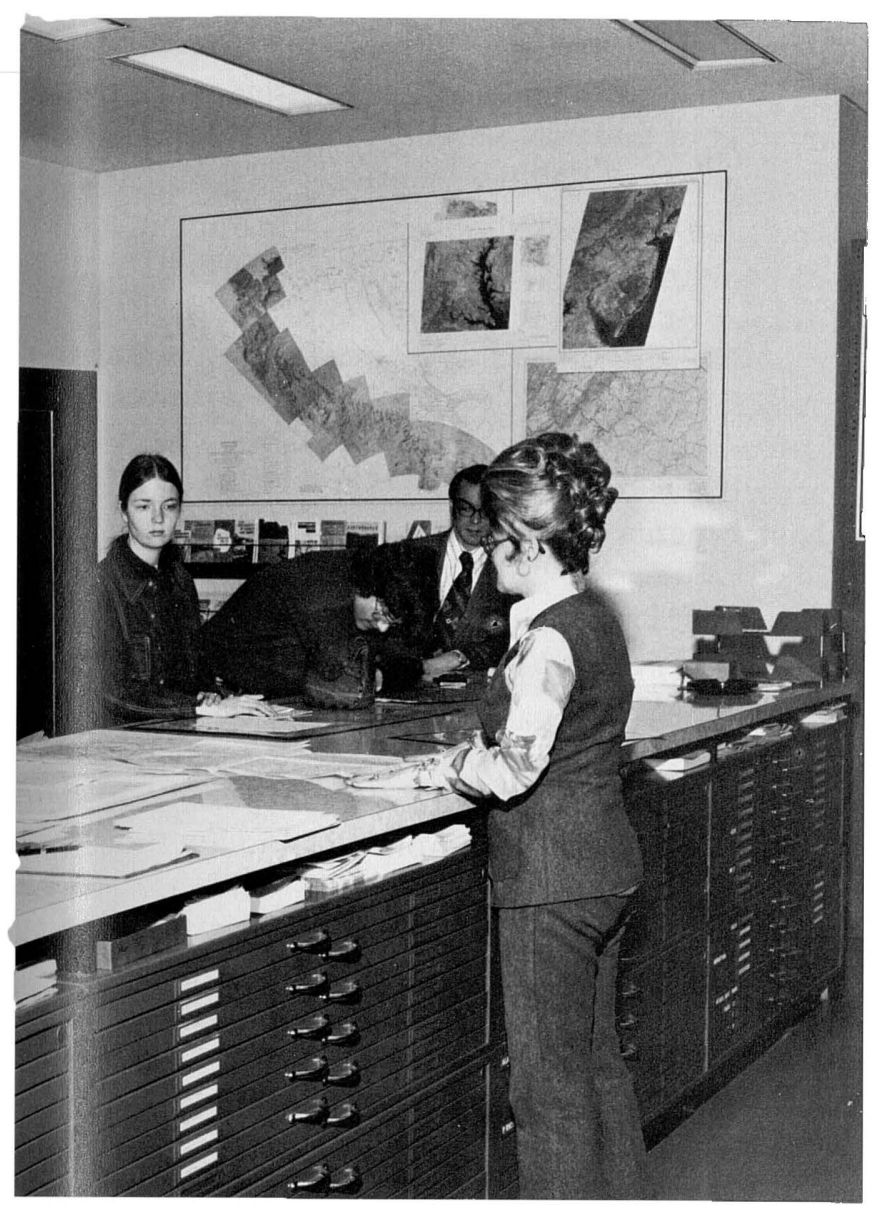

\section{OVERVIEW}

Four organizational units of the Geological Survey provide essential managerial, administrative, and technical services to support the Survey's scientific and regulatory programs:

- Office of the Director, through the Director, Associate Director, Assistant Directors, and their respective staffs (excluding the Land Information and Analysis Office), provides executive direction, coordinates interagency and intrabureau activities, and guides program development.

- Administrative Division supplies the Survey's programs with budgetary, financial, procurement, personnel, and other administrative services and manages the Survey's National Center facilities in Reston, Va.

- Computer Center Division operates a nationwide computing system and provides Survey scientists with a wide range of automatic data processing services.

- Publications Division edits the Survey's scientific and technical publications as well as nontechnical

\section{Prozram Support Activities}

booklets, prints maps, distributes maps and monographs, and answers queries from the public about the Survey's work and reports.

Although operated and funded for the most part by the Geologic Division, the Geological Survey Library is also described in this section because of its importance to the research activities of all Survey programs.

Program support activities are financed by direct appropriations ("General Administration" and"Facilities" "budget activities, table 26), assessments on direct and reimbursable program funds of other budget activities (table 43), and reimbursements from other agencies ("Miscellaneous Services to Other Accounts," table 26).

\section{GENERAL ADMINISTRATION}

General administrative expenses include the executive direction and coordination of Survey programs by the Director's Office and the provision of financial, procurement, personnel, and other administrative services by the Administrative Division.

During 1975, general administrative expenses (table 43) amounted to $\$ 10.8$ million. These expenses were funded from three sources: the General Administration budget activity, about $\$ 3.7$ million; assessments on the direct programs of other activities, $\$ 5.1 \mathrm{mil}-$ lion; and assessments on the reimbursable programs, $\$ 2.0$ million. No assessments are made on cooperative funds from State and local governments. Despite the bigger Geological Survey budget, more employees, and increased use of grants and contracts, general administrative expenses continued to represent only about 3.2 percent of the total Survey budget and have increased less than one half of a percent over the past five years (table 43).

Significant events and accomplishments during the year included:

- Personnel recruiting-More than 1,400 eligible candidates were evaluated in the course of filling some 700 positions, many in highly specialized scientific and engineering fields such as geology, exploration geophysics, and mining and petroleum engineering.

- Minority group programs - In 1971 the Director established the Minority Participation in the Earth Sciences program to encourage young people to 
seek careers in the earth sciences. Under the auspices of this program, the Survey negotiated cooperative education agreements with eight colleges and, through the Government Employee's Training Act, provided tuition for eight minority-group students to pursue an education in the earth sciences. Under provisions of the Intergovernmental Personnel Act, three Survey scientists served as visiting professors in the earth sciences departments of three minority-group colleges. The Survey also employed 95 minority-group students in summer work programs to provide on-the-job experience.

- Training-Personnel training serves to strengthen on-the-job expertise as well as provide opportunities for career development. In fiscal year 1975, there were 4,995 instances in which employees received formal training, 67 percent more than in 1974.

- Conflict of interest-On March 3, 1975, the General Accounting Office reported on apparent conflicts of interest by Geological Survey employees (General Accounting Office, 1975). The report, part of a study of 49 Federal agencies, concluded:

Many USGS employees have financial interests which appear to conflict with their Government duties. Many of these holdings violate the Organic Act of 1879. We believe that the ownership of these conflicting interests is due to deficiencies in the Department's financial disclosure system and that they will have to be corrected to prevent the situation that now exists from continuing.

To resolve the issues raised by the General Accounting Office report, the Survey's Director took the following actions:

1. On January 24,1975 , prior to the conclusion of the General Accounting Office study, the Director instructed the Personnel Officer to direct employees who had reported financial holdings in oil or mining enterprises to divest themselves of these holdings within 90 days.

2. He issued a Survey Administrative Digest (March 5, 1975) to all employees, setting forth the provisions of the Organic Act of 1879 and reiterating the Survey's long-standing regulations prohibiting employees from owning any interest in oil or mining enterprises.

3. He asked the Department Ethics Counselor to have the Department Solicitor review each case of conflict of interest identified in the General Accounting Office report.

On July 3, 1975, the Department of the Interior issued new regulations governing employee responsibilities and conduct. In accordance with these new regulations, all employees were asked either to certify that they do not have holdings in violation of regulations or to come into compliance through
Of the 49 cases identified in the General Accounting Office report, 20 were found not to be in conflict, and the remainder divested themselves of all financial holdings which had the appearance of conflict of interest. No employee has been found to have an actual conflict of interest.

- Freedom of Information Act-Government agencies are now required to respond to Freedom of Information Act requests within ten days and to make available indexes of the types of agency information available. The Geological Survey has established strict procedures for handling these requests in accordance with the law. The impact of the new amendments on the Survey during the last 4 months of fiscal year 1975 was slight-only 30 formal requests for information were received.

- Flexitime experiment-On May 12, 1975, the Geological Survey began a 1-year experiment with flexible working hours for all employees in the Washington, D.C., area. Flexible hours, popularly known as "Flexitime," allow employees to vary their working hours around a "core time" (9:00 a.m. to 3:30 p.m.) when all employees must be present. An initial evaluation indicates that the experiment has been successful. A comprehensive evaluation will be conducted before deciding to continue or expand Flexitime within the Bureau.

- Procurement and contracting activities-Increases in the Survey's programs, especially those related to energy resources, and personnel ceilings have led the Survey to depend more and more on the private sector for services. Over the past five fiscal years the Survey's procurement and contracting program has increased tenfold, from $\$ 9$ million in fisc al year 1970 to $\$ 97$ million in fiscal year 1975 (fig. 57). During this period, personnel responsible for procurement and contracting increased from 34 to 55 . To enable proportionately fewer personnel to handle this rapidly expanding workload and to in prove the procurement process, the Survey awarde contracts for the design of an automated procurement information system and for the preparation of guides to the handling of small purchases, the writing of specifications, and the preparing and submitting of applications for scientific research rrants.

\section{FACILITIES}

The Facilities activity covers the operation of the National Center, which consists of office, labo atory, industrial, and warehouse space in Reston, Va. Funds appropriated for facilities management for 1975 amounted to $\$ 10.8$ million. These funds were maintained in a separate account under the control of the Assistant Director for Administration. 


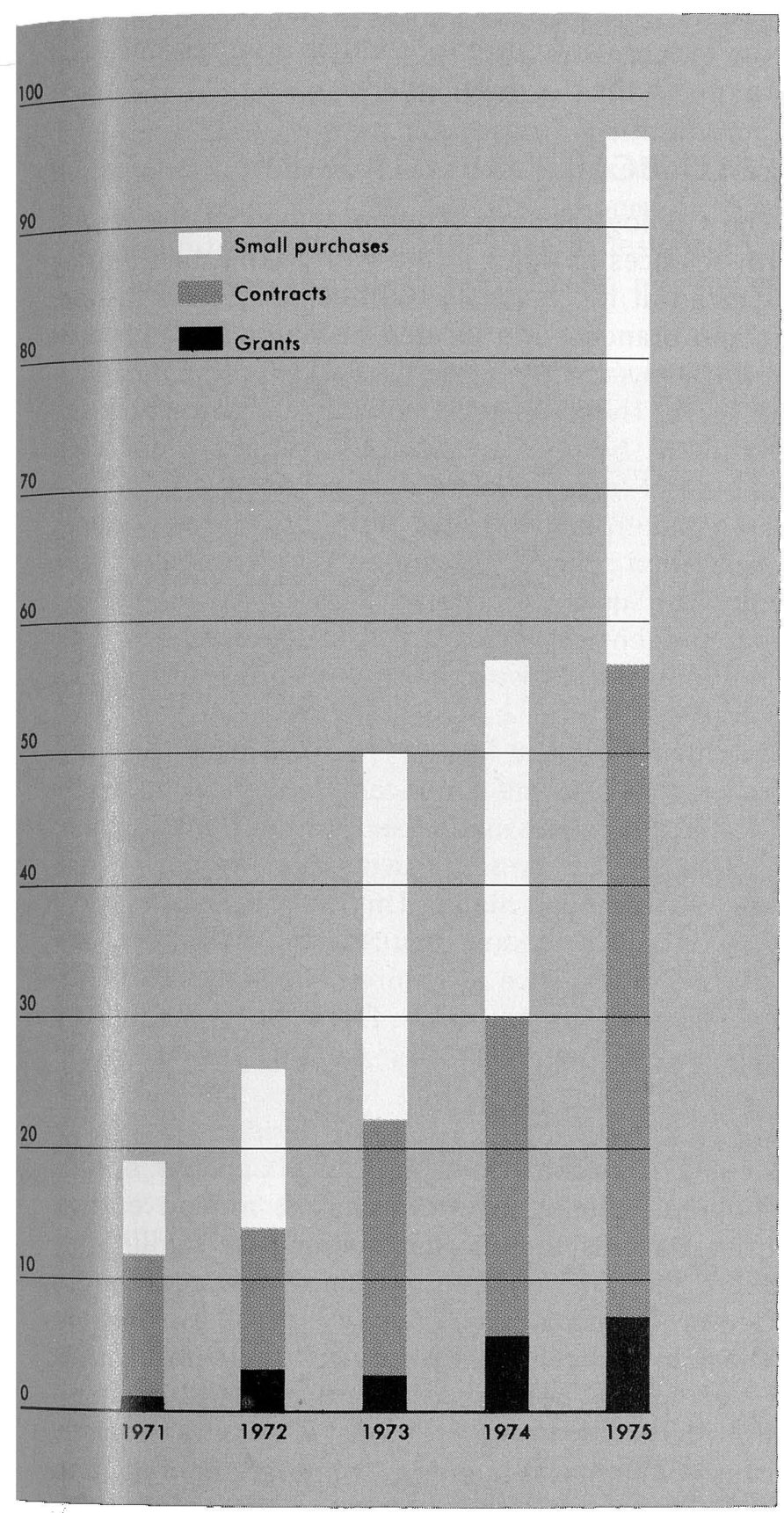

FIGURE 57.-Geological Survey expenditures on grants, contracts, and small purchases, fiscal years 1971-75.

In early March 1975 the Geological Survey completed the relocation of 2,300 employees to the $\mathrm{Na}$ tional Center in Reston, Va., having thus consolidated 30 offices in 17 widely scattered locations throughout the Washington, D.C., area.

\section{COMPUTER TECHNOLOGY}

The Computer Center Division operates a nationwide system of computer facilities and terminals to provide automatic data processing services for the Geological Survey. The primary computer installation, located at the National Center, consists of two interconnected large-scale IBM 370/155 computers. Together, these computers provide high-speed magnetic core memory for $\mathbf{8}$ million characters of information and on-line magnetic disk storage for 5 billion characters of information. During 1975, more than 800 users from 77 remote locations submitted approximately 260,000 jobs to these computers (fig. 58).

In addition to the Reston computer facility, the Survey operates a number of other computers:

- Burroughs Corporation Model B-6700 computer at the Earth Resources Observation Systems Data Center, Sioux Falls, S. Dak.

- Digital Equipment Corporation Model 1070 computer at Denver, Colo.

- Systems Engineering Laboratories, Inc., Model 86 computer at Rolla, Mo.

- A number of special-purpose computers and minicomputers for use in field and laboratory investigations.

The growth of Survey computer use between 1974 and 1975 is reflected in the following statistics:

- During 1975, 260,000 jobs were submitted to the National Center computers, an increase of 39 percent (table 54).

- 70 terminals were connected to the National Center computers for remote entry and processing of batch-oriented tasks, an increase of 30 percent.

- \$5.4 million was spent on in-house data processing and related services, an increase of 4 percent (table 55).

- \$2.1 million was spent on contracts for commercial data processing services, an increase of 80 percent.

Much of this growth can be attributed to the expansion of Survey programs in energy research and development, resource evaluation, lease supervision, and information dissemination, and to the transition from routine batch-processing techniques to more sophisticated interactive processing methods which make use of time-sharing systems and software for data-base management. Program managers, faced with stringent personnel ceilings and increasing workloads, are using automatic data processing techniques to improve the productivity of their staffs. For example, remote terminals give Survey scientists rapid access to information about the availability of maps, aerial photographs, and space imagery; bibliographies of scientific literature; and a variety of data files. In many cases the time required to assemble data for research or to answer requests for information has been significantly shortened. While much still remains to be learned about how to use these tools to greatest advantage, their potential for improving the productivity and quality of Survey programs appears to be 


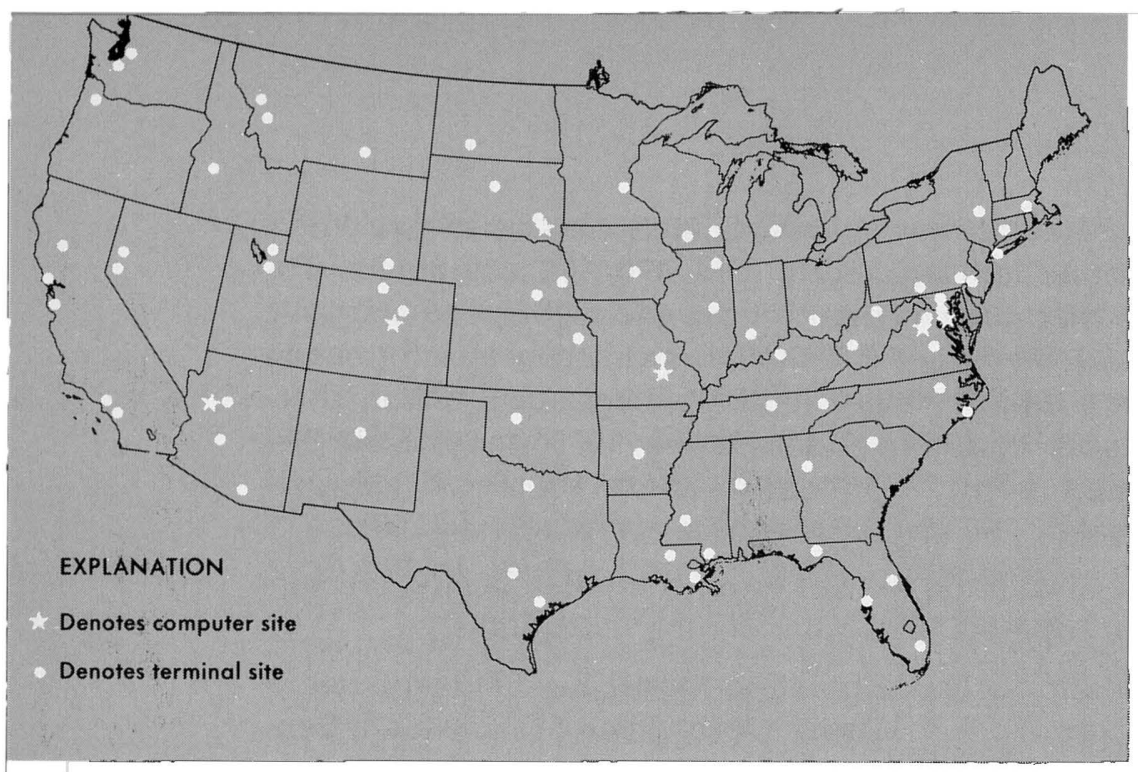

FIGURE 58.-Geological Survey computing network.

great. Projections by the Computer Center Division suggest that Survey scientists and engineers will be using approximately 600 terminal devices by 1980 . Some examples of computer applications in operation or under development during 1975 are listed below:

- Development of a number of geologic data bases dealing with mineral resources, energy resources, and geochemical analyses.

- Operation of a real-time seismic monitoring and earthquake detection network.

- Expansion of the National Water Data Storage and Retrieval System (WATSTORE) to include groundwater data.

- Simulation of surface-water and ground-water behavior in areas expected to be mined for coal and oil shale.

- Development of automated cartographic methods to produce maps from spatial digital data.

- Royalty accounting.

- Tracking the development of Outer Continental Shelf oil and gas leases.

- Processing remote sensing data.

Highlights of computer support activities during fiscal year 1975 included:

- The procurement of System 2000 provided Survey computer users with a comprehensive set of database management procedures for defining new data bases, modifying the definition of existing data bases, and retrieving and updating data.

- Significant enhancements were made to the control program of the IBM 370/155 when a performance analysis revealed that one control routine consumed an exorbitant amount of central-processingunit time. This routine was modified to reduce processing time by one third; thus an additional 4 hours of computer time a day were made available to users. This enhancement deferred the acquisition of a second computer by almost one year.

- The installation of a second IBM 370/155 computer
The new configuration ensures that either processor can execute any current or future program designed to run on the previous system.

\section{GEOLOGICAL SURVEY LIBRARY}

The Geological Survey operates one of the largest earth-sciences libraries in the world. The main library is located at the Survey's National Center in Reston, Va., and branches are located at major research centers in Denver, Colo.; Menlo Park, Calif.; and Flagstaff, Ariz. These libraries collectively contain nearly 1.9 million books, monographs, serials, pamphlets, single-sheet maps, field records, photographs, and related material (table 56). Although these holdings are intended primarily to support the research of the Geological Survey, the library also serves other Government agencies, State geological surveys, academic institutions, and research organizations throughout the country.

The main library at Reston is now using a computer terminal to access the American Geological Institute's GEO-REF, the only broad-based, on-line, bibliographic search service presently available for the geosciences in the United States. This system is an efficient and economical means of furthering the use of the library's earth-science literature collection. Additional terminals are planned for the Denver and Menlo Park libraries. To benefit from the cataloging activities of more than 600 participating libraries, the Survey library has also joined with other Federal libraries in searching the Ohio College Library Center's on-line monograph catalog of more than 2 million ertries. Terminal access to this information has significantly reduced the time required to catalog new acquisitions and to process catalog cards.

The demand for library services increased turing the year partly because of the consolidation of research activities in the National Center and partly because of increases in energy, minerals, and en ironmental program activities. The growth in dem nd is reflected in the following statistics (table 56):

- 52,092 library visits, an increase of 18 percent.

- 80,991 items circulated, an increase of 31 percent.

- 16,965 items loaned to other libraries, an increase of 30 percent.

- 14,774 reference questions answered, an incre ase of 5 percent.

Acquisitions during 1975 included 49,800 issues of periodicals and serials, 12,900 books and monographs, and 21,800 maps.

\section{PUBLICATIONS PROGRAM}

Results of research and investigations conducted by the Geological Survey are made available to the public through increasingly diverse information services 
and publications. Developing mechanisms to make the right piece of data, report, or map available at the right time is a formidable challenge.

The number of reports approved for publication by the Geological Survey has steadily increased during the past 5 years (fig. 59). About 63 percent of the 2,900 reports prepared in 1975 were designated for publication in professional journals and monographs

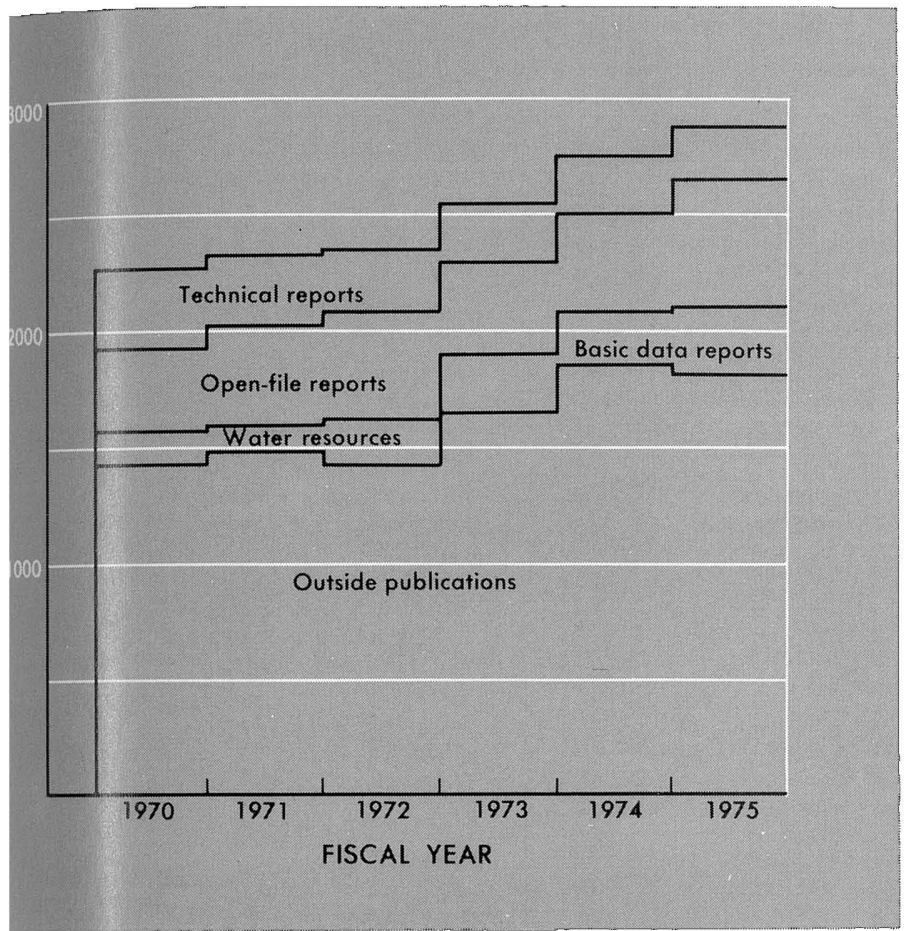

FIGURE 59.-Number of reports approved for publication, fiscal years $1970-75$.

outside the Survey, about 20 percent were released to the open file, and the remainder were scheduled for publication by the Survey (table 45). The Survey also produced over 8,700 topographic, hydrologic, and geologic maps in 1975 (fig. 60 and table 46). A 47-percent increase in the production of topographic maps offset the slowing production of flood-prone area maps after completion of the first phase of the flood-hazards mapping program.

The Publications Division edits the Survey's scientific and technical publications printed by the Government Printing Office, prepares nontechnical booklets, produces reproduction manuscripts for geologic and hydrologic maps, and prints and distributes all Survey maps. Most of the maps are printed at the National Center, but in recent years a substantial number have been printed by commercial firms under contract.

The Publications Division also operates nine Public Inquiries Offices throughout the country that answer queries about the Survey's work and sell maps and books over the counter as agents of the Government Printing Office. Division operating statistics are summarized in table 57.

Highlights of the Publications Division's program in fiscal year 1975 included:

- Acquisition of a 60-inch 5-color printing press which will accommodate 80 percent of the maps to be printed with one pass through the press, as opposed to three passes (for 5-color maps) on the older 2-color presses.

- Purchase of an automated imposition machine to replace tedious manual methods of making printing plates.

- Development of new map paper specifications, with the approval of the Congressional Joint Committee on Printing, which reduced paper costs by 32 cents per pound. Applied to the purchase of 2.4 million pounds of paper during 1975, these new specifications saved the Survey more than $\$ 750,000$.

- Transmittal of 169 technical manuscripts to the Government Printing Office for printing.

- Distribution of 385,000 copies of technical reports.

- Printing of 18.3 million copies of 7,531 maps including 2,575 flood-prone area leaflets and maps.

- Distribution of 10.6 million copies of maps of which 7.8 million copies were sold for $\$ 3.46$ million.

\section{REFERENCE}

General Accounting Office, 1975, Effectiveness of the financial disclosure system for employees of the U.S. Geological Survey: U.S. General Accounting Office Rept. no. FPCD75-131 (March 3. 1975) 9 p.

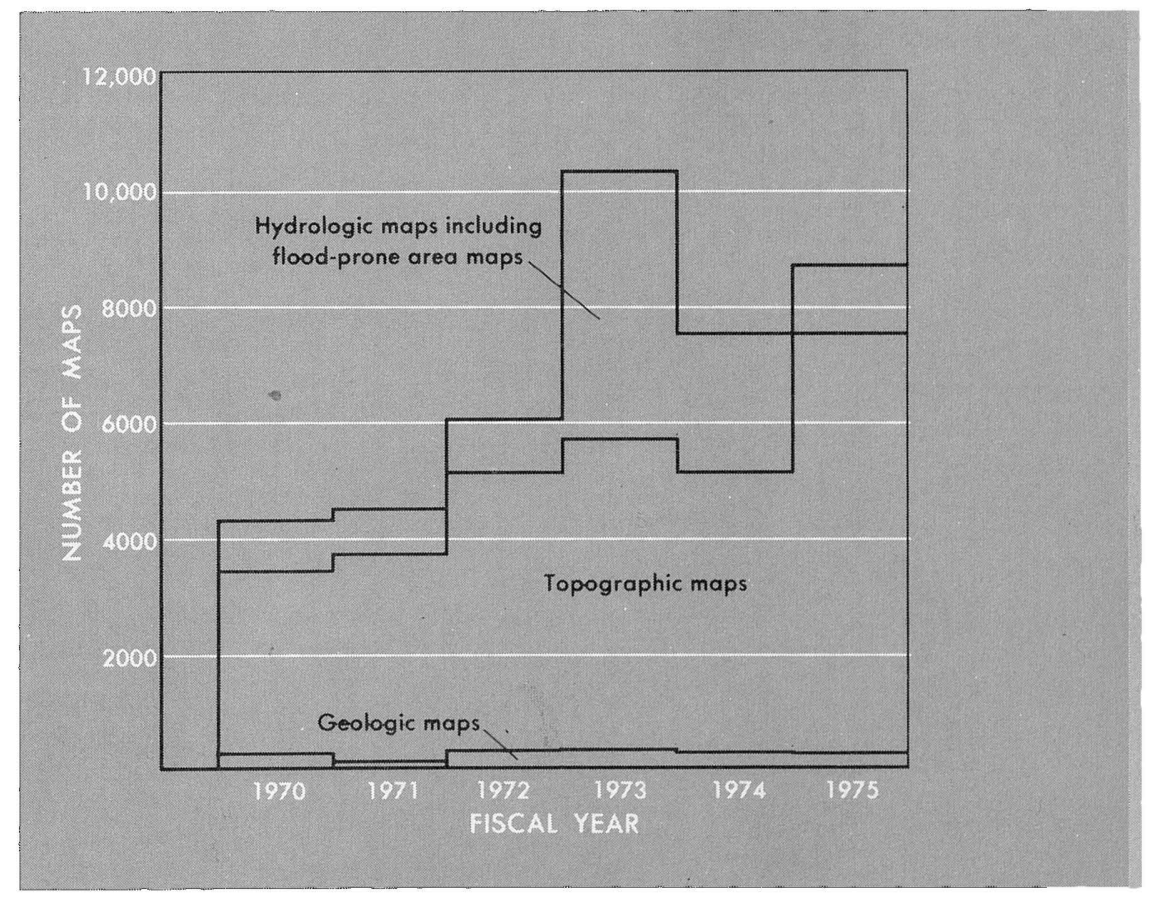

FIGURE 60.-Number of maps produced, fiscal years 1970-75. 


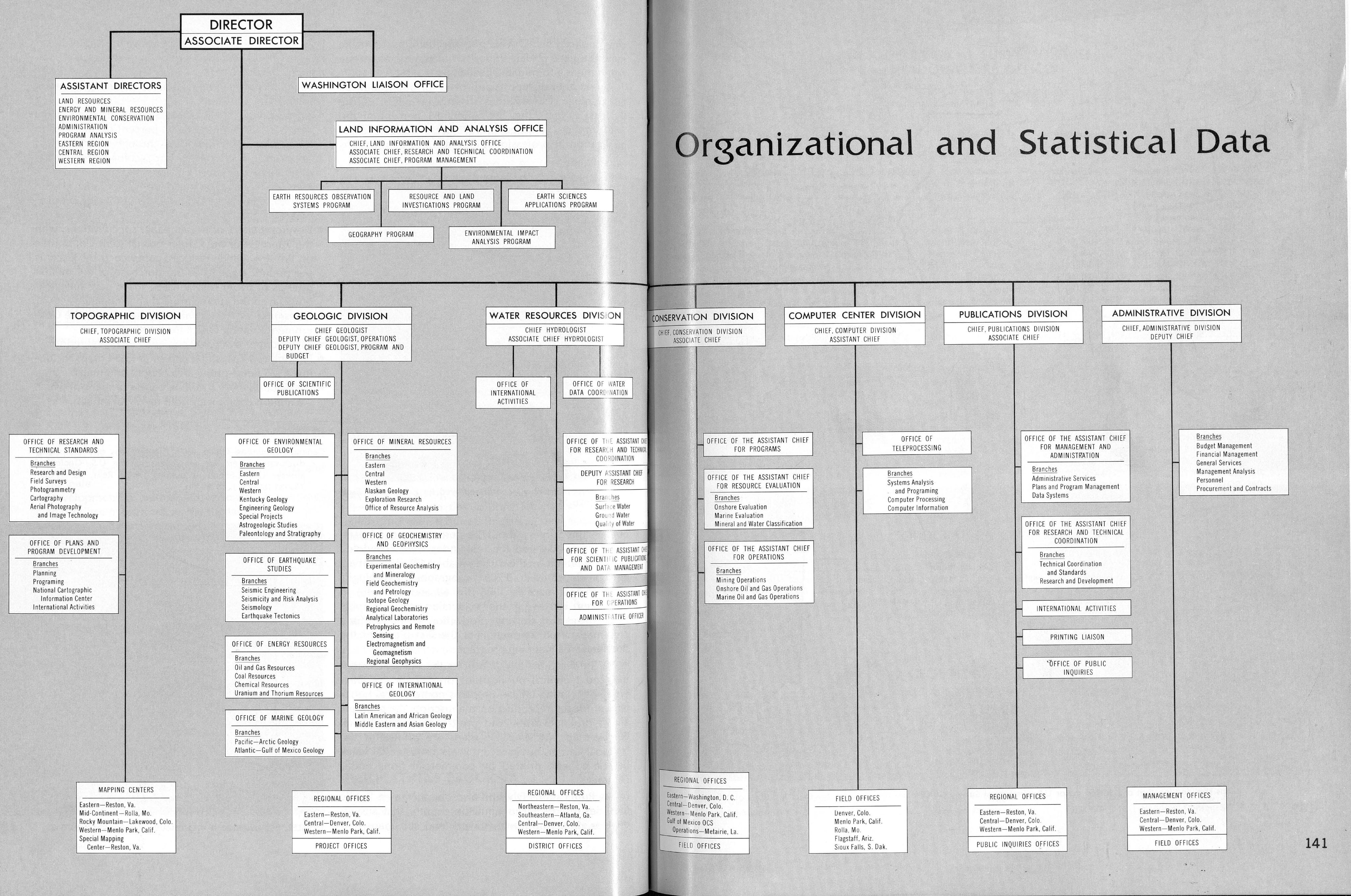




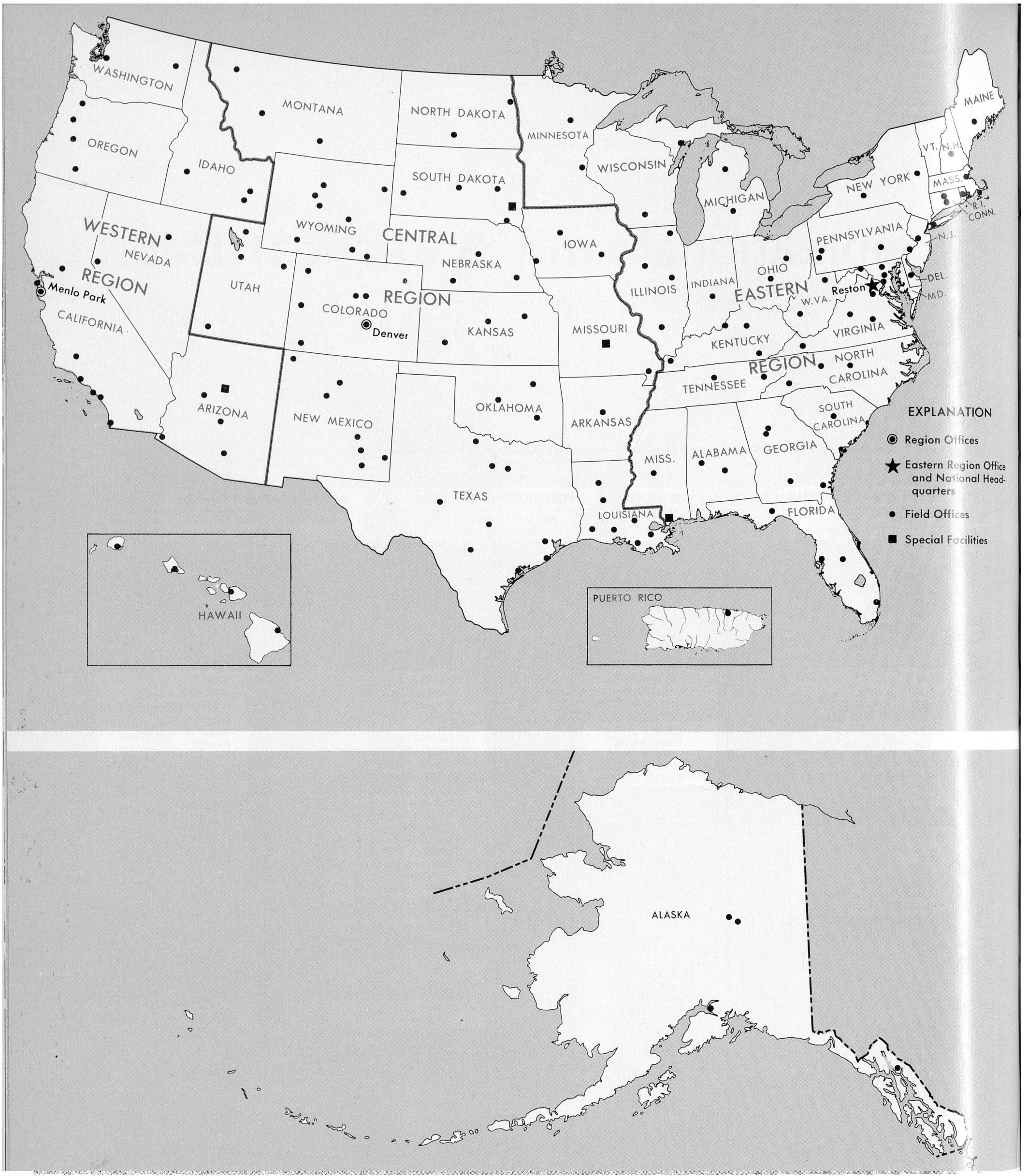




\section{U.S. GEOLOGICAL SURVEY OFFICES HEADQUARTERS OFFICES}

12201 Sunrise Valley Drive

National Center, Reston, VA 22092

Official

Name

Telephone number

Address

OFFICE OF THE DIRECTOR

Director

Associate Director

Washington Liaison Officer

Assistant Director-Land Resources Assistant Director-Energy and Mineral Resources -Assistant Director-Environmental Conservation -..Assistant Director-Administration _._._._. Assistant Director-Program Analysis _. Assistant Director-Eastern Region Assistant Director-Central Region

Assistant Director-Western Region

Information Officer
V. E. McKelvey

W. A. Radlinski

Frank E. Clarke

James R. Balsley Montis R. Klepper Henry W. Coulter Edmund J. Grant Dale D. Bajema William B. Overstreet Albert E. Letey, Acting

George E. Robinson, Acting Frank H. Forrester
(703)860-7411 (703)860-7412 (202)343-3888

(703)860-7488 (703)860-7481 (703)860-7491 (703)860-7201 (703)860-7435 (703)860-7414 (303)234-4630

(415)323-8111 ext. 2711

(703)860-7444
National Center, STOP 101. National Center, STOP 102. National Center, STOP 103. Room 4441, Interior Bldg., Washington, D.C. 20240. National Center, STOP 104. National Center, STOP 171. National Center, STOP 106. National Center, STOP 201. National Center, STOP 105. National Center, STOP 109. Box 25046, STOP 101,

Denver Federal Center, Denver, CO 80225.

345 Middlefield Road

Menlo Park, CA 94025.

National Center, STOP 119.

\section{LAND INFORMATION AND ANALYSIS OFFICE}

Chief

Associate Chief, Research and Technical Coordination Associate Chief, Program Management Earth Resources Observation System Program, Chief Geography Program, Chief Resource and Land Investigations Program, Chief Environmental Impact Analysis Program, Chief ...Earth Sciences Applications Program, Chief
James R. Balsley Philip Cohen, Acting Winston Sibert, Acting John M. DeNoyer James R. Anderson J. Ronald Jones Daniel B. Krinsley, Acting Donald R. Nichols, Acting
(703) $860-7488$ (703)860-7471

(703)860-6855 (703)860-7881 (703)860-6344 (703)860-6717

(703)860-7455

(703)860-6961
National Center, STOP 104. National Center, STOP 703. National Center, STOP 702. National Center, STOP 730. National Center, STOP 710. National Center, STOP 750 . National Center, STOP 760 National Center, STOP 720

\section{TOPOGRAPHIC DIVISION}

Chief

Associate Chief

Office of Research and Technical Standards, Chief Office of Plans and Program Development, Chief National Cartographic Information Center, Chief -Special Mapping Center, Chief
Robert H. Lyddan Rupert B. Southard Hugh B. Loving, Acting Doyle G. Frederick John R. Swinnerton Roy E. Fordham
(703)860-6231 (703)860-6232 (703)860-6291 (703)860-6281 (703)860-6187 (703)860-7760
National Center, STOP 516. National Center, STOP 516. National Center, STOP 519. National Center, STOP 514. National Center, STOP 507. National Center, STOP 560. 1925 Newton Square East Reston, VA 22090.

\section{GEOLOGIC DIVISION}

Chief Geologist

Depúty Chief Geologist, Operations _. Deputy Chief Geologist, Program and Budget -..-Office of Scientific Publications, Chief

Office of Environmental Geology, Chief

Office of Earthquake Studies, Chief Office of Energy Resources, Chief

Office of Marine Geology, Chief _. Office of Mineral Resources, Chief

Office of Geochemistry and Geophysics, Chief -..Office of International Geology, Chief
Richard P. Sheldon Robert E. Davis Donald H. Dow George E. Becraft John C. Reed, Jr. Robert M. Hamilton Charles Masters Charles Masters, Acting Edwin W. Tooker

Richard S. Fiske John A. Reinemund
(703)860-6531 (703)860-6532 (703)860-6544 (703) $860-6575$ (703)860-6411 (703) $860-6471$ (703) $860-6431$ (703) $860-6431$ (703)860-6562 (703) $860-6584$ (703)860-6418
National Center, STOP 911. National Center, STOP 911. National Center, STOP 910. National Center, STOP 904 National Center, STOP 908. National Center, STOP 905. National Center, STOP 915 National Center, STOP 915. National Center, STOP 913. National Center, STOP 906. National Center, STOP 917. 


\section{WATER RESOURCES DIVISION}

Chief Hydrologist

Associate Chief Hydrologist

Assistant Chief Hydrologist, Scientific Publications and Data Management

Assistant Chief Hydrologist, Operations

Assistant Chief Hydrologist, Research and

Technical Coordination

Office of Water Data Coordination, Chief

Office of International Activities, Chief
O. Milton Hackett

George W. Whetstone

Vacant

Edward A. Moulder

R. H. Langford

James R. Jones
Joseph S. Cragwall, Jr.
(703)860-6921

(703)860-6921

(703)860-6877 (703)860-6801

(703)860-6971

(703)860-6931

(703)860-6548
National Center, STOP 409. National Center, STOP 408.

National Center, STOP 440. National Center, STOP 441.

National Center, STOP 14 National Center, STOP 417. National Center, STOP 470 .

\section{CONSERVATION DIVISION}

Chief

Associate Chief -

Assistant Chief, Resources Evaluation _-

Assistant Chief, Operations

Assistant Chief, Programs
Russell G. Wayland

Robert F. Evans

Robert L. Rioux

John Duletsky

Harold L. Pumphrey
(703)860-7524 (703)860-7524 (703)860-7571 (703)860-7515

(703)860-7581
National Center, STOP 600. National Center, STOP 600 . National Center, STOP 640. National Center, STOP 620 . National Center, STOP 630 .

\section{COMPUTER CENTER DIVISION}

Chief

Assistant Chief

Office of Teleprocessing
Carl E. Diesen

Charles H. Tyler

Ralph N. Eicher
(703)860-7106 (703)860-7109 (703)860-7119
National Center, STOP 801 National Center, STOP 801. National Center, STOP 805

\section{PUBLICATIONS DIVISION}

Chief

Associate Chief

Assistant Chief, Management and Administration -Assistant Chief, Research and Technical Coordination

Office of Public Inquiries, Chief

Printing Liaison Officer

International Activities
Harry D. Wilson, Jr. John H. Eric Melvin E. Hanes

Bernard J. Thien Robbie S. Ritchey Jesse R. Upperco A. L. Dilonardo
(703)860-7181 (703)860-7181 (703)860-7188

(703)860-7183 (703)860-7185 (703)860-7622 (703)860-6791
National Center, STOP 341 National Center, STOP 341. National Center, STOP 341.

National Center, STOP $3 \% 1$. National Center, STOP $3 \$ 1$. National Center, STOP 330. National Center, STOP $3 \% 8$.

\section{ADMINISTRATIVE DIVISION}

Chief

Deputy Chief

Personnel Officer

Contracts Officer
Edmund J. Grant

Lewis Menen

Maxine C. Millard

William Burk
(703)860-7201

(703)860-7203

(703)860-6127

(703)860-7261
National Center, STOP 201. National Center, STOP 202. National Center, STOP 25. National Center, STOP 205.

\section{SELECTED FIELD OFFICES \\ LAND INFORMATION AND ANALYSIS OFFICE EARTH RESOURCES OBSERVATION SYSTEMS DATA CENTER \\ Official in charge \\ Telephone number}

Location

South Dakota
Allen H. Watkins
(605)594-6123
Address

EROS Data Center, Sioux Falls, SD 57198.

\section{TOPOGRAPHIC DIVISION}

REGIONAL MAPPING CENTERS

Mopping Center

Eastern Midcontinent
Chief

Peter F. Bermel

A. Carroll McCutchen
Telephone number

(703)860-6352

(314)364-3680

ext. 111 


\section{SELECTED FIELD OFFICES-CONTINUED}

Mapping Center

Rocky Mountain

Western
Chief

Albert E. Letey

Roy R. Mullen
Telephone number

(303)234-2351 Box 25046, STOP 510, Denver Federal Center, Denver, CO 80225.

(415)323-8111 345 Middlefield Road, Menlo Park, CA 94025

\section{GEOLOGIC DIVISION}

\section{REGIONAL OFFICES}

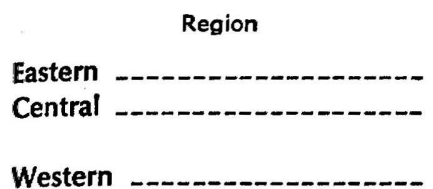

Regional Geologist

Eugene H. Roseboom, Jr. Ralph L. Erickson

George Gryc
Telephone number

(703)860-6631

(303)234-3625

ext. 2214
Address

National Center, STOP 953, Reston, VA 22092.

Box 25046, STOP 911, Denver Federal Center, Denver, CO 80225.

345 Middlefield Road, Menlo Park, CA 94025.

\section{WATER RESOURCES DIVISION}

REGIONAL OFFICES

Region

Northeastern

Southeastern

Central

Western

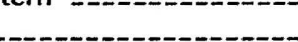

Regional Hydrologist

Joseph T. Callahan

Leslie B. Laird

Alfred Clebsch, Jr.

William H. Robinson, Acting
Telephone number

(703)860-6985

(404)526-5395

(303)234-3661

(415)323-8111 ext. 2337

\section{DISTRICT OFFICES}

State

Alabama

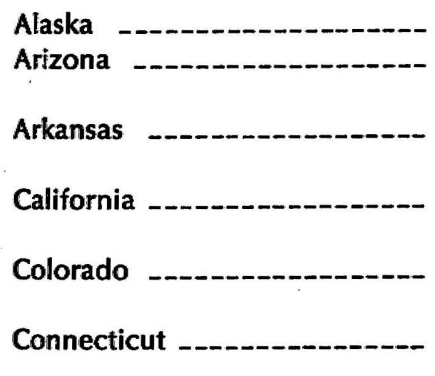

Delaware

District of Columbia

Florida

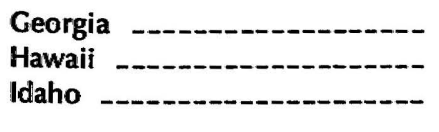

Illinois

Indiana _-

lowa

Kansas

District Chief

William J. Powell

Harry Hulsing

Horace M. Babcock

Richard T. Sniegocki

Lee R. Peterson

James E. Biesecker

Frederick H. Ruggles, Jr.

Walter F. White, Jr Walter F. White, Jr.

Clyde S. Conover

John R. George

Frank T. Hidaka

Edwin E. Harris

Lawrence A. Martens

James L. Cook

Sulo W. Wiitala

J. S. Rosenhein

Philip A. Emery

Albert N. Cameron
Telephone number

(205)752-8104

(907)277-5526

(602)792-6671

(501)378-5246

(415)323-8111

ext. 2326

(303)234-5092

(203)244-2528

(301)661-4664

(301)661-4664

(904)386-1118

(808)955-0251

(208)342-2711

ext. 2537.

(217)359-3918

(317)269-7101

(319)338-0581

ext. 521

(913)864-4321

(502)582-524

(504)387-0181

ext. 281.

(617)223-2822
(404)526-4858
Louisiana

Maine
John A. Baker

\section{Address}

National Center, STOP 433, Reston, VA 22092.

1459 Peachtree St. NE., Suite 200, Atlanta, GA 30309.

Box 25046, STOP 406, Denver Federal Center, Denver, CO 80225.

345 Middlefield Road, Menlo Park, CA 94025.

\section{Address}

P.O. Box V, 202 Oil and Gas Board Bldg., University of Alabama, University, AL 35486.

Skyline Bldg., 218 E St., Anchorage, AK 99501.

Federal Bldg., 301 W. Congress St., Tucson, AZ 85701.

2301 Federal Office Bldg., 700 W. Capital Ave., Little Rock, AR 72201.

855 Oak Grove Averiue, Menlo Park, CA 94025.

Box 25046, STOP 415, Denver Federal Center, Denver, CO 80225.

P.O. Box 715, 235 Post Office Bldg., 135 High Street, Hartford, CT 06101.

See Maryland District Office.

See Maryland District Office.

325 John Knox Road, Suite F-240, Tallahassee, FL 32303.

6481 Peachtree Industrial Blvd., Doraville, GA 30340.

1833 Kalakaua Ave., 5th Floor, Honolulu, HI 96815.

Box 036, 365 Federal Bldg., 550 W. Fort Street, Boise, ID 83724.

P.O. Box 1026, 605 N. Neil St., Champaign, IL 61820.

1819 N. Meridian St., Indianapolis, IN 46202.

P.O. Box 1230, 269 Federal BIdg., lowa City, IA 52240.

1950 Avenue A-Campus West, University of Kansas, Lawrence, KS 66045.

572 Federal Bldg., 600 Federal Place, Louisville, KY 40202.

P.O. Box 66492, 6554 Florida Blvd., Baton Rouge, LA 70896.

See Massachusetts District Office. 


\section{WATER RESOURCES DIVISION DISTRICT OFFICES-CONTINUED}

\section{State}

Maryland

Massachusetts

Michigan

Minnesota

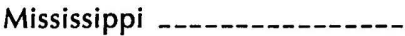

Missouri

Montana

Nebraska

Nevada

New Hampshire

New Jersey

New Mexico

New York

North Carolina

North Dakota

Ohio

Oklahoma _.....-.

Oregon

Pennsylvania

Puerto Rico

Rhode Island

South Carolina

South Dakota

Tennessee

Texas

Utah

Vermont

Virginia

Washington

West Virginia

Wisconsin

Wyoming
District Chief

Walter F. White, Jr. John A. Baker

T. Ray Cummings

Charles R. Collier

Lamar E. Carroon

Anthony Homyk

George M. Pike

Kenneth A. Mac Kichan

John P. Monis

John A. Baker

Harold Meisler

William E. Hale

Robert J. Dingman

Ralph C. Heath

Walter R. Scott

James F. Blakey

James H. Irwin

Stanley F. Kapustka

Norman H. Beamer

Ernest D. Cobb

John A. Baker

John S. Stallings

John E. Powell

Stanley P. Sauer

I. Dale Yost

Theodore Arnow

John A. Baker

William E. Forrest

John E. McCall

Vacant

William W. Barnwell

Samuel W. West
Telephone number

(301)661-4664

(617)223-2822

(517)372-1910

ext. 561

(612)725-7841

(601)969-4600

(314)364-3680 ext. 185

(406)449-5263

(402)471-5082

(702)882-1388

(617)223-2822

(609)599-3511

(505)766-2246

(518)472-3107

(919)755-4510

(701)255-4011 ext. 227

(614)469-5553

(405)231-4256

(503)234-3361

ext. 4776

(717)782-3468

(809)783-4660

(617)223-2822

(803)765-5966

(605)352-8651

ext. 258

(615)749-5424

(512)397-5766

(801)524-5663

(617)223-2822

(804)782-2427

(206)593-6510

(304)343-6181

ext. 310 .

(608)262-2488

(307)778-2220 ext. 2111

\section{Address}

8809 Satyr Hill Road, Parkville, MD 21234.

150 Causeway St., Suite 1001, Boston, MA 02114.

2400 Science Parkway, Red Cedar Research Park, Okemos, MI 48864.

1033 Post Office Bldg., St. Paul, MN 55101.

430 Bounds Street, Jackson, MS 39206.

1400 Independence Rd., Rolla, MO 65401.

P.O. Box 1696, 421 Federal Bldg., Helena, MT 59601.

406 Federal Bldg. and U.S. Courthouse, 100 Centennial Mall North, Lincoln, NE 68508.

227 Federal Bldg., 705 N. Plaza St., Carson, City, NV 89701.

See Massachusetts District Office.

P.O. Box 1238, 420 Federal Bldg., 402 East State Street, Trenton, NJ 08607.

P.O. Box 4369, Geology Bldg., University of New Mexico, Albuquerque, NM 87106.

P.O. Box 1350, 343 U.S. Post Office and Courthouse Bldg., Albany, NY 12201.

P.O. Box 2857, 436 Century Sta. P.O. Bldg., Raleigh, NC 27602.

P.O. Box 778, 332 New Federal Bldg., 3rd St. and Rosser Avenue, Bismarck, ND 58501.

975 West Third Avenue, Columbus, OH 43212.

201 NW. 3rd St., Rm. 621, Oklahoma City, OK 73102.

P.O. Box 3202, 830 NE. Holladay St., Portland, OR 97208.

P.O. Box 1107, 4th Floor, Federal Bldg., 228 Walnut

St., Harrisburg, PA 17108.

P.O. Box 34168, Bldg. 652, Ft. Buchanan, PR 00934. See Massachusetts District Office.

2001 Assembly St., Suite 200, Columbia, SC 29201.

P.O. Box 1412, 231 Federal Bldg., Huron, SD 57350.

A-413 Federal Bldg., U.S. Courthouse, Nashville, TN 37203.

649 Federal Bldg., 300 East 8th St., Austin, TX 78701. 8002 Federal Bldg., 125 S. State St., Salt Lake City, UT 84138.

See Massachusetts District Office.

200 W. Grace St., Rm. 304, Richmond, VA 23220

1305 Tacoma Avenue South, Rm. 300, Tacoma, V:A 98402.

3303 Federal BIdg. and U.S. Courthouse, 500 Quarrier Street East, Charleston, WV 25301.

1815 University Avenue, Rm. 200, Madison, WI 53706.

P.O. Box 2087, 4015 Warren Ave., Cheyenne, W/Y 82001.

\section{CONSERVATION DIVISION REGIONAL OFFICES}

\section{Region}

Eastern
Conservation Manager

George Brown

George H. Horn
Telephone number

(202)254-3137

(303)234-2855
Address

1725 K St., NW., Suite 213, Washington, DC 20244.

Box 25046, STOP 609, Denver Federal Center, Denver, CO 80225 . 


\section{CONSERVATION DIVISION REGIONAL OFFICES-CONTINUED}

Region

Gulf of Mexico Outer

Continental Shelf

Operations

Western
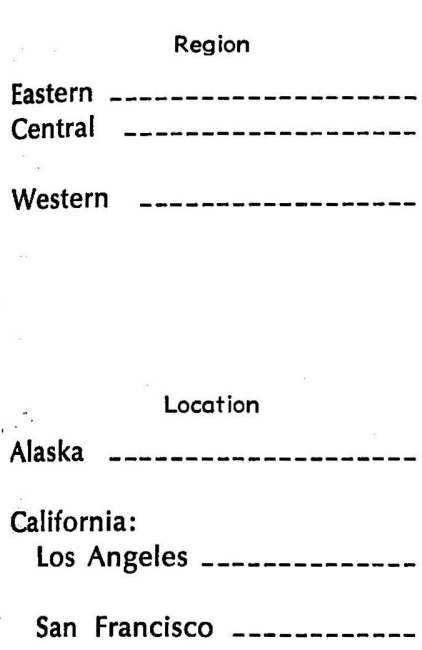

Colorado

District of Columbia

Texas

Utah

Virginia

Washington
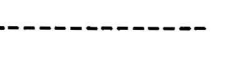

\section{政}

Conservation Manager Telephone number

A. Dewey Acuff

Willard C. Gere
(504)837-4720

ext. 381

(415)323-8111

ext. 2563

Address

\section{PUBLICATIONS DIVISION}

\section{REGIONAL OFFICES}

\begin{tabular}{lcc}
\multicolumn{1}{c}{ Official in charge } & Telephone number & Address \\
Lewis D. Brown & $(703) 860-6761$ & National Center, STOP 328, Reston, VA 22092. \\
John L. Heller & $(303) 234-4974$ & $\begin{array}{c}\text { Box 25046, STOP 303, Denver Federal Center, Den- } \\
\text { ver, CO 80225. }\end{array}$ \\
Fred Kunkel & $\begin{array}{c}\text { (415)323-8111 } \\
\text { ext. } 2537\end{array}$ &
\end{tabular}

PUBLIC INQUIRIES OFFICES

\begin{tabular}{|c|c|c|}
\hline Official in charge & Telephone number & Address \\
\hline Margaret I. Erwin & (907)277-0577 & $\begin{array}{l}108 \text { Skyline Bldg., } 502 \text { 2nd Ave., Anchorage, AK } \\
99501 .\end{array}$ \\
\hline Lucy E. Birdsall & (213)688-2850 & $\begin{array}{l}7638 \text { Federal Bldg., } 300 \mathrm{~N} \text {. Los Angeles Street, Los } \\
\text { Angeles, CA } 90012 .\end{array}$ \\
\hline Jean V. Molleskog & (415)556-5627 & $\begin{array}{l}504 \text { Custom House, } 555 \text { Battery Street, San Francisco, } \\
\text { CA } 94111 .\end{array}$ \\
\hline Sylvia T. Huhta & (303)837-4169 & $\begin{array}{l}1012 \text { Federal Bldg., } 1961 \text { Stout St., Denver, CO } \\
80202 \text {. }\end{array}$ \\
\hline Bruce A. Hubbard & (202)343-8073 & $\begin{array}{l}1028 \text { GSA Bidg., 19th and F Sts., NW., Washington, } \\
\text { DC } 20244 .\end{array}$ \\
\hline Mildred V. Smith & $(214) 749-3230$ & $\begin{array}{l}\text { 1C45 Federal Bldg., } 1100 \text { Commerce Street, Dallas, } \\
\text { TX } 75202 .\end{array}$ \\
\hline Wendy R. Hassibe & (801)524-5652 & $\begin{array}{l}8102 \text { Federal Bldg., } 125 \text { South State Street, Salt Lake } \\
\text { City, UT } 84138 .\end{array}$ \\
\hline A. Ernestine Jones & (703)860-6167 & $\begin{array}{l}\text { 1C402 National Center, STOP 302, } 12201 \text { Sunrise } \\
\text { Valley Drive, Reston, VA } 22092 .\end{array}$ \\
\hline Eula Thune & (509)456-2524 & $\begin{array}{l}678 \text { U.S. Court House, West } 920 \text { Riverside Avenue, } \\
\text { Spokane, WA } 99201 .\end{array}$ \\
\hline
\end{tabular}

\section{BRANCH OF DISTRIBUTION OFFICES}

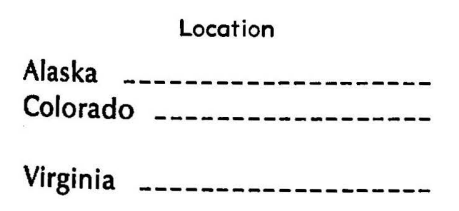

Official in charge

Natalie Cornforth

Dwight F. Canfield

John J. Curry
Telephone number

(907)452-1951

(303)234-3832

(703)557-2751

\section{Address}

310 First Avenue, Fairbanks, AK 99701. Box 25286, STOP 306, Denver Federal Center, Denver, CO 80225.

1200 South Eads Street, Arlington, VA 22202.

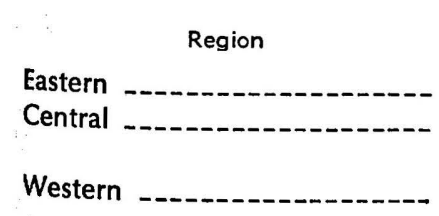

Regional Management
Officers

Roy Heinbuch

Thomas J. Lyons

Avery W. Rogers

\section{ADMINISTRATIVE DIVISION}

REGIONAL MANAGEMENT OFFICES

Telephone number

(703)860-7691

(303)234-3736

(415)323-2211
Address

National Center, STOP 290, Reston, VA 22092.

Box 25046, STOP 202, Denver Federal Center, Denver, CO 80225 .

345 Middlefield Road, Menlo Park, CA 94025. 


\section{COOPERATORS AND OTHER FINANCIAL CONTRIBUTORS DURING FISCAL FINANCIAL YEAR 1975}

[Cooperators listed are those with whom the U.S. Geological Survey had a written agreement for fiscal cooperation in fiscal year 1975 , cosigned by responsible officials of the Geological Survey and the cooperating agency. Agencies with whom the Geological Survey had research contracts and agreements for different projects were made with the parent agency and with a subdivision of the parent agency]

\section{FEDERAL COOPERATORS}

Department of Agriculture:
Agriculture Research Service
Forest Service
Soil Conservation Service
Statistical Reporting Service

Department of the Air Force: AFWL/PRP Kirtland AFB

Air Force Academy

Air Force Headquarters, Washington, D.C.

Air Force Systems Command

Air Force Weapons Laboratory (PRP)

Alaskan Air Command

Edwards Air Force Base

Eglin Air Force Base

Headquarters (AF-SC)

Headquarters (AFTAC/AC)

Headquarters Pacific Air Forces

Headquarters 321st Combat Support Group (SAC)

Homestead Air Force Base

Office of Scientific Research

Rocket Propulsion Laboratory

Vandenburg Air Force Base

Department of the Army:

Army Electronics Command

Army Research Office

Cold Regions Research and Engineering Laboratory

Construction Engineering Research Laboratory

Corps of Engineers

White Sands Missile Range

Department of Commerce, National Oceanic and Atmospheric Administration:

\section{Buoy Office}

Environmental Data Service

Environmental Research Laboratories

National Environmental Satellite Service

National Marine Fisheries Service

National Ocean Survey

National Weather Service

Department of Defense:

Advanced Research Projects Agency

Defense Intelligence Agency

Defense Mapping Agency (IAGS)

Defense Nuclear Agency

U.S. Arms Control and Disarmament Agency

Department of Health, Education, and Welfare, Public Health Service
Department of Housing and Urban Development

Department of the Interior: Alaska Power Administration Bonneville Power Administration Bureau of Indian Affairs

Bureau of Land Management

Bureau of Mines

Bureau of Outdoor Recreation

Bureau of Reclamation

Fish and Wildlife Service

National Park Service

Office of Land Use and Water Planning

Office of Saline Water

Office of Water Resources Research

U.N. Geothermal Symposium

Water Resources Council

Department of Justice

Department of the Navy:

Key West Naval Station

Marine Corps, Camp Pendleton

Naval Air Development Center

Naval Facilities Engineering Command

Naval Weapons Center

Office of Naval Petroleum and Oil Shale Reserves

Office of Naval Research

Public Works Center, Guam

Department of State:

Agency for International Development International Boundary and Water Commission International Joint Commission

Department of Transportation: Federal Highway Administration Office of the Secretary

Energy Research and Development Administration: Albuquerque Operations Office

Division of Applied Technology

Division of Administrative Services

Division of Reactor Research and Development

Idaho Operations Office

Nevada Operations Office

Oak Ridge Operations Office

Office of the Director of Regulation

Richland Operations Office

Rocky Flats Division

San Francisco Operations Office

Savannah River Operations Office 
FEDERAL COOPERATORS-CONTINUED

Environmental Protection Agency:

Management Division

National Environmental Research Center

Office of Radiation Programs

Office of Research and Development

Office of Solid Waste

Office of Water Programs

Pacific Northwest Environmental Research Laboratory

Water and Hazardous Materials

Federal Energy Administration

General Services Administration
National Academy of Sciences

National Aeronautics and Space Administration

National Science Foundation

Nuclear Regulatory Commission

Office of Emergency Preparedness

Pacific Northwest River Basins Commission

Tennessee Valley Authority

Veterans Administration

\section{STATE, COUNTY, AND LOCAL COOPERATORS}

Alabama:

Alabama Forestry Commission

Alabama Highway Department

City of Mobile

County of Jefferson

Geological Survey of Alabama

Alaska:

Alaska Department of Aviation

Alaska Department of Fish and Game

Alaska Department of Highways

Alaska Department of Natural Resources

Alaska Geological Survey

City and Borough of Juneau

City of Anchorage

City of Cordova

City of Kenai

City of Kodiak

City of Seward

Department of Environmental Conservation

Greater Anchorage Area Borough

Kenai Borough

North Star Borough

University of Alaska

Arizona:

Arizona Game and Fish Department

Arizona Highway Department

Arizona Water Commission

City of Flagstaff

City of Nogales

City of Safford

City of Tucson

City of Williams

Department of Health Services

Fload Control District of Maricopa County

Gila Valley Irrigation District

Lyman Water Company

Maricopa County Municipal Water Conservation District No. 1

Office of the Governor

Pima County Board of Supervisors

Salt River Valley Water User's Association

San Carlos Irrigation and Drainage District

Show Low Irrigation Company

University of Arizona
Arkansas:

Arkansas Department of Pollution Control and Ecology

Arkansas Division of Soil and Water Resources

Arkansas Geological Commission

Arkansas State Highway Commission

California:

Alameda County Flood Control and Water Conservation District.

Alameda County Water District

Antelope Valley-East Kern Water Agency

Berrenda Mesa Water District

Big Bear Lake Pest Abatement District

California Department of Conservation, Division of Mines and Geology

California Department of Fish and Game

California Department of Water Resources

California Division of Highways, Materials and Research Department

California Water Resources Control Board

Casitas Municipal Water District

Chino Basin Municipal Water District

City and County of San Francisco:

Hetch Hetchy Water Supply

Water Department

City of Modesto, Public Works Department

City of Redding

City of San Diego

City of San Jose

City of San Rafael

City of Santa Barbara

City of Santa Cruz

Coachella Valley County Water District

Contra Costa County Flood Control and Water Conservation District

County of Fresno

County of Madera

County of Modoc

County of Sacramento, Department of Public Works

County of San Diego, Board of Supervisors

County of San Mateo

Department of Transportation, Office of Structures

Desert Water Agency

East Bay Municipal Utility District 


\section{STATE, COUNTY, AND LOCAL COOPERATORS-CONTINUED}

California-Continued

Fern Valley Water District

Georgetown Divide Public Utility District

Goleta County Water District

Hoopa Valley Tribe

Imperial County Department of Public Works

Imperial Irrigation District

Indian Wells Valley County Water District

Kern County

Kern County Water Agency

Lake County Flood Control and Water Conservation District Livermore Amador Valley Water Management Agency

Los Angeles County, Department of County Engineers

Los Angeles County Flood Control District

Los Angeles Department of Water and Power

Madera Irrigation District

Marin Municipal Water District

Merced Irrigation District

Metropolitan Water District of Southern California

Mojave Water Agency

Montecito County Water District

Monterey County Flood Control and Water Conservation

District

Napa County Flood Control and Water Conservation District

North Marin County Water District

Orange County Flood Control District

Orange County Water District

Oroville-Wyandotte Irrigation District

Pacheco Pass Water District

Paradise Irrigation District

Placer County Department of Public Works

Riverside County Flood Control and Water Conservation District

San Benito County Water Conservation and Flood Control District

San Bernardino County Flood Control District

San Bernardino Valley Municipal Water District

San Luis Obispo County and Cities Area Planning Coordinating Council

San Luis Obispo County Flood Control and Water Conservation District

Santa Ana Watershed Planning Agency

Santa Barbara County Flood Control and Water Conservation District

Santa Barbara County Water Agency

Santa Clara County Flood Control and Water District

Santa Cruz County Flood Control and Water Conservation District

Santa Cruz County Planning Department

Santa Margarita and San Luis Rey Watershed Planning Agencies

Santa Maria Valley Water Conservation District

Santa Ynez River Water Conservation District.

Siskiyou County Flood Control and Water Conservation District

Solano Irrigation District

Tehachapi-Cummings County Water District

Terra Bella Irrigation District

Tulare County Flood Control District

Turlock Irrigation District

United Water Conservation District

University of California:

Department of Engineering

School of Forestry and Conservation

Scripps Institute of Oceanography
California-Continued

Valley Community Services District

Valley Sanitary District

Ventura County Flood Control District, Riverside County

Western Municipal Water District

Woodbridge Irrigation District

Yolo County Flood Control and Water Conservation District

Colorado:

Arkansas River Compact Administration

Cherokee Water District

City and County of Denver, Board of Water Commissioners

City of Aspen

City of Aurora, Department of Public Utilities

City of Colorado Springs, Department of Public Utilities

City of Fort Collins

City of Pueblo

Colorado City Water and Sanitation District

Colorado Department of Local Affairs

Colorado Department of Natural Resources:

Division of Water Resources

Division of Wildlife

Geological Survey

Colorado Department of Public Health, Water Pollution Control Commission

Colorado River Water Conservation District

Colorado Water Conservation Board

Eagle County Commissioners

El Paso County Board of Commissioners

El Paso County Water Association

Huerfano County Conservation District

Jefferson County Health Department

Kiowa-Bijou Groundwater Management District

Larimer County Planning Office

Lower South Platte Water Conservation District

Metro Denver Sewage Disposal District No. 1

Northern Colorado Water Conservation District

Pikes Peak Area Council of Governments

Pitkin County Board of County Commissioners

Rio Grande Water Conservation District

San Luis Valley Water Conservation District

Southeastern Colorado Water Conservancy District

Southern Ute Indian Tribe

Southwestern Water Conservation District

State of Colorado, Department of Highways

Teller County

Urban Drainage and Flood Control District

Connecticut:

City of Hartford, Department of Public Works

City of New Britain, Board of Water Commissioners

City of Torrington

Connecticut Geological and Natural History Survey

Department of Environmental Protection

Department of Transportation

State of Connecticut, Office of State Planning

Town of Faiffield

Delaware

Delaware Geological Survey, University of Delaware

Department of Highways and Transportation, Division of Highways

District of Columbia:

Department of Environmental Services 


\section{STATE, COUNTY, AND LOCAL COOPERATORS-CONTINUED}

Florida:

Brevard County

Broward County

Broward County Air and Water Pollution Control Board

Central and Southern Florida Flood Control District

City of Boca Raton

City of Clearwater

City of Cocoa

City of Deerfield Beach

City of Fort Lauderdale

City of Fort Myers

City of Gainesville

City of Hallandale

City of Hollywood

City of Jacksonville

City of Juno Beach

City of Miami, Department of Water and Sewers

City of Pensacola

City of Perry

City of Pompano Beach

City of Riviera Beach

City of St. Petersburg

City of Sarasota

City of Tallahassee

City of Tampa

City of Temple Terrace

City of West Palm Beach

Collier County

Collier County Water Management District No. 1

Collier County Water Management District No. 7

Department of Pollution Control

Division of State Planning

East Central Florida Regional Planning Council

Englewood Water District

Escambia County

Florida Department of Natural Resources:

Bureau of Geology

Division of Parks and Recreation

Florida Department of Transportation

Game and Fresh Water Fish Commission

Hendry County

Hillsborough County

Jacksonville Area Planning Board

Jacksonville Recreation and Public Area

Lake County

Lake Worth Drainage District

Lee County

Loxahatchee River Environmental Control District

Manasota Basin Board

Manatee County, Board of County Commissioners

Marion County

Martin County

Metropolitan Dade County

Northwest Florida Water Management District

Orange County

Osceola County

Palm Beach County

Pinellas County

Reedy Creek Improvement District

Sarasota County

School of Marine and Atmospheric Science, University of Miami Division of Planning

Seminole County

Southwest Water Management District

St. Johns River Water Management
Florida-Continued

Suwanee River Authority

Suwanee River Water Management District

Tampa Bay Regional Planning Commission

Tampa Port Authority

Village of Tequesta

Volusia County

Walton County

Georgia:

Chatham County

City of Brunswick

Dekalb County

Department of Natural Resources:

Earth and Water Division

Environmental Protection Division

Department of Transportation

Hawaii:

City and County of Honolulu

Honolulu Board of Water Supply

State Department of Health

State Department of Land and Natural Resources

State Department of Transportation

Idaho:

City of Kellogg

Idaho Bureau of Mines and Geology

Idaho Department of Health and Welfare

Idaho Department of Highways

Idaho Department of Transportation

Idaho Department of Water Administration

Idaho State University

Idaho Water Resources Board

Southeast Idaho Council of Governments

Illinois:

Bloomington and Normal Sanitary District

City of Springfield

Cook County, Forest Preserve District

Du Page County

Environmental Protection Agency

Fountain Head Drainage District

Fulton County

Illinois Institute of Environmental Quality

Kane County

Lake County

McHenry County Regional Planning Commission

Sanitary District of Bloom Township

State Department of Registration and Education:

Illinois State Geological Survey

Illinois State Water Survey

State Department of Transportation:

Division of Highways

Division of Water Resources Management

The Metropolitan Sanitary District of Greater Chicago

University of Illinois at Urbana-Champaign

Indiana:

City of Indianapolis

Indiana Board of Health

Indiana Department of Natural Resources

Indiana Highway Commission

Town of Carmel 


\section{STATE, COUNTY, AND LOCAL COOPERATORS-CONTINUED}

lowa:

City of Cedar Rapids

City of Des Moines

City of Fort Dodge

lowa Geological Survey

lowa Natural Resources Council

lowa State Highway Commission, Highway Research Board

lowa State University

lowa State University, Agricultural and Home Economics Experiment Station

Linn County

University of lowa, Institute of Hydraulic Research

Kansas:

City of Wichita

Kansas State Department of Health

Kansas State Water Resources Board

Kansas-Oklahoma Arkansas River Commission

State Geological Survey of Kansas

State Highway Commission of Kansas

Kentucky:

Bureau of Highways, Department of Transportation

Department of Natural Resources

Kentucky Geological Survey, University of Kentucky

University of Kentucky Research Foundation

Louisiana:

Louisiana Department of Highways

Louisiana Department of Public Works

Louisiana Office of State Planning

Louisiana State University

Sabine River Authority of Louisiana

Sabine River Compact Administration

Maine:

Department of Environmental Protection

Maine Department of Economic Development

Maine Department of Transportation

Maine Geological Survey

Maine Public Utilities Commission

Maryland:

City of Baltimore, Water Division

Department of Natural Resources, Water Resources Administration

Maryland Department of Health and Mental Hygiene

Maryland Department of Transportation, The State Highway Administration

Maryland Geological Survey

Maryland National Capital Park and Planning Commission

Montgomery County

Washington Suburban Sanitary Commission

Massachusetts:

Department of Natural Resources, Division of Mineral Resources

Department of Public Works:

Division of Highways

Division of Waterways

152

Metropolitan District Commission
Massachusetts-Continued

State Water Resources Commission: Division of Water Pollution Contro

Division of Water Resources

Michigan:

Michigan Department of Agriculture, Soil and Water Conservation Division

Michigan Department of Natural Resources:

Geological Survey Division

Water Resources Commission

Minnesota:

Metropolitan Council of the Twin Cities Area

Metropolitan Sewer Board of the Twin Cities Area

Minnesota Department of Highways

Minnesota Department of Natural Resources, Division of Waters, Soils, and Minerals

Minnesota Pollution Control Agency

Minnesota State Planning Agency

Pelican River Watershed District

Mississippi:

City of Jackson

Harrison County Development Commission

Jackson County Board of Supervisors

Jackson County Port Authority

Mississippi Air and Water Pollution Control Commission

Mississippi Board of Water Commissioners

Mississippi Geological Survey

Mississippi Research and Development Center

Mississippi State Highway Department

Mississippi State University

Pat Harrison Waterway District

Pearl River Basin Dev̀elopment District

Pearl River Valley Water Supply District

Yellow Creek Port Authority

Missouri:

Curators of the University of Missouri

Department of Natural Resources:

Division of Environmental Quality, Clean Water Commission

Research Technical Information

Metropolitan St. Louis Sewer District

Missouri Department of Business and Administration, Division of Geological Surveys and Water Resources

Missouri State Highway Commission

Missouri Water Pollution Board

St. Louis County

Montana:

Endowment and Research Foundation-Montana State University

Lewis and Clark County, Board of County Commissioners

Montana Bureau of Mines and Geology

Montana Department of Health and Environmental Sciences

Montana Department of Intergovernmental Relations

Montana Department of Natural Resources

Montana State Fish and Game Department

Montana State Highway Commission

Old West Regional Commission 


\section{STATE, COUNTY, AND LOCAL COOPERATORS-CONTINUED}

Nebraska:

Clay County Ground Water Conservation District Filmore County Ground Water Conservation District Hamilton County Ground Water Conservation District Kansas-Nebraska Big Blue River Compact Administration Lower Loup Natural Resources District Lower Platte South Natural Resources District Nebraska Department of Environmental Control Nebraska Department of Water Resources Nebraska Game and Parks Commission Nebraska Natural Resources Commission Seward County Ground Water Conservation District State Department of Roads University of Nebraska, Conservation and Survey Division Upper Big Blue Natural Resources District

York County Ground Water Conservation District

Nevada:

Nevada Bureau of Mines and Geology

Nevada Department of Conservation and Natural Resources Nevada State Highway Department

New Hampshire:

New Hampshire Department of Resources and Economic Development

New Hampshire Water Resources Board

New Hampshire Water Supply and Pollution Control Commission

New Jersey:

Bergen County

Camden County Board of Freeholders

Delaware River Basin Commission

New Jersey Department of Agriculture, State Soil Conservation Committee

New Jersey Department of Environmental Protection

New Jersey Department of Transportation

North Jersey District Water Supply Commission

Passaic Valley Water Commission

Rutgers State University

Township of Cranford

New Mexico:

Albuquerque Metropolitan Arroyo Flood Control Authority

City of Las Cruces

Costilla Creek Compact Commission

Elephant Butte Irrigation District

Interstate Stream Commission

New Mexico Bureau of Mines and Mineral Resources

New Mexico State Engineer

New Mexico State Highway Department

Pecos River Commission

Rio Grande Compact Commission

University of New Mexico

New York:

Board of Hudson River-Black River Regulating District

Central New York State Parks Commission

City of Albany

City of Auburn

City of New York:

Board of Water Supply

Environmental Protection Agency

County of Chautauqua

County of Cortland
New York-Continued

County of Dutchess:

Board of Supervisors

Department of Public Works

County of Nassau, Department of Public Works

County of Onondaga:

Department of Public Works

Water Authority

County of Orange

County of Putnam

County of Rockland Drainage Agency

County of Suffolk:

Department of Environmental Control

Water Authority

County of Ulster, Ulster County Legislature

County of Westchester, Department of Public Works

County of Wyoming

Department of Environmental Conservation:

Environmental Management

Environmental Quality

Environmental Research

Facilities and Construction Management

Department of Transportation

Monroe County Water Authority

New York State College of Agriculture and Life Sciences

New York State Department of Health

New York State Education Department, Museum and Science Service

Oswegatchie-Cranberry Reservoir Commission

Power Authority of the State of New York

State University of New York, College of Environmental Science and Forestry

Town of Brighton

Town of Clarkstown

Town of Middlebury

Town of Warwick

Village of Nyack

North Carolina:

City of Asheville, Public Works Department

City of Burlington

City of Charlotte

City of Durham, Department of Water Resources

City of Greensboro

City of Winston-Salem

North Carolina Department of Conservation and Development, Division of Mineral Resources

North Carolina Department of Natural and Economic Resources, Office of Earth Resources

North Carolina Department of Water and Air Resources

State Department of Transportation

Triangle "J" Council of Governments

Water Research Institute

Wilson County

North Dakota:

North Dakota Geological Survey

Oliver County, Board of County Commissioners

State Highway Department

State Water Commission

Ohio:

City of Canton

City of Columbus, Department of Public Service

Miami Conservancy District 


\section{Ohio-Continued}

Ohio Department of Natural Resources

Ohio Department of Transportation

Ohio Department of Transportation, Division of Highways

Ohio Environmental Protection Agency

Three Rivers Watershed District

Oklahoma:

City of Oklahoma City, Water Department

Oklahoma Department of Highways

Oklahoma Geologic Survey

Oklahoma Soil Conservation Board

Oklahoma Water Resources Board

State Department of Health, Environmental Health Service

Oregon:

Burnt River Irrigation District

City of Astoria

City of Corvallis

City of Eugene, Water and Electric Board

City of McMinnville, Water and Light Department

City of Portland, Bureau of Water Works

City of The Dalles

Confederated Tribes of the Umatilla Indian Reservation

Confederated Tribes of the Warm Springs Reservation

Coos Bay-North Bend Water Board

Coos County, Board of Commissioners

Cowlitz County

Douglas County

Lakeside Water District

Lane County, Department of General Administration

Oregon State Board of Higher Education

Oregon State Game Commission

Oregon State Highway Commission

Oregon State Water Resources Department

Pennsylvania:

Chester County Commissioners

Chester County Health Department

Chester County Water Resources Authority

City of Bethlehem

City of Easton

City of Harrisburg

City of Philadelphia, Water Department

Department of Environmental Management

Pennsylvania Department of Environmental Resources:

Bureau of Topographic and Geologic Survey

Bureau of Water Quality Management

Office of Engineering and Construction

State Soil and Water Conservation Commission

Pennsylvania Department of Transportation
Pennsylvania-Continued

Pennsylvania Office of State Planning and Development

Susquehanna River Basin Commission

Rhode Island:

City of Providence, Department of Public Works

State Department of Natural Resources:

Division of Fish and Wildlife

Division of Planning and Development

State Department of Transportation, Division of Roads and Bridges

State Water Resources Board

South Carolina:

Commissioners of Public Works, Spartanburg Water Works

South Carolina State Development Board

State Development Board, Division of Geology

State Highway Department

State Land Resources Conservation Commission

State Pollution Control Authority

State Public Service Authority

State Water Resources Commission

South Dakota:

Black Hills Conservancy Subdistrict

City of Sioux Falls

City of Watertown

East Dakota Conservancy Subdistrict

South Dakota Department of Natural Resource Development

South Dakota Department of Transportation and State Geological Survey

Tennessee:

Chickasaw Basin Authority

City of Chattanooga

City of Franklin

City of Lawrenceburg

City of Manchester

City of Memphis, Board of Light, Gas, and Water Commissioners

Lincoln County

Metropolitan Government of Nashville and Davidson Courty

Murfreesboro Water and Sewer Department

Tennessee Department of Conservation:

Division of Geology

Division of Water Resources

Tennessee Department of Highways

Tennessee Department of Public Health, Division of Nater Quality Control

Tennessee Department of Transportation

Tennessee Game and Fish Commission 


\section{STATE, COUNTY, AND LOCAL COOPERATORS-CONTINUED}

Tennessee-Continued

Tennessee State Planning Office

University of Tennessee

Texas:

City of Austin

City of Dallas, Public Works Department

City of Fort Worth

City of Houston

County of Dallas

Sabine River Compact Administration

Texas Highway Department

Texas Water Development Board

Utah:

Bear River Commission

Salt Lake County

State Department of Highways

State Department of Natural Resources, Division of Water Rights

Utah Geological and Mineralogical Survey

Utah Legislative Council

Vermont:

State Department of Highways

State Department of Water Resources, Planning and Development Division

Vermont Geological Survey

Virginia:

City of Alexandria

City of Newport News, Department of Public Utilities

City of Norfolk:

Department of Utilities

Division of Water Supply

City of Roanoke

City of Staunton

County of Chesterfield

County of Fairfax

Virginia Department of Conservation and Economic Development, Division of Mineral Resources

Virginia Department of Highways

Virginia Polytechnic Institute and State University

Virginia State Water Control Board

Washington:

Chehalis Tribal Council

City of Port Angeles

City of Seattle, Department of Lighting

City of Tacoma:

Department of Public Utilities
Washington-Continued

Department of Public Works

Clark County Public Utility District

Coleville Business Council

Cowlitz County Public Utility District

Municipality of Metropolitan Seattle

Pacific County

Quinault Business Committee

Squaxin Indian Tribe

Swinomish Tribal Council

The Evergreen State College

Tulalip Tribal Council

University of Washington

Washington State Department of Ecology

Washington State Department of Fisheries

Washington State Department of Game

Washington State Department of Highways

Washington State Department of Natural Resources, Division of Mines and Geology

Yakima Tribal Council

West Virginia:

Clarksburg Water Board

Morgantown Water Commission

West Virginia Department of Highways

West Virginia Department of Natural Resources, Division of Water Resources

West Virginia Geological and Economic Survey

Wisconsin:

City of Madison

City of Middleton

Dane County

Douglas County

Madison Metropolitan Sewerage District

Southeastern Wisconsin Regional Planning Commission

State Department of Natural Resources

State Department of Transportation, Division of Highways

The University of Wisconsin-Extension, Geological and Natural History Survey

Town of Kronenwetter

Wyoming:

City of Cheyenne, Board of Public Utilities

State Highway Commission of Wyoming

Wyoming Department of Economic Planning and Development

Wyoming Game and Fish Commission

Wyoming State Agriculture Commission

Wyoming State Department of Environmental Quality

Wyoming State Engineer 


\section{OTHER COOPERATORS AND CONTRIBUTORS}

Appalachian Regional Commission

Coastal Plains Regional Commission

Government of Algeria

Government of American Samoa

Government of Brazil

Government of Burma

Government of Colombia

Government of Guam

Government of Iran

Government of Jordan

Government of Nepal

Government of Nicaragua

Government of Oman

Government of Peru
Government of the Philippines

Government of Saudi Arabia

Government of Thailand

Government of Turkey

Government of Yemen

Northern Great Plains Resources Programs

Ozarks Regional Commission

Permittees and licensees of the Federal Power Commission

Puerto Rico:

Gobierno Municipal De Bayamón

Puerto Rico Department of Natural Resources

Puerto Rico Environmental Quality Board

Puerto Rico Water Resources Authority

Trust Territory of the Pacific Islands

United Nations

Virgin Islands, Department of Public Works

\section{STATISTICAL DATA}

TABLE 25.-Original and revised budget structure of the Surveys, Investigations, and Research appropriation for 1975

\begin{tabular}{|c|c|}
\hline Budget activity & Organizational unit \\
\hline \multicolumn{2}{|c|}{ ORIGINAL STRUCTURE } \\
\hline $\begin{array}{l}\text { Special Resource and Environ- } \\
\text { mental Projects: } \\
\text { Urban Area Studies. } \\
\text { Mineral Policy. } \\
\text { Geothermal Investigations. }\end{array}$ & $\begin{array}{l}\text { Office of Land Information } \\
\text { and Analysis, Geologic Di- } \\
\text { vision, and Conservation } \\
\text { Division. }\end{array}$ \\
\hline
\end{tabular}

Geothermal Investigations.

Energy Impact Evaluations.

Arctic Environmental Studies.

Alaska Pipeline Related Investigations.

Topographic Surveys and Mapping.

Geologic and Mineral Resource Surveys and Mapping.

Mineral Discovery Loan Program.

Water Resources Investigations.

Conservation of Lands and Minerals.

General Administration.

Facilities.

Earth Resources Observation Systems.

Geologic Division.

Topographic Division.

Geologic Division.

Geologic Division.

Water Resources Division.

Conservation Division.

Office of the Director and Administrative Division. Administrative Division.

Office of Land Information and Analysis.

\begin{tabular}{|c|c|}
\hline Budget activity & Organizational unit \\
\hline \multicolumn{2}{|c|}{ ORIGINAL STRUCTURE-Continued } \\
\hline $\begin{array}{l}\text { Resource and Land Investiga- } \\
\text { tions. } \\
\text { Land Use Data and Analysis. }\end{array}$ & $\begin{array}{l}\text { Office of Land Informatio: } \\
\text { and Analysis. } \\
\text { Office of Land Information } \\
\text { and Analysis. }\end{array}$ \\
\hline \multicolumn{2}{|c|}{ REVISED STRUCTURE } \\
\hline
\end{tabular}

Geologic Division.

Topographic Division.

Geologic Division.

Water Resources Division.

Conservation Division.

Office of the Director and Administrative Division.

Administrative Division.

Land Information and Analysis Office. 
TABLE 26.-Geological Survey budget, by activity and sources of funds, fiscal years 1970-75 [ In thousands of dollars. Detail may not add to totals becouse of rounding]

\begin{tabular}{|c|c|c|c|c|c|c|}
\hline Budget activity & 1970 & 1971 & 1972 & 1973 & 1974 & 1975 \\
\hline \multicolumn{7}{|c|}{ CURRENT DOLLARS } \\
\hline Total & $\$ 157,387$ & $\$ 173,243$ & $\$ 188,996$ & $\$ 211,944$ & $\$ 249,437$ & $\$ 338,764$ \\
\hline $\begin{array}{l}\text { Direct program } \\
\text { Reimbursable program }\end{array}$ & $\begin{array}{r}103,308 \\
54,079 \\
\end{array}$ & $\begin{array}{r}114,080 \\
59,163 \\
\end{array}$ & $\begin{array}{r}130,951 \\
58,045 \\
\end{array}$ & $\begin{array}{r}149,971 \\
61,973 \\
\end{array}$ & $\begin{array}{r}171,983 \\
77,454 \\
\end{array}$ & $\begin{array}{r}253,605 \\
85,159 \\
\end{array}$ \\
\hline $\begin{array}{l}\text { States, counties, and municipalities } \\
\text { Miscellaneous non-Federal sources } \\
\text { Other Federal agencies }\end{array}$ & $\begin{array}{r}23,098 \\
3,135 \\
27,846\end{array}$ & $\begin{array}{r}24,687 \\
3,240 \\
31,236\end{array}$ & $\begin{array}{r}25,857 \\
3,383 \\
28,805\end{array}$ & $\begin{array}{r}28,011 \\
3,620 \\
30,342\end{array}$ & $\begin{array}{r}32,443 \\
4,695 \\
40,316\end{array}$ & $\begin{array}{r}35,124 \\
6,399 \\
43,636\end{array}$ \\
\hline Alaska Pipeline Related Investigations & 739 & 1,401 & 1,401 & 1,239 & 890 & 344 \\
\hline $\begin{array}{l}\text { Direct program } \\
\text { Reimbursable program }\end{array}$ & $\begin{array}{r}709 \\
30\end{array}$ & $\begin{array}{r}1,336 \\
65\end{array}$ & $\begin{array}{r}1,339 \\
62\end{array}$ & $\begin{array}{r}1,239 \\
--\end{array}$ & 890 & $\begin{array}{r}344 \\
--\end{array}$ \\
\hline Other Federal agencies & 30 & 65 & 62 & -- & -- & - \\
\hline Topographic Surveys and Mapping & 35,695 & 37,426 & 38,737 & 40,271 & 43,664 & 52,597 \\
\hline $\begin{array}{l}\text { Direct program } \\
\text { Reimbursable program }\end{array}$ & $\begin{array}{r}28,493 \\
7,202 \\
\end{array}$ & $\begin{array}{r}31,153 \\
6,273 \\
\end{array}$ & $\begin{array}{r}34,545 \\
4,192 \\
\end{array}$ & $\begin{array}{r}35,172 \\
5,099 \\
\end{array}$ & $\begin{array}{r}37,161 \\
6,503 \\
\end{array}$ & $\begin{array}{r}45,350 \\
7,247 \\
\end{array}$ \\
\hline $\begin{array}{l}\text { States, counties, and municipalities } \\
\text { Miscellaneous non-Federal sources } \\
\text { Other Federal agencies }\end{array}$ & $\begin{array}{r}4,526 \\
286 \\
2,390\end{array}$ & $\begin{array}{r}3,901 \\
355 \\
2,017\end{array}$ & $\begin{array}{r}3,204 \\
357 \\
631\end{array}$ & $\begin{array}{r}3,719 \\
600 \\
780\end{array}$ & $\begin{array}{r}4,942 \\
643 \\
918\end{array}$ & $\begin{array}{r}4,995 \\
594 \\
1,658\end{array}$ \\
\hline Geologic and Mineral Resource Surveys and Mapping ${ }^{1}$ & 46,796 & 49,015 & 51,529 & 57,979 & 73,563 & 114,477 \\
\hline $\begin{array}{l}\text { Direct program } \\
\text { Reimbursable program }\end{array}$ & $\begin{array}{l}31,056 \\
15,740 \\
\end{array}$ & $\begin{array}{l}31,919 \\
17,096 \\
\end{array}$ & $\begin{array}{l}34,244 \\
17,285 \\
\end{array}$ & $\begin{array}{l}42,895 \\
15,084\end{array}$ & $\begin{array}{l}49,877 \\
23,686 \\
\end{array}$ & $\begin{array}{r}89,018 \\
25,459 \\
\end{array}$ \\
\hline $\begin{array}{l}\text { States, counties, and municipalities } \\
\text { Miscellaneous non-Federal sources } \\
\text { Other Federal agencies }\end{array}$ & $\begin{array}{r}1,292 \\
2,260 \\
12,188\end{array}$ & $\begin{array}{r}1,322 \\
2,280 \\
13,494\end{array}$ & $\begin{array}{r}1,359 \\
2,317 \\
13,609\end{array}$ & $\begin{array}{r}1,556 \\
2,306 \\
11,222\end{array}$ & $\begin{array}{r}1,681 \\
2,684 \\
19,321\end{array}$ & $\begin{array}{r}1,550 \\
3,751 \\
20,158\end{array}$ \\
\hline Water Resources Investigations ${ }^{2}$ & 59,607 & 66,084 & 71,324 & 78,103 & 88,352 & 101,437 \\
\hline $\begin{array}{l}\text { Direct program } \\
\text { Reimbursable program }\end{array}$ & $\begin{array}{l}31,585 \\
28,022 \\
\end{array}$ & $\begin{array}{l}34,581 \\
31,503 \\
\end{array}$ & $\begin{array}{l}37,446 \\
33,878 \\
\end{array}$ & $\begin{array}{l}40,185 \\
37,918 \\
\end{array}$ & $\begin{array}{l}45,433 \\
42,919 \\
\end{array}$ & $\begin{array}{l}53,420 \\
48,017 \\
\end{array}$ \\
\hline $\begin{array}{l}\text { States, counties, and municipalities } \\
\text { Miscellaneous non-Federal sources } \\
\text { Other Federal agencies }\end{array}$ & $\begin{array}{r}17,280 \\
559 \\
10,183\end{array}$ & $\begin{array}{r}19,464 \\
571 \\
11,468\end{array}$ & $\begin{array}{r}21,294 \\
679 \\
11,905\end{array}$ & $\begin{array}{r}22,736 \\
664 \\
14,518\end{array}$ & $\begin{array}{r}25,820 \\
721 \\
16,378\end{array}$ & $\begin{array}{r}28,546 \\
901 \\
18,570\end{array}$ \\
\hline Conservation of Lands and Minerals ${ }^{3}$ & 7,527 & 9,704 & 13,467 & 14,748 & 18,213 & 36,082 \\
\hline $\begin{array}{l}\text { Direct program } \\
\text { Reimbursable program }\end{array}$ & $\begin{array}{r}7,497 \\
30 \\
\end{array}$ & $\begin{array}{r}9,670 \\
34 \\
\end{array}$ & $\begin{array}{r}13,441 \\
26 \\
\end{array}$ & $\begin{array}{r}14,700 \\
48 \\
\end{array}$ & $\begin{array}{r}18,172 \\
41 \\
\end{array}$ & $\begin{array}{r}36,032 \\
50 \\
\end{array}$ \\
\hline $\begin{array}{l}\text { Miscellaneous non-Federal sources } \\
\text { Other Federal agencies }\end{array}$ & $\begin{array}{r}2 \\
28\end{array}$ & $\begin{array}{r}2 \\
32\end{array}$ & $\begin{array}{r}1 \\
25\end{array}$ & $\begin{array}{r}3 \\
45\end{array}$ & $\overline{41}$ & $\begin{array}{r}4 \\
46\end{array}$ \\
\hline Land Information and Analysis * & 1,967 & 3,539 & 7,289 & 13,125 & 13,003 & 16,994 \\
\hline $\begin{array}{l}\text { Direct program } \\
\text { Reimbursable program }\end{array}$ & $\begin{array}{r}1,101 \\
866 \\
\end{array}$ & $\begin{array}{l}2,373 \\
1,166 \\
\end{array}$ & $\begin{array}{r}6,714 \\
575 \\
\end{array}$ & $\begin{array}{r}11,876 \\
1,249 \\
\end{array}$ & $\begin{array}{r}11,458 \\
1,545 \\
\end{array}$ & $\begin{array}{r}15,461 \\
1,533 \\
\end{array}$ \\
\hline $\begin{array}{l}\text { States, counties, and municipalities } \\
\text { Miscellaneous non-Federal sources } \\
\text { Other Federal agencies }\end{array}$ & $\overline{--}$ & $1,1 \overline{--}$ & $5 \overline{--}$ & $\begin{array}{r}-- \\
1,249\end{array}$ & $\begin{array}{l}5 \overline{-} \\
952\end{array}$ & $\begin{array}{r}33 \\
1,093 \\
407\end{array}$ \\
\hline General administration ${ }^{5}$ & 2,867 & 3,048 & 3,187 & 3,217 & 3,517 & 3,671 \\
\hline Direct program & 2,867 & 3,048 & 3,187 & 3,217 & 3,517 & $\overline{3,671}$ \\
\hline Facilities ${ }^{\bullet}$ - & -- & -- & 35 & 687 & 5,475 & 10,309 \\
\hline Direct program & -- & -- & 35 & 687 & 5,475 & 10,309 \\
\hline Miscellaneous services to other accounts & 2,189 & 3,026 & 2,027 & 2,575 & 2,760 & 2,853 \\
\hline Reimbursable program & 2,189 & 3,026 & 2,027 & 2,575 & 2,760 & 2,853 \\
\hline $\begin{array}{l}\text { Miscellaneous non-Federal sources } \\
\text { Other Federal agencies }\end{array}$ & $\begin{array}{r}28 \\
2,161\end{array}$ & $\begin{array}{r}32 \\
2,994\end{array}$ & $\begin{array}{r}29 \\
1,998\end{array}$ & $\begin{array}{r}47 \\
2,528\end{array}$ & $\begin{array}{r}54 \\
2,706\end{array}$ & $\begin{array}{r}56 \\
2,797\end{array}$ \\
\hline
\end{tabular}

See footnotes at end of table. 
TABLE 26.-Geological Survey budget, by activity and sources of funds, fiscal years 1970-75-Continued [In thousands of dollars. Detail may not add to totals because of rounding]

\begin{tabular}{|c|c|c|c|c|c|c|}
\hline Budget activity & 1970 & 1971 & 1972 & 1973 & 1974 & 1975 \\
\hline \multicolumn{7}{|c|}{ CONSTANT 1967 DOLLARS ${ }^{7}$} \\
\hline - - - - - - & $\$ 138,180$ & $\$ 144,610$ & $\$ 152,171$ & $\$ 164,298$ & $\$ 178,936$ & $\$ 219,265$ \\
\hline $\begin{array}{l}\text { Direct program } \\
\text { Reimbursable program }\end{array}$ & $\begin{array}{l}90,701 \\
47,479 \\
\end{array}$ & $\begin{array}{l}95,225 \\
49,385\end{array}$ & $\begin{array}{r}105,436 \\
46,735 \\
\end{array}$ & $\begin{array}{r}116,257 \\
48,041 \\
\end{array}$ & $\begin{array}{r}123,374 \\
55,562 \\
\end{array}$ & $\begin{array}{r}164,146 \\
55,119 \\
\end{array}$ \\
\hline $\begin{array}{l}\text { States, counties, and municipalities } \\
\text { Miscellaneous non-Federal sources } \\
\text { Other Federal agencies }\end{array}$ & $\begin{array}{r}20,279 \\
2,752 \\
24,448\end{array}$ & $\begin{array}{r}20,607 \\
2,705 \\
26,073\end{array}$ & $\begin{array}{r}20,819 \\
2,724 \\
23,192\end{array}$ & $\begin{array}{r}21,714 \\
2,806 \\
23,521\end{array}$ & $\begin{array}{r}23,273 \\
3,368 \\
28,921\end{array}$ & $\begin{array}{r}22,734 \\
4,142 \\
28,243\end{array}$ \\
\hline Alaska Pipeline Related Investigations & 649 & 1,169 & 1,128 & 960 & 638 & 223 \\
\hline $\begin{array}{l}\text { Direct program } \\
\text { Reimbursable program }\end{array}$ & $\begin{array}{r}623 \\
26 \\
\end{array}$ & $\begin{array}{r}1,115 \\
54 \\
\end{array}$ & $\begin{array}{r}1,078 \\
50 \\
\end{array}$ & $\begin{array}{r}960 \\
-- \\
\end{array}$ & $\begin{array}{r}638 \\
-- \\
\end{array}$ & $\begin{array}{r}223 \\
-- \\
\end{array}$ \\
\hline Other Federal agencies & 26 & 54 & 50 & -- & -- & -- \\
\hline Topographic Surveys and Mapping & 31,339 & 31,240 & 31,189 & 31,218 & 31,323 & 34,043 \\
\hline $\begin{array}{l}\text { Direct program } \\
\text { Reimbursable program }\end{array}$ & $\begin{array}{r}25,016 \\
6,323 \\
\end{array}$ & $\begin{array}{r}26,004 \\
5,236 \\
\end{array}$ & $\begin{array}{r}27,814 \\
3,375 \\
\end{array}$ & $\begin{array}{r}27,265 \\
3,953 \\
\end{array}$ & $\begin{array}{r}26,658 \\
4,665 \\
\end{array}$ & $\begin{array}{r}29,353 \\
4,690 \\
\end{array}$ \\
\hline $\begin{array}{l}\text { States, counties, and municipalities } \\
\text { Miscellaneous non-Federal sources } \\
\text { Other Federal agencies }\end{array}$ & $\begin{array}{r}3,974 \\
251 \\
2,098\end{array}$ & $\begin{array}{r}3,256 \\
296 \\
1,684\end{array}$ & $\begin{array}{r}2,580 \\
287 \\
508\end{array}$ & $\begin{array}{r}2,883 \\
465 \\
605\end{array}$ & $\begin{array}{r}3,545 \\
461 \\
659\end{array}$ & $\begin{array}{r}3,233 \\
384 \\
1,073\end{array}$ \\
\hline Geologic and Mineral Resource Surveys and Mapping ${ }^{1}$ & 41,085 & 40,914 & 41,489 & 44,945 & 52,771 & 74,095 \\
\hline $\begin{array}{l}\text { Direct program } \\
\text { Reimbursable program }\end{array}$ & $\begin{array}{l}27,266 \\
13,819 \\
\end{array}$ & $\begin{array}{l}26,644 \\
14,270\end{array}$ & $\begin{array}{l}27,572 \\
13,917 \\
\end{array}$ & $\begin{array}{l}33,252 \\
11,693 \\
\end{array}$ & $\begin{array}{l}35,780 \\
16,991\end{array}$ & $\begin{array}{l}57,6,17 \\
16,478 \\
\end{array}$ \\
\hline $\begin{array}{l}\text { States, counties, and municipalities } \\
\text { Miscellaneous non-Federal sources } \\
\text { Other Federal agencies }\end{array}$ & $\begin{array}{r}1,134 \\
1,984 \\
10,701\end{array}$ & $\begin{array}{r}1,103 \\
1,903 \\
11,264\end{array}$ & $\begin{array}{r}1,094 \\
1,866 \\
10,957\end{array}$ & $\begin{array}{l}1,206 \\
1,788 \\
8,699\end{array}$ & $\begin{array}{r}1,206 \\
1,925 \\
13,860\end{array}$ & $\begin{array}{r}1,003 \\
2,628 \\
13,047\end{array}$ \\
\hline 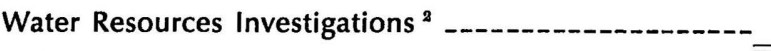 & 52,333 & 55,162 & 57,427 & 60,545 & 63,380 & 65,655 \\
\hline $\begin{array}{l}\text { Direct program } \\
\text { Reimbursable program }\end{array}$ & $\begin{array}{l}27,731 \\
24,602 \\
\end{array}$ & $\begin{array}{r}28,866 \\
26,296\end{array}$ & $\begin{array}{l}30,150 \\
27,277\end{array}$ & $\begin{array}{l}31,151 \\
29,394 \\
\end{array}$ & $\begin{array}{r}32,592 \\
30,788 \\
\end{array}$ & $\begin{array}{l}34,576 \\
31,679\end{array}$ \\
\hline $\begin{array}{l}\text { States, counties, and municipalities } \\
\text { Miscellaneous non-Federal sources } \\
\text { Other Federal agencies }\end{array}$ & $\begin{array}{r}15,171 \\
491 \\
8,940\end{array}$ & $\begin{array}{r}16,247 \\
477 \\
9,572\end{array}$ & $\begin{array}{r}17,145 \\
547 \\
9,585\end{array}$ & $\begin{array}{r}17,625 \\
515 \\
11,254\end{array}$ & $\begin{array}{r}18,522 \\
517 \\
11,749\end{array}$ & $\begin{array}{r}18,477 \\
583 \\
12,019\end{array}$ \\
\hline Conservation of Lands and Minerals ${ }^{3}$ & 6,608 & 8,100 & 10,843 & 11,432 & 13,065 & 23,354 \\
\hline $\begin{array}{l}\text { Direct program } \\
\text { Reimbursable program }\end{array}$ & $\begin{array}{r}6,582 \\
26 \\
\end{array}$ & $\begin{array}{r}8,072 \\
28 \\
\end{array}$ & $\begin{array}{r}10,822 \\
21 \\
\end{array}$ & $\begin{array}{r}11,395 \\
37 \\
\end{array}$ & $\begin{array}{r}13,036 \\
29 \\
\end{array}$ & $\begin{array}{r}23,22 \\
32 \\
\end{array}$ \\
\hline $\begin{array}{l}\text { Miscellaneous non-Federal sources } \\
\text { Other Federal agencies }\end{array}$ & $\begin{array}{r}2 \\
24\end{array}$ & $\begin{array}{r}2 \\
26\end{array}$ & $\begin{array}{r}1 \\
20\end{array}$ & $\begin{array}{r}2 \\
35\end{array}$ & $\overline{29}$ & $\begin{array}{r}2 \\
30\end{array}$ \\
\hline Land Information and Analysis " & 1,727 & 2,954 & 5,869 & 10,174 & 9,328 & 10,999 \\
\hline $\begin{array}{l}\text { Direct program } \\
\text { Reimbursable program }\end{array}$ & $\begin{array}{l}967 \\
760 \\
\end{array}$ & $\begin{array}{r}1,981 \\
973 \\
\end{array}$ & $\begin{array}{r}5,406 \\
463 \\
\end{array}$ & $\begin{array}{r}9,206 \\
968 \\
\end{array}$ & $\begin{array}{l}8,220 \\
1,108 \\
\end{array}$ & $\begin{array}{r}10,607 \\
\square 92 \\
\end{array}$ \\
\hline $\begin{array}{l}\text { States, counties, and municipalities } \\
\text { Miscellaneous non-Federal sources } \\
\text { Other Federal agencies }\end{array}$ & $\overline{--}$ & $9 \overline{--}$ & $\begin{array}{l}-- \\
463\end{array}$ & $9 \overline{--}$ & $\begin{array}{l}4 \overline{25} \\
683\end{array}$ & $\begin{array}{l}21 \\
708 \\
: 63\end{array}$ \\
\hline General administration ${ }^{5}$ & 2,517 & 2,544 & 2,566 & 2,494 & 2,523 & 2,76 \\
\hline Direct program & 2,517 & 2,544 & 2,566 & 2,494 & 2,523 & $2, \overline{76}$ \\
\hline Facilities $^{\circ}$ - & -- & -- & 28 & 532 & 3,928 & 6,672 \\
\hline Direct program & -- & -- & 28 & 532 & 3,928 & $\overline{6,6}, \overline{72}$ \\
\hline Miscellaneous services to other accounts & 1,922 & 2,526 & 1,632 & 1,996 & 1,980 & 1,447 \\
\hline Reimbursable program & 1,922 & 2,526 & 1,632 & 1,996 & 1,980 & 1,847 \\
\hline $\begin{array}{l}\text { Miscellaneous non-Federal sources } \\
\text { Other Federal agencies }\end{array}$ & $\begin{array}{r}25 \\
1,897 \\
\end{array}$ & $\begin{array}{r}27 \\
2,499 \\
\end{array}$ & $\begin{array}{r}23 \\
1,609 \\
\end{array}$ & $\begin{array}{r}36 \\
1,960 \\
\end{array}$ & $\begin{array}{r}39 \\
1,941 \\
\end{array}$ & $\begin{array}{r}37 \\
1,810 \\
\end{array}$ \\
\hline $\begin{array}{l}\text { I Funds include: Mineral Discovery Loan Program activity for fi } \\
1970-75 \text {; and parts of Geothermal Investigations, Minerals Po } \\
\text { Arctic Environmental Studies components of the Special Reso } \\
\text { Environmental Projects activity for fiscal years } 1971-75 \text {. Fund } \\
\text { the Land Resource Analysis program for fiscal years } 1973-75 \text {. } \\
\text { a Funds exclude Employee Compensation Payments subactivity } \\
\text { years } 1970-75 \text {. } \\
3 \text { Funds include parts of Geothermal Investigations componer } \\
\text { Special Resource and Environmental Projects activity for fis } \\
1972-75 \text {. } \\
\text { Budget activity funds are reconstructed for fiscal years } 197\end{array}$ & $\begin{array}{l}\text { I years inc } \\
\text { ey, and } 19 \\
\text { ce and of } \\
\text { exclude ye } \\
\text { Mi } \\
\text { fiscal an } \\
\text { of the } \\
\text { years } \\
-75 \text { and cu }\end{array}$ & $\begin{array}{l}\text { nclude: Earth R } \\
970-75 \text {; Urban } \\
\text { f the Special } \\
\text { ears } 1970-75 ; \\
\text { Aineral Resource } \\
\text { ind the Land Us } \\
5 \text { Funds include } \\
\text { Vater Resources } \\
6 \text { Budget activit } \\
7 \text { Gross Nationc } \\
\text { urrent to constan }\end{array}$ & $\begin{array}{l}\text { Resources Obs } \\
\text { Area Studies } \\
\text { Resource and } \\
\text { Land Resource } \\
\text { Surveys and } \\
\text { Se Data and A } \\
\text { e Employee C } \\
\text { Investigations } \\
\text { ty began in fis } \\
\text { al Product im }\end{array}$ & $\begin{array}{l}\text { rvation Syste } \\
\text { and Energy Ir } \\
\text { Environmenta } \\
\text { S Analysis pr } \\
\text { Mapping activ } \\
\text { nalysis activit } \\
\text { ompensation } \\
\text { activity for } \\
\text { cal year } 1972 \text {. } \\
\text { plicit price d }\end{array}$ & $\begin{array}{l}\text { m activity f } \\
\text { npact Evaluat } \\
\text { Projects act } \\
\text { ogram of th } \\
\text { ity for fiscal } \\
\text { for fiscal ye } \\
\text { payments sub } \\
\text { iscal years } 1 \\
\text { eflater was }\end{array}$ & $\begin{array}{l}\text { or fisca years } \\
\text { tion comoonents } \\
\text { tivity fo: fiscal } \\
\text { e Geologic and } \\
\text { years } 1974-75 ; \\
\text { ar } 1975 \text {; } \\
\text { activity of the } \\
970-75 \text {. } \\
\text { used to convert }\end{array}$ \\
\hline
\end{tabular}


TABLE 27.-Geological Survey Federal-State Cooperative program funds, by State, fiscal years 1970-75

[ $\mathrm{ln}$ thousands of dollars]

\begin{tabular}{|c|c|c|c|c|c|c|}
\hline State & 1970 & 1971 & 1972 & 1973 & 1974 & 1975 \\
\hline $\begin{array}{l}\text { Total }^{2} \text { - } \\
\quad \text { Total State share }\end{array}$ & $\begin{array}{r}\$ 46,399 \\
23,098 \\
\end{array}$ & $\begin{array}{r}\$ 49,274 \\
24,687 \\
\end{array}$ & $\begin{array}{r}\$ 50,651 \\
25,857 \\
\end{array}$ & $\begin{array}{r}\$ 55,633 \\
28,011 \\
\end{array}$ & $\begin{array}{c}\$ 65,256 \\
32,443 \\
\end{array}$ & $\begin{array}{r}\$ 70,151 \\
35,124 \\
\end{array}$ \\
\hline Alabama state share & $\begin{array}{l}826 \\
435\end{array}$ & $\begin{array}{l}846 \\
467\end{array}$ & $\begin{array}{l}839 \\
461\end{array}$ & $\begin{array}{l}928 \\
514\end{array}$ & $\begin{array}{r}1,094 \\
554\end{array}$ & $\begin{array}{r}1,212 \\
623\end{array}$ \\
\hline Alaska State share & $\begin{array}{l}417 \\
258\end{array}$ & $\begin{array}{l}411 \\
203\end{array}$ & $\begin{array}{l}619 \\
330\end{array}$ & $\begin{array}{l}838 \\
399\end{array}$ & $\begin{array}{l}897 \\
410\end{array}$ & $\begin{array}{r}1,162 \\
410\end{array}$ \\
\hline Arizona & $\begin{array}{l}819 \\
412\end{array}$ & $\begin{array}{l}869 \\
444\end{array}$ & $\begin{array}{r}1,021 \\
540\end{array}$ & $\begin{array}{r}1,001 \\
510\end{array}$ & $\begin{array}{r}1,144 \\
576\end{array}$ & $\begin{array}{r}1,248 \\
646\end{array}$ \\
\hline $\begin{array}{l}\text { Arkansas } \\
\text { State share }-\end{array}$ & $\begin{array}{l}464 \\
222\end{array}$ & $\begin{array}{l}492 \\
239\end{array}$ & $\begin{array}{l}506 \\
250\end{array}$ & $\begin{array}{l}596 \\
288\end{array}$ & $\begin{array}{l}857 \\
455\end{array}$ & $\begin{array}{l}887 \\
410\end{array}$ \\
\hline California State share & $\begin{array}{l}3,474 \\
1,677\end{array}$ & $\begin{array}{l}4,014 \\
1,951\end{array}$ & $\begin{array}{l}3,893 \\
1,936\end{array}$ & $\begin{array}{l}4,115 \\
2,053\end{array}$ & $\begin{array}{l}4,789 \\
2,280\end{array}$ & $\begin{array}{l}4,690 \\
2,337\end{array}$ \\
\hline 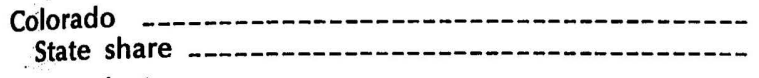 & $\begin{array}{l}951 \\
464\end{array}$ & $\begin{array}{l}944 \\
477\end{array}$ & $\begin{array}{l}995 \\
507\end{array}$ & $\begin{array}{r}1,128 \\
575\end{array}$ & $\begin{array}{r}1,484 \\
837\end{array}$ & $\begin{array}{l}2,445 \\
1,324\end{array}$ \\
\hline $\begin{array}{l}\text { Connecticut } \\
\text { State share }\end{array}$ & $\begin{array}{l}585 \\
277\end{array}$ & $\begin{array}{l}619 \\
302\end{array}$ & $\begin{array}{l}617 \\
304\end{array}$ & $\begin{array}{l}687 \\
292\end{array}$ & $\begin{array}{l}814 \\
374\end{array}$ & $\begin{array}{r}1,069 \\
523\end{array}$ \\
\hline $\begin{array}{l}\text { Delaware } \\
\text { State share }\end{array}$ & $\begin{array}{l}88 \\
52\end{array}$ & $\begin{array}{r}112 \\
73\end{array}$ & $\begin{array}{r}111 \\
75\end{array}$ & $\begin{array}{r}121 \\
81\end{array}$ & $\begin{array}{r}130 \\
74\end{array}$ & $\begin{array}{l}194 \\
106\end{array}$ \\
\hline $\begin{array}{l}\text { District of Columbia } \\
\text { State share }\end{array}$ & $\begin{array}{r}12 \\
6\end{array}$ & $\begin{array}{r}12 \\
6\end{array}$ & $\begin{array}{l}2 \\
1\end{array}$ & $\begin{array}{l}3 \\
1\end{array}$ & $\begin{array}{l}3 \\
1\end{array}$ & $\begin{array}{l}3 \\
1\end{array}$ \\
\hline $\begin{array}{l}\text { Florida } \\
\text { State share }-1\end{array}$ & $\begin{array}{l}2,959 \\
1,456\end{array}$ & $\begin{array}{l}3,119 \\
1,539\end{array}$ & $\begin{array}{l}3,398 \\
1,719\end{array}$ & $\begin{array}{l}3,643 \\
1,858\end{array}$ & $\begin{array}{l}5,083 \\
2,552\end{array}$ & $\begin{array}{l}5,575 \\
2,781\end{array}$ \\
\hline $\begin{array}{l}\text { Georgia } \\
\text { State share }-1\end{array}$ & $\begin{array}{l}652 \\
354\end{array}$ & $\begin{array}{l}751 \\
400\end{array}$ & $\begin{array}{l}799 \\
437\end{array}$ & $\begin{array}{l}2,008 \\
1,041\end{array}$ & $\begin{array}{l}3,239 \\
1,611\end{array}$ & $\begin{array}{l}3,083 \\
1,531\end{array}$ \\
\hline $\begin{array}{l}\text { Hawaii } \\
\text { State share }-1\end{array}$ & $\begin{array}{l}598 \\
284\end{array}$ & $\begin{array}{l}649 \\
334\end{array}$ & $\begin{array}{l}622 \\
314\end{array}$ & $\begin{array}{l}653 \\
337\end{array}$ & $\begin{array}{l}691 \\
339\end{array}$ & $\begin{array}{l}697 \\
341\end{array}$ \\
\hline $\begin{array}{l}\text { Idaho } \\
\text { State share }-\end{array}$ & $\begin{array}{l}546 \\
261\end{array}$ & $\begin{array}{l}633 \\
308\end{array}$ & $\begin{array}{l}619 \\
307\end{array}$ & $\begin{array}{l}675 \\
344\end{array}$ & $\begin{array}{l}718 \\
353\end{array}$ & $\begin{array}{l}749 \\
366\end{array}$ \\
\hline $\begin{array}{l}\text { Illinois } \\
\text { State share }\end{array}$ & $\begin{array}{l}549 \\
263\end{array}$ & $\begin{array}{l}650 \\
316\end{array}$ & $\begin{array}{l}653 \\
341\end{array}$ & $\begin{array}{l}646 \\
333\end{array}$ & $\begin{array}{l}544 \\
277\end{array}$ & $\begin{array}{r}645 \\
323\end{array}$ \\
\hline $\begin{array}{l}\text { Indiana } \\
\text { State share }\end{array}$ & $\begin{array}{l}895 \\
428\end{array}$ & $\begin{array}{l}906 \\
439\end{array}$ & $\begin{array}{l}994 \\
491\end{array}$ & $\begin{array}{r}1,107 \\
590\end{array}$ & $\begin{array}{r}1,363 \\
678\end{array}$ & $\begin{array}{r}1,288 \\
632\end{array}$ \\
\hline $\begin{array}{l}\text { lowa } \\
\text { State share }-1\end{array}$ & $\begin{array}{l}457 \\
218\end{array}$ & $\begin{array}{l}442 \\
214\end{array}$ & $\begin{array}{l}517 \\
255\end{array}$ & $\begin{array}{l}525 \\
259\end{array}$ & $\begin{array}{l}608 \\
299\end{array}$ & $\begin{array}{l}617 \\
302\end{array}$ \\
\hline $\begin{array}{l}\text { Kansas } \\
\text { State share }-1\end{array}$ & $\begin{array}{r}1,286 \\
619\end{array}$ & $\begin{array}{r}1,324 \\
645\end{array}$ & $\begin{array}{r}1,362 \\
675\end{array}$ & $\begin{array}{r}1,358 \\
676\end{array}$ & $\begin{array}{r}1,402 \\
686\end{array}$ & $\begin{array}{r}1,424 \\
716\end{array}$ \\
\hline $\begin{array}{l}\text { Kentucky } \\
\text { State share }\end{array}$ & $\begin{array}{r}1,738 \\
842\end{array}$ & $\begin{array}{r}1,900 \\
939\end{array}$ & $\begin{array}{l}2,033 \\
1,008\end{array}$ & $\begin{array}{l}2,212 \\
1,039\end{array}$ & $\begin{array}{l}2,451 \\
1,122\end{array}$ & $\begin{array}{l}2,728 \\
1,229\end{array}$ \\
\hline $\begin{array}{l}\text { Louisiana } \\
\text { State share }\end{array}$ & $\begin{array}{r}1,071 \\
567\end{array}$ & $\begin{array}{r}1,167 \\
621\end{array}$ & $\begin{array}{r}1,212 \\
655\end{array}$ & $\begin{array}{r}1,240 \\
674\end{array}$ & $\begin{array}{r}1,900 \\
980\end{array}$ & $\begin{array}{r}1,740 \\
902\end{array}$ \\
\hline $\begin{array}{l}\text { Maine } \\
\text { State share }-\end{array}$ & $\begin{array}{r}151 \\
80\end{array}$ & $\begin{array}{r}158 \\
84\end{array}$ & $\begin{array}{r}163 \\
89\end{array}$ & $\begin{array}{r}168 \\
91\end{array}$ & $\begin{array}{r}175 \\
96\end{array}$ & $\begin{array}{l}248 \\
127\end{array}$ \\
\hline $\begin{array}{l}\text { Maryland } \\
\text { State share }-\end{array}$ & $\begin{array}{l}594 \\
296\end{array}$ & $\begin{array}{l}580 \\
295\end{array}$ & $\begin{array}{l}620 \\
321\end{array}$ & $\begin{array}{l}695 \\
356\end{array}$ & $\begin{array}{l}851 \\
435\end{array}$ & $\begin{array}{r}1,011 \\
530\end{array}$ \\
\hline $\begin{array}{l}\text { Massachusetts } \\
\text { State share }\end{array}$ & $\begin{array}{l}946 \\
463\end{array}$ & $\begin{array}{r}1,126 \\
595\end{array}$ & $\begin{array}{r}1,159 \\
614\end{array}$ & $\begin{array}{r}1,379 \\
625\end{array}$ & $\begin{array}{r}1,346 \\
656\end{array}$ & $\begin{array}{r}1,618 \\
810\end{array}$ \\
\hline $\begin{array}{l}\text { Michigan } \\
\text { State share }-\end{array}$ & $\begin{array}{l}993 \\
473\end{array}$ & $\begin{array}{l}865 \\
407\end{array}$ & $\begin{array}{l}859 \\
417\end{array}$ & $\begin{array}{r}947 \\
425\end{array}$ & $\begin{array}{r}930 \\
436\end{array}$ & $\begin{array}{r}1,054 \\
505\end{array}$ \\
\hline $\begin{array}{l}\text { Minnesota } \\
\text { State share }-1\end{array}$ & $\begin{array}{r}1,369 \\
673\end{array}$ & $\begin{array}{r}1,434 \\
707\end{array}$ & $\begin{array}{r}1,369 \\
681\end{array}$ & $\begin{array}{r}1,420 \\
727\end{array}$ & $\begin{array}{r}1,903 \\
966\end{array}$ & $\begin{array}{r}1,639 \\
817\end{array}$ \\
\hline $\begin{array}{l}\text { Mississippi } \\
\text { State share }-\end{array}$ & $\begin{array}{l}444 \\
275\end{array}$ & $\begin{array}{l}551 \\
316\end{array}$ & $\begin{array}{l}592 \\
357\end{array}$ & $\begin{array}{l}593 \\
340\end{array}$ & $\begin{array}{l}645 \\
325\end{array}$ & $\begin{array}{l}743 \\
415\end{array}$ \\
\hline $\begin{array}{l}\text { Missouri }-1-1 \\
\text { State share }-\end{array}$ & $\begin{array}{l}776 \\
374\end{array}$ & $\begin{array}{l}863 \\
420\end{array}$ & $\begin{array}{l}792 \\
413\end{array}$ & $\begin{array}{l}732 \\
375\end{array}$ & $\begin{array}{l}657 \\
322\end{array}$ & $\begin{array}{l}678 \\
337\end{array}$ \\
\hline $\begin{array}{l}\text { Montana } \\
\text { State share }\end{array}$ & $\begin{array}{l}318 \\
172\end{array}$ & $\begin{array}{l}393 \\
212\end{array}$ & $\begin{array}{l}401 \\
221\end{array}$ & $\begin{array}{l}402 \\
223\end{array}$ & $\begin{array}{l}505 \\
255\end{array}$ & $\begin{array}{l}587 \\
287\end{array}$ \\
\hline $\begin{array}{l}\text { Nebraska } \\
\text { State share }\end{array}$ & $\begin{array}{l}440 \\
211\end{array}$ & $\begin{array}{l}502 \\
246\end{array}$ & $\begin{array}{l}553 \\
274\end{array}$ & $\begin{array}{l}588 \\
298\end{array}$ & $\begin{array}{l}705 \\
344\end{array}$ & $\begin{array}{l}731 \\
358\end{array}$ \\
\hline
\end{tabular}

\footnotetext{
See footnotes at end of table.
} 
TABLE 27.-Geological Survey Federal-State Cooperative program funds, by State, fiscal years 1970-75—Continued [in thousands of dollars]

\begin{tabular}{|c|c|c|c|c|c|c|}
\hline State & 1970 & 1971 & 1972 & 1973 & 1974 & 1975 \\
\hline Nevada state share & $\begin{array}{l}482 \\
225\end{array}$ & $\begin{array}{l}513 \\
234\end{array}$ & $\begin{array}{l}578 \\
271\end{array}$ & $\begin{array}{l}640 \\
288\end{array}$ & $\begin{array}{l}689 \\
304\end{array}$ & $\begin{array}{l}846 \\
332\end{array}$ \\
\hline $\begin{array}{l}\text { New Hampshire } \\
\text { State share }\end{array}$ & $\begin{array}{r}116 \\
56\end{array}$ & $\begin{array}{r}113 \\
55\end{array}$ & $\begin{array}{r}100 \\
50\end{array}$ & $\begin{array}{r}139 \\
67\end{array}$ & $\begin{array}{r}177 \\
97\end{array}$ & $\begin{array}{r}172 \\
73\end{array}$ \\
\hline $\begin{array}{l}\text { New Jersey } \\
\text { State share }\end{array}$ & $\begin{array}{l}735 \\
363\end{array}$ & $\begin{array}{l}785 \\
390\end{array}$ & $\begin{array}{l}822 \\
418\end{array}$ & $\begin{array}{l}856 \\
433\end{array}$ & $\begin{array}{r}1,051 \\
530\end{array}$ & $\begin{array}{l}977 \\
501\end{array}$ \\
\hline $\begin{array}{l}\text { New Mexico } \\
\text { State share }\end{array}$ & $\begin{array}{l}842 \\
432\end{array}$ & $\begin{array}{l}888 \\
462\end{array}$ & $\begin{array}{l}963 \\
509\end{array}$ & $\begin{array}{r}1,107 \\
601\end{array}$ & $\begin{array}{r}1,332 \\
662\end{array}$ & $\begin{array}{r}1,439 \\
714\end{array}$ \\
\hline $\begin{array}{l}\text { New York } \\
\text { State share }\end{array}$ & $\begin{array}{r}1,800 \\
866\end{array}$ & $\begin{array}{r}1,989 \\
973\end{array}$ & $\begin{array}{l}2,224 \\
1,111\end{array}$ & $\begin{array}{l}2,395 \\
1,229\end{array}$ & $\begin{array}{l}2,796 \\
1,415\end{array}$ & $\begin{array}{l}2,977 \\
1,585\end{array}$ \\
\hline $\begin{array}{l}\text { North Carolina } \\
\text { State share }\end{array}$ & $\begin{array}{l}883 \\
419\end{array}$ & $\begin{array}{l}938 \\
437\end{array}$ & $\begin{array}{l}946 \\
457\end{array}$ & $\begin{array}{r}1,038 \\
492\end{array}$ & $\begin{array}{r}1,586 \\
771\end{array}$ & $\begin{array}{r}1,885 \\
942\end{array}$ \\
\hline $\begin{array}{l}\text { North Dakota } \\
\text { State share }\end{array}$ & $\begin{array}{l}689 \\
337\end{array}$ & $\begin{array}{l}661 \\
325\end{array}$ & $\begin{array}{l}714 \\
361\end{array}$ & $\begin{array}{l}899 \\
461\end{array}$ & $\begin{array}{l}763 \\
369\end{array}$ & $\begin{array}{l}998 \\
489\end{array}$ \\
\hline $\begin{array}{l}\text { Ohio } \\
\text { State share }\end{array}$ & $\begin{array}{l}912 \\
486\end{array}$ & $\begin{array}{l}979 \\
521\end{array}$ & $\begin{array}{l}990 \\
518\end{array}$ & $\begin{array}{r}1,028 \\
520\end{array}$ & $\begin{array}{l}978 \\
481\end{array}$ & $\begin{array}{r}7,093 \\
563\end{array}$ \\
\hline $\begin{array}{l}\text { Oklahoma } \\
\text { State share }\end{array}$ & $\begin{array}{l}579 \\
312\end{array}$ & $\begin{array}{l}664 \\
359\end{array}$ & $\begin{array}{l}614 \\
333\end{array}$ & $\begin{array}{l}634 \\
340\end{array}$ & $\begin{array}{l}702 \\
344\end{array}$ & $\begin{array}{l}748 \\
368\end{array}$ \\
\hline $\begin{array}{l}\text { Oregon } \\
\text { State share }\end{array}$ & $\begin{array}{l}625 \\
312\end{array}$ & $\begin{array}{l}606 \\
307\end{array}$ & $\begin{array}{l}727 \\
372\end{array}$ & $\begin{array}{l}828 \\
432\end{array}$ & $\begin{array}{l}896 \\
439\end{array}$ & $\begin{array}{l}902 \\
443\end{array}$ \\
\hline $\begin{array}{l}\text { Pennsylvania } \\
\text { State share }\end{array}$ & $\begin{array}{l}2,322 \\
1,164\end{array}$ & $\begin{array}{l}2,178 \\
1,088\end{array}$ & $\begin{array}{l}2,167 \\
1,092\end{array}$ & $\begin{array}{l}2,047 \\
1,042\end{array}$ & $\begin{array}{l}2,357 \\
1,195\end{array}$ & $\begin{array}{r}2,415 \\
7,209\end{array}$ \\
\hline $\begin{array}{l}\text { Rhode Island } \\
\text { State share }\end{array}$ & $\begin{array}{l}91 \\
48\end{array}$ & $\begin{array}{l}97 \\
52\end{array}$ & $\begin{array}{l}92 \\
50\end{array}$ & $\begin{array}{l}90 \\
50\end{array}$ & $\begin{array}{l}97 \\
52\end{array}$ & $\begin{array}{r}110 \\
54\end{array}$ \\
\hline $\begin{array}{l}\text { South Carolina } \\
\text { State share }\end{array}$ & $\begin{array}{l}340 \\
178\end{array}$ & $\begin{array}{l}374 \\
196\end{array}$ & $\begin{array}{l}403 \\
212\end{array}$ & $\begin{array}{l}574 \\
301\end{array}$ & $\begin{array}{l}546 \\
279\end{array}$ & $\begin{array}{l}574 \\
284\end{array}$ \\
\hline $\begin{array}{l}\text { South Dakota } \\
\text { State share }\end{array}$ & $\begin{array}{l}399 \\
219\end{array}$ & $\begin{array}{l}409 \\
226\end{array}$ & $\begin{array}{l}424 \\
236\end{array}$ & $\begin{array}{l}423 \\
230\end{array}$ & $\begin{array}{l}471 \\
227\end{array}$ & $\begin{array}{l}515 \\
251\end{array}$ \\
\hline $\begin{array}{l}\text { Tennessee } \\
\text { State share }\end{array}$ & $\begin{array}{l}535 \\
284\end{array}$ & $\begin{array}{l}546 \\
292\end{array}$ & $\begin{array}{l}538 \\
294\end{array}$ & $\begin{array}{l}589 \\
321\end{array}$ & $\begin{array}{l}851 \\
422\end{array}$ & $\begin{array}{l}952 \\
470\end{array}$ \\
\hline $\begin{array}{l}\text { Texas } \\
\text { State share }\end{array}$ & $\begin{array}{l}3,103 \\
1,545\end{array}$ & $\begin{array}{l}3,835 \\
1,922\end{array}$ & $\begin{array}{l}3,717 \\
1,925\end{array}$ & $\begin{array}{l}3,794 \\
1,949\end{array}$ & $\begin{array}{l}4,046 \\
2,027\end{array}$ & $\begin{array}{l}4,261 \\
2,100\end{array}$ \\
\hline Utah State share & $\begin{array}{l}852 \\
407\end{array}$ & $\begin{array}{l}868 \\
421\end{array}$ & $\begin{array}{l}967 \\
486\end{array}$ & $\begin{array}{r}1,069 \\
530\end{array}$ & $\begin{array}{r}1,068 \\
534\end{array}$ & $\begin{array}{r}, 361 \\
838\end{array}$ \\
\hline $\begin{array}{l}\text { Vermont } \\
\text { State share }\end{array}$ & $\begin{array}{r}121 \\
72\end{array}$ & $\begin{array}{r}124 \\
62\end{array}$ & $\begin{array}{r}125 \\
64\end{array}$ & $\begin{array}{r}129 \\
66\end{array}$ & $\begin{array}{r}144 \\
73\end{array}$ & $\begin{array}{r}130 \\
64\end{array}$ \\
\hline $\begin{array}{l}\text { Virginia } \\
\text { State share }\end{array}$ & $\begin{array}{r}1,675 \\
850\end{array}$ & $\begin{array}{r}1,119 \\
577\end{array}$ & $\begin{array}{l}797 \\
420\end{array}$ & $\begin{array}{l}793 \\
421\end{array}$ & $\begin{array}{l}905 \\
466\end{array}$ & $\begin{array}{l}858 \\
442\end{array}$ \\
\hline $\begin{array}{l}\text { Washington } \\
\text { State share }\end{array}$ & $\begin{array}{r}1,686 \\
801\end{array}$ & $\begin{array}{r}1,774 \\
856\end{array}$ & $\begin{array}{r}1,800 \\
881\end{array}$ & $\begin{array}{r}1,988 \\
962\end{array}$ & $\begin{array}{l}2,121 \\
1,037\end{array}$ & $\begin{array}{r}2,208 \\
, 104\end{array}$ \\
\hline $\begin{array}{l}\text { West Virginia } \\
\text { State share }\end{array}$ & $\begin{array}{l}386 \\
213\end{array}$ & $\begin{array}{l}457 \\
249\end{array}$ & $\begin{array}{l}482 \\
263\end{array}$ & $\begin{array}{l}620 \\
332\end{array}$ & $\begin{array}{l}946 \\
521\end{array}$ & $\begin{array}{l}775 \\
448\end{array}$ \\
\hline $\begin{array}{l}\text { Wisconsin } \\
\text { State share }\end{array}$ & $\begin{array}{r}1,162 \\
556\end{array}$ & $\begin{array}{r}1,229 \\
584\end{array}$ & $\begin{array}{r}1,285 \\
619\end{array}$ & $\begin{array}{r}1,354 \\
638\end{array}$ & $\begin{array}{r}1,563 \\
775\end{array}$ & $\begin{array}{r}706 \\
883\end{array}$ \\
\hline $\begin{array}{l}\text { Wyoming } \\
\text { State share }\end{array}$ & $\begin{array}{l}588 \\
297\end{array}$ & $\begin{array}{l}626 \\
315\end{array}$ & $\begin{array}{l}589 \\
316\end{array}$ & $\begin{array}{l}612 \\
310\end{array}$ & $\begin{array}{l}698 \\
328\end{array}$ & $\begin{array}{l}853 \\
514\end{array}$ \\
\hline $\begin{array}{l}\text { American Samoa } \\
\text { State share }\end{array}$ & $\begin{array}{l}42 \\
20\end{array}$ & $\begin{array}{l}65 \\
32\end{array}$ & $\begin{array}{l}72 \\
36\end{array}$ & $\begin{array}{l}64 \\
32\end{array}$ & $\begin{array}{l}63 \\
31\end{array}$ & $\begin{array}{l}70 \\
32\end{array}$ \\
\hline $\begin{array}{l}\text { Guam } \\
\text { State share }\end{array}$ & $\begin{array}{l}21 \\
10\end{array}$ & $\begin{array}{l}25 \\
12\end{array}$ & $\begin{array}{l}36 \\
18\end{array}$ & $\begin{array}{l}43 \\
21\end{array}$ & $\begin{array}{l}62 \\
31\end{array}$ & $\begin{array}{l}65 \\
32\end{array}$ \\
\hline $\begin{array}{l}\text { Puerto Rico } \\
\text { State share }\end{array}$ & $\begin{array}{l}902 \\
470\end{array}$ & $\begin{array}{l}964 \\
484\end{array}$ & $\begin{array}{r}1,042 \\
494\end{array}$ & $\begin{array}{r}1,347 \\
557\end{array}$ & $\begin{array}{r}1,303 \\
682\end{array}$ & $\begin{array}{r}293 \\
585\end{array}$ \\
\hline $\begin{array}{l}\text { Trust Territories } \\
\text { State share }\end{array}$ & $\begin{array}{l}74 \\
35\end{array}$ & $\begin{array}{l}93 \\
45\end{array}$ & $\begin{array}{r}105 \\
52\end{array}$ & $\begin{array}{r}125 \\
62\end{array}$ & $\begin{array}{r}117 \\
58\end{array}$ & $\begin{array}{r}170 \\
84\end{array}$ \\
\hline $\begin{array}{l}\text { Virgin Islands } \\
\text { State share }\end{array}$ & $\begin{array}{r}19 \\
9\end{array}$ & $\begin{array}{l}23 \\
12\end{array}$ & $\begin{array}{r}12 \\
6\end{array}$ & 3 & s & $\begin{array}{l}33 \\
31\end{array}$ \\
\hline
\end{tabular}

1 Includes Federal funds from direct program

2 Reimbursable program funds from States, counties, and municipalities.

municipalities.
Included with Puerto Rico funds. 
TABLE 28.-Geological Survey reimbursable program funds from other Federal agencies, by agency, fiscal years 1970-75 [In thousands of dollars]

\begin{tabular}{|c|c|c|c|c|c|c|}
\hline Agency & 1970 & 1971 & 1972 & 1973 & 1974 & 1975 \\
\hline Total & $\$ 27,846$ & $\$ 31,236$ & $\$ 28,805$ & $\$ 30,342$ & $\$ 40,316$ & $\$ 43,636$ \\
\hline Appalachian Regional Commission & -- & -- & -- & - & 189 & 179 \\
\hline Department of Agriculture & 290 & 310 & 268 & 273 & 356 & 891 \\
\hline Department of Commerce & -- & 233 & 85 & 73 & 1 & 154 \\
\hline Department of Defense & 6,303 & 7,863 & 9,123 & 8,443 & 13,351 & 11,247 \\
\hline Department of Housing and Urban Development & 182 & 713 & 1,202 & 2,095 & 3,581 & 3,069 \\
\hline Department of the Interior & 3,584 & 3,408 & 1,714 & 2,208 & 2,312 & 9,361 \\
\hline Bonneville Power Administration & -- & -- & 101 & 118 & 136 & 105 \\
\hline $\begin{array}{l}\text { Bureau of Commercial Fisheries } \\
\text { Bureau of Indian Affairs }\end{array}$ & 4 & -- & -- & $14 \overline{9}$ & $\overrightarrow{340}$ & $6 \overline{07}$ \\
\hline Bureau of Land Management & $\overline{12 \overline{0}}$ & $1 \overline{6} \overline{6}$ & $20 \overline{5}$ & 207 & $\begin{array}{l}340 \\
251\end{array}$ & 5,114 \\
\hline Bureau of Mines & $\overline{17}$ & - & 80 & $-\overline{-1}$ & $=$ & 1,735 \\
\hline Bureau of Reclamation & 2,517 & 2,358 & 656 & 855 & 676 & 721 \\
\hline & 4 & 12 & 11 & -- & $-\overline{0}$ & $=-$ \\
\hline & -- & $-\overline{-1}$ & 101 & 256 & 380 & 372 \\
\hline $\begin{array}{l}\text { National Park Service } \\
\text { Office of Saline Water }\end{array}$ & 414 & 647 & 508 & 459 & 529 & 617 \\
\hline $\begin{array}{l}\text { Office of Saline Water } \\
\text { Office of the Secretary }\end{array}$ & $\overline{11 \overline{7}}$ & -- & 31 & 156 & -- & - \\
\hline $\begin{array}{l}\text { Otfice of the Secretary } \\
\text { Office of Territories }\end{array}$ & 408 & $2 \overline{25}$ & $\overline{21}$ & $\overline{8}$ & -- & - \\
\hline Department of State & 2,271 & 2,697 & 2,789 & 2,756 & 2,177 & 1,698 \\
\hline Department of Transportation & -- & -- & -- & -- & -- & 4 \\
\hline Energy Research and Development Administration ${ }^{2}$--- & 3,400 & 3,072 & 3,112 & 3,011 & 4,029 & 3,501 \\
\hline Environmental Protection Agency & 570 & 579 & 627 & 916 & 1,127 & 1,389 \\
\hline Federal Energy Administration & -- & -- & -- & -- & -- & 353 \\
\hline National Aeronautics and Space Administration & 7,347 & 7,029 & 6,017 & 6,507 & 5,672 & 3,449 \\
\hline National Oceanic and Atmospheric Administration & -- & -- & -- & -- & 2,001 & 434 \\
\hline National Science Foundation & 483 & 1,279 & 906 & 333 & 1,375 & 1,928 \\
\hline Nuclear Regulatory Commission _._. & -- & -- & -- & -- & -- & 1,195 \\
\hline Ozark Regional Commission & -- & -- & -- & -- & 60 & 49 \\
\hline Tennessee Valley Authority _. & 160 & 204 & 198 & 255 & 212 & 252 \\
\hline Miscellaneous Federal agencies & 1,095 & 855 & 766 & 944 & 1,168 & 1,686 \\
\hline Miscellaneous services to other accounts & 2,161 & 2,994 & 1,998 & 2,528 & 2,706 & 2,797 \\
\hline
\end{tabular}

1 Included in miscellaneous Federal agencies.

also funds from the Nuclear Regulatory Commission in fiscal year i975.

TABLE 29._Alaska Pipeline Related Investigations, reimbursable program funds from other Federal agencies, by agency, fiscal years 1970-75

[ In thousands of dollars]

\begin{tabular}{|c|c|c|c|c|c|c|}
\hline Agency & 1970 & 1971 & 1972 & 1973 & 1974 & 1975 \\
\hline Total & $\$ 30$ & $\$ 65$ & $\$ 62$ & -- & -- & $\ldots$ \\
\hline Department of the Interior & $\$ 30$ & $\$ 65$ & $\$ 65$ & -- & -- & -- \\
\hline $\begin{array}{l}\text { Bureau of Commercial Fisheries } \\
\text { Bureau of Land Management } \\
\text { Bureau of Sports Fisheries }\end{array}$ & $\begin{array}{r}4 \\
22 \\
4\end{array}$ & $\begin{array}{l}\overline{53} \\
12\end{array}$ & $\begin{array}{l}\overline{51} \\
11\end{array}$ & $\begin{array}{l}-- \\
--\end{array}$ & -- & -- \\
\hline
\end{tabular}


TABLE 30.-Topographic Surveys and Mapping direct program funds, by subactivity, fiscal years 1970-75 [ In thousands of dollars]

\begin{tabular}{lrrrrrrr}
\hline \multicolumn{1}{c}{ Subactivity } & \multicolumn{1}{c}{1970} & 1971 & 1972 & 1973 & 1974 & 1975 \\
\hline \multicolumn{1}{c}{ Cotal direct program $-1-1$} \\
\hline
\end{tabular}

1 Funds are reconstructed for fiscal years 1970-72 and include the Map

Revision and Maintenance subactivity.
2 National Cartographic Information Center funds included in the

Quadrangle Mapping and Revision subactivity prior to fiscal year 1975.

3 Gross National Product implicit price deflator was used to conver

current to constant 1967 dollars.

TABLE 31.-Topographic Surveys and Mapping Federal-State Cooperative program funds, by State, fiscal years 1970-75 [ In thousands of dollars]

\begin{tabular}{|c|c|c|c|c|c|c|}
\hline State & 1970 & 1971 & 1972 & 1973 & 1974 & 1975 \\
\hline $\begin{array}{l}\text { Total }^{1} \text { State share } \\
\quad \text { Total }\end{array}$ & $\begin{array}{r}\$ 9,052 \\
4,526\end{array}$ & $\begin{array}{r}\$ 7,802 \\
3,901\end{array}$ & $\begin{array}{r}\$ 6,408 \\
3,204\end{array}$ & $\begin{array}{r}\$ 7,438 \\
3,719\end{array}$ & $\begin{array}{r}\$ 9,884 \\
4,942\end{array}$ & $\begin{array}{r}\$ 9,990 \\
4,995\end{array}$ \\
\hline $\begin{array}{l}\text { Alabama } \\
\text { State share }\end{array}$ & $\begin{array}{l}56 \\
28\end{array}$ & $\begin{array}{l}50 \\
25\end{array}$ & $\begin{array}{l}50 \\
25\end{array}$ & $\begin{array}{l}50 \\
25\end{array}$ & $\begin{array}{l}40 \\
20\end{array}$ & $\begin{array}{l}62 \\
31\end{array}$ \\
\hline $\begin{array}{l}\text { Arkansas } \\
\text { State share }\end{array}$ & $\begin{array}{l}40 \\
20\end{array}$ & $\begin{array}{l}50 \\
25\end{array}$ & $\begin{array}{l}46 \\
23\end{array}$ & $\begin{array}{l}54 \\
27\end{array}$ & $\begin{array}{l}58 \\
29\end{array}$ & $\begin{array}{l}72 \\
36\end{array}$ \\
\hline $\begin{array}{l}\text { California } \\
\text { State share }\end{array}$ & $\begin{array}{l}554 \\
277\end{array}$ & $\begin{array}{l}432 \\
216\end{array}$ & $\begin{array}{r}186 \\
93\end{array}$ & $\begin{array}{r}186 \\
93\end{array}$ & $\begin{array}{r}198 \\
99\end{array}$ & $\begin{array}{l}252 \\
126\end{array}$ \\
\hline $\begin{array}{l}\text { Colorado } \\
\text { State share }\end{array}$ & -- & -- & -- & -- & $\begin{array}{l}4 \\
2\end{array}$ & $\begin{array}{l}830 \\
415\end{array}$ \\
\hline $\begin{array}{l}\text { Connecticut } \\
\text { State share }\end{array}$ & $\begin{array}{l}56 \\
28\end{array}$ & $\begin{array}{l}40 \\
20\end{array}$ & $\begin{array}{l}40 \\
20\end{array}$ & $\begin{array}{l}40 \\
20\end{array}$ & $\begin{array}{r}120 \\
60\end{array}$ & $\begin{array}{r}124 \\
62\end{array}$ \\
\hline $\begin{array}{l}\text { Florida } \\
\text { State share }\end{array}$ & $\begin{array}{l}988 \\
494\end{array}$ & $\begin{array}{l}580 \\
290\end{array}$ & $\begin{array}{l}580 \\
290\end{array}$ & $\begin{array}{l}572 \\
286\end{array}$ & $\begin{array}{l}578 \\
289\end{array}$ & $\begin{array}{l}454 \\
227\end{array}$ \\
\hline $\begin{array}{l}\text { Georgia } \\
\text { State share }\end{array}$ & $\begin{array}{r}16 \\
8\end{array}$ & $\begin{array}{l}40 \\
20\end{array}$ & $\begin{array}{l}56 \\
28\end{array}$ & $\begin{array}{r}1,218 \\
609\end{array}$ & $\begin{array}{l}2,294 \\
1,147\end{array}$ & $\begin{array}{r}992 \\
996\end{array}$ \\
\hline $\begin{array}{l}\text { Illinois } \\
\text { State share }\end{array}$ & $\begin{array}{r}100 \\
50\end{array}$ & $\begin{array}{r}168 \\
84\end{array}$ & $\begin{array}{r}150 \\
75\end{array}$ & $\begin{array}{r}120 \\
60\end{array}$ & $\begin{array}{l}30 \\
15\end{array}$ & $\begin{array}{l}70 \\
35\end{array}$ \\
\hline $\begin{array}{l}\text { Indiana } \\
\text { State share }\end{array}$ & $\begin{array}{r}138 \\
69\end{array}$ & $\begin{array}{r}136 \\
68\end{array}$ & $\begin{array}{r}136 \\
68\end{array}$ & $\begin{array}{r}134 \\
67\end{array}$ & $\begin{array}{r}136 \\
68\end{array}$ & $\begin{array}{r}136 \\
68\end{array}$ \\
\hline lowa State share & $\begin{array}{l}46 \\
23\end{array}$ & $\begin{array}{l}44 \\
22\end{array}$ & -- & -- & -- & -- \\
\hline $\begin{array}{l}\text { Kansas } \\
\text { State share }-10\end{array}$ & $\begin{array}{l}268 \\
134\end{array}$ & $\begin{array}{l}266 \\
133\end{array}$ & $\begin{array}{l}266 \\
133\end{array}$ & $\begin{array}{l}248 \\
124\end{array}$ & $\begin{array}{l}286 \\
143\end{array}$ & $\begin{array}{l}268 \\
134\end{array}$ \\
\hline $\begin{array}{l}\text { Kentucky } \\
\text { State share }\end{array}$ & $\begin{array}{r}178 \\
89\end{array}$ & $\begin{array}{l}200 \\
100\end{array}$ & $\begin{array}{l}210 \\
105\end{array}$ & $\begin{array}{r}182 \\
91\end{array}$ & $\begin{array}{l}278 \\
139\end{array}$ & $\begin{array}{l}254 \\
127\end{array}$ \\
\hline $\begin{array}{l}\text { Louisiana } \\
\text { State share }\end{array}$ & $\begin{array}{l}62 \\
31\end{array}$ & $\begin{array}{l}60 \\
30\end{array}$ & $\begin{array}{l}60 \\
30\end{array}$ & $\begin{array}{l}50 \\
25\end{array}$ & $\begin{array}{r}152 \\
76\end{array}$ & $\begin{array}{r}120 \\
60\end{array}$ \\
\hline $\begin{array}{l}\text { Maine } \\
\text { State share }\end{array}$ & $\begin{array}{l}40 \\
20\end{array}$ & $\begin{array}{l}40 \\
20\end{array}$ & $\begin{array}{l}40 \\
20\end{array}$ & $\begin{array}{l}40 \\
20\end{array}$ & $\begin{array}{l}40 \\
20\end{array}$ & $\begin{array}{l}40 \\
20\end{array}$ \\
\hline $\begin{array}{l}\text { Maryland } \\
\text { State share }\end{array}$ & -- & $\begin{array}{l}-- \\
--\end{array}$ & $\begin{array}{l}20 \\
10\end{array}$ & $\begin{array}{l}22 \\
11\end{array}$ & $\begin{array}{l}20 \\
10\end{array}$ & $\begin{array}{l}20 \\
10\end{array}$ \\
\hline
\end{tabular}


TABLE 31.-Topographic Surveys and Mapping Federal-State Cooperative program funds, by State, fiscal years 1970-75-Continued [ In thousands of dollars]

\begin{tabular}{|c|c|c|c|c|c|c|}
\hline State & 1970 & 1971 & 1972 & 1973 & 1974 & 1975 \\
\hline $\begin{array}{l}\text { Massachusetts } \\
\text { State share }\end{array}$ & $\begin{array}{r}150 \\
75\end{array}$ & $\begin{array}{l}200 \\
100\end{array}$ & $\begin{array}{l}200 \\
100\end{array}$ & $\begin{array}{r}196 \\
98\end{array}$ & $\begin{array}{r}190 \\
95\end{array}$ & $\begin{array}{l}250 \\
125\end{array}$ \\
\hline $\begin{array}{l}\text { Michigan } \\
\text { State share }\end{array}$ & $\begin{array}{l}306 \\
153\end{array}$ & $\begin{array}{r}100 \\
50\end{array}$ & $\begin{array}{r}100 \\
50\end{array}$ & $\begin{array}{r}100 \\
50\end{array}$ & $\begin{array}{r}100 \\
50\end{array}$ & $\begin{array}{r}100 \\
50\end{array}$ \\
\hline $\begin{array}{l}\text { Minnesota } \\
\text { State share }\end{array}$ & $\begin{array}{c}856 \\
428\end{array}$ & $\begin{array}{c}884 \\
442\end{array}$ & $\begin{array}{l}734 \\
367\end{array}$ & $\begin{array}{l}708 \\
354\end{array}$ & $\begin{array}{r}1,092 \\
546\end{array}$ & $\begin{array}{l}840 \\
420\end{array}$ \\
\hline Missouri State share & $\begin{array}{l}242 \\
121\end{array}$ & $\begin{array}{l}226 \\
113\end{array}$ & $\begin{array}{r}184 \\
92\end{array}$ & $\begin{array}{r}130 \\
65\end{array}$ & $\begin{array}{r}134 \\
67\end{array}$ & $\begin{array}{r}134 \\
67\end{array}$ \\
\hline Nevada share & $\begin{array}{l}34 \\
17\end{array}$ & $\begin{array}{l}36 \\
18\end{array}$ & $\begin{array}{l}40 \\
20\end{array}$ & $\begin{array}{l}40 \\
20\end{array}$ & $\begin{array}{l}58 \\
29\end{array}$ & $\begin{array}{l}54 \\
27\end{array}$ \\
\hline $\begin{array}{l}\text { New Mexico } \\
\text { State share }\end{array}$ & -- & -- & -- & -- & -- & $\begin{array}{r}16 \\
8\end{array}$ \\
\hline $\begin{array}{l}\text { New York } \\
\text { State share }\end{array}$ & $\begin{array}{r}338 \\
169\end{array}$ & $\begin{array}{l}272 \\
136\end{array}$ & $\begin{array}{l}380 \\
190\end{array}$ & $\begin{array}{l}234 \\
117\end{array}$ & $\begin{array}{l}366 \\
183\end{array}$ & $\begin{array}{l}226 \\
113\end{array}$ \\
\hline $\begin{array}{l}\text { North Carolina } \\
\text { State share }\end{array}$ & $\begin{array}{l}216 \\
108\end{array}$ & $\begin{array}{l}220 \\
110\end{array}$ & $\begin{array}{l}220 \\
110\end{array}$ & $\begin{array}{r}172 \\
86\end{array}$ & $\begin{array}{l}670 \\
335\end{array}$ & $\begin{array}{l}890 \\
445\end{array}$ \\
\hline $\begin{array}{l}\text { Nörth Dakota } \\
\text { State share }\end{array}$ & $\begin{array}{r}156 \\
78\end{array}$ & $\begin{array}{r}100 \\
50\end{array}$ & $\begin{array}{r}112 \\
56\end{array}$ & $\begin{array}{l}242 \\
121\end{array}$ & $\begin{array}{l}88 \\
44\end{array}$ & $\begin{array}{l}222 \\
111\end{array}$ \\
\hline $\begin{array}{l}\text { Ohio } \\
\text { State share }\end{array}$ & $\begin{array}{r}150 \\
75\end{array}$ & $\begin{array}{r}150 \\
75\end{array}$ & $\begin{array}{r}150 \\
75\end{array}$ & $\begin{array}{r}150 \\
75\end{array}$ & $\begin{array}{r}150 \\
75\end{array}$ & $\begin{array}{r}150 \\
75\end{array}$ \\
\hline $\begin{array}{l}\text { Oklahoma } \\
\text { State share }\end{array}$ & $\begin{array}{r}152 \\
76\end{array}$ & $\begin{array}{c}166 \\
83\end{array}$ & $\begin{array}{c}126 \\
63\end{array}$ & $\begin{array}{r}112 \\
56\end{array}$ & $\begin{array}{r}110 \\
55\end{array}$ & $\begin{array}{r}110 \\
55\end{array}$ \\
\hline $\begin{array}{l}\text { Oregon } \\
\text { State share }\end{array}$ & $\begin{array}{l}60 \\
30\end{array}$ & $\begin{array}{l}60 \\
30\end{array}$ & $\begin{array}{l}60 \\
30\end{array}$ & $\begin{array}{l}78 \\
39\end{array}$ & $\begin{array}{l}44 \\
22\end{array}$ & $\begin{array}{l}92 \\
46\end{array}$ \\
\hline $\begin{array}{l}\text { Pennsylvania } \\
\text { State share }\end{array}$ & $\begin{array}{l}904 \\
452\end{array}$ & $\begin{array}{l}700 \\
350\end{array}$ & $\begin{array}{l}550 \\
275\end{array}$ & $\begin{array}{l}326 \\
163\end{array}$ & $\begin{array}{l}392 \\
196\end{array}$ & $\begin{array}{l}312 \\
156\end{array}$ \\
\hline $\begin{array}{l}\text { South Carolina } \\
\text { State share }\end{array}$ & -- & -- & -- & $\begin{array}{r}120 \\
60\end{array}$ & -- & $\begin{array}{l}36 \\
18\end{array}$ \\
\hline $\begin{array}{l}\text { South Dakota } \\
\text { State share }\end{array}$ & $\begin{array}{l}34 \\
17\end{array}$ & $\begin{array}{l}38 \\
19\end{array}$ & $\begin{array}{l}50 \\
25\end{array}$ & $\begin{array}{l}50 \\
25\end{array}$ & $\begin{array}{l}50 \\
25\end{array}$ & $\begin{array}{l}50 \\
25\end{array}$ \\
\hline $\begin{array}{l}\text { Tennessee } \\
\text { State share }\end{array}$ & $\begin{array}{l}40 \\
20\end{array}$ & $\begin{array}{l}42 \\
21\end{array}$ & $\begin{array}{r}12 \\
6\end{array}$ & $\begin{array}{l}38 \\
19\end{array}$ & $\begin{array}{l}50 \\
25\end{array}$ & $\begin{array}{l}44 \\
22\end{array}$ \\
\hline $\begin{array}{l}\text { Texas } \\
\text { State share }\end{array}$ & $\begin{array}{l}864 \\
432\end{array}$ & $\begin{array}{r}1,162 \\
581\end{array}$ & $\begin{array}{l}694 \\
347\end{array}$ & $\begin{array}{l}742 \\
371\end{array}$ & $\begin{array}{l}726 \\
363\end{array}$ & $\begin{array}{l}686 \\
343\end{array}$ \\
\hline Utah State share & $\begin{array}{l}96 \\
48\end{array}$ & $\begin{array}{r}104 \\
52\end{array}$ & $\begin{array}{l}72 \\
36\end{array}$ & $\begin{array}{r}114 \\
57\end{array}$ & $\begin{array}{r}120 \\
60\end{array}$ & $\begin{array}{r}100 \\
50\end{array}$ \\
\hline $\begin{array}{l}\text { Vermont } \\
\text { State share }\end{array}$ & $\begin{array}{l}20 \\
10\end{array}$ & $\begin{array}{l}20 \\
10\end{array}$ & $\begin{array}{l}20 \\
10\end{array}$ & $\begin{array}{l}20 \\
10\end{array}$ & $\begin{array}{l}40 \\
20\end{array}$ & $\begin{array}{l}34 \\
17\end{array}$ \\
\hline $\begin{array}{l}\text { Virginia } \\
\text { State share }\end{array}$ & $\begin{array}{r}1,160 \\
580\end{array}$ & $\begin{array}{l}510 \\
255\end{array}$ & $\begin{array}{r}166 \\
83\end{array}$ & $\begin{array}{r}132 \\
66\end{array}$ & $\begin{array}{l}232 \\
116\end{array}$ & $\begin{array}{l}218 \\
109\end{array}$ \\
\hline $\begin{array}{l}\text { Washington } \\
\text { State share }\end{array}$ & $\begin{array}{l}50 \\
25\end{array}$ & $\begin{array}{l}50 \\
25\end{array}$ & $\begin{array}{l}32 \\
16\end{array}$ & $\begin{array}{l}32 \\
16\end{array}$ & $\begin{array}{l}34 \\
17\end{array}$ & $\begin{array}{l}6 \\
3\end{array}$ \\
\hline $\begin{array}{l}\text { West Virginia } \\
\text { State share }\end{array}$ & $\begin{array}{l}220 \\
110\end{array}$ & $\begin{array}{r}198 \\
99\end{array}$ & $\begin{array}{l}206 \\
103\end{array}$ & $\begin{array}{l}298 \\
149\end{array}$ & $\begin{array}{l}506 \\
253\end{array}$ & $\begin{array}{l}228 \\
114\end{array}$ \\
\hline $\begin{array}{l}\text { Wisconsin } \\
\text { State share }\end{array}$ & $\begin{array}{l}402 \\
201\end{array}$ & $\begin{array}{l}398 \\
199\end{array}$ & $\begin{array}{l}400 \\
200\end{array}$ & $\begin{array}{l}402 \\
201\end{array}$ & $\begin{array}{l}412 \\
206\end{array}$ & $\begin{array}{l}414 \\
207\end{array}$ \\
\hline $\begin{array}{l}\text { Wyoming } \\
\text { State share }\end{array}$ & $\begin{array}{r}10 \\
5\end{array}$ & $\begin{array}{r}10 \\
5\end{array}$ & $\begin{array}{r}10 \\
5\end{array}$ & $\begin{array}{r}10 \\
5\end{array}$ & $\begin{array}{r}10 \\
5\end{array}$ & $\begin{array}{r}10 \\
5\end{array}$ \\
\hline $\begin{array}{l}\text { Puerto Rico } \\
\text { State share }\end{array}$ & $\begin{array}{l}50 \\
25\end{array}$ & $\begin{array}{l}50 \\
25\end{array}$ & $\begin{array}{l}50 \\
25\end{array}$ & $\begin{array}{l}76 \\
38\end{array}$ & $\begin{array}{l}76 \\
38\end{array}$ & $\begin{array}{l}74 \\
37\end{array}$ \\
\hline
\end{tabular}

1 Includes Federal funds from direct program.
2 Reimbursable program funds from States, counties, and municipalities. 
TABLE 32.-Topographic Surveys and Mapping reimbursable program funds from other Federal agencies, by agency, fiscal years 1970-75

[ In thousands of dollars]

\begin{tabular}{|c|c|c|c|c|c|c|}
\hline Agency & 1970 & 1971 & 1972 & 1973 & 1974 & 1975 \\
\hline Total & $\$ 2,390$ & $\$ 2,017$ & $\$ 631$ & $\$ 780$ & $\$ 918$ & $\$ 1,658$ \\
\hline Department of Agriculture & -- & -- & -- & -- & 95 & 326 \\
\hline Department of Commerce & -- & 181 & -- & -- & -- & -- \\
\hline Department of Defense & -- & -- & -- & 35 & 92 & 183 \\
\hline Department of the Interior & 1,497 & 1,125 & 21 & 68 & 238 & 441 \\
\hline $\begin{array}{l}\text { Bureau of Indian Affairs } \\
\text { Bureau of Land Management } \\
\text { Bureau of Reclaimation } \\
\text { Office of Territories }\end{array}$ & $\begin{array}{r}-- \\
1,0 \overline{9} \\
408\end{array}$ & $\begin{array}{r}-- \\
900 \\
225\end{array}$ & $\overrightarrow{--}$ & $\begin{array}{l}60 \\
-- \\
-\overline{8}\end{array}$ & $\begin{array}{r}165 \\
73 \\
-- \\
--\end{array}$ & $\begin{array}{r}198 \\
243 \\
--\end{array}$ \\
\hline Department of Transportation & -- & -- & -- & -- & -- & 4 \\
\hline National Aeronautics and Space Administration & 246 & 326 & 138 & 207 & 235 & 97 \\
\hline National Science Foundation & 356 & 202 & 256 & 198 & 46 & 2.37 \\
\hline Miscellaneous Federal agencies & 291 & 183 & 216 & 272 & 212 & 350 \\
\hline
\end{tabular}

TABLE 33.-Geologic and Mineral Resource Surveys and Mapping direct program funds, by subactivity, fiscal years 1970-75 [ In thousands of dollars]

\begin{tabular}{|c|c|c|c|c|c|c|}
\hline Subactivity & 1970 & 1971 & 1972 & 1973 & 1974 & 195 \\
\hline \multicolumn{7}{|c|}{ CURRENT DOLLARS } \\
\hline Total direct program & $\$ 31,056$ & $\$ 31,919$ & $\$ 34,244$ & $\$ 42,895$ & $\$ 49,877$ & $\$ 89,0 ! 8$ \\
\hline Land Resource Surveys ${ }^{1}$ & 13,675 & 14,519 & 15,154 & 19,246 & 23,077 & $33,3,35$ \\
\hline Mineral Resource Surveys ${ }^{2}$ & 13,548 & 13,424 & 13,524 & 14,026 & 14,971 & $18,0: 7$ \\
\hline Energy Resource Surveys & 2,578 & 2,639 & 3,144 & 5,197 & 6,696 & 22,376 \\
\hline Offshore Geologic Surveys & 1,255 & 1,337 & 2,422 & 4,426 & 5,133 & $15,2: 0$ \\
\hline \multicolumn{7}{|c|}{ CONSTANT DOLLARS ${ }^{3}$} \\
\hline Total direct program & 27,266 & 26,643 & 27,572 & 33,252 & 35,780 & 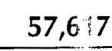 \\
\hline Land Resource Surveys ${ }^{1}$ & 12,006 & 12,119 & 12,201 & 14,919 & 16,555 & $21,6 \cdot 8$ \\
\hline Mineral Resource Surveys ${ }^{2}$ & 11,895 & 11,205 & 10,889 & 10,873 & 10,740 & $11,6: 2$ \\
\hline Energy Resource Surveys & 2,263 & 2,203 & 2,532 & 4,029 & 4,803 & 14,433 \\
\hline Offshore Geologic Surveys & 1,102 & 1,116 & 1,950 & 3,431 & 3,682 & $9,8: 4$ \\
\hline
\end{tabular}

1 Funds adjusted for fiscal years 1970-73 to include geologic mapping in support of Mineral Resource Surveys. 2 Funds adjusted for fiscal years 1970-73 to exclude geologic mapping
and to include the Mineral Discovery Loan Program octivity for fiscal years 3 Gross National Product implicit price deflator was used to convert current to constant 1967 dollars. 
TABLE 34.-Geologic and Mineral Resource Surveys and Mapping Federal-State Cooperative funds, by State, fiscal years 1970-75 [In thousands of dollars]

\begin{tabular}{|c|c|c|c|c|c|c|}
\hline State & 1970 & 1971 & 1972 & 1973 & 1974 & 1975 \\
\hline $\begin{array}{l}\text { Total }^{1} \\
\text { State share }\end{array}$ & $\begin{array}{c}\$ 2,766 \\
1,292 \\
\end{array}$ & $\begin{array}{r}\$ 2,825 \\
1,322 \\
\end{array}$ & $\begin{array}{r}\$ 2,941 \\
1,359 \\
\end{array}$ & $\begin{array}{r}\$ 4,270 \\
1,556 \\
\end{array}$ & $\begin{array}{r}\$ 4,254 \\
1,681 \\
\end{array}$ & $\begin{array}{r}\$ 4,541 \\
1,550 \\
\end{array}$ \\
\hline Alabama & - & -- & -- & 10 & 10 & 15 \\
\hline State share & $\ldots$ & -- & -- & 10 & 5 & 5 \\
\hline Alaska & -- & - & 160 & 332 & 238 & 476 \\
\hline State share & -- & -- & 80 & 135 & 93 & 75 \\
\hline Arkansas & 51 & 50 & 51 & 85 & 125 & 165 \\
\hline State share & 25 & 25 & 25 & 36 & 27 & 27 \\
\hline California & 86 & 127 & 71 & 79 & 362 & 57 \\
\hline State share & 39 & 63 & 33 & 22 & 80 & 21 \\
\hline Colorado & 101 & 74 & 42 & 50 & -- & - \\
\hline State share & 45 & 41 & 20 & 30 & -- & - \\
\hline Connecticut & 162 & 150 & 141 & 235 & 208 & 258 \\
\hline State share & 75 & 75 & 69 & 69 & 75 & 75 \\
\hline Georgia & -- & -- & 2 & -- & 6 & 10 \\
\hline State share & -- & -- & 1 & -- & 3 & 5 \\
\hline Hawaii & -- & -- & -- & -- & -- & -- \\
\hline State share & $\overrightarrow{0}$ & -- & -- & -- & -- & -- \\
\hline 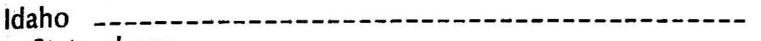 & 23 & -- & -- & -- & -- & -- \\
\hline State share & 12 & -- & -- & -- & -- & -- \\
\hline lowa & -- & -- & -- & -- & 16 & -- \\
\hline State share & -- & -- & -- & -- & 8 & -- \\
\hline Kansas & -- & -- & -- & -- & -- & -- \\
\hline State share & -- & -- & -- & -- & -- & - \\
\hline Kentucky - & 1,048 & 1,100 & 1,158 & 1,332 & 1,454 & 1,599 \\
\hline State share & 510 & 550 & 575 & 600 & 630 & 675 \\
\hline Maryland & 58 & 45 & 20 & 27 & 14 & 19 \\
\hline State share & 28 & 23 & 10 & 10 & 7 & 9 \\
\hline Massachusetts & 355 & 410 & 417 & 633 & 563 & 581 \\
\hline State share & 164 & 205 & 205 & 205 & 228 & 205 \\
\hline Michigan & 150 & 166 & 153 & 216 & 178 & 158 \\
\hline State share & 65 & 68 & 65 & 65 & 65 & 65 \\
\hline Minnesota & -- & -- & -- & -- & -- & -- \\
\hline State share & -- & -- & -- & - & - - & -- \\
\hline Nevada & 158 & 173 & 192 & 249 & 254 & 384 \\
\hline State share & 70 & 70 & 80 & 90 & 90 & 105 \\
\hline New Hampshire & 26 & 24 & 25 & 31 & 59 & 50 \\
\hline State share & 13 & 12 & 13 & 13 & 39 & 13 \\
\hline New Mexico & $\ldots$ & - & -- & 20 & 40 & 11 \\
\hline State share & -- & -- & -- & 10 & 20 & -- \\
\hline New York & - & -- & -- & -- & 20 & 21 \\
\hline State share & -- & -- & -- & -- & 10 & 10 \\
\hline North Carolina & 25 & 51 & 35 & 99 & 40 & 18 \\
\hline State share & 6 & 6 & 6 & 12 & 6 & 18 \\
\hline Pennsylvania & 93 & 19 & 15 & 30 & 10 & -- \\
\hline State share & 30 & 8 & 8 & 15 & 5 & -- \\
\hline South Carolina & -- & -- & -- & -- & -- & 5 \\
\hline State share & -- & -- & -- & -- & -- & $\mathbf{5}$ \\
\hline Texas & -- & -- & -- & 3 & -- & - \\
\hline State share & -- & -- & -- & 3 & -- & -- \\
\hline Utah & -- & -- & 11 & 18 & 7 & 6 \\
\hline State share & -- & -- & 3 & 7 & 7 & 4 \\
\hline Washington & 58 & 53 & 58 & 122 & 67 & 134 \\
\hline State share & 25 & 25 & 20 & 30 & 20 & 30 \\
\hline West Virginia & - & - & - & 20 & 20 & 21 \\
\hline State share & -- & -- & -- & 10 & 10 & 10 \\
\hline Wisconsin & 48 & 50 & 55 & 82 & 76 & 68 \\
\hline State share & 17 & 8 & 8 & 8 & 8 & 8 \\
\hline Wyoming & 29 & 48 & 15 & 27 & 26 & 11 \\
\hline State share & 2 & 4 & 2 & 2 & 2 & 2 \\
\hline Puerto Rico & $29 \overline{5}$ & 270 & 320 & 570 & $46 \overline{1}$ & 474 \\
\hline State share & 166 & 131 & 136 & 174 & 243 & 183 \\
\hline Virgin Islands & -- & 15 & -- & -- & -- & -- \\
\hline State share & -- & 8 & -- & . -- & -- & - \\
\hline
\end{tabular}

1 Includes Federal funds from direct program.

2 Reimbursable program funds from States, counties, and municipalities. 
TABLE 35.-Geologic and Mineral Resource Surveys and Mapping reimbursable program funds from other Federal agencies, by agency, fiscal years 1970-75

[ln thousands of dollars]

\begin{tabular}{|c|c|c|c|c|c|c|}
\hline Agency & 1970 & 1971 & 1972 & 1973 & 1974 & 1975 \\
\hline Total & $\$ 12,188$ & $\$ 13,494$ & $\$ 13,609$ & $\$ 11,222$ & $\$ 19,321$ & $\$ 20,158$ \\
\hline Appalachian Regional Commission _- & -- & -. & -- & -- & 189 & 179 \\
\hline Department of Defense & 2,344 & 3,179 & 3,219 & 1,431 & 5,670 & 2,648 \\
\hline Department of Housing and Urban Development & -- & -. & 281 & 294 & 224 & 817 \\
\hline Department of the Interior & -- & -- & 134 & 156 & _- & 5,719 \\
\hline $\begin{array}{l}\text { Bureau of Indian Affairs } \\
\text { Bureau of Land Management } \\
\text { Bureau of Mines } \\
\text { Bureau of Reclamation } \\
\text { Office of Saline Water }\end{array}$ & $\begin{array}{l}-- \\
-- \\
-- \\
--\end{array}$ & $\begin{array}{l}-- \\
-- \\
-- \\
--\end{array}$ & $\begin{array}{l}-- \\
-\overline{80} \\
23 \\
31\end{array}$ & $\begin{array}{l}-- \\
-- \\
-- \\
15 \overline{6}\end{array}$ & $\begin{array}{l}-- \\
-- \\
-- \\
--\end{array}$ & $\begin{array}{r}243 \\
3,741 \\
1,735 \\
--\end{array}$ \\
\hline Department of State & 1,555 & 1,711 & 1,987 & 1,975 & 1,510 & 1,056 \\
\hline Energy Research and Development Administration ${ }^{1}$-.- & 1,945 & 1,858 & 2,090 & 2,134 & 3,125 & 2,542 \\
\hline Federal Energy Administration & -- & -- & -- & -- & -- & 353 \\
\hline National Aeronautics and Space Administration --.--- & 5,924 & 5,454 & 5,038 & 4,708 & 4,745 & 2,938 \\
\hline National Oceanic and Atmospheric Administration.--- & -- & -- & -- & -- & 2,001 & $\$ 34$ \\
\hline National Science Foundation & 127 & 1,077 & 650 & 135 & 1,329 & 1,604 \\
\hline Nuclear Regulatory Commission & -- & -- & -- & -- & -- & 1,195 \\
\hline Miscellaneous Federal agencies & 293 & 215 & 210 & 389 & 528 & 673 \\
\hline
\end{tabular}

1 Includes Atomic Energy Commission funds for fiscal years 1970-74. See

Includes Atomic Energy Commission funds for fiscal years 1970-74. Se
also funds from the Nuclear Regulatory Commission in fiscal year 1975 .

TABLE 36.-Water Resources Investigations direct program funds, by subactivity, fiscal years 1970-75 [ In thousands of dollars]

\begin{tabular}{|c|c|c|c|c|c|c|}
\hline Subactivity & 1970 & 1971 & 1972 & 1973 & 1974 & $19: 5$ \\
\hline \multicolumn{7}{|c|}{ CURRENT DOLLARS } \\
\hline Total direct program ${ }^{1}$ & $\$ 31,585$ & $\$ 34,581$ & $\$ 37,446$ & $\$ 40,185$ & $\$ 45,433$ & $\$ 53, \therefore 20$ \\
\hline National Water Data System & 29,876 & 32,360 & 34,849 & 37,523 & 42,993 & $48,-191$ \\
\hline $\begin{array}{l}\text { Federal program } \\
\text { Federal-State program }{ }^{2}\end{array}$ & $\begin{array}{l}12,575 \\
17,301\end{array}$ & $\begin{array}{l}13,177 \\
19,183\end{array}$ & $\begin{array}{l}14,841 \\
20,008\end{array}$ & $\begin{array}{l}16,334 \\
21,189\end{array}$ & $\begin{array}{l}17,695 \\
25,298\end{array}$ & $\begin{array}{l}21,183 \\
27,008\end{array}$ \\
\hline Critical National water problems & 1,709 & 2,221 & 2,597 & 2,662 & 2,440 & 5,229 \\
\hline \multicolumn{7}{|c|}{ CONSTANT 1967 DOLLARS $^{3}$} \\
\hline Total direct program ${ }^{1}$ & 27,731 & 28,866 & 30,150 & 31,151 & 32,592 & 34,576 \\
\hline National Water Data System & 26,230 & 27,012 & 28,059 & 29,088 & 30,842 & 31,172 \\
\hline $\begin{array}{l}\text { Federal program } \\
\text { Federal-State program }\end{array}$ & $\begin{array}{l}11,040 \\
15,190\end{array}$ & $\begin{array}{l}10,999 \\
16,013\end{array}$ & $\begin{array}{l}11,949 \\
16,110\end{array}$ & $\begin{array}{l}12,662 \\
16,426\end{array}$ & $\begin{array}{l}12,694 \\
18,148\end{array}$ & $\begin{array}{l}13,711 \\
17,431\end{array}$ \\
\hline Critical National water problems & 1,501 & 1,854 & 2,091 & 2,063 & 1,750 & $3,3: 4$ \\
\hline
\end{tabular}

1 Direct program funds exclude the Employee Compensation Payments

subactivity for fiscal years 1970-75.

2 Federal share of Federal-State cooperative program.

3 Gross National Product implicit price deflator was used to convert current to constant 1967 dollars. 
TABLE 37.-Water Resources Investigations Federal-State Cooperative program funds, by State, fiscal years 1970-75 [In thousands of dollars]

\begin{tabular}{|c|c|c|c|c|c|c|}
\hline State & 1970 & 1971 & 1972 & 1973 & 1974 & 1975 \\
\hline $\begin{array}{l}\text { Total }^{1} \\
\quad \text { State share } \\
\end{array}$ & $\begin{array}{r}\$ 34,581 \\
17,280\end{array}$ & $\begin{array}{r}\$ 38,647 \\
19,464 \\
\end{array}$ & $\begin{array}{r}\$ 41,302 \\
21,294 \\
\end{array}$ & $\begin{array}{r}\$ 43,925 \\
22,736 \\
\end{array}$ & $\begin{array}{r}\$ 51,118 \\
25,820 \\
\end{array}$ & $\begin{array}{r}\$ 55,554 \\
28,546 \\
\end{array}$ \\
\hline Alabama State share & $\begin{array}{l}770 \\
407\end{array}$ & $\begin{array}{l}796 \\
442\end{array}$ & $\begin{array}{l}789 \\
436\end{array}$ & $\begin{array}{l}868 \\
479\end{array}$ & $\begin{array}{r}1,044 \\
529\end{array}$ & $\begin{array}{r}1,135 \\
587\end{array}$ \\
\hline Alaska $\quad$ State share & $\begin{array}{l}417 \\
258\end{array}$ & $\begin{array}{l}411 \\
203\end{array}$ & $\begin{array}{l}459 \\
250\end{array}$ & $\begin{array}{l}506 \\
264\end{array}$ & $\begin{array}{l}659 \\
317\end{array}$ & $\begin{array}{l}686 \\
335\end{array}$ \\
\hline Arizona state share & $\begin{array}{l}819 \\
412\end{array}$ & $\begin{array}{l}869 \\
444\end{array}$ & $\begin{array}{r}1,021 \\
540\end{array}$ & $\begin{array}{r}1,001 \\
510\end{array}$ & $\begin{array}{r}1,144 \\
576\end{array}$ & $\begin{array}{r}1,248 \\
646\end{array}$ \\
\hline $\begin{array}{l}\text { Arkansas } \\
\text { State share }\end{array}$ & $\begin{array}{l}373 \\
177\end{array}$ & $\begin{array}{l}392 \\
189\end{array}$ & $\begin{array}{l}409 \\
202\end{array}$ & $\begin{array}{l}457 \\
225\end{array}$ & $\begin{array}{l}674 \\
399\end{array}$ & $\begin{array}{l}650 \\
347\end{array}$ \\
\hline $\begin{array}{l}\text { California } \\
\text { State share }\end{array}$ & $\begin{array}{l}2,834 \\
1,361\end{array}$ & $\begin{array}{l}3,455 \\
1,672\end{array}$ & $\begin{array}{l}3,636 \\
1,810\end{array}$ & $\begin{array}{l}3,850 \\
1,938\end{array}$ & $\begin{array}{l}4,229 \\
2,101\end{array}$ & $\begin{array}{l}4,381 \\
2,190\end{array}$ \\
\hline $\begin{array}{l}\text { Colorado } \\
\text { State share }\end{array}$ & $\begin{array}{l}850 \\
419\end{array}$ & $\begin{array}{l}870 \\
436\end{array}$ & $\begin{array}{l}953 \\
487\end{array}$ & $\begin{array}{r}1,078 \\
545\end{array}$ & $\begin{array}{r}1,480 \\
835\end{array}$ & $\begin{array}{r}1,615 \\
909\end{array}$ \\
\hline $\begin{array}{l}\text { Connecticut } \\
\text { State share }\end{array}$ & $\begin{array}{l}367 \\
174\end{array}$ & $\begin{array}{l}429 \\
207\end{array}$ & $\begin{array}{l}436 \\
215\end{array}$ & $\begin{array}{l}412 \\
203\end{array}$ & $\begin{array}{l}486 \\
239\end{array}$ & $\begin{array}{l}687 \\
386\end{array}$ \\
\hline Delaware & $\begin{array}{l}88 \\
52\end{array}$ & $\begin{array}{r}112 \\
73\end{array}$ & $\begin{array}{r}111 \\
75\end{array}$ & $\begin{array}{r}121 \\
81\end{array}$ & $\begin{array}{r}130 \\
74\end{array}$ & $\begin{array}{l}194 \\
106\end{array}$ \\
\hline $\begin{array}{l}\text { District of Columbia } \\
\text { State share }\end{array}$ & $\begin{array}{r}12 \\
6\end{array}$ & $\begin{array}{r}12 \\
6\end{array}$ & $\begin{array}{l}2 \\
1\end{array}$ & $\begin{array}{l}3 \\
1\end{array}$ & $\begin{array}{l}3 \\
1\end{array}$ & $\begin{array}{l}3 \\
1\end{array}$ \\
\hline $\begin{array}{l}\text { Florida } \\
\text { State share }\end{array}$ & $\begin{array}{r}1,971 \\
962\end{array}$ & $\begin{array}{l}2,539 \\
1,249\end{array}$ & $\begin{array}{l}2,818 \\
1,429\end{array}$ & $\begin{array}{l}3,071 \\
1,572\end{array}$ & $\begin{array}{l}4,505 \\
2,263\end{array}$ & $\begin{array}{l}5,055 \\
2,521\end{array}$ \\
\hline Georgia & $\begin{array}{l}636 \\
346\end{array}$ & $\begin{array}{l}711 \\
380\end{array}$ & $\begin{array}{l}741 \\
408\end{array}$ & $\begin{array}{l}790 \\
432\end{array}$ & $\begin{array}{l}939 \\
461\end{array}$ & $\begin{array}{r}1,081 \\
530\end{array}$ \\
\hline Hawaii state share & $\begin{array}{l}598 \\
284\end{array}$ & $\begin{array}{l}649 \\
334\end{array}$ & $\begin{array}{l}622 \\
314\end{array}$ & $\begin{array}{l}653 \\
337\end{array}$ & $\begin{array}{l}691 \\
339\end{array}$ & $\begin{array}{l}697 \\
341\end{array}$ \\
\hline Idaho State share & $\begin{array}{l}523 \\
249\end{array}$ & $\begin{array}{l}633 \\
308\end{array}$ & $\begin{array}{l}619 \\
307\end{array}$ & $\begin{array}{l}675 \\
344\end{array}$ & $\begin{array}{l}718 \\
353\end{array}$ & $\begin{array}{l}749 \\
366\end{array}$ \\
\hline Illinois State share & $\begin{array}{l}449 \\
213\end{array}$ & $\begin{array}{l}482 \\
232\end{array}$ & $\begin{array}{l}503 \\
266\end{array}$ & $\begin{array}{l}526 \\
273\end{array}$ & $\begin{array}{l}514 \\
262\end{array}$ & $\begin{array}{l}575 \\
288\end{array}$ \\
\hline $\begin{array}{l}\text { Indiana } \\
\text { State share }\end{array}$ & $\begin{array}{l}757 \\
359\end{array}$ & $\begin{array}{l}770 \\
371\end{array}$ & $\begin{array}{l}858 \\
423\end{array}$ & $\begin{array}{l}973 \\
523\end{array}$ & $\begin{array}{r}1,227 \\
610\end{array}$ & $\begin{array}{r}1,152 \\
564\end{array}$ \\
\hline lowa State share & $\begin{array}{l}411 \\
195\end{array}$ & $\begin{array}{l}398 \\
192\end{array}$ & $\begin{array}{l}517 \\
255\end{array}$ & $\begin{array}{l}525 \\
259\end{array}$ & $\begin{array}{l}592 \\
291\end{array}$ & $\begin{array}{l}617 \\
302\end{array}$ \\
\hline Kansas $\quad$ State share & $\begin{array}{r}1,018 \\
485\end{array}$ & $\begin{array}{r}1,058 \\
512\end{array}$ & $\begin{array}{r}1,096 \\
542\end{array}$ & $\begin{array}{r}1,110 \\
552\end{array}$ & $\begin{array}{r}1,116 \\
543\end{array}$ & $\begin{array}{r}1,156 \\
582\end{array}$ \\
\hline $\begin{array}{l}\text { Kentucky } \\
\text { State share }\end{array}$ & $\begin{array}{l}512 \\
243\end{array}$ & $\begin{array}{l}600 \\
289\end{array}$ & $\begin{array}{l}665 \\
328\end{array}$ & $\begin{array}{l}698 \\
348\end{array}$ & $\begin{array}{l}719 \\
353\end{array}$ & $\begin{array}{l}875 \\
427\end{array}$ \\
\hline $\begin{array}{l}\text { Louisiana } \\
\text { State share }\end{array}$ & $\begin{array}{r}1,009 \\
536\end{array}$ & $\begin{array}{r}1,107 \\
591\end{array}$ & $\begin{array}{r}1,152 \\
625\end{array}$ & $\begin{array}{r}1,190 \\
649\end{array}$ & $\begin{array}{r}1,748 \\
904\end{array}$ & $\begin{array}{r}1,620 \\
842\end{array}$ \\
\hline Maine State share & $\begin{array}{r}111 \\
60\end{array}$ & $\begin{array}{r}118 \\
64\end{array}$ & $\begin{array}{r}123 \\
69\end{array}$ & $\begin{array}{r}128 \\
71\end{array}$ & $\begin{array}{r}135 \\
76\end{array}$ & $\begin{array}{l}208 \\
107\end{array}$ \\
\hline $\begin{array}{l}\text { Maryland } \\
\text { State share }\end{array}$ & $\begin{array}{l}536 \\
268\end{array}$ & $\begin{array}{l}535 \\
272\end{array}$ & $\begin{array}{l}580 \\
301\end{array}$ & $\begin{array}{l}646 \\
335\end{array}$ & $\begin{array}{l}817 \\
418\end{array}$ & $\begin{array}{l}972 \\
511\end{array}$ \\
\hline $\begin{array}{l}\text { Massachusetts } \\
\text { State share }\end{array}$ & $\begin{array}{l}441 \\
224\end{array}$ & $\begin{array}{l}516 \\
290\end{array}$ & $\begin{array}{l}542 \\
309\end{array}$ & $\begin{array}{l}550 \\
322\end{array}$ & $\begin{array}{l}593 \\
333\end{array}$ & $\begin{array}{l}787 \\
480\end{array}$ \\
\hline $\begin{array}{l}\text { Michigan } \\
\text { State share }\end{array}$ & $\begin{array}{l}537 \\
255\end{array}$ & $\begin{array}{l}599 \\
289\end{array}$ & $\begin{array}{l}606 \\
302\end{array}$ & $\begin{array}{l}631 \\
310\end{array}$ & $\begin{array}{l}652 \\
321\end{array}$ & $\begin{array}{l}796 \\
390\end{array}$ \\
\hline $\begin{array}{l}\text { Minnesota } \\
\text { State share }\end{array}$ & $\begin{array}{l}513 \\
245\end{array}$ & $\begin{array}{l}550 \\
265\end{array}$ & $\begin{array}{l}635 \\
314\end{array}$ & $\begin{array}{l}712 \\
373\end{array}$ & $\begin{array}{l}811 \\
420\end{array}$ & $\begin{array}{l}799 \\
397\end{array}$ \\
\hline $\begin{array}{l}\text { Mississippi } \\
\text { State share }\end{array}$ & $\begin{array}{l}444 \\
275\end{array}$ & $\begin{array}{l}551 \\
316\end{array}$ & $\begin{array}{r}592 \\
357\end{array}$ & $\begin{array}{l}593 \\
340\end{array}$ & $\begin{array}{l}645 \\
325\end{array}$ & $\begin{array}{l}743 \\
415\end{array}$ \\
\hline Missouri $\quad$ State share & $\begin{array}{l}534 \\
253\end{array}$ & $\begin{array}{l}637 \\
307\end{array}$ & $\begin{array}{l}608 \\
321\end{array}$ & $\begin{array}{l}602 \\
310\end{array}$ & $\begin{array}{r}523 \\
255\end{array}$ & $\begin{array}{l}544 \\
270\end{array}$ \\
\hline Montana & $\begin{array}{l}318 \\
172\end{array}$ & $\begin{array}{l}393 \\
212\end{array}$ & $\begin{array}{l}401 \\
221\end{array}$ & $\begin{array}{l}402 \\
223\end{array}$ & $\begin{array}{r}505 \\
255\end{array}$ & $\begin{array}{l}587 \\
287\end{array}$ \\
\hline $\begin{array}{l}\text { Nebraska } \\
\text { State share }\end{array}$ & $\begin{array}{l}440 \\
211\end{array}$ & $\begin{array}{l}502 \\
246\end{array}$ & $\begin{array}{l}553 \\
274\end{array}$ & $\begin{array}{l}588 \\
298\end{array}$ & $\begin{array}{l}705 \\
344\end{array}$ & $\begin{array}{l}731 \\
358\end{array}$ \\
\hline
\end{tabular}


TABLE 37.-Water Resources Investigations Federal-State Cooperative program funds, by State, fiscal years 1970-75-Continued [In thousands of dollars]

\begin{tabular}{|c|c|c|c|c|c|c|}
\hline State & 1970 & 1971 & 1972 & 1973 & 1974 & 1975 \\
\hline $\begin{array}{l}\text { Nevada } \\
\text { State share }\end{array}$ & $\begin{array}{l}290 \\
138\end{array}$ & $\begin{array}{l}304 \\
146\end{array}$ & $\begin{array}{l}346 \\
171\end{array}$ & $\begin{array}{l}351 \\
178\end{array}$ & $\begin{array}{l}377 \\
185\end{array}$ & $\begin{array}{l}408 \\
200\end{array}$ \\
\hline $\begin{array}{l}\text { New Hampshire } \\
\text { State share }\end{array}$ & $\begin{array}{l}90 \\
43\end{array}$ & $\begin{array}{l}89 \\
43\end{array}$ & $\begin{array}{l}75 \\
37\end{array}$ & $\begin{array}{r}108 \\
54\end{array}$ & $\begin{array}{r}118 \\
58\end{array}$ & $\begin{array}{r}122 \\
60\end{array}$ \\
\hline $\begin{array}{l}\text { New Jersey } \\
\text { State share }\end{array}$ & $\begin{array}{l}735 \\
363\end{array}$ & $\begin{array}{l}785 \\
390\end{array}$ & $\begin{array}{l}822 \\
418\end{array}$ & $\begin{array}{l}856 \\
433\end{array}$ & $\begin{array}{r}1,051 \\
530\end{array}$ & $\begin{array}{l}977 \\
501\end{array}$ \\
\hline $\begin{array}{l}\text { New Mexico } \\
\text { State share }\end{array}$ & $\begin{array}{l}842 \\
432\end{array}$ & $\begin{array}{l}888 \\
462\end{array}$ & $\begin{array}{l}963 \\
509\end{array}$ & $\begin{array}{r}1,087 \\
591\end{array}$ & $\begin{array}{r}1,292 \\
642\end{array}$ & $\begin{array}{r}1,412 \\
706\end{array}$ \\
\hline $\begin{array}{l}\text { New York } \\
\text { State share }\end{array}$ & $\begin{array}{r}1,462 \\
697\end{array}$ & $\begin{array}{r}1,717 \\
837\end{array}$ & $\begin{array}{r}1,844 \\
921\end{array}$ & $\begin{array}{l}2,161 \\
1,112\end{array}$ & $\begin{array}{l}2,410 \\
1,222\end{array}$ & $\begin{array}{l}2,730 \\
1,462\end{array}$ \\
\hline $\begin{array}{l}\text { North Carolina } \\
\text { State share }\end{array}$ & $\begin{array}{l}642 \\
305\end{array}$ & $\begin{array}{l}667 \\
321\end{array}$ & $\begin{array}{l}691 \\
341\end{array}$ & $\begin{array}{l}767 \\
394\end{array}$ & $\begin{array}{l}876 \\
430\end{array}$ & $\begin{array}{l}977 \\
479\end{array}$ \\
\hline $\begin{array}{l}\text { North Dakota } \\
\text { State share }\end{array}$ & $\begin{array}{l}533 \\
259\end{array}$ & $\begin{array}{l}561 \\
275\end{array}$ & $\begin{array}{l}602 \\
305\end{array}$ & $\begin{array}{l}657 \\
340\end{array}$ & $\begin{array}{l}675 \\
325\end{array}$ & $\begin{array}{l}776 \\
378\end{array}$ \\
\hline $\begin{array}{l}\text { Ohio } \\
\text { State share }\end{array}$ & $\begin{array}{l}762 \\
411\end{array}$ & $\begin{array}{l}829 \\
446\end{array}$ & $\begin{array}{l}840 \\
443\end{array}$ & $\begin{array}{l}878 \\
445\end{array}$ & $\begin{array}{l}828 \\
406\end{array}$ & $\begin{array}{l}943 \\
488\end{array}$ \\
\hline $\begin{array}{l}\text { Oklahoma } \\
\text { State share }\end{array}$ & $\begin{array}{l}427 \\
236\end{array}$ & $\begin{array}{l}498 \\
276\end{array}$ & $\begin{array}{l}488 \\
270\end{array}$ & $\begin{array}{l}522 \\
284\end{array}$ & $\begin{array}{l}592 \\
289\end{array}$ & $\begin{array}{l}638 \\
313\end{array}$ \\
\hline $\begin{array}{l}\text { Oregon } \\
\quad \text { State share }\end{array}$ & $\begin{array}{l}565 \\
282\end{array}$ & $\begin{array}{l}546 \\
277\end{array}$ & $\begin{array}{l}667 \\
342\end{array}$ & $\begin{array}{l}750 \\
393\end{array}$ & $\begin{array}{l}852 \\
417\end{array}$ & $\begin{array}{l}810 \\
397\end{array}$ \\
\hline $\begin{array}{l}\text { Pennsylvania } \\
\text { State share }\end{array}$ & $\begin{array}{r}1,325 \\
682\end{array}$ & $\begin{array}{r}1,459 \\
730\end{array}$ & $\begin{array}{r}1,602 \\
809\end{array}$ & $\begin{array}{r}1,691 \\
864\end{array}$ & $\begin{array}{r}1,955 \\
994\end{array}$ & $\begin{array}{l}2.103 \\
1.053\end{array}$ \\
\hline $\begin{array}{l}\text { Rhode Island } \\
\text { State share }\end{array}$ & $\begin{array}{l}91 \\
48\end{array}$ & $\begin{array}{l}97 \\
52\end{array}$ & $\begin{array}{l}92 \\
50\end{array}$ & $\begin{array}{l}90 \\
50\end{array}$ & $\begin{array}{l}97 \\
52\end{array}$ & $\begin{array}{r}110 \\
54\end{array}$ \\
\hline $\begin{array}{l}\text { South Carolina } \\
\text { State share }\end{array}$ & $\begin{array}{l}340 \\
178\end{array}$ & $\begin{array}{l}374 \\
196\end{array}$ & $\begin{array}{l}403 \\
212\end{array}$ & $\begin{array}{l}454 \\
241\end{array}$ & $\begin{array}{l}546 \\
279\end{array}$ & $\begin{array}{l}333 \\
261\end{array}$ \\
\hline $\begin{array}{l}\text { South Dakota } \\
\text { State share }\end{array}$ & $\begin{array}{l}365 \\
202\end{array}$ & $\begin{array}{l}371 \\
207\end{array}$ & $\begin{array}{l}374 \\
211\end{array}$ & $\begin{array}{l}373 \\
205\end{array}$ & $\begin{array}{l}421 \\
202\end{array}$ & $\begin{array}{l}765 \\
226\end{array}$ \\
\hline $\begin{array}{l}\text { Tennessee } \\
\text { State share }\end{array}$ & $\begin{array}{l}495 \\
264\end{array}$ & $\begin{array}{l}504 \\
271\end{array}$ & $\begin{array}{l}526 \\
288\end{array}$ & $\begin{array}{l}551 \\
302\end{array}$ & $\begin{array}{l}801 \\
397\end{array}$ & $\begin{array}{l}708 \\
148\end{array}$ \\
\hline $\begin{array}{l}\text { Texas } \\
\text { State share }\end{array}$ & $\begin{array}{l}2,239 \\
1,113\end{array}$ & $\begin{array}{l}2,673 \\
1,341\end{array}$ & $\begin{array}{l}3,023 \\
1,578\end{array}$ & $\begin{array}{l}3,049 \\
1,575\end{array}$ & $\begin{array}{l}3,320 \\
1,664\end{array}$ & $\begin{array}{l}3,375 \\
1,757\end{array}$ \\
\hline $\begin{array}{l}\text { Utah } \\
\text { State share }\end{array}$ & $\begin{array}{l}756 \\
359\end{array}$ & $\begin{array}{l}764 \\
369\end{array}$ & $\begin{array}{l}884 \\
447\end{array}$ & $\begin{array}{l}937 \\
466\end{array}$ & $\begin{array}{l}941 \\
467\end{array}$ & $\begin{array}{r}1,255 \\
784\end{array}$ \\
\hline $\begin{array}{l}\text { Vermont } \\
\text { State share }\end{array}$ & $\begin{array}{r}101 \\
62\end{array}$ & $\begin{array}{r}104 \\
52\end{array}$ & $\begin{array}{r}105 \\
54\end{array}$ & $\begin{array}{r}109 \\
56\end{array}$ & $\begin{array}{r}104 \\
53\end{array}$ & $\begin{array}{l}96 \\
47\end{array}$ \\
\hline Virginia $\quad$ State share & $\begin{array}{l}515 \\
270\end{array}$ & $\begin{array}{l}609 \\
322\end{array}$ & $\begin{array}{l}631 \\
337\end{array}$ & $\begin{array}{l}661 \\
355\end{array}$ & $\begin{array}{l}673 \\
350\end{array}$ & $\begin{array}{l}340 \\
333\end{array}$ \\
\hline $\begin{array}{l}\text { Washington } \\
\text { State share }\end{array}$ & $\begin{array}{r}1,578 \\
751\end{array}$ & $\begin{array}{r}1,671 \\
806\end{array}$ & $\begin{array}{r}1,710 \\
845\end{array}$ & $\begin{array}{r}1,834 \\
916\end{array}$ & $\begin{array}{l}2,020 \\
1,000\end{array}$ & $\begin{array}{l}2.368 \\
1371\end{array}$ \\
\hline $\begin{array}{l}\text { West Virginia } \\
\text { State share }\end{array}$ & $\begin{array}{l}166 \\
103\end{array}$ & $\begin{array}{l}259 \\
150\end{array}$ & $\begin{array}{l}276 \\
160\end{array}$ & $\begin{array}{l}302 \\
173\end{array}$ & $\begin{array}{l}420 \\
258\end{array}$ & $\begin{array}{l}326 \\
324\end{array}$ \\
\hline $\begin{array}{l}\text { Wisconsin } \\
\text { State share }\end{array}$ & $\begin{array}{l}712 \\
338\end{array}$ & $\begin{array}{l}781 \\
377\end{array}$ & $\begin{array}{l}830 \\
411\end{array}$ & $\begin{array}{l}870 \\
429\end{array}$ & $\begin{array}{r}1,075 \\
561\end{array}$ & $\begin{array}{r}1.224 \\
568\end{array}$ \\
\hline Wyoming State share & $\begin{array}{l}549 \\
290\end{array}$ & $\begin{array}{l}568 \\
306\end{array}$ & $\begin{array}{l}564 \\
309\end{array}$ & $\begin{array}{l}575 \\
303\end{array}$ & $\begin{array}{l}662 \\
321\end{array}$ & $\begin{array}{l}332 \\
307\end{array}$ \\
\hline $\begin{array}{l}\text { American Samoa } \\
\text { State share }\end{array}$ & $\begin{array}{l}42 \\
20\end{array}$ & $\begin{array}{l}65 \\
32\end{array}$ & $\begin{array}{l}72 \\
36\end{array}$ & $\begin{array}{l}64 \\
32\end{array}$ & $\begin{array}{l}63 \\
31\end{array}$ & $\begin{array}{l}70 \\
32\end{array}$ \\
\hline Guam State share & $\begin{array}{l}21 \\
10\end{array}$ & $\begin{array}{l}25 \\
12\end{array}$ & $\begin{array}{l}36 \\
18\end{array}$ & $\begin{array}{l}43 \\
21\end{array}$ & $\begin{array}{l}62 \\
31\end{array}$ & $\begin{array}{l}65 \\
32\end{array}$ \\
\hline $\begin{array}{l}\text { Puerto Rico } \\
\text { State share }\end{array}$ & $\begin{array}{l}557 \\
279\end{array}$ & $\begin{array}{l}644 \\
328\end{array}$ & $\begin{array}{l}672 \\
333\end{array}$ & $\begin{array}{l}701 \\
345\end{array}$ & $\begin{array}{l}766 \\
401\end{array}$ & $\begin{array}{r}745 \\
365\end{array}$ \\
\hline $\begin{array}{l}\text { Trust Territories } \\
\text { State share }\end{array}$ & $\begin{array}{l}74 \\
35\end{array}$ & $\begin{array}{l}93 \\
45\end{array}$ & $\begin{array}{r}105 \\
52\end{array}$ & $\begin{array}{r}125 \\
62\end{array}$ & $\begin{array}{r}117 \\
58\end{array}$ & $\begin{array}{r}170 \\
84\end{array}$ \\
\hline $\begin{array}{l}\text { Virgin Islands } \\
\text { State share }\end{array}$ & $\begin{array}{r}19 \\
9\end{array}$ & $\begin{array}{l}8 \\
4\end{array}$ & $\begin{array}{r}12 \\
6\end{array}$ & -- & 3 & $\begin{array}{l}33 \\
31\end{array}$ \\
\hline
\end{tabular}

1 Includes Federal funds from direct program.

2 Reimbursable program funds from States, counties, and municipalities.

Included with Puerto Rico funds. 
TABLE 38.-Water Resources Investigations reimbursable program funds from other Federal agencies, by agency, fiscal years 1970-75 [ In thousands of dollars]

\begin{tabular}{|c|c|c|c|c|c|c|}
\hline Agency & 1970 & 1971 & 1972 & 1973 & 1974 & 1975 \\
\hline Total & $\$ 10,183$ & $\$ 11,468$ & $\$ 11,905$ & $\$ 14,518$ & $\$ 16,378$ & $\$ 18,570$ \\
\hline Department of Agriculture & 290 & 310 & 268 & 273 & 261 & 565 \\
\hline Department of Commerce & -- & 52 & 85 & 73 & 1 & 154 \\
\hline Department of Defense & 3,934 & 4,659 & 5,879 & 6,953 & 7,554 & 8,391 \\
\hline Department of Housing and Urban Development & -- & 358 & 921 & 1,801 & 3,018 & 2,252 \\
\hline Department of the Interior & 2,057 & 2,218 & 1,497 & 1,984 & 2,026 & 3,190 \\
\hline $\begin{array}{l}\text { Bonneville Power Administration } \\
\text { Bureau of Indian Affairs }\end{array}$ & -- & -- & 101 & $\begin{array}{r}118 \\
89\end{array}$ & $\begin{array}{l}101 \\
175\end{array}$ & $\begin{array}{l}105 \\
256\end{array}$ \\
\hline Bureau of Land Management & 98 & 113 & $1 \overline{54}$ & 207 & 178 & 1,130 \\
\hline Bureau of Reclamation & 1,428 & 1,458 & 633 & 855 & 676 & 721 \\
\hline Fish and Wildlife Service & & & 101 & 256 & 367 & 361 \\
\hline National Park Service & 414 & 647 & 508 & 459 & 529 & 617 \\
\hline Office of the Secretary & 117 & -- & -. & -- & -- & -- \\
\hline Department of State & 716 & 986 & 802 & 781 & 667 & 642 \\
\hline Energy Research and Development Administration ${ }^{3}$-.- & 1,455 & 1,214 & 1,022 & 877 & 904 & 959 \\
\hline Environmental Protection Agency & 570 & 579 & 627 & 916 & 1,127 & 1,389 \\
\hline National Aeronautics and Space Administration _.....-- & 493 & 438 & 266 & 343 & 284 & 235 \\
\hline National Science Foundation & -- & -- & -- & -- & -- & 67 \\
\hline Tennessee Valley Authority & 160 & 204 & 198 & 255 & 212 & 252 \\
\hline Miscellaneous Federal agencies & 508 & 450 & 340 & 262 & 325 & 474 \\
\hline
\end{tabular}

Included with miscellaneous Federal agencies funds.
a Includes Atomic Energy Commission funds for fiscal years 1970-74.

TABLE 39.-Conservation of Lands and Minerals direct program funds, by subactivity, fiscal years 1970-75 [In thousands of dollars]

\begin{tabular}{|c|c|c|c|c|c|c|}
\hline Subactivity & 1970 & 1971 & 1972 & 1973 & 1974 & 1975 \\
\hline \multicolumn{7}{|c|}{ CURRENT DOLLARS } \\
\hline Total direct program & $\$ 7,497$ & $\$ 9,670$ & $\$ 13,441$ & $\$ 14,700$ & $\$ 18,172$ & $\$ 36,032$ \\
\hline Outer Continental Shelf Lands & 2,594 & 4,234 & 7,626 & 8,114 & 10,957 & 23,196 \\
\hline $\begin{array}{l}\text { Regulation of OCS Oil and Gas Operations } \\
\text { OCS Oil and Gas Tract Selection and Resource }\end{array}$ & 1,599 & 3,104 & $4,4,935$ & 5,398 & $6,34 \overline{2}$ & 10,051 \\
\hline Evaluation & 995 & 1,130 & 2,691 & 2,716 & 4,615 & 13,145 \\
\hline Federal and Indian Lands & 4,903 & 5,436 & 5,815 & 6,586 & 7,215 & 12,836 \\
\hline Regulation of Operations on Leases & 3,875 & 4,353 & 4,574 & $\overline{5,127}$ & 5,552 & 8,428 \\
\hline Oil and Gas & 2,835 & 3,185 & 3,336 & 3,739 & 3,941 & 5,262 \\
\hline Energy Minerals (Coal and Uranium) & 545 & 612 & 332 & 373 & 393 & 508 \\
\hline $\begin{array}{l}\text { Oil Shale } \\
\text { Geothermal }\end{array}$ & -- & $\begin{array}{l}-- \\
--\end{array}$ & -- & $\begin{array}{l}-- \\
--\end{array}$ & $1 \overline{-\overline{8}}$ & $\begin{array}{r}315 \\
1,012\end{array}$ \\
\hline Non-energy Minerals & 495 & 556 & 906 & 1,015 & 1,070 & 1,331 \\
\hline Resource Classification and Evaluation & 1,028 & 1,083 & 1,241 & 1,459 & 1,663 & 4,408 \\
\hline Oil and Gas & 301 & 319 & 156 & 150 & 202 & 223 \\
\hline Coal - & 91 & 97 & 640 & 618 & 832 & 2,380 \\
\hline 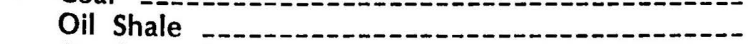 & -- & -- & -- & -- & -- & 295 \\
\hline Geothermal & $\ldots$ & -- & 48 & 281 & 138 & 961 \\
\hline Non-energy Minerals & 294 & $3 \overline{12}$ & 55 & .53 & 71 & 81 \\
\hline Water Resources Development & 342 & 355 & 342 & 357 & 420 & 468 \\
\hline
\end{tabular}


TABLE 39.-Conservation of Lands and Minerals direct program funds, by subactivity, fiscal years 1970-75-Continued

\begin{tabular}{|c|c|c|c|c|c|c|}
\hline Subactivity & 1970 & 1971 & 1972 & 1973 & 1974 & 1975 \\
\hline \multicolumn{7}{|c|}{ CONSTANT 1967 DOLLARS ${ }^{1}$} \\
\hline Total direct program & 6,582 & 8,072 & 10,822 & 11,395 & 13,036 & 23,322 \\
\hline Outer Continental Shelf Lands & 2,278 & 3,534 & 6,140 & 6,290 & 7,860 & 15,014 \\
\hline Regulation of OCS Oil and Gas Operations & 1,404 & $2, \overline{591}$ & 3,973 & 4,185 & 4,549 & $6, \overline{506}$ \\
\hline $\begin{array}{l}\text { Research on OCS Operational Safety Devices ---- } \\
\text { OCS Oil and Gas Tract Selection and Resource }\end{array}$ & -- & -- & -- & -- & -- & -- \\
\hline Evaluation & 874 & 943 & 2,167 & 2,105 & 3,311 & 8,508 \\
\hline Federal and Indian Lands & 4,304 & 4,538 & 4,682 & 5,105 & 5,176 & 8,308 \\
\hline Regulation of Operations on Leases & 3,402 & 3,634 & 3,683 & 3,974 & 3,983 & $5, \overline{455}$ \\
\hline Oil and Gas & 2,489 & 2,659 & 2,686 & 2,898 & 2,827 & 3,406 \\
\hline Energy Minerals & 478 & 511 & 267 & 289 & 282 & 329 \\
\hline Oil Şhale & -- & -- & -- & -- & -- & 204 \\
\hline Geothermal & & & -- & & 106 & 655 \\
\hline Non-energy Minerals & 435 & 464 & 730 & 787 & 768 & 861 \\
\hline Resource Classification and Evaluation & 902 & 904 & 999 & 1,131 & 1,193 & 2,853 \\
\hline Oil and Gas & 264 & 266 & 126 & 116 & 145 & $\overline{144}$ \\
\hline Coal - & 80 & 81 & 515 & 479 & 597 & 1,541 \\
\hline Oil Shale & -- & -- & -- & -- & 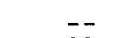 & 191 \\
\hline Geothermal & -- & -- & 39 & 218 & 99 & 622 \\
\hline Non-energy Minerals & 258 & 261 & 44 & 41 & 51 & 52 \\
\hline Water Resources Development & 300 & 296 & 275 & 277 & 301 & 303 \\
\hline
\end{tabular}
1 Gross National Product implicit price deflator was used to convert
current to constant 1967 dollars.

TABLE 40.-Conservation of Lands and Minerals reimbursable program funds from other Federal agencies, fiscal years $1970-75$ [In thousands of dollars]

\begin{tabular}{|c|c|c|c|c|c|c|}
\hline Agency & 1970 & 1971 & 1972 & 1973 & 1974 & 1975 \\
\hline Total & $\$ 28$ & $\$ 32$ & $\$ 25$ & $\$ 45$ & $\$ 41$ & $\$ 46$ \\
\hline Department of Defense & 25 & 25 & 25 & 24 & 25 & 25 \\
\hline
\end{tabular}

TABLE 41.-Land Information and Analysis direct program funds, by subactivity, fiscal years 1970-75 [ [ In thousands of dollars]

\begin{tabular}{|c|c|c|c|c|c|c|}
\hline Subactivity ${ }^{1}$ & 1970 & 1971 & 1972 & 1973 & 1974 & $i ; 75$ \\
\hline \multicolumn{7}{|c|}{ CURRENT DOLLARS } \\
\hline Total direct program & $\$ 1,101$ & $\$ 2,373$ & $\$ 6,714$ & $\$ 11,876$ & $\$ 11,458$ & $\$ 15,461$ \\
\hline Earth Sciences Applications & -- & 452 & 970 & 1,519 & 1,580 & 1,600 \\
\hline $\begin{array}{l}\text { (Urban Area Studies) }^{2} \\
\text { (Land Resource Surveys-Land Resource Analysis) }^{3}\end{array}$ & -- & (452) & (970) & $\begin{array}{l}(987) \\
(532)\end{array}$ & $\begin{array}{r}(1,020) \\
(560)\end{array}$ & $\begin{array}{r}(1,020) \\
580)\end{array}$ \\
\hline Resource and Land Investigations" & -- & -_ & -. & -- & 916 & 959 \\
\hline Geography - - & -- & -- & -- & '-- & -- & 2,013 \\
\hline (Land Use and Data Analysis) ${ }^{s}$ & - & -- & -- & -- & -- & $(2,013)$ \\
\hline Earth Resources Observation Systems ${ }^{\circ}$ & 1,101 & 1,921 & 5,744 & 10,357 & 8,962 & 8,284 \\
\hline Environmental Impact Analysis ${ }^{7}$ & -- & -- & -- & -- & -- & 2.605 \\
\hline (Energy Impact Evaluation) & -- & -- & -_ & -- & -- & $(2.605)$ \\
\hline
\end{tabular}

Environmental Impact Analysis ${ }^{7}-1-1$
(Energy Impact Evaluation)

Earth Sciences Applications

CONSTANT 1967 DOLLARS

\begin{tabular}{rrrrrr}
967 & 1,981 & 5,406 & 9,206 & 8,220 & 10,007 \\
\hline \hline-- & 377 & 781 & 1,177 & 1,134 & 1,035 \\
\hline-- & $(377)$ & $(781)$ & $(765)$ & $(732)$ & $660)$ \\
\hline-- & -- & $(412)$ & $(402)$ & $375)$
\end{tabular}


TABLE 41.-Land Information and Analysis direct program funds, by subactivity, fiscal years 1970-75-Continued

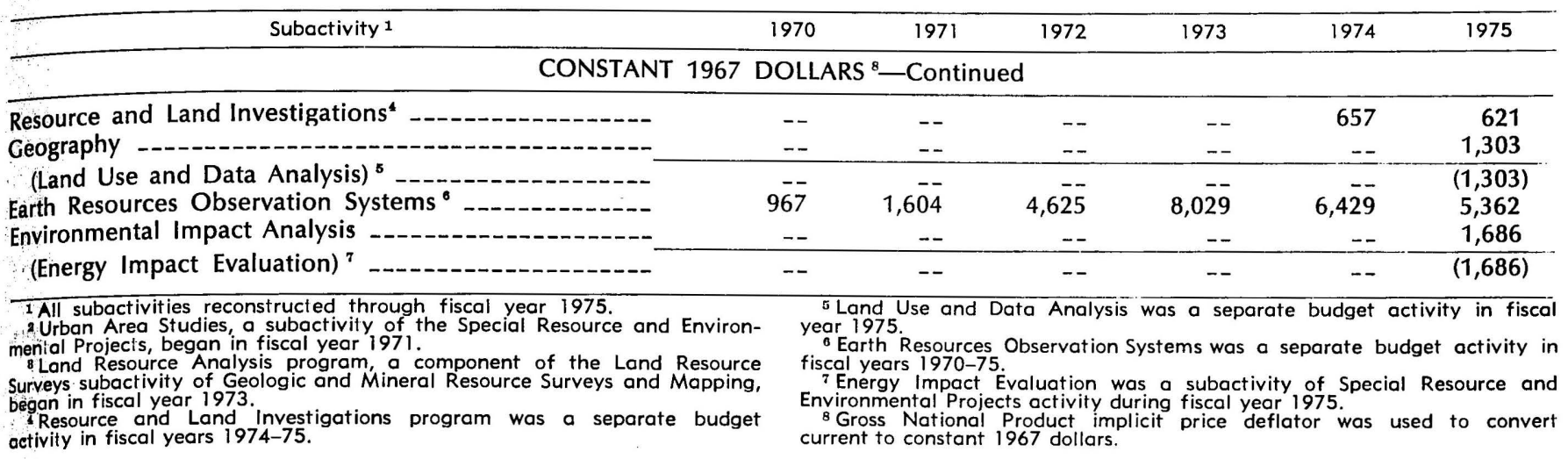

TABLE 42.-Land Information and Analysis reimbursable program funds from other Federal agencies, by agency, fiscal years 1970-75

[In thousands of dollars]

\begin{tabular}{|c|c|c|c|c|c|c|}
\hline Agency & 1970 & 1971 & 1972 & 1973 & 1974 & 1975 \\
\hline Total & $\$ 866$ & $\$ 1,166$ & $\$ 575$ & $\$ 1,249$ & $\$ 952$ & $\$ 407$ \\
\hline Department of Defense & -- & -- & -- & -- & 10 & -- \\
\hline Department of Housing and Urban Development & 182 & 355 & -- & -- & 339 & -- \\
\hline Department of the Interior & -- & -- & -- & -- & 48 & 11 \\
\hline $\begin{array}{l}\text { Bonneville Power Administration } \\
\text { Fish and Wildlife Service }\end{array}$ & -- & -- & -- & -- & $\begin{array}{l}35 \\
13\end{array}$ & $\overline{11}$ \\
\hline National Aeronautics and Space Administration & 684 & 811 & 575 & 1,249 & 408 & 179 \\
\hline Ozark Regional Commission & -- & -- & -- & -- & 60 & 49 \\
\hline Miscellaneous Federal agencies & -- & - & -- & -- & 87 & 168 \\
\hline
\end{tabular}

TABLE 43.-Program support funds, by activity, fiscal years 1970-75 [ In thousands of dollars]

\begin{tabular}{|c|c|c|c|c|c|c|}
\hline Program support activity & 1970 & 1971 & 1972 & 1973 & 1974 & 1975 \\
\hline \multicolumn{7}{|c|}{ CURRENT DOLLARS } \\
\hline General Administrative Expenses ${ }^{1}$ & $\$ 4,622$ & $\$ 5,335$ & $\$ 6,422$ & $\$ 7,173$ & $\$ 8,197$ & $\$ 10,806$ \\
\hline $\begin{array}{l}\text { General Administration }{ }^{2} \\
\text { Direct program assessments } \\
\text { Reimbursable program assessments }\end{array}$ & $\begin{array}{r}2,867 \\
500 \\
1,255\end{array}$ & $\begin{array}{r}3,048 \\
962 \\
1,325\end{array}$ & $\begin{array}{l}3,187 \\
1,669 \\
1,566\end{array}$ & $\begin{array}{l}3,217 \\
2,352 \\
1,604\end{array}$ & $\begin{array}{l}3,517 \\
2,770 \\
1,910\end{array}$ & $\begin{array}{l}3,671 \\
5,126 \\
2,009\end{array}$ \\
\hline Electronic data processing and related services ${ }^{5}$ & 4,931 & 5,582 & 4,862 & 6,168 & 6,987 & 8,425 \\
\hline $\begin{array}{l}\text { Funded by Survey programs }{ }^{\circ} \\
\text { Funded by miscellaneous accounts }\end{array}$ & $\begin{array}{l}3,239 \\
1,692\end{array}$ & $\begin{array}{l}3,068 \\
2,514\end{array}$ & $\begin{array}{l}3,351 \\
1,511\end{array}$ & $\begin{array}{l}4,177 \\
1,991\end{array}$ & $\begin{array}{l}4,828 \\
2,159\end{array}$ & $\begin{array}{l}6,129 \\
2,296\end{array}$ \\
\hline Publication services ${ }^{8}$ & 8,713 & 9,615 & 10,667 & 11,656 & 11,932 & 13,004 \\
\hline $\begin{array}{l}\text { Funded by Survey programs }{ }^{\circ} \\
\text { Funded by miscellaneous accounts }\end{array}$ & $\begin{array}{r}8,370 \\
343\end{array}$ & $\begin{array}{r}9,248 \\
367\end{array}$ & $\begin{array}{r}10,297 \\
370\end{array}$ & $\begin{array}{r}11,147 \\
509\end{array}$ & $\begin{array}{r}11,432 \\
500\end{array}$ & $\begin{array}{r}12,488 \\
516\end{array}$ \\
\hline \multicolumn{7}{|c|}{ CONSTANT 1967 DOLLARS } \\
\hline General Administrative Expenses ${ }^{1}$ & 4,058 & 4,453 & 5,171 & 5,560 & 5,880 & 6,994 \\
\hline $\begin{array}{l}\text { General Administration }{ }^{2} \\
\text { Direct program assessments } \\
\text { Reimbursable program assessments }\end{array}$ & $\begin{array}{r}2,517 \\
439 \\
1,102\end{array}$ & $\begin{array}{r}2,544 \\
803 \\
1,106\end{array}$ & $\begin{array}{l}2,566 \\
1,344 \\
1,261\end{array}$ & $\begin{array}{l}2,494 \\
1,823 \\
1,243\end{array}$ & $\begin{array}{l}2,523 \\
1,987 \\
1,370\end{array}$ & $\begin{array}{l}2,376 \\
3,318 \\
1,300\end{array}$ \\
\hline Electronic Data processing and related services ${ }^{5}$ & 4,566 & 4,659 & 3,915 & 4,781 & 5,012 & 5,453 \\
\hline $\begin{array}{l}\text { Funded by Survey programs }{ }^{\circ} \\
\text { Funded by miscellaneous accounts }\end{array}$ & $\begin{array}{l}2,999 \\
1,567\end{array}$ & $\begin{array}{l}2,561 \\
2,098\end{array}$ & $\begin{array}{l}2,698 \\
1,217\end{array}$ & $\begin{array}{l}3,238 \\
1,543\end{array}$ & $\begin{array}{l}3,463 \\
1,549\end{array}$ & $\begin{array}{l}3,967 \\
1,486\end{array}$ \\
\hline
\end{tabular}

See footnotes at end of table. 
TABLE 43.-Program support funds, by activity, fiscal years 1970-75-Continued

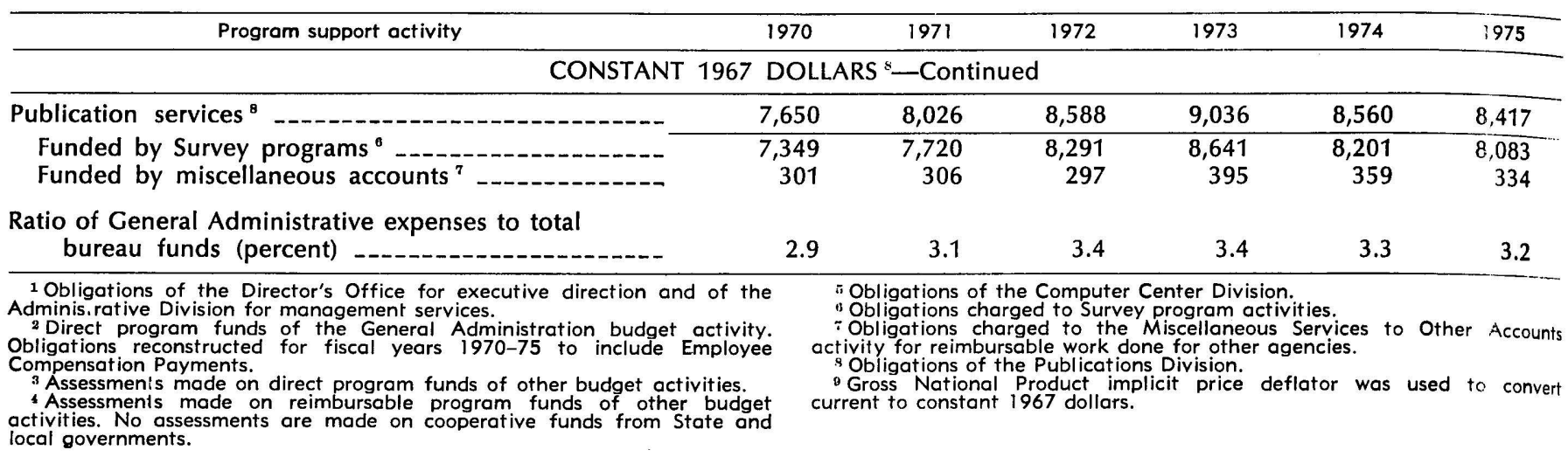

TABLE 44.-Geological Survey end-of-year employment, by organizational unit, fiscal years 1970-75

\begin{tabular}{|c|c|c|c|c|c|c|}
\hline Organizational unit & 1970 & 1971 & 1972 & 1973 & 1974 & 1775 \\
\hline Total & 9,134 & 9,192 & 9,224 & 9,387 & 9,921 & 10,435 \\
\hline $\begin{array}{l}\text { Permanent employment } \\
\text { Other than permanent employment }\end{array}$ & $\begin{array}{l}8,098 \\
1,036\end{array}$ & $\begin{array}{l}8,173 \\
1,019 \\
\end{array}$ & $\begin{array}{l}8,002 \\
1,222\end{array}$ & $\begin{array}{l}8,089 \\
1,298 \\
\end{array}$ & $\begin{array}{l}8,357 \\
1,564\end{array}$ & $\begin{array}{l}8 . \overline{999} \\
1.436 \\
\end{array}$ \\
\hline Topographic Division & 2,132 & 2,079 & 2,045 & 2,020 & 1,956 & 1377 \\
\hline $\begin{array}{l}\text { Permanent employment } \\
\text { Other than permanent employment }\end{array}$ & $\begin{array}{r}1,936 \\
196\end{array}$ & $\begin{array}{r}1,893 \\
186\end{array}$ & $\begin{array}{r}1,828 \\
217\end{array}$ & $\begin{array}{r}1,758 \\
262\end{array}$ & $\begin{array}{r}1,762 \\
194\end{array}$ & $\begin{array}{r}1.719 \\
158\end{array}$ \\
\hline Geologic Division & 2,058 & 2,048 & 2,060 & 2,147 & 2,406 & 2,372 \\
\hline $\begin{array}{l}\text { Permanent employment } \\
\text { Other than permanent employment }\end{array}$ & $\begin{array}{r}1,783 \\
275\end{array}$ & $\begin{array}{r}1,765 \\
283\end{array}$ & $\begin{array}{r}1,706 \\
354\end{array}$ & $\begin{array}{r}1,766 \\
381\end{array}$ & $\begin{array}{r}1,888 \\
518\end{array}$ & $\begin{array}{r}2 . \lcm{35} \\
437\end{array}$ \\
\hline Water Resources Division & 3,364 & 3,427 & 3,409 & 3,419 & 3,611 & 3,510 \\
\hline $\begin{array}{l}\text { Permanent employment } \\
\text { Other than permanent employment }\end{array}$ & $\begin{array}{r}2,886 \\
478\end{array}$ & $\begin{array}{r}2,965 \\
462\end{array}$ & $\begin{array}{r}2,876 \\
533\end{array}$ & $\begin{array}{r}2,900 \\
519\end{array}$ & $\begin{array}{r}2,910 \\
701\end{array}$ & $\begin{array}{r}2,957 \\
553\end{array}$ \\
\hline Conservation Division & 479 & 492 & 549 & 568 & 647 & 390 \\
\hline $\begin{array}{l}\text { Permanent employment } \\
\text { Other than permanent employment }\end{array}$ & $\begin{array}{r}461 \\
18\end{array}$ & $\begin{array}{r}475 \\
17\end{array}$ & $\begin{array}{r}529 \\
20\end{array}$ & $\begin{array}{r}547 \\
21\end{array}$ & $\begin{array}{r}612 \\
35\end{array}$ & $\begin{array}{r}926 \\
64\end{array}$ \\
\hline Land Information and Analysis Office & -- & -- & 51 & 72 & 85 & 14 \\
\hline $\begin{array}{l}\text { Permanent employment } \\
\text { Other than permanent employment }\end{array}$ & -- & -- & $\begin{array}{l}39 \\
12\end{array}$ & $\begin{array}{l}52 \\
20\end{array}$ & $\begin{array}{l}68 \\
17\end{array}$ & $\begin{array}{l}89 \\
25\end{array}$ \\
\hline Director's Office ${ }^{1}$ & 77 & 94 & 64 & 57 & 64 & 66 \\
\hline $\begin{array}{l}\text { Permanent employment } \\
\text { Other than permanent employment }\end{array}$ & $\begin{array}{l}67 \\
10\end{array}$ & $\begin{array}{l}79 \\
15\end{array}$ & $\begin{array}{l}51 \\
13\end{array}$ & $\begin{array}{r}55 \\
2\end{array}$ & $\begin{array}{r}62 \\
2\end{array}$ & $\begin{array}{r}57 \\
9\end{array}$ \\
\hline Administrative Division & 351 & 362 & 360 & 382 & 408 & 141 \\
\hline $\begin{array}{l}\text { Permanent employment } \\
\text { Other than permanent employment }\end{array}$ & $\begin{array}{r}328 \\
23\end{array}$ & $\begin{array}{r}336 \\
26\end{array}$ & $\begin{array}{r}326 \\
34\end{array}$ & $\begin{array}{r}341 \\
41\end{array}$ & $\begin{array}{r}366 \\
42\end{array}$ & $\begin{array}{r}398 \\
43\end{array}$ \\
\hline Facilities $^{2}$ - & -- & -- & -- & -- & 15 & 30 \\
\hline $\begin{array}{l}\text { Permanent employment } \\
\text { Other than permanent employment }\end{array}$ & -- & -- & -- & -- & 15 & $\begin{array}{l}30 \\
--\end{array}$ \\
\hline Computer Center Division & 157 & 153 & 170 & 174 & 182 & 198 \\
\hline $\begin{array}{l}\text { Permanent employment } \\
\text { Other than permanent employment }\end{array}$ & $\begin{array}{r}134 \\
23\end{array}$ & $\begin{array}{r}142 \\
11\end{array}$ & $\begin{array}{r}150 \\
20\end{array}$ & $\begin{array}{r}153 \\
21\end{array}$ & $\begin{array}{r}159 \\
23\end{array}$ & $\begin{array}{r}178 \\
20\end{array}$ \\
\hline Publications Division & 516 & 537 & 516 & 548 & 547 & 37 \\
\hline $\begin{array}{l}\text { Permanent employment } \\
\text { Other than permanent employment }\end{array}$ & $\begin{array}{r}503 \\
13\end{array}$ & $\begin{array}{r}518 \\
19\end{array}$ & $\begin{array}{r}497 \\
19\end{array}$ & $\begin{array}{r}517 \\
31\end{array}$ & $\begin{array}{r}515 \\
32\end{array}$ & $\begin{array}{r}310 \\
27\end{array}$ \\
\hline
\end{tabular}

1 Includes Land Information and Analysis Office personnel for fiscal
years $1970-71$.

years $1970-71$.
Administrative Division personnel assigned to the operation of the

2Administrative Division perso
Survey's Headquarter facilities. 
TABLE 45.-Number of Geological Survey reports approved for publication, by organizational unit, fiscal years 1970-75

\begin{tabular}{|c|c|c|c|c|c|c|}
\hline Organizational Unit & 1970 & 1971 & 1972 & 1973 & 1974 & 1975 \\
\hline Total $\quad$ To & 2,292 & 2,320 & 2,351 & 2,548 & 2,755 & 2,888 \\
\hline $\begin{array}{l}\text { Book reports }{ }^{1} \\
\text { Journal of Research articles } \\
\text { Open file reports } \\
\text { Basic data reports } \\
\text { Outside publications }\end{array}$ & $\begin{array}{r}217 \\
133 \\
386 \\
110 \\
1,446\end{array}$ & $\begin{array}{r}183 \\
126 \\
399 \\
131 \\
1,481\end{array}$ & $\begin{array}{r}163 \\
106 \\
447 \\
196 \\
1,439\end{array}$ & $\begin{array}{r}147 \\
107 \\
380 \\
255 \\
1,659\end{array}$ & $\begin{array}{r}155 \\
90 \\
440 \\
230 \\
1,840\end{array}$ & $\begin{array}{r}144 \\
85 \\
570 \\
256 \\
1,833\end{array}$ \\
\hline Topographic Division & 45 & 53 & 42 & 53 & 53 & 33 \\
\hline $\begin{array}{l}\text { Book reports } \\
\text { Journal of Research articles } \\
\text { Open file reports } \\
\text { Outside publications }\end{array}$ & $\begin{array}{r}-\overline{2} \\
3 \\
40\end{array}$ & $\begin{array}{l}-- \\
-- \\
\overline{53}\end{array}$ & $\begin{array}{l}-- \\
-- \\
42\end{array}$ & $\begin{array}{r}-\overline{2} \\
\overline{51}\end{array}$ & $\begin{array}{r}-\overline{1} \\
\overline{52}\end{array}$ & $\begin{array}{l}-- \\
-- \\
--\end{array}$ \\
\hline Geologic Division & 1,328 & 1,311 & 1,329 & 1,419 & 1,546 & 1,811 \\
\hline $\begin{array}{l}\text { Book reports } \\
\text { Journal of Research articles } \\
\text { Open file reports } \\
\text { Outside publications }\end{array}$ & $\begin{array}{r}109 \\
94 \\
205 \\
920\end{array}$ & $\begin{array}{r}93 \\
90 \\
189 \\
939\end{array}$ & $\begin{array}{r}102 \\
78 \\
258 \\
891\end{array}$ & $\begin{array}{r}91 \\
79 \\
216 \\
1,033\end{array}$ & $\begin{array}{r}96 \\
69 \\
245 \\
1,136\end{array}$ & $\begin{array}{r}90 \\
70 \\
379 \\
1,272\end{array}$ \\
\hline Water Resources Division & 850 & 865 & 875 & 953 & 1,002 & 926 \\
\hline $\begin{array}{l}\text { Book reports } \\
\text { Journal of Research articles } \\
\text { Open file reports } \\
\text { Basic data reports } \\
\text { Outside publications }\end{array}$ & $\begin{array}{r}100 \\
37 \\
158 \\
110 \\
445\end{array}$ & $\begin{array}{r}88 \\
36 \\
200 \\
131 \\
410\end{array}$ & $\begin{array}{r}59 \\
28 \\
180 \\
196 \\
412\end{array}$ & $\begin{array}{r}54 \\
26 \\
149 \\
255 \\
369\end{array}$ & $\begin{array}{r}56 \\
20 \\
181 \\
230 \\
515\end{array}$ & $\begin{array}{r}50 \\
15 \\
152 \\
256 \\
453\end{array}$ \\
\hline Conservation Division & 12 & 11 & 15 & 17 & 18 & 44 \\
\hline $\begin{array}{l}\text { Book reports } \\
\text { Open file reports } \\
\text { Outside publications }\end{array}$ & $\begin{array}{l}7 \\
3 \\
2\end{array}$ & $\begin{array}{r}-\overline{5} \\
6\end{array}$ & $\begin{array}{l}1 \\
8 \\
6\end{array}$ & $\begin{array}{r}\overline{13} \\
4\end{array}$ & $\begin{array}{r}2 \\
11 \\
5\end{array}$ & $\begin{array}{r}1 \\
32 \\
11\end{array}$ \\
\hline Director's Office ${ }^{3}$ & 57 & 80 & 90 & 106 & 136 & 74 \\
\hline $\begin{array}{l}\text { Book reports } \\
\text { Open file reports } \\
\text { Outside publications }\end{array}$ & $\begin{array}{r}1 \\
17 \\
39\end{array}$ & $\begin{array}{r}2 \\
5 \\
73\end{array}$ & $\begin{array}{r}1 \\
1 \\
88\end{array}$ & $\begin{array}{r}2 \\
2 \\
102\end{array}$ & $\begin{array}{r}1 \\
3 \\
132\end{array}$ & $\begin{array}{r}3 \\
7 \\
64\end{array}$ \\
\hline
\end{tabular}

1 Book reports include U.S. Geological Survey Professional Papers, Bulle-

tins, Water-Supply Papers, Circulars, and other report series. 2 . Before January 1973 articles were published as part of the annual

"Before January 1973 articles Were published as part of the annual
"Geological Survey Research" Professional Paper.
3. Includes reports of the Land Information and Analysis Office, Admin-

'Includes reports of the Land Information and Analysis Office, Admin
istrative Division, Computer Center Division, and Publications Division.

TABLE 46.-Number of maps produced by the Geological Survey, by organizational unit, fiscal years 1970-75

\begin{tabular}{|c|c|c|c|c|c|c|}
\hline Organizational Unit & 1970 & 1971 & 1972 & 1973 & 1974 & 1975 \\
\hline Total $^{1}$ - & 4,243 & 4,553 & 6,094 & 10,304 & 7,361 & 8,713 \\
\hline Topographic Division & 3,174 & 3,541 & 4,817 & 5,313 & 4,938 & 7,279 \\
\hline Quadrangle maps & 2,984 & 3,346 & 4,641 & 5,117 & 4,780 & 7,087 \\
\hline $\begin{array}{l}\text { New standard quadrangles } \\
\text { Orthophotoquads } \\
\text { Revisions } \\
\text { Reprints }\end{array}$ & $\begin{array}{r}1,620 \\
719 \\
645\end{array}$ & $\begin{array}{r}1,692 \\
9 \overline{5} \\
701\end{array}$ & $\begin{array}{r}2,5 \overline{44} \\
1,2 \overline{-} \\
874\end{array}$ & $\begin{array}{r}2,347 \\
49 \\
1,118 \\
1,603\end{array}$ & $\begin{array}{r}2,052 \\
15 \\
966 \\
1,747\end{array}$ & $\begin{array}{r}2,016 \\
2,869 \\
923 \\
1,279\end{array}$ \\
\hline Small scale and special maps & 132 & 135 & 112 & 148 & 121 & 162 \\
\hline $\begin{array}{l}\text { 1:250,000 series } \\
\text { Antarctica } \\
\text { State bases } \\
\text { Other } \\
\text { Reprints }\end{array}$ & $\begin{array}{r}9 \\
4 \\
3 \\
12 \\
104\end{array}$ & $\begin{array}{r}19 \\
10 \\
6 \\
13 \\
87\end{array}$ & $\begin{array}{r}26 \\
-\overline{8} \\
20 \\
58\end{array}$ & $\begin{array}{r}57 \\
5 \\
2 \\
25 \\
59\end{array}$ & $\begin{array}{r}50 \\
-- \\
-\overline{8} \\
63\end{array}$ & $\begin{array}{r}52 \\
4 \\
2 \\
24 \\
80\end{array}$ \\
\hline Topographic map indexes & 58 & 60 & 64 & 48 & 37 & 30 \\
\hline Geologic Division ${ }^{2}$ & 226 & 119 & 315 & 320 & 215 & 229 \\
\hline Water Resources Division & 841 & 876 & 952 & 4,650 & 2,192 & 1,198 \\
\hline $\begin{array}{l}\text { Hydrologic maps } \\
\text { Flood prone area maps }\end{array}$ & $\begin{array}{r}39 \\
802\end{array}$ & $\begin{array}{r}49 \\
827\end{array}$ & $\begin{array}{r}47 \\
905\end{array}$ & $\begin{array}{r}84 \\
4,566\end{array}$ & $\begin{array}{r}52 \\
2,140\end{array}$ & $\begin{array}{r}58 \\
1,140\end{array}$ \\
\hline Conservation Division ${ }^{3}$ & 2 & 17 & 10 & · 8 & 9 & 5 \\
\hline Director's Office ${ }^{3}$ & -- & -- & -- & 13 & 7 & 2 \\
\hline
\end{tabular}

1 Additional maps are produced for inclusion in book reports.

Miscellaneous maps and charts. 
TABLE 47.-Oil and gas operations on Outer Contental Shelf lands, calendar years 1970-75

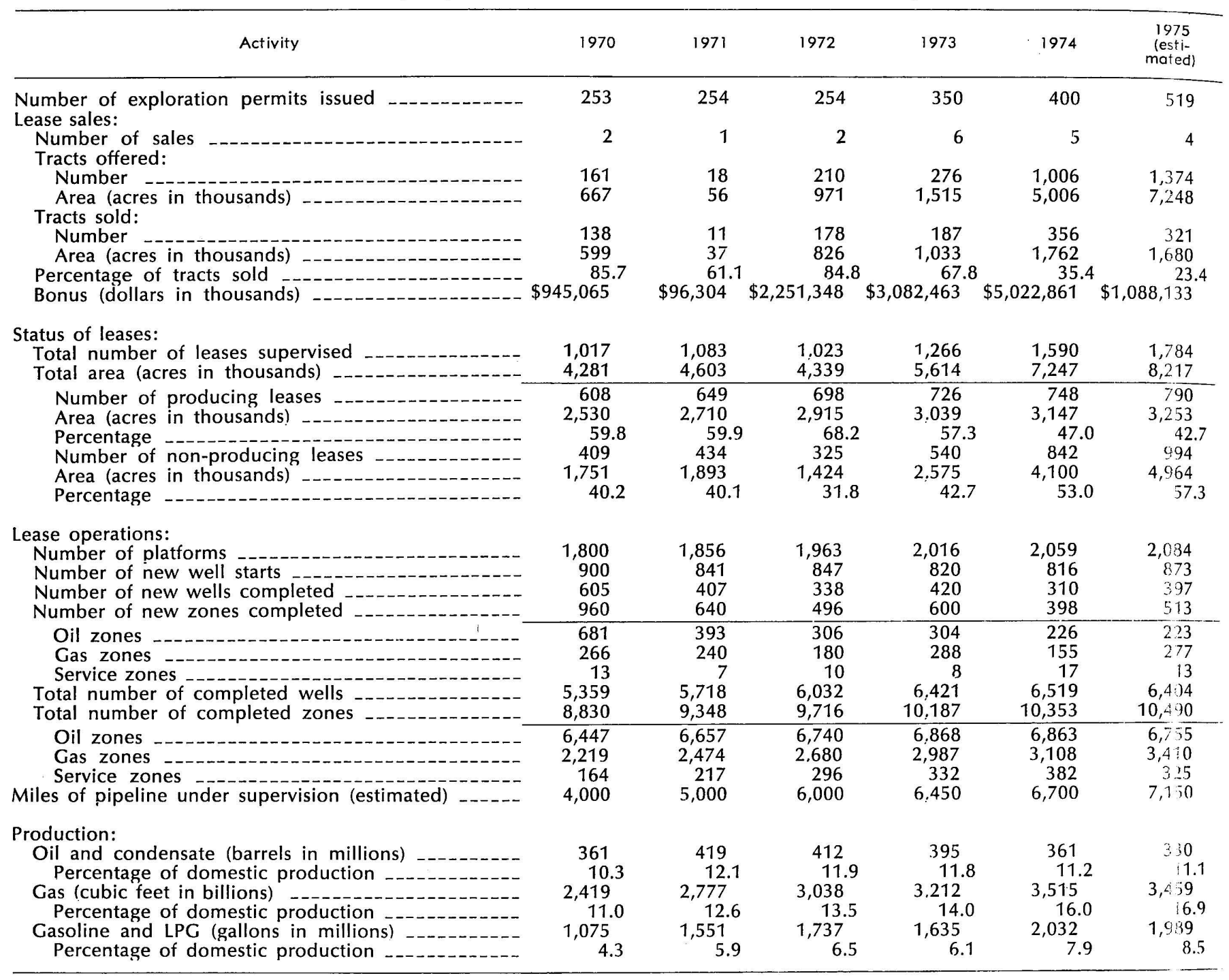

TABLE 48.-Revenues from leases on Outer Continental Shelf lands, calendar years 1970-75 [Dollars in thousands]

\begin{tabular}{|c|c|c|c|c|c|}
\hline Source of revenue & 1971 & 1972 & 1973 & 1974 & $\begin{array}{c}19 ; 5 \\
\text { (esi- } \\
\text { matcd) }\end{array}$ \\
\hline Total revenue & $\$ 456,012$ & $\$ 2,624,958$ & $\$ 3,494,981$ & $\$ 5,598,758$ & $\$ 1,723,724$ \\
\hline $\begin{array}{lr}\text { Bonuses } & \\
\text { Minimum royalties } & \\
\text { Rentals } & \\
\text { Number of accounts } & 1,746 \\
\text { Shut-in gas payments } & \end{array}$ & $\begin{array}{c}96,304 \\
1,891 \\
7,742 \\
(735) \\
32\end{array}$ & $\begin{array}{r}2,251,347 \\
2,020 \\
7,985 \\
(529) \\
50\end{array}$ & $\begin{array}{r}, 082,463 \\
2,391 \\
8,949 \\
(647) \\
53\end{array}$ & $\begin{array}{r}5,022,861 \\
2,048 \\
13.533 \\
(1,036) \\
32\end{array}$ & $\begin{array}{r}1,088,133 \\
2,300 \\
18,000 \\
(1,270) \\
30\end{array}$ \\
\hline $\begin{array}{l}\text { Rovalties } \\
\text { Production value } \\
\quad \text { Number of acounts }\end{array}$ & $\begin{array}{r}350,042 \\
(2,135,677) \\
(754) \\
\end{array}$ & $\begin{array}{r}363,556 \\
(2,229,179) \\
(912) \\
\end{array}$ & $\begin{array}{r}401,126 \\
(2,486,865) \\
(1,158) \\
\end{array}$ & $\begin{array}{r}560,284 \\
(3,570,054) \\
(2,260) \\
\end{array}$ & $\begin{array}{r}615,561 \\
(3,925,923) \\
(2,00) \\
\end{array}$ \\
\hline $\begin{array}{l}\text { Oil and condensate: } \\
\text { Royalties } \\
\text { Production value }\end{array}$ & $\begin{array}{c}253,229 \\
(1,481,681)\end{array}$ & $\begin{array}{c}247,689 \\
(1,453,966)\end{array}$ & $\begin{array}{c}271,491 \\
(1,620,732)\end{array}$ & $\begin{array}{c}384,367 \\
(2,398,794)\end{array}$ & $\begin{array}{c}399, ; 31 \\
(2,428,374)\end{array}$ \\
\hline $\begin{array}{l}\text { Gas: } \\
\text { Royalties } \\
\text { Production value } \\
\text { Gasoline and LPG: }\end{array}$ & $\begin{array}{r}87,406 \\
(549,648)\end{array}$ & $\begin{array}{c}105,892 \\
(663,648)\end{array}$ & $\begin{array}{c}118,245 \\
(736,878)\end{array}$ & $\begin{array}{c}142,257 \\
(881,634)\end{array}$ & $\begin{array}{r}195,908 \\
(1,210,314)\end{array}$ \\
\hline $\begin{array}{l}\text { Royalties } \\
\text { Production value }\end{array}$ & $\begin{array}{c}5,944 \\
(80,563)\end{array}$ & $\begin{array}{c}6,525 \\
(89,214)\end{array}$ & $\begin{array}{c}7,768 \\
(105,437)\end{array}$ & $\begin{array}{c}19,797 \\
(254,744)\end{array}$ & $\begin{array}{r}16,376 \\
(216,043)\end{array}$ \\
\hline
\end{tabular}


TABLE 48.-Revenues from leases on Outer Continental Shelf lands, calendar years 1970-75-Continued

\begin{tabular}{|c|c|c|c|c|c|c|c|}
\hline & Commodity & 1970 & 1971 & 1972 & 1973 & 1974 & $\begin{array}{r}1975 \\
\text { (esti- } \\
\text { mated) }\end{array}$ \\
\hline $\begin{array}{l}\text { Salt: } \\
\text { Royalties } \\
\text { Production value } \\
\text { Sulfur: }\end{array}$ & - & $\begin{array}{r}8 \\
(49)\end{array}$ & $\begin{array}{c}11 \\
(67)\end{array}$ & $\begin{array}{c}11 \\
(65)\end{array}$ & $\begin{array}{l}11 \\
(69)\end{array}$ & $\begin{array}{l}10 \\
(62)\end{array}$ & $\begin{array}{r}8 \\
(54)\end{array}$ \\
\hline $\begin{array}{l}\text { Royalties } \\
\text { Production value }\end{array}$ & - & $\begin{array}{r}3,236 \\
(24,637)\end{array}$ & $\begin{array}{r}3,452 \\
(23,718)\end{array}$ & $\begin{array}{r}3,439 \\
(22,287)\end{array}$ & $\begin{array}{r}3,611 \\
(23,749)\end{array}$ & $\begin{array}{c}3,853 \\
(34,820)\end{array}$ & $\begin{array}{r}3,738 \\
(69,738)\end{array}$ \\
\hline
\end{tabular}

TABLE 49.-Oil, gas, and geothermal operations on Federal and Indian lands, calendar years 1970-75

\begin{tabular}{|c|c|c|c|c|c|c|}
\hline Actiivty & 1970 & 1971 & 1972 & 1973 & 1974 & 1975 \\
\hline \multicolumn{7}{|l|}{$\begin{array}{l}\text { Competitive oil and gas lease sales Federal lands: } \\
\text { Tracts offered: }\end{array}$} \\
\hline $\begin{array}{l}\text { Number of tracts } \\
\text { Area (acres) }\end{array}$ & $\begin{array}{r}255 \\
41,796\end{array}$ & $\begin{array}{r}418 \\
121962\end{array}$ & $\begin{array}{r}464 \\
130.546\end{array}$ & $\begin{array}{r}339 \\
86681\end{array}$ & 421 & 390 \\
\hline \multicolumn{7}{|l|}{ Tracts sold: } \\
\hline Number of tracts & 185 & 206 & 279 & 311 & & 334 \\
\hline $\begin{array}{l}\text { Area (acres) } \\
\text { Percentage of tracts sold }\end{array}$ & $\begin{array}{l}38,724 \\
72.6\end{array}$ & 52,102 & 88,326 & 89,315 & 65,247 & 90,367 \\
\hline Bonus (dollars in thousands) & $\$ 479$ & $\$ 1,163$ & $\$ 1,118$ & $\$ 2,203$ & $\$ 2,296$ & $\$ 6,334$ \\
\hline \multicolumn{7}{|l|}{ Status of oil and gas leases: } \\
\hline Total number of leases supervised & 115,993 & 112,784 & 113,158 & 115,761 & 123,652 & 126,718 \\
\hline Total area (acres in thousands) ------ & 70,767 & 70,628 & 75,213 & 79,116 & 89,829 & 93,604 \\
\hline $\begin{array}{l}\text { Number of producing lea: } 2 s \\
\text { Area (acres in thousands) }\end{array}$ & $\begin{array}{r}11,135 \\
5562\end{array}$ & $\begin{array}{r}11.285 \\
5.600\end{array}$ & 11,640 & 11,953 & 12,386 & 13,036 \\
\hline $\begin{array}{l}\text { Area (acres in thousands) } \\
\text { Percentage }\end{array}$ & $\begin{array}{r}5,563 \\
9.6\end{array}$ & $\begin{array}{r}5,629 \\
10.0\end{array}$ & $\begin{array}{c}5,741 \\
10.3\end{array}$ & $\begin{array}{c}5,902 \\
10.3\end{array}$ & $\begin{array}{c}6,349 \\
10.0\end{array}$ & $\begin{array}{c}6,680 \\
10.3\end{array}$ \\
\hline $\begin{array}{l}\text { Number of non-producing leases } \\
\text { Area (acres in thousands) }\end{array}$ & 104,858 & 101,499 & 101,518 & 103,808 & 111,266 & 113,682 \\
\hline $\begin{array}{l}\text { Area (acres in thousands) } \\
\text { Percentage }\end{array}$ & 65,204 & 64,999 & 69,472 & 73,214 & 83,480 & 86,924 \\
\hline 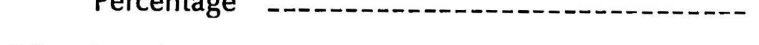 & 90.4 & & & & 90.0 & 89.7 \\
\hline \multicolumn{7}{|l|}{$\begin{array}{l}\text { Oil and gas lease operations: } \\
\text { Number of new well starts }\end{array}$} \\
\hline Number of new well starts & 1,765 & 1,651 & 1,956 & 1,848 & 2,312 & 2,321 \\
\hline Number of new wells completed & 1,083 & 883 & 1,045 & 1,132 & 1,280 & 1,617 \\
\hline Number of new zones completed & 1,104 & 907 & 1,081 & 1,172 & 1,341 & 1,660 \\
\hline Oil zones & 829 & 589 & 660 & 507 & 701 & 927 \\
\hline Gas zones - & 234 & 271 & 374 & 601 & 579 & 614 \\
\hline Service zones - & 41 & 47 & 47 & 64 & 61 & 119 \\
\hline $\begin{array}{l}\text { Total number of completed wells } \\
\text { Total number of completed zones }\end{array}$ & $\begin{array}{l}36,587 \\
38,368\end{array}$ & $\begin{array}{l}36,936 \\
38,686\end{array}$ & $\begin{array}{r}37,441 \\
39,159\end{array}$ & $\begin{array}{l}38,199 \\
39,991\end{array}$ & $\begin{array}{l}38,372 \\
40,251\end{array}$ & $\begin{array}{l}38,218 \\
40,300\end{array}$ \\
\hline $\begin{array}{l}\text { Total number of completed zones } \\
\text { Oil zones }\end{array}$ & 23,511 & 23,366 & 23,282 & 23,139 & 22,791 & $\frac{40,300}{21,866}$ \\
\hline $\begin{array}{l}\text { Oil zones } \\
\text { Gas zones }\end{array}$ & 9,913 & 10,159 & 10,421 & 11,083 & 11,487 & 12,282 \\
\hline Service zones - & 4,944 & 5,161 & 5,456 & 5,769 & 5,973 & 6,152 \\
\hline \multicolumn{7}{|l|}{ Oil and gas production: } \\
\hline Oil and condensate (barrels in millions) & 243 & 228 & 217 & 208 & 208 & 198 \\
\hline Percentage of domestic production & 6.9 & 6.6 & 6.3 & 6.2 & 6.4 & 6.4 \\
\hline Gas (cubic feet in billions) & 1,135 & 1173 & 1,124 & 1,153 & 1,234 & 1,057 \\
\hline Percentage of domestic production & 5.2 & 5.2 & 5.0 & & & \\
\hline Gasoline and LPG (gallons in millions) & 626 & 713 & 641 & 669 & 567 & 521 \\
\hline Percentage of domestic production & 2.5 & 2.7 & 2.4 & 2.5 & 2.2 & 2.1 \\
\hline \multicolumn{7}{|l|}{$\begin{array}{l}\text { Status of geothermal leases: } \\
\text { Total numberm }\end{array}$} \\
\hline $\begin{array}{l}\text { Total number of leases in effect } \\
\text { Total area (acres in thousands) }\end{array}$ & -- & -- & -- & -- & -- & 552 \\
\hline Toral area (acres in thousands) & -- & -- & -- & -- & - & 1,270 \\
\hline
\end{tabular}

TABLE 50.- Royalties from oil and gas leases on Federal and Indian lands, calendar years 1970-75 [Dollars in thousands

\begin{tabular}{|c|c|c|c|c|c|c|}
\hline Commodity & 1970 & 1971 & 1972 & 1973 & 1974 & $\begin{array}{c}1975 \\
\text { (esti- } \\
\text { mated) }\end{array}$ \\
\hline $\begin{array}{l}\text { Total royalties } \\
\text { Total production value }\end{array}$ & $\begin{array}{r}\$ 114,439 \\
(916,406) \\
\end{array}$ & $\begin{array}{l}\$ 115,997 \\
(938,276) \\
\end{array}$ & $\begin{array}{c}\$ 115,204 \\
(918,360) \\
\end{array}$ & $\begin{array}{r}\$ 134,568 \\
(1,074,758) \\
\end{array}$ & $\begin{array}{r}\$ 219,630 \\
(1,728,536) \\
\end{array}$ & $\begin{array}{r}\$ 245,345 \\
(1,915,768) \\
\end{array}$ \\
\hline $\begin{array}{l}\text { Oil and condensate: } \\
\text { Royalties } \\
\text { Production value }\end{array}$ & $\begin{array}{r}90,374 \\
(706,756)\end{array}$ & $\begin{array}{c}90,753 \\
(714,767)\end{array}$ & $\begin{array}{c}87,594 \\
(678,085)\end{array}$ & $\begin{array}{c}100,963 \\
(783,149)\end{array}$ & $\begin{array}{c}176,566 \\
(1,349,656)\end{array}$ & $\begin{array}{r}193,608 \\
(1,459,088)\end{array}$ \\
\hline
\end{tabular}


TABLE 50.-Royalties from oil and gas leases on Federal and Indian lands, calendar years 1970-75-Continued

\begin{tabular}{|c|c|c|c|c|c|c|}
\hline Commodity & 1970 & 1971 & 1972 & 1973 & 1974 & $\begin{array}{l}1975 \\
\text { (esti- } \\
\text { mated) }\end{array}$ \\
\hline Gas: & & & & & & \\
\hline $\begin{array}{l}\text { Royalties } \\
\text { Production value } \\
\text { Gasoline and } \mathrm{PG} \text {. }\end{array}$ & $\begin{array}{r}22,479 \\
(177,512)\end{array}$ & $\begin{array}{c}23,449 \\
(187,032)\end{array}$ & $\begin{array}{c}25,905 \\
(206,625)\end{array}$ & $\begin{array}{c}31,263 \\
(248,768)\end{array}$ & $\begin{array}{c}39,798 \\
(315,490)\end{array}$ & $\begin{array}{c}47,508 \\
(374,785)\end{array}$ \\
\hline $\begin{array}{l}\text { Royalties } \\
\text { Production value }\end{array}$ & $\begin{array}{r}1,564 \\
(31,617)\end{array}$ & $\begin{array}{c}1,771 \\
(35,921)\end{array}$ & $\begin{array}{r}1,686 \\
(33,226)\end{array}$ & $\begin{array}{c}2,323 \\
(42,398)\end{array}$ & $\begin{array}{c}3,238 \\
(62,758)\end{array}$ & $\begin{array}{r}3,789 \\
(76,632)\end{array}$ \\
\hline $\begin{array}{l}\text { All others: } \\
\text { Royalties } \\
\text { Production value }\end{array}$ & $\begin{array}{c}22 \\
(521)\end{array}$ & $\begin{array}{c}24 \\
(556)\end{array}$ & $\begin{array}{c}19 \\
(424)\end{array}$ & $\begin{array}{c}19 \\
(424)\end{array}$ & $\begin{array}{r}28 \\
(632)\end{array}$ & $\begin{array}{r}440 \\
5,263\end{array}$ \\
\hline
\end{tabular}

TABLE 51.-Mining operations on Federal and Indian lands by commodity, fiscal years 1970-75

\begin{tabular}{|c|c|c|c|c|c|c|}
\hline Activity and commodity & 1970 & 1971 & 1972 & 1973 & 1974 & 1975 \\
\hline $\begin{array}{l}\text { Total number leases supervised } \\
\text { Total area (acres in thousands) } \\
\text { Total number of producible mines } \\
\text { Total commodity production (tons in thousands) }\end{array}$ & $\begin{array}{r}2,491 \\
4,372 \\
414 \\
39,051\end{array}$ & $\begin{array}{r}2,566 \\
5,873 \\
405 \\
46,363\end{array}$ & $\begin{array}{r}2,647 \\
5,924 \\
343 \\
48,135\end{array}$ & $\begin{array}{r}2,579 \\
7,566 \\
338 \\
51,782\end{array}$ & $\begin{array}{r}2,488 \\
7,830 \\
377 \\
65,810\end{array}$ & $\begin{array}{r}2,479 \\
7,977 \\
435 \\
88,270\end{array}$ \\
\hline
\end{tabular}

Coal:

Number of leases supervised

Area (acres in thousands)

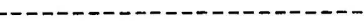

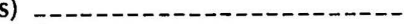

Percentage of domestic production

$\begin{array}{rrrrrr}548 & 558 & 560 & 561 & 563 & 56 \\ 782 & 903 & 934 & 1,038 & 977 & 1,02 \\ 12,044 & 17,263 & 18,966 & 24,247 & 32,139 & 43,59 \\ 2.0 & 3.1 & 3.2 & 4.1 & 5.4 & .2\end{array}$

Phosphate:

Number of leases supervised

Area (acres in thousands)

duction

otash:

Number of leases supervised

Area (acres in thousands)

Production (tons in thousands)

Percentage of domestic production

Sodium:

Number of leases supervised

Area (acres in thousands)

Percentage of domestic production

- - - - -

227

227
170
3,702

243
145
3,256
8.4

226
136
3,124
7.7

219
131
3,156
7.4

194
100
6.258
14.0

19
10
5,77
1.8

Oil shale:

Number of leases supervised

Area (acres in thousands)

Production (tons in thousands)

Other:

Number of leases supervised

Area (acres in thousands)

Production (tons in thousands)

(-

164
265
13,842

$\begin{array}{rr}159 & 164 \\ 250 & 249 \\ 14,175 & 12,476 \\ 81.6 & 72.0\end{array}$

$\begin{array}{cr}163 & 158 \\ 246 & 238 \\ 13,196 & 14,383 \\ 75.5 & 79.2\end{array}$

16

13,842

15,45

87.8

$\begin{array}{rrrrrr}91 & 91 & 87 & 84 & 84 & 8 \\ 138 & 138 & 133 & 132 & 132 & 132 \\ 2,390 & 2,230 & 2,606 & 2,336 & 2,092 & 2,82 \ell \\ 72.9 & 62.5 & 66.5 & 50.5 & 45.4 & 58.9\end{array}$

$\begin{array}{rrrrrr} & & & & & \\ -- & -- & -- & -- & 4 & 4 \\ -- & -- & -- & -- & 20.4 & 20.4 \\ & -- & -- & -- & -- & \\ 61 & 1,515 & 1,610 & 1,552 & 1,485 & 1,471 \\ 17 & 4,437 & 4,472 & 6,019 & 6,363 & 6,465 \\ 73 & 9,439 & 10,963 & 8,847 & 10,938 & 20,623\end{array}$

TABLE 52.-Revenues from mining leases on Federal and Indian lands by commodity, fiscal years 1970-75 [Dollars in thousands; detail may not add to totals because of rounding]

\begin{tabular}{|c|c|c|c|c|c|c|}
\hline Commodity & 1970 & 1971 & 1972 & 1973 & 1974 & 1975 \\
\hline Total revenue & $\$ 12,153$ & $\$ 21,851$ & $\$ 14,841$ & $\$ 16,484$ & $\$ 470,464$ & $\$ 31,59$ \\
\hline $\begin{array}{l}\text { Bonuses } \\
\text { Total royalties } \\
\text { Total production value }\end{array}$ & $\begin{array}{r}370 \\
11,783 \\
(244,184)\end{array}$ & $\begin{array}{r}7,627 \\
14,224 \\
(293,983) \\
\end{array}$ & $\begin{array}{r}14,841 \\
(301,665)\end{array}$ & $\begin{array}{r}34 \\
16,450 \\
(335,282)\end{array}$ & $\begin{array}{c}449,192^{1} \\
21,272 \\
(463,811)\end{array}$ & $\begin{array}{r}3 \\
31,56 \\
(681,28)\end{array}$ \\
\hline $\begin{array}{l}\text { Coal: } \\
\text { Royalties } \\
\text { Production value }\end{array}$ & $\begin{array}{r}1,760 \\
(48,064)\end{array}$ & $\begin{array}{c}2,654 \\
(70,552)\end{array}$ & $\begin{array}{c}3,119 \\
(78,256)\end{array}$ & $\begin{array}{c}4,044 \\
(93,307)\end{array}$ & $\begin{array}{c}5,535 \\
(140,307)\end{array}$ & $\begin{array}{c}8,33 \\
(224,94\end{array}$ \\
\hline
\end{tabular}


TABLE 52.- Revenues from mining leases on Federal and Indian lands by commodity, fiscal years 1970-75-Continued

\begin{tabular}{|c|c|c|c|c|c|c|}
\hline Commodity & 1970 & 1971 & 1972 & 1973 & 1974 & 1975 \\
\hline \multicolumn{7}{|l|}{ Phosphate: } \\
\hline $\begin{array}{l}\text { Royalties } \\
\text { Production value }\end{array}$ & $\begin{array}{r}952 \\
(10,755)\end{array}$ & $\begin{array}{c}838 \\
(9,669)\end{array}$ & $\begin{array}{r}811 \\
(9,674)\end{array}$ & $\begin{array}{r}842 \\
(11,314)\end{array}$ & $\begin{array}{c}1,618 \\
(31,158)\end{array}$ & $\begin{array}{r}1,538 \\
(28,383)\end{array}$ \\
\hline $\begin{array}{l}\text { Potash: } \\
\text { Royalties } \\
\text { Production value }\end{array}$ & $\begin{array}{r}2,880 \\
(65,480)\end{array}$ & $\begin{array}{r}3,695 \\
3,691\end{array}$ & 3,104 & 3,270 & 3,962 & 5,565 \\
\hline \multicolumn{7}{|l|}{$\begin{array}{l}\text { Sodium: } \\
\text { Sodiut }\end{array}$} \\
\hline $\begin{array}{l}\text { Royalties } \\
\text { Production value } \\
\text { Copper: }\end{array}$ & $\begin{array}{c}2,189 \\
(53,181)\end{array}$ & $\begin{array}{r}1,960 \\
(47,680)\end{array}$ & $\begin{array}{r}2,531 \\
(59,728)\end{array}$ & $\begin{array}{c}2,547 \\
(58,179)\end{array}$ & $\begin{array}{r}2,439 \\
(56,240)\end{array}$ & $\begin{array}{r}5,046 \\
(109,590)\end{array}$ \\
\hline $\begin{array}{l}\text { Copper: } \\
\text { Royalties }\end{array}$ & 180 & 198 & 153 & 158 & 563 & 1,331 \\
\hline \multicolumn{7}{|l|}{ Fluospar: } \\
\hline $\begin{array}{l}\text { Royalties } \\
\text { Production value }\end{array}$ & 14 & 40 & 70 & 86 & 31 & -. \\
\hline \multicolumn{7}{|l|}{ Lead and zinc: } \\
\hline Royalties & 1,431 & 1,765 & 1,695 & 2,192 & 3,241 & 5,109 \\
\hline \multicolumn{6}{|l|}{ Limestone: } & $(115,340)$ \\
\hline Royalties & 2 & 4 & 3 & 4 & & 10 \\
\hline 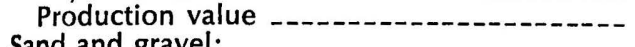 & (48) & (75) & (20) & (54) & (86) & (83) \\
\hline \multicolumn{7}{|l|}{ Sand and gravel: } \\
\hline $\begin{array}{l}\text { Royalties } \\
\text { Production value }\end{array}$ & 342 & 614 & 886 & 623 & 633 & 842 \\
\hline \multicolumn{7}{|l|}{$\begin{array}{l}\text { Silica-pumice: } \\
\text { Royalties }\end{array}$} \\
\hline Royalties _. & -- & -- & -- & 1 & -- & -- \\
\hline $\begin{array}{l}\text { Production value }-\ldots-.- \\
\end{array}$ & -- & -- & -- & (14) & -- & -- \\
\hline \multicolumn{7}{|l|}{$\begin{array}{l}\text { Uranium: } \\
\text { Royalties } \\
\text { Production value }\end{array}$} \\
\hline $\begin{array}{l}\text { Royalties } \\
\text { Production value }-1,-1\end{array}$ & $\begin{array}{r}1,838 \\
(15,743)\end{array}$ & $\begin{aligned} 2,176 \\
(18,370)\end{aligned}$ & $\begin{array}{r}2,205 \\
(18,394)\end{array}$ & $\begin{array}{c}2,303 \\
(18,822)\end{array}$ & $\begin{array}{c}2,224 \\
(22,014)\end{array}$ & $\begin{array}{r}2,664 \\
(16,938)\end{array}$ \\
\hline \multicolumn{7}{|l|}{ Zinc: } \\
\hline $\begin{array}{l}\text { Royalties } \\
\text { Production value }\end{array}$ & 130 & 206 & 214 & 336 & 936 & 1,066 \\
\hline \multicolumn{7}{|l|}{ Other: } \\
\hline Royalties & 65 & 75 & 50 & 42 & 84 & 56 \\
\hline Production value & $(3,272)$ & $(3,478)$ & $(2,546)$ & $(4,490)$ & $(5,146)$ & $(3,155)$ \\
\hline
\end{tabular}

1 Includes bonuses of $\$ 448,797,000$ from four competitive oil shale lease sales.

TABLE 53.-Information products ordered from the EROS Data Center, fiscal years 1973-75

\begin{tabular}{|c|c|c|c|c|c|c|}
\hline \multirow{2}{*}{ Product } & \multicolumn{2}{|c|}{1973} & \multicolumn{2}{|c|}{1974} & \multicolumn{2}{|c|}{1975} \\
\hline & Items & Dollars & Items & Dollars & Items & Dollars \\
\hline Totals & 165,023 & $\$ 374,318$ & 284,097 & $\$ 836,747$ & 414,084 & $\$ 1,609,842$ \\
\hline Landsat images ...- & 81,071 & 228,042 & 157,178 & $528 ; 514$ & 195,125 & 760,263 \\
\hline Landsat computer-compatible data tapes & & 1,600 & 228 & 36,480 & 879 & 169,300 \\
\hline $\begin{array}{l}\text { Leminl, Apollo, and Skylab images and photographs } \\
\text { Aerial photographs }\end{array}$ & 83,942 . & 144,676 & $\begin{array}{r}17,201 \\
109,490\end{array}$ & $\begin{array}{r}34,421 \\
237,332\end{array}$ & $\begin{array}{r}28,049 \\
190,031\end{array}$ & 566,806 \\
\hline
\end{tabular}

TABLE 54.-Number of jobs processed by Geological Survey computer faciliites, by organizational unit, fiscal years 197375

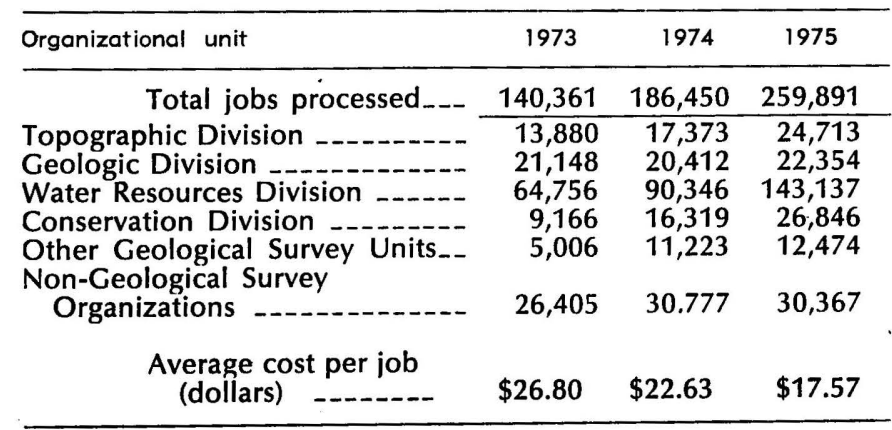


TABLE 55.-Geological Survey expenditures for automatic data processing services, fiscal years 1971-75 [Dollars in thousands]

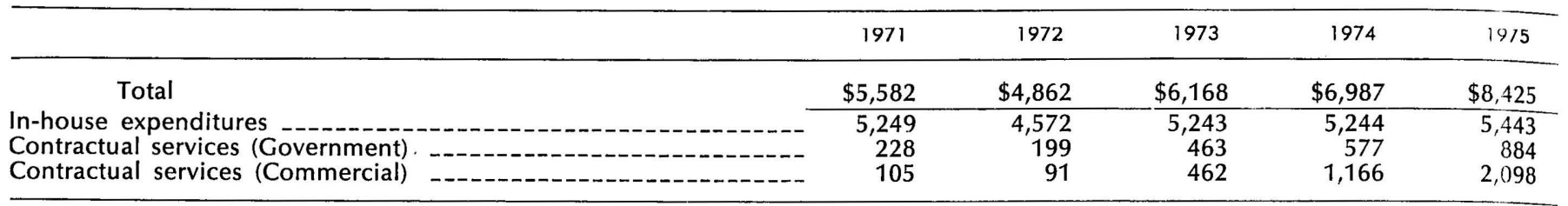

TABLE 56.-Geological Survey Library operating statistics, fiscal years 1970-751

[N.A., not applicable]

\begin{tabular}{|c|c|c|c|c|c|c|c|}
\hline Activity & 1970 & 1971 & 1972 & 1973 & 1974 & 1975 & $\begin{array}{l}\text { Estimated } \\
\text { total } \\
\text { holdings }\end{array}$ \\
\hline $\begin{array}{l}\text { Library acquisitions: } \\
\text { Total number of items }\end{array}$ & 70,955 & 80,401 & 94,445 & 84,208 & 91,047 & 136,106 & $1,864,000$ \\
\hline $\begin{array}{l}\text { Bound and unbound issues of periodicals and } \\
\text { serials } \\
\text { Books and monographs } \\
\text { Pamphlets and reprints } \\
\text { Single-sheet maps } \\
\text { Photographs and negatives } \\
\text { Aerial photographs } \\
\text { Field record notebooks and related materials }\end{array}$ & $\begin{array}{r}40,327 \\
7,274 \\
5,816 \\
12,723 \\
1,820 \\
2,768 \\
227\end{array}$ & $\begin{array}{r}47,194 \\
10,189 \\
5,221 \\
14,091 \\
2,568 \\
777 \\
361\end{array}$ & $\begin{array}{r}50,322 \\
7,693 \\
2,660 \\
19,817 \\
12,558 \\
1,100 \\
295\end{array}$ & $\begin{array}{r}45,499 \\
7,183 \\
2,425 \\
20,653 \\
7,121 \\
1,019 \\
308\end{array}$ & $\begin{array}{r}48,095 \\
11,600 \\
2,901 \\
19,439 \\
7,818 \\
812 \\
382\end{array}$ & $\begin{array}{r}49,775 \\
12,891 \\
2,798 \\
21,777 \\
3,485 \\
45,000 \\
380\end{array}$ & $\begin{array}{r}585,000 \\
315,(000 \\
350,000 \\
350,000 \\
200,000 \\
52,000 \\
12,000\end{array}$ \\
\hline New serial titles (number of titles) & 304 & 542 & 959 & 650 & 434 & 657 & N.A. \\
\hline $\begin{array}{l}\text { Library users: } \\
\text { Total number of visits }\end{array}$ & 43,900 & 42,497 & 47,744 & 45,526 & 43,948 & 52,092 & N.A. \\
\hline $\begin{array}{l}\text { Geological Survey users } \\
\text { Other users }\end{array}$ & $\begin{array}{r}38,577 \\
5,323\end{array}$ & $\begin{array}{r}35,897 \\
6,600\end{array}$ & $\begin{array}{r}39,141 \\
8,603\end{array}$ & $\begin{array}{r}37,211 \\
8,315\end{array}$ & $\begin{array}{r}37,327 \\
6,621\end{array}$ & $\begin{array}{r}46,210 \\
5,882\end{array}$ & $\begin{array}{l}\text { N.A. } \\
\text { N.A. }\end{array}$ \\
\hline $\begin{array}{l}\text { Library circulation: } \\
\text { Total number of items }\end{array}$ & 73,941 & 78,075 & 69,302 & 66,327 & 61,656 & 80,991 & N. A. \\
\hline $\begin{array}{l}\text { Books and periodicals } \\
\text { Maps }\end{array}$ & $\begin{array}{r}71,122 \\
2,819\end{array}$ & $\begin{array}{r}75,850 \\
2,225\end{array}$ & $\begin{array}{r}66,627 \\
2,675\end{array}$ & $\begin{array}{r}63,980 \\
2,347\end{array}$ & $\begin{array}{r}59,402 \\
2,254\end{array}$ & $\begin{array}{r}76,658 \\
4,333\end{array}$ & $\begin{array}{l}\text { N.A. } \\
\text { N.A. }\end{array}$ \\
\hline $\begin{array}{l}\text { Interlibrary loans: } \\
\quad \text { Total number of items }\end{array}$ & 19,634 & 18,548 & 19,156 & 16,308 & 15,252 & 20,356 & N.A. \\
\hline $\begin{array}{l}\text { Items loaned } \\
\text { Items borrowed }\end{array}$ & $\begin{array}{r}16,102 \\
3,532\end{array}$ & $\begin{array}{r}15,272 \\
3,276\end{array}$ & $\begin{array}{r}16,138 \\
3,018\end{array}$ & $\begin{array}{r}13,818 \\
2,490\end{array}$ & $\begin{array}{r}13,073 \\
2,179\end{array}$ & $\begin{array}{r}16,965 \\
3,391\end{array}$ & $\begin{array}{l}\text { N.A. } \\
\text { N.A. }\end{array}$ \\
\hline Reference queries & 12,091 & 13,302 & 13,093 & 11,358 & 14,047 & 14,774 & NA. \\
\hline
\end{tabular}

1 Statistics include the operations of the Survey's main library in
Reston, Va. and branch libraries in Denver, Colo.; Menlo Park, Calif.,

and Flágstaff, Ariz.

TABLE 57.-Publications Division operating statistics, fiscal years 1970-75

\begin{tabular}{|c|c|c|c|c|c|c|}
\hline Activity & 1970 & 1971 & 1972 & 1973 & 1974 & 195 \\
\hline $\begin{array}{l}\text { Number of public inquiries (thousands) } \\
\text { Book reports: }\end{array}$ & 127 & 143 & 154 & 155 & 179 & 244 \\
\hline $\begin{array}{l}\text { Number of books published } \\
\text { Number of copies distributed (thousands) } \\
\text { Number of booklets distributed (millions) }\end{array}$ & $\begin{array}{r}256 \\
527 \\
2.4\end{array}$ & $\begin{array}{r}204 \\
473 \\
2.2\end{array}$ & $\begin{array}{r}278 \\
464 \\
1.7\end{array}$ & $\begin{array}{r}173 \\
452 \\
1.8\end{array}$ & $\begin{array}{r}145 \\
399 \\
1.2\end{array}$ & $\begin{array}{r}1 \% 9 \\
315 \\
1.5\end{array}$ \\
\hline $\begin{array}{l}\text { Maps: } \\
\text { Number of maps printed } \\
\text { Number of copies printed (millions) } \\
\text { Number of copies distributed (millions) } \\
\text { Number of copies sold (millions) } \\
\text { Receipts from map sales (dollars in millions) }\end{array}$ & $\begin{array}{r}4,660 \\
16.9 \\
7.4 \\
5.0 \\
\$ 1.87 \\
497\end{array}$ & $\begin{array}{r}5,494 \\
19.1 \\
8.1 \\
5.6 \\
\$ 2.00 \\
480\end{array}$ & $\begin{array}{r}6,269 \\
18.2 \\
9.5 \\
6.2 \\
\$ 2.25 \\
533\end{array}$ & $\begin{array}{r}6,049 \\
21.0 \\
10.3 \\
7.2 \\
\$ 3.00 \\
628\end{array}$ & $\begin{array}{r}9,109 \\
20.0 \\
9.9 \\
7.3 \\
\$ 3.19 \\
625\end{array}$ & $\begin{array}{r}7,5.1 \\
18.3 \\
10.6 \\
7.8 \\
\$ 3.46 \\
792\end{array}$ \\
\hline
\end{tabular}

1 Books printed by the Government Printing Office

2 Book distributed for official use and without charge. Number does

not include copies distributed by the Government Printing Office.
4 Includes topographic index maps distributed for official use and without charge and maps sold over the counter and by mail.
5 Deposited to Miscellaneous Receipts in the U.S. Treasury. 


\section{CHRONOLOGY OF LEADERSHIP OF THE U.S. GEOLOGICAL SURVEY}

\begin{tabular}{|c|c|c|c|}
\hline YEAR & $\begin{array}{l}\text { PRESIDENT } \\
\text { OF THE } \\
\text { UNITED STATES }\end{array}$ & $\begin{array}{c}\text { SECRETARY, } \\
\text { DEPARTMENT OF THE INTERIOR }\end{array}$ & $\begin{array}{c}\text { DIRECTOR, } \\
\text { GEOLOGICAL SURVEY }\end{array}$ \\
\hline 1877 & Rutherford B. Hayes & Carl Schurz & \\
\hline 1879 & & & Clarence King \\
\hline 1881 & $\begin{array}{l}\text { James A. Garfield } \\
\text { Chester A. Arthur }\end{array}$ & Samuel J. Kirkwood & John Wesley Powell \\
\hline 1882 & & Henry M. Teller & \\
\hline 1885 & Grover Cleveland & Lucius Q. C. Lamar & \\
\hline 1888 & & William F. Villas & \\
\hline 1889 & Benjamin Harrison & John W. Noble & \\
\hline 1893 & Grover Cleveland & Hoke Smith & \\
\hline 1894 & & & Charles D. Walcott \\
\hline 1896 & & David R. Francis & \\
\hline 1897 & William McKinley & Cornelius N. Bliss & \\
\hline 1899 & & Ethan Allen Hitchcock & \\
\hline 1901 & Theodore Roosevelt & & \\
\hline 1907 & & James R. Garfield & George Otis Smith \\
\hline 1909 & William Howard Taft & Richard A. Ballinger & \\
\hline 1911 & & Walter L. Fisher & \\
\hline 1913 & Woodrow Wilson & Franklin K. Lane & \\
\hline 1920 & & John B. Payne & \\
\hline 1921 & Warren G. Harding & Albert B. Fall & \\
\hline 1923 & Calvin Coolidge & Hubert Work & \\
\hline 1928 & & Roy O. West & \\
\hline 1930 & Herbert Hoover & Ray L. Wilbur & \\
\hline 1931 & & & Walter C. Mendenhall \\
\hline 1933 & Franklin D. Roosevelt & Harold L. Ickes & \\
\hline 1943 & & & William E. Wrather \\
\hline 1945 & Harry S. Truman & & \\
\hline 1946 & & Julius A. Krug & \\
\hline 1949 & & Oscar L. Chapman & \\
\hline 1953 & Dwight D. Eisenhower & Douglas McKay & \\
\hline 1956 & & Fred A. Seaton & Thomas B. Nolan \\
\hline 1961 & John F. Kennedy & Stewart L. Udall & \\
\hline 1963 & Lyndon B. Johnson & & \\
\hline 1965 & & & William T. Pecora \\
\hline 1969 & Richard M. Nixon & Walter J. Hickel & \\
\hline 1971 & & Rogers C.B. Morton & Vincent E. McKelvey \\
\hline 1974 & Gerald R. Ford & & \\
\hline 1975 & & $\begin{array}{c}\text { Stanley K. Hathaway } \\
\text { Thomas S. Kleppe }\end{array}$ & \\
\hline
\end{tabular}




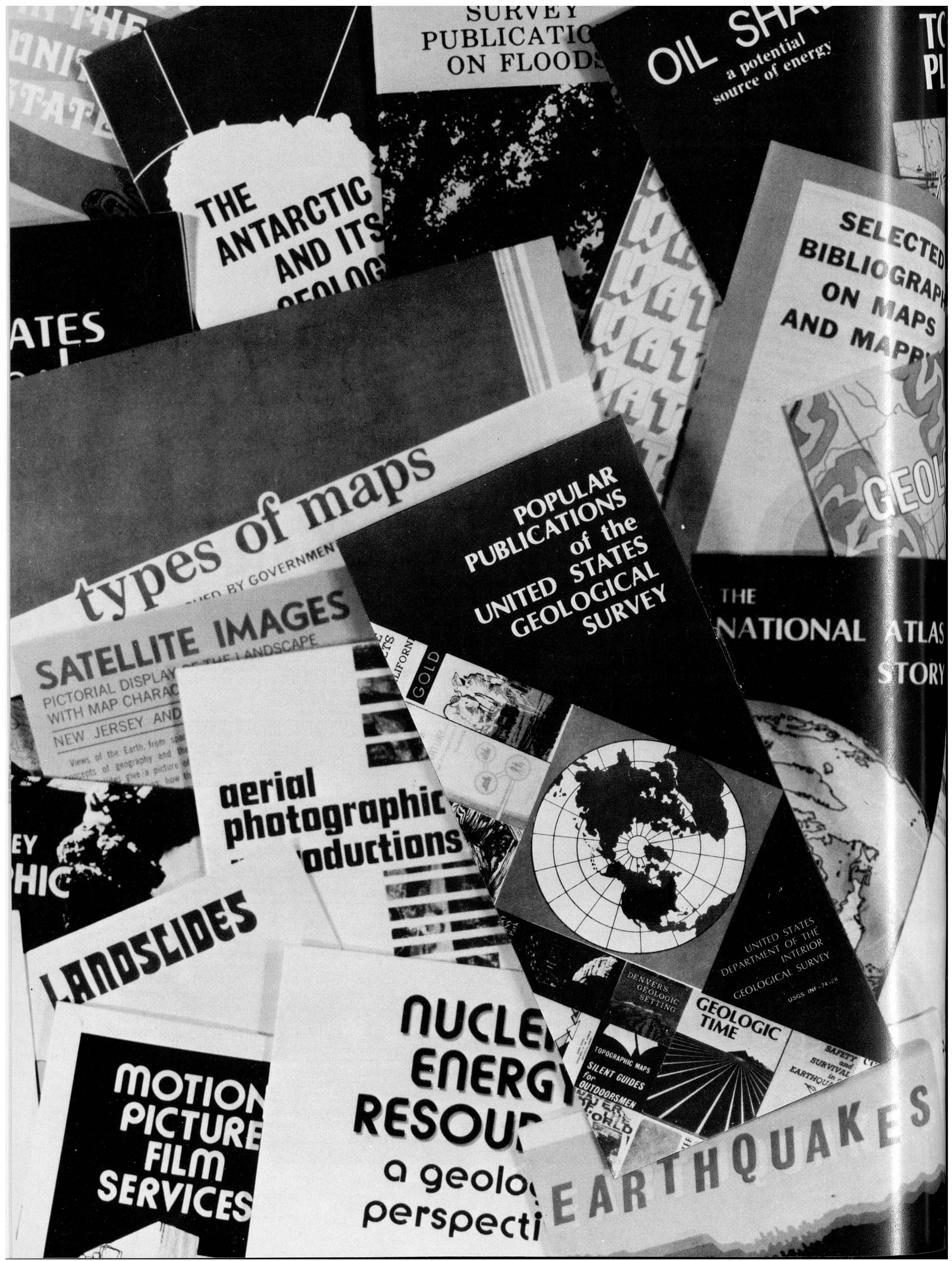




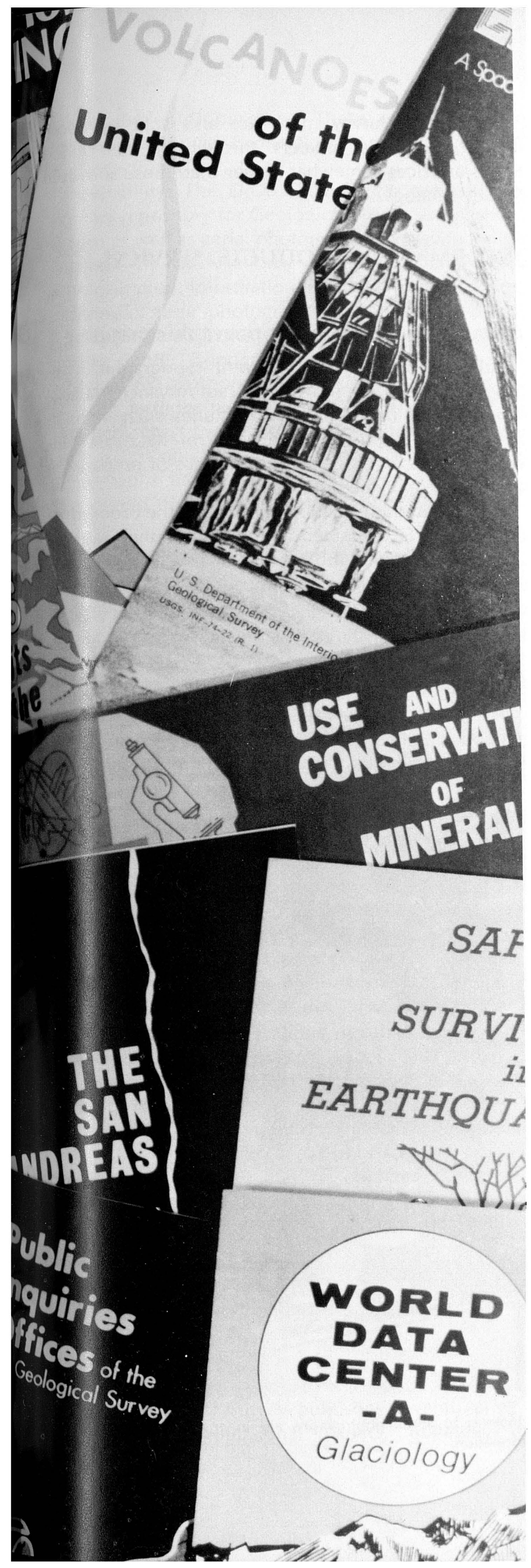

\section{Guide to Publications and Information Services}

Throughout this report reference has been made to information services and publications of the Geological Survey. This section lists the major publications series and information services provided by the Survey and describes how the public may acquire further information about them. Italicized items in the text refer to major headings in the list of information products, services, and sources.

\section{INSTRUCTIONS FOR ORDERING BOOK REPORTS AND MAPS}

Mail orders for Geological Survey publications must be accompanied by payment in the form of check or money order payable to "U.S. Geological Survey." Postage stamps are not accepted. Do not send cash. Remittances must be in United States currency. The list prices shown in Publications of the Geological Survey, New Publications of the Geological Survey, Topographic Map Indexes, and in other catalogs of Survey reports are subject to change. Prices include the cost of domestic surface transportation. For transmittal outside the U.S.A. (except to Canada and Mexico) a surcharge of 25 percent of the net bill should be included to cover surface transportation.

\section{Ordering books and monographs}

To order books, give the series designation and number, such as "Geological Survey Bulletin 738," and the full title. Professional Papers, Bulletins, WaterSupply Papers, Techniques of Water-Resources Investigations, bulk quantities of most nontechnical publications, and some miscellaneous reports, including some from all the foregoing series that have gone out of print at the Government Printing Office, may still be obtained from:

Branch of Distribution

U.S. Geological Survey

1200 South Eads Street

(703) 557-2751

Arlington, VA 22202 
or from Geological Survey Public Inquiries Offices (authorized agents of the Superintendent of Documents). Periodicals (Journal of Research of the U.S. Geological Survey, Earthquake Information Bulletin) can be obtained ONLY from:

\section{Superintendent of Documents \\ U.S. Government Printing Office \\ Washington, DC 20402.}

On orders of 100 copies or more of the same report sent to the same address, a 25-percent discount is allowed. Limited quantities of circulars and nontechnical publications may be obtained (usually free of charge) by writing to Public Inquiries Offices or the Branch of Distribution Offices. Open-File Reports, Topographic Instructions, Water-Resources Investigations reports, and reports available only through the National Technical Information Service may be ordered according to instructions under appropriate headings in this guide.

\section{Ordering maps}

To order maps give name or series designation and number such as "Fairfax, Va., 7.5-minute" or "GQ-851." Address mail orders to:

$\begin{array}{ll}\text { Branch of Distribution } & \text { (703) } 557-2751 \\ \text { U.S. Geological Survey } & \text { Hours: } 8: 00-4: 00 \\ 1200 \text { South Eads Street } & \\ \text { Arlington, VA } 22202 & \end{array}$

for maps of areas east of the Mississippi River, including Minnesota, Puerto Rico, and the Virgin Islands, and to:

$$
\begin{array}{ll}
\text { Branch of Distribution } & \text { (303) 234-3832 } \\
\text { U.S. Geological Survey } & \text { Hours: 8:00-4:00 } \\
\text { Box 25286, STOP 306 } & \\
\text { Denver Federal Center (Bldg. 41) } & \\
\text { Denver, CO 80225 } &
\end{array}
$$

for maps of areas west of the Mississippi River, including Alaska, Hawaii, Louisiana, Guam, and American Samoa.

Residents of Alaska may order Alaskan maps from:

$$
\begin{array}{ll}
\text { Distribution Section } & \text { (907) 452-1951 } \\
\text { U.S. Geological Survey } & \text { Hours: } 8: 00-5: 00 \\
310 \text { First Avenue } & \\
\text { Fairbanks, AK } 99701 . &
\end{array}
$$

On an order amounting to $\$ 300$ or more at the list price, a 30-percent discount is allowed; no other discount is applicable. The discount applies to all published maps and charts distributed by the Geological Survey.

\section{Over-the-counter services}

U.S. Geological Survey books may be obtained over the counter from all Public Inquiries Offices (except Reston, Va.) and from the Branch of Distribution Office in Arlington, $\mathrm{Va}$. Maps may be obtained over the counter from all Public Inquiries Offices, Branch of Distribution Offices, and the Mid-Continent and West-
Geological Survey maps are also sold by about 1,550 commercial dealers throughout the United States at prices somewhat higher than those shown in Survey catalogs.

\section{INFORMATION PRODUCTS, SERVICES, AND SOURCES}

\section{Advance material from topographic mapping}

Advance material from current topographic mapping is indicated on individual State Advance Material Indexes. This material, which includes such items as aerial photographs, geodetic control data, and advance copies of maps in various stages of preparation and editing, may be purchased.

Availability: Information concerning the ordering of these items is contained in the text of the State indexes. Requests for the indexes or inquiries concerning the availability of advance material should be directed to the Mapping Centers or to the National Cartographic Information Center.

\section{Aerial photographs}

The Geological Survey acquires vertical aerial photographs for use in topographic and geologic mapping. Contact prints, enlargements, and photoindexes

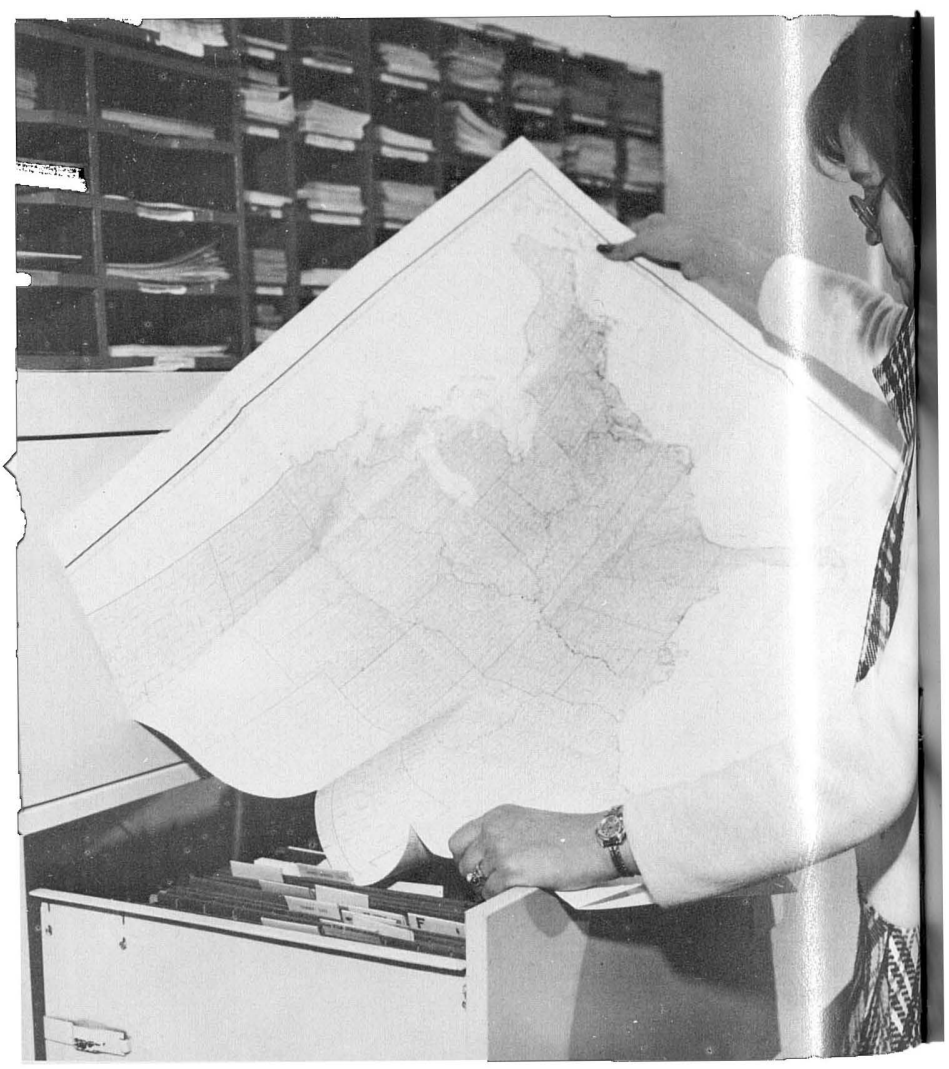

Indexes to aerial photographs aid in answering request for information. 
are available for purchase. These services are described in a Popular Publication, "Aerial Photographic Reproductions."

Availability: The EROS Data Center serves as the primary repository for Geological Survey aerial photographs as well as aerial photographs and space images acquired by the National Aeronautics and Space Administration. Information about the availability and ordering of aerial photographs may be obtained from the EROS Data Center, National Cartographic Information Center, Topographic Division Mapping Centers, and EROS Applications Assistance Facilities. All of these facilities have microfilm browse files of the data and access to the EROS Data Center's computerized index of aerial photographs. Special-purpose photographs may be purchased from the Photographic Library and the Glaciology-World Data Center-A.

\section{Alaska Technical Data Unit}

The Alaska Technical Data Unit maintains a reference library of maps, reports, field notebooks, and photographs related to the Geological Survey's fieldwork in Alaska.

Availability: Information on the use of this reference collection may be obtained from:

Technical Data Unit
Branch of Alaskan Geology
U.S. Geological Survey
345 Middlefield Road
Menlo Park, CA 94025 .

(415) 323-8111

ext. 2342

Hours: $7: 45-4: 15$

Menlo Park, CA 94025.

\section{Antarctic data}

The Scientific Committee on Antarctic Research (SCAR) maintains distribution centers for the exchange of Antarctic cartographic materials published by 12 member nations. The SCAR depository for the United States is operated by the National Cartographic Information Center. The SCAR files include two copies of all cartographic publications received from SCAR member nations and what is believed to be the world's largest collection of photographs of Antarctica (about 250,000 prints).

Availability: Information on Antarctic data and contact prints of Antarctic aerial photographs (acquired by the United States) may be obtained through the National Cartographic Information Center. Visits to the SCAR Mapping Center should be arranged through:

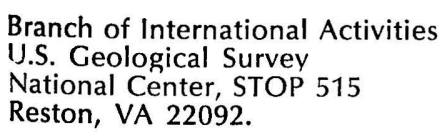

Branch of International Activities

U.S. Geological Survey

National Center, STOP 515

Reston, VA 22092.

\section{Books and reports}

The Geological Survey publishes several series of monographs, Professional Papers, Bulletins, and
Water-Supply Papers which present the results of geologic and hydrologic field investigations and research. Topographic Instructions and Techniques of Water Resources Investigations describe field and laboratory methods and procedures. Open-file reports and Water-Resources Investigations reports describe the results of field investigations and research which require immediate release for interim use pending publication or which have limited interest. These reports are listed in Publications of the Geological Survey. New reports are announced in New Publications of the Geological Survey.

Availability: Professional Papers, Bulletins, WaterSupply Papers, and Techniques of Water Resources Investigations are sold by Public Inquiries Offices, the Branch of Distribution Office, Arlington, Va., and the Superintendent of Documents (see "Instructions for ordering book reports and maps"). Instructions for obtaining Open-File Reports, Topographic Instructions, Water-Resources Investigations reports, and reports available only through the National Technical Information Service are given under the headings italicized above. Books and reports of the Geological Survey may be consulted in Geological Survey Libraries (see Library services) and in various Depository libraries.

\section{Branch of Distribution Offices}

The Geological Survey maintains three offices to distribute Survey publications and maps:

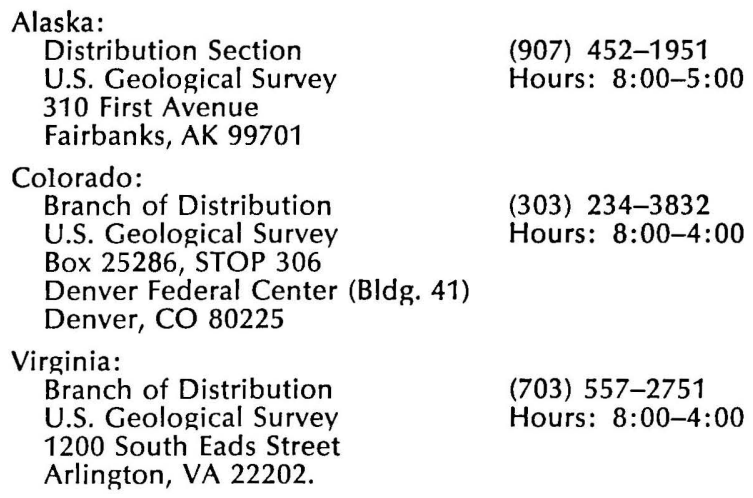

All mail orders for maps and publications should be sent to the Arlington, Va., office. All offices provide over-the-counter services for maps. Books may also be purchased over the counter from the Arlington, Va., office.

\section{Cartographic data}

See the National Cartographic Information Center.

\section{Catalog of Information on Water Data}

See Water data. 


\section{Circulars}

Circulars are informal Survey publications designed to present summary statements and reports of popular interest to a wide range of audiences. Circulars are listed in Publications of the Geological Survey. New circulars are announced in New Publications of the Geological Survey.

Availability: Circulars are free on application to the Public Inquiries Offices or to the Branch of Distribution Office in Arlington, Va.

\section{Depository libraries}

Many libraries throughout the United States are depository libraries of the Superintendent of Documents and maintain collections of Geological Survey publications and maps for reference by the general public. These libraries are listed on State list of publications on hydrology and geology and on the State Topographic Map Indexes.

\section{Earthquake data}

See National Earthquake Information Service.

\section{Earthquake Information Bulletin}

The Earthquake Information Bulletin is published bimonthly by the Geological Survey to provide current information on earthquakes and seismological activities of interest to both general and specialized readers. Correspondence and inquiries concerning the bulletin (other than subscription orders) should be directed to:

$$
\begin{aligned}
& \text { Earthquake Information Bulletin } \\
& \text { U.S. Geological Survey } \\
& \text { National Center, STOP } 904 \\
& \text { Reston, VA 22092. } \\
& \text { Availability: Subscriptions to the Butl } \\
& \text { rchased from: } \\
& \text { Superintendent of Documents } \\
& \text { U.S. Government Printing Office } \\
& \text { Washington, DC 20402. }
\end{aligned}
$$

Availability: Subscriptions to the Bulletin may be purchased from:

\section{Energy- and mineral-resources data files}

The Geological Survey has developed several energy- and mineral-resource data files, four of which are operational; the remaining files are in various stages of development. Computerized Resource Information Bank (CRIB) at present contains over 30,000 mineral-resource records for the United States (15 percent) and the rest of the world ( 85 percent). Each record contains data on location, products and byproducts, exploration and development history, geology and mineralogy, and bibliographic references.

The Rock Analysis Storage System (RASS) is a geochemical data bank containing limited geologic de-

of rocks. This file contains over 200,000 records and is increasing in size at a rate of 30,000 records per year.

The National Coal Resources Data System (NCRDS) is nearing completion of a 30,000-record inventory of coal resources and chemical analyses which are available by location, resource delimiters, or tonnage.

The Petroleum Data System contains approximately 68,000 records on oil and gas pools in the United States and Canada.

Availability: The CRIB and Petroleum Data System files are directly accessible by the public through commercial time-sharing computer systems. Some geochemical and geophysical data are also available from the National Technical Information Service on magnetic tape. Such data releases are announced in New Publications of the Geological Survey. For further information contact:

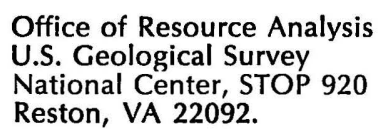

\section{EROS Applications Assistance Facilities}

The EROS Data Center operates several Applications Assistance Facilities which maintain microfilm copies of aerial photographs and space images siored at the Center. Scientific personnel are available to assist users in selecting the appropriate data to apply to a variety of resource and environmental prob ems and to assist users in ordering data through a computer inquiry system.

Availability: It is recommended that Applica ions Assistance Facilities be contacted by phone or $\mathrm{m}$ il in advance, so that suitable arrangements can be made for a visit if desired. EROS Applications Assistance Facilities are located in the following states:

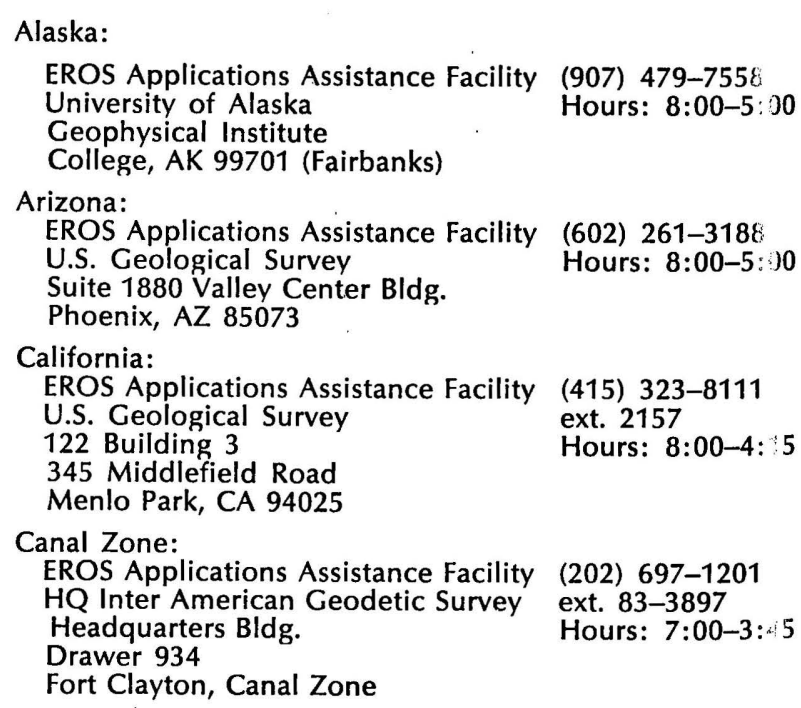




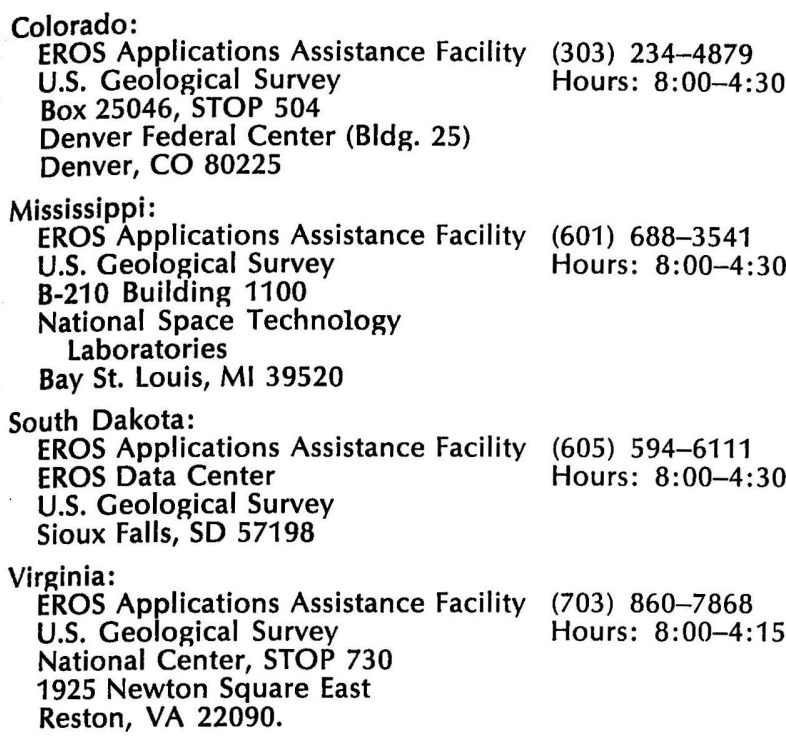

\section{EROS Data Center}

The Earth Resources Observation Systems (EROS) Data Center, located near Sioux Falls, South Dakota, provides remotely sensed data as well as user assistance to scientists, resource planners, managers, and the public. These data include aerial photographs acquired by the Department of the Interior and aerial photographs and images acquired by the National Aeronautics and Space Administration with research aircraft and with Landsat, Skylab, Apollo, and Gemini spacecraft. The primary functions of the Center are data storage and reproduction and user assistance and training. A Popular Publication, "The EROS Data Center," describes the operations, data products, services, and procedures for ordering remotely sensed data. Guidance in the use of remotely sensed data is available at the EROS Data Center in the form of scheduled training courses and workshops. The Center periodically offers courses on the application of remote sensing to such fields as agriculture, forestry, geography, geology, and hydrology. Visitors to the Center also receive assistance in the operation of specialized equipment such as densitometers, additive color viewers, zoom transfer scopes, and stereo viewers, and in the use of computerized multispectral systems to classify specific phenomena.

Availability: Orders for photographs and images may be placed directly with:

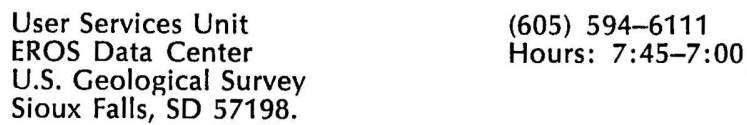

Microfilm copies of the data may be viewed at locations having EROS Data Reference Files. The microfilmed data may be viewed and orders for data may be placed at EROS Applications Assistance Facilities, the Topographic Division Mapping Centers in Menlo Park, Calif., Denver, Colo., and Rolla, Mo., and at the National Cartographic Information Center.

\section{EROS Data Reference Files}

The EROS Data Center has established EROS Data Reference Files at several locations in the United States to enable users to view microfilm copies of aerial photographs and space images available from the Center before placing an order by mail. Applications assistance is not provided.

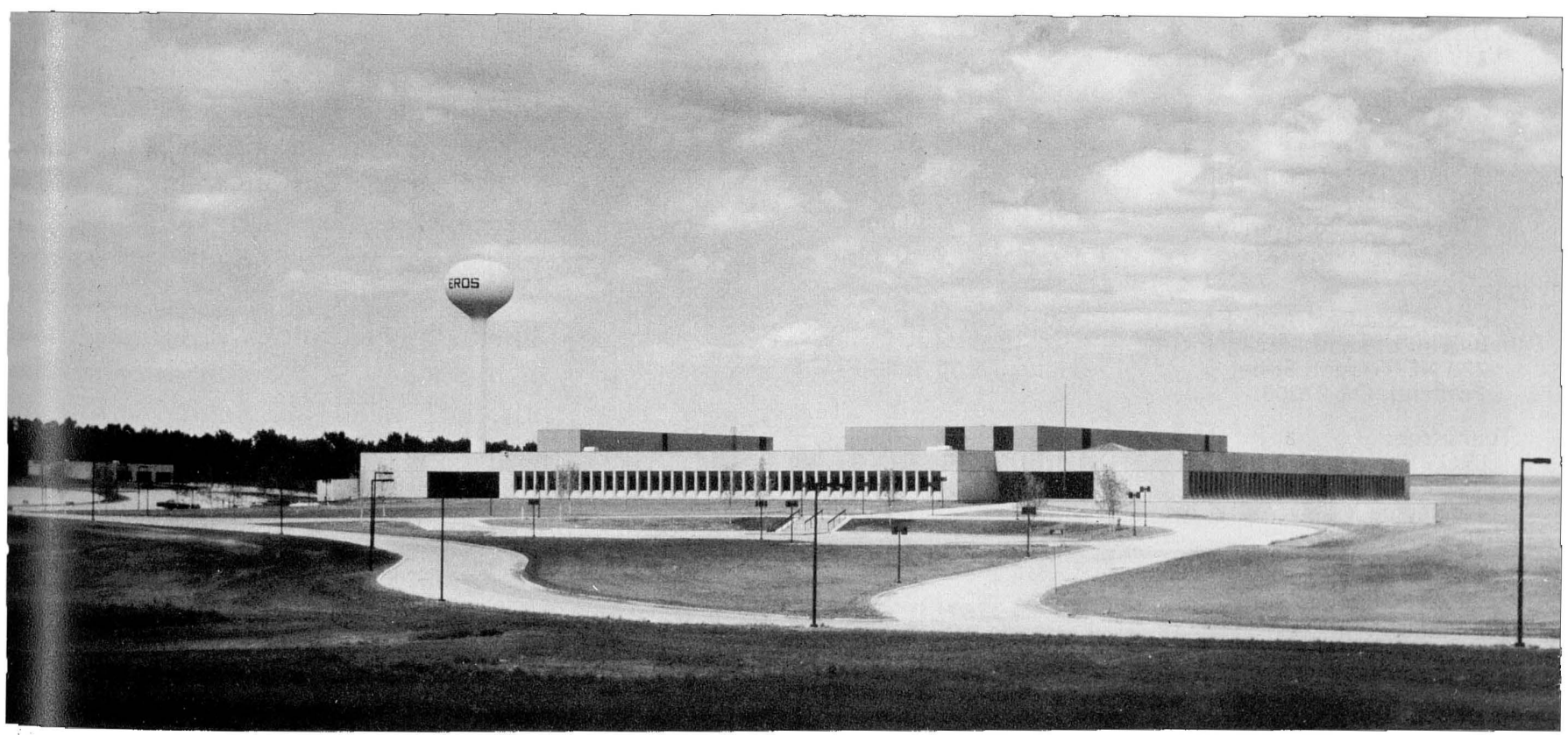

EROS Data Center, Sioux Falls, South Dakota. 
Availability: EROS Data Reference Files may be consulted at the following locations:

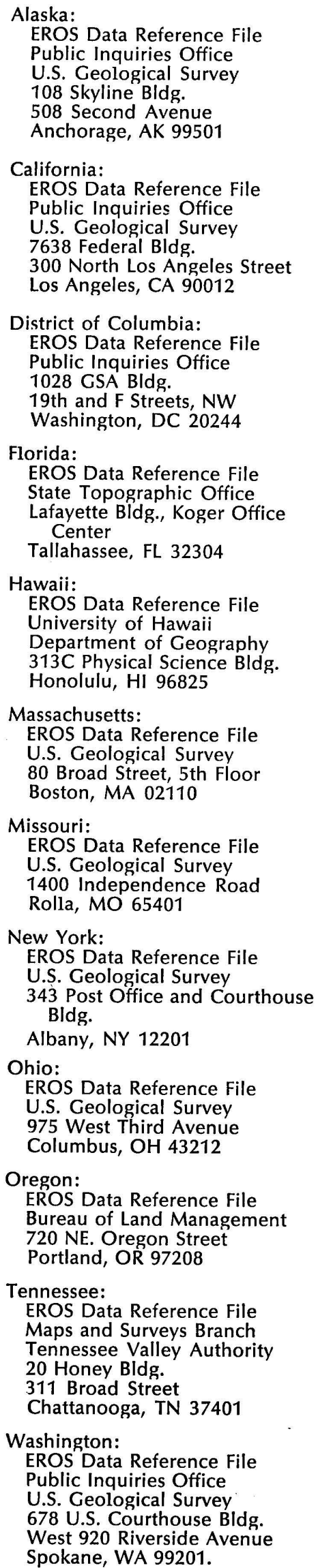

(907) 277-0577

Hours: 9:00-5:30

(213) 688-2850 Hours: $9: 00-4: 30$

(202) 343-8073 Hours: $8: 15-3: 45$

(904) 488-2168 Hours: $8: 15-5: 15$

(808) 944-8463 Hours: $8: 00-4: 00$

(617) 223-7202 Hours: 9:00-5:00

(314) 364-3680 ext. 111 Hours: 8:00-5:00

(518) 474-3107 Hours: $8: 00-4: 30$

(614) 469-5553 Hours: $8: 00-4: 30$

(503) 234-3361

ext. 4000

Hours: 8:00-4:00

(615) 755-2133 Hours: 8:00-4:00

(509) 456-2524 Hours: 9:00-4:30

\section{Flood information}

The Geological Survey collects basic information on the flow of streams, including the maximum flow during floods; studies areas that have been flooded frequently or with unusual severity; and conducts research on the magnitude, frequency, and other characteristics of floods in drainage basins throughout the United States. The basic information collected, the completed studies of areas, and the results of research are published as Water-Supply Papers, Hydrologic Investigations Atlases, or Circulars. Descriptions of monthly streamflow conditions and recent flood events in the U.S. appear in Water Resources Review. A Popular Publication, "U.S. Geological Survey Publications on Floods," describes each type of flood report and lists the publications since 1950.

The Survey, in cooperation with the U.S. Department of Housing and Urban Development, is currently conducting a mapping program to delineate the approximate flood boundaries of streams throughout the Nation. The information on flood-prone areas is presented on topographic quadrangle maps which serve as valuable guides for public agencies and private citizens concerned with future land development.

Availability: Flood-prone-area maps and leaflet are free and may be obtained by contacting the District Chief of the Water Resources Division at the U.S. Geological Survey's District Office in your state (p. 145).

\section{Geologic, hydrologic, and miscellaneous maps}

The Geological Survey publishes several series of technical maps that present geologic and hydro ogic data. The Hydrologic Investigations Atlases cortain information on hydrology and geohydrology in nap and graph form. Geologic Quadrangle Maps and riost Miscellaneous Geologic Investigations Maps are multicolored geologic maps. Other map series inciude Geophysical Investigations Maps, Oil and Gas Invstigations Maps and Charts, Mineral Investigations field Studies Maps, Mineral Investigations Resource Maps, Geologic Atlas of the Moon, Atlas of Mars, and special geologic maps, such as the Geologic Map of the United States. These maps are listed in Publications of the Geological Survey. New maps are announced in New Publications of the Geological Survey.

Availability: These maps may be consulted in Cieological Survey Libraries (see Library services) or Depository libraries. Maps may be purchased from Public Inquiries Offices or from the Branch of Distribution Office in Arlington, Va. (see "Instructions for ordering books and maps"'). 


\section{Glaciology- World Data Center-A}

The Geological Survey and the National Academy of Sciences operate one of three international data centers serving the field of glaciology. Located in Tacoma, Wash., World Data Center-A facilitates the international exchange of glaciological data and serves as a national information center for texts and pictures related to snow and ice research. A Popular Publication, "World Data Center-A: Glaciology," describes the facility which includes a research library, a photograph library, a map collection, and a historical collection of data on glacial variations and climatic changes. The Center provides copies of research papers and data upon request, on an exchange basis or at the cost of reproduction. Space and facilities are available for those who wish to examine the collection personally. For information contact:

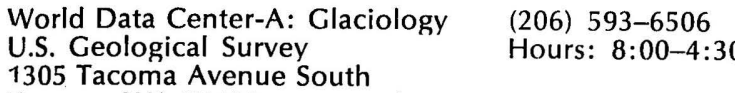

\section{Hydrologic maps}

See Geologic, hydrologic, and miscellaneous maps.

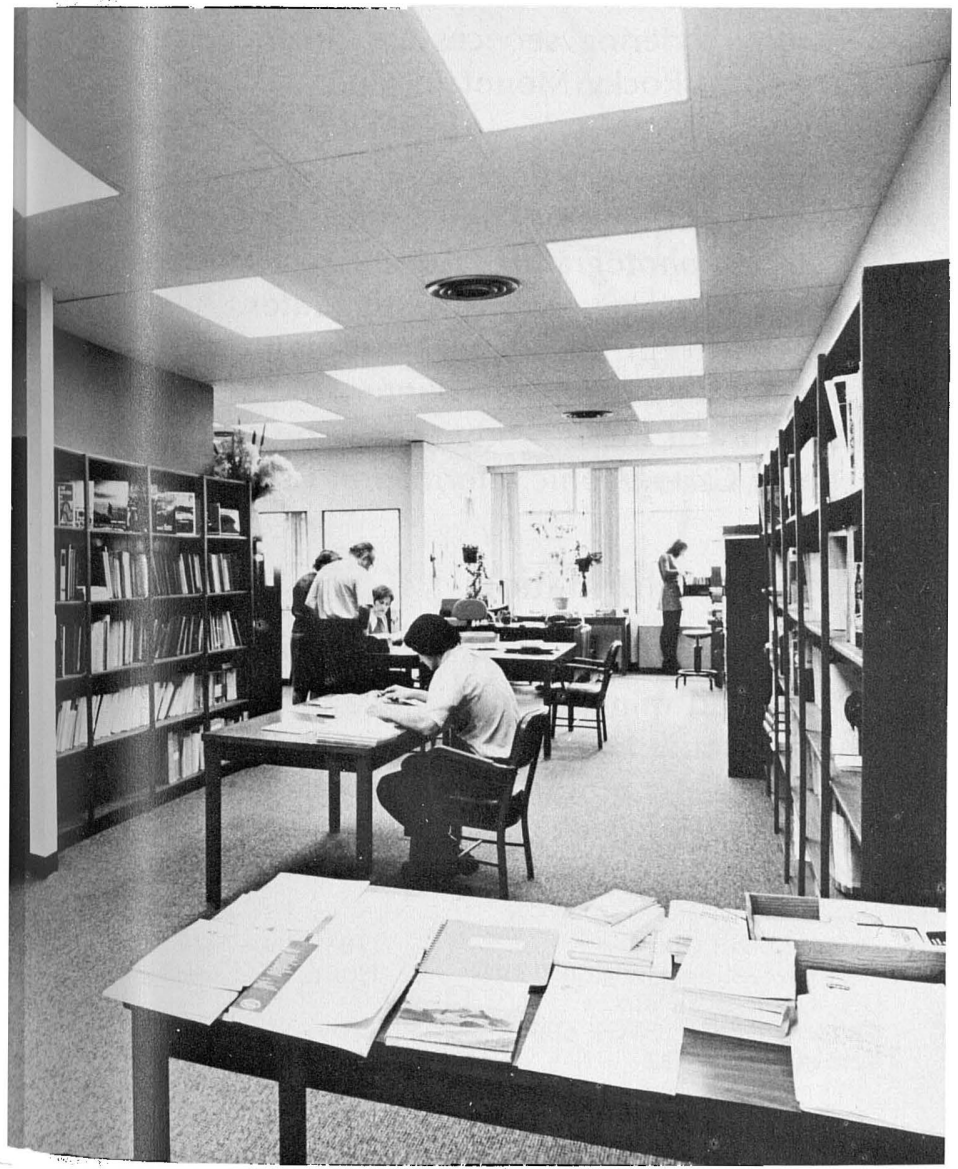

Reading room at World Data Center-A, Tacoma, Washington.

\section{Journal of Research of the U.S. Geological Survey}

The "Journal of Research of the U.S. Geological Survey" is a bimonthly periodical designed to provide relatively rapid publication of short scientific papers by Survey personnel.

Availability: Subscriptions and single issues can be purchased from:

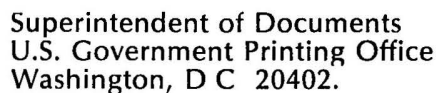

\section{Land use data}

See National Cartographic Information Center.

\section{Library services}

The Geological Survey Library is one of the largest earth-science libraries in the world. The main library is in Reston, Va.; three branch libraries are located in Denver, Colo.; Menlo Park, Calif.; and Flagstaff, Ariz. All libraries are open to the public. Librarians wishing to borrow books, periodicals, and maps for the use of their patrons are requested to use the approved American Library Association interlibrary loan form. A Popular Publication, "U.S. Geological Survey Library," describes the Library's collections.

Geological Survey libraries are located as follows:

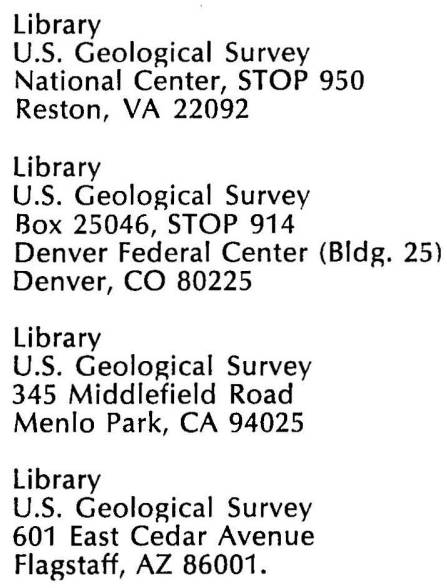

Libraries are closed on Saturdays, Sundays, and Federal holidays.

\section{Map reference libraries}

See Depository libraries.

\section{Map separates}

Special maps for special needs can be made from the scribed sheets which are used to produce the Geological Survey's Topographic Quadrangle Maps. Quadrangle maps are published in five colors-black, 


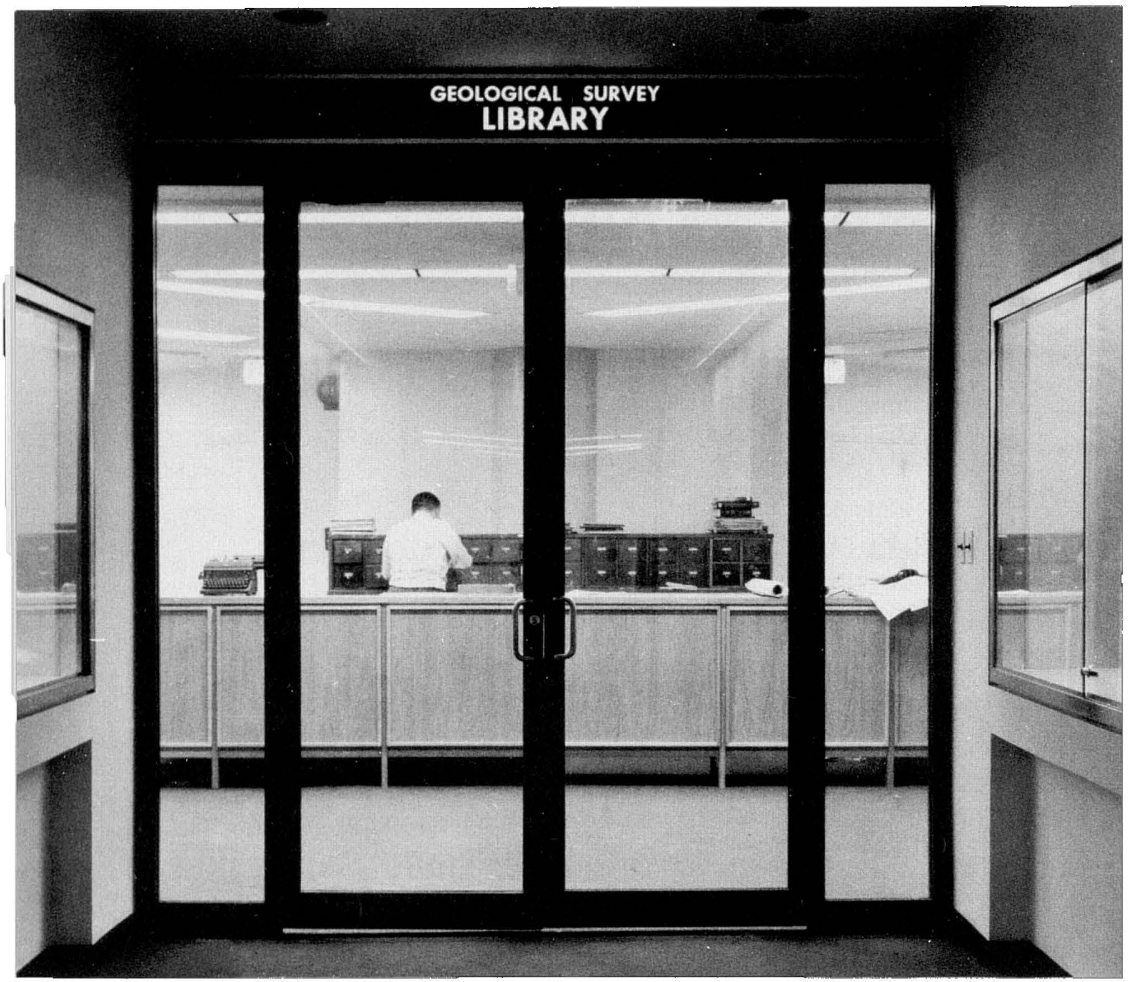

Entrance to National Center Library, Reston, Virginia.

brown, blue, red, and green. Each color is printed from a separate pressplate, and each pressplate is prepared from one or more scribed negatives called color separates. Film positive or negative copies of each individual color separate can be combined to make a single film positive or negative. The purchaser of film copy of color separates can then add or delete map detail by standard cartographic procedures. Limited base maps, street atlases, regional planning maps, and road maps are but a few of the special-purpose maps which can be prepared from the color separates.

Availability: Copies of color separates are available in either positive or negative form from the Topographic Division Mapping Center where the original materials are filed. Inquiries and orders may be made directly to the Mapping Center responsible for your geographic area of interest (fig. 61) or to the National Cartographic Information Center.

\section{Mapping Centers}

The Geological Survey's topographic mapping activities are conducted from four regional Mapping Centers and a Special Mapping Center (fig. 61):
Eastern Mapping Center U.S. Geological Survey National Center, STOP 567
(703) 860-6352 Hours: $7: 45-4: 15$
Mid-Continent Mapping Center

U.S. Geological Survey

1400 Independence Road

Rolla, MO 65401

Rocky Mountain Mapping Center

U.S. Geological Survey

Box 25046, STOP 510

Denver Federal Center (Bldg. 25)

Denver, CO 80225

Western Mapping Center

U.S. Geological Survey

345 Middlefield Road

Menlo Park, CA 94025

Special Mapping Cente

U.S. Geological Survey

National Center, STOP 560

1925 Newton Square East

Reston, VA 22090.

Alaska is assigned to the Rocky Mountain Mapping Center; Hawaii, including the Pacific Trust Territories, to the Western Mapping Center; and Puerto Rico, including the Virgin Islands (U.S.), to the Eastern Mapping Center.

Each Mapping Center, except the Special Mapping Center, functions as an extension of the National Cartographic Information Center by providing information to the public about Aerial photographs, space images, Advance materials from topographic mapping, Map separates, and other cartographic data. Microfilm copies of the aerial photographs and pace images stored at the EROS Data Center and computer-inquiry ordering services are provided $b$ ! the Mid-Continent, Rocky Mountain, and Western Mapping Centers.

The mapping centers publish Advance Material Indexes and accept inquiries and orders for Geol gical Survey Aerial photographs, Advance material from topographic mapping, and Map separates. All mapping centers except the Eastern Mapping Center sell topographic maps over the counter. Inquiries bout the availability of these products may be sent also to the National Cartographic Information Center.

\section{Mineral lease information}

The Geological Survey is responsible for regulating oil and gas and mineral lease operations on Federal and Indian lands. Information describing these programs, statistics on production and collected roy ties, reserve estimates, and other related information is available from:

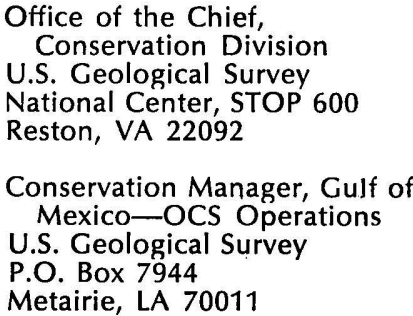

(703) 860-7524

(504) 837-4720

ext. 381

Hours: $8: 00-4: 30$ Hours: $7: 45-4: 15$ ext. 111

(303) 234-2351

Hours: $8: 00-4: 30$

(415) 323-8111

ext. 2411

(703) 471-1711
Hours: $7: 45-4: 15$ 
Conservation Manager,

Eastern Region

1725 K Street, N W., Suite 213

Washington, DC 20244

Conservation Manager, Central Region

U.S. Geological Survey

Box 25046, STOP 609

Denver Federal Center

Denver, CO 80225

Conservation Manager, Western Region

U.S. Geological Survey

345 Middlefield Road

Menlo Park, CA 94025.

\section{Motion picture films}

Geological Survey motion picture films, produced for educational and training purposes, are available for loan or purchase. Subjects range from popular accounts of volcanic eruptions to technical descriptions of procedures used in topographic, geologic, and hydrologic investigations. A Popular Publication, "Motion Picture Film Services of the U.S. Geological
Survey," describes the contents of currently available films and loan procedures.

Availability: These films are available on a free-loan, short-term (2-3 days) basis to educational institutions, professional and scientific societies, civic and industrial groups, and other established organizations. For further information contact:

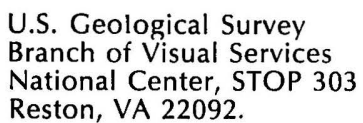

(703) 860-6171

(415) 323-8111

ext. 2563

Hours: $7: 45-4: 15$

Hours: $7: 45-4: 15$

Reston, VA 22092

\section{National Atlas}

The "National Atlas of the United States of Ameri$\mathrm{ca}^{\prime \prime}$ was published in 1970. The Atlas was compiled as a reference tool for use by public officials, business and industrial organizations, libraries, educational institutions, and scholars throughout the world who seek information about the United States. The 431page volume contains 336 pages of multicolored maps and an index with more than 41,000 entries. Twentyeight individual map sheets are available as separate sales items.

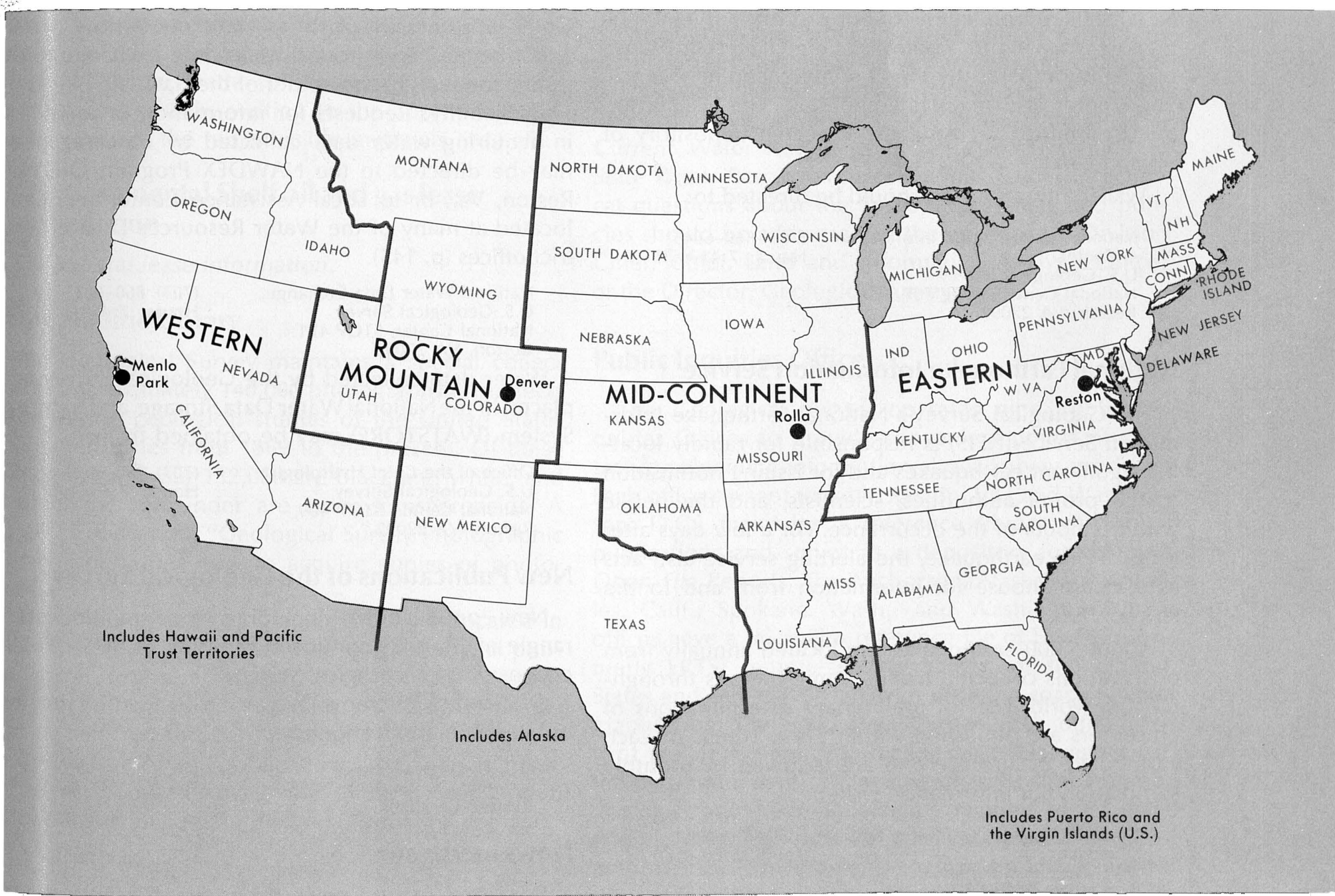


Availability: The National Atlas may be purchased at Public Inquiries Offices in Reston, Va., and Washington, D.C., or from the Branch of Distribution Office in Arlington, $\mathrm{Va}$.

\section{National Cartographic Information Center}

The National Cartographic Information Center (NCIC) provides a central source of information about U.S. maps and charts, aerial photographs and space images, geodetic control, land use data, and related cartographic data that are available from over 30 Federal agencies, all States, and many private organizations.

$\mathrm{NClC}$ collects and indexes information on these data holdings and assists users with finding and obtaining the data. $\mathrm{NCIC}$ provides a direct inquiry and ordering service for Aerial photographs and Space images from the EROS Data Center; provides information and accepts orders for Advance material from topographic mapping and Map separates held by the Topographic Division; and refers orders for Geological Survey maps to the Branch of Distribution Offices. $\mathrm{NCIC}$ sells reproductions of out-of-print Survey topographic maps and copies of digital terrain tapes originally prepared by the Defense Mapping Agency. The Center also maintains and staffs the U.S. Scientific Committee on Antarctic Research depository of Antarctic data.

Availability: Inquiries should be directed to:

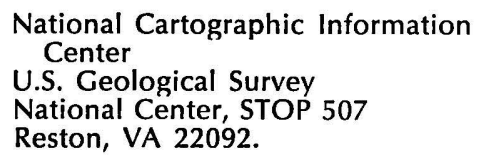

\section{National Earthquake Information Service}

The Geological Survey's National Earthquake Information Service (NEIS) is responsible for rapidly locating significant earthquakes and for issuing notification to the proper authorities, scientists, and the public within 2 hours of the occurrence. For a few days after a disastrous earthquake, the alerting service also acts as a clearinghouse for information from and to the stricken area.

About 5,000 earthquakes are located annually from observations collected from seismic stations throughout the world. Lists of preliminary determinations of epicenters are published within a few weeks of each earthquake occurrence and are followed by monthly summaries. For information write:

National Earthquake Information Service

U.S. Geological Survey

Box 25046, STOP 967

Denver Federal Center
(303) 234-3994

Hours: $8: 00-4: 30$

\section{National Technical Information Service}

Some Geological Survey reports, including computer programs, data and information supplemental to map or book publications, and data files, are released through the National Technical Information Service (NTIS). Reports available through NTIS include Water-Resources Investigations (generally of local interest) and Computer Contributions. Geological Survey reports that are released through NTIS, together with their NTIS order numbers and prices, are announced in New Publications of the Geological Survey.

Availability: These reports, available either in paper copies, in microfiche, or sometimes as magnetic tapes, can be purchased ONLY from:

\section{National Technical Information Service U.S. Department of Commerce} Springfield, VA 22161.

\section{National Water Data Exchange}

The National Water Data Exchange (NAWDEX) serves as a clearinghouse for hydrologic data accuired by Federal and non-Federal organizations which are members of NAWDEX. These organizations collect water information, such as data on surface water, water quality, and ground water; the exchange refers public requests to the holder of the data.

Availability: Requests for information or assistance in acquiring water data collected by other agencies may be directed to the NAWDEX Program Office in Reston, Va., or to Local Assistance Centers currently located at many of the Water Resources Division district offices (p. 145).

$\begin{array}{ll}\text { National Water Data Exchange } & \text { (703) } 860-6031 \\ \text { U.S. Geological Survey } & \text { Hours: } 7: 45-4: 15 \\ \text { National Center, STOP } 421 & \end{array}$

National Center, STOP 421

Water data collected by the Geological Survey and placed in the National Water Data Storage and Retrieval System (WATSTORE) may be obtained from:

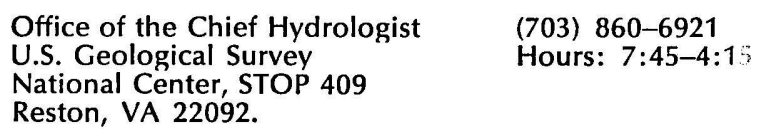

\section{New Publications of the Geological Survey}

New publications, including topographic cuadrangle maps, are announced monthly in "New fublications of the Geological Survey."

Availability: A free subscription to this list may be obtained on application to:
U.S. Geological Survey
National Center, STOP 329
(703) $860-6713$
Reston, VA 22092.
Hours: $7: 45-4: 15$

\section{News media services}

Press and feature news releases and related visual materials pertaining to Geological Survey activities 
and programs are prepared by the Survey's Information Office for use by the news media.

Availability: These materials may be obtained from:

$\begin{array}{ll}\text { Information Office } & \text { (703) } 860-7444 \\ \text { U.S. Geological Survey } & \text { Hours: } 7: 45-4: 15 \\ \text { National Center, STOP } 119 & \\ \text { Reston, VA 22092. } & \end{array}$

Reston, VA 22092.

\section{Oil and gas lease information}

See Mineral lease information.

\section{Open-File Reports}

Manuscript reports, maps, data, and other preliminary material are available for public use and consultation. Since May 1974, all reports and maps released only in the open files have been listed monthly in New Publications of the Geological Survey. Annual listings of reports issued prior to this date are published as Circulars ("Reports and maps of the Geological Survey released only in the open files").

Availability: Open-File Reports are available only for public inspection at one or more of the Geological Survey Libraries (see Library services), Public Inquiries Offices, and other depositories listed in "New Publications of the Geological Survey," Arrangements can generally be made to reproduce these reports at private expense by writing to the appropriate depository, where the reproducible materials are held.

\section{Outer Continental Shelf oil and gas lease information}

See Mineral lease information.

\section{Photographic Library}

The Geological Survey maintains a special collection of approximately 140,000 photographs of subjects taken during geological studies of the United States and its territories from 1869 to the present. Of these photographs, about 132,000 are black and white, and most of the remainder are color transparencies. A Popular Publication, "Geological Survey Photographic Library," describes how to acquire copies of photographs.

Availability: The Photographic Library is located in Denver, Colo., and may be used by the general public. Persons may select material from the collection for reproduction by visiting the library. Photographs may also be selected through a search of the illustrations in Geological Survey publications. A charge is made for prints, copy negatives, and duplicates of $35-\mathrm{mm}$ color transparencies. For further information contact:

\footnotetext{
Photographic Library

U.S. Geological Survey

Box 25046, STOP 914

Denver Federal Center (Bldg. 25)

Denver, CO 80225.
}

\section{Popular Publications}

In addition to its technical publications, the Geological Survey also publishes a series of popular publications to inform the general public and to answer inquiries about geology, hydrology, topographic mapping, and related earth sciences. Currently available booklets are listed in a catalog "Popular Publications of the Geological Survey."

Availability: Single copies of the catalog and any popular publication are available free on request from Public Inquiries Offices or Branch of Distribution Offices. Additional copies or bulk quantities may be purchased from the Branch of Distribution Office in Arlington, Va.

\section{Program information}

Technical programs of the Geological Survey are carried out by the Topographic, Geologic, Water Resources, and Conservation Divisions and the Land Information and Analysis Office. Information about current program activities may be obtained from several sources. Questions of a general nature should be directed to the Public Inquiries Offices. Questions about current Geological Survey activities in a particular State should be referred to the Survey's Water Resources Division District Office in that State (p. 145). Current Water Resources projects are described in State Water-Resources Investigations Folders. Technical questions about the Survey's programs and policies should be addressed to the appropriate Division Chief; Chief, Land and Information Analysis Office; or the Director, Geological Survey (p. 143).

\section{Public Inquiries Offices}

The Geological Survey operates nine Public Inquiries Offices to provide convenient points of contact for obtaining information about Survey products. Each office (except those in Reston, Va., and Washington, D.C.) maintains a reference library of Survey publications and serves as a depository for selected Open-File Reports. The Anchorage, Alaska; Los Angeles, Calif.; Spokane, Wash.; and Washington, D.C., offices have a microfilm reference file of Landsat (formerly ERTS) remote-sensing images of the United States and can assist users with ordering space photographs from the EROS Data Center. Each office (except that in Reston, Va.), acting as a sales agent for the Superintendent of Documents, sells topographic, geologic, and hydrologic maps relating to its geographic area, and book reports and maps of general interest. Mail orders for maps should be sent to the appropriate Branch of Distribution Office. Public Inquiries Offices are located in the following states: 
Alaska:

Public Inquiries Office

U.S. Geological Survey

108 Skyline Bldg.

508 Second Avenue

Anchorage, AK 99501

California:

Public Inquiries Office

U.S. Geological Survey

7638 Federal Bldg.

300 North Los Angeles Street

Los Angeles, CA 90012

Public Inquiries Office

U.S. Geological Survey

504 Custom House

555 Battery Street

San Francisco, CA 94111

Colorado:

Public Inquiries Office

U.S. Geological Survey

1012 Federal Bldg.

1961 Stout Street

Denver, CO 80202

District of Columbia:

Public Inquiries Office

U.S. Geological Survey

1028 GSA Bldg.

19 th and F Streets NW.

Washington, DC 20244

Texas:

Public Inquiries Office

U.S. Geological Survey

1C45 Federal Bldg.

1100 Commerce Street

Dallas, TX 75202

Utah:

Public Inquiries Office

U.S. Geological Survey

8102 Federal Bldg.

125 South State Street

Salt Lake City, UT 84138

Virginia:

Public Inquiries Office

U.S. Geological Survey

1C402 National Center, STOP 302

12201 Sunrise Valley Drive

Reston, VA 22092

\section{Washington:}

Public Inquiries Office

U.S. Geological Survey

678 U.S. Courthouse

West 920 Riverside Avenue

Spokane, WA 99201.

\section{Publications of the Geological Survey}

Results of research and investigations by the Geological Survey are made available to the public through Professional Papers, Bulletins, Water-Supply Papers, Circulars, miscellaneous reports, and several map and atlas series. All books, maps other than topographic quadrangle maps, and related Survey publications are listed in the catalogs, "Publications of the Geological Survey, 1879-1961" and "Publications of the Geological Survey, 1962-1970." Yearly supplements keep these catalogs up to date (see also New

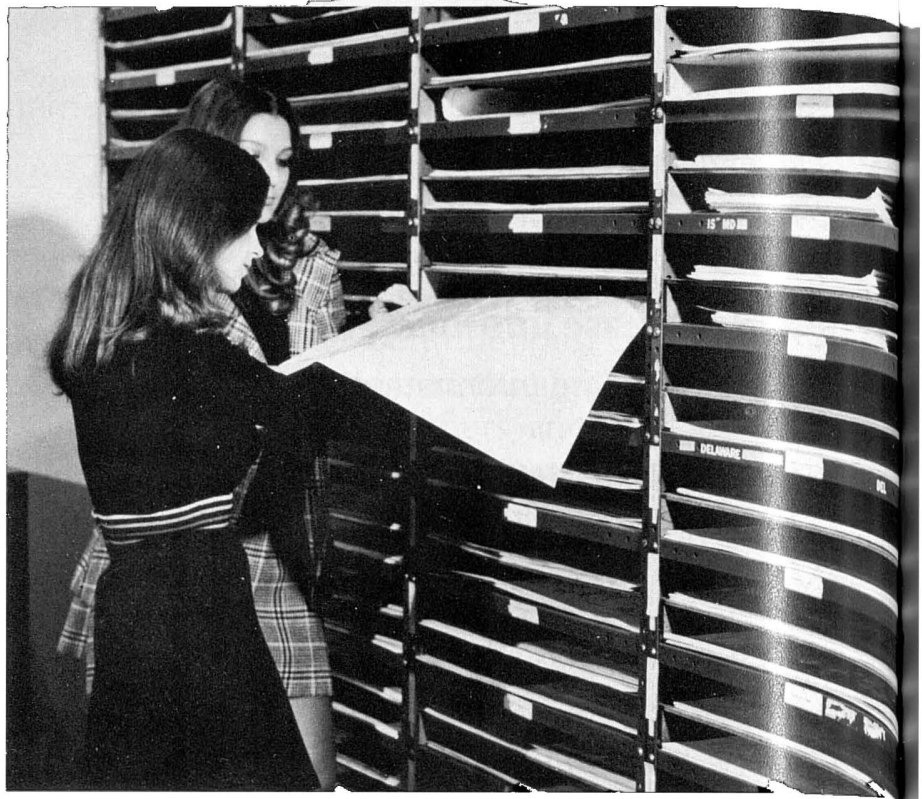

Selecting maps from stock at a Public Inquiries Office.

Availability: The catalogs and annual supplements are available free on request from Geological survey Public Information Offices and Branch of Distrikution Offices.

\section{Reports}

See Books and reports.

\section{Satellite image maps}

Satellite images are converted into a map by fitting a common reference grid to the image or mosaic. The Geological Survey publishes satellite-image mips at scales of $1: 250,000$ and $1: 500,000$ and in variols experimental formats and renditions of the images.

Availability: Contact the National Cartographic Information Center for information on map coverage. Satellite image maps may be purchased from lublic Inquiries Offices and from the Branch of Distrib:tion Office at Arlington, Va.

\section{Space images}

See the EROS Data Center.

\section{State list of publications on hydrology and geology}

"Geologic and Water-Supply Reports and Naps, (State)," list Geological Survey publications by state and give the location of Depository libraries where Survey reports and maps may be consulted.

Availability: They are available free on request from Public Inquiries Offices and from the Branch of Distribution Office at Arlington, Va. 


\section{State Water-Resources Investigations Folders}

A series of folders entitled "Water-Resources Investigations in (State)" inform the public about the current water-resources program of the Geological Survey in the 50 States and Puerto Rico, the Virgin Islands, Guam, and American Samoa.

Availability: The folders are available free on request from Survey Water Resources Division District Offices (p. 145) or from:

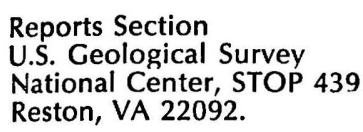

\section{Technical exhibits}

More than 200 exhibit panels are available on loan from the Geological Survey for display at professional meetings, technical conventions, and other public gatherings. These panels illustrate recent work of the Geological Survey in conservation, geology, hydrology, and topography. Structural supports and lighting for free-standing displays are provided.

Availability: Geological Survey exhibit panels are available on loan. For information contact any one of the following offices:

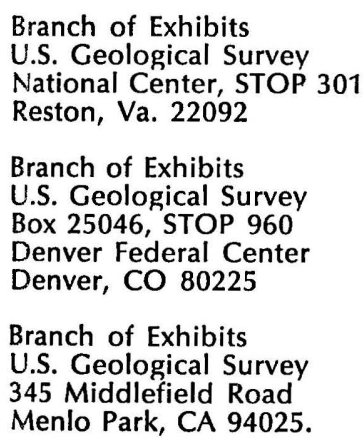

(703) 860-6010 Hours: $7: 45-4: 15$

(303) 234-3566

Hours: 8:00-5:00

(415) 323-8111

ext. 2389

Hours: 7:45-4:15

\section{Techniques of Water-Resources Investigations}

Techniques of Water-Resources Investigations describe the methodology and techniques used by the Geological Survey to collect, analyze, and process hydrologic data. These reports are listed in Publications of the Geological Survey. New reports are announced in New Publications of the Geological Survey.

Availability: Techniques of Water-Resources Investigations are sold by Public Inquiries Offices, Branch of Distribution Office, Arlington, Va., and the Superintendent of Documents (see "Instructions for ordering book reports and maps").

\section{Topographic Instructions}

Topographic Instructions describe the techniques and criteria used by the Geological Survey to obtain aerial photographs, make field surveys, and compile

topographic maps. These reports are listed in Publications of the Geological Survey. New reports are announced in New Publications of the Geological Survey.

Availability: Topographic Instructions can be obtained ONLY from:

Technical Information Office

U.S. Geological Survey

National Center, STOP 520

Reston, VA 22092

\section{Topographic maps}

The Geological Survey publishes the national topographic map series, which consists of several quadrangle and other map series. They include quadrangle maps at scales of $1: 24,000,1: 20,000$ (Puerto Rico), $1: 62,500,1: 63,360$ (Alaska), 1:100,000, 1:250,000, and $1: 1,000,000$. In addition there are metropolitan-area maps, county maps, National Park maps, State and U.S. base maps, maps of Antarctica, and special maps of principal rivers and their flood plains. Orthophotoquads, Satellite image maps, and other special-purpose maps are also published by the Survey. Topographic Map Indexes showing the coverage of published maps for each State are available free upon request. See also Advanced material available from topographic mapping and Map separates.

Availability: Topographic maps may be consulted in Geological Survey Libraries (see Library services) or Depository libraries. Maps may be purchased over the counter from Public Inquiries Offices or from Branch of Distribution Offices (see "Instructions for ordering books and maps"). Information about the availability of maps published by the Geological Survey or maps available from other agencies may be obtained from the National Cartographic Information Center.

\section{Topographic Map Indexes}

State index maps, "Index to Topographic Mapping in (State)," show the location of available 7.5-minute quadrangles $(1: 24,000)$ and 15-minute quadrangles $(1: 62,500)$. In addition, the indexes list other special maps and sheets pertinent to a particular State and of general interest. Depository libraries, where published maps of the Geological Survey may be consulted, and commercial dealers, who carry in stock some or all of the maps described in the index, are also listed.

Availability: State index maps are available free on request from Public Inquiries Offices, the National Cartographic Information Center, regional Mapping Centers, and the Branch of Distribution Office at Arlington, Va.

\section{Water data}

The Geological Survey collects a wide range of water-related information (see also Flood information). Much of this information is stored in computer 
files soon after it is collected and can be retrieved by computer terminals located in most Water Resources Division District Offices. Much of the data is also published annually for each State.

Beginning with the 1960 water year (October 1, 1959), daily streamflow records, discharge measurements, reservoir contents, and station descriptions have been published annually on a State-boundary basis in "Water Resources Data for (State): Part 1, Surface Water Records." The data are also published in Water-Supply Papers at 5-year intervals. The first group of "Surface Water Supply" papers covers the water years 1961-65.

Indexes, which list all streamflow and reservoir stations for which records have been published in Geological Survey reports through September 30, 1970, are titled "Index of Surface Water Records to September 30, 1970-Part (number and basin)."

Annual publication of water-quality records began in 1964 with "Water Resources Data for (State): Part 2, Water Quality Records." The annual publication in the Geological Survey Water-Supply Papers of "Quality of Surface Water of the United States" by drainage basins has been continued. Distribution of the State water-resources data (parts 1 and 2) is limited.

Availability: Inquiries about the availability of water data collected by the Geological Survey should be directed to the Survey's Water Resources Division District Office in the appropriate State. Similarly, requests for free copies of "Water Resources Data for (State)" should also be addressed to the appropriate District Office (p. 145). Indexes of surface-water records are published as Circulars.

Information about Federal, State, and local agency collection of various water data is available in three national indexes to the "Catalog of Information on Water Data" supplemented by index maps showing the location of water-data-collection sites. Current editions of the indexes are as follows: (1) Station listings for streamflow and stage, quality of surface water, and quality of ground water, 1974 (21 volumes by water-resources regions); (2) index to areal investigations and miscellaneous water-data activities, 1970 (one volume); and (3) index to ground-water stations,
1968 (one volume). These indexes are available free on request. Address inquiries to:

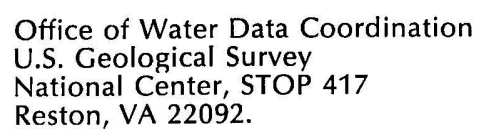

Assistance in determining the availability of water data may be obtained from the National Water Data Exchange. Inquiries about accessing or purchasing magnetic tape copies of Survey water-data files should be addressed to:

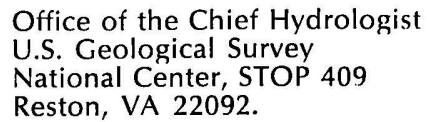

\section{Water-Resources Investigations reports}

Water-Resources Investigations reports describe the results of investigations which are principally of local interest, such as the water resources of intrastate river basins, counties, or specific sites. Reports are listed in Publications of the Geological Survey. New reports are announced in New Publications of the Geological Survey.

Availability: Most Water-Resources Investications reports are microfilmed and are available from the National Technical Information Service. Selected reports are not sold but may be examined a local Geological Survey offices listed in New Publications of the Geological Survey and at:

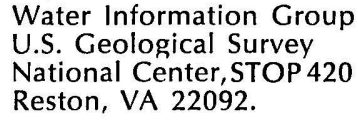

\section{Water Resources Review}

The Water Resources Review, prepared in cooperation with the Canadian Department of the. Erivironment, is a monthly summary of streamflow and ground-water conditions, reservoir content;, and other water data of current interest to the United States and southern Canada. Special-purpose issues describing floods or other hydrologic events and summary issues are published as needed.

Availability: Subscriptions are free on request to:

Water Resources Review

U.S. Geological Survey

National Center, STOP 419

(703) 860-6884

Reston, VA 22092. 



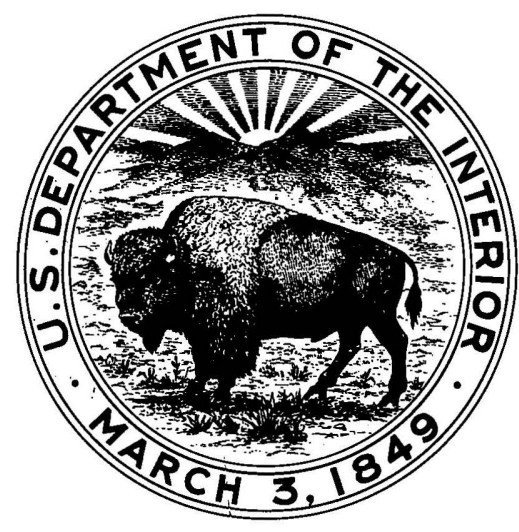

As the Nation's principal conservation agency, the Department of the Interior has responsibility for most of our nationally owned public lands and natural resources. This includes fostering the wisest use of our land and water resources, protecting our fish and wildlife, preserving the environmental and cultural values of our national parks and historical places, and providing for the enjoyment of life through outdoor recreation. The Department assesses our energy and mineral resources and works to assure that their development is in the best interest of all our people. The Department also has a major responsibility for American Indian reservation communities and for people who live in Island Territories under U.S. Administration.

Cover photograph of the USGS National Center courtesy of Edward B. Templeman, USGS 


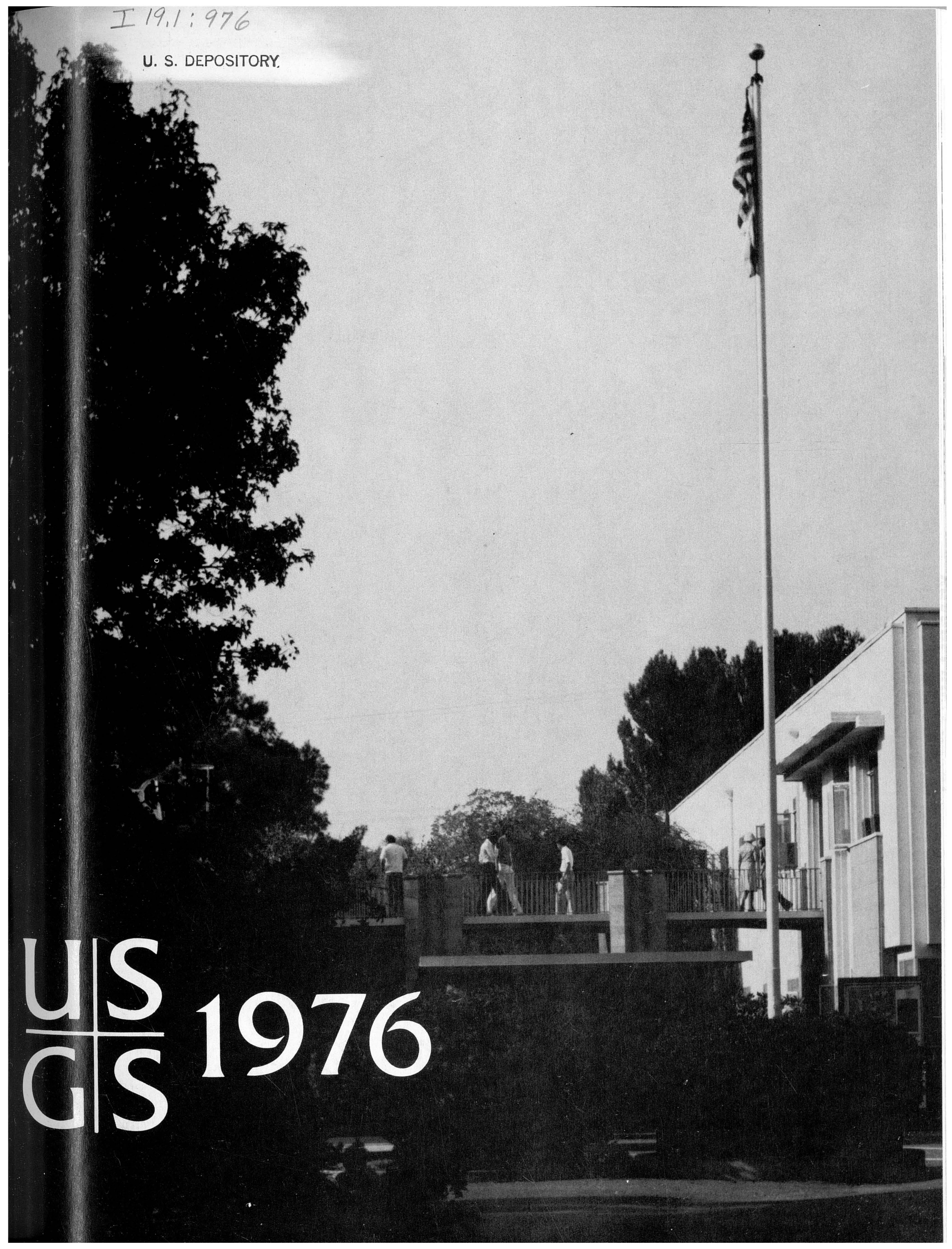





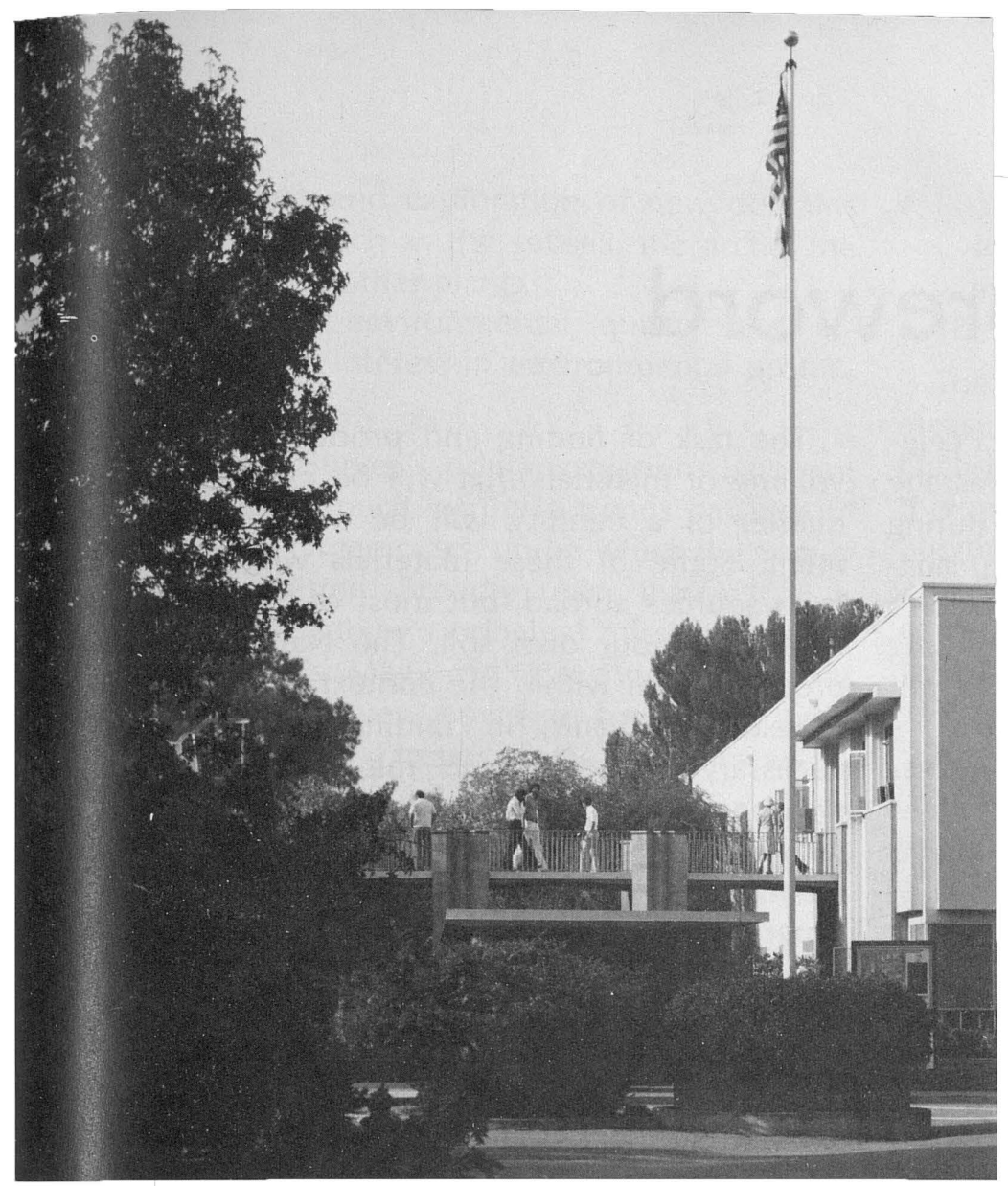

United States

Geological Survey

Annual Report,

Fiscal Year 1976

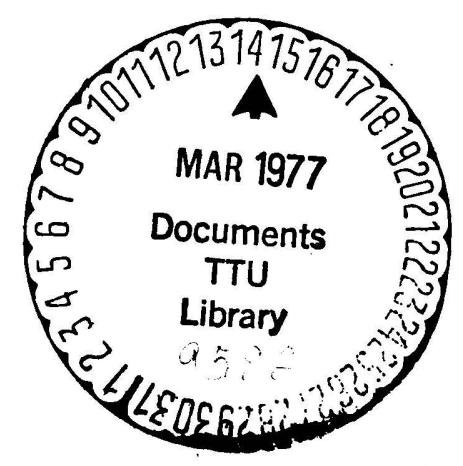




\section{Foreword}

On July 4, 1976, the United States of America celebrated its Bicentennial. This report summarizes the progress made by the U.S. Geological Survey during the last year of the Bicentennial in collecting, analyzing, and publishing information about the Nation's mineral, water, and land resources and in supervising mineral operations authorized by lease and permit on the Federal lands.

As the Nation reflects on its first 200 years of history, the Geological Survey would like to call attention to the years ahead. Perhaps a quarter of a century from now this country will mark the passage of yet another milestone, namely the completion of the building of a Second America.

What this means is that, if one were to add up the resource production, construction, and consumption that has taken place until now as the First America, the equivalent accomplishment will likely be completed by the end of the 20th Century. Thus we shall have to grow, mine, transport, build, manufacture, and distribute as much in the way of material goods as has been done in all previous American history. It has taken us more than 400 years to build the First America. We will build the Second in 25.

What exactly will this entail? To meet the needs of an estimated population of 270 million people by the year 2000, major urban areas will have to be expanded. They are already increasing at the rate of 2,590 square kilometers $(1,000$ square miles) annually, which is like adding a new Boston or Washington, D.C., each year. The areas coming under the economic, planning, and development influence of these metropolitan centers is expanding at 10 times this rate-25,900 square kilometers $(10,000$ square miles) a year-an area larger than the State of New Hampshire. It is projected that the land areas expected to undergo development, coupled with those needed for highways and surface mining, will amount to more than 233,000 square kilometers $(90,000$ square miles) during this time period-nearly equivalent to the State of Wyoming.

Building this Second America will require prodigious amounts of resources, including energy, materials, water, and land. Just to maintain the present levels of consumption of oil and gas, for example, will require about 150 billion barrels of oil and more than 500 trillion cubic feet of gas-substantially more than we have produced and used throughout our ii history.
The task of finding and producing the increased volume of materials that will be needed in the next quarter of a century will be a formidable assignment. Some of these materials will be purchased from sources abroad, but most of them will have to come from our own soil. The Nation will have to produce them within the context of rising costs and increasing difficulty in finding and extracting the necessary materials with minimal damage to the environment. If the Second America is not built intelligently, the Nation could do as much environmental damage as was done in building the First America; however, we are much closer to the limits of tolerance than ever before, and the risk of such environmental damage is much more serious than in the past.

To build and sustain the Second America, and do it right, will be a challenge to all-politicians, scientists, engineers, economists, businessmen, the labor force, and the public at large.

The Geological Survey is ready to do its part in meeting the challenge of the future. For the past 98 years the Agency has been accumulating the data necessary to assess and inventory the Nation's mineral and energy resources. During the years ahead, efforts will continue to improve these estimates, fill in the gaps in the data banks, and pinpoint new potential sources and deposits. New thrusts will be miade in mapping, assessing water resources, conservation, and in providing other earth-science data for public use.

To understand how the Geological Survey will respond to the challenge of the future, it is usaful to look at the national trends which currently intuence the direction and content of the Survey's acivities. Some of these are:

- Continued population and urban growth, ircreasing the human use of the land and water, increasing the natural hazard risk to the population, and increasing concern for land-use and roning information.

- Economic growth, increasing the demand fo minerals and fuels.

- Continued withdrawal of public lands from mineral entry, resulting in an increasing need for areal resource appraisal.

- Growth in the development and use of tox c and hazardous materials (including nuclear energy), increasing problems of waste disposal. 
- The opening up and exploration of new domains and frontiers, such as the subsea, the arctic, the deep crust, and other planets.

- Deterioration of environmental quality and increased public interest in environmental protection.

The Geological Survey's primary missions have not been affected very much by these trends because of the way the 1879 Organic Act, under which the Survey operates, was written. Broadly read, the Act is as descriptive of the Survey's principal missions now as it was in the 1800's. Many of the secondary missions of the Geological Survey, however, have been influenced by these national trends. Some examples are:

- Growth of the Conservation Division's lease-management activity and inception and growth of its tract-evaluation function.

- Inception of the Environmental Impact Analysis program and growth in environmental studies.

- Inception of a national land-use and land-cover mapping and analysis program.

- Growth of natural hazard studies and inception of research for developing a prediction capability for these phenomena.

- Inception of automation in data storage and handling.

- Increasing activities in the coastal zone and the identification of this area as a critical one for topographic mapping, land-use mapping, studying the onshore impact of offshore activities, and for water, estuarine, and geologic studies.

- Inception and growth of the Earth Resources Observation Systems (EROS) program, the EROS Data Center and planetary, subsea, and antarctic studies and exploration.

- Inception of wilderness and native-land mineral resource evaluations.

- Growth in energy and mineral resource assessments and new responsibilities for exploration and environmental protection on the Federal lands.

These are some of the new programs and activities that the Geological Survey has recently implemented in response to national trends and issues. In addition to creating new programs and influencing the secondary missions of the Geological Survey, national trends have also changed the character of the organization in terms of its methods of operation. Some examples include:

- A shift to carrying out an increasing percentage of the operation through grants and contracts.

- Replacement of professionals by highly trained and skilled technicians and subprofessionals.
- Establishment of basic research and factfinding studies that are more diverse and becoming more multidisciplinary in character.

- The initiation of a shift to the metric system.

The reader will find that throughout this report all measurements are in metric units followed by the English-system equivalents in parentheses. The use of this measurement system is part of an effort by the Survey to help the Nation shift to the metric system, as called for by Public Law 94-168. The impact of the conversion on Geological Survey programs is illustrated by an essay in the "Perspectives" section entitled "Metrication-What It Means to Mapping."

Probably the most difficult problem and greatest challenge that the Geological Survey will face in the future is how to communicate its information more effectively to the public, the States, other Federal agencies, the Congress, and the Administration. One way is through the publication of an annual report. This year's report for fiscal year 1976 consists of five parts:

- The Year in Review-a review of the major issues, events, achievements, and program accomplishments of the Geological Survey.

- Perspectives-a series of short essays covering activities related to national issues, interdivisional programs and recent advances in the earth sciences.

- Missions, Organizations, and Budget-a description of the major roles of the Geological Survey and the organization and budget it takes to carry out these missions.

- A description of significant activities and program highlights for each of the eight operating divisions and offices.

- A set of statistical tables and related information which documents workloads, production, and accomplishments.

Supplemented by Professional Paper 1000, "Geological Survey Research 1976," the latest in a series of annual reviews of technical results of the Geological Survey's research programs, this Annual Report provides a comprehensive description of the activities of the Federal Government's largest earth-science agency.

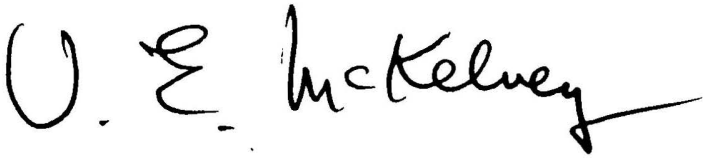

V. E. McKelvey,

Director, U.S. Geological Survey 


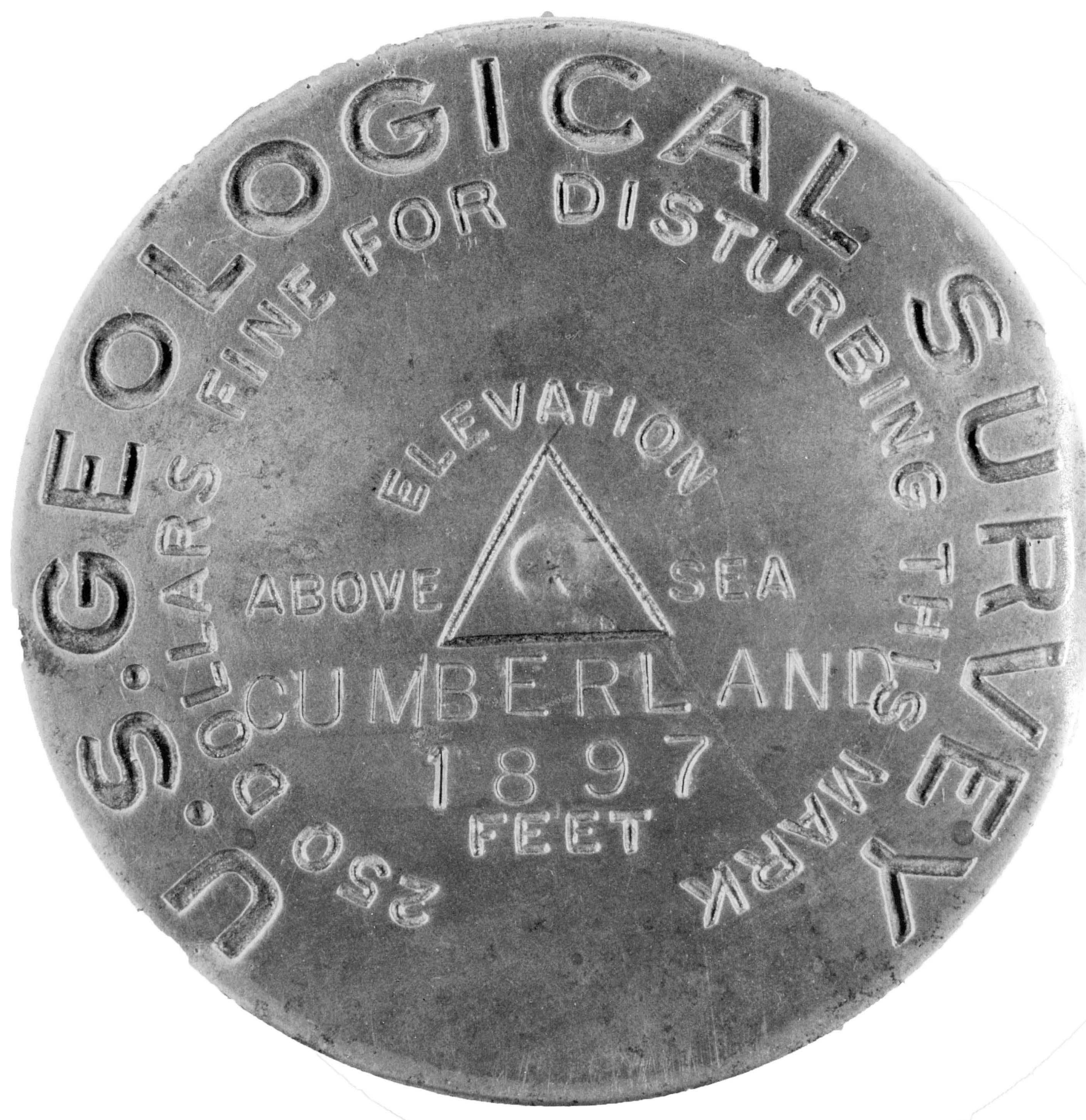




\section{II • Foreword}

\section{1 - The Year in Review}

$9 \cdot$ Perspectives

9 - Role of Earth Sciences in Federal Coal Development in the West

17 - How Much Water in a 12-Ounce Can? A Perspective on Water-Use Information

28 - The Federal-State Cooperative Water-Resource Program, A Unique Partnership in Government

30 - Prospects for Automated Mapping

34 - Metrication-What It Means to Mapping

39 - Plate Tectonics and Man

53 - Outer Continental Shelf Safety in Oil and Gas Operations

59 - Missions, Orzanization, and Budzet

67 - Topographic Surveys and Mapping

87 - Geologic and Mineral Resource Surveys and Mapping

111 - Water Resources Investigations

131 - Conservation of Lands and Minerals

149 - Land Information and Analysis

167 - Program Support Activities

$175 \cdot$ Organizational and Statistical Data

$176 \bullet$ Offices and cooperators

189 - Tables 26-55, summary statistical data 


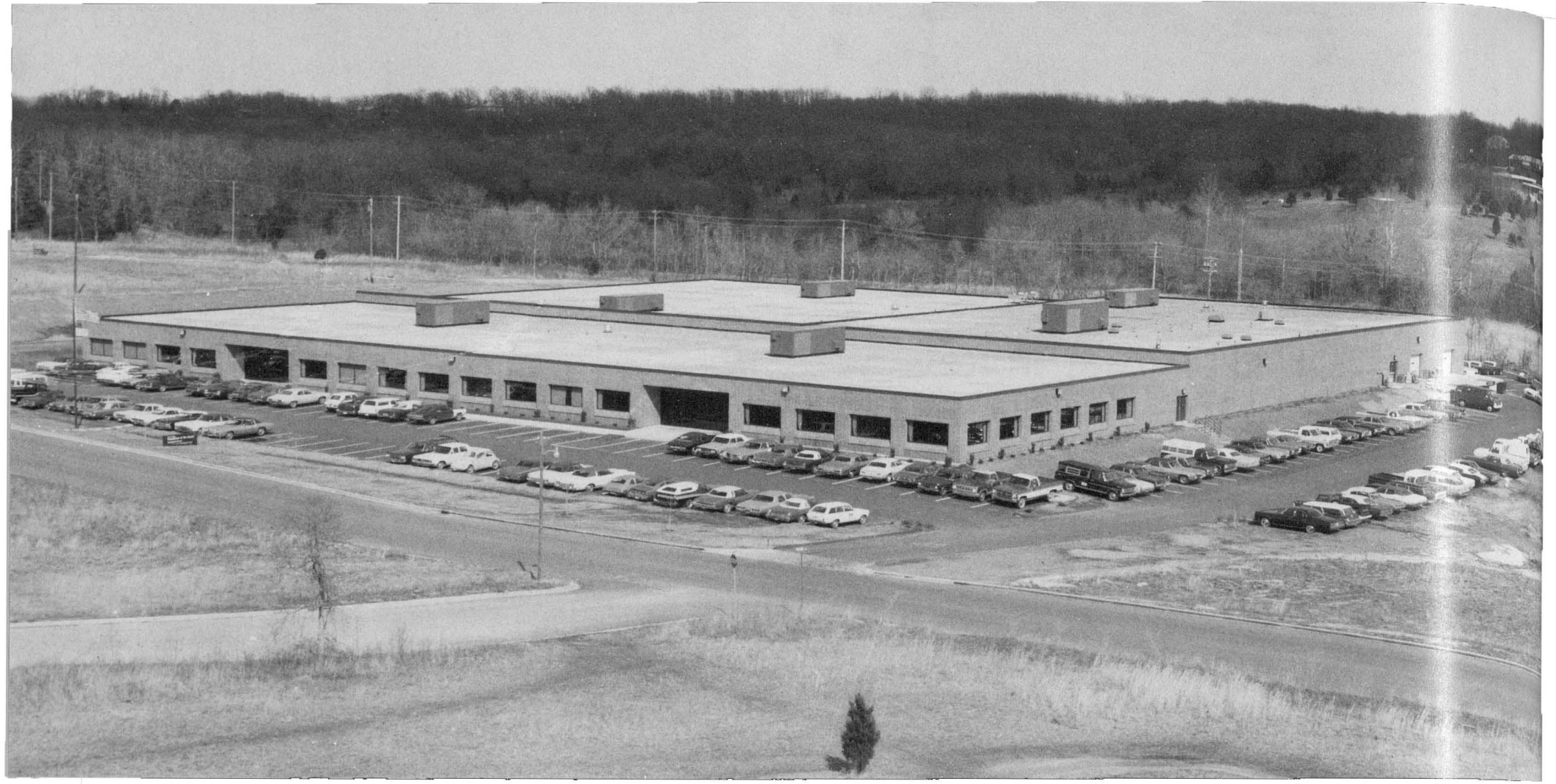

Two new USGS facilities: Top, Mid-Continent Mapping Center in Rolla, Missouri; bottom, National Water Quality Labo atory in Denver, Colorado.

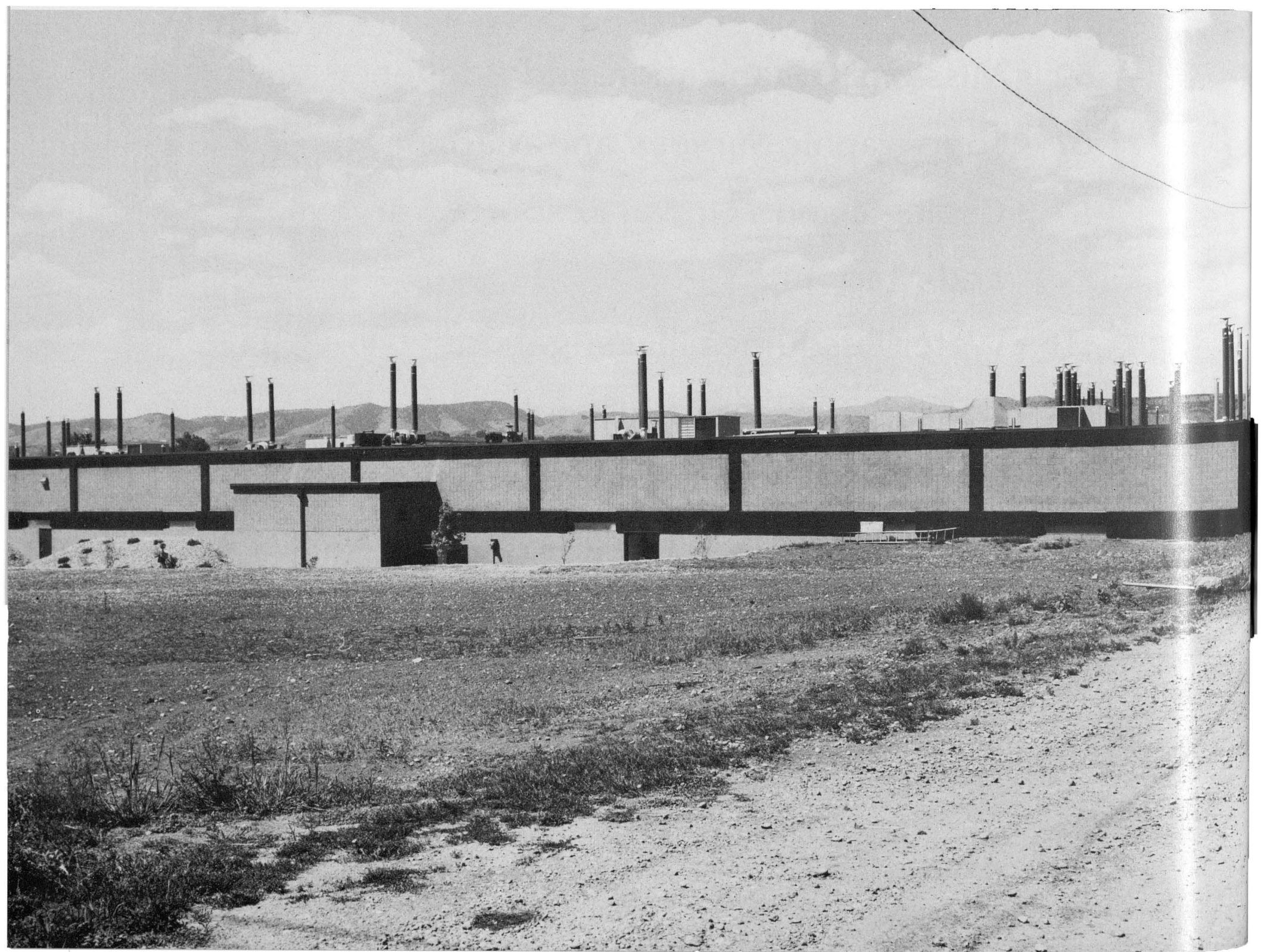




\section{The Year in Review}

\section{INTRODUCTION}

During fiscal year 1976, the Geological Survey was involved in many critical issues of national significance such as the identification and assessment of potential energy and mineral sources, appraisal of the magnitude and quality of water resources, the reduction of hazards from earthquakes and other geologic processes, land-use mapping, and the supervision of lease operations on the Federal lands. The Survey was also involved in assessing the Nation's geothermal potential, in developing a reliable earthquake-prediction capability, collecting and analyzing water data, and producing topographic, geologic, and hydrologic maps in support of energy and mineral programs.

Statistics for fiscal year 1976 indicate that 10,000 maps of all types were produced, that 3,400 reports were approved for publication, and that 158,000 water-quality analyses were made. Additional groundand surface-water measurements were made at 33,820 stations throughout the United States. The Geological Survey also supervised 2,557 leases on the public lands covering 3.7 million hectares (9.1 million acres) and collected $\$ 950,000,000$ in royalties and rentals. During fiscal year 1976 and the transition quarter, the library acquired 142,000 new publications. In addition, more than 407,000 photographs and digital tapes were ordered from the EROS Data Center, and 398,965 inquiries for data and information were handled by the Public Inquiries Offices.

\section{FACILITIES}

The Geological Survey operates three major field centers in Rolla, Mo., Menlo Park, Calif., and Denver, Colo. During fiscal year 1976, the facilities at each of these centers were expanded.

On May 19, 1976, a new center was dedicated at Rolla. The $\$ 2$ million facility was built on a 2.8 -hectare (7-acre) tract and provides a gross area of over 8,825 square meters $(95,000$ square feet).

The new center allows the consolidation under one roof of a number of functions that were previously performed in several separate facilities in the Rolla area. The facility houses about 340 scientists, hydrol- ogists, engineers, cartographers, technicians, and administrative personnel from the Survey's Administrative, Computer Center, Conservation, Topographic, and Water Resources Divisions. The center will also serve as a headquarters for about 110 field employees. Additionally, the General Services Administration maintains a small force at the center, and a Health Unit affords emergency medical treatment and conducts routine health services for all personnel.

In June 1976, construction was completed on the Geological Survey's National Water Quality Laboratory in Denver. The new 4,600-square-meter $(49,000-$ square-foot) building will house 150 people and bring together 5 water-quality analytical and research laboratories that were previously scattered around the Denver area. The facility will enhance the Survey's capability to handle the growing load of chemical analyses of water, sediment, and related substances from projects ranging from the analysis of waterquality effects of mining to the measurement of pesticide concentrations in the hydraulic environment.

Also in Denver, the Geological Survey Library and several geology laboratories were moved into the Stevenson Building adjacent to the Denver Federal Center. Remodeling efforts were also begun in Building 85 at the Federal Center to ready 5,600 square meters $(60,000$ square feet) of space for the Conservation Division.

Denver was also the scene of an unfortunate event of major consequences. On Friday, March 19, 1976, a fire occurred during the night in Building 25 at the Denver Federal Center. This building houses the Central Region Headquarters of the Geological Survey. The areas burned included approximately 2,700 square meters $(29,000$ square feet) on the second floor, including one major Water Resources Division laboratory, five major Geologic Division laboratories, and nine two-man geologic laboratories and supporting office space. Heat, smoke, and water caused damage to more than 11,600 square meters $(125,000$ square feet) of the two-story building. The cost of reconstructing the building was estimated at $\$ 4.5 \mathrm{mil}-$ lion, and the repair and replacement cost of equipment totaled $\$ 2.4$ million. 
In California, the Geological Survey leased the 7,500square-meter (81,000-square-foot) Shell Building adjacent to the main Survey complex in Menlo Park. The building will house offices of the Geologic and Computer Center Divisions. Occupancy began in September 1976.

\section{ENERGY, MINERALS, AND GEOLOGY}

The task of assessing and developing the energy resources of the Nation's lands continued to shape and direct many of the activities of the Geological Survey.

During 1976, the Geologic Division made available to the public 68,000 records of the Petroleum Data System and 35,000 records of the Computerized Resource Information Base (CRIB) System and, in addition, either developed or expanded 14 other data bases, including those for isotopic ages, geologic map indexes, United Nations seabeds data, oil shale, geothermal energy, and uranium and thorium. The first phase of the National Coal Resource Data System, involving regional coal-resource information, became operational, with the capability of data manipulation and retrieval.

The Geological Survey continued to produce general reports on topics of broad national earth-science interest. During fiscal year 1976, the Survey published, among others, reports on the probablistic estimates of maximum earthquake accelerations, on paleotectonic investigations of the Pennsylvanian System, and on landslide occurrence and landslide susceptibility.

A new map of the United States showing equal lines of magnetic declination was published in August 1975. It is the first declination map issued since 1970. Magnetic declination, also referred to as "variation of the compass," is the angle between true north and magnetic north. Because the Earth's magnetic field is constantly changing, new measurements must be made at regular intervals. From these measurements, magnetic lines are depicted on periodically updated maps which are used extensively by marine and aircraft navigators, civil engineers, surveyors, cartographers, and earth scientists.

During fiscal year 1976, the first in a series of Geological Survey regional assessments that will inventory the vast and largely unappraised mineral resources of Alaska was completed and published as an introductory circular and 12 separate maps. The prototype assessment area lies in the Nabesna quadrangle about 363 kilometers (225 miles) north of Anchorage and is the first to be completed under the Geological Survey's Alaska Mineral Resources Assessment program authorized by Congress on July 1,1974 . The mans 2 show the surface distribution of copper, lead, gold, chromium, and cobalt and include three-dimensional diagrams showing the relative distribution and concentrations of these and seven other metals, including silver, nickel, and zinc.

Similar regional assessments now underway in other parts of Alaska are designed to produce a badly needed, rapid, yet accurate assessment of Alaska's mineral resources. In view of the growing mineral shortages and the large role that Alaska is expected to have in supplying the Nation's future mineral needs, the assessment will play an important part in the planning of a viable long-range national minerals policy. Assessment began this year on nine quadrangles covering 122,247 square kilometers $(47,200$ square miles) after the completion of five sheets during fiscal year 1975. A total of 32 quadrangles will have been assessed when the project is completed.

The first report for the Minerals for Energy Production program was released as Professional Paper 1006. This program responds to the need to know what nonfuel minerals will be required to assure that U.S. energy-material production goals can be met. This initial report is in two parts: (1) Assessment of demand for nonfuel minerals, 1975-80; and (2) evaluation of available supplies of those materials that will be stressed. The report states that present production rates of most of these materials are considerably below estimates of the anticipated need for met ting energy goals by 1990 .

In August 1975, the Geological Survey published, as Circular 726, the first comprehensive assessment of geothermal resources of the Nation. The report sh:ows that huge quantities of heat exist in "hot spots" in the Western States and in some geologically favor able zones of the Gulf coast. The assessment was made with the support of the Energy Research and Deve opment Administration.

Although there are numerous locations where thermal systems exist, for most of them very litt $e$ is known about exact size, temperature, and especially how much heat can be recovered. While geothe mal energy is not a panacea, it is an extremely impor ant alternative energy source, and the study shows that the potential is large enough to justify both exploration and technological research and development

As part of a small international cooperative program, a team of Geological Survey scientists, working with their counterparts in the Saudi Arabia Directo ate General of Mineral Resources announced in May $\{976$ that a mine in western Saudi Arabia is now believed to have been the principal producer of King Solomon's gold. Although many mines scattered throughout the region may have contributed gold to King Solomon's treasuries, the principal producer and most licely candidate to be the fabled Biblical Ophir is the Mahd 
adh Dhahab (Cradle of Gold) mine, located about midway between Mecca and Madinah.

A joint Department of the Interior and Department of State program that provides on-the-spot information about the availability of mineral resources was begun during the fiscal year. The key new element was the establishment of a Geological Survey/Bureau of Mines training program for State Department personnel that will help people on foreign assignments acquire resources information overseas. The early success of the program has already encouraged the Department of State to expand it.

In February 1976, it was announced that the U.S. Geological Survey would represent the United States on the Executive Committee of the recently established World Coal Reserves and Resources Service of the International Energy Agency. The Service, established last November, will act as a central clearing house for the collection and distribution of computerized data on world reserves and resources of coal for determining the location, amount, quality, minability, and usability of coal resources throughout the world. The Service will also provide basic information from which nations can plan fossil-energy production and consumption, the interplay of energy sources, future commitments, gas and oil conversion from coal, and location of industrial complexes.

The International Energy Agency is a group of industrial Nations-Belgium, West Germany, Italy, the United Kingdom, and the United States-joined in an effort to reduce the impact of oil-price increases through a variety of measures, including research on alternate energy sources, especially coal. Members of the Agency belong to the Organization for Economic Cooperation and Development. Implementing agreements establishing the World Coal Reserves and Resources Service were signed in Paris on November 20, 1975 , by the U.S. Ambassador to the Organization for Economic Cooperation and Development. Through the U.S. Geological Survey and the Bureau of Mines, the United States will provide the computer capability for the Service and, with Britain's National Coal Board, will jointly run the Service for member nations.

Interest in coal increased this year because of recent legislation and because of the pressing need to develop this valuable and abundant resource. The Department of the Interior has lifted its moratorium and resumed its Coal Leasing program. The Geological Survey has been assigned the lead role in preparing three environmental impact statements on proposed coal development and is involved in four similar statements being directed by the Bureau of Land Management. In addition, because of the strong interest in coal at the State government level, a special Coal Committee comprised of State geologists was formed to provide inputs to the Geological Survey and to review environmental impact statements, resource assessments, and work plans. As part of a FederalState Cooperative program, several State geological surveys provide data directly to the Coal Data System through contracted efforts.

During the summer of 1976, two Viking spacecraft landed on the surface of the planet Mars. The site-selection team, comprised of employees from the Geological Survey's Flagstaff, Ariz., operation, played a key role in the success of this venture.

As the Nation's major civilian mapping agency, the Geological Survey has prepared more than 100 maps of Mars, Mercury, Venus, and the Moon in support of manned and unmanned exploration efforts by the United States and the Soviet Union. Preliminary geologic mapping of the Moon has been completed, and the work on mapping of Mars is nearing completion. About 40 percent of Mercury has been mapped from Mariner-10 data, and preliminary mapping of Venus is underway. Such mapping of the planets not only aids in the selection of future landing sites but also serves to summarize our present knowledge of astrogeology. The staff at the Flagstaff Computation Center also provided computer support for the Viking mission and assisted in making cartographic digital-image enhancements of the photographs sent back to the Earth.

\section{LEASE MANAGEMENT AND EVALUATION}

On June 11, 1976, the Secretary of the Interior signed new Geological and Geophysical Regulations. These regulations will provide additional data for the Government, make it available to the public in a timely manner, and help to control the geological and geophysical exploration procedures. Also issued were Outer Continental Shelf Orders (the basic guidelines or regulations under which lessees carry out their activities) for the Gulf of Alaska and the Atlantic Ocean.

In Novernber 1975, the Geological Survev announced that final approval had been granted for the first of two deep stratigraphic test wells to be drilled in Federal waters on the mid-Atlantic Outer Continental Shelf. Drilling began on December 14, 1975, and was completed in March 1976. The well was drilled to a depth of 4,890 meters $(16,043$ feet), 146 kilometers (91 miles) seaward from the New Jersey shoreline in 91 meters (298 feet) of water. The area is known as the Baltimore Canyon.

A second well, in the Georges Bank area, was approved in March 1976. This area lies about 120 kilometers ( 75 miles) seaward from Cape Cod, Mass., in about 43 meters (140 feet) of water. 
These Atlantic Outer Continental Shelf tests will provide useful geologic information to participating companies and to the Federal Government as an aid in evaluating tracts to be offered in the mid-Atlantic lease sale. The data from the first well were made available to the public through Open-File Report 76774 on November 1, 1976.

Final Revised Coal Mining Operating Regulations were issued on May 17, 1976. These regulations were issued to ensure that coal mining would be carried out in an environmentally acceptable manner.

\section{NATIONAL PETROLEUM RESERVE OF ALASKA}

In April 1976, the Naval Petroleum Reserves Act (Public Law 94-258) was passed by Congress. This act transferred jurisdiction of the National Petroleum Reserve in Alaska, formerly Naval Petroleum Reserve Number 4, from the Department of the Navy to the Department of the Interior and required continuation of an exploratory drilling program begun by the Navy. On April 22, 1976, the responsibility for carrying out the provisions of this Act was assigned to the Geological Survey. Assumption of the responsibilities will take place on June 1, 1977.

The National Petroleum Reserve in Alaska encompasses some 95,830 square kilometers $(37,000$ square miles) of Alaska, or an area roughly the size of Indiana. The Geological Survey's major responsibilities consist of management of the following programs:

1. The evaluation and assessment of the petroleum resources of the reserve.

2. Exploration, development for production, and operation of the South Barrow gas field, or such other fields as may be necessary, to supply gas at reasonable and equitable rates to the village of Barrow and other nearby communities and installations of the Department of Defense and other agencies.

3. Restoration of certain areas within the reserve that have been disturbed by previous petroleum exploration activities to an environmentally acceptable state.

A planning group for the National Petroleum Reserve in Alaska has been established to provide for continuation of the Navy plan to collect more than 16,000 kilometers $(10,000$ miles) of seismic data and to drill 26 wells, to study and plan for the evaluation and assessment of the petroleum reserves, and to continue service from the South Barrow gas field. Additional efforts are underway for the review and preparation of environmental impact statements covering the activities associated with drilling and overall 4 management of the reserve.

\section{GEOLOGIC HAZARDS}

The Geological Survey is engaged in major efforts to delineate the hazards associated with earthquakes, volcanic eruptions, landslides, mudflows, ground subsidence, and floods.

The Survey's Reactor Hazards Research program has delineated reverse faults in Virginia and Georgia, the presence of which suggests that movement has occurred in recent geologic time. Investigations are continuing on the history and nature of the movement to provide a basis for assessing the safety and environmental problems in siting important engineering structures, such as nuclear facilities.

Two reports were produced in fiscal year 1976 related to land subsidence, or the sinking of the land surface. The reports, produced in cooperation with the California Department of Water Resources and the U.S. Army Corps of Engineers, indicate that subsidence is taking place in several parts of the Nation and could become more prevalent in the future.

The reports note that at least 11,100 square kilometers (4,300 square miles) of economically important farmland in the San Jacquin Valley of California has subsided more than 3 meters ( 1 foot) since the 1920 's and that an area around Baytown, Tex., has suifered from tidal flooding because the land surface ha subsided more than 2.4 meters ( 8 feet) since 1920; it could subside another meter (3.28 feet) by $198 \%$.

Most of the Nation's subsidence problems are caused by large withdrawals of ground water and petroleum. Certainly, one can expect subsidence problems to multiply during the coming decades as more underground water, oil, gas, and other mineral resources are withdrawn to meet the Nation's growing needs.

In February 1976, the Geological Survey announced that a recent land uplift of as much as 25 centimeters ( 12 inches) had been discovered astride a large section of California's San Andreas fault, abcut 64 kilometers (40 miles) north of Los Angeles.

The land swelling, the shape of a huge kidne a 193-kilometer (120-mile) axis oriented roughly eastwest and extending from the Pacific Ocean in o the Mojave Desert. This uplift is receiving close att $n$ ntion from the Survey's earthquake specialists b cause similar swelling has occurred before some earthquakes in California and elsewhere. Such uplifts, however, have also occurred without subsequent earthquakes.

Centered north of Los Angeles, near Palmdile in the western Mojave Desert, the swelling appa ently began about 1960 near the junction of the San Andreas and Garlock faults. Since then, it has yrown east-southeastward to include an area of about $₫ 2,000$ square kilometers $(4,500$ square miles). The signifi- 
cance of the rapid uplift is not fully understood. Concern, however, is warranted because it occurs astride a sector of the San Andreas fault that has remained "locked" since a great earthquake in 1857. Thus, considerable strain is building up in this area.

Since the initial identification of the uplift, and recognition that it could be a precursor to a significant earthquake event, the Survey's efforts to monitor geodetic changes in the area and to evaluate the phenomenon have been expanded to include installation of additional instruments (seismographs, tiltmeters, strainmeters, creepmeters, magnetometers, and others). The National Science Foundation and the Geological Survey have provided funds to begin the new studies.

Responsible State and local officials in the affected area have been notified of the potential for a hazard and are being kept abreast of current developments.

Disastrous earthquakes during 1975 and 1976 in China, Guatemala, the Soviet Union, and the Philippines increased public concern about the possibility of a similar event occurring here in the United States.

On November 7, 1975, the Geological Survey proposed a specific Federal plan for the issuance of earthquake predictions and warnings for consideration by Federal, State, and local agencies. Even though there is no operational capability for reliable earthquake prediction at the present time, such a capability is developing.

In the proposed plan, the U.S. Geological Survey has the responsibility for issuing the prediction, including advice and instructions as to defensive measures to be taken.

A major eruption of Mauna Loa Volcano on the Island of Hawaii before July 1978 has also been predicted by Survey scientists on the basis of an analysis of the volcano's past eruptive history. This eruption, which is likely to occur along Mauna Loa's northeast rift zone, could destroy parts of the city of Hilo, 48 kilometers (30 miles) to the east, depending upon the volume of extruded lava and the duration of volcanic activity. The volcano's summit eruption on July 5 and 6,1975 , is regarded as a precursor to, first, another small summit eruption and, second, a much larger, potentially dangerous flank eruption. The location of the predicted flank outbreak is based largely on the occurrence along the northeast rift in July 1975 of thousands of small earthquakes inferred to be associated with the injection of large amounts of magma (molten rock) into the rift zone.

\section{SURVEYING AND MAPPING}

The Geological Survey is responsible for carrying out the National Mapping program. In addition to producing and distributing topographic maps of the
United States, the organization is also responsible for handling all cartographic data, for providing simplified public access to the data, for defining Federal mapping standards, and for developing a digital cartographic base for the country.

In fiscal year 1976 and the transition quarter, the Topographic Division produced 291 intermediatescale products, including 1:100,000-scale quadrangle maps and 1:50,000- and 1:100,000-scale county maps. The switch to this intermediate-scale product is also a step toward the eventual shift from the English to the metric system of measurement since these maps are metric in scale. This effort was in response to the immediate requirements of the Bureau of Land Management, the Soil Conservation Service, and several States, but the maps will meet the needs of other organizations as well.

Another notable accomplishment was the acquisition and installation of advanced equipment that will simultaneously produce an orthophoto, a contour plot, and a digital terrain model. This new equipment provides improved orthophoto production canabilitv and allows the economical preparation of digital terrain information, which previously has been an expensive and time-consuming process.

A new 50-State map produced during the Bicentennial fiscal year is the first detailed Survey map of the United States to show Alaska and Hawaii in their proper size and geographic position relative to the other 50 States. Not shown on the five-color, 39-bv58-inch, 1:6,000,000-scale-one centimeter equals 60 kilometers ( 1 inch equals approximately 95 miles)map is the string of uninhabited islands and reefs in the Hawaiian chain which stretches northwestward for about 1,930 kilometers (1,200 miles) from the main inhabited Hawaiian Islands to Midway Island.

To improve the Geological Survey's capability to systematically review and revise out-of-date maps, a new inspection and review procedure was also adopted and implemented during the fiscal year.

To facilitate the collection, reproduction, and sale of space and aircraft imagery and photography, the Geological Survey operates the EROS Data Center near Sioux Falls, S. Dak. This facility also serves as the data center for the Topographic Division's National Cartographic Information Center. In December 1975, NCIC announced that, in addition to the 6 million frames of data held at the EROS Data Center, information on more than 7 million aerial photographs is being added to the files as a result of an agreement with the Department of Agriculture.

Under the agreement, two agencies of the Department of Agriculture-the Soil Conservation Service and the Agricultural Stabilization and Conservation Service-are supplying the Survey's National Cartographic Information Center with descriptions-such as location, date, area covered, scale, and film char- 
acteristics - of their aerial photographs, which cover most of the United States. The agencies will also supply information on their plans for collecting new photographs.

The addition of this information contributes substantially towards the goal of the Survey's National Cartographic Information Center of providing complete centralized information and access to cartographic data in the form of maps, aerial photographs, space imagery, and geodetic control. Efforts will also continue to provide access to other data held by Federal, State, and private organizations.

\section{WATER RESOURCES}

The Geological Survey has the principal responsibility for appraising the source, quantity, quality, and movement of the Nation's water resources. In addition, it is the lead agency for coordinating the activities of all Federal agencies in the acquisition of certain water data on streams, lakes, reservoirs, estuaries, and ground water.

In September 1975, the Survey announced that the first part of a new water-quality monitoring network designed to provide a balanced yearly picture of water quality in U.S. streams on a national and regional scale was in operation. Known as the National Stream Quality/Quantity Accounting Network (NASQAN), the network now consists of 345 stations that measure 46 physical, chemical, and biological water-quality characteristics, including temperature, specific conductance, and a variety of bacteria, dissolved minerals, trace elements, nutrients, and organic and biological constituents. Measurements are made either continuously, daily, monthly, or quarterly, and the network will be expanded to 525 stations.

The primary objectives of NASQAN are to account for the quantity and quality of water moving within and from the United States, to depict a real variability of water quality, to detect changes in stream quality, and to lay the groundwork for future assessments of changes in stream quality.

The Water Resources Division also announced that more than 150 million streamflow, water-quality, and ground-water measurements collected at more than 100,000 sites across the country are now available through the National Water Data Storage and Retrieval System (WATSTORE). The WATSTORE system contains several data files in which water data are grouped and stored by common characteristics and data-collection frequencies. Currently, files are maintained for the storage of: (1) surface-water, qualityof-water, and ground-water data measured on a continuous or daily basis, (2) annual peak values for and ground-water sites, and (4) geological and inventory data for ground-water sites.

\section{LAND INFORMATION AND ANALYSIS}

The Geological Survey continued its efforts to interpret and display land-resource information in ways that are readily accessible and understandable to a wide range of earth-science data users. During fiscal year 1976, a consolidation of several multidisciplinary land-resource and environmental programs known as the Land Information and Analysis Office completed five urban area study projects located in the Baltimore-Washington area, the Connecticut Valley, the greater Pittsburgh area, the Tucson-Phoenix area, and the San Francisco Bay region. An evaluation of the San Francisco Bay region study by the consulting firm A. D. Little indicated that the study has significant value in advancing the region's receptivity to earth-science data in the planning process.

As part of the Resource and Land Information (RALI) program, the survey released two reports, a "Guide to State Programs for the Reclamation of Surface Mined Areas" (Circular 731) and a "Directory of U.S. Geological Survey Program Activities in the Coastal Areas, 1974-76" (Bulletin 1428).

Under the Geography program, 1:250,000-scale land-use and land-cover maps completed for $: 170$,000 square kilometers $(450,000$ square miles), including the entire States of Kansas, Florida, and Pennsylvania. This brings the total area mapped to $1,950,000$ square kilometers $(750,000$ square miles) since the nationwide program began in fiscal year 1973. Work was also expanded in the area of Landsat digival imagery land use and land-use change, and in the search for semiautomated techniques to detect lanc-cover change.

The Earth Resources Observation Systems program published "ERTS-1, a New Window on Our Flanet" (Professional Paper 929). The book consists of 85 case histories on the use and application of ERTS- (now Landsat-1) data to earth-resource mapping, monitoring, and inventory.

In October 1975, the 1st William T. Pecora Memorial Symposium was held at the EROS Data Center in Sioux Falls, S. Dak. The symposium was named for the late Director of the Geological Survey and Inder Secretary of the Department of the Interior. [r. Pecora played a lead role in the establishment of the EROS program in 1966. The meeting focused on the use of satellite imagery and other remotely sensed data in exploring for new mineral and fuel deposits.

In the Environmental Impact Analysis prograin, the Survey held the lead or joint-lead responsibility for the preparation of 20 environmental impact statements during fiscal year 1976 . They also participated 
in a nonlead capacity in the preparation of 15 other impact statements and reviewed 2,812 additional impact statements and related documents to assist other agencies in areas of Geological Survey jurisdiction and expertise.

\section{ADMINISTRATION AND TECHNICAL SUPPORT}

For Geological Survey employees in the Washington area, May 1976 marked the completion of a 1year experiment with an alternative work schedule called "Flexitime." This particular working-hour arrangement allows employees to start their workday any time betwen 7:00 a.m. and 9:00 a.m. and quit $81 / 2$ hours later. The experiment proved so successful that it has since been adopted as a permanent policy for Survey employees throughout the United States. The use of Flexitime, which gives workers more control over the structure of their lives, resulted in not only noticeable increases in employee job satisfaction but a 20 percent decrease in short-term absences, a substantial reduction in traffic congestion and tardiness, and, in some cases, longer hours for service to the public. In an evaluation of the experiment, employees cited decreases in commuting time, greater ability to schedule personal activities, and a new absence of anxiety about getting to work "on time" as the most important benefits of the new system. Supervisors noted decreases in overtime usage, better utilization of specialized equipment over a longer operating day, and effective use of "quiet time" at the beginning and end of the day. The Survey is now the largest Federal organization using Flexitime, and its approach is being used as a model for dozens of other similar experiments now underway in both the public and private sectors.

To expand the computational capability of the computers operated by the Geological Survey, an agreement was signed in August 1975 for three compatible time-sharing computers. The three systems will be placed at the major Geological Survey offices in Reston, Va., Denver, Colo., and Menlo Park, Calif. Benchmark testing, technical evaluation, and cost evaluation of equipment proposed by vendors were completed during fiscal year 1976. A contract was awarded to the Honeywell Corporation on August 10, 1976, and installation is scheduled for the three locations in fiscal year 1977.

The technical and scientific information collected by the Geological Survey has to be made available to the general public in the most effective, efficient, and timely manner possible. Three major improvements in this public service were realized during fiscal year 1976: (1) The revision of Government Printing Office procedures for the sale of out-of-print books, which enabled the Eastern Region's Branch of Distribution to receive and fill 5,867 orders for a total of 23,561 out-of-print books that would otherwise not have been available; (2) the use of commercial typesetting and printing contracts to cut down on lengthy delays involved in printing publications; and (3) the addition of a new five-color press, which has significantly increased the Survey's ability to react quickly to the public demand for printed maps.

Approximately 5 years ago the Geological Survey began a program for increasing minority participation in the earth sciences. Currently there are 21 active projects underway with an annual budget of $\$ 450,000$. The projects are directed to a few major objectives:

- To help establish earth-science programs, or strengthen existing earth-science departments, at colleges with substantial minority enrollments.

- To help young minority people who aspire to careers in the earth-sciences to realize their ambitions by providing study-related employment opportunities for them in the Survey during the summer months and the opportunity for fulltime employment upon graduation.

- To stimulate interest in the earth sciences and earthscience careers among younger children of minority groups.

In addition to the assistance programs, the Geological Survey also built an exhibits trailer containing rocks, minerals, instruments, maps, and other paraphernalia of the earth-science profession. From 1972 to 1974 , the trailer toured some 27 States, visiting more than 152 minority colleges and secondary schools, and received more than 110,000 visitors. In 1975 the trailer was placed in Rock Creek Park in Washington, D.C., where it now serves as a field laboratory for college students and for the District's public schools.

One of the most successful Geological Survey programs to help advance minority participation in the earth sciences is the joint geology program carried out in cooperation with Howard University in Washington, D.C. After discussions in 1971 with officials of the university, it was decided to re-establish a geology department at Howard. Initially the Geological Survey provided an acting chairman for the department along with three part-time instructors, laboratory equipment, teaching aids, and an assortment of rocks, minerals, fossils, and maps.

In 1972-73, seven courses in geology were offered, and by the fall of 1973 six geology majors had been enrolled. This past year the department had $30 \mathrm{ma}-$ jors enrolled and had acquired a permanent chairman and two full-time faculty members. The Geological Survey still provides some part-time teaching, but by and large the Howard University Geology Department is now self-sustaining. 


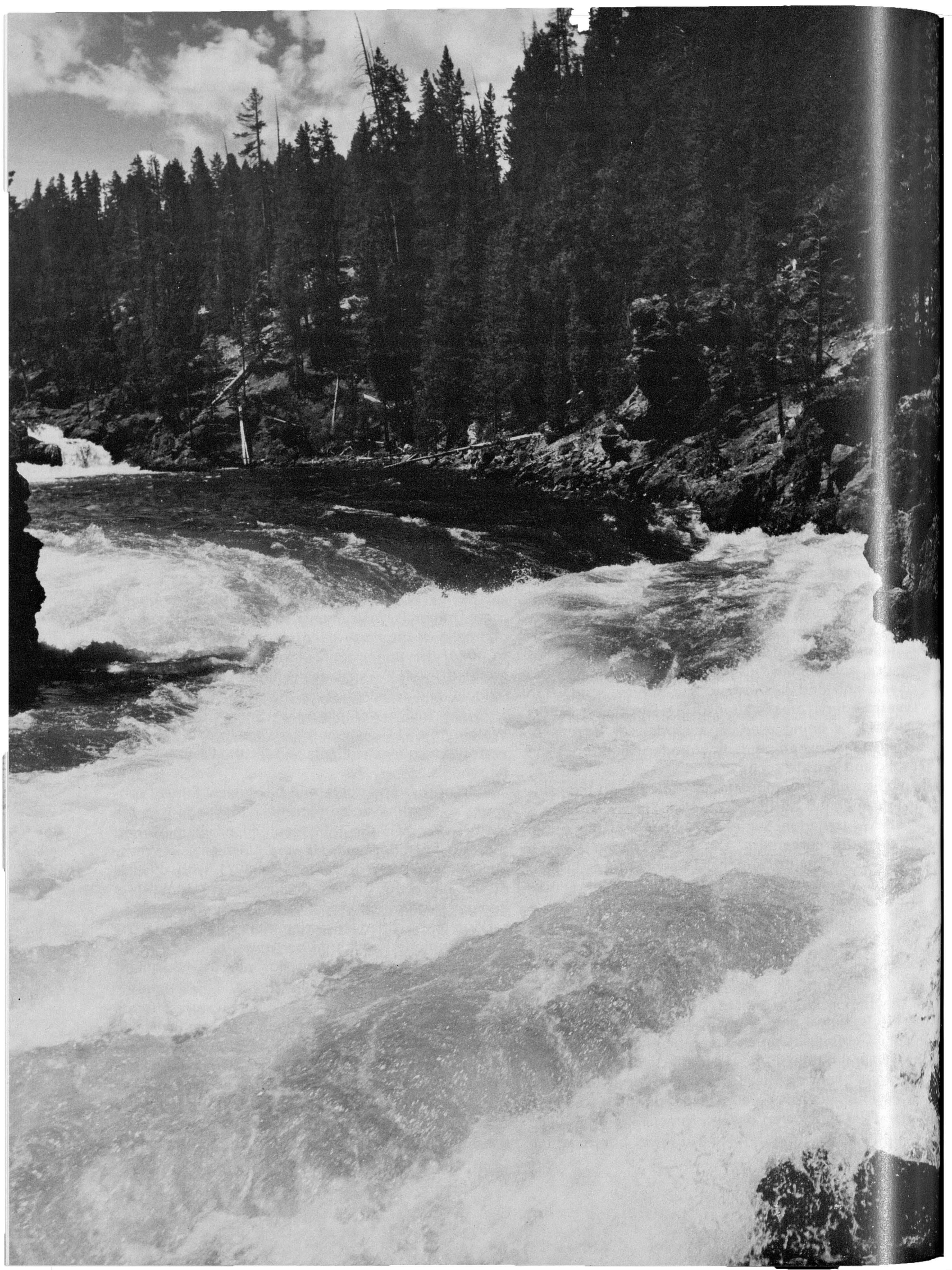




\title{
Perspectives
}

\section{Role of Earth Sciences in \\ Federal Coal Development in the West}

\author{
By William R. Keefer
}

\section{INTRODUCTION}

Beneath the prairies and tablelands of the Rocky Mountains and Northern Great Plains lie some of the most valuable natural resources in the United States. Their worth, in terms of present market values, exceeds $\$ 1$ million an acre over extensive areas. These statements, of course, refer to the vast deposits of coal and lignite (figs. 1 and 2) which make up some two-thirds of the country's estimated total coal resources of nearly 4 trillion tons (Averitt, 1975, p. 14). Largely by-passed in favor of coals from the eastern and central parts of the United States in earlier years, western coal is now considered by many energy experts to be the key to the current national effort to gain a greater measure of energy self-sufficiency.

But the sudden burst of interest in western coal has met vigorous opposition. As the realization of the magnitude of the proposals being made for new mining, processing, and utilization of coal began to grow in the early 1970's, citizens-not only from the affected regions but from across the entire countrycommenced to worry seriously about the potential environmental, social, economic, and political problems. Searching questions arose that demanded immediate attention and study. Did the United States in fact need that much additional coal to solve its projected energy shortages? What were the alternatives? Should coal from mines in the West be converted into electrical power at mine-mouth generating plants, ur should it be shipped to powerplants closer to the large power markets? Could the arid and semiarid regions of the West be satisfactorily restored after surface mining? Would the influx of new people into sparsely inhabited areas significantly change prevail-

The Wilderness Act of 1964 directs the USGS to help in the mineral surveys of national wilderness and primitive areas. ing life styles and social and economic structures? Were local governments capable of providing the necessary new community services? What would be the effects on air and water quality, on wildlife habitats, and on recreational and scenic values? Should water-already in short supply for traditional uses-be diverted for industrial purposes? These and many other complex and highly controversial matters were identified, debated, and, in some instances, referred to the courts for legal action. Policymakers and decisionmakers thus faced, and continue to face, formidable tasks in providing satisfactory answers and solutions. In many cases, such tasks have been severely hampered by a general lack of information upon which to base solid conclusions.

Much of the hard questioning has been aimed at the Federal Government, which owns a substantial share of the western coal lands and whose surfaceand resource-management agencies exert a strong influence over coal development. In response to public pressures, and to conform to the requirements of the National Environmental Policy Act of 1969, the Federal Government has redoubled efforts in recent years to promote policies and programs that seek to strike a proper balance between resource development, land-use planning, and environmental protection. Accordingly, extensive investigations, such as the Southwest Energy Study and the Northern Great Plains Resources Program, were undertaken during the early 1970 's, and numerous legislative acts and other regulations have been imposed to achieve this broad objective. An important milestone in Federal coal policy was marked in 1971 by a decision to suspend all Federal coal leasing, except in special circumstances, to allow for a period of time in which 


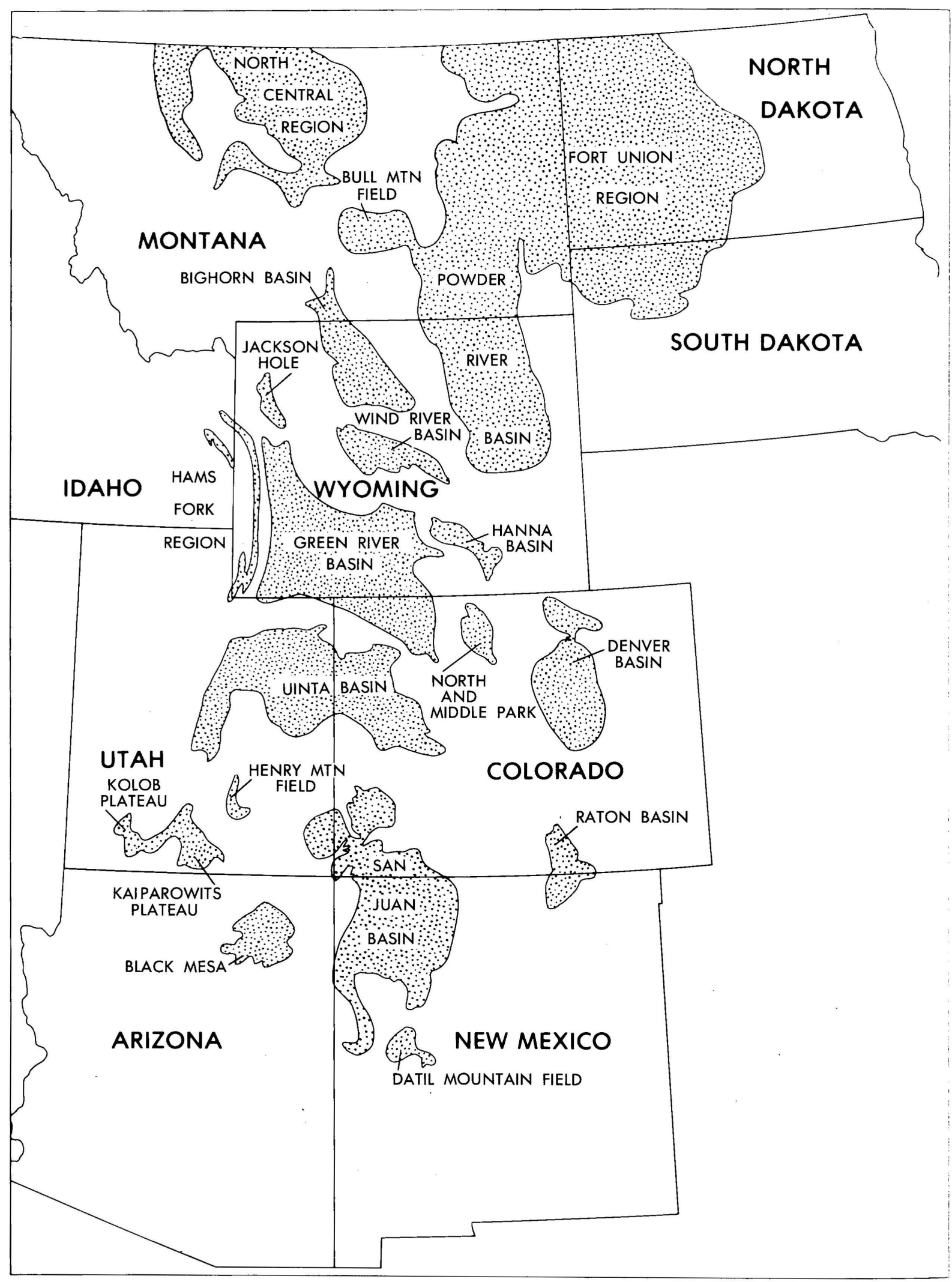

FIGURE 1.-Index map showing major coal-bearing areas (stippled) in the Rocky Mountains and Northern Great Plains 


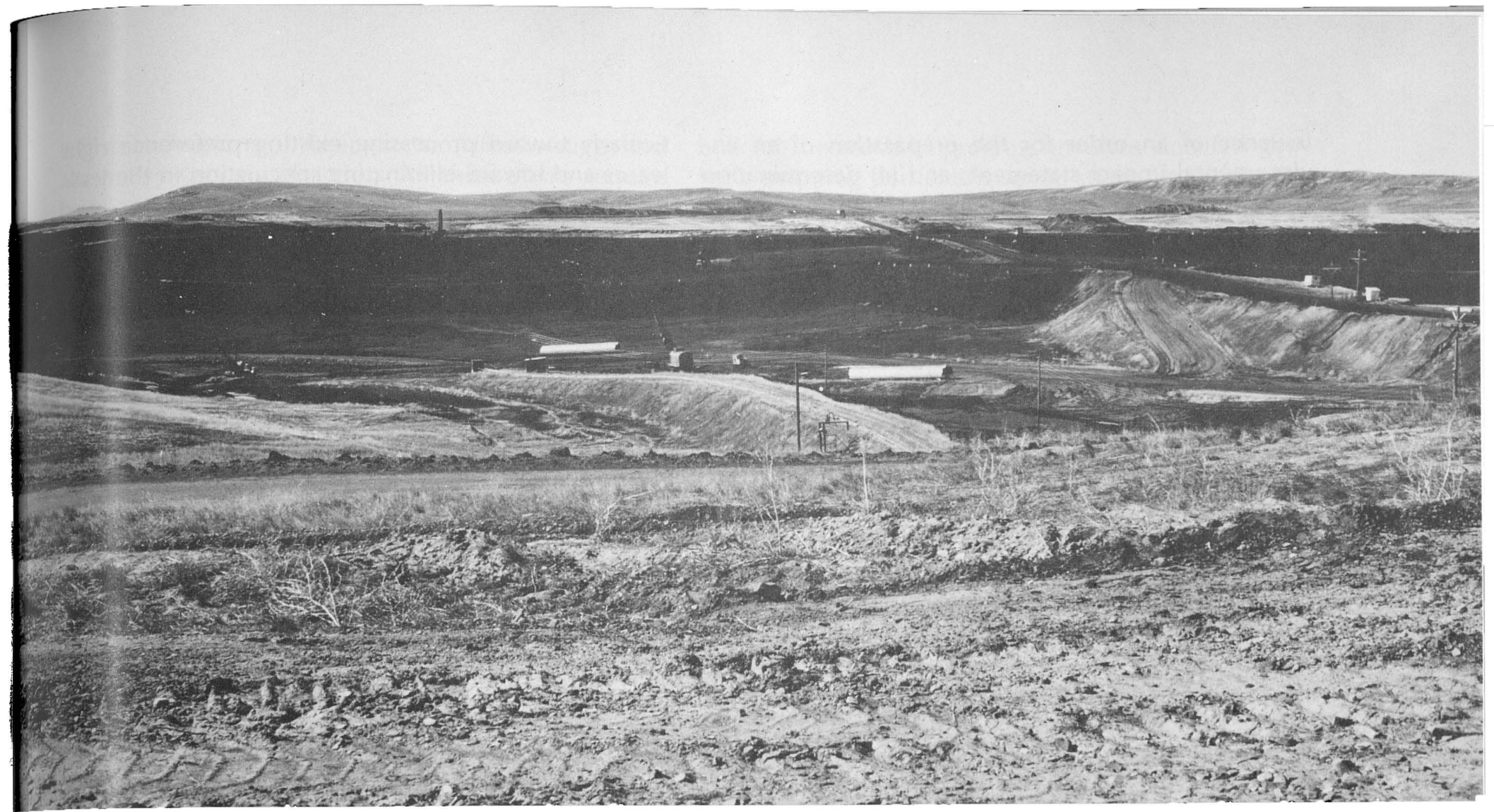

FIGURE 2.-The Wyodak-Anderson coal bed exposed in the south pit of Wyodak mine, about 8 kilometers (5 miles) east of Gillette, Wyo. This deposit, which is the principal strippable coal in the eastern Powder River Basin, is 27 meters (90 feet) thick and overlain by less than 15 meters (50 feet) of overburden at this locality.

to study the status of existing leases and to determine whether additional leases would indeed be needed to spur new production. At the time of that decision, leases and pending preference rights lease applications, which are a prelude to actual mining operations, existed for lands that contained an estimated 16 and 11 billion tons of federally owned coal, respectively. It was not until early 1976 that new policies were formulated, including specific requirements to speed the development or relinquishment of deposits already under lease and calling for tightly controlled procedures for the granting of new leases (see below).

The Department of the Interior plays a dominant role in surface- and resource-management activities on the public lands. Within Interior, the U.S. Geological Survey is the principal agency that gathers data on the physical characteristics of the land and on the nature of its water and mineral resources. In addition, the Survey is charged with responsibilities for approving, controlling, and monitoring all mining and reclamation on federally owned coal lands. The full range of the professional and technical capabilities of the agency-in geology, hydrology, geochemistry, geophysics, mining engineering, topography, and geography-are currently being brought to bear on the many decisions that have to be made, in the public interest, about the orderly management and development of these resources and on the proper treatment of compex environmental problems inherent in increased coal exploitation and utilization.

\section{PRINCIPAL ELEMENTS OF THE FEDERAL COAL LEASING PROGRAM}

The current leasing policy of the Department of the Interior was outlined by a press release issued on January 26, 1976. It includes six major elements:

Energy Mineral Activity Recommendation System (EMARS).-This program, designed by the Bureau of Land Management as the chief surface-management agency of the Department of the Interior, calls for a careful analysis to determine the need for coal and to minimize environmental impacts through (1) development of land-use plans that identify and inventory not only mineral resources but also other values such as agriculture, wildlife, recreation, and water resources; (2) nomination of specific tracts, either for leasing or for nonleasing, by State and local governments, industry, environmental groups, and the public at large and comparison of these nominations with information contained in the land-use plans; (3) analysis of the environmental effects of the proposed lease offering and, if deemed necessary, 
issuance of an order for the preparation of an environmental impact statement; and (4) determination of the economic value of the coal deposit(s) being considered for lease. As will be noted, EMARS incorporates much of what is listed in the following five policy elements and thus depends heavily upon geologic, hydrologic, coal-resource, and related earthscience data from the U.S. Geological Survey.

Competitive leasing.-All future lease offerings are subject to competitive bidding based on fair market values as determined by Survey coal-resource specialists. The new surface-management and leasing procedures for federally owned coal are detailed in the Federal Register of May 17, 1976 (Vol. 41, No. 96, p. 20252-20261).

Regulation of surface mining and reclamation.New regulations, adopted by the Department of the Interior on May 17, 1976 (Federal Register, Vol. 41, No. 96, p. 20261-20273), provide strict standards to be enforced by mining supervisors of the U.S. Geological Survey for all coal-mining activities on Federal lands. Included in the new regulations are requirements for coal-mine operators to minimize, control, or prevent adverse environmental effects-such as soil erosion, pollution of surface or ground water, and disruption of the normal flow of surface and ground water-and to restore the land to useful purposes after surface mining.

Regional Environmental Impact Statements (EIS).Situations in which Federal actions concerning coal development involve the granting of individual leases at widely separated localities, but which nevertheless combine to produce a cumulative effect within a defined geographical area, require that regional environmental impact statements be prepared according to the provisions and guidelines set forth in the National Environmental Policy Act of 1969 (see discussion below). Nine such regional statements have been or are being prepared, principally by personnel of the U.S. Geological Survey and the Bureau of Land Management, for areas of planned or proposed development in North Dakota, Montana, Wyoming, Utah, Colorado, and New Mexico.

Diligent Development.-Requirements for actual performance in mining operations and schedules for payment of royalities are designed to foster development of Federal coal in a timely fashion, but only of those coals that can be produced in an environmentally safe and economically sound manner. Specific consideration must therefore be given by the U.S. Geological Survey staff to the quality and quantity of coal resources and to environmental conditions in order to evaluate the potential for mining in existing and future lease tracts. This procedure is aimed par- ticularly toward processing existing preference right leases and toward eliminating speculation in the leasing of federally owned coal.

Adherence to "Commercial Quantities" Criteria.Determination of "commercial quantities" is based on whether a given coal deposit is judged by resource specialists to be of such character and size that a prudent person would be justified in the expenditure of his time and money with a reasonable prospect of profitability in developing a mine. This definition is being applied in the processing of existing preference right lease applications to determine whether a given lease should be granted or denied.

\section{Coal Leasing Amendments Act}

Recently (August 1976), legislative action termed the "Federal Coal Leasing Amendments Act of 1976" (for purposes of amending the Mineral Leasirg Act of 1920) directs the Secretary of the Interior to initiate a comprehensive exploratory program within the U.S. Geological Survey to obtain sufficient information for evaluating the extent, location, and development potential of the known recoverable coal resources of Federal coal lands. Further, the ac calls for such data as are necessary to estimate the amounts of coal that are recoverable by deep-mining operations and by surface-mining operations, respectively, within a given lease tract and requires that these data be made an integral part of a comprehensive land-use plan for the area in question.

\section{Compliance with NEPA}

One of the most far-reaching influences on the conduct of Federal coal development in the West is that embodied in the National Environmental Policy Act (NEPA) passed in 1969. This act requires that an environmental impact statement be prepared tor all situations in which a major Federal action is being proposed. As mentioned previously, it has a eady been determined that proposals involving thevelopment of several individual but scattered coal lease tracts within a defined geographic area constitute a major Federal action and therefore require the preparation of a regional environmental inpact statement. Among its many provisions, the act directs Federal agencies to adopt procedures which will insure that presently unquantified environmental values are given appropriate consideration in decisionmaking along with economic and technical considerations. A report detailing the characteristics and conditions of the existing environment is therefore specifically required, together with an analysis of the environmental impacts of the proposed action as 
well as evaluations of the impacts related to suggested alternative courses of action. All these items require basic and interpretive earth-science-data inputs from the U.S. Geological Survey.

\section{Adherence to air quality standards}

Air quality standards established by the Environmental Protection Agency place a maximum limit on the amount of sulfur dioxide fumes- 0.52 gram per million joules (1.2 pounds per million British thermal units)-that can be emitted during coal combustion. Although western coals commonly contain less than 1 percent sulfur, their heat value is also low enough to become a critical factor in many cases. Strict adherence to Environmental Protection Agency standards therefore requires obtaining specific data on coal quality - data such as are now being obtained in U.S. Geological Survey and U.S. Bureau of Mines laboratories-for all deposits being considered for development.

\section{EARTH-SCIENCE DATA REQUIREMENTS AND THE ROLE OF THE U.S. GEOLOGICAL SURVEY}

Knowledge and understanding of coal resources, and of the physical environment in which these resources are located, form the cornerstone for all phases of the Federal coal-leasing and coal-development process. Because coal is a layered sedimentary rock occurring only in certain geologic formations, geologists usually know where to find it and can estimate roughly about how much is present. These kinds of general information, obtained during many decades of geologic mapping and coal-resource and related studies by U.S. Geological Survey and other geologists throughout the sedimentary basins of the West, in former years met most of the needs for data about coal-bearing public lands. At present this accumulated body of general knowledge is of considerable value, especially in the making of broad, basinwide resource appraisals. But the new coal programs clearly depend upon more detailed information than is now available for most of the principal coal fields of the West if these programs are to achieve orderly and optimum development of federally owned coal resources with an acceptable environmental impact and are to assure a fair monetary return to the public.

Currently, U.S. Geological Survey geologists are engaged in a wide range of investigations designed to upgrade the existing coal-resource data bases. The bulk of the work in progress involves detailed geologic mapping and stratigraphic studies of coal beds and related rocks and limited drilling in selected areas within most of the major western coal basins. The resulting maps and other reports show the distribution, thickness, and other characteristics of coal beds, and the information can be used for comprehensive coal-resource evaluations at specific sites and for determinations of fair market value for competitive leasing purposes (for example, see Bowers, 1973; Fassett, 1966; Kent, 1976; and Roehler, 1976). To a lesser extent, broad regional compilations and syntheses of data are also being pursued to establish regional stratigraphic and structural relations and coal depositional patterns that can be applied to predict coal occurrences in areas yet to be explored in detail (fig. 3). These kinds of data are especially useful in preparing regional land-use plans, in providing a basis for the initial selection of tracts for future leasing, and in identifying critical information gaps that need to be filled by new mapping and drilling. Additional activities are directed toward improving methods for identifying and delineating coal beds through use of seismic, magnetic, sonar, and borehole techniques. Another important program element is a computerized coal-resource information system (National Coal Reserve Data System) which is being maintained for updating and manipulation of data.

Coal quality is another vital factor in resource evaluation and environmental impact assessment. Physical and chemical properties of coal may vary markedly from one bed to another within the same area and from place to place within the same bed. Rank, heat value, sulfur content, and proportions of moisture and ash determine, in large measure, the overall value and best uses of coal. In addition, the amounts and distribution of minor constituents, some of which may be harmful to human and animal health and some of which may have economic potential as by-products, must also be thoroughly studied and evaluated. Considerable efforts are currently being made by U.S. Geological Survey geologists and geochemists to obtain and analyze representative samples of coal from all the western coal fields. Many data have already been accumulated and published (for example, see Swanson and others, 1976, p. 337-479), and investigations are continuing across a broad front.

Water is a critical commodity in the arid and semiarid regions of the West. In fact, water availabilityrather than coal availability - may be the most critical factor in determining the kind and size of the development that eventually takes place in some 


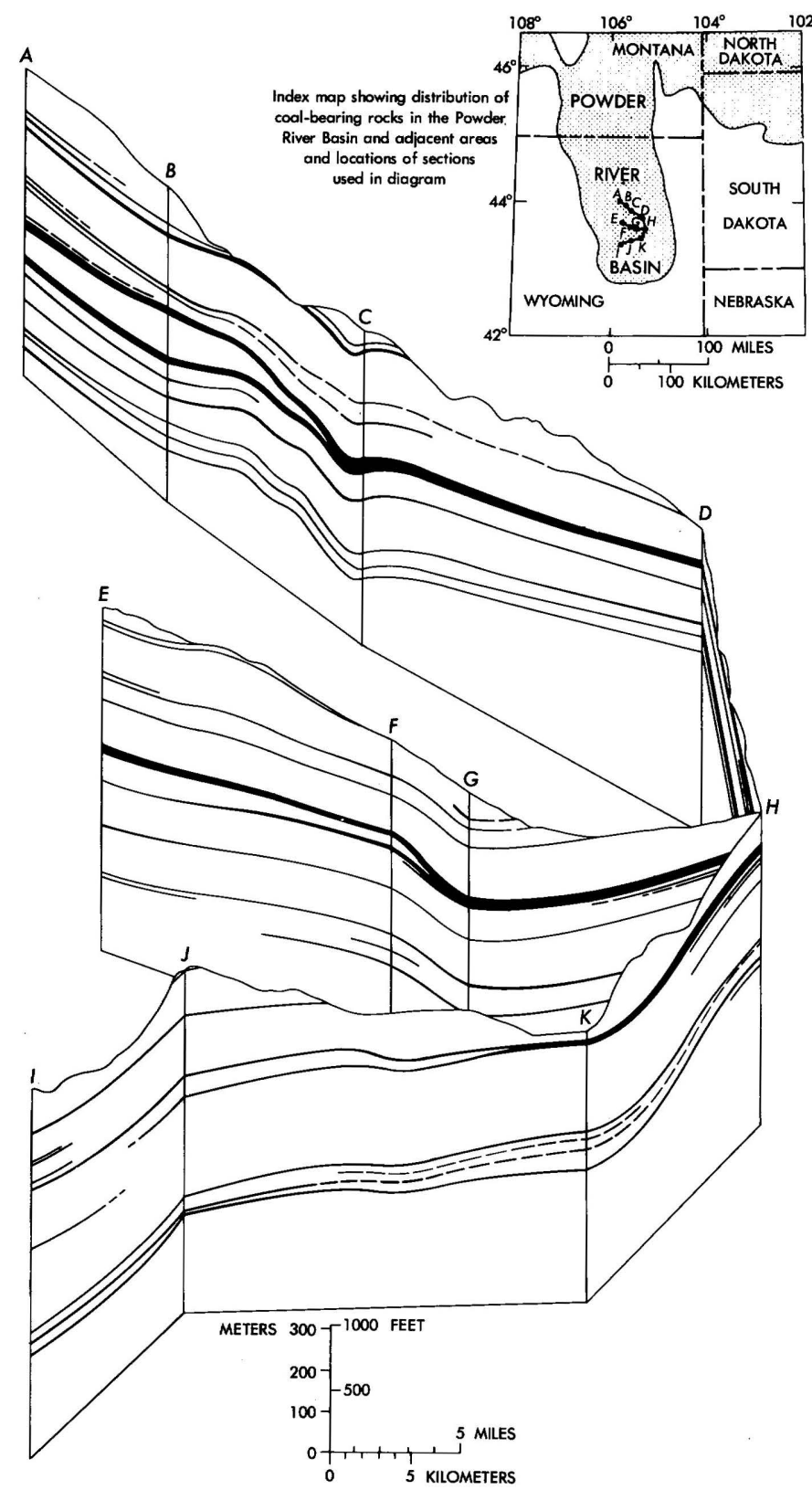

FIGURE 3.-Diagram showing distribution of coal beds (solid lines, but dashed where correlations are uncertain) within several hundred square miles of the Powder River Basin in northeastern Wyoming. Information is based chiefly on interpretation of drill data (sections $A, B, C$, and so on are drill holes) by N. M. Denson and J. H. Dover, U.S. Geological Survey. The present land surface is shown by the uneven profile at the top of each section panel.

areas. Concerns over water supplies, as well as the potential disruption and pollution effects of surface mining on existing surface- and ground-water systems, have resulted in Federal programs calling for the extensive collection of baseline hydrologic data throughout the western coal areas. Information on depth and movement of shallow ground water and yield is also required by regulations controlling the mining of federally owned coal.

Studies of the quality and quantity of surface and ground water in the Western United States have long been a traditional part of the basic program of the U.S. Geological Survey. The large body of accumulated hydrologic data is now being applied toward (1) evaluating water availability to meet the water needs for coal mining and processing, for energy conversion plants, and for surface-mine reclamation; (2) assessing potential effects of surface mining on existing hydrologic conditions; and (3) monitoring changes in hydrologic conditions as mining and reclamation proceed. New and/or expanded hydrologic investigations, tailored to specific requirements in the new Federal coal programs, have also been initiated. One of the most significant of these is an evaluation of the potential of the Madison Limestone aquifer in the Powder River Basin of northeastern Wyoming and southeastern Montana to supply water for coal-slurry pipelines and other industrial uses.

The overriding goals of Federal coal policits and programs are to produce adequate supplies of coal and to avoid significant damage to the existing environment. To achieve these goals, and to assist in the preparation of required environmental analysis reports and impact statements and in the erforcement of Federal mining regulations, it has bicome necessary to establish a baseline of existing ervironmental conditions in each of the principal coalbearing areas of the West. Such baseline data are needed for predicting the changes in the ervironment that will be caused by future minin and associated activities and are also needed then for monitoring those changes through close observations and quantitative measurements as they take place. Because potential environmental problems var considerably from one area to another, both in kird and in *degree, it is just as important to pursue sroad regional investigations to assess the cumulative effects of long-term, large-scale development on an entire region as it is to determine impacts at specific local sites.

The preparation of a comprehensive en ironmental baseline involves the acquisition of large amounts of integrated geologic, hydrologic, geochemical, and engineering data, a task for which the U.S. Geological Survey is well suited in view of the multidisciplinary aspects of its professional and technical staff. Currently, Survey earth scientists are engaged in mapping and related studies of land forms, landscape characteristics, and active gerlogic processes in selected areas of the western coal fields. Interpretations of these data are being used to pre- 
dict how future mining, reclamation, and industrial activities may be affected by alteration or disturbance of the present landscape, and, conversely, how the landscape may react to these modifications. One such area being investigated is in the eastern Powder River Basin of Wyoming (fig. 1), for which preliminary results have been published (Keefer and Hadley, 1976). Additional studies are directed toward identifying geologic hazards, determining surface- and ground-water conditions, measuring erosion rates and sediment yields (fig. 4), and evaluating factors that bear on reclamation potential, all of which con- tribute to advance understanding of potential environmental problems.

Knowledge of the distribution and concentration of chemical elements in the natural environment is likewise of prime importance in efforts to predict, measure, and interpret changes in existing environmental conditions as coal exploitation and related industrialization take place. Redistribution of elements in landscape materials resulting from these activities, for example, could be detrimental, or in some instances beneficial, to future uses of the affected land and to the quality of ground and sur-

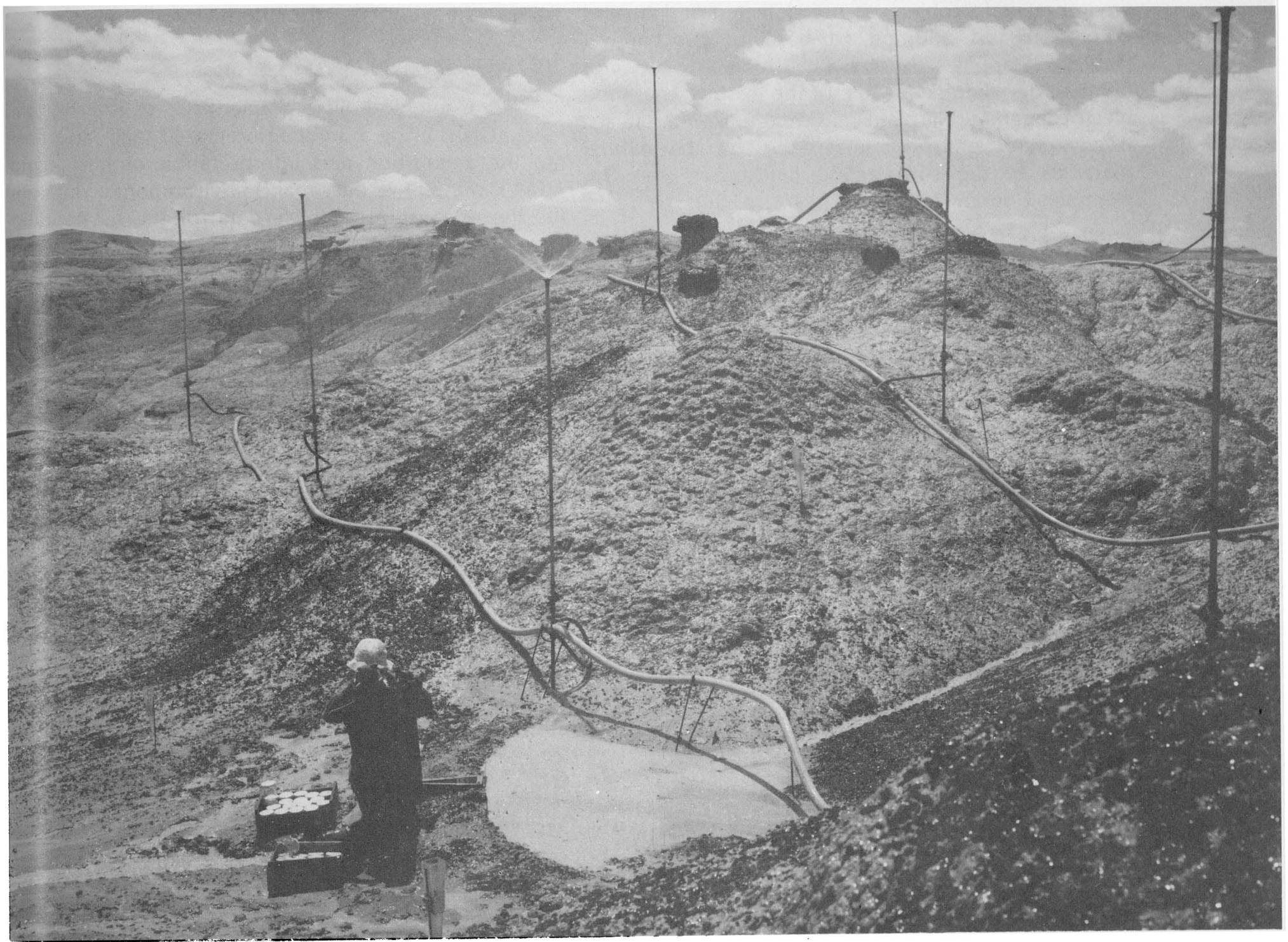

FIGURE 4.-A recently developed rainfall simulator is used by the Geological Survey to determine runoff and erosion rates from various types of terrain. The simulator is shown here in operation on badlands of the Cretaceous Fruitland Formation in New Mexico, a possible coal surface mining site. About 3.8 centimeters $\left(1 \frac{1}{2}\right.$ inches) of "rainfall" in 45 minutes is applied to an area of approximately 325 square meters $(3,500$ square feet). Outflow from the area is trapped in the small pond (center foreground) and then released and measured through a calibrated flume (left side of the pond). Water samples are then obtained boxes a sediment in the runoff from the test area. 
face water. Geochemical studies and sampling programs are being conducted by U.S. Geological Survey personnel in several of the coal-bearing regions of the West with current emphasis on the Northern Great Plains (U.S. Geological Survey, 1976). Soils, plants, rocks (including coal), and surface and ground water are being analyzed to determine their geochemical properties, both locally and regionally, as a basis for establishing baselines in advance of the large-scale modifications that are now anticipated from mining and related activities. Concentrations of trace metals, such as arsenic, mercury, and selenium, and other potentially harmful elements receive special attention because they can cause environmental problems if not detected and treated accordingly. In addition to baseline geochemical studies, sampling and analytical programs are also being undertaken near some of the existing coal-fired electrical generating plants to determine what effects, if any, stack emissions may have on the natural materials of the surrounding landscapes (see, for example, Connor and others, 1976, p. 56).

All the U.S. Geological Survey earth-science datagathering programs discussed above focus directly on the agency's decisionmaking responsibilities in coalresource management and mining regulation. Specific responsibilities include classifying federally owned coal lands, defining known coal-resource areas, delineating logical mining units, assessing nominations for competitive coal leasing, determining fair market value for purposes of evaluating competitive bids and establishing royalty payments, and approving and supervising all mining and reclamation activities on federally owned coal lands. The needs for earthscience data are clearly evident in all phases of these activities, but perhaps the needs are best exemplified by the duties imposed on the Survey's mining supervisors for enforcing the many provisions embodied in the Federal coal-mining regulations. Proper and effective discharge of these responsibilities involves not only detailed knowledge of coal resources and mining and reclamation practices, but of the whole range of environmental matters as well.

\section{SUMMARY}

U.S. Geological Survey scientists, engineers, and technicians bring a unique, integrated team approach to the acquisition and interpretation of basic land, water, mineral resource, and environmental data and to the application of these data for the sound management of federally owned coal resources and for the solution of complex environmental problems inherent in increased coal production and utilization. The multidisciplinary aspect of the Survey's earthscience data-gathering activities can be summerized as shown in the following table:

\begin{tabular}{|c|c|c|c|c|c|}
\hline \multirow[b]{2}{*}{$\begin{array}{l}\text { Major supporting disciplines in } \\
\text { the U.S. Geological Survey }\end{array}$} & \multicolumn{5}{|c|}{$\begin{array}{l}\text { Some principal elements in the Federal coal-leasing } \\
\text { and coal-development system that require ea-th-science data }\end{array}$} \\
\hline & $\begin{array}{c}\text { Coal- } \\
\text { resource } \\
\text { evaluation }\end{array}$ & $\begin{array}{l}\text { Land-use } \\
\text { planning }\end{array}$ & $\begin{array}{c}\text { Environ- } \\
\text { mental } \\
\text { impact } \\
\text { analysis }\end{array}$ & $\begin{array}{l}\text { Lease } \\
\text { tract } \\
\text { selection }\end{array}$ & $\begin{array}{c}\text { Regulation } \\
\text { of } \\
\text { mining } \\
\text { and } \\
\text { reclamation }\end{array}$ \\
\hline Geology _- & $\times$ & $x$ & $x$ & $x$ & $x$ \\
\hline Hydrology _ & -- & $x$ & $\dot{x}$ & $x$ & $x$ \\
\hline Geochemistry _- & $x$ & -- & $x$ & $x$ & $x$ \\
\hline Geophysics & $x$ & -- & --- & --- & -- \\
\hline Mining Engineering & --- & -- & -- & $x$ & $x$ \\
\hline Topography __- & $x$ & $x$ & $x$ & $x$ & $x$ \\
\hline Geography _- & -- & $x$ & -- & --- & --- \\
\hline
\end{tabular}

$X$, important data input from the discipline indicated.

Earth science plays a vital role in each step of the decisionmaking process from the initial coal-resource assessment for the selection of lease tracts to the final approval and supervision of actual mining operations. Much of the current U.S. Geological Survey involvement in western coal development is but an expansion or modification of scientific, technological, and management activities that have formed an integral part of the agency's basic program cover vast areas, and only a cursory invento y of data indicates that existing knowledge is as yet inadequate for many of the tasks and decisions that lie ahead. However, new Federal coal programs, and the correspondingly enlarged responsibilities of the U.S. Geological Survey, have had the immediate effects of sharply focusing attention on the urgency for more extensive earth-science data-gathering activities and of emphasizing a greater need to direct them in the most timely, efficient, and coordirated manner. 


\section{REFERENCES CITED}

Averitt, Paul, 1975, Coal resources of the United States, January 1, 1974: U.S. Geol. Survey Bull. 1412, 131 p.

Bowers, W. E., 1973, Geologic map and coal resources of the Griffen Point quadrangle, Garfield County, Utah: U.S. Geol. Survey Coal Inv. Map C-61.

Connor, J. J., Keith, J. R., and Anderson, B. M., 1976, Tracemetal variation in soils and sagebrush in the Powder River Basin, Wyoming and Montana: U.S. Geol. Survey Jour. Research, v. 4, no. 1, p. 49-59.

Fassett, J. E., 1966, Geologic map of the Mesa Portales quadrangle, Sandoval County, N. Mex.: U.S. Geol. Survey Geologic Quadrangle Map GQ-490.

Keefer, W. R., and Hadley, R. F., 1976, Land and natural resource information and some potential environmental ef- fects of surface mining of coal in the Gillette area, Wyoming: U.S. Geol. Survey Circ. 743, 27 p.

Kent, B. H., 1976, Geologic map and coal sections of the Wildcat quadrangle, Campbell County, Wyoming: U.S. Geol. Survey Misc. Field Studies Map MF-735.

Roehler, H. W., 1976, Geology and mineral resources of the Cooper Ridge NE quadrangle, Sweetwater County, Wyoming: U.S. Geol. Survey Open-File Rept. 76-494.

Swanson, V. E., Medlin, J. H., Hatch, J. R., Coleman, S. L., Wood, G. H., Jr., Woodruff, S. D., and Hildebrand R. T., 1976, Collection, analysis, and evaluation of coal samples in 1975: U.S. Geol. Survey Open-File Rept. 76-468, 503 p.

U.S. Geological Survey, 1976, Geochemical survey of the western energy regions: U.S. Geol. Survey Open-File Rept. 76729.

\title{
How Much Water in a 12-ounce Can? A Perspective on Water-Use Information
}

\author{
By I. C. James II, J. C. Kammerer, and C. R. Murray
}

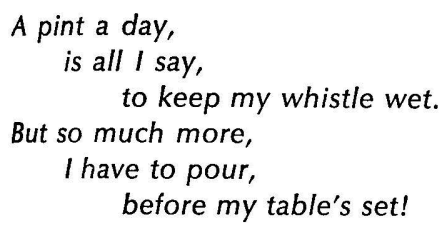

B. L. Anon.

\section{WATER USE AND ITS VARIATIONS}

\section{The 12-ounce can}

On a hot afternoon after mowing the lawn, or after returning home from a round of golf, or when just resting from your daily toil, have you ever gone to the refrigerator to satisfy your thirst with a 12ounce (355-milliliter) can of your favorite beverage? You want to relax and reflect on the activities of the day, but your act of consuming the contents of that 12-ounce can is the culmination of a long chain of processes requiring energy, materials, water, labor, and management. Let us consider your effect as a consumer on the water resources of the Nation and try to answer the question, "How much water is in a 12-ounce can?" Twelve ounces, of course-threeeights of a quart, or, in the metric system, 0.355 liter (0.000355 cubic meter). But wait a minute; let's rephrase the question to "How much water did it take to manufacture the 12-ounce can?" Doesn't it take water to clean the can before it is filled, water to produce the steel or aluminum used in the can, water to mine the coal that is used in converting iron ore to metallic iron in making steel used in the can, and water for cooling in the thermal electric plants that supply these industries with electric energy?

Let us use that can from which you were about to pour your 12-ounce drink as an example for exploring the ramifications of one of our simple daily waterconsumption decisions. The fabrication of metal cans requires a small quantity of water for a variety of in-plant purposes such as cooling and washing. In 1968 nationwide water withdrawals for this industry totaled 7 billion liters ( 7.4 billion quarts). The average in-plant water use per can is about 0.2 liter of water withdrawn. This small direct use of water is an obvious consequence of your consumption of a beverage in a 12-ounce can. But what of the indirect uses of water necessary to sustain the industries that directly supply the can manufacturers with goods and services?

Using 1967 data, it is estimated that supporting industries directly supplying the metal-can fabrication industry withdraw about 23 liters (24.3 quarts) of water per can produced. Each of these supporting industries in turn must purchase goods and services from still other industries. As those purchases "ripple out" through our economy, additional economic sectors become involved. The accumulated water withdrawals for all the indirect suppliers total 40 liters (42.3 quarts) per can, thus increasing water withdrawals by both direct and indirect suppliers to about 63 liters (66.6 quarts) per can.

You might question the need for this type of information; certainly, your individual decision to 
CAN FABRICATION

AN AVERAGE OF 0.2 LITER OF WATER IS WITHDRAWN FOR THE MANUFACTURE OF A SINGLE CAN

\section{DIRECT INPUTS}

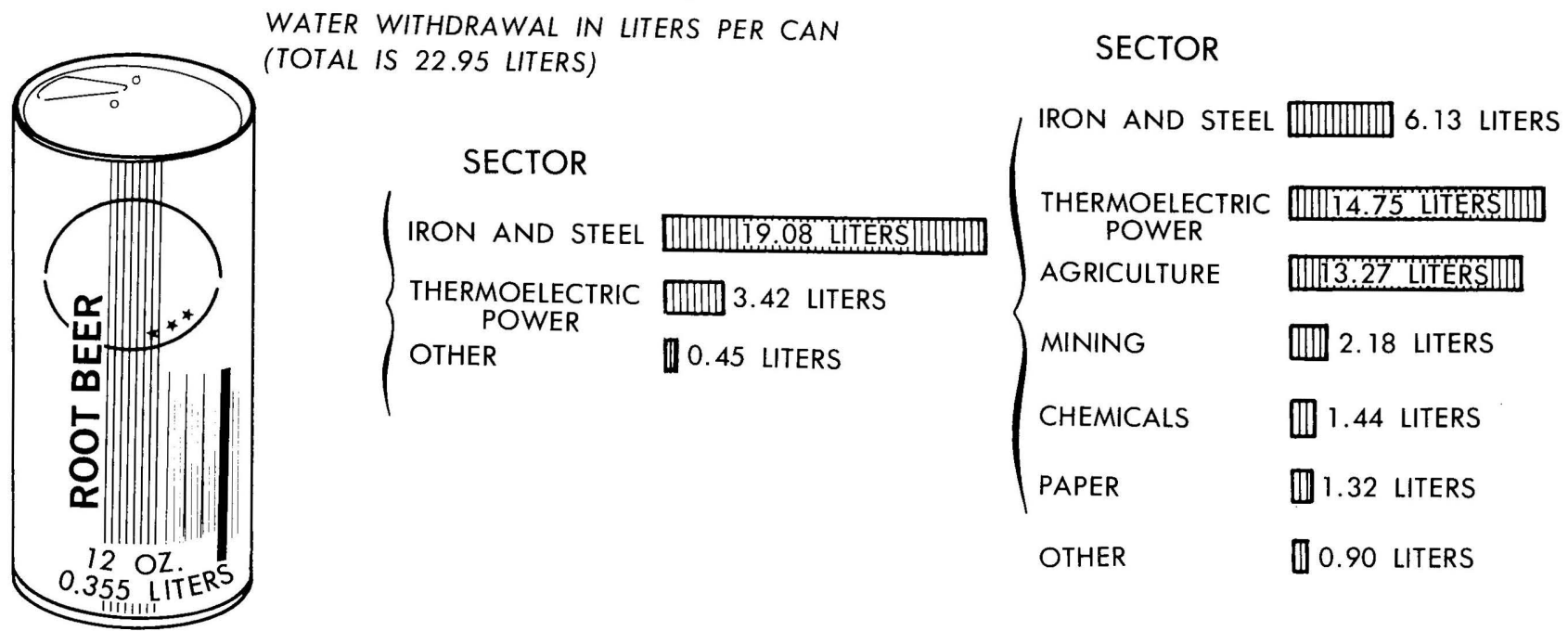

WATER WITHDRAWALS IN LITERS PER CAN (TOTAL IS 39.99 LITERS)

WATER WITHDRAWAL IN LITERS PER CAN

FIGURE 5. - Water withdrawals by direct and indirect suppliers for the fabrication of a 12-ounce beverage can. ( 1 liter equals approximately 1 quart.)

production of one aluminum can requires the equivalent of 10 cubic meters (about 11 short tons) of water going through turbines in a 15-meter (50foot) high dam. This also is a water use, but the water is not withdrawn from the river; therefore, the quantity and the quality of the water are not perceptibly affected.

\section{Water for steel: wide variations}

The largest indirect water use in the example of the 12-ounce can is in the iron and steel industry. A more detailed look at this industry illustrates some interesting water-use facts that must be considered in producing water-use information.

Steel-industry data have often been used to show the wide range in water use that occurs within a single industry. Inasmuch as more than 95 percent of gross water use in steel plants is for cooling, comparisons of quantities used for cooling are very significant. Data (gross use, including reuse) compiled by Walling and Otts (1967, p. 364) for 25 integrated steel plants and steel-processing plants showed ranges of 14 to 409 cubic meters $(3,750$ to 108,000 gallons) required to produce 907 kilograms (1 short ton) of ingot steel. As these authors pointed out, some factors that affect cooling-water requirements are the age and condition of a plant, procedures of operation, and quality of cooling water. Costs of water withdrawal also significantly affect the amount withdrawn. Russell and Vaughan (1976) estimated that a change in the price of water from $\$ 0.0044$ to $\$ 0.01$ per cubic meter would reduce water withdrawals by more than 80 percent; further price increases, however, would have little additional effect. The quantity of water actually consumed would remain about the same or increase slightly with price increases.

\section{Water uses in the home and per capita use}

Household uses of water also vary greatly in magnitude. Household uses are internationally expressed in terms of liters (1 liter equals 1.0567 quarts) per day per person, and depend upon such characteristics as climate, accessibility (connected or not connected to a public water-supply system), water quality, water pressure, cost, outdoor needs (lawn, garden, pool), and whether or not the water supply is metered. Although a person needs less than 2 liters (2.1 quarts) of water a day (from liquid and solid foods) to survive, in the United States, the actual daily household use (indoor and outdoor) ranges from less than 40 liters (42.3 quarts) per capita in some homes without plumbing to several hundred liters per capita in affluent homes with watered lawns. Lawn watering and toilet flushing are the two largest household uses of water. Table 1 shows a hypothetical example of average daily water use in the future by a family of four (assuming that family has two bathrooms, a garbage-disposal unit, a dishwasher, an automatic laundry, and two automobiles). 
TABLE 1.-Anticipated daily domestic uses of water by a family of four. (Adapted from Reid, 1965, p. 18.)

\begin{tabular}{|c|c|c|c|c|}
\hline \multirow[b]{2}{*}{ Family use of water } & \multicolumn{4}{|c|}{ Average daily use } \\
\hline & $\begin{array}{l}\text { Liters } \\
\text { per day } \\
\text { per family }\end{array}$ & $\begin{array}{c}\text { Liters } \\
\text { per day } \\
\text { per capita }\end{array}$ & $\begin{array}{c}\text { Gallons } \\
\text { per day } \\
\text { per family }\end{array}$ & $\begin{array}{l}\text { Gallons } \\
\text { per day } \\
\text { per capita }\end{array}$ \\
\hline Drinking and water used in kitchen & 30 & 7.6 & 8 & 2 \\
\hline Dishwasher (3 loads per day) & 57 & 14 & 15 & 3.75 \\
\hline Toilet (16 flushes per day) & 363 & 91 & 96 & 24 \\
\hline Bathing ( 4 baths or showers per day) & 303 & 76 & 80 & 20 \\
\hline Laundering (6 loads per week) & 129 & 32 & 34 & 8.5 \\
\hline Automobile washing ( 2 carwashes per month) & 38 & 9.5 & 10 & 2.5 \\
\hline $\begin{array}{l}\text { Lawn watering ( } 180 \text { hours per year) } \\
\text { Garbage disposal unit ( } 1 \text { percent of all }\end{array}$ & 379 & 95 & $100^{\prime}$ & 25 \\
\hline other uses) & 13 & 3 & 3 & 0.75 \\
\hline Total & 1,312 & 328.0 & 346 & 86.50 \\
\hline
\end{tabular}

Daily per capita water use in the United States is sometimes expressed as a nationwide average for a given year. The average daily per capita household use for 1970 was about 280 liters (297 quarts) per person for homes connected to public water-supply systems; however, the total average daily per capita use of freshwater for all withdrawal uses-for agricultural irrigation, self-supplied rural homes (domestic and livestock uses), self-supplied industries, and public supplies-was nearly 6,000 liters $(6,360$ quarts) per capita for the same year (table 2).

TABLE 2.-Estimated daily per capita use of freshwater in the United States.

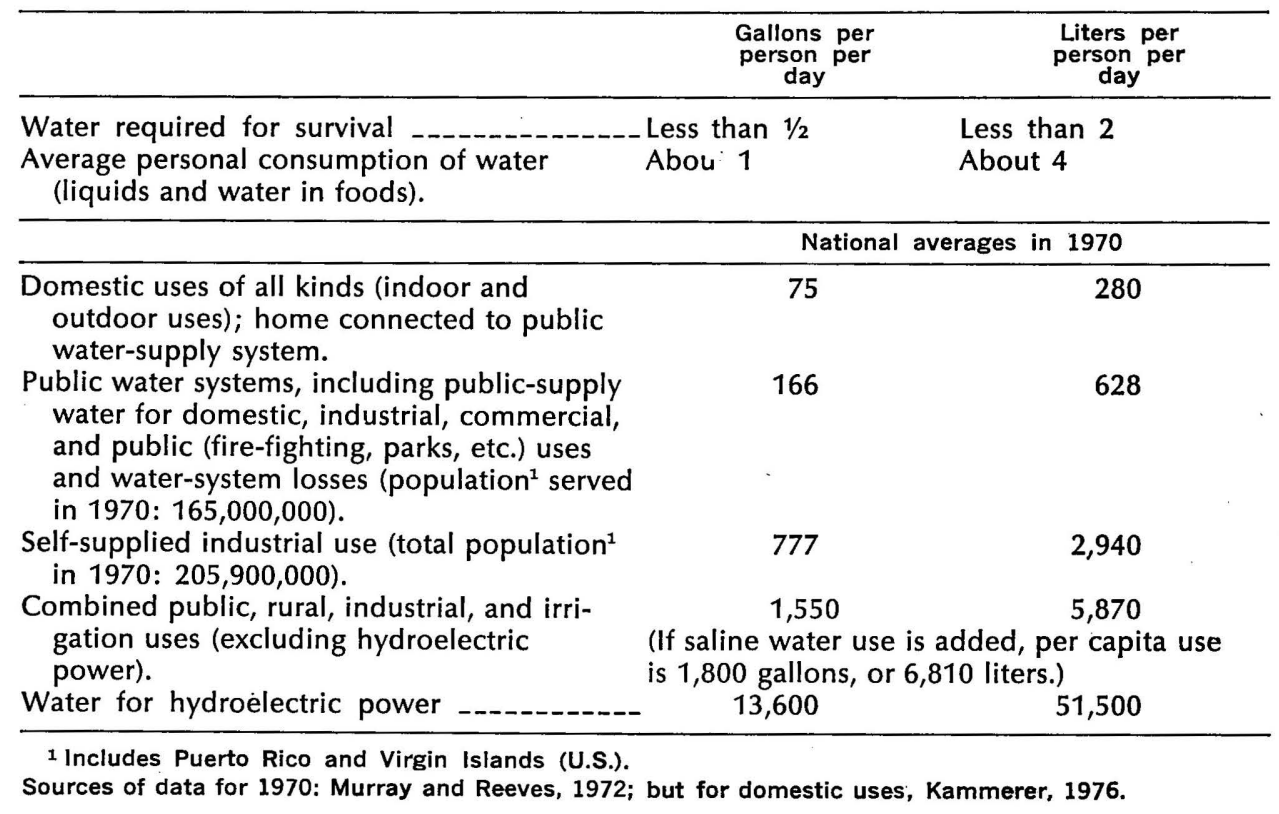

\section{WATER AS A COMMODITY: HISTORY AND LEGAL CONCEPTS}

One of the most significant trends in our water-use picture is the change since colonial times, when water was considered an essentially free resource, to the present, when water has become a very expensive commodity in some locations.

English common law regarded water as a commonproperty resource for those who owned land along uses were for power in milling and manufact: ring processes, and those uses were not consumptive or otherwise detrimental to water used by other riparian owners. This doctrine was brought by the colonists to the Eastern United States where it still strongl influences the water laws of the Eastern States. Or the other hand, water legislation in most of the We tern States was more influenced by Spanish law and custom, and it was generally adapted to meet the particular needs of miners, farmers, and ranchers in arid regions. The appropriation doctrine which evolved as 
a key element of western water law held that the person who first diverted water and put it to a beneficial use had a right to maintain that diversion and use. Any subsequent upstream diverters could only operate on the condition that prior rights were being satisfied. This was a doctrine that recognized water rights as real property, but it frequently did not provide for marketing arrangements, and the concept of setting a price for water still had not been developed. The idea of free water for those who would develop and use it fit well with the concepts of westward expansion; the natural resources of the West were presumed to be available for those with the initiative to exploit them.

As water needs of the public increased for such purposes as fire protection, dust control, sanitation, disease eradication, and domestic consumption, there was a significant increase in the extent of water-supply systems, leading to a general transition from private to public ownership of water companies. In the West, the simple irrigation systems on individual farms gave way to large irrigation districts that required the capital and efforts of many. User charges to recover the capital costs and provide for operating and maintenance costs became accepted, but the mechanisms for pricing and marketing water rights developed slowly.

As increases in water use deplete the easily developable supplies, more costly additional supplies are being sought. As the costs of water go up, water resources become more and more like other economic commodities for which there are supplies, demands, and a pricing and marketing structure to balance the supplies and demands. The influences and concepts of economists are being utilized in the study of water use. More commonly, water is being thought of as another input to a production process for which substitutions can be made. In the case of industry, treatment and recycling of water can substantially reduce withdrawals, but only with the expense of additional capital investments and increased energy and chemical costs. To be able to predict water use, some knowledge of the options for substitution that the factory, farm, or home manager has available is necessary so that the impacts of their decisions can be anticipated as the prices of water and other commodities change.

These few examples of water use and its variations and economic ramifications illustrate only some of the complexity and importance of water-use information. U.S. Geological Survey programs that define the time and space availability of the Nation's water supplies provide information, which-when compared to the water demands of industrial, agricultural, and municipal users-provide an assessment of our abili- ties to meet these current and future demands. However, studies and assessments of water use have not achieved the detail or degree of accurracy that is now found in water-supply information. Because water use is substantially affected by variables-economics, technology, and custom-much different than those affecting water supply, the methods and techniques for measuring and projecting water use must be developed from concepts and technical disciplines that go beyond the natural and physical sciences. The U.S. Geological Survey is cognizant of these needs and, in cooperation with State and local governments, is developing programs to acquire water-use data that are of the same order of accuracy as its water-supply data.

Simply stated, in the hydrologic cycle water moves from the atmosphere to the land and sea and back again into the atmosphere. Water use-both natural and controlled-occurring during the land-sea part of the hydrologic cycle includes (1) evapotranspiration from irrigated, nonirrigated, and wild vegetation, (2) evaporation from water surfaces, (3) withdrawal of water from streams, lakes, reservoirs, and wells, (4) dilution, assimilation, and transport of wastes, and (5) occupancy of surface waters as a habitat (by fish, wildlife, and so forth), a transport route (navigation), and a recreational facility.

For purposes of estimation and measurement, these water uses are grouped into three principal categories:

1. Withdrawal (or "off-channel") uses, such as withdrawal from a well or diversion from a stream, for public supplies, irrigation, and industry;

2. Nonwithdrawal, such as for hydroelectric power, navigation, recreation, preservation of wildlife and sport fishing habitat, salinity control, waste dilution, and transport;

3. Nonsupply uses (also sometimes referred to as "water losses" or "preemptive consumptive use $^{\prime \prime}$ ), such as evaporation from lakes and reservoirs and evapotranspiration from nonirrigated food and fiber crops.

Withdrawal uses are the most measurable and measured of the three categories of use, but they are measured far less frequently and systematically than water supplies (for example, the flow of water in streams). Figure 6 compares a few of the national water-use statistics for 1970 with respect to average quantities withdrawn and the part of the withdrawals that was consumed.

Nonwithdrawal uses (water uses that are not dependent on diversion of water from ground- or surface-water sources) may be categorized as flow uses and onsite uses. Navigation, hydroelectric power, sport fishing habitat, freshwater sweetening of saline estuaries, and the disposition and dilution of waste- 


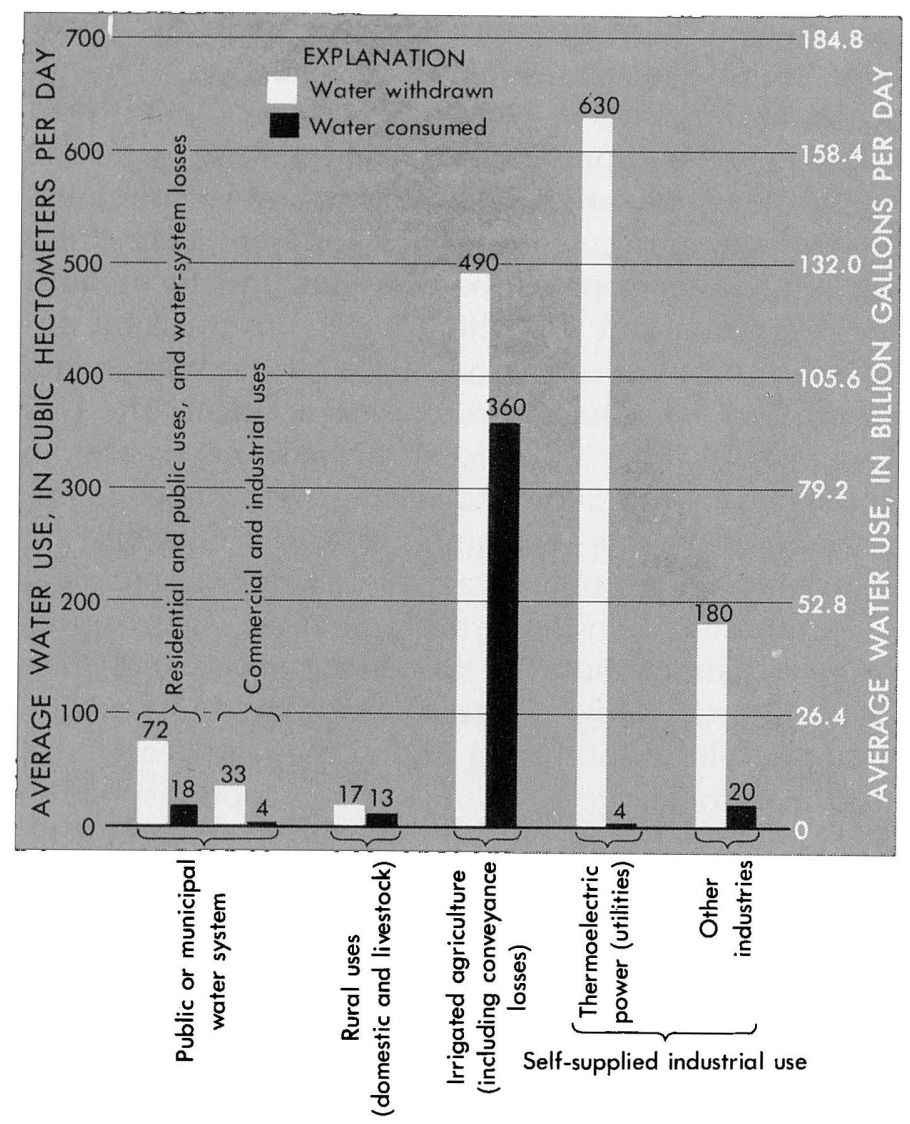

FIGURE 6.-Estimated water withdrawn and water consumed in the United States in 1970. Totals above each bar are in metric units; 1 cubic hectometer $=1$ million cubic meters= 264 million gallons. (Adapted from Murray and Reeves, 1972.)

water are commonly classified as flow uses; all these uses are accomplished by free-flowing water moving in a defined channel. Onsite uses are of two principal types: (1) water use which occurs in a watercourse, lake, reservoir, or other body of water, and (2) water use resulting from improvement of natural conditions, a use that is sometimes called "preservation use." Stream evaporation from an increased heat load is an example of the first type of onsite use, and water lost from improvements to swamps, wetlands, and fish hatcheries are examples of the second type. Many of the nonwithdrawal uses cannot be readily measured, thus presenting a hydrologic challenge for more accurate determination and for evaluation of their effect on the quantity and quality of water resources for all uses.

Perhaps surprisingly, more than 10 times as much water is used consumptively - in the category, "nonsupply uses" - by the naturally occurring processes of evaporation and transpiration in the growth of vegetation (forests, grasses, and nonirrigated crops) in the United States than is supplied nationwide for all with- atmosphere by this natural process is also referred to as a "consumptive and preemptive use," or sometimes as "water losses"; it is the remainder after runoff (streamflow) has been subtracted from precipitation. The sustained availability of large quantities of this nonsupply water-most of which occurs as soil moisture-constitutes a major natural resource. Without significant amounts of local soil moisture, commercial agriculture, as well as public parks and residential lawns and gardens, would not be possible unless there were major importation of water from other locations. Another nonsupply use is the evaporation of water from large water surfaces, such as lakes, rivers, and snow and ice fields. An extremely rough estimate of average nonsupply water use in the conterminous United States is 16,000 cubic heciometers per day ( 20 inches per year times 3 million square miles), most of which is evapotranspiration from vegetation. Nace (1967, p. 4) has pointed out that actual daily per capita water use for all purposes in an advanced society amounts to "many thousands of gallons, drawn chiefly from soil moisture."

\section{SUPPLY VERSUS DEMAND (WATER USE) IN 1970}

In the general terms of average nationwide water supply (based on streamflow), the United States has a great abundance of water-more than 3 tines as much as was withdrawn in 1970 and 14 times as much as was consumed during usage and therefore unavailable for reuse. Table 3 shows some supply-versusdemand relationships for the aggregated easters, central, and western parts of the Nation as well as or all the 48 conterminous States. What these data do not reveal is the great time and space variability and inequality of supply versus demand.

With resspect to variability of supply, table 4 shows the wide variations in flow of 8 large streams turing the past 15 years. Even the range in long-term average runoff per unit drainage area among these stre $\mathrm{ms}$ is significant. For example, using the 30-year refcrence period, 1941 to 1970 , as a common time base for making comparisons, the runoffs from the Delaware River and Ohio River basins are more than 11 and 8 times, respectively, the runoff of the Missouri River basin; this fact is obviously a natural consequence of the drier climate of the Missouri River drainag area in comparison with the more humid conditions that prevail in the Eastern States.

The Southwestern United States is the only area of the Nation where the amount of freshwater that is consumed actually exceeds the average runoff. Murray and Reeves, describing water use in 1970 1972, 
TABLE 3.-Estimated water supply versus water demand-regional (eastern, central, and western) water use in the conterminous United States in 1970. (Adapted from Murray and Reeves, 1972.)

\begin{tabular}{|c|c|c|c|c|c|c|c|c|c|}
\hline \multirow[b]{3}{*}{ Region } & \multicolumn{4}{|c|}{$\begin{array}{l}\text { The water we have ... } \\
\text { Average flow of streams in the } 48 \text { conter- } \\
\text { minous States } \\
\text { (Includes ground-water component of base } \\
\text { streamflow) }\end{array}$} & \multicolumn{5}{|c|}{$\begin{array}{l}\text { The water we use . . . } \\
\text { Water withdrawn and water consumed }\end{array}$} \\
\hline & \multicolumn{2}{|c|}{ Area } & \multirow{2}{*}{$\begin{array}{c}\text { Strean } \\
\text { Cubic } \\
\text { hecto- } \\
\text { meters } \\
\text { per day }\end{array}$} & \multirow{2}{*}{$\begin{array}{c}\text { discharge } \\
\text { Thousand } \\
\text { cubic } \\
\text { feet per } \\
\text { second }\end{array}$} & \multirow{2}{*}{$\begin{array}{c}\begin{array}{c}\text { Population } \\
\text { in } 1970\end{array} \\
\begin{array}{c}\text { Million } \\
\text { people }\end{array}\end{array}$} & \multicolumn{2}{|c|}{$\begin{array}{c}\text { Withdrawals } \\
\text { in } 1970\end{array}$} & \multicolumn{2}{|c|}{$\begin{array}{c}\text { Water consumec } \\
1970\end{array}$} \\
\hline & $\begin{array}{c}1,000 \\
\text { square } \\
\text { kilo- } \\
\text { meters }\end{array}$ & $\begin{array}{l}1,000 \\
\text { square } \\
\text { miles }\end{array}$ & & & & $\begin{array}{l}\text { Cubic } \\
\text { hecto- } \\
\text { meters } \\
\text { per day }\end{array}$ & $\begin{array}{l}\text { Billion } \\
\text { gallons } \\
\text { per day }\end{array}$ & $\begin{array}{l}\text { Cubic } \\
\text { hecto- } \\
\text { meters } \\
\text { per day }\end{array}$ & $\begin{array}{l}\text { Billion } \\
\text { gallons } \\
\text { per day }\end{array}$ \\
\hline $\begin{array}{l}31 \text { Eastern States }{ }^{1} \text { ( } 8 \text { eastern regions) --- } \\
10 \text { Central States }^{2} \text { (parts east of Con- }\end{array}$ & 2,713 & 1,047 & 2,800 & 1,100 & 144.7 & 770 & 2.10 & 45 & 12 \\
\hline $\begin{array}{l}\text { tinental Divide; } 5 \text { central regions) } \\
7 \text { Western States (parts west of Con--- }\end{array}$ & 2,980 & 1,150 & 640 & 260 & 27.1 & 240 & $j 4$ & 110 & 28 \\
\hline tinental Divide; 5 western regions) & 2,132 & 823 & 1,100 & 460 & 30.3 & 370 & 100 & 170 & 45 \\
\hline 48 States (conterminous United States) -- & 7,825 & 3,020 & 4,500 & 1,800 & 202 & 1,400 & 360 & 320 & 85 \\
\hline
\end{tabular}

1 Excludes some parts of Arkansas, lowa, Louisiana, Minnesota, and Missouri.

NOTE: Stream-discharge and water-use data rounded to 2 significant figures.

p. 13), stated "Both water withdrawals and consumption in the Lower Colorado Region exceed the supply originating in the area; this is made possible by augmentation of the supply by inflow of water from the Upper Colorado Region, importation of surface water, repeated withdrawals of the same surface water, and mining of ground water."

Water use in 1970 is compared with average annual runoff in figure 7 . The first number shown within each region is the percentage of average runoff withdrawn

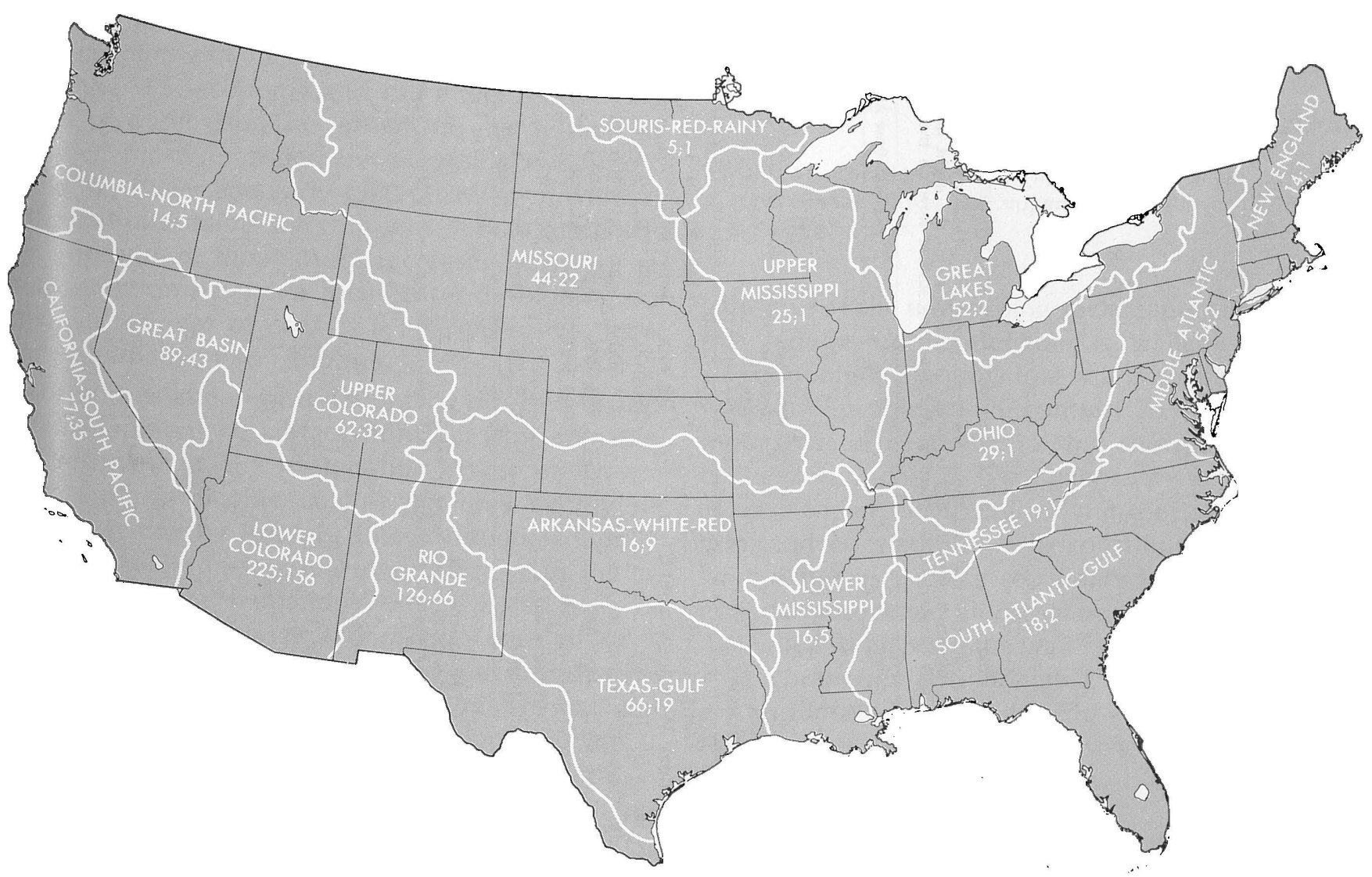

FIGURE 7.-Water withdrawn (used) in 1970 as a percentage (first number) of annual runoff (long-term average), and water consumed in 1970 as a percentage (second number) of annual runoff, in each water-resource region in the conterminous United States. (Adapted from Murray and Reeves, 1972, p. 17.) 
TABLE 4.-Maximum and minimum flows and runoff of eight large rivers since 1960

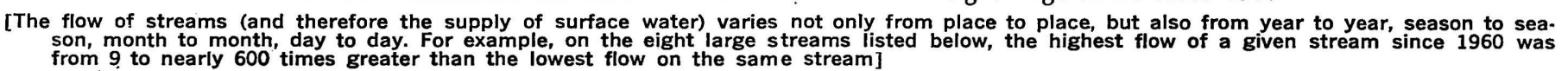

\begin{tabular}{|c|c|c|c|c|c|c|c|c|c|}
\hline \multirow[b]{2}{*}{ Station } & \multirow[b]{2}{*}{$\begin{array}{l}\text { Drainage } \\
\text { area, in } \\
\text { square } \\
\text { kilometers }\end{array}$} & \multicolumn{3}{|c|}{ Highest flow since October 1960} & \multicolumn{3}{|c|}{ Lowest flow since October 1960} & \multirow[b]{2}{*}{$\begin{array}{c}\text { Average } \\
\text { runoff } \\
1941-70, \\
\text { in } \\
\text { cubic } \\
\text { meters } \\
\text { per day } \\
\text { per } \\
\text { square } \\
\text { kilometer }\end{array}$} & \multirow[b]{2}{*}{$\begin{array}{c}\text { Average } \\
\text { runoff } \\
1970, \\
\text { in } \\
\text { cubic } \\
\text { meters } \\
\text { per day } \\
\text { per } \\
\text { square } \\
\text { kilometer }\end{array}$} \\
\hline & & Date & $\begin{array}{c}\text { Discharge, } \\
\text { in } \\
\text { cubic } \\
\text { hecto- } \\
\text { meters } \\
\text { per day }\end{array}$ & $\begin{array}{c}\text { Runoff, } \\
\text { in } \\
\text { cubic } \\
\text { meters } \\
\text { per day } \\
\text { per } \\
\text { square } \\
\text { kilometer }\end{array}$ & Date & $\begin{array}{c}\text { Discharge, } \\
\text { in } \\
\text { cubic } \\
\text { hecto- } \\
\text { meters } \\
\text { per day }\end{array}$ & $\begin{array}{c}\text { Runoff, } \\
\text { in } \\
\text { cubic } \\
\text { meters } \\
\text { per day } \\
\text { per } \\
\text { square } \\
\text { kilometer }\end{array}$ & & \\
\hline Delaware River at Trenton, N.J & 17,560 & June 30,1973 & 330 & 18,800 & Oct. 31,1963 & 2.89 & 165 & 1,550 & 1,480 \\
\hline Potomac River near Washington, D.C & 29,940 & June 24,1972 & 878 & 29,300 & Sept. 10, 1966..- & 1.47 & 49.1 & 825 & 858 \\
\hline Ohio River at Louisville, Ky & 236,100 & Mar. 12,1964 & 1,920 & 8,130 & Aug. 2, 1965 & 12.5 & 52.9 & 1,140 & 1,080 \\
\hline Apalachicola River at Chattahoochee, Fla & 44,500 & Mar. 8, 1966_-- & 401 & 9,010 & Nov. $8,1962 \ldots$ & 14.9 & 335 & 1,190 & 1,060 \\
\hline Missouri River at Hermann, Mo & $1,368,000$ & Apr. 25, 1973 & 1,220 & 890 & Dec. 23,1963 & 14.8 & 10.8 & 137 & 151 \\
\hline Mississippi River at Vicksburg, Miss & $2,964,300$ & May 12,1973 & 4,800 & 1,620 & Jan. 8, 1964 & 308 & 104 & 466 & 460 \\
\hline Sacramento River at Verona, Calif & 55,056 & Jan. 26,1970 & 190 & 3,450 & Oct. 11, 1961 & 14.9 & 271 & 867 & 1,050 \\
\hline Snake River at Weiser, Idaho & 179,230 & Dec. 25,1964 & 177 & 988 & July $18,1961 \ldots$ & 18.9 & 105 & 243 & 254 \\
\hline
\end{tabular}

Approximate equivalents:
1 square kilometer $=0.386$ square mile.

1 cubic hectometer per day $=409$ cubic feet per second.
1 cubic meter per day per square kilometer $=0.001$ cubic foot per second per square mile. 
in 1970, and the second number is the percentage of average runoff consumed in 1970. Average runoff is the maximum amount of water that would be perennially available if the maximum water-resource development and management were accomplished. However, the actual dependable supply, even under those circumstances, might be as little as one-third of the average runoff in some parts of the Nation because of wide variations in flow from season to season and from year to year and because of topographic, geologic, hydrologic, ecologic, and economic constraints on reservoir construction.

\section{WHAT ARE SOME OF OUR INFORMATION NEEDS?}

Water-use information is needed at all levels of water-resource planning-from the designing of an individual household's self-supplied water system to planning for the development of our largest river basins. The analyses of the effects of potential legal or policy water decisions also require water-use information, whether the issue at hand is a temporary ban on lawn watering or a national policy on nuclearpowerplant siting.

The past few years have demonstrated how rapidly radical changes can affect the directions of some sectors of the U.S. economy and can affect the national pattern of water use. The growth in energy demand hit been mostly satisfied by increasing oil imports during the 1960 's and early 1970's. However, with the realization of possible interruptions of oil imports and their subsequent momentous increases in price, national attention has been focused on developing our extensive reserves of coal as a less expensive, more secure alternative to oil imports.

Most of this attention is now being directed toward the development of surface-minable (strip-minable) coal reserves in the water-short Western United States. Surface-minable coal is the only energy resource that can be brought into production rapidly, and it is usually less costly to produce than underground coal. The semiarid Western States have 63 percent of the demonstrated reserve base of strippable coal in the United States, and much of this has a desirably low sulfur content. Figure 8 shows the location of some of the principal western deposits of coal, including those minable by surface methods. Comparing this with the existing water uses in figure 7 , it can be seen that the coal deposits occur in areas in which the existing water use is high.

Direct water requirements for surface coal mining are not large; the modest demands for sanitary and dust-control purposes can usually be met locally. Irri-

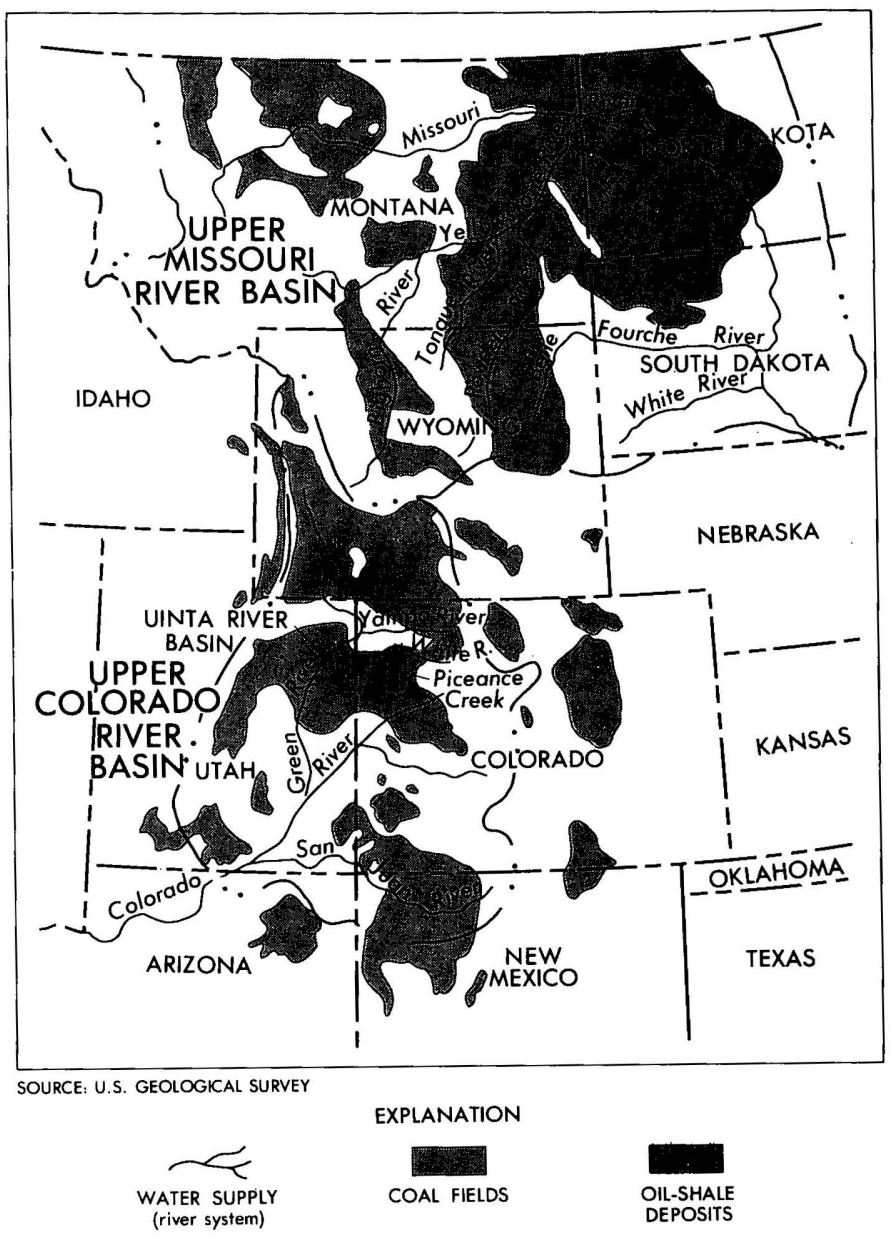

FIGURE 8.--Location of coal fields and oil-shale deposits in upper Missouri River and upper Colorado River basins, Western United States.

gation of spoils undergoing reclamation in arid areas may require more water than is available on a mine site but only in amounts that will not cause significant water-use problems. In contrast to these relatively modest water needs for mining and reclamation, the conversion of coal to secondary forms of energy such as gas, oil, or electricity for transportation, distribution, and consumption will constitute a significantly large water use. These secondary industries will also generate associated industrial and commercial growth that will also increase the water use.

The preponderance of high-grade oil-shale deposits are also located in the semiarid West (fig. 9). In addition to water used for processing and cooling in shaleretorting operations, water is used for compacting the spent shale material.

The very great demands that will be made on water and environmental resources for energy conversion are only "the tip of the iceberg" compared to the ensuant demands that will be made for industrial, residential, and commercial development. These in- 


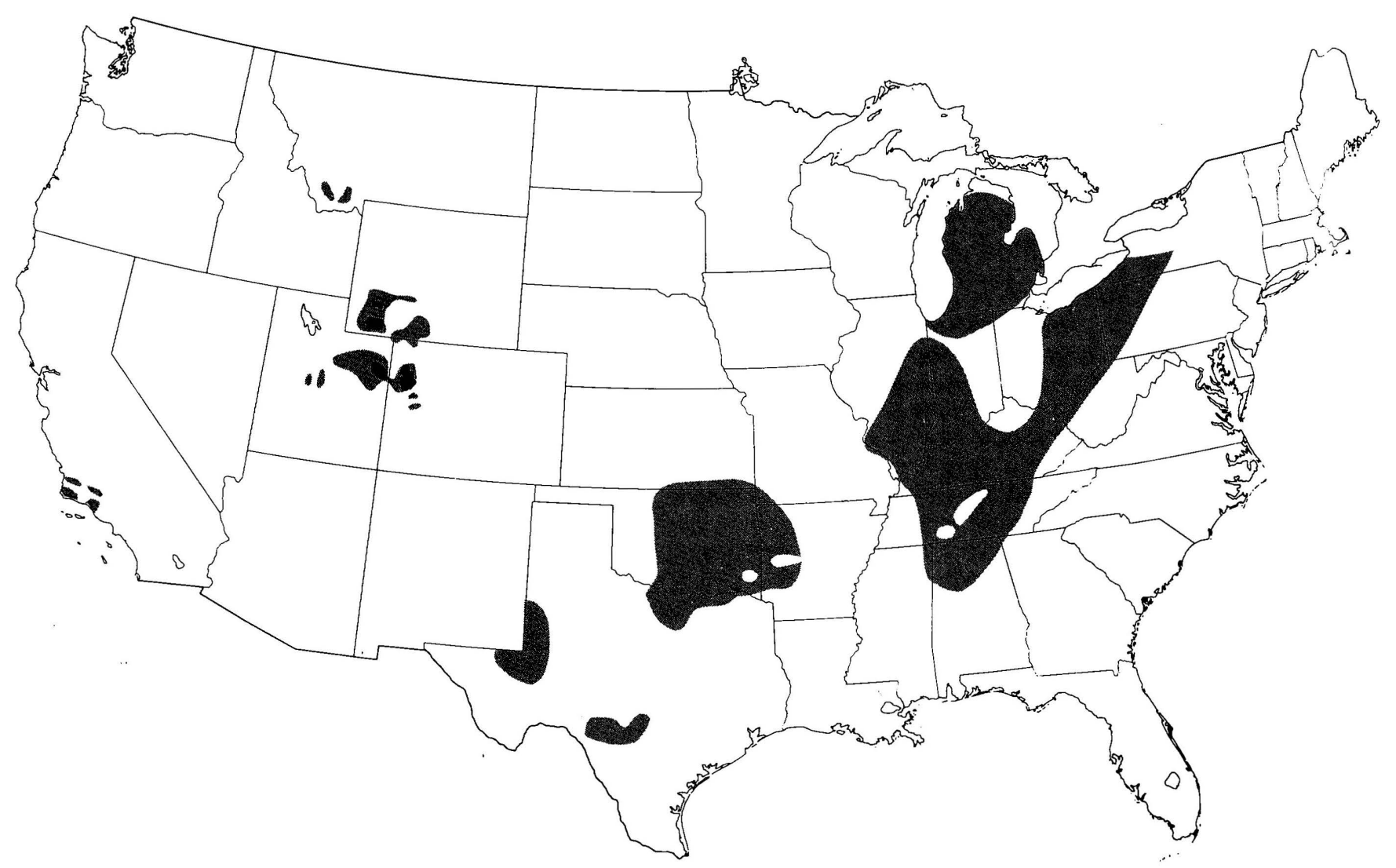

FIGURE 9.-Principal reported oil-shale deposits in the conterminous United States. Solid-black areas in Colorado, Uta:, and Wyoming are known to contain high-grade deposits.

creased water-use needs cannot be met by the already overcommitted available water supply; rather, they must come from a transfer of water rights from one type of use to another.

This will often mean that water which up to now has been used for agricultural purposes will subsequently be sold to industrial users. If the water was used to irrigate hay and feed-grain crops, its loss might considerably change the character of ranching and, hence, change the ambience of the area. Most water users, especially industrial users, have options for using less water, but these options require higher capital investments and operating costs. If a user can legally buy water from other users, he will do so, but if water transfers are not permitted, the costs of reducing water use will eventually be passed on to consumers. To thoroughly evaluate the social, environmental, and economic effects of energy development, detailed information on water-use options and their costs must be developed for the energy-conversion industries and for other major water users who will be directly or indirectly involved in energy production and development. Also to be considered are industries that are purposely located near energyconversion industries in order to utilize products or
Detailed analyses of plant-level options for converting coal to gas, oil, and electricity and the effects of these options on water use have been unde taken, and some are near completion. Methods for projecting water use for secondary development resulting from increased energy development and for relating these water demands to supply capabilities ayd environmental resources are being studied.

\section{HOW ARE WATER-USE INFORMATIOW SYSTEMS DEVELOPED?}

It is necessary for a planner or designer of a new water-supply system to study other similar systems in order to estimate water demands for the new system, but, because this type of information is ofter scattered throughout thousands of reports from owns, cities, public-health agencies, and engineering firms, it is not always easy to find. Aggregate water-use information for a region or an industry is even more difficult to assemble because some companies are hesitant to disclose information about their operations that might be useful to competitors.

The need for a more centralized source of vateruse information has led to the development of some 
data-collection and data-reporting systems. These have usually been based on periodic assessments made by conducting many interviews and canvasses, collecting data from secondary sources, and estimating to fill the gaps. The quality of water-use information ranges from the accuracy obtained for metered uses to the uncertainty of hydrologic estimates of irrigation conveyance losses. In fact, a major proportion of existing water-use data consists of estimates that are of such limited accuracy as to be useful only in very general assessments of water problems.

The economic fact that consumers usually use less of a commodity as it becomes more expensive, but use more of it as their incomes increase, indicates that information on income and water prices, as well as a number of related items of information about household size, house-lot size, and property values, may be helpful in estimating variations in water use. Equations can be developed to make these estimates, but statistical analyses must be based on data that include economic and demographic information as well as water-use information.

For estimating the effects of changing prices and technology on industrial water use, another type of detailed analysis can be made on an industry-byindustry basis for industries that use large amounts of water. These plant-level analyses of the processes involve detailed engineering-economic studies of how existing plants are operated or how new plants should be designed and operated in order for the company operating the plant to maximize profits under current prices and regulations. Existing plants often cannot significantly change their rate of water-use without extensive retrofitting. New plants, however, have a much wider range of process technologies to choose from for minimizing production costs under changed economic conditions. For cooling purposes, one of the largest uses of industrial water, a lower water use can usually be achieved at a cost of increased water consumption, and the converse is also usually true. The recent increases in energy prices relative to water costs may alter the historical trend toward less waterintensive cooling systems. Plant-level analyses of the total costs of various cooling systems can be used to determine the directions that future changes in water use will take.

\section{SUMMARY AND CONCLUSIONS}

We can estimate past and present water uses, but total water needs for most withdrawal uses are changing; water use is responsive to prices, technology, customs, and regulations. Although inventory systems for estimating water use are good indicators of past and present uses, such systems are not as accurate or as frequently reported as we would like, and they do not show us future water-use trends.

Providing more complete and accurate water-use information will involve the work of many hydrologists, engineers, and economists. It will require more detailed and complete water-use data and a wider knowledge of local factors. Much of the information can be collected by State or local agencies, and a well planned, nationally consistent effort can produce data that will serve many purposes. However, providing water-use information for all purposes will require additional comprehensive statistical-data and engineering analyses of water-use options at the plant level. These analyses can provide information on changing conditions, and, with this knowledge, it will be possible to construct computer models for regional assessments of water use in relation to water supply.

For most of our Nation, the period of free and easily developed water supplies has ended; in some areas, water use is approaching or exceeding the available supply. We are, however, not running out of water. Much still remains to be done toward modifying the occurrence of water to better fit regional demands, and, more importantly, many options for modifying water use and reuse remain to be explored. The development of new water supplies will take more time than the development of methods for better utilizing water through reuse, conservation, and new technologies.

Sometime in the future, the manufacture of a 12ounce beverage can will have considerably different water-use effects. We must prepare for these effects if that 12-ounce can is to continue to be available to us.

\section{REFERENCES}

Kammerer, J. C., 1976, Water quantity requirements for public supplies and other uses, in Gehm, H. W., and Bregman, J. I., Handbook of water resources and pollution control: New York, N.Y., Van Nostrand Reinhold Co., p. 44-83.

Murray, C. R., and Reeves, E. B., 1972, Estimated use of water in the United States in 1970: U.S. Geol. Survey Circ. 676, $37 \mathrm{p}$.

Nace, R. L., 1967, Are we running out of water?: U.S. Geol. Survey Circ. 536, 7 p.

Reid, G. W., 1965, Projection of future municipal water requirements: Southwest Water Works Jour., v. 46, no. 12, p. $18,20$.

Russell, G. S., and Vaughan, W. J., 1976, Steel production: Processes, products, and residuals: Baltimore, Md., The Johns Hopkins University Press, 328 p.

Walling, F. B., and Otts, L. E., Jr., 1967, Water requirements of the iron and steel industry: U.S. Geol. Survey Water-Supply Paper 1330-H, p. 341-394. 


\title{
The Federal- State Cooperative Water-Resource Program, A Unique Partnership in Government
}

\author{
By J. S. Cragwall, Jr.
}

The Federal-State Cooperative water-resources program of the U.S. Geological Survey is a unique, mutually beneficial working partnership between the U.S. Geological Survey on the one hand and public agencies in all 50 States on the other. It began in 1895 and in the ensuing decades has produced water data and reports that are used as a basis for national and local decisionmaking and planning wherever water-resources and water-quality problems exist. It is a partnership in equity, funded primarily on a 50-50 basis, an arrangement that has stood well the test of time.

\section{ORIGIN AND DEVELOPMENT}

From its inception in 1879, the U.S. Geological Survey has regarded cooperation on scientific matters, both formal and informal, as essential. The first formal cooperative arrangement was with the State of Massachusetts in 1884 for preparation of a topographic map of the State. The Director of the Survey, Major Powell, and the Board of Commissioners of the State of Massachusetts agreed that the State would pay onehalf the expense of topographic fieldwork and the Federal Survey one-half, the latter to engrave the maps and give transfers of the plates to the State Commissioners.

Cooperation that offered the advantage of pooling severely limited resources toward gaining mutual advantages increased steadily and by 1895 included water-resources investigations. The States and their subdivisions offering more funds or other resources than the Survey could match because of its limited budget or because the Survey was anxious that the work done contributed to the fulfillment of its national responsibilities. It was this condition that was elaborated by Director Wolcott in the Survey's annual report of 1901.

One important point to be considered in all such work is that the general plans and methods of the Federal Survey cannot be set aside on account of State cooperation. At the present time the funds available for cooperation are so limited that its further extension is dependent upon increase of appropriations by Congress. It is against the policy of the Survey that work on important areas or subjects should be stopped in
The Director is willing to enter into a cooperative agreement only when the interests of the country as a whole will be benefited.

With that brief account of its roots, we turn our attention to the Federal-State Cooperative program of the Survey's Water Resources Division.

Although cooperation was begun with Kansas in 1895 for stream gaging, appropriations earnarked specifically for cooperative studies were first made to the Survey by Congress in fiscal year 1906. Thu began the partnership between the States and the Ceological Survey that continues to this day as the fou!ndation of the Water Resources Division's program. Eecords of the Division's first cooperative ventures with State and local agencies are vague. The agreemen s were rather informal and varied a great deal from tate to State. In some instances most of the money $v$ as furnished by the Survey; in others, by the State. 'n general, however, because of the usefulness of th a work to them and the very small size of the Federal appropriation, the States contributed more than ralf the cost of the studies.

Beginning with fiscal year 1929, and in resp onse to the demands of State officials and engineering organizations, Congress established the principle o 50-50 matching funds between the Survey and St te and local agencies. This principle recognizes a m ituality of benefit from the partnership arrangement. On the one hand, State willingness to participate is prima facie evidence of value to the State. It shc uld be recognized, however, that in view of the rapi offerings of cooperative funds by the States, it $h$ s been the skills and impartiality of the Survey that ha e been so eagerly sought by the States and local ;overnments. Most water projects studied or underta ken are under controversy among conflicting interes $\$$. Data and studies produced by the Survey are acceted by both sides in interstate, intrastate, State-loc 1 , and international disputes. In these days of growi.ig tendencies toward adversary proceedings, it is important to preserve those impartial services that $t$ nd to broaden the base of acceptability and narrow the scope of controversy.

On the other hand, information required s carry out Federal-agency missions, interstate and oternational compacts, Federal law and court decres $s$, congressionally mandated studies, and region il and 
national assessments and planning activities is patentIy in the Federal interest. All these various studies and projects depend heavily on the data base acquired through the cooperative program as well as through special investigations made with Federal funds appropriated for that purpose or transferred from other Federal agencies. For example, in 1976 the Survey stream-gaging stations used for river forecasting by the National Weather Service represented an outlay of $\$ 5$ million for work by the Geological Survey; of this amount, the Federal-State Cooperative program provided more than $\$ 2$ million. As another example, in 1976, Survey-funded stations providing data used by the U.S. Army Corps of Engineers represented an outlay of $\$ 6$ million, of which $\$ 2$ million was from the cooperative program.

\section{THE PROGRAM TODAY}

The program has grown and has changed with time. Today the program is a composite of activities covered by more than 500 cooperative agreements with jurisdictions in all the States and several of the territories, wherever there are water problems. Through this network of contacts with the "real" world of water conservation, development, and use, the Survey's Water Resources Division has been able to anticipate and to respond to changing priorities. Thus, the work is diversified, problem oriented, and strongly interdisciplinary. For example, the activities listed in a recent sampling of a few State programs include: collection of long-term multipurpose data (surface water, ground water, and water quality); special interpretive studies of the physical, chemical, and biological characteristics of water resources; and appraisals for environmental impact analysis, energy development, coastal-zone management, subsurface waste storage, waste utilization, land-use planning, floodplain management, and flood-warning systems.

The Federal-State contribution to the waterresources mission of the Geological Survey can be measured in terms of dollar support to the overall effort of the Water Resources Division. From 1941 to 1976 , a period for which reliable records are available, 57 cents of each dollar spent on data collection and research by the Water Resources Division came from the Federal-State cooperative program. Other measures are activity and output. For example, in 1976, of the 8,000 stations comprising the basic streamflow network, the cooperative program was the sole support for 2,600 stations and contributed to the support for 2,500 others. Of about 1,200 active projects (areal, topical, and research) underway, about 700 were in the cooperative program, and of about 750 reports published on water resources, about 500 came from the cooperative program.

Administratively the cooperative program has several distinctive characteristics. It is decentralized; the work is done through 47 district offices, nearly one for each State. Details of programs are negotiated at State or local level by representatives of the Survey with representatives of the cooperating agencies. Implementation is under Survey direction and by Survey staff, principally, but there is an accountability for performance to the State partners. Mutual trust based on years of satisfactory collaboration has minimized the paperwork usually associated with cost-shared programs, and to formalize the arrangement a simple one-page standard cooperative agreement is used with few exceptions.

Advantages from the administrative arrangement accrue to both Federal and State sides. Most evident is the cost-sharing that approximately doubles the activity that might be afforded by each. Additionally, what is in effect a pooling of manpower in the relatively small field of hydrology provides advantages of scale for recruiting, training, and career opportunity; for supportive activities such as laboratories and research; and for mobility to meet new needs where and as they develop. Cost-sharing and decentralization increase the responsiveness of the program to grass-roots, real-world needs and provides early indication of emerging local problems that often merge and become national problems. Unified management provides common standards nationwide, uniformly reliable and comparable output, and assures the availability of that output to the public at large.

\section{AN EVALUATION}

The Nation's ability to cope with new and challenging problems in water management rests largely on data and surveys made over the preceding years in the cooperative program. For example, flood-plain management (including flood-plain zoning and flood insurance) is a relatively new concept in the national scene for abating flood damages. But the procedures and data on which flood-plain management programs depend have their origin in the Survey's cooperative programs with State and local agencies. As another example, ground water-so important to the community, the farm, and the home-was investigated in the early days almost entirely within the cooperative program, when there was little recognition of ground water as a national problem. Today, the potential for pollution of ground water is receiving national attention, for, once contaminated, ground water may be ruined as a resource and become instead a danger to 
health. The source of most knowledge of ground water now being used by concerned national agencies was first evolved as part of the cooperative program. Similarly, environmental assessment, now part of all national planning, uses water-resources information from many of the reports that have stemmed from the cooperative program.

The long reliance of State and local authorities upon the U.S. Geological Survey for water facts and water studies and for funds and staff to do the work reflect the cooperators' experience that the Survey has been an effective supplier of data and services and has at the same time maintained high scientific and engineering standards. The Survey offers a core of talent that is rooted in research-and so advances the application of research to practice; it assures impartiality - if one party pays for the work, the adversary party will credit the results; it offers continuitywater information gains in value with length of record; it offers transferability-lessons learned in a study anywhere in the country are available for another.

Perhaps the strongest point of all in evaluating the existing Federal-State Cooperative program, and determining whether any change is desirable, is the uncertainty about what direction the future is taking. This Nation-along with most other nations - is in the midst of convulsive changes, the only certain factor being the continuity of basic human needs on an ascending scale. Water is one of the most valuable resources, and to fail to have it assessed correctly could result in failure to use it intelligently, with farreaching disastrous effects. Because the availability of water of suitable quality is a fundamental limiting factor in an expanding economy, a comprehensive and forward-looking data-collection operation is imperative to the best planning for the future development and use of the Nation's water resources. The job is too large to be supported at either Federal or State level alone; on the other hand, the jointly planned and funded cooperative program provides budgetmakers with the most convincing assurance that the work is designed to meet both national and local needs.

\section{THE OUTLOOK}

In looking ahead, the main purpose of the rederalState Cooperative program from the national point of view will continue to be to provide facts needed to maintain relevance to problems in advance of their blossoming as national crises, to match resources to the work to be done, and to assure availability of information nationally to all users. From the State and local point of view, the objective will be to assure impartiality, skill, and continuity in the maintensince of an adequate water-data base. The cooperative program has successfully satisfied both objectives in the past and should continue to do so in the future.

\title{
Prospects for Automated Mapping
}

\author{
By Morris M. Thompson and Madonna K. Elliott
}

Cartographers have been talking about the prospects for complete automation of map production ever since modern computers first displayed their wondrous powers. There is relatively little realization of these prospects today, however, because research has usually been fragmented, and few developments have proved to be cost effective. At the same time, optical and mechanical improvements have upgraded mapping equipment to the extent that, with the computer plugged in at a few points, mapping productivity has steadily increased. For example, in 1965 it look about 27 man-hours to complete 1 square mile of topographic mapping at the scale of $1: 24,000$; in 1975 the same work took only about 12 man-hours. Even so, only some 36,000 of the $54,0001: 24,000$ scale general-purpose topographic maps it takes to cover the 48 conterminous States have been published, and a fourth of these need revision. The fact is 30 that current methods of producing and maintaining cartographic information are not meeting all of today's needs, let alone the projected needs of the future.

By all accounts, our Nation faces extensive shortages of natural resources before the turn of the century. Consumption of resources is at an all-tir:e high and is steadily increasing to fulfill society's expectations for a better quality of life. The land is pr ssured relentlessly by population growth, urbanization and suburbanization, new technology, and increased leisure time for outdoor recreation.

Planners, decisionmakers, environmentalis 5 , and developers all face the need to analyze millions of acres of land, often without a complete inver ory of the resources and physical features or of the teractions of the environment and human activitics. The prerequisite for such an inventory is a carto,raphic base of one kind or another. The demand toda is not only for conventional maps and charts in increased 


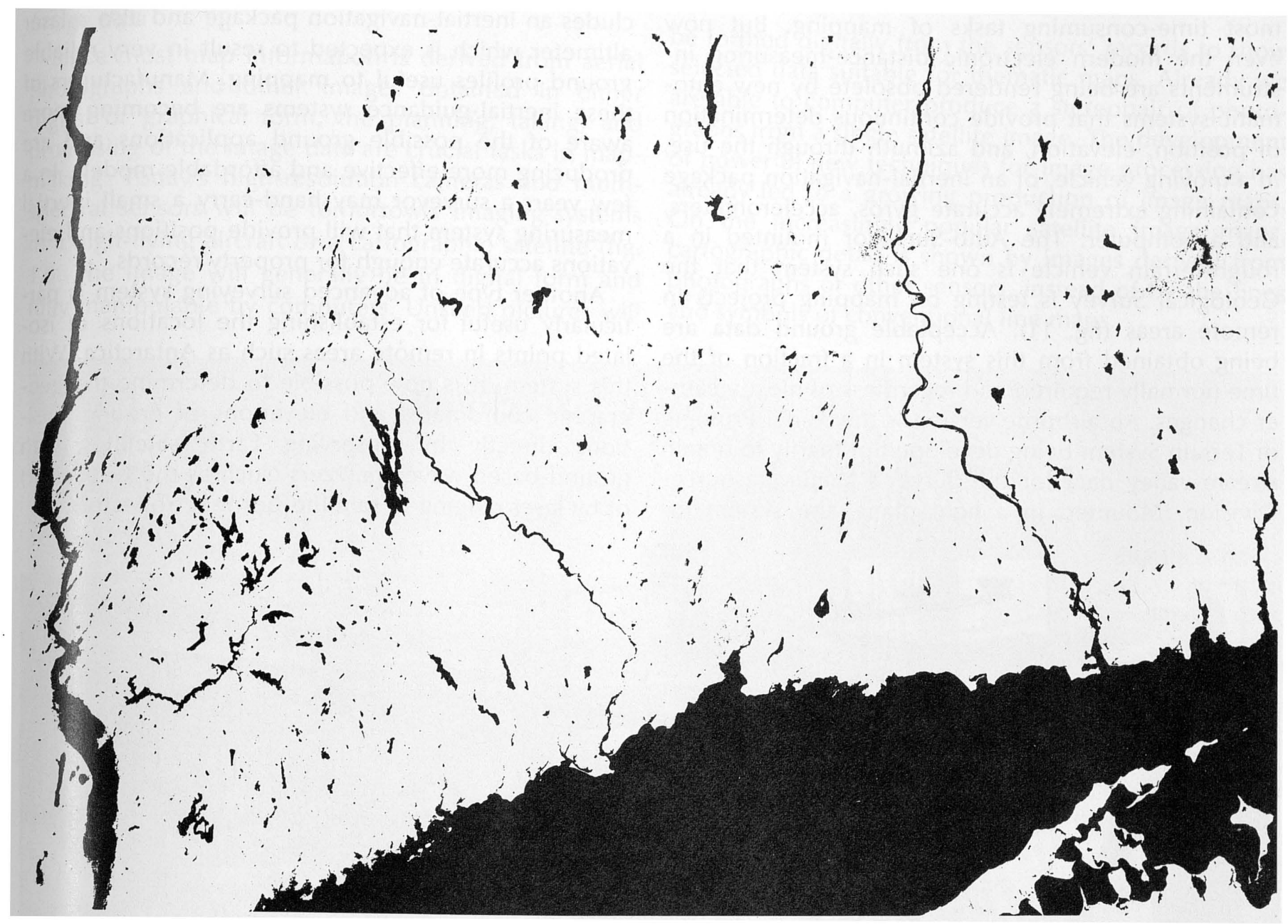

FIGURE 10.-Autographic theme extraction of open water from space (Skylab) image data. Area shown is same as area covered by the Hartford, Conn., 1:250,000-scale quadrangle $\left(1^{\circ} \times 2^{\circ}\right)$. The prominent stream at left is the Hudson River; Long Island Sound is at the bottom.

quantities, but for photomaps, slope maps, land-use maps, county maps, regional maps, urban maps, flood-insurance maps, and thematic maps (fig. 10) of endless variety. The key to storing, updating, and quickly retrieving this vast body of information is the computer. When the data are digitized, that is, coded in computer-readable form, they can be rapidly manipulated to produce maps of any desired content and form, and they can be correlated with other geographically related information systems for total problem analyses.

Fortunately, automated mapping techniques are now emerging from research laboratories to give new hope of meeting the immense cartographic requirements of the days to come. The techniques are based on powerful data-processing systems, on ingenious inertial-guidance packages, on sophisticated use of spacecraft, on highly selective remote sensors, and on wide-ranging methods for processing and analyzing imagery. Conventional map-production methods will be changed radically, mainly to expedite the process.
In each major phase of the mapping operation the prospect of automation is becoming reality. These major phases can be set down in outline form:

1. Acquisition of geodetic data to tie the map to correct positions and elevations on the Earth's surface.

2. Acquisition of image data in the form of aerial photography or other sensing systems to provide detailed map information.

3. Compilation of the map from the image data, in proper relationship to the geodetic data.

4. Finishing the map by preparation of color-separated printing plates from the manuscript material for line maps, or completion of appropriate cartographic requirements for image maps.

Let us now consider the outlook for automation in each of these phases:

\section{Geodetic data}

Ground surveys to establish horizontal position and elevation have constituted one of the costliest and 
most time-consuming tasks of mapping. But now even the modern electronic distance-measuring instruments are being rendered obsolete by new automatic systems that provide continuous determination of position, elevation, and azimuth through the use, in a moving vehicle, of an inertial-navigation package containing extremely accurate gyros, accelerometers, and a computer. The Auto-Surveyor mounted in a rough-terrain vehicle is one such system that the Geological Survey is testing on mapping projects in remote areas (fig. 11). Acceptable ground data are being obtained from this system in a fraction of the time normally required and regardless of most weather changes. An airborne version is the Aerial Profiling of Terrain System being developed primarily to obtain stream-valley data for the Survey's Water Resources Division. Mounted in a light plane, the system in- cludes an inertial-navigation package and also a laser altimeter which is expected to result in very reliable ground profiles useful to mapping. Manufacturers of these inertial-guidance systems are becoming more aware of the possible ground applications and are producing more effective and affordable models. In a few years a surveyor may hand-carry a small inertial measuring system that will provide positions and elevations accurate enough for property records.

Another type of advanced surveying system is particularly useful for establishing the locations of isolated points in remote areas such as Antarctica. With this system, it is now possible to determine the geographic coordinates and elevations of ground positions directly by observing Earth satellites with ground-based wave analyzers (such as the Geoceiver) or by laser ranging to satellite-borne retroflectors.

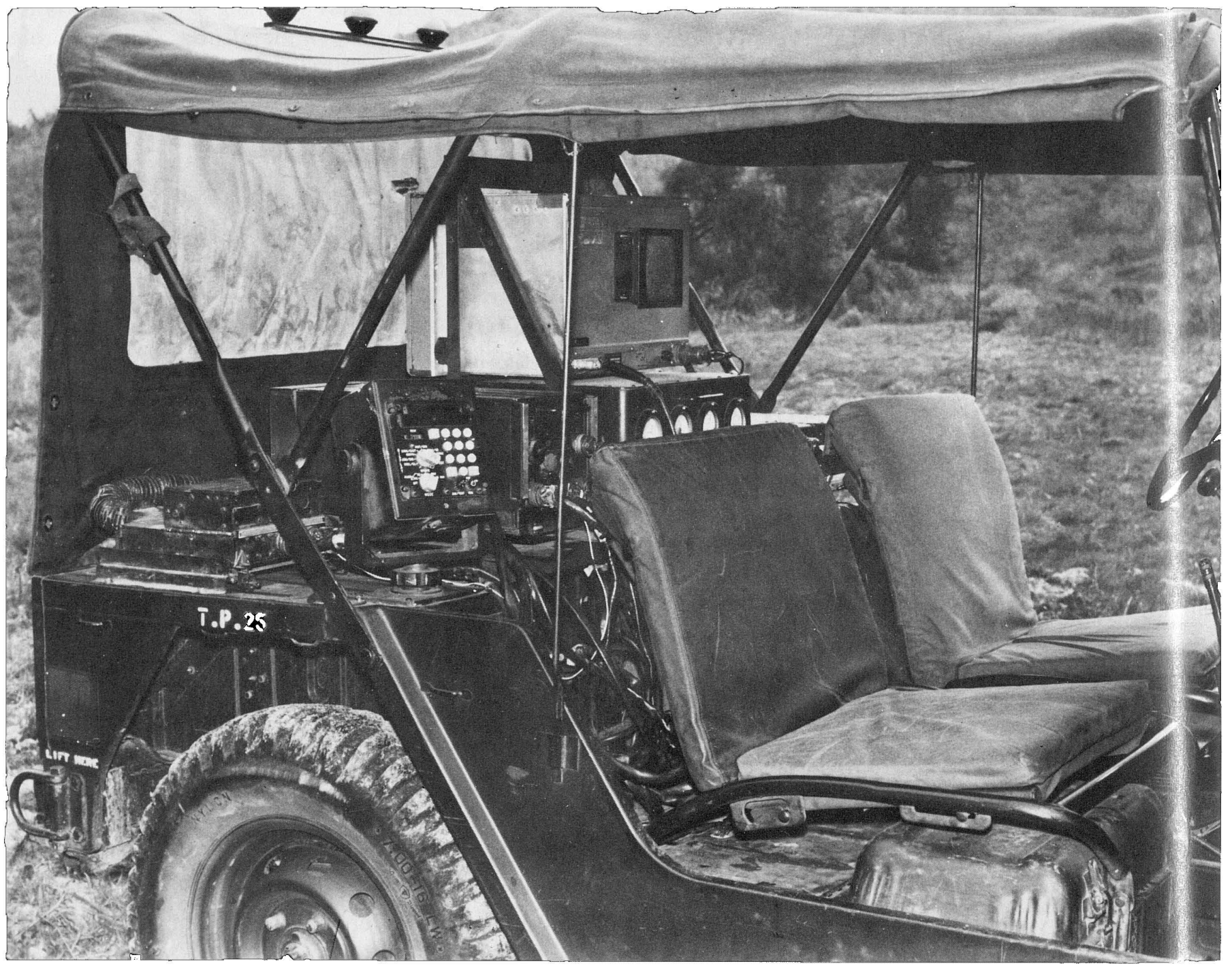

FIGURE 11.-Four-wheel-drive vehicle equipped with an inertial package for automated surveying. The system, which includes gyroscopes, accelerometers, and small computer, provides a continuous record of the position and elevation of the venicle as it proceeeds along its course. 


\section{Image data}

Since most map information is derived from aerial photographs and other images obtained in either digital or graphical form, the planning, taking, and processing of the image data are crucial tasks in mapmaking. Today's high-resolution cameras and multispectral sensors will be tomorrow's imaging systems in a high-flying aircraft or a cartographic satellite (fig. 12). The image will generally be in digital form and fully manipulable by computers. Unseen pictures will be formed digitally from the sensors' records to show selected data suitable for thematic maps. Already we are able to computer-produce a stereopair of photographs from a single satellite image. The development of powerful new techniques for image processing has already led to a growing production of image maps. On the increasingly popular satellite image maps, cartographic detail is shown by images derived from photographs or other sensors, instead of by the lines and symbols of conventional line maps.

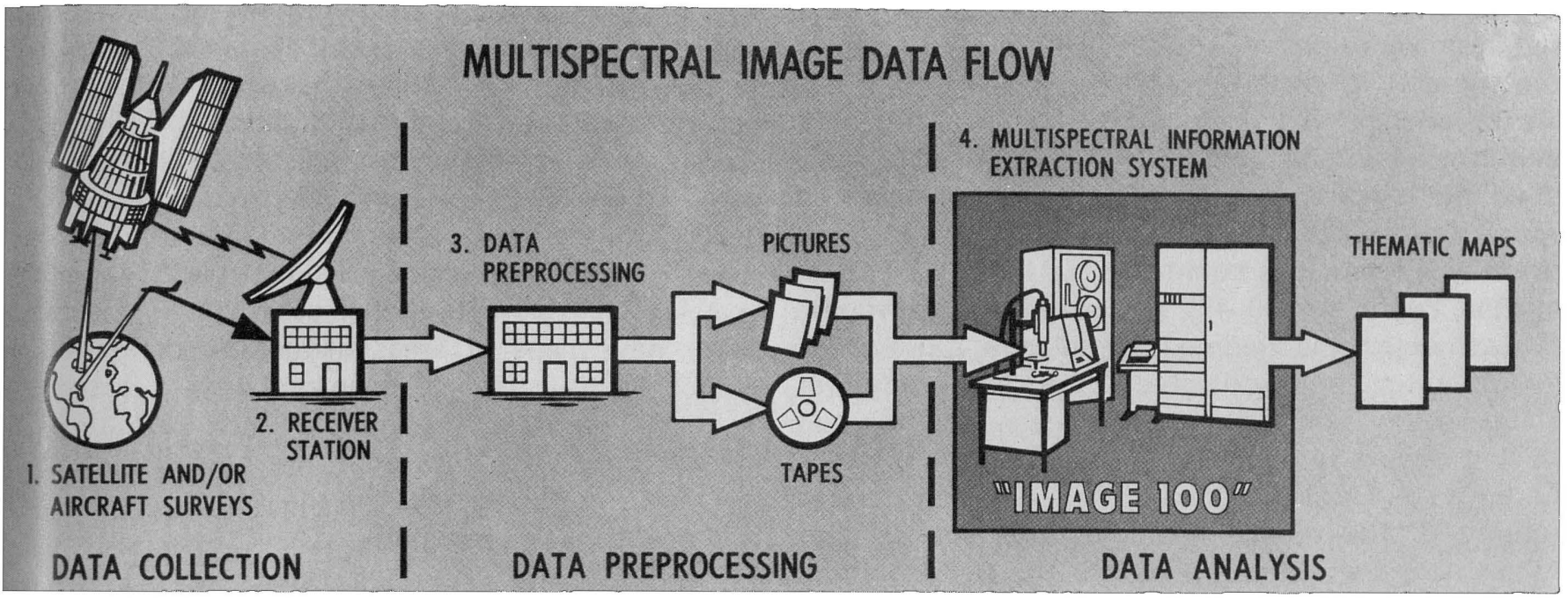

FIGURE 12.-Automated imaging system.

\section{Cartographic compilation}

A breakthrough in automating the laborious and exacting compilation of topographic data occurred this year. The Geological Survey acquired a fully automated photogrammetric machine (p. 80) in which the photographs are automatically scanned and correlated to provide concurrently a contour drawing, a digital terrain model (dense grid of elevations) recorded on magnetic tape, and an orthophotograph (correctly positioned imagery). Here automation will cut production time from weeks to days and reduce the incidence of error. This and similar future systems will provide a ready means of accomplishing relief shading, slope mapping, production of a line or image map at any desired scale, or solution of interdisciplinary problems. This impressive new system, called the Gestalt Photo Mapper II, is in operation at the Survey's Eastern Mapping Center in Reston, Va.

Map finishing

Even though the image maps are gaining wide acceptance, there will always be a need for the line map. However, for the application of automated techniques to the preparation of color-separated plates for lithoprinting, the line map must bear new symbols that are computer-compatible and that enable effi- cient use of automated precision-plotting systems now on the market. Duplication in drafting will be eliminated by the current development of instruments and techniques for digitizing map data in the course of compilation. Given map data in digital form, the system of the future will make press-ready reproducibles at a variety of scales and with selected content. It will also be possible to gain rapid access to map data through local computer terminals.

\section{The cogent question}

Thus automation promises many things for cartography: speeding mapmaking, increasing product quality and desirability, improving access to the information, and extending the usefulness of the data. Right now, the installation of automated equipment and techniquse entails large capital investments, as much as a million dollars a unit, and the question is frequently raised: "Can we afford to automate?" In view of the complete and up-to-date national cartographic data base within our grasp-a new resource that society will find indispensable as it seeks to manage the environment, a unique resource that will continually grow to supply the demand-the more cogent question is: "Can we afford not to automate?" 


\title{
Metrication-What It Means to Mapping
}

\author{
by Marshall S. Wright, Jr.
}

\section{WHERE WE HAVE BEEN}

Recently the Congress of the United States authorized the use of the metric system throughout the country. Recently? Well, not too recently ... . one hundred and ten years ago, to be exact. Nothing much happened as a result of that legislation, and the next significant mile post was in 1875 when the Treaty of the Meter was signed by 18 nations including the United States. The treaty provided for improved metric weights and measures and the establishment of an international organization devoted to matters of weights and measures, but, again, the implementation of metrication in this country made little gain. Then, in 1968, Public Law 90-472 authorized a 3-year metric study to determine the impact of increasing use of the metric system on the United States. The study was made by the National Bureau of Standards, and in 1971 a report to the Congress, entitled "A Metric America-A Decision Whose Time Has Come," was submitted. The report recommended, among other things, that the Nation change to the metric system "deliberately and carefully," that the change be done through a coordinated national program, that various sectors of our society work out their own detailed plans and timetables, that priority be given to educating school children and the public at large to think in metric terms, and that the Congress establish a target date 10 years ahead by which time the United States will have become "predominantly, though not exclusively, metric."

The latest metric legislation is contained in Public Law 94-168, called the "Metric Conversion Act of $1975^{\prime \prime}$ enacted by the Congress and signed by the President in December of 1975. The act states "that the policy of the United States shall be to coordinate and plan the increasing use of the metric system in the United States and to establish a United States Metric Board to coordinate the voluntary conversion to the metric system." This is not a particularly strong law (note "plan the increasing use" and "voluntary conversion"). No specific timetable is set forth in the act, but it unquestionably moves the Nation a major step forward toward the inevitable day of metric conversion. Inevitable? Yes, absolutely! After all, we and Barbados, Burma, Gambia, Ghana, Jamaica, Liberia, Muscat and Oman, Nauru, Sierra Leone, Southern Yemen, Tonga, and Trinidad are the only nations left in the entire world that are not fully committed to the much longer, and the Geological Survey believes that the time has come to move firmly and intelligently toward the metrication of the maps and other cartographic data it produces under the National Mapping Program for the benefit of the Nation.

The production of maps in the metric system is not new to the Survey's Topographic Division even though more than 99 percent of its standard quadrangle maps are in the English system with contours shown in foot units and map scales usually keyed to inches, feet, and/or miles. The exceptions are the standard quadrangle maps of Puerto Rico at a scale of $1: 20,000$ with the contours in metric intervals and maps of some areas in Alaska that were made at a scale of $1: 25,000$ with metric contours. A number of other new maps of areas within the conterminous United States have also been prepared at a scale of 1:100,000 with metric contours. Thus, from a technical and operational viewpoint, we have the ab!lity to compile and publish maps in the metric system now. The problems lie elsewhere.

\section{WHERE WE ARE TODAY}

A brief description of just what the metric system is may be in order. The system is called the Ir:ternational System (SI) throughout the world. (SI is the standard abbreviation for the official name, Sy steme International D'Unites.) The great advantage of the system is its simplicity, there being only sever: basic units covering all weights and measures: (1) the meter for length, (2) the kilogram for weight, (3) kelvin for thermodynamic temperature, ${ }^{1}$ (4) the second for time, (5) the ampere for electric current, (6) the candela for luminous intensity, and (7) the mole for amount of substance. A special case is the liter which is the unit for measuring volume-this is no considered a basic unit, however, since the liter is actually defined in terms of the meter. The system is arther simplified by the fact that it is based on 10 and that the base units can thus be multiplied or divicied by simply moving the decimal point in workin with numbers or by using standard prefixes in working with words. Typical prefixes are kilo (meaniry one thousand) as in kilogram and kilometer, milli (neaning one thousandth) as in milliliter and millineter, and centi (meaning one hundredth) as in centimeter $\begin{gathered}1 \text { Degrees celsius } \\ \text { familiar. }\end{gathered}$
$\left.{ }^{\circ} \mathrm{C}=\mathrm{K}-273.15\right)$ are also acceptable and most 
and centigram. Thus, if one wants to know how many meters there are in 2.36 kilometers, the answer is instantly perceived to be 2,360 , whereas if one wants to know how many feet there are in 2.36 miles, it is necessary to multiply by 5,280 .

The precise definition of just what some of these basic units represent is not always so simple. Some people may not know that the official definition of the meter is "the length equal to $1,650,763.73$ wavelengths in vacuum of the radiation corresponding to the transition between the levels $2 p_{10}$ and $5 d_{5}$ of the Krypton-86 atom." And this is one of the simpler definitions! Fortunately, however, the average person need never be concerned with such a basic definition of the length of a meter. It should suffice to know that the meter is about the height of a doorknob or a workcounter. It is also fortunate for map users that they are primarily concerned with only one of the seven basic metric units in the conversion of maps to the International System-the meter for horizontal and vertical measurement.

The Topographic Division of the U.S. Geological Survey began a preliminary investigation into the pros and cons of converting its mapping effort to the metric system several years ago with the appointment of a "metrication" committee that was charged with considering the ramifications of metrication and with drawing up recommendations on how to proceed. A number of experimental maps were prepared to evaluate various combinations of metric scales and contour intervals and to evaluate transition products with metric units and equivalents and vice versa.

Then, in the summer of 1975, before the "Metric Conversion Act of $1975^{\prime \prime}$ became a reality, the Division decided that the time had come to assume firm leadership in the mapmaking community and to move ahead deliberately with this clearly inevitable task. While the in-house production problems associated with the conversion were well understood and solvable, the impact on, and the desires of, the map-user community were not adequately documented. Accordingly, in December 1975, a questionnaire was sent to about 150 representative map-using agencies and individuals throughout the country. The list included all State cooperators, other selected State offices, all map-using Federal departments and agencies (about 40), a number of university professors, private mapping companies, and several professional societies. The list provided a representative cross section of those who make use of the National Mapping program products.

A letter accompanying the questionnaire explained the Survey's desire to prepare a specific metrication plan and detailed the steps already taken in that direction. It described metric mapping practices in other countries and also set forth, for consideration, various sequences of contour intervals. The questionnaire itself asked for comments and advice concerning: (1) the most suitable and practical scales for a metric map series; (2) the most suitable and practical contour intervals; (3) whether the standard quadrangle maps for the 48 conterminous States should be completed in the English system or whether transition to the International System should be begun; (4) when the 7.5-minute series is converted to metric should it be at a scale of $1: 20,000 ; 1: 24,000 ;$ or $1: 25,000$ ?; (5) what special problems would users encounter if new mapping continued to be at a scale of $1: 24,000$ but with metric contours?; (6) what problems would be encountered if the scale were changed to $1: 20,000$ or $1: 25,000$ ?; and (7) what special information would best help users to convert from the English to the metric system?

The response to the questionnaire was gratifying. Seventy percent responded, and most returns clearly reflected serious thought and consideration. Persuasive logic was present in the reasoning behind some of the answers, and some of the opinions were expressed vehemently. Of course, many conflicting views were expressed, but the responses to the questionnaire may be summarized briefly, as follows:

1. There was a $21 / 2$-to- 1 preference for a scale series of $1,2.5,5,10(1: 10,000 ; 1: 25,000 ; 1: 50,000$; $1: 100,000 ; 1: 250,000 ; 1: 500,000 ; 1: 1,000,000)$ compared to the $1,2,5,10$ series $(1: 10,000$; $1: 20,000 ; 1: 50,000 ; 1: 100,000 ; 1: 200,000$; $1: 500,000 ; 1: 1,000,000)$. A few people, however, prefer some other scale series.

2. There was a 5 -to- 1 preference for contour-interval sequence of $1,2,5,10,20,50$ or 100 meters compared to a sequence of $1,2.5,5,10,25,50$, or 100 meters. A few people indicated a preference for some other series, including a sequence of $1,2,4,8,16,32$ meters.

3. There was a 4-to-3 preference for completing the mapping of individual States at 1:24,000 before converting to the metric system. It should be noted here, however, that State officials were overwhelmingly in favor of completing their own States at 1:24,000 before converting, with 32 being in favor of completing at $1: 24,000$ and 10 favoring immediate conversion; 5 of those 10 were States which are already completely mapped at $1: 24,000$, and therefore their "votes" on this subject can be discounted to some extent. 
4. There was a 2-to-1 preference for converting the 7.5-minute quadrangle maps to a scale of $1: 25,000$ rather than $1: 20,000$. Several people recommended retaining the $1: 24,000$ scale.

5. As to the problems to be encountered, if metric contours are shown on 1:24,000 maps, the answers ranged from "no problem" to "the user would be utterly confused." Many pointed out the obvious difficulty of matching metric contours on one sheet to foot contours on adjoining sheets.

6. Only about 20 percent of the responders made specific comments about problems that would be caused by changing the map scale from $1: 24,000$ to $1: 20,000$ or $1: 25,000$. Of those, a number objected to the $1: 20,000$ scale because the map sheets would be too large for existing files. Many pointed out the problem of matching adjacent sheets at two different scales.

7. The comments on special information that would help users convert from the English to the metric system included "show horizontal and vertical bar graphs," "put warning flags stating boldly that these are metric maps," "make all maps put out in the metric system distinctly different," "put instructions for use on the face of the maps," and "show contour numbers in red."

A review of the responses pointed out one inescapable fact: it is not possible to make everyone happy about certain basic decisions that must be made. There were impassioned pleas for going to the 1:20,000 scale, equally impassioned pleas for changing to $1: 25,000$, and pleas for staying at $1: 24,000$; it is quite impractical to adopt a multiscale policy (except possibly during a transition period). This situation is also true for the metric contour intervals to be adopted, although there was much less sharply divided opinion on that matter among the map users. Among the map producers, however, there were strong differences of opinion on the optimum contour-interval sequence. Within the Topographic Division, the contour interval, not the scale, was the tough nut to crack. Some individuals felt that a halving (or doubling) sequence-such as $1,2,4,8,16,32$ meters or $1.25,2.5,5,10,20,40$ meters-would lend itself best to the use of supplemental contours and to the derivation of a map series at other scales and contour intervals, whereas others felt that the use of fractional numbers or unconventional numbers-such as 8,16 , and $32-$ would be difficult for many users to handle. However, after much in-house discussion of the pros and cons of various sequences, a consensus was reached. The following basic decisions have been made:

1. The scale of $1: 25,000$ will be the basic scale for the metric 7.5-minute quadrangle mapping series.

2. Contour intervals of $1,2,5,10,20,50$, and 100 meters will be the basic intervals for the various maps in the National Mapping Program.

3. All new county maps will be prepared as metric editions at scales of either $1: 50,000$ or $1: 100$,000 .

4. Sixty-minute by 30 -minute quadrangle maps will be prepared as metric editions at 1:100,000.

5. Complete revisions of $1: 250,000$-scale maps will be metric editions.

These basic decisions were reached after very careful consideration of the impact on the user community, compatibility with other mapping systems (the military does much mapping at $1: 25,000$ and the National Oceanic and Atmospheric Administration plots 1-meter underwater contours on its charts, for example), in-house production and mainterance problems, and the economy of conversion. Every attempt has been made to accommodate the pieferences of other mapping agencies as well as those of users in reaching these decisions.

Fortunately, considerable latitude and flexibitty is possible during the transition period, and the Survey's Topographic Division is, therefore, in a positic $n$ to accommodate the varying wishes of different users as to how the conversion work is implemente and thus to keep the majority of the users happy. With this desire to accommodate well in mind, the folowing operating procedures were formulated:

1. New 7.5-minute maps will be prepared a full metric versions $(1: 25,000$ scale with metric contours) for all those States willing to accept such mapping.

2. New $1: 24,000$ maps will be prepared with metric contours for those States that are willirg to accept metric contours but have such a paitern of completed mapping that $1: 24,000$ scale is needed to maintain scale continuity.

3. New 1:24,000 maps will be prepared with foot contours for those States which insist on delaying metric conversion until complete $1: 2,000$ coverage of those States is available.

4. Any complete revisions of existing 7.5-m:nute maps will be metric editions.

The Topographic Division believes that this acommodation of the unique problems of the indiv dual States is appropriate and reasonable. It is eas to understand the argument that a State, especially one 
with a patchwork quilt coverage of 1:24,000 mapping, should have its program completed at that scale before a conversion is made. It should be pointed out, however, that this feeling is not universal among States that are only partially mapped at 1:24,000. In fact, seven such States have expressed a definite desire to begin conversion immediately with all new maps to be metric. One State even hinted that it would withdraw its cooperative funds if there was any delay in converting to the metric system.

Metric mapping was actually underway during fiscal year 1976 in several geographic areas and in various types of mapping. In New York (one of the States wishing to convert immediately even though the State is not completely mapped at $1: 24,000$ ), a 40-quadrangle mapping project in the Lake Placid area (the site of the 1980 Winter Olympics) is being done at a scale of 1:25,000 with metric contours. This area includes 32 quadrangles in New York and 8 in neighboring Vermont. Far to the South, in Georgia, which is almost completely mapped at $1: 24,000$ because of a very large cooperative program over the past few years, a complete revision project involving more than forty 7.5 -minute quadrangles is being done in the metric system. Several States have requested a limited amount of quadrangle mapping with metric contours at the standard scale of 1:24,000. A county map of King County, Wash., the Killdeer $30-$ by $60-$ minute quadrangle in North Dakota, and the map of the North Cascade National Park in Washington have all been published at a scale of 1:100,000 with metric contours, the forerunners of things to come.

\section{WHERE WE ARE GOING}

With the basic decisions having been made about the conversion of new mapping to the metric system and with some such mapping actually in production, the Survey's Topographic Division is buckling down to the enormous task of working out the exact details of an efficient conversion plan. There are actually two very different tasks involved in the conversion of the National Mapping program products, one having to do with any new mapping to be undertaken and the other with changing some 36,000 existing English-system quadrangle maps to the metric system. The first task will be simpler from a production viewpont than the second task but rather complicated from a planning viewpoint because the Division is dealing with 50 different States that, conceivably, have many different ideas about how their programs should be phased into the metric system. Probably four or five different approaches will be necessary for converting the programs of the 50 States, but separate negotiations with each State will be needed to work out the best approach for both the States and the Survey. Some of these negotiations have already taken place, and others are in progress.

Concurrently, the groundwork necessary for making the conversion is underway. Typical of this effort is the preparation of a plan for the use of metric contour intervals for the entire United States and its territories. This plan, developed painstakingly by highly experienced topographers, assigns a specific metric contour interval to every quadrangle in the country and its territories; the intervals to be used are assigned primarily on the basis of the amount of relief in the area and, to some extent, the land use. According to the plan, five different contour intervals, $1,2,5,10$, or 20 meters, will be used. The 1 -meter interval will be used in some coastal plain areas and in other areas with very little relief, and the 20-meter interval will be used in extremely rugged terrain such as Glacier National Park. It is estimated that less than 5 percent of the Nation's 54,000 7.5-minute quadrangles will have 1 -meter contours and that only about 2 percent will have 20-meter contours; the remaining 93 percent will have contours at $2-, 5-$, or 10-meter intervals.

Plans are also being made to accomplish new mapping under two different approaches, one with complete metric conversion and the other with only a partial conversion. The simplest approach, of course, is to compile and publish new maps at $1: 25,000$ with metric contours. The production problems involved are practically nil, and the transition to this type of mapping would be smooth and would cause no increase in the cost of map production. A more complicated and less efficient approach will be necessary for States in which the mapping officials are opposed to the use of metric contours now or opposed to changing to $1: 25,000$ scale before their State is completely mapped at $1: 24,000$. The scale problem is less difficult than the contour problem. With the knowledge that the maps will be converted to $1: 25,000$ at some time in the future, two sets of negatives can be made, one at 1:24,000 for immediate publication and the other at $1: 25,000$ to be held until the 1:25,000 publication is authorized. The contours, however, are another matter because there is no magic way to convert satisfactorily from foot contours to metric contours. Two sets of contours can of course be compiled, one for immediate use and one to be used for the subsequent metric edition, but this is certainly time consuming and costly. A possible alternative-the derivation of metric contours from foot contours by use of an automatic scanning and/or computer-aided plotting system-is being investigated. 
One other option is available for converting foot contours to metric contours, and this leads to the matter of "soft" conversion as compared to "hard" conversion. Soft conversion involves simply a relabeling of a particular measurement without making any change in the interval or size being measured, whereas hard conversion involves the actual changing of the interval or size to an even standard metric size. A good example is the milk, soft-drink, or liquor bottling industry which has millions of quart bottles in use and also has a major investment in machinery to manufacture quart bottles. Under the soft conversion concept, it is a relatively simple matter to relabel these bottles "0.95 liters" (or "0.946353 liters" to be more precise), but it is a quite different matter, under hard conversion, to scrap millions, or perhaps billions of existing quart bottles and the machinery that makes them and retool for the manufacture of liter bottles. The economics involved will undoubtedly lead to a combination of soft and hard conversions in the bottling industry and in a great variety of other industries as well, with soft conversion dominating the early phases of the transition period and the hard conversion catching up and finally taking over completely at the end of the transition period. The length of the period will probably be related significantly to the normal "life" of the particular product involved, and these different "lives" of course make it difficult to set one inflexible period of time during which all phases of our society must be totally converted to the SI system. It's easier to convert sign boards than locomotives.

The matter of soft and/or hard conversion or a combination of both for existing maps is being studied by the Survey's Topographic Division at this writing, and costs must be measured against user impact. It is not extremely difficult to remake printing plates at 1:25,000 and to relabel English values to metric values, but it would be a major undertaking to recompile the contours into the adopted even metric intervals. Relabeling of the contours on a 20 foot-contour-interval map (to the nearest whole metric value) would result in the 800 -foot contour becoming a 244-meter contour, the 820 -foot contour becoming a 250-meter contour, and so on, and the contours would of course portray the terrain just as well as they did before this soft conversion. But would this type of conversion be satisfactory to the majority of the users? Or is such a conversion necessary at all? Should the maps be converted to the new scale only in the near future with true metric contouring being delayed until the maps are due for complete revision anyway? These questions are being and will be discussed with the various State officials and other map users.

Educating the map-user community to the use of metric maps is an educational process that probably will evolve in two ways, one being a general campaign at the national level and the other being a specific program to be developed by the Topographic Division. The general national program is already underway on an informal basis; some elementary, junior high and high schools are already teaching the International System, and a majority of others are making plans to do so. The recently enacted "Metric Conversion Act of 1975" will add substantial impetus to the systematic education of the general public. To aid the user in adapting to the new metric maps, educational information probably should be mainly limited to that which can be printed right on the metric editions of the maps, such as dual horizontal and vertical bar scales, a prominent note calling the user's attention to the scale and contour interval, and possibly a conversion table. A possible supplement under consideration is a one-sheet "throw away" to be furnished with each quadrangle map distributed during the first year or two of the conversion period. This sheet might include a cut-out 1:25,000 scale to facilitate measurement on the map. Considered for a time wa: dual numbering on the map itself, showing, for example, 800 feet in brown for an index contour and 244 meters in red. This idea has been discarded because the experience of other countries in converting from English to metric units indicates clearly that, as long as dual units are shown, the average person us the unit he is familiar with and ignores the other, thus not really learning to think in the metric systen.

When will the National Mapping Program be completely converted to the metric system? A precise timetable cannot be drawn up at the present for one simple reason-uncertainty as to the availabilty of funds. This timetable primarily concerns the conversion of the 36,000 existing quadrangle maps bccause new mapping in the metric system should cost no more than mapping in the English system. The 36,000 existing maps could all be converted in relatively short period of time-possibly 3 years-w with a massive infusion of funding and allocation $c$ personnel. On the other hand, the conversion, per se, could cost almost nothing if left to normal attition, that is, the conversion to metrication of map only when they are to be completely revised. More practical, however, than either of these two apprcaches would be a combined program with a reascnable level of funding set aside annually to convert certain percentage of maps with others being con erted through the complete revision process. Done this 
way, conversion would, of course, take longer, but funding and manpower needs could be better planned. And this approach would permit the Division to have all presently existing maps converted within about 10 years. As to new mapping, it is the Division's goal to have all new maps of those States willing to convert immediately compiled in the metric system beginning in fiscal year 1977 and to have all other new maps compiled in a manner to permit ready and economical conversion to metric editions, also beginning in fiscal year 1977.

Thus, the Survey's Topographic Division has faced the issue of map metrication, developed a plan that pays attention to both map users and map producers, and is moving ahead with implementation of the plan. Metrication in the National Mapping program is underway and will increase substantially over the next few months. Fiscal year 1977 should see the myriad of details of conversion worked out and the program moving into high gear.

\section{REFERENCES}

Adams, Priscilla P., ed., 1976, Metrication-Myths and realitiesFacing the issues: 1976 Ann. Rept. of the Am. Natl. Metric Council, $32 \mathrm{p}$.

National Bureau of Standards, 1971, A metric America-A decision whose time has come: U.S. Natl. Bur. Standards Spec. Pub. 345, 170 p.

Page, Chester H., and Vigoureaux, Paul, eds., 1971, The International System of Units (SI): U.S. Natl. Bur. Standards Spec. Pub. 330, 42 p.

\title{
Plate Tectonics and Man
}

\author{
By Warren Hamilton
}

\section{INTRODUCTION}

Coastal and inland California ground past one another for less than a minute, at 5:13 a.m. on April 18, 1906, and produced the San Francisco earthquake. The coastal side lurched as much as 6 meters (20 feet) northwestward, along a fracture, a part of the San Andreas fault, 430 kilometers (270 miles) long. In those catastrophic moments, the two sides released strains which had been building for about a century as the part of the Earth's outer shell beneath the Pacific Ocean moved slowly but inexorably past that part beneath North America. The steady motions are continuing, and future great earthquakes are a certainty. The year 1976 has seen an unusual abundance of destructive earthquakes around the Pacific Ocean.

Like most earthquakes, that of 1906 was a manifestation of the fragmentation of the Earth's outer shell into large and small plates, all moving relative to all others with steady velocities that reach 13 centimeters (5 inches) per year-pulling apart here, slipping past one another there, sliding beneath another somewhere else, and in other places colliding slowly to build some of our most spectacular mountain ranges. Earthquakes are the most dramatic way in which these plate motions affect man, and our new understanding of the motions permits a comprehension of earthquakes which could not be approached until a decade ago. Most volcanic eruptions are also produced by the plate motions. The distribution of the mineral deposits and fossil fuels upon which our civilization depends has to a large extent been controlled by plate motions and interactions.

The basic understanding of plate motions was developed primarily during the 1960 's in a conceptual revolution as profound for the earth sciences as was the earlier development of the concept of evolution in biology and of atomic and molecular structure in physics and chemistry. We know the new field as plate tectonics: the "plate" is the basic unit of the system, and "tectonics" (from the Greek work tekton, meaning builder) refers to the processes and products of motions within the Earth.

This essay ranges broadly over Earth processes and materials in an attempt to give an integrated view of their relationships. Many of the concepts presented are accepted by most earth scientists, but others are controversial.

\section{DEVELOPMENT OF THE CONCEPTS}

Science is cumulative, and advances are made in the light of knowledge gained painstakingly by many researchers. A survey of the development of plate tectonics illustrates the progressive and cooperative nature of science and the way in which research in diverse fields produces unifying concepts of practical value to society. The concepts of plate tectonics were developed slowly at first, then with a rush, by earth scientists, government and academic, of many nations. Some of those scientists and their contributions are mentioned here. Many others were important also.

The reality of continental drift was reasonably well established during the 1930's, as Alexander Du Toit of South Africa and others followed up on the pioneering work a decade and more earlier by Alfred Wegener of Germany and Emile Angand of Switzerland. The distribution of indicators of past climates-for example, the presence in now-tropical India of continental glacial deposits of the same 300-million-year age as fossilized tropical reefs and equatorial forests in lands now in the Arctic-required that the con- 
tinents had moved slowly about the globe. Reassembly of continents in patterns suggested by their shapes provided remarkable continuity for similar, truncated geologic terrains. The "drifters" mostly visualized continents, mistakenly, as rafts sliding over the ocean floors; most geophysicists regarded this as impossible, and only a vocal minority of earth scientists supported the concepts. David Griggs, then at Harvard, had a view of ideas to come when he suggested that the mountain systems around the Pacific were caused by the ocean floors plunging beneath the continents.

Geophysicists changed sides in increasing numbers in the 1950's as the science of paleomagnetism expanded rapidly and provided powerful new evidence for drift. Many rocks, such as volcanic rocks crystallized from lava, contain tiny grains of magnetite and other magnetic minerals which retain the magnetic orientation of the Earth's magnetic field of the time at which the rocks formed. Early studies of this phenomenon had been made mostly in France and Japan during the 1920's, but scientists in other nations became involved subsequently. The magnetic orientations of rocks indicated fossil latitudes, which proved to be about the same, for the various continents, as those indicated by paleoclimatology and other geologic and paleontologic criteria. Among the "drifter" geologists, still a minority, S. Warren Carey of Australia was adding important new concepts.

The 1950 's also saw the gathering of an enormous amount of geophysical data from the oceans, particularly by research vessels from American oceanographic institutions, and the 70 percent of the Earth's surface that is covered by water began to yield its secrets. A globe-girdling system of interconnecting submarine ridges was recognized, in part lying midway between continents, like Africa and South America, that appeared, on geologic grounds, to be moving apart. Bruce Heezen of Columbia University suggested that new oceanic crust was being formed at the ridges and added to great plates moving apart. Great submarine trenches were also delineated, particularly along the convex oceanic sides of the volcanic arcs which make up the "ring of fire" around the Pacific, and from these trenches inclined zones of earthquakes dip as deep as 700 kilometers (450 miles) into the mantle beneath and behind the volcanic arcs. Harry Hess of Princeton University was probably the first to see the broad outline of what was to emerge as plate tectonics when he reasoned that oceanic crust was formed at spreading ridges behind drifting plates and was destroyed at the same rate elsewhere as oceanic plates tipped down at the trenches and slid deep into the mantle along the seismic zones. Robert Coats of
National Oceanographic and Atmospheric Administration were among those who early suggested applications of these processes to the geology of the continents. Others saw the motions of the continents themselves clearly enough, but not the way these motions involved the floors of the oceans.

Paleomagnetic researchers demonstrated that the Earth's magnetic field has been "normal" during about half of geologic time and "reversed" (a magnetic compass would point south instead of north) the other half and that the intervals of contrasted polarity were extremely irregular. Allan Cox, Richard Doell, and Brent Dalrymple, all then of the U.S. Geologica Survey, built up during the early 1960's a precise magnetic-reversal time scale for these polarity periods during the past 4 million years. Frederick Vine and D. H. Matthews, English scientists, suggested that the alternating belts of highly and weakly masnetic oceanic crust, known by then to trend along the midocean ridges, represented magnetic recordings a new crust formed in the gap behind separating plate and that the belts would record symmetrically, or: opposite sides of the young ridges, the periods of time represented by the magnetic-chronology time cale. They tested the suggestion against several small ridge sectors and showed that it fit. The Lamont Geol gical Observatory of Columbia University then be came involved with its unique computerized data ba.k of marine magnetic surveys, and James Heirtzler, Ellen Herron, Xavier Le Pichon, and Walter Pitmal', III, showed in the late $1960^{\prime}$ s that ridge after ridge $t \mathrm{t}$ the pattern, and they carried the magnetic time scale back 75 million years. Only 3 years previously, He tzler and Le Pichon had written that no spreading was needed to explain the magnetic stripes-but they abandoned their previous position when it be ame untenable.

Also in the late 1960 's Le Pichon (a Frenchman) Dan McKenzie (English), and Jason Morgan (Americ n, at Princeton) deduced from magnetic, bathymetric and other data the geometric principles by whicl the great pieces moved. Bryan Isacks, Jack Oliver, and Lynn Sykes, all then of Lamont, showed that se smic data, including the distribution and slip directio is of earthquakes, fit the new concepts in detail. Johr: Bird (then at the State University of New York at Alb nny), Gregory Davis (University of Southern Califo nia), John Dewey, (English and now at Albany), W liam Dickinson (Stanford University), Tanya Atwater and Daniel Karig (both then at the Scripps Institutic $n$ of Oceanography, University of California), George Plafker and Warren Hamilton (U.S. Geological Survey), among others, showed how the geology of contirents and volcanic island arcs could be explained in terms of the new concepts. 
By 1970, the concepts had been developed, proved, and broadly applied. The 1970's have produced an enormous amount of additional evidence. The research drilling of the ocean floors by the Deep Sea Drilling Project, for example, has confirmed the ages of the magnetic "stripes," the recognition of which provided the breakthrough in the initial concepts. There have already been many refinements and extensions of our knowledge and understanding. Soviet and Eastern European earth scientists are slowly recognizing the importance of the new field, but have yet to contribute significantly to its concepts.

\section{THE CONCEPTS}

The Earth's crust is broken into moving plates of "lithosphere" (fig. 13). There are seven very large plates, each consisting of both oceanic and continental portions, and a dozen or more small plates (not all of which are shown on fig. 13). Each plate is about 80 kilometers (50 miles) thick and can be pictured as having a shallow part that deforms by elastic bending or by brittle breaking, and a deeper part that yields plastically, beneath which is a viscous layer on which the entire plate slides. The plates tend to be internally rigid, and they interact mostly at their edges. Spherical geometry requires that any motion between two portions of a spherical surface be expressed as the rotation of one relative to the other, defined by an angular displacement and by a pole of relative rotation, and that all trajectories of relative motions be along small circles to that pole. (Latitude lines are small circles relative to the Earth's geographic pole). These theoretical constraints are largely met by all of the criteria by which plate motions are demonstrated. The magnetic "stripes" along the midocean ridges define spherical angles: velocities of separation of adjacent plates are constant in angle, not in linear value. The direction of slip in earthquakes along plate boundaries, and the orientation of strike-slip faults that form or offset those boundaries, are in the corresponding small-circle directions.

All plates are moving relative to all others. There are grounds for suggesting that the African plate may now be approximately fixed relative to the deep mantle, but if so it is the only such plate. Velocities of

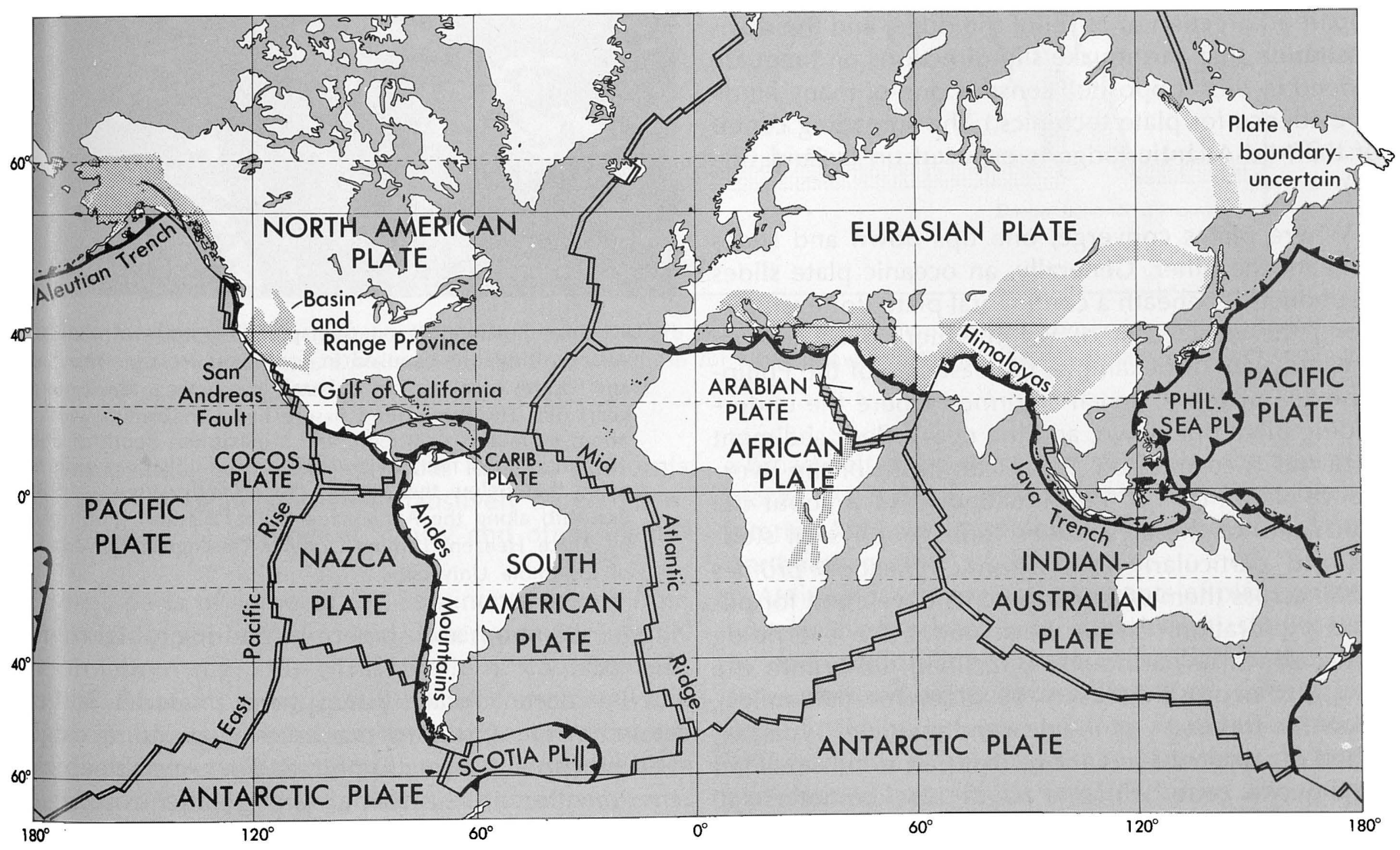

FIGURE 13.-Lithosphere plates of the world, showing boundaries that are presently active. Double line: zone of spreading, from which plates are moving apart. Line with barbs: zone of underthrusting (subduction), where one plate is sliding beneath another; barbs on overriding plate. Single line: strike-slip fault, along which plates are sliding past one another. Stippled area: part of a continent, exclusive of that along a plate boundary, which is undergoing active extensional, compressional, or strikeslip faulting. Compiled and adapted from many sources; much simplified in complex areas. 
relative motion between adjacent plates range from less than 1 centimeter (a small fraction of an inch) to about 13 centimeters ( 5 inches) per year. Although these velocities are slow by human standards, they are extremely rapid by geologic ones: a motion of 5 centimeters (2 inches) per year, for example, adds up to 50 kilometers (30 miles) in only 1 million years, and some plate motions have been continuous for 100 million years.

Plates are now pulling apart primarily along the system of great submarine ridges in the world's oceans. Hot material from the deeper mantle wells up into the gap, and some of it melts and is erupted on the surface as lava or is injected near the surface to crystallize as other igneous rocks. The ridge stands high because its material is hot, and hence low in density. As the plates move apart, the ridge material gradually cools and contracts, and its surface sinks. Ridges generally form steplike alternations of spreading centers perpendicular to the direction of motion and of strike-slip faults parallel to that direction. (The actual sense of movement along these "transform" faults, conceptualized first by Canadian Tuzo Wilson -an antidrifter of the 1950's, but a major contributor to plate tectonics in the 1960's-is opposite to the apparent direction of offset of the ridge, and the demonstration that earthquake slip directions on them are indeed in this "opposite" sense is one of many kinds of evidence for plate tectonics.) The spreading center of the Mid-Atlantic Ridge is exposed on Iceland (fig. 14).

Where plates converge, one tips down and slides beneath the other. Generally, an oceanic plate slides ("subducts") beneath a continental plate (for example, along the west coast of South America) or another oceanic plate (for example, the east side of the Philippine Sea plate). A trench is formed where the undersliding plate tips down, and the ocean-floor sediment it carries is scraped off against the front of the overriding plate (fig. 15). We now know much about the mechanics of these junctions from geophysical studies and particularly from seismic-reflection profiles made across them with instruments developed for oilfield exploration. Farther back under the overriding plate, zones of earthquakes, inclined down into the mantle to depths that reach 700 kilometers (450 miles), show the trajectory of the descending plate. Typically, a belt of volcanoes lies above that part of this inclined earthquake zone, which is about 125 kilometers (80 miles) deep. The melting which ultimately produces the volcanoes may start with the forcing out of water, previously combined in the crystal structures of various minerals, by the increase of pressure on the

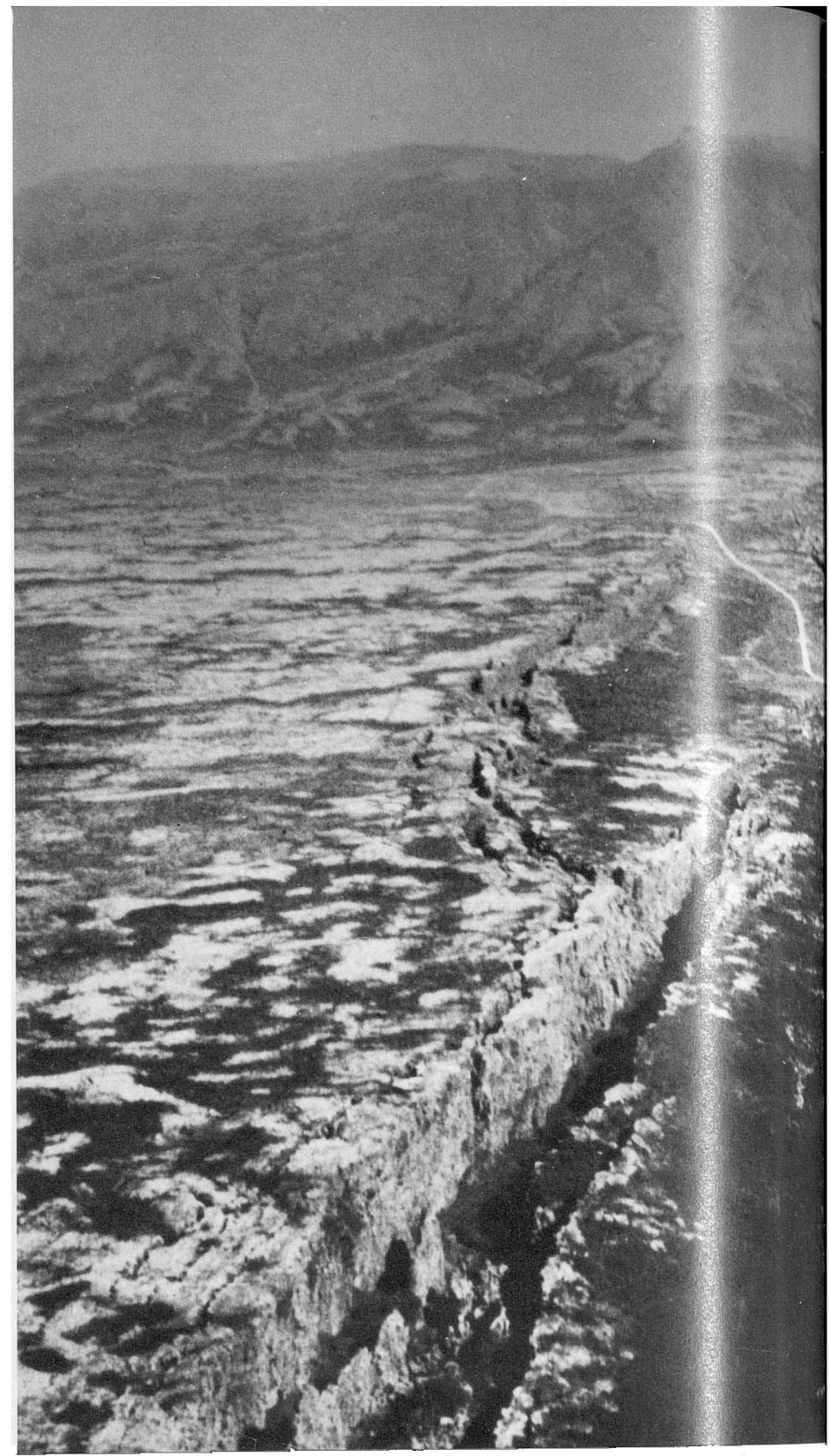

FIGURE 14.-Tension rift on the spreading crest of the MidAtlantic Ridge, as exposed in southwest Iceland. The faults and fissures break a plain of basalt lava flows a few th usand years old. The foreground fissure has a maximum width of about 60 meters (200 feet), and a maximum depth o: about 45 meters ( 150 feet) below the rim on the near side and twice that below the rim on the far side. View is northeastward along the Almannagja (Great Fissure). Photograph by Bruce Heezen, Lamont-Doherty Geological Observatory of Columbia University.

ing temperature, and so permits melting, of surrounding rock.

New oceanic-plate (lithosphere) material is generated by the upwelling processes at spreading ridges. Old lithosphere is consumed, and recycled dee into the mantle, at the same rate at the convergent trenches. The balance is global only: the formation of lithosphere at the Mid-Atlantic Ridge is compersated by subduction primarily in the western Pacific.

Plates slide past one another along strike-slip taults, which can be either on land or at sea. The best k rown 


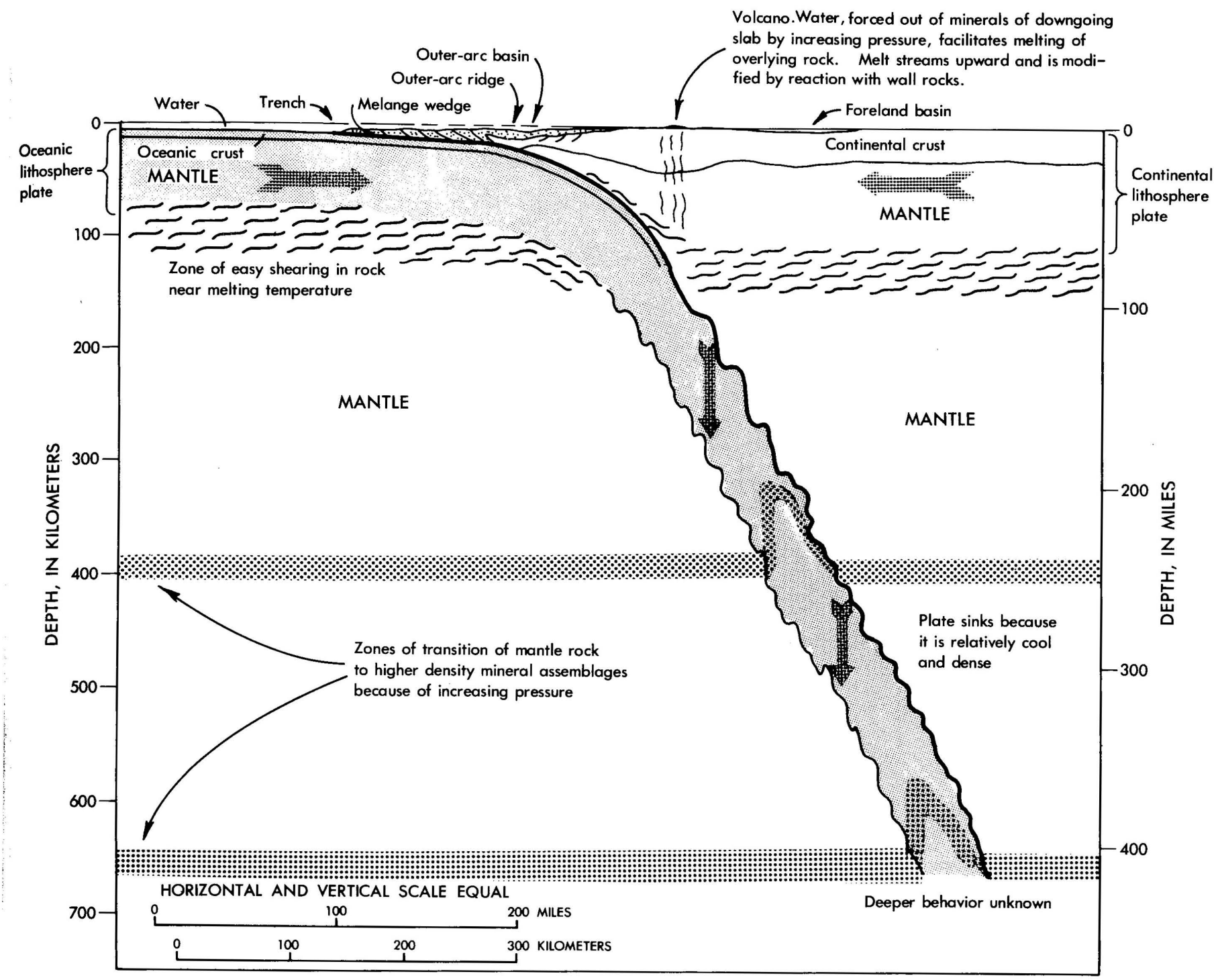

FIGURE 15.-Cross section through a subduction system where an oceanic lithosphere plate is converging with and sliding beneath a continental one. Details and dimensions are those for western Java and the Java Trench system, but other continentalmargin systems are similar.

of these faults is the San Andreas fault of California (fig. 16) now being studied exhaustively by geoscientists of the U.S. Geological Survey and other institutions.

Large parts of some of the continents depart from ideal rigid-plate behavior, and undergo much internal deformation (fig. 13). The western conterminous United States is now being broadly stretched and sheared: although most of the relatively northwestward motion of the Pacific plate past North America is taken up along the San Andreas fault, a part is distributed far inland, and the continental crust is stretched and shattered into the many block ranges and basins and other structures. Slight extension is affecting eastern Africa. Most complex is Eurasia, into which Arabia and India are now being rammed, with a broad belt being deformed in front of the advancing pieces. As India is pushed north into and beneath interior Asia, a huge region is being shoved obliquely northeastward out of the way.

Although the integrated concepts of plate tectonics were proved primarily by geophysical studies-and by deep-sea drilling - of the ocean basins, they have revolutionized our understanding of continental geology. By seeing how the geologic features of modern environments relate to present plate boundaries, we can deduce how similar features in the ancient geologic record related to ancient boundaries. Plate motions have dominated tectonic and magmatic processes for the past 2,500 million years. During that time, however, the interior of the Earth has become cooler and less mobile, so that details of the processes 


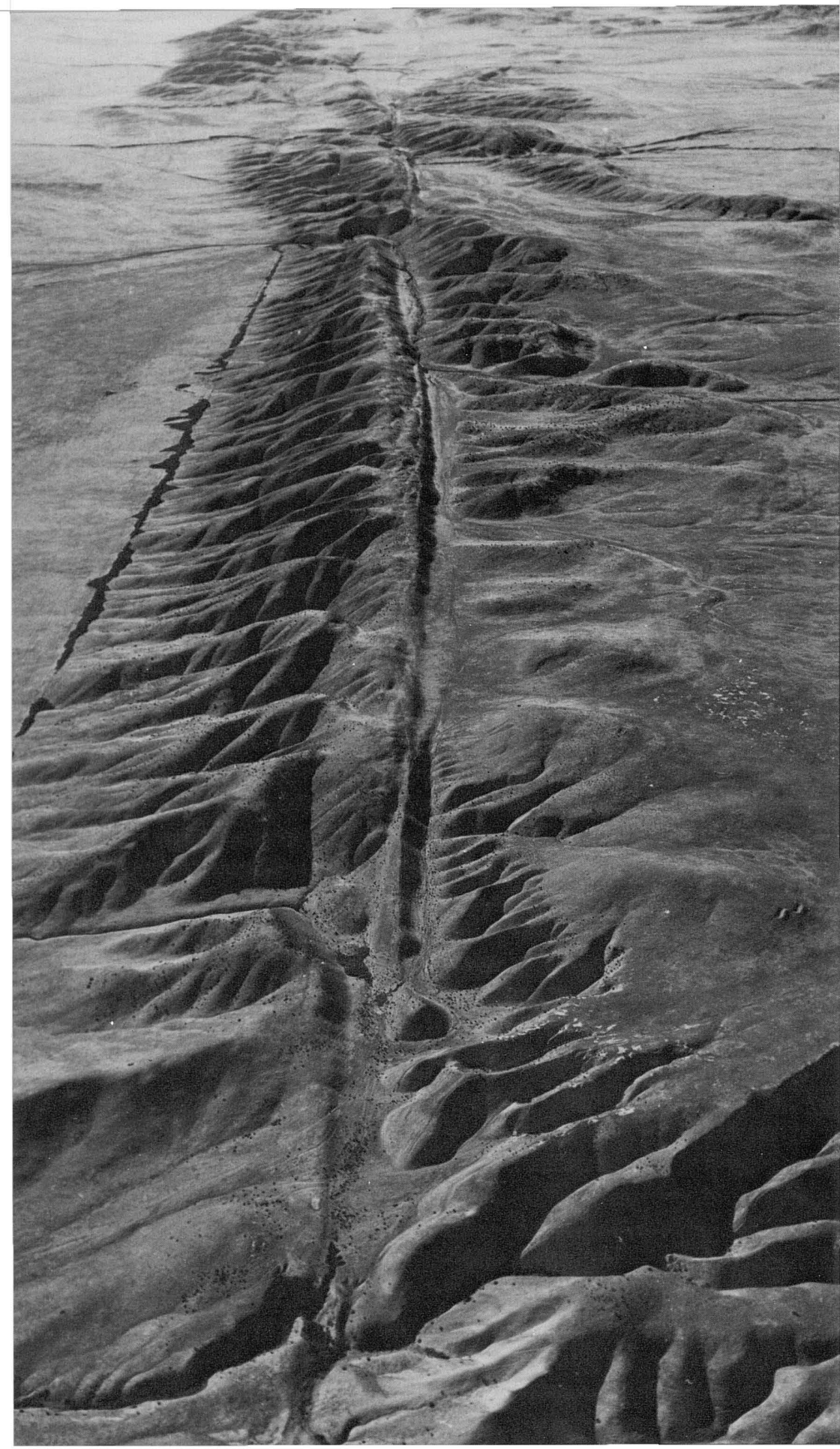

FIGURE 16.-Aerial view northwestward along the San Andreas fault in central California. The Carrizo Plain is on the left The fault marks the major boundary between the Pacific and North American plates, which are moving inexorably past one another at a rate of about 5 centimeters ( 2 inches) per year; about two-thirds of the total motion is taken up on the San Andreas. Photograph by Robert Wallace, U.S. Geological Survey.

have changed gradually. Rocks formed between about 2,500 and 3,800 million years ago show that the Earth then had a solid crust, and also oceans, but that the crust was much more fragmented and mobile and underlain by much hotter mantle than is now the case. There are no known rocks older than 3,800 miltion years. The Earth accreted from the collapsing solar nebula mostly between about 4,600 and 4,400 milion years ago and likely was completely molten during part of the period before 3,800 million years.

All present oceanic plates will sooner or later vanish beneath other plates. The oldest ocean floor remaining anywhere in the world is less than $200 \mathrm{mi}$ ilion years old. Continents stand high because they are composed of thick, light material-too light to be dragged deep into the mantle, along with ocecinicplate material, so continents are jammed toge her when an intervening ocean floor disappears ben ath one of them. If present major plate motions cont nue for another 50 million years, Australia will be cron ded against China, and the island complexes of Indor esia and the Philippines will be squashed into a mour ain system between the colliding continents. Many such past collisions can be recognized in the geolog of the continents.

The propulsive mechanism for plate motions is still a matter of speculation, and those working with the problem hold conflicting opinions. The greater pa t of the motions represent very slight differences in pin velocity about the Earth's axis: spreading ridges and subduction zones tend to be alined more north-sc uth than east-west, and poles of relative rotation betw een moving plates are concentrated at high latitu les. These facts indicate that the Earth's rotation is an mportant part of the mechanism.

\section{EARTHQUAKES}

Most earthquakes occur along or near the bour daries of lithosphere plates, and narrow earthquake $k$ alts outline the plates. Conversely, the recognition, accompanying the ability to locate distant earthque kes precisely, that. earthquakes are mostly confined to 
narrow connecting zones which have distinctive bathymetric settings, was one of the major developments that led to the concepts of plate tectonics. Narrow zones of earthquakes follow the spreading centers and strike-slip faults shown on fig. 13. Inclined zones of earthquakes extend deep into the mantle from the indicated subduction-zone trenches. There are also many earthquakes within those continental terrains undergoing distributed deformation. Shallow earthquakes represent sudden slippages that release strain stored elastically in rock over long periods. Whether deep-mantle subduction-zone earthquakes represent similar elastic rebound or an abrupt contraction of part of a descending lithosphere plate into rock of higher-density minerals is uncertain; these deep earthquakes are mostly small enough, and distant enough from the surface, so that their potential for human disaster is small.

Only a small fraction of the energy released in an earthquake goes into the seismic waves. Most is absorbed locally by moving, deforming, and heating rock, and the proportion so absorbed increases irregularly with increasing size of earthquakes. The size of an earthquake is normally expressed as its "magnitude," an imperfect indication of seismic energy alone. An increase in magnitude of one unit the maximum recorded is about 8.7 ) denotes an increase in amplitude of seismic waves by a factor of 10 and an increase in total seismic energy by an irregular factor of about 30 . The number of earthquakes in each magnitude interval decreases by about a factor of 10 with each unit of increased magnitude, so the energy released by great earthquakes is far greater than the total released by small and intermediate ones. Minor earthquakes do not generally represent a safety valve adequate enough to dissipate the energy that is stored for great earthquakes, although slow creep along a fault can provide at least a partial release. On the other hand, the occurrence of a great earthquake does not prove that all dangerous strain has been released, for during this century there have been a number of pairs of great or severe earthquakes, separated by only months, days, or even hours, at virtually the same locations.

The magnitude of an earthquake depends upon the length and breadth of the fault plane of slippage, as well as on the amount of slip. The spot locations ("epicenters") given for earthquakes are the sites of initial breakage, but from such a site the slip propagates along the fault, with a velocity up to that of the outward-radiating seismic shear-wave front (3 kilometers, or nearly 2 miles, per second), until the entire affected segment can be in motion at once. Oceanic spreading centers are so hot at shallow depth that the solid rock above them can not store enough elastic strain to produce great earthquakes, and the infrequent large earthquakes that do occur in ridge systems are mostly on the longer strike-slip ("transform") faults, aiong which spreading on one ridge segment is stepped to that on the next. Great earthquakes occur primarily along convergent (subducting) and strike-slip plate boundaries and within those parts of the continents undergoing intraplate deformation (fig. 17), for these are the settings where fault breaks of adequate size are possible. Matters dealing particularly with the earthquakes of the Western United States are discussed here in these terms.

\section{SUBDUCTION-ZONE EARTHQUAKE: ALASKA, 1964}

A great subduction-zone earthquake of magnitude 8.5 struck south-central Alaska on March 27, 1964. Here Pacific lithosphere that is moving northwestward tips down at the Aleutian Trench and slides, with gentle inclination, beneath a melange wedge similar to that illustrated by fig. 15, dragging the base of the wedge very slowly northwestward. Compressive strain stored slowly at the base of the wedge resulted in sudden faulting that broke violently through to the surface. The results of the earthquake were studied exhaustively by Geological Survey and other scientists, whose work, reported in the many separate chapters of Professional Papers 541 through 546 and in other publications, makes this the best documented earthquake of subduction-zone type.

During the several minutes of the earthquake, the continental shelf and the deep-water slope from it down to the Aleutian Trench were uplifted by amounts that locally reached at least 9 meters (30 feet). The sea floor was raised an average of perhaps 3 meters (10 feet) over an area approximately 800 kilometers (500 miles) long, trending southwestward past the Kenai Peninsula and Kodiak Island, and 250 kilometers (150 miles) wide. Simultaneously, the uplifted terrain was narrowed, and the coastal part of it moved as much as 18 meters (60 feet) toward the trench. These changes represent by far the greatest movements of rock yet demonstrated to have accompanied an earthquake, although presumably other great subductionzone earthquakes around the Pacific (fig. 17) have had comparable submarine effects. Analysis of the seismic record and geologic results of the earthquake indicate that a large part of the melange wedge behind the Aleutian Trench suddenly slipped forward, up the gently dipping surface of the oceanic lithosphere beneath, releasing strain stored as its base had been dragged back slowly over many decades. The slippage did not continue along the base of the wedge to the trench but rather broke up through the wedge, thrusting its rear part upward. 


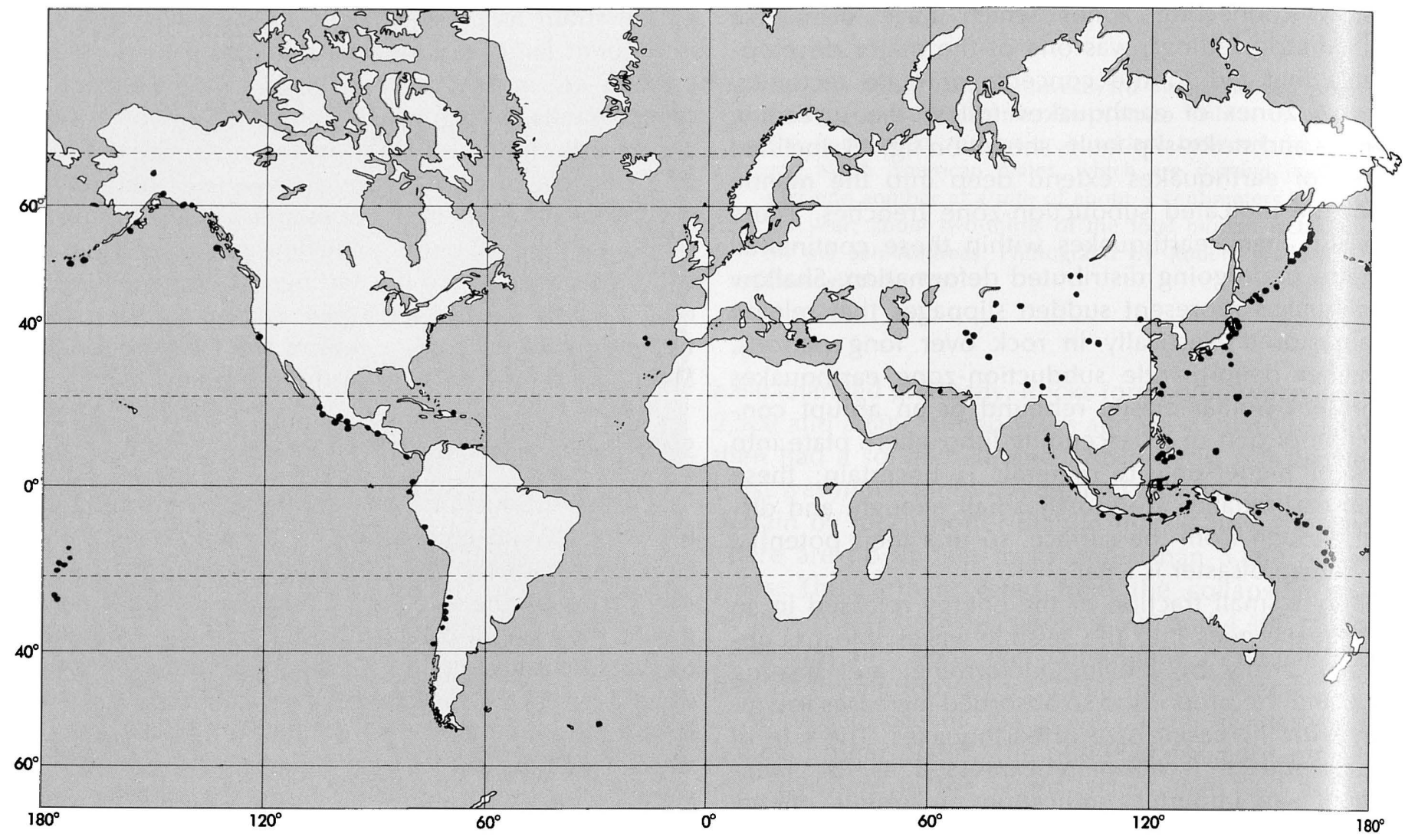

FIGURE 17.-World map showing the location of earthquakes of magnitude 8.0 and higher, 1897-1976. These great earthc $c_{i}$ uakes occur primarily along convergent or strike-slip plate boundaries and in zones of compressive or strike-slip deformation vithin continents. Data from the "World Seismicity Map," compiled by Arthur Tarr and printed by the U.S. Geological Sur:ey in 1974, with newer locations added.

\section{SEISMIC SEA WAVES}

When the sea floor is raised suddenly during a great earthquake, water is raised with it, the sea surface is tipped, and water rushes away; or, if the floor is dropped, water rushes in. An enormous mass of water is suddenly set in motion, and complex sloshing back and forth continues for many hours. The result is a train of water waves of a unique type, the seismic sea wave or "tsunami" (its Japanese name). The velocity of a water-wave form increases with its length, and in the deep ocean these uniquely long waves travel at about 800 kilometers (500 miles) per hour. The waves at sea are something like an hour apart at a given point, are only perhaps 30 centimeters ( 1 foot) high, and are virtually undetectable. As a wave approaches land, however, its bottom is slowed down by contact with the shallowing sea floor, whereas the top is slowed much less and catches up with the bottom. Where sea-floor topography and orientation are optimal for a tsunami from a given direction, the wave can hump up into a breaking wall of water 9 meters (30 feet) or more high, and rush onto the shore to cause enormous destruction. Nearby coastal points, where the bottom configuration is different, may record the same wave only as a rapid surge and vithdrawal of water, with much lower height.

The most extensive sudden changes in depth of the sea floor, and hence the greatest seismic sea iraves, result from shallow subduction-zone earthquakes, such as the Alaska earthquake of 1964. The enormous change in sea-floor configuration during that $e$ arthquake produced a train of seismic sea waves wich battered Alaskan coastal communities facing th uplifted region. Damage was most severe at Kodiak Harbor, where the first wave rose as a high swel! and did little damage, but the second, an hour after the first, and the third, another hour later, hit as breakingwater walls that ran up on shore as high as 9 meters (30 feet) above high-tide levels. Away from A aska, the waves in the train were highest going southeastward, perpendicular to the axis of the uplift, and did much damage along the Pacific coast as far south as San Diego. The most severe damage at a long disiance from Alaska was at Crescent City in northern Ca ifornia, where the fifth wave, following a train of four successively decreasing waves an hour or so apart, 
crested 6 meters (20 feet) above mean lower low water.

Another great subduction-zone earthquake of magnitude about 8.0 off southwest Mindanao in the Philippine Islands in August 1976 produced tsunamis that killed 5,000 people along nearby coasts. The 1964 Alaska earthquake represented part of the motion between the gigantic Pacific and North American plates, whereas the 1976 Philippine one resulted from motion between two small, young plates that have complex boundaries.

\section{STRIKE-SLIP EARTHQUAKES: THE SAN ANDREAS FAULT SYSTEM}

From the Gulf of California to the corner of the Gulf of Alaska, the Pacific lithosphere plate is sliding relatively northwestward past the North American plate. (Complications along Oregon, Washington, and southern British Columbia, much simplified on fig. 13, are mentioned in the subsequent section on volcanoes.) The strike-slip fault along which most of this motion is presently being taken up is exposed on land along most of the length of California, where we know it as the San Andreas fault. The effect of the 1906 earthquake of magnitude 8.5, during which the northern sector of the fault broke, was described briefly in the opening paragraph of this essay.

The Pacific and North American plates are sliding past one another at a steady 5 or 6 centimeters ( 2 or $2 \frac{1}{2}$ inches) per year. About two-thirds of this movement is taken up by slippage along the San Andreas and related structures, whereas the rest is taken up by other structures, mostly farther inland in the Basin and Range province. The sides of each active fault, like the San Andreas, generally remain stuck together until enough strain has accumulated in the flanking, bending rocks to rupture the bond and permit the lagging parts to suddenly catch up with the rest. Earthquakes on the San Andreas rarely reach deeper than about 15 kilometers (10 miles), and presumably the two sides flow smoothly past each other, without sudden ruptures, in the hot region of easy recrystallization beneath this depth. In some areas, notably that near Hollister, south of San Francisco, the two sides of the surface fault slide past one another almost constantly, with only small earthquakes, steadily increasing the offset of such features as fences and roads.

The overall San Andreas rate is about 3 or 4 centimeters (1 $1 \frac{1}{2}$ inches) per year, and a great earthquake like that of 1906 releases strains accumulated over 50 to 200 years. One cannot, however, predict recurrence intervals from this simple relationship. Moderate, large, and great earthquakes may be interspersed, and even great earthquakes do not release all stored energy. Some of the plate motion is stored in elastic bending of the rocks, to be released during earth- 8 quakes; but some is taken up in permanent, slow deformation by rock folding and other processes.

A long sector of the San Andreas fault, extending from well south of the part that broke during 1906 southeast to near Los Angeles, broke during an 1857 earthquake that may have been more severe than the 1906 San Francisco event. Historical documentation is poor, but geological evidence within the sector pictured in figure 16 indicates that horizontal shifts during the 1857 earthquake probably reached 15 meters (50 feet), and averaged 10 meters (30 feet) over a considerable length. Moderate earthquakes in 1899, 1907 , and 1916 occurred along and southeast of the southeast part of the 1857 sector, but the whole sector is now very quiet seismically. The growth during the last 15 years of the "Palmdale bulge," more than 250 kilometers (150 miles) long and up to 25 centimeters (10 inches) high, across the southeast end of the 1857 sector, leads some fault watchers to anticipate another major earthquake here soon.

Farther southeast along the San Andreas system in the Imperial Valley region of southeastern California, the deformational style changes, and with it earthquake patterns, in accord with the changing geometry of the lithosphere plate boundary. The Pacific plate is moving northwestward relative to North America, so it is sliding past North America through California, but it is pulling obliquely away from North America in northern Mexico, thus moving Baja California away from the mainland and opening the Gulf of California (fig. 13). This pulling apart is accomplished by a series of short spreading centers stepped to one another by transform faults, and the northernmost spreading centers have produced much of Imperial Valley itself. There were severe earthquakes, near magnitude 7, along transform and related faults in and near the Imperial Valley of California and the adjacent Colorado River Delta region of Mexico in 1899, 1903, 1915, 1918, 1934, 1948, and 1968. The transform faults proper may be too short to store enough strain to produce great earthquakes, but other active strike-slip faults farther west in southwestern California and northern Baja California are long enough to do the job.

A very severe earthquake, magnitude about 7.7 , east of Peking in northeast China in July, 1976, killed perhaps half a million people in one of the greatest natural disasters of recorded history. Unsafe buildings, urban congestion, and unstable, alluvial ground contributed to the extremely high casualties from this earthquake, which released far less energy than did the many great earthquakes during this century. The shock resulted from intra-plate strike-slip motion 
along a fault about 150 kilometers (90 miles) long. Subsidiary compressional faulting on related structures accompanied the main shock, and an extensional-fault earthquake of magnitude 7.2 followed only 15 hours later in the same area.

\section{COMPRESSIVE DEFORMATION WITHIN THE CONTINENT: SAN FERNANDO, 1971}

Both the Pacific and North American plates are moving relative to the deep mantle; thus, so also is the San Andreas fault boundary itself, which is slowly changing its shape as the adjacent plates deform. In southern California, the sector of the fault from north of Los Angeles to east of San Bernardino has rotated slowly counterclockwise, from a northwest to a westnorthwest trend. The result is that in this sector pure strike-slip (sideways) motion is becoming more difficult, and oblique compression of the continental crust is taking place. The San Fernando earthquake of February 9, 1971, was a small manifestation of this changing pattern. The effects of the earthquake were described in Professional Paper 733, published soon after the event, and subsequent more detailed reports by Geological Survey and other scientists.

The San Fernando earthquake was of only moderate size, magnitude 6.5, and resulted in surface slips of mostly less than 30 centimeters ( 1 foot) along short, discontinuous breaks in a zone 15 kilometers (9 miles) long. The surface faults trend eastward along the south edge of the San Gabriel Mountains, and the earthquake represented an increment in the growth of the range, the frontal part of which shifted southwestward and upward, ramping obliquely about 1 to 2 meters (3 to 7 . feet) up a fault surface dipping moderately northward beneath the range. Most of the shift was displayed at the surface as a broad bulge, identified by surveying, and only locally did a large part of it appear in the surface breaks.

Despite the modest size of the earthquake, 64 people were killed by it, and property damage approached \$1 billion. Damage was particularly heavy above the ramplike fault; accelerations locally exceeded gravity, which most seismic engineers had assumed to be improbable. The earth-filled Lower Van Norman Dam, holding back a large reservoir above the San Francisco Valley city area, was so heavily damaged that likely it would have failed had the earthquake continued much longer.

Other damaging earthquakes within the southern California oblique-compression region include events in 1902, 1925, 1927, 1933, and 1952 which ranged in magnitude between 6.3 and 7.7. Much larger earthquakes have occurred in analogous settings on other continents; hence they may occur here also, and,
Barbara Channel might have had a magnitude as large as 8 .

\section{TENSIONAL DEFORMATION: THE BASIN AND RANGE PROVINCE}

The San Andreas fault is the most important single structure in the broad boundary zone between the Pacific and North American plates, but some northwestward motion is distributed far inland across the Western United States. The resulting oblique extension of the continental plate has produced the Basin and Range province, which includes eastern California, Nevada, and western Utah, and similar terrains in western Montana, Idaho, eastern Oregon, southern Arizona, and New Mexico (fig. 13). Because the general direction of motion, relative to the continental interior, is northwestward and the amount of that motion increases westward toward the Pacific, the deformation tends to be expressed by strike-slip f ulting on structures oriented approximately northw estward and by extensional ("normal") faulting on structures with other orientations. The tensional faults have blocked out the mountains and besins which characterize the province. The surface fi ults tend to follow the pre-extension structural grair, of the near-surface rocks: the mechanical propertie; of the crust determine the details of its response to the regional stresses.

West-central Nevada had oblique-slip and nor nalslip earthquakes with magnitudes of 7.1 to 7.6 in 1915, 1932, and 1954. A normal-fault earthquak: of magnitude 7.1 struck the West Yellowstone regio: 1 of southwestern Montana in 1959 (see Professional P per 435) and provided a particularly good example of the discordance between large surface faults (length; to 23 kilometers, or 14 miles, and slips to 6 meter , or 20 feet) and crustal deformation at depth. Ovens Valley in east-central California was struck by a magnitude 7 plus earthquake in 1872, and the oblicueextension fault slip reached 8 meters (25 feet).

The major extensional faults, both as observed eologically and as known from earthquake offsets, 1 ave near-surface dips commonly near $60^{\circ}$ toward their downdropped sides. Extension is obviously requ red to accommodate such dropping down an inclined surface. The majority view holds that the obser/ed steep fault dips continue downward until a $n$ ore plastic substrate is reached and that the total amcunt of extension across the Basin and Range province uring the last several tens of millions of years has $b$ en on the order of 10 percent of the width of the piovince. A contrary argument is that the faults $n$ ust instead flatten downward and give way to horizo ital laminar shear at depth and that the width of the $\mathrm{p}$ ? $\mathrm{v}$ ince has been almost doubled by the extension. he 
province is characterized by a thin crust, by high temperatures at shallow depth, and by volcanism of a type which typically accompanies extension; these features may be products of the thinning of the crust by extreme extension.

Fault scarps no older than a few thousand years are present in many parts of the Basin and Range province and attest to the frequency of major earthquakes. The length and height of some of these scarps, and the amount of associated tilting and warping, suggest that some of the earthquakes-for example those in the Centennial Valley region of southwestern Montana and the Death Valley region of eastern Californiahad magnitudes near 8 . Much of the seismicity during this century has been concentrated along a belt trending northward from southern Nevada through central Utah and into southwestern Montana. Some of the young fault scarps are within this belt, but most are not; the most imposing young scarps anywhere in the province, for example, are in the Death Valley region, which is presently almost aseismic. We still know little about stress-transfer mechanisms, strain-accumulation rates, and similar problems in the province, but it appears that recurrence intervals on individual active faults are typically thousands of years and that the faults tend to remain locked and aseismic during most of the strain-buildup period between episodes of breaking.

\section{VOLCANOES}

Most volcanoes are products of lithosphere-plate motions. The "ring of fire" around the Pacific represents one type of this volcanism. The chains of volcanoes in the island arcs (such as the Aleutian Islands) and continental margins (such as the Andes) around much of the ocean form above undersliding oceanic plates. The main volcanic axis is typically about 125 kilometers ( 80 miles) above the inclined zone of earthquakes that marks the descent of the lithosphere plate into the deep mantle (fig. 15), so processes related to the descent and to that depth must control the melting of the magmas. The melts that arrive at the surface, to erupt in volcanoes, have been profoundly modified by reactions with the mantle and crustal rocks through which they have risen. Lavas formed in this setting have distinctive compositions and systematic variations that relate directly to their height above the subducting plate. These characteristics permit us to recognize rocks formed in similar settings in the geologic past and to estimate even the depths to the long-dead seismic zones above which they formed. Where, in ancient terrains, the volcanic rocks have been eroded away, we now see granites and other rocks which crystallized slowly within the crust from similar magmas.
The high volcanoes of the Cascade Range in Oregon and Washington-Mount Hood and Mount Rainier, for example-form a short chain of this type, vigorously active until not many thousand years ago but now showing only infrequent activity. The decline in volcanism reflects a plate-boundary change now underway to the west: there was until recently rapid subduction of a small Pacific plate beneath northern California, Oregon, and Washington, but the pattern is presently changing; the San Andreas fault system is now breaking across the small plate. Small quantities of magma are still rising into the volcanoes, and small eruptions are likely to occur every 50 years or so. Of the possible eruptive types, lava itself poses little hazard, but glowing avalanches and volcanic mudflows (see next paragraph) could be damaging.

In the tropics, volcanoes of this type are a boon as well as a bane. Tropical soils are heavily leached, but volcanic areas generally have fertile soils because mineral nutrients are replenished by frequent ash falls. Java, half the size of California, can support its population of 90 million people only because of its young volcanic soils. But Javanese volcanoes-many of which show continuous hot-water and steam activity and actually erupt every few years-also cause much destruction. The common major hazard is the volcanic mudflow, for which the Javanese term "lahar" is generally used in geology. Lahars are mixtures of mud and volcanic rock which flow down volcano sides and thence down stream valleys beyond, sometimes as far away as 65 kilometers (40 miles). A lahar can be either cold, triggered by heavy rains or earthquakes affecting the steep, unstable slope of a volcano, or hot, representing a mixture of new lava, water from crater lakes (or from melting ice, in a site such as the Cascades), and surficial materials picked up along the way. Still more destructive, but fortunately rare, are great volcanic explosions, of which that of the island of Krakatoa in 1883 is the most famous. Here, between Java and Sumatra, sea water and magma combined to produce a steam explosion which blew the top 20 cubic kilometers (5 cubic miles) of the volcano into the air; the resulting giant sea waves killed 35,000 people.

The volcanoes of the western conterminous United States away from the Cascades are byproducts of the rifting of continental crust. The deeper part of the continental crust is hot enough so that it would melt if the pressure could be released; thinning of the crust does decrease the pressure and permits partial melting. There have been no historic eruptions of these rifting-type volcanoes in the non-Cascade West, but there were prehistoric eruptions every few hundred years, so more can be expected in the future. The common activity has consisted of the building of a 
cinder cone and the eruption of small lava flows, likely completed within a decade in many cases. Much less frequent, perhaps every 100,000 years, has been the huge ash-flow tuff type of eruption; a very large mass of magma reaches the surface and erupts as giant fountains, perhaps a kilometer or two (a mile) high, which collapse and spread thin sheets of lava and hot frothy ash over areas that can reach more than 5,000 square kilometers (several thousand square miles). No eruption of this type has been observed, but study of the products indicates that successive fountains and outflows can be only minutes or hours apart and that composite sheets a hundred meters or more (hundreds of feet) thick can be built in days. Yeilowstone National Park is formed mostly of such ash-flow sheets and related lavas and probably is underlain now by a large magma chamber, to which is due the geyser activity; future ash-flow eruptions are probable, but there is no reason to anticipate one soon.

The Hawaiian Islands are huge volcanoes. Hawaii, largest of the islands, rises about 9,000 meters $(30,000$ feet) above the deep-ocean floor and has volcanic eruptions typically every few years. The volcanoes have been largely built in succession, each one to the northwest being older than than that to the southeast, and Hawaii itself is at the southeast end. The chain of volcanoes continues northwestward as the foundations for atolls as far as Midway and then as submarine mountains-sunken volcanoes-all the way to Kamchatka, and the general age progression continues throughout. A popular explanation for the volcanism and its age progression is that the Pacific lithosphere plate is drifting slowly northwestward over a "hot spot," in the deeper mantle, from which magmas keep rising through the plate above.

\section{MINERAL DEPOSITS}

Many mineral deposits have a plate-tectonic explanation. The great bulk of the metallic minerals mined in the Western United States-copper, molybdenum, tungsten, gold, silver, lead, and so onformed from magmas above subduction zones, like that of fig. 15, during the period from 100 to 15 million years ago. Pacific Ocean lithosphere was then sliding rapidly beneath North America, and belts of volcanoes formed, with granites crystallizing from the large magma chambers beneath the volcanoes. The metals were concentrated in the last-remaining liquids in the magma chambers, after crystallization of the voluminous silicate minerals. Where conditions were favorable, as generally they were not, these enriched liquids altered and replaced the igneous rocks or the binations of metals concentrate at different levels in the chamber, so the depth of erosion into an igneous complex controls the type of ore deposit that may be found within it. There are also provincial variations in types of deposits, and it is likely that depth of melting of the initial magma (which would be very different in composition from the final magma reaching the surface) and the composition of the mantle and crustal rocks through which the magma rises and reacts are important in determining what, if any, metals are concentrated within it.

Copper occurs, for example, in and near the tops of granite masses that crystallized near the surface, after their magmas had risen through thick crust, either old-continental or young-volcanic, but generally not where similar magmas rose through very thick sedimentary rocks. Much silver occurs in the throats of volcanoes, the magmas of which in many cases did rise through thick strata. Tin forms primarily from granites generated by melting within the crust, rather than by melting within the mantle. Overall, our knowledge of these relationships is fragmentary and more empirical than genetic.

Other ore deposits occur in the zones of tectonic accretion where oceanic materials are scraped off against continental margins from undersliding oce anic plates. Large masses of mantle rocks are in many places sliced into these complexes; such rocks contain a small fraction of nickel, which is concentrited in residual soils by tropical weathering and there forms enormous potential resources. Mercury occurs primarily in such accretion settings, although its genesis is unclear. Copper formed within oce inic crust can also be added to continental margins in the scraped-off complexes. Volcanic island arcs, complete with whatever ore deposits formed within and beneath their volcanoes, are plastered against continents in these zones.

Secondary processes can obscure the plate-tectonic relationships. Tin most commonly reaches comme: cial concentrations where the effects of tropical weathering are superimposed on those of magmatic processes. Gold, present in tiny quantities in either magn atic or subduction complexes, is concentrated as placer deposits by streams. The uranium ores in Wyoning and the Colorado Plateau may have formed when volcanic ash, washed and blown 800 kilometers $\$ 500$ miles) inland from volcanic belts, was deposited in strata from which the traces of uranium were leacned out by oxidizing ground water to be redepositer as concentrates in other strata containing organic rnatter.

Many important ore deposits do not appear to be related to plate motions. Most iron ore is sedimen ary rock, formed on shallow marine shelves $1,800-2,400$ 
million years ago when the Earth probably had an atmosphere that contained almost no oxygen. (Oxygen is produced primarily by photosynthesis of plants, which release oxygen as they combine hydrogen from water with carbon dioxide to make carbohydrates.) Ancient placer uranium deposits, such as the Blind River deposits in Canada and the Witwatersrand gold deposits of South Africa, probably owe their origins also to an oxygen-free atmosphere. The lead and zinc of the Mississippi Valley region were dissolved out of limestone, in which they occur in minute proportion, and then precipitated as concentrates. The copper and nickel at Sudbury, Canada, and the platinum at Rustenburg, South Africa, occur as precipitates from great pools of magma which may have been melted by meteorites or comets that collided with the Earth and exploded nearly 2,000 million years ago.

\section{PETROLEUM AND NATURAL GAS}

Oil and natural gas occur in sedimentary strata in wedges and basins that mostly are byproducts of the motions of lithosphere plates. Oil and gas are generated by the breakdown of organic matter, which makes up 1 percent of typical dark-shale source rock. Time-temperature processes-the higher the temperature, the shorter the time-change the organic material into a small amount of gas and liquid petroleum and a larger amount of solid hydrocarbons; the gas and liquid migrate through pore spaces. Too high a temperature produces gas only or destroys all of the hydrocarbons. The migrating components tend to move upward, channeled along permeable strata, and accumulate where migration paths are blocked by impermeable materials. The formation of an oil field requires an uncommonly fortunate combination of organic source beds, an appropriate thermal history, and a migration path ending in a trap. Only a minute proportion of the Earth's sedimentary rock contains recoverable petroleum and gas. Most petroleum occurs in rocks less than 200 million years old, is trapped in anticlines in either porous sandstone or limestone, and is shallower than 3,000 meters $(10,000$ feet).

Most oil, including that of the Persian Gulf, which represents more than half of the global total of reserves, occurs in continental-shelf strata. These sedimentary rocks are deposited on rifted continental margins. When a continent is split and the pieces are separated as an ocean spreads between them, the edge of the continental crust slowly spreads oceanward, thins, and subsides. Sedimentation keeps the top of the subsiding shelf subhorizontal, whereas deeper layers tend to have progressively greater, but still gentle, oceanward dips. Oil generated in such strata migrates mostly up-dip, toward the continent. Gulf coast American oil, both onshore and offshore, formed in this setting. The exploration now underway on the offshore Atlantic Outer Continental Shelf of the Eastern United States is based on the hope that there may be large quantities of oil there, but drilling of possible trapping structures identified by geophysical methods will of course be necessary to test the hope.

Another important setting for oil accumulation is the foreland basin, which in various forms develops on the landward side of subduction systems (fig. 15). In the United States, small oil fields in western Wyoming and the large Prudhoe Bay field of northern Alaska exemplify this setting. The latter field may prove to be the largest ever found in North America.

The outer-arc basins, which occur between trench and volcanic belt in an active subduction system (fig. 15), commonly contain strata and structures which appear from geophysical studies to be favorable for petroleum. Drilling has generally shown, however that subsurface temperatures are too low for the generation of oil. The presence deep beneath the basins of cool oceanic plates insulates the basins from the normal flow of heat from the interior of the Earth. Here is an example of a negative way in which platetectonic concepts are used to guide oil exploration: most companies have written off outer-arc basins.

Oil also occurs in broad basins within continents. Some of these basins are products of the wrenching of continental plates during collisions with other plates, whereas others are not related directly to plate interactions and perhaps have subsided because of cooling at the base of the lithosphere plate.

\section{COAL}

Coal is formed from wood and other plant debris, buried beneath other sediments and transformed slowly, under the influence of heat and pressure, from a mixture of cellulose and other carbohydrates to a high-carbon residue. Most coal represents swamp deposits, and practically all is younger than 350 million years old. Recoverable coal contains about 10 times as much energy as did the initial total supply of oil and gas available to man, so our society will be fueled by coal long after oil and gas are exhausted.

Coal swamps mostly originated through interactions of lithosphere plates. The Appalachian coal of the United States, for example, formed about 275-310 million years ago in a foreland basin, analogous in its early stages to that of figure 15 but complicated in later stages by the collision of Africa with North Amer- 
ica. (The modern Atlantic Ocean began to open about 200 million years ago, rifting approximately along the previous collision suture.) The basin was alternately flooded by the sea, then drained, the coal swamps forming during the emergent periods. The fluctuations of sea level were themselves byproducts of plate motions. Although the Appalachian coal swamps lay near the equator, North America having since drifted to its present position, there was then a large continentwhose fragments now comprise South America, Africa, India, Australia, and Antarctica-which had drifted over the south pole. This southern continent underwent repeated glaciation and deglaciation, comparable to the much younger glacial cycles of the Pleistocene of North America and Eurasia. Sea level dropped 100 meters or more (hundreds of feet) each time ice sheets expanded on the southern continent, and coal swamps developed elsewhere.

The Western United States coals are younger, mostly 50 to 80 million years old. The older of these formed in a broad foreland basin, typically in coastal swamps along the west side of a shallow inland sea. The presence of the sea-that is, the high sea level of the time-may have been due to rapid sea-floor spreading. New sea floor formed by spreading stands high and subsides slowly with age, so the faster the spreading the higher the general level of the sea floor and the greater the volume of water that overflows onto the continents. The younger and much more important of the coals in the Rocky Mountain region formed in vast swamps in more local basins that were produced by oblique compression of the continental crust of the entire western interior, crumpling it into broad basins and ranges of a type altogether different from those formed later in the Basin province farther west. These younger coals represent one of the world's great energy reserves and include coals of uncommon thickness; one extensive layer of pure coal is 70 meters ( 230 feet) thick.

\section{LIFE}

The formation of planets must be a common byproduct of the condensation of stars, and there must be countless planets in other stellar systems upon which highly evolved living organisms are present. Not on all planets, of course. Life on Earth reflects various fortunate circumstances; for example, our planet is large enough to hold hydrosphere and atmosphere, and the Sun is at a distance which gives the Earth a surface temperature mostly within the narrow range of liquid water.

The course of evolution of life on Earth has been much influenced by plate motions. The Earth has had contrasted areas of land and sea throughout its 3,800 million years of geologic history, although how much of the present water was early at the surface and how much has since been differentiated out by volcanic processes is debatable. The initial continents of an internally stable Earth, without the rejuvenating processes of uplift, mountain building, formation of new continental material, and magmatism, would long since have disappeared beneath the sea, leveled by land and sea erosion, limiting potential life forms.

Unicellular organisms were certainly preserit by 2,000 million years ago, and less convincing evicence puts them back as far as 3,300 million years. Metazoamulticellular organisms in which differentiated cells perform different functions-appeared about 700 million years ago. Only about 600 million year. ago did the oxygen content of the atmosphere rech a level, still far below that of the present, at which animals could afford the oxygen-expensive luxuy of shells, hard parts, and large muscles, and only then did the rush of evolution of higher organisms ge underway.

As continental pieces have drifted about the Larth, they have carried biotas that had been shared with other lands before rifting but then evolved in isolation during the transport period. The modern flora of Australia, for example, has evolved from three dom nant stocks. The longest isolated was shared with frica before the rifting between them, and the next-lo igest was shared with New Zealand, Antarctica, and South America, before these too were sundered; the yc ungest assemblage, a tropical flora of Asian affinity was carried in on an island arc that collided with New Guinea, which is the north part of the Australian continent, only about 25 million years ago. When continents collide or are connected by volcanic or (ther land bridges, their independently evolved passe gers mingle, and, at least among the mammals, tho e of the larger landmass are generally better suited $t$ new competition and tend to replace those 0 the smaller. The primitive placental ungulates and narsupial carnivores of South America, for exar nple, evolved and thrived in isolation on the island continent after it separated from Africa but mostly vanished quickly when the Panama land bridge was suilt by volcanoes only a few million years ago, permi ting interchange with North American and Eurasian fa nas. Much of the geological evidence for the detais of past plate motions comes from subcontinents now juxtaposed but carrying fossil assemblages that nust have originated far apart.

Dinosaurs thrived in warm, equable climates and disappeared some 70 million years ago when, and 
possibly because, climates in most parts of the world became more sharply seasonal. The major cause of climatic change was a lowering of sea level, draining vast climate-moderating inland seas, which might have been due to a slowdown in oceanic spreading rates and hence to a deepening of average ocean depths. The mammals, with their superior mechanisms for conserving or dissipating heat, had previously been small and primitive, but their evolution then accelerated. Man is of course one product of that evolution.

\section{SUMMARY}

Plate-tectonic concepts permit an understanding of the interrelationships between the processes operating within the Earth. We have begun to integrate into a genetic, unifying framework the descriptive findings of the earth sciences. The geologic processes which affect society-both harmfully through earthquakes and other catastrophic events, and beneficially through mineral and fuel resources-are largely controlled by the motions of lithosphere plates.

\title{
Outer Continental Shelf Safety in Oil and Gas Operations
}

\author{
By Ronald W. Taylor and Richard B. Krahl
}

As the Nation continues to expand its efforts to find more oil and gas, the role of the U.S. Geological Survey's Conservation Division in supervising and regulating these activities is becoming more significant, especially for operations on the Outer Continental Shelf.

The general public still recalls the Santa Barbara oilspill of 1969 and the two major-oil platform fires the following year in the Gulf of Mexico. The concern for the environment that resulted from these incidents spread nationwide.

To help prevent similar events from occurring and to insure strict adherence to safety and pollution-prevention regulations, Geological Survey inspectors visit oil and gas operations on the Outer Continental Shelf to make unannounced safety and operations inspections. They check to see that the drilling and production platforms are properly marked for air/sea navigation, safety, and identification and to make sure that there are blowout preventers installed and that the casing and casing cements are correct. They may also check to see that abandoned wells are properly plugged or that the operating wells are producing oil and gas in paying quantities. They check flow rates, maintenance, and inspection records and make sure that waste materials are disposed of properly. Their checklists also require them to inspect such things as welding permits, electrical circuits, fireproofing, safety and escape devices, and the conditions of drip pans under motors and to analyze the drilling mud.

The Survey's inspection program has been designed to assure that petroleum from the Nation's offshore resources is produced with the greatest possible regard for human life and the safety of the marine environment. Through uniform enforcement of regulations and periodic inspections, the public can be assured of safe, prudent, and pollution-free operations.
Safety is an ongoing and continual consideration in the conduct of petroleum operations on the submerged lands of the Outer Continental Shelf contiguous to the coasts of the United States. Procedures instituted by the U.S. Geological Survey and other Federal Government agencies are aimed at protecting human life, the waters and biota overlying the shelf, and the adjoining coastal State waters and shorelines. The term "safety," therefore, is used in the context of protection of human life and prevention of environmental harm.

The importance of safety and pollution control to petroleum operations on the Outer Continental Shelf cannot be overemphasized. This fact is recognized by the Code of Federal Regulations throughout Title 30 CFR Part 250, the regulations under which the Geological Survey administers the provisions pertaining to oil and gas operations on the Outer Continenta! Shelf. Included in this part is the Survey's responsibility (under Title 30 CFR Part 250.12) to "prevent damage to, or waste of, any natural resource, or injury to life or property." Also Title 30 CFR Part 250.30 charges the lessees with a like responsibility.

The Survey's annual report for fiscal year 1975, as well as this current report for fiscal year 1976, lists under Conservation of Lands and Minerals, "Regulation of Operations," a number of major studies of oil and gas operations on the Outer Continental Shelf. As mentioned therein, a Geological Survey work group was established on OCS safety and pollution control, chaired by the Associate Director. This work group reviewed the major studies on the subject (list given in above references) and recommended the implementation of 19 major categories for improvement in a report issued in May 1973 and supplemented in May and November 1974.

These categories and their status in fiscal year 1976 are listed in table 21 elsewhere in this annual report. 
The Geological Survey's OCS Lease Management Safety and Pollution-Prevention program for oil and gas drilling and producing operations includes the following management responsibilities:

- The Director, through the Chief of the Conservation Division, is responsible for establishing the general safety, pollution-prevention, and pollution-control policy and for providing management direction and review of the lease management program.

- The Associate Director, as chairman of the Work Group on OCS Safety and Pollution Control, is responsible for the overall results of the Work Group's review program.

- The Chief of the Conservation Division, through regional conservation managers, area supervisors, and district supervisors, is responsible for implementing the Survey's Safety and Pollution-Prevention Policy in accordance with the program document.

Documentation of the program shows 16 functional elements that involve Government and industry responsibilities in safety on the Outer Continental Shelf, as follows:

1. Pre- and post-lease information development and evaluation.

2. Research and development.

3. Development and use of standards.

4. Development and use of OCS Orders and other orders to lessee compliance.

5. Review of lessee applications and plans.

6. Platform/structure design and construction verification.

7. Pipeline approval and inspection.

8. Field compliance evaluation.

9. Equipment-failure reporting, analysis, and information exchange.

10. Pollution surveillance and cleanup.

11. Accident investigation and reporting.

12. Enforcement actions.

13. Training and qualification of lessee personnel.

14. Training of Geological Survey personnel.

15. Motivation.

16. Audit and review.

These functions are being actively pursued, with a very strong tie-in with the day-by-day supervision of drilling and producing operations in the Outer Continental Shelf, including on-site inspections.

U.S. Geological Survey supervision begins before any drilling by an operator on the Outer Continental Shelf, as an operator must submit an Application for Permit to Drill to the Survey. This application must contain a contingency plan for handling emergencies, ploration and development; significant geological markers anticipated; and specific information concerning the drilling rig, casing program, cementing program, drilling-fluid program, and blowout-preventer equipment. Geological Survey geologists, geophysicists, and engineers review the application for compliance with appropriate Outer Continental Shelf Orders and Regulations. Hazardous conditions such as surface faulting, potential sea-bottom slides, shallow gas pockets, or deeper abnormal pressures are made known to, and discussed with, the operator. Appropriate changes are required in the drilling program before the Permit to Drill is approved.

The design of the integrated casing, cementing, drilling mud, and blowout-preventer system must take into account the depths at which petroleum-bearing formations are expected to be penetrated; the formation fracture gradients, and the pressures to be encountered.

The operator is required to case and cemerit all wells with a sufficient number of strings of casing to prevent the release of fluids from any stratum, to prevent communication between separate strata, to support unconsolidated segments, and to provide a means of control of formation pressures and fluids (fig. 18). Drive pipe may be set by drilling, dring, or jetting to a minimum depth of about 30 meters (100 feet) beneath the ocean floor to support unconsolidated deposits and to provide hole stabilit for initial drilling operations. If this portion of the hole is drilled, the drilling fluid utilized may not contain oil or toxic substances, and the entire length of trive casing must be cemented back to the ocean floo: All subsequent casing strings must be securely ceme ted. Before drilling below the drive pipe, at least on remotely controlled annular-type blowout preventc $r$, as well as equipment for circulating the drilling fluid to the drilling structure, must be installed. Choke and kill lines must be provided for diversion of hydrocarbons and other fluids. The diverter system must be equipped with automatic remote-controlled $v$ Ives which open, prior to shutting-in the well, at least two lines venting in different directions to accomplish downwind diversion.

Subsequent to drilling below the drive pipe the conductor and surface casing strings are set anc cemented. Vertical depth at this point varies betveen 450 and 1,370 meters $(1,500$ and 4,500 feet). Pricr to drilling below the surface casing string, or an intermediate casing string, additional requirements are imposed upon the blowout-preventer system. At this time, the blowout-preventer system must inc ude a minimum of: (1) four remotely controlled, hycraulically operated blowout preventers including two equipped with pipe rams, one with blind rams and 


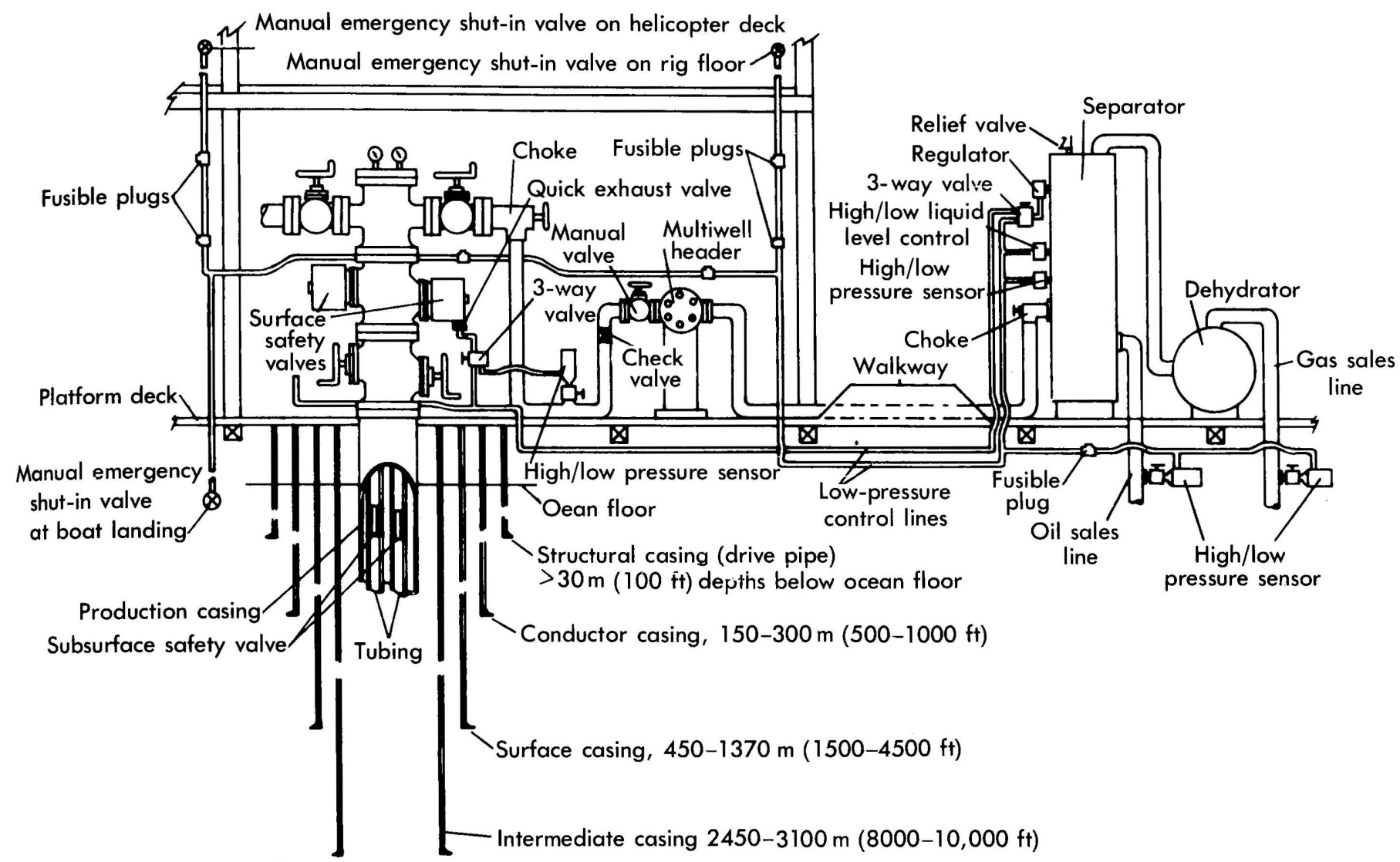

FIGURE 18.-Schematic diagram of an offshore drilling rig showing required features for the safety of personnel and equipment and the prevention of pollution.

one annular type; (2) a drilling spool with side outlets, if side outlets are not provided in the blowoutpreventer body; (3) a choke line and manifold; (4) a kill line separate from a choke line; and (5) a fill-up line. Subsea blowout-preventer stacks used with floating drilling vessels must be equipped with blindshear rams.

Ram-type blowout preventers and related control equipment must be tested at the rated working pressure of the stack assembly or at 70 percent of the minimum internal yield pressure of the casing, whichever is the lesser. Annular-type preventers must be tested at 70 percent of these pressure requirements. These tests are conducted: (1) when installed, (2) before drilling out after each string of casing is set, (3) not less than once each week from each of the control stations, and (4) following repairs that require disconnecting a pressure seal in the assembly. While drill pipe is in use, ram-type blowout preventers must be actuated to test proper functioning once each trip, but in no event less than once each day. The annular-type blowout preventers must be actuated on the drill pipe once each week. Accumulators or accumulators and pumps must maintain a pressure capacity reserve at all times to provide for repeated operation of hydraulic preventers. An operable remote blowout-preventer control station must be provided in addition to the one on the drilling rig floor.

Blowout-prevention drills are conducted weekly for each drilling crew to insure that all equipment is operational and that the crews are properly trained to carry out emergency duties. These drills and tests must be recorded in the driller's log.

Geological Survey personnel also oversee production operations. Production-system analyses include a review of the proposed mechanical-flow and safetysystem schematic diagram of the platform to insure that the production system conforms to safety standards. The design of the structure, the production processing equipment, the personnel facilities, and the incoming and departing pipelines are checked for compliance with requirements to assure that these components will properly integrate into an effective platform-safety system. This safety system includes subsurface safety valves, an automatic failclose wellhead valve, a flowline which is protected by high- and low-pressure sensors, a check valve, and pressure vessels protected with high and low pressure and liquid-level sensors (fig. 18). Any abnormal operating condition will result in an automatic production-system shut-in. Pneumatic and hydraulic control systems are equipped with fusible links which 
melt in the event of a fire and, as a result of the loss of pressure, activate fail-close valves. Emergency shut-in controls, located at strategic points on the platform, are an integral part of the safety shut-in system and afford a backup means for manually effecting a complete shut-in of the entire facility. In addition to such manual controls at the central panel, others are located on the boat landing and helicopter pad for use in the event of an emergency evacuation of the facility. In establishing safety-system requirements, stress is placed on requiring backup devices and procedures that provide for an additional margin of safety even if a critical item of equipment fails.

The Geological Survey has the specific responsibility to inspect, monitor, and document the day-to-day activities and operations of the petroleum industry on the Outer Continental Shelf by making on-site inspections and witnessing the tests of safety and pollution-prevention equipment. The inspection program administers a fair, but firm, uniform enforcement policy that insures conformance to standards that result in operations that are as safe, prudent, and pollution free as is possible.

To facilitate inspections, the Outer Continental Shelf Orders and Regulations have been condensed into a computerized checklist composed of questions that are answered by the inspection team either positively for compliance or negatively for noncompliance. Each incident of noncompliance requires that the inspector take a prescribed enforcement action which will result in either a warning or a shutdown of operations. If the incident requires a shutdown, the condition must be corrected before operations can be resumed.

The checklist used by the inspectors is a listing of potential incidents of noncompliance. The actual incidents of noncompliance observed are counted at each inspection site, and the ratio, actual to poten- tial, is used as a basic measurement of the degree of compliance.

Inspection teams of petroleum engineering technicians travel to the OCS facilities by helicopter or boat, observing the water surface en route for any evidence of pollution. Inspections of drilling rigs and related equipment in the Gulf of Mexico are conducted at least once during the drilling of each wildcat well and during the drilling of the first development well from a platform. New production facilities are inspected upon commencement of operations. All major platforms are scheduled for inspection semiannually. Drilling rigs in frontier areas are inspected daily.

Blowouts, fires, pipeline leaks, and other accidents are investigated by inspection teams. These investigations establish the contributing factors in accidents in order to help avoid similar incidents in the future. The Geological Survey has instituted "Safety flert" notices to inform all operators of the probable cause of individual accidents and to describe the hazar dous situations that resulted in these accidents. This information enables all operators not involved in a particular incident to evaluate similar situations in their jurisdiction.

Table 5, which gives accident and spillage atistics, shows the progress over the last 6 calc ndar years towards safe and pollution-free oil and ga operations on the Outer Continental Shelf. The total oil spillage steadily declined except for three arge spillages in 1973 and two large pipeline spillag es in 1974. The statistics for total accidents from all c uses show a large drop in fatalities in 1971; they hav 2 remained essentially constant since then. During this 6-year period, oil/condensate (1971) and gas (974) production have peaked. New well starts (driling) have remained fairly constant although there w:s an 8 percent increase during the last year. How ever,

TABLE 5.-Accident and spillage statistics for the Outer Continental Shelf, calendar years 1970-75

\begin{tabular}{|c|c|c|c|c|c|c|c|c|c|c|c|}
\hline \multirow[b]{2}{*}{$\begin{array}{l}\text { Calendar } \\
\text { year }\end{array}$} & \multicolumn{3}{|c|}{ Total accidents 1} & \multicolumn{2}{|c|}{ Total of all spills } & \multirow{2}{*}{$\begin{array}{l}\text { Oil and } \\
\text { conden- } \\
\text { sate } \\
\text { produc- } \\
\text { tion } \\
\text { (barrels, } \\
\text { in } \\
\text { millions) }\end{array}$} & \multirow{2}{*}{$\begin{array}{c}\text { Gas } \\
\text { produc- } \\
\text { tion } \\
\text { (cubic } \\
\text { feet, } \\
\text { in } \\
\text { billions) }\end{array}$} & \multirow{2}{*}{$\begin{array}{c}\text { New } \\
\text { well } \\
\text { starts }\end{array}$} & \multirow[b]{2}{*}{$\begin{array}{l}\text { Active } \\
\text { leases }\end{array}$} & \multirow{2}{*}{$\begin{array}{l}\text { Fixed } \\
\text { struc- } \\
\text { tures } \\
\text { (end of } \\
\text { year) }\end{array}$} & \multirow{2}{*}{$\begin{array}{c}\text { E sti- } \\
\text { m ited } \\
\text { mi eage } \\
\text { of } \\
\text { pir aline } \\
\text { si ser- } \\
v \text { sed }\end{array}$} \\
\hline & Number & $\begin{array}{c}\text { Fatali- } \\
\text { ties }\end{array}$ & Injuries & Number & $\begin{array}{c}\text { Barrels } \\
\text { of oil } \\
\text { spilled }\end{array}$ & & & & & & \\
\hline 1970 & 24 & 33 & 58 & Unknown & Unknown & 361 & 2,419 & 900 & 1,017 & 1,800 & 4,300 \\
\hline 1971 & 35 & 11 & 16 & 1,256 & 2,778 & 419 & 2,777 & 841 & 1,083 & 1,891 & 5700 \\
\hline 1972 & 41 & 10 & 9 & 1,161 & 1,182 & 412 & 3,038 & 847 & 1,023 & 1,935 & 6. .00 \\
\hline 1973 & 44 & 9 & 15 & 1,175 & $23,096^{2}$ & 395 & 3,212 & 820 & 1,266 & 2,001 & $6+50$ \\
\hline 1974 & 39 & 9 & 22 & 1,137 & $23,388^{3}$ & 361 & 3,515 & 816 & 1,590 & 2,054 & 6.700 \\
\hline 1975 & 46 & $17^{4}$ & 14 & 1,128 & 977 & 330 & 3,459 & 882 & 1,792 & 2,079 & $7,: 50$ \\
\hline
\end{tabular}

1 Includes blowouts, fires, explosions, falls, vessel collisions or sinkings, drownings, electrocutions, asphyxiations, blows, etc.

2 Includes (a) 9,935 barrels-structure supporting oil storage tank bent, ruptured tank;

(b) 7.000 barrels-barge developed a leak in heavy seas and partially sank, releasing oil, and

3 Includes (a) 19,833 barrels-dragging anchor. snagged and ruptured pipeline and

Includes (a) 19,833 barrels-dragging anchor. snagged and ruptured pipeline and 
the number of active leases supervised, the mileage of pipelines supervised, and the number of fixed structures at the end of the year have all steadily increased. For instance, the number of active leases which were supervised (with all drilling and production operations being inspected) increased by 24 percent, 26 percent, and 13 percent for each of the last 3 years, respectively. In effect, the consistency in fatalities, when considered along with the increased activities, represents a reduction in the fatal accident rate.

It is not realistic to think that a 100 -percent accident- and pollution-free environment can ever be achieved in offshore oil and gas operations. Such things as human error and equipment/material failure probably will always contribute to accidents and pollution. Good examples of this may be found in the footnotes at the bottom of table 5. However, Government's role on the Outer Continental Shelf involving safety, which includes the studies on safety and the procedures and equipment required by the Geological Survey in drilling and production operations, is to constantly strive to make the Outer Continental Shelf as safe and pollution free as is technically possible. 


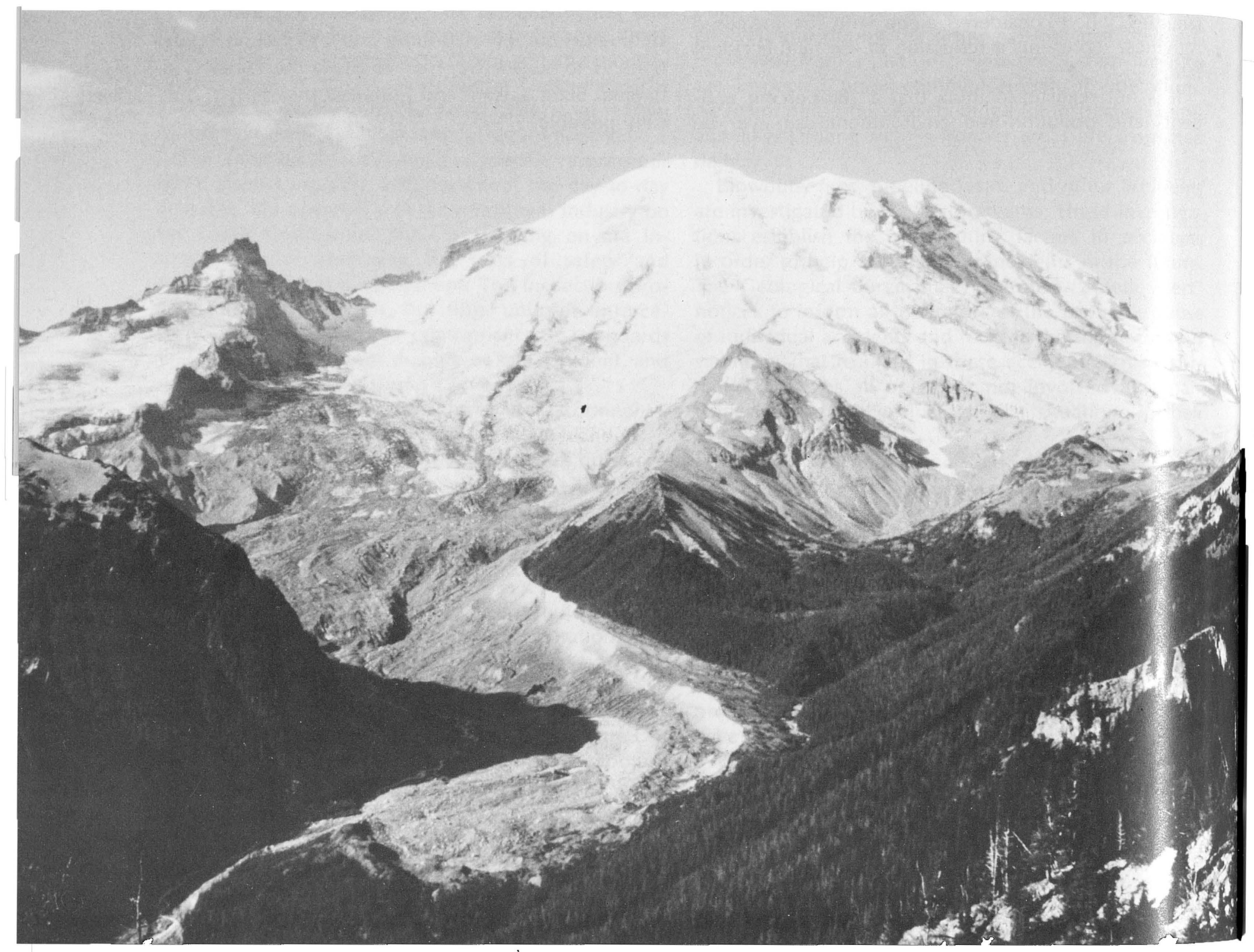

Several major USGS research projects involve Mount Rainier, including glaciology and the stratigraphy of volcanic rocks and glacial deposits. 


\section{Missions, Orzanization, and Budzet}

For nearly a century, the U.S. Geological Survey has served Federal, State, and local governments, and the public, by collecting, analyzing, and publishing detailed information about the Nation's mineral, land, and water resources. The Geological Survey was created in 1879 to study the geologic structure and mineral resources of the public domain and to provide information to support development of the West. Congress and the Secretary of the Interior later expanded the Survey's responsibilities to include topographic mapping; chemical and physical research; stream gaging and water-supply assessments; supervision of mineral exploration and development activities on Federal and Indian lands; engineering supervision of waterpower permits; and administration of a minerals exploration program.

Although the emphasis and balance of the Survey's programs have changed over the years, they still reflect the fact-finding mission described in the brief authorizing legislation of 1879 . Today, that mission has two objectives. First, the Survey is charged with increasing the knowledge of the extent, distribution, character, and origins of the Nation's natural resources and of the geologic processes that affect the use of the land so that man may adjust his activities to the constraints imposed by the environment and so that the Earth's resources may be managed wisely. Second, and no less important, are the Survey's regulatory responsibilities-classifying Federal lands and supervising mineral lease development on Federal and Indian lands. By working closely with the Bureau of Land Management and other land-management agencies, the Survey seeks to identify and conserve the Nation's public resources and supervise their development so that the public receives its fair share for leased resources and so that damage to other resource, environmental, and social values is minimized during exploration and development.

Both missions call for objective and impartial reporting of investigations, identification of natural constraints on land use and resource development, and analyses of the consequences of alternative policies or actions related to resource development, conservation, and environmental protection.

\section{ORGANIZATION}

The scientific and regulatory mission of the Geological Survey is carried out by five organizational units, each of which is responsible for one of the Survey's major programs or budget activities (see the organizational chart and table 26 in the section entitled "Organizational and Statistical Data").

- The Topographic Division produces maps delineating the physical features of land areas in the United States and its outlying areas and in Antarctica. The division also collects and distributes information on the availability of aerial photographs and space images, maps and charts, geodetic data, and related cartographic information through the National Cartographic Information Center.

- The Geologic Division conducts research on geologic processes and the Earth's history and thereby provides information that permits man to adjust intelligently to the Nation's environment and to use the Earth's resources wisely. The Geologic Division determines the composition and structure of the rocks and materials that lie at and beneath the Earth's surface, identifies potential energy and mineral resources (including those of the Outer Continental Shelf), and develops and distributes knowledge about natural hazards such as earthquakes, volcanic eruptions, and land subsidence.

- The Water Resources Division assesses the quantity and quality of the Nation's water supply, develops the knowledge necessary to predict the environmental consequences of alternative plans for developing water resources, coordinates Federal water-data-acquisition activities, collects and distributes information about the availability of water data through the National Water Data Exchange, and develops and distributes information about natural hazards such as floods and land subsidence.

- The Conservation Division classifies the public lands with respect to leasable mineral and waterpower sites and supervises exploration and development authorized under leases and permits on Federal and Indian lands. 
- The Land Information and Analysis Office coordinates and administers interrelated, interdisciplinary programs of the Geological Survey, as well as other units of the Department of the Interior, with the objective of interpreting and displaying resource information in ways that are readily accessible and understandable to a wide range of potential users, particularly land-use planners and decisionmakers.

The structure of the Survey's budget closely parallels the structure of its organization. Each program division (Topographic, Geologic, Water Resources, Conservation, and the Land Information and Analysis Office) is responsible for one of the Survey's major budget activities (tables 6 and 7). A small program-Alaska Pipeline Related Investigations-is currently administered by the Geologic Division with technical assistance from the Water Resources Division.

TABLE 6.-Geological Survey obligations for fiscal year 1976, by activity (dollars in thousands)

[Data in other chapters may differ because of rounding]

\begin{tabular}{|c|c|c|c|}
\hline Activity & $\begin{array}{c}\text { FY } \\
1976\end{array}$ & $\begin{array}{l}\text { Percent } \\
\text { change } \\
\text { relative } \\
\text { to FY } \\
1975 \\
1975\end{array}$ & $\begin{array}{l}\text { Transition } \\
\text { quarter } \\
\text { (esti- } \\
\text { mated) }\end{array}$ \\
\hline Total & $\$ 353,970$ & +4 & $\$ 102,816$ \\
\hline Direct program & 264,434 & +4 & 77,756 \\
\hline Reimbursable program --- & 89,536 & +5 & 25,060 \\
\hline $\begin{array}{l}\text { Alaska Pipeline Related } \\
\text { Investigations }\end{array}$ & 287 & -17 & 112 \\
\hline $\begin{array}{l}\text { Topographic Surveys and } \\
\text { Mapping }\end{array}$ & 52,220 & -1 & 13,393 \\
\hline Direct program & 45,354 & -- & 11,553 \\
\hline Reimbursable program & 6,866 & -5 & 1,840 \\
\hline $\begin{array}{l}\text { Geologic and Mineral } \\
\text { Resource Surveys and } \\
\text { Mapping - }\end{array}$ & 115,554 & +1 & 32,997 \\
\hline Direct program & 92,322 & +4 & 24,837 \\
\hline Reimbursable program & 23,232 & -9 & 8,160 \\
\hline Water Resources Investigations & 112,480 & +11 & 29,726 \\
\hline Direct program --- & 57,176 & +7 & 15,922 \\
\hline Reimbursable program & 55,304 & +15 & 13,804 \\
\hline $\begin{array}{l}\text { Conservation of Lands and } \\
\text { Minerals }\end{array}$ & 41,677 & +16 & 13,487 \\
\hline Direct program & 41,489 & +15 & $\overline{13,440}$ \\
\hline Reimbursable program & 188 & +276 & 47 \\
\hline Land Information and Analysis & 17,278 & +2 & 8,859 \\
\hline Direct program & 14,908 & -4 & 7,806 \\
\hline Reimbursable program & 2,370 & +55 & 1,053 \\
\hline General administration & 3,398 & -7 & 1,493 \\
\hline Facilities - & 9,500 & -8 & 2,593 \\
\hline $\begin{array}{l}\text { Miscellaneous services to } \\
\text { other accounts }\end{array}$ & 1,576 & -45 & 156 \\
\hline
\end{tabular}

These research, fact-finding, and regulatory programs receive executive direction from the Office of the Director and technical and administrative support from the Administrative, Computer Center, and Publications Divisions. The "General administration" and "Facilities". budget activities fund the Office of the Director, the Administrative Division, and the operation of the Survey's National Center facilities, located in Reston, Virginia. Other administrative and management services provided by the Administrative Division and technical services provided by the Computer Center and Publications Divisions are financed through assessments of the program divisions. Although it is not a budget activity, the entry "Miscellaneous services to other accounts" represents reimbursements received from other Federal agencies for data-processing and publication services and for the sale of materials from stock.

\section{BUDGET}

The total funds obligated by the Geological survey in fiscal year 1976 amounted to $\$ 354$ million, an increase of $\$ 15.2$ million over fiscal year 1975 . (See fig. 19.) The increase was understated because of a provision in a new law that allowed obligational au hority to be carried forward into what was called a transition quarter (the period between fiscal years 19\%5 and 1977-July 1 to September 30, 1976). This chan se was authorized by the passage of the Congre sional Budget and Improvement Control Act of 1974 : Public Law 93-344). Thus, the fiscal year, which used to begin on July 1 , now starts on October 1 . Durig this period an unobligated amount of $\$ 8.4$ millio from fiscal year 1976 was carried forward. Obligation s from appropriated funds in fiscal year 1976 providec: about 75 percent of the total funds available to the urvey. The remaining 25 percent was from Federal, State, and local agencies and from miscellaneous nc $1-F e d-$ eral sources (fig. 20).

The allocation of funds to the Survey's five pr ncipal budget activities (Topographic Surveys and Mosping, Geologic and Mineral Resource Surveys and Mc pping, Water Resources Investigations, Conservation o Lands and Minerals, and Land Information and An slysis), which had been changing dramatically in the pest few years, remained relatively unchanged in fisc year 1976 (fig. 21). The Water Resources Investigatic ns activity share increased from 30 percent of the total funding to 32 percent. The Conservation of Lan $1 \mathrm{~s}$ and Minerals activity share increased from approxi nately 
11 percent to 12 percent. The other major activities showed small decreases in the percentage share of funding. (See fig. 22.)

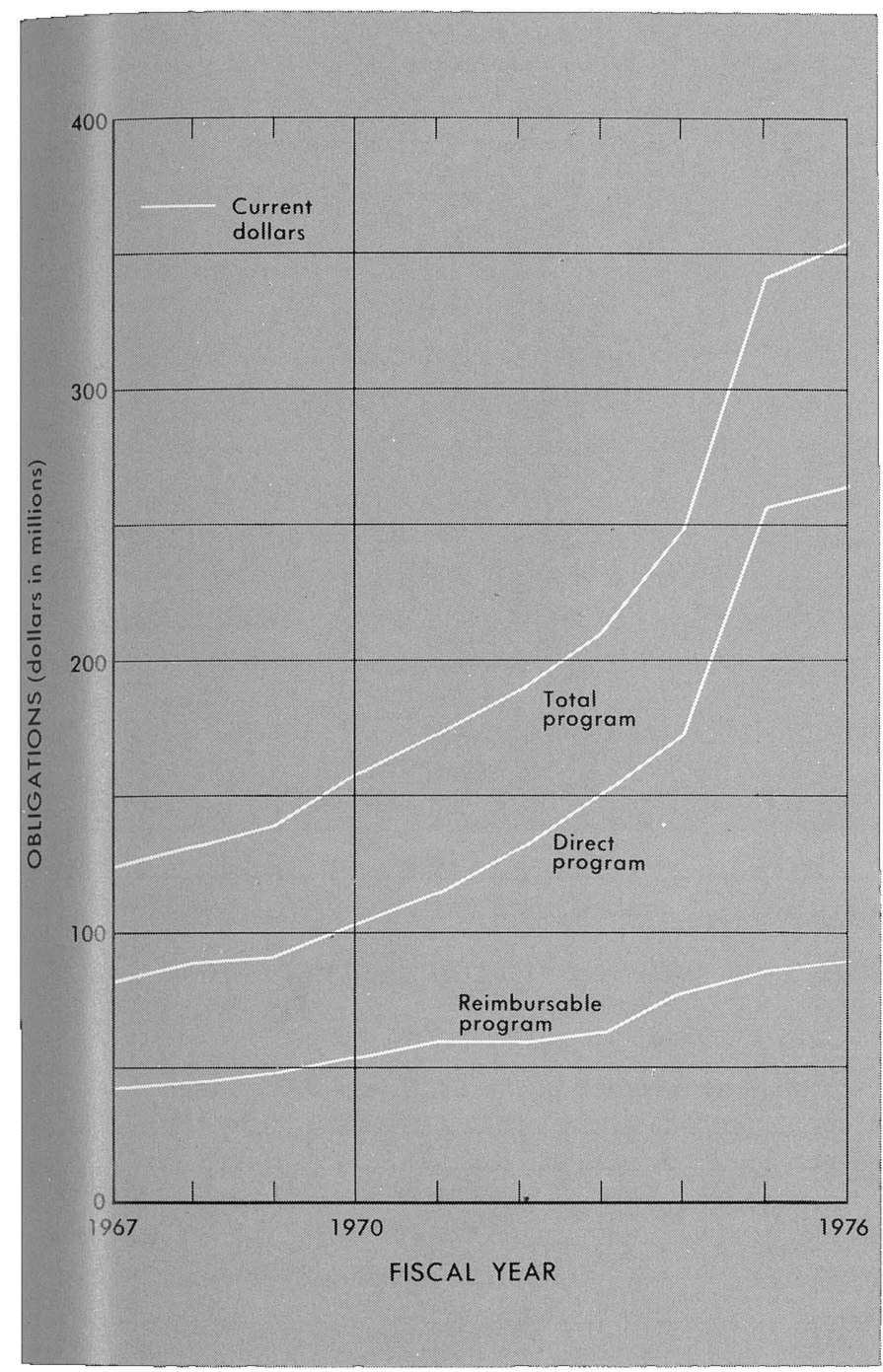

FICURE 19.-Geological Survey budget, by source of funds, fiscal years 1967-76.

An alternative way of looking at the Survey's budget is by area of study (fig. 23).

\section{PERSONNEL}

Unlike the budget, which has increased 185 percent since 1967, the number of permanent full-time employees involved in the Survey's programs remained more or less constant through fiscal year 1973 (fig. 24 and table 45). In fiscal years 1974-76, 785 additional permanent full-time positions were filled, an increase of 13 percent over fiscal year 1973. The distribution of permanent full-time employees by organizational unit is shown in figure 25. The Water Resources Division employs 32 percent of the permanent full-time

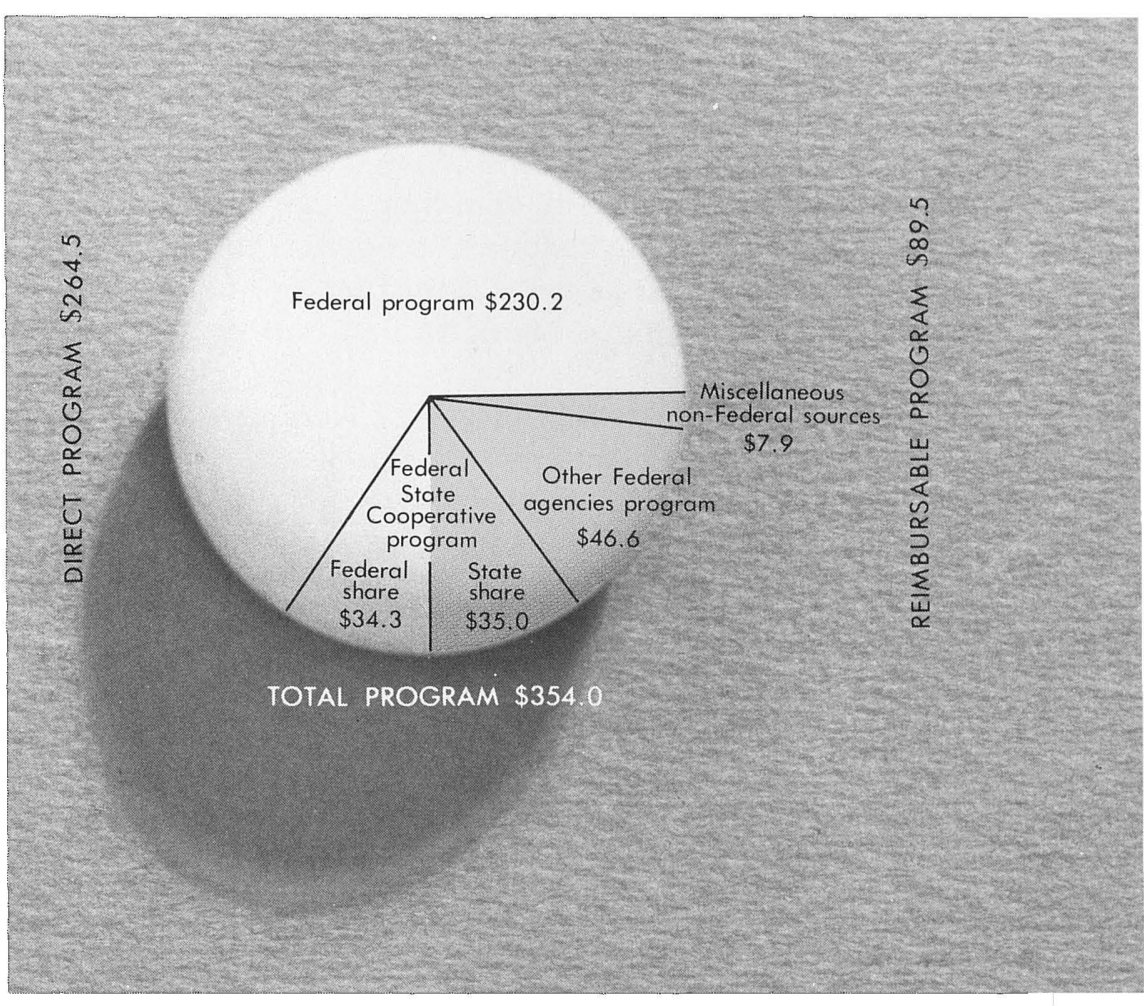

FIGURE 20.--Sources of Geological Survey funds in fiscal year 1976 (dollars in millions).

employees; Geologic Division, 23.2 percent; Topographic Division, 18.5 percent; and Conservation Division, 12.4 percent.

Again, as in fiscal year 1975, the professionalism of the Survey's programs is reflected in the composition of its work force. At the end of fiscal year 1976, the Survey employed 9,142 people on a permanent fulltime basis, 78 percent of whom (up 2 percent from fiscal year 1975) were employed in professional or technical positions (figure 26). The Survey's trained work force provides the Federal Government with an important pool of scientific expertise and specialized skills in the earth sciences. To augment this trained permanent work force, at the end of fiscal year 1976, 1,730 people were on the rolls in employment categories other than permanent full time.

\section{DEFINITIONS}

Some of the terms used to describe the Geological Survey's budget, which appear frequently throughout the next few chapters, are explained here. Funds appropriated directly to the Survey are categorized under several budget activities or broad functional areas, such as Topographic Surveys and Mapping and Water 


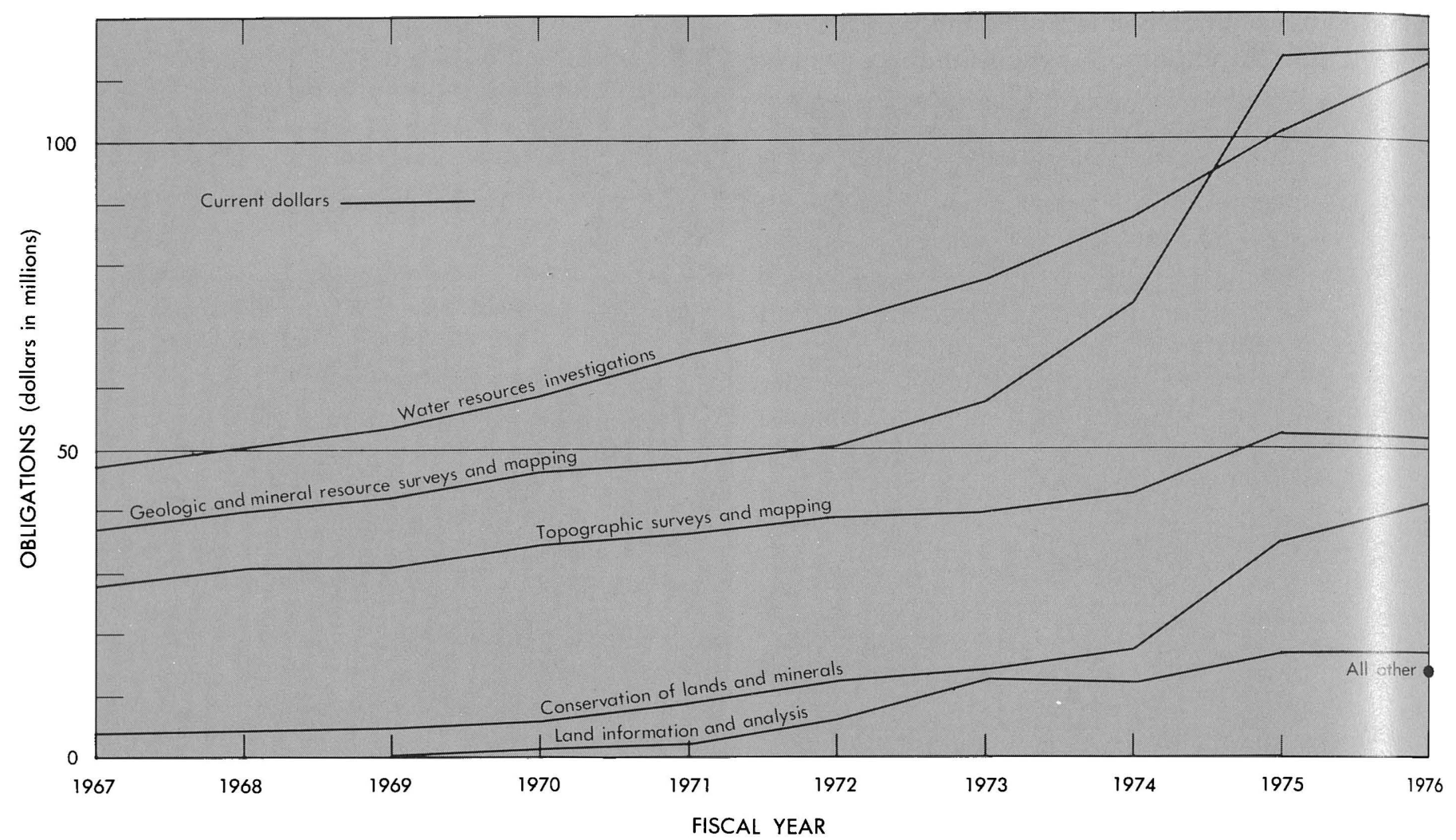

FIGURE 21.-Geological Survey budget by activity, fiscal years 1967-76.

TABLE 7.-Participation of Survey organizational units in areas of study included in the fiscal year 1976 budget

\begin{tabular}{|c|c|c|c|c|c|c|}
\hline Area of study & $\begin{array}{l}\text { Topo- } \\
\text { graphic } \\
\text { Divi- } \\
\text { sion }\end{array}$ & $\begin{array}{l}\text { Geologic } \\
\text { Divi- } \\
\text { sion }\end{array}$ & $\begin{array}{l}\text { Water } \\
\text { Resources } \\
\text { Divi- } \\
\text { sion }\end{array}$ & $\begin{array}{c}\text { Conserva. } \\
\text { tion } \\
\text { Divi- } \\
\text { sion }\end{array}$ & $\begin{array}{c}\text { Land } \\
\text { Informa- } \\
\text { tion and } \\
\text { Analysis } \\
\text { Office }\end{array}$ & $\begin{array}{l}\text { Office } \\
\text { f the } \\
\text { Director } \\
\text { and } \\
\text { adrinistra- } \\
\text { tive } \\
\text { Divi- } \\
\text { sion }\end{array}$ \\
\hline \multicolumn{7}{|l|}{ Energy: } \\
\hline OCS oil and gas & -- & $\times$ & -_ & $\times$ & -- & -- \\
\hline Onshore oil and gas & -- & $\times$ & -- & $\times$ & -- & -- \\
\hline Coal & -- & $x$ & $\times$ & $\times$ & -- & -- \\
\hline Uranium and thorium & -- & $x$ & $x$ & $x$ & -- & -- \\
\hline Oil shale & _- & $x$ & $\times$ & $\times$ & -- & -- \\
\hline Geothermal energy & -- & $x$ & $\times$ & $x$ & -- & -- \\
\hline \multicolumn{7}{|l|}{ Minerals: } \\
\hline Metallic and nonmetallic minerals & -- & $x$ & -- & $\times$ & -- & -- \\
\hline Mineral and fuels information system & -- & $x$ & -- & -.. & -- & -- \\
\hline Multipurpose geologic baselines & -. & $\times$ & -- & -- & -- & -- \\
\hline \multicolumn{7}{|l|}{ Hazards: } \\
\hline Earthquakes & -- & $\times$ & -- & -- & -- & -- \\
\hline Volcanoes, landslides, and engineering - & -- & $x$ & -- & -- & -- & -- \\
\hline Floods & -- & -- & $x$ & -- & -- & -- \\
\hline Water quality & -- & -- & $\times$ & -- & -- & -- \\
\hline \multicolumn{7}{|l|}{ Water: } \\
\hline Water-data networks & -- & -- & $\times$ & -- & -- & -- \\
\hline Areal water-resource appraisals & -- & -- & $x$ & $x$ & -- & -- \\
\hline Special water-resource studies & -- & -- & $x$ & -- & -- & -- \\
\hline Standard topographic mapping & $x$ & -- & - & -- & -- & -- \\
\hline Modernization of mapping technology & $x$ & -- & -- & -- & -- & -- \\
\hline Land resource decision products & $\times$ & -- & -- & -- & $x$ & -- \\
\hline Environmental impact statements & -- & -- & -- & -- & $\times$ & -- \\
\hline Earth Resources Observation Systems & -- & -- & -- & -- & $\times$ & -- \\
\hline General administration and facilities & -- & -- & -- & -- & -- & $x$ \\
\hline
\end{tabular}




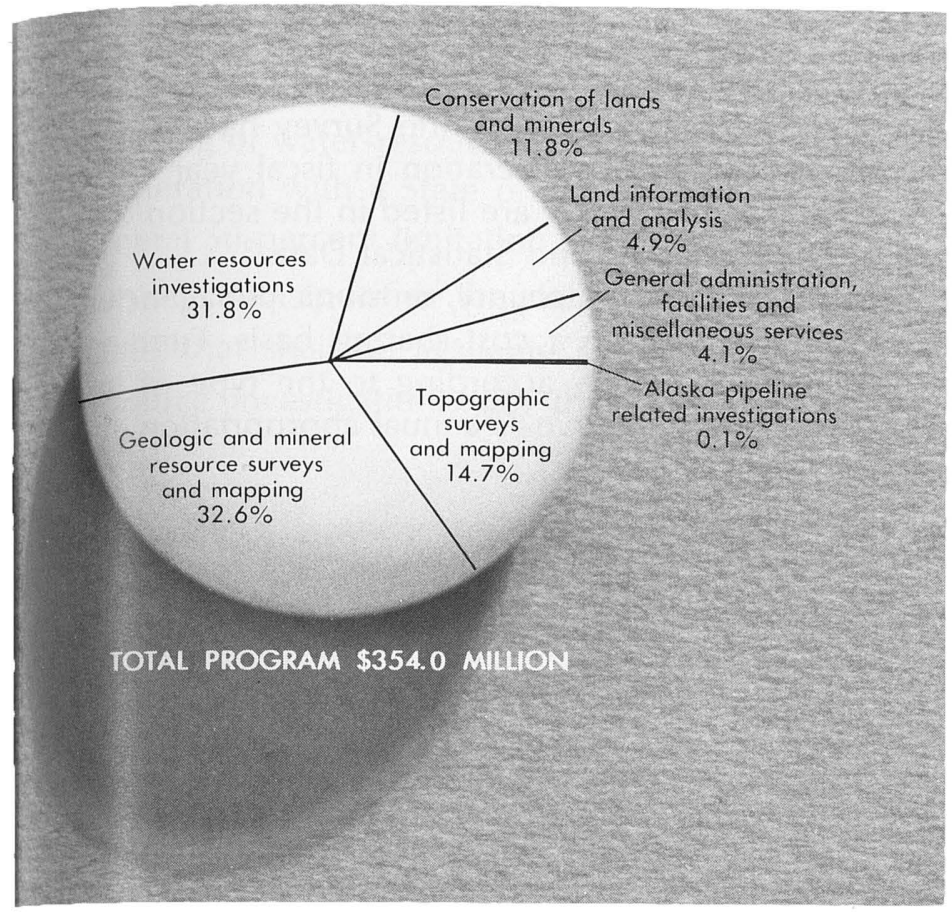

FIGURE 22.-Distribution of Geological Survey funds by budget activity in fiscal year 1976.
Resources Investigations. These activities are further subdivided and categorized as subactivities, programs, and program elements, depending upon the size and complexity of the activity. But the term "program" is used more generally and may refer to the entire budget, a budget activity, or a subactivity or may denote work supported by funds from a particular source, especially in the case of funds received from reimbursement.

Funds to support Survey programs come from two sources: (1) An annual Congressional appropriation and (2) reimbursements from Federal and non-Federal agencies. Federal funds, under the title "Surveys, Investigations, and Research," support the Survey's directly appropriated programs under each budget activity. Other funds from State and local agencies, Federal agencies, permittees and licensees of the Federal Power Commission, foreign countries, and international organizations pay for various information products and services provided by the Survey's reimbursable programs.

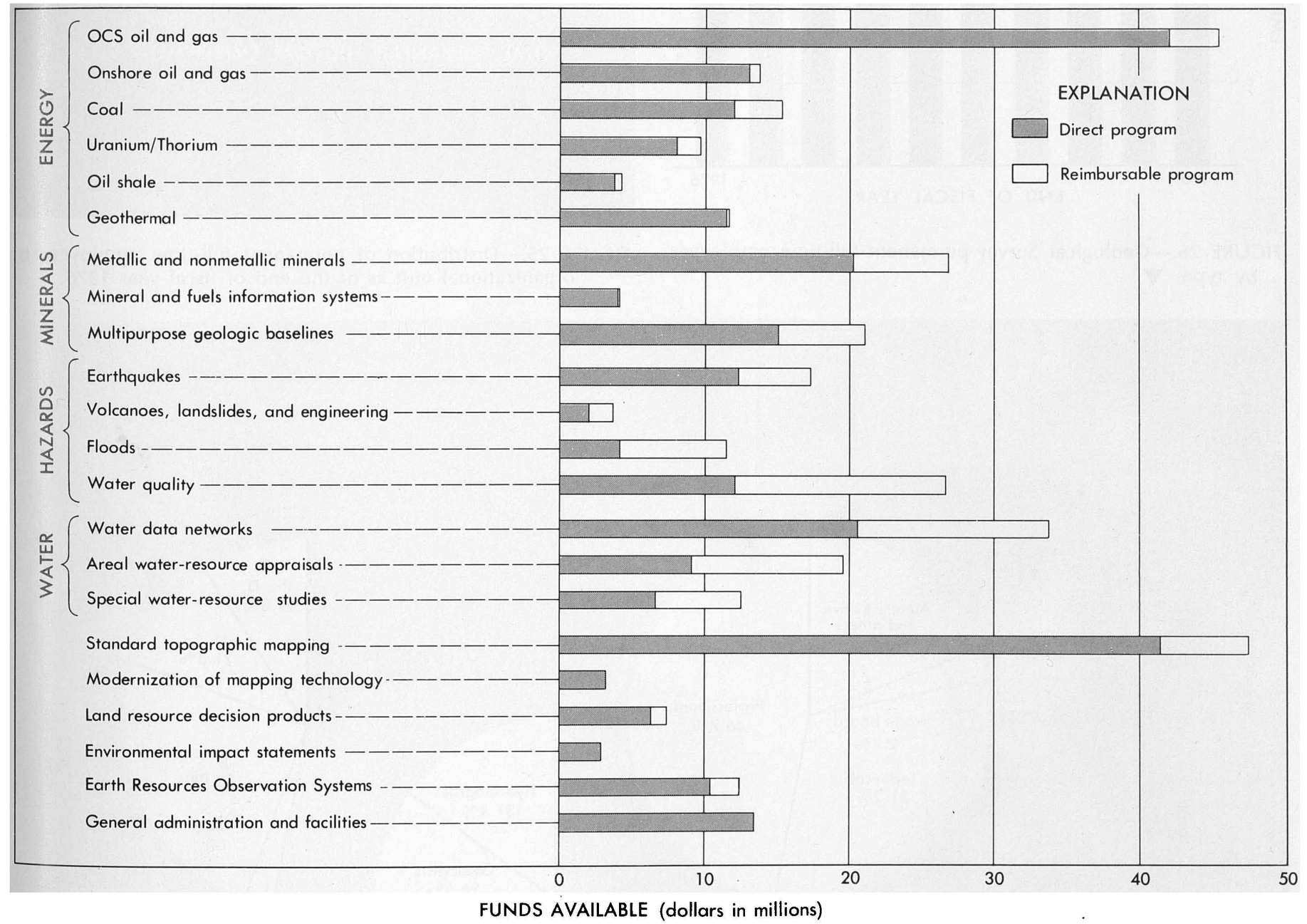

FIGURE 23.-Distribution of Geological Survey obligations for fiscal year 1976, by areas of study. 
Whereas directly appropriated programs are aimed at resource investigations and research on problems of nationwide concern, the reimbursable programs enable the Survey to apply its earth-science expertise to the specific problems of Federal, State, and local agencies. The results of these investigations contribute in a very substantial way to the solution of urgent national resource problems and respond directly to the changing mutual needs of Federal, State, and local

FIGURE 24.-Geological Survey end-of-year employment, fiscal years 1967-76.

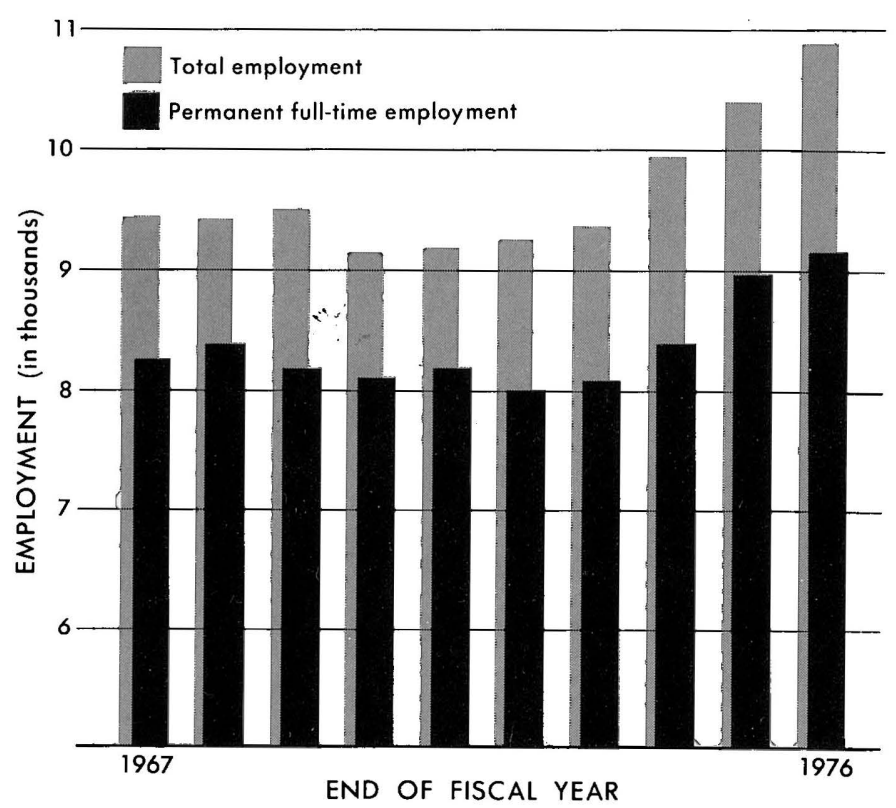

FIGURE 26.-Geological Survey permanent full-time employees by type. governments for earth-science information. Agencies and organizations with which the Survey had formal agreements for fiscal cooperation in fiscal year 1976 and the transition quarter are listed in the section entitled "Organizational and Statistical Data."

Work done for State, county, or municipal agencies may be performed on a cost-sharing basis. Funding arrangements may vary according to the type of investigation, and the Survey's annual appropriation act

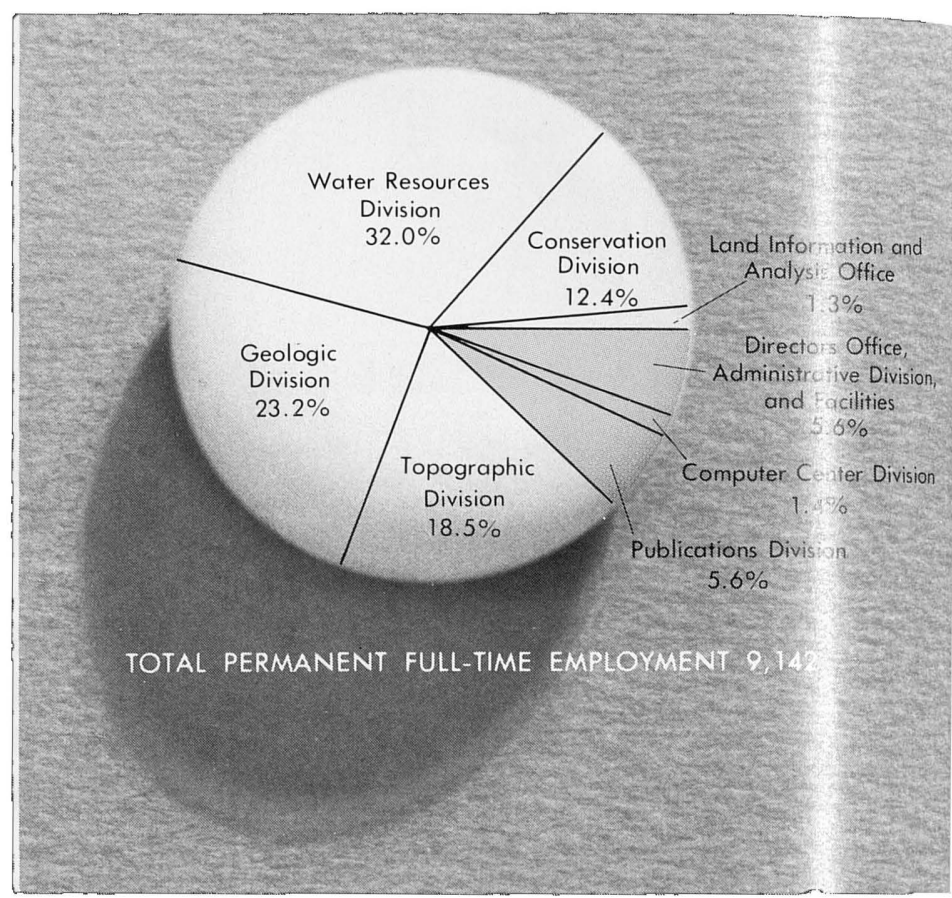

FIGURE 25.-Distribution of permanent full-time employ es by organizational unit as of the end of fiscal year 1976

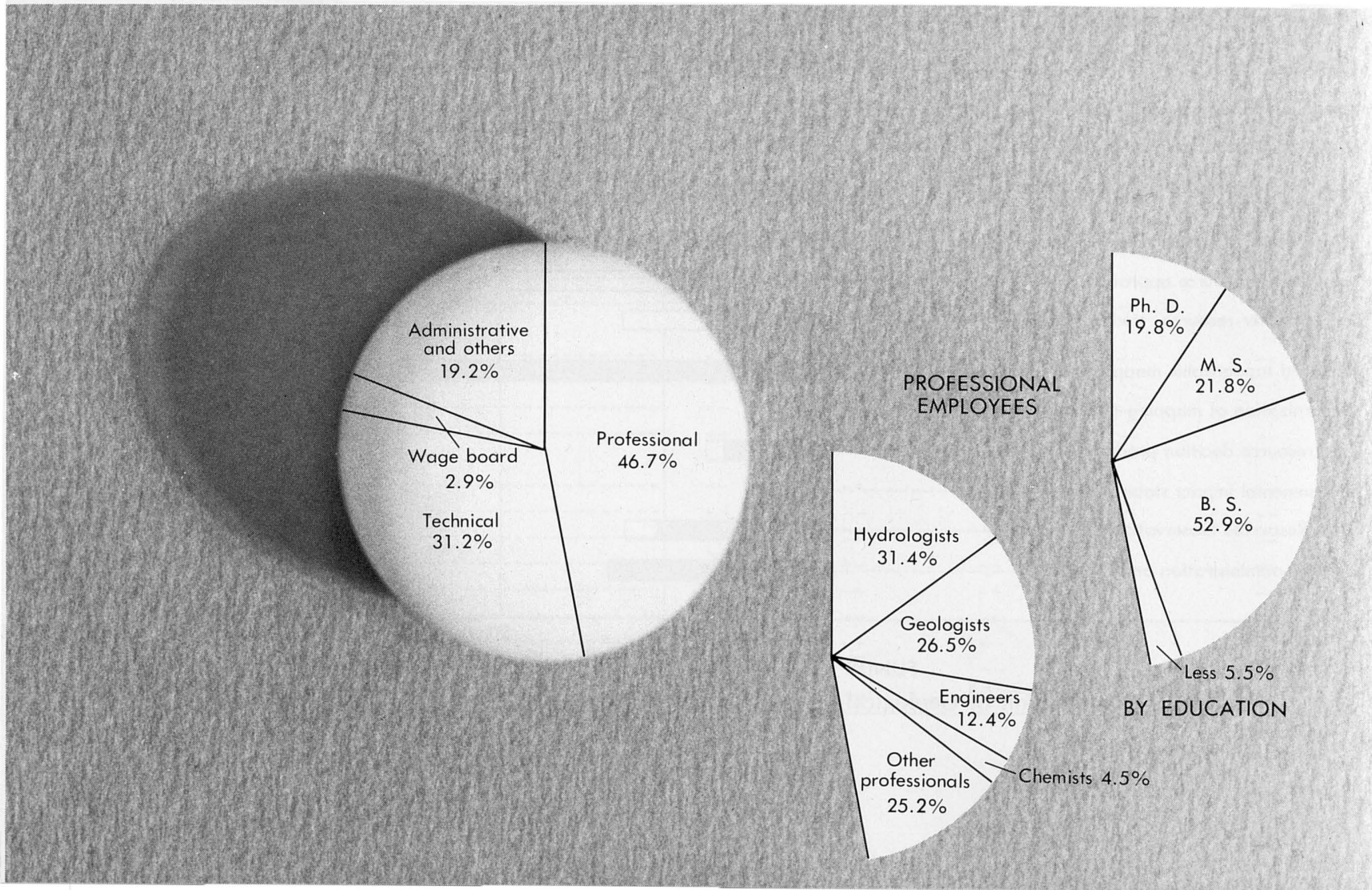


stipulates that Federal funds may not be used to finance more than one-half the cost of any topographic mapping or water-resource investigation carried on in cooperation with a State or municipality. Within this general 50-percent limitation, each annual appropriation act also specifies the dollar amount of Federal funds that shall be available for cooperative waterresource investigations. On the other hand, appro- priated funds may be used to pay for more than 50 percent of the cost of other Survey cooperative programs. The activities jointly funded by State and local reimbursable program funds (State share) or direct program funds (Federal share) are collectively referred to as the Federal-State Cooperative program. Other work done by the Survey for specific Federal agencies and non-Federal organizations is usually performed on a fully reimbursable basis. 


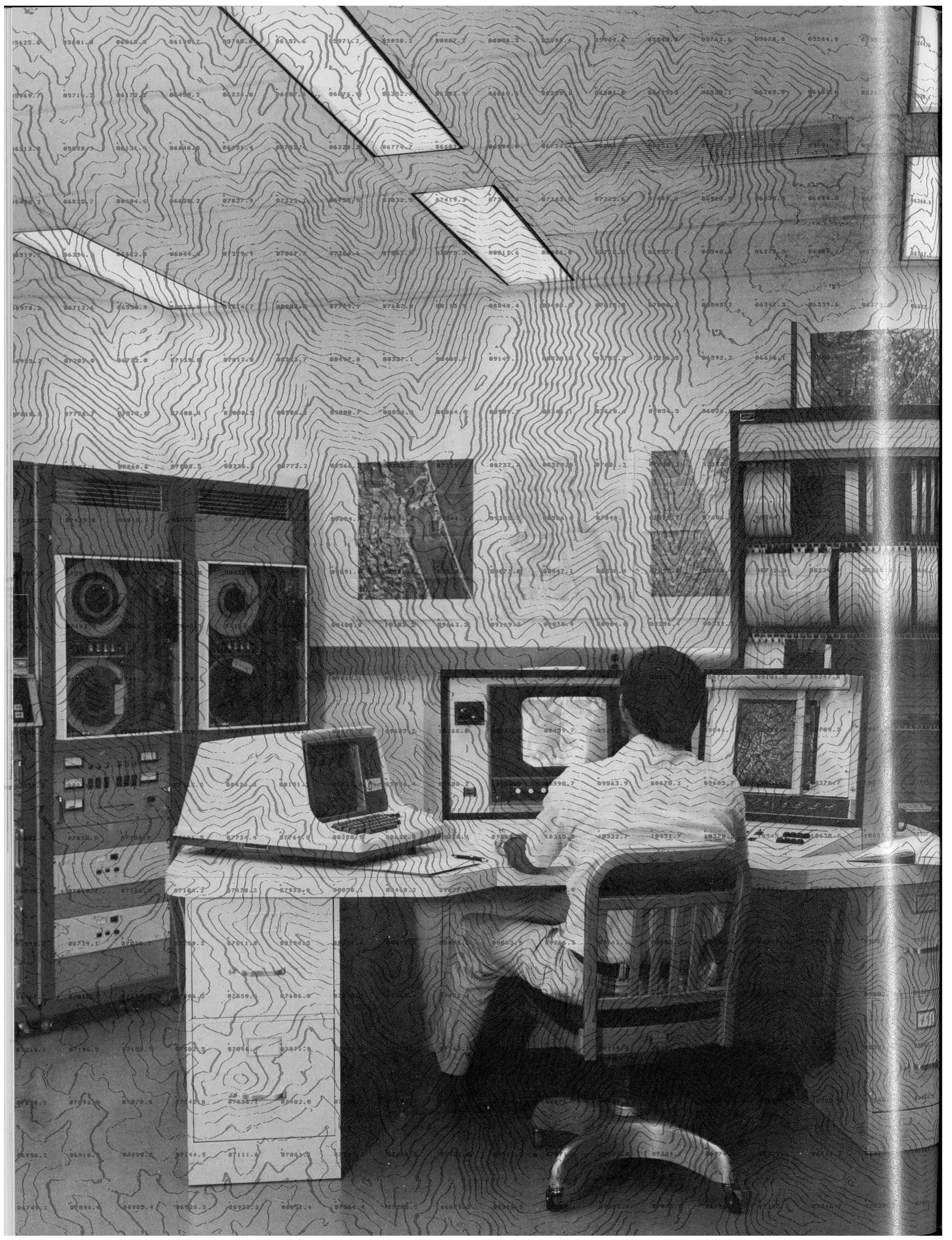




\section{Topozraphic Surveys and Mapping}

\section{OVERVIEW}

The National Mapping program is designed to provide accurate and up-to-date basic cartographic data for the United States in forms that can be readily applied to dealing with the problems of the day. Topographic maps, with detailed and precisely referenced information about the natural and manmade features on the Earth's surface, continue to be the most important product, with 1,444 new 1:24,000-scale topographic maps produced during the year ending June 30, 1976, plus 295 in the transitional quarter ending September 30 (table 8). However, more orthophotoquads (photoimage maps) were produced during the year than any other type of map, providing useful

TABLE 8.-Mapping production for fiscal year 1976 and transition quarter (TQ) (in square miles)

\begin{tabular}{|c|c|c|c|c|c|c|c|c|}
\hline \multirow[b]{2}{*}{ State or territory } & \multicolumn{2}{|c|}{$\begin{array}{l}1: 24,000-s c a l e \\
\text { topographic }\end{array}$} & \multicolumn{2}{|c|}{$\begin{array}{l}1: 24,000 \text {-scale } \\
\text { orthophotoquads }\end{array}$} & \multicolumn{2}{|c|}{$\begin{array}{l}1: 24,000-\text { scale } \\
\text { revisions }\end{array}$} & \multicolumn{2}{|c|}{$\begin{array}{l}\text { Intermediate } \\
\text { scale }\end{array}$} \\
\hline & $\begin{array}{c}\mathrm{FY} \\
1976\end{array}$ & TQ & $\begin{array}{c}\text { FY } \\
1976\end{array}$ & TQ & $\begin{array}{c}\text { FY } \\
1976\end{array}$ & TQ & $\begin{array}{l}\text { FY } \\
1976\end{array}$ & TQ \\
\hline Alabama & 854 & 248 & 2,772 & ---- & 1,869 & 306 & 12,298 & 2,641 \\
\hline Alaska $^{1}$ & 1,525 & ---- & ---- & ---- & ---- & --- & ---- & 250 \\
\hline Arizona & 2,982 & 1,117 & 2,480 & 2,418 & 778 & ---- & 8,098 & --- \\
\hline Arkansas & 2,177 & 120 & 2,013 & $-\ldots$ & 4,685 & ---- & 5,057 & ---- \\
\hline California - & 2,021 & 549 & 12,285 & 595 & 4,123 & 1,404 & 46,473 & 11,015 \\
\hline Colorado & 5,810 & 174 & 2,088 & ---- & 1,040 & ---- & 10,799 & 9,383 \\
\hline Connecticut & 166 & ---- & 2,408 & ---- & ---- & $-\cdots$ & ----- & ---- \\
\hline Delaware & ---- & ---- & ---- & ---- & 7 & ---- & 1,070 & ---- \\
\hline District of Columbia & ----- & $-\ldots-$ & ---- & $-\ldots-$ & ----- & $-\ldots--$ & ---- & ----- \\
\hline Florida & 7,651 & 64 & ---- & ---- & 455 & 376 & 1,878 & ---- \\
\hline Georgia _n- & 7,126 & 631 & 6,804 & 630 & 626 & 63 & 480 & ---- \\
\hline Hawaii & ----- & ---- & ----- & ---- & ----- & ---- & 1,772 & ---- \\
\hline Idaho & 5,178 & 2,868 & 17,874 & 3,672 & 54 & ---- & 22,124 & 1,698 \\
\hline Illinois & 234 & ---- & 3,990 & 6,270 & 513 & 1,180 & 6,319 & 453 \\
\hline Indiana & $-\cdots-$ & ---- & ---- & ---- & 344 & ---- & 1,615 & 870 \\
\hline lowa & $-\ldots-$ & ----- & $-\ldots-$ & 4,218 & 500 & 432 & 971 & 875 \\
\hline Kansas - & 4,318 & 580 & 2,867 & $-\ldots-$ & 2,487 & 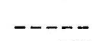 & 2,317 & 257 \\
\hline Kentucky - - & $-\ldots--$ & ---- & ---- & 1,711 & 237 & 72 & 6,707 & ---- \\
\hline Louisiana & 1,698 & ---- & 7,424 & ---- & 612 & 384 & 902 & $\ldots-$ \\
\hline Maine & 74 & ---- & 901 & ----- & ----- & ---- & 798 & ---- \\
\hline Maryland & ---- & ---- & ---- & ---- & 1,675 & 110 & 1,628 & ---- \\
\hline Massachusetts & ---- & ---- & ---- & ----- & 999 & ---- & 1,441 & ---- \\
\hline Michigan & ---- & 830 & 10,962 & ---- & 386 & 1,451 & 1,711 & ---- \\
\hline Minnesota & 10,503 & 442 & 416 & $-\cdots--$ & ----- & 398 & 1,691 & ---- \\
\hline Mississippi _- & ---- & ---- & 7,371 & ---- & 558 & ---- & 1,752 & 762 \\
\hline Missouri & 1,060 & ---- & 936 & 3,978 & 2,762 & ---- & 3,465 & ---- \\
\hline Montana & 5,126 & 2,115 & 10,098 & 1,836 & ---- & ---- & 33,752 & 3,296 \\
\hline Nebraska & ---- & ----- & 8,176 & ---- & ----- & ---- & 1,803 & ---- \\
\hline Nevada & 1,574 & 772 & 19,488 & 2,030 & 2,243 & ---- & 30,333 & 9,018 \\
\hline New Hampshire _. & $-\ldots$ & ---- & 1,620 & ---- & 220 & ---- & 1,806 & ---- \\
\hline New Jersey & ---- & ----- & ---- & ----- & $-\ldots-$ & ---- & 339 & $-\ldots$ \\
\hline New Mexico & 4,860 & 371 & 6,704 & 369 & 54 & ---- & 2,849 & ---- \\
\hline New York & ---- & ---- & ----- & 770 & 968 & 55 & 1,022 & ---- \\
\hline North Carolina & 1,214 & 121 & 12,705 & 3,267 & 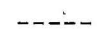 & 1,870 & 607 & ---- \\
\hline North Dakota & ---- & 104 & 4,646 & 707 & ---- & ---- & 2,182 & 1,302 \\
\hline
\end{tabular}

See footnote at end of table.

A contour plot, derived from digital terrain data produced by the Gestalt Photo Mapper II, superimposed on a photograph of the equipment. The capabilities of the photo mapper are described on page 80 . 
TABLE 8.-Mapping production for fiscal year 1976 and transition quarter (TQ) (in square miles) - Continued

\begin{tabular}{|c|c|c|c|c|c|c|c|c|}
\hline \multirow[b]{2}{*}{ State or territory } & \multicolumn{2}{|c|}{$\begin{array}{c}1: 24,000-\text { scale } \\
\text { topographic }\end{array}$} & \multicolumn{2}{|c|}{$\begin{array}{l}1: 24,000 \text {-scale } \\
\text { orthophotoquads }\end{array}$} & \multicolumn{2}{|c|}{$\begin{array}{c}1: 24,000-\text { scale } \\
\text { revisions }\end{array}$} & \multicolumn{2}{|c|}{$\begin{array}{l}\text { Intermediate } \\
\text { scale }\end{array}$} \\
\hline & $\begin{array}{c}\text { FY } \\
1976\end{array}$ & TQ & $\begin{array}{c}\text { FY } \\
1976\end{array}$ & TQ & $\begin{array}{l}\text { FY } \\
1976\end{array}$ & TQ & $\begin{array}{c}\text { FY } \\
1976\end{array}$ & TQ \\
\hline Ohio -n-1- & ---- & ---- & ---- & ---- & 4,021 & 54 & 1,660 & \\
\hline Oklahoma & 2,110 & ---- & 4,719 & ---- & 3,637 & ---- & 9,912 & \\
\hline Oregon - & 1,822 & 854 & 9,180 & 2,700 & ---- & 20 & 29,262 & \\
\hline Pennsylvania _- & $-\cdots-$ & ---- & ---- & ---- & 468 & ---- & 4,771 & \\
\hline Rhode Island & ---- & ---- & ---- & ---- & 752 & ---- & 186 & \\
\hline South Carolina & 321 & ----- & 4,464 & ---- & 1,508 & ---- & ----- & \\
\hline South Dakota & 3,131 & 700 & 4,173 & ---- & 3 & ----- & 1,975 & \\
\hline Tennessee & ---- & ----- & ---- & $-\cdots$ & 1,553 & 302 & 2,237 & \\
\hline Texas - & 7,383 & 1,903 & 192 & ---- & 2,774 & 942 & 962 & \\
\hline Utah - - & 1,561 & 1,116 & 3,480 & 1,334 & 48 & ---- & 2,100 & \\
\hline Vermont & 32 & $-\cdots$ & $-\cdots$ & ---- & ---- & ---- & 1,621 & \\
\hline Virginia & $-\ldots--$ & ---- & 2,006 & ---- & 1,430 & ---- & 2,568 & \\
\hline Washington & ---- & 249 & 3,788 & 2,626 & 3,379 & 53 & 16,542 & 3,74 \\
\hline West Virginia & ---- & ---- & ---- & ---- & 233 & 2,406 & 1,812 & \\
\hline Wisconsin & 1,124 & 622 & 2,173 & 1,696 & 357 & 1,149 & 1,631 & \\
\hline Wyoming --1-- & 327 & $-\cdots--$ & 1,526 & ---- & ---- & ---- & 9,598 & \\
\hline Guam _-- & ---- & ---- & ----- & ---- & ---- & ---- & ---- & \\
\hline Puerto Rico ${ }^{1}$ & ---- & ---- & ---- & ---- & ---- & ---- & ---- & \\
\hline Samoa - & ---- & ---- & ---- & ---- & $-\cdots-$ & ---- & ---- & \\
\hline Virgin Islands _. & ----- & ----- & ----- & ----- & $-\cdots$ & ----- & ---- & \\
\hline
\end{tabular}

1 1:63,360 and 1:25,000-scale for Alaska; 1:20,000-scale for Puerto Rico.

land information for 3,197 , plus 730 in the transition quarter, 7.5-minute quadrangle areas. Considering the year's output of maps and the rapid rate of man's changes in his use of the land, it is not surprising that revision mapping now amounts to about 900 quadrangles annually.

Fiscal year 1976 and the transition quarter saw a collaboration between mapmakers and map users that resulted in a wider variety of products. Agronomists of the Soil Conservation Service and engineers of the Bureau of Land Management now work from Geological Survey base maps for land classification and management. Techniques were developed to provide customs officials with current rectified aerial photographs at 1:25,000 scale overlaid with map information for border surveillance. County officials in several States can refer to a single map of their jurisdiction for assistance in resolving many questions. Through a cooperative program with the National Ocean Survey, Department of Commerce, both the developers and the protectors of the Nation's coastal wetlands will soon be working from the same base data-maps with both topographic and bathymetric information.

Other new roles for the Geological Survey are being suggested-programs for large-scale urban mapping, systematic high-altitude photography, and digitization of planimetric and relief data. These apparently diverse requirements must be addressed by the National Mapping Program because of the need for coordination and standardization. Systems ar being developed for putting map and image inform ation in digital form, either during the mapping process or after the map is completed. With this capability, will be possible to develop a national cartographic data bank that can respond more quickly to new and changing user requirements.

The current plan is to complete $1: 24,000$ scale topographic coverage of the country as rapidy as practical-in about a decade at the present rate---and in the interim to provide orthophotoquads for ureas unmapped at this scale. The capability to provide base map data at intermediate scales (primarily $1: 100.000$ ) will be expanded. And guidelines for large-scale napping of urban areas are in the offing. Equipmen and techniques will continue to be updated to accor:modate the increasing demand for new and re ised maps, the economic and timely production of gital data, and conversion to the metric system. $A$ the same time, the States will be encouraged to er arge the national network of cartographic information centers.

\section{Coordination of mapping}

Federal domestic mapping activities are coordinated by the Geological Survey for the Departinent of the Interior. According to procedures established 
by the Office of Management and Budget Circular A-16 (Bureau of the Budget, 1967), the Survey requests other Federal agencies to identify their mapping requirements and considers their requirements in formulating the mapping program. State and local governments also indicate requirements for cartographic data; 15 States (Alaska, Colorado, Idaho, Illinois, lowa, Maine, Michigan, Minnesota, Montana, Nebraska, Nevada, New Mexico, Texas, Utah, and Wyoming) each have a State mapping advisory committee that provides advice and guidance for planning the mapping program. Requests from private individuals are also considered in setting priorities. In fiscal year 1976, under cooperative mapping agreements (costs are shared equally) with 37 States and Puerto Rico, the cooperating agencies participated directly in the selection of areas to be mapped.

Yearly requests for new and revised topographic maps-a total of 41,869 requests for 27,478 quadrangles in 1976-far exceed the Survey's production capability and funding level. As a result, requests are increasing for orthophotoquads as preliminary coverage for unmapped areas or as updating supplements to available line maps. The Survey recently acquired its first automated photomapping system capable of concurrently producing corrected aerial imagery and the corresponding terrain elevations in both digital and contour form. This new system offers an alternative to current mapping methods that will make basic cartographic data available faster when most needed. A principal user of cartographic data is the Geological Survey itself, which is responsible for mapping the location and determining the extent of the Nation's physical resources and for helping to solve a wide range of environmental problems.

\section{Highlights}

Noteworthy achievements and events of fiscal year 1976 and the transition quarter include:

- Formulation of a flexible policy for metrication in the topographic mapping program. Implementation considers impact on the user as determined from an extensive survey.

- Opening of National Cartographic Information Center regional offices (in Virginia, Missouri, Colorado, and California) to provide easier customer access and more complete acquisition of information.

- Agreement with Texas establishing the first FederalState information center in Austin for collecting and distributing cartographic data.
- Completion of 2,700 (plus 600 in the transition quarter) new and revised maps, ranging in scale from $1: 24,000$ to $1: 250,000$. In addition, about 3,200 (plus 730 in the transition quarter) orthophotoquads were produced.

- Addition of over 1.36 million square kilometers $(525,000$ square miles) of aerial photography to the national aerial photo data base (plus 435,000 square kilometers, or 168,000 square miles, in the transition quarter).

- Accommodation of a large increase in intermediate-scale mapping to meet the special needs of Government and State agencies (259 intermediate-scale maps this year, plus 32 in the transition quarter, compared with 9 last year).

- Acquisition of an automated photomapping system to expedite production of basic cartographic data in image, contour, and digital form.

- Development of a technique to make color orthophotoquads from dual-camera, black-and-white photographs with a resultant improvement in interpretability and, hence, value to users.

- Expansion of photoinspection and map revision procedures to provide a more systematic review of map completeness.

- Completion of new facilities for Mid-Continent Mapping Center in Rolla, Mo., to consolidate operations and modernize laboratories.

- Completion of the pilot large-scale mapping projects, including user reviews and development of guidelines for large-scale mapping.

\section{Budget}

The Topographic Surveys and Mapping budget covers three subactivities: (1) Quadrangle mapping and revision, the primary responsibility of mapping centers in Reston, Va., Rolla, Mo., Denver, Colo., and Menlo Park, Calif., (2) small-scale and special mapping, the primary responsibility of a fifth mapping center in Reston, and (3) the National Cartographic Information Center, headquartered in Reston with offices in the mapping centers.

For fiscal year 1976, Topographic Surveys and Mapping amounted to $\$ 52.2$ million (plus $\$ 13.3$ million in the transition quarter) (fig. 27 and table 9). Included are funds from 37 States and Puerto Rico, which, when matched by Federal funds, amounted to $\$ 7.4$ million (plus $\$ 1.8$ million in the transition quarter) for cooperative mapping. Cooperative projects mutually benefit the State and the national program.

The National Mapping Program was carried out by 1,693 career employees, many with special training in 


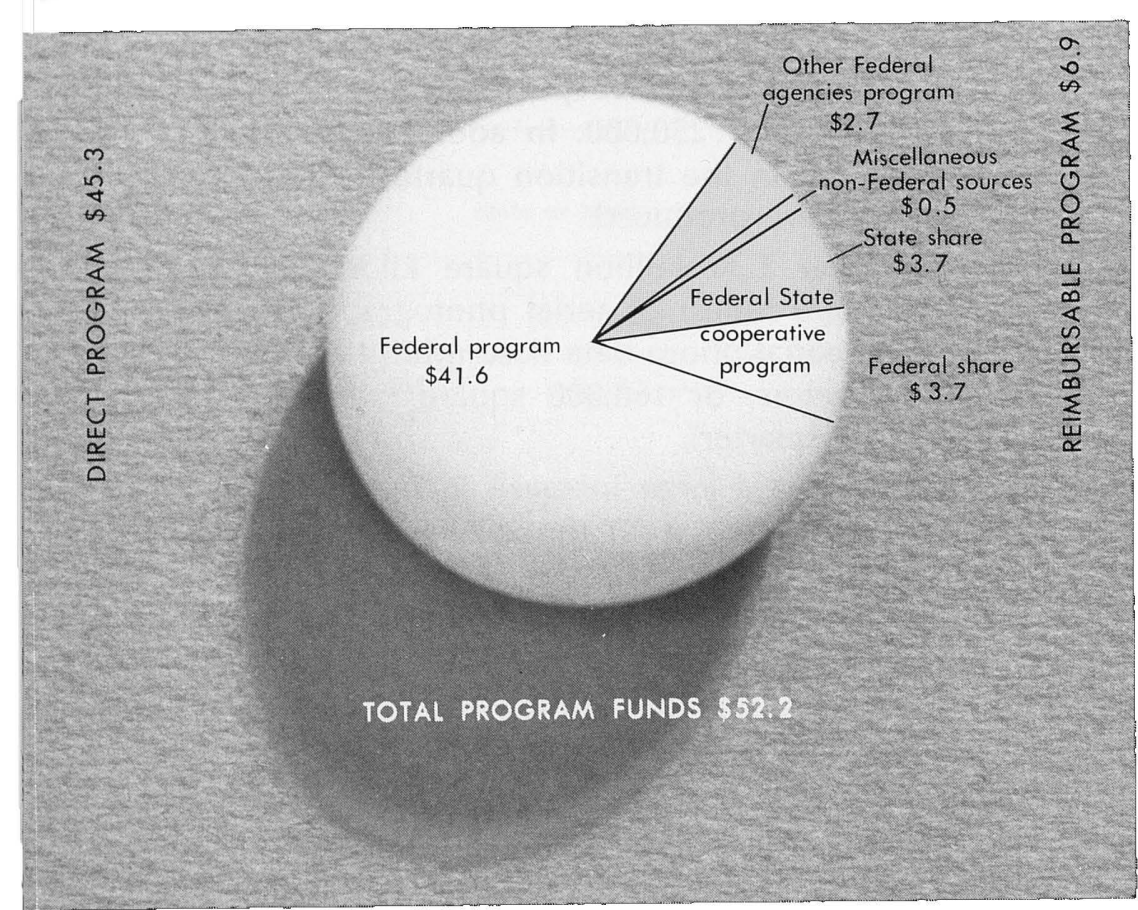

FIGURE 27.-Sources of fiscal year funds for Topographic Surveys and Mapping (dollars in millions).

TABLE 9.-Topographic Surveys and Mapping activity obligations for fiscal years 1975 and 1976 and transition quarter, by program (dollars in millions)

[Data may differ from that in statistical tables because of rounding]

\begin{tabular}{|c|c|c|c|}
\hline \multirow{2}{*}{ Program } & \multicolumn{2}{|c|}{ Fiscal year } & \multirow{2}{*}{$\begin{array}{c}\text { Transition } \\
\text { quarter }\end{array}$} \\
\hline & 1975 & 1976 & \\
\hline 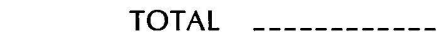 & $\$ 52.60$ & $\$ 52.22$ & $\$ 13.29$ \\
\hline Direct programs ${ }^{1}$ & 45.35 & 45.35 & 11.55 \\
\hline $\begin{array}{l}\text { Quadrangle Mapping and } \\
\text { Revision } \\
\text { Small-Scale and Special }\end{array}$ & 41.15 & 38.26 & 9.40 \\
\hline $\begin{array}{l}\text { Mapping - } \\
\text { National Cartographic }\end{array}$ & 2.66 & 5.36 & 1.73 \\
\hline Information Center - & 1.54 & 1.73 & .42 \\
\hline Reimbursable programs & 7.25 & 6.87 & 1.74 \\
\hline $\begin{array}{l}\text { States, counties, and } \\
\text { municipalities }\end{array}$ & 5.00 & 3.67 & .88 \\
\hline $\begin{array}{l}\text { Miscellaneous non-Federal } \\
\text { sources }\end{array}$ & .59 & .50 & .13 \\
\hline Other Federal agencies & 1.66 & 2.70 & .73 \\
\hline
\end{tabular}

1 Includes matching reimbursable funds from States, counties, and municipalities.

cartography, data processing, engineering, photographic technology, and physical sciences. About 200 additional employees, many on work-study programs, served as temporary aides and professional consultants.

\section{QUADRANGLE MAPPING AND REVISION}

Aerial photographs of the land surface are essential to the mapping process. In fiscal year 1976, the Sur-
(525,000 square miles) of aerial photography, 10 percent more than last year (plus 435,000 square kilometers, or 168,000 square miles, in the transition quarter). Three-fourths of the photographs were taken from altitudes higher than 11,700 meters (39,000 feet) for use in photomapping and map revision. The aerial mapping cameras used by private contractors on photomissions for the Survey and other governmental agencies must meet accuracy specifications. For this purpose, the Survey operates the Optical Calibration Laboratory, which, during the year, tested and calibrated 88 complete cameras and 14 lenses (fig. 28).

Field control surveys are needed to present map features in correct relationship to each other and to the Earth's surface. Horizontal ground control establishes and maintains correct scale, position, and orientation of the map. Vertical control governs the contours and spot elevations which show the shape of the terrain. The resulting geodetic data-positions, elevations, and descriptions of control points--are used to prepare the map base, the framework on which map detail is compiled. The Survey is in the process of transferring computer records of its geodetic surveys to the National Geodetic Survey Information Center of the National Oceanic and Atmospheric Administration. By 1985 the national bank of reliable geodetic information should be readjusted to a new North American Datum.

During fiscal year 1976, 1,405 standard topographic maps were published, covering 211,120 square kilometers (81,200 square miles) (plus 237 maps covering 35,440 square kilometers, or 13,680 square mil s in the transition quarter), or 2.2 percent of the U.S. domain (fig. 29). Most of the maps are in the 7.5minute series, $1: 24,000$ scale (15-minute si-ries, $1: 62,500$ scale until replaced; $1: 63,360$ and $1: 25,000$ in Alaska). In addition to meeting the needs of many users, these are the basic maps from which smaller scale and special maps are usually derived. As national coverage in the 7.5-minute series increases, the revision mapping workload increases. With special emphasis on coverage of urban, coastal-zone, tansportation corridor, and other areas where chang in culture are rapid, published maps are checked against current aerial photographs at appropriate intervals and, if necessary, revised. About 6567.5 -minute maps were revised in 1976 (plus 165 in the transition c: larter).

By reprocessing the aerial photographs to co rect for distortions, orthophotographs are produced that can be applied in many ways. In a standard quadrangle format with grid and name information superimposed, the orthophotograph is called ar: orthophotoquad. About 3,200 orthophotoquads were 


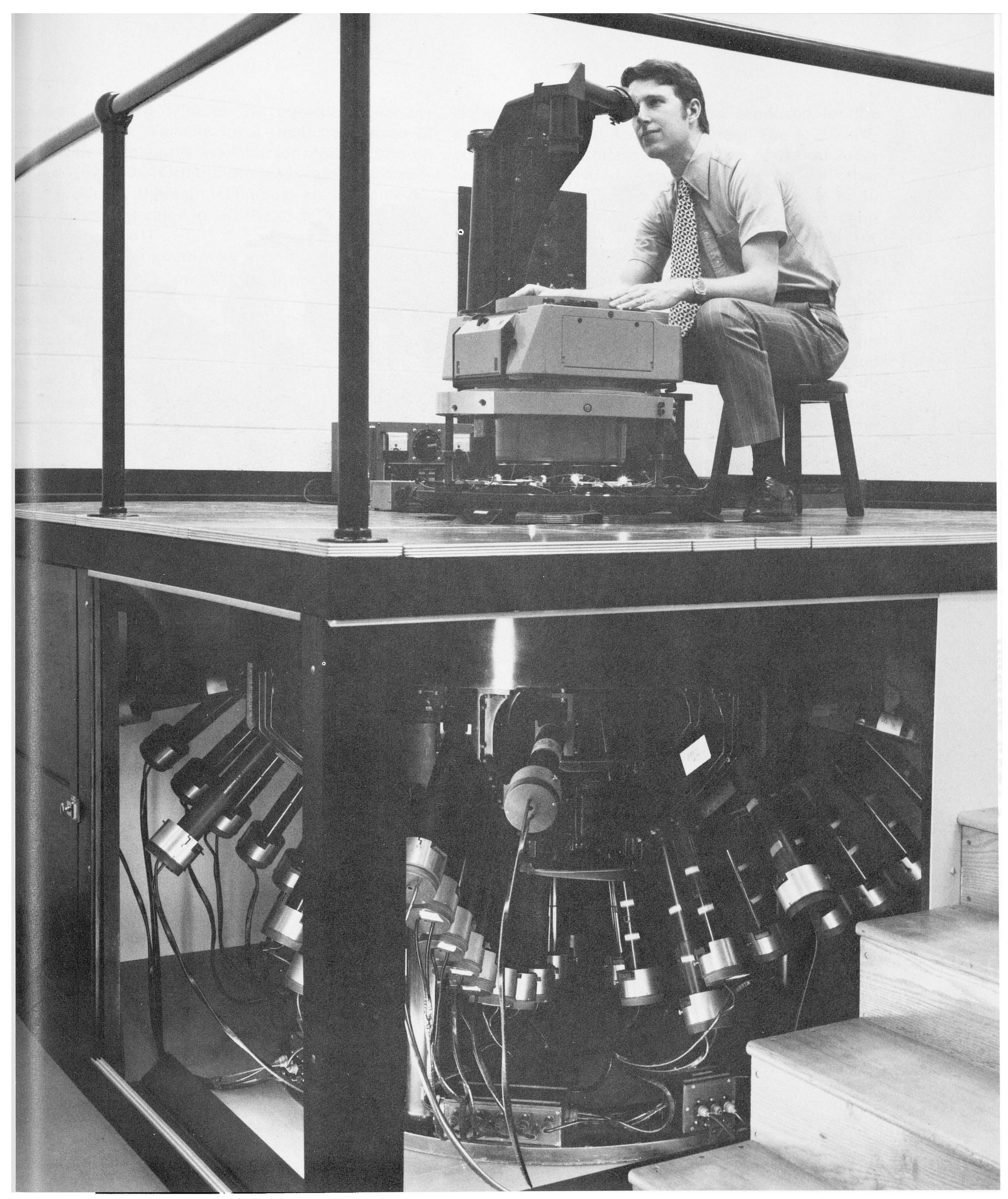

FIGURE 28.-Aerial mapping camera being tested atop multicollimator camera calibrator. 

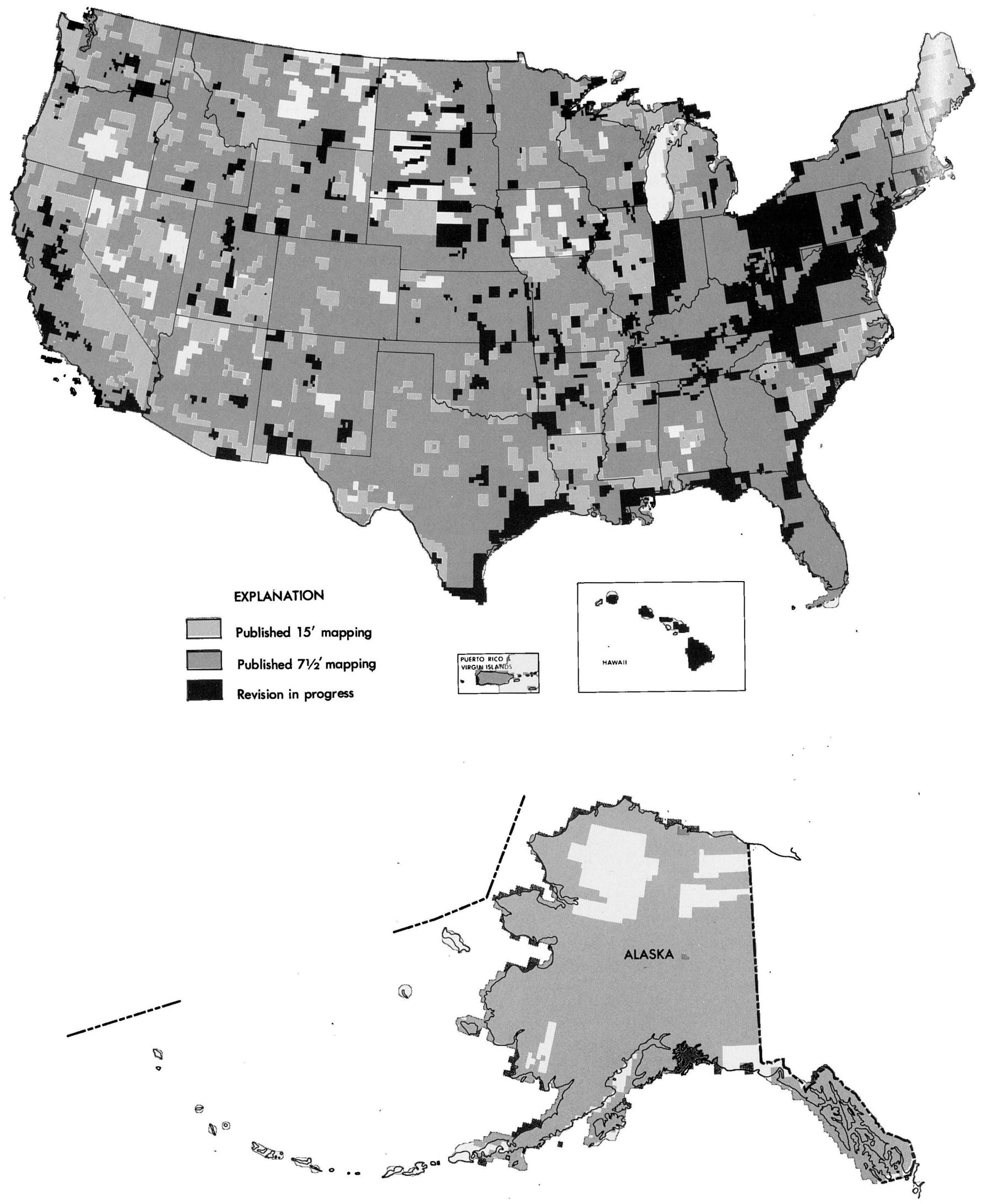

FIGURE 29.-Status of standard topographic mapping and revision. 
prepared in 1976 (730 in the transition quarter); printed stock is available for a small percentage of these, with the majority available for reproduction on request (fig. 30). Orthophotoquads are black-andwhite products, although techniques are being developed for adding color to aid the user in interpreting the imagery (p. 81).

The orthophotograph may also be combined with the line detail of a topographic map. In many areas where conventional line maps are ineffective in portraying the special character of the terrain, orthophotomaps are standard rather than the usual line maps. About 600 orthophotomaps are in various stages of production; the largest projects cover Florida swamps, Minnesota lake regions, and coastal stretches of Louisiana and Georgia.

\section{SMALL-SCALE AND SPECIAL MAPPING}

The 1:250,000-scale topographic map series provides the largest scale complete coverage available for the United States and is thus valuable to many Federal and State agencies with regional concerns. The maps are also used by the Survey for preparing State base maps, the 1:1,000,000-scale International Map of the World, various geologic maps, and spe- cial-purpose maps such as those produced for the Land Use Data and Analysis program. The 1:250,000scale maps of Standard Metropolitan Statistical Areas are generally revised every 5 to 7 years. Most other quadrangles in this series are revised every 8 to 10 years; in fiscal year 1976, 46 revisions were completed (plus 11 in the transition quarter), and 100 more were in production. Terrain data digitized from the contours on the 1:250,000-scale maps are available on magnetic tape from the National Cartographic Information Center (fig. 31).

To meet the need for basic map data at various levels of detail and at scales between 1:24,000 and $1: 250,000$, the intermediate-scale map series was introduced in 1975. The user can select the map content from 21 categories of data and choose county, regional, or $30^{\prime} \times 60^{\prime}$ quadrangle format. County maps are also being prepared on request at 1:50,000 scale with a choice of five to seven categories of data. The capability is being developed to provide intermediate-scale map data in digital as well as graphic form. In fiscal year 1976, priority was given to completing 259 intermediate-scale maps for Federal and State agencies (plus 32 in the transition quarter) (fig. 32).

Because of a critical need for map data in the coastal areas, the Geological Survey and National

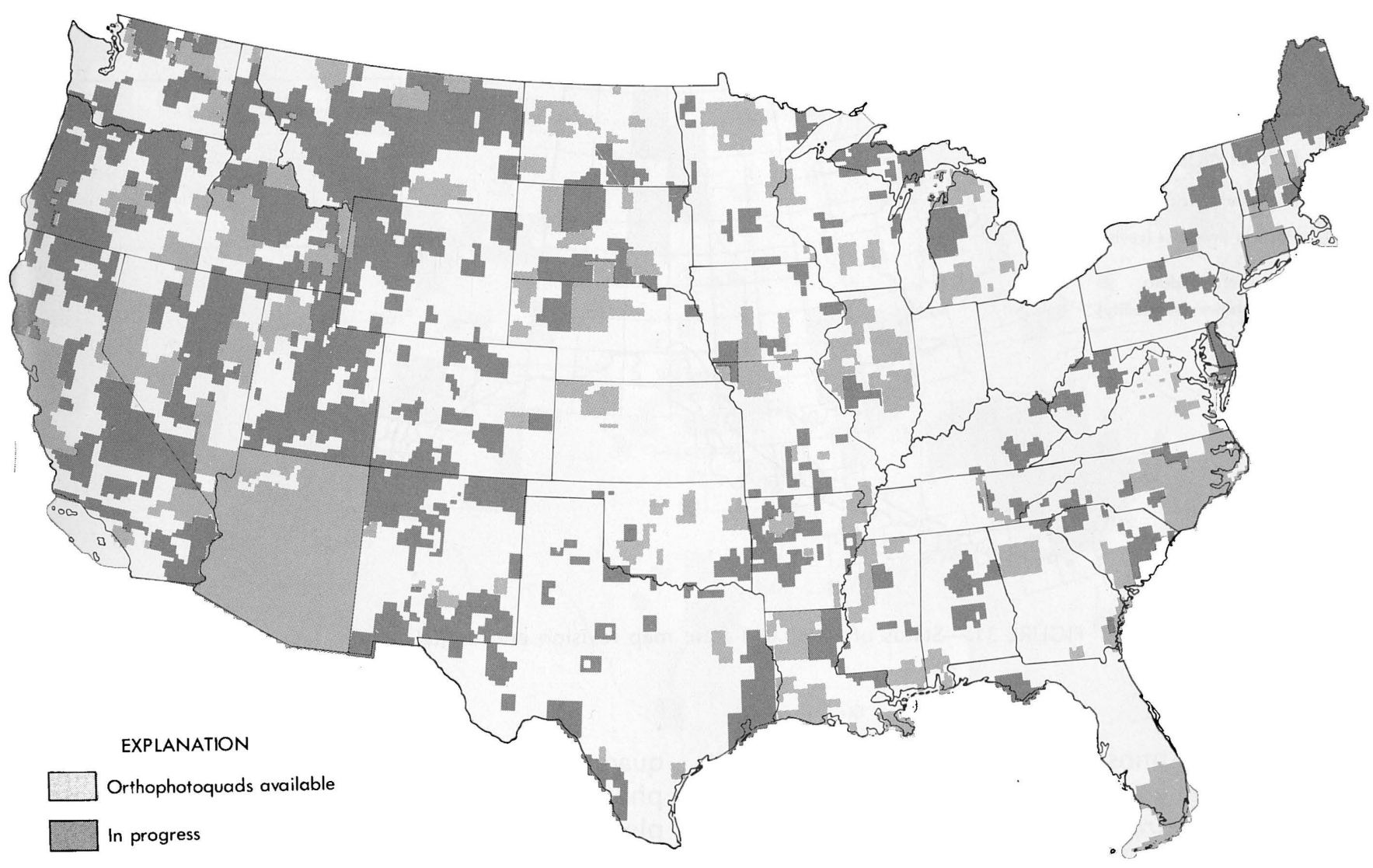

FIGURE 30.-Status of orthophotoquad production. 


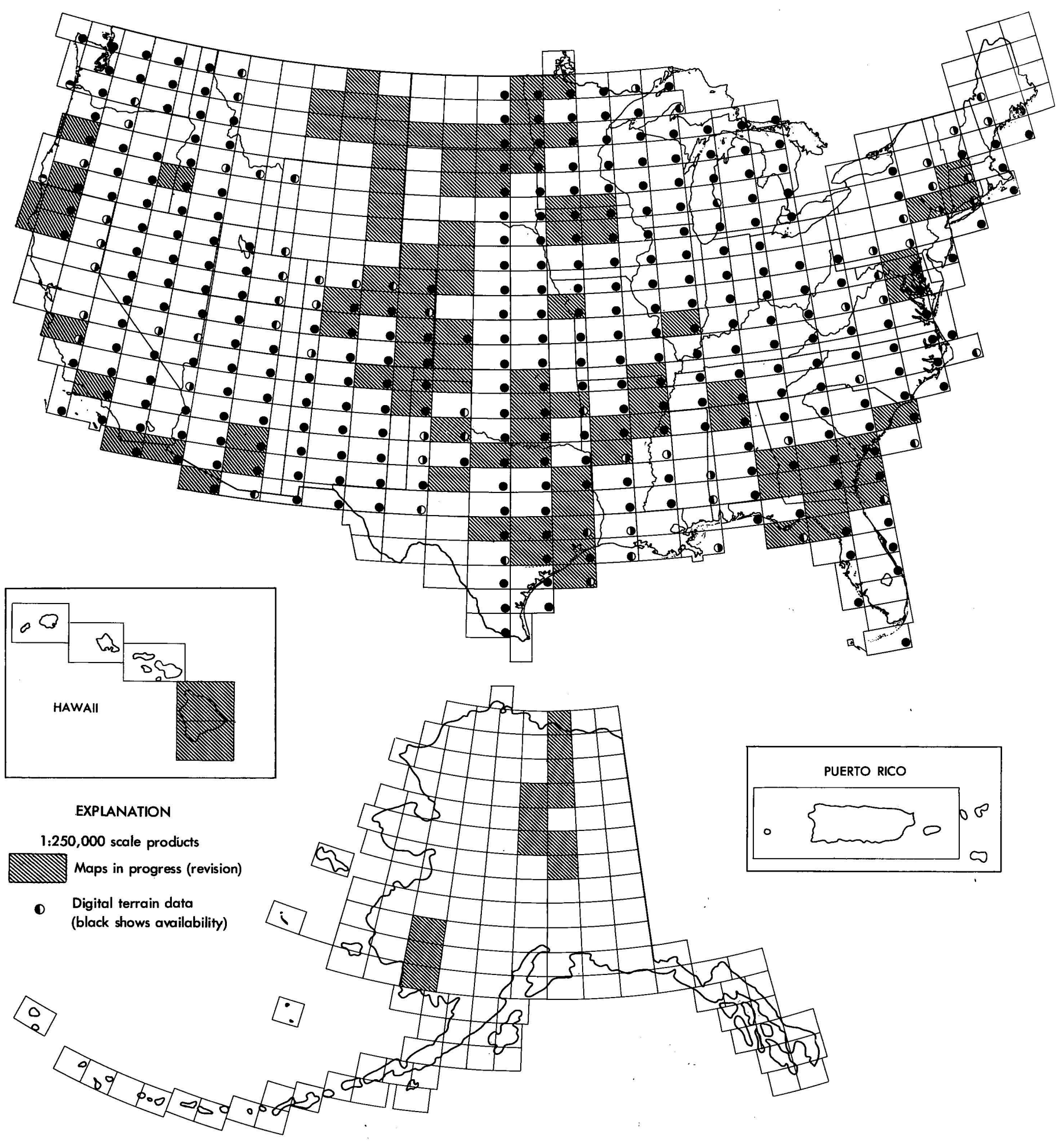

FIGURE 31.-Status of 1:250,000-scale map revision and digital terrain data.

Oceanic and Atmospheric Administration, Department of Commerce, have started producing topographic-bathymetric maps for the coastal zones of the United States. Three versions of a topographic- quadrangle-an orthophotoquad (fig. 33), orthophotomap, and interim-revised line map-were completed for evaluation by representative users. Dual-scale coverage of the Georgia coastlinetopographic-bathymetric at $1: 100,000$ and ortho- 
photo-bathymetric at $1: 24,000$-is in production. Bathymetric data are also being added to ten $1: 250$,000-scale topographic maps.

The Survey also produces national park maps, normally standard topographic maps combined into one or more sheets covering the park area with, in some cases, companion shaded-relief editions. During 1976 and the transition quarter, six new park maps were published, and seven more were in production. A folded and jacketed map of Mount Rainier National Park, Wash. (1:50,000), was distributed during the summer by the National Park Service for user appraisal.

\section{INTERNATIONAL COOPERATION}

The Geological Survey provides technical assistance and training in surveying and mapping to many other countries under formal agreements and reimbursable funding. An agreement between the Survey and the Ministry of Hydraulics of Algeria provides for prepa- ration of Landsat image mosaics, for personnel training, and for establishment of a technical user assistance office for remote sensing data. A Fourth Extension Agreement was made with Saudi Arabia to aid the Ministry of Petroleum and Mineral Resources in topographically mapping areas for geologic investigations, under which 545 square kilometers (210 square miles) were mapped this year. The Survey has agreements with Canada's Department of Energy, Mines, and Resources and with Mexico's Comisión de Estudios del Territorio Nacional to exchange cartographic data for the international border areas. This year the agreements were renegotiated to include aerial photographs and various photoimage products.

Fiscal year 1976 marked the 19th consecutive year that the Survey participated in the National Science Foundation's U.S. Antarctic Research Program. In support of geophysical and glaciological studies, Survey personnel conducted ground surveys and operated satellite-tracking and seismological equipment. A variety of maps of Antarctic regions were prepared: $1: 250,000$ topographic maps (fig. 34A), 1:500,000

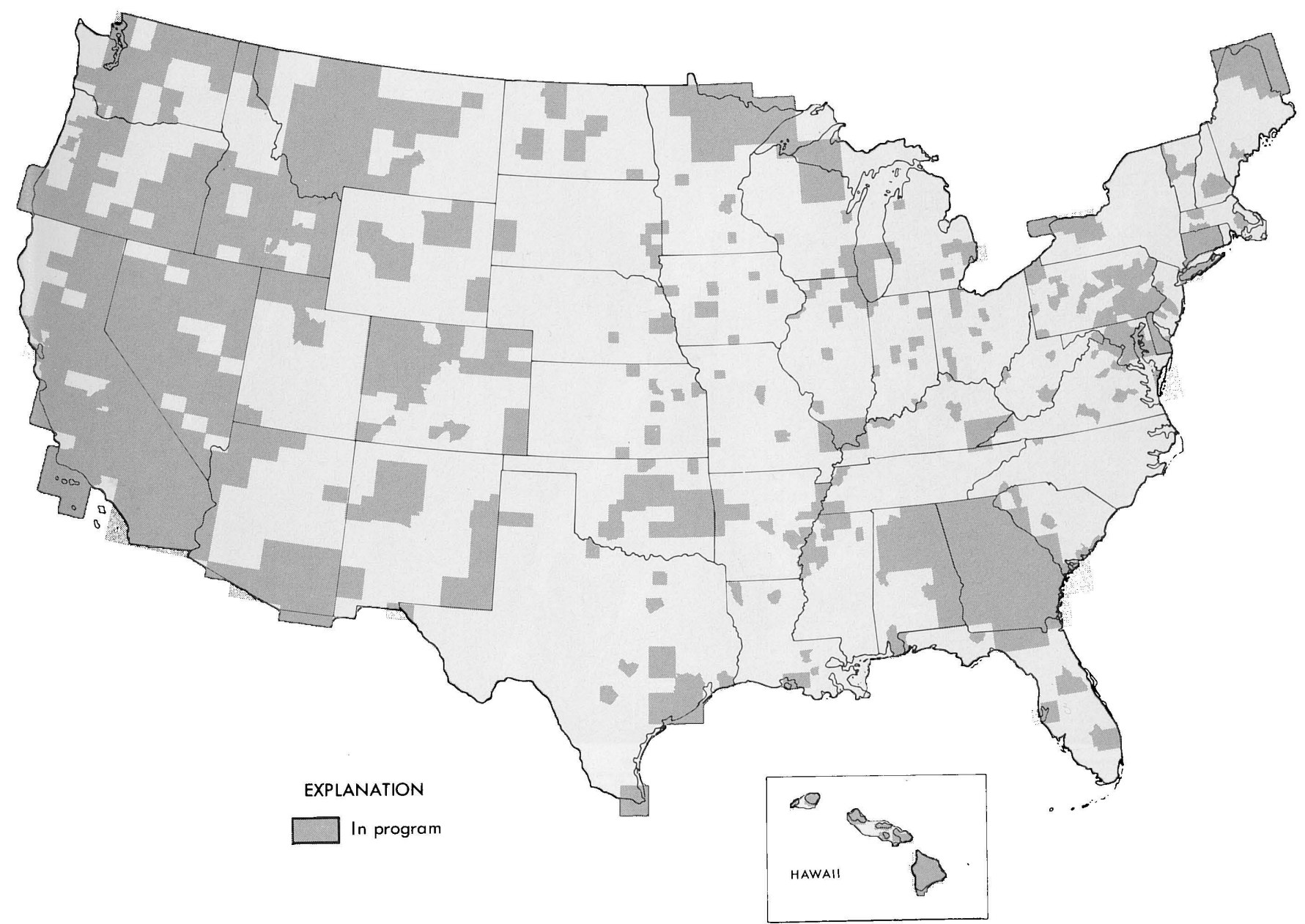

FIGURE 32.-Status of the Intermediate-Scale Mapping program. 


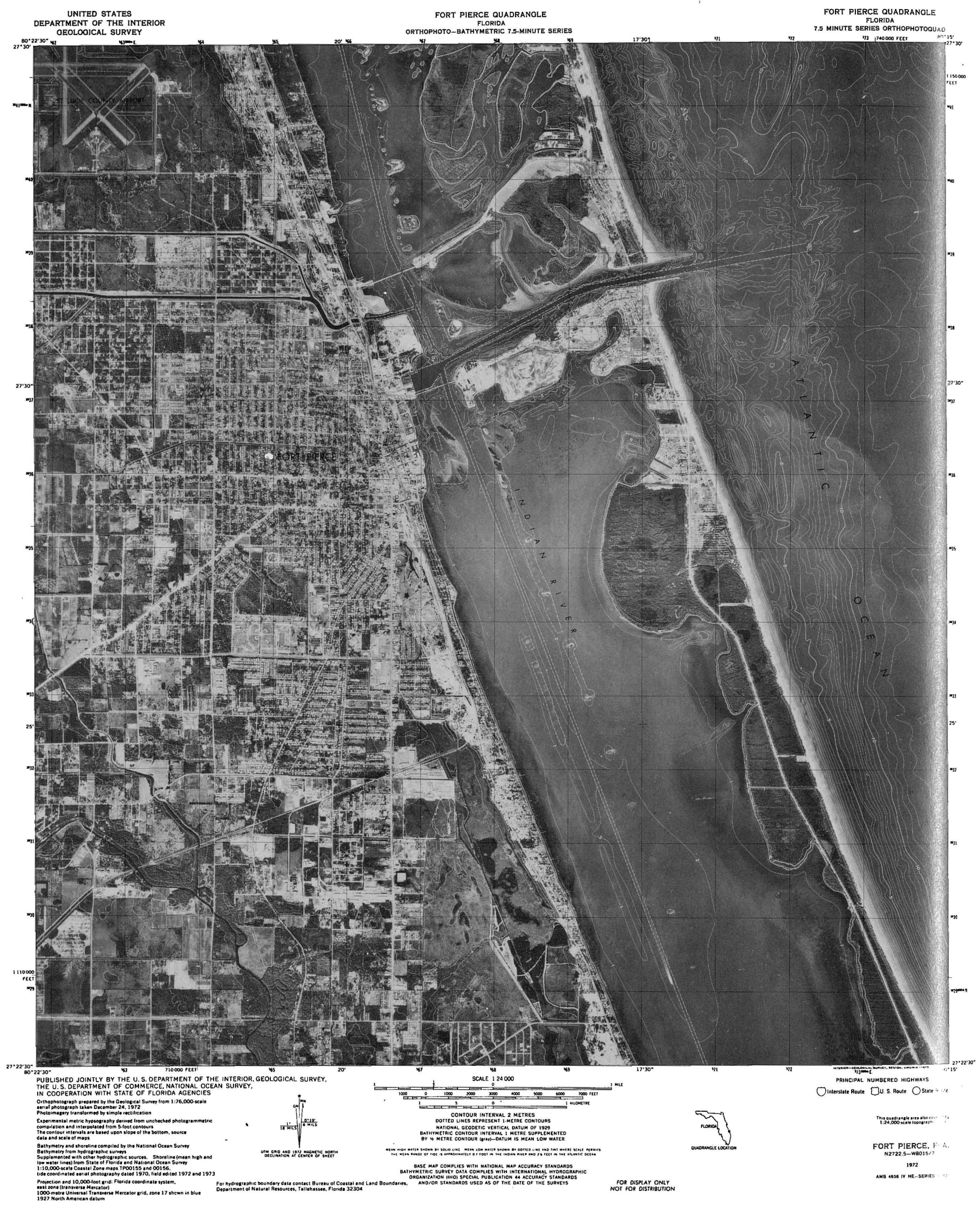

76 FIGURE 33. Experimental orthophotoquad showing both topography and bathymetry (Fort Pierce, Fla.; scale of original is 1:24,000). 


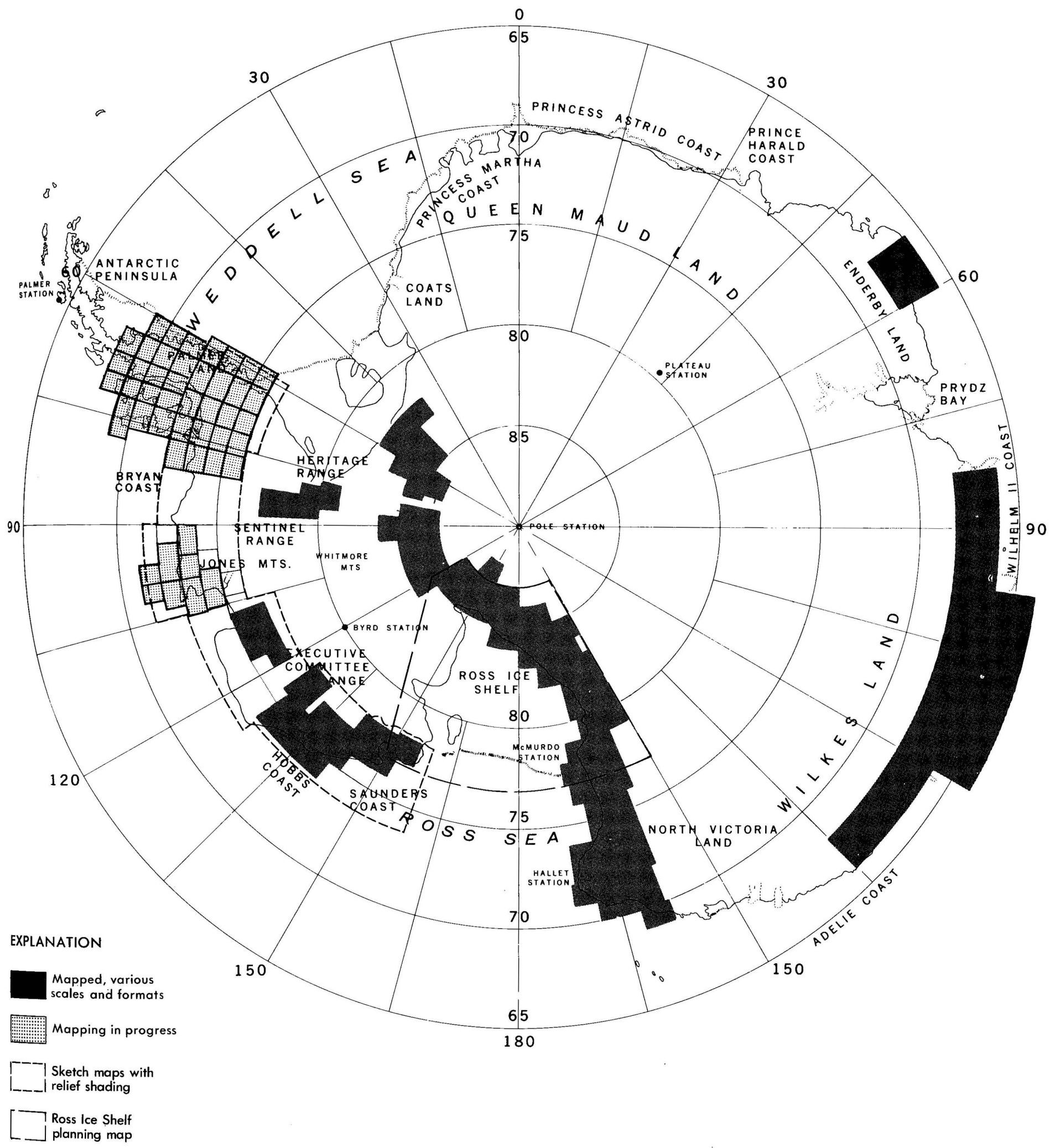

FIGURE 34A.-Status of mapping in Antarctica. 


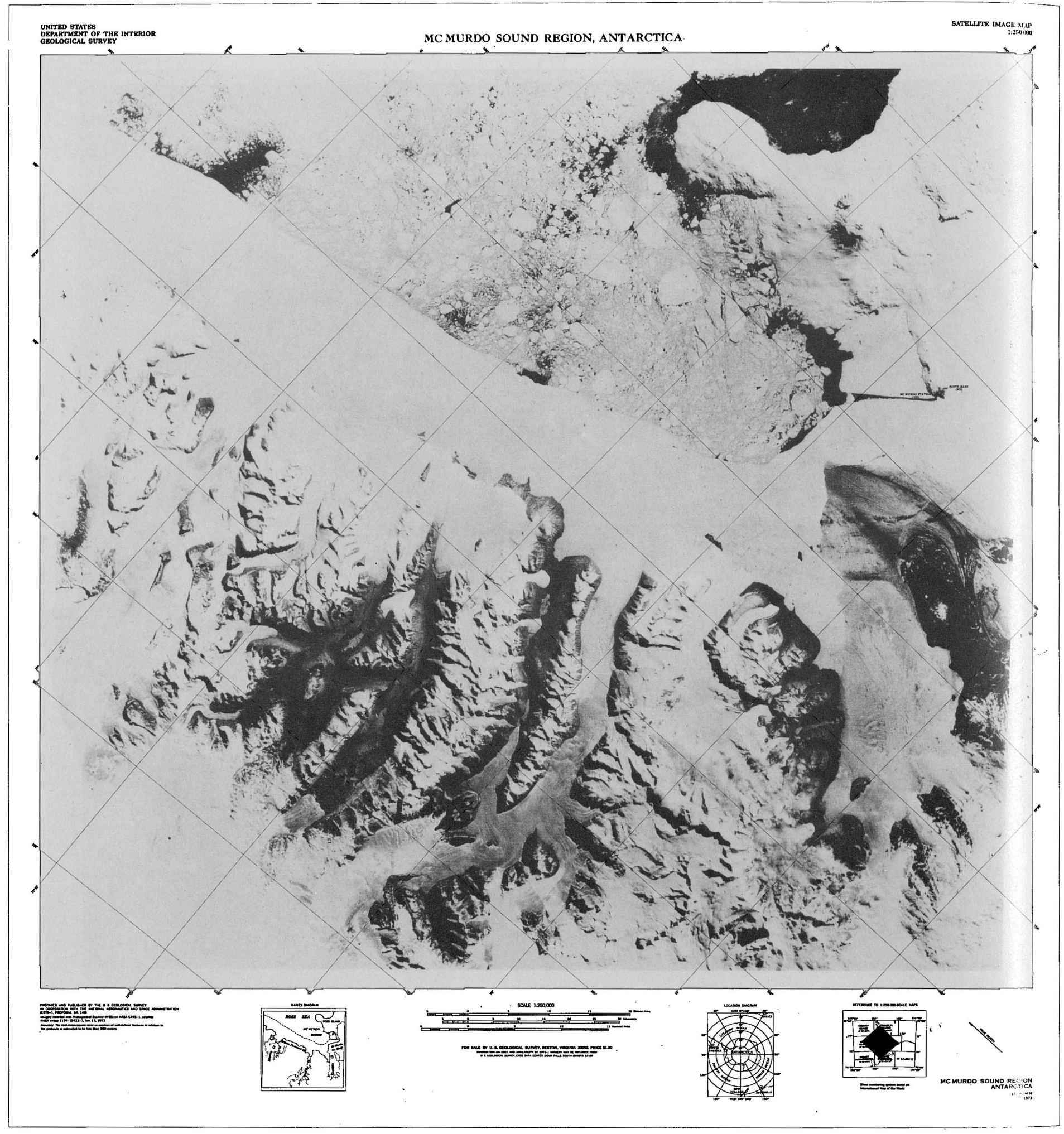

FIGURE 34B.-Landsat image map of McMurdo Sound region, Antarctica. 
planimetric sketch maps, and small-scale satellite image maps. This year six Landsat image maps of portions of Antarctica were prepared at scales of $1: 250,000,1: 500,000$, and $1: 1,000,000$; the $1: 250$ 000 -scale map of McMurdo Sound (fig. 34B) offers a spectacular view of volcanic mountains and sea ice.

\section{NATIONAL CARTOGRAPHIC INFORMATION CENTER}

The goal in establishing the National Cartographic Information Center in 1974 is to improve public access to cartographic data collected by Federal, State, and local agencies and by private firms. In the Federal sector alone, the cartographic data holdings are estimated at 1.5 million maps and charts, 25 million aerial and space photographs, and 1.5 million geodetic positions. The Center generally does not obtain the actual cartographic data but rather collects and organizes information about the data and, if possible, about acquisition plans of participating organizations and provides this information and ordering assistance to users. The headquarters office has been receiving about 5,000 inquiries a month.

Many government and private organizations have shown serious interest in the mission of the National Cartographic Information Center. In fiscal year 1976, five more Federal agencies formally agreed to supply information on their cartographic holdings. The first State to participate in the network is Texas; a joint information center will be opened in Austin with a telecommunications link to the EROS Data Center, the principal affiliate for aerial and space imagery. This pilot cartographic information center may well become a model for similar outlets in other States. By the year's end, other agencies that have agreements with the National Cartographic Information Center that relate to cartographic information management included the:

Agriculture Stabilization and Conservation
Service
Bureau of Land Management
Defense Intelligence Agency
Forest Service
National Archives and Records Service
National Oceanic and Atmospheric
Administration, National Ocean Survey
Soil Conservation Service
Texas Water Development Board,
Texas Natural Resources Information System

In addition, four regional offices were opened, in Reston, Va., Rolla, Mo., Denver, Colo., and Menlo Park, Calif., to provide convenient customer access and complete acquisition of information at the local level.

For information on aerial photography, the National Cartographic Information Center has developed the Aerial Photography Summary Record System. To date, nine Federal agencies have provided the Center with data on coverage and technical characteristics of vast photograph collections and on plans for new photography projects, in digital form for direct input to the system. Several workshops were held with the cooperating agencies to explain the system's capabilities and how to code and retrieve information.

The National Cartographic Information Center is coordinating the transfer of Geological Survey geodetic data to the National Oceanic and Atmospheric Administration, which is assembling the National Geodetic Data Base. This year, the Survey mapping centers began organizing the records for 40,000 horizontal control stations. The tasks of evaluating and formatting the numerical observation data have begun, and new text-processing equipment is being acquired for digitizing the station descriptions. The transfer of data is slated for completion in time to lend support to the upcoming readjustment in 1983 to the new North American Datum.

\section{RESEARCH AND RELATED DEVELOPMENTS}

The Survey is continually searching for ways to improve mapping productivity and to respond more quickly to users' diverse requirements. Among the new instruments and technological developments investigated during the year (U.S. Geological Survey, 1976), the following seem particularly important to the future of cartography:

- Inertial surveying systems.-Adaptation of inertial navigation systems to ground surveying problems promises to provide the needed accuracy and to make control surveys far more productive. Ground positions and elevations can be established automatically by inertial measuring systems carried in a truck, helicopter, or light plane. A Litton Auto-Surveyor owned by the Bureau of Land Management was brought to Denver for tests oriented to Geological Survey map control requirements; the resulting horizontal positions generally agreed within half a meter, but vertical accuracy was inadequate for most 1:24,000-scale mapping. A military version of the system, on loan from the Defense Mapping Agency, was used for the first production test in Maine, a mapping project requiring ground data for nearly one-quarter of the State; the results are currently being evaluated. The Aerial Profiling of Terrain 
System is being designed for the Survey by the Charles Stark Draper Laboratory (Cambridge, Mass.) to carry a three-coordinate scheme of reference in a light airplane, to an accuracy of 0.15 meter vertically and 3 meters horizontally. Design of the system was prompted by the need for flood-plain delineation, but other potential field applications include establishing map control and obtaining map elevation information. The contract work has focused on maximum accuracy with light-weight and low-power elements, and the design phase is expected to be completed in December 1976.

- Advanced image-correlation system.-This year the Survey acquired a Gestalt Photo Mapper II (GPM2), the first production model in the United
States or elsewhere. The GPM2 (fig. 35) automatically corrects for the distortion in the aerial imagery and concurrently produces orthophotographs and the corresponding terrain data in contour and digital (magnetic-tape) form. The entire process is executed under computer control with the operator intervening occasionally to assist in correlating the images. Production time is related to various characteristics of the aerial photographs and of the terrain pictured; during 2 months of operation, production time has ranged from 1 to 7 hours to process the overlap area of a stereographic pair of photographs.

- Digital cartographic data.-In digital form cartographic data can be processed rapidly and eco-

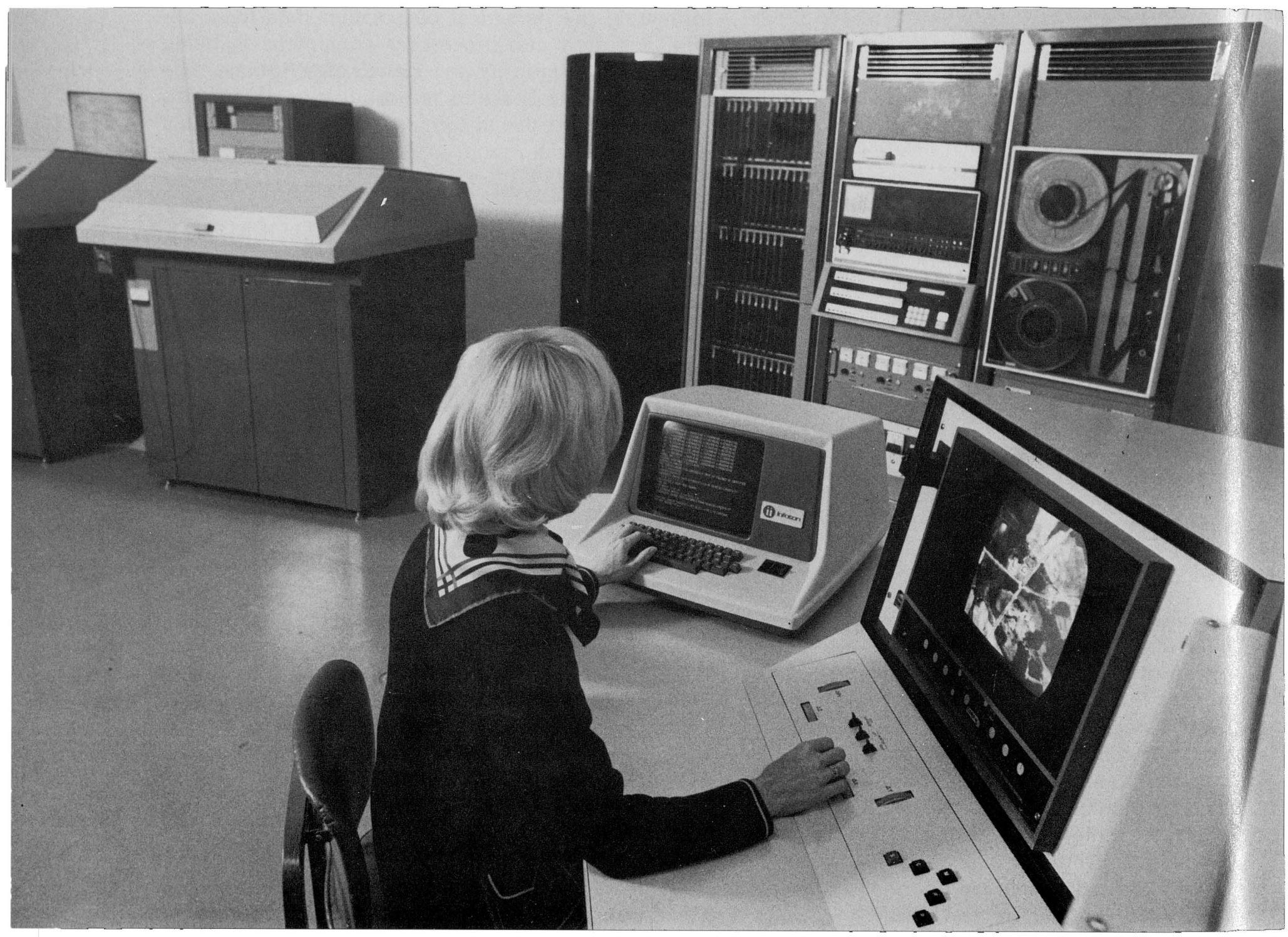

FIGURE 35.- The Survey has acquired a Gestalt Photo Mapper II, an advanced mapping system that concurrently produc s an orthophoto, a contour drawing, and digital terrain data. 
nomically and can be related with other types of data. The product can be a computer model or a map of selected content and scale. This year the Survey began equipping the mapping centers for digitizing mapped information (planimetric features such as the public land net) or for digitizing directly from aerial photographs (topographic features such as drainage and relief). An interim structure for the Digital Cartographic Data Base is being designed for use with the new hardware. Special-purpose cartographic data bases are being acquired from the Bureau of the Census and other agencies and adapted for Survey use. A pilot project is being carried on within the Survey, in connection with research on energy sources, to determine how best to digitize terrain elevations and planimetric data; the objective is to combine the surface data with digitized subsurface data on geologic structures in a National Coal Resources Data System so as to readily provide statistics on coal volume and overburden.

- Digitally controlled differential rectifiers.-The Digital Profile Recording and Output System was developed by the Survey to provide terrain data that can control the offline production of orthophotos, contour plots, and slope information. The first production unit went into operation this year. The design of the system is sufficiently flexible to accommodate several types of profiling instruments and film-exposing units. This approach is proving worthwhile and is thus being adapted to three other profiling instruments and two other exposing units.

- Digital processing of imagery.-The Geological Survey Center of Astrogeology at Flagstaff, Ariz., has been developing techniques for digitally correlating imagery and elevation data to form a new altered image. A stereographic pair of Landsat images was produced by digitally introducing relief displacement (parallax) into one image; when the original and processed images are viewed together, the observer sees a stereoimage. Another application is the production of shaded-relief renditions of maps. The digital terrain data are converted to values of slope, which are used to compute the brightness levels (based on the desired Sun angle and direction) that control production of the shaded image. Computergenerated shaded-relief maps were prepared that range in scale from $1: 24,000$ to $1: 250,000$.

- Coastal Zone Mapping Handbook.-A draft edition of the Coastal Zone Mapping Handbook, a joint project of the Geological Survey and the National Oceanic and Atmospheric Administration, was completed and subsequently reviewed by 200 Federal and State agencies. The handbook includes general guidelines for mapping coastal areas, sources of technical assistance and data, and product samples. Many people think that a more definitive map representation of the nation's wetlands is needed and should be based on a standard wetland classification system. The Survey is investigating the problem by experimentally mapping wetlands in Florida, Georgia, Mississippi, and South Dakota, areas which vary significantly in vegetation and other characteristics.

- Experimental color orthophotoquad.-Success in applying color to Landsat multispectral imagery shifted attention back to the earliest method of obtaining color pictures from black-and-white records. That method is to obtain at least two spectrally filtered records of the same area on black-and-white film and apply suitable color inks on a printing press. In this way, the Survey is experimentally adding color to the orthophotoquad. Real contrast and high resolution are obtained by taking simultaneous aerial pictures on panchromatic and black-and-white infrared films. The color contrasts provided in lithoprinting help the user interpret the perhaps unfamiliar aerial view. This technique was used to prepare several color renditions of a specimen image map for the U.S. Customs Service; one of these renditions will be chosen to complete the mapping of a $320-\mathrm{km}$ strip along the United States-Canadian border.

- Metrication.-After the passage of the Metric Conversion Act of 1975, a representative group of 150 Federal, State, and private organizations that will be affected by metric conversion in mapping were asked for opinions and advice on technical details of metrication. The replies showed preference for the 1:25,000 scale for 7.5-minute quadrangle maps and the contour-interval sequence of $1,2,5,10,20,50$, and 100 meters. The replies from States varied widely, from preferring to metricate now to insisting on waiting until 1:24,000-scale coverage is complete for the State. Individual State plans for completing 7.5-minute coverage and metricating will consider the problems and requirements of the State concerned. New metric topographic mapping commenced in New York with a project comprising thirty-two $1: 25,000$-scale quadrangles covering the area where the 1980 Winter Olympics will be held. Also, all new 1:100,000-scale maps will be metric as well as complete revisions of published maps. 


\section{VIRGINIA}

Index to
Topographic and other MAP COVERAGE

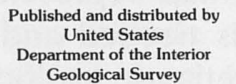

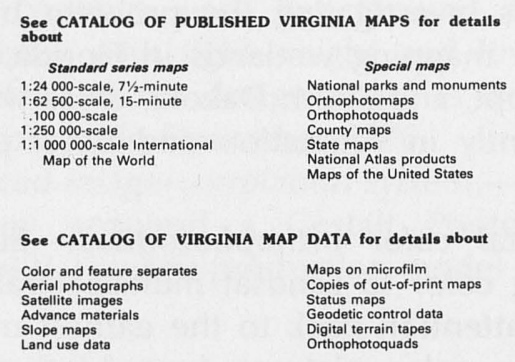

1:250 000-scale Series

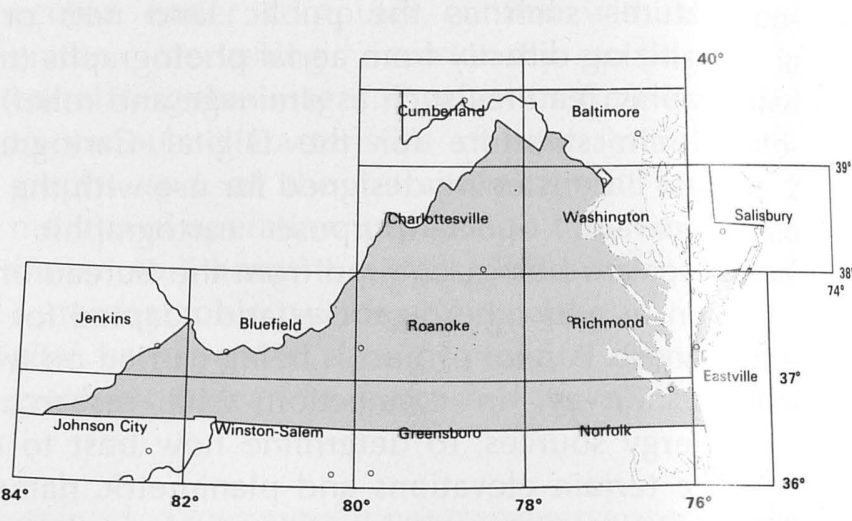

International Map of the World Series
1:1 000 000-scale

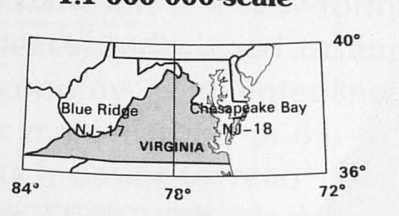

Sectional Map Series, 1:2 000 000-scale

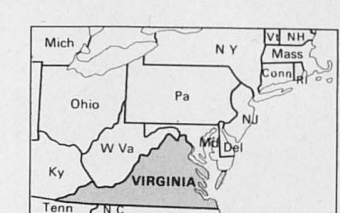

State Map Series
1:500 000- and 1:1 000 000-scale

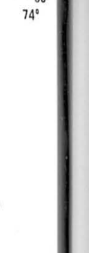

\section{(1)}

${ }^{2}<8^{\circ} \xi$

275 i.

ing

$1 / 1010$

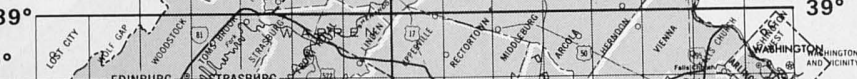

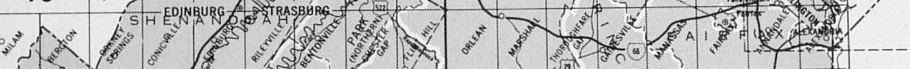

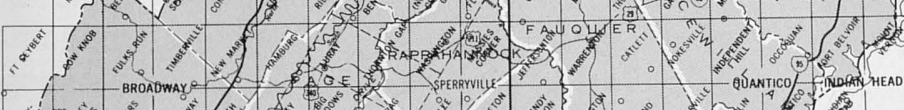

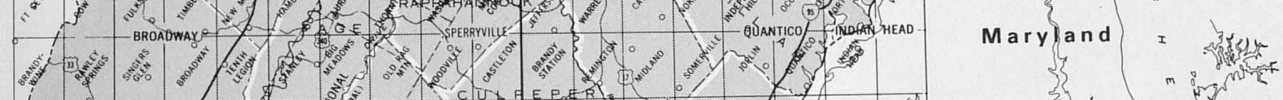

West virginia

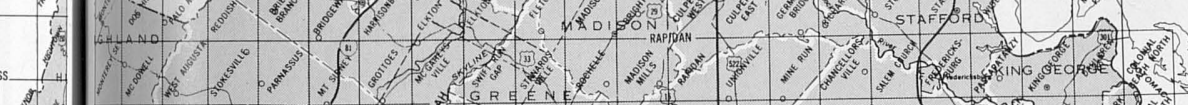

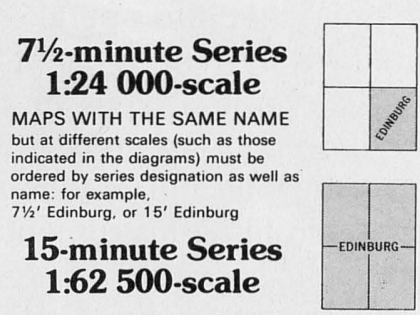

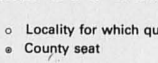

\section{${ }^{81^{\circ}}$}

$\int^{81}$

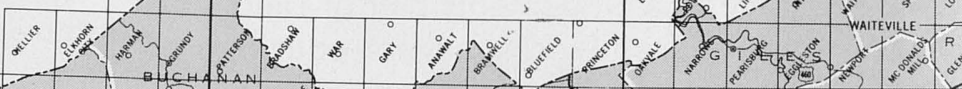

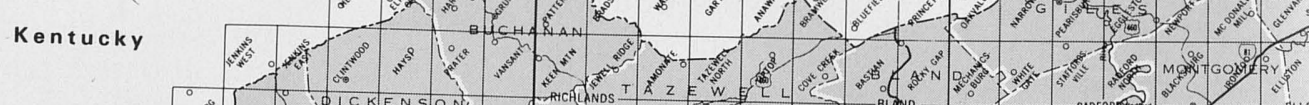

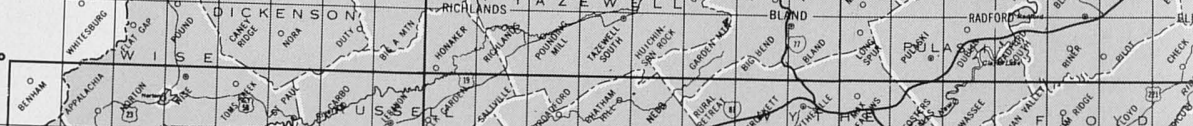

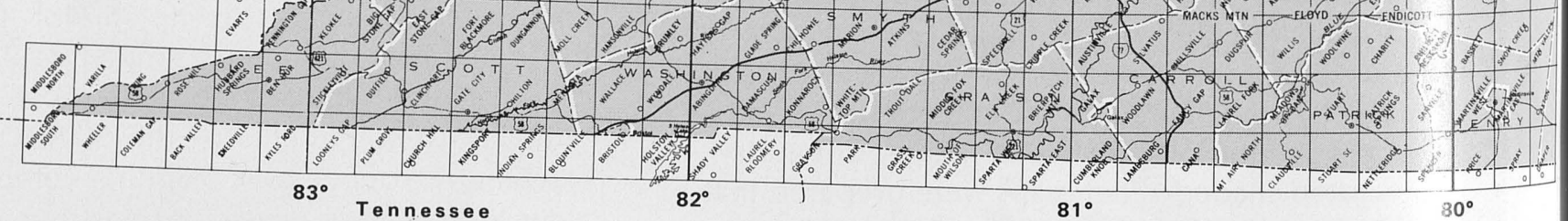

${ }^{83^{\circ}}$ Tennesse

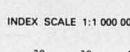

10




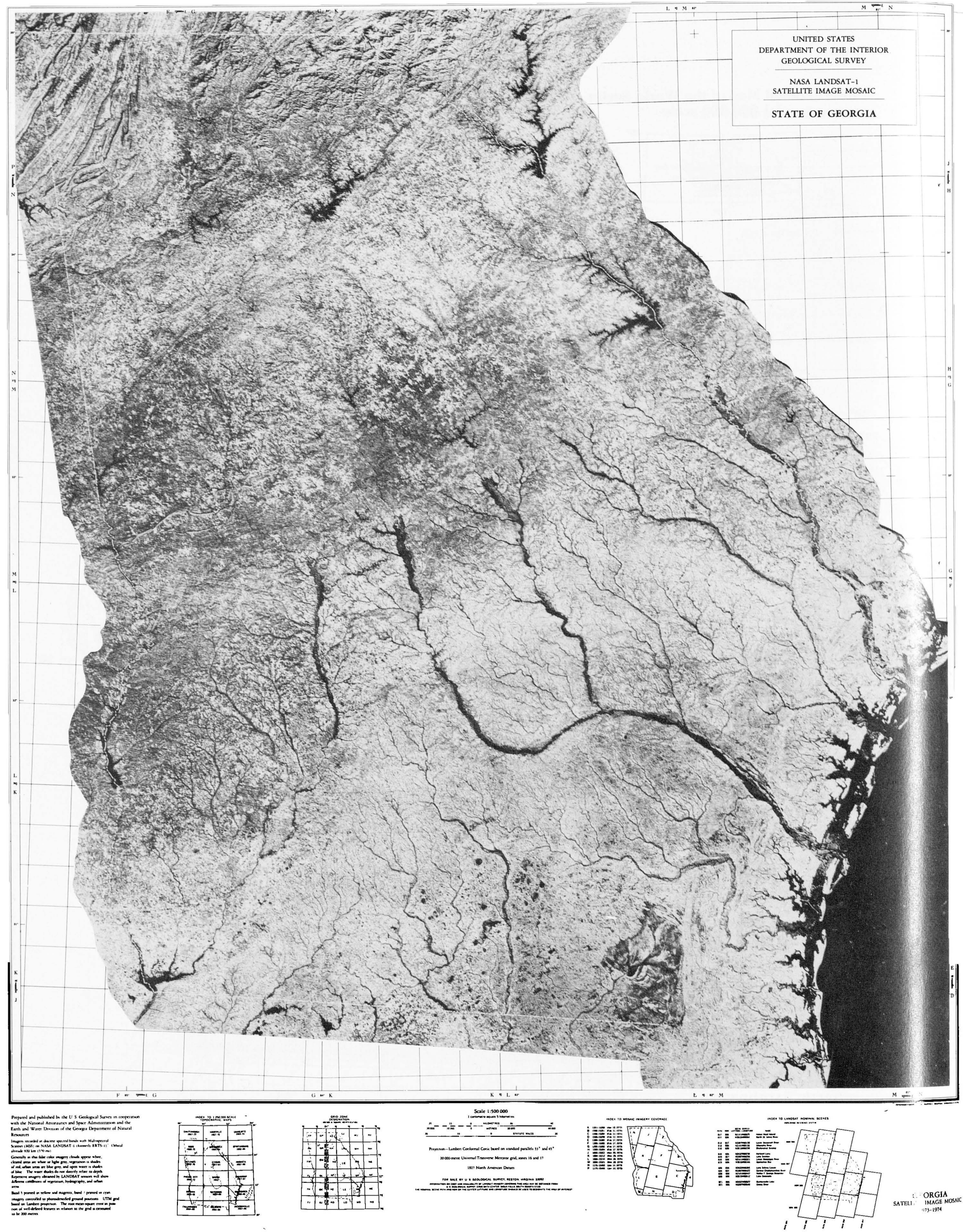


- Prototype State index to topographic maps and other map products.-The present system of providing information on the availability and coverage of cartographic data was critically reviewed. The first result is a new format for State map sales indexes, redesigned to improve readability and economy of maintenance. The new Virginia index map (fig. 36, p. 83) in black, gray, and red is much easier to read than the former light-green rendition with black overprint. One standard fold will replace the 11 fold sizes now used. New typefaces were chosen, and insets were added to show coverage in several map series. Two companion catalogs, one for published maps and the other for map data, with detachable order forms, will accompany the new index map.

- Cartographic applications of satellite imagery.The studies of cartographic applications of satellite imagery continued, with both Landsat- 1 and -2 still functioning. A 1:500,000-scale satellite image mosaic of Georgia (fig. 37) that shows the general extent of the flood plains was prepared for State use in regional geologic studies. A fundamental problem is the best way of processing Landsat data for distribution in image form. A second edition of the Upper Chesapeake Bay satellite image map shows the improvement due to digital image processing. Other experiments indicated that conventional photoprocessing of spectral records into a color composite may not be optimum for some mapping purposes. Consultation and coordination with mapmakers and others throughout the world indicate that cartographic applications of Landsat data are manifold and accelerating. For example, Canadians are using Landsat imagery to revise maps at scales as large as 1:50,000, and the U.S. Defense Mapping Agency has used the imagery to revise hydrographic charts of international waters. However, should operational spacecraft retaining the basic specifications of the experimental Landsats be launched to maintain the established sequence and flow of repetitive and consistent coverage now relied on by several nations that have established receiving stations, it must be understood that the data are directly usable only at small scales-generally 1:500,000 and smaller. Experience shows that Landsat imagery must be supplemented by other more detailed and larger scale data to provide cartographers with all the information they need to produce complete topographic maps at scales of $1: 250,000$ and larger.

\section{References}

Bureau of the Budget, 1967, Coordination of surveying and mapping activities: Bureau of the Budget Circular A-16 (revised), May 6, 1967, 3 p.

U.S. Geological Survey, 1976, Mapping-An annual report of USGS cartographic research: USGS Topographic Division, 520 National Center, Reston, Va. 22092, 75 p.

4FIGURE 37.-Satellite image mosaic of Georgia (scale of the original is 1:500,000). 

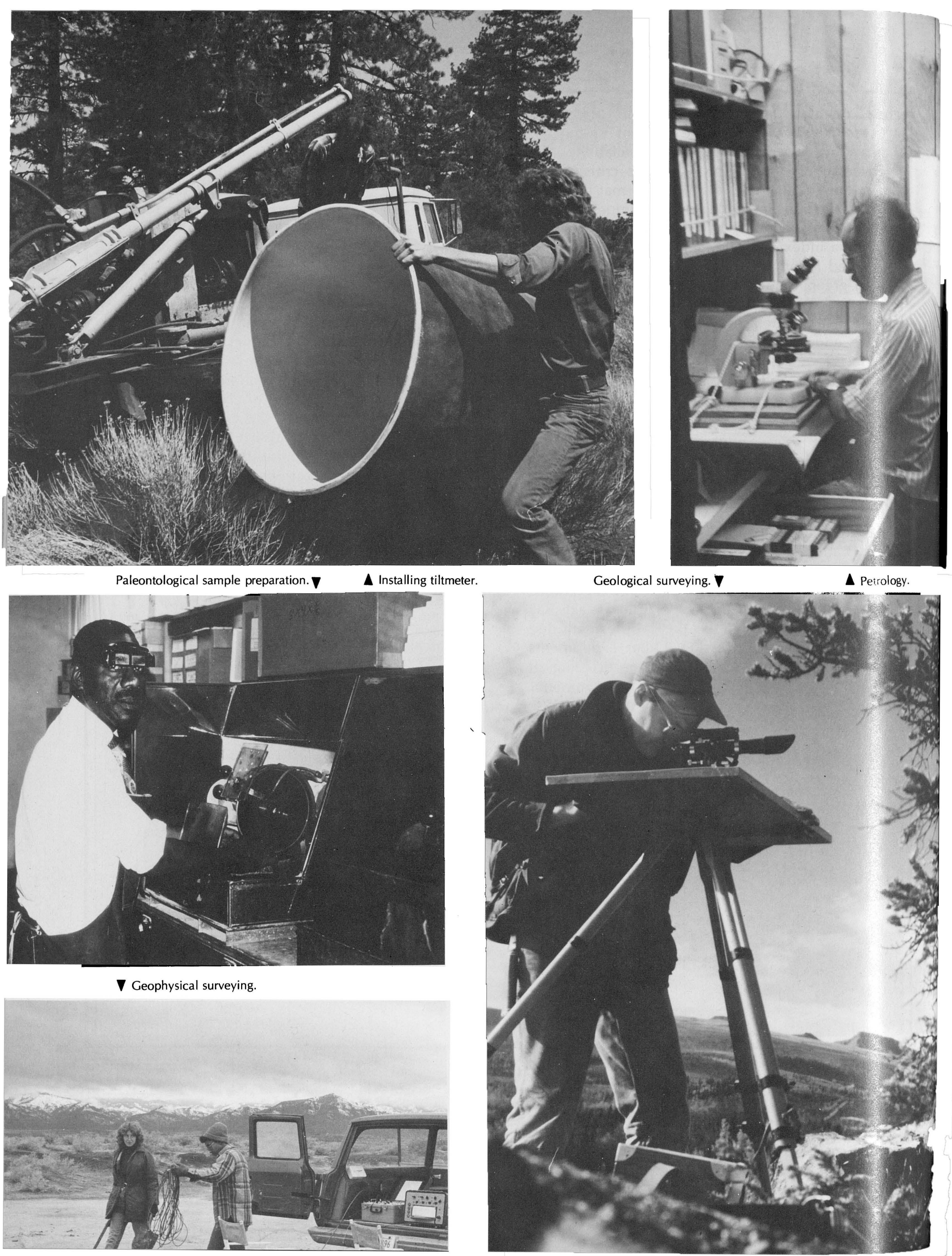


\section{Geologic and Mineral Resource Surveys and Mapping}

\section{OVERVIEW}

The national program of geologic research and investigations, under the direction of the Geologic $\mathrm{Di}$ vision, continues to study the physical resources and geologic processes that substantially influence our lives. The relationship of geologic research to human welfare is particularly significant in:

- Geologic hazards such as earthquakes, volcanic eruptions, and landslides in urban and suburban areas.

- Development and use of energy resources, including oil and gas, coal, uranium, and geothermal waters, and the effects on the environment of the Earth's surface and atmosphere.

- Depletion of known mineral reserves and the corresponding impacts on national and world economies.

To assist in the solution of such problems, the Geologic Division conducts an extensive research and investigation program that provides geological, geophysical, and geochemical information on geologic hazards, land resources, and mineral and energy resources. The national geologic program is divided into four subactivities: Land Resource Surveys; Mineral Resource Surveys; Energy Resource Surveys; and Offshore Geologic Surveys.

Land Resource Surveys provide basic geological, geophysical, and geochemical data required to evaluate the Nation's land resources. Other research programs of this subactivity are aimed at mitigating geologic hazards, identifying the environmental problems created by developing and utilizing energy resources, and investigating the geologic processes and historical geologic events that lead to the physical and chemical composition and structure of the Earth, Moon, and planets.

Mineral Resource Surveys provide information on the resource assessment of metallic and nonmetallic minerals by studying the geology, geochemistry, and geophysics of known mineral occurrences and potentially mineralized areas and by developing new or improved exploration techniques. The mineral resource assessment programs respond to legislative actions such as the Geological Survey's Organic Act (1879), the Strategic Raw Materials Act (1938), the Wilderness Act (1964), the Mining and Minerals Policy Act (1970), and the Alaska Native Claims Settlement Act (1971).
Energy Resource Surveys provide updated information on the location, quantity, and quality of the $\mathrm{Na}$ tion's energy resources through studies of coal, oil and gas, oil shale, uranium and thorium, and geothermal areas.

Offshore Geologic Surveys provide assessment of the potential mineral and energy resources of the submerged continental margins of the United States and determine the geologic hazards that may affect the environment in developing and utilizing off-shore resources.

\section{Budget and Personnel}

In fiscal year 1976, obligations of the Geologic and Mineral Resource Surveys and Mapping activity were $\$ 92.3$ million. This amount was supplemented by approximately $\$ 1.5$ million from 15 States and $\$ 21.6$ million from other Federal agencies and non-Federal sources (table 10 and fig. 38 ).

At the end of fiscal year 1976, the Geologic Division had 2,119 permanent full-time employees and 590 temporary or part-time employees.

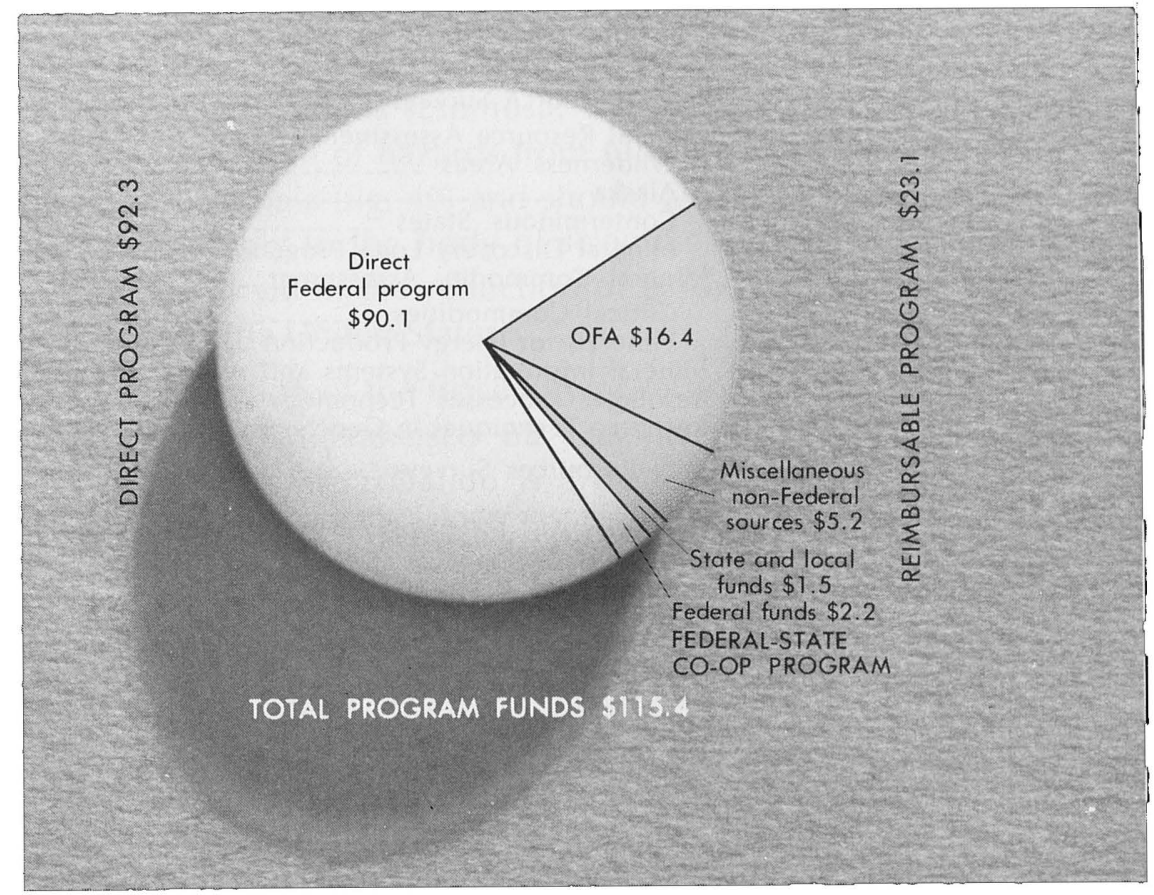

FIGURE 38.-Sources of fiscal year 1976 funds for Geologic and Mineral Resource Surveys and Mapping (dollars in millions). 


\section{Highlights}

Major highlights of fiscal year 1976 included the following events and accomplishments:

- Discovery of an anomalous uplift, up to 25 centimeters (12 inches) in an area larger than 12,000 square kilometers $(4,600$ square miles) in southern California, which may be a precursor to an earthquake.

- Revision of the standard classification chart of landslides and slope movement for use by engineers.

- Location of significant mineralization in the Scotchman Peak Wilderness study area, Montana-Idaho, which is similar to the strata-bound copper deposit being developed 3.2 kilometers (1.9 miles) to the east.
- Completion of mineral resource assessment for approximately one-third of the land area being considered for preservation under Section 17(d) (2) of the Alaska Native Claims Settlement Act.

- Compilation of mineral resource information for 23 Indian reservations totaling 3.2 million hectares (7.9 million acres) in Colorado, Michigan, Nevada, New Mexico, Utah, and Wisconsin.

- Description of the geologic character, age, and origin of United States ball clay and fireclay deposits used for making high-grade refractories.

- Compilation of the mineral and water resources report for the State of Wisconsin.

- Comparison of the approach and efficiency of resource programs conducted in Canada and

TABLE 10.-Geologic and Mineral Resource Surveys and Mapping activity and Alaska Pipeline Related Investigations activity obligations for fiscal years 1975 and 1976 and transition quarter by programs (dollars in millions)

[Data may differ from that in statistical tables because of rounding]

\begin{tabular}{|c|c|c|c|c|c|}
\hline Program & $\begin{array}{c}\text { Fiscal year } \\
1975\end{array}$ & & $\begin{array}{c}\text { Fiscal year } \\
1976\end{array}$ & & $\begin{array}{c}\text { Transition } \\
\text { quarter }\end{array}$ \\
\hline Total _- & $\$ 114.48$ & & $\$ 115.44$ & & $\$ 32.17$ \\
\hline Direct Programs & 89.02 & & 92.32 & & 24.81 \\
\hline Land Resource Surveys & 33.38 & & 34.08 & & 9.68 \\
\hline $\begin{array}{l}\text { Earthquake Hazards } \\
\text { Volcano Hazards } \\
\text { Environmental Aspects of Energy } \\
\text { Enctic Environmental Studies } \\
\text { Regional Mapping and Analysis }\end{array}$ & $\begin{array}{r}10.97 \\
.64 \\
5.35 \\
.40 \\
1.26 \\
14.76 \\
\end{array}$ & & $\begin{array}{r}11.26 \\
.68 \\
5.23 \\
.37 \\
1.29 \\
15.24 \\
\end{array}$ & & $\begin{array}{r}3.78 \\
.17 \\
1.21 \\
.10 \\
.36 \\
4.06 \\
\end{array}$ \\
\hline $\begin{array}{l}\text { Regional Geology } \\
\text { Geophysical Surveys } \\
\text { Geochemical Surveys } \\
\text { Dating and Correlation } \\
\text { Geologic Processes }\end{array}$ & $\begin{array}{l}9.34 \\
4.32 \\
1.10 \\
\end{array}$ &. & $\begin{array}{l}9.22 \\
4.76 \\
1.26 \\
\end{array}$ & & $\begin{array}{r}2.48 \\
1.26 \\
.32 \\
\end{array}$ \\
\hline Mineral Resource Surveys & 18.02 & & 19.78 & & 5.31 \\
\hline $\begin{array}{l}\text { Mineral Resource Assessment } \\
\text { Wilderness Areas } \\
\text { Alaska } \\
\text { Conterminous States } \\
\text { Mineral Discovery Loan Program } \\
\text { Mineral Commodity Assessment }\end{array}$ & $\begin{array}{r}7.77 \\
1.24 \\
2.52 \\
1.67 \\
.25 \\
2.09\end{array}$ & . & $\begin{array}{r}6.97 \\
1.46 \\
3.48 \\
1.85 \\
.18 \\
2.02\end{array}$ & . & $\begin{array}{r}1.89 \\
.35 \\
1.03 \\
.46 \\
.05 \\
.54\end{array}$ \\
\hline $\begin{array}{l}\text { Critical Commoditiès } \\
\text { Minerals for Energy Production } \\
\text { Mineral Information Systems and Analysis } \\
\text { Resources Processes Technology } \\
\text { Resource Techniques in Geochemistry and Geophysics }\end{array}$ & $\begin{array}{r}1.50 \\
.59 \\
.96 \\
5.14 \\
4.14 \\
\end{array}$ & & $\begin{array}{r}1.48 \\
.54 \\
1.66 \\
5.23 \\
3.90 \\
\end{array}$ & $\cdot$ & $\begin{array}{r}.42 \\
.12 \\
.69 \\
1.27 \\
.92 \\
\end{array}$ \\
\hline Energy Resources Surveys & 22.38 & & 23.00 & . & 5.86 \\
\hline $\begin{array}{l}\text { Coal and Gas } \\
\text { Oil Shale } \\
\text { Uranium and Thorium } \\
\text { Geothermal Energy } \\
\text { Energy Resource Data System }\end{array}$ & $\begin{array}{l}1.64 \\
4.93 \\
1.19 \\
4.23 \\
9.06 \\
1.33 \\
\end{array}$ & & $\begin{array}{l}2.32 \\
5.14 \\
1.07 \\
4.45 \\
8.65 \\
1.38 \\
\end{array}$ & . & $\begin{array}{r}.51 \\
1.23 \\
.28 \\
1.07 \\
2.55 \\
.22 \\
\end{array}$ \\
\hline $\begin{array}{l}\text { Offshore Geologic Surveys } \\
\text { Oil and Gas Resources Appraisal } \\
\text { Environmental Investigations } \\
\text { Marine Geology Investigations }\end{array}$ & $\begin{array}{r}15.24 \\
10.07 \\
3.93 \\
1.24 \\
\end{array}$ & & $\begin{array}{r}15.47 \\
9.49 \\
4.50 \\
1.49 \\
\end{array}$ & & $\begin{array}{r}3.96 \\
2.24 \\
1.37 \\
.35 \\
\end{array}$ \\
\hline Reimbursable Programs & 25.46 & & 23.12 & & 7.36 \\
\hline $\begin{array}{l}\text { State, counties, and municipalities } \\
\text { Miscellaneous non-Federal sources } \\
\text { Other Federal agencies }\end{array}$ & $\begin{array}{r}1.55 \\
3.75 \\
20.16 \\
\end{array}$ & & $\begin{array}{r}1.48 \\
5.24 \\
16.40 \\
\end{array}$ & & $\begin{array}{r}.38 \\
1.12 \\
5.86 \\
\end{array}$ \\
\hline Alaska Pipeline Related Investigations & .34 & & .31 & & .08 \\
\hline
\end{tabular}


United States in terms of existing public policies for the mineral industries.

- Studies of Landsat images for lineaments, structural zones, and hydrothermal alteration of rocks and soils that have proven effective in focusing attention on potential ore deposits in Alaska, Arizona, Nevada, Mexico, Brazil, and Pakistan.

- Completion of geologic maps for about 2,590 square kilometers $(1,000$ square miles) of an area bearing low-sulfur coal in Wyoming, Montana, Kentucky, Virginia, and West Virginia.

- Initiation of a 5-year program with the Energy Research and Development Administration to evaluate and characterize black shales in the Appalachian and Illinois Basins.

- Continuation of geologic studies in Alaska that resulted in significant discovery of a potential uranium-thorium deposit.

\section{LAND RESOURCE SURVEYS}

\section{Earthquake Hazards}

The goal of the earthquake prediction and hazardmitigation program is to reduce casualties, damage, and social and economic disruption caused by earthquakes. The social, economic, and political actions that can be taken to attain this goal are based on technological capabilities that require development through research. The primary objectives of this research are to develop capabilities to:

- Predict the time, place, magnitude, and effects of earthquakes so that effective preparatory action can be taken.

- Control or alter seismic phenomena to make them less hazardous.

- Assess seismic risk and evaluate earthquake hazards so that appropriate construction and landuse plans can be implemented.

- Improve economically feasible design and construction methods for building earthquake-resistant structures of all types and for upgrading existing structures.

- Understand the factors that influence public utilization of earthquake-mitigation methods and information.

Responsibility for research on these objectives is shared between the Survey and the National Science Foundation, which is responsble for the last two objectives.

Highlights of the program during fiscal year 1976 included:
- Discovery of an anomalous uplift of up to 25 centimeters (12 inches) in southern California (Castle and Yerkes, 1976). This uplift, which began about 1960 and has grown to include an area of more than 12,000 square kilometers $(4,600$ square miles), clearly seems to represent an episode of anomalous crustal deformation in the region and may be the precursor of a large earthquake in the region (fig. 39).

- Investigation of the Chinese methods used in predicting earthquakes. China has suffered greatly from earthquakes. The greatest earthquake disaster known occurred there in 1556 when over 800,000 people died. About 100,000 died in 1920 from a magnitude 8.6 shock in Kansu and Shansi Provinces, and in 1927 about 200,000 were killed by a tremor of magnitude 8.3 near Nanshan. Two additional disastrous earthquakes in 1966 (casualties unknown) prompted the government of the People's Republic of China to launch an intensive effort to predict earthquakes. Surprisingly, more than 10,000 trained workers and many amateurs are engaged in the program, which utilizes much modern equipment. In 1976, a delegation of Survey scientists visited the Liaoming region to study the Chinese methods of predicting earthquakes, just prior to the magnitude 8.0 earthquake in Hopeh Province on July 27-28, 1976, that may have killed approximately 500,000 people.

- Investigation, at the request of the Guatemalan Government, into the geologic, seismologic, and engineering effects of and hazards resulting from the February 4, 1976, earthquake. The results of the investigations (Espinosa, 1976) should aid in the reduction of hazards from future earthquakes in Guatemala (fig. 40) and should also contribute measurably to the body of scientific information that will aid in the reduction of earthquake hazards in the United States.

- Demonstration of the feasibility of seismic zonation for the San Francisco Bay region (Borecherdt, 1975). Seismic zonation is a necessary basis for development of regional land-use policies aimed at minimizing future losses during earthquakes.

\section{Volcano Hazards}

The Volcano Hazards program is designed to mitigate the hazards posed by the active volcanoes in Hawaii and in the Cascade Range of the Western United States. During fiscal year 1976, considerable 


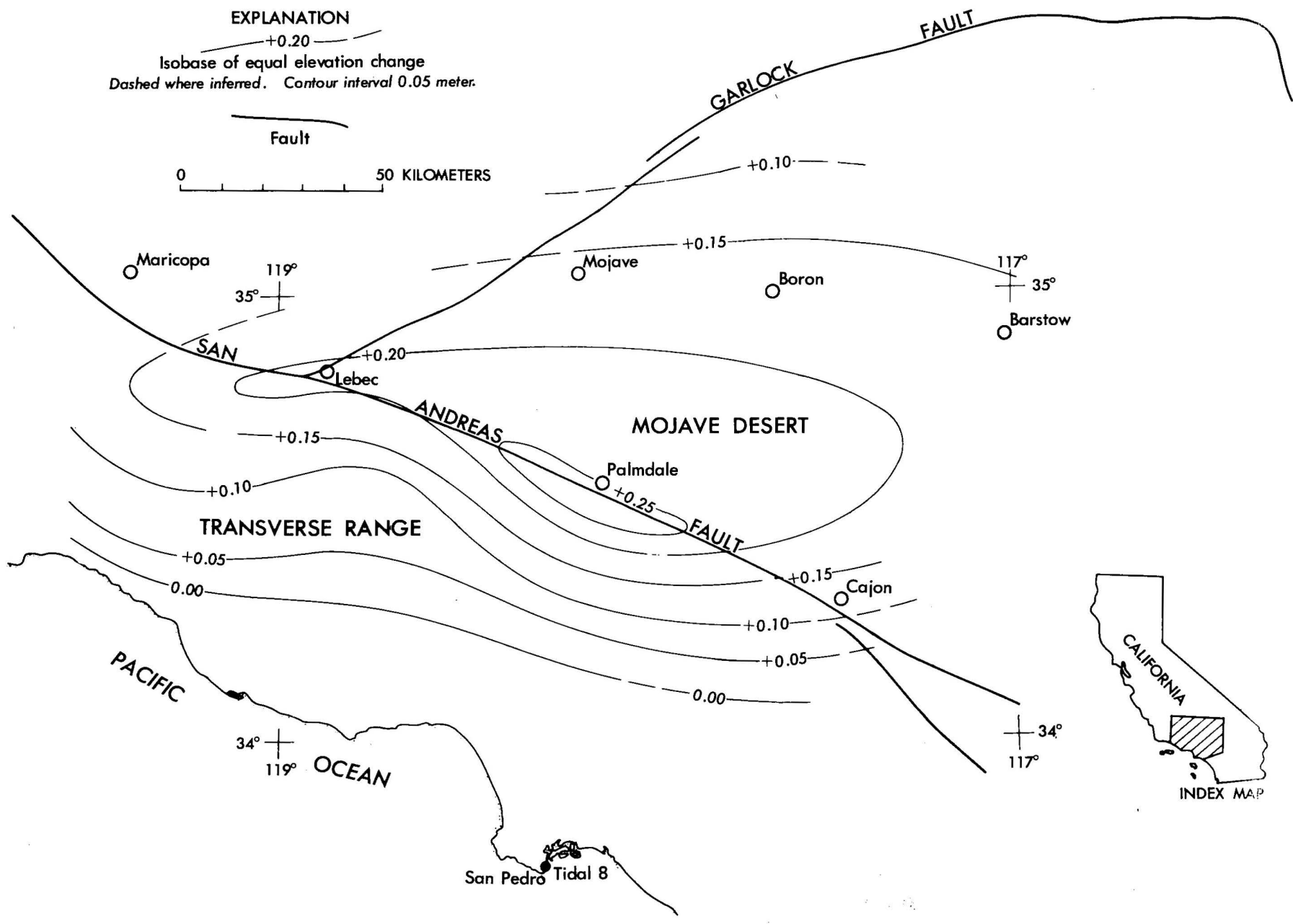

FIGURE 39.-Minimum uplift in the Transverse Range and adjacent parts of the Mojave Desert, California, during the period 1959-74 relative to benchmark Tidal 8 at San Pedro.

attention was devoted to the July 4-5, 1975, vigorous eruption of Mauna Loa after a 25 -year period of quiescence; the November 29, 1975, Kalapana earthquake, tsunami, and eruption, the largest seismic event in Hawaii since 1868; and the continued high level of thermal activity at Mount Baker, Wash.

Significant accomplishments of fiscal year 1976 activities included:

- Prediction of a major eruption of Mauna Loa Volcano before the summer of 1978, based on analyses of the volcano's past eruptive history and continuing inflation trend.

- Determination that the increased thermal activity at Mount Baker has not signaled an impending major eruption but that potential hazards of avalanches and mudflow remain.

- Preliminary evaluation of the feasibility of using bombs to divert potentially destructive lava flows in Hawaii.

- Establishment of a precisely measured triangle linking Mauna Kea, Mauna Loa, and Hualalal Vol- canoes to provide baselines for long-term, largescale crustal changes of the Hawaiian Island chain.

- Provision of expertise in monitoring eruptive activity at Cotopaxi Volcano, Ecuador, and Soufriere Volcano, Guadeloupe.

\section{Environmental Aspects of Energy}

The Environmental Aspects of Energy program acquires, interprets, and distributes geologic, hydrologic, geophysical, geochemical, and related information, which is required in analyzing and soving environmental problems associated with energyresource extraction and utilization and the planning, siting, and construction of facilities for energy conversion and distribution.

\section{ENERGY LANDS}

Studies conducted in the energy lands on the basis of environmentally oriented earth-science data seek to assist in the orderly, safe, and efficient develop- 

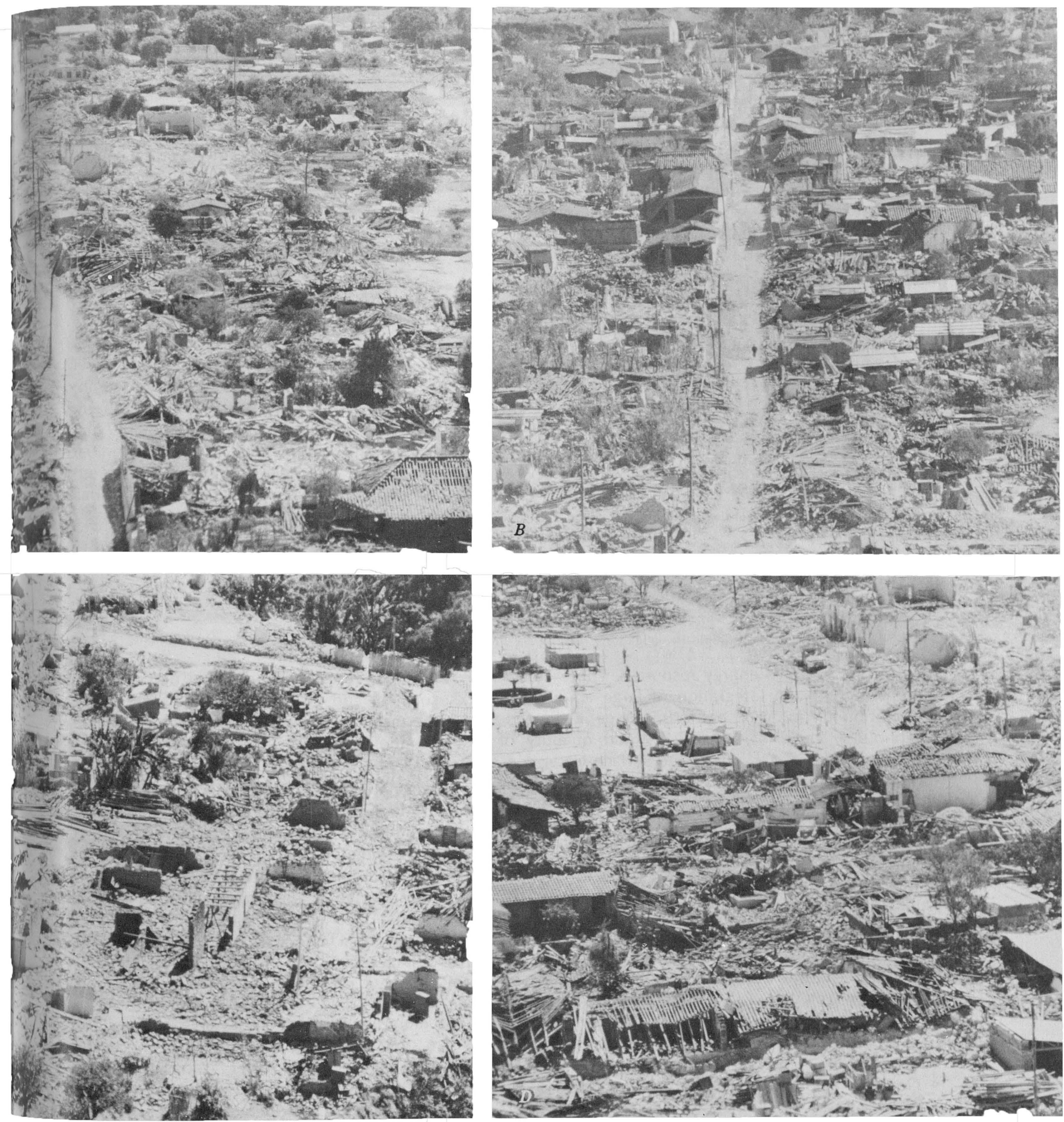

FIGURE 40.-Photographs of earthquake damage to structures in Guatemala towns of $A$, Joyabai, $B$, Compala, $C$, Tecpan, and $D$, San Martin Jilotepeque. 


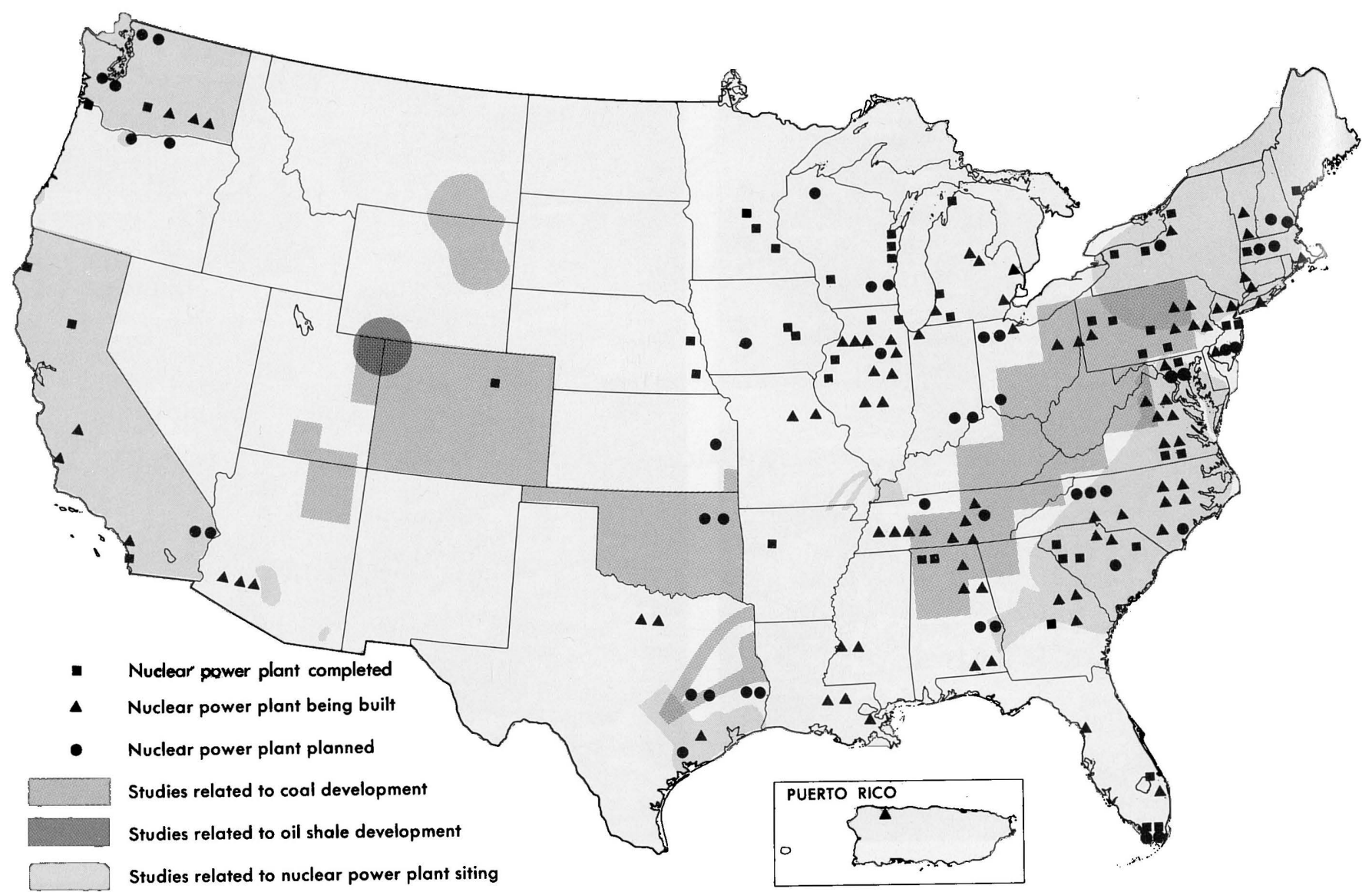

FIGURE 41.-Geologic investigations relating to environmental aspects of energy resource development.

ment of the Nation's energy resources. These contributions include the integration of large amounts of information on bedrock and surficial geology, geomorphology, geochemistry, quality and quantity of coal and overburden, ground- and surface-water conditions, and erosional and weathering patterns. They aid in making decisions on leasing of Federal lands, preparation of environmental impact statements, efforts by States in enforcement of health, safety, and environmental laws, and enactment of legislation to regulate and control mining and siting of energy facilities.

Program accomplishments during fiscal year 1976 included:

- Landslide-hazard maps of Washington, Butler, and Beaver Counties, Pa., emphasizing landslide deposits and their statistical density, landslide susceptibility, and areal quantitative distribution of landslides.

- Geologic maps of the northern part of the Powder River Basin showing areas of alluvial valley floors that are important for agriculture.

- A report of landslide occurrence and susceptibility in the western Powder River Basin.
- An energy-resources map of Colorado showing coal, oil and gas, uranium, oil shale, and geothermal areas and energy conversion and distribution facilities.

Future energy lands investigations include: studies of environmental factors associated with minirg of coal in Alaska; mapping of surficial and bedrock geologic units in the San Juan basin, New Mexico; compilation of geologic studies of the coal regien in North Dakota; environmental aspects of uranium mining; environmental disturbance caused by mining coal in the Eastern United States; and erodibil ty of surficial material as a constraint on the use of offroad vehicles.

\section{REACTOR SAFETY RESEARCH}

Accelerated construction of nuclear power reactors is part of most strategies for meeting the exparding demand for electrical power in the United States; about 100 have now been built or are under construction (fig. 41). The operational safety of these reactors is sensitive to geologic hazards such as fault movement, earthquake, volcanic eruption, ground deformation induced by man's activities, and other 
failures due to foundation and construction materials. These hazards are evaluated through the Reactor Hazards Research program and through a companion program sponsored by the Nuclear Regulatory Commission to meet specific needs arising from applications for reactor licenses. The Reactor Hazards Research program continues to look beyond immediate licensing of nuclear reactors to delineate regional geologic hazards that may pose constraints on reactor siting and to develop techniques needed in regional studies.

Program accomplishments during fiscal year 1976 included:

- Investigating the Charleston, S.C., earthquake of 1886 by studying the various structures in the Cenozoic Coastal Plain sediments and the underlying basement rock.

- Finding evidence of apparent tectonic quiescence in southeastern California where seismicity and late Quaternary faulting are rare.

- Documenting a major offshore fault that dominates the central California coast.

- Locating reverse faults near the Fall Line in Virginia and Georgia that suggest extensive faulting associated with older extensional structures.

- Evaluating the extent of Quaternary deformation in central Washington and along the east side of the Great Valley in California.

\section{NATIONAL ENVIRONMENTAL OVERVIEW}

As land development increases and as more of our natural resources are being extracted, it is important to have data on the constraints imposed by our physical environment. A series of U.S. maps at a scale of $1: 7,500,000$ are providing basic geologic data useful for management of energy, land, and mineral resources at the national level.

During fiscal year 1976, the following maps were completed:

- A preliminary landslide map (fig. 42).

- A map showing areas of sinkholes in limestone (karst topography).

- A map showing the location of nuclear reactor sites with a tabulation of the geologic setting at each site.

- A map showing the volcanic hazards within the United States.

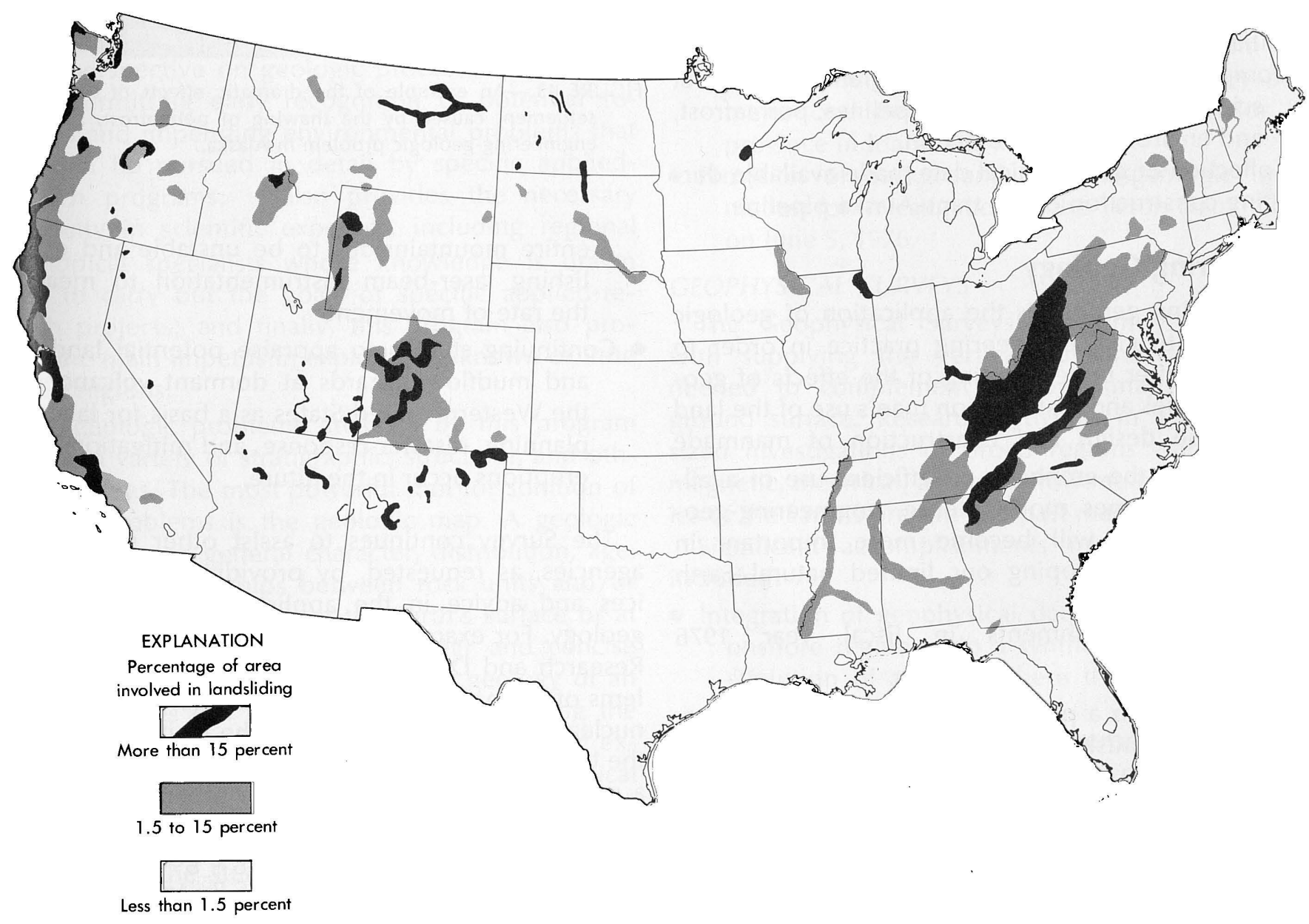

FIGURE 42.-Generalized map of areas affected by landsliding in the conterminous United States. 
Additional maps scheduled for preparation will cover the following topics: active faults, density of faults, surficial materials, water availability for cooling powerplants, swelling clays, radioactive-waste disposal sites, bedrock lithology, impact structures, coal strip mines, and strippable coal deposits.

\section{Arctic Environmental Studies}

The arctic and subarctic regions of Alaska pose special geologic problems in the development of natural resources, transportation systems, and urban areas, primarily because of the unusual environmentalgeologic conditions of permafrost or perennially frozen ground (fig. 43) along the routes of the transAlaska oil pipeline from Prudhoe Bay to Valdez and the arctic gas pipeline from Prudhoe Bay to Canada.

Accomplishments of the program during fiscal year 1976 included:

- Completion of reconnaissance engineering-geologic investigations of the Arctic Coastal Plain between Prudhoe Bay and the Canadian border.

- Completion of about two-thirds of the surficial engineering-geologic mapping of the central Brooks Range.

- Initiation of a seismic study in northeastern Alaska.

- Completion of an exchange program with Soviet scientists and engineers on pipelines, permafrost, and environmental protection.

- Collection of geotechnical data made available during construction of the trans-Alaska pipeline.

\section{Engineering Geology}

Engineering geology is the application of geologic knowledge to civil engineering practice in order to achieve a better understanding of the effects of geologic processes and materials on man's use of the land and on the design and construction of manmade structures. As the emphasis on efficient use of available land becomes more intense, engineering-geologic knowledge will become more important in planning and developing our limited natural Earth resources.

Major accomplishments in fiscal year 1976 included:

- Participating in a program to evaluate earthquakeinduced landslides in Guatemala and predicting subsequent failure of slopes weakened by the earthquake.

- Revising the standard classification chart of landslides and slope movement for use by engineers.

- Recognizing massive downslope movements in the 94 Rocky Mountain area of Colorado that cause

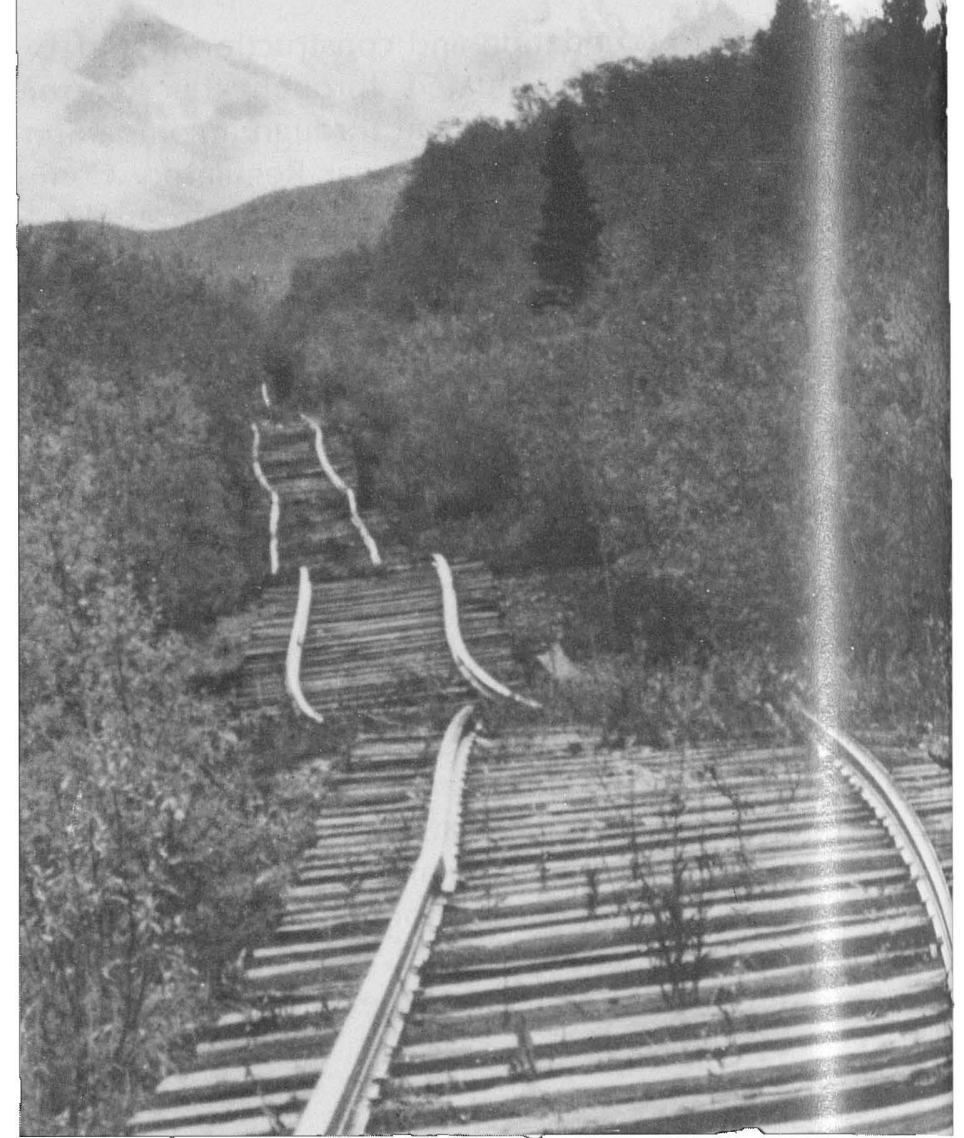

FIGURE 43.-An example of the dramatic effects of differential settlement caused by the thawing of permafrost, a serious engineering-geologic problem in Alaska.

entire mountainsides to be unstable and establishing laser-beam instrumentation to measure the rate of movement.

- Continuing studies to appraise potential landslide and mudflow hazards at dormant volcanoes in the Western United States as a basis for lanc-use planning, disaster response, and mitigation when eruptions occur in the future.

The Survey continues to assist other government agencies, as requested, by providing technical services and advice in the applications of engineering geology. For example, support is given to the Erergy Research and Development Administration on problems of radioactive-waste disposal and on condu ting nuclear tests. A treaty between the United States and the U.S.S.R. provides that, when one country concucts a peaceful nuclear explosion, the other country s to be represented at the site to verify certain aspec $s$ of the project. The Survey is training a geologic tean to be ready to travel to the U.S.S.R. to observe the construction of explosive emplacement holes and to verify the geologic data of the site. 


\section{Regional Mapping and Analysis}

The Regional Mapping and Analysis program provides baseline geological, geophysical, and geochemical information. Its objective is to increase and refine fundamental knowledge about the geologic framework of the Nation as necessary to support the current applied-research programs and help in the early recognition of future earth-science problems and resource opportunities. The program determines the distribution and properties of rocks and other geologic materials, investigates the relative and absolute ages of earth materials, and investigates the processes responsible for the formation, modification, and distribution of materials within the Earth and on its surface.

\section{REGIONAL GEOLOGY}

An understanding of the regional geologic framework of the Nation is fundamental to assessing the country's land, mineral, and energy resources. The Regional Geology program is designed to provide this foundation and is therefore one of the most vital programs of the Survey. The program provides regional synthesis and scientific studies that, in the long run, may be of greater significance than shortrange mission objectives. The program provides a broad perspective on geologic processes and conditions, permitting early recognition of potential resources and impending environmental problems that can then be pursued in detail by specific appliedresearch programs; it also provides the necessary continuity in scientific expertise, including regional and topical specialists whose knowledge is drawn upon to carry out the goals of specific applied-research projects; and finally, this program also provides the main impetus in exploring unknown or little known regions.

The geologic problems attacked by this program demand a variety of stratigraphic, structural, and other techniques. The most powerful tool for solution of geologic problems is the geologic map. A geologic map displays the general character, distribution, age, and spatial relationships between rock units and/or surficial deposits exposed at the Earth's surface or at depth below the surface. It is a clear and concise statement of what is known about the geology of an area. Inferences can be drawn from it regarding the geologic history, the three-dimensional form and extent of rock bodies, and the physical and chemical processes that have shaped and modified them. A geologic map can be used directly for land-use planning and for the studies of mineral and energy resources. Geologic maps ranging in scale from $1: 2,500,000$ to $1: 20,000$ and related reports are major products of this program.
The selection of geologic problems attacked by the program is guided by relevance to environmental and resource problems, by the needs of other Federal and State agencies, and by scientific importance. Through cooperative agreements with several States, the program furnishes Statewide geologic mapping and analysis.

Program accomplishments for fiscal year 1976 included:

- Recognition that the inner limit of coastal plain sediments along the middle Atlantic seaboard may be a zone of faulting.

- Publication of an analysis of the tectonic history of southwestern New England.

- Interpretation of the bends in the Appalachian Mountain chain as resulting from opening of the early Atlantic Ocean 600-800 million years ago.

- Development of a hypothesis that a hot spot below the crust explains the presence of young volcanoes and faults in Idaho, Nevada, Utah, Wyoming, and western Oregon.

- Identification of active faults, volcanic hazards, and landslide and rockfall hazards in Idaho and California.

- Discoveries of oil, gas, coal, limestone, gravel, copper, and titanium occurrences. Data from the program served as the basis for discovery of a major coal field in Kentucky and a major oil province in Idaho and Wyoming.

- Provision of background regional-geologic information for investigation of the Teton Dam failure on June 5, 1976.

\section{GEOPHYSICAL SURVEYS}

The Geophysical Surveys program is concerned with supplying the vertical subsurface dimension needed to complement geologic mapping of the ground surface. Research activities in 1976 emphasized investigations of broad regions using gravity, magnetic, electrical, and heat-flow methods and studies of the Earth's present and past magnetic field.

Significant accomplishments in fiscal year 1976 included:

- Integration of geophysical data from offshore and onshore regions into a synthesis of the tectonic evolution of an area where three plates of the Earth's crust are converging.

- Interpretation of stripe-shaped aeromagnetic anomalies of the California coast as resulting from a plate of the Earth's crust plunging beneath a large mass of sheared rocks.

- Development of computer programs for efficient analysis of electrical-resistivity survey data from regions of ground-water and geothermal resources. 
- Confirmation that self-potential electrical anomalies are sometimes associated with local eruptive centers of volcanoes in Hawaii.

- Determination, based on magnetic studies of ancient lake sediments, that the Earth's magnetic field was only one-tenth as strong as the presentday field during a brief period 700,000 years ago when the magnetic field reversed its direction.

- Identification, based on geomagnetic observatory data, of large 25-year variations of the Earth's magnetic field caused by processes active within the Earth's core.

\section{GEOCHEMICAL SURVEYS}

Geochemical Surveys provide data on variations of chemical elements in rocks, soils, and vegetation. This information establishes baselines against which to compare future observations and is used in pollution control, environmental health research, and mineral resource evaluations. Continuing activities are the development of statistical anaytical methods, compilation of rock-analysis data, operation of a geochemicaldata system, investigation of trace elements in the human food chain, and studies of urban-area geochemistry.

Accomplishments during fiscal year 1976 included:

- Publication of reports on trace-element concentrations in the plants and soils of the State of Missouri.

- Demonstration that natural vegetation is a pollution indicator. Studies of phosphate-processing plants and coal-burning powerplants indicate that trace metals from the industrial facilities are being concentrated in the surrounding vegetation.

- Confirmation of the presence of anomalous levels of plutonium in surface soils downwind from the Rocky Flats Nuclear Weapons Plant, Colorado. These studies, in cooperation with the Colorado Department of Health, have resulted in public reexamination of the State standard for plutonium in soil.

\section{DATING AND CORRELATION-PALEONTOLOGY AND STRATIGRAPHY}

The Paleontology and Stratigraphy program compiles and interprets basic data on the distribution of fossils (fig. 44) within the stratigraphic column. The data are used to analyze the age, correlation, and paleoenvironment of sedimentary rocks, to study evolutionary trends of species, and to provide a framework for interpretation of geologic history. Research activities are directed toward developments of new principles and techniques. The stratigraphic and paleontologic information directly supports mission pro- which to respond to future missions that require an understanding of the history and geologic framework of the Earth.

Highlights of the program during fiscal year 1976 included:

- Developing a method of petroleum exploration using the color of fossil conodonts, a small toothlike or platelike structure composed of apatite, to tell the degree to which sedimentary rocks have been heated.

- Showing that sediments in the lakes of Minnesota have changed in response to human settlement and the introduction of pollutants.

- Refining the dates and history of delta building, and shoreline retreats and advances in the Atlantic Coastal Plain to aid in the search for offchore energy resources.

\section{DATING AND CORRELATION-ISOTOPE GEOLOGY}

The Isotope Geology program investigates, develops, and utilizes methods for determining ag of rocks and minerals, geochemical methods for sudying geological processes, and neutron-activation methods of field chemical analysis for minera exploration. This work provides the basic data necessary for understanding Earth history and the geclogic processes that have been active in shaping the Earth for the last 4.5 billion years and for solving a rreat variety of problems, ranging from mineral exfioration to nuclear-plant site evaluation, in which krowledge of the age of rocks or geologic events is esential.

Highlights of the program during fiscal year 1976 included:

- Determining that the age of the beginning of itchblende mineralization in a mine near Gillup, N. Mex., is probably $159,000 \pm 30,000$ years ago, by far the youngest age for known uranium mineralization in the United States.

- Initiating the use of thermoluminescence or carbonate minerals. This technique, which halready been shown useful in dating volcanic rocks 5,000 to 500,000 years old, should rove invaluable in studies of geothermal resotirces, reactor hazards, earthquake hazards, and iadioactive-waste disposal.

- Exploring the potential of using the isotopes cf hydrogen and oxygen in well water near the Oroville Dam, Calif., in the prediction of 6 arthquakes. Anomalies of deuterium, a heavy isotope of hydrogen, were observed starting about 3 days before two earthquakes in Septe:nber 1975 and at the same time as three earthquakes in January 1976. 


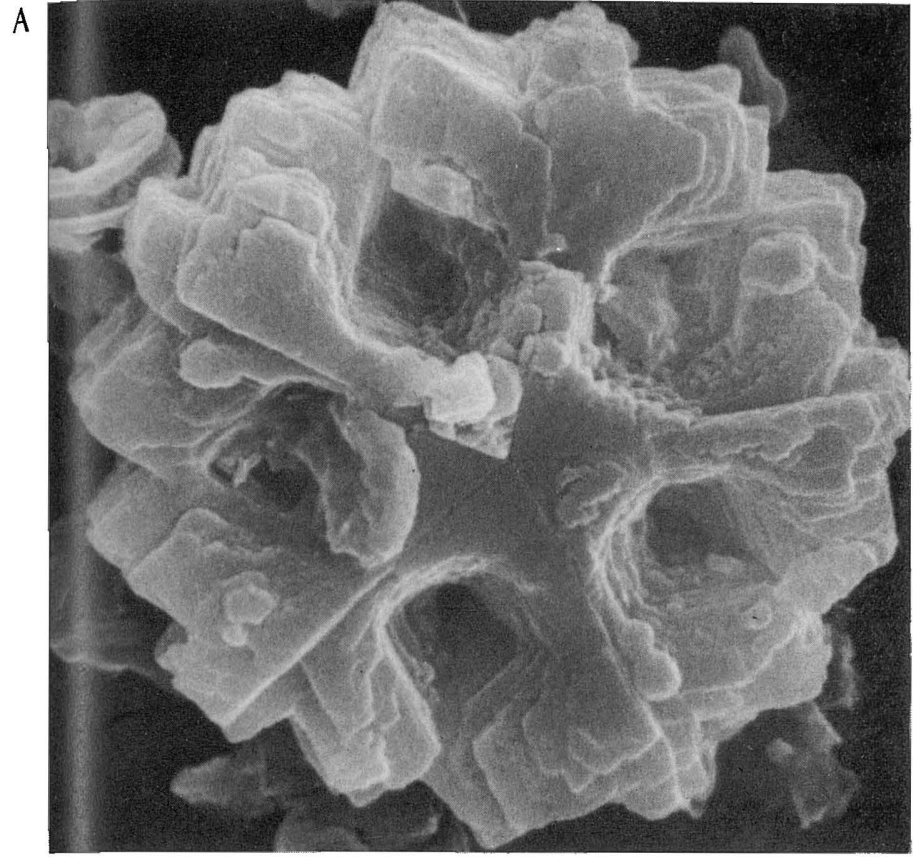

B

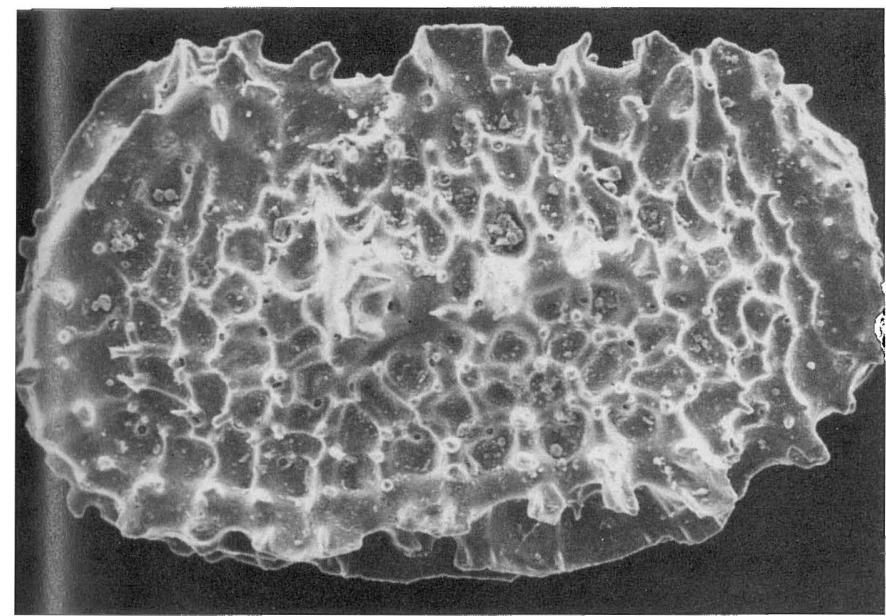

- Developing a field radioactive activation probe for drill holes that permits hydrogen and aluminum analysis of coal in the ground.

- Dating a diamond-bearing kimberlitic pipe in southern Wyoming at $377 \pm 36$ million years old.

- Dating gneiss in the Upper Peninsula of Michigan at 3,500 million years old. Previously rocks of this age in the Lake Superior region had been found only in southwestern Minnesota.

\section{GEOLOGIC PROCESSES}

The Geologic Processes program studies the fundamental properties of rocks and minerals and the fluids associated with them in nature. When these properties are related to the temperatures and pressures at the time of the rocks' and minerals' origin, useful geologic thermometers and barometers result.

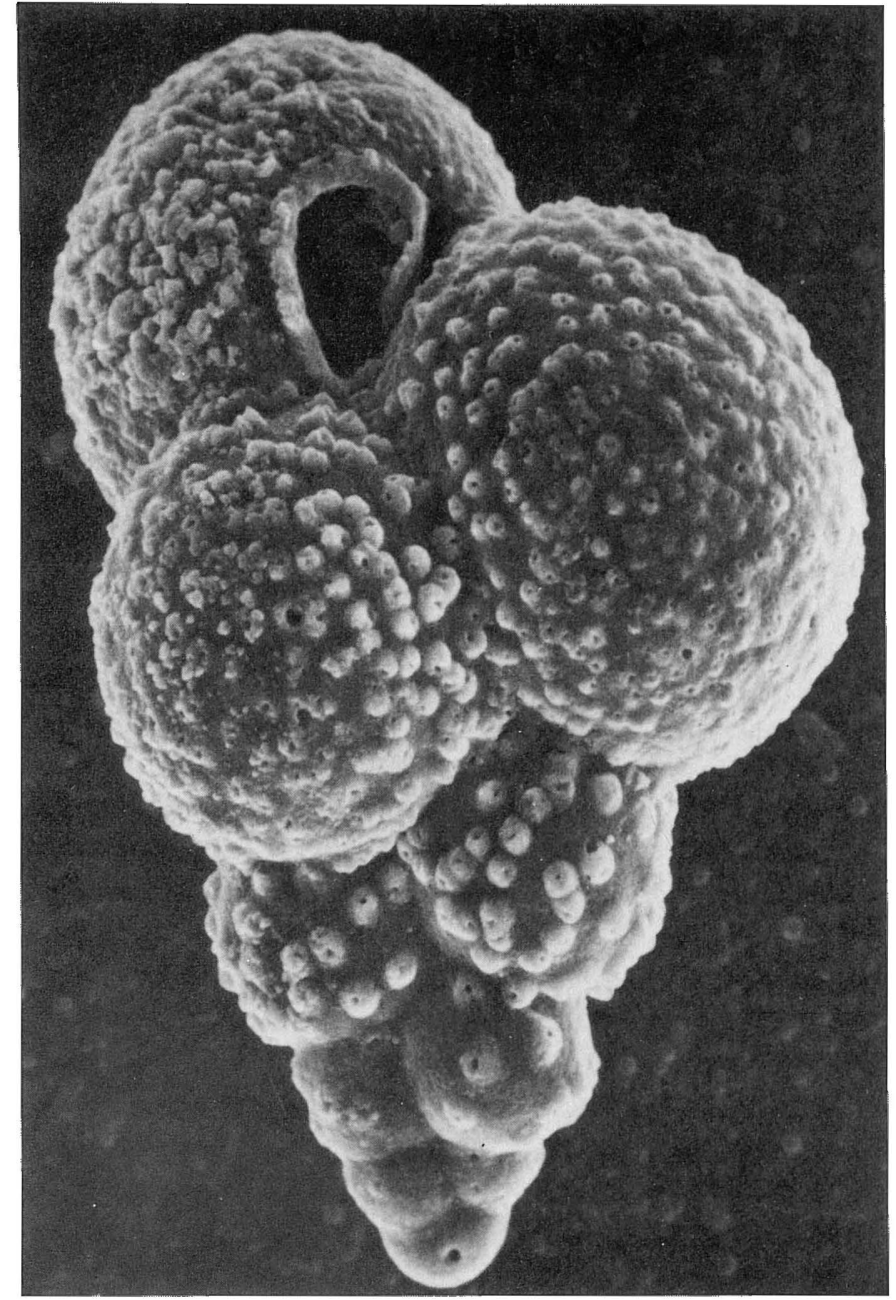

FIGURE 44.-Three scanning electron photomicrographs representing three important groups of microfossils: $A$, a platelet from a planktic calcareous alga subspecies, Pemma basquense basquense; $B$, an ostracode (a microscopic crustacean) female of Acetoleberis plummeri; and $\mathrm{C}$, a foraminifer (shelled protozoan), Guembelitria cretacea.

Current studies of the relationship of volcanic activity to plate tectonics, the significance of chemical differentiation in igneous rocks and in ground water, and the mechanisms of mineral formation in rocks will contribute to future resource evaluations of many types of mineral deposits. Some criteria for the selection of appropriate sites for the disposal of radioactive wastes, the nature of the release of toxic chemicals into mine drainage, and a basis for economical solution mining may be forthcoming from studies in progress.

Accomplishments for fiscal year 1976 included:

- Using a sulfate-water isotope geothermometer to calculate subsurface temperatures for many geothermal systems. This work resulted in a considerable increase in indicated reserves of geothermal energy and a better estimate of the importance of the mixing of subsurface waters. 
- Measuring the volume of complex brine systems in geothermal reservoirs to gain useful information for engineering purposes and model studies.

- Continuous monitoring of the chemistry and temperature of fumaroles on Mount Baker, Wash., by using electrochemical sensors and radiotelemetry.

\section{MINERAL RESOURCE SURVEYS}

\section{Mineral Resource Assessment-Land}

During 1976, the Survey conducted mineral resource assessments of Federal lands administered by the Department of the Interior and other agencies, lands for which congressional actions require evaluation of mineral potential before their reclassification, and non-Federal lands having high potential for discovery of mineral resources. Lands under study as a result of congressional actions include those proposed for withdrawal from mineral or other development as wilderness areas or under Section 17(d)(2) of the Alaskan Native Claims Settlement Act (Alaskan D-2 lands). Studies of Department of the Interior lands were conducted in Indian reservation lands and in the California desert areas. Areas judged to have high mineral potential were under study in Alaska (fig. 45) and the conterminous United States (fig. 46) as part of continuing systematic investigations of the mineral resource endowment of the Nation.

\section{WILDERNESS AREAS}

Areas of wild unspoiled beauty are recognized as a national heritage worthy of preservation, but some of these areas also may host future supplies of critically needed mineral resources. More than 12.5 million hectares ( 31 million acres) have been proposed for wilderness status by Federal agencies since passage of the Wilderness Act in 1964. The Congress requires an assessment of the resource potential of proposed wilderness areas before granting wilderness status and the concomitant prohibition of mining activity. To date, the Survey, in cooperation with the Bureau of Mines, has completed mineral surveys of 7.5 million hectares (18.5 million acres) of land proposed for designation as wilderness areas.

Accomplishments for fiscal year 1976 included:

- Publication of five wilderness area assessments (Scapegoat Wilderness additions, Montana; Scotchman Peak study area, Montana-Idaho; South Warner Wilderness, California; Cloud Peak additions, Wyoming; and Bradwell BaySopchoppy, Florida).

- Location of significant mineralization in the Scotchman Peak Wilderness area, Montana-Idaho. This mineralization has a surface geochemical expression and geologic setting that suggest the possible presence of a strata-bound copper deposit similar to the one now being developed 3.2 kilometers $(1.9$ miles) to the east.

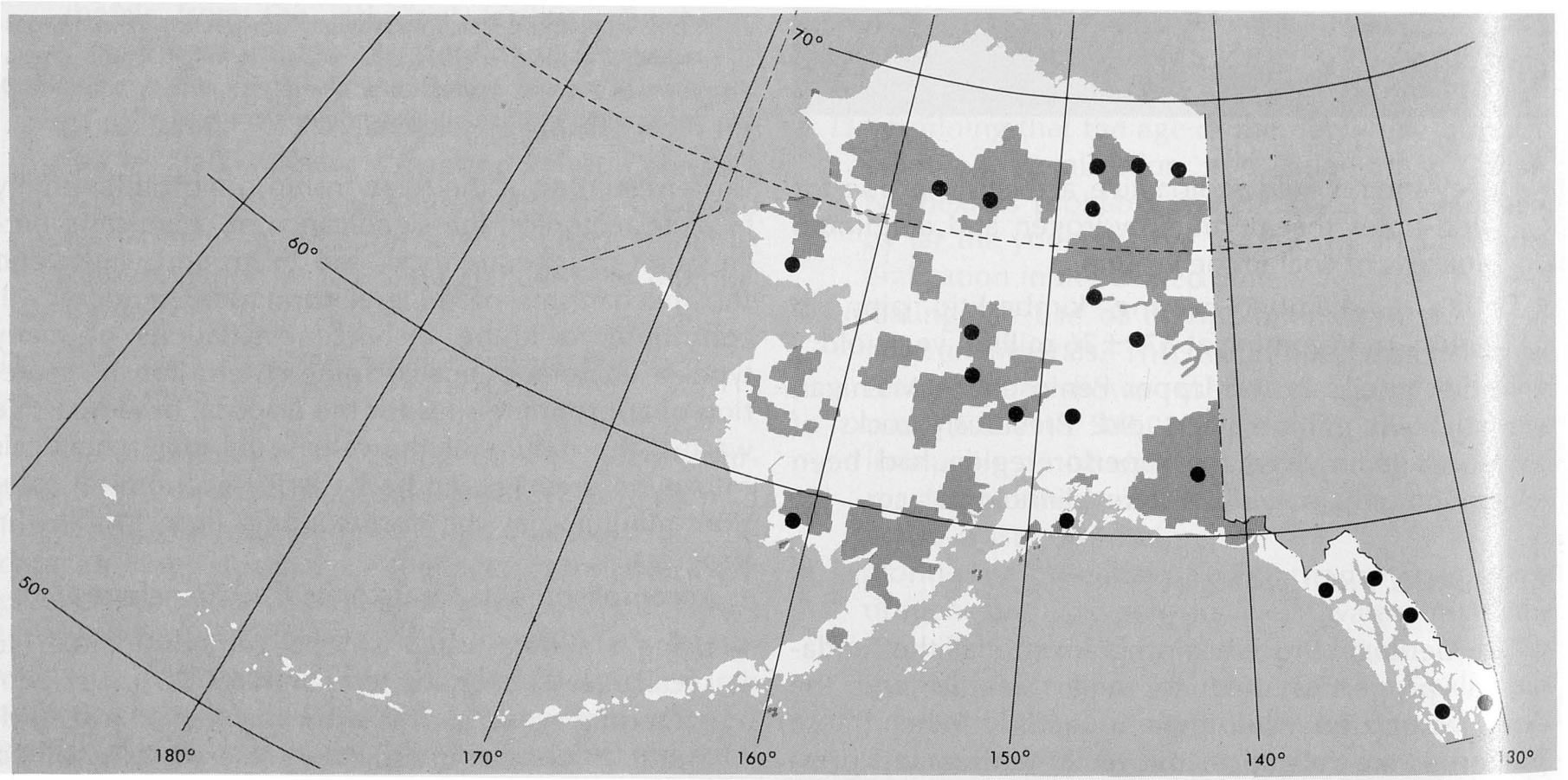




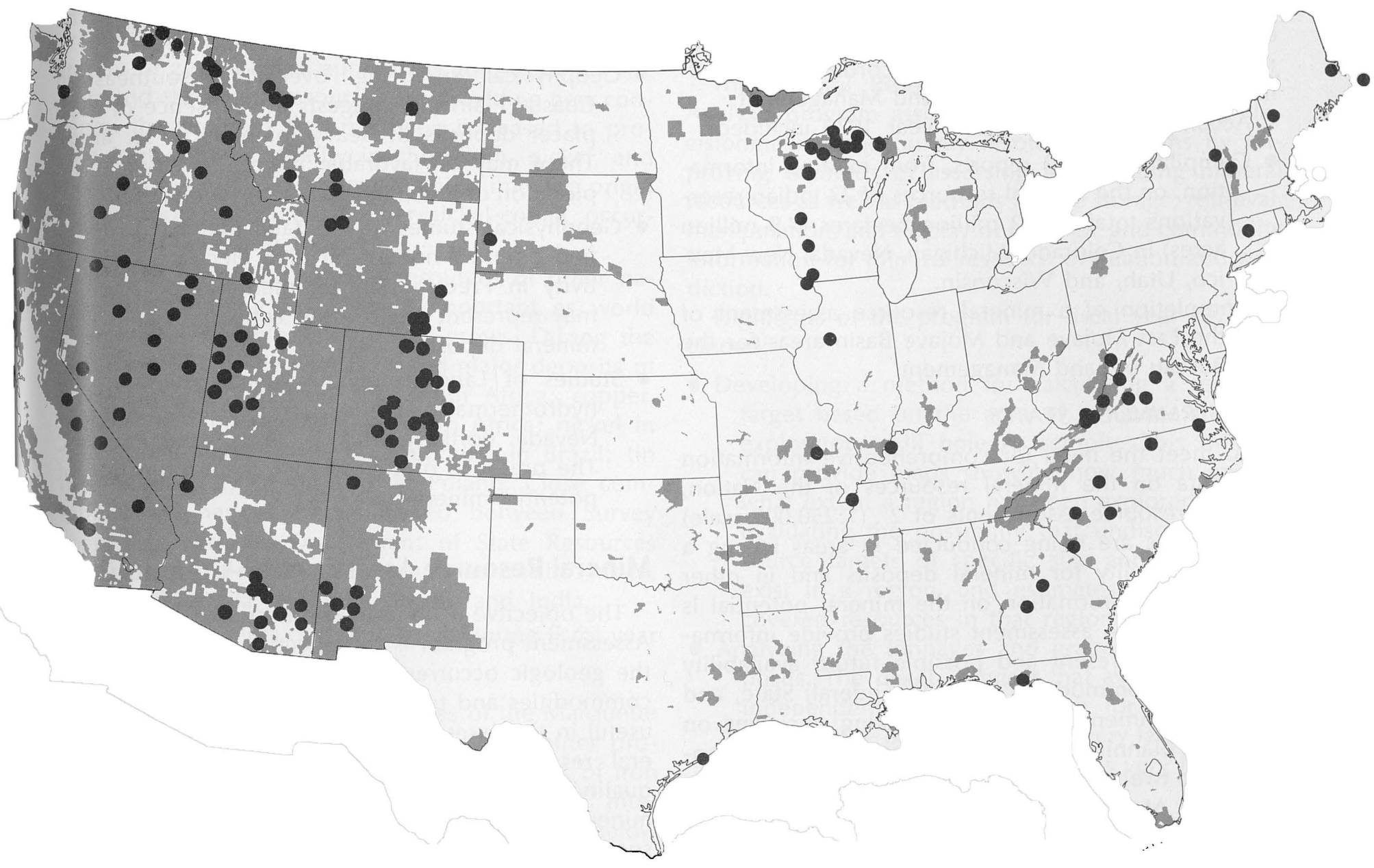

FIGURE 46.- Map of the conterminous States showing Federal lands and Indian reservations (shaded) and location of fiscal year 1976 Mineral Resource Survey projects.

\section{ALASKA D-2 LANDS}

The D-2 lands of Alaska are specified in the Alaska Native Claims Settlement Act as national interest lands for the National Parks, National Wild and Scenic Rivers, National Forest, and National Wildlife Refuge systems. Mineral assessment studies of these lands, which total 33.6 million hectares (83 million acres), are being conducted in cooperation with the Bureau lof Mines under the Survey's regional Alaska Mineral Resource Assessment program. Final determination of the classification and possible inclusion of the D-2 lands in the four national systems is scheduled to be made by Congress in December 1978.

The accomplishment for fiscal year 1976 was:

- Completion of mineral resource assessment for approximately one-third of the Alaska D-2 lands area.

\section{ALASKA}

An intensive systematic study of Alaska's mineral potential is being conducted under the Survey's Alaska Mineral Resource Assessment program. This program (Cobb, 1976) involves systematic mapping, field sampling, geostatistical compilations, and mineral economic modeling of 1:250,000-scale quadrangle areas covering an average of about 17,000 square kilometers $(6,500$ square miles) and publication of the resulting information and data in resource map folios containing a text and geologic, geochemical, and geophysical maps, interpretive maps based on Landsat satellite imagery, and maps showing the location of known and potential mineral resources.

Highlights of the program during fiscal year 1976 included:

- Completion of the fieldwork for four quadrangles. Fieldwork is in progress in 12 additional quadrangles and is scheduled in 18 others.

- Publication of the Nabesna quadrangle folio.

\section{INDIAN AND DESERT LANDS}

Joint Survey and Bureau of Mines mineral resource assessments of Indian lands include studies made from compilations and interpretations of published and unpublished reports and records and from re- 
connaissance field examinations. Studies of California desert lands consist of mineral resource summaries made from existing maps and records of areas administered by the Bureau of Land Management.

Accomplishments for fiscal year 1976 included:

- Compilation of 12 reports, from existing information, on the mineral resources of 23 Indian reservations totaling 3.2 million hectares $(7.9$ million acres) in Colorado, Michigan, Nevada, New Mexico, Utah, and Wisconsin.

- Completion of a mineral resource assessment of the East Mojave and Mojave Basin areas for the Bureau of Land Management.

\section{CONTERMINOUS STATES}

To meet the need for comprehensive information and data on the mineral resources of the Nation, mineral resource assessments of $2^{\circ}(1: 250,000$-scale) quadrangles are being conducted in areas having a high probability for mineral deposits and in other areas where information on the mineral potential is required. These assessment studies provide information on the present and possible future availability of mineral commodities and give Federal, State, and local governments a basis for making decisions on land-use planning. In 1976, studies were being conducted in twelve $2^{\circ}$ quadrangles in Arizona, Colorado, Missouri, Montana, North Carolina, Oregon, Utah, and Washington. Detailed geologic mapping at larger scales is being done to support resource assessment investigations and to provide an improved understanding of the origin and occurrence of mineral resources. Geophysical mapping, in mineral resource study areas, provides data on gravity, magnetic, and electrical properties of rocks to outline structures and mineral deposits below the Earth's surface.

Highlights and accomplishments of the program in fiscal year 1976 included:

- Publication of a map showing potential for copper mineralization in the Tucson urban area. This map adds to previously published contributions resulting from the Survey's mineral resource studies that provide Arizona State and local agencies with information for land-use planning.

- Publication of a map outlining the occurrence of platinum-group metals in the Medford-Coos Bay, Ore., $2^{\circ}$ quadrangle. Studies of mineral potential in this area are contributing information on scarce mineral commodities.

- Geophysical mapping in southwest New Mexico that indicates that Basin and Range structures of tilted fault blocks unexpectedly persist northwestward and northward beneath the cover of fluoride mineralization and thermal springs in the area supports this interpretation.

- Geophysical surveying over the southeastern Coastal Plain that suggests the presence of local placer deposits of heavy minerals in six areas. These may be favorable targets for surface exploration of ilmenite, zircon, and monazite.

- Geophysical studies in Montana that have identified a buried horizon of high electrical conductivity in Precambrian sedimentary rocks which may represent a pyrrhotite zone associated with mineral deposits.

- Studies of Landsat imagery that show areas of hydrothermally altered rock in Alaska, Arizona, Nevada, northern Mexico, Brazil, and Pakistan. The presence of altered rock is an indication of potential mineralization.

\section{Mineral Resource Assessment-Commodity}

The objective of the Mineral Resource Commodity Assessment program is to collect data worldwicle on the geologic occurrences and availability of mineral commodities and to develop new geologic concepts useful in the assessment of and exploration for mineral resources. Information on location, quantity, quality, and geologic characteristics of deposits of 43 mineral commodities is analyzed by mineral resource specialists. New trends in exploration by industry are of particular interest to the specialist as mineral potential is being assessed in new regions and in new geologic settings.

An important group of mineral commodities (aluminum, chromium, cobalt, nickel, manganese, and platinum) is presently imported. Mineral comr odity specialists provide resource estimates and long-:ange forecasts of supply of these critical minerals. Emphasis is given to the study of alternative domestic sources of materials that may provide future options for domestic production in the event of disruption of foreign supplies, nationalization, or international cartel actions and attendant large price increases.

Another important group of minerals (copper lead, zinc, molybdenum, fluorspar, and iron) is avcilable domestically, but known deposits are being depleted and must be replaced by new discoveries. These mineral commodities and others, such as barite, bentonite, niobium, and silver, are essential in energy production, and the demand for them will increase greatly in the next decade as the United States strives for self-sufficiency in energy. Specialists provicie resource estimates, long-range projections of mineral supply from known deposits, and an estimate of future discovery requirements for these cómmodities. 
The Mineral Resource Commodity Assessment program has been greatly expanded during the past year: studies of geostatistical approaches to copper, nickel, zinc, and chromium resources are providing new concepts; the program staff has been increased to provide long-term continuity in chromium, nickel, and mercury studies; and an investigation into the origin of sea-floor manganese-copper-nickel-cobalt occurrences has been initiated.

Knowledge of the mineral resources of other nations is becoming increasingly important as world competition for mineral supplies grows. During the past year, Survey geologists visited major deposits of chromium in Greenland and South Africa; copper, manganese, and platinum in South Africa; nickel in New Caledonia and Canada; niobium in Brazil; tin in Southeast Asia; and zinc in Poland. Close communication has been established between Survey specialists and the Department of State Resources Attaché and Reporting Program in South Africa, Brazil, Venezuela, Australia, Japan, and India.

Accomplishments of the program during fiscal year 1976 included:

- Estimating the iron-ore resources of the Marquette Range, Mich., with the aid of a computer program that calculates the number of tons of iron formation within specific limits of grade, mineralogy, grain size, thickness, and depth below the surface.

- Correlating the fluorspar districts in the Rocky Mountain region with a large rift zone that extends from Mexico to Canada. This correlation indicates that the rift zone may contain undiscovered fluorspar deposits.

- Describing the geologic character, age, and origin of U.S. ball clay and fireclay cieposits used for making high-grade refractories.

- Determining from studies of domestic copper resources that, by the year 2000, output, based on projected production rates, will supply only one-half of the probable annual demand. The study also indicates that additional supply will have to come from new discoveries or imports.

- Compiling a report on the mineral and water resources of the State of Wisconsin.

- Finding that important amounts of the platinumgroup metals are present in the Brady Glacier, Alaska, nickel-copper deposit.

- Developing computer-generated contour maps showing the thickness and grade of the kaolinite and bauxite deposits in Georgia. These maps are useful in determining the kaolin and aluminum resources of the State.

\section{Mineral Resource Information Systems and Analysis}

The Mineral Resource Information Systems and Analysis program assists national mineral policy decisionmaking and Survey resource programs by improving methods of assessing and locating mineral resources as well as methods for the storage, retrieval, manipulation, and display of geologic and commodity information for mineral resource evaluation and prediction.

Highlights of the program for fiscal year 1976 included:

- Developing a method for calculating a resource target based on the area of influence from an exploratory drill hole or sample. This method can provide maps showing how much and to what extent a region has been explored, graphs evaluating the possibility that undiscovered resource targets of specific size and shape may exist in a region, and estimates of the undiscovered resources in that region.

- Analyzing the tonnages and grades of nickel deposits. The results suggest that average grade is independent of total tonnage for sulfide- and laterite-type deposits and that very large tonnage low-grade deposits are as rare as very large tonnage high-grade deposits.

- Comparing and contrasting the efficiency of resource programs in terms of existing public policies for the mineral industries of Canada and the United States.

- Assessing the available supplies of materials required by the energy industries. Demand shows that significant increases in aluminum, barite, bentonite, iron, and tungsten production above 1975 levels will be needed to satisfy the demands of the energy industries.

- Developing a computer program called Geologic Retrieval and Synopsis Program (GRASP) that now permits interactive access to earth-science data banks.

\section{Resource Processes Research}

The Resource Processes Research program develops knowledge of the fundamental mechanisms by which minerals are deposited in concentrations large enough to become resource materials. This knowledge is essential for success in the assessment of, or exploration for, minerals. Observation, measurement, and analysis of the geologic, geochemical, and geophysical characteristics of known mineral occurrences aid in identifying resource exploration targets. Data obtained from a variety of field and laboratory studies 
range from the documentation of mining districts and mineral belts and the collection of relevant geologic observations, maps, and samples to experimental studies of the physical and chemical properties of minerals and mineralized rocks. An important goal of the program is a working model that permits predicting as well as pinpointing and evaluating such mineral concentrations.

The scientific insights and technology of the Resource Processes Research program provide the basis for resource assessment of domestic lands; evaluation of global availability of critical mineral commodities; and development and use of computerized resource-information files and resource-analysis capability.

Highlights and accomplishments of the program for fiscal year 1976 included:

- Resource evaluation, based on geologic mapping near Tucson, Ariz., that shows that an intrusive rock is the source of the base metal deposits formed in adjacent rocks.

- Age determinations of alunite from the Cordero mining district, Nevada-Oregon, that show that eruptive and tectonic features developed in a caldera fracture system that preceded ore deposition by as much as 4 million years. Late hydrothermal solutions made use of the caldera ring fractures as conduits and the adjacent sediments as the host for mercury deposition.

- Geologic, mineralogic, and stratigraphic studies at Kennecott, Alaska, that strongly suggest that the copper lodes were formed in sediments of the salt-flat type underlying impervious shallow marine limestone. Copper was leached from subjacent greenstones by meteoric water that migrated into the salt-caliche aquifer where the copper was precipitated.

- Discovery that the ore minerals in organic sediments include sphalerite (ZnS) found in substantial amounts in the Illinois Basin coal beds. U.S. zinc production could be increased by 25 percent if this sphalerite were recovered as the coal is mined, Another discovery is manganese enrichment in carbonate-cemented rocks overlying petroleum reservoirs. These manganese materials luminesce and can be detected by airborne technology when present in excess of 1,500 parts per million manganese.

- Identification of oxygen stable isotopes in fluid inclusions in sphalerite crystals ( $\mathrm{ZnS}$ ) at Creede, Colo., that indicate that a very complex plumbing system formed this ore deposit. This information may provide guides for a search for exten-

\section{Resource Techniques in Geochemistry and Geophysics}

A fully effective Mineral Resource Assessment program depends, in part, on improved geochemical and geophysical information and methods, which augment geologic information and assist in identifying surface mineral anomalies and buried or low-grade mineral concentrations. Until recently, worldwide efforts to discover mineral deposits have concentrated on deposits exposed at the surface or concealed by only a thin veneer of surficial material. Consequently, geochemical techniques for the detection of buried mineral deposits are just beginning to be developed. As the more easily found, near-surface ore bodies are depleted in the relatively near future, the hardto-find concealed deposits become the necessary targets of exploration. The surface parameters characterizing an exposed ore deposit differ from those describing concealed or new types of mineral deposits. Yet, established and well-proven geochemical techniques employed in the detection of exposed deposits are still being used in this country in the search for concealed deposits. New innovative approaches leading to the discovery of concealed deposits are imperative if the United States is to remain viably independent of foreign sources for mineral comnodities. An intensive research program is needed to assure that adequate exploration methods will be available to find concealed deposits for future reseives.

Program highlights and accomplishments for fiscal year 1976 included:

- Reconnaissance geochemical surveys in mountainous areas of Alaska. The surveys have shown that heavy mineral concentrates, secondary manganese-iron oxide, and organic-rich materisls are effective sample media to test stream-drainage headwater areas of 5 to 13 square kilometers (1.9 to 5 square miles).

- Determination that oxalic acid leachates of rocks, soils, and stream sediments from arid climates of the Southwest have proven effective in cetecting mineral-bearing environments underlying volcanic rocks.

- Studies of 23 elements in cores and drill cuttings from the Kalamazoo porphyry copper deposit, Arizona, that delineated five geochemical zones spatially related to the ore deposit. The extent of the outermost zone, at least 1,000 meters $(3,280$ feet), suggests that concealed deposits can be detected at the surface even though buried to that depth.

- Demonstration, using computer technique and data on the Coeur d'Alene district, Idaho, that several volatile elements (antimony, arsenic, sul- 
fur, tellurium, cadmium, and lead) formed substantial halos around the stock that intruded a preexisting mineral belt. Production data show that 85 percent of the Coeur d'Alene ores were derived from the halo area but that only one-half of the reconstructed halo area has thus far been prospected.

- Analyses of galena from Leadville, Colo. These analyses have shown that molybdenum, tin, tungsten, and indium increase toward the center of mineralization and that radiogenic lead, silver, and gold decrease.

- Analyses of soil and rock samples from northeastern Minnesota that show a 29-km-long (18mile) linear nickel-copper anomaly within the Duluth gabbro. The lineament is believed to lie along a major fracture zone having large displacement.

- Development of new chemical methods to determine trace elements of oxalic acid leachates. A quantitative determination method for phosphorus oxide $\left(\mathrm{P}_{2} \mathrm{O}_{5}\right)$, and a new sequential fractionation procedure to determine trace elements in manganese oxides, amorphous iron oxides, crystalline iron oxides, sulfides, and silicates are among recent advancements in geochemical research.

- Computer interpretation of satellite data that resulted in defining a high-amplitude negative anomaly of probable crustal origin in western Africa, possibly related to mineral deposits.

- Establishment of a modern physics laboratory in Denver to make experimental and theoretical studies of electric, dielectric, and elastic properties of rocks and soils to lead to a better understanding of the physical processes involved in mineral deposition and to assist in interpretation of geophysical data.

\section{ENERGY RESOURCE SURVEYS}

\section{Coal}

The Coal Resources Investigation program appraises the amount and quality of coal resources by conducting research to determine the physical and chemical characteristics of coal; by collecting, analyzing, and evaluating geologic, geochemical, and mining data to provide information for the selection of future mine sites; by developing and utilizing geophysical techniques to aid in assessing the thickness, depth, and composition of coal beds; by determining the geologic processes that partly or wholly control the selection, development, and operation of existing and future mines; by studying the organic, metallic, and mineral contaminants in coal as related to depositional environments, diagenesis, and complete geo- logic history; and by continuing expansion of the computerized National Coal Resources Data System (NCRDS).

Accomplishments for fiscal year 1976 included:

- Collecting 2,250 samples of coal for chemical analyses of 60 elements.

- Estimating the remaining coal resources of the United States to be 3.58 trillion tons.

- Investigating 12 potential coal-mine sites on Federal land in cooperation with the Bureau of Land Management, Bureau of Reclamation, and Montana Bureau of Mines and Geology.

- Geologically mapping about 2,590 square kilometers (1,000 square miles) of lands containing low-sulfur coal in Wyoming, Montana, Kentucky, Virginia, and West Virginia.

\section{Oil and Gas}

The Oil and Gas Resources Investigation program improves resource appraisal techniques and estimates by gathering and interpreting geological and geophysical data; provides up-to-date technical expertise; develops new geological and geophysical data through ongoing topical investigations; and designs and develops resource information which can be used in planning national energy policies.

Accomplishments for fiscal year 1976 included:

- Completion of a study, for the Federal Energy Administration, to develop new methods for assessing future oil and gas finding rates in different regions of the United States. Finding rates are important in determining the contribution of exploration activity to future oil and gas production rates.

- Location of several areas in New Mexico and Colorado which may be highly prospective for oil and gas from fractured Cretaceous shales.

- Location, in a sparsely explored part of Wyoming, of an area that may contain oil and gas stratigraphic traps.

- Completion of a small-diameter borehole gravity meter that will be especially useful in evaluating fractured shale and tight gas-sand reservoirs.

- Initiation of a program in cooperation with the Energy Research and Development Administration to evaluate and characterize black shales. These shales may be an important source of future gas production in the United States.

\section{Oil Shale}

The ultimate aim of the Oil Shale Resources Investigation program is to inventory the oil shale resources of the United States and to understand the geologic setting in which the shale exists. The present work is concentrated on the Green River Formation 
of the central Rocky Mountain area, probably the thickest and richest oil shale in the world.

Highlights of the program during fiscal year 1976 included:

- Assessment of the equitability of a proposed exchange of land between Superior Oil Company and the Federal government.

- Determination of the optimum resource characteristics for the Bureau of Mines deep-shaft pilot mine in the Piceance Creek basin, Colorado.

- Comparison of the geologic characteristics and mineral potential of tracts of land nominated for in-situ oil shale leases in Colorado and Utah.

- Appraisal of the data-gathering procedures used by the lessees on Federal oil shale lease tracts.

\section{Uranium and Thorium}

The Uranium and Thorium Investigations program consists of research on the theories of origin of uranium; on the paleomagnetic properties of uranium deposits; and on the source-rich areas. Geochemical exploration techniques include gaseous emanation studies and analyses of stream and spring waters and their associated sediments and precipitates. Geophysical exploration techniques include a variety of radiometric and non-nuclear techniques that measure the physical properties associated with uranium deposits.

Fiscal year 1976 accomplishments included:

- Studies of Paleozoic rocks in the Eastern United States that have led to renewed interest in the potential of undiscovered uranium deposits.

- Development of new thorium reserve and resource figures for the Lemhi Pass district, Idaho.

- Studies of hard-rock uranium occurrences that indicate new areas for exploration, particularly in the Northeastern and Eastern United States.

- Studies of natural waters and modern sediments that resulted in improved geochemical techniques and in the identification of several favorable uranium exploration areas.

- Constructing a mobile helium-detection instrument for uranium exploration.

- Constructing a nuclear borehole tool for inhole uranium analysis.

- Studies in Alaska that resulted in significant discovery of a potentially large rare-earth uraniumthorium deposit.

\section{Geothermal Energy}

The Geothermal Energy Investigations program assesses the magnitude of regional and national geothermal resources. Promising target areas are identi- ment are studied. The program also develops a scientific basis for improving assessment and exploration methodology and assists the Energy Research and Development Administration in technologic research.

Significant results and accomplishments for fiscal year 1976 included:

- Geologic mapping of the San Francisco volcanic field, Arizona. The results indicate that there is a reasonable prospect for finding hot igneous rock in the subsurface east of the San Francisco Mountains.

- Geologic mapping of the Collayomi fault zone, south of Clear Lake, Calif. The mapping indicates that the zone is probably active and has experienced right-lateral slip as well as normal displacement. This zone may be a major control of the northeast extent of The Geysers geothermal field.

- Modification and update of the Geothermal Computer Data File (GEOTHERM) that has added information from the U.S. hot spring file and the international geothermal field data.

- Indications that the thermal anomaly at Roosevelt Hot Springs in southeastern Utah is magmatic in origin and large in size.

- Determination that the two deep geothermal wells at Raft River, Idaho, are producing from a common aquifer, suggesting that the geothermal reservoir is large and potentially productive. It has a $170^{\circ} \mathrm{C}$ water temperature and a shut-in pressure of about 10,546 grams per square centimeter (150 pounds per square inch).

- Geologic mapping at Mount Shasta, Calif. The mapping has revealed that the volcano is a compound feature consisting of four separate but overlapping cores. The youngest core is colly a few thousand years old. The youth of the vo cano has considerable significance in evaluatin, the geothermal potential of the volcanic system.

\section{Energy Resource Data}

The Geological Survey is building and maintaining computerized files of energy resource data to use in preparing accurate resource estimates and to meet public needs for such data for independent appraisals.

The National Coal Resources Data System (NCRDS) contains 30,000 records of coal resources by area. It will contain additional information on individual mines and boreholes, and it will include sofware for computing resources and overburden volume.

The Petroleum Data System (PDS) includes information on 68,000 oil and gas fields and pools in the United. States. The data cover geologic occurrence, 
engineering information on the reservoirs, and analyses of crude oil, brine, and natural gas. Annual and cumulative production is given as well as size in acres or number of wells. Enhanced recovery prospects are identified. Center locations and outlines of the fields are now being digitized to permit graphic display of the fields, together with information selected from the data file.

The United Nations Seabed Data file contains a summary of petroleum and selected mineral statistics for 120 countries, including offshore areas. The software associated with the file allows the user to make limited retrievals of information for the purpose of generating summary reports.

The Oil Shale Data Storage and Retrieval System is designed to store oil shale Fischer assay and saline mineral data and to compute oil-yield thicknesses and resource estimates.

The Computerized Resources Information Bank (CRIB) contains the basic information needed to characterize one or more mineral commodities, a mineral deposit, or several related deposits and consists of text, numeric data, and codes.

The Geothermal Resources Computer File (GEOTHERM) is made up of 1,000 records relating to the location, exploration, evaluation, and use of geothermal energy and resources. Data are included on boreholes, water analyses, and heat values.

The Well History Control System (WHCS) contains basic information on oil and gas wells, including location, production tests, formations, cores, drillstem tests, depths, and log runs. It is composed of 800,000 records.

The Uranium-Thorium Data Bank is being built to link a variety of existing computerized files to precise deposit locations. Nonproprietary portions of the file will be selected and reformatted for input into CRIB.

\section{OFFSHORE GEOLOGIC SURVEYS}

\section{Oil and Gas Resource Appraisal}

The objectives of the Oil and Gas Resource Appraisal program are:

- To provide estimates of the oil and gas resource potential of the Outer Continental Shelf areas.

- To help define areas having significant petroleum potential.

- To provide geological and geophysical data and analysis of the areas that have potential petroleum resources.

The most effective method of assessing the resources in offshore sedimentary basins is by the widespread use of geophysical data with the available geological information. The geophysical data consist of common depth point seismic reflection for deeppenetration, single-channel seismic reflection for intermediate-depth recording, high-resolution seismic reflection for shallow and near-surface horizons, seismic refraction, shipborne gravity and magnetics, and aeromagnetics. The geologic information is derived from sea-floor samples collected by waterbottom coring equipment and dredge. Additional geologic information is obtained from shallow core holes, deep stratigraphic test wells, and nearby onshore wells.

The accomplishments and results during fiscal year 1976 included:

- Collecting and analyzing various geophysical data. - Analyzing 1,937 dredge samples of rock and bottom sediments.

- Conducting a shallow core drilling program on the Atlantic Outer Continental Shelf. This project consisted of drilling (fig. 47) and retrieving 1,030 meters (3,380 feet) of core from 20 sites ranging in depth from about 20 to 300 meters (66 to 985 feet). The holes were located from the Georgia Embayment to Georges Bank. Water depths at the locations were from 20 to about 1,000 meters (66 to 3,280 feet). Preliminary shipboard analyses detected methane in shallow sediments, and large amounts of freshwater were found in the deeper strata offshore from the northeast coastal States.

\section{Environmental Investigations}

The Environmental Investigations program assesses the potential impacts of geologic hazards on the development of offshore oil and gas resources. Hazards to drilling structures and/or pipelines may occur in areas of active faulting, unstable sediment masses, and excessive erosion of sedimentation. Field studies which compile this information for leasing decisions and baseline data were conducted during fiscal year 1976 in the north and mid-Atlantic Outer Continental Shelf areas, in the central and western Gulf of Mexico, off the southern California coast, and in the Alaska area.

The activities and highlights for fiscal year 1976 included:

- Completion of 2,900 kilometers (1,800 miles) of high-resolution geophysical surveys in the Georges Bank area. The area is a complex network of channels, which appear to be cutting into the bank surface, and large sand dunes.

- Recovery of cores from Georges Bank containing material identified as glacial till. This work has 


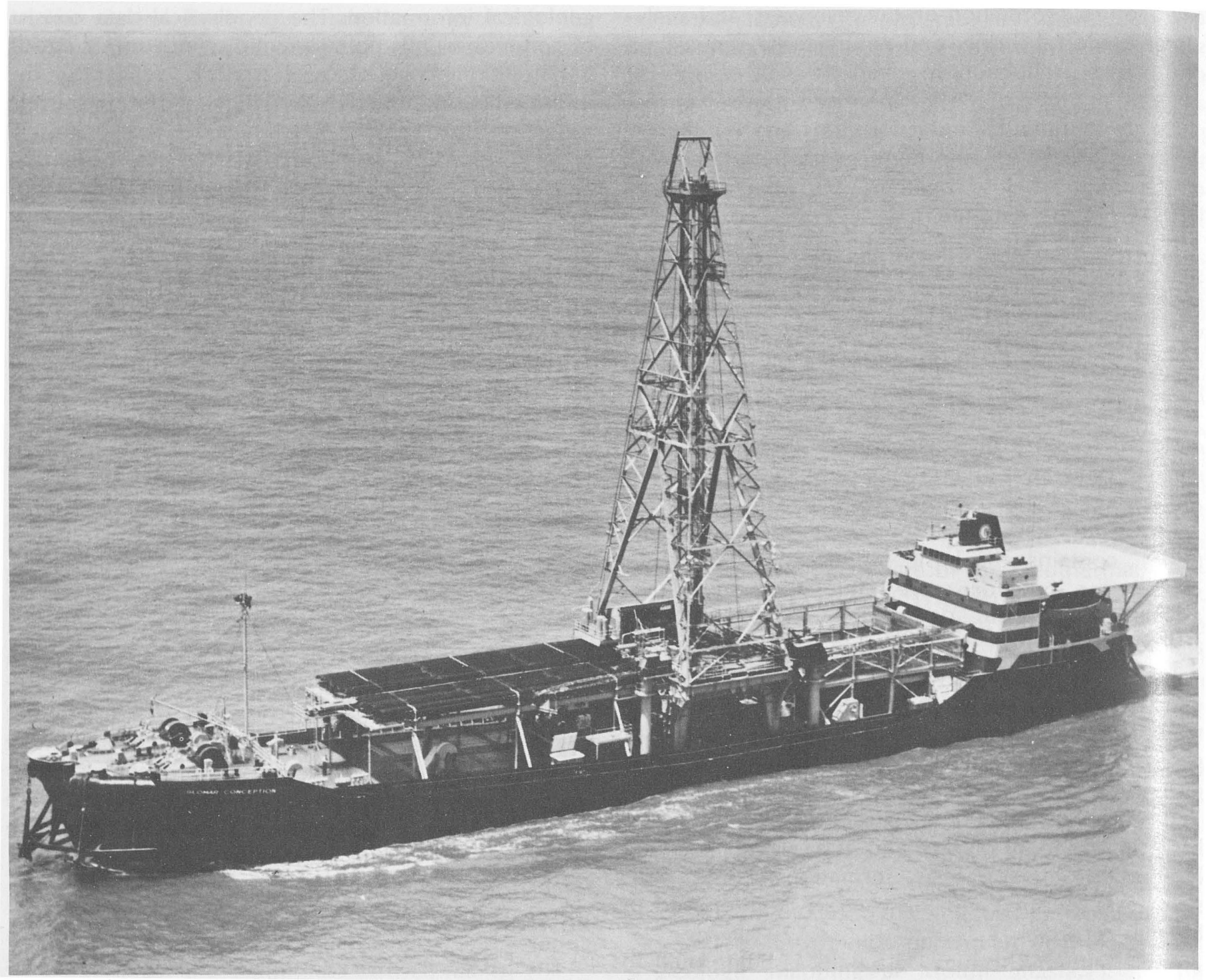

FIGURE 47.-The Glomar Conception was used by the Survey in a 60-day scientific expedition to increase the geologic knou edge of the Atlantic Outer Continental Shelf. (Photograph courtesy of Global Marine, Inc.)

extended the known limit of continental glaciation several hundred kilometers into the Atlantic Ocean.

- Photographing sand waves at a depth of 80 meters (262 feet) during the passing of a surface storm.

- Observations by manned submersible in the north and mid-Atlantic Outer Continental Shelf. The observations. were made to calibrate the instrument packages containing current, pressure, temperature, and suspended sediment sensors.

- Completion of 2,000 kilometers (1,243 miles) of high-resolution geophysical surveys in the south Atlantic Outer Continental Shelf. These surveys show active cut and fill sediment transport. Deep core material documents a change in position of the Gulf Stream.
- Mapping in the Gulf of Alaska and off the southern California coast revealed submarine landsiides and sea-floor faults. Tracts that had poten ially unstable sea floors were subsequently withd awn from the lease sales schedule.

\section{Marine Geology Investigations}

The Marine Geology Investigations focus on topics necessary to the development of applied programs. Geochemical studies of deep-sea manganese nodules and the development of deep-ocean remote-sensing geophysical instruments are two examples of fiture major programs as the Nation develops its Outer Continental Shelf areas for mineral and hydrocârbon resources. Other research activities not directed specifically toward Outer Continental Shelf develop nent 
include research on coastal-zone processes, minable minerals on the shelf, and engineering properties of sea-floor sediments.

The highlights of the program for fiscal year 1976 included:

- Mapping the faults in the offshore area to the west of the extension of onshore faults in the Puget Sound area.

- Mapping, using geophysical methods, the offshore and north of the Diablo Canyon nuclear powerplant site in central California.

- Studying the triggering of large submarine landslides by cycle loading of storm waves in the Mississippi River Delta area.

\section{ASTROGEOLOGY}

The exploration of the Moon and planets by the National Aeronautics and Space Administration has provided an opportunity to compare geologic materials, processes, and histories of other planets with those of Earth. The Astrogeology program is designed to exploit the geologic potential of space exploration.

The lunar part of the program has evolved from an earlier emphasis on geologic mapping to a current emphasis on studies of processes and on integration of the vast amounts of geologic, geochemical, and geophysical data generated by the Apollo program. The long history of impact cratering on the Moon has led to studies of cratering processes including shock effects on lunar rocks, studies of impact and explosive craters on Earth, and stratigraphic investigations of material thrown out of the enormous lunar basins.

The planetary studies are focused mainly on Mars and Mercury. The Survey is coordinating an effort to map geologically both planets at a scale of 1:5,000,000 . Studies of Martian processes are aimed at wind erosion, volcanoes, and water erosion (fig. 48). Mercury offers another perspective on the history of impact cratering and the distribution and source of impacting bodies. Radar techniques are being developed for application to the study of Venus.

Highlights of the program for fiscal year 1976 included:

- Completion of topographic maps of Mars (from photographs taken from orbit) near the Viking Lander I landing site prior to its successful landing.

- Completion of a topographic map of Mars.

- Completion of a shaded-relief map of Mercury.

- Completion of a true-color mosaic of Nevada from Landsat imagery.

- Preparation of a geologic map of the entire Moon and a new geologic map of Mars.

\section{INTERNATIONAL ACTIVITIES}

International Activities form a significant part of the Survey's research and investigations. These activities include technical assistance to earth-resources institutions in foreign countries, scientific cooperation and exchange of knowledge with counterpart agencies, and participation in international commissions and scientific programs.

Technical assistance is conducted at the request of, and is funded by, international organizations and other U.S. Government agencies and foreign governments and is authorized by the Agency for International Development, Department of State. This assistance, which involved 25 countries during 1976, provides a mechanism for using Survey scientific expertise in achieving the objectives of the Foreign Assistance Act. It also affords an opportunity for the Survey to develop contacts, study geologic phenomena, and test geologic concepts with counterpart agencies abroad.

Scientific cooperation and exchange are conducted partly on behalf of other Federal agencies and partly as an extension of the Survey's domestic geologic research. In 1976, cooperative research on geological and resources problems was conducted with 15 foreign countries. In addition, Survey scientists participated in seven major international scientific programs and participated in several international commissions during the year.

\section{Resources Attaché and Reporting Program}

The Survey continued to cooperate with the Department of State and the Bureau of Mines in developing an expanded Resources Attaché and Reporting program to collect, organize, and synthesize international mineral and energy resource data. At the end of fiscal year 1976, 11 resources attaché positions had been established in U.S. embassies abroad.

\section{Transfer of Technology}

Transfer of remote-sensing technology to foreign countries continued to receive special emphasis. Training courses or seminars were conducted by Survey personnel in Thailand, Nepal, Saudi Arabia, and Iran. The multidisciplinary remote-sensing project in Thailand, sponsored by the Agency for International Development, was completed during the year. This 4-year project assisted the resource agencies and institutions of Thailand in applying data derived from Landsat imagery in their ongoing effort to provide improved information for development and management of earth resources. Twenty-two organi- 


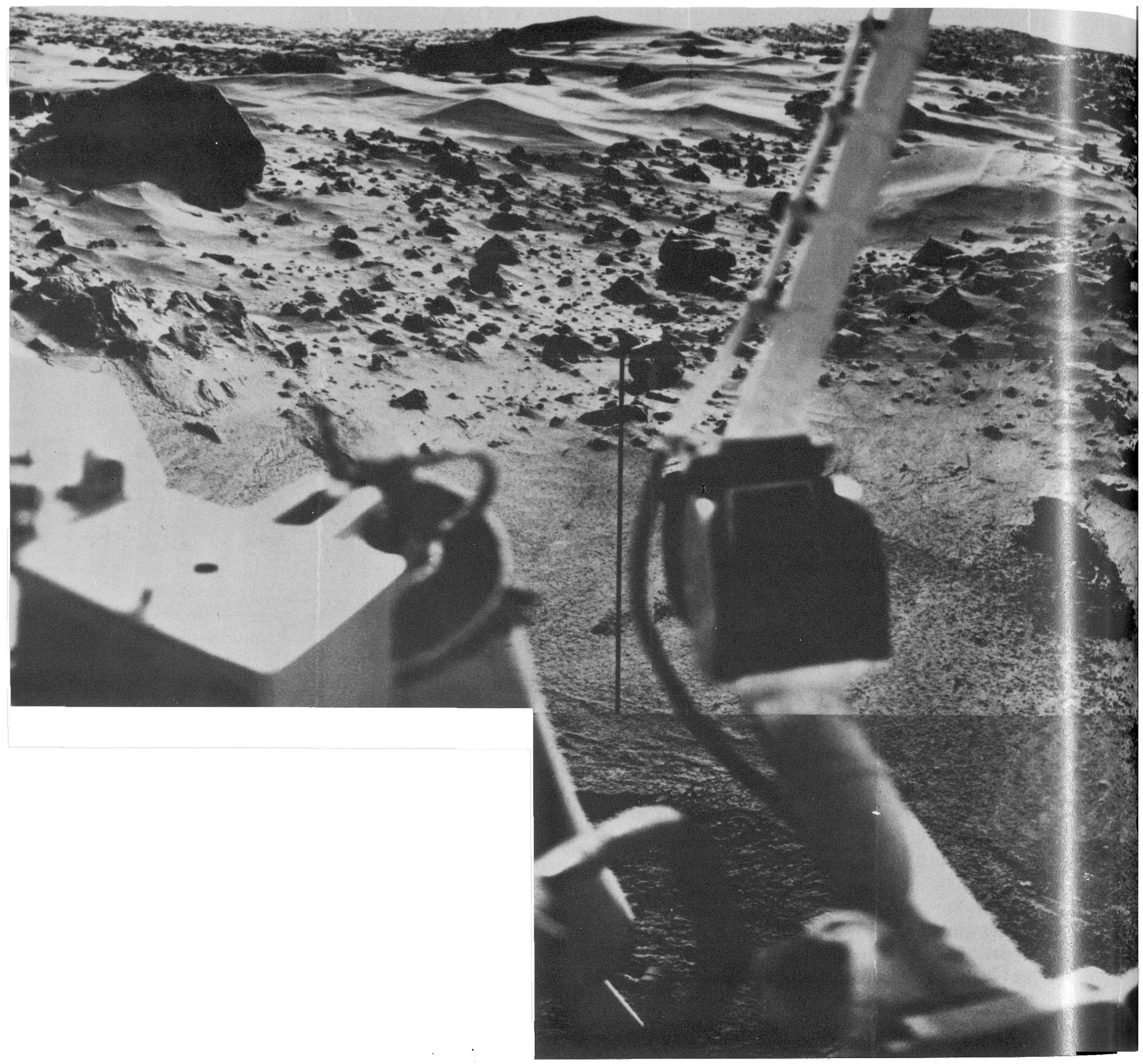

FIGURE 48.-This panorama of the Martian surface is a composite of high-resolution pictures taken by Viking Lander I camera: A sample of soil was obtained from the trench in the center of the picture. The surface is strewn with a variety of angular rckss, and fine material has formed tails on the lee side of the rocks by winds. 


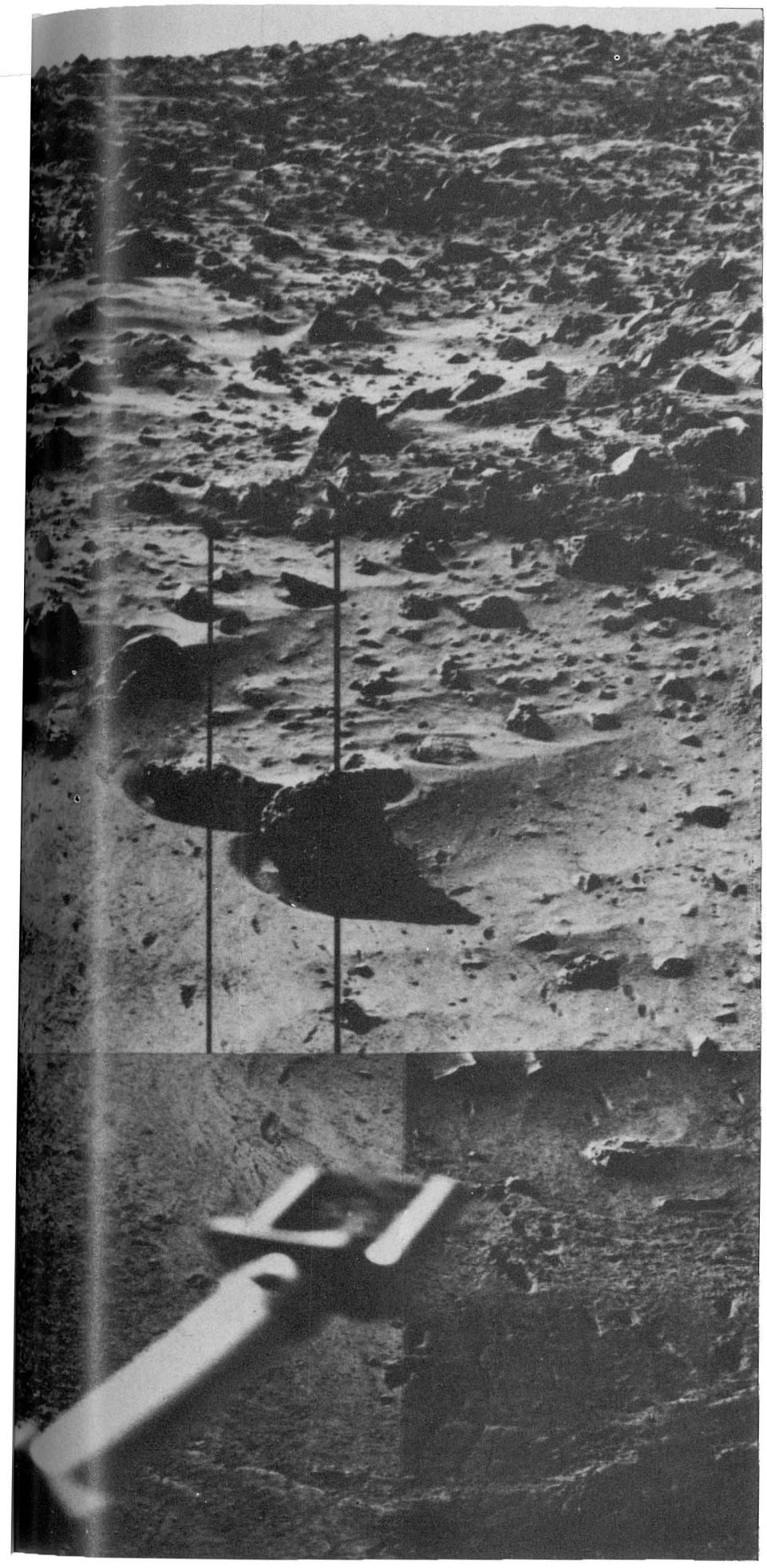

zations participated in the project, which was coordinated by the National Research Council of Thailand.

Major highlights for the International Activities in fiscal year 1976 included:

- Investigation into the geologic, seismologic, and engineering effects of and hazards resulting from the February 4, 1976, Guatemala earthquake.

- Assistance in the establishment of a Center for Earthquake Hazard Reduction in Nicaragua.

- Investigation of the volcanic activity at Cotopaxi Volcano, near Quito, Ecuador, during July 1975.

- Consultation on slope stability studies in La Paz, Bolivia, ground-water development proposals in Assam, India, and resource development and remote-sensing programs in Central America.

\section{ALASKA PIPELINE AND RELATED INVESTIGATIONS}

The Alaska Pipeline and Related Investigations activity collects geologic and hydrologic information. This information is used as the basis for safeguards against possible pollution and environmental damage that might result from the construction and use of the trans-Alaska pipeline. The Arctic Environmental Studies program augments the pipeline investigations by conducting engineering geologic studies.

Principal accomplishments and highlights of the program during fiscal year 1976 included:

- Continuation of mapping and investigation of engineering-geologic conditions critical to proper construction and safe operation of the pipeline.

- Continuation of monitoring channel erosion, streamflow, and water quality at 35 sites along the pipeline route and monitoring glacial and river icing at selected locations.

- Continuation of earthquake monitoring at several locations to evaluate possible hazards. A resurvey was made where the pipeline crosses the Denali fault in order to determine if fault movement has occurred in that area during the past few years.

\section{REFERENCES}

Borcherdt, R. D., ed., 1975, Studies for seismic zonation of San Francisco Bay region: U.S. Geol. Survey Prof. Paper 941-A, p. A102.

Castle, R. O., Church, J. P., and Elliott, M. R., 1976, A seismic uplift in southern California: Science, v. 192, p. 251-253.

Cobb, E. H., ed., 1976, The United States Geological Survey in Alaska: Organization and status of programs in 1976: U.S. Geol. Survey Circ. 732, 64 p.

Espinosa, A. F., ed., 1976, The Guatemalan earthquake of February 4, 1976: A preliminary report: U.S. Geol. Survey Prof. Paper 1002, 90 p. 


\section{Water Resources Investizations}

\section{Introduction-Functions and Authority}

The availability of water in usable form is a major determinant in defining the quality of life. As the demand for water increases, decisions regarding its allocation and use become more difficult and more critical. In 1976, the expanding search for new energy sources, the droughts in California and Great Britain, the disastrous flood on Big Thompson River in Colorado were striking examples of the vital need for understanding and judiciously assessing our water resources.

Managing the Nation's water resources is a major concern at all levels of government, but the Water Resources Division of the Geological Survey has the principal responsibility at the Federal level for appraising this vital resource. The Survey's program, through its numerous cooperative efforts with State and local governments, is uniquely structured to gather and evaluate water information. The Water Resources Division's role is that of a scientific organization concerned with presenting impartial, factual information and analyses on which decisionmakers can rely. It publishes the data which are used by other Federal agencies, State, and local governments and by all groups charged with managing or developing water resources. Water reports and maps are made available to the public in Federal, State, and local publications and in technical journals (tables 46 and 47). In 1976, more than 1,000 such water reports and approximately 1,400 maps were issued. Some reports were released to the open file and made available for public use at selected depositories.

In the Water Resources Division's Federal-State Cooperative program, 583 State and local agencies cooperate with financial support and services, matching in equal amount the funds provided by congressional appropriation. For many years this arrangement has assured responsiveness to water-information needs at all levels of government. It has enabled the Federal Government to be aware of urgent State and local problems and has contributed to valuable information exchange. Although studies conducted within the Federal-State Cooperative program are usually linked to State and local water problems, they are of substantial national interest because the information developed is applicable in other areas or forms a part of the information base for larger areas. Therefore, one of the benefits of the cooperative program has been the elimination of more costly multiplicity of effort. Through a network of offices in all 50 States, as well as Puerto Rico and Guam

$\checkmark$ Stream gaging by cable car. (fig. 49), the Water Resources Division works closely with State and local agencies. The addresses of the Division's District Offices are listed in the chapter on organization and statistical data.

A broad category of responsibility for water data was assigned to the U.S. Geological Survey when, in 1964 , it was designated the lead agency for coordinating water-data-acquisition activities of all Federal agencies, including information on streams, lakes, reservoirs, estuaries, and ground water. This function has effectively minimized duplication of data-collection activities among Federal agencies and has strengthened the overall data base and the accessibility of these data to users.

\section{Highlights}

- The comprehensive Madison Limestone GroundWater Study was begun to assess the adequacy of ground-water supplies for coal development in Wyoming, Montana, South Dakota, and Nebraska. The first test well of 1,323.1 meters (4,341 feet) has been completed. Preliminary pumping tests indicate the well yield is about 1,477.0 liters per minute ( 700 gallons per minute).

- Studies on radioactive-waste disposal as they relate to ground-water contamination are in progress at four State-owned, commercially operated sites and at two Federally operated solid-waste burial sites.

- The ever-increasing concern for clean water in the environment and pure water for drinking has led to more than 50 studies in progress within the Federal-State Cooperative program which relate to the potential for pollution of ground water.

- Results of the Intensive River Quality Assessment of Oregon's Willamette River basin demonstrated that methodology for assessing river basins must be tailored carefully to the particular basin under study. This tailoring is necessary because there are cause-effect relationships that are unique to each basin.

- A 4,553.8 square-meter (49,000 square-foot) laboratory complex in Denver, Colo., was completed. Eighty-five percent of the building houses an analytical-services laboratory, which emphasizes the increased importance of an expanded water-quality program in monitoring the impact of nature and man on the Nation's water resources. 


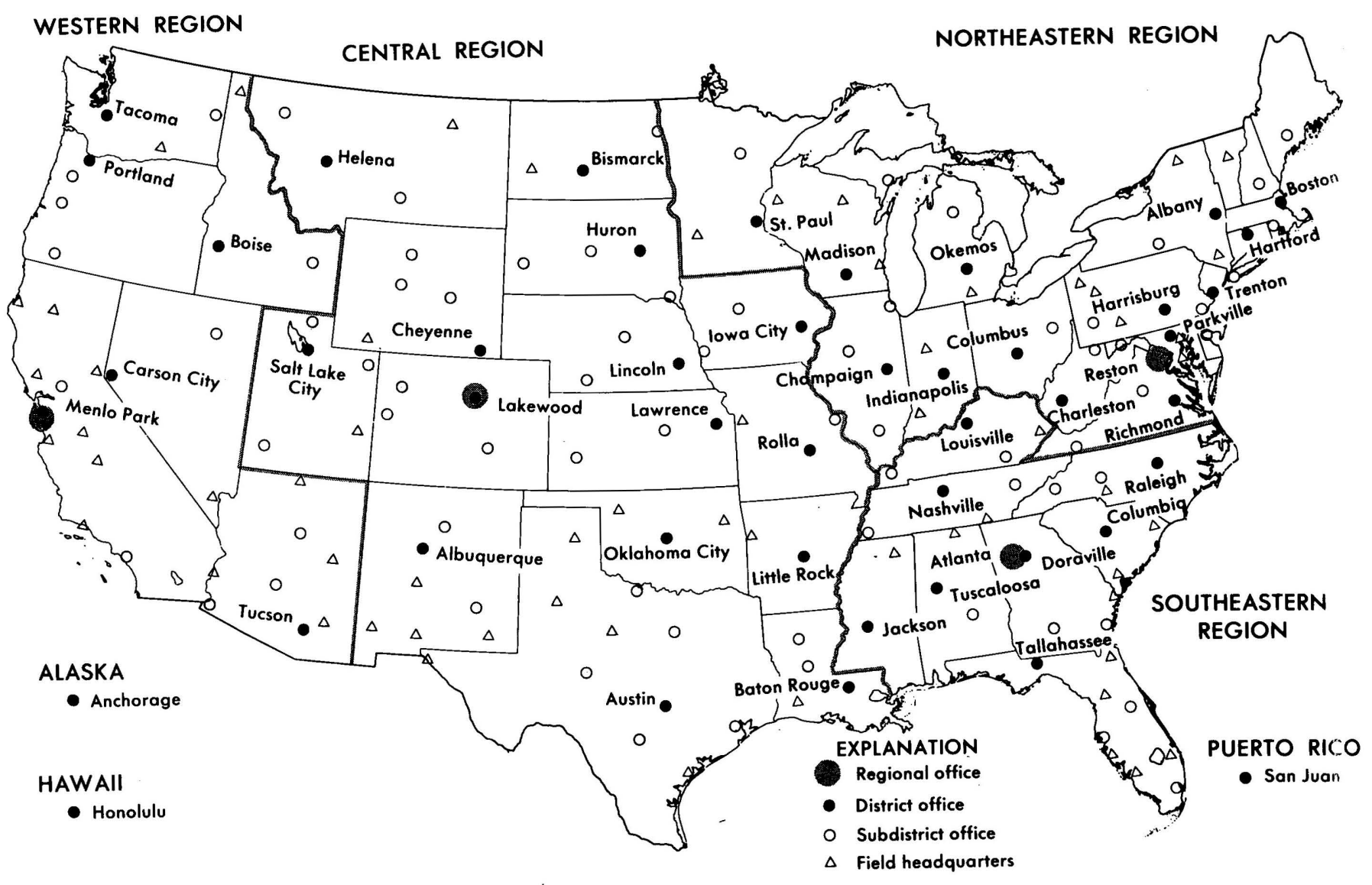

FIGURE 49.-Location of principal offices of the Geological Survey's Water Resources Division in the conterminous United States. Cities named are those where regional and district offices a re located. In addition to the subdistrict offices noted on the map, there are two subdistrict offices in Alaska, three in Hawaii, and one on Guam, all in the western region.

- In cooperation with other Federal agencies, the Osceola National Forest project was begun to predict the potential impacts of strip mining for phosphate on surface- and ground-water resources.

- Preliminary interpretations of data gathered at Redwood National Park, Calif., indicate that timber harvesting outside the park boundaries has had identifiable effects on the hydrologic environment of the park. The lumber companies involved have voluntarily changed their timberharvest practices. Investigations on the hydrology of the area are continuing in cooperation with the National Park Service.

- The Federal-State Cooperative program placed special emphasis on water investigations related to the development of new energy sources, such as the availability of water for coal mining and processing. Other high-priority activities of the program included water quality, urban-area problems, and other matters related to environ-
- Seventeen Hydrologic Investigations Atlases were released which delineate the inundated areas and maximum water-surface elevations resulting from failure of the Teton Dam in southeastern Idaho. A formal report is in preparation.

- Professional papers were published on three disastrous floods: those caused by Hurricane Agnes in June 1972, record floods of 1973 on the Mississippi River, and the severe floods of March-April 1973 in the Southeastern United States.

- Regional flood-frequency reports were prepared for 14 States. They describe results of analyses and the various techniques for estimating the magnitude and frequency of floods at ungaged sites.

- The National Water Data Exchange (NAWDEX) was established. It maintains two computerized data bases (a Water Data Sources Directory anc a Master Water Data Index) to assist data users in identifying, locating, and acquiring needed water data. 
- WATSTORE, the computerized data storage and identifying, locating, and acquiring needed water Data System, was made available for direct online use by other Federal and non-Federal organizations.

- Under the sponsorship of the Office of Water Data Coordination, two chapters of the "National Handbook of Recommended Methods for Water-Data Acquisition" on chemical and physical quality of water and hydrometeorological observations were completed.

\section{Budget and personnel}

In fiscal year 1976, the $\$ 112.5$ million obligated for the Water Resources Investigations activity came from three sources (fig. 50 and table 11):

1. Direct Congressional appropriations for the Federal program.

2. Joint congressional and State and local appropriations for the Federal-State Cooperative program.

3. Funds transferred from other Federal agencies and State and local agencies for reimbursable programs.

The work funded by these three sources is divided into a number of subactivities and programs. (See table 11.)

Approximately 2,900 full-time personnel carried out the many water-resources studies and data-collection activities of the Water Resources Division. In 1976, the Division employed 1,287 hydrologists, 168 engineers and other scientists, 989 technical specialists and aids, and about 450 persons who provided administrative, secretarial, and clerical services. In addition, at the end of the fiscal year, approximately 700 persons were employed in a variety of capacities on a part-time basis.

\section{FEDERAL PROGRAM}

The Federal program, amounting to $\$ 29.3$ million $^{1}$ in fiscal year 1976 (approximately 26 percent of the Geological Survey's total water program), is designed to provide nationwide resource data for planning and management and to improve the scientific basis of hydrologic investigations and techniques. Water-data collection, resources investigations, and research activities support that segment of the National Water Data System in which the Federal interest is paramount, including the public domain, interstate river basins and aquifers, and other areas of international or interstate concern.

1 In fiscal year 1976, $\$ 58.1$ million was appropriated for the Water Resources Investigations activity, $\$ 28.0$ million of which was used to The balance, $\$ 30.1 \mathrm{mil}$ lion, is referred to here as the Federal program.
The Federal program supports the operation of more than 700 surface-water measurement stationsstage and/or discharge-throughout the Nation, including nearly 650 sites where stream discharge is measured continuously. The program also includes the operation of the National Stream Quality/Quantity Accounting Network (fig. 51), hydrologic research, and the publication of water reports.

\section{FEDERAL-STATE COOPERATIVE PROGRAM}

The Federal-State Cooperative program consists of projects funded on an equal matching basis by the Geological Survey and State and local agencies-583 in fiscal year 1976 (table 12). The cooperative program totaled $\$ 56$ million. These projects contribute to the solution of urgent national and State problems and complement the federally funded part of the National Water Data System. Once the Federal interest in a proposed project is identified, cooperative projects are jointly planned at State or local levels and by Federal representatives.

Efficient and effective conservation, development, and utilization of the Nation's water resources are dependent upon an adequate data base. The FederalState Cooperative program provides more than half of that base and is a continuing program which directly responds to the changing mutual needs of Federal, State, and local governments for data.

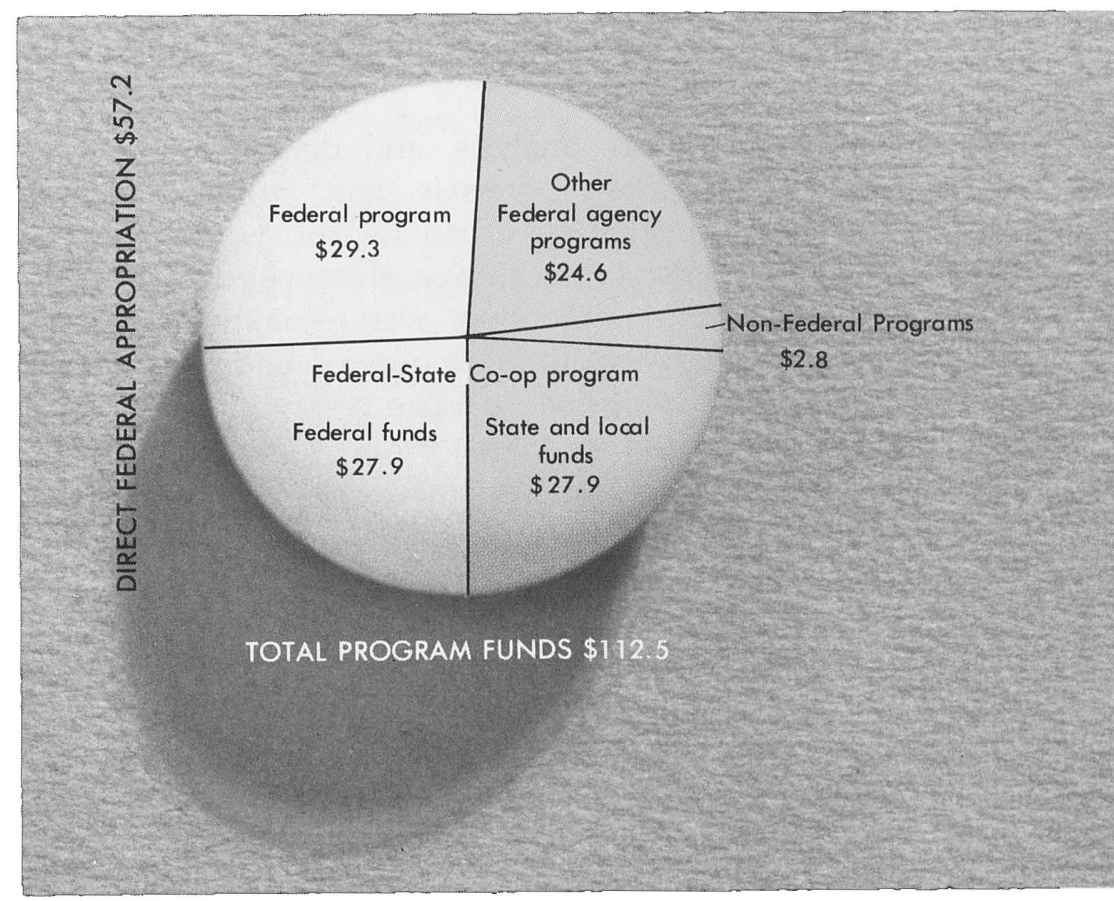

FIGURE 50.-Sources of fiscal year 1976 funds for Water Resources Investigations (dollars, in millions). 
TABLE 11.-Water Resources Investigations activity obligations for fiscal year 1976, by program (dollars in millions) [Data may differ from that in statistical tables because of rounding]

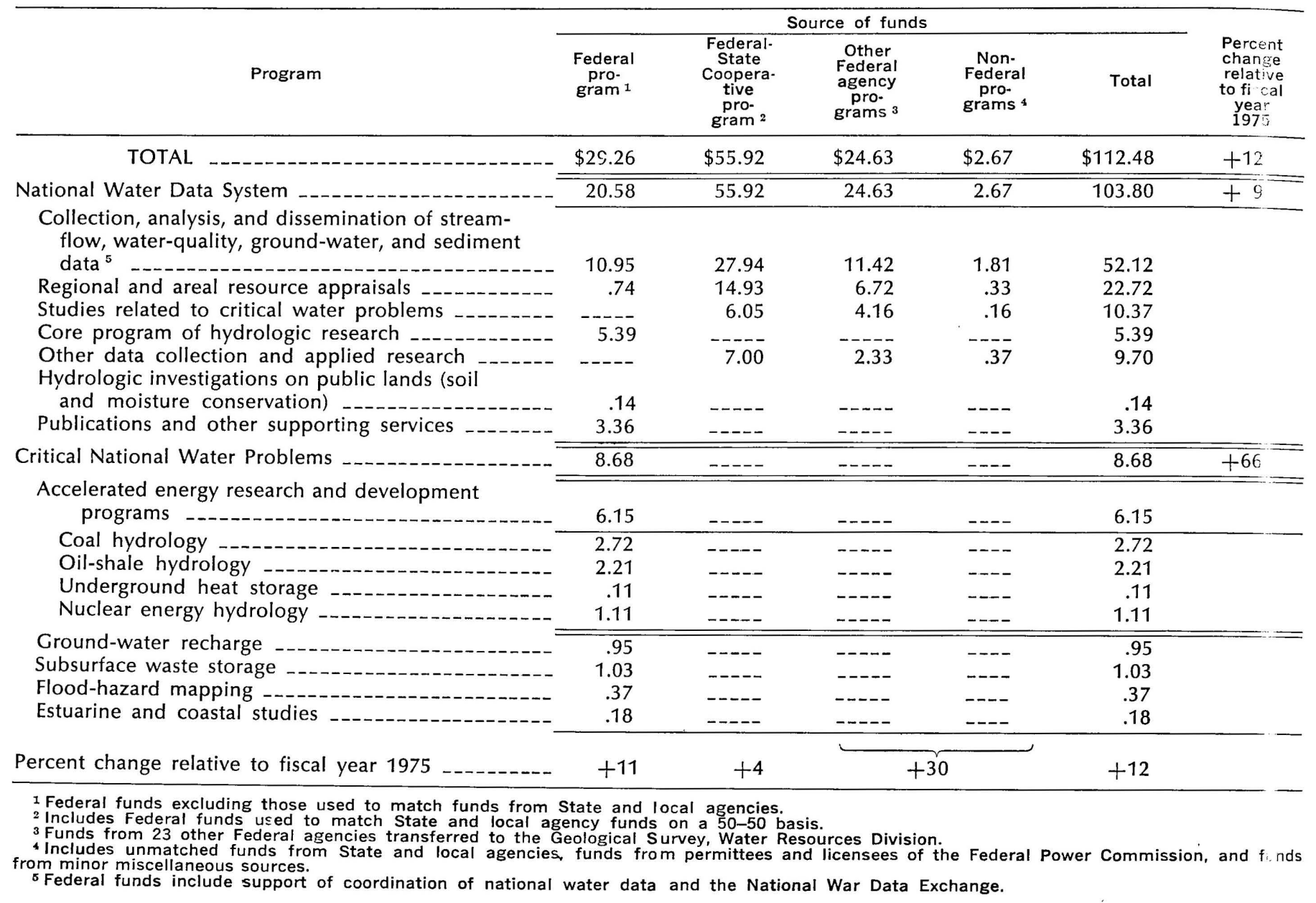

Activities in the Federal-State Cooperative program in 1976 included:

- Data collection, analysis, and dissemination.

- Areal resource appraisals and problem-related studies, including urban hydrology, sedimentation, lakes, hydrobiology, stream-system modeling, aquifer modeling, water-quality modeling, saline waters, flood frequency and magnitude, floods and droughts, waste disposal, and others.

- Studies related to critical problems including relation of coal and oil development to water resources, surface- and ground-water contamination, estuarine problems, artificial recharge, and flood-hazard mapping.

- Applied research on hydrologic problems, principles, and techniques.

Activities under the Federal-State Cooperative program have provided most of the information required for wise use of the Nation's water. Local water problems have the potential for becoming national or regional problems. Examples are floods, land droughts may be analogous or similar to those found elsewh re. The accumulation of water information from the 0 operative-program studies has increased the reliab ity of predictive methods and generated many new te $h$ niques.

In fiscal year 1976, the Federal-State Cooperat ve program placed special emphasis on water investi ations related to the accelerated development of $n: w$ energy sources as, for example, in studies involv ng the availability of water for coal mining and proce :sing. Other high-priority activities included intensif $a d$ work in water quality, urban-area problems, c id environmental improvement.

Reports published in the past year include, amc ig others:

- Plan of study of the hydrology of the Madis $n$ Limestone and associated rocks in parts of Mc 1tana, North Dakota, South Dakota, and Wyomiı g.

- Geothermal investigations in Idaho.

- Effects of urbanization on streamflow and sedime it transport in the Rock Creek and Anacostia Riv :r basins, Montgomery County, Md. 


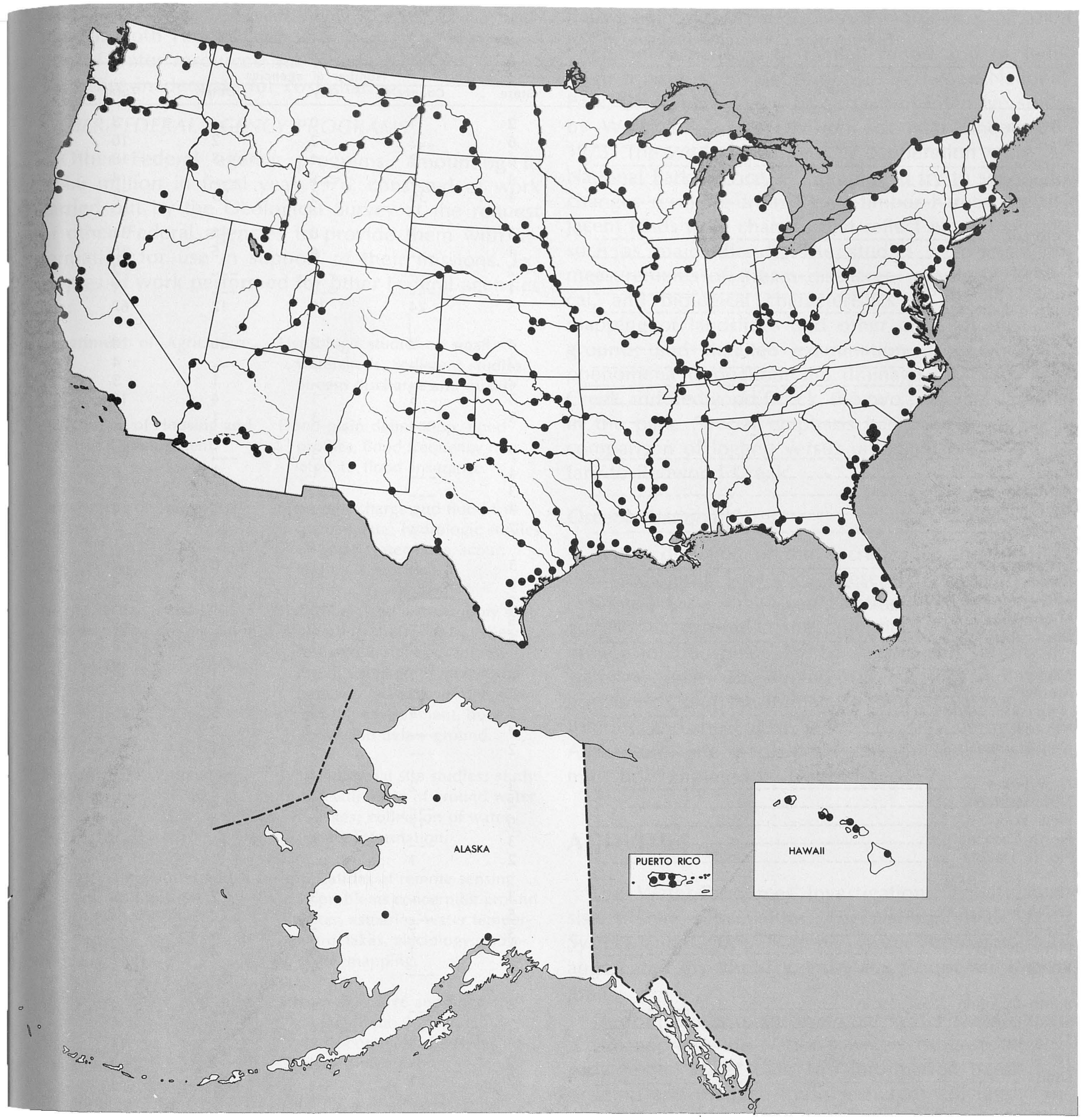

FIGURE 51.-Location of stations in the National Stream Quality/Quantity Accounting Network in operation as of January 1, 1976.

- Ground-water quality at the site of a proposed deep-well injection system for treated wastewater, West Palm Beach, Fla.

- Geochemical effects of recharging the Magothy aquifer, Bay Park, N.Y., with tertiary-treated sewage.
- Chemical quality of ground water in the TehamaColusa Canal Service Area, Sacramento Valley, Calif.

\section{NON-FEDERAL PROGRAM}

Non-Federal reimbursable funds are unmatched funds received by the Geological Survey from State 
TABLE 12.- State and local agencies, by State, with which the Geological Survey had a written agreement for fiscal cooperition (Federal-State Cooperative program) in Water Resources Investigations in fiscal year 1976

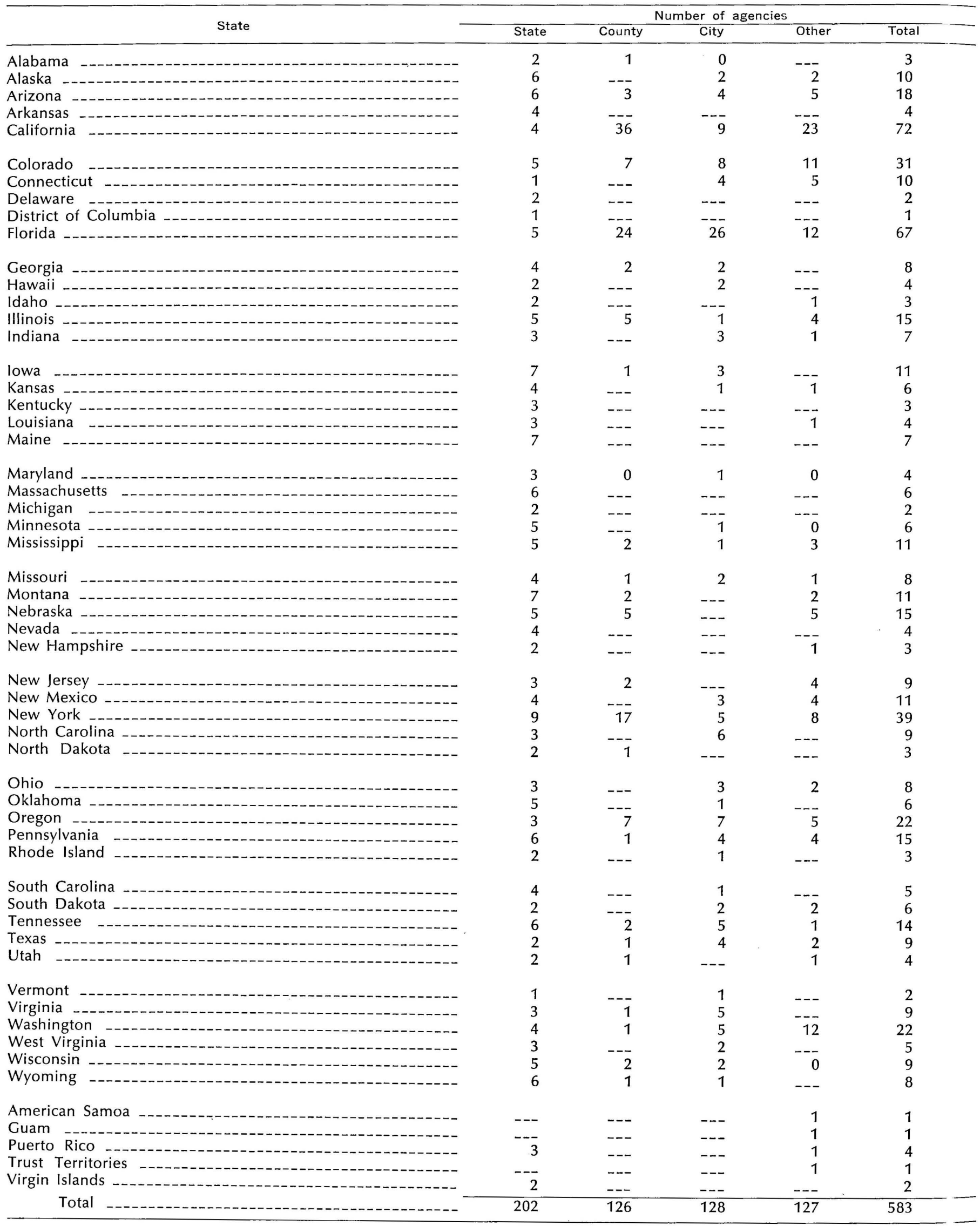


and local agencies ( $\$ 2.7$ million) in situations where there is both Federal and State interest in investigation of water resources but where matching Federal funds are inadequate for cost sharing.

\section{OTHER FEDERAL AGENCY PROGRAMS}

Other Federal agency programs, amounting to $\$ 24.6$ million in fiscal year 1976, consisted of work carried out by the Geological Survey at the request of other Federal agencies to provide them with information for use in support of their missions. Examples of work performed for other Federal agencies are:

\section{Department of Agriculture_._. Hydrologic studies on small watersheds. Sediment studies. Stream discharge and quality.}

Department of Housing and Urban Development.

Department of Transportation.

Energy Research and Development Administration.

Environmental Protection Agency.

National Aeronautics and Space Administration.

Applications of remote sensing to problems concerning ground water, estuaries, water temperature, lakes, glaciology, snowcover mapping.

Tennessee Valley Authority_-_ Stream-discharge and flood-frequency data; hydrologic studies on watersheds, including sedimentation.

Denartment of DefenseCorps of Engineers.

Tidal flows in estuaries, subsidence studies; streamflow data, ground-water studies, sedimentation, and water-quality studies.

In cooperating with other Federal agencies, the U.S. Geological Survey plays a significant role in undertaking studies which affect the preservation of environmental quality in our national parks and public lands. In 1976, two typical water-related studies were underway:

\section{Redwood National Park}

Changing patterns of rainfall runoff and of sediment transport and deposition in Redwood National Park, Calif., have been the subject of intensive study by Water Resources Division scientists since early 1973. The work, performed in cooperation with the National Park Service, is intended to try to segregate changes resulting from heavy timber harvest in adjacent lands from changes that reflect natural events, such as major floods. The studies have included measurements of stream discharge; physical, chemical, and biological characteristics of the streams; mapping of landslides and other areas of unstable ground; and detailed examination of geomorphic phenomena throughout the drainage basins of Mill Creek and Redwood Creek, the two principal streams in the park. Special emphasis has been given to a comparison of logged versus unlogged basins tributary to Redwood Creek.

\section{Osceola National Forest}

At the direction of the Secretary of the Interior, the Geological Survey is presently evaluating the hydrogeology of the Osceola National Forest in northern Florida to predict the potential impacts of strip mining for phosphate on the surface and subsurface water resources. The Bureau of Mines, Fish and Wildlife Service, and the Bureau of Land Management in Interior, and the Forest Service (U.S. Department of Agriculture) are participating in the study, which must be completed by December 1977.

\section{ACTIVITIES}

The Water-Resources Investigations activity consists of two subactivities: The National Water-Data System and Critical National Water Problems, both augmented by the Federal-State Cooperative program.

The objectives of the National Water-Data System are to appraise the Nation's water resources and to provide the water data and information needed to develop and manage these resources efficiently. Investigations include collecting basic information at hydrologic-data stations, making areal studies, and conducting supportive research. The programs comprise more than 90 percent of the water-resources studies carried out by the Geological Survey and constitute a major part of the government-wide water-data-collection activities. For example, in 1974, the Geological Survey operated more than 70 percent of all surface-water stations (streamflow, lake level, and water stage) reported by 17 Federal agencies and 


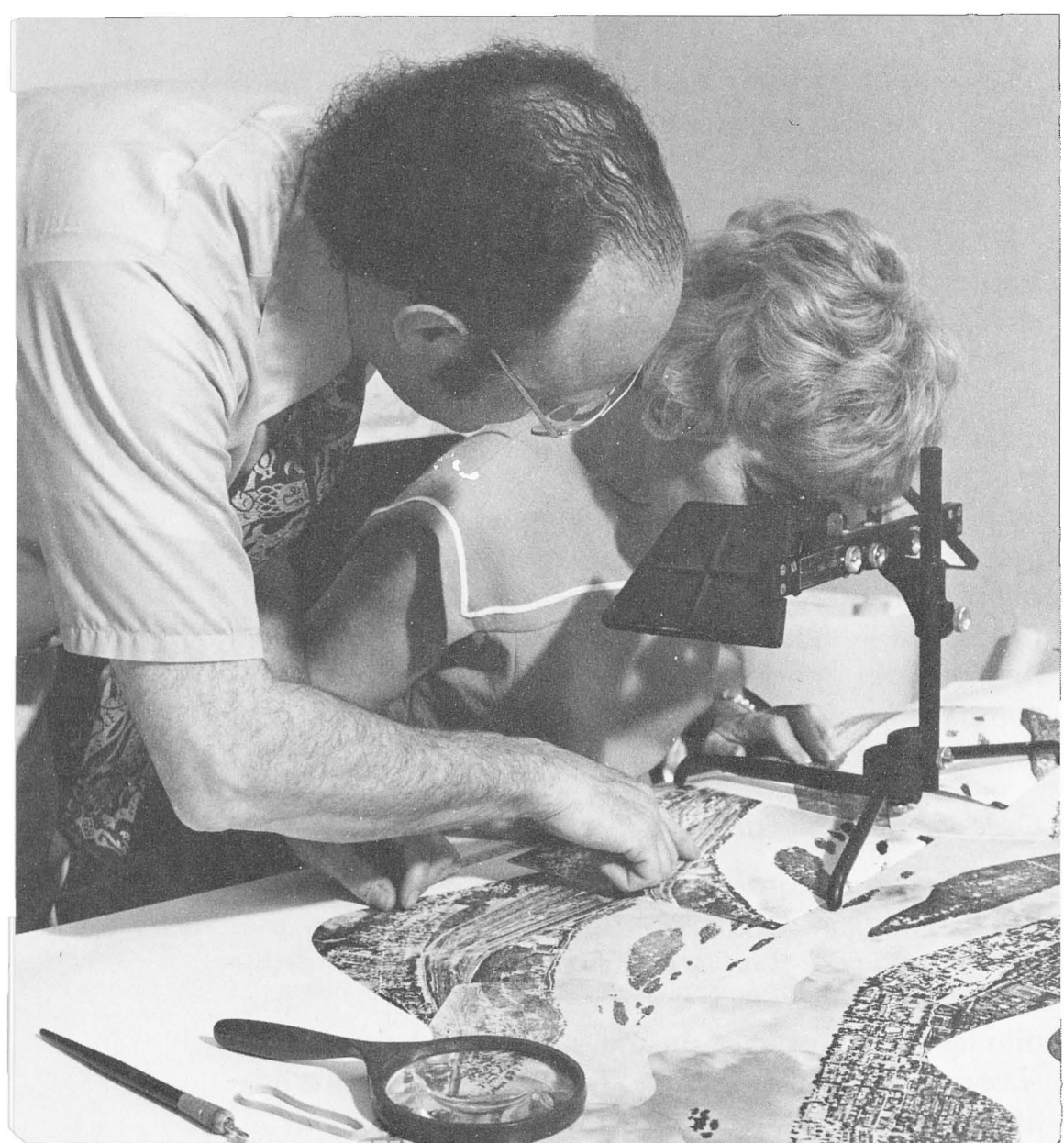

Studying flood photographs to aid in flood-prone mapping.

approximately 200 non-Federal agencies. The Survey was also responsible for 35 percent of all sites at which the quality of ground and surface water was measured.

The Critical National Water Problems activity focuses on two principal areas: (1) water availability for energy development, conversion, and storage, and (2) impact on the hydrologic regime from the above or associated energy activities.

The availability of an adequate water supply is paramount to the development of all major forms of energy. Moreover, environmental concerns dictate that such use should not be detrimental to those hydrologic systems involved. These two requirements have guided the water-resources effort conducted under the program, Critical National Water Problems. The program involves:

1. Determination of water-supply availability for coal and oil-shale mining, conversion and reclamation, transportation of coal, and nuclear-powerplant cooling-water requirements; tries exist, or are imminent, to permit assessment of environmental impacts;

3. Site-specific studies and modeling of actua or possible impacts of energy developments such as delineation of potential areas of waste siorage, including radioactive waste; and

4. Studies of ground-water recharge, mapping of flood-prone areas, and investigations of estuaries and water resources of coastal areas

In addition to the nationwide monitoring programs in fiscal year 1976, 29 studies were in progres to determine water-supply availability, 36 to establish baseline hydrologic conditions, and 38 on predictive modeling. Many such studies serve multiple $\mathrm{n}$ ceds with a total of 81 projects specified as energy-related.

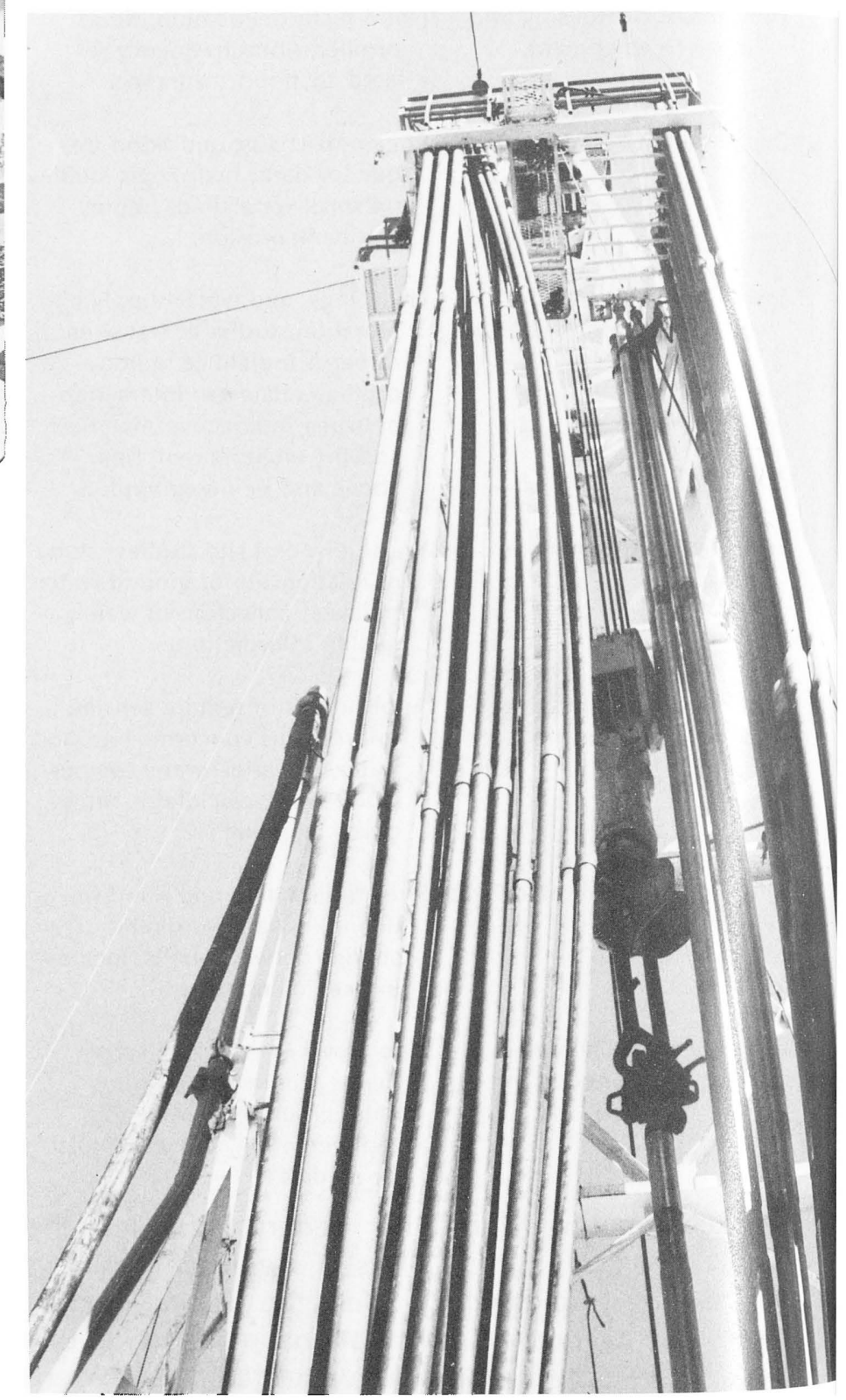

Massive drill at Madison Limestone Ground-Water Proje t. 


\section{Elements of the National Water-Data System}

\section{INTERAGENCY WATER-DATA COORDINATION}

The Survey's Office of Water-Data Coordination continued during fiscal year 1976 to work closely with a large number of Federal and non-Federal agencies, organizations, and individuals in the planning, design, and documentation of water-data networks and in the planning and development of standards for water-data acquisition (table 13). This coordination effort, mandated by Office of Management and Budget Circular A-67, involves about 20 Federal agencies and approximately 200 non-Federal agencies that collect water data. It affects about 50 Federal agencies and more than 600 non-Federal agencies that use water data.

A major function of the interagency coordination activity during fiscal year 1976 was the preparation and release of "Regional Plans for the Acquisition of Water Data" for each of the 21 major waterresources regions of the United States. The field information was summarized and expanded to include national water-data activities and was released as the "Federal Plan for the Acquisition of Water Data -Fiscal Year 1977." A new edition of the 21-volume "Catalog of Information on Water Data" also was released.

Emphasis was placed during the year on workgroup activities related to production of the 10 chapters for the "National Handbook of Recommended Methods for Water-Data Acquisition," an update of a preliminary report issued in 1972. Two chapters, Chapter 5 on "Chemical and Physical Quality of Water" and Chapter 10 on "Hydrometeorological Measurements," were completed and have been under review by Federal and non-Federal experts in these data fields. Another interagency activity resulted in the release of the report, "Development of a Catalog of Information for Surface Meteorological Data." The report discusses the needs for such data and their availability. It also proposes a systematic means of communicating the information.

Another major activity during the year was preparation and publication of 27 maps in the new nationwide series of four-color State Hydrologic Unit maps (scale 1:500,000), leaving only six State maps to be completed (fig. 52).

\section{COLLECTION, ANALYSIS, AND DISSEMINATION OF BASIC WATER DATA}

The collection and analysis of basic water records, such as stream discharge, lake stage, water levels in wells, the chemical and biological characteristics and sediment loads of streams, and water-use statistics are basic aspects of water-resources investigations. These kinds of measurements are necessary first steps in determining how much and what kind of water is available when and where. Comparisons can then be made of the water used and water needed. Basic water data are essential not only in determining the adequacy of water supplies but also in designing culverts, bridges, dams, and other public works, in planning for actions to prevent or lessen the damages and

TABLE 13.-Participation in water-data coordination activities with the Geological Survey's Office of Water Data Coordination, fiscal year 1976

Activity Participants

Federal:

1. Coordination of Federal water-data programs through the Interagency Advisory Committee on Water Data.

32 Federal agencies.

2. Development of recommended methods for collecting water data; includes Coordinating Council for Water-Data Acquisition Methods (18 Federal agencies).

25 Federal agencies and 170 scientists in 10 working groups.

3. Design and development of national system for handling water data through Federal Interagency Water Data Handling Work Group.

4. Design of small-watershed network for data on water quality; Ad Hoc Working Group on Water-Quality Data Needs for Small Watersheds.

5. Develop improved communication for interagency coordination, through the Interagency Working Group on Improved Communications Mechanisms.

6. Field coordination and development annually of 21 regional plans and a Federal plan for water-data acquisition.

13 Federal agencies.

8 Federal agencies.

8 Federal agencies

28 Federal agencies and 140 field officials.

Non-Federal:

1. Consultation with non-Federal community of data users through the Advisory Committee on Water Data for Public Use.

2. Review and consultation with the Ad Hoc Working Group on "National Handbook of Recommended Methods for Water-Data Acquisition."

3. Assessment of river quality through an Ad Hoc Working Group of the Advisory Committee on Water Data for Public Use.

9 Members.

4. Develop improved communications for coordination activities through an Ad Hoc Working Group on Improved Communica tions Mechanisms. 

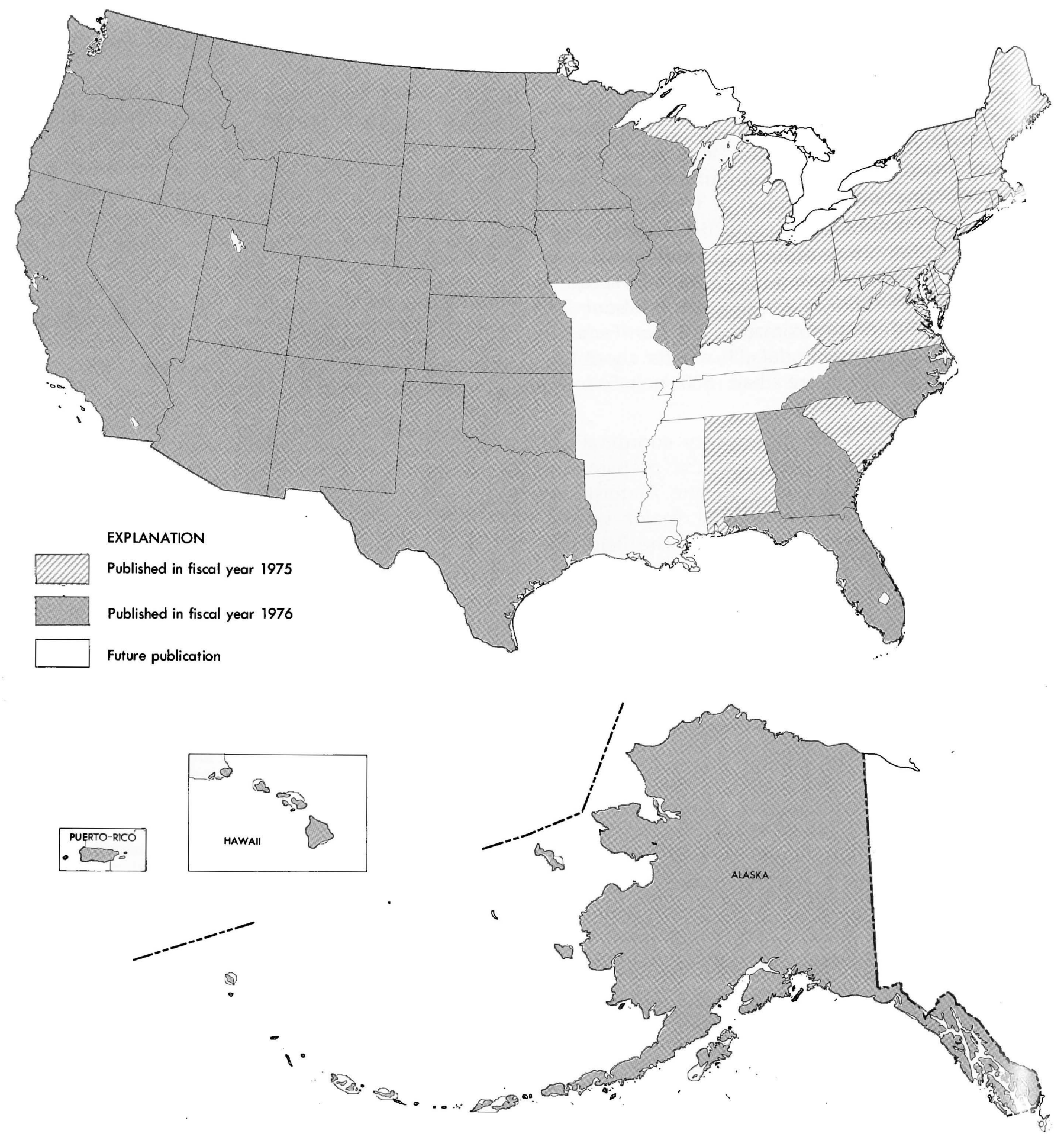

FIGURE 52.--Location of areas covered by maps published in the Survey's series of State Hydrologic Unit maps (scale 1:500,0:0).

impacts of floods and droughts, in determining the feasibility of water-power and irrigation developments, and to some extent in planning projects for water-pollution control, navigation, and outdoor recreation. About 40 percent of the water funds that ports basic-data activities-the largest single major element of the National Water-Data System.

In 1976, the Survey maintained continuous discharge records at 7,820 stream sites, analyzed v/ater quality at more than 5,000 stream sites, and measured water levels or other parameters periodically in nore than 21,000 wells (table 14). 
TABLE 14.-Number and type of measurement sites (stations) of the Geological Survey, July 1976

\begin{tabular}{|c|c|c|c|c|c|}
\hline Type of station & $\begin{array}{c}\text { Federal } \\
\text { program }\end{array}$ & $\begin{array}{c}\text { Federal- } \\
\text { State } \\
\text { Cooperative } \\
\text { program }\end{array}$ & $\begin{array}{c}\text { Other } \\
\text { Federal } \\
\text { agency } \\
\text { programs }\end{array}$ & $\begin{array}{c}\text { Non- } \\
\text { Federal } \\
\text { program }{ }^{1}\end{array}$ & Total \\
\hline \multicolumn{6}{|c|}{ SURFACE-WATER FLOW OR CONTENTS } \\
\hline TOTAL & 792 & 12,728 & 2,483 & 591 & 16,594 \\
\hline Continuous discharge & 713 & 4,891 & 1,827 & 389 & 7,820 \\
\hline Partial discharge (high flow. and/or low flow) & 54 & 7,395 & 472 & 42 & 7,963 \\
\hline Lake reservoir and contents & 25 & 442 & 184 & 160 & 811 \\
\hline \multicolumn{6}{|c|}{ SURFACE-WATER QUALITY } \\
\hline TOTAL & 745 & 4,216 & 1,230 & 39 & 6,230 \\
\hline Surface-water stations (excluding temperature only) & 504 & 3,510 & 955 & 38 & 5,007 \\
\hline Sediment stations & 241 & 706 & 275 & 1 & 1,223 \\
\hline \multicolumn{6}{|c|}{ GROUND WATER } \\
\hline \multicolumn{3}{|c|}{$\begin{array}{l}\text { Sites at which water levels and/or pumpage } \\
\text { are collected annually or more frequently } \\
\text { Approximate number of sites at which well or spring records } \\
\text { are maintained by computer file }\end{array}$} & \multicolumn{2}{|c|}{21,400 (total) } & \\
\hline
\end{tabular}

1 Includes permittees and licensees of the Federal Power Commission.

Most of the streamflow and stream-quality data that the Survey collects and analyzes are published not only in various Federal and State reports but are also filed in computer storage. WATSTORE, the data storage and retrieval system for the National Water-Data System, now contains approximately 70 percent of the streamflow and water-stage data and 35 percent of the quality of ground- and surface-water data collected by the Federal sector.

Two major files in WATSTORE were made available to outside users in 1976, and several Federal and State agencies have registered as users. Those files are the Daily Values File and Station Header File. The enormous volume of surface-water data collected by the U.S. Geological Survey's Water Resources Division and other agencies may be accessed directly by users nationwide through their own computer terminals. These two files plus others in the WATSTORE system are available through more than 50 terminals in U.S. Geological Survey field offices.

In 1976, WATSTORE was augmented by the addition of the Ground Water Site Inventory (GWSI) data base. This data base contains basic physical, geohydrologic, and geologic data about wells, springs, test borings, and other sources of ground water. By the end of the year, the GWSI data base contained records for more than half a million sites. By 1980 it is expected to grow to a million records.

The National Water Data Exchange (NAWDEX) was established in 1976 to assist users of water data to identify, locate, and acquire needed data. It provides a nationwide service for indexing and describing the characteristics of data available from the entire spectrum of data-collection activities throughout the Federal and non-Federal sectors of the water-data community. Requests for needed water data are received by a central program office and referred to those organizations that can best respond to the request. NAWDEX maintains two computerized data bases: (1) a Water Data Sources Directory, which identifies and describes more than 300 organizations that collect water data, and (2) a Master Water Data Index, which currently identifies and describes the water data available from more than 61,500 sites nationwide. The contents of the Index are expected to triple in 1977. As of October 1976, the NAWDEX organization was composed of four Federal and three non-Federal members.

During the year, major emphasis was placed on "baseline water quality." The baseline surface-waterquality concept involves a system of continuing multipurpose measurements of stream quality designed to be the factual base for waste-management and watersupply studies by all concerned levels of government. During fiscal year 1976, 345 stream sites were operated as part of the National Stream Quality/Quantity Accounting Network (NASQAN).

More than 40 chemical, physical, and biological characteristics (table 15) are being measured at each of the 345 NASQAN stream sites (fig. 51); in addition to these analyses, radiochemical determinations are being made at 50 sites, and pesticide-residue determinations are being made at 153 of the network sites. The NASQAN program provides balanced and unbiased information for evaluating stream-quality conditions and changes. In terms of Federal interest, NASQAN is designed to respond to the stream-information requirements of agencies such as the Water Resources Council, the Council on Environmental Quality, and the U.S. Army Corps of Engineers and of 
special groups such as the National Commission on Water Quality. The NASQAN network complements the efforts of the Environmental Protection Agency in fulfilling the information requirements specified under Section 104(a)(5) of the Federal Water Pollution Control Amendments of 1972 (Public Law 92-500), which calls for the establishment of a nationwide water-quality surveillance system.

Increasing implementation of the Federal Water Pollution Control Amendments of 1972 (PL 92-500) and the added impetus of the Safe Drinking Water Act (PL 93-523) directed more attention to the quality of ground water. In addition to more than 50 studies in the Federal-State Cooperative program concerned with waste-disposal sites such as landfills, industrialwaste ponds, and unsewered urban areas, federally sponsored subsurface waste studies are increasing.

TABLE 15.-Characteristics measured at NASQAN stations [Frequencies: C, continuous; $D$, daily; $M$, monthly; $Q$, quarterly]

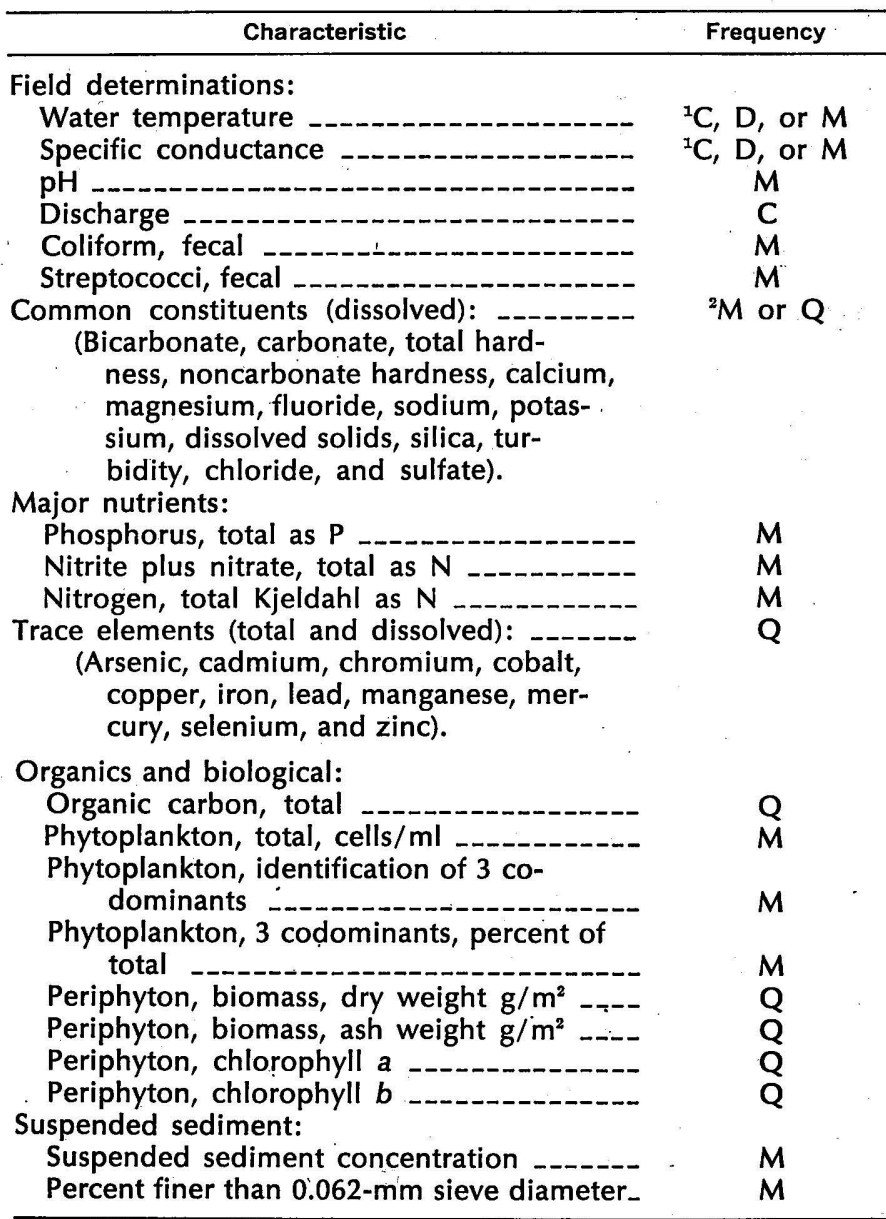

1 Continuous or daily depending upon whether the station is equipped with a monitor or whether daily observations are made. Monthly meas urements made at stations where a long-term record is available.

.2 Quarterly or monthly, depending upon whether relationships have been conductance and concentrations of various

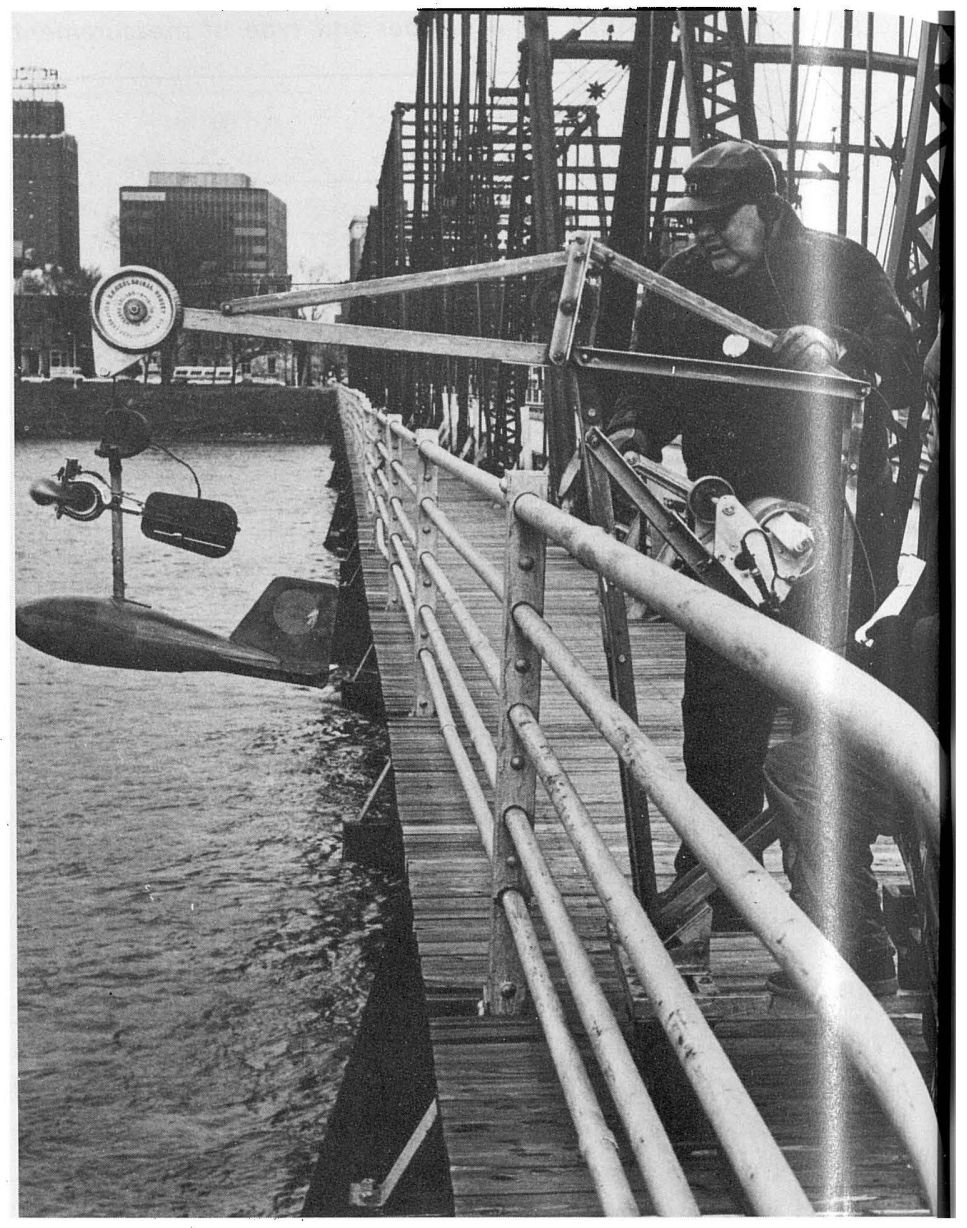

Current-meter measurement of flow of Susquehanna River at Harrisburg, Pa.

The subjects include pollution from feedlots, mine waste, and the residuals of chemical-warfare manufacture, research in seismic effects of deep-well injection, development and use of borehole geophysical tools for evaluating injection aquifers, and the impacts of disposal of treated municipal wastewater in pits on Long Island.

The Survey is conducting a pilot program of riverquality assessments. The first study was completed in 1976 on the Willamette River basin of Oregon. Results of the study have had a significant impact on decisionmaking processes for the basin, and nationally as well. The study found that further waste treatment, in addition to existing basin-wide treatment, would produce insignificant improvement in the dissolvedoxygen concentrations in the river and that augmentation of the low flows from headwater streams was necessary for maintaining the State's high dissolvedoxygen standards.

\section{SUPPORTING SERVICES}

In addition to the publishing of reports and maps, this support program includes management of the 
Water Resources Division Training Center at Lakewood, Colo. In 1976, 38 courses in hydrology were given to 850 scientific and technical personnel. Participants included not only Survey personnel but also representatives of cooperating State agencies and foreign hydrologic organizations. Some training courses were held at other locations that provided either a hydrologic setting or the laboratory facilities essential to the presentation of the course material.

The subject matter of the courses ranged from instructions on the operation of hydrologic instruments to the programming of sophisticated hydrologic computer models. The classroom training is coupled to a video-tape production system that provides video tapes of courses for loan to all offices.

Another supporting service is the Central Laboratory System of the Water Resources Division. The newly constructed laboratory complex in Denver,

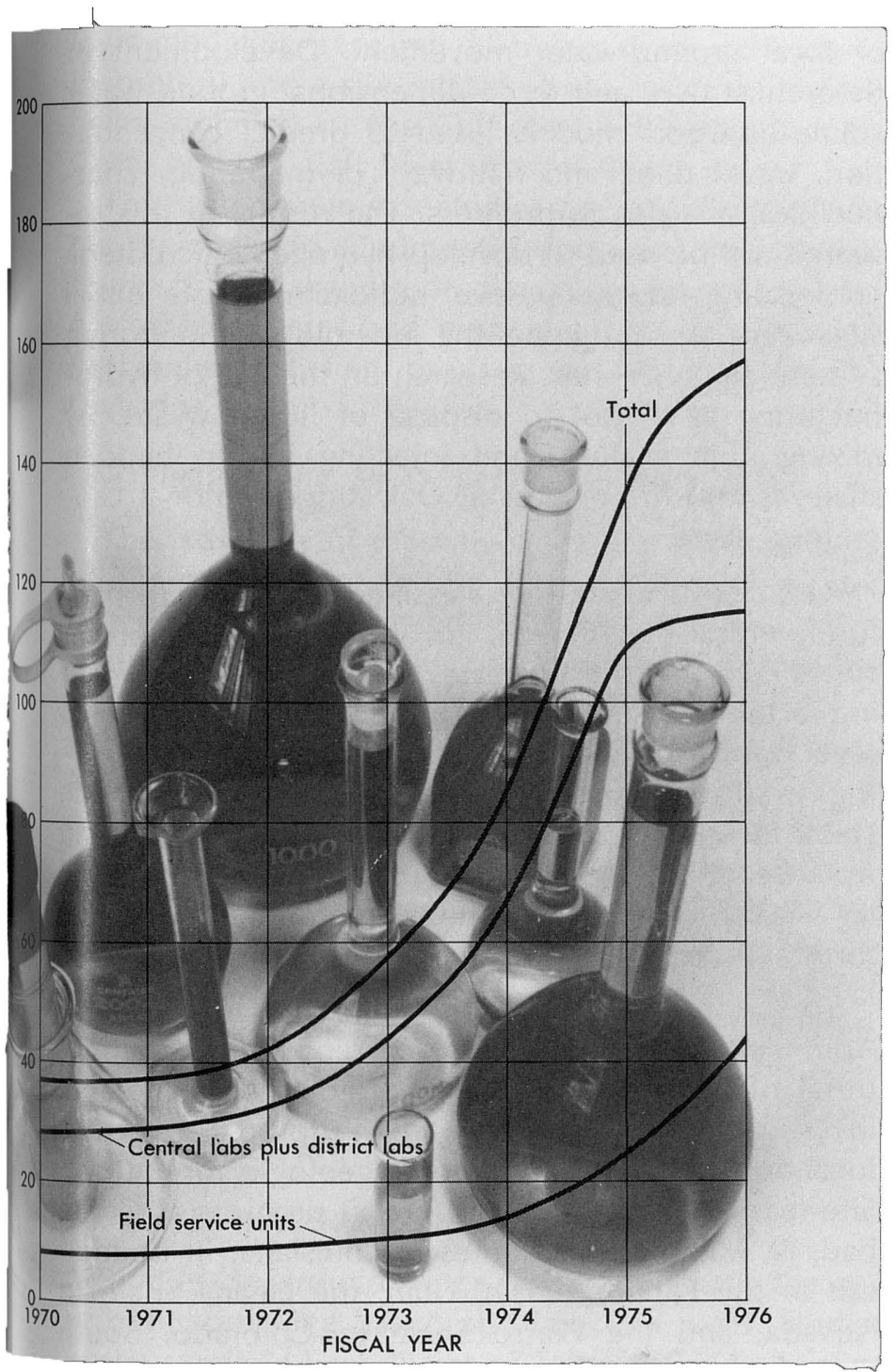

FIGURE 53.-Number of water-quality analyses performed by the Water Resources Division, 1970-76.
Colo., and the Atlanta, Ga., and Albany, N.Y., facilities, together, have the capacity for determining virtually all the physical, chemical, and biological characteristics of water samples for the national program. During fiscal year 1976, about 114,000 analyses were made by the Central Laboratory System (fig. 53). The Denver laboratory also houses 16 project offices concerned with methods development and applied research in water resources.

\section{INTERNATIONAL ACTIVITIES}

For more than two decades, the Water Resources Division has been active in technical assistance programs under the United States Foreign Assistance Act, sponsored mostly by the Agency for International Development and its predecessors in the Department of State. In the last few years, however, much of the technical-assistance activity has been funded by reimbursable agreements with the Department of State.

The Division has been appointed by the Department of State as the lead agency for the U.S. National Committee on Scientific Hydrology and provides its Secretariat. The Committee represents the hydrologic community of the United States primarily for the International Hydrological Program, under the aegis of UNESCO, but it also concerns itself with the Commission for Hydrology of the World Meteorological Organization. Highlights of the 1976 program of technical assistance included:

- Provision of technical advice on water resources to the Kingdom of Saudi Arabia. Comparative studies were made of alternative sources of water to supply Ar Riyad area.

- Improvement of existing geologic maps by interpretation of Landsat imagery of the Yemen Arab Republic. Test drilling and monitoring produced new information on occurrence and fluctuations of ground water.

- Planning and supervision of test and production drilling programs in water-short areas of Kenya.

\section{Critical National Water Problems}

\section{COAL HYDROLOGY}

Many of the coal-hydrology projects are concerned wholly or partly with the adequacy of water supply for direct mining use, coal gasification, cooling and processing use, or transport via slurry pipelines. In the latter case, 1976 saw increased concern on the part of the States and the Congress with plans to utilize ground water from the deep Madison aquifer, underlying parts of Wyoming, Montana, South Dakota, and Nebraska, for transport of coal in a slurry pipeline. These concerns prompted Congress to direct the U.S. 
Geological Survey to make a 5-year study of the Madison aquifer and the availability of water, as well as possible impacts through its use. Exploratory drilling began in 1976, with the first test well in northeastern Wyoming. Additional sites may be selected in Wyoming, Montana, and South Dakota; drilling to depths as great as 3,050 meters $(10,000$ feet) may be required. The resulting improved model of the Madison acquifer is expected to permit a quantitative assessment of the water supply available from the regional system.

Coal-hydrology studies involve the concurrent determination of available water supplies and baseline water-quality data reflecting pre-mining or current mining and reclamation conditions. Such information is essential to the assessing of any future impacts caused by additional mining and by new conversion industries. It is expected that baseline-monitoring needs will increase as coal-leasing restrictions are eased and reclamation standards are adopted.

\section{OIL-SHALE HYDROLOGY}

Water problems, and potential environmental impacts related to mining, waste disposal, and refining of oil shale, are major constraints to oil-shale development. The oil-shale program is providing the data on the surface- and ground-water hydrology needed to: (1) predict the amount and quality of ground water present in the oil shale and how it will affect underground mining, surface mining, and in-situ oil-extraction processes; (2) predict the effects on ground and surface water of the disposal of a tremendous volume of spent shale; and (3) provide baseline data to enable the Department of the Interior to evaluate the long-term impacts of oil-shale development on water quantity and quality both in the oil-shale region and on the Colorado River basin.

The area under immediate study covers about $64,750.1$ square kilometers (25,000 square miles) in Colorado, Utah, and Wyoming and includes four Federal prototype leases, as well as several developments on private lands. In addition to baseline monitoring of the surface- and ground-water quantity and quality, basic hydrogeologic data on aquifer properties and the relation of surface water to ground water are being obtained by core drilling and aquifer testing and are being used to develop predictive models of the hydrologic system to simulate the effects of mining. Geochemical and geomorphic research is determining the pollution risks of the wastes that are associated with mining and surface processing.

\section{NUCLEAR HYDROLOGY}

One method for managing nuclear waste is to store acteristics of the geologic formations at the disjosal site are such as to isolate the waste from the env ronment until radionuclides in the waste decay to a safe emission level. The length of retention time required is dependent on the half-lives of radionuclides is, the waste, and retention time may be more than teis of thousands of years.

Water is the principal medium in which vaste products can be moved away from a disposal site. Current research, therefore, is aimed at unders:anding the transport of waste in water. This researc 1 includes studies in geochemistry, ground-water n ovement, and solute transport. Geochemical st dies include sorption, solubility of radionuclides, and interaction between waste and geological forma ons. Such studies are performed both in laboratorie: and in the field at waste burial sites. Ground-water $t$ acer studies are in progress in the Amargosa Dese $t$ of Nevada to develop a methodology for determir tion of local ground-water movement. Developme $t$ of theoretical two- and three-dimensional ground-i ater solute-transport models, used to predict conce itration, travel time, and pathways of migrating $r$ dionuclides, are also in progress. The results of th: research will be used to develop hydrogeologic $\mathrm{cr}$ eria for locating future low-level radioactive-waste $I$ urial sites and for designing the hydrologic monit ring systems for such sites. Research on the use of h drofracturing as a tool to dispose of liquid wast mixing it in a slurry and injecting it into be ded shale, is also in progress at Oak Ridge National aboratory, Tenn.

Radioactive wastes are classified according to heir form, either liquid, gas, or solid, and are $\mathrm{fl}$ ther classified as high-level wastes or other wastes ac ording to the level of radioactivity of their source. ighlevel wastes, by definition, result only from reprc essing irradiated reactor fuels. Other wastes in lude spent ion-exchange resins and filter sludges res iting from treatment of contaminated liquids, contami ated air filters, clothing, laboratory equipment, ar i so forth.

To support the Energy Research and Develop nent Administration in its search for repositories fo: disposal of high-level wastes, hydrologic and ger ogic investigations by the Survey are in progress at vi jous locations and involve different geologic forma ons. Site-feasibility investigations are in progress at arlsbad, N. Mex., at salt domes in Louisiana, in be ded salt in the Paradox Basin, Utah, the Eleana Sha e in Nevada, and the Pierre Shale in Colorado, : suth and North Dakota, and adjacent States. Also u: derway is a study of seismicity, a part of the investig tion of bedded sait in New Mexico associated witl the 
injection of oil-field brine in the Central Basin Platform in the area of Texas and New Mexico.

\section{GEOTHERMAL PROGRAM}

Hydrologic investigations are an integral part of the Survey's multidisciplinary Geothermal program. The hydrologic-research activities are intimately related to the geological, geochemical, and geophysical phases of the program, and the projects of the hydrologic specialists involve most of the fields into which the Geothermal program is divided. Resourceassessment projects with emphasis on hydrogeology are being carried out on both regional reconnaissance levels and detailed site-investigation levels.

Hydrologic modeling; water chemistry and physics; techniques of drilling, logging, and hydrologic testing; and environmental effects are other important fields of geothermal research. The hydrologic-modeling research is being done on both a theoretical and a site-related basis. The main regions being modeled are the Gulf coast, the Salton Trough, Calif., and the Raft River area of Idaho.

The water-chemistry studies are coordinated with the regional and site investigations, and they include research and analysis on the geochemistry of geopressured systems and trace elements in support of the Federal leasing program of the Conservation Division.

\section{UNDERGROUND HEAT STORAGE PROGRAM}

The feasibility of repetitively cycling large amounts of thermal energy in the form of heated ground water is being evaluated, including the theoretical analysis of thermal diffusion in ground water and of thermal conductivity of aquifer materials.

Field tests are presently being performed near Mobile, Ala., by the Water Resources Institute at Auburn University, Ala., jointly funded by the Survey and the Energy Research and Development Administration through the Office of Water Research and Technology. The U.S. Geological Survey is serving as technical monitor. Field data from such tests will permit verification of digital aquifer-system models. These models are kindred to models being developed for geothermal studies and waste-heat disposal studies, all of which are complementary.

\section{GROUND-WATER RECHARGE}

Studies on ground-water recharge include the use of both spreading basins and injection wells. Studies in the semiarid High Plains of Texas and New Mexico are developing methods to predict the amount of water that can be returned to aquifers by examining the fundamental properties that control movement of water into aquifers, the rock-water interactions that occur during storage, and the diffusion-dispersion phenomena accompanying water movement after emplacement. In another area, a report has been completed on the relative merits of various mensuration techniques of the parameters related to the design of pits for artificial recharge on Long Island, N.Y.

Accomplishments to date in these studies on ground-water recharge include:

- Demonstration under experimental field conditions that recharge is technically feasible at selected locations on the southern High Plains.

- Development of a method for determining the permeability of the unsaturated materials above the water table by monitoring air-pressure changes at depth.

- Development of unique instrumentation for extraction of water samples from the unsaturated zone to depths greater than 30.5 meters (100 feet) below land surface. This instrumentation makes feasible the routine monitoring of quality changes in percolating water deep in the unsaturated zone beneath spreading sites.

- Demonstration of the utility of water-quality modeling techniques to predict water-quality changes at depth beneath spreading sites .

- Improvement of core-barrel sampling equipment that has resulted in increased core-sample recovery from unconsolidated or poorly consolidated aquifers.

- Development of geophysical-logging techniques that relate the logged parameters of gamma radiation, neutron response, resistivity, and natural gamma radiation to the movement of recharge water.

- Development of a methodology for visual examination of pore space and demonstration of clogging mechanisms through use of the scanning electron microscope and microanalysis.

\section{MAPPING IN FLOOD-PRONE AREAS}

The mapping program in flood-prone areas, begun in 1969, is directed toward rapid identification of areas subject to inundation. The program has received a high priority to meet flood-plain management and land-use planning needs as expressed in recommendations of the Task Force on Federal Flood Control Policy (House Document 465, 89th Congress) and the National Flood Insurance Act of 1968. During 1973 and 1974, the Federal Flood Insurance Administration (Department of Housing and Urban Development) provided substantial funding to accelerate the program. 
The Geological Survey published about 700 maps of flood-prone areas in 1976. Since the beginning of the program in 1969, the Survey has prepared and printed more than 12,500 maps and 1,000 descriptive pamphlets and has printed 220 maps prepared by the Soil Conservation Service. The maps identify the flood-prone areas of virtually all the developed and developing parts of the Nation. Yet to be mapped are many areas of potential future development, public lands for which management and planning decisions are needed, and recreational lands.

Flood-prone-area maps show on a 7.5-minute quadrangle topographic map base (scale 1:24,000, 1 centimeter on the map equals 240 meters) the approximate boundaries of areas having a 1-percent chance of being flooded in any given year. The maps are used extensively to meet local planning needs and to meet objectives of the National Flood Insurance Act of 1968 and the National Disaster Protection Act of 1973.

The flood-prone-area maps are stocked in field offices of the Water Resources Division for general distribution to the public without charge. As many as 200 separate requests each month are received in some of the field offices.

In addition to conducting reconnaissance flood mapping, the Geological Survey is one of several agencies that are conducting flood-insurance studies for the Department of Housing and Urban Development. These studies include flood-profile information and delineation of 100-year floods on city or community maps of scales such as 1:4,800 (1 centimeter on the map equals 48 meters). Since 1970, such studies have been undertaken by the Survey in about 400 communities.

Documentation of major flood events that occur every year in the United States provides flood information required for the prudent management of flood-plain land. In 1976 the U.S. Geological Survey and the National Weather Service (National Oceanic and Atmospheric Administration) published joint reports on investigations of three large floods. Cooperative reports on disastrous floods during February and July 1976 in Maine and Colorado, respectively, are in preparation. In addition, during 1976, the Geological Survey released to the open file investigative reports for five severe floods covering parts of six States. The flood caused by the failure of Teton Dam, Idaho, in June 1976, was documented by the publication in August 1976 of 17 hydrologic atlases of the area affected (HA 565-HA 581). A formal report on the Teton Dam flood is in progress.

The National Water Data Storage and Retrieval

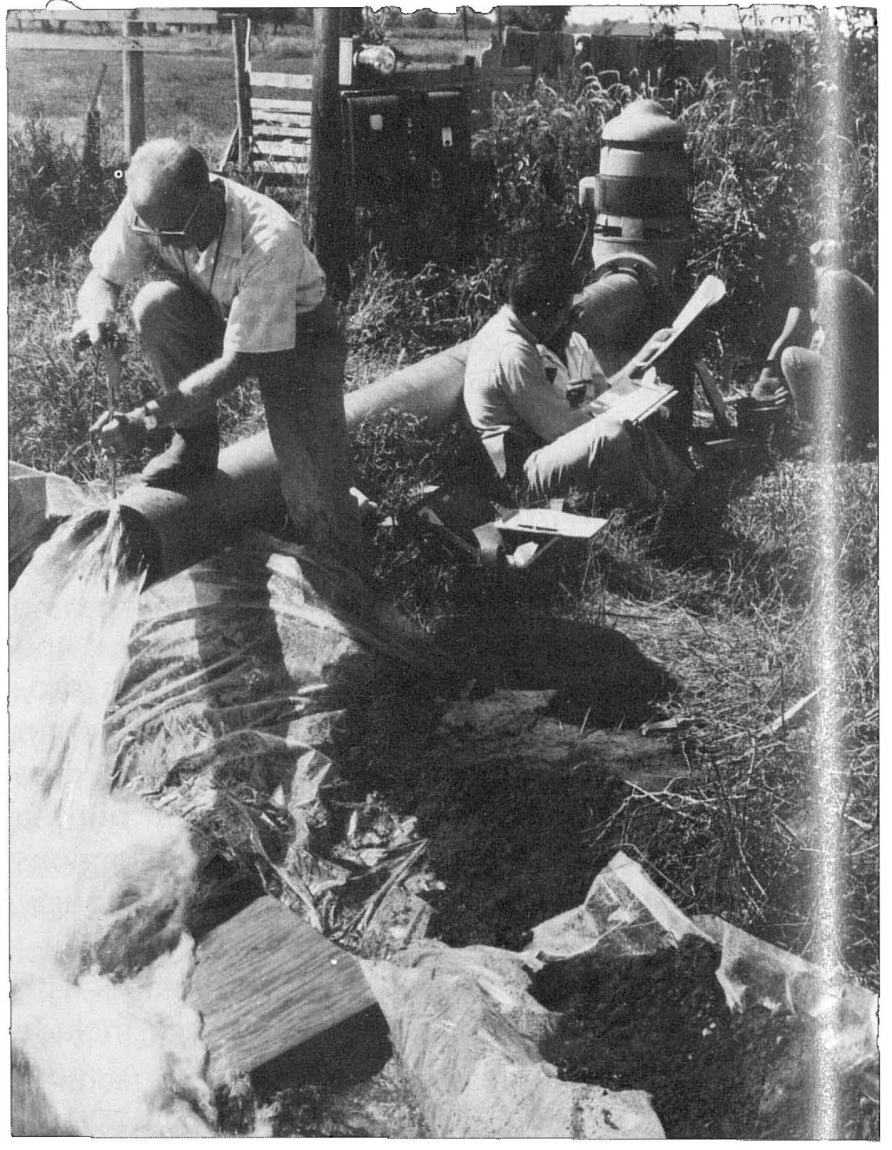

Measuring rate of flow in pumping well.

flood records for more than 12,000 surface-v:ater sites and contains more than 325,000 peak observations. In 1976, this file of annual maximum streamflow (peak discharge) values and gage-height (s!age) values was released for public use through the Survey's WATSTORE system.

\section{SUBSURFACE WASTE STORAGE}

The Survey's subsurface-waste-storage pro ram consists of: (1) regional delineation and descriftion of deep saline-aquifer systems that are poten ially useful for waste storage, (2) assessment of the digradation of ground-water quality that has been ca: sed, or may be caused, by waste disposal or other :xisting activities, (3) determination of the field valu.s of hydrodynamic dispersion of waste in ground $v$ ater, and (4) other fundamental studies in geology, hy trology, chemistry, and physics related to the move nent of waste in aquifers. The purpose of the progran is to define the hydrologic principles and techn ques relevant to the use and management of subsu face space for storage of waste to prevent endang ring usable water resources. The pressures to store $w$ stes underground keep building because of incre sing legal restraints on surface discharge and dis osal practices. The impact of contamination on gr und 
water is long lasting, although usually limited in area. Each year, however, many new points of pollution are created and few are eliminated.

Studies related to potential waste-disposal sites or to impacts of existing waste-disposal activities on ground-water quality in 1976 include: development and testing a method of measuring tectonic stress in boreholes to evaluate the potential of injectionpressure-induced seismic events; characterizing the impact and quality of water reaching the water table beneath recharge basins utilized for the disposal of treated municipal sewage on Long Island; mapping potential waste-injection aquifers o. the Atlantic and Gulf Coastal Plains; and investigating the generation and movement of leachate from oil-shale and coal strip-mine wastes.

Only part of the subsurface-waste-storage program is directly concerned with the impacts of potential ground-water degradation from energy-related activities such as mine-waste disposal. However, data on industrial waste-injection problems and potential disposal horizons (porous rock formations), or on the percolation from surface disposal sites, industrialwaste lagoons, and spray irrigation of wastewater, all find applications in energy developments. Many of the studies that yield data and insights into waste movement involve areas where waste disposal was practiced for many years before pollution was observed or before the public became concerned. Studies of these sites will show the long-term effects of waste movement, dispersion, dilution, retention, and diminution and will provide information that can be used in the planning of all kinds of waste-disposal developments, including those that are energy related.

\section{ESTUARINE AND COASTAL STUDIES}

Estuarine and coastal studies determine the substances entering estuaries and coastal waters, their movement in the waters, their effect on the environment, and their subsequent fate; they determine factors and impacts affecting present and future usability of freshwater supplies in coastal areas. Maninduced stresses on estuarine ecosystems frequently result from increased urbanization. These stresses are manifested in the need for disposal of sewage and storm runoff, improved navigation facilities, expanded water supplies, and increased energy requirements. The primary purpose of the Geological Survey's water-related projects in estuaries is to provide data for design and to evaluate the hydraulic, chemical, and biological changes induced by human activities.

During 1976, estuarine and coastal studies continued on the biogeochemistry and circulation patterns in San Francisco Bay. A comparative study of major estuaries on the west coast was undertaken. Studies continued on the impact of waste disposal in the Rhode River estuary, a tributary to Chesapeake Bay, and in the Duwamish River estuary of Washington. Digital flow models of estuarine dynamics are being developed to appraise some of the present and future effects and interrelationships of natural and manmade impacts on estuaries. Two-dimensional models of water circulation and solute transport are currently being used in studies of Tampa Bay in Florida and Port Royal Sound in South Carolina. Research into the development of three-dimensional models is continuing. Studies to evaluate the flow patterns, freshwater-saltwater balances, sediment transport, and ecologic composition of estuaries are currently being conducted in California, Delaware, Florida, Maryland, North Carolina, Oregon, South Carolina, Texas, and Washington. Many of these studies are cooperative efforts with other Federal, State, and local agencies that are attempting to define the consequences of planned changes in estuarine water balances.

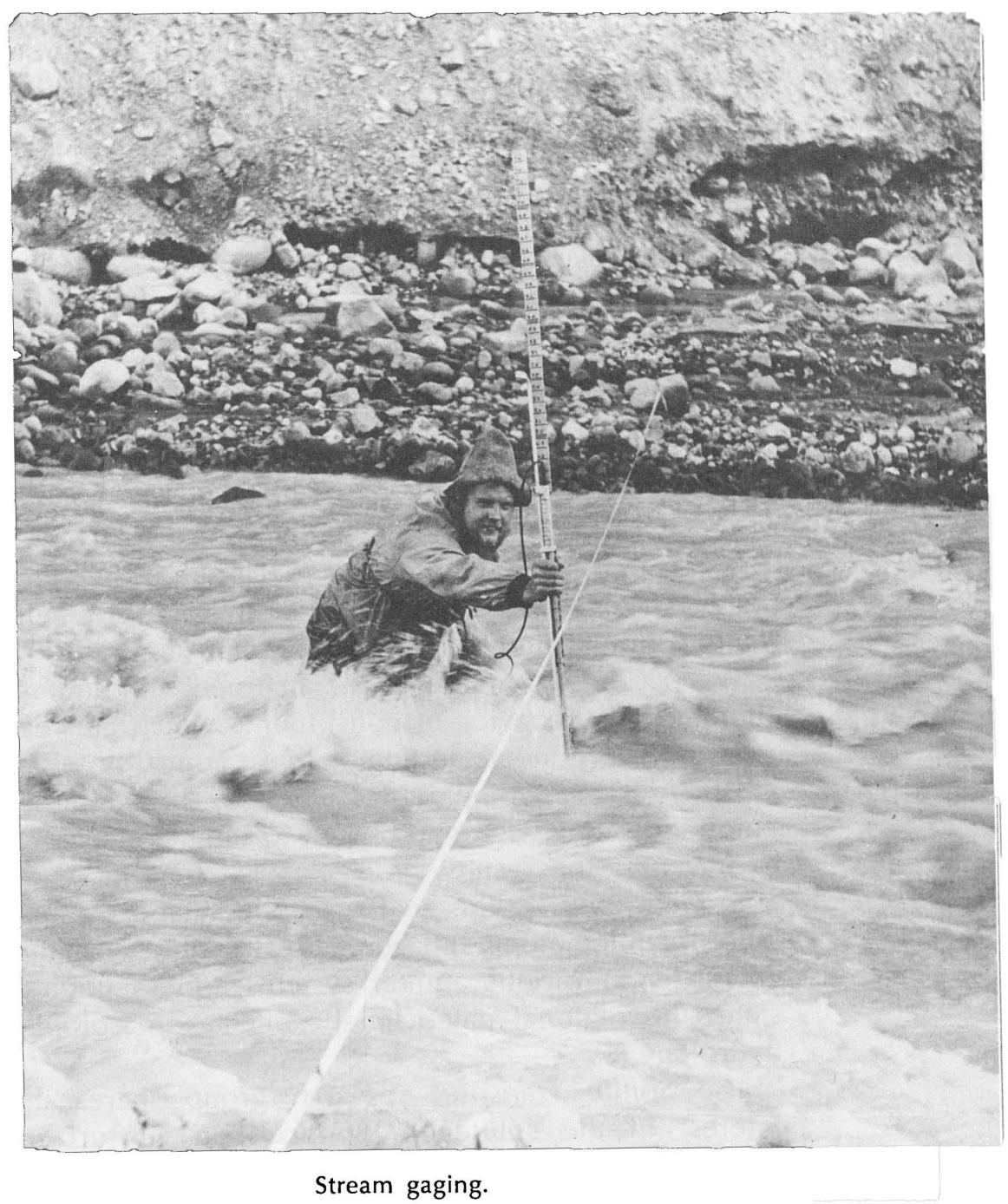




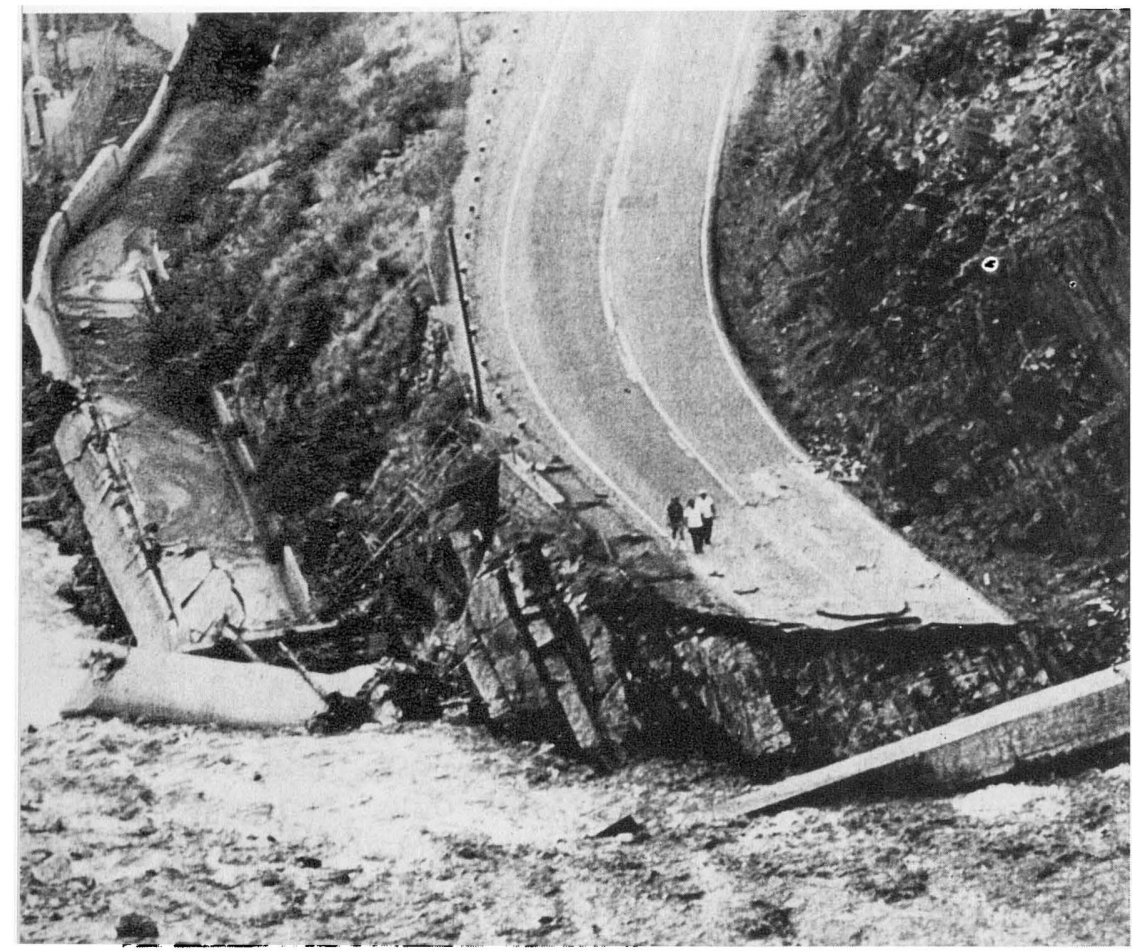

Destruction caused by flash flood on Big Thompson River, Love land, Colo. (Photograph courtesy of United Press International, Inc.)

\section{Research and Development}

Mission: to understand hydrologic systems sufficiently well to predict quantitatively the response of hydrologic systems to stress-both natural and manmade.

Water Resources Division research supports the programs of the Division by (1) providing operational products (analytical methods, instrumentation for data collection, and predictive models), and (2) making available to the Division a group of consultants and instructors to spend up to 30 percent of their time in district consultation and in-house teaching. The research program accounts for about 17 percent of the Division's total appropriation. It has been divided into a number of subdiscipline areas:

Water Chemistry research is concerned with understanding the behavior of constituents which can be measured. An understanding of these controls assists in the design of appraisal studies by providing a guide indicating where and when to sample and how to interpret the results.

In Geochemistry the goal is to understand the relation of mineralogy and geologic structure to water chemistry in various aquifer systems and to understand the regional paleoclimatic effects on isotopic hydrology.

The Solute Transport research group shares its interest in the solutes of surface and subsurface jectives are to increase the understanding of the factors which determine the concentrations of particular solutes and to develop methods for identification of the most relevant processes affecting the concentrations and for measuring the parameters controlling these processes.

The objective of the Hydrogeology discipline is to obtain the maximum useful information possible from a point source (a borehole, for example) and surface mapping and combine that data with geologic insight to extrapolate the data for regional incerpretations.

The Groundwater Physics research objectives are to develop techniques for evaluating and manaçing ground-water systems using mathematical morels and for conducting field studies to understand fundamental principles of movement of fluids through porous media.

In the Surface Water discipline, emphasis is placed on developing and improving flow models that sirulate natural rainfall and runoff situations. The molels can then be used for estimating flood peaks, determining effects of temperature on winter rur off, making step-regression studies of inflow to reserv jirs to develop flow forecasting for low-flow periods, ind

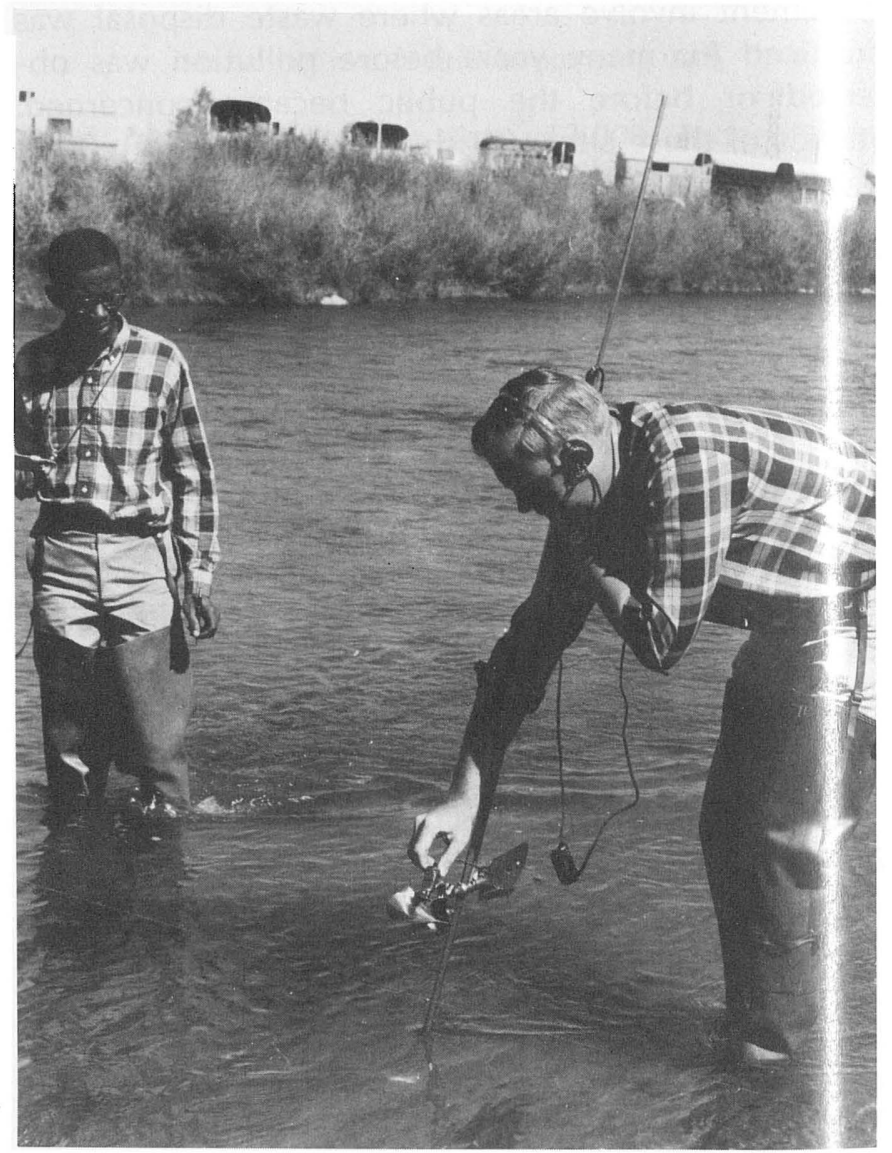

Measuring and recording streamflow, velocity, and depth iformation. 
determining reservoir-yield and bank-storage relations.

Surface Water Physics is involved in numerical simulation of one-, two-, and three-dimensional flow and transport models.

The Sediment research discipline is working to develop deterministic and stochastic models of sediment-transport processes. These models should aid in assessing the causal factors involved in changing stream-sediment loads with time, the rates at which rivers change their morphologic features, particularly as to catastrophic events and sources, pathways, and sediment sinks in rivers.

The Snow and Ice research group is concerned with defining the hydrologic cycle of major basins in the western mountains where as much as 90 percent of the runoff is thought to be derived from snowmelt. As some glaciers respond in a very sensitive way to slight, long-term changes in climate, the group is also studying the response of glaciers to changes of input (snowfall) and output (melting), the meteorological factors which determine input and output, and the climatic change as recorded by glaciers, glacier runoff, and glacier hazards.

Unsaturated Zone and Evapotranspiration research involves studies of evapotranspiration and flow in the unsaturated zone to evaluate the feasibility of such water-management techniques as: artificial groundwater recharge, clearing phreatophytes or lowering the water table to salvage evapotranspiration from ground water, modification of upland vegetation to increase runoff, and evaluation of radioactive-waste burial grounds.

Ecology research has varied objectives and approaches. They are mainly problem- or environmentoriented and all are water related. The environments studied range from mountains to estuaries, from the arctic tundra to deserts, and from lakes and streams to wetlands and ground-water reservoirs. Living organisms receive most emphasis in all projects and range in type from bacteria to fish and from microscopic algae to giant cacti and forest trees.

The basic objective of Hydrologic Systems research is to develop mathematical techniques and digital computer programs to solve complex hydrologic problems.

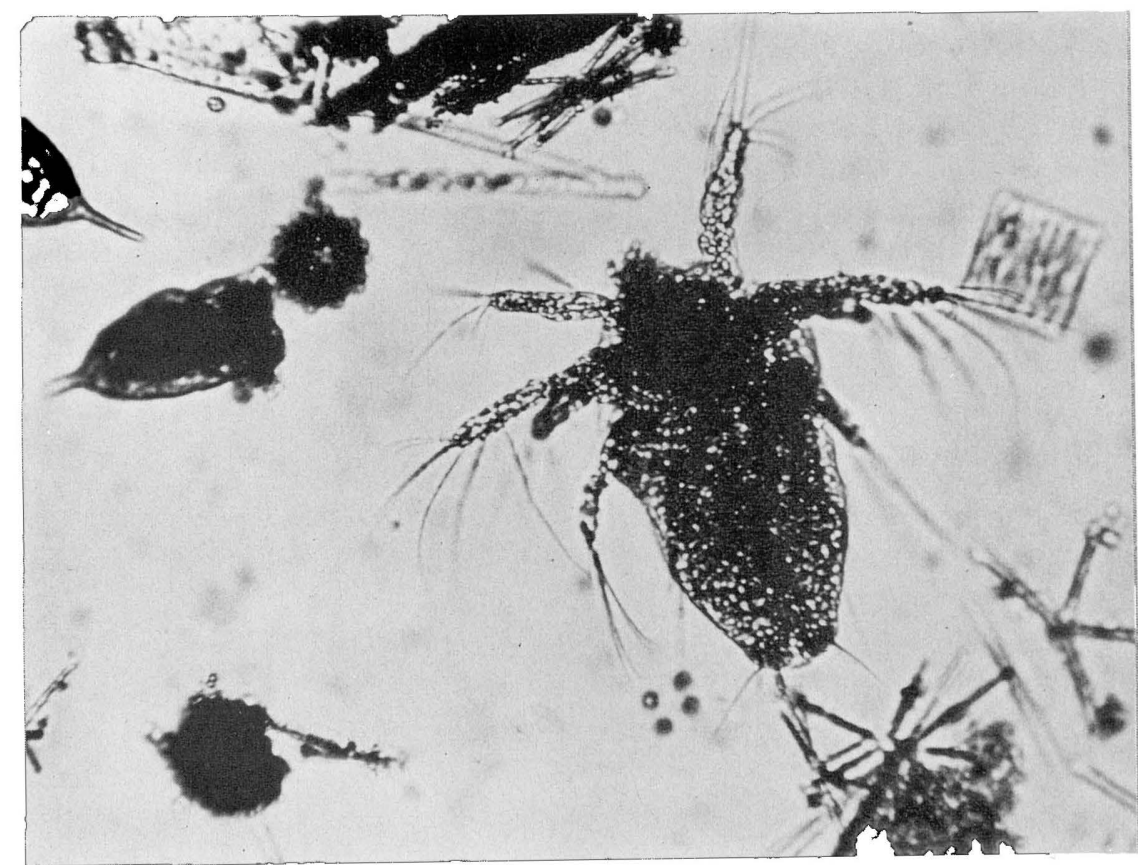

Sample of river water seen through a microscope; both aquatic plants and animals are visible.

\section{SELECTED REFERENCES}

Davis, G. H., and Wood, L. A., 1974 Water demands for expanding energy development: U.S. Geol. Survey Circ. 703. $14 \mathrm{p}$.

Edwards, Melvin D., 1976, A national water data exchange: Remarks presented at the Symposium on Environmental Monitoring: Status, Trends and Data Banks, American Chemical Society, New York, N.Y., April 4-9, 1976, 5 p.

Ficke, J. F., and Hawkinson, R. O., 1975, The National Stream Quality Accounting Network (NASQAN)-Some questions and answers: U.S. Geol. Survey Circ. 719, 23 p.

Marcus, Philip A., 1976, Directory to U.S. Geological Survey program activities in coastal areas 1974-76: U.S. Geol. Survey Bull. 1428, 154 p.

Meyer, Gerald, 1975, Ground water-the big picture: Remarks before the 8th Annual Water Resources Seminar, University of Minnesota, Nov. 24, 1975, 6 p.

Pickering, R. J., 1976, Measurement of "turbidity" and related characteristics of natural waters: U.S. Geol. Survey OpenFile Rept. 76-153, 7 p.

Rickert, David A., and Hines, Walter G., 1975, A practical framework for river-quality assessment: U.S. Geol. Survey Circ. 715-A, 17 p.

U.S. Geological Survey, 1975, WATSTORE, U.S. Geological Survey's national water data storage and retrieval system: U.S. Geol. Survey, 15 p. 


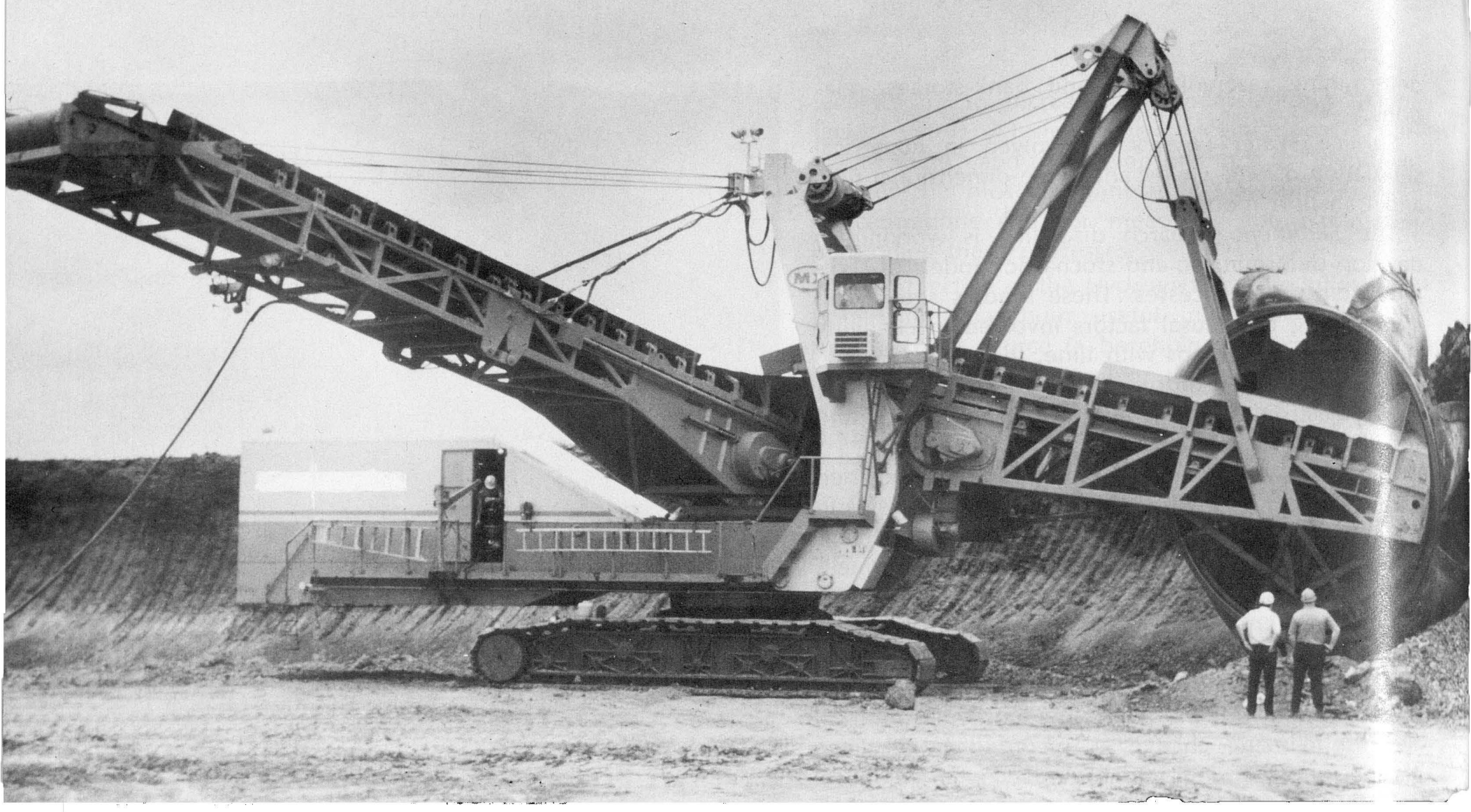

Above, a bucket wheel excavator being used to strip overburden above coal seam at a strip mine. Bottom, offshore oil and gas platforms ii. the Santa Barbara Channel, California. The USGS Conservation Division supervises operations such as these on Federal and Indian lands.

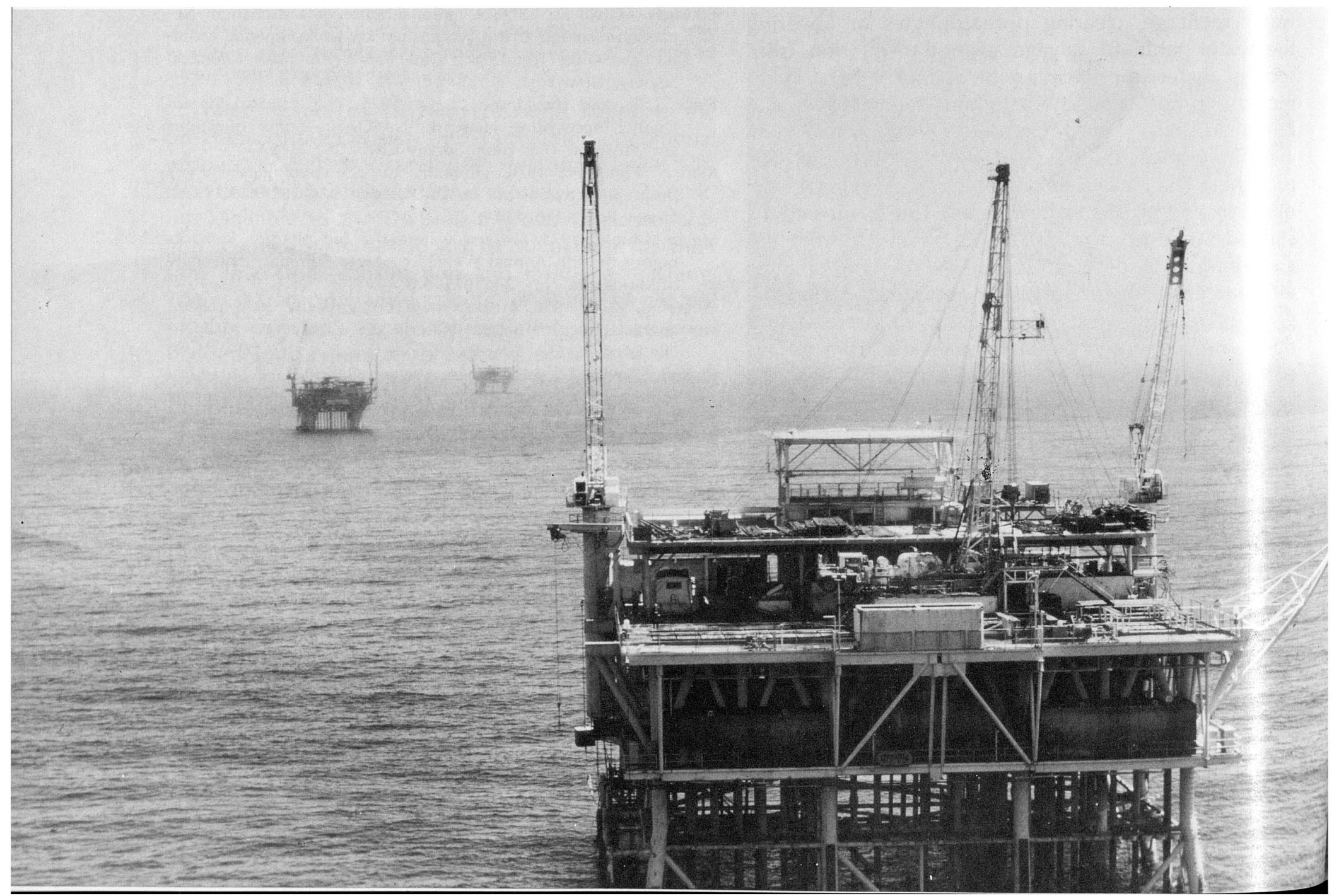




\section{Conservation of Lands and Minerals}

\section{OVERVIEW}

The Conservation of Lands and Minerals activity has three major missions:

- Classification of public lands according to their content of leasable minerals and their value for water-power and water-storage purposes.

- Evaluation of mineral tracts that are subject to competitive leasing.

- Supervision and regulation of exploration, development, and production of minerals on Federal, Indian, and Outer Continental Shelf lands authorized by lease, license, and prospecting permits, including the collection of royalties and certain rentals that result from those operations.

From data acquired in the pursuit of these missions, the Geological Survey provides technical advice and information on the leasing or disposal of mineral rights, as well as resource-management information, to land-management agencies, including the Bureau of Land Management, the Bureau of Indian Affairs, the Bureau of Reclamation, the Forest Service, the General Services Administration, and the Department of Defense. The Geological Survey also implements and enforces all lease stipulations and operating regulations and certain leasing regulations that are issued by the Bureau of Land Management and the Bureau of Indian Affairs.

The importance of Federal and Indian lands to the Nation's domestic supply of energy and mineral resources is illustrated in figure 54. In fiscal year 1976, 8 percent of the coal, 9 percent of the uranium, 18 percent of the oil, and 23 percent of the natural gas produced in the United States came from leased Federal and Indian lands. The share of the Nation's coal that was produced on Federal and Indian leases has increased about 300 percent since 1970, uranium has increased nearly 100 percent, and gas produced has increased almost 44 percent; oil has remained essentially unchanged. In fiscal year 1976, the value of all energy and mineral commodities produced

FIGURE 54.-Production from Federal and Indian lands percentage of total U.S. production in fiscal year 1976.
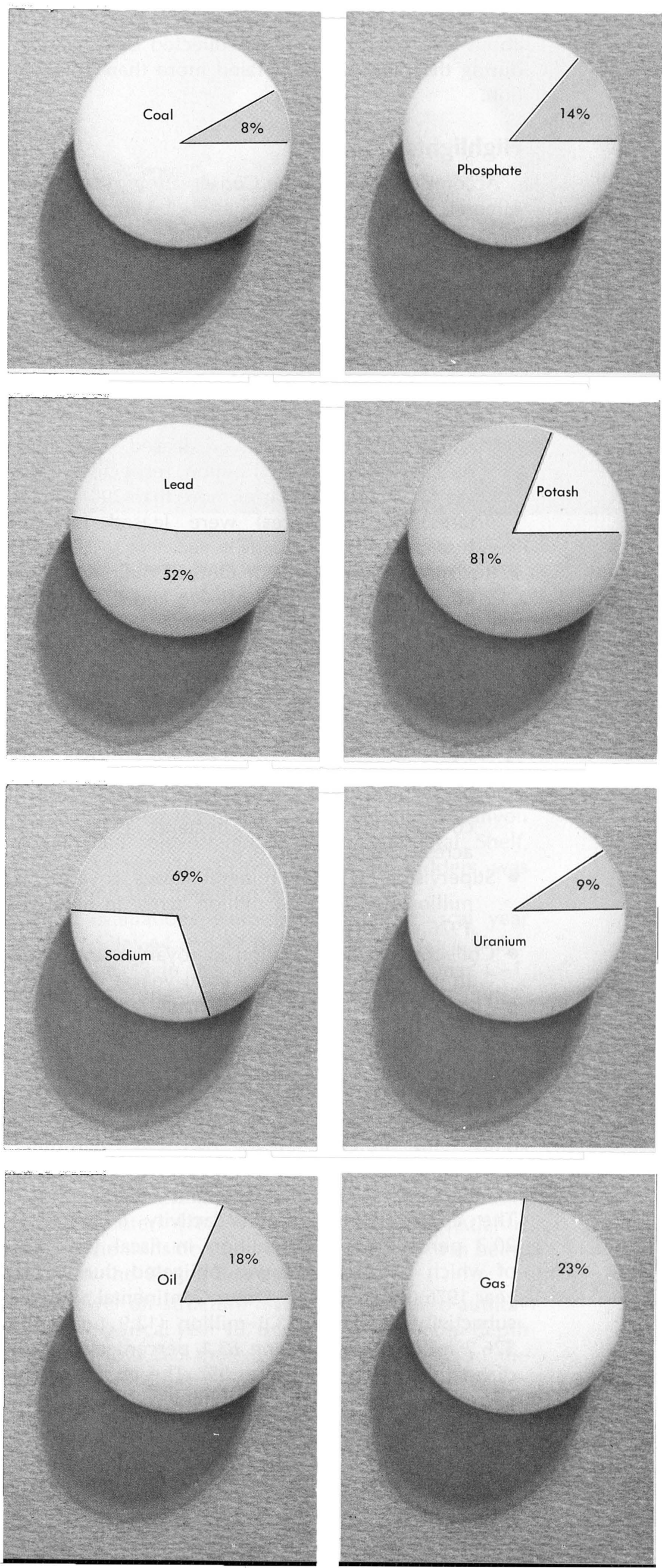
from leased Federal and Indian lands amounted to about $\$ 6.8$ billion. Royalties collected by the Survey during the same period totaled more than $\$ 931 \mathrm{mil}-$ lion.

\section{Highlights}

Accomplishments of the Conservation of Lands and Minerals activity in 1976 included the following:

- Completion of tract evaluations for four Outer Continental Shelf lease sales covering 2.8 million hectares (6.9 million acres) in fiscal year 1975, four sales covering 1.9 million hectares $(4.7$ million acres) in fiscal year 1976, and one sale covering more than 300,000 hectares $(800,000$ acres) in the transition quarter. During these two fiscal years, 700,000 and 500,000 hectares (1.8 million and 1.2 million acres) were leased for bonuses of $\$ 2.0$ billion and $\$ 1.3$ billion, respectively; during the transition quarter, more than 200,000 hectares $(500,000$ acres) were leased for cash bonuses of $\$ 1.1$ billion.

- Revision and updating of Outer Continental Shelf Orders for the Gulf of Mexico and Pacific areas.

- Supervision of 1,683 offshore oil and gas leases covering 3.1 million hectares ( 7.7 million acres) in fiscal year 1975 and 1,886 leases covering 3.6 million hectares ( 8.8 million acres) in fiscal year 1976.

- Supervision of 125,718 onshore oil and gas leases covering 37.5 million hectares (92.7 million acres) in fiscal year 1975 and 125,847 leases covering 37.2 million hectares $(92.0$ million acres) in fiscal year 1976.

- Supervision of 2,557 mineral leases covering 3.7 million hectares (9.1 million acres) in fiscal year 1976.

- Collection of $\$ 950$ million in royalties and rentals from all sources during fiscal year 1976.

- Tract evaluation for 12 geothermal lease sales during fiscal year 1976. More than 51,000 hectares $(126,000$ acres $)$ in 65 tracts were leased, for a total bonus of $\$ 987,256$.

\section{BUDGET AND PERSONNEL}

Fiscal year 1976 was a period of continued growth for the Conservation of Lands and Minerals activity. The appropriation for this activity increased by 20.3 percent to $\$ 43.3$ million in fiscal year 1976, of which $\$ 41.4$ million was obligated during fiscal year 1976 (table 16). The Outer Continental Shelf land subactivity increased $\$ 3.0$ million (12.9 percent) to $\$ 26.2$ million, representing 63.1 percent of the total direct program funding (fig. 55). The increase in the of the total increase, reflects (1) the administration's decision to select and evaluate an increased number of Outer Continental Shelf tracts so as to encourage domestic energy production and (2) the need to inspect more drilling and production operations on recently leased tracts and increased activity on older tracts. The increased funds covered additional staffing, several large contracts for helicopter service to transport inspectors offshore to monitor operations, and the acquisition of geophysical data with which to select and evaluate tracts for lease sales.

TABLE 16.-Conservation of Lands and Minerals activity ob/gations for fiscal year 1976 and the transition quarter by program (dollars in millions)

[Data may differ from that in statistical tables because of roundir y]

\begin{tabular}{|c|c|c|c|c|}
\hline Program & $\begin{array}{l}\text { Fiscal } \\
\text { year } \\
1976\end{array}$ & 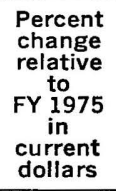 & $\begin{array}{l}\text { Transit } \\
\text { quart } \\
197\end{array}$ & on \\
\hline Total $^{1}$ & $\$ 41.4$ & +15 & $\$ 13$ & 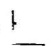 \\
\hline Outer Continental Shelf Lands & 26.2 & +13 & 9 & $?$ \\
\hline $\begin{array}{l}\text { Regulation of OCS oil and } \\
\text { gas } \\
\text { Research on OCS safety }\end{array}$ & 12.2 & & 3. & 1 \\
\hline $\begin{array}{l}\text { devices } \\
\text { OCS oil and gas tract }\end{array}$ & .5 & & & $i$ \\
\hline selection and evaluation & 13.5 & & & 7 \\
\hline Federal and Indian Lands & 15.2 & +19 & 4 & $\therefore$ \\
\hline Regulation of operations -- & 10.8 & & 3 & 1 \\
\hline $\begin{array}{l}\text { Oil and gas } \\
\text { Energy minerals (coal and }\end{array}$ & 7.0 & & & 3 \\
\hline uranium) & 1.0 & & & 3 \\
\hline Oil shale & .4 & & & 1 \\
\hline Geothermal _._- & 1.0 & & & ; \\
\hline Nonenergy minerals & 1.4 & & & + \\
\hline $\begin{array}{l}\text { Resource classification and } \\
\text { evaluation }\end{array}$ & 4.4 & & & $?$ \\
\hline Oil and gas & .3 & & & 1 \\
\hline Coal & 2.2 & & & j \\
\hline Oil shale & .3 & & & 1 \\
\hline Geothermal _. & 1.0 & & & $?$ \\
\hline $\begin{array}{l}\text { Nonenergy minerals } \\
\text { Water-resource develop- }\end{array}$ & .2 & & & 1 \\
\hline ment & .4 & & & 1 \\
\hline
\end{tabular}

Increased workload in resource classification ind evaluation and supervision of development and $\mathrm{f}$ duction operations also resulted in a budget incre ise of $\$ 2.5$ million (45.1 percent) for the Federal nd Indian Lands subactivity.

Staffing of the activity increased from 926 \& ermanent full-time employees at the end of fiscal $y$ sar 1975 to 1,135 in fiscal year 1976 (table 45). Mos of the increased positions were filled by geophysic ;s, geologists, and petroleum and mining engineers. 


\section{PROGRAMS AND ACTIVITIES}

The operating environments, logistics, and technologies for exploration and development of offshore resources are completely different from those onshore. The Outer Continental Shelf Lands and onshore Federal and Indian Lands subactivities, however, both comprise: (1) resource evaluation and (2) supervision of operations. Both subactivities involve prelease responsibilities for supervision of exploration, development, and production operations and the computation and collection of royalty and certain rental payments. The onshore program also includes the classification of Federal lands for leasable mineral and water-resource development potential.

\section{Outer Continental Shelf lands}

Outer Continental Shelf leases are issued by the Bureau of Land Management, but the operating regulations are implemented and enforced by the Geological Survey. The Bureau of Land Management and the Geological Survey consult closely on the significant actions that take place before each lease sale (Adams and others, 1975). The Survey provides the Bureau of Land Management with:

- Petroleum-resource assessments and other technical information used to identify areas for leasing and to schedule lease sales.

- Environmental baseline data and geologic-hazards information for use in preparing environmental impact statements for each lease sale.

- Resource evaluations for use in jointly selecting tracts for each lease sale and in establishing fair market value for each tract.

\section{RESOURCE EVALUATION}

On the Outer Continental Shelf, resource evaluation activities are concentrated on identifying target areas for future lease sales, advising the Bureau of Land Management on the selection of tracts to offer for sale, estimating the value of oil and gas on each tract offered, determining the fair market value for each tract, and determining geologic hazards on specific tracts.

Between 1954 and 1966, Outer Continental Shelf tracts were selected for lease sales without an evaluation of their hydrocarbon potential. In 1967, the Geological Survey established a mineral-resource evaluation program to improve methods of selecting and evaluating shelf tracts for leasing. The Survey has since much expanded its geological, geophysical, and engineering capability to map, select, and evaluate the potential resource of the Outer Continental Shelf (fig. 56)

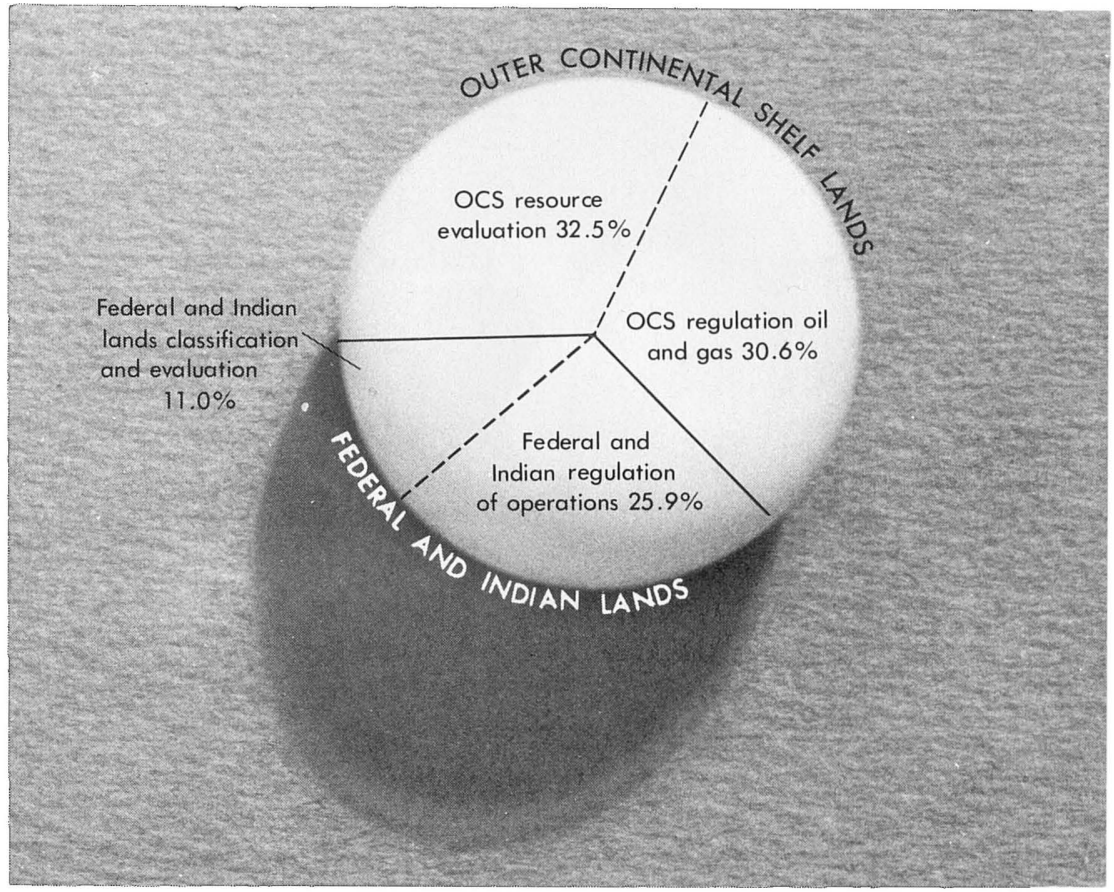

FIGURE 55.-Distribution of Conservation of Land and Minerals direct program funds by subactivity and program.

During fiscal year 1976, four Outer Continental Shelf lease sales were held: two in the Gulf of Mexico, one in the frontier area off of southern California, and one in the frontier Gulf of Alaska area. The southern California sale was the first to offer tracts in the outer banks region. The sale of eastern Gulf of Alaska tracts was the first Federal lease sale for offshore Alaska. The first lease sale in the Baltimore Canyon area of the mid-Atlantic Outer Continental Shelf, drawing $\$ 1,127,936,425$ from successful bidders, was held during the transition quarter.

Tract evaluations were begun during fiscal year 1976 for Sales 44 and 47 in the Gulf of Mexico, Sales 40, 42, and 43 in the Atlantic Shelf, and Sales C-1, 45, and 46 in the Alaskan Outer Continental Shelf.

The Department of the Interior continued in 1976 to authorize deep off-structure stratigraphic test drilling in frontier shelf areas, begun in 1974. During fiscal year 1976, one test well was completed in the eastern Gulf of Alaska, one in the Pacific (southern California), and two in the Atlantic shelf (midAtlantic and north Atlantic). Drilling depths ranged from 1,510 meters $(5,150$ feet) in the Gulf of Alaska to 4,900 meters $(16,071$ feet) in the north Atlantic shelf. In the transition quarter, one test well was being drilled in the Bering Sea off Alaska.

Shallower off-structure test drilling was also authorized during fiscal year 1976 for holes ranging in depth from 150 to 1,200 meters (500 to 4,000 feet) in the frontier shelf areas of Alaska. 


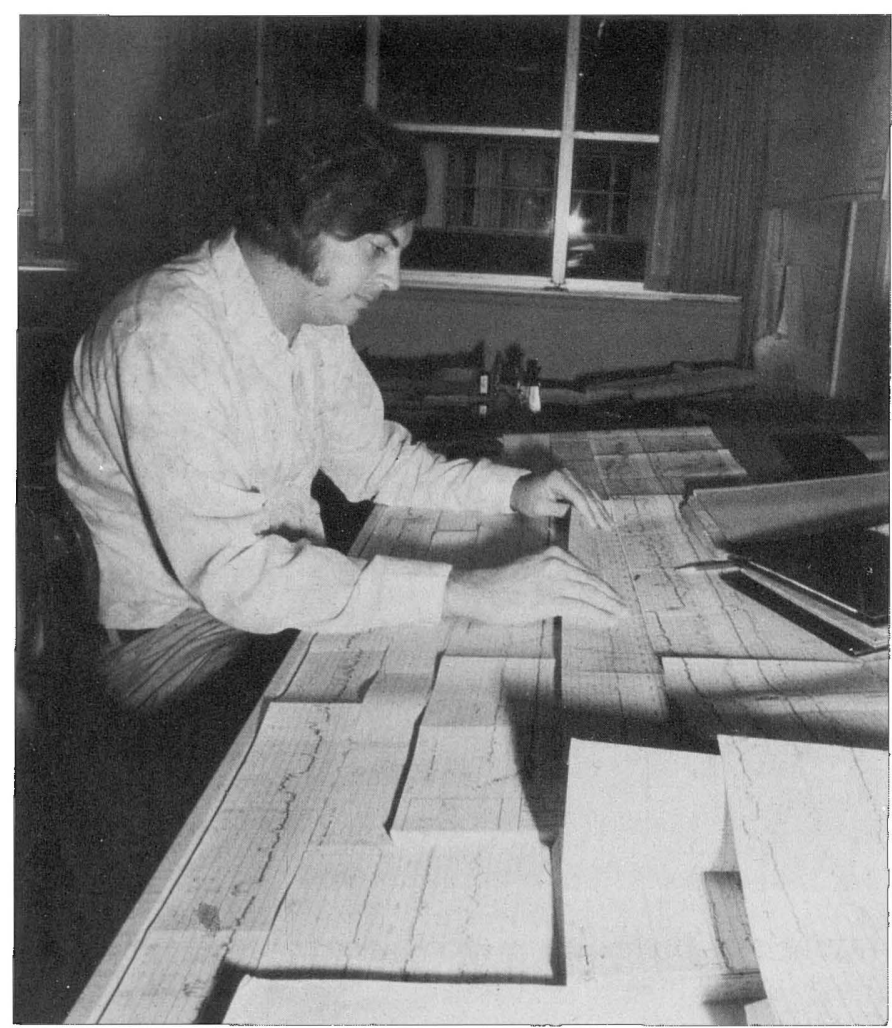

FIGURE 56.-Geologist studying well logs of oil and gas wells in the Gulf of Mexico.

During fiscal year 1976 and the transition quarter, the Survey purchased 41,013 kilometers (25,490 miles) of common-depth-point seismic data to help locate potential hydrocarbon-bearing structures, 61,338 kilometers $(38,122$ miles) of high-resolution seismic data to help detect the presence of shallow geological hazards, and 45,271 kilometers $(28,136$ miles) of gravity data and 48,249 kilometers (29,987 miles) of magnetic data for specialized studies. The total cost was $\$ 7.1$ million.

\section{SUPERVISION OF OPERATIONS}

After leases are issued by the Bureau of Land Management, the Geological Survey supervises oil and gas exploratory, development, and production operations of the lease operator on Outer Continental Shelf lands to assure that operations conform with Department of the Interior operating regulations and orders and that royalties paid to the Government are correct and represent a fair market value for its share of the resources produced. Supervision of lessee operations involves:

- Review and approval of plans to conduct operations (fig. 57).

- Inspection of operations (fig. 58) and computation
In fiscal year 1976, considerable activity was directed toward updating the Outer Continental Shelf Orders. A list of all the orders and their status as of the end of fiscal year 1976 are shown in table 17.

The Survey supervised oil and gas operations on 1,792 leases covering 3.4 million hectares (8.3 million acres) of the Outer Continental Shelf during calendar year 1975. Most of these operations were in the Gulf of Mexico; 74 leases were located offshore California. Total production from these leases amounted to 44.6 million tonnes ${ }^{1}$ ( 330 million barrels) of oil and 98 billion cubic meters $(3,459$ billion cubic feet) of natural gas. The total value of all petroleum products produced on Outer Continental Shelf lands was $\$ 3.9$ billion.

During calendar year 1975, Survey personnel for the Gulf of Mexico made 2,218 inspections of drilling rigs, 2,593 inspections of production platforms, and many overflights of other sites, while flying between inspections, in order to check for oilspills. As a result of these inspections, the Survey issued 1,700 warnings on individual items found not to comply with regulations and ordered 1,107 zones and 117 platforms shut-in until violations of orders and regulations were corrected. The oilspills and fires and explosions associated with Outer Continental Shelf oil and as operations during the last 6 years are summarized in tables 18 and 19. ${ }^{1} \mathrm{~A}$ conversion factor of 7.4 barrels $=1$ tonne was used in this re-
port.

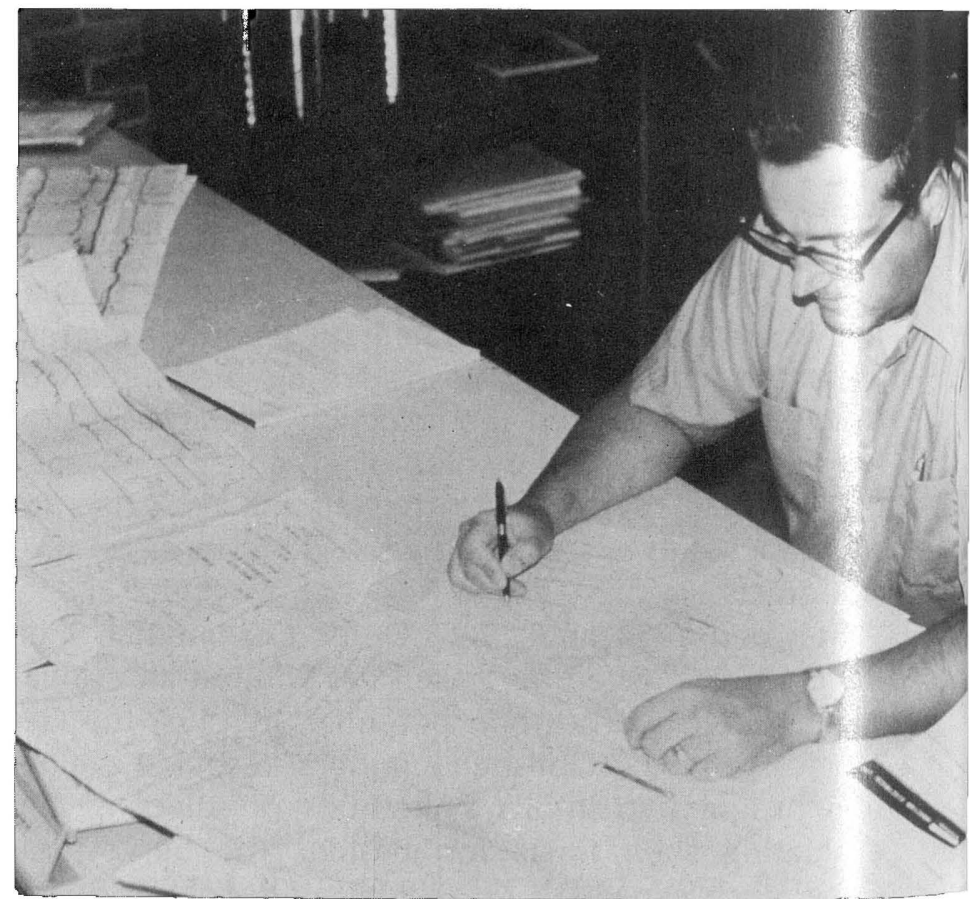

FIGURE 57.-Geologist reviews geologic information for potential geologic hazards in an area before approval of driling plans. 
TABLE 17.-Status of Outer Continental Shelf Orders at the end of fiscal year 1976

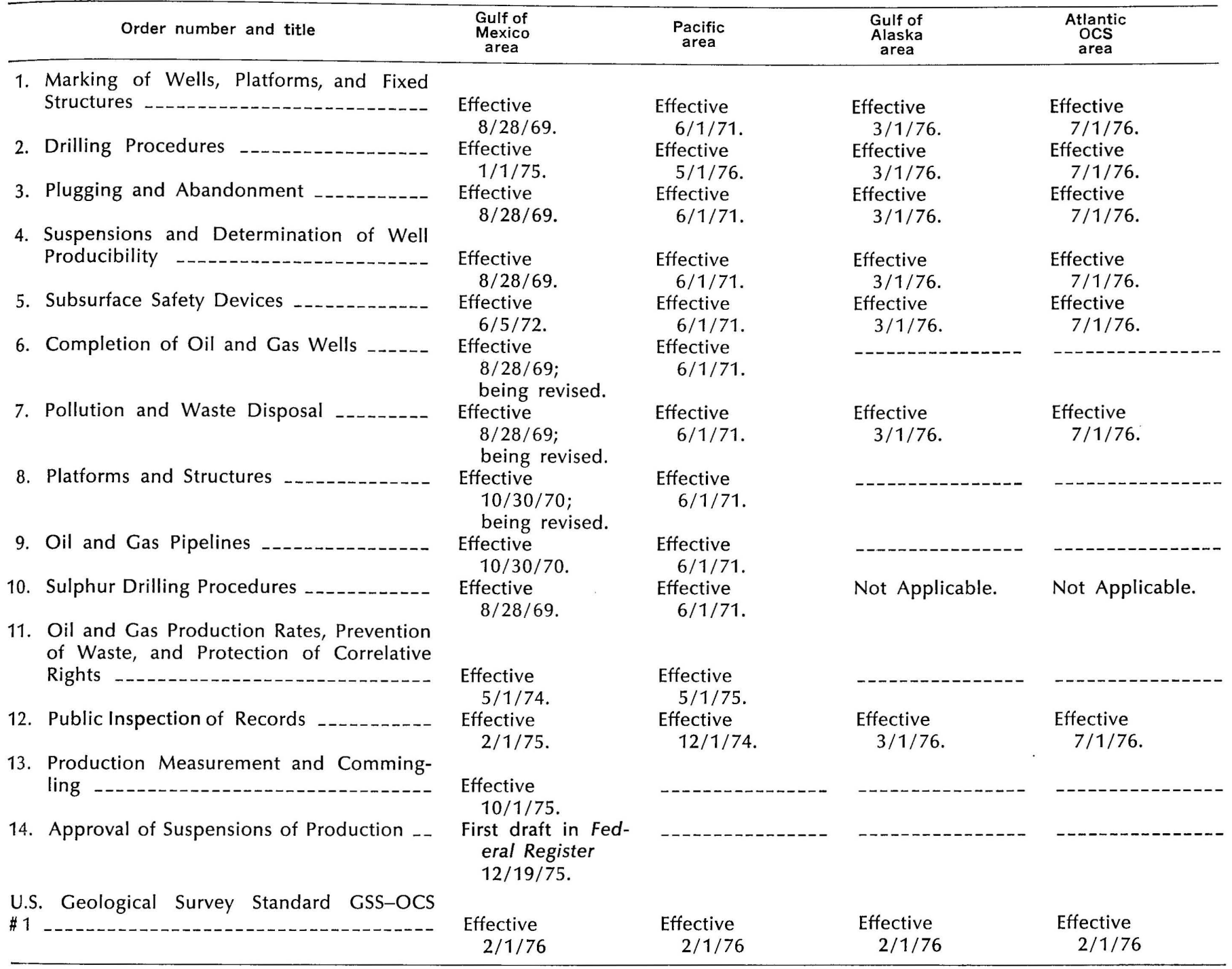

In calendar year 1975 , royalty revenue from the sale of petroleum and sulfur products amounted to $\$ 616$ million, an increase of $\$ 56$ million over calendar year 1974 and \$215 million over calendar year 1973 .

Oil production from the Outer Continental Shelf has been declining since 1971 (fig. 59) because discoveries have not kept pace with the declining production from older fields.

Production of natural gas increased yearly from 1953 until 1975, the first year that has shown a decline. The value of the produced gas, however, increased 50 percent because of higher prices. Production is expected to continue to decrease over the next few years unless significant discoveries are made and brought on production.

Inasmuch as production usually trails lease sales by 3-10 years, the impact of the accelerated leasing program has not yet been fully felt, but requests for approval of exploration plans and notices of intent to drill have increased.

FIGURE 58.-Engineer technician inspecting drilling operation on offshore platform.

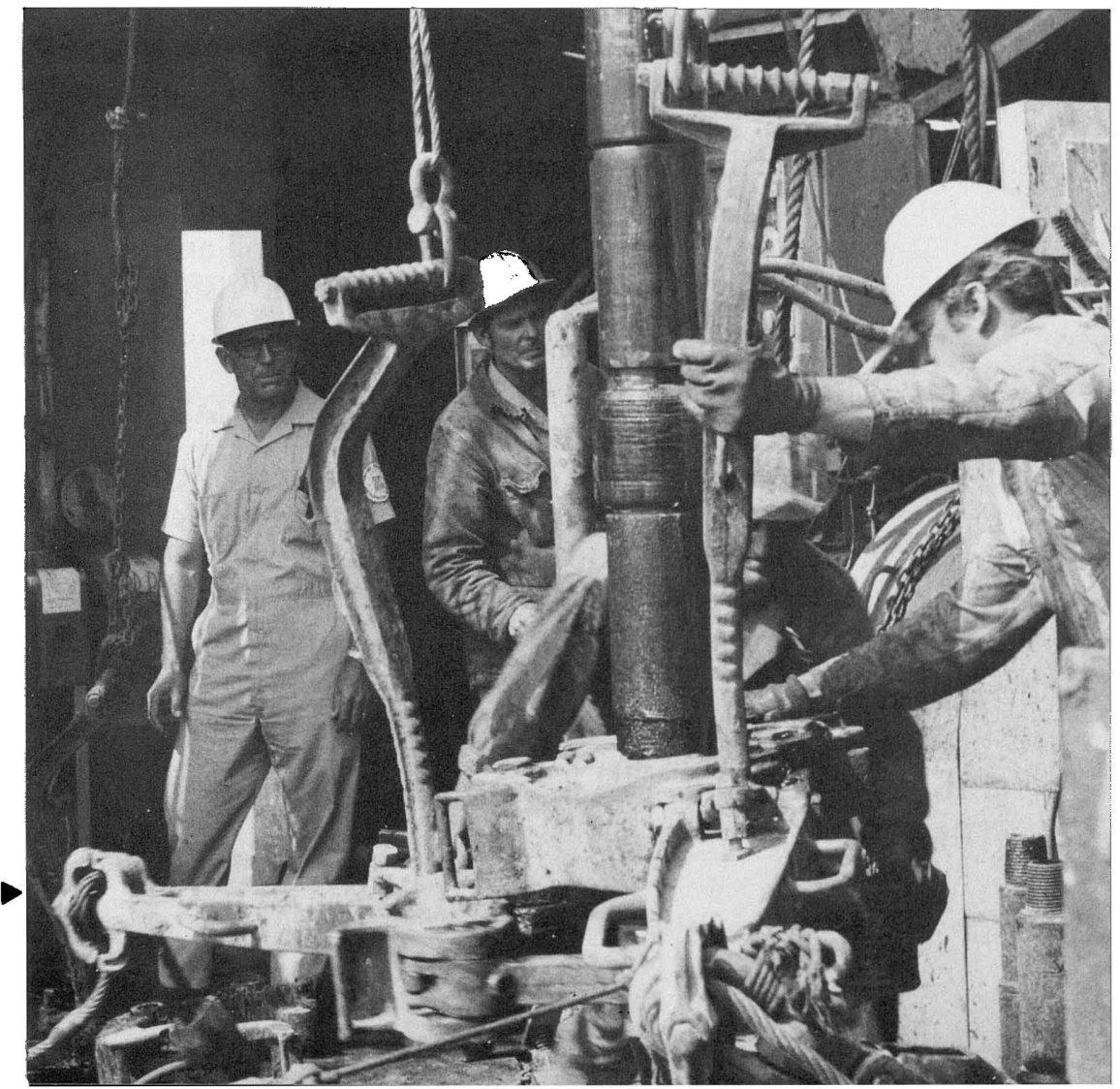


TABLE 18-Hydrocarbon spills on Outer Continental Shelf, calendar years 1971-75

\begin{tabular}{|c|c|c|c|c|c|}
\hline \multirow{2}{*}{\multicolumn{2}{|c|}{$\begin{array}{c}\text { Calendar } \\
\text { year }\end{array}$}} & \multicolumn{2}{|c|}{$\begin{array}{c}\text { Spilis of } 50 \text { barrels } \\
\text { or more }\end{array}$} & \multicolumn{2}{|c|}{$\begin{array}{l}\text { Spills of less than } \\
50 \text { barrels }\end{array}$} \\
\hline & & \multirow{2}{*}{$\begin{array}{c}\text { Number } \\
11\end{array}$} & \multirow{2}{*}{$\begin{array}{c}\begin{array}{c}\text { Barrels } \\
\text { spilled }\end{array} \\
1,285\end{array}$} & \multirow{2}{*}{$\frac{\text { Number }}{1,245}$} & \multirow{2}{*}{$\begin{array}{c}\begin{array}{c}\text { Barrels } \\
\text { spilled }\end{array} \\
1,493\end{array}$} \\
\hline 1971 & _...... & & & & \\
\hline 1972 & - & 2 & 150 & 1,159 & 1,032 \\
\hline 1973 & - - & 4 & ${ }^{1} 22,175$ & 1,171 & 921 \\
\hline 1974 & ------- & 8 & 222,721 & 1,129 & 667 \\
\hline 1975 & -------- & 2 & 266 & 1,126 & 711 \\
\hline
\end{tabular}

19,935 barrels spilled from a ruptured storage tank (1/9/73) and 7,000 barrels spilled from a leaking barge $(1 / 26 / 73)$.

2 19,850 barrels spilled from a pipeline broken when a ship's anchor dragged on the seabed $(4 / 17 / 74)$.

TABLE 19.-Fires and explosions on the Outer Continental Shelf, calendar years 1970-75

\begin{tabular}{llccc}
\hline $\begin{array}{l}\text { Calendar } \\
\text { year }\end{array}$ & $\begin{array}{c}\text { Number } \\
\text { of } \\
\text { events }\end{array}$ & Injuries & Fatalities \\
\hline 1970 & -12 & 31 & 17 \\
1971 & -19 & 16 & 1 \\
1972 & 12 & 9 & 0 \\
1973 & - & 9 & 2 \\
1974 & - & 15 & 0 \\
1975 & 30 & 11 & 10 \\
\hline
\end{tabular}

I A tanker collided with a platform. Oil escaping from the tanke ignited and set the ship afire. Six men died in the blaze $(8 / 15 / 75)$.

\section{Federal and Indian lands}

The Geological Survey classifies and evaluates the mineral and waterpower and reservoir-site resources on Federal lands onshore and supervises exploration, development, and production operations on both Federal and Indian land leases. Public land laws provide for the leasing of specific minerals such as oil and gas, coal, oil shale, asphaltic minerals, sodium, potash, phosphate, and geothermal resources and of sulfur in New Mexico and Louisiana only. The laws pertaining to Indian and acquired lands authorize the leasing of all metalliferous and nonmetalliferous minerals.

The Survey in fiscal year 1976 continued to provide the Department of the Navy with technical advice on Naval Petroleum Reserve lands and supervised operations for the drilling and production of oil and gas on Naval Petroleum Reserve No. 2 (Buena Vista) in California.

\section{RESOURCE EVALUATION AND CLASSIFICATION}

The purpose of resource-classification actions by the Geological Survey is to retain for the Federal Government the title to leasable minerals and water-resource development sites that otherwise might be lost with disposal of the surface rights. Basic geologic, geophysical, and engineering data are compiled and

FIGURE 59.-Oil and gas production from Outer Continental Shelf lands, calendar years 1966-76.
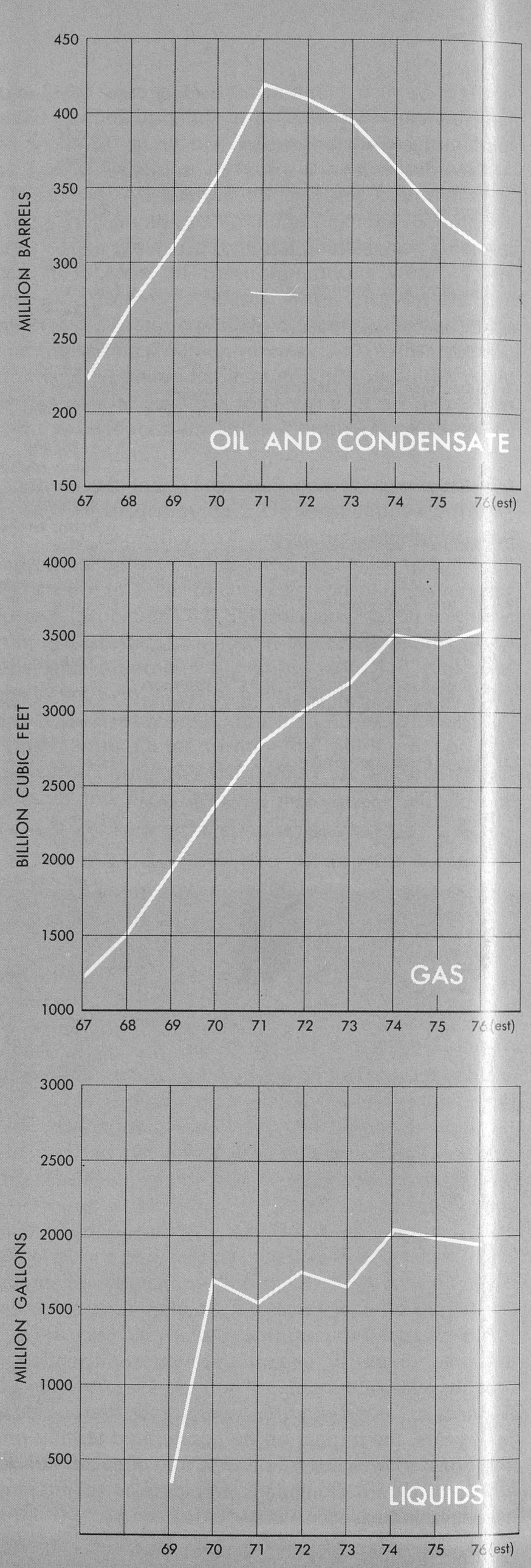
used (1) to classify Federal mineral lands and waterpower and reservoir sites, (2) to delineate prospectively valuable mineral areas, and (3) to modify or eliminate outstanding mineral withdrawals and waterpower- and reservoir-site classification or withdrawals.

At the end of fiscal year 1976, 17.2 million hectares (42.5 million acres) of withdrawn land had been classified as mineral land, and 18.5 million hectares (45.7 million acres) remained to be classified (table 20).

In complying with requests for 15,000 mineral reports by other Federal agencies during fiscal 1976, the Survey designated 950 million hectares (2.35 billion acres) of land as prospectively valuable for leasable minerals.

Once it has been classified as mineral land, Federal land must be evaluated to determine whether or not it is subject to competitive leasing or noncompetitive leasing (coal land is subject only to competitive leasing).

The Survey recommends lands for leasing whenever there is reason to believe that sufficient competitive interest exists or that leasing would be in the best interests of the United States. For lands designated as subject to competitive leasing, the Geological Survey makes a presale evaluation of each parcel of Federal land offered competitively for leasing in order to establish a fair market value for their sales.

Leasing procedures and regulations differ with each commodity. Lands within the boundaries of Known Leasing Areas are subject to competitive leasing and are not subject to lease by application. For example, when a new oil and gas field is discovered, the Survey establishes an undefined Known Geologic Structure and informs the Bureau of Land Management. This action prevents any further noncompetitive leasing of the area until the boundaries of the Known Geologic Structure can be more accurately determined and its description can be published in the Federal Register.
Most Indian lands are leased by competitive bidding, and the Bureau of Indian Affairs has usually relied on the Survey to parcel the tracts for sale, to recommend stipulations to be included in the leases to protect other uses, to prevent environmental damage through supervision, and to recommend acceptance or rejection of high bids offered. Complete presale evaluations for Indian land lease sales are made only when requested by the Bureau of Indian Affairs.

- Oil and gas.-Lands containing oil and gas are leased competitively if they are located on Known Geologic Structures of producing oil and gas fields as defined from analysis of well logs, core sampling data, production records, and maps that are required to be submitted to the Geological Survey by lessees and operators. During calendar year 1976, approximately 460 tracts covering 35,500 hectares $(87,600$ acres) were sold in 28 competitive oil and gas lease sales of Federal lands (table 50). During the same period, the Survey classified more than 74,000 hectares $(183,000$ acres $)$ in undefined Known Geologic Structures.

- Geothermal resources.-Since 1971, Federal lands have been put into Known Geothermal Resources Areas on the basis of geological, geophysical, or geochemical indicias (fig. 60) or on the basis of overlapping noncompetitive lease applications. As of the end of fiscal year 1976 and transition quarter, 1,286,050 hectares $(3,176,542$ acres) have been placed in 133 Known Geothermal Resources Areas in 11 Western States. These lands have been available for competitive leasing since the beginning of the geothermal leasing program in 1974. As of the end of fiscal year 1976 and the transition quarter, 800 leases covering 690,000 hectares (1.7 million acres) of Federal lands have been leased.

TABLE 20.-Status of Federal land classifications, fiscal year 1976 [Acres in thousands]

\begin{tabular}{|c|c|c|c|c|c|c|}
\hline \multirow{2}{*}{ Commodity } & \multirow{2}{*}{$\begin{array}{c}\text { Mineral } \\
\text { lands } \\
\text { withdrawn }\end{array}$} & \multicolumn{2}{|c|}{ Classified lands } & \multirow{2}{*}{$\begin{array}{l}\text { Prospec- } \\
\text { tively } \\
\text { valuable } \\
\text { lands }{ }^{1}\end{array}$} & \multicolumn{2}{|c|}{ Known leasing areas } \\
\hline & & Nonmineral & Mineral & & Undefined & $\overline{\text { Defined }}$ \\
\hline Total & 45,708 & 38,145 & 42,486 & $2,348,563$ & 5,953 & 25,253 \\
\hline Oil and gas & - - - - & ---- & 4 & $1,476,001$ & 5,335 & 11,864 \\
\hline Oil shale & 14,206 & 98 & $-\ldots$ & 14,372 & $-\ldots-\ldots$ & $-\ldots$ \\
\hline Asphaltic minerals & ---- & ---- & ---- & 17,941 & ----- & $--\ldots$ \\
\hline Coal & 20,471 & 33,445 & 48,560 & 350,800 & ---- & 9,654 \\
\hline Geothermal resources & ---- & $\ldots$ & 110,560 & 102,544 & ---- & 3,029 \\
\hline Phosphate & 1,620 & 4,625 & 414 & 30,601 & 2 & 40 \\
\hline Potash & 9,411 & -...- & $-\ldots--$ & 80,928 & $4 \overline{9}$ & 378 \\
\hline Sodium & $-\ldots$ & $-\ldots$ & 625 & 267,442 & 567 & 288 \\
\hline Sulfur & $-\ldots-$ & ---- & ---- & 5,593 & ---- & ---- \\
\hline
\end{tabular}




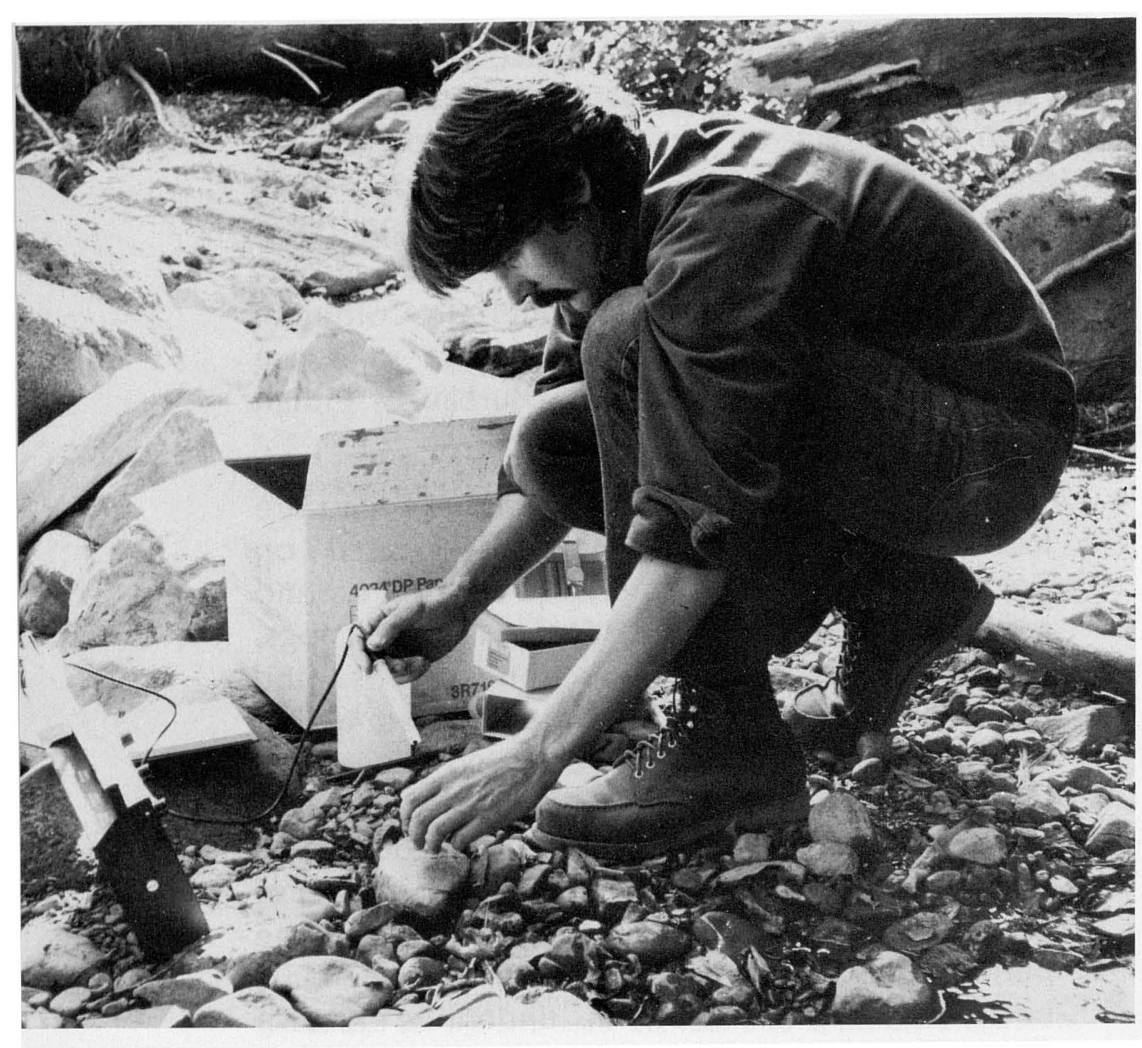

FIGURE 60.-Geologist sampling the water near a geothermal spring.

- Coal.-The coal-resource evaluation program has been providing basic geologic and engineering data and analyses for use in the Bureau of Land Management's Energy Minerals Activity Recommendation System and the coal leasing program. Basic data collected for the program include field mapping and core drilling. During fiscal year 1976 and the transition quarter, 81 primary coal projects and 10 projects involving coal of the Conservation of Lands and Minerals activity on Federal land were in progress in seven Western States (fig. 61). Drilling and coring were conducted in Colorado, New Mexico, Montana, North Dakota, Utah, and Wyoming. The data derived from these activities contributed to the definition of five new Known Recoverable Coal Resource Areas (formerly Known Coal Leasing Areas) covering 160,800 hectares $(397,183$ acres) (fig. 62).

To facilitate the reporting of the quality and quantity of coal deposits on Federal land and to assess the potential of that coal for commercial development, a series of coal-resource occurrence maps and coaldevelopment-potential overlays are being prepared for submittal to the Bureau of Land Management's Energy Minerals Activity Recommendation System program. The maps are restricted to areas within de- source Areas. As of the end of the transition quarter, the equivalent of 100 quadrangles had been completed.

Thirty-nine leasable mineral and waterpower landclassification maps at a scale of $1: 250,000$ were completed and placed in the open file by the end of the transition quarter. Eight of these maps are scheduled for publication during fiscal year 1977. Fifty-eight additional maps are in various stages of completion. These maps provide an overall picture of land classification by the Geological Survey useful in showing resource relationships for the coal-leasing program and for land-use planning.

Five coal-investigation maps were published during fiscal year 1976 .

In anticipation of the lifting of the moratorium on leasing of Federal coal lands, the Geological Survey established a task force during the first half of $f_{\text {iscal }}$ year 1976 to speed development of procedures for evaluating coal tracts and to determine their fair rnarket value.

On January 26, 1976, the Secretary of the Interior lifted the moratorium, clearing the way for resunption of coal leasing and the processing of pencing preference-right leases. The Bureau of Land Management subsequently published regulations for their

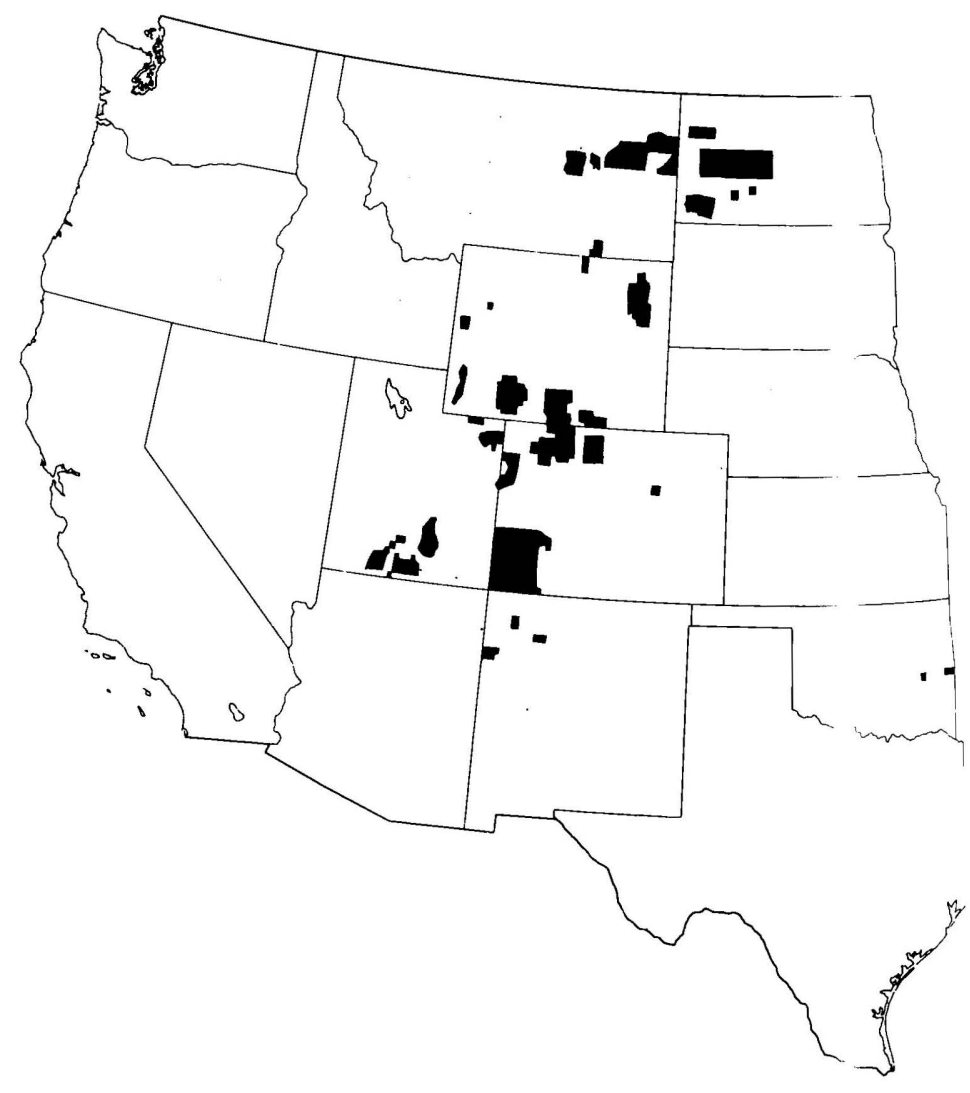

FIGURE 61.-Areas of active coal projects of the Conservition of Lands and Minerals activity on Federal lands dtring fiscal year 1976 . 


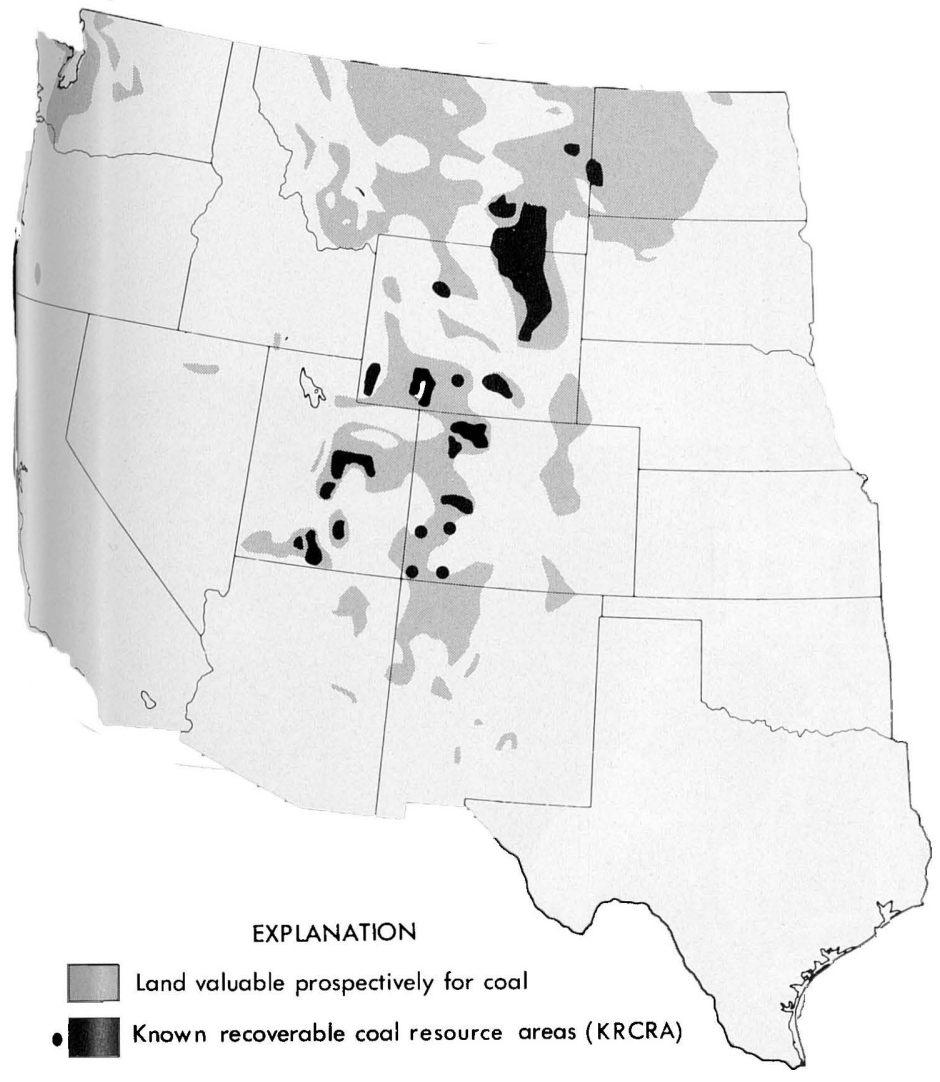

FIGURE 62.--Status of coal classification on Federal and Indian lands in the Western United States.

program, which affects both the coal leasing process and the regulatory functions of the Geological Survey's Conservation Division. The Bureau's reconsideration of these coal leasing regulations and their Energy Minerals Activity Recommendation System has been prompted by the enactment into law on August 4, 1976, of the Federal Coal Leasing Amendments of 1975. The Geological Survey will continue to be responsible for (1) the identification of Known Recoverable Coal Resource Areas as principal leasing target areas, (2) preparation of coal-resource occurrence maps and coal-development-potential overlays, and (3) participation in the selection and evaluation of proposed coal lease tracts for future lease sales. Other provisions of the Federal Coal Leasing Amendments Act of 1975 will require further study before they can be fully implemented.

- Waterpower--Potential water-power and waterstorage sites on Federal lands are classified as valuable or not valuable for development in order to retain the Government's right to authorize or license hydroelectric or water-storage development on such lands. Of the 5.7 million hectares (14 million acres) so withdrawn, 2,040 hectares (5,050 acres) were classified or reclassified in fiscal year 1976 and 2,200 hectares (5,450 acres) during the transition quarter. About 3.6 million hectares ( 9 million acres) of the total are withdrawn for possible use at the Ramparts Reservoir site on the Yukon River, Alaska.

- Other leasable minerals._-During fiscal year 1976, about 28,220 hectares $(69,710$ acres) were classified in Known Potash Leasing Areas in New Mexico. Field mapping was in progress in 10 quadrangles for phosphate deposits.

\section{SUPERVISION OF OPERATIONS}

After leases are issued by the Bureau of Land Management or the Bureau of Indian Affairs, the Geological Survey is responsible for supervising oil, gas, and mining operations on Federal and Indian lands and geothermal operations on Federal lands. In this regulatory program, oil, gas, geothermal, and mining operations are treated separately because of the different technologies and engineering disciplines used by each type of operation. The major program requirements, however, are basically the same, and they are similar to those of the Outer Continental Shelf subactivity: (1) review and approval of exploration and development plans; (2) supervision of exploration, development, and production operations (fig. 63); and (3) computation and collection of royalties and certain rentals.

Related activities such as unitization, method-ofproduction measurement, transportation allowances, commingling of products, off-lease storage, and sales contracts also require the prior approval or concurrence of the Survey.

\section{Oil, Gas, and Geothermal Operations}

At the end of calendar year 1976, there were 125,900 oil and gas leases covering 38.2 million hectares (94.4 million acres) (table 50). These leases were located in 33 States. During calendar year 1976, total oil and gas production from these leases amounted to 25.9 million tonnes (192 million barrels of oil), a decrease of nearly 4 percent from calendar year 1975, and 34 billion cubic meters $(1,200$ billion cubic feet) of natural gas, an increase of 8 percent over calendar year 1975. Survey personnel made over 19,200 inspections of oil and gas lease operations, prepared 2,551 environmental analyses of proposed new wells, approved 2,246 new wells (both exploratory and development wells), and processed 5,700 other types of applications.

At the end of fiscal year 1976, the Geological Survey was maintaining 14,726 producing oil and gas lease accounts, an increase of 5.7 percent over fiscal year 1975, and at that time the Survey also had under its jurisdiction 2,129 rental accounts for Federal land 


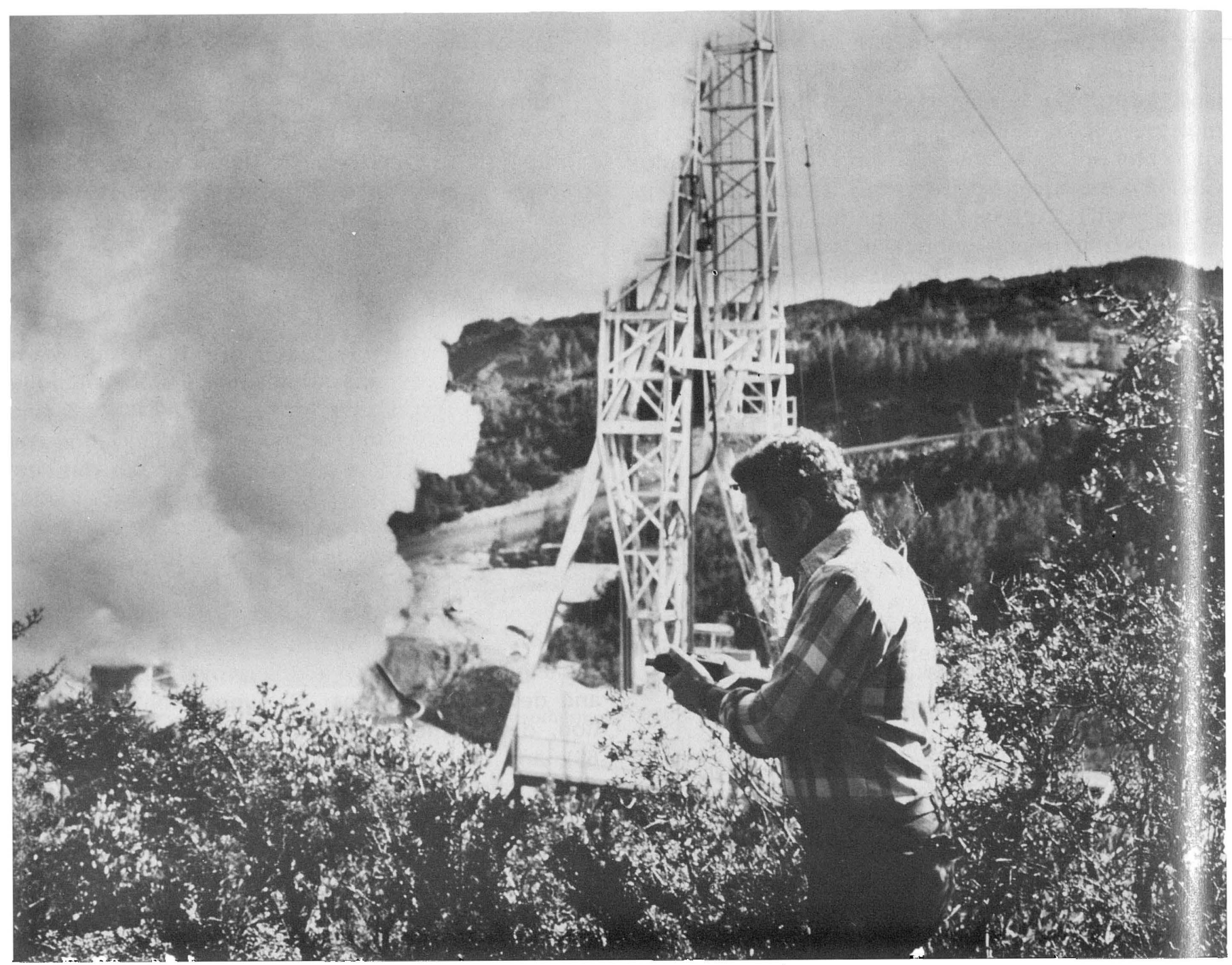

FIGURE 63.-Engineer taking noise readings near geothermal well at The Geysers, California.

leases. Total royalty revenue from the sale of oil, gas, and liquid products in calendar year 1976 amounted to $\$ 266$ million; the increase of $\$ 21$ million over calendar year 1975 reflects increased prices for those commodities.

About 6.4 percent of the Nation's domestic production of oil and 6.0 percent of its production of natural gas came from onshore Federal and Indian lands. Oil production from these lands, however, has been declining since 1968 (fig. 64) because new discoveries have not kept pace with the decline in production from older fields. The increasing demand for natural gas, which has caused greater effort to be directed toward finding new gas reserves, may account for some of the decline in oil production as well as the small increase in gas production. Liquid hydrocarbon products, which are extracted from natural gas produced from gas wells and from casing-head gas produced in association with oil, increased slightly during the year despite the decline in oil production.
The Geothermal Leasing program began in $1: 74$ when the Department of the Interior published re ulations governing the leasing of geothermal resources. By the end of fiscal year 1976, 24 wells had be en drilled under lease; 18 of the wells were conside: ed to be producible or usable, 4 were still being drill $d$, and 2 were abandoned. Most of the wells were loca ed in The Geysers geothermal field in northern California, the only commercially producing field in the United States; the others were in the East Mesa and Mono-Long Valley in southern California and in the Roosevelt Hot Springs in Utah, where the first Fed ral Geothermal Unit was formed and approved in Aril 1976. During the transition quarter, one additional well was drilled, and one well was considered p:oducible or usable. The completed wells on Federal lands that are capable of producing hot water and or steam remain shut-in because of the lack of facili ies necessary to convert the geothermal resources into usable energy. 

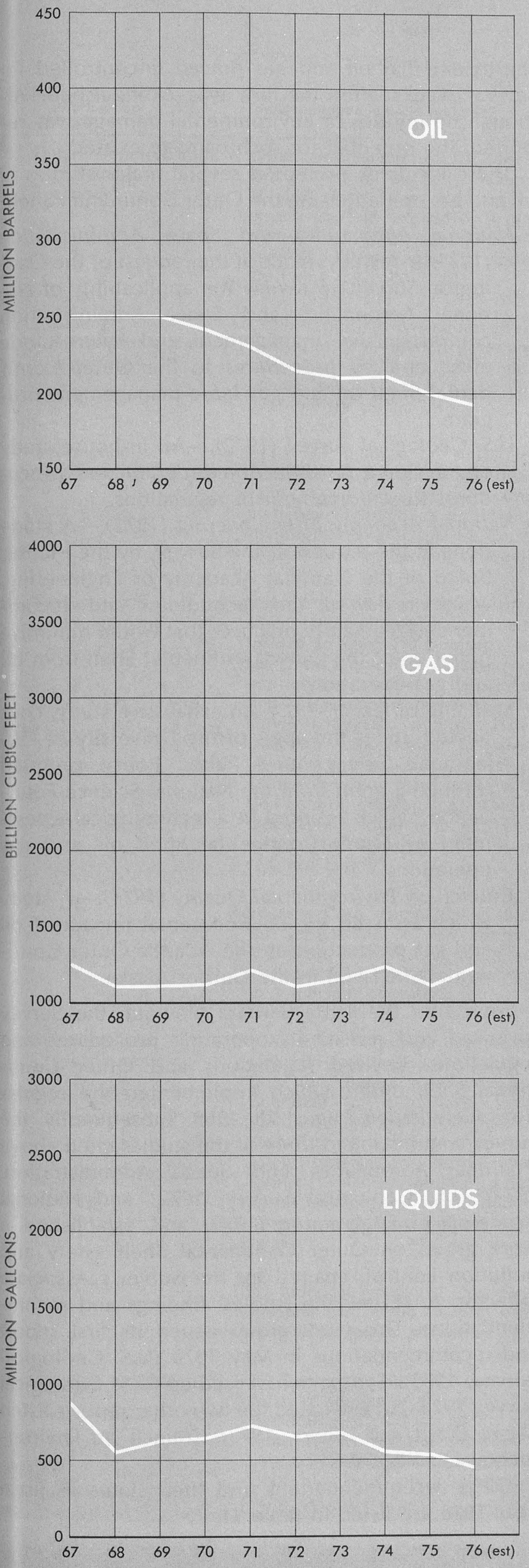

\section{Mining Operations}

During fiscal year 1976, the Survey supervised 2,557 mineral leases covering 3.6 million hectares $(9$ million acres) of Federal and Indian lands in 32 States. The number of leases under supervision has increased over the previous fiscal year by 78 leases. Total production of solid mineral commodities under lease during the year, for example, increased 6.8 percent to 81.5 million tons valued at $\$ 813$ million as a result of continuing increases in the demand for energy minerals (such as coal and uranium), fertilizer minerals (such as potash), and metallic minerals (such as lead, zinc, and copper).

Survey personnel made more than 2,000 producing lease and permit inspections, reviewed and approved new or modified exploration and mining plans, prepared environmental analyses, and assisted in the preparation of 27 environmental impact statements; four environmental impact statements cleared the Council on Environmental Quality. Royalties from 184 producing lease accounts totaled $\$ 36$ million, an increase over 1975 of 16 percent. Revenues from 801 rental accounts provided an additional $\$ 3$ million.

The importance of Federal and Indian lands to the Nation's domestic production of solid minerals is shown by figure 54 .

- Coal.-Eight percent of the Nation's coal production in fiscal year 1976 came from leases on Federal and Indian lands in Montana, Wyoming, Colorado, Utah, New Mexico, and Arizona. It is estimated that production from existing leases could be increased from 52 million tons in 1976 to 213 million tons in 1980, an increase of nearly 310 percent. At the end of the fiscal year, 189 preference-right leases covering approximately 175,000 hectares $(432,000$ acres) were pending a decision by the Secretary of the Interior on future coal leasing policy, and the coal leasing and operating regulations were revised. One preference-right lease covering approximately 6,000 hectares $(15,000$ acres) in Wyoming was issued during fiscal year 1976.

- Oil shale.-In 1971, the Department of the Interior initiated the Prototype Oil-Shale Leasing program to encourage private industry to develop oilshale mining and processing technology on a commercial scale, to insure the environmental integrity of the affected areas, to develop environmental safeguards and land-restoration techniques, and to develop management expertise in leasing and supervising oil-shale development. After the preparation of an environmental impact statement, the Department competitively leased four tracts of land in Utah and Colorado em-

FIGURE 64.-Oil and gas production from Federal and Indian lands, calendar years $1966-76$. 
bracing 8,300 hectares $(20,400$ acres $)$ for a bonus of $\$ 449$ million. The lease terms require each lessee to file a detailed development plan with the Survey for review and approval on or before the third anniversary date of the lease. Furthermore, the lease terms require the bonus payments to be paid in five annual installments and permit the lessee to credit against the fourth and fifth payments any expenditures incurred prior to the third anniversary of the lease that are directly attributable to operations for the development of the lease. The Survey's mining supervisor is responsible for determining that such expenditures credited by the lessee are properly attributable to development operations.

During 1975, four companies submitted their initial exploration plans for evaluation and approval by the Survey. Initial work also began on projects involving collecting baseline environmental data, monitoring air and water quality, and developing guidelines for future operations.

- Fertilizer minerals.-A large increase in the demand for fertilizer minerals has accelerated the production and leasing activities for potash and phosphate during the past few years. Eighty-one percent of the Nation's potash is produced from Federal lands, and 14 percent of phosphate comes from Federal and Indian lands. In Idaho, the principal western phosphate-producing State, 117 phosphate prospecting-permit applications and 15 lease applications are pending.

\section{REVIEW OF ISSUES IN FISCAL YEAR 1976}

During this fiscal year, several issues continued to have significant impact on the Conservation of Lands and Minerals activity.

\section{Regulation of Outer Continental Shelf lease operations}

On January 28, 1969, a well being drilled in the Santa Barbara Channel off southern California blew out. Although the flow of fluids from the well was effectively controlled by closing the blowout preventer, oil and gas continued to flow for 11 days through subsurface fractures to the ocean floor and subsequently to the water surface. The Santa Barbara oilspill drew national attention to the potential of damage from offshore oil and gas installations if adequate safety and environmental controls are not maintained. Public concern was further heightened when a fire broke out on an oil and gas platform in the Gulf of Mexico on February 19, 1970. This fire the extent that oil and gas flowed uncontrolled for several weeks after the fire was extinguished. Although no injuries or environmental damage was reported, the potential for such damage existed.

These incidents prompted several major studies of oil and gas operations on the Outer Continental Shelf:

- National Aeronautics and Space Administration (1971). - A study, made at the request of the Geological Survey, to review the applicability of National Aeronautics and Space Administration contract-quality management and failure-mode effect analysis procedures to the Outer Continental Shelf oil and gas lease-management program.

- U.S. Geological Survey (1972).-An in-house study of the Survey's inspection program and procedures for enforcement of regulations.

- National Academy of Engineering (1972).-A study done at the request of the Survey, by the Marine Board of the National Academy of Engineering, which reviewed the technology and recommended regulatory practices that would minin ize pollution of the Outer Continental Shelf from oil and gas operations.

- Kash and others (1973).--An exhaustive study, conducted under the aegis of the University of Oklahoma's Science and Public Policy program through a grant from the National Science Fo :ndation, which resulted in a technological assessment of Outer Continental Shelf oil and gas operations.

- Council on Environmental Quality (1974).-A study which assessed the environmental impact of oil and gas production on the Atlantic Outer Continental Shelf and in the Gulf of Alaska.

Soon after the Santa Barbara blowout, the Survey reviewed and revised its operating procedures and regulations. Revised regulations and Outer Continental Shelf orders which implemented the regulations were issued August 28, 1969. Subsequently, the Survey commissioned three of the studies cited above (National Aeronautics and Space Administration, 1971; U.S. Geological Survey, 1972; and National Academy of Engineering, 1972) and established a work group on Outer Continental Shelf safety and pollution control, chaired by the Survey's Associate Director, to review the studies' findings and recommendations. This work group issued its first report and recommendations in May 1973 (U.S. Geological Survey, 1973). Supplemental studies (U.S. Geological Survey, 1974a, b) evaluated the two other reports listed above (Kash and others, 1973; Council on Environmental Quality, 1974).

These recommendations and their status in fiscal year 1976 are listed in table 21. 


\begin{tabular}{cc}
\hline $\begin{array}{c}\text { Work group } \\
\text { recommendation }\end{array}$ & \multicolumn{1}{c}{$\begin{array}{c}\text { Implementation in fiscal year } 1976 \\
\text { or before }\end{array}$} \\
\hline $\begin{array}{l}\text { 1. Failure reports and } \\
\text { corrective }\end{array}$ & $\begin{array}{l}\text { A system was established for opera- } \\
\text { tors to report, quarterly, failures }\end{array}$ \\
& $\begin{array}{l}\text { of subsurface safety valves. The } \\
\text { system can be expanded to in- } \\
\text { clude other types of equipment } \\
\text { failures. Failure-reporting forms } \\
\text { are being designed. }\end{array}$
\end{tabular}

2. Accident investigation and reporting.

3. Information exchange.

\section{Research and development.}

\section{Standards and} specifications.

Accident-reporting procedures were revised to define better causes and effects of accidents. Geological Survey reports of accidents are available for public inspection.

Reports on failures of subsurface safety valves are distributed quarterly to all operators. A safety alert system has been established to inform operators of the causes of accidents and pollution events.

American Petroleum Institute-sponsored committees have been formed to encourage industry research on sand-probe development and testing, orifice coefficients, and oil detection and removal. The Survey contracted with the Harry Diamond Laboratories to assess industry research and development concerning safety and pollution control, development of communications equipment and flow meters, fire suppression, and subsea inspections.

Aerospace Corp. completed a study for verification of new offshore structures, as well as a design review of Shell's Cognac platform in 1,100 feet of water.

The American Petroleum Institute established standards and specifications for: design, installation, and operation of subsurface safety valve systems; analysis, design, installation, and testing of surface safety systems on offshore platforms; wellhead surface safety valves; design and installation of production-platform piping systems.

The American National Standards Institute has agreed to form committees to review standards.

6. Systems analysis _- The Geological Survey contracted for pilot studies on the analysis of the design of platform facility systems. The Survey also provided a research grant to Rice University to draft standards on platform-systems design analysis.

\begin{tabular}{lc}
\hline $\begin{array}{c}\text { Work group } \\
\text { recommendation }\end{array}$ & \multicolumn{1}{c}{$\begin{array}{c}\text { Implementation in fiscal year } 1976 \\
\text { or before }\end{array}$} \\
\hline 7. Engineering \\
documentation.
\end{tabular}$\quad \begin{aligned} & \text { The revision of OCS Order No. 8 } \\
& \text { (Platforms and Structures) requires } \\
& \text { extensive documentation of con- } \\
& \text { struction design and safety sys- } \\
& \text { tems. }\end{aligned}$

8. Wearout prevention.

The revision of OCS Order No. 8 requires the monitoring of sand erosion of valves and lines. Industry is conducting research on sanderosion detectors.

9. Training and certification.

OCS Order No. 2 (Drilling Procedures) (Pacific Area) requires well-control training for supervisory and drilling personnel. OCS Order No. 8 requires training for all personnel working with safety devices. Procedures have been established to insure that minimum training standards are met. Training of inspectors is to be evaluated on an individual basis. Training sources are (1) on-the-job training, (2) technical schools, and (3) indoctrination sessions.

10. Motivation

As a result of work group recommendations, industry published a bulletin (American Petroleum Institute, 1974) on ways to motivate employees to be concerned with safety and pollution prevention.

11. Lease Management program.

This program on the OCS has been buttressed to provide adequate staff and funds to mount an optimum effort.

12. Inspection procedures.

\section{OCS order} development.

14. Standardization of forms.
Uniform inspection and enforcement procedures have been established. A computerized platform inspection system has been developed.

Procedures were established for development of new OCS orders and revision of existing orders.

Public participation (including affected States) in the development of OCS Orders is provided through the placing of notices of proposed rulemaking in the Federal Register.

The technical adequacy of OCS Orders was assured by providing for review by the American $\mathrm{Na}$ tional Standards Institute.

Forms have not yet been standardized. 
TABLE 21.-Status of Outer Continental Shelf recommendations -Continued

\begin{tabular}{cc}
\hline $\begin{array}{c}\text { Work group } \\
\text { recommendation }\end{array}$ & $\begin{array}{c}\text { Implementation in fiscal year } 1976 \\
\text { or before }\end{array}$ \\
\hline 15. Safety and & The Marine Board of the National \\
advisory & Academy of Engineering estab- \\
committees. & lished a committee to review OCS \\
& operations (National Academy of \\
& Engineering, 1974a, b; National \\
Research Council, 1975a, b). The & Geological Survey established \\
& safety committees in field opera- \\
& tions offices. Oil companies have \\
& established internal safety and \\
anti-pollution groups.
\end{tabular}

16. Memorandum of understanding with the Occupational Safety and Health

Administration.

17. Memorandum of understanding on pipelines.

18. Memorandum of understanding on standards for discharge from platforms and rigs.

19. Subsea production systems.

A task force was assembled to assess the current state of the art, and comments were solicited through a notice in the Federal Register.

Two reports on subsea systems were prepared.

\section{Regulation of Federal and Indian lease operations}

In December 1973, the Geological Survey began an intensive review of the onshore regulatory program in order to define deficiencies in the program and to recommend corrective actions. The National Aeronautics and Space Administration, assisted by the Martin Marietta Corporation, was requested to study the Conservation Division's responsibilities, authority, and procedures for supervising leases on Federal and Indian lands, to define techniques for measuring program performance and industry compliance, to recommend ways of improving leasehold inspections,
The Geological Survey also requested that the Department of the Interior's Office of Audit and Investigations undertake a study of the onshore-royalty accounting system.

The National Aeronautics and Space Administration's component of the study was completed in December 1974 (National Aeronautics and Space Administration and Martin Marietta Corporation, 1974). Their report contained 79 numbered recommendations, many of which had subparts. The study recommendations addressed overall program management and contained various suggestions for clarifying and interpreting Department regulations governing onshore operations. These regulations provide guilelines but do not explicitly define the criteria which lessees or operators must meet in conducting operations on leases. In the past, it has been left to Iccal Survey officials to interpret and enforce these regulations, and, as a result, there has been. a lack of uniformity in the application of standards and pro $\mathrm{e}-$ dures.

Subsequent to the completion of the National Acronautics and Space Administration's study, the Sur ey established a task force to review the onshore-lt ase management report. After extensive review by the managers responsible for the various operations in May 1975, the Survey adopted nearly all the reci mmendations as presented or as slightly modified (iJ.S. Geological Survey, 1975). Implementation of cer ain of the recommendations was commenced in fical year 1976, and further corrective actions will be undertaken in fiscal year 1977.

The Office of Audit and Investigations report on accounting procedures (Office of Audit and Invest gations, 1975) concluded that improvements $v$ re needed in several areas and that increased staff vas needed to handle the work load. The areas identi ed for improvement were:

- Lessee reporting procedures.

- Royalty accounting procedures.

- Determination of value and volume of oil and gas production.

The Geological Survey generally agreed with the findings of the study and immediately took stef: to implement them. With the additional people rovided in fiscal year 1976, the Survey has restruct red the chief accountant's responsibilities to provide for overall systems management and policy developn ent. Positive action has also been taken to streamline accounting operations through such means as requ:ring uniform reporting, eliminating duplicative repor ing, and making more extensive use of automatio: to handle accounting data and audit reporting. Cou led with these modifications is an aggressive effort $t$ : in- 


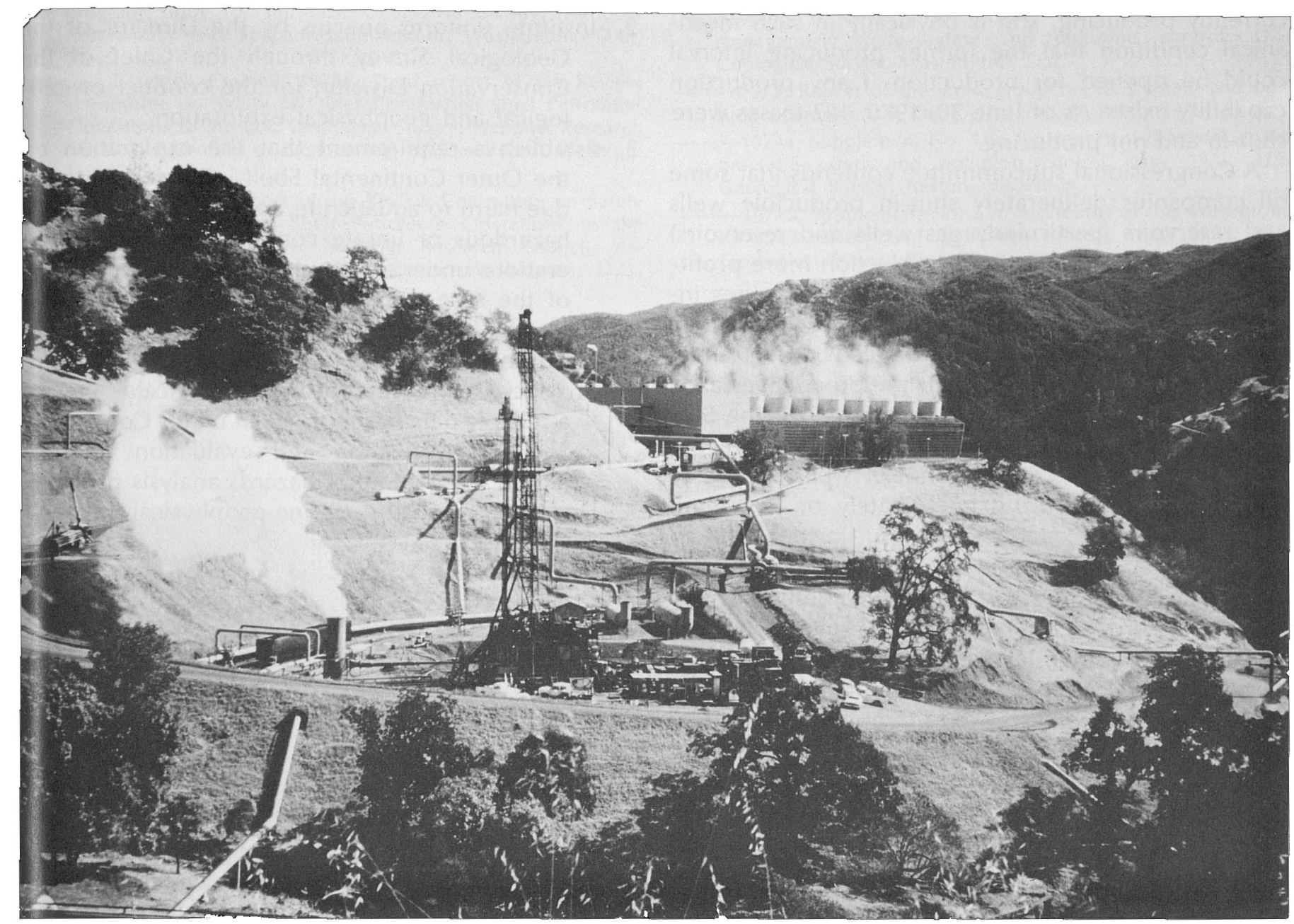

Well being drilled for geothermal steam in California.

sure prompt and accurate royalty reporting and payment. The Geological Survey expects to have fully implemented all recommendations early in fiscal year 1977.

\section{Royalty oil}

The Mineral Leasing Act of 1920, the Acquired Lands Leasing Act of 1947, and the Outer Continental Shelf Lands Act of 1953 authorize the Secretary of the Interior to sell royalty oil accruing to the United States under oil and gas leases issued under those acts. In order to assist small business enterprise, the Congress has authorized and directed the Secretary, when he determines that supplies of crude oil are not sufficient in the open market for refineries not having their own source of crude oil, to grant a preference to such refineries in the sale of royalty oil for processing or use in such refineries but not for resale in kind. The Act of July 13, 1946, provides that the sale of royalty oil to such refineries may be a private sale at not less than the market price and that in selling such oil the Secretary may at his discretion prorate such oil among such refineries in the area in which the oil is produced.

During fiscal year 1976, 3.8 million tonnes (28.4 million barrels) of royalty oil from operations conducted on the Outer Continental Shelf (Gulf of Mexico and Pacific) were taken by oil refineries under 45 separate contracts, and 1.3 million tonnes $(9.8$ million barrels) of royalty oil from Federal onshore leases were taken by oil refineries under 24 separate contracts. The royalty oil was allocated pursuant to the regulations contained in Title 30, Parts 225 and225a, of the Code of Federal Regulations as they apply to onshore and OCS royalty oil, respectively. It is anticipated that the total volume of royalty oil distributed during fiscal year 1977 will increase substantially.

\section{Shut-in wells}

Still of major concern during fiscal year 1976 was the question of shut-in oil and gas wells. The Geological Survey defines a "shut-in well" as any well which at some time in the past was a producing well, is not 
currently producing, and is physically in such mechanical condition that the former producing interval could be opened for production if any production capability exists. As of June 30, 1976, 182 leases were shut-in and not producing.

A Congressional subcommittee contends that some oil companies deliberately shut-in producible wells and reservoirs (particularly gas wells and reservoirs) until higher prices will make production more profitable. Industry's response was that reserve figures include behind-the-pipe reserves in wells with multiple sands which could not be produced concurrently. Where multiple horizons occur, the productive sands are produced sequentially. In January 1975, the Survey asked 10 companies that appeared to have the most questionable cases of shut-in wells on leases either to start producing immediately or to submit reasons and data explaining why shut-in status should be permitted. Subsequently, in March 1975, 3 of these 10 lessees were required to submit additional data supporting the shut-in status of their wells. As a result of these actions, two lessees chose to terminate one lease each in fiscal year 1975. Then, in fiscal year 1976, one other lessee chose to terminate two leases. However, in general, the inquiries disclosed that the wells and leases were shut-in because transportation facilities did not exist, or production equipment was ordered but not yet delivered and installed, or the gas reserves had been depleted to the point where further production was not economical.

\section{Geological and geophysical regulations regarding exploration}

On June 11, 1976, the Secretary of the Interior signed regulations governing prelease geological and geophysical exploration of the Outer Continental Shelf. These regulations standardize prelease exploration procedures on the outer shelf and provide for protection of the marine environment. They cover the conduct of exploration operations such as gravity, magnetic, and seismic surveys; shallow test drilling; and deep "off-structure" drilling to determine geological conditions in a particular area. One especially significant provision of the regulations requires that the exploratory data acquired under a permit must, upon request, be submitted to the Geological Survey. Other provisions call for the ultimate public release of submitted data. An environmental impact statement on the regulations was published in April 1976.

Implementation of the regulations will:

1. Revoke various notices and agreements governing 146
2. Institute uniform policies by the Director of the Geological Survey through the Chief of the Conservation Division for the conduct of geological and geophysical exploration.

3. Establish a requirement that the exploration on the Outer Continental Shelf will not cause undue harm to aquatic life, cause pollution, create hazardous or unsafe conditions, endanger operations under a lease, interfere with other uses of the area, or disturb any sites, structures, or objects of historical or archeological significance.

4. Provide ready access for the Geological Survey to a reliable data base for use in Outer Continental Shelf tract-selection and evaluation program and in the geological hazards analysis program.

5. Decrease the cost of marine geophysical data previously purchased from industry.

6. Schedule the release to the public of all geological and geophysical data submitted to the Geological Survey.

\section{REFERENCES}

Adams, M. V., John, C. B., Kelly, R. F., LaPointe, A. E., and Meurer, R. W., 1975, Mineral resource management of the Outer Continental Shelf: U.S. Geol. Survey Circ. 720, 32 p. American Petroleum Institute, 1974, Employee Motivation Programs for Safety and Prevention of Pollution in Offsiore Operations: American Petroleum Institute, Washington, D.C., 50 p.

Council on Environmental Quality, 1974, OCS oil and gas -an environmental assessment, $A$ report to the President: Council on Environmental Quality, Washington, D.C. (U.S. Government Printing Office), $5 \mathrm{v}$.

Kash, D. E., and others, 1973, Energy under the oceans: Nortian, Okla., University of Oklahoma Press, $378 \mathrm{p}$.

National Academy of Engineering, 1972, Outer Continental helf resource development safety-a review of technology and regulations for the systematic minimization of environmental intrusion from petroleum products: National f,cademy of Engineering, Marine Board, Panel on Operational Safety in Offshore Resource Development, Washin ton, D.C., 197 p.

1974a, First report of the Review Committee on Safey of Outer Continental Shelf Petroleum Operations to the U ited States Geological Survey: National Academy of Enginee ing, Marine Board, Review Committee on Safety of Outer Continental Shelf Petroleum Operations, Washington, D.C., 6 p. 1974b, Second report of the Review Committee on S:ifety of Outer Continental Shelf Petroleum Operations tc the U.S. Geological Survey: National Academy of Engineering, Marine Board, Review Committee on Safety of Outer Continental Shelf Petroleum Operations, Washington, D.C., 0 p.

National Aeronautics and Space Administration 1971, Feasioility study report-applications of NASA contract quality nanagement techniques and failure mode effect analysis procedures to the USGS Outer Continental Shelf oil anc gas lease management program: National Aeronautics and Space Administration, George C. Marshall Space light Center, Huntsville, Ala., 65 p.

National Aeronautics and Space Administration, and $N$ artin Marietta Corporation, 1974, Onshore lease management 
program study for the U.S. Geological Survey: National Aeronautics and Space Administration, Washington, D.C., $91 \mathrm{p}$.

National Research Council, 1975a, Third report of the Review Committee on Safety of Outer Continental Shelf Petroleum Operations to the U.S. Geological Survey: National Research Council, Assembly of Engineering, Marine Board, Washington, D.C., $12 \mathrm{p}$.

1975b, Fourth report of the Review Committee on Safety of Outer Continental Shelf Petroleum Operations to the U.S. Geological Survey: National Research Council, Assembly of Engineering, Marine Board, Washington, D.C., $25 \mathrm{p}$.

Office of Audit and Investigations, 1975, Review of royalty accounting system for onshore oil and gas leases: U.S. Department of the Interior, Office of Audit and Investigations, Washington, D.C., $106 \mathrm{p}$.
U.S. Geological Survey, 1972, Outer Continental Shelf lease management study-safety and pollution control: U.S. Geological Survey, Washington, D.C.

1973, Report of the work group on OCS safety and pollution control: U.S. Geological Survey, Reston, Va., 33 p.

-1974a, Supplement No. 1 to the report of the work group on OCS safety and pollution control, May 1973: U.S. Geological Survey, Reston, Va., 17 p.

-1974b, Supplement No. 2 to the report of the work group on OCS safety and pollution control, May 1973: U.S. Geological Survey, Reston, Va., 12 p.

1975, Conservation Division Task Force Report on the Onshore lease management study for the U.S. Geological Survey by National Aeronautics and Space Administration and a support team from Martin Marietta Corporation: U.S. Geological Survey, Reston, Va., 120 p.

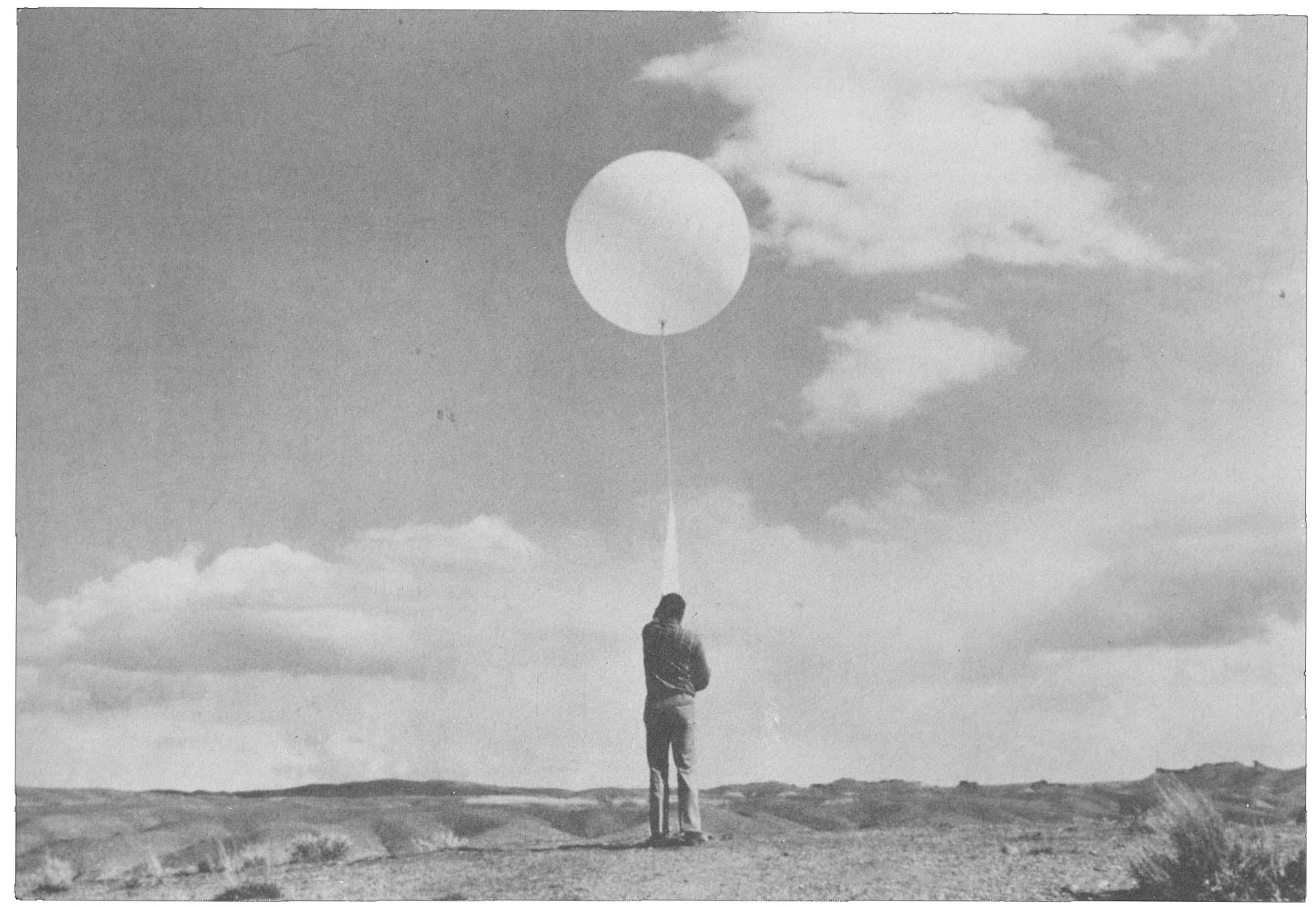

Meteorologist preparing to release a pilot balloon as part of an upper-air-quality study to facilitate monitoring the environmental impact of future oil-shale development in Utah. 
elected officials, planners, public interest groups, the legal profession, social scientists, and the general public. The task of achieving these objectives is carried on by five multidisciplinary programs:

- Earth Sciences Applications (ESA).

- Resource and Land Investigations (RAĹl).

- Geography.

- Earth Resources Observation Systems (EROS).

- Environmental Impact Analysis (EIA).

\section{Principal issues}

The principal issues faced by the Land Information and Analysis Office in fiscal year 1975 carried on into fiscal year 1976. These issues basically fall within two categories.

1. The recent rapid growth of Federal and State legislation responding to concerns such as energy development, coastal-zone management, hazards reduction, environmental impact, and water quality has greatly stimulated need for earthscience information to plan and manage land and water resources. Examples are the demands on the research and data-collection activities of the Geological Survey from recently mandated Federal programs such as the Department of Housing and Urban Development Community Block Grants/Entitlement Grants and Comprehensive Planning Assistance Program, National Flood Insurance Program, Disaster Relief Act, EPA-208 Program, the Department of Commerce Coastal Zone Management Program, and related State and local legislation and regulations.

2. The increasing concentration of the Nation's population in urban areas and the need for greater and more efficient use of land have focused attention on the opportunities and constraints the Earth poses to growth and development. For example, Kansas City is developing subsurface space for factories and warehousing; Chicago is excavating vast underground cavities for storage of storm-water runoff; and cities throughout the United States are placing utilities, communication, and transportation networks in tunnels. These trends, along with the increase in highdensity, major structures in urban areas, have escalated the requirements for accurate earthscience data in support of planning and decisionmaking.

Although the Survey has already done much to foster the integration of earth-science information into the planning process through urban-area studies address issues of data content and interpretation and to apply the results of Survey work to a broad spectrum of resource and environmental managers. The Survey is hopeful of strengthening this effort to meet national needs for earth-science information.

\section{Highlights}

- Completion of five urban-area study projects in the Baltimore-Washington area, the Connecticut Valley area, the greater Pittsburgh area, the San Francisco Bay region, and the Tucson-Phoenix area.

- Publication of "A Guide to State Programs for the Reclamation of Surface Mined Areas" (U.S. Geological Survey Circ. 731, by Imhoff and others, 1976) which provides an inventory of each State's programs requiring reclamation of surface mined areas.

- Production of land-use and land-cover maps for $1,170,000$ square kilometers $(450,000$ square miles), including the entire States of Kansas, Florida, and Pennsylvania, bringing the total area mapped to $1,950,000$ square kilometers $(750,000$ square miles) since the nationwide land-use mapping program started in fiscal year 1975

- Publication of "ERTS-1, A New Window on cur Planet" (U.S. Geological Survey Prof. Paper 9 29, by Williams and Carter, 1976) which presents 85 case histories on the use and application of ERTS-1 (now Landsat-1) data to earth-resou ce mapping, monitoring, and inventory.

- Preparation, with lead or joint-lead responsibility, of 20 environmental impact statements and participation in a nonlead capacity in the preparation of 15 statements; 29 of the total number were energy related. Review of 2,812 impact statements and related documents.

\section{Budget and personnel}

Obligations for Land Information and Analsis Office activities in fiscal year 1976 amounted to $\$ 17.28$ million, an increase of 4 percent over fiscal y ar 1975 (table 22 and fig. 65). The EROS Program trarisition quarter obligations of $\$ 4.84$ million incluced $\$ 2.93$ million for the procurement of a digital imaseprocessing system for installation at the EROS Data Center to provide higher quality Landsat imagery on a production basis.

Cooperative programs with State agencies were carried on by the Geography program for land-ise and land-cover mapping. 
TABLE 22.-Land Information and Analysis Office obligations for fiscal year 1976 and the transition quarter (dollars in millions)

[Data may differ from that in statistical tables because of rounding]

\begin{tabular}{|c|c|c|c|c|}
\hline Program & $\begin{array}{c}\text { Fiscal } \\
\text { year } \\
1975\end{array}$ & $\begin{array}{c}\text { Fiscal } \\
\text { year } \\
1976\end{array}$ & $\begin{array}{l}\text { Percent } \\
\text { change }\end{array}$ & $\begin{array}{c}\text { Transition } \\
\text { quarter }\end{array}$ \\
\hline Total & $\$ 16.99$ & $\$ 17.28$ & + & $\$ 8.92$ \\
\hline Total obligations & 15.46 & 14.91 & -4 & 7.79 \\
\hline Earth Sciences Applications program & 1.60 & 1.63 & + & .41 \\
\hline Resource and Land Investigations program & .96 & .74 & -23 & .49 \\
\hline Geography program & 2.01 & 2.34 & +16 & .75 \\
\hline Earth Resources Observation Systems program & 8.28 & 8.16 & -1 & 4.84 \\
\hline Environmental Impact Analysis program & 2.61 & 2.04 & -22 & 1.30 \\
\hline Reimbursable programs & 1.31 & 1.90 & +45 & .64 \\
\hline State, counties, and municipalities & .03 & .13 & +333 & .02 \\
\hline Miscellaneous non-Federal sources & 1.09 & 1.50 & +38 & .47 \\
\hline Other Federal agencies & .18 & .27 & +50 & .15 \\
\hline Working funds & .23 & .47 & +104 & .49 \\
\hline Ozark Regional Commission & .05 & .03 & -40 & ----- \\
\hline National Aeronautics and Space Administration & .18 & .44 & +144 & .06 \\
\hline National Park Service & $-\cdots--$ & $-\cdots--$ & ----- & .04 \\
\hline Environmental Protection Agency & $-\cdots--$ & ---- & ---- & .21 \\
\hline Department of Transportation & ---- & ----- & ----- & .18 \\
\hline
\end{tabular}

The work of the Land Information and Analysis Office is partly accomplished through private contracts and research grants. Of fiscal year 1976 funds, \$5.0 million (24 percent) was expended on contracts and $\$ 0.16$ million on research grants. Contract services were the major source of support for operations at the EROS Data Center.

The programs of the Land Information and Analysis Office were carried out by 195 full-time career employees in 1976; at the end of the year 157, were assigned to the Office's programs (table 45), and 38 were assigned to other Survey offices in support of the work of the Land Information and Analysis Office. In addition, contract support services at the EROS Data Center amounted to 296 man-years. Personnel of the Topographic, Computer Center, and Administrative Divisions were also assigned to the EROS Data Center.

\section{EARTH SCIENCES APPLICATIONS PROGRAM}

\section{Programs and activities}

The Earth Sciences Applications program was established to provide a unit within the U.S. Geological Survey to direct and coordinate multidisciplinary Geological Survey projects specifically concerned with disseminating earth-science data to land-resource decisionmakers in readily usable forms. The program's objectives are threefold: (1) to interpret, demonstrate, and encourage the use of earth-science

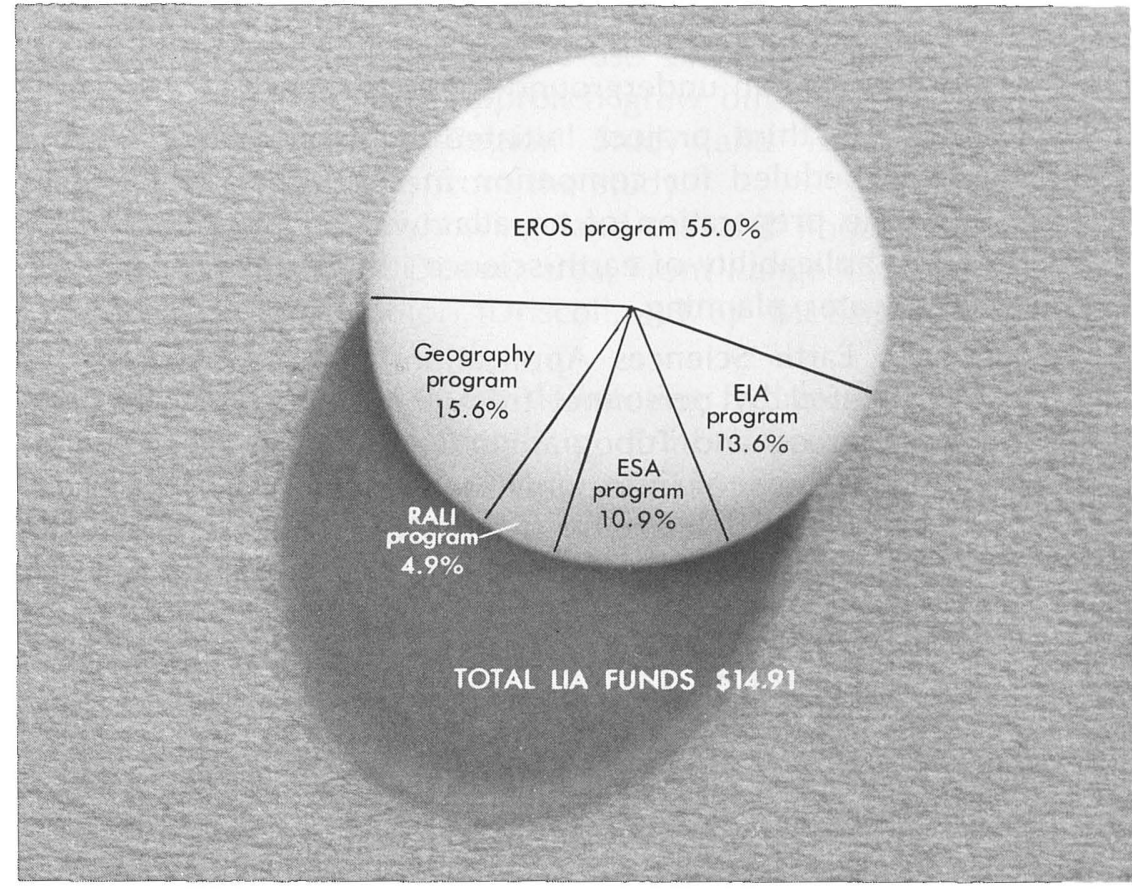

FIGURE 65.-Distribution of Land Information and Analysis funds in fiscal year 1976 (dollars in millions).

information for land-resource decisionmaking through specially designed projects, interaction with users, technical assistance, publication of specially designed map and book reports, and project evaluation; (2) to stimulate development of multidisciplinary studies in the Survey through coordination and integration of activities; and (3) to serve as the focal point within the Survey for multidisciplinary studies 
to support the work of other Federal, State, and local agencies.

In the course of addressing these objectives, the Earth Sciences Applications program has undertaken the study of eight selected urban and adjoining areas. Five of these studies-those located in the Baltimore-Washington area, the Connecticut Valley area, the greater Pittsburgh area, the San Francisco Bay region, and the Tucson-Phoenix area-were completed at the end of fiscal year 1976 as scheduled. Three ongoing studies in Puget Sound, Wash., Denver, Colo., and Fairfax County, Va., will be greatly strengthened in fiscal year 1977 and will build on experiences gained in the other urban studies.

The Earth Sciences Applications program initiated three new projects in fiscal year 1976. Two tunneling-feasibility studies for rapid transit systems, funded by the Department of Transportation through the Earth Sciences Applications program, were undertaken in the central business districts of MinneapolisSt. Paul, Minn., and Los Angeles, Calif. The main objective of these projects, which are to be completed in fiscal year 1977, is to assess the need for, and the availability of, hydrologic and geologic data relevant to the construction, maintenance, and operation of an underground transit system.

A third project initiated in fiscal year 1976 and scheduled for competion in fiscal year 1977 entails the preparation of an atlas which demonstrates the applicability of earth-science information to land and water planning.

Earth Sciences Applications program studies are staffed by personnel from the Geologic, Water Resources, and Topographic Divisions supported by allocations of personnel and funds from the Earth Sciences Applications and Geography programs. In fiscal year 1976, approximately $\$ 1.6$ million was allocated specifically to the urban-area studies; in addition, these studies were able to build upon about $\$ 0.4$ million of related research in the project areas conducted by other divisions of the Geological Survey. An additional $\$ 0.2$ million was available from the Department of Transportation.

The urban areas selected for study are characterized by their geologic and geographic diversity and by rapidly growing populations accompanied by an attendant increasing demand on land and water resources. By carefully collating, documenting, and interpreting data on geologic and hydrologic constraints on certain land uses, these projects have provided a basis for assessing unforeseen social and economic costs. The variety of earth-science input into this evaluation process is great. To date, the total number of releases from the eight urban-area studies such diverse information as the character, thickness, and erodibility of soils; quantity and quality of surface and ground water; definition of hazards associated with floods, earthquakes, landslides, subsidence, and poor foundation materials; and distribution of mineral resources, landforms, slopes, and watercourses. Publications have also dealt specifically with techniques of applying earth-science data to land-use planning.

One of the goals of these experimental studies has been to foster a desire and capability on the part of local governments to continue the development and application of earth-science data long after the studies are terminated. This objective has been reached by a variety of techniques, each unique to the political structure, resource capability, and interests of individual urban areas. For example, in the Connecticut Valley Urban Area Project, several innovative programs were developed to stimulate dissemination of information. Most notably in this respect, the project office worked with the Connecticut State Geological Survey, Cooperative Extension Service, and Department of Environmental Protection in establi hing a series of land-use workshops to inform poten ial local users-town planning, zoning, and conservation commission members in all 169 Connecticut tov'ns -of the types of earth-science data available and their applicability to the planning process. The success of this endeavor was measured both by the local users' receptive attitude towards the workshops and the data presented and by the interest and partici sation of several Federal agencies, among them the soil Conservation Service, Environmental Protect on Agency, and regional agencies.

In the San Francisco Bay Region Environment ind Resources Planning Study, a quite different appro ch resulted in a significant degree of success in wc $\mathrm{k}$ ing with county and regional organizations to des gn highly usable products and achieve their assimilation into the planning process. A close working asso iation with the Association of Bay Area Governme ts, which functioned as both a user and producer, vas designed into the project.

As a user, the Association of Bay Area Governments applied San Francisco Bay Region Study results extensively in its capacity as an $A-95^{1}$ nd environmental impact statement and report revew agency and through its involvement in many area planning programs. As an initial step in the asso iation-sponsored San Mateo Coast Corridor Study, products from the bay study project were usec to identify areas of critical environmental concern and those parts of the corridor with limited development

\footnotetext{
1 The A-95 review process was established by the Federal Offic e of Management and Budget, pursuant to its revised Circular A-95. It re quires that all requests for Federal aid be reviewed by designated tat and regional governmental agencies.
} 
potential because of natural hazards. The Association then used basic data and interpretive maps from the bay study project in developing a new and imaginative methodology for assessing the capability and costs of land to support various types and degrees of land use (fig. 66).

The success of the San Francisco Bay project in producing usable information is demonstrated by its ready acceptance by the local governments. All eight counties in the San Francisco Bay region have made extensive use of project material in their planning studies, plans, ordinances, and other planning activities (Kockelman, 1976). Of particular interest are the uses of bay region study results in the preparation of ordinances and other types of legislation, for they demonstrate the application of land information as major development determinants. Several counties have developed ordinances which deal with geologic studies and natural hazards and rely in large part on the project products for implementation (for example, Santa Clara County Ordinance No. NS-1203.31).

The continued application of earth-science data to the legislative process seems assured as the Federal and State governments become increasingly aware of the vital importance of this information to the planning process. Examples of this awareness are already manifest in the California State mandates restricting developments in active fault zones and requiring all jurisdictions to prepare seismic safety planning elements. Similarly, recent Federal rules and guidelines-such as the 1974 Federal Insurance Administration guidelines for mandatory purchase of flood insurance and the 1975 Department of Housing and Urban Development Comprehensive Planning Assistance Program requiring counties to collect, analyze, and apply earth-science information-recognize the need for the acquisition and application of such data to land-use decisions.

Despite these encouraging signs of increasing acceptance, persistent danger exists that the momentum generated by these studies will be lost without developing stronger Federal support of local and State efforts. This would be a critical loss, indeed, when so much remains to be accomplished in terms of refining earth-science output and insuring integration of this information into the planning process. Failure to recognize the constraints certain geologic and hydrologic conditions place on development can result in tragedy (fig. 67). On the other hand, certain geologic and economic conditions can provide opportunities, aesthetic as well as economic, for better planning. As concluded by A. D. Little, Inc. (1975), in their evaluation of the San Francisco Bay Region Study on behalf of the Department of Housing and Urban Development, "... the consequences of not following through with the urban studies program can be more costly-in terms of dollars, lives, and resources wasted-than the costs of fulfilling the potential of this concept."

\section{Accomplishments}

Fiscal year 1976 was a successful and productive year for the Earth Sciences Applications program. Accomplishments of project activities during fiscal year 1976 included:

- Publication of "Geologic Conditions Related to Waste-Disposal Planning in the Southern Hood Canal Area, Washington" (Carson and others, 1975). The Puget Sound Urban Area Study also completed an analysis of the effects on water quality of recent increased volcanic activity at Mount Baker.

- Completion of two evaluations of the San Francisco Bay Region Environment and Resources Planning Study (A. D. Little, Inc., 1975; Kockelman, 1976).

- Completion of Association of the (San Francisco) Bay Area Governments' study, "Land Capability Analysis." The study develops and demonstrates a methodology for the application of earthscience information to land-use planning and decisionmaking. This approach grew out of the San Francisco Bay Region Study and relies heavily on products from the study.

- Publication of maps showing land-use and floodprone areas in the Denver area, Front Range Urban Corridor, Colo. (Driscoll, 1976; McCain and Hotchkiss, 1975).

- Completion of seven maps delineating hydrologic and geologic conditions in Prince Georges County, Md., and the District of Columbia.

- Publication (by the Appalachian Regional Commission) of the results of a study concerning the dissemination of geological information generated by the Greater Pittsburgh Region Study to local officials involved in making land-use decisions (Wissel and others, 1976).

- Publication of "Landsliding in Allegheny County, Pennsylvania" (Briggs and Pomeroy, 1976) which discusses geologic factors affecting landsliding and ramifications for engineering considerations and land-use control.

- Publication of three resource identification maps: "Occurrences of Commercially Important Nonmetalliferous Minerals in the Phoenix Area, Arizona" and "Mineral Construction Materials in the Phoenix Area, Arizona," prepared by authors from the Arizona Bureau of Mines (Moore and Varga, 1976), and "Map Showing Potential for Copper Deposits" (U.S. Geol. Survey, 1976). 


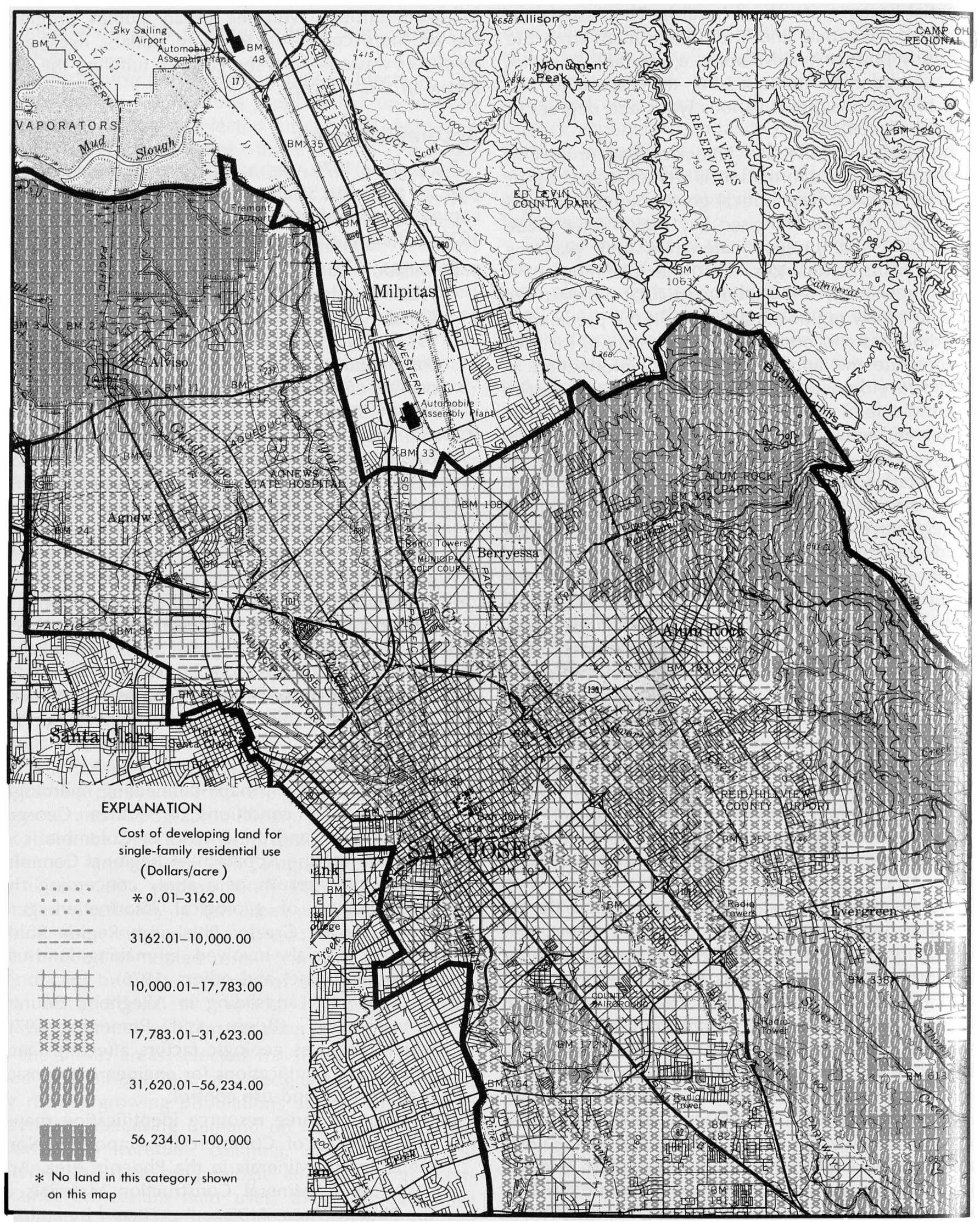

154

FIGURE 66.-Cost of developing land for single-family residential use. 


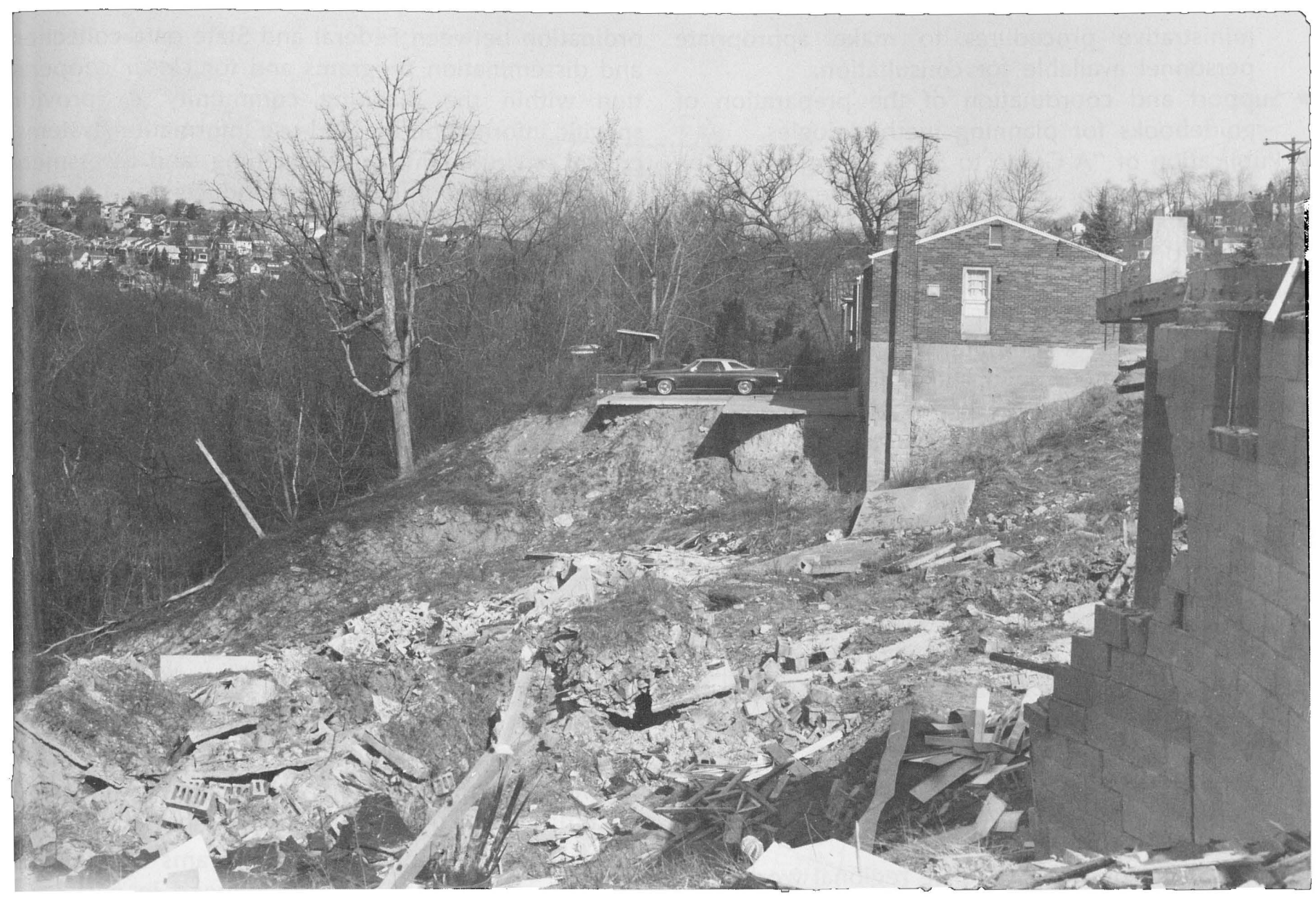

FIGURE 67.- -Landslide largely in landfill, Lawnwood Avenue, Brentwood and Baldwin Boroughs, greater Pittsburgh area, Pennsylvania. Warped wall of partly dismantled house in right foreground resulted from movement of footings that were not set in bedrock. House in right background is set on bedrock and apparently is not distressed structurally even though side and back yards have slipped away.. Note large trees inclined strongly downslope behind car and house, evidence of a history of movement in the area. (Photographed in April 1975.)

\section{RESOURCE AND LAND INVESTIGATIONS PROGRAM}

\section{Program and activities}

The Resource and Land Investigations (RALI) program is a Department of the Interior program, administered by the Geological Survey, whose purpose is to improve technical communication between the collectors and analysts of resource and land information and the planners, managers, and decisionmakers in government, industry, and the public sector. This goal is accomplished by coordinating the activities of the several bureaus in the Department of the Interior in those cases where a multidisciplinary perspective would improve the Department's ability to communicate with the planning community and by coordinating the Department's technical response to complex issues relating to land-resource analysis. To improve the transfer of technical information in the planning community, directories, catalogs, and bibliographies are compiled and distributed that describe the information products, services, and research. The program also provides for technical assistance to planners in the acquisition and interpretation of information and in the development, selection, and application of planning tools.

\section{Accomplishments}

The Resource and Land Investigations program accomplishments in fiscal year 1976 included the following activities:

- Identification and assessment of the utility of selected information products, geographic data systems, and data sources to State and local planning communities.

- Development and distribution of directories of data holdings and special information products of the Department of the Interior.

- Identification of technical expertise in the Department needed by regional, State, and local planning communities and development of ad- 
ministrative procedures to make appropriate personnel available for consultation.

- Support and coordination of the preparation of guidebooks for planning methodologies.

- Publication of "A Guide to State Programs for the Reclamation of Surface Mined Areas" (Imhoff and others, 1976).

- Publication of a "Directory to U.S. Geological Survey Program Activities in Coastal Areas, 197476" (Marcus, 1976).

- Development of a computer program to automate the preparation of onshore facility scenarios, given various levels and rates of oil and gas production (publication in review, scheduled for release as a Survey open-file report in February 1977).

- Completion of an agreement with Department of the Interior Library (Office of Library Services) to produce a "Directory to the U.S. Department of the Interior Information Sources," to be published in 1977.

- Completion of an agreement with the Colville Indian Tribe, the Washington State University, and the American Society of Planning Officials to conduct a natural-resource management study utilizing a computerized land-use analysis system.

- Sponsorship of a series of five regional workshops around the country, attended by delegates appointed by the Governors of every State, to transfer the results of the Resource and Land Investigations studies on Critical Environmental Areas and Land Use Information Systems.

- Completion of an agreement with the Council on Environmental Quality to produce a bi-annual "Environmental Indicators" publication and an annual "Compendium of Environmental Statistics."

- Completion of an agreement with the Environmental Protection Agency to conduct workshops to transfer to State and local agencies the methodology and information to be used for the assessment of onshore impact of oil and gas development on the Outer Continental Shelf.

The Resource and Land Investigations program was named the coordinator of Geological Survey responses to States' requests for technical assistance under the provisions of the Coastal Zone Management amendment (Public Law 94-370) which formally links Outer Continental Shelf development and coastal-zone planning.

The reports, bibliographies, and assistance on planning techniques have been well received, and user responses have identified the need for more co- ordination between Federal and State data-collection and dissemination programs and for closer cooperation within the planning community to provide specific information for land-use information systems, critical environmental area planning, and assessment of the utility of information products for planning needs.

\section{GEOGRAPHY PROGRAM}

\section{Programs and activities}

The Geography program links and integrates social-science information and the techniques of geographic analysis with earth-science information collected by the Geological Survey. Activities include:

- Mapping land use and land cover on a nationwide basis.

- Developing and demonstrating techniques of landuse and land-cover mapping using remotely sensed data and a geographic-information system.

- Conducting field investigations and participating in multidisciplinary studies that contribute to sclutions of problems arising from interactions of land-use practices and environmental factors.

- Contributing to the National Atlas project.

Planning and implementing programs designec to promote wise use of the land depend in part on a knowledge of the present distribution of and temporal changes in different types of land use and land cover and on a knowledge of where urbanization and other types of development are occurring. The location, area, and percentages of land use and land cover are among the types of statistical data usec by Federal and State legislators and local officials to determine land-use policy, to project demands for different types of land use, to predict where fucure development pressures will occur, and to formulate plans for regional development. Current land-use and land-cover data also support Federal and State planning for developing energy resources, manaying public lands, siting facilities, developing recreational areas, managing water resources, and assessing potential and actual natural disaster damages.

\section{National land-use and land-cover mapping and data compilation}

In fiscal year 1976, the Geography program continued the nationwide land-use and land-cover mapping and data-compilation effort, established by the Geological Survey in fiscal year 1975 as the Land Use Data and Analysis program and designed to alleviate or remedy many of the shortcomings of various types of existing data (fig. 68). Maps of current land use 


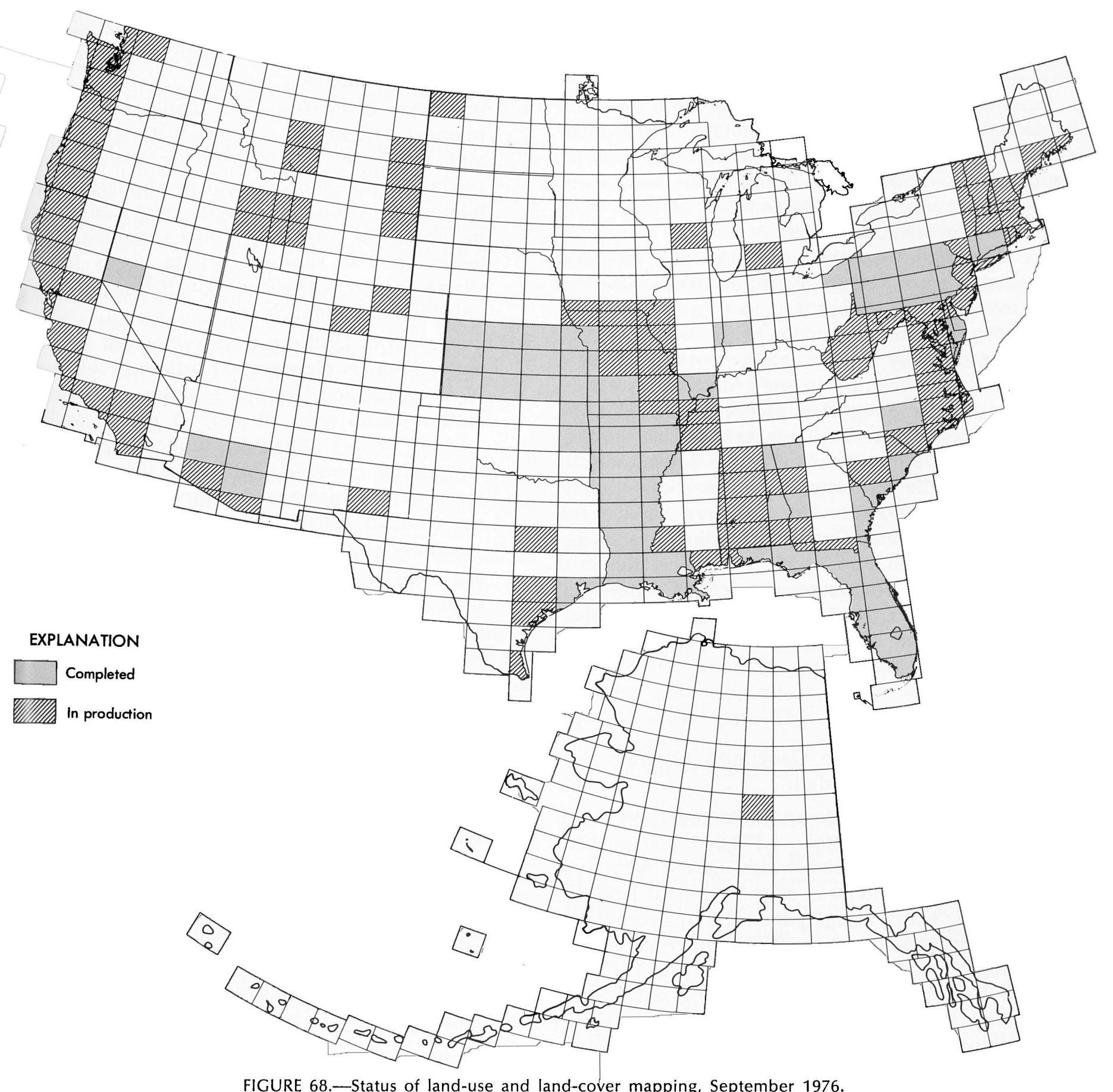

and land cover for the entire Nation are being compiled at a scale of $1: 250,000$ and at a scale of $1: 100$,000 where such new intermediate-scale maps are available. Additional maps of federally owned lands, political units, census county subdivisions, and hydrologic units are being prepared in overlay format to relate to the current land-use and land-cover data.

The classification system being employed to map land use and land cover was developed after consultation with many Federal and State agencies. It incorporates common terminology and can accom-

modate land-use and land-cover data gathered in greater detail (Anderson and others, 1976).

A computerized geographic-information system has been developed to store and retrieve the data compiled under the national land-use and land-cover mapping program and related research projects. The system includes: (1) entry of digitized land-use and land-cover maps and other related data; (2) editing and updating of the data base; and (3) retrieval and manipulation of the data for area measurement, comparative analysis with other data, and other analytic 
applications. Statistical summaries are prepared that present land-use and land-cover data for counties, watersheds, census county subdivisions, and federally owned land.

Experimental and demonstration land-use and land-cover maps are produced to test various mapping techniques, remotely sensed data applications, regional applications, classification variation, computer applications, and combinations of map scale and minimum mapping unit.

The Geography program has provided technical assistance to users of Geological Survey land-use and land-cover data and maps and to those who desire to use the data in conjunction with computer software developed by the Geography program or who need the data converted to use with other systems. For example, the Geography program is cooperating with and assisting the U.S. Fish and Wildlife Service, the Bureau of Outdoor Recreation, the Bureau of Land Management, the Environmental Protection Agency, the Soil Conservation Service, the Forest Service, the Appalachian Regional Commission, the Ozarks Regional Commission, the Pacific Northwest Regional Commission, the Four Corners Regional Commission, and many State and local agencies to utilize the Survey's land-use and land-cover data in their resource management and planning.

\section{Accomplishments}

Accomplishment of the Geography program during fiscal year 1976 included:

- Compilation of land-use and land-cover maps and data for approximately $1,170,000$ square kilometers (450,000 square miles) during fiscal year 1976 , the second year of the national land-use mapping effort, bringing the total area completed for such mapping to $1,950,000$ square kilometers $(750,000$ square miles). As in fiscal year 1975 , the emphasis continued on mapping coastal areas, energy-production areas, other areas for which such mapping was desired by other U.S. Geological Survey units and other Federal agencies, and areas for which cooperative agreements for landuse and land-cover mapping had been made. Map and overlay sets for sixty 1:250,000-scale quadrangles were released to the open file in fiscal year 1976, which brings the total released to 86 sets.

- Mapping was completed under cooperative agreements for the States of Kansas (funded by the Ozarks Regional Commission), Florida, and Pennsylvania and the Atlanta (Georgia) Metropolitan Region. Cooperative agreements were ping for the States of West Virginia, Alabama, Missouri, and North Carolina. Arkansas and Louisiana were previously mapped under cooperative agreements.

- Compilation of land-use and land-cover maps at regional $(1: 250,000)$, intermediate $(1: 100,000)$, and large scale $(1: 24,000)$ for the Atlanta Metropolitan Region and adjacent quadrangles in fulfillment of cooperative agreement obligations, in support of Atlanta Regional Commission activities, and in support of data needs for the Water Resources Division's Chattahoochee River Quality Assessment Study.

- Compilation of land-use-change maps at land-use and land-cover classification system Levels II and III for urban and regional settings in the southeastern Idaho area, in support of an Environmental Impact Analysis program study on monitoring capability following the release of the southeast Idaho environmental impact statement on phosphate-resource development.

- Completion of a test, in cooperation with the Fublications Division, demonstrating the feasibility of lithographic printing of land-use and landcover maps from polygon digital information stored on magnetic tape.

- Initiation of research activities directed toward creating operational land-use and land-cover maps from Landsat digital data for the northern Great Plains and the southern Alaskan coastal region.

- Completion of final reports for the Central Atlantic Regional Ecological Test Site Project dealing with land-use climatology, regional analysis, and eographic-information system development.

- Completion of research on the development $\mathrm{o}$ the oil and gas industry on the Louisiana coast realing with impacts on land use and land cove: of canal system expansion, maritime facilities sing, and labor force changes since 1947.

- Land-use and land-cover data for thirty-five 1: 50 ,000 -scale quadrangles $(620,000$ square kilom ters or 240,000 square miles) and data from 21 related overlays comprising 20 million bytes of information were digitized through a coriract for automated laser line-following digitizing and entered into the Geography program inform tion system.

- Completion of implementation of aGeography program information system in the State of Louiciana and initiation in several other States.

- Development of the capability to convert pol/gon maps to grid cells of any selected size. 
- Design and implementation of a data base having land-use and land-cover data as the central elements.

- Implementation of a highly efficient data-compaction routine.

- Provision of the initial impetus and partial funding for the seminar series conducted by the International Geographical Union, Commission on Geographical Data Sensing and Processing, for the purpose of studying spatial data bases within the Geological Survey.

- Publication of a map of land-use change, 1970-72, for the Washington urban area (U.S. Geol. Survey, 1975) and release of maps of land use and land-use change for Boston, Cedar Rapids, New Haven, Phoenix, Pontiac, Pittsburgh, San Francisco, and Tucson.

- Completion of a demonstration of land-use and land-cover classification of the Puget Sound region from Landsat digital data in collaboration with the Pacific Northwest Regional Commission, local planning agencies, National Aeronautics and Space Administration, and the Earth Resources Observation Systems program. Initiation of steps to incorporate machine processing of satellite data for use in the nationwide land-use and land-cover mapping and data-compilation program.

- Completion of studies of the use of Skylab sensors in analysis of urban land use and land-use change in urban areas. Also continued research in spatial analysis of digital land-use and landcover data, as distinguished from spectral analysis, in the search for semiautomated techniques to detect land-use and land-cover change.

- Publication of "A Land Use and Land Cover Classification System for Use With Remote Sensor Data" (Anderson and others, 1976). This system is being applied in the nationwide land-use and land-cover mapping and data-compilation program.

\section{EARTH RESOURCES OBSERVATION SYSTEMS PROGRAM}

\section{Program and activities}

The Earth Resources Observation Systems (EROS) program, administered by the Geological Survey for the Department of the Interior, develops techniques to obtain and analyze remotely sensed data and promotes the use of these techniques in fulfilling the resource and environmental inventory and management responsibilities of the Department. This objective is accomplished in cooperation with the National Aeronautics and Space Administration, the National Oceanic and Atmospheric Administration, and other Federal agencies.

Program personnel work closely with representatives of the Department's bureaus and offices to coordinate and jointly sponsor applications of remote-sensing technology. Much of the research, which has resulted in the demonstration of numerous new applications, has been made possible by the experimental data acquired through the National Aeronautics and Space. Administration's Landsat and Skylab programs and their aerial remote-sensing research program. Other research draws on data collected by other systems, such as the environmental satellites of the National Oceanic and Atmospheric Administration and aerial remote-sensing activities sponsored by Department of the Interior bureaus and other Federal and State agencies.

\section{EROS Data Center}

The EROS Data Center in Sioux Falls, S. Dak., maintains an extensive archive of aerial and space photography, processes and distributes photographic and digital products, and provides extensive user training and technical assistance in the use of remotely sensed data. The Data Center's archive is a major component of the Survey's National Cartographic Information Center.

\section{TRAINING AND ASSISTANCE}

A major function of the Data Center is to communicate the results of remote-sensing research to potential users. Technical training programs, ranging in length from a few days to 1 month, stress the use of remotely sensed data to particular applications such as forest inventories or mineral exploration (fig. 69).

During fiscal year 1976, the Data Center sponsored 9 orientation courses, 17 discipline- or techniqueoriented workshops, 3 structured courses, 2 international training courses, and 1 technical symposium. Courses and workshops were attended by 720 people.

In addition to formal courses, the Data Center operates a laboratory that provides visiting scientists with access to sophisticated equipment for processing digital imagery. This equipment is used for research, demonstration projects, and training. Data Center scientists also assist individual Federal, State, and local agencies in applying remotely sensed data to specific problems. In 1976 more than 600 scientists and resource managers attended demonstrations of the methods or conducted research analyses of Landsat data in the laboratory. 


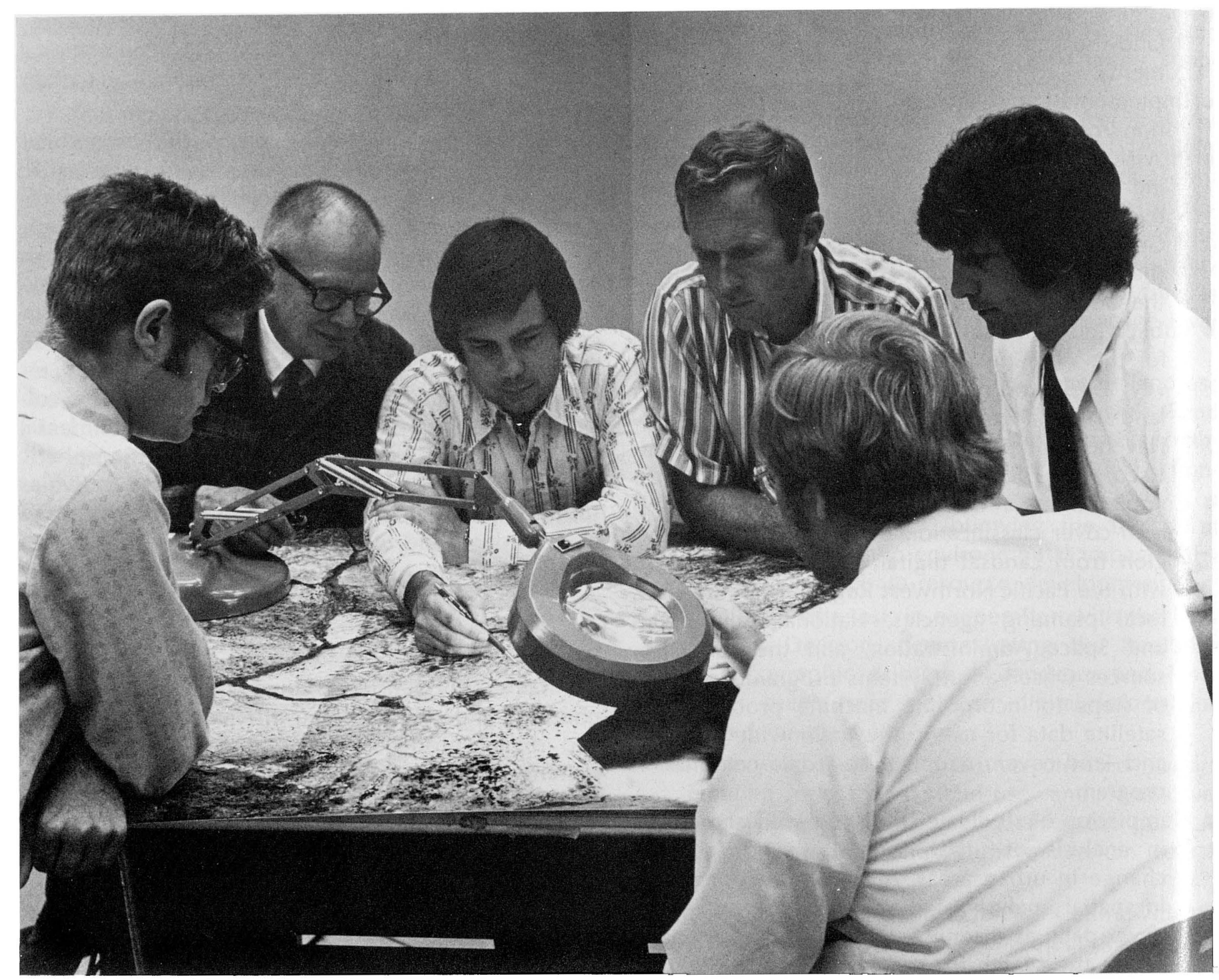

FIGURE 69.-A specialist in remotely sensed data shows students an interpretation technique at a technical training course.

\section{DATA PRODUCTION AND DISSEMINATION}

The EROS Data Center produces and distributes materials from data collected by satellites and aircraft. Data archived at the center, as of June 30, 1976, totaled over 6.5 million images, including over 800,000 frames of Landsat images and Landsat data in the form of computer compatible magnetic tapes. Aerial and space imagery holdings increase at an average rate of 38,000 frames per month, of which 20,000 are Landsat imagery.

The demand for reproductions of the data increased rapidly in fiscal year 1976 (tables 23 and 24). The Data Center distributed 25 percent more frames of Landsat imagery than in 1975, and, in addition, sales of computer compatible tapes increased from 879 to 2,289 , an increase of 160 percent. This indicates an increased trend toward use of digital pro-
TABLE 23.-Demand for remotely sensed data

\begin{tabular}{|c|c|c|}
\hline Fiscal year & & $\begin{array}{l}\text { Thousar: } \\
\text { of dolla }\end{array}$ \\
\hline 1973 & 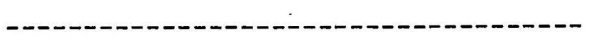 & $\$ 0.4$ \\
\hline 1974 & 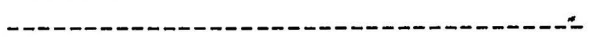 & .9 \\
\hline 1975 & 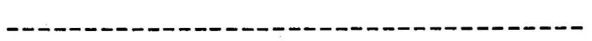 & 1.6 \\
\hline 1976 & 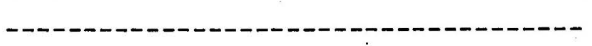 & 2.5 \\
\hline
\end{tabular}

TABLE 24.-EROS Data Center customer profile

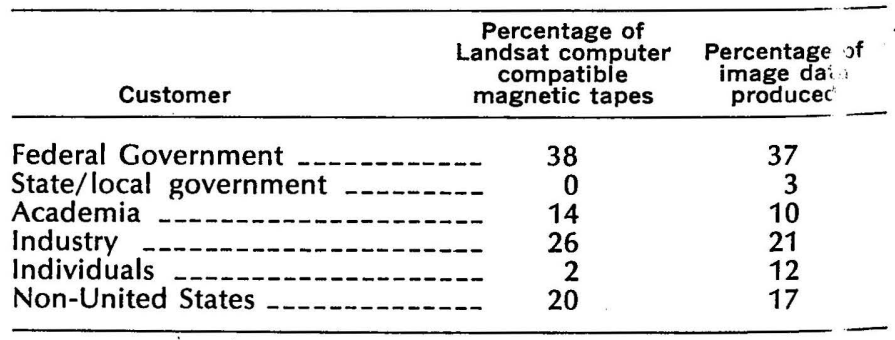


products constituted 67 percent of the dollar-value data produced by the center during fiscal year 1976 .

Procurement actions are in progress for a digital image-processing system at the EROS Data Center which will supply superior data products to customers in a shorter time. The new capability that is being implemented by Goddard Space Flight Center and the EROS Data Center will provide for: (1) shorter data delivery times for the digital tapes and film products; data will be available about 2 weeks after acquisition at ground stations instead of the 6 to 7 weeks using the present system; (2) high-quality film products derived directly from the archival highdensity digital tape, which will retain over 50 percent of the information content lost by the present photographic-film archival system; and (3) geometrically corrected tape and film products.

\section{Environmental monitoring}

Landsat data were used for mapping and classification of lands in southeast Idaho to aid in preparation of an environmental impact statement on the effects of phosphate mining.

\section{Remote-sensing education}

The Survey aided in establishing a remote-sensing capability at the Washington Technical Institute, the District of Columbia Land Grant College, under the U.S. Geological Survey Committee on Minority Education in Earth Science. Two courses of one semester each were taught in 1976. A diazo printer and coloradditive viewer, for analysis of Landsat images, were acquired and used in the courses.

\section{Subsurface analysis}

The integration of remote-sensing techniques into subsurface geologic analysis has been described in a report by Taranik and Trautwein (1976). Examples included are an exploration model for ground water in the Tucson, Ariz., area and an exploration model for mineralization in southeast Idaho.

\section{Accomplishments}

- Distribution of over 400,000 frames of imagery valued at more than $\$ 2$ million.

- An increase in distribution of computer compatible magnetic tapes of Landsat data from 879 in fiscal year 1975 to 2,289 in fiscal year 1976 .

- Initiation of a major digital image-processing system to provide higher quality image data for customers from Landsat-C and later satellites.

- Visits of over 17,000 persons to the EROS Data Center to become acquainted with applications of satellite data.
- In October 1975, the first W. T. Pecora Memorial Symposium was held in Sioux Falls, S. Dak., under the sponsorship of the American Mining Congress. The symposium was on the application of remote-sensing techniques to mineral and fuel exploration. Thirty of the papers will be published as a U.S. Geological Survey professional paper.

- Publication of "ERTS-1, A New Window on Our Planet" (Williams and Carter, 1976). It consists of 85 case histories on the use and application of ERTS-1 (now Landsat-1) data to earth resource mapping, monitoring, and inventorying.

\section{ENVIRONMENTAL IMPACT ANALYSIS PROGRAM}

\section{Program and activities}

The Environmental Impact Analysis (EIA) program provides an integrated Geological Survey response to the requirements of the National Environmental Policy Act through:

- Direction, coordination, and expertise in the preparation of environmental impact statements for which the Survey has lead or joint responsibility.

- Scientific and technical support of the preparation of statements for which the Survey has contributing responsibility.

- Technical analyses and review of statements and related documents prepared by other agencies.

- Manuals, guidelines, and training courses on the preparation and review of statements.

- Environmental research.

The National Environmental Policy Act requires that a Federal agency contemplating a major action that could significantly affect the quality of the environment must prepare a detailed statement of the possible environmental impacts. The Act further requires that statements must be reviewed by other Federal agencies having pertinent jurisdiction or expertise. In final form, the statement plays an essential role in an agency's decisionmaking process.

The Geological Survey becomes involved as a lead agency in the preparation of statements through the Conservation Division's supervision of mineral-resource exploration, development, extraction, and reclamation operations on Federal lands. The Survey becomes involved as a participating agency, in a nonlead role, both through its supervisory function, as described above, and through its special expertise in the areas of geology, hydrology, and mining and petroleum engineering. 
In accordance with guidelines set by the Council on Environmental Quality, Federal agencies submit environmental impact statements to the Department of the Interior for review. The statements are assigned by the Department to one or more bureaus, primarily on the basis of legal jurisdiction or special expertise.

The principal objectives of the Environmental Impact Analysis program are to:

- Provide a core group of multidisciplinary specialists to assure the continuity of quality standards through acquired expertise in the preparation and review of environmental impact statements and through associated research and training.

- Reduce the time required for preparation and review of environmental impact statements.

The Environmental Impact Analysis program is organized functionally into three branches:

The Preparation Branch directs, coordinates, and reviews the work of the task forces preparing environmental impact statements throughout the United States. The task-force approach provides great flexibility through its rapid utilization of experienced scientists with topical and areal knowledge of the resource under study. During fiscal year 1976 and the transition quarter, the workload associated with preparing environmental impact statements increased about 30 percent; 70 percent of the total effort was for coal-related statements.

The Review Branch provides technical analyses and review of statements and related documents prepared by the Geological Survey task forces, the Department of the Interior, and other Federal agencies. The level of effort required to review environmental statements increased by about 10 percent this year.

The Research and Training Branch supports and improves the activities of the other two branches by training new members, by preparing guidelines and manuals for task-force leaders and members, and by encouraging, sponsoring, and developing new methodologies for environmental statement preparation and impact monitoring. During the year the workload associated with these branch activities increased approximately 50 percent.

The growing participation of Federal, State and local agencies in the preparation of environmental impact statements has led to a wider range of jurisdictional concerns and a greater variety of related actions to be addressed in a single statement. This increasing complexity strains the current methods of task-force management and organization and the present format of the statements. Innovations in managerial techniques and imaginative restructuring of the statements, including increased use of com- puters, are required to meet the present problems and challenges.

The preparation of environmental impact statements is immensely expensive in terms of time and cost. Research concerned with reducing the bulk, time, and cost involved in the preparation of the environmental impact statements was started during fiscal year 1976. The first step concentrates on an overall reduction in bulk by restructuring the statements by stringent editing, use of summarization, use of highly structured supporting materials for ease of reference, and maximum use of charts, matrices, and graphics. Subsequent improvements will include use of improved analytical methods such as computermodeling techniques for analyzing alternative actions and their impacts.

\section{Accomplishments}

During the fiscal year 1976 and the transition quarter, the Survey:

- Took lead or joint-lead responsibility for the preparation of 20 environmental impact statements. Seventeen statements concerned the development of onshore coal, uranium, oil and gas, nd offshore oil and gas operations. The other three concerned critical minerals, leasing, and regilations (fig. 70 and table 25). Five of these stitements were completed during the year.

- Participated in a nonlead capacity in the preparation of 15 impact statements for which other Federal agencies had lead responsibility. Tw of these statements were energy related, involving principally coal and oil and gas-leasing operations and projects involving mine-mouth electric generating plants and related transinission lines, pipelines, and water supply. The remainder dealt with critical minerals. One of these statements was completed during the ear (fig. 70 and table 25).

- Provided technical information, gathered by cther Survey programs, to the U.S. Forest Service for 7 impact statements on geothermal energy resources and to the Bureau of Land Manager ent for 12 impact statements on leasing of the J.S. Outer Continental Shelf.

- Reviewed and commented on 2,812 impact s atements and related documents.

- Prepared guidance manuals to aid in the mar agement and administration of task forces ar $\mathrm{d}$ in the writing of environmental impact statements.

- Conducted training seminars for personnel assigned to task forces.

- Initiated research for reduction of bulk, time and cost of preparing environmental impact satements. 


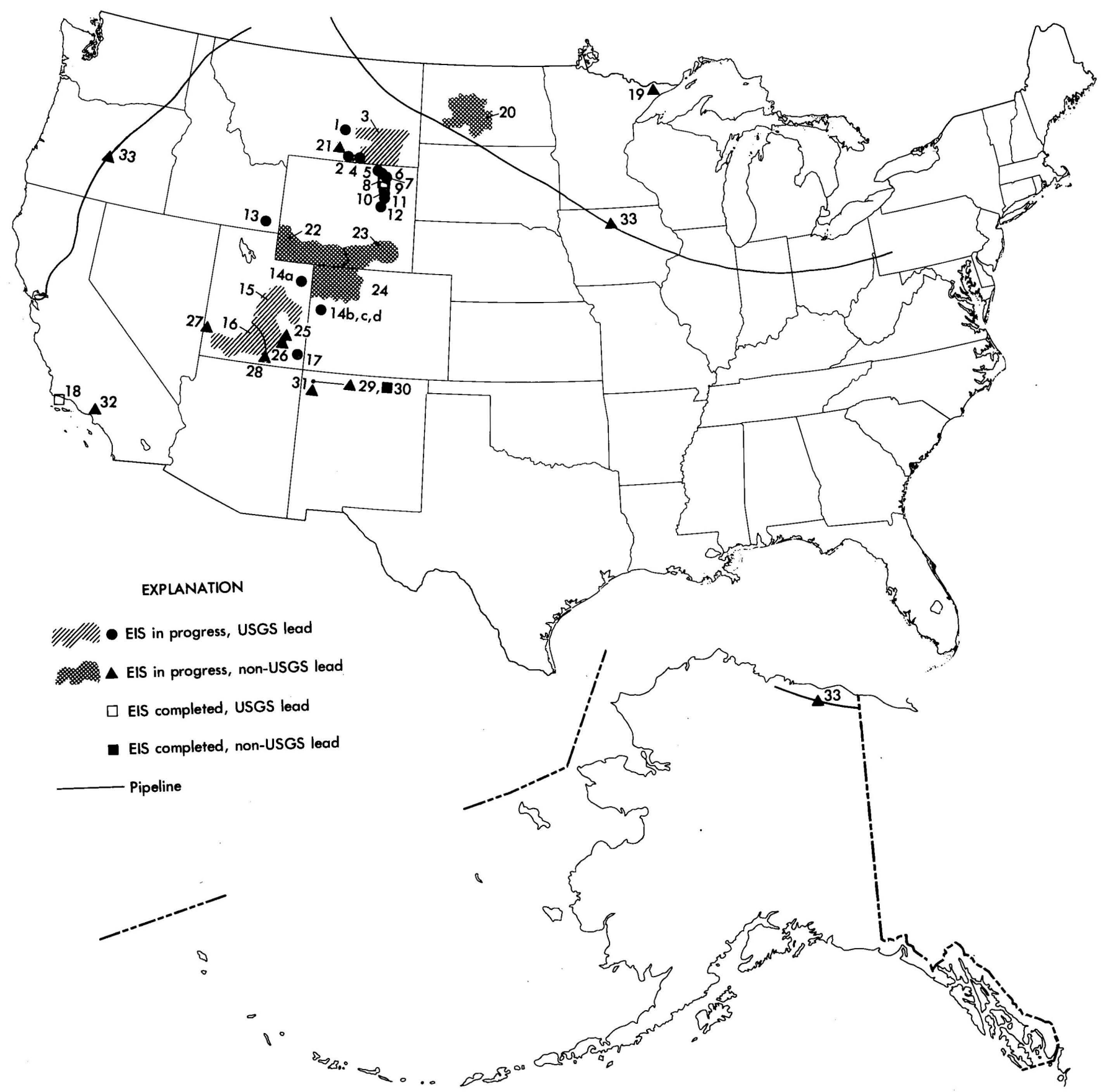

FIGURE 70.-Locations for which environmental impact statements (EIS) were in progress or completed during fiscal year 1976 and transition quarter. (Locality numbers are keyed to table 25.)

- Initiated research concerned with developing methodologies for delineating, measuring, and monitoring environmental impacts of phosphate strip mining in southeastern Idaho (fig. 70). These methodologies, developed in cooperation with other Federal agencies and State and local governments, can be used by the local or State agencies who will assume the monitoring costs and responsibilities. 
TABLE 25.-Environmental impact statements completed or in progress during fiscal year 1976 and transition quarter (locality numbers are keyed to fig. 70 )

\begin{tabular}{cccc}
\hline Title & State & Locality & number \\
Project description \\
\hline GEOLOGICAL SURVEY LEAD OR JOINT-LEAD RESPONSIBILITY
\end{tabular}

Westmoreland coal mine

Crow Shell (Youngs Creek) coal mine ${ }^{1}$

Northern Powder River regional coal leasing and mining

Decker coal mines

Eagle Butte coal mine

East Gillette coal mine

Caballo coal mine

Belle Ayr South coal mine ${ }^{2}$

Cordero coal mine ${ }^{2}$

Coal Creek coal mine

Rochelle coal mine

Bear Creek uranium mine and mill

Phosphate leasing and development

Oil-shale tract leasing

Central Utah regional coal leasing and development

Southern Utah regional coal leasing and development

Glen Canyon National Recreation Area fireflood project ${ }^{3}$

Santa Barbara Channel development ${ }^{2}$

Coal operating regulations (30 CFR, part 211$)^{2}$

Geological and geophysical regulations ${ }^{2}$

Montana 1

Determine impacts of proposed mining and reclamation plan in the Crow-ceded area in south-central Montana.

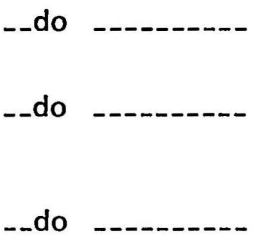

Wyoming - - - -

do

-do

-do

-do

_do

-do 11

-do

daho

Colorado-

Utah

Utah$$
\text { h }
$$

do

--do

o

California 18

Nationwide

- do ${ }^{4}$
Evaluate impacts of mine and transportation system on Crow Indian Reservation.

Evaluate individual and cumulative regional impacts of leasing and mining in southcentral Montana.

U.S. Geological Survey and State of Montana project to determine impact of proposed mining and reclemation plan.

Determine impacts of A max Coal Co.'s proposed mine north of Gillette.

Determine impacts of errMcGee Co.'s proposed line north of Gillette.

Determine impacts of C rter Oil Co.'s proposed inine southeast of Gillette.

Determine impacts of ming and reclamation plan fo expanded Amax Coal o.'s mine.

Determine impacts of Sur Oil Co.'s proposed mining and reclamation plan sout of Gillette.

Determine impacts of At ntic Richfield Co.'s prop osed mining and reclamation plan south of Gillette.

Evaluate impacts of Peasody Coal Co.'s project in ea tern Powder River Basin.

Determine impacts of Rocky Mountain Energy Co.'s nining and milling operatic $n$ in the national grasslands suth of Gillette. ${ }^{3}$

Determine separate and c llective impacts of $16 \mathrm{~m}$. ing plans on Federal lease olds in southeastern Idaho.

Evaluate impacts of leasi ig 4 tracts for in situ produ tion of shale oil.

Evaluate individual and umulative regional impac : of leasing and mining.

$$
\text { Do. }
$$

Evaluate impacts of Oil [ velopment Co. of Utah's ilot fireflood project to e ract oil from bituminous andstone.

Examine impacts of furth $r$ oil and gas developmer: in channel.

Examine impact of prorosed revised regulations on lessees, permittees, an i licensees during discc very, testing, development, mining, and reclamation.

Examine impacts of prof osed regulations governing "uter Continental Shelf geoli gical and geophysical explor tion. 
TABLE 25.-Environmental impact statements completed or in progress during fiscal year 1976 and transition quarter-Continued

\begin{tabular}{|c|c|c|}
\hline Project & $\begin{array}{l}\text { Locality } \\
\text { number }\end{array}$ & Lead agency \\
\hline \multicolumn{3}{|c|}{ GEOLOGICAL SURVEY PARTICIPATION } \\
\hline $\begin{array}{l}\text { INCO copper-nickel open-pit mine } \\
\text { West-central North Dakota regional coal leasing and development } \\
\text { Westmoreland coal leasing } \\
\text { Sweetwater-Kemmerer regional coal leasing and development } \\
\text { Hanna Basin-Atlantic Rim regional coal leasing and development } \\
\text { Regional coal leasing and development } \\
\text { Emery coal mine and power-generation plant } \\
\text { Allen-Warner Valley coal mining, power generation, and slurry pipeline } \\
\text { Alunite mining and processing } \\
\text { Kaiparowits coal mine and power-generation plant }{ }^{1} \\
\text { El Paso coal mine and gasification plant }{ }^{2} \\
\text { WESCO coal mine and gasification plant } \\
\text { Exxon uranium exploration leasing } \\
\text { Los Padres phosphate leasing } \\
\text { Natural gas transportation system }\end{array}$ & 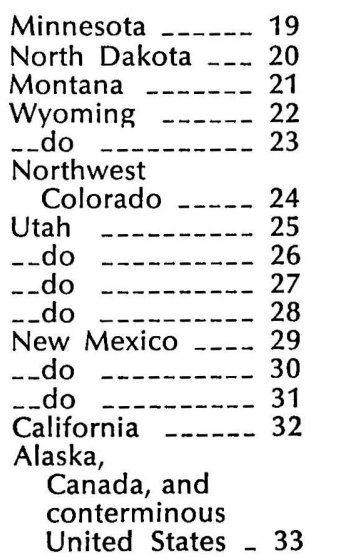 & $\begin{array}{l}\text { Forest Service. } \\
\text { Bureau of Land Management. } \\
\text { Bureau of Indian Affairs. } \\
\text { Bureau of Land Management. } \\
\text { Do. } \\
\text { Do. } \\
\text { Do. } \\
\text { Do. } \\
\text { Do. } \\
\text { Do. } \\
\text { Do. } \\
\text { Bureau of Reclamation. } \\
\text { Bureau of Indian Affairs. } \\
\text { Bureau of Land Management. } \\
\text { Bureau of Land Management } \\
\text { and State of Alaska. }\end{array}$ \\
\hline
\end{tabular}

1 Inactive.

2 Completed.
3 Joint-lead responsibility with Nuclear Regulatory Agency and Forest Service.
4 Not shown in figure 70 .

5 Joint-lead responsibility with Bureau of Land Management.

\section{REFERENCES}

A. D. Little, Inc., 1975, An evaluation of the San Francisco Bay region environment and resources planning study [draft report to U.S. Dept. of Housing and Urban Development] San Francisco, California, 93 p.

Anderson, J. R., Harđy, E. E., Roach, J. T., and Witmer, R. E., 1976, A land use and land cover classification system for use with remote sensor data: U.S. Geol. Survey Prof. Paper 964, 28 p., refs.

Briggs, R. P., and Pomeroy, J. S., 1976, Landsliding in Allegheny County, Pennsylvania: U.S. Geol. Survey Circ. 728, 18 p.

Carson, R. J., Smith, Mackey, and Foxworthy, B. L., 1975, Geologic conditions related to waste-disposal planning in the southern Hood Canal area, Washington: U.S. Geol. Survey Misc. Inv. Map 1-853-D, scale 1:62,500.

Driscoll, L. B., 1976, Land-use classification map of the greater Denver area, Front Range Urban Corridor: U.S. Geol. Survey Misc. Inv. Map 1-856-E, scale 1:100,000.

Imhoff, E. A., Friz, T. O., and La Fevers, J. R., 1976, A guide to State programs for the reclamation of surface mined areas: U.S. Geol. Survey Circ. 731, 33 p.

Kockelman, W. J., 1976, Use of U.S. Geol. Survey earth-science products by county planning agencies in the San Francisco Bay region, California: U.S. Geol. Survey open-file rept. 76547.
Marcus, P. A., ed., 1976, Directory to U.S. Geological Survey program activities in coastal areas, 1974-76: U.S. Geol. Survey Bull. 1428, 154 p.

McCain, J. F., and Hotchkiss, W. R., 1975, Flood-prone areas of the greater Denver area, Front Range Urban Corridor, Colorado: U.S. Geol. Survey Misc. Inv. Map 1-856-D, scale $1: 100,000$

Moore, R. T., and Varga, R. T., 1976, Maps showing nonmetallic mineral deposits in the Phoenix area, Arizona: U.S. Geol. Survey Misc. Inv. Map 1-845-J (2 sheets), scales 1:250,000 and $1: 500,000$.

Taranik, J. V., and Trautwein, C. M., 1976, Integration of geological remote-sensing techniques in subsurface analysis: U.S. Geol. Survey open-file rept. 76-402, 60 p., 28 figs., 2 tables.

U.S. Geological Survey, 1975, Land use change map, 1970-1972, Washington urban area, D.C., Md., and Va.: U.S. Geol. Survey Misc. Inv. Map I-858-D, scale 1:100,000.

1976, Map showing potential for copper deposits: U.S. Geol. Survey open-file rept. 76-958, scale 1:250,000.

Williams, R. S., and Carter, W. D., Jr., eds., 1976, ERTS-1, a new window on our planet: U.S. Geol. Survey Prof. Paper 929, $362 \mathrm{p}$.

Wissel, P., O'Conner, R., and Cigler, B., 1976, The use of geological information in the Greater Pittsburgh area: Appalachian Regional Commission Rept. ARC 74-19-2564, 23 p. 


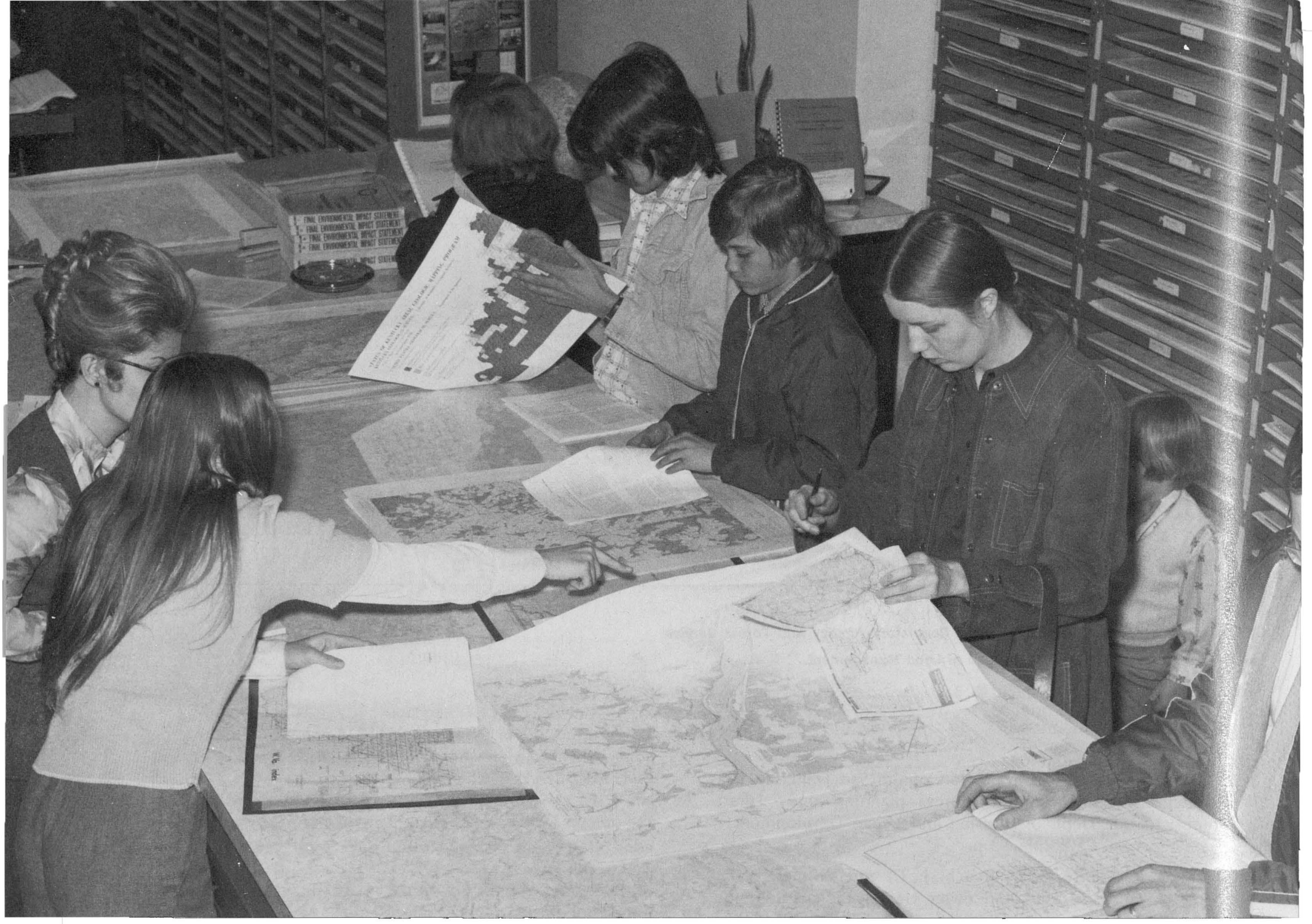

Two of the program support activities: Top, Public Inquiries Offices throughout the country distribute USGS maps and boo $s$ to the public; bottom, the Computer Center Division maintains a nationwide computer network.

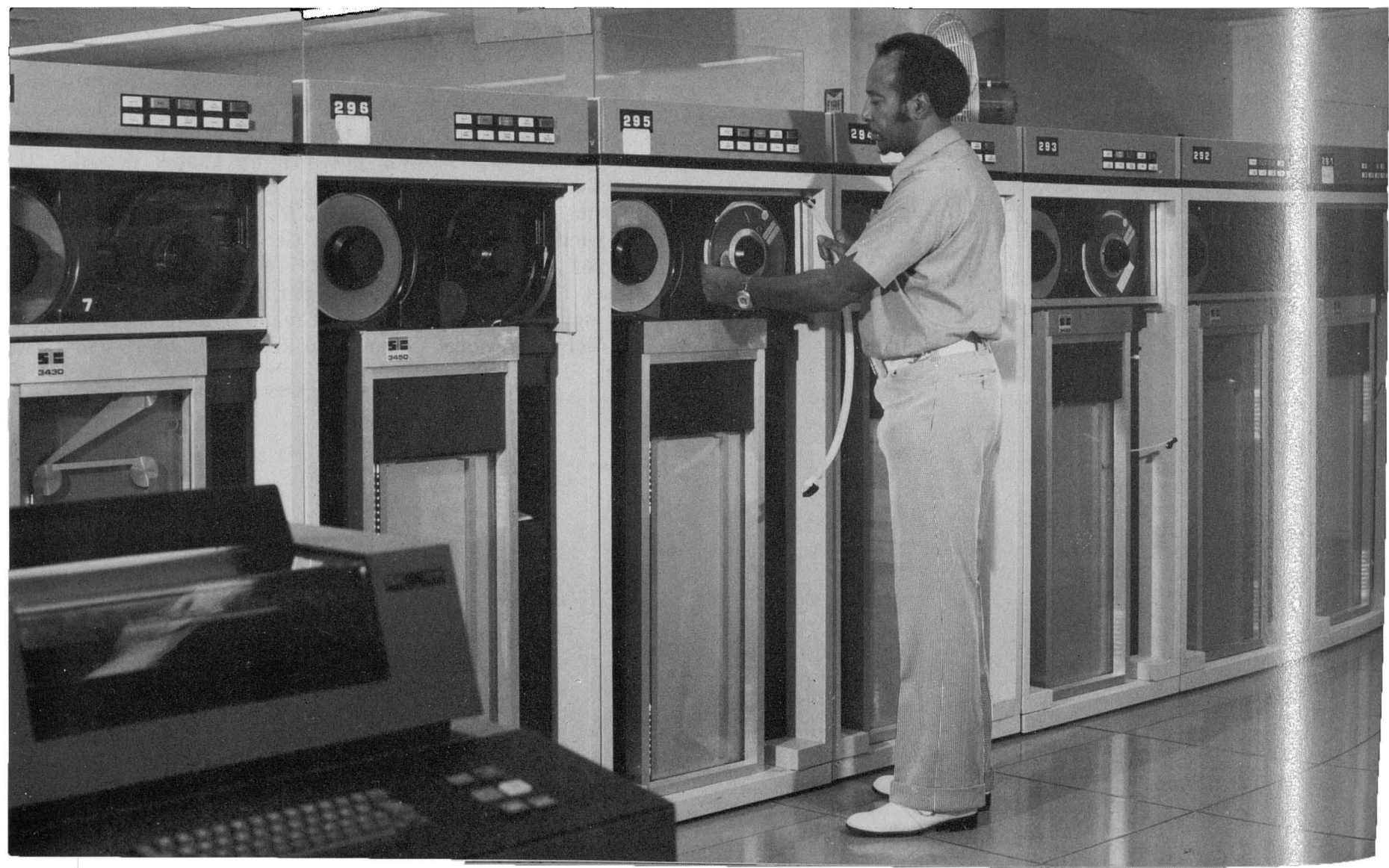




\section{Prozram Support Activities}

\section{OVERVIEW}

Four organizational units of the Geological Survey provide essential managerial, administrative, and technical services to support the Survey's scientific and regulatory programs:

- Office of the Director, through the Director, the Associate Director, the Assistant Directors, and their respective staffs (excluding the Land Information and Analysis Office), provides executive direction, coordinates interagency and intrabureau activities, and guides program development.

- Administrative Division supplies the Survey's programs with budgetary, financial, procurement, personnel, and other administrative services and manages the Survey's National Center in Reston, Virginia.

- Computer Center Division operates a nationwide computing system and provides Survey scientists with a wide range of automatic data-processing services.

- Publications Division edits the Survey's scientific and technical publications, as well as its nontechnical booklets; prints maps; distributes maps and monographs; and answers inquiries from the public about the Survey's work and reports.

Although the Geological Survey Library is operated and funded for the most part by the Geologic Division, it is also described in this section because of its importance to the research activities of all Survey programs.

Program support activities are financed by direct appropriations ("General administration" and "Facilities" budget activities, table 26), assessments on direct and reimbursable program funds of other budget activities (table 26), and reimbursements from other agencies ("Miscellaneous services to other accounts," table 26).

\section{GENERAL ADMINISTRATION}

General administrative expenses include the executive direction and coordination of Survey programs by the Director's Office and the provision of financial, procurement, personnel, and other administrative services by the Administrative Division.

During fiscal year 1976 and the transition quarter, general administrative expenses (table 26) amounted to $\$ 15.1$ million. These expenses were funded from three sources: (1) The "General administration" budget activity, about $\$ 4.9$ million; (2) assessments on the directly appropriated activities, $\$ 7.2$ million; and (3) assessments on the reimbursable programs, $\$ 3.0$ million. No assessments are made on cooperative funds from State and local governments. Despite the Geological Survey's larger budget, greater number of employees, and increased use of grants and contracts, general administrative expenses continued to represent only about 3.0 percent of the total Survey budget and have increased less than one-half of one percent over the past 5 years (table 26).

Significant events and accomplishments during the year included:

\section{FLEXITIME TEST}

The successful completion of a 1-year experiment with flexible working hours for all Survey employees in the Washington, D.C., area resulted in implementation of the policy. Although several Federal organizations are now studying or testing the Flexitime concept, the Survey, whose 10,000 employees now enjoy flexible hours, is one of the first-and the largest-Federal establishments to adopt the concept.

In accordance with the Flexitime policy, employees are permitted to work an 8-hour day any time between 7:00 a.m. and 5:30 p.m., provided that they are present for the "core time," 9:00 a.m. to 3:30 p.m., minus the lunch break. Employees may vary their starting times each day to conform to their personal needs and individual lifestyles. The enthusiasm of both employees and supervisors for the concept was supported by responses to questionnaires sent to all employees before the policy was adopted permanently. Among the findings of the survey were:

- Reductions in absenteeism-During the experiment, short-term leave usage decreased by more than 20 percent, probably because employees were able to schedule personal activities outside of working hours. 
- Tardiness-71 percent of all supervisors felt that tardiness declined.

- Employee morale-Substantial increases were noted, and Flexitime has also been a recruitment incentive. It is also believed that Flexitime has helped reduce personnel turnover, particularly among students and working mothers.

- Productivity -27 percent of all supervisors felt that the amount of work accomplished increased as a result of Flexitime; only 5 percent felt that there had been a decrease.

- Overtime usage-Decreases in the amount of paid overtime required under Flexitime were reported by 62 prcent of all supervisors.

- Utilization of specialized equipment-Offices were able to make greater use of specialized equipment because of the longer operating day.

- Quiet time-73 percent of all supervisors felt that they and their employees benefited from "quiet time" periods before and after core time.

- Traffic and transportation-Morning and evening traffic congestion around the National Center was eased, and 56 percent of all employees reported some reduction in their commuting time.

No major problems were experienced. Communications might have worsened slightly in some areas, but improvements have also been cited, since the longer workday enables the Survey to provide better service to the public and to communicate more easily with other agencies.

\section{NEW USGS CENTER IN ROLLA, MISSOURI}

May 19, 1976, marked the dedication of a Geological Survey Center in Rolla, Missouri. All Survey activities in the Rolla area, previously located in four different buildings, were consolidated under one roof. The largest of these activities is the Mid-Continent Mapping Center, whose area of responsibility comprises 14 States. Particular consideration was given to developing a facility with suitable equipment and space to help the mapping center satisfy the Nation's needs for products such as orthophotomaps, slope maps, regional and county maps, and land use maps. Construction began in 1974 on the 8,825-squaremeter (95,000-square-foot) single-story brick and cinder block building. Special features include a computer room with a recessed floor and a photographic laboratory with vibration-isolating pads in the concrete floors under the cameras. This 930-squaremeter (10,000-square-foot) laboratory also has special plumbing with a filtered water supply and interceptor tanks to remove chemicals before wastewater enters the sewer system. The first emergency system in the building features smoke detectors, sprinklers, battery- the city's fire department. Nearly $\$ 2,000,000$ was spent on the project. Approximately 340 employees work at the Rolla Center.

\section{PROCUREMENT AND CONTRACTING ACTIVITIES}

Increases in the Survey's programs, especially those related to energy resources, and personnel ceilings have led the Survey to depend more frequently on the private sector for services. Over the past 7 fiscal years, the Survey's procurement and contracting program has increased tenfold, from $\$ 9$ million in fiscal year 1970 to $\$ 99$ million in fiscal year 1976 (fig. 71).

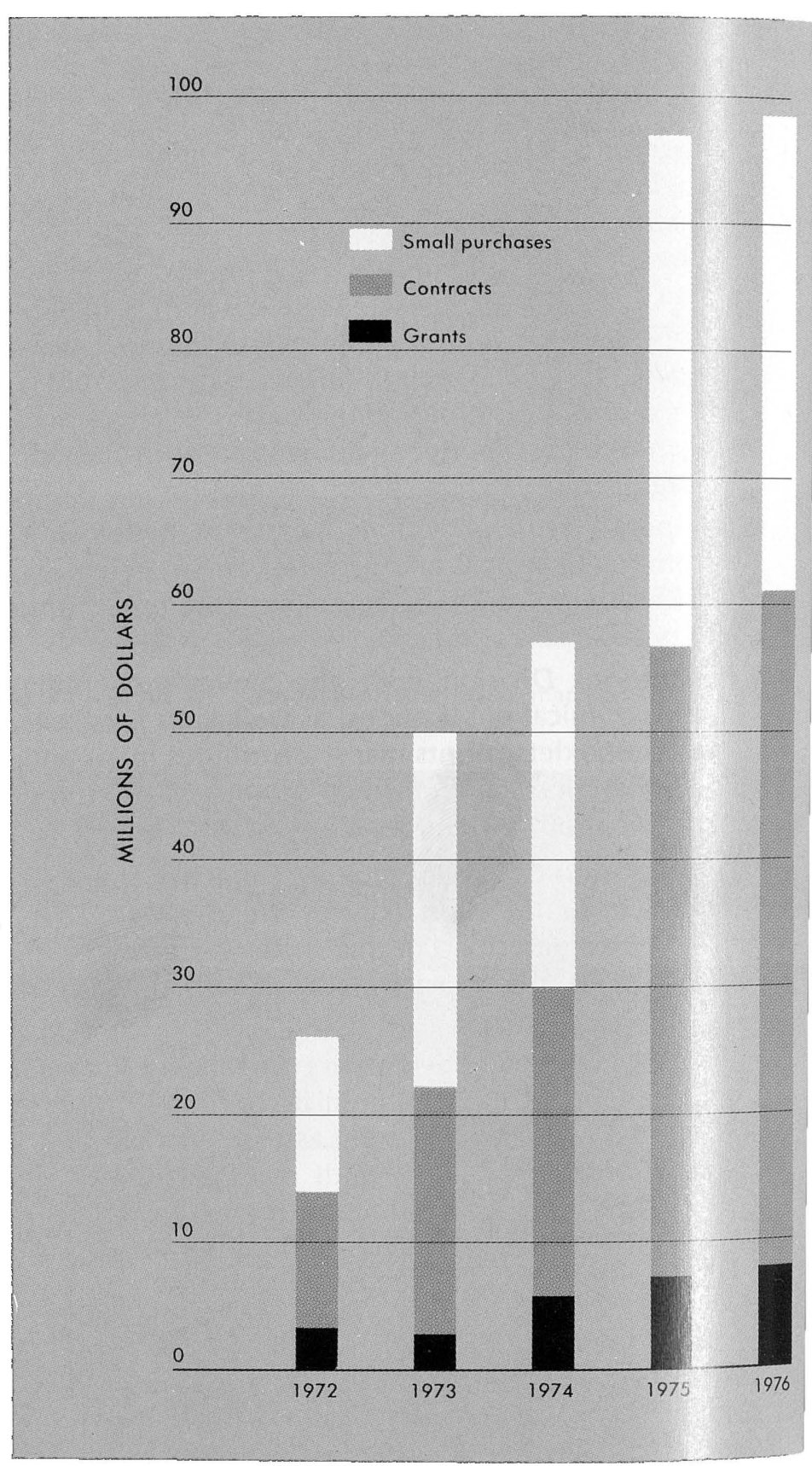

FIGURE 71.-Geological Survey expenditures on grants, contracts, and small purchases, fiscal years 1972-76. 
During this period, personnel responsible for procurement and contracting increased from 34 to 67. Also, the type of procurement has changed substantially. At the start of the decade, practically all of the Geological Survey's procurement actions were for lowcost, commercially available equipment. Now the procurement program includes research and development contracts, grants for research, complex service contracts, and contracts for sophisticated equipment whose performance characteristics and specifications are often not available on the commercial market.

\section{CONSUMER REPRESENTATION PLAN}

As part of the increasing emphasis in the Executive Branch on responsiveness to consumer concerns, the Survey contributed to the preparation of the first Department of the Interior Consumer Representation Plan; initiated development of a Consumer Representation Plan for the Survey; and designated individuals to act as contact on consumer affairs for headquarters, divisional, and regional offices.

\section{FIRE AT THE CENTRAL REGION HEADQUARTERS}

In March 1976, a fire in the two-story building that houses the Survey's Central Region offices in Denver, Colo., destroyed six major laboratories, nine smaller laboratories, and supporting office space. In addition, there was smoke and water damage and extensive structural damage to the building. The cost of reconstructing the building was estimated at $\$ 4.5$ million; repair and replacement costs of critical items, as cited in a budget supplemental request, totaled $\$ 2.4$ million. Disruption of normal operations was minimized through implementation of an existing Emergency Preparedness Plan. In accordance with the plan, regional managers established priority actions and provided direction and liaison to facilitate those actions. The General Services Administration furnished valuable technical assistance, and plans were initiated immediately to build or relocate the affected laboratories and offices and the library, which suffered water damage.

The existence of a large quantity of combustibles, particularly chemicals, made the fire difficult to suppress. Controls on combustibles and ignition sources have since been expanded, and other preventive actions have been taken to (1) limit amounts of combustibles stored; (2) properly store all equipment, materials, and supplies; and (3) provide adequate staffing to guard buildings outside of normal working hours.

\section{FACILITIES}

The "Facilities" activity covers the operation of the National Center, which consists of office, laboratory, industrial, and warehouse space in Reston, Virginia. Funds appropriated for facilities management in fiscal year 1976 and the transition quarter amounted to \$12 million (table 26). These funds were maintained in a separate account under the control of the Assistant Director for Administration.

\section{COMPUTER TECHNOLOGY}

The Computer Center Division operates a nationwide system of computer facilities and terminals to provide automatic data-processing services for the Geological Survey. The primary computer installation, located at the National Center, consists of two interconnected large-scale IBM 370/155 computers. Together, these computers provide high-speed magnetic core memory for 8 million characters of information and on-line magnetic disk storage for 6.6 billion characters of information. During fiscal year 1976 and the transition quarter, more than 800 users from 84 remote locations (fig. 72) submitted approximately 423,000 jobs to these computers.

In addition to the Reston computer facility, the Survey operates a number of other computers:

- Burroughs Corporation Model B-6700 computer at the Earth Resources Observation Systems Data Center in Sioux Falls, South Dakota.

- Digital Equipment Corporation Model 1070 computer at Denver, Colorado.

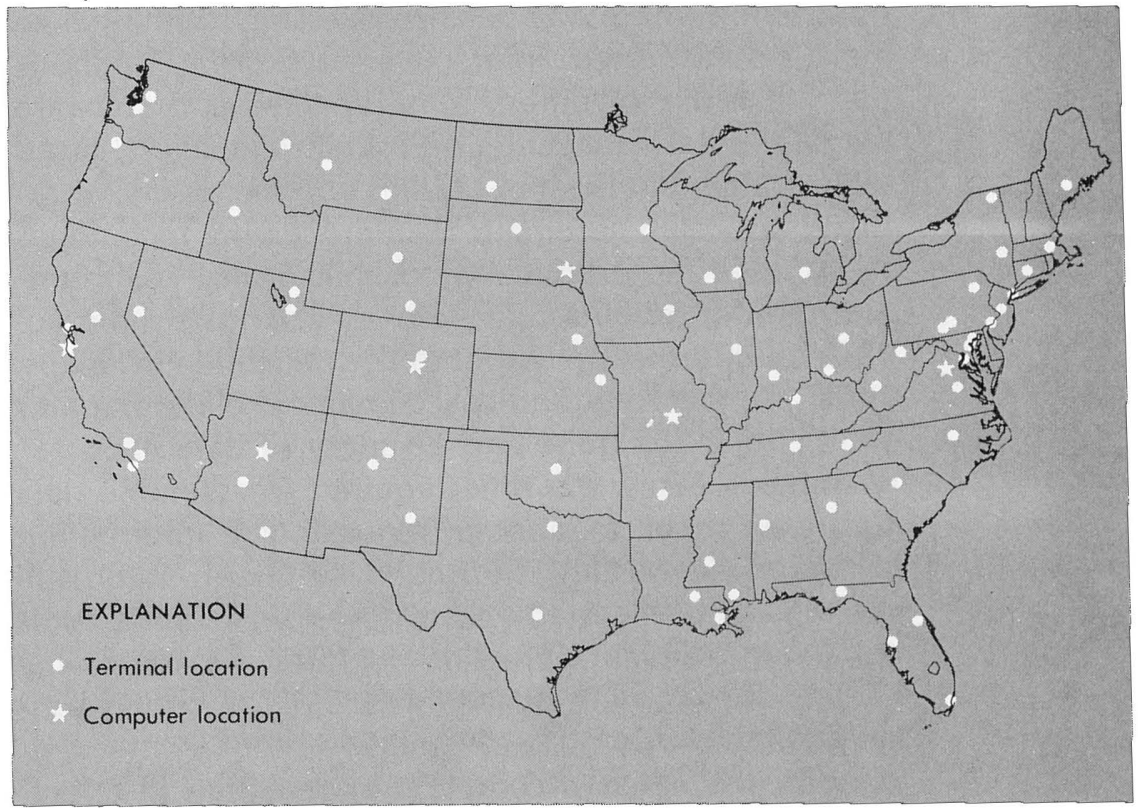

FIGURE 72.-Geological Survey computing network. A terminal site in Alaska is currently under construction. 
- Systems Engineering Laboratories, Inc., Model 86 computer at Rolla, Missouri.

- Digital Equipment Corporation Model 11/20 and Model 11/45 computers at Flagstaff, Arizona.

- A number of special-purpose computers and minicomputers for use in field and laboratory investigations.

The Survey is increasingly charged with providing direction to both Government and industry in all phases of energy-related exploration, development, and production. Concomitantly, Survey requirements for increased computation capacity accelerated in fiscal year 1976. This growth is reflected in the following statistics:

- 55 terminals were connected to the National Center computers for remote entry and time-sharing, an increase of 24 percent.

- \$13.9 million was spent on in-house data processing and related services, and $\$ 2.5$ million was spent on contracts for commercial data-processing services.

- On-line storage capacity was increased by 1,600 million bytes by the addition of 16 units of double-density disk drives.

- A \$15 million contract was awarded to the Honeywell Corporation for three Series 60-Level 68 Multics time-sharing computers to be installed in Reston, Virginia; Denver, Colorado; and Menlo Park, California.

Much of this activity can be attributed to the continued expansion of Survey activities in energy research and development, resource evaluation, lease supervision, and information dissemination and to the transition from routine batch-processing techniques to more sophisticated interactive processing methods that make use of time-sharing systems and software for data-base management. Program managers, faced with stringent personnel ceilings and increasing workloads, are using automatic data processing techniques to improve the productivity of their staffs. For example, remote terminals give Survey scientists rapid access to information about the availability of maps, aerial photographs, and space imagery, bibliographies of scientific literature, and a variety of data files.

In many cases, the time required to assemble data for research or to answer requests for information has been significantly shortened. Although much still remains to be learned about how to use these tools to greatest advantage, their potential for improving the productivity and quality of Geological Survey programs appears to be great.

Some examples of computer applications in operation or under development during 1976 are listed below:
- Development of a number of geologic data bases dealing with mineral resources, energy resources, and geochemical analyses.

- Operation, of a real-time seismic monitoring and earthquake detection network.

- Expansion of the National Water Data Storage and Retrieval System to include ground-water data.

- Simulation of surface-water and ground-water behavior in areas expected to be mined for coal and oil shale.

- Development of automated cartographic methods to produce maps from spatial digital data.

- Royalty accounting.

- Tracking and development of Outer Continental Shelf oil and gas leases.

- Processing of remote-sensing data.

- Provision of custom enhancements to Landsat pictures containing areas of special geologic interest.

Highlights of computed support activities included:

- An RFP was issued on August 8, 1975, asking industry to bid on specifications for three conipatible time-sharing computers, one each at Menlo Park, California; Denver, Colorado; and Reston, Virginia. The specifications for the three computers met long-term Geological Survey requirements at the three locations. Benchmark testing, technical evaluation, and cost evaluation of equipment proposed by vendors was conpleted during fiscal year 1976. A contract was awarded to the Honeywell Corporation on Algust 10, 1976, with installation scheduled for tie three locations early in fiscal year 1977.

- The Flagstaff Computation Center provided conputer support for the Viking Mars landing mission. The Flagstaff computer was used to provide cartographic digital image enhancements of the photographs sent back to Earth. The selection of the final landing site for Viking I was based on the calculations made by the Flagstaff compurer.

\section{PUBLICATIONS PROGRAM}

Results of research and investigations conducted by the Geological Survey are made available to the $\mathrm{p}$ lic through increasingly diverse information services and publications. Developing mechanisms to ass re timely release of data and maps is a formidable ct allenge.

The number of reports approved for publication by the Geological Survey continues to increase (fig. 3 ). About 64 percent of the 4,300 reports prepared in iscal year 1976 and the transition quarter wre designated for publication in professional jourrals and monographs outside the Survey; about 23 per- 


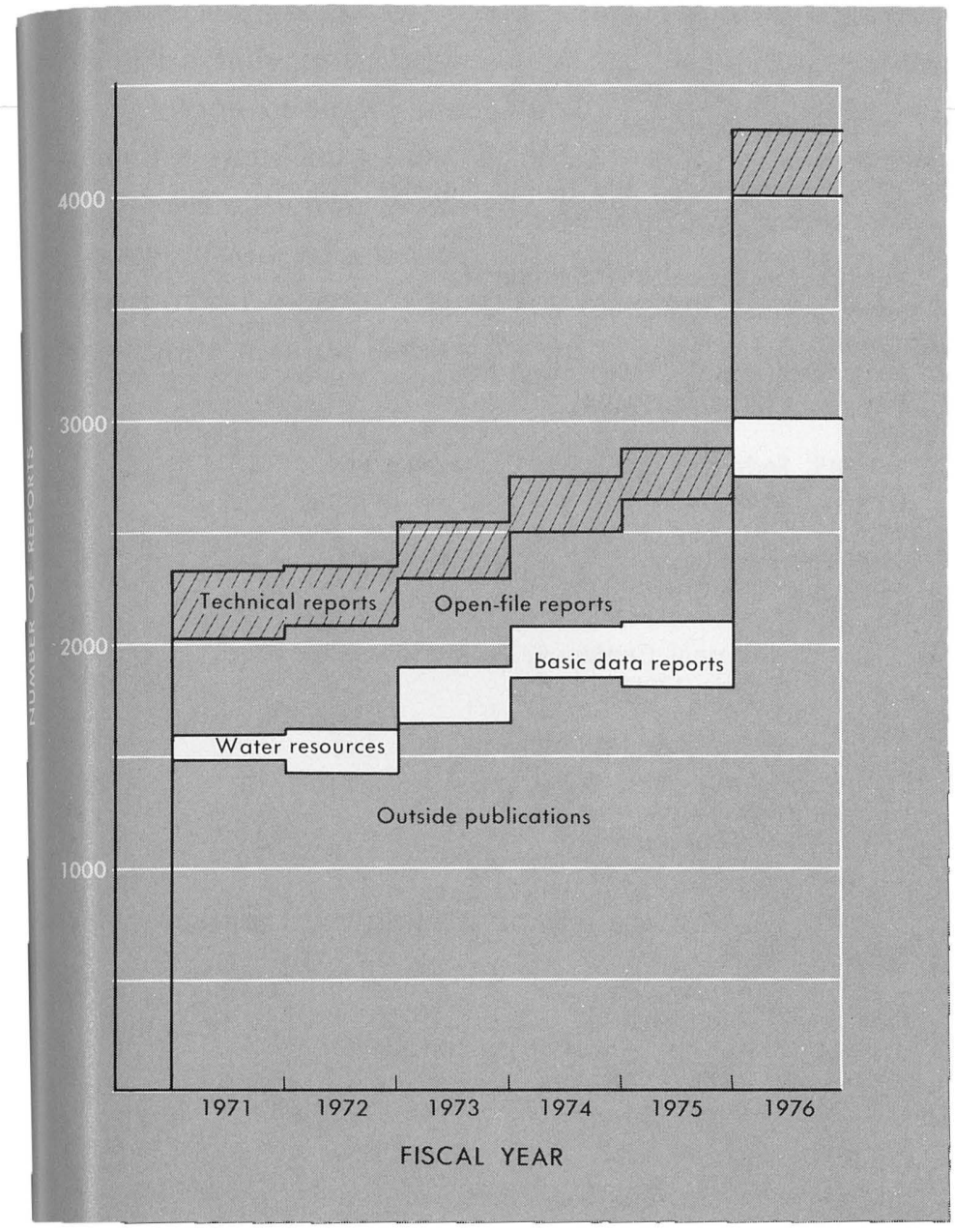

FIGURE 73.-Number of reports approved for publication, fiscal years 1971-76. (1976 figures include transition quarter.)

cent were placed in open file; and the remainder were scheduled for publication by the Survey (table 46). The Survey also produced over 11,000 topographic, hydrologic, and geologic maps in fiscal year 1976 and the transition quarter (fig. 74 and table 47).

The Publications Division edits the Survey's scientific and technical publications printed by the Government Printing Office, prepares nontechnical booklets, produces reproduction material for geologic and hydrologic maps, änd prints and distributes all Survey maps. Most of the maps are printed at the $\mathrm{Na}$ tional Center, but in recent years a substantial number have been printed by commercial firms under contract.

The Publications Division also operates nine Public Inquiries Offices throughout the country that answer queries about the Survey's work and sell maps and books over the counter as agents of the Government Printing Office.

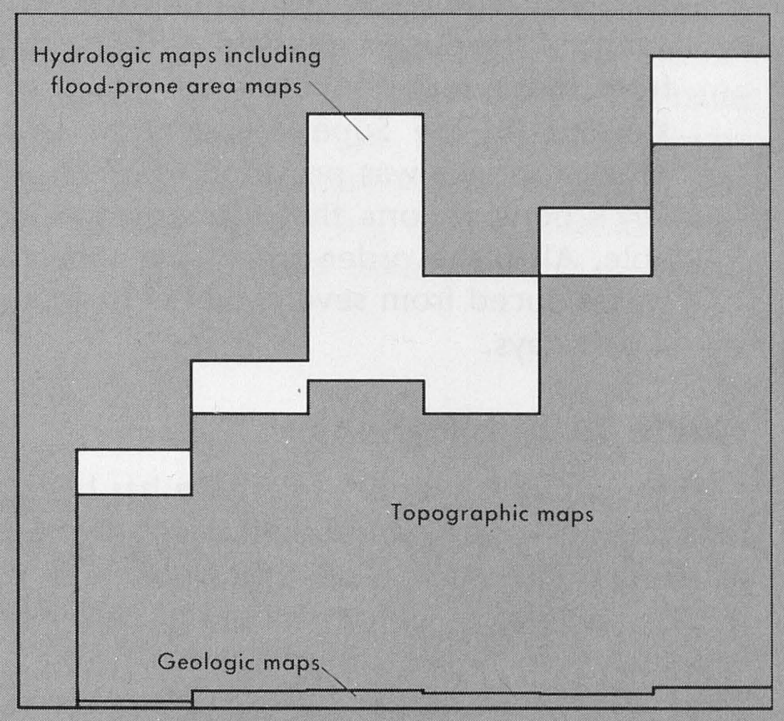

FIGURE 74.-Number of maps produced, fiscal years 1971-76. (1976 figures include transition quarter.) (Does not include maps produced by the Conservation Division and the Director's Office.)

Highlights of the Publications Division's program in fiscal year 1976 included:

- Installation in fiscal year 1975 of a five-color printing press enabled the Publications Division to reduce the average cost of printing new maps by more than 25 percent. This 60 -inch press accommodates approximately 80 percent of the maps printed with one pass-through, as opposed to three passes on the older two-color press. In addition, the acquisition of an automated imposition machine reduced the time required for making printing plates by 50 percent.

- To make urgently needed results of scientific investigations available to the public on a timely basis, the Publications Division, through the Government Printing Office, established a commercialcontracts system for printing books. This system has reduced the printing time of book reports from an average of 5 months to an average of $41 / 2$ weeks.

- In April 1975, the Publications Division's Branch of Distribution of the Eastern Region became an agent of the Superintendent of Documents of the Government Printing Office for the sale of Survey book publications. These publications are sold over the counter and by mail. Many Survey books were not stocked by the Superintendent of Documents because their subject matter was 
of interest only to a specialized clientele and were low in sales. Current indications are that, since the Branch of Distribution has become an agent of the Superintendent of Documents, sales from these reports will match those of reports stocked by the Superintendent of Documents. Thus, a service was provided to users of the Survey's book reports that formerly was not available. Also, the order-processing time for books was reduced from several weeks to an average of 2 or 3 days.

\section{Guide to publications}

Throughout this report, reference has been made to information services and publications of the Geological Survey. This section describes how and where the public may acquire information and obtain products.

To buy Survey book publications; to buy maps of areas east of the Mississippi; or to request Survey circulars, catalogs, pamphlets, and leaflets (limited quantities free), write or visit:

\section{U.S. Geological Survey}

Branch of Distribution

1200 S. Eads St.

Arlington, Virginia 22202

Include check payable to U.S. Geological Survey.

To buy maps of areas west of the Mississippi; or to request Survey catalogs, pamphlets, and leaflets (limited quantities free), write or visit:

\author{
U.S. Geological Survey \\ Branch of Distribution \\ Box 25286, Bldg. 41, Federal Center \\ Denver, Colorado 80225
}

Include check payable to U.S. Geological Survey.

To get on the mailing list for the monthly list of "New Publications of the Geological Survey" (free), write:

U.S. Geological Survey

Mailing List Unit, 329 National Center

12201 Sunrise Valley Dr.

Reston, VA 22092

To start a subscription to the "Journal of Research of the U.S. Geological Survey," the "Earthquake Information Bulletin," or the "Preliminary Determination of Epicenters", write:

Superintendent of Documents

Government Printing Office

Washington, DC 20402

"Journal of Research": $\$ 18.90$ per year (plus $\$ 4.75$ for foreign mailing)

"Earthquake Bulletin": $\$ 3.00$ per year (plus $75 \phi$ for foreign mailing)

"Preliminary Determination of Epicenters": \$4.35 per year (plus \$1.10 for foreign mailing)

Include check payable to U.S. Geological Survey. interest, visit the Public Inquiries Offices in the following states:

Alaska:

108 Skyline Bldg., 508 2d Ave.

Anchorage, Alaska 99501

California:

7638 Federal Bldg., 300 N. Los Angeles St.

Los Angeles, California 90012

504 Customhouse, 555 Battery St.

San Francisco, California 94111

Colorado:

1012 Federal Bldg., 1961 Stout St.

Denver, Colorado 80294

Texas:

1-C-45, Federal Bldg., 1100 Commerce St.

Dallas, Texas 75202

Utah:

8105 Federal Bldg., 125 S. State St.

Salt Lake City, Utah 84138

Virginia:

1-C-402, National Center, 12201 Sunrise Valley Dr.

Reston, Virginia 22092

Washington:

678 U.S. Courthouse, W. 920 Riverside Ave.

Spokane, Washington 99201

Washington, D.C.:

1028 General Services Bldg., 19th and F Sts., NW.

Washington, D.C. 20244

To obtain information on cartographic data, write or visit:

U.S. Geological Survey

National Cartographic Information Center

507 National Center

12201 Sunrise Valley Dr.

Reston, Virginia 22092

To obtain information on satellite and space photography, write or visit:

U.S. Geological Survey

EROS Data Center

Sioux Falls, South Dakota 57198

\section{GEOLOGICAL SURVEY LIBRARY}

The Geological Survey Library is one of the largest earth-science libraries in the world. The main library is located at the Survey's National Center in Reston, Virginia; branches are located at major research $c-n-$ ters in Denver, Colorado; Menlo Park, California; and Flagstaff, Arizona. These libraries collectively contain more than 1.9 million items, including books, monographs, serials, pamphlets, single-sheet maps, phctographs and negatives, aerial photographs, microforns, field record notebooks, and related materials. Although these holdings are intended primarily to s:..pport the research of the Geological Survey, the lib:ary also serves other Government agencies, State geological surveys, academic institutions, and research organizations throughout the country.

The main library at Reston currently is involved in developing a computerized cataloging manual for 
maps. Hopefully, the system, which will be housed at and operated by the Ohio College Library Center, will be fully operational by early 1977 . Cooperative cataloging of single-sheet maps by those repositories having significant collections will give earth-science libraries easier access to the thousands of geoscience maps produced annually. All map-cataloging data will be put on magnetic tape, the ultimate aim being to generate a book catalog of the library's map collec- tion and to produce a monthly list of current map acquisitions.

A fire at the Denver Federal Center in March 1976 disrupted library services and resulted in the relocation of all library operations in new facilities outside the Denver Federal Center. One result of this disruption is that public-service statistics (users, circulation, interlibrary lending/borrowing, and reference queries) are lower than might otherwise be expected. (See table 55.)

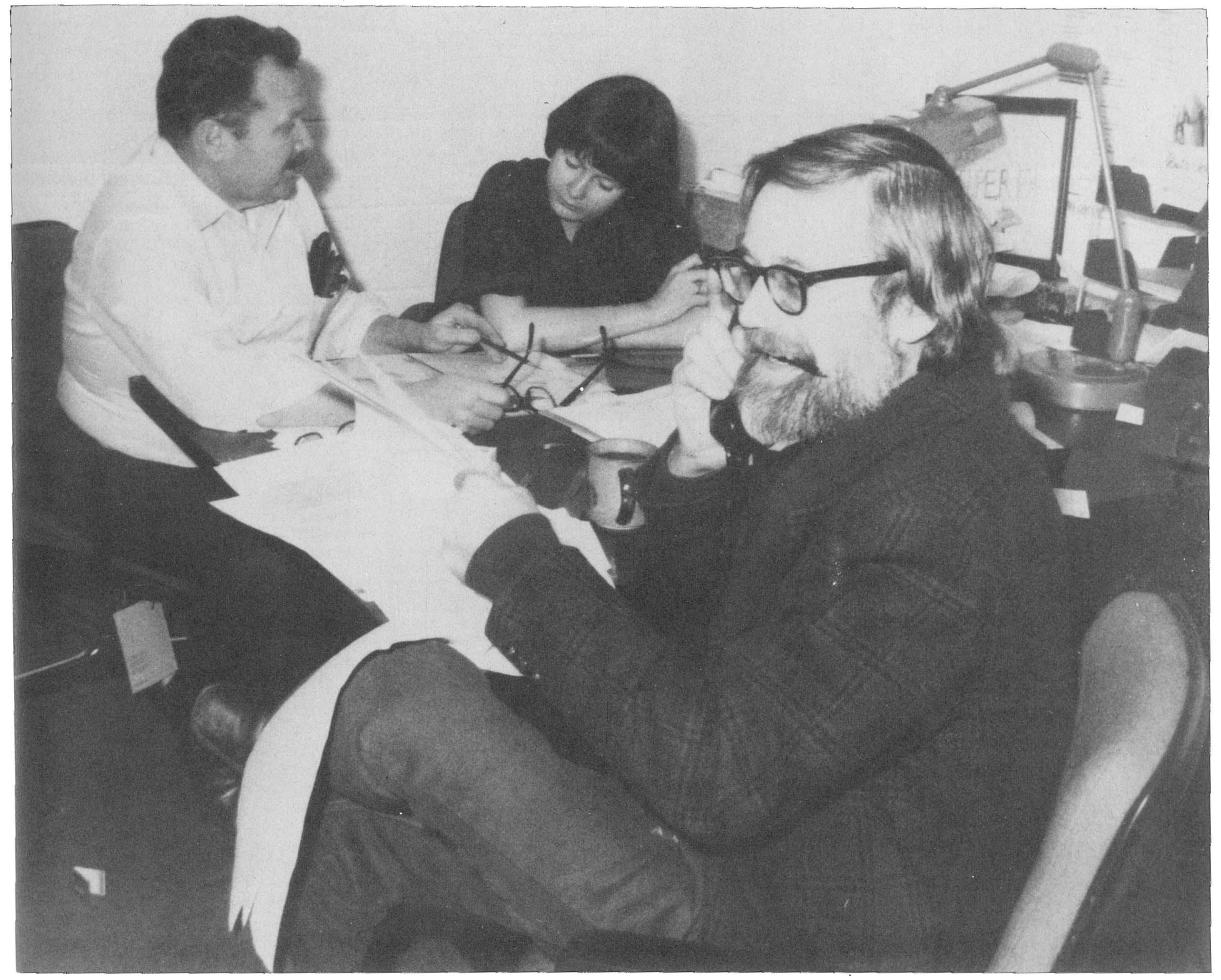

USGS editors and illustrators work together to produce publications resulting from Survey programs. 


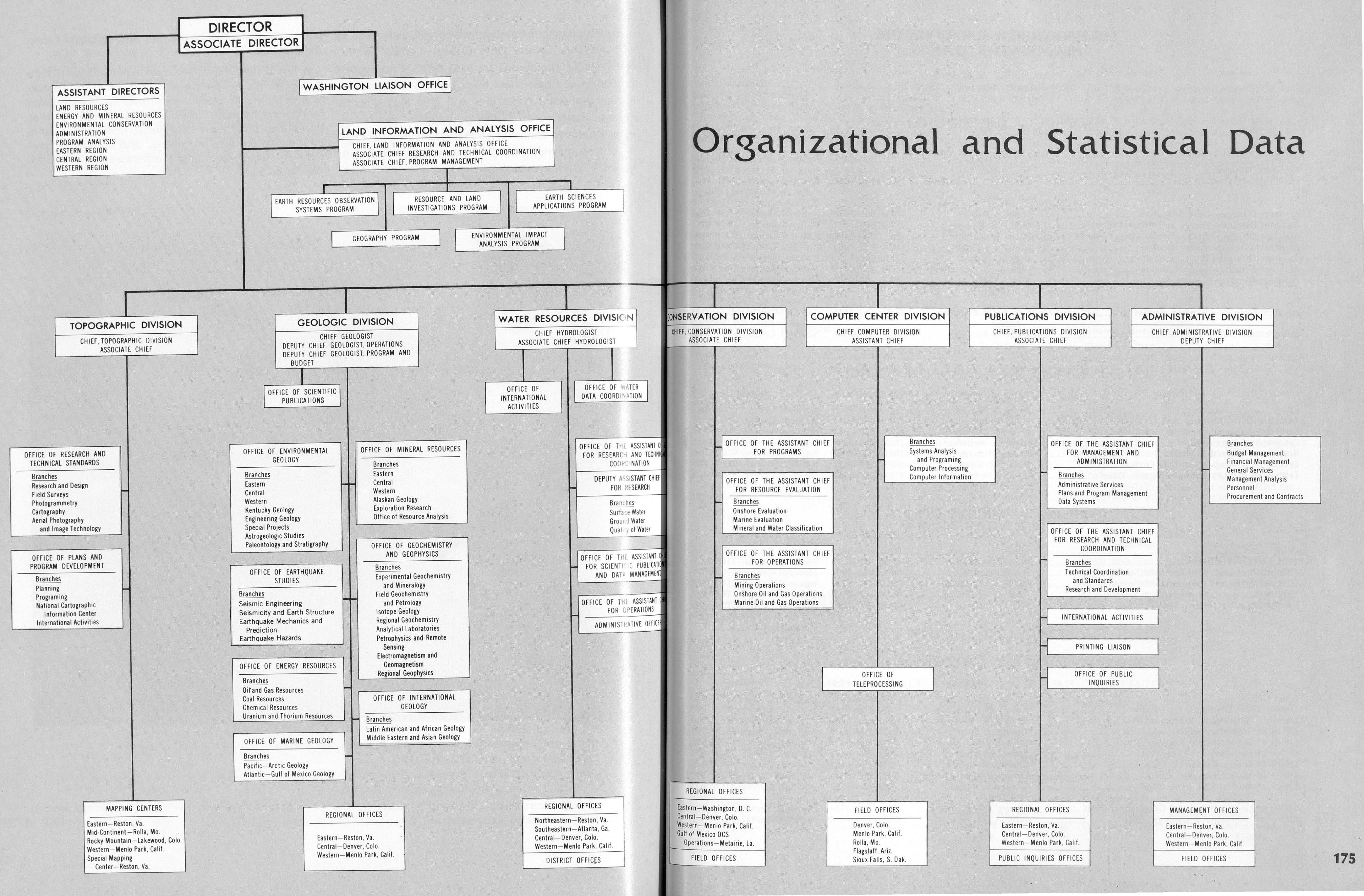




\section{U.S. GEOLOGICAL SURVEY OFFICES HEADQUARTERS OFFICES}

12201 Sunrise Valley Drive

National Center, Reston, VA 22092

\section{OFFICE OF THE DIRECTOR}

Official

Director

Associate Director

Washington Liaison Officer

Assistant Director-Land Resources

Assistant Director-Energy and Mineral Resources -

Assistant Director-Environmental Conservation

Assistant Director-Administration

Assistant Director-Program Analysis

Assistant Director-Eastern Region

Assistant Director-Central Region

Assistant Director-Western Region

Information Officer

\section{Name}

V. E. McKelvey

W. A. Radlinski

George W. Whetstone

James R. Balsley

Montis R. Klepper

Henry W. Coulter

Edmund J. Grant

Dale D. Bajema

William B. Overstreet

Alfred Clebsch, Jr., Acting

George E. Robinson, Acting

Frank H. Forrester
Telephone number

(703) 860-7411

(703) 860-7412

(202) 343-3888

(703) 860-7488

(703) 860-7481

(703) 860-7491

(703) 860-7201

(703) 860-7435

(703) 860-7414

(303) 234-4630

(415) 323-8111

(703) 860-7444

\section{LAND INFORMATION AND ANALYSIS OFFICE}

\section{Official}

Chief

Associate Chief, Research and Technical Coordination Earth Resources Observation Systems Program, Chief Geography Program, Chief

Resource and Land Investigations Program, Chief Environmental Impact Analysis Program, Chief Earth Sciences Applications Program, Chief

\section{Name}

James R. Balsley

Philip Cohen

John M. DeNoyer

James R. Anderson

J. Ronald Jones

Daniel B. Krinsley

Donald R. Nichols
Telephone number

(703) 860-7488

(703) 860-7471

(703) 860-7881

(703) 860-6344

(703) 860-6717

(703) $860-7455$

(703) $860-6961$
Address

National Center, STOP 101. National Center, STOP 102. National Center, STOP 103.

Rm. 4441, Interior Bldg., Washington, DC 20240.

National Center, STOP 104. National Center, STOP 171. National Center, STOP 106. National Center, STOP 201. National Center, STOP 105. National Center, STOP 109.

Denver Federal Center,

Box 25046, STOP 101, Denver, CO 80225.

345 Middlefield Rd. Menlo Park, CA 94025.

National Center, STOP 119.

\section{TOPOGRAPHIC DIVISION}

\section{Official}

Chief

Associate Chief

Office of Research and Technical Standards, Chief Office of Plans and Program Development, Chief National Cartographic Information Center, Chief Special Mapping Center, Chief

\section{Name}

Robert H. Lyddan

Rupert B. Southard

Roy R. Mullen

Doyle G. Frederick

John R. Swinnerton

Roy E. Fordham
Telephone number

(703) 860-6231

(703) $860-6232$

(703) 860-6291

(703) 860-6281

(703) $860-6187$

(703) $860-7760$

\section{GEOLOGIC DIVISION}

Official

Chief Geologist

Deputy Chief Geologist, Operations

Office of Scientific Publications, Chief

Office of Environmental Geology, Chief

Office of Earthquake Studies, Chief

Office of Energy Resources, Chief

Office of Marine Geology, Chief

Office of Mineral Resources, Chief
Office of Geochemistry and Geophysics, Chief Office of International Geology, Chief

\section{Name}

Richard P. Sheldon

Robert E. Davis

Donald $H$. Dow

George E. Becraft

John C. Reed, Jr.

Robert M. Hamilton

Charles Masters

Charles Masters, Acting

George E. Becraft;

Acting

Robert Tilling, Acting

John A. Reinemund
Telephone number

(703) 860-6531

(703) 860-6532

(703) 860-6544

(703) 860-6575

(703) 860-6411

(703) 860-6471

(703) 860-6431

(703) $860-6431$

(703) 860-6562

(703) 860-6584

(703) $860-6418$

\section{Address}

National Center, STOP 104 National Center, STOP 703 National Center, STOP 73 \%. National Center, STOP 710. National Center, STOP 750. National Center, STOP 760. National Center, STOP 720 .

\section{Address}

National Center, STOP 516. National Center, STOP 515. National Center, STOP 519 . National Center, STOP 514. National Center, STOP 507. National Center, STOP 560 1925 Newton Square East, Reston, VA 22090.

\section{Address}

National Center, STOP 9:0. National Center, STOP 910. National Center, STOP 910. National Center, STOP 904. National Center, STOP 90:8. National Center, STOP 905. National Center, STOP 915. National Center, STOP 915 National Center, STOP 913.

National Center, STOP 906. National Center, STOP 9:7. 


\section{Name}

Chief Hydrologist

Associate Chief Hydrologist

Assistant Chief Hydrologist, Scientific Publications and

Data Management

Assistant Chief Hydrologist, Operations

Assistant Chief Hydrologist, Research and Technical

Coordination

Office of Water Data Coordination, Chief

Office of International Activities, Chief
Joseph S. Cragwall, Jr.

O. Milton Hackett

Vacant

Thomas J. Buchanan

Edward A. Moulder

R. H. Langford

James R. Jones
Telephone number

(703) 860-6921

(703) 860-6921

(703) 860-6877

(703) 860-6801

(703) 860-6971

(703) 860-6931

(703) $860-6548$

\section{CONSERVATION DIVISION}

Official

Chief

Associate Chief

Assistant Chief, Operations

Assistant Chief, Programs

\section{Name}

Russell G. Wayland

Robert F. Evans

Robert L. Rioux

John Duletsky

Harold L. Pumphrey
Telephone number

(703) 860-7524

(703) $860-7524$

(703) $860-7571$

(703) $860-7515$

(703) $860-7581$

\section{COMPUTER CENTER DIVISION}

Official

Chief

Assistant Chief

Office of Teleprocessing

\section{Name}

Carl E. Diesen

Charles H. Tyler

Ralph N. Eicher
Telephone number

(703) 860-7106

(703) 860-7109

(703) 860-7119

\section{PUBLICATIONS DIVISION}

Official

Chief

Associate Chief

Assistant Chief, Management and Administration Assistant Chief, Research and Technical Coordination -Office of Public Inquiries

Printing Liaison Officer

International Activities

\section{Name}

Harry D. Wilson, Jr. Melvin E. Hanes Van M. Rayburn Bernard J. Thien Robbie S. Ritchey Jesse R. Upperco A. L. Dilonardo
Telephone number

(703) 860-7181

(703) 860-7181

(703) $860-7181$

(703) 860-7183

(703) 860-7185

(703) $860-7622$

(703) 860-6791

\section{ADMINISTRATIVE DIVISION}

Official

Chief

Deputy Chief

Personnel Officer

Contracts Officer
Name

Edmund J. Grant Lewis Menen Maxine C. Millard William Burk
Telephone number (703) 860-7201 (703) 860-7203

(703) $860-6127$

(703) $860-7261$
Address

National Center, STOP 409 National Center, STOP 408

National Center, STOP 440. National Center, STOP 441.

National Center, STOP 414 National Center, STOP 417. National Center, STOP 470
Address

National Center, STYP 600. National Center, STOP 600. National Center, STOP 640. National Center, STOP 620. National Center, STOP 630.

\section{Address}

National Center, STOP 801. National Center, STOP 801. National Center, STOP 805.

\section{SELECTED FIELD OFFICES}

\section{LAND INFORMATION AND ANALYSIS OFFICE EARTH RESOURCES OBSERVATION SYSTEMS DATA CENTER}

Location

South Dakota
Official in charge

Allen H. Watkins
Telephone number

(605) 594-6123
Address

National Center, STOP 341. National Center, STOP 341. National Center, STOP 341. National Center, STOP 341. National Center, STOP 341. National Center, STOP 330. National Center, STOP 341.
Address

National Center, STOP 201 National Center, STOP 202. National Center, STOP 215. National Center, STOP 205.

\section{TOPOGRAPHIC DIVISION}

\section{REGIONAL MAPPING CENTERS}

Mapping Center

Eastern Midcontinent
Chief

Peter F. Bermel Lawrence H. Borgerding, Acting
Telephone number

(703) 860-6352 (314) 364-3680, ext. 111
Address

EROS Data Center, Sioux Falls, SD 57198.

\section{Address}

National Center, STOP 567. 1400 Independence Rd., Rolla, MO 65401. 
Chief

Rocky Mountain

Western
Albert E. Letey

Rob M. Collier, Acting
Telephone number

(303) 234-2351

(415) 323-8111, ext. 2411
Address

Box 25046, STOP 510, Denver Federal Center, Denver, CO 80225 .

345 Middlefield Rd., Menlo Park, CA 94025.

\section{GEOLOGIC DIVISION}

\section{REGIONAL OFFICES}

Eastern

Telephone number

(703) 860-6631

Eugene H. Roseboom, Jr.

William R. Keefer

George Gryc
(303) 234-3625

(415) 323-8111

\section{WATER RESOURCES DIVISION}

\section{REGIONAL OFFICES}

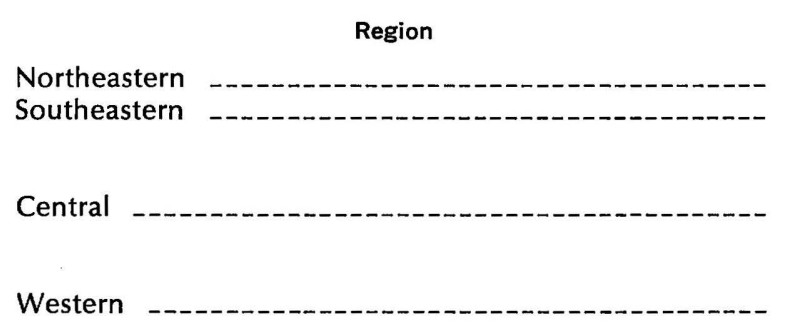

Regional Hydrologist Joseph T. Callahan Leslie B. Laird

\section{Alfred Clebsch, Jr.}

William H. Robinson

\section{DISTRICT OFFICES}

\section{State}

Alabama

Alaska

Arizona

Arkansas

California

Colorado

Connecticut

Delaware

District of Columbia

Florida

Georgia

\section{District Chief}

William J. Powell

Harry Hulsing

Horace M. Babcock

Richard T. Sniegocki

Lee R. Peterson

James E. Biesecker

Frederick H. Ruggles, Jr.

Walter F. White, Jr. Walter F. White, Jr. Clyde S. Conover

John R. George
Telephone number

(703) 860-6985

(404) 881-4395

(303) 234-3661

(415) 323-8111
Telephone number

(205) 752-8104

(907) 277-5526

(602) 792-6671

(501) 378-5246

(415) 323-8111, ext. 2326

(303) 234-5092

(203) 244-2528

(301) 828-1535

(301) 828-1535

(904) 386-1118

(404) 526-4858
Address

National Center, STOP 433

1459 Peachtree St. NE.

Suite 200,

Atlanta, GA 30392.

Box 25046, STOP 406,

Denver Federal Cente:

Denver, CO 80225.

345 Middlefield Rd. Menlo Park, CA 940:5.

\section{Address \\ P.O. Box. V, 202 Oil and Gas Board Bldg., University of Alabam: University, AL 35486 \\ 218 E St.,} Anchorage, AK 99501.

Federal Bldg. 301 W. Congress St. Tucson, AZ 85701. 2301 Federal Office Blç., 700 W. Capital Ave., Little Rock, AR 722 1. 855 Oak Grove Ave. Menlo Park, CA 9402:

Box 25046, STOP 415 , Denver Federal Cente: Denver, CO 80225

P.O. Box 715 235 Post Office Bldg. 135 High St.

Hartford, CT 06101 See Maryland District Ofice. See Maryland District Ofice. 325 John Knox Rd., Suite F-240,

Tallahassee, FL 32303

6481 Peachtree Industrial Blvd.,

Doraville, GA 30340 . 


\section{WATER RESOURCES DIVISION DISTRICT OFFICES-CONTINUED}

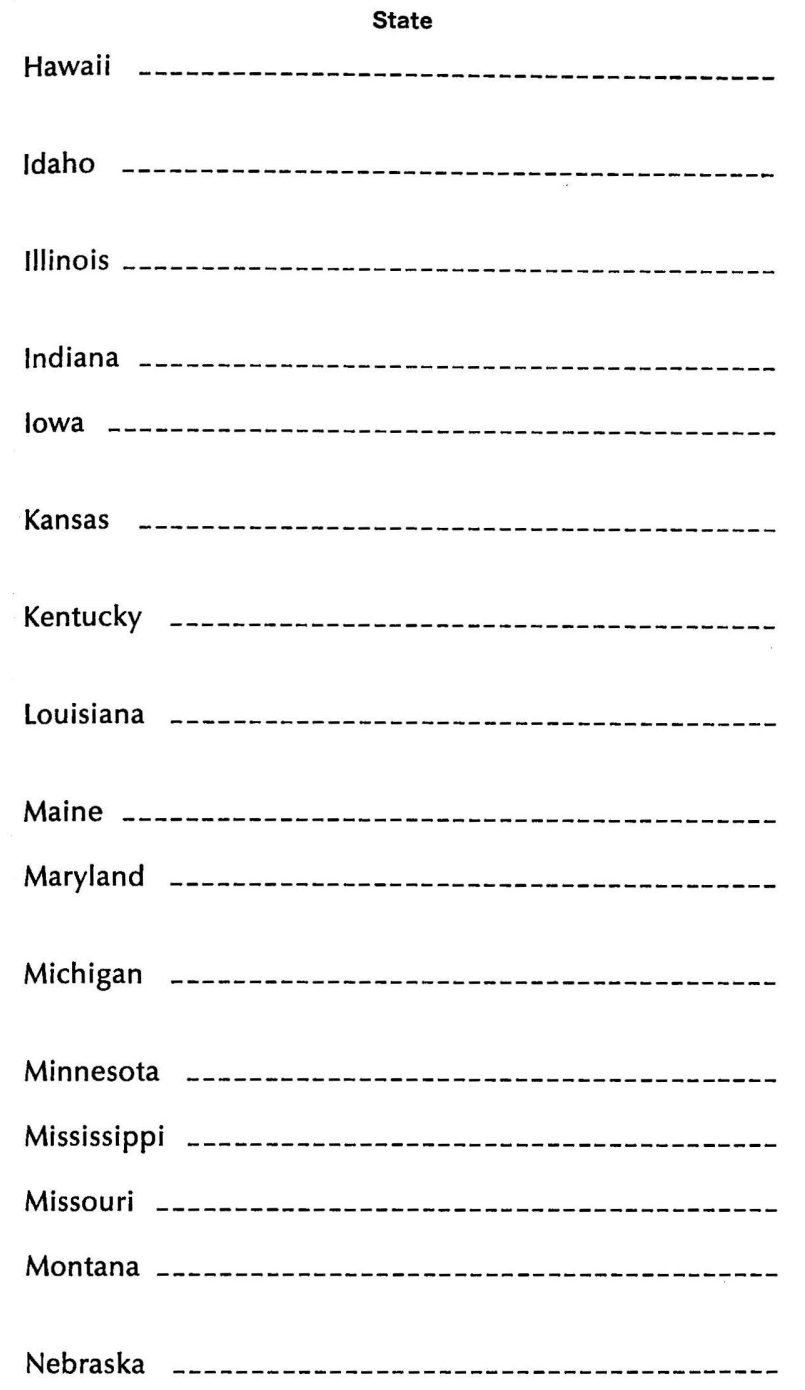

Nebraska

Nevada

New Hampshire

New Jersey

New Mexico

New York

North Carolina

North Dakota
District Chief

Frank T. Hidaka

Edwin E. Harris

Lawrence A. Martens

James L. Cook

Sulo W. Wiitala

J. S. Rosenshein

Philip A. Emery

Albert N. Cameron

John A. Baker

Walter F. White, Jr.

T. Ray Cummings

Charles R. Collier

Lamar E. Carroon

Anthony Homyk

George M. Pike

Kenneth A. Mac Kichan

John P. Monis

John A. Baker

Harold Meisler

William E. Hale

Robert J. Dingman

Ralph C. Heath

Walter R. Scott
Telephone number

(808) 955-0251

(208) 384-1750, ext. 2537

(217) 359-3918

(317) 269-7101

(319) 338-0581 ext. 521

(913) 864-4321

(502) 582-5241

(504) 387-0181 ext. 281

(617) 223-2822

(301) 828-1535

(517) 372-1910 ext. 561

(612) 725-7841

(601) 969-4600

(314) 361-3680 ext. 185 (406) 449-5011 ext. 5263

(402) 471-5082

(702) 882-1388

(617) 223-2822

(609) 599-3511, ext. 212

(505) 766-2246

(518) 472-3107

(919) 755-4510

(701) 255-4011

ext. 227
Address

1833 Kalkaua Ave., 5th Floor,

Honolulu, HI 96815.

Box 036, 365 Federal Bldg.,

550 W. Fort St.,

Boise, ID 83724.

P.O. Box 1026

605 N. Neil St.,

Champaign, IL 61820.

1819 N. Meridian St.,

Indianapolis, IN 46202.

P.O. Box 1230, 269 Federal Bldg.,

lowa City, IA 52240.

1950 Ave. A-Campus West,

University of Kansas,

Lawrence, KS 66045.

572 Federal Bldg. 600 Federal PI. Louisville, KY 40202.

P.O. Box 66492 6554 Florida Blvd., Baton Rouge, LA 70896.

See Massachusetts District Office.

208 Carroll Bldg. 8600 La Salle Rd. Towson, MD 21204.

2400 Science Parkway,

Red Cedar Research Park, Okemos, MI 48864.

1033 Post Office Bldg. St. Paul, MN 55101.

430 Bounds St., Jackson, MS 39206.

1400 Independence Rd.,

Rolla, MO 65401.

P.O. Box 1696, 421 Federal Bldg.,

Helena, MT 59601.

406 Federal Bldg. and U.S. Courthouse

100 Centennial Mall North,

Lincoln, NE 68503.

227 Federal Bldg.,

705 N. Plaza St.,

Carson City, NV 89701.

See Massachusetts District Office.

P.O. Box 1238

420 Federal Bldg.,

402 E. State St.,

Trenton, NJ 08607.

P.O. Box 26659

Western Bank Bldg., Rm. 815 ,

505 Marquette NW.

Albuquerque, NM 87125.

343 U.S. Post Office and Courthouse Bldg.,

Albany, NY 12201.

P.O. Box 2857

436 Century Station P.O. Bldg.

Raleigh, NC 27602.

332 New Federal Bldg.,

3d St. and Rosser Ave., 


\section{WATER RESOURCES DIVISION DISTRICT OFFICES-CONTINUED}

State

Ohio

Oklahoma

Oregon

Pennsylvania

Puerto Rico

Rhode Island

South Carolina

South Dakota

Tennessee

Texas

Utah

Vermont

Virginia

Washington

West Virginia

Wisconsin

Wyoming
District Chief

James F. Blakey

James H. Irwin

Stanley F. Kapustka

Norman H. Beamer

Ernest D. Cobb

John A. Baker

John S. Stallings

John E. Powell

Stanley P. Sauer

I. Dale Yost

Theodore Arnow

John A. Baker

William E. Forrest

John E. McCall

David H. Appel

William W. Barnwell

Samuel W. West
Telephone number

(614) 469-5553

(405) 231-4256

(503) 234-3361, ext. 4776

(717) $782-3468$

(809) $783-4660$

(617) 223-2822

(803) 765-5966

(605) 352-8651, ext. 258

(615) 749-5424

(512) 397-5766

(801) 524-5663

(617) 223-2822

(804) $782-2427$

(206) 593-6510

(304) 343-6181

(608) 262-2488

(307) 778-2220, ext. 2111

\section{Address}

975 West Third Ave.,

Columbus, OH 43212.

201 NW. 3d St., Rm. 621

Oklahoma City, OK

73102.

P.O. Box 3202,

830 NE. Holladay St.,

Portland, OR 97208.

P.O. Box 1107, 4th Floor, Federal Bldg.,

228 Walnut St.

Harrisburg, PA 17108.

P.O. Box 34168, Bldg. 652 ,

Ft. Buchanan, PR 00934.

See Massachusetts District Office.

2001 Assembly St., Suite 200,

Columbia, SC 29201.

P.O. Box 1412,

231 Federal Bldg., Huron, SD 57350.

A-413 Federal Bldg.,

U.S. Courthouse, Nashville, TN 37203.

649 Federal Bldg., 300 E. 8th St., Austin, TX 78701.

8002 Federal Bldg., 125 S. State St., Salt Lake City, UT 84138.

See Massachusetts Districî Office.

200 W. Grace St., Rm. 304, Richmond, VA 23220.

1305 Tacoma Ave. S., Rm. 300 ,

Tacoma, WA 98402.

3303 Federal Bldg. and U.S. Courthouse,

500 Quarrier St. E.,

Charleston, WV 2530\%.

1815 University Ave., Rri. 200,

Madison, WI 53706.

P.O. Box 2087

4015 Warren Ave., Cheyenne, WY 82001.

\section{CONSERVATION DIVISION}

\section{REGIONAL OFFICES}

Eastern

Gulf of Mexico Outer Continental Shelf Operations _-.-

Western

\section{Conservation \\ George Brown \\ George H. Horn}

A. Dewey Acuff

Willard C. Gere
Telephone number

(202) 254-3137

(303) 234-2855

(504) 837-4720, ext. 9381

(415) 323-8111, ext. 2563

\section{Address}

1725 K St., NW.,

Suite 213,

Washington, DC 2024.

Box 25046, STOP 609,

Denver Federal Center,

Denver, CO 80225.

P.O. Box 7944,

434 Imperial Office Bld

3301 N. Causeway Blvi.,

Metairie, LA 70011.

345 Middlefield Rd., Menlo Park, CA 94025. 


\section{PUBLICATIONS DIVISION}

REGIONAL OFFICES

\begin{tabular}{ll} 
Eastern & \multicolumn{2}{c}{ Official in charge } \\
Central & Lewis D. Brown \\
Western &
\end{tabular}
Telephone number
(703) 860-6761
(303) $234-4974$
National Center, STOP
Box 25046, STOP 303 ,
Denver Federal Center,
Denver, CO 80225
(415) 323-8111, 345 Middlefield Rd.,
ext. 2537 Menlo Park, CA 94025.

\section{PUBLIC INQUIRIES OFFICES}

\begin{tabular}{|c|c|}
\hline Location & Official in charge \\
\hline Alaska - & Margaret I. Erwin \\
\hline California: & \\
\hline San Francisco - & Jean V. Molleskog \\
\hline Colorado - & Alice M. Coleman \\
\hline District of Columbia & Bruce A. Hubbard \\
\hline Texas - - & $\begin{array}{l}\text { Jimmie L. Wilkinson, } \\
\text { Acting }\end{array}$ \\
\hline Utah & Wendy R. Hassibe \\
\hline Virginia & A. Ernestine Jones \\
\hline
\end{tabular}
Telephone number
(907) 277-0577
Address
08 Skyline Bldg.,
502 2d Ave.
Anchorage, AK 99501.
(213) 688-2850 7638 Federal Bldg.,
300 N. Los Angeles St.,
(415) 556-5627 504 Custom House,
555 Battery St.,
94111.
1012 Federal Bldg.
1961 Stout St.,
Denver, CO 80294.
(202) 343-8073 1028 GSA Bldg., 19th and F Sts. NW.,
Washington, DC 20244.
(214) 749-3230 1C45 Federal Bldg.,
1100 Commerce St.,
Dallas, TX 75202.
(801) 524-5652 8105 Federal Bldg.,
125 S. State St.,
Salt Lake City, UT 84138 .
(703) 860-6167 1C402 National Center, STOP 302
12201 Sunrise Valley Dr., Reston, VA 22092.
(509) 456-2524 678 U.S. Courthouse,
W. 920 Riverside Ave., Spokane, WA 99201.

\section{BRANCH OF DISTRIBUTION OFFICES}

$\begin{array}{ll}\text { Llaska } & \begin{array}{r}\text { Official in charge } \\ \text { Nation Cornforth }\end{array} \\ \text { Volorado } & \text { Dwight F. Canfield }\end{array}$

\begin{tabular}{cc} 
Telephone number & \multicolumn{1}{c}{ Address } \\
(907) 452-1951 & $\begin{array}{c}310 \text { First Ave., } \\
\text { Fairbanks, AK 99701. } \\
\text { Box 25286, STOP 306, } \\
\text { Denver. Federal Center, } \\
\text { (303) 234-3832 }\end{array}$ \\
$\begin{array}{c}\text { Denver, CO 80225. } \\
\text { (703) 557-2781 }\end{array}$ & $\begin{array}{l}\text { 1200 S. Eads St., } \\
\text { Arlington, VA 22202. }\end{array}$
\end{tabular}

ADMINISTRATIVE DIVISION

REGIONAL MANAGEMENT OFFICES

Region

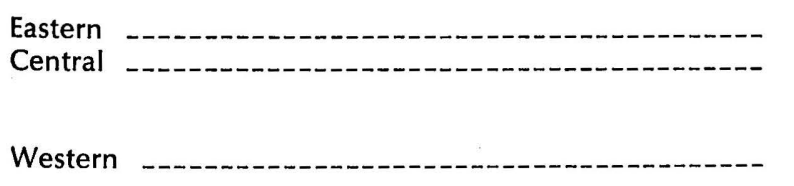

$$
\begin{gathered}
\text { Regional Management } \\
\text { Officer }
\end{gathered}
$$

Roy Heinbuch

Thomas J. Lyons

Avery W. Rogers
Telephone number

(703) 860-7.691

(303) 234-3736

(415) 323-2211

\section{Address}

National Center, STOP 290

Box 25046, STOP 202 ,

Denver Federal Center, Denver, CO 80225

345 Middlefield Rd Menlo Park, CA 94025. 


\section{COOPERATORS AND OTHER FINANCIAL CONTRIBUTORS DURING FISCAL FINANCIAL YEAR 1976 AND TRANSITION QUARTER}

[Cooperators listed are those with whom the U.S. Geological Survey had a written agreement for financial cooperation in fiscal year 1976 and the transition quarter, cosigned by responsible officiais of the Geological Survey and the cooperating agency. Agencies with whom the Geological Survey where separate cooperative agreements for different projects were made with the parent agency and with a subdivision of the parent agency]

\section{FEDERAL COOPERATORS}

\author{
Department of Agriculture: \\ Agricultural Research Service \\ Forest Service \\ Saudi Joint Commission \\ Soil Conservation Service \\ Statistical Reporting Service \\ Department of the Air Force: \\ AFWL/PRP Kirtland AFB \\ Air Force Academy \\ Air Force Headquarters, Washington, D.C. \\ Headquarters (AFTAC/AC) \\ Headquarters Pacific Air Forces \\ Headquarters 321st Combat Support Group (SAC) \\ Homestead Air Force Base \\ Vandenburg Air Force Base \\ Department of the Army: \\ Army Research Office \\ Cold Regions Research and Engineering Laboratory \\ Construction Engineering Research Laboratory \\ Corps of Engineers \\ Rocky Mountain Arsenal \\ White Sands Missile Range
}

Department of Commerce, National Oceanic and Atmospheric Administration:

Economic Development Administration

Environmental Research Laboratories

National Ocean Survey

National Weather Service

Old West Regional Commission

Department of Defense:

Advanced Research Projects Agency

Defense Intelligence Agency

Defense Nuclear Agency

U.S. Arms Control and Disarmament Agency

Department of Health, Education and Welfare, Public Health Service

Department of Housing and Urban Development

Department of the Interior:

Alaska Power Administration

Bonneville Power Administration

Bureau of Indian Affairs

Bureau of Land Management

Bureau of Mines

182
Department of the Interior-continued

Fish and Wildlife Service

National Park Service

Office of Land Use and Water Planning

Office of Saline Water

Office of the Secretary

Office of Water Policy Coordination

U.N. Geothermal Symposium

Water Resources Council

Department of the Navy:

Marine Corps, Camp Pendleton

Naval Facilities Engineering Command

Naval Weapons Center

Underwater Systems Center

Department of State:

Agency for International Development

International Joint Commission

Department of Transportation, Federal Highway Administration

Department of the Treasury, U.S. Customs Service

Energy Research and Development Administration: Albuquerque Operations Office Division of Applied Technology

Division of Administrative Services

Division of Geothermal Energy

Division of Reactor Research and Development

Grand Junction Office

Idaho Operations Office

Nevada Operations Office

Oak Ridge Operations Office

Richland Operations Office

San Francisco Operations Office

Savannah River Operations Office

Environmental Protection Agency:

Enforcement Division

National Environmental Research Center

Office of Energy, Minerals, and Industry

Office of Radiation Programs

Office of Research and Development

Office of Water Programs

Pacific Northwest Environmental Research Laboratory

Technical Services Branch

Upper Mississippi River Basin Commission

Federal Energy Administration

General Services Administration

National Aeronautics and Space Administration 


\section{FEDERAL COOPERATORS-CONTINUED}

National Science Foundation

Nuclear Regulatory Commission

Office of Emergency Preparedness
Pacific Northwest River Basins Commission

Tennessee Valley Authority

Veterans Administration

\section{STATE, COUNTY, AND LOCAL COOPERATORS}

Alabama:

Alabama Development Office

Alabama Highway Department

Commission of Jefferson County

Geological Survey of Alabama

Alaska:

Alaska Department of Fish and Game

Alaska Department of Highways

Alaska Geological and Geophysical Survey

Alaska Pipeline Coordination Office

City of Anchorage

Department of Environmental Conservation

Greater Anchorage Area Borough

Kenai Borough

North Star Borough

Arizona:

Arizona Game and Fish Department

Arizona Highway Department

Arizona Water Commission

City of Flagstaff

City of Nogales

City of Safford

City of Tucson

Department of Health Services

Flood Control District of Maricopa County

Gila Valley Irrigation District

Maricopa County Municipal Water Conservation District No. 1

Pima County Board of Supervisors

Salt River Valley Water User's Association

San Carlos Irrigation and Drainage District

Show Low Irrigation Company

University of Arizona

\section{Arkansas:}

Arkansas Department of Pollution Control and Ecology

Arkansas Division of Soil and Water Resources

Arkansas Geological Commission

Arkansas State Highway Commission

California:

Alameda County Flood Control and Water Conservation District Alameda County Water District

Antelope Valley-East Kern Water

California Department of Conservation, Division of Mines and Geology

California Department of Transportation

California Department of Water Resources

California Water Resources Control Board
California-continued

Casitas Municipal Water District

City and County of San Francisco:

Hetch Hetchy Water Supply

Water Department

City of Lompoc

City of Merced

City of Modesto, Public Works Department

City of San Diego

City of San Rafael

City of Santa Barbara, Public Works Department

Coachella Valley County Water District

Contra Costa County Flood Control and Water Conservation District

County of Fresno

County of Madera, Flood Control and Water Conservation Agency

County of Modoc, Public Works Department

County of San Diego, Department of Sanitation and Flood Control

County of San Mateo, Engineer and Road Commissioner

Desert Water Agency

East Bay Municipal Utility District

Georgetown Divide Public Utility District

Goleta County Water District

Humboldt County, Department of Public Works

Imperial County Department of Public Works

Imperial Irrigation District

Indian Wells Valley County Water District

Kern County Water Agency

Lake County Flood Control and Water Conservation District

Livermore Amador Valley Water Management Agency

Los Angeles County, Department of County Engineers

Los Angeles County Flood Control District

Los Angeles Department of Water and Power

Madera Irrigation District

Marin County Department of Public Works

Merced Irrigation District

Metropolitan Water District of Southern California

Mojave Water Agency

Montecito County Water District

Monterey County Flood Control and Water Conservation

$$
\text { District }
$$

Napa County Flood Control and Water Conservation District

North Marin County Water District

Orange County Environmental Management Agency

Orange County Water District

Oroville-Wyandotte Irrigation District

Pacheco Pass Water District

Paradise Irrigation District

Riverside County Flood Control and Water Conservation District 


\section{STATE, COUNTY, AND LOCAL COOPERATORS-CONTINUED}

California-continued

San Benito County Water Conservation and Flood Control District

San Bernardino County Flood Control District

San Bernardino Valley Municipal Water District

San Luis Obispo County:

Engineering Department

Flood Control and Water Conservation District

Santa Barbara County Flood Control and Water Conservation District

Santa Clara Valley Water District

Santa Cruz County Flood Control and Water Conservation District

Santa Margarita and San Luis Rey Watershed Planning Agencies

Santa Maria Valley Water Conservation District

Santa Ynez River Water Conservation District

Siskiyou County Flood Control and Water Conservation District

Terra Bella Irrigation District

Tulare County Flood Control District

Turlock Irrigation District

Twentynine Palms Water District

United Water Conservation District

University of California, School of Forestry and Conservation

Ventura County Flood Control District, Riverside County

Western Municipal Water District

Woodbridge Irrigation District

Yolo County Flood Control and Water Conservation District

\section{Colorado:}

Arkansas River Compact Administration

Boulder City-County Department of Health

City and County of Denver, Board of Water Commissioners

City of Aspen

City of Aurora, Department of Public Utilities

City of Colorado Springs, Department of Public Utilities

City of Fort Collins

Colorado City Water and Sanitation District

Colorado Department of Local Affairs

Colorado Department of Natural Resources:

Division of Water Resources

Division of Wildlife

Geological Survey

Colorado Department of Public Health, Water Pollution Control Commission

Colorado River Water Conservation District

Colorado Water Conservation Board

Denver Regional Council of Governments

Eagle County Commissioners

El Paso County:

Board of Commissioners

Water Association

Jefferson County Health Department

Kiowa-Bijou Groundwater Management District

Metro Denver Sewage Disposal District No. 1

Park County Board of County Commissioners

Pikes Peak Area Council of Governments

Pitkin County Board of County Commissioners

Rio Grande Water Conservation District

Southeastern Colorado Water Conservancy District

Southern Ute Indian Tribe.

Southwestern Water Conservation District

State of Colorado, Department of Highways

Urban Drainage and Flood Control District

Connecticut:
Connecticut-continued

City of New Britain, Board of Water Commissioners

City of Torrington

Department of Environmental Protection

Town of Fairfield

Town of Farmington

Town of Manchester

Town of Newton

Town of South Windsor

Town of Wilton

Delaware:

Delaware Geological Survey, University of Delaware

Department of Highways and Transportation, Division of Highways

District of Columbia, Department of Environmental Services

Florida:

Brevard County

Broward County

Broward County Air and Water Pollution Control Board

Central and Southern Florida Flood Control District

City of Boca Raton

City of Boyntin Beach

City of Clearwater

City of Cocoa

City of Deerfield Beach

City of Fort Lauderdale

City of Fort Myers

City of Gainesville

City of Hallandale

City of Hollywood

City of Jacksonville

City of Juno Beach

City of Miami-Dade Water and Sewer Authority and the C ty of Miami Beach

City of Pensacola

City of Perry

City of Pompano Beach

City of Riviera Beach

City of St. Petersburg

City of Sarasota

City of Tallahassee

City of Tampa

City of West Palm Beach

Charlotte County

Collier County Water Management District No. 1

Collier County Water Management District No. 7

Department of Environmental Regulations

Department of Pollution Control

Division of State Planning

Englewood Water District

Escambia County

Florida Department of Natural Resources:

Bureau of Geology

Division of Parks and Recreation

Florida Department of Transportation

Florida Keys Aqueduct Authority

Hendry County

Hillsborough County

Jacksonville Area Planning Board

Lake County

Lake Worth Drainage District

Lee County 


\section{STATE, COUNTY, AND LOCAL COOPERATORS-CONTINUED}

Florida-continued

Loxahatchee River Environmental Control District

Manasota Basin Board

Manatee County, Board of County Commissioners

Marion County

Martin County

Metropolitan Dade County

Northwest Florida Water Management District

Old Plantation Drainage District

Orange County

Palm Beach County

Pinellas County

Reedy Creek Improvement District

Sarasota County

Seminole County

Southwest Water Management District

St. Johns River Water Management

Sunshine Drainage District

Suwanee River Authority

Suwanee River Water Management District

Town of Highland Beach

Village of Tequesta

Volusia County

Walton County

Georgia:

Chatham County

City of Brunswick

City of Valdosta

Dekalb County

Department of Natural Resources:

Earth and Water Division

Environmental Protection Division

Department of Transportation

Hawaii:

City and County of Honolulu

Honolulu Board of Water Supply

Maui County, Department of Public Works

State Department of Land and Natural Resources

State Department of Transportation

Idaho:

Idaho Department of Transportation

Idaho Department of Water Resources

Mann Creek Irrigation District

Illinois:

Bloomington and Normal Sanitary District

City of Springfield

Cook County, Forest Preserve District

DuPage County Highway Department

Environmental Protection Agency

Fountain Head Drainage District

Fulton County-East Liverpool Drainage and Levee District

Kane County Highway Department

Lake County Highway Department

McHenry County Regional Planning Commission

Sanitary District of Bloom Township

State Department of Registration and Education, Illinois State Water Survey

State Department of Transportation, Division of Water Resources Management

The Metropolitan Sanitary District of Greater Chicago

University of Illinois at Urbana-Champaign, Board of Trustees
Indiana:

City of Indianapolis

City of Logansport

Indiana Board of Health

Indiana Department of Natural Resources

Indiana Highway Commission

Town of Carmel

lowa:

City of Cedar Rapids

City of Des Moines

City of Fort Dodge

lowa Geological Survey

lowa Natural Resources Counci

lowa State Highway Commission, Highway Research Board

lowa State University:

Department of Agricultural Engineering

Department of Science and Technology, Agricultural Experiment Station

Kansas:

City of Wichita

Kansas State Department of Health

Kansas State Water Resources Board

Kansas-Oklahoma Arkansas River Commission

State Geological Survey of Kansas

State Highway Commission of Kansas

Kentucky:

Bureau of Highways, Department of Transportation

Department of Natural Resources and Environmental Protection:

Division of Conservation

Division of Water Quality

Kentucky Geological Survey, University of Kentucky

Louisiana:

Capital Area Ground Water Conservation Commission

Louisiana Department of Highways

Louisiana Department of Public Works

Sabine River Compact Administration

Maine:

Department of Environmental Protection

Greater Portland Council of Governments, Androscoggin Regional Planning Agency

Maine Department of Transportation

Maine Public Utilities Commission

South Kennebec Regional Planning Commission

South Maine Regional Planning Agency

Maryland:

City of Baltimore, Bureau of Engineering, Water Supply Division

Maryland Department of Health and Mental Hygiene

Maryland Department of Transportation, The State Highway Administration

Maryland Geological Survey

Massachusetts:

Department of Public Works:

Division of Research and Materials

Division of Highways

Division of Waterways

Metropolitan District Commission 


\section{STATE, COUNTY, AND LOCAL COOPERATORS-CONTINUED}

Massachusetts-continued

State Water Resources Commission:

Division of Water Pollution Control

Division of Water Resources

Michigan:

Michigan Department of Agriculture, Soil and Water Conservation Division

Michigan Department of Natural Resources:

Environmental Protection Branch

Geological Survey Division

Minnesota:

City of Lakeville

Minnesota Department of Natural Resources, Division of Natural Waters

Minnesota State Planning Agency

Mississippi:

City of Jackson

Harrison County Development Commission

Jackson County Port Authority

Marine Research Council

Mississippi Air and Water Pollution Control Commission

Mississippi Board of Water Commissioners

Mississippi Geological Survey

Mississippi Research and Development Center

Mississippi State Highway Department

Pat Harrison Waterway District

Pearl River Valley Water Supply District

Missouri:

Curators of the University of Missouri

Department of Natural Resources:

Division of Environmental Quality, Clean Water Commission

Division of Geology and Land Survey

Division of Research and Technical Information

Metropolitan St. Louis Sewer District

Missouri Office of Administration

Missouri State Highway Commission

Springfield Sanitary District

St. Louis County

Montana:

Endowment and Research Foundation-Montana State University Flathead Drainage 208 Project

Lewis and Clark County, Board of County Commissioners

Missoula and Powell Counties

Montana Bureau of Mines and Geology

Montana Department of Health and Environmental Sciences

Montana Department of Natural Resources, Environmental Protection Branch

Montana State Fish and Game Department

Montana State Highway Commission

Yellowstone-Tongue Area Planning and Organization

Nebraska:

Blue River Association of Ground Water Conservation Districts Clay County Ground Water Conservation District Filmore County Ground Water Conservation District Hamilton County Ground Water Conservation District Kansas-Nebraska Big Blue River Compact Administration Lower Elkhorn Natural Resources District
Nebraska-continued

Nebraska Department of Water Resources

Nebraska Natural Resources Commission

Seward County Ground Water Conservation District

State Department of Roads

University of Nebraska, Water Resources Institute

Upper Big Blue Natural Resources District

York County Ground Water Conservation District

Nevada:

Department of Human Resources (Environmental Protection Services)

Nevada Bureau of Mines and Geology

Nevada Department of Conservation and Natural Resources

Nevada State Highway Department

New Hampshire:

New Hampshire Department of Resources and Economic Development

New Hampshire Water Resources Board

New Hampshire Water Supply and Pollution Control Commission

Strafford-Rockingham Regional Council

New Jersey:

Bergen County

Camden County Board of Freeholders

Delaware River Basin Commission

Morris County Municipal Utilities Authority

New Jersey Department of Agriculture, State Soil Conservation Committee

New Jersey Department of Environmental Protection

North Jersey District Water Supply Commission

Passaic Valley Water Commission

Rutgers State University

Township of Cranford

New Mexico:

Albuquerque Metropolitan Arroyo Flood Control Authority

City of Las Cruces

Costilla Creek Compact Commission

Interstate Stream Commission

New Mexico Bureau of Mines and Mineral Resources

New Mexico State Engineer

New Mexico State Highway Commission

Pecos River Commission

Rio Grande Compact Commission

State Planning Office

New York:

Board of Hudson River-Black River Regulating District

Central New York State Parks Commission

City of Albany

City of Auburn

City of New York:

Board of Water Supply

Environmental Protection Administration

City of Rochester, Water Bureau

County of Chautauqua

County of Cortland

County of Dutchess, Department of Planning

County of Nassau, Department of Public Works 
New York-continued

County of Onondaga:

Department of Public Works

Water Authority

County of Orange, Department of Public Works

County of Putnam, Highway Department

County of Rockland Drainage Agency

County of Suffolk:

Department of Environmental Control

Water Authority

County of Ulster, Ulster County Legislature

County of Westchester, Department of Public Works

County of Wyoming

Department of Environmental Conservation:

Bureau of Monitoring and Surveillance

Facilities and Construction Management

Office of Program Development

Department of Transportation

Monroe County Water Authority

Nassau-Suffolk Regional Planning Board

New York State Department of Health

New York State Education Department, Museum and Science Service

Oswegatchie-Cranberry Reservoir Commission

Power Authority of the State of New York

State University of New York, College of .Environmental Science and Forestry

Susquehanna River Basin Commission

Town of Waterford Commissioners

North Carolina:

Board of Transportation

City of Asheville, Public Works Department

City of Burlington

City of Charlotte

City of Durham, Department of Water Resources

City of Greensboro

City of Winston-Salem

North Carolina Department of Natural and Economic Resources, Office of Earth Resources

State Department of Transportation

University of North Carolina, Water Resources Research Institute

Ohio:

City of Canton

City of Columbus, Department of Public Service

City of Toledo

Miami Conservancy District

Ohio Department of Natural Resources

Ohio Department of Transportation

Ohio Department of Transportation, Division of Highways

Ohio Environmental Protection Agency

Ohio River Valley Water Sanitation Commission

Three Rivers Watershed District

Toledo Metropolitan Area Council of Governments

Oklahoma:

City of Oklahoma City, Water Department

Oklahoma Department of Highways

Oklahoma Geologic Survey

State Pollution Control Coordinating Board

Oklahoma Water Resources Board

State Department of Health, Environmental Health Service
Oregon:

Burnt River Irrigation District

City of Corvallis

City of Eugene, Water and Electric Board

City of McMinnville, Water and Light Department

City of Portland:

Bureau of Water Works

Department of Public Utilities

Columbia Region Association of Governments

Confederated Tribes of the Umatilla Indian Reservation

Confederated Tribes of the Warm Springs Reservation

Coos Bay-North Bend Water Board

Coos County, Board of Commissioners

Department of Fish and Wildlife

Douglas County, Board of Commissioners

Lakeside Water District

Land County, Board of Commissioners

Multnomah County, Board of County Commissioners

Oregon State Highway Commission

Oregon State Water Resources Department

Rogue Valley Council of Governments

Pennsylvania:

Chester County Water Resources Authority

City of Bethlehem

City of Easton

City of Harrisburg

City of Philadelphia, Water Department

Department of Environmental Management

Pennsylvania Department of Environmental Resources:

Bureau of Topographic and Geologic Survey

Bureau of Water Quality Management

Office of Planning and Research

Office of Resource Management

Pennsylvania Department of Transportation

Slippery Rock State College

South Carolina:

Commissioners of Public Works, Spartanburg Water Works

Department of Health and Environmental Control, Bureau of Waste Water and Stream Quality

State Highway Department

State Public Service Authority

State Water Resources Commission

South Dakota:

Black Hills Conservancy Subdistrict

City of Sioux Falls

City of Watertown

East Dakota Conservancy Subdistrict

South Dakota Department of Natural Resource Development

South Dakota Department of Transportation and Board of Transport

South Dakota Department of Transportation and State Geological Survey

Tennessee:

Chickasaw Basin Authority

City of Franklin

City of Lawrenceburg

City of Manchester

City of Memphis, Board of Light, Gas, and Water Commissioners

Lincoln County Public Utilities Board

Metropolitan Government of Nashville and Davidson County, Department of Public Works 


\section{STATE, COUNTY, AND LOCAL COOPERATORS-CONTINUED}

Tennessee-continued

Murfreesboro Water and Sewer Department

Tennessee Department of Conservation:

Division of Geology

Division of Water Resources

Tennessee Department of Public Health, Division of Water Quality Control

Tennessee Department of Transportation

Tennessee Wildlife Resources Agency

University of Tennessee Water Resources Research Center

Texas:

City of Austin

City of Dallas, Public Works Department

City of Fort Worth

City of Houston

County of Dallas

Sabine River Compact Administration

Texas Highway Department

Texas Water Development Board

Utah:

Bear River Commission

Salt Lake County

State Department of Natural Resources, Division of Water Rights

Utah Geological and Mineralogical Survey

Vermont:

City of Springfield

State Department of Highways

State Department of Water Resources, Planning and

Development Division

Virginia:

City of Alexandria

City of Newport News, Department of Public Utilities

City of Norfolk

City of Roanoke

City of Staunton

County of Chesterfield

County of Fairfax

Virginia Department of Conservation and Economic

Development, Division of Mineral Resources

Virginia Department of Highways

Virginia State Water Control Board

Washington:

Chehalis Tribal Council

City of Port Angeles

City of Seattle, Department of Lighting
Washington-continued

City of Tacoma:

Department of Public Utilities

Department of Public Works

Clark County:

Department of Public Works

Public Utility District

Cowlitz County Public Utility District

Kilsap County Board of Commissioners

Lower Elwah Tribal Council

Makah Tribal Council

Municipality of Metropolitan Seattle

Nisqually Indian Community Council

Pacific County Board of County Commissioners

Port Gamble Tribal Council

Quilente Tribal Council

Quinault Tribal Council

Suquamish Tribal Council

Swinomish Tribal Council

The Evergreen State College

Tulalip Tribe Board of Directors

University of Washington

Washington State Department of Ecology

West Virginia:

Clarksburg Water Board

Morgantown Water Commission

West Virginia Department of Highways

West Virginia Department of Natural Resources, Division of Water Resources

West Virginia Geological and Economic Survey

Wisconsin:

City of Madison

City of Middleton

Dane County Regional Planning Commission

Douglas County Soil and Water Conservation District

Southeastern Wisconsin Regional Planning Commission

State Department of Natural Resources

State Department of Transportation, Division of Highways

State Soil and Water Conservation Districts

The University of Wisconsin-Extension, Geological and Natt:al History Survey

Wyoming:

City of Cheyenne, Board of Public Utilities

Geological Survey of Wyoming

State Highway Commission of Wyoming

University of Wyoming, Water Resources Institute

Wyoming Department of Economic Planning and Developm int

Wyoming State Department of Agriculture

Wyoming State Department of Environmental Quality

Wyoming State Engineer 


\section{OTHER COOPERATORS AND CONTRIBUTORS}

Appalachian Regional Commission

Coastal Plains Regional Commission

Government of Algeria

Government of Saudi Arabia

Ozarks Regional Commission

Permittees and licensees of the Federal Power Commission
Puerto Rico:

North Metropolitan 208 Area Wide Planning Commission

Puerto Rico Aqueduct and Sewer Authority

Puerto Rico Department of Natural Resources

Puerto Rico Environmental Quality Board

United Nations

Virgin Islands:

College of Virgin Islands

Department of Public Works

\section{ORGANIZATIONAL AND STATISTICAL DATA}

[Data in these statistical tables may differ slightly from data in the individual division chapters because of rounding]

TABLE 26.-Geological Survey budget, by activity and sources of funds, fiscal years 1971-76 and transition quarter [In thousands of dollars. Detail may not add to totals because of rounding]

\begin{tabular}{|c|c|c|c|c|c|c|c|}
\hline Budget activity & 1971 & 1972 & 1973 & 1974 & 1975 & 1976 & $\begin{array}{c}\text { Transition } \\
\text { quarier } \\
\text { (estimated) }\end{array}$ \\
\hline Total & $\$ 173,243$ & $\$ 188,996$ & $\$ 211,944$ & $\$ 249,437$ & $\$ 338,764$ & $\$ 353,970$ & $\$ 102,816$ \\
\hline Direct program & 114,080 & 130,951 & 149,971 & 171,983 & 253,605 & 264,434 & 77,756 \\
\hline Reimbursable program & 59,163 & 58,045 & 61,973 & 77,454 & 85,159 & 89,536 & 25,060 \\
\hline $\begin{array}{l}\text { States, counties, and municipalities - } \\
\text { Miscellaneous non-Federal sources - } \\
\text { Other Federal agencies }\end{array}$ & $\begin{array}{r}24,687 \\
3,240 \\
31,236\end{array}$ & $\begin{array}{r}25,857 \\
3,383 \\
28,805\end{array}$ & $\begin{array}{r}28,011 \\
3,620 \\
30,342\end{array}$ & $\begin{array}{r}32,443 \\
4,695 \\
40,316\end{array}$ & $\begin{array}{r}35,124 \\
6,399 \\
43,636\end{array}$ & $\begin{array}{r}35,006 \\
7,923 \\
46,607\end{array}$ & $\begin{array}{r}9,114 \\
2,264 \\
13,682\end{array}$ \\
\hline Alaska Pipeline Related Investigations_ & 1,401 & 1,401 & 1,239 & 890 & 344 & 287 & 112 \\
\hline Direct program & 1,336 & 1,339 & 1,239 & 890 & 344 & 287 & 112 \\
\hline Reimbursable program & 65 & 62 & ------ & $-\cdots--$ & $-\cdots---$ & ------ & $--\cdots--$ \\
\hline Other Federal agencies & 65 & 62 & ----- & ------ & ----- & ----- & ------ \\
\hline Topographic Surveys and Mapping --- & 37,426 & 38,737 & 40,271 & 43.664 & 52,597 & 52,220 & 13,393 \\
\hline Direct program & 31,153 & 34,545 & 35,172 & 37,161 & 45,350 & 45,354 & 11,553 \\
\hline Reimbursable program & 6,273 & 4,192 & 5,099 & 6,503 & 7,247 & 6,866 & 1,840 \\
\hline $\begin{array}{l}\text { States, counties, and } \\
\text { municipalities -- } \\
\text { Miscellaneous non-Federal }\end{array}$ & 3,901 & 3,204 & 3,719 & 4,942 & 4,995 & 3,675 & 940 \\
\hline $\begin{array}{c}\text { sources } \\
\text { Other Federal agencies }\end{array}$ & $\begin{array}{r}355 \\
2,017\end{array}$ & $\begin{array}{l}357 \\
631\end{array}$ & $\begin{array}{l}600 \\
780\end{array}$ & $\begin{array}{l}643 \\
918\end{array}$ & $\begin{array}{r}594 \\
1,658\end{array}$ & $\begin{array}{r}501 \\
2,690\end{array}$ & $\begin{array}{l}160 \\
740\end{array}$ \\
\hline
\end{tabular}


TABLE 26.-Geological Survey budget, by activity and sources of funds, fiscal year 1971-76 and transition quarter-Continued

\begin{tabular}{|c|c|c|c|c|c|c|c|}
\hline Budget activity & 1971 & 1972 & 1973 & 1974 & 1975 & 1976 & $\begin{array}{c}\text { Transition } \\
\text { quarter } \\
\text { (estimated) }\end{array}$ \\
\hline $\begin{array}{l}\text { Geologic and Mineral Resource } \\
\text { Surveys and Mapping }{ }^{1}\end{array}$ & 49,015 & 51,529 & 57,979 & 73,563 & 114,477 & 115,554 & 32,997 \\
\hline $\begin{array}{l}\text { Direct program } \\
\text { Reimbursable program }\end{array}$ & $\begin{array}{l}31,919 \\
17,096\end{array}$ & $\begin{array}{l}34,244 \\
17,285\end{array}$ & $\begin{array}{l}42,895 \\
15,084\end{array}$ & $\begin{array}{l}49,877 \\
23,686\end{array}$ & $\begin{array}{l}89,018 \\
25,459\end{array}$ & $\begin{array}{l}92,322 \\
23,232\end{array}$ & $\begin{array}{r}24,837 \\
8,160\end{array}$ \\
\hline $\begin{array}{l}\text { States, counties, and } \\
\text { municipalities } \\
\text { Miscellaneous non-Federal }\end{array}$ & 1,322 & 1,359 & 1,556 & 1,681 & 1,550 & 1,467 & 392 \\
\hline $\begin{array}{l}\text { sources - } \\
\text { Other Federal agencies }\end{array}$ & $\begin{array}{r}2,280 \\
13,494\end{array}$ & $\begin{array}{r}2,317 \\
13,609\end{array}$ & $\begin{array}{r}2,306 \\
11,222\end{array}$ & $\begin{array}{r}2,684 \\
19,321\end{array}$ & $\begin{array}{r}3,751 \\
20,158\end{array}$ & $\begin{array}{r}4,936 \\
16,829\end{array}$ & $\begin{array}{l}1,323 \\
6,445\end{array}$ \\
\hline Water Resources Investigations ${ }^{2}$ & 66,084 & 71,324 & 78,103 & 88,352 & 101,437 & 112,480 & 29,726 \\
\hline $\begin{array}{l}\text { Direct program } \\
\text { Reimbursable program }\end{array}$ & $\begin{array}{l}34,581 \\
31,503\end{array}$ & $\begin{array}{l}37,446 \\
33,878\end{array}$ & $\begin{array}{l}40,185 \\
37,918\end{array}$ & $\begin{array}{l}45,433 \\
42,919\end{array}$ & $\begin{array}{l}53,420 \\
48,017\end{array}$ & $\begin{array}{l}57,176 \\
55,304\end{array}$ & $\begin{array}{l}15,922 \\
13,804\end{array}$ \\
\hline $\begin{array}{l}\text { States, counties, and } \\
\text { municipalities } \\
\text { Miscellaneous non-Federal }\end{array}$ & 19,464 & 21,294 & 22,736 & 25,820 & 28,546 & 29,735 & 7,730 \\
\hline $\begin{array}{l}\text { sources } \\
\text { Other Federal agencies }\end{array}$ & $\begin{array}{r}571 \\
11,468\end{array}$ & $\begin{array}{r}679 \\
11,905\end{array}$ & $\begin{array}{r}664 \\
14,518\end{array}$ & $\begin{array}{r}721 \\
16,378\end{array}$ & $\begin{array}{r}901 \\
18,570\end{array}$ & $\begin{array}{r}940 \\
24,629\end{array}$ & $\begin{array}{r}270 \\
5,804\end{array}$ \\
\hline $\begin{array}{l}\text { Conservation of Lands and } \\
\quad \text { Minerals }^{3}\end{array}$ & 9,704 & 13,467 & 14,748 & 18,213 & 36,082 & 41,677 & 13,487 \\
\hline $\begin{array}{l}\text { Direct program - } \\
\text { Reimbursable program }\end{array}$ & $\begin{array}{r}9,670 \\
34\end{array}$ & $\begin{array}{r}13,441 \\
26\end{array}$ & $\begin{array}{r}14,700 \\
48\end{array}$ & $\begin{array}{r}18,172 \\
41\end{array}$ & $\begin{array}{r}36,032 \\
50\end{array}$ & $\begin{array}{r}41,489 \\
188\end{array}$ & $\begin{array}{r}13,440 \\
47\end{array}$ \\
\hline $\begin{array}{l}\text { Miscellaneous non-Federal } \\
\text { sources - } \\
\text { Other Federal agencies }-\end{array}$ & $\begin{array}{r}2 \\
32\end{array}$ & $\begin{array}{r}1 \\
25\end{array}$ & $\begin{array}{r}3 \\
45\end{array}$ & 41 & $\begin{array}{r}4 \\
46\end{array}$ & $\begin{array}{r}1 \\
187\end{array}$ & $\begin{array}{r}1 \\
46\end{array}$ \\
\hline Land Information and Analysis " & 3,539 & 7,289 & 13,125 & 13,003 & 16,994 & 17,278 & $8,85^{\circ}$ \\
\hline $\begin{array}{l}\text { Direct program } \\
\text { Reimbursable program }\end{array}$ & $\begin{array}{l}2,373 \\
1,166\end{array}$ & $\begin{array}{r}6,714 \\
575\end{array}$ & $\begin{array}{r}11,876 \\
1,249\end{array}$ & $\begin{array}{r}11,458 \\
1,545\end{array}$ & $\begin{array}{r}15,461 \\
1,533\end{array}$ & $\begin{array}{r}14,908 \\
2,370\end{array}$ & $\begin{array}{l}7,80 € \\
1,053\end{array}$ \\
\hline $\begin{array}{l}\text { States, counties, and } \\
\text { municipalities } \\
\text { Miscellaneous non-Federal }\end{array}$ & --- & & $\cdots$ & ------ & 33 & 130 & 52 \\
\hline $\begin{array}{c}\text { sources } \\
\text { Other Federal agencies }\end{array}$ & 1,166 & 575 & 1,249 & $\begin{array}{l}593 \\
952\end{array}$ & $\begin{array}{r}1,093 \\
407\end{array}$ & $\begin{array}{r}1,496 \\
144\end{array}$ & $\begin{array}{l}496 \\
50\end{array}$ \\
\hline General Administration ${ }^{5}$ & 3,048 & 3,187 & 3,217 & 3,517 & 3,671 & 3,398 & 1,49 \\
\hline Direct program --- & 3,048 & 3,187 & 3,217 & 3,517 & 3,671 & 3,398 & 1,493 \\
\hline Facilities ${ }^{8}$ - & --- - - & 35 & 687 & 5,475 & 10,309 & 9,500 & 2,59 \\
\hline Direct program & ----- & 35 & 687 & 5,475 & 10,309 & 9,500 & 2,59 \\
\hline $\begin{array}{l}\text { Miscellaneous services to other } \\
\text { accounts }\end{array}$ & 3,026 & 2,027 & 2,575 & 2,760 & 2,853 & 1,576 & $15 t$ \\
\hline Reimbursable program & 3,026 & 2,027 & 2,575 & 2,760 & 2,853 & 1,576 & 150 \\
\hline $\begin{array}{l}\text { Miscellaneous non-Federal } \\
\text { sources - } \\
\text { Other Federal agencies }\end{array}$ & $\begin{array}{r}32 \\
2,994\end{array}$ & $\begin{array}{r}29 \\
1,998\end{array}$ & $\begin{array}{r}47 \\
2,528\end{array}$ & $\begin{array}{r}54 \\
2,706\end{array}$ & $\begin{array}{r}56 \\
2,797\end{array}$ & $\begin{array}{r}49 \\
1,527\end{array}$ & $\begin{array}{r}12 \\
14\end{array}$ \\
\hline \multicolumn{3}{|c|}{ 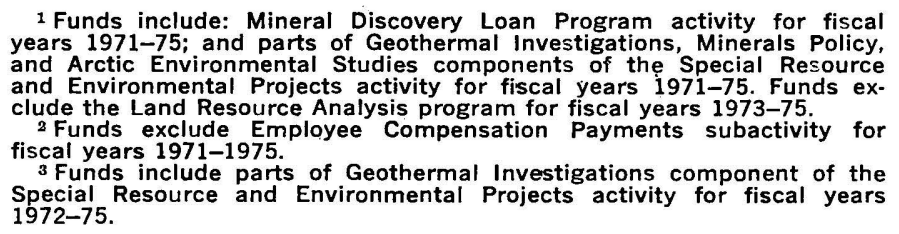 } & \multicolumn{5}{|c|}{ 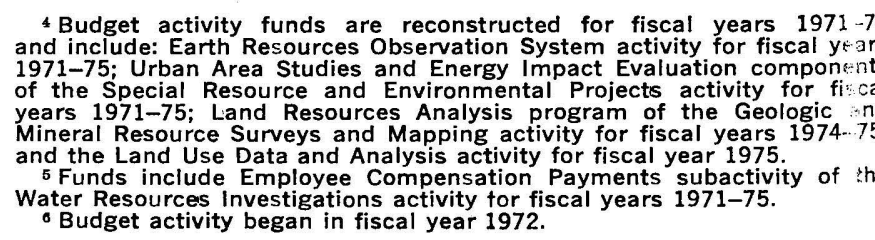 } \\
\hline
\end{tabular}


-TABLE 27.-Geological Survey Federal-State Cooperative program funds, by State, fiscal years 1971-76 and the transition quarter [In thousands of dollars]

\begin{tabular}{|c|c|c|c|c|c|c|c|}
\hline State & 1971 & 1972 & 1973 & 1974 & 1975 & 1976 & $\begin{array}{l}\text { Transition } \\
\text { quarter }\end{array}$ \\
\hline Total $^{1}$ & $\$ 49,274$ & $\$ 50,651$ & $\$ 55,633$ & $\$ 65,256$ & $\$ 70,151$ & $\$ 68,219$ & $\$ 2,584$ \\
\hline Total State share ${ }^{2}$ & 24,687 & 25,857 & 28,011 & 32,443 & 35,124 & 35,037 & 1,265 \\
\hline Alabama & 846 & 839 & 928 & 1,094 & 1,212 & 1,106 & 6 \\
\hline State share & 467 & 461 & 514 & 554 & 623 & 553 & 3 \\
\hline 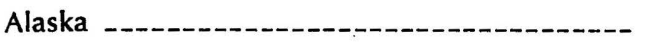 & 411 & 619 & 838 & 897 & 1,162 & 772 & $\ldots$ \\
\hline State share & 203 & 330 & 399 & 410 & 410 & 410 & ---- \\
\hline Arizona & 869 & 1,021 & 1,001 & 1,144 & 1,248 & 1,267 & $\ldots-\cdots$ \\
\hline State share & 444 & 540 & 510 & 576 & 646 & 682 & ----- \\
\hline Arkansas _. & 492 & 506 & 596 & 857 & 887 & 797 & 28 \\
\hline State share & 239 & 250 & 288 & 455 & 410 & 371 & 14 \\
\hline California _- & 4,014 & 3,893 & 4,115 & 4,789 & 4,690 & 4,778 & 102 \\
\hline State share & 1,951 & 1,936 & 2,053 & 2,280 & 2,337 & 2,446 & 69 \\
\hline Colorado & 944 & 995 & 1,128 & 1,484 & 2,445 & 2,089 & 158 \\
\hline State share & 477 & 507 & 575 & 837 & 1,324 & 1,150 & 79 \\
\hline Connecticut _-_---- & 619 & 617 & 687 & 814 & 1,069 & 850 & 115 \\
\hline - & 302 & 304 & 292 & 374 & 523 & 416 & 43 \\
\hline Delaware - & 112 & 111 & 121 & 130 & 194 & 214 & ------ \\
\hline State share & 73 & 75 & 81 & 74 & 106 & 119 & ----- \\
\hline District of Columbia & 12 & 2 & 3 & 3 & 3 & 3 & ------ \\
\hline State share & 6 & 1 & 1 & 1 & 1 & 2 & ---- \\
\hline Florida & 3,119 & 3,398 & 3,643 . & 5,083 & 5,575 & 5,653 & 76 \\
\hline State share & 1,539 & 1,719 & 1,858 & 2,552 & 2,781 & 2,851 & 38 \\
\hline Georgia _... & 751 & 799 & 2,008 & 3,239 & 3,083 & 2,482 & 244 \\
\hline State share & 400 & 437 & 1,041 & 1,611 & 1,531 & 1,241 & 122 \\
\hline Hawaii _- & 649 & 622 & 653 & 691 & 697 & 865 & ----- \\
\hline State share & 334 & 314 & 337 & 339 & 341 & 492 & ----- \\
\hline Idaho _- & 633 & 619 & 675 & 718 & 749 & 837 & ----- \\
\hline State share & 308 & 307 & 344 & 353 & 366 & 419 & $-\cdots-$ \\
\hline Illinois & 650 & 653 & 646 & 544 & 645 & 816 & 8 \\
\hline State share & 316 & 341 & 333 & 277 & 323 & 450 & 4 \\
\hline Indiana & 906 & 994 & 1,107 & 1,363 & 1,288 & 1,496 & 2 \\
\hline State share & 439 & 491 & 590 & 678 & 632 & 782 & 1 \\
\hline lowa & 442 & 517 & 525 & 608 & 617 & 807 & 64 \\
\hline State share & 214 & 255 & 259 & 299 & 302 & 405 & 32 \\
\hline Kansas _- & 1,324 & 1,362 & 1,358 & 1,402 & 1,424 & 1,511 & 104 \\
\hline State share & 645 & 675 & 676 & 686 & 716 & 757 & 52 \\
\hline Kentucky _-1- & 1,900 & 2,033 & 2,212 & 2,451 & 2,728 & 2,809 & 481 \\
\hline State share & 939 & 1,008 & 1,039 & 1,122 & 1,229 & 1,301 & 210 \\
\hline Louisiana & 1,167 & 1,212 & 1,240 & 1,900 & 1,740 & 1,660 & 22 \\
\hline State share & 621 & 655 & 674 & 980 & 902 & 862 & 11 \\
\hline
\end{tabular}

See footnotes at end of table. 
TABLE 27.-Geological Survey Federal-State Cooperative program funds by State, fiscal years 1971-76 and the transition quarter-Continued

\begin{tabular}{|c|c|c|c|c|c|c|c|}
\hline State & 1971 & 1972 & 1973 & 1974 & 1975 & 1976 & $\begin{array}{l}\text { Transition } \\
\text { quarter }\end{array}$ \\
\hline Maine & 158 & 163 & 168 & 175 & 248 & 334 & 20 \\
\hline State share & 84 & 89 & 91 & 96 & 127 & 196 & 10 \\
\hline Maryland _. & 580 & 620 & 695 & 851 & 1,011 & 1,005 & 2 \\
\hline State share & 295 & 321 & 356 & 435 & 530 & 522 & 1 \\
\hline Massachusetts & 1,126 & 1,159 & 1,379 & 1,346 & 1,618 & 1,615 & 122 \\
\hline State share & 595 & 614 & 625 & 656 & 810 & 779 & 66 \\
\hline Michigan _- & 865 & 859 & 947 & 930 & 1,054 & 1,068 & 45 \\
\hline State share & 407 & 417 & 425 & 436 & 505 & 525 & 19 \\
\hline Minnesota & 1,434 & 1,369 & 1,420 & 1,903 & 1,639 & 1,171 & $-\cdots$ \\
\hline State share & 707 & 681 & 727 & 966 & 817 & 624 & 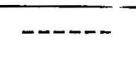 \\
\hline Mississippi & 551 & 592 & 593 & 645 & 743 & 634 & $-\cdots--$ \\
\hline State share & 316 & 357 & 340 & 325 & 415 & 317 & $-\cdots$ \\
\hline Missouri _. & 863 & 792 & 732 & 657 & 678 & 629 & 76 \\
\hline State share & 420 & 413 & 375 & 322 & $33 \overline{7}$ & 315 & 38 \\
\hline Montana - - & 393 & 401 & 402 & 505 & 587 & 549 & ------ \\
\hline State share & 212 & 221 & 223 & 255 & 287 & 283 & 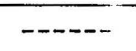 \\
\hline Nebraska & 502 & 553 & 588 & 705 & 731 & 769 & $-\cdots-$ \\
\hline State share & 246 & 274 & 298 & 344 & 358 & 396 & ---- \\
\hline Nevada _...- & 513 & 578 & 640 & 689 & 846 & 933 & 35 \\
\hline State share & 234 & 271 & 288 & 304 & 332 & 378 & 19 \\
\hline New Hampshire _... & 113 & 100 & 139 & 177 & 172 & 224 & 13 \\
\hline State share & 55 & 50 & 67 & 97 & 73 & 98 & $\Xi$ \\
\hline New Jersey - & 785 & 822 & 856 & 1,051 & 977 & 1,073 & ---- \\
\hline State share & 390 & 418 & 433 & 530 & 501 & 569 & ---- \\
\hline New Mexico _- & 888 & 963 & 1,107 & 1,332 & 1,439 & 1,500 & 2 \\
\hline State share & 462 & 509 & 601 & 662 & 714 & 779 & 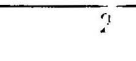 \\
\hline New York _. & 1,989 & 2,224 & 2,395 & 2,796 & 2,977 & 2,770 & 12 \\
\hline State share & 973 & 1,111 & 1,229 & 1,415 & 1,585 & 1,610 & $t$ \\
\hline North Carolina _. & 938 & 946 & 1,038 & 1,586 & 1,885 & 1,442 & 12 \\
\hline State share & 437 & 457 & 492 & 771 & 942 & 725 & 6 \\
\hline North Dakota _- & 661 & 714 & 899 & 763 & 998 & 980 & 11 \\
\hline State share & 325 & $3 \overline{61}$ & 461 & 369 & 489 & 490 & 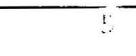 \\
\hline Ohio - & 979 & 990 & 1,028 & 978 & 1,093 & 1,237 & 3 \\
\hline State share & $5 \overline{21}$ & 518 & 520 & 481 & 563 & 672 & 15 \\
\hline Oklahoma - & 664 & 614 & 634 & 702 & 748 & 777 & 36 \\
\hline State share & 359 & 333 & 340 & 344 & 368 & 388 & 18 \\
\hline Oregon & 606 & 727 & 828 & 896 & 902 & 886 & 2 \\
\hline State share & 307 & 372 & 432 & 439 & 443 & 454 & $1 ?$ \\
\hline
\end{tabular}

See footnotes at end of table. 
TABLE 27.- Geological Survey Federal-State Cooperative program funds by State, fiscal years 1971-76 and the transition quarter-Continued

\begin{tabular}{|c|c|c|c|c|c|c|c|}
\hline State & 1971 & 1972 & 1973 & 1974 & 1975 & 1976 & $\begin{array}{c}\text { Transition } \\
\text { quarter }\end{array}$ \\
\hline Pennsylvania - & 2,178 & 2,167 & 2,047 & 2,357 & 2,415 & 2.489 & 32 \\
\hline State share & $1, \overline{088}$ & 1,092 & 1,042 & 1,195 & 1,209 & 1,282 & 16 \\
\hline Rhode Island - & 97 & 92 & 90 & 97 & 110 & 123 & --- \\
\hline State share & 52 & 50 & 50 & 52 & 54 & 61 & ---- \\
\hline South Carolina & 374 & 403 & 574 & 546 & 574 & 540 & - - - - \\
\hline State share & 196 & 212 & 301 & 279 & 284 & 270 & $\overline{-----}$ \\
\hline South Dakota & 409 & 424 & 423 & 471 & 515 & 518 & 28 \\
\hline State share & 226 & 236 & 230 & 227 & 251 & 259 & 14 \\
\hline Tennessee - & 546 & 538 & 589 & 851 & 952 & 1,017 & $---\cdot-$ \\
\hline State share & 292 & 294 & 321 & 422 & 470 & 509 & $-\cdots$ \\
\hline Texas - & 3,835 & 3,717 & 3,794 & 4,046 & 4,261 & 4,315 & 170 \\
\hline State share & 1,922 & 1,925 & 1,949 & 2,027 & 2,100 & 2,177 & 85 \\
\hline Utah - & 868 & 967 & 1,069 & 1,068 & 1,361 & 1,299 & 47 \\
\hline State share & 421 & 486 & 530 & 534 & 838 & 746 & 25 \\
\hline Vermont & 124 & 125 & 129 & 144 & 130 & 139 & ----- \\
\hline State share & 62 & 64 & 66 & 73 & 64 & 69 & $-\ldots$ \\
\hline Virginia - & 1,119 & 797 & 793 & 905 & 858 & 726 & 14 \\
\hline State share & 577 & 420 & 421 & 466 & 442 & 378 & 7 \\
\hline Washington - & 1,774 & 1,800 & 1,988 & 2,121 & 2,208 & 2,028 & 17 \\
\hline State share & 856 & 881 & 962 & 1,037 & 1,104 & 1,020 & 9 \\
\hline West Virginia -- & 457 & 482 & 620 & 946 & 775 & 705 & 43 \\
\hline State share & 249 & 263 & 332 & 521 & 448 & 418 & 30 \\
\hline Wisconsin - & 1,229 & 1,285 & 1,354 & 1,563 & 1,706 & 1,864 & 222 \\
\hline State share & 584 & 619 & 638 & 775 & 883 & 1,007 & 108 \\
\hline Wyoming -- & 626 & 589 & 612 & 698 & 853 & 752 & 4 \\
\hline State share - & 315 & 316 & 310 & 328 & 514 & 402 & 2 \\
\hline American Samoa - & 65 & 72 & 64 & 63 & 70 & 40 & $-\cdots$ \\
\hline State share - & 32 & 36 & 32 & 31 & 32 & 20 & $-\cdots$ \\
\hline Guam & 25 & 36 & 43 & 62 & 65 & 66 & $-\cdots-$ \\
\hline State share & 12 & 18 & 21 & 31 & 32 & 33 & $-\cdots$ \\
\hline Puerto Rico - & 964 & 1,042 & 1,347 & 1,303 & 1,293 & 1,002 & 38 \\
\hline State share -- & 484 & 494 & 557 & 682 & 585 & 463 & 11 \\
\hline Trust Territories & 93 & 105 & 125 & 117 & 170 & 170 & $-\cdots--$ \\
\hline State share & 45 & 52 & 62 & 58 & 84 & 85 & $-\cdots--$ \\
\hline Virgin Islands & 23 & 12 & $\left({ }^{3}\right)$ & $\left({ }^{3}\right)$ & 33 & 18 & ----- \\
\hline State share & 12 & 6 & $\left({ }^{8}\right)$ & $\left(3^{3}\right)$ & 31 & 9 & ---- \\
\hline
\end{tabular}

1 Includes Federal funds from direct program.

2 Includes reimbursable program funds from States, counties, and

municipalities.
$\mathbf{3}$ Included with Puerto Rico funds. 
TABLE 28.-Geological Survey reimbursable program funds from other Federal agencies, by agency, fiscal years 1971-76 and transition quarter

[ In thousands of dollars]

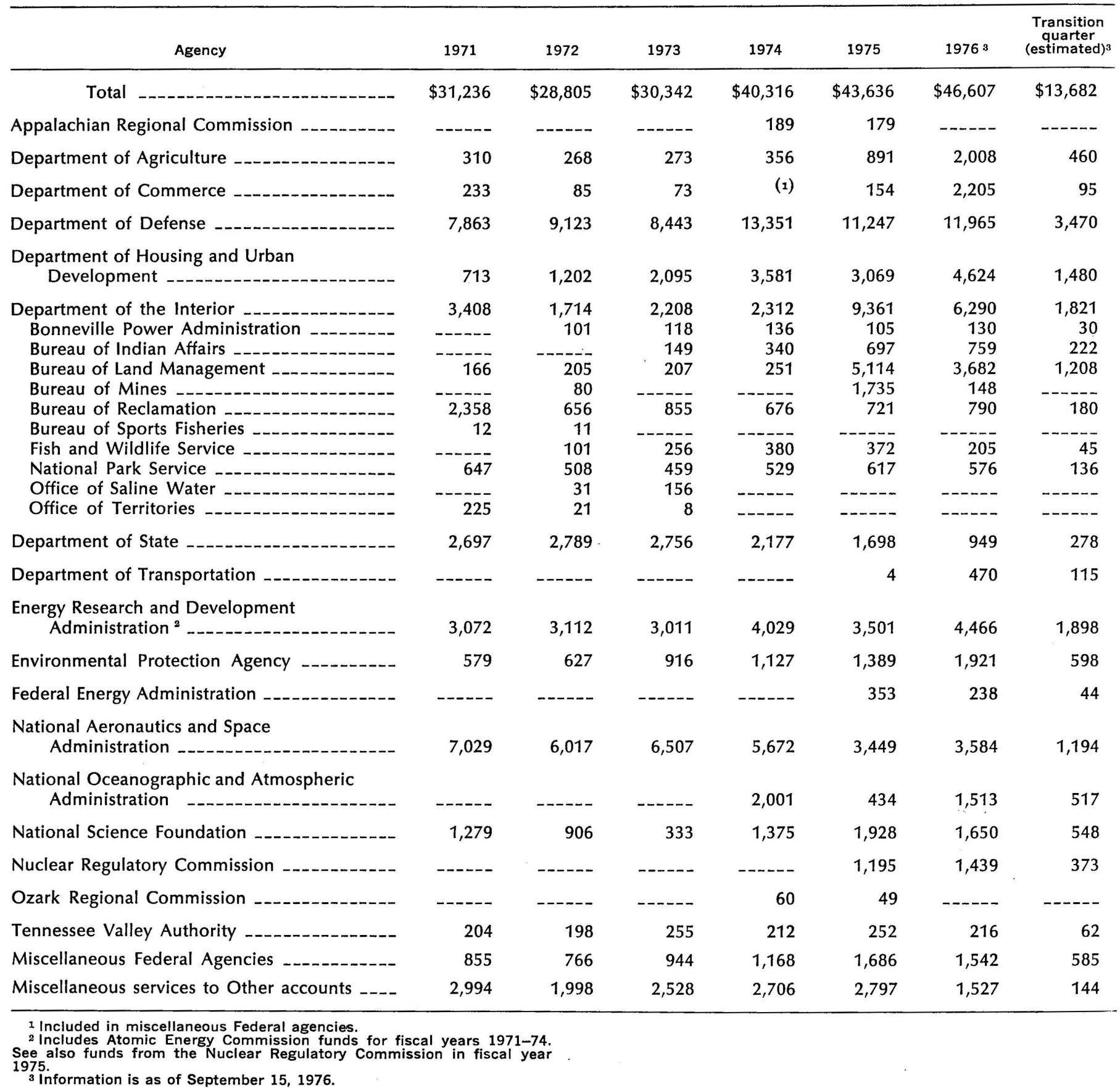

TABLE 29.-Alaska Pipeline Related Investigations, reimbursable program funds from other Federal agencies, by agency, fiscal years 1971-76 and transition quarter

[In thousands of dollars]

\begin{tabular}{crrrrr}
\hline Agency & 1971 & 1972 & 1973 & 1974 & 1975 \\
\hline Total & $\$ 65$ & $\$ 62$ & & \\
\hline
\end{tabular}


TABLE 30.-Topographic Surveys and Mapping direct program funds, by subactivity, fiscal years 1971-76 and transition quarter [In thousands of dollars]

\begin{tabular}{|c|c|c|c|c|c|c|c|}
\hline Subactivity & 1971 & 1972 & 1973 & 1974 & 1975 & 1976 & $\begin{array}{l}\text { Transition } \\
\text { quarter }^{3}\end{array}$ \\
\hline Total direct program & $\$ 31,153$ & $\$ 34,545$ & $\$ 35,172$ & $\$ 37,161$ & $\$ 45,350$ & $\$ 45,354$ & 11,553 \\
\hline Quadrangle Mapping and Revision ${ }^{1}$ & 29,090 & 32,710 & 33,433 & 35,046 & 41,148 & 38,266 & 9,401 \\
\hline Small Scale and Special Mapping _....... & 2,063 & 1,835 & 1,739 & 2,115 & 2,661 & 5,358 & 1,730 \\
\hline National Cartographic Information Center ${ }^{2}$ & $(150)$ & $(300)$ & $(675)$ & $(1,043)$ & 1,541 & 1,730 & 422 \\
\hline
\end{tabular}

1 Funds are reconstructed for fiscal years 1971-72 and include the 2 National Cartographic Information Center funds included in the Map Revision and Maintenance subactivity.

Quadrangle Mapping and Revision subactivity prior to fiscal year 1975 . 3 Actual obligations.

TABLE 31.-Topographic Surveys and Mapping Federal-State Cooperative program funds, by State, fiscal years 1971-76 and transition quarter

[In thousands of dollars]

\begin{tabular}{|c|c|c|c|c|c|c|c|}
\hline State & 1971 & 1972 & 1973 & 1974 & 1975 & 1976 & $\begin{array}{c}\text { Transition } \\
\text { quarter }\end{array}$ \\
\hline $\begin{array}{l}\text { Total }^{1} \\
\text { Total State }^{2}\end{array}$ & $\begin{array}{r}\$ 7,802 \\
3,901\end{array}$ & $\begin{array}{r}\$ 6,408 \\
3,204\end{array}$ & $\begin{array}{r}\$ 7,438 \\
3,719\end{array}$ & $\begin{array}{r}\$ 9,884 \\
4,942\end{array}$ & $\begin{array}{r}\$ 9,990 \\
4,995\end{array}$ & $\begin{array}{r}\$ 7,350 \\
3,675\end{array}$ & $\begin{array}{r}\$ 1,764 \\
882\end{array}$ \\
\hline $\begin{array}{l}\text { Alabama } \\
\text { State share }\end{array}$ & $\begin{array}{l}50 \\
25\end{array}$ & $\begin{array}{l}50 \\
25\end{array}$ & $\begin{array}{l}50 \\
25\end{array}$ & $\begin{array}{l}40 \\
20\end{array}$ & $\begin{array}{l}62 \\
31\end{array}$ & $\begin{array}{l}48 \\
24\end{array}$ & ---- \\
\hline $\begin{array}{l}\text { Arkansas } \\
\text { State share - }\end{array}$ & $\begin{array}{l}50 \\
25\end{array}$ & $\begin{array}{l}46 \\
23\end{array}$ & $\begin{array}{l}54 \\
27\end{array}$ & $\begin{array}{l}58 \\
29\end{array}$ & $\begin{array}{l}72 \\
36\end{array}$ & $\begin{array}{l}74 \\
37\end{array}$ & $\begin{array}{l}28 \\
14\end{array}$ \\
\hline $\begin{array}{l}\text { California } \\
\text { State share }-\end{array}$ & $\begin{array}{l}432 \\
216\end{array}$ & $\begin{array}{r}186 \\
93\end{array}$ & $\begin{array}{r}186 \\
93\end{array}$ & $\begin{array}{r}198 \\
99\end{array}$ & $\begin{array}{l}252 \\
126\end{array}$ & $\begin{array}{l}206 \\
103\end{array}$ & $\begin{array}{l}66 \\
33\end{array}$ \\
\hline $\begin{array}{l}\text { Colorado } \\
\text { State share }\end{array}$ & ----- & ---- & ---- & $\begin{array}{l}4 \\
2\end{array}$ & $\begin{array}{l}830 \\
415\end{array}$ & $\begin{array}{l}420 \\
210\end{array}$ & $\begin{array}{r}158 \\
79\end{array}$ \\
\hline $\begin{array}{l}\text { Connecticut } \\
\text { State share }\end{array}$ & $\begin{array}{l}40 \\
20\end{array}$ & $\begin{array}{l}40 \\
20\end{array}$ & $\begin{array}{l}40 \\
20\end{array}$ & $\begin{array}{r}120 \\
60\end{array}$ & $\begin{array}{r}124 \\
62\end{array}$ & $\begin{array}{r}110 \\
55\end{array}$ & $\begin{array}{l}56 \\
28\end{array}$ \\
\hline $\begin{array}{l}\text { Florida } \\
\quad \text { State share }-\end{array}$ & $\begin{array}{l}580 \\
290\end{array}$ & $\begin{array}{l}580 \\
290\end{array}$ & $\begin{array}{l}512 \\
286\end{array}$ & $\begin{array}{l}578 \\
289\end{array}$ & $\begin{array}{l}454 \\
227\end{array}$ & $\begin{array}{l}450 \\
225\end{array}$ & $\begin{array}{l}76 \\
38\end{array}$ \\
\hline $\begin{array}{l}\text { Georgia } \\
\text { State share }\end{array}$ & $\begin{array}{l}40 \\
20\end{array}$ & $\begin{array}{l}56 \\
28\end{array}$ & $\begin{array}{r}1,218 \\
609\end{array}$ & $\begin{array}{l}2,294 \\
1,147\end{array}$ & $\begin{array}{r}1,992 \\
996\end{array}$ & $\begin{array}{r}1,340 \\
670\end{array}$ & $\begin{array}{l}244 \\
122\end{array}$ \\
\hline $\begin{array}{l}\text { Illinois } \\
\text { State share }\end{array}$ & $\begin{array}{r}168 \\
84\end{array}$ & $\begin{array}{r}150 \\
75\end{array}$ & $\begin{array}{r}120 \\
60\end{array}$ & $\begin{array}{l}30 \\
15\end{array}$ & $\begin{array}{l}70 \\
35\end{array}$ & $\begin{array}{l}70 \\
35\end{array}$ & $\begin{array}{l}8 \\
4\end{array}$ \\
\hline $\begin{array}{l}\text { Louisiana } \\
\text { State share --- }\end{array}$ & $\begin{array}{r}136 \\
68\end{array}$ & $\begin{array}{r}136 \\
68\end{array}$ & $\begin{array}{r}134 \\
67\end{array}$ & $\begin{array}{r}136 \\
68\end{array}$ & $\begin{array}{r}136 \\
68\end{array}$ & $\begin{array}{r}108 \\
54\end{array}$ & $\begin{array}{l}2 \\
1\end{array}$ \\
\hline lowa State share & $\begin{array}{l}44 \\
22\end{array}$ & ----- & $-\cdots$ & ----- & --- n & $\begin{array}{r}176 \\
88\end{array}$ & $\begin{array}{l}64 \\
32\end{array}$ \\
\hline $\begin{array}{l}\text { Kansas } \\
\text { State share }-1\end{array}$ & $\begin{array}{l}266 \\
133\end{array}$ & $\begin{array}{l}266 \\
133\end{array}$ & $\begin{array}{l}248 \\
124\end{array}$ & $\begin{array}{l}286 \\
143\end{array}$ & $\begin{array}{l}268 \\
134\end{array}$ & $\begin{array}{l}266 \\
133\end{array}$ & $\begin{array}{r}104 \\
52\end{array}$ \\
\hline $\begin{array}{l}\text { Kentucky } \\
\text { State share }\end{array}$ & $\begin{array}{l}200 \\
100\end{array}$ & $\begin{array}{l}210 \\
105\end{array}$ & $\begin{array}{r}182 \\
91\end{array}$ & $\begin{array}{l}278 \\
139\end{array}$ & $\begin{array}{l}254 \\
127\end{array}$ & $\begin{array}{l}204 \\
102\end{array}$ & $\begin{array}{l}60 \\
30\end{array}$ \\
\hline $\begin{array}{l}\text { Louisiana } \\
\quad \text { State share }\end{array}$ & $\begin{array}{l}60 \\
30\end{array}$ & $\begin{array}{l}60 \\
30\end{array}$ & $\begin{array}{l}50 \\
25\end{array}$ & $\begin{array}{r}152 \\
76\end{array}$ & $\begin{array}{r}120 \\
60\end{array}$ & $\begin{array}{l}90 \\
45\end{array}$ & $\begin{array}{l}22 \\
11\end{array}$ \\
\hline $\begin{array}{l}\text { Maine } \\
\text { State share }\end{array}$ & $\begin{array}{l}40 \\
20\end{array}$ & $\begin{array}{l}40 \\
20\end{array}$ & $\begin{array}{l}40 \\
20\end{array}$ & $\begin{array}{l}40 \\
20\end{array}$ & $\begin{array}{l}40 \\
20\end{array}$ & $\begin{array}{l}40 \\
20\end{array}$ & $\begin{array}{l}20 \\
10\end{array}$ \\
\hline $\begin{array}{l}\text { Maryland } \\
\text { State share }\end{array}$ & ---- & $\begin{array}{l}20 \\
10\end{array}$ & $\begin{array}{l}22 \\
11\end{array}$ & $\begin{array}{l}20 \\
10\end{array}$ & $\begin{array}{l}20 \\
10\end{array}$ & $\begin{array}{l}30 \\
15\end{array}$ & $\begin{array}{l}2 \\
1\end{array}$ \\
\hline $\begin{array}{l}\text { Massachusetts } \\
\text { State share }\end{array}$ & $\begin{array}{l}200 \\
100\end{array}$ & $\begin{array}{l}200 \\
100\end{array}$ & $\begin{array}{r}196 \\
98\end{array}$ & $\begin{array}{r}190 \\
95\end{array}$ & $\begin{array}{l}250 \\
125\end{array}$ & $\begin{array}{l}250 \\
125\end{array}$ & $\begin{array}{l}6 \\
3\end{array}$ \\
\hline $\begin{array}{l}\text { Michigan } \\
\text { State share }\end{array}$ & $\begin{array}{r}100 \\
50\end{array}$ & $\begin{array}{r}100 \\
50\end{array}$ & $\begin{array}{r}100 \\
50\end{array}$ & $\begin{array}{r}100 \\
50\end{array}$ & $\begin{array}{r}100 \\
50\end{array}$ & $\begin{array}{r}100 \\
. \quad 50\end{array}$ & - n-- \\
\hline
\end{tabular}


TABLE 31.-Topographic Surveys and Mapping Federal-State Cooperative program funds, by State, fiscal years 1971-76 and transition quarter-Continued

\begin{tabular}{|c|c|c|c|c|c|c|c|}
\hline State & 1971 & 1972 & 1973 & 1974 & 1975 & 1976 & $\begin{array}{l}\text { Transition } \\
\text { quarter }\end{array}$ \\
\hline Minnesota & 884 & 734 & 708 & 1,092 & 840 & 246 & ----- \\
\hline State share & 442 & 367 & 354 & 546 & 420 & 123 & ----- \\
\hline Missouri & 226 & 184 & 130 & 134 & 134 & 110 & 44 \\
\hline State share & 113 & 92 & 65 & 67 & 67 & 55 & 22 \\
\hline - & 36 & 40 & 40 & 58 & 54 & 58 & 32 \\
\hline State share & 18 & 20 & 20 & 29 & 27 & 29 & 16 \\
\hline $\begin{array}{l}\text { New Mexico } \\
\text { State share }\end{array}$ & ------ & ------ & ----- & ------ & 16 & 16 & ------ \\
\hline State share -- & ------ & ----- & $--\cdots--$ & $-\cdots--$ & 8 & 8 & ------ \\
\hline New York - & 272 & 380 & 234 & 366 & 226 & ----_- & 12 \\
\hline State share - & 136 & 190 & 117 & 183 & 113 & ------ & 6 \\
\hline North Carolina _- & 220 & 220 & 172 & 670 & 890 & 502 & 124 \\
\hline State share --1-- & 110 & 110 & 86 & 335 & 445 & 251 & 62 \\
\hline North Dakota & 100 & 112 & 242 & 88 & 222 & 198 & 10 \\
\hline State share & 50 & 56 & 121 & 44 & 111 & 99 & 5 \\
\hline Ohio -1- & 150 & 150 & 150 & 150 & 150 & 150 & 38 \\
\hline State share - & 75 & 75 & 75 & 75 & 75 & 75 & 19 \\
\hline Oklahoma & 165 & 126 & 112 & 110 & 110 & 110 & 36 \\
\hline State share - - & 83 & 63 & 56 & 55 & 55 & 55 & 18 \\
\hline 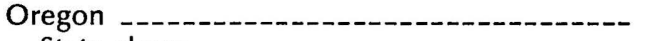 & 60 & 60 & 78 & 44 & 92 & 32 & 24 \\
\hline State share & 30 & 30 & 39 & 22 & 46 & 16 & 12 \\
\hline Pennsylvania & 700 & 550 & 326 & 392 & 312 & 224 & 32 \\
\hline State share ---- & 350 & 275 & 163 & 196 & 156 & 112 & 16 \\
\hline South Carolina & ----- & --.--- & 120 & ----- & 36 & ----- & ----- \\
\hline State share - - & $-\cdots--$ & ----- & 60 & $-\cdots--$ & 18 & $-\cdots-$ & $-\cdots$ \\
\hline South Dakota & 38 & 50 & 50 & 50 & 50 & 50 & 28 \\
\hline State share - & 19 & 25 & 25 & 25 & 25 & 25 & 14 \\
\hline - & 42 & 12 & 38 & 50 & 44 & 16 & ------ \\
\hline State share - & 21 & 6 & 19 & 25 & 22 & 8 & ---- \\
\hline Texas & 1,162 & 694 & 742 & 726 & 686 & 682 & 170 \\
\hline State share - & 581 & 347 & 371 & 363 & 343 & 341 & 85 \\
\hline 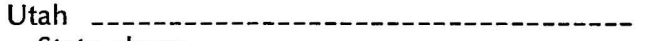 & 104 & 72 & 114 & 120 & 100 & 100 & 40 \\
\hline State share & 52 & 36 & 57 & 60 & 50 & 50 & 20 \\
\hline Vermont & 20 & 20 & 20 & 40 & 34 & 20 & ----- \\
\hline State share --_- & 10 & 10 & 10 & 20 & 17 & 10 & $-\cdots$ \\
\hline Virginia & 510 & 166 & 132 & 232 & 218 & 188 & 14 \\
\hline State share & 255 & 83 & 66 & 116 & 109 & 94 & 7 \\
\hline Washington - & 50 & 32 & 32 & 34 & 6 & 28 & 6 \\
\hline State share & 25 & 16 & 16 & 17 & 3 & 14 & 3 \\
\hline West Virginia & 198 & 206 & 298 & 506 & 228 & 142 & 26 \\
\hline State share & 99 & 103 & 149 & 253 & 114 & 71 & 13 \\
\hline Wisconsin & 398 & 400 & 402 & 412 & 414 & 410 & 208 \\
\hline State share -- & 199 & 200 & 201 & 206 & 207 & 205 & 104 \\
\hline Wyoming -- & 10 & 10 & 10 & 10 & 10 & 10 & 4 \\
\hline State share & 5 & 5 & 5 & 5 & 5 & 5 & 2 \\
\hline Puerto Rico - & 50 & 50 & 76 & 76 & 74 & 76 & ----- \\
\hline State share & 25 & 25 & 38 & 38 & 37 & 38 & ----- \\
\hline
\end{tabular}


TABLE 32.-Topographic Surveys and Mapping reimbursable program funds from other Federal agencies, by agency, fiscal years years 1971-76 and transition quarter

[ In thousands of dollars]

\begin{tabular}{|c|c|c|c|c|c|c|c|}
\hline Agency & 1971 & 1972 & 1973 & 1974 & 1975 & 19761 & $\begin{array}{c}\text { Transition } \\
\text { quarter } \\
\text { (estimated) }\end{array}$ \\
\hline Total & $\$ 2,017$ & $\$ 631$ & $\$ 780$ & $\$ 918$ & $\$ 1,658$ & $\$ 2,691$ & $\$ 740$ \\
\hline Department of Agriculture & $-\ldots--$ & $-\ldots--$ & ------ & 95 & $\overline{326}$ & 1,256 & 320 \\
\hline Department of Commerce & 181 & -..-.-- & -.--.-- & ..- & & 187 & 5 \\
\hline Department of Defense & --.--- & ------ & 35 & 92 & 183 & 151 & 50 \\
\hline Department of the Interior & 1,125 & 21 & 68 & 238 & 441 & 284 & 150 \\
\hline Bureau of Indian Affairs & ----- & ---- & 60 & 165 & 198 & 209 & 50 \\
\hline Bureau of Land Management & -..--.- & -..-- & ...-.- & 73 & 243 & 74 & 100 \\
\hline Bureau of Reclamation & 900 & ------ & ---.-- & ------ & ------ & 1 & ---- \\
\hline Office of Territories & 225 & 21 & 8 & -..--- & -.-.-- & & \\
\hline Department of Transportation & --.- & & & ------ & 4 & 257 & 50 \\
\hline National Aeronautics and Space Administration & 326 & 138 & 207 & 235 & 97 & 132 & \\
\hline National Science Foundation & 202 & 256 & 198 & 46 & 257 & 112 & 20 \\
\hline Miscellaneous Federal Agencies & 183 & 216 & 272 & 212 & 350 & 312 & 145 \\
\hline
\end{tabular}

1 Information is as of September $15,1976$.

TABLE 33.-Geologic and Mineral Resource Surveys and Mapping direct program funds, by subactivity, fiscal years 1971-76 [In thousands of dollars]

\begin{tabular}{|c|c|c|c|c|c|c|}
\hline Subactivity & 1971 & 1972 & 1973 & 1974 & 1975 & 1976 \\
\hline Total direct program & $\$ 31,919$ & $\$ 34,244$ & $\$ 42,895$ & $\$ 49,877$ & $\$ 89,018$ & $\$ 92,322$ \\
\hline Land Resource Surveys ${ }^{1}$ & 14,519 & 15,154 & 19,246 & 23,077 & 33,385 & 34,077 \\
\hline Mineral Resource Surveys ${ }^{2}$ & 13,424 & 13,524 & 14,026 & 14,971 & 18,017 & 19,775 \\
\hline Energy Resource Surveys _. & 2,639 & 3,144 & 5,197 & 6,696 & 22,376 & 23,000 \\
\hline Offshore Geologic Surveys _. & 1,337 & 2,422 & 4,426 & 5,133 & 15,240 & 15,470 \\
\hline
\end{tabular}

1 Funds adjusted for fiscal years 1971-73 to include geologic mapping

in support of Mineral Resource Surveys.

73 to exclude geologic mapping

years 1971-73.

TABLE 34.-Geologic and Mineral Resource Surveys and Mapping Federal-State Cooperative funds, by State, fiscal years 1971-76 and transition quarter

[In thousands of dollars]

\begin{tabular}{|c|c|c|c|c|c|c|c|}
\hline State & 1971 & 1972 & 1973 & 1974 & 1975 & 1976 & $\begin{array}{c}\text { Transition } \\
\text { quarter }\end{array}$ \\
\hline $\begin{array}{l}\text { Total } \\
\quad{ }^{1} \\
\text { State }\end{array}$ & $\begin{array}{r}\$ 2,825 \\
1,322 \\
\end{array}$ & $\begin{array}{r}\$ 2,941 \\
1,359 \\
\end{array}$ & $\begin{array}{r}\$ 4,270 \\
1,556 \\
\end{array}$ & $\begin{array}{r}\$ 4,254 \\
1,681 \\
\end{array}$ & $\begin{array}{r}\$ 4,541 \\
1,550 \\
\end{array}$ & $\begin{array}{r}\$ 3,910 \\
1,479 \\
\end{array}$ & $\begin{array}{r}\$ 782 \\
364 \\
\end{array}$ \\
\hline $\begin{array}{l}\text { Alabama } \\
\text { State share }\end{array}$ & ----- & ---- & $\begin{array}{l}10 \\
10\end{array}$ & $\begin{array}{r}10 \\
5\end{array}$ & $\begin{array}{r}15 \\
5\end{array}$ & ---- & - n \\
\hline $\begin{array}{l}\text { Alaska } \\
\text { State share }-\end{array}$ & ----- & $\begin{array}{r}160 \\
80\end{array}$ & $\begin{array}{l}332 \\
135\end{array}$ & $\begin{array}{r}238 \\
93\end{array}$ & $\begin{array}{r}476 \\
75\end{array}$ & ----- & --- n \\
\hline $\begin{array}{l}\text { Arkansas } \\
\quad \text { State share }\end{array}$ & $\begin{array}{l}50 \\
25\end{array}$ & $\begin{array}{l}51 \\
25\end{array}$ & $\begin{array}{l}85 \\
36\end{array}$ & $\begin{array}{r}125 \\
27\end{array}$ & $\begin{array}{r}165 \\
27\end{array}$ & $\begin{array}{r}110 \\
27\end{array}$ & ---- \\
\hline $\begin{array}{l}\text { California } \\
\text { State share }\end{array}$ & $\begin{array}{r}127 \\
63\end{array}$ & $\begin{array}{l}71 \\
33\end{array}$ & $\begin{array}{l}79 \\
22\end{array}$ & $\begin{array}{r}362 \\
80\end{array}$ & $\begin{array}{l}57 \\
21\end{array}$ & $\begin{array}{l}99 \\
66\end{array}$ & $\begin{array}{l}36 \\
36\end{array}$ \\
\hline $\begin{array}{l}\text { Colorado } \\
\text { State share }\end{array}$ & $\begin{array}{l}74 \\
41\end{array}$ & $\begin{array}{l}42 \\
20\end{array}$ & $\begin{array}{l}50 \\
30\end{array}$ & ---- & ---- & ----- & ----- \\
\hline $\begin{array}{l}\text { Connecticut } \\
\text { State share }-\end{array}$ & $\begin{array}{r}150 \\
75\end{array}$ & $\begin{array}{r}141 \\
69\end{array}$ & $\begin{array}{r}235 \\
69\end{array}$ & $\begin{array}{r}208 \\
75\end{array}$ & $\begin{array}{r}258 \\
75\end{array}$ & $\begin{array}{r}200 \\
75\end{array}$ & $\begin{array}{l}59 \\
15\end{array}$ \\
\hline $\begin{array}{l}\text { Georgia } \\
\text { State share }\end{array}$ & ---- & $\begin{array}{l}2 \\
1\end{array}$ & ---1 & $\begin{array}{l}6 \\
3\end{array}$ & $\begin{array}{r}10 \\
5\end{array}$ & ----- & ----- \\
\hline
\end{tabular}


TABLE 34.-Geologic and Mineral Resource Surveys and Mapping Federal-State Cooperative funds, by State, fiscal years 1971-76 and transition quarter-Continued

\begin{tabular}{|c|c|c|c|c|c|c|c|}
\hline State & 1971 & 1972 & 1973 & 1974 & 1975 & 1976 & $\begin{array}{c}\text { Transition } \\
\text { quarter }\end{array}$ \\
\hline Hawaii _......... & --.--- & ----- & ------ & -..--- & $-\ldots-\ldots$ & ------ & -.-.-- \\
\hline State share & ----- & ----- & ------ & ----- & ----- & ------ & ----- \\
\hline Idaho & ------ & -..---- & ---.-- & ------ & ------ & --- & -..--- \\
\hline State share & ----- & $-\ldots-$ & ----- & ----- & $-\cdots-$ & $\ldots \ldots-$ & $-\cdots-$ \\
\hline lowa & -..--- & ------ & --.--- & 16 & ...... & .....- & --.-.- \\
\hline State share & ----- & ----- & ----- & 8 & $-\cdots-$ & ------ & $-\cdots--$ \\
\hline Kansas -.---.-- & ------ & -.---- & ------ & ----.-- & ------ & -....- & ----- \\
\hline State share --_- & ----- & $--\cdots--$ & ----- & ----- & ----- &.---- & $---\infty-$ \\
\hline Kentucky --- & 1,100 & 1,158 & 1,332 & 1,454 & 1,599 & 1,643 & 421 \\
\hline State share & 550 & 575 & 600 & 630 & 675 & 718 & 180 \\
\hline Maryland ......... & 45 & 20 & 27 & 14 & 19 & ------ & -----. \\
\hline State share & 23 & 10 & 10 & 7 & 9 & ------ & ------ \\
\hline Massachusetts _-_- & 410 & 417 & 633 & 563 & 581 & 630 & 116 \\
\hline State share & 205 & 205 & 205 & 228 & 205 & 205 & 63 \\
\hline Michigan _........ & 166 & 153 & 216 & 178 & 158 & 148 & 45 \\
\hline State share & 68 & 65 & 65 & 65 & 65 & 65 & 19 \\
\hline Minnesota & ------ & $-\ldots-\ldots-$ & ------ &.----- & ----- & ----- &.---- \\
\hline State share & $--\ldots-$ &.----- & ------ & -.--.- & ------ & -....- & $-\ldots-$. \\
\hline Nevada _...-..-- & 173 & 192 & 249 & 254 & 384 & 396 & 3 \\
\hline State share & 70 & 80 & 90 & 90 & 105 & 110 & 3 \\
\hline 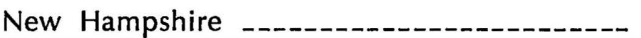 & 24 & 25 & 31 & 59 & 50 & 53 & 13 \\
\hline State share & 12 & 13 & 13 & 39 & 13 & 13 & 3 \\
\hline New Mexico _-_--- & -....- & -..... & 20 & 40 & 11 & 18 & 2 \\
\hline State share - & -..-- & ----- & 10 & 20 & -..-- & 18 & 2 \\
\hline New York & --.--- & -.-..-- & ------ & 20 & 21 & ------ & --.--- \\
\hline State share & $--\cdots-$ & ----- & ----- & 10 & 10 & ----- & ----- \\
\hline North Carolina & 51 & 35 & 99 & 40 & 18 & ------ & ------ \\
\hline State share & 6 & 6 & 12 & 6 & 18 & ----- & ----- \\
\hline Pennsylvania & 19 & 15 & 30 & 10 & ------ & -.---- & -.-.-- \\
\hline State share & 8 & 8 & 15 & 5 & ----- & ----- & ----- \\
\hline South Carolina & -..---- & -..--- & ------ & -.---- & 5 & -.....- & -...-- \\
\hline State share & ------ & ----- & ------ & ----- & 5 & $-\cdots-$ & ---- \\
\hline Texas & -..--- & -.-.-- & 3 & -.---- & ------ & -...-- & $-\cdots-\cdots$ \\
\hline State share & -..--- &.----- & 3 & ------ & ------ & -..--- & ----- \\
\hline Utah & -..--- & 11 & 18 & 7 & 6 & 37 & 7 \\
\hline State share & $-\cdots--$ & 3 & 7 & 7 & 4 & 4 & 5 \\
\hline Washington - & 53 & 58 & 122 & 67 & 134 & 81 & 11 \\
\hline State share & 25 & 20 & 30 & 20 & 30 & 35 & 6 \\
\hline West Virginia & ......- & ...-.-- & 20 & 20 & 21 & 3 & 17 \\
\hline State share & $---\cdots-$ & ----- & 10 & 10 & 10 & 3 & 17 \\
\hline Wisconsin & 50 & 55 & 82 & 76 & 68 & 121 & 14 \\
\hline State share - & 8 & 8 & 8 & 8 & 8 & 8 & 4 \\
\hline Wyoming - & 48 & 15 & 27 & 26 & 11 & 35 & ......- \\
\hline State share & 4 & 2 & 2 & 2 & 2 & 2 &.----- \\
\hline
\end{tabular}


TABLE 34.-Geologic and Mineral Resource Surveys and Mapping Federal-State Cooperative funds, by State, fiscal years 1971-76 and transition quarter-Continued

\begin{tabular}{|c|c|c|c|c|c|c|c|}
\hline State & 1971 & 1972 & 1973 & 1974 & 1975 & 1976 & $\begin{array}{c}\text { Transition } \\
\text { quarter }\end{array}$ \\
\hline $\begin{array}{l}\text { Puerto Rico } \\
\text { State share }\end{array}$ & $\begin{array}{l}270 \\
131\end{array}$ & $\begin{array}{l}320 \\
136\end{array}$ & $\begin{array}{l}570 \\
174\end{array}$ & $\begin{array}{l}461 \\
243\end{array}$ & $\begin{array}{l}474 \\
183\end{array}$ & $\begin{array}{l}336 \\
130\end{array}$ & $\begin{array}{l}38 \\
11\end{array}$ \\
\hline $\begin{array}{l}\text { Virgin Islands } \\
\text { State share }\end{array}$ & $\begin{array}{r}15 \\
8\end{array}$ & - - & - & - - & - & - & 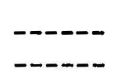 \\
\hline
\end{tabular}

1 Includes Federal funds from direct program.

2 Includes reimbursable program funds from States, counties, and municipalities.

TABLE 35.-Geologic and Mineral Resource Surveys and Mapping reimbursable program funds from other Federal agencies, by agency, fiscal years $1971-76$ and transition quarter

[ In thousands of dollars]

\begin{tabular}{|c|c|c|c|c|c|c|c|}
\hline Agency & 1971 & 1972 & 1973 & 1974 & 1975 & $1976^{2}$ & $\begin{array}{c}\text { Transition } \\
\text { quarter } \\
\text { (estimated)2 }\end{array}$ \\
\hline Total & $\$ 13,494$ & $\$ 13,609$ & $\$ 11,222$ & $\$ 19,321$ & $\$ 20,158$ & $\$ 16,828$ & $\$ 6,261$ \\
\hline Appalachian Regional Commission & --.--- & ------ & -.-.-- & 189 & 179 & -..-- & --.--- \\
\hline $\begin{array}{l}\text { Department of Defense } \\
\text { Department of Housing and Urban Develop- }\end{array}$ & 3,179 & 3,219 & 1,431 & 5,670 & 2,648 & 2,443 & 1,080 \\
\hline ment & --.--- & 281 & 294 & 224 & 817 & ------ & --.--- \\
\hline Department of the Interior & ----- & 134 & 156 & ----- & 5,719 & 2,330 & 867 \\
\hline $\begin{array}{l}\text { Bureau of Indian Affairs } \\
\text { Bureau of Land Management } \\
\text { Bureau of Mines }\end{array}$ & --o- & $-\cdots--$ & ----- & ----- & $\begin{array}{r}243 \\
3,741 \\
1735\end{array}$ & $\begin{array}{r}370 \\
1,851 \\
109\end{array}$ & $\begin{array}{l}121 \\
746\end{array}$ \\
\hline $\begin{array}{l}\text { Bureau of Mines } \\
\text { Bureau of Reclamation }\end{array}$ & $-\cdots$ & $\begin{array}{l}80 \\
23\end{array}$ & -n- & ----- & $\begin{array}{r}1,135 \\
-\end{array}$ & 109 & ---- \\
\hline Department of Commerce & -....- & $\ldots$ & - n- & -n- & -n- & 342 & -...- \\
\hline Office of Saline Water & .....- & 31 & 156 & -.---- & -.....- & -....- & $-\ldots--$ \\
\hline Department of State & 1,711 & 1,987 & 1,975 & 1,510 & 1,056 & 359 & ----- \\
\hline $\begin{array}{l}\text { Energy Research and Development Adminis- } \\
\text { tration }^{1}\end{array}$ & 1,858 & 2,090 & 2,134 & 3,125 & 2,542 & 3,324 & 1,578 \\
\hline Federal Energy Administration & - & $-\ldots-$ & $-\ldots$ & ---- & 353 & 77 & 44 \\
\hline National Aeronautics and Space Administration & 5,454 & 5,038 & 4,708 & 4,745 & 2,938 & 2,800 & 1,049 \\
\hline $\begin{array}{l}\text { National Oceanographic and Atmospheric Ad- } \\
\text { ministration }\end{array}$ & - & $\cdots$ & & 2,001 & 434 & 1,513 & 517 \\
\hline National Science Foundation & 1,077 & 650 & 135 & 1,329 & 1,604 & 1,538 & 528 \\
\hline Nuclear Regulatory Commission & -...-- & ------ & -...-- & ------ & 1,195 & 1,439 & 373 \\
\hline Miscellaneous Federal Agencies _. & 215 & 210 & 389 & 528 & 673 & 663 & 225 \\
\hline
\end{tabular}

1 Includes Atomic Energy Commission funds for fiscal years 1971-74.

1 Includes Atomic Energy Commission funds for fiscal years 1971-74.
See also funds from the Nuclear Regulatory Commission in fiscal year
1975 .

2 Information is as of September 15, 1976.

TABLE 36.-Water Resources Investigations direct program funds, by subactivity, fiscal years 1971-76

[In thousands of dollars]

\begin{tabular}{|c|c|c|c|c|c|c|}
\hline Subactivity & 1971 & 1972 & 1973 & 1974 & 1975 & 1976 \\
\hline Total direct program ${ }^{1}$ & $\$ 34,581$ & $\$ 37,446$ & $\$ 40,185$ & $\$ 45,433$ & $\$ 53,420$ & $\$ 57,176$ \\
\hline National Water Data System _...... & 32,360 & 34,849 & 37,523 & 42,993 & 48,191 & 48,494 \\
\hline $\begin{array}{l}\text { Federal program } \\
\text { Federal-State program }\end{array}$ & $\begin{array}{l}13,177 \\
19,183\end{array}$ & $\begin{array}{l}14,841 \\
20,008\end{array}$ & $\begin{array}{l}16,334 \\
21,189\end{array}$ & $\begin{array}{l}17,695 \\
25,298\end{array}$ & $\begin{array}{l}21,183 \\
27,008\end{array}$ & $\begin{array}{l}20,577 \\
27,917 \\
\end{array}$ \\
\hline Critical National water problems & 2,221 & 2,597 & 2,662 & 2,440 & 5,229 & 8,682 \\
\hline
\end{tabular}

1 Direct program funds exclude the Employee Compensation Payments

subactivity for fiscal years $1971-76$.
2 Federal share of Federal-State Cooperative program. 
TABLE 37.-Water Resources Investigations-Federal-State Cooperative program funds, by State, fiscal years 1971-76 [In thousands of dollars]

\begin{tabular}{|c|c|c|c|c|c|c|}
\hline State & 1971 & 1972 & 1973 & 1974 & 1975 & 1976 \\
\hline 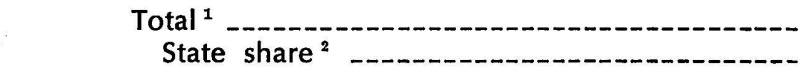 & $\begin{array}{r}\$ 38,647 \\
19,464\end{array}$ & $\begin{array}{r}\$ 41,302 \\
21,294\end{array}$ & $\begin{array}{r}\$ 43,925 \\
22,736\end{array}$ & $\begin{array}{r}\$ 51,118 \\
25,820\end{array}$ & $\begin{array}{r}\$ 55,554 \\
28,546\end{array}$ & $\begin{array}{r}\$ 56,709 \\
29,753\end{array}$ \\
\hline $\begin{array}{l}\text { Alabama } \\
\text { State share }\end{array}$ & $\begin{array}{l}796 \\
442\end{array}$ & $\begin{array}{l}789 \\
436\end{array}$ & $\begin{array}{l}868 \\
479\end{array}$ & $\begin{array}{r}1,044 \\
529\end{array}$ & $\begin{array}{r}1,135 \\
587\end{array}$ & $\begin{array}{r}1,024 \\
512\end{array}$ \\
\hline $\begin{array}{l}\text { Alaska } \\
\text { State share }\end{array}$ & $\begin{array}{l}411 \\
203\end{array}$ & $\begin{array}{l}459 \\
250\end{array}$ & $\begin{array}{l}506 \\
264\end{array}$ & $\begin{array}{l}659 \\
317\end{array}$ & $\begin{array}{l}686 \\
335\end{array}$ & $\begin{array}{l}772 \\
410\end{array}$ \\
\hline $\begin{array}{l}\text { Arizona } \\
\text { State share }-\end{array}$ & $\begin{array}{l}869 \\
444\end{array}$ & $\begin{array}{r}1,021 \\
540\end{array}$ & $\begin{array}{r}1,001 \\
510\end{array}$ & $\begin{array}{r}1,144 \\
576\end{array}$ & $\begin{array}{r}1,248 \\
646\end{array}$ & $\begin{array}{r}1,267 \\
682\end{array}$ \\
\hline $\begin{array}{l}\text { Arkansas } \\
\text { State share }-\end{array}$ & $\begin{array}{l}392 \\
189\end{array}$ & $\begin{array}{l}409 \\
202\end{array}$ & $\begin{array}{l}457 \\
225\end{array}$ & $\begin{array}{l}674 \\
399\end{array}$ & $\begin{array}{l}650 \\
347\end{array}$ & $\begin{array}{l}613 \\
307\end{array}$ \\
\hline $\begin{array}{l}\text { California } \\
\text { State share }\end{array}$ & $\begin{array}{l}3,455 \\
1,672\end{array}$ & $\begin{array}{l}3,636 \\
1,810\end{array}$ & $\begin{array}{l}3,850 \\
1,938\end{array}$ & $\begin{array}{l}4,229 \\
2,101\end{array}$ & $\begin{array}{l}4,381 \\
2,190\end{array}$ & $\begin{array}{l}4,473 \\
2,277\end{array}$ \\
\hline $\begin{array}{l}\text { Colorado } \\
\quad \text { State share }-1\end{array}$ & $\begin{array}{l}870 \\
436\end{array}$ & $\begin{array}{l}953 \\
487\end{array}$ & $\begin{array}{r}1,078 \\
545\end{array}$ & $\begin{array}{r}1,480 \\
835\end{array}$ & $\begin{array}{r}1,615 \\
909\end{array}$ & $\begin{array}{r}1,669 \\
940\end{array}$ \\
\hline $\begin{array}{l}\text { Connecticut } \\
\text { State share }\end{array}$ & $\begin{array}{l}429 \\
207\end{array}$ & $\begin{array}{l}436 \\
215\end{array}$ & $\begin{array}{l}412 \\
203\end{array}$ & $\begin{array}{l}486 \\
239\end{array}$ & $\begin{array}{l}687 \\
386\end{array}$ & $\begin{array}{l}540 \\
286\end{array}$ \\
\hline $\begin{array}{l}\text { Delaware } \\
\text { State share }-1\end{array}$ & $\begin{array}{r}112 \\
73\end{array}$ & $\begin{array}{r}111 \\
75\end{array}$ & $\begin{array}{r}121 \\
81\end{array}$ & $\begin{array}{r}130 \\
74\end{array}$ & $\begin{array}{l}194 \\
106\end{array}$ & $\begin{array}{l}214 \\
119\end{array}$ \\
\hline $\begin{array}{l}\text { District of Columbia } \\
\text { State share }\end{array}$ & $\begin{array}{r}12 \\
6\end{array}$ & $\begin{array}{l}2 \\
1\end{array}$ & $\begin{array}{l}3 \\
1\end{array}$ & $\begin{array}{l}3 \\
1\end{array}$ & $\begin{array}{l}3 \\
1\end{array}$ & $\begin{array}{l}3 \\
2\end{array}$ \\
\hline $\begin{array}{l}\text { Florida } \\
\quad \text { State share }\end{array}$ & $\begin{array}{l}2,539 \\
1,249\end{array}$ & $\begin{array}{l}2,818 \\
1,429\end{array}$ & $\begin{array}{l}3,071 \\
1,572\end{array}$ & $\begin{array}{l}4,505 \\
2,263\end{array}$ & $\begin{array}{l}5,055 \\
2,521\end{array}$ & $\begin{array}{l}5,147 \\
2,593\end{array}$ \\
\hline $\begin{array}{l}\text { Georgia } \\
\text { State share }-1,-\end{array}$ & $\begin{array}{l}711 \\
380\end{array}$ & $\begin{array}{l}741 \\
408\end{array}$ & $\begin{array}{l}790 \\
432\end{array}$ & $\begin{array}{l}939 \\
461\end{array}$ & $\begin{array}{r}1,081 \\
530\end{array}$ & $\begin{array}{r}1,142 \\
571\end{array}$ \\
\hline 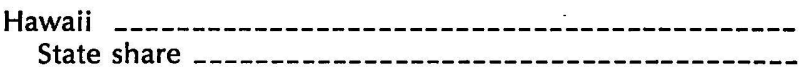 & $\begin{array}{l}649 \\
334\end{array}$ & $\begin{array}{l}622 \\
314\end{array}$ & $\begin{array}{l}653 \\
337\end{array}$ & $\begin{array}{l}691 \\
339\end{array}$ & $\begin{array}{l}697 \\
341\end{array}$ & $\begin{array}{l}865 \\
492\end{array}$ \\
\hline $\begin{array}{l}\text { Idaho } \\
\text { State }\end{array}$ & $\begin{array}{l}633 \\
308\end{array}$ & $\begin{array}{l}619 \\
307\end{array}$ & $\begin{array}{l}675 \\
344\end{array}$ & $\begin{array}{l}718 \\
353\end{array}$ & $\begin{array}{l}749 \\
366\end{array}$ & $\begin{array}{l}837 \\
419\end{array}$ \\
\hline $\begin{array}{l}\text { Illinois }-1 \\
\text { State share }-1-0\end{array}$ & $\begin{array}{l}482 \\
232\end{array}$ & $\begin{array}{l}503 \\
266\end{array}$ & $\begin{array}{l}526 \\
273\end{array}$ & $\begin{array}{l}514 \\
262\end{array}$ & $\begin{array}{l}575 \\
288\end{array}$ & $\begin{array}{l}746 \\
415\end{array}$ \\
\hline $\begin{array}{l}\text { Indiana } \\
\text { State }\end{array}$ & $\begin{array}{l}770 \\
371\end{array}$ & $\begin{array}{l}858 \\
423\end{array}$ & $\begin{array}{l}973 \\
523\end{array}$ & $\begin{array}{r}1,227 \\
610\end{array}$ & $\begin{array}{r}1,152 \\
564\end{array}$ & $\begin{array}{r}1,388 \\
728\end{array}$ \\
\hline lowa late share -1 & $\begin{array}{l}398 \\
192\end{array}$ & $\begin{array}{l}517 \\
255\end{array}$ & $\begin{array}{l}525 \\
259\end{array}$ & $\begin{array}{l}592 \\
291\end{array}$ & $\begin{array}{l}617 \\
302\end{array}$ & $\begin{array}{l}631 \\
317\end{array}$ \\
\hline $\begin{array}{l}\text { Kansas } \\
\quad \text { State }\end{array}$ & $\begin{array}{r}1,058 \\
512\end{array}$ & $\begin{array}{r}1,096 \\
542\end{array}$ & $\begin{array}{r}1,110 \\
552\end{array}$ & $\begin{array}{r}1,116 \\
543\end{array}$ & $\begin{array}{r}1,156 \\
582\end{array}$ & $\begin{array}{r}1,245 \\
624\end{array}$ \\
\hline $\begin{array}{l}\text { Kentucky } \\
\text { State share }-1-0\end{array}$ & $\begin{array}{l}600 \\
289\end{array}$ & $\begin{array}{l}665 \\
328\end{array}$ & $\begin{array}{l}698 \\
348\end{array}$ & $\begin{array}{l}719 \\
353\end{array}$ & $\begin{array}{l}875 \\
427\end{array}$ & $\begin{array}{l}962 \\
481\end{array}$ \\
\hline 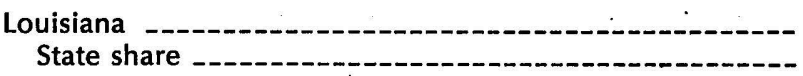 & $\begin{array}{r}1,107 \\
591\end{array}$ & $\begin{array}{r}1,152 \\
625\end{array}$ & $\begin{array}{r}1,190 \\
649\end{array}$ & $\begin{array}{r}1,748 \\
904\end{array}$ & $\begin{array}{r}1,620 \\
842\end{array}$ & $\begin{array}{r}1,570 \\
817\end{array}$ \\
\hline $\begin{array}{l}\text { Maine }-1-10 \\
\text { State share }-1\end{array}$ & $\begin{array}{r}118 \\
64\end{array}$ & $\begin{array}{r}123 \\
69\end{array}$ & $\begin{array}{r}128 \\
71\end{array}$ & $\begin{array}{r}135 \\
76\end{array}$ & $\begin{array}{l}208 \\
107\end{array}$ & $\begin{array}{l}294 \\
176\end{array}$ \\
\hline $\begin{array}{l}\text { Maryland }--1 \\
\text { State share }-1\end{array}$ & $\begin{array}{l}535 \\
272\end{array}$ & $\begin{array}{l}580 \\
301\end{array}$ & $\begin{array}{l}646 \\
335\end{array}$ & $\begin{array}{l}817 \\
418\end{array}$ & $\begin{array}{l}972 \\
511\end{array}$ & $\begin{array}{l}975 \\
507\end{array}$ \\
\hline $\begin{array}{l}\text { Massachusetts }-1- \\
\text { State share }-\end{array}$ & $\begin{array}{l}516 \\
290\end{array}$ & $\begin{array}{l}542 \\
309\end{array}$ & $\begin{array}{l}550 \\
322\end{array}$ & $\begin{array}{l}593 \\
333\end{array}$ & $\begin{array}{l}787 \\
480\end{array}$ & $\begin{array}{l}735 \\
449\end{array}$ \\
\hline
\end{tabular}


TABLE 37.-Water Resources Investigations-Federal-State Cooperative program funds, by State, fiscal years 1971-76-Continued

\begin{tabular}{|c|c|c|c|c|c|c|}
\hline State & 1971 & 1972 & 1973 & 1974 & 1975 & 1976 \\
\hline $\begin{array}{l}\text { Michigan } \\
\quad \text { State share }\end{array}$ & $\begin{array}{l}599 \\
289\end{array}$ & $\begin{array}{l}606 \\
302\end{array}$ & $\begin{array}{l}631 \\
310\end{array}$ & $\begin{array}{l}652 \\
321\end{array}$ & $\begin{array}{l}796 \\
390\end{array}$ & $\begin{array}{l}820 \\
410\end{array}$ \\
\hline $\begin{array}{l}\text { Minnesota } \\
\text { State share }\end{array}$ & $\begin{array}{l}550 \\
265\end{array}$ & $\begin{array}{l}635 \\
314\end{array}$ & $\begin{array}{l}712 \\
373\end{array}$ & $\begin{array}{l}811 \\
420\end{array}$ & $\begin{array}{l}799 \\
397\end{array}$ & $\begin{array}{l}925 \\
501\end{array}$ \\
\hline $\begin{array}{l}\text { Mississippi } \\
\text { State share }\end{array}$ & $\begin{array}{l}551 \\
316\end{array}$ & $\begin{array}{l}592 \\
357\end{array}$ & $\begin{array}{l}593 \\
340\end{array}$ & $\begin{array}{l}645 \\
325\end{array}$ & $\begin{array}{r}743 \\
415\end{array}$ & $\begin{array}{l}634 \\
317\end{array}$ \\
\hline $\begin{array}{l}\text { Missouri } \\
\quad \text { State share }-\end{array}$ & $\begin{array}{l}637 \\
307\end{array}$ & $\begin{array}{l}608 \\
321\end{array}$ & $\begin{array}{l}602 \\
310\end{array}$ & $\begin{array}{l}523 \\
255\end{array}$ & $\begin{array}{l}544 \\
270\end{array}$ & $\begin{array}{l}519 \\
260\end{array}$ \\
\hline $\begin{array}{l}\text { Montana } \\
\text { State share }-\end{array}$ & $\begin{array}{l}393 \\
212\end{array}$ & $\begin{array}{l}401 \\
221\end{array}$ & $\begin{array}{l}402 \\
223\end{array}$ & $\begin{array}{l}505 \\
255\end{array}$ & $\begin{array}{l}587 \\
287\end{array}$ & $\begin{array}{l}549 \\
283\end{array}$ \\
\hline $\begin{array}{l}\text { Nebraska } \\
\text { State share }\end{array}$ & $\begin{array}{l}502 \\
246\end{array}$ & $\begin{array}{l}553 \\
274\end{array}$ & $\begin{array}{l}588 \\
298\end{array}$ & $\begin{array}{l}705 \\
344\end{array}$ & $\begin{array}{l}731 \\
358\end{array}$ & $\begin{array}{l}769 \\
396\end{array}$ \\
\hline $\begin{array}{l}\text { Nevada } \\
\text { State share }-\end{array}$ & $\begin{array}{l}304 \\
146\end{array}$ & $\begin{array}{l}346 \\
171\end{array}$ & $\begin{array}{l}351 \\
178\end{array}$ & $\begin{array}{l}377 \\
185\end{array}$ & $\begin{array}{l}408 \\
200\end{array}$ & $\begin{array}{l}479 \\
239\end{array}$ \\
\hline $\begin{array}{l}\text { New Hampshire } \\
\text { State share }\end{array}$ & $\begin{array}{l}89 \\
43\end{array}$ & $\begin{array}{l}75 \\
37\end{array}$ & $\begin{array}{r}108 \\
54\end{array}$ & $\begin{array}{r}118 \\
58\end{array}$ & $\begin{array}{r}122 \\
60\end{array}$ & $\begin{array}{r}171 \\
85\end{array}$ \\
\hline $\begin{array}{l}\text { New Jersey } \\
\text { State share }-1\end{array}$ & $\begin{array}{l}785 \\
390\end{array}$ & $\begin{array}{l}822 \\
418\end{array}$ & $\begin{array}{l}856 \\
433\end{array}$ & $\begin{array}{r}1,051 \\
530\end{array}$ & $\begin{array}{l}977 \\
501\end{array}$ & $\begin{array}{r}1,073 \\
569\end{array}$ \\
\hline $\begin{array}{l}\text { New Mexico } \\
\text { State share }-\end{array}$ & $\begin{array}{l}888 \\
462\end{array}$ & $\begin{array}{l}963 \\
509\end{array}$ & $\begin{array}{r}1,087 \\
591\end{array}$ & $\begin{array}{r}1,292 \\
642\end{array}$ & $\begin{array}{r}1,412 \\
706\end{array}$ & $\begin{array}{r}1,466 \\
753\end{array}$ \\
\hline $\begin{array}{l}\text { New York } \\
\text { State share }-\end{array}$ & $\begin{array}{r}1,717 \\
837\end{array}$ & $\begin{array}{r}1,844 \\
921\end{array}$ & $\begin{array}{l}2,161 \\
1,112\end{array}$ & $\begin{array}{l}2,410 \\
1,222\end{array}$ & $\begin{array}{l}2,730 \\
1,462\end{array}$ & $\begin{array}{l}2,770 \\
1,610\end{array}$ \\
\hline $\begin{array}{l}\text { North Carolina } \\
\text { State share }\end{array}$ & $\begin{array}{l}667 \\
321\end{array}$ & $\begin{array}{l}691 \\
341\end{array}$ & $\begin{array}{l}767 \\
394\end{array}$ & $\begin{array}{l}876 \\
430\end{array}$ & $\begin{array}{l}977 \\
479\end{array}$ & $\begin{array}{l}940 \\
474\end{array}$ \\
\hline $\begin{array}{l}\text { North Dakota } \\
\text { State share }-\end{array}$ & $\begin{array}{l}561 \\
275\end{array}$ & $\begin{array}{l}602 \\
305\end{array}$ & $\begin{array}{l}657 \\
340\end{array}$ & $\begin{array}{l}675 \\
325\end{array}$ & $\begin{array}{l}776 \\
378\end{array}$ & $\begin{array}{l}782 \\
391\end{array}$ \\
\hline $\begin{array}{l}\text { Ohio } \\
\text { State share }-\end{array}$ & $\begin{array}{l}829 \\
446\end{array}$ & $\begin{array}{l}840 \\
443\end{array}$ & $\begin{array}{l}878 \\
445\end{array}$ & $\begin{array}{l}828 \\
406\end{array}$ & $\begin{array}{l}943 \\
488\end{array}$ & $\begin{array}{r}1,087 \\
597\end{array}$ \\
\hline $\begin{array}{l}\text { Oklahoma } \\
\text { State share }\end{array}$ & $\begin{array}{l}498 \\
276\end{array}$ & $\begin{array}{l}488 \\
270\end{array}$ & $\begin{array}{l}522 \\
284\end{array}$ & $\begin{array}{l}592 \\
289\end{array}$ & $\begin{array}{l}638 \\
313\end{array}$ & $\begin{array}{l}667 \\
333\end{array}$ \\
\hline $\begin{array}{l}\text { Oregon } \\
\text { State share }-\end{array}$ & $\begin{array}{l}546 \\
277\end{array}$ & $\begin{array}{l}667 \\
342\end{array}$ & $\begin{array}{l}750 \\
393\end{array}$ & $\begin{array}{l}852 \\
417\end{array}$ & $\begin{array}{l}810 \\
397\end{array}$ & $\begin{array}{l}854 \\
438\end{array}$ \\
\hline $\begin{array}{l}\text { Pennsylvania } \\
\text { State share }\end{array}$ & $\begin{array}{r}1,459 \\
730\end{array}$ & $\begin{array}{r}1,602 \\
809\end{array}$ & $\begin{array}{r}1,691 \\
864\end{array}$ & $\begin{array}{r}1,955 \\
994\end{array}$ & $\begin{array}{l}2,103 \\
1,053\end{array}$ & $\begin{array}{l}2,165 \\
1,120\end{array}$ \\
\hline $\begin{array}{l}\text { Rhode Island } \\
\text { State share }\end{array}$ & $\begin{array}{l}97 \\
52\end{array}$ & $\begin{array}{l}92 \\
50\end{array}$ & $\begin{array}{l}90 \\
50\end{array}$ & $\begin{array}{l}97 \\
52\end{array}$ & $\begin{array}{r}110 \\
54\end{array}$ & $\begin{array}{r}123 \\
61\end{array}$ \\
\hline $\begin{array}{l}\text { South Carolina } \\
\text { State share }\end{array}$ & $\begin{array}{l}374 \\
196\end{array}$ & $\begin{array}{l}403 \\
212\end{array}$ & $\begin{array}{l}454 \\
241\end{array}$ & $\begin{array}{l}546 \\
279\end{array}$ & $\begin{array}{l}533 \\
261\end{array}$ & $\begin{array}{l}540 \\
270\end{array}$ \\
\hline $\begin{array}{l}\text { South Dakota } \\
\text { State share }\end{array}$ & $\begin{array}{l}371 \\
207\end{array}$ & $\begin{array}{l}374 \\
211\end{array}$ & $\begin{array}{l}373 \\
205\end{array}$ & $\begin{array}{l}421 \\
202\end{array}$ & $\begin{array}{l}465 \\
226\end{array}$ & $\begin{array}{l}468 \\
234\end{array}$ \\
\hline $\begin{array}{l}\text { Tennessee } \\
\text { State share }\end{array}$ & $\begin{array}{l}504 \\
271\end{array}$ & $\begin{array}{l}526 \\
288\end{array}$ & $\begin{array}{l}551 \\
302\end{array}$ & $\begin{array}{l}801 \\
397\end{array}$ & $\begin{array}{l}908 \\
448\end{array}$ & $\begin{array}{r}1,001 \\
501\end{array}$ \\
\hline $\begin{array}{l}\text { Texas } \\
\text { State share }\end{array}$ & $\begin{array}{l}2,673 \\
1,341\end{array}$ & $\begin{array}{l}3,023 \\
1,578\end{array}$ & $\begin{array}{l}3,049 \\
1,575\end{array}$ & $\begin{array}{l}3,320 \\
1,664\end{array}$ & $\begin{array}{l}3,575 \\
1,757\end{array}$ & $\begin{array}{l}3,633 \\
1,836\end{array}$ \\
\hline $\begin{array}{l}\text { Utah } \\
\text { State share }-1\end{array}$ & $\begin{array}{l}764 \\
369\end{array}$ & $\begin{array}{l}884 \\
447\end{array}$ & $\begin{array}{l}937 \\
466\end{array}$ & $\begin{array}{l}941 \\
467\end{array}$ & $\begin{array}{r}1,255 \\
784\end{array}$ & $\begin{array}{r}1,162 \\
692\end{array}$ \\
\hline
\end{tabular}

See footnotes at end of table. 
TABLE 37.-Water Resources Investigations-Federal-State Cooperative program funds, by State, fiscal years 1971-76-Continued

\begin{tabular}{|c|c|c|c|c|c|c|}
\hline State & 1971 & 1972 & 1973 & 1974 & 1975 & 1976 \\
\hline Vermont & 104 & 105 & 109 & 104 & 96 & 119 \\
\hline State share & 52 & 54 & 56 & 53 & 47 & 59 \\
\hline Virginia & 609 & 631 & 661 & 673 & 640 & 538 \\
\hline State share & 322 & 337 & 355 & 350 & 333 & 284 \\
\hline - & 1,671 & 1,710 & 1,834 & 2,020 & 2,068 & 1,919 \\
\hline State share & 806 & 845 & 916 & 1,000 & 1,071 & 971 \\
\hline West Virginia & 259 & 276 & 302 & 420 & 526 & 500 \\
\hline State share & 150 & 160 & 173 & 258 & 324 & 314 \\
\hline Wisconsin & 781 & 830 & 870 & 1,075 & 1,224 & 1,333 \\
\hline State share & 377 & 411 & 429 & 561 & 668 & 794 \\
\hline Wyoming ---- & 568 & 564 & 575 & 662 & 832 & 707 \\
\hline State share & 306 & 309 & 303 & 321 & 507 & 395 \\
\hline American Samoa & 65 & 72 & 64 & 63 & 70 & 40 \\
\hline State share & 32 & 36 & 32 & 31 & 32 & 20 \\
\hline Guam -.--.-. & 25 & 36 & 43 & 62 & 65 & 66 \\
\hline State share & 12 & 18 & 21 & 31 & 32 & 33 \\
\hline 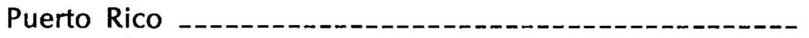 & 644 & 672 & 701 & 766 & 745 & 590 \\
\hline State share & 328 & 333 & 345 & 401 & 365 & 295 \\
\hline Trust Territories -1 & 93 & 105 & 125 & 117 & 170 & 170 \\
\hline State share & 45 & 52 & 62 & 58 & 84 & 85 \\
\hline Virgin Islands & 8 & 12 & $\left(^{3}\right)$ & $\left({ }^{3}\right)$ & 33 & 18 \\
\hline State share & 4 & 6 & -.- & -....-- & 31 & 9 \\
\hline
\end{tabular}

1 Includes Federal funds from direct program.

2 Includes reimbursable program funds from States, counties, and

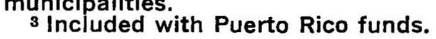

TABLE 38.-Water Resources Investigations reimbursable program funds from other Federal agencies, by agency, fiscal years 1971-76 and transition quarter

[ In thousands of dollars]

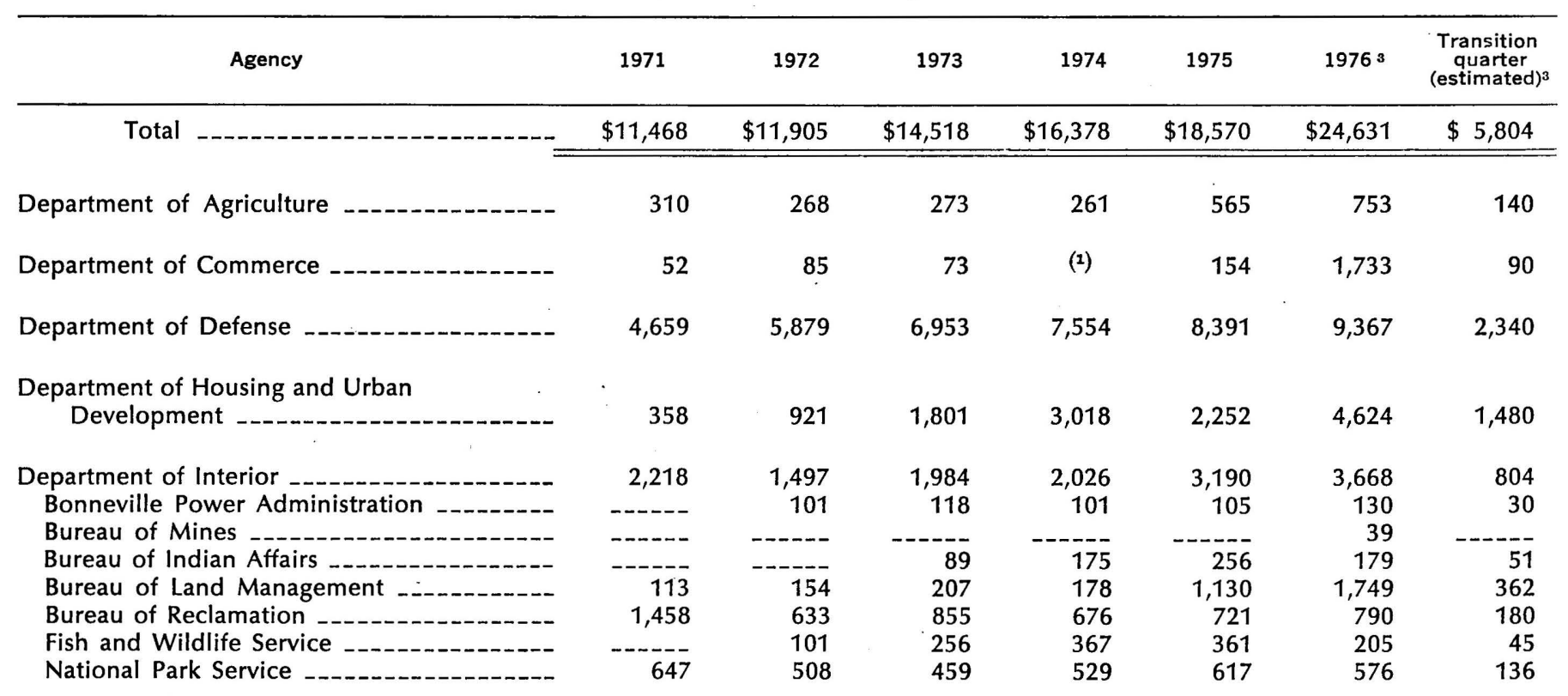


TABLE 38.-Water Resources Investigations reimbursable program funds from other Federal agencies, by agency, fiscal years 1971-76 and transition quarter-Continued

\begin{tabular}{|c|c|c|c|c|c|c|c|}
\hline Agency & 1971 & 1972 & 1973 & 1974 & 1975 & $1976^{3}$ & $\begin{array}{c}\text { Transition } \\
\text { quarter } \\
\text { (estimated) }\end{array}$ \\
\hline Department of State & 986 & 802 & 781 & 667 & 642 & 589 & 144 \\
\hline Department of Transportation & ---- & $-\cdots-$ & $\cdots$ & $-\cdots-$ & 47 & 214 & 65 \\
\hline Environmental Protection Agency & 579 & 627 & 916 & 1,127 & 1,389 & 1,921 & 342 \\
\hline $\begin{array}{l}\text { Energy Research and Development } \\
\text { Administration }{ }^{2}\end{array}$ & 1,214 & 1,022 & 877 & 904 & 959 & 1,142 & 280 \\
\hline $\begin{array}{l}\text { National Aeronautics and Space } \\
\text { Administration }\end{array}$ & 438 & 266 & 343 & 284 & 235 & 213 & 20 \\
\hline $\begin{array}{l}\text { National Science Foundation } \\
\text { Tennessee Valley Authority }\end{array}$ & 204 & $---\overline{1}-1-5$ & -355 & $-\overline{212}$ & $\begin{array}{r}67 \\
252\end{array}$ & 216 & $-\overline{62}$ \\
\hline Miscellaneous Federal agencies & 450 & 340 & 262 & 325 & 494 & 191 & 37 \\
\hline
\end{tabular}

1 Included with miscellaneous Federal agencies funds.

for fiscal years $1971-74$

3 Information is as of September 15, 1976.

TABLE 39.-Conservation of Lands and Minerals direct program funds, by subactivity, fiscal years 1971-76 and transition quarter [In thousands of dollars]

\begin{tabular}{|c|c|c|c|c|c|c|c|}
\hline Subactivity & 1971 & 1972 & 1973 & 1974 & 1975 & 1976 & $\begin{array}{c}\text { Transition } \\
\text { quarter }\end{array}$ \\
\hline Total direct program & $\$ 9,670$ & $\$ 13,441$ & $\$ 14,700$ & $\$ 18,172$ & $\$ 36,032$ & $\$ 41,489$ & \\
\hline Outer Continental Shelf Lands & 4,234 & 7,626 & 8,114 & 10,957 & 23,196 & 26,194 & ---- \\
\hline Federal and Indian Lands & 5,436 & 5,815 & 6,586 & 7,215 & 12,836 & 15,295 & --- \\
\hline
\end{tabular}

TABLE 40.-Conservation of Lands and Minerals reimbursable program funds from other Federal agencies, fiscal years 1971-76 and transition quarter [In thousands of dollars]

\begin{tabular}{|c|c|c|c|c|c|c|c|}
\hline Agency & 1971 & 1972 & 1973 & 1974 & 1975 & $1976^{1}$ & $\begin{array}{c}\text { Transition } \\
\text { quarter }{ }^{1}\end{array}$ \\
\hline Total & $\$ 32$ & $\$ 25$ & $\$ 45$ & $\$ 41$ & $\$ 46$ & $\$ 186$ & $\$ 47$ \\
\hline Department of Defense & 25 & 25 & 24 & 25 & 25 & 25 & 6 \\
\hline Miscellaneous Federal agencies & 7 & ... & 21 & 16 & 21 & 161 & 41 \\
\hline
\end{tabular}

I Information is as of September 15, 1976.

TABLE 41.-Land Information and Analysis direct program funds, by subactivity fiscal years 1971-76 [In thousands of dollars]

\begin{tabular}{|c|c|c|c|c|c|c|}
\hline Subactivity & 1971 & 1972 & 1973 & 1974 & 1975 & 1976 \\
\hline Total direct program & $\$ 2,373$ & $\$ 6,714$ & $\$ 11,876$ & $\$ 11,458$ & $\$ 15,461$ & $\$ 14,908$ \\
\hline Earth Sciences Applications & 452 & 970 & 1,519 & 1,580 & 1,600 & 1,629 \\
\hline Resource and Land Investigations & ----- & ------ & ----- & 916 & 959 & 740 \\
\hline Geography -- & ----- & ----- & ----- & $-\cdots$ & 2,013 & 2,341 \\
\hline Earth Resources Observation Systems & 1,921 & 5,744 & 10,357 & 8,962 & 8,284 & 8,158 \\
\hline Environmental Impact Analysis & ----- & - & $\ldots$ & --.--- & 2,605 & 2,040 \\
\hline
\end{tabular}


TABLE 42.-Land Information and Analysis reimbursable program funds from other Federal agencies, by agency, fiscal years 1971-76 and transition quarter

[In thousands of dollars]

\begin{tabular}{|c|c|c|c|c|c|c|c|}
\hline Agency & 1971 & 1972 & 1973 & 1974 & 1975 & $1976^{1}$ & $\begin{array}{l}\text { Transition } \\
\text { quarter } \\
\text { (estimated)1 }\end{array}$ \\
\hline Total & $\$ 1,166$ & $\$ 575$ & $\$ 1,249$ & $\$ 952$ & $\$ 407$ & $\$ 744$ & $\$ 503$ \\
\hline Department of Defense & $-\cdots-$ & --- & ---- & 10 & ---- & --- & ---- \\
\hline $\begin{array}{l}\text { Department of Housing and Urban } \\
\text { Development }\end{array}$ & 355 & --- & ---- & 339 & --- & --- & ---- \\
\hline Department of the Interior & ----- & --- & ----- & 48 & 11 & 15 & ---- \\
\hline $\begin{array}{l}\text { Bureau of Mines } \\
\text { Bonneville Power Administration } \\
\text { Fish and Wildlife Service } \\
\text { Bureau of Land Management }\end{array}$ & 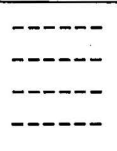 & $\begin{array}{l}---- \\
---- \\
---- \\
----\end{array}$ & $\begin{array}{l}--- \\
---- \\
----\end{array}$ & $\begin{array}{r}---\overline{35} \\
13 \\
---\end{array}$ & $---\overline{11}$ & $\begin{array}{r}3 \\
-- \\
4 \\
8\end{array}$ & $\begin{array}{l}---- \\
---- \\
---- \\
----\end{array}$ \\
\hline Environmental Protection Agency _. & ----- & --- & ---- & --- & --- & --- & 206 \\
\hline $\begin{array}{l}\text { National Aeronautics and Space } \\
\text { Administration }\end{array}$ & 811 & 575 & 1,249 & 408 & 179 & 443 & 125 \\
\hline Ozark Regional Commission _. & --- -- & ---- & ---- & 60 & 49 & 31 & --- \\
\hline Miscellaneous Federal agencies _._. & ----- & ---- & ---- & 87 & 168 & 255 & 172 \\
\hline
\end{tabular}

1 Information is as of September 15, 1976.

TABLE 43.-Land Information and Analysis Federal-State Cooperative program funds, by State, fiscal years 1971-76 and transition quarter

\begin{tabular}{|c|c|c|c|c|c|c|c|}
\hline State & 1971 & 1972 & 1973 & 1974 & 1975 & 1976 & $\begin{array}{l}\text { Transition } \\
\text { quarter }\end{array}$ \\
\hline Total $^{1}$ & ------ & ----- & ----- & ---- & 66 & 250 & 38 \\
\hline Total State share ${ }^{2}$ & ----- & ----- & ----- & ---- & 33 & 130 & 19 \\
\hline Alabama & -...-- & $-\ldots---$ & $\ldots$ & ---- & -- & 34 & 6 \\
\hline State share & ---- & ----- & $-\cdots-$ & $---\cdots$ & - & 17 & 3 \\
\hline Florida & - - - - & --.--- & -----. & -.--- & 66 & 56 & -- \\
\hline State share & ----- & ----- & 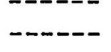 & 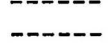 & 33 & 33 & -- \\
\hline Missouri & ---- & ---- & ----- & ----- & -- & --- & 32 \\
\hline State share & ----- & ----- & --n-- & ---- & - & -- & 16 \\
\hline Pennsylvania _- & ----- & ------ & ------ & ------ & -- & 100 & -- \\
\hline State share & ----- & ---- & $---1-$ & $-1-n$ & - & 50 & -- \\
\hline West Virginia & ------ & 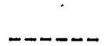 & ---.-- & ------ & -- & 60 & -- \\
\hline State share & ---- & ----- & ----- & ---- & -- & 30 & -- \\
\hline
\end{tabular}

1 Includes Federal funds from direct program.

2 Includes reimbursable funds from States, counties, and municipalities. 
TABLE 44.-Program support funds, by activity, fiscal years 1971-76 and transition quarter [In thousands of dollars]

\begin{tabular}{|c|c|c|c|c|c|c|c|}
\hline Program support activity & 1971 & 1972 & 1973 & 1974 & 1975 & 1976 & $\begin{array}{c}\text { Transition } \\
\text { quarter } \\
\text { (estimated) }\end{array}$ \\
\hline \multicolumn{8}{|l|}{ General Administrative } \\
\hline Expenses $^{1} \quad$ - & $\$ 5,335$ & $\$ 6,422$ & $\$ 7,173$ & $\$ 8,197$ & $\$ 10,806$ & $\$ 11,451$ & $\$ 3,675$ \\
\hline General Administration ${ }^{2}$ & 3,048 & 3,187 & 3,217 & 3,517 & 3,671 & 3,398 & 1,492 \\
\hline Direct program assessments ${ }^{3}$ & 962 & 1,669 & 2,352 & 2,770 & 5,126 & 5,766 & 1,466 \\
\hline Reimbursable program assessment ${ }^{4}$ & 1,325 & 1,566 & 1,604 & 1,910 & 2,009 & 2,287 & 717 \\
\hline \multicolumn{8}{|l|}{ Electronic data processing and related } \\
\hline services $^{5}$ & 5,582 & 4,862 & 6,168 & 6,987 & 8,425 & 7,432 & 1,922 \\
\hline Funded by Survey programs ${ }^{\circ}$ & 3,068 & 3,351 & 4,177 & 4,828 & 6,129 & 6,700 & 1,908 \\
\hline Funded by miscellaneous accounts ${ }^{7}$ & 2,514 & 1,511 & 1,991 & 2,159 & 2,296 & 732 & 14 \\
\hline Publication services & 9,615 & 10,667 & 11,656 & 11,932 & 13,004 & 15,468 & 3,608 \\
\hline Funded by Survey programs ${ }^{\circ}$ & 9,248 & 10,297 & 11,147 & 11,432 & 12,488 & 14,662 & 3,469 \\
\hline Funded by miscellaneous accounts ${ }^{7}$ & 367 & 370 & 509 & 500 & 516 & 806 & 139 \\
\hline
\end{tabular}

TABLE 45.-Geological Survey end-of-year employment, by organizational unit, fiscal years 1971-76

\begin{tabular}{|c|c|c|c|c|c|c|}
\hline Organizational unit & 1971 & 1972 & 1973 & 1974 & 1975 & 1976 \\
\hline Total & 9,192 & 9,224 & 9,387 & 9,921 & 10,435 & 10,872 \\
\hline $\begin{array}{l}\text { Permanent employment } \\
\text { Other than permanent employment }\end{array}$ & $\begin{array}{l}8,173 \\
1,019 \\
\end{array}$ & $\begin{array}{l}8,002 \\
1,222 \\
\end{array}$ & $\begin{array}{l}8,089 \\
1,298 \\
\end{array}$ & $\begin{array}{l}8,357 \\
1,564 \\
\end{array}$ & $\begin{array}{l}8,999 \\
1,436 \\
\end{array}$ & $\begin{array}{l}9,142 \\
1,730 \\
\end{array}$ \\
\hline Topographic Division & 2,079 & 2,045 & 2,020 & 1,956 & 1,877 & 1,876 \\
\hline $\begin{array}{l}\text { Permanent employment } \\
\text { Other than permanent employment }\end{array}$ & $\begin{array}{r}1,893 \\
186\end{array}$ & $\begin{array}{r}1,828 \\
217\end{array}$ & $\begin{array}{r}1,758 \\
262\end{array}$ & $\begin{array}{r}1,762 \\
194\end{array}$ & $\begin{array}{r}1,719 \\
158\end{array}$ & $\begin{array}{r}1,693 \\
183\end{array}$ \\
\hline Geologic Division & 2,048 & 2,060 & 2,147 & 2,406 & 2.572 & 2,709 \\
\hline $\begin{array}{l}\text { Permanent employment } \\
\text { Other than permanent employment }\end{array}$ & $\begin{array}{r}1,765 \\
283\end{array}$ & $\begin{array}{r}1,706 \\
354\end{array}$ & $\begin{array}{r}1,766 \\
381\end{array}$ & $\begin{array}{r}1,888 \\
518\end{array}$ & $\begin{array}{r}2,135 \\
437\end{array}$ & $\begin{array}{r}2,119 \\
590\end{array}$ \\
\hline Water Resources Division & 3,427 & 3,409 & 3,419 & 3,611 & 3.610 & 3,632 \\
\hline $\begin{array}{l}\text { Permanent employment } \\
\text { Other than permanent employment }\end{array}$ & $\begin{array}{r}2,965 \\
462\end{array}$ & $\begin{array}{r}2,876 \\
533\end{array}$ & $\begin{array}{r}2,900 \\
519\end{array}$ & $\begin{array}{r}2,910 \\
701\end{array}$ & $\begin{array}{r}2,957 \\
653\end{array}$ & $\begin{array}{r}2,924 \\
708\end{array}$ \\
\hline Conservation Division & 492 & 549 & 568 & 647 & 990 & 1,218 \\
\hline $\begin{array}{l}\text { Permanent employment } \\
\text { Other than permanent employment }\end{array}$ & $\begin{array}{r}475 \\
17\end{array}$ & $\begin{array}{r}529 \\
20\end{array}$ & $\begin{array}{r}547 \\
21\end{array}$ & $\begin{array}{r}612 \\
35\end{array}$ & $\begin{array}{r}926 \\
64\end{array}$ & $\begin{array}{r}1,135 \\
83\end{array}$ \\
\hline Land Information and Analysis Office & ----- & 51 & 72 & 85 & 114 & 157 \\
\hline $\begin{array}{l}\text { Permanent employment } \\
\text { Other than permanent employment }\end{array}$ & --- & $\begin{array}{l}39 \\
12\end{array}$ & $\begin{array}{l}52 \\
20\end{array}$ & $\begin{array}{l}68 \\
17\end{array}$ & $\begin{array}{l}89 \\
25\end{array}$ & $\begin{array}{r}11 \overline{6} \\
41\end{array}$ \\
\hline
\end{tabular}

See footnotes at end of table. 
TABLE 45.-Geological Survey end-of-year employment, by organizational unit, fiscal years 1971-76-Continued

\begin{tabular}{|c|c|c|c|c|c|c|}
\hline Organizational unit & 1971 & 1972 & 1973 & 1974 & 1975 & 1976 \\
\hline Director's Office ${ }^{1}$ & 94 & 64 & 57 & 64 & 66 & 64 \\
\hline $\begin{array}{l}\text { Permanent employment } \\
\text { Other than permanent employment }\end{array}$ & $\begin{array}{l}79 \\
15\end{array}$ & $\begin{array}{l}51 \\
13\end{array}$ & $\begin{array}{r}55 \\
2\end{array}$ & $\begin{array}{r}62 \\
2\end{array}$ & $\begin{array}{r}57 \\
9\end{array}$ & $\begin{array}{l}54 \\
10\end{array}$ \\
\hline Administrative Division & 362 & 360 & 382 & 408 & 441 & 491 \\
\hline $\begin{array}{l}\text { Permanent employment } \\
\text { Other than permanent employment }\end{array}$ & $\begin{array}{r}336 \\
26\end{array}$ & $\begin{array}{r}326 \\
34\end{array}$ & $\begin{array}{r}341 \\
41\end{array}$ & $\begin{array}{r}366 \\
42\end{array}$ & $\begin{array}{r}398 \\
43\end{array}$ & $\begin{array}{r}426 \\
65\end{array}$ \\
\hline Facilities $^{2}$ - & $-\cdots-$ & -..-- & ------ & 15 & 30 & 37 \\
\hline $\begin{array}{l}\text { Permanent employment } \\
\text { Other than permanent employment }\end{array}$ & - n- & ----- & - n & $\begin{array}{r}15 \\
----\end{array}$ & 30 & 37 \\
\hline Computer Center Division & 153 & 170 & 174 & 182 & 198 & 146 \\
\hline $\begin{array}{l}\text { Permanent employment } \\
\text { Other than permanent employment }\end{array}$ & $\begin{array}{r}142 \\
11\end{array}$ & $\begin{array}{r}150 \\
20\end{array}$ & $\begin{array}{r}153 \\
21\end{array}$ & $\begin{array}{r}159 \\
23\end{array}$ & $\begin{array}{r}178 \\
20\end{array}$ & $\begin{array}{r}130 \\
16\end{array}$ \\
\hline Publications Division & 537 & 516 & 548 & 547 & 537 & 542 \\
\hline $\begin{array}{l}\text { Permanent employment } \\
\text { Other than permanent employment }\end{array}$ & $\begin{array}{r}518 \\
19\end{array}$ & $\begin{array}{r}497 \\
19\end{array}$ & $\begin{array}{r}517 \\
31\end{array}$ & $\begin{array}{r}515 \\
32\end{array}$ & $\begin{array}{r}510 \\
27\end{array}$ & $\begin{array}{r}508 \\
34\end{array}$ \\
\hline
\end{tabular}

1 Includes Land Information and Analysis Office personnel for fiscal

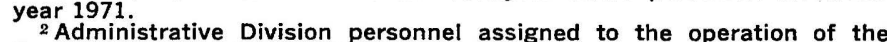
Survey's Headquarter facilities.

TABLE 46.-Number of Geological Survey reports approved for publication, by organizational unit, fiscal years 1971-76 and transition quarter

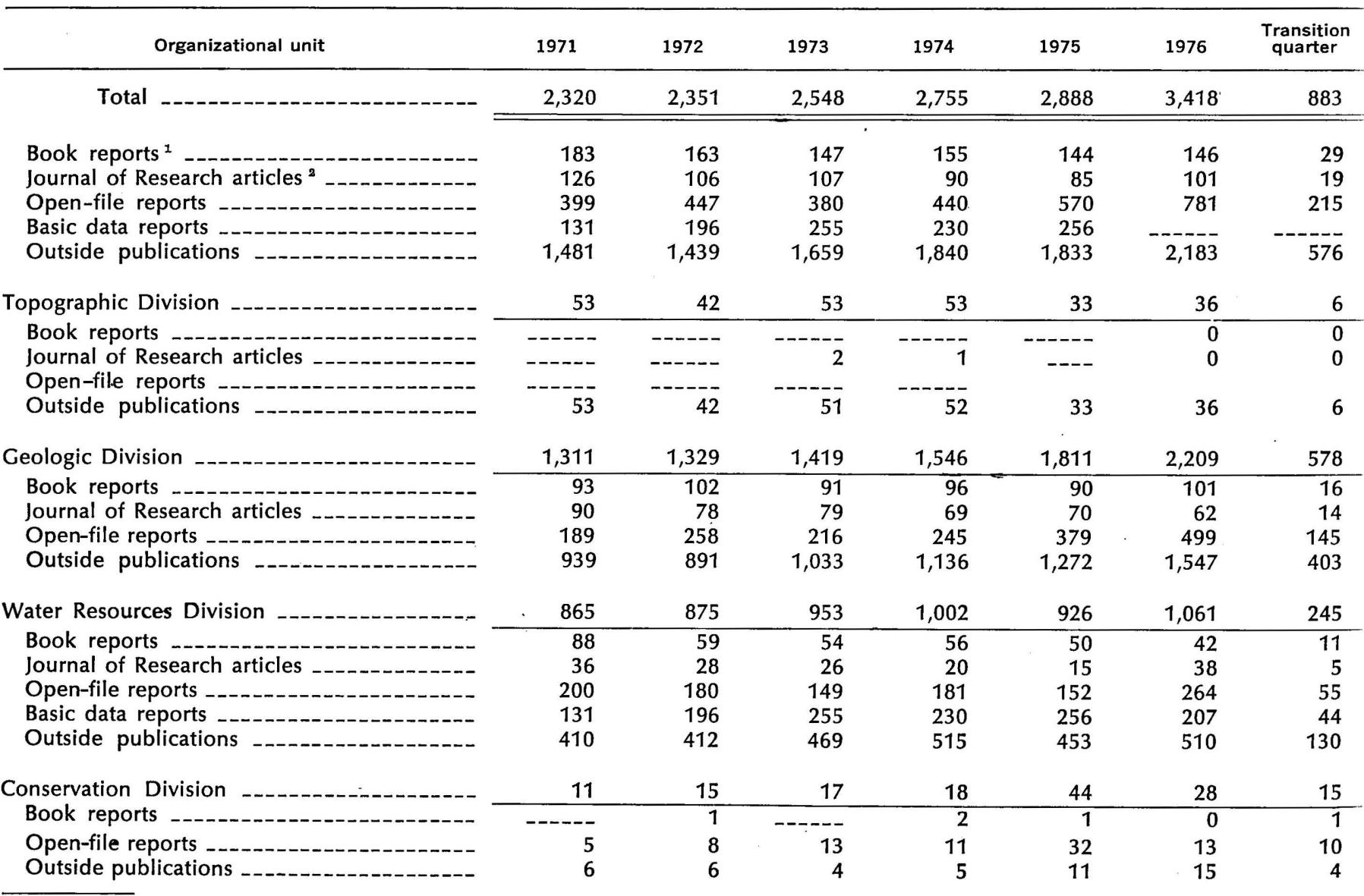


TABLE 46.-Number of Geological Survey reports approved for publication, by organizational unit, fiscal years 1971-76 and transition quarter-Continued

\begin{tabular}{|c|c|c|c|c|c|c|c|}
\hline State & 1971 & 1972 & 1973 & 1974 & 1975 & 1976 & $\begin{array}{c}\text { Transition } \\
\text { quarter }\end{array}$ \\
\hline 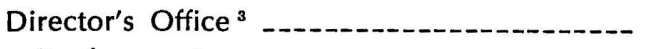 & 80 & 90 & 106 & 136 & 74 & 84 & 39 \\
\hline $\begin{array}{l}\text { Book reports } \\
\text { Open-file reports } \\
\text { Outside publications } \\
\text { Journal of Research }\end{array}$ & $\begin{array}{r}2 \\
5 \\
73 \\
----\end{array}$ & $\begin{array}{r}1 \\
1 \\
88 \\
-\end{array}$ & $\begin{array}{r}2 \\
2 \\
102 \\
\end{array}$ & $\begin{array}{r}1 \\
3 \\
132 \\
\end{array}$ & $\begin{array}{r}3 \\
7 \\
64 \\
-\end{array}$ & $\begin{array}{r}3 \\
5 \\
75 \\
1\end{array}$ & $\begin{array}{r}1 \\
5 \\
33 \\
0\end{array}$ \\
\hline
\end{tabular}

2 Book reports include U.S. Geological Survey Professional Papers,

Bulletins, Water-Supply Papers, Circulars, and other report series.

Before January 1973 articles were published as part of the annual

"Geological Survey Research" Professional Paper.

Includes reports of the Land Information and Analysis Office, Admin istrative Division, Computer Center Division, and Publications Division.

TABLE 47.-Number of maps produced by the Geological Survey, by organizational unit, fiscal years 1971-76 and transition quarter

\begin{tabular}{|c|c|c|c|c|c|c|c|}
\hline Organizational unit & 1971 & 1972 & 1973 & 1974 & 1975 & 1976 & $\begin{array}{c}\text { Transition } \\
\text { quarter }\end{array}$ \\
\hline Total $^{1}$ & 4,553 & 6,094 & 10,304 & 7,361 & 8,722 & 9,099 & 2,310 \\
\hline Topographic Division & 3,541 & 4,817 & 5,313 & 4,938 & 7,288 & 7,339 & 2,080 \\
\hline Quadrangle maps - & 3,346 & 4,641 & 5,117 & 4,780 & 7,087 & 6,757 & 1,970 \\
\hline $\begin{array}{l}\text { New standard quadrangles } \\
\text { Orthophotoquads } \\
\text { Revisions } \\
\text { Reprints }-1 .-\end{array}$ & $\begin{array}{r}1,692 \\
953 \\
701\end{array}$ & $\begin{array}{r}2,544 \\
-1,223 \\
874\end{array}$ & $\begin{array}{r}2,347 \\
49 \\
1,118 \\
1,603\end{array}$ & $\begin{array}{r}2,052 \\
15 \\
966 \\
1,747\end{array}$ & $\begin{array}{r}2,016 \\
2,869 \\
923 \\
1,279\end{array}$ & $\begin{array}{r}1,405 \\
3,197 \\
656 \\
1,499\end{array}$ & $\begin{array}{l}237 \\
730 \\
165 \\
838\end{array}$ \\
\hline Small scale and special maps & 135 & 112 & 148 & 121 & 171 & 582 & 114 \\
\hline $\begin{array}{l}\text { 1:250,000 series } \\
\text { Antarctica } \\
\text { State bases }- \\
\text { Other } \\
\text { Reprints } \\
\text { Intermediate scale }-\end{array}$ & $\begin{array}{r}19 \\
10 \\
6 \\
13 \\
87 \\
-\end{array}$ & $\begin{array}{r}26 \\
-8 \\
20 \\
58\end{array}$ & $\begin{array}{r}57 \\
5 \\
2 \\
25 \\
59 \\
\end{array}$ & $\begin{array}{r}50 \\
-8 \\
-0 \\
-1\end{array}$ & $\begin{array}{r}52 \\
4 \\
2 \\
24 \\
80 \\
9\end{array}$ & $\begin{array}{r}37 \\
6 \\
34 \\
112 \\
73 \\
259\end{array}$ & $\begin{array}{r}5 \\
-1 \\
6 \\
54 \\
32\end{array}$ \\
\hline Topographic maps indexes & 60 & 64 & 48 & 37 & 30 & 61 & 16 \\
\hline Geologic Division ${ }^{2}$ & 119 & 315 & 320 & 215 & 229 & 285 & 71 \\
\hline Water Resources Division & 876 & 952 & 4,650 & 2,192 & 1,198 & 1,358 & 109 \\
\hline $\begin{array}{l}\text { Hydrologic maps } \\
\text { Flood-prone area maps }\end{array}$ & $\begin{array}{r}49 \\
827\end{array}$ & $\begin{array}{r}47 \\
905\end{array}$ & $\begin{array}{r}84 \\
4,566\end{array}$ & $\begin{array}{r}52 \\
2,140\end{array}$ & $\begin{array}{r}58 \\
1,140\end{array}$ & $\begin{array}{l}653 \\
705\end{array}$ & $\begin{array}{l}70 \\
39\end{array}$ \\
\hline Conservation Division ${ }^{3}$ & 17 & 10 & 8 & 9 & 5 & 14 & ----- \\
\hline Director's office ${ }^{3}$ & -....- & -...-- & 13 & 7 & 2 & 103 & 46 \\
\hline
\end{tabular}

1 Additional maps are produced for inclusion in book reports. 2 Geologic and geophysical maps.

3 Miscellaneous maps and charts.

TABLE 48.-Oil and gas operations on the Outer Continental Shelf lands, calendar years 1971-76

\begin{tabular}{|c|c|c|c|c|c|c|}
\hline Activity & 1971 & 1972 & 1973 & 1974 & 1975 & $\begin{array}{l}1976 \\
\text { (estimated) }\end{array}$ \\
\hline Number of exploration permits issued & 254 & 254 & 350 & 400 & 517 & 550 \\
\hline $\begin{array}{l}\text { Lease sales: } \\
\text { Number of sales } \\
\text { Tracts offered: }\end{array}$ & 1 & 2 & 6 & 5 & 4 & 4 \\
\hline $\begin{array}{l}\text { Number } \\
\text { Area (acres in thousands) }\end{array}$ & $\begin{array}{l}18 \\
56\end{array}$ & $\begin{array}{l}210 \\
971\end{array}$ & $\begin{array}{r}276 \\
1,515\end{array}$ & $\begin{array}{l}1,006 \\
5,006\end{array}$ & $\begin{array}{l}1,374 \\
7,248\end{array}$ & $\begin{array}{r}536 \\
2,827\end{array}$ \\
\hline $\begin{array}{l}\text { Tracts sold: } \\
\text { Number } \\
\text { Area (acres in thousands) } \\
\text { Percentage of tracts sold } \\
\text { Bonus (dollars in thousands) }\end{array}$ & $\begin{array}{r}11 \\
37 \\
61.1 \\
\$ 96,304\end{array}$ & $\begin{array}{r}178 \\
826 \\
84.8 \\
\$ 2,251,348\end{array}$ & $\begin{array}{r}187 \\
1,033 \\
67.8 \\
\$ 3,082,463\end{array}$ & $\begin{array}{r}356 \\
1,762 \\
35.4 \\
\$ 5,022,861\end{array}$ & $\begin{array}{r}321 \\
1,680 \\
23.4 \\
\$ 1,088,133\end{array}$ & $\begin{array}{r}241 \\
1,276 \\
45.9 \\
\$ 2,242,899\end{array}$ \\
\hline
\end{tabular}

See footnotes at end of table. 
TABLE 48.-Oil and gas operations on the Outer Continental Shelf lands, calendar years 1971-76-Continued

\begin{tabular}{|c|c|c|c|c|c|c|}
\hline Activity & 1971 & 1972 & 1973 & 1974 & 1975 & $\begin{array}{c}1976 \\
\text { (estimated) }\end{array}$ \\
\hline \multicolumn{7}{|l|}{ Status of leases: } \\
\hline Total number of leases supervised & 1,083 & 1,023 & 1,266 & 1,590 & 1,792 & 2,200 \\
\hline Total area (acres in thousands) & 4,603 & 4,339 & 5,614 & 7,247 & 8,322 & 10,300 \\
\hline Number of producing leases & 649 & 698 & 726 & 748 & 790 & 850 \\
\hline Area (acres in thousands) & 2,710 & 2,915 & 3,039 & 3,147 & 3,253 & 3,500 \\
\hline Percentage & 59.9 & 68.2 & 57.3 & 47.0 & 44.0 & 38.6 \\
\hline Number of non-producing leases & 434 & 325 & 540 & 842 & 1,002 & 1,350 \\
\hline Area (acres in thousands) & 1,893 & 1,424 & 2,575 & 4,100 & 5,069 & 6,800 \\
\hline Percentage & 40.1 & 31.8 & 42.7 & 53.0 & 56.0 & 61.4 \\
\hline \multicolumn{7}{|l|}{ Lease operations: } \\
\hline Number of platforms & 1,856 & 1,963 & 2,016 & 2,059 & 2,084 & 2,100 \\
\hline Number of new well starts & 841 & 847 & 820 & 816 & 892 & 900 \\
\hline Number of new wells completed & 407 & 338 & 420 & 310 & 392 & 405 \\
\hline Number of new zones completed & 640 & 496 & 600 & 398 & 515 & 520 \\
\hline Oil zones & 393 & 306 & 304 & 226 & 225 & $\overline{210}$ \\
\hline Gas zones & 240 & 180 & 288 & 155 & 277 & 295 \\
\hline Service zones & 7 & 10 & 8 & 17 & 13 & 15 \\
\hline Total number of completed wells & 5,718 & 6,032 & 6,421 & 6,218 & 6,104 & 5,990 \\
\hline Total number of completed zones & 9,348 & 9,716 & 10,187 & 8,750 & 9,074 & 9,465 \\
\hline Oil zones & 6,657 & 6,740 & 6,868 & 4,418 & 4,519 & 4,600 \\
\hline Gas zones & 2,474 & 2,680 & 2,987 & 2,403 & 2,765 & 3,110 \\
\hline Service zones & 217 & 296 & 332 & 416 & 325 & 340 \\
\hline Other zones ${ }^{1}$ & ----- & -.--n- & - - - - - & 1,513 & 1,465 & 1,415 \\
\hline Miles of pipeline under supervision & & & & & & \\
\hline (estimated) & 5,000 & 6,000 & 6,450 & 6,700 & 7,150 & 7,400 \\
\hline \multicolumn{7}{|l|}{ Production: } \\
\hline Oil and condensate (barrels in millions) _.-- & 419 & 412 & 395 & 361 & 330 & 310 \\
\hline Percentage of domestic production & 12.1 & 11.9 & 11.8 & 11.2 & 10.8 & 10.6 \\
\hline Gas (cubic feet in millions) & 2,777 & 3,038 & 3,212 & 3,515 & 3,459 & $3,36 ?$ \\
\hline Percentage of domestic production & 12.6 & 13.5 & 14.0 & 16.0 & 17.2 & 18. \\
\hline Gasoline and LPG (gallons in millions) & 1,551 & 1,737 & 1,635 & 2,032 & 1,983 & 1,920 \\
\hline Percentage of domestic production & 5.9 & 6.5 & 6.1 & 7.9 & 7.9 & 8.0 \\
\hline
\end{tabular}

${ }^{1}$ New classification since 1974.

TABLE 49.- Revenues from bases on Outer Continental Shelf lands, calendar years 1971-76 [Dollars in thousands]

\begin{tabular}{|c|c|c|c|c|c|c|}
\hline Source of revenue & 1971 & 1972 & 1973 & 1974 & 1975 & $\begin{array}{l}1976 \\
\text { (estimated: }\end{array}$ \\
\hline Total revenue & $\$ 456,012$ & $\$ 2,624,958$ & $\$ 3,494,981$ & $\$ 5,598,758$ & $\$ 1,723,325$ & $\$ 2,913,039$ \\
\hline Bonuses & 96,304 & $2,251,347$ & $3,082,462$ & $5,022,861$ & $1,088,133$ & $2,242,899$ \\
\hline Minimum royalties & $.1,891$ & 2,020 & 2,391 & 2,048 & 2,086 & 2,100 \\
\hline $\begin{array}{l}\text { Rentals } \\
\text { Number of accounts }\end{array}$ & $\begin{array}{l}7,742 \\
(735)\end{array}$ & $\begin{array}{r}7,985 \\
(529)\end{array}$ & $\begin{array}{r}8,949 \\
(647)\end{array}$ & $\begin{array}{l}13,533 \\
(1,036)\end{array}$ & $\begin{array}{l}17,522 \\
(1,203)\end{array}$ & $\begin{array}{l}21,000 \\
(1,430 ;\end{array}$ \\
\hline $\begin{array}{l}\text { Shut-in-gas payments } \\
\text { Totals: }\end{array}$ & 32 & 50 & 53 & 32 & 40 & 40 \\
\hline $\begin{array}{l}\text { Royalties } \\
\text { Production value } \\
\text { Number of accounts }\end{array}$ & $\begin{array}{r}350,042 \\
(2,135,677) \\
(754) \\
\end{array}$ & $\begin{array}{r}363,556 \\
(2,229,179) \\
(912) \\
\end{array}$ & $\begin{array}{r}401,126 \\
(2,486,865) \\
(1,158) \\
\end{array}$ & $\begin{array}{r}560,284^{1} \\
(3,570,054)^{1} \\
(2,260)^{1}\end{array}$ & $\begin{array}{r}615,545 \\
(3,924,915) \\
(2,468) \\
\end{array}$ & $\begin{array}{r}647,000 \\
(4,102,000 \\
(2,850 \\
\end{array}$ \\
\hline $\begin{array}{l}\text { Oil and condensate: } \\
\text { Royalties } \\
\text { Production value }\end{array}$ & $\begin{array}{c}253,229 \\
(1,481,681)\end{array}$ & $\begin{array}{c}247,689 \\
(1,453,968)\end{array}$ & $\begin{array}{c}271,491 \\
(1,620,732)\end{array}$ & $\begin{array}{c}384,367 \\
(2,398,794)\end{array}$ & $\begin{array}{c}399,527 \\
(2,428,849)\end{array}$ & $\begin{array}{r}401,000 \\
(2,459,000\end{array}$ \\
\hline $\begin{array}{l}\text { Gas: } \\
\text { Royalties } \\
\text { Production value }\end{array}$ & $\begin{array}{c}87,406 \\
(549,648)\end{array}$ & $\begin{array}{c}105,892 \\
(663,648)\end{array}$ & $\begin{array}{c}118,245 \\
(736,878)\end{array}$ & $\begin{array}{c}142,257 \\
(881,634)\end{array}$ & $\begin{array}{c}195,198 \\
(1,205,678)\end{array}$ & $\begin{array}{r}228,000 \\
(1,409,000\end{array}$ \\
\hline
\end{tabular}


TABLE 49.-Revenues from bases on Outer Continental Shelf lands, calendar years 1971-76-Continued

\begin{tabular}{|c|c|c|c|c|c|c|}
\hline Source of revenue & 1971 & 1972 & 1973 & 1974 & 1975 & $\begin{array}{c}1976 \\
\text { (estimated) }\end{array}$ \\
\hline \multicolumn{7}{|l|}{ Gasoline and LPG: } \\
\hline $\begin{array}{l}\text { Royalties } \\
\text { Production value }\end{array}$ & $\begin{array}{c}5,944 \\
(80,563)\end{array}$ & $\begin{array}{c}6,525 \\
(89,214)\end{array}$ & $\begin{array}{c}7,768 \\
(105,437)\end{array}$ & $\begin{array}{c}19,797 \\
(254,744)\end{array}$ & $\begin{array}{c}16,376 \\
(216,043)\end{array}$ & $\begin{array}{r}18,000 \\
(234,000)\end{array}$ \\
\hline \multicolumn{7}{|l|}{ Salt: } \\
\hline $\begin{array}{l}\text { Royalties } \\
\text { Production value }\end{array}$ & $\begin{array}{c}11 \\
(67)\end{array}$ & $\begin{array}{c}11 \\
(65)\end{array}$ & $\begin{array}{c}11 \\
(69)\end{array}$ & $\begin{array}{c}10 \\
(62)\end{array}$ & $\begin{array}{c}8 \\
(54)\end{array}$ & 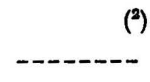 \\
\hline \multicolumn{7}{|l|}{ Sulfur: } \\
\hline $\begin{array}{l}\text { Royalties } \\
\text { Production value }\end{array}$ & $\begin{array}{c}3,452 \\
(23,718)\end{array}$ & $\begin{array}{c}3,439 \\
(22,287)\end{array}$ & $\begin{array}{r}3,611 \\
(23,749)\end{array}$ & $\begin{array}{c}3,853 \\
(34,820)\end{array}$ & $\begin{array}{c}3,738 \\
(69,738)\end{array}$ & $\left({ }^{2}\right)$ \\
\hline
\end{tabular}

1 Includes $\$ 3,950,000$ of lost oil and gas.

2 Productive leases transferred to Louisiana by Supreme Court decree

of June 16, 1975.

TABLE 50.-Oil, gas, and geothermal operations on Federal and Indian lands, calendar years 1971-76

\begin{tabular}{|c|c|c|c|c|c|c|}
\hline Activity & 1971 & 1972 & 1973 & 1974 & 1975 & $\begin{array}{c}1976 \\
\text { (estimated) }\end{array}$ \\
\hline \multicolumn{7}{|l|}{$\begin{array}{l}\text { Competitive oil and gas lease sales: } \\
\text { Federal lands: }\end{array}$} \\
\hline \multicolumn{7}{|l|}{ Tracts offered: } \\
\hline Number of tracts & 418 & 464 & 339 & 421 & 420 & 480 \\
\hline Area acres & 121,962 & 130,546 & 86,681 & 98,064 & 102,397 & 96,900 \\
\hline \multicolumn{7}{|l|}{ Tracts sold: } \\
\hline Number of tracts & 206 & 279 & 311 & 295 & 356 & 460 \\
\hline Area acres & 52,102 & 88,326 & 89,315 & 65,247 & 92,967 & 87,600 \\
\hline Percentage of tracts sold & 49.3 & 60.1 & 91.7 & 70.1 & 84.8 & 95.8 \\
\hline Bonus (dollars in thousands) & $\$ 1,163$ & $\$ 1,118$ & $\$ 2,203$ & $\$ 2,296$ & $\$ 6,399$ & $\$ 6,710$ \\
\hline \multicolumn{7}{|l|}{ Status of oil and gas leases: } \\
\hline Total number of leases supervised & 112,784 & 113,158 & 115,761 & 123,652 & 125,720 & 125,900 \\
\hline Total area (acres in thousands) & 70,628 & 75,213 & 79,116 & 89,829 & 93,717 & 94,425 \\
\hline Number of producing leases & 11,285 & 11,640 & 11,953 & 12,386 & 12,961 & 13,400 \\
\hline Area (acres in thousands) & 5,629 & 5,741 & 5,902 & 6,349 & 6,564 & 6,700 \\
\hline Percentage & 10.0 & 10.3 & 10.3 & 10.0 & 10.3 & 10.6 \\
\hline Number of non-producing leases & 101,499 & 101,518 & 103,808 & 111,266 & 112,759 & 112,500 \\
\hline Area (acres in thousands) & 64,999 & 69,472 & 73,214 & 83,480 & 84,153 & 87,725 \\
\hline Percentage & 90.0 & 89.7 & 89.7 & 90.0 & 89.7 & 89.4 \\
\hline \multicolumn{7}{|l|}{ Oil and gas lease operations: } \\
\hline Number of new well starts & 1,651 & 1,956 & 1,848 & 2,312 & 2,277 & 1,830 \\
\hline Number of new wells completed & 883 & 1,045 & 1,132 & 1,280 & 1,569 & 1,215 \\
\hline Number of new zones completed & 907 & 1,081 & 1,172 & 1,341 & 1,646 & 1,234 \\
\hline Oil zones --1- & 589 & 660 & 507 & 701 & 923 & 761 \\
\hline Gas zones & 271 & 374 & 601 & 579 & 606 & 420 \\
\hline Service zones & 47 & 47 & 64 & 61 & 117 & 53 \\
\hline Total number of completed wells & 36,936 & 37,441 & 38,199 & 38,372 & 38,218 & 37,465 \\
\hline Total number of completed zones & 38,686 & 39,159 & 39,991 & 40,251 & 40,292 & 39,374 \\
\hline Oil zones & 23,366 & 23,282 & 23,139 & 22,791 & 21,868 & 21,034 \\
\hline Gas zones & 10,159 & 10,421 & 11,083 & 11,487 & 12,272 & 12,203 \\
\hline Service zones - & 5,161 & 5,456 & 5,769 & 5,973 & 6,152 & 6,137 \\
\hline \multicolumn{7}{|l|}{ Oil and gas production: } \\
\hline Oil and condensate (barrels in millions) & 228 & 217 & 208 & 208 & 200 & 192 \\
\hline Percentage of domestic production & 6.6 & 6.3 & 6.2 & 6.4 & 6.3 & 6.6 \\
\hline Gas (cubic feet in billions) & 1,173 & 1,124 & 1,153 & 1,234 & 1,111 & 1,200 \\
\hline Percentage of domestic production & 5.2 & 5.0 & 5.1 & 5.6 & 5.3 & 6.3 \\
\hline Gasoline and LPG (gallons in millions) & 713 & 641 & 669 & 567 & 521 & 450 \\
\hline Percentage of domestic production & 2.7 & 2.4 & 2.5 & 2.2 & 2.1 & 1.9 \\
\hline \multicolumn{7}{|l|}{ Status of geothermal leases: } \\
\hline Total number of leases in effect & $-\ldots--$ & -..--- & ----- & ----- & 552 & 800 \\
\hline Total area (acres in thousands) & ------ & -.....- & -...-- & -..--- & $1 ; 270$ & 1,704 \\
\hline
\end{tabular}


TABLE 51.-Royalties from oil and gas leases on Federal and Indian lands, calendar years 1971-76

[Dollars in thousands]

\begin{tabular}{|c|c|c|c|c|c|c|}
\hline Commodity & 1971 & 1972 & 1973 & 1974 & 1975 & $\begin{array}{c}1976 \\
\text { (estimated) }\end{array}$ \\
\hline $\begin{array}{l}\text { Total royalties } \\
\text { Total production value }\end{array}$ & $\begin{array}{l}\$ 115,997 \\
(938,276)\end{array}$ & $\begin{array}{l}\$ 115,204 \\
(918,360)\end{array}$ & $\begin{array}{c}\$ 134,568 \\
(1,074,758)\end{array}$ & $\begin{array}{c}\$ 219,630 \\
(1,728,536)\end{array}$ & $\begin{array}{c}\$ 245,345 \\
(1,915,768)\end{array}$ & $\begin{array}{c}\$ 266,200 \\
(2,067,200)\end{array}$ \\
\hline $\begin{array}{l}\text { Oil and condensate: } \\
\text { Royalties } \\
\text { Production value }\end{array}$ & $\begin{array}{c}90,753 \\
(714,767)\end{array}$ & $\begin{array}{r}87,594 \\
(678,085)\end{array}$ & $\begin{array}{c}100,963 \\
(783,149)\end{array}$ & $\begin{array}{c}176,566 \\
(1,349,656)\end{array}$ & $\begin{array}{c}193,608 \\
(1,459,088)\end{array}$ & $\begin{array}{c}197,500 \\
(1,486,000)\end{array}$ \\
\hline $\begin{array}{l}\text { Gas: } \\
\text { Royalties } \\
\text { Production value }\end{array}$ & $\begin{array}{c}23,449 \\
(187,032)\end{array}$ & $\begin{array}{c}25,905 \\
(206,625)\end{array}$ & $\begin{array}{c}31,263 \\
(248,768)\end{array}$ & $\begin{array}{c}39,798 \\
(315,490)\end{array}$ & $\begin{array}{c}47,508 \\
(374,785)\end{array}$ & $\begin{array}{c}65,000 \\
(515,000)\end{array}$ \\
\hline $\begin{array}{l}\text { Gasoline and LPG: } \\
\text { Royalties } \\
\text { Production value }\end{array}$ & $\begin{array}{c}1,771 \\
(35,921)\end{array}$ & $\begin{array}{c}1,686 \\
(33,226)\end{array}$ & $\begin{array}{c}2,323 \\
(42,398)\end{array}$ & $\begin{array}{r}3,238 \\
(62,758)\end{array}$ & $\begin{array}{r}3,789 \\
(76,632)\end{array}$ & $\begin{array}{c}2,800 \\
(61,400)\end{array}$ \\
\hline $\begin{array}{l}\text { All others: } \\
\text { Royalties } \\
\text { Production value }\end{array}$ & $\begin{array}{c}24 \\
(556)\end{array}$ & $\begin{array}{c}19 \\
(424)\end{array}$ & $\begin{array}{c}19 \\
(443)\end{array}$ & $\begin{array}{c}28 \\
(632)\end{array}$ & $\begin{array}{c}440 \\
(5,263)\end{array}$ & $\begin{array}{c}900 \\
(4,800)\end{array}$ \\
\hline
\end{tabular}

TABLE 52.-Mining operations on Federal and Indian lands by commodity, fiscal years 1971-76 and transition quarter

\begin{tabular}{|c|c|c|c|c|c|c|c|}
\hline Activity and commodity & 1971 & 1972 & 1973 & 1974 & 1975 & 1976 & $\begin{array}{l}\text { Transition } \\
\text { quarter }\end{array}$ \\
\hline Total number of leases supervised _ & 2,566 & 2,647 & 2,579 & 2,488 & 2,479 & 2,557 & 2,575 \\
\hline Total area (acres in thousands) & 5,873 & 5,924 & 7,566 & 7,830 & 7,977 & 9,096 & 9,167 \\
\hline $\begin{array}{l}\text { Total number of producible mines }- \\
\text { Total commodity production (tons }\end{array}$ & 405 & 343 & 338 & 377 & 435 & 450 & 450 \\
\hline in thousands) & 36,101 & 39,004 & 42,028 & 54,978 & 76,113 & 81,554 & 21,000 \\
\hline \multicolumn{8}{|l|}{ Coal: } \\
\hline Number of leases supervised & 558 & 560 & 561 & 563 & 565 & 570 & 573 \\
\hline Area (acres in thousands) & 903 & 934 & 1,038 & 977 & 1,023 & 1,057 & 1,060 \\
\hline Production (tons in thousands) & 17,263 & 18,966 & 24,247 & 32,139 & 43,590 & 52,491 & 14,000 \\
\hline Percentage of domestic production & 3.1 & 3.2 & 4.1 & 5.4 & 7.2 & 7.9 & 8.5 \\
\hline \multicolumn{8}{|l|}{ Phosphate: } \\
\hline Number of leases supervised & 243 & 226 & 219 & 194 & 194 & 279 & 280 \\
\hline Area (acres in thousands) & 145 & 136 & 131 & 100 & 100 & 114 & 114 \\
\hline Production (tons in thousands) & 3,256 & 3,124 & 3,156 & 6,258 & 5,772 & 6,937 & 1,500 \\
\hline Percentage of domestic production & 8.4 & 7.7 & 7.4 & 14.0 & 11.8 & 13.9 & 12.0 \\
\hline \multicolumn{8}{|l|}{ Potash: } \\
\hline Number of leases supervised & 159 & 164 & 163 & 158 & 161 & 163 & 163 \\
\hline Area (acres in thousands) & 250 & 249 & 246 & 238 & 237 & 237 & 237 \\
\hline Production (tons in thousands) ${ }^{1}$ & 3,913 & 3,345 & 3,442 & 3,551 & 3,302 & 3,576 & 1,000 \\
\hline Percentage of domestic production ------. & 81.6 & 72.0 & 75.5 & 79.2 & 87.8 & 81.3 & 83.0 \\
\hline \multicolumn{8}{|l|}{ Sodium: } \\
\hline Number of leases supervised & 91 & 87 & 84 & 84 & 84 & 89 & 90 \\
\hline Area (acres in thousands) & 138 & 133 & 132 & 132 & 132 & 136 & 138 \\
\hline Production (tons in thousands) & 2,230 & 2,606 & 2,336 & 2,092 & 2,826 & 3,311 & 950 \\
\hline Percentage of domestic production & $\quad 62.5$ & 66.5 & 50.5 & 45.4 & 58.9 & 69.2 & 79.4 \\
\hline \multicolumn{8}{|l|}{ Oil shale: } \\
\hline Number of leases supervised & ------ & ------ & ------ & 4 & 4 & 4 & 4 \\
\hline Area (acres in thousands) & ---- & ----- & ----- & 20.4 & 20.4 & 20.4 & $20 .+3$ \\
\hline Production (tons in thousands) & ----- & ----- & ----- & ----- & $--\cdots-$ & ---- & ----- \\
\hline \multicolumn{8}{|l|}{ Other: } \\
\hline Number of leases supervised & 1,515 & 1,610 & 1,552 & 1,485 & 1,471 & 1,452 & 1,465 \\
\hline Area (acres in thousands) & 4,437 & 4,472 & 6,019 & 6,363 & 6,465 & 7,532 & 7,598 \\
\hline Production (tons in thousands) & 9,439 & 10,963 & 8,847 & 10,938 & 20,623 & 15,239 & 3,550 \\
\hline
\end{tabular}

1 Converted to refined tons, 1976 estimated in part. 
TABLE 53.- Revenues from mining leases on Federal and Indian lands by commodity, fiscal years 1971-76 and transition quarter [Dollars in thousands; detail may not add to totals because of rounding]

\begin{tabular}{|c|c|c|c|c|c|c|c|}
\hline Commodity & 1971 & 1972 & 1973 & 1974 & 1975 & $1976^{2}$ & $\begin{array}{c}\text { Transition } \\
\text { quarter } \\
\text { (estimated) }\end{array}$ \\
\hline Total revenue & $\$ 21,851$ & $\$ 14,841$ & $\$ 16,484$ & $\$ 470,464$ & $\$ 31,596$ & $\$ 36,479$ & $\$ 11,012$ \\
\hline $\begin{array}{l}\text { Bonuses } \\
\text { Total royalties } \\
\text { Total production value }-\end{array}$ & $\begin{array}{r}7,627 \\
14,224 \\
(293,983) \\
\end{array}$ & $\begin{array}{c}-14, \overline{841} \\
(301,665) \\
\end{array}$ & $\begin{array}{r}34 \\
16,450 \\
(335,282) \\
\end{array}$ & $\begin{array}{c}449,192^{1} \\
21,272 \\
(463,811) \\
\end{array}$ & $\begin{array}{r}4 \\
31,560 \\
(681,281)\end{array}$ & $\begin{array}{r}50 \\
36,429 \\
(813,221) \\
\end{array}$ & $\begin{array}{r}12 \\
11,000 \\
(240,000) \\
\end{array}$ \\
\hline $\begin{array}{l}\text { Coal: } \\
\text { Royalties } \\
\text { Production value } \\
\text { Phosphate: }\end{array}$ & $\begin{array}{r}2,654 \\
(70,552)\end{array}$ & $\begin{array}{r}3,119 \\
(78,256)\end{array}$ & $\begin{array}{r}4,044 \\
(93,307)\end{array}$ & $\begin{array}{r}5,535 \\
(140,307)\end{array}$ & $\begin{array}{c}8,335 \\
(224,947)\end{array}$ & $\begin{array}{c}10,949 \\
(337,312)\end{array}$ & $\begin{array}{c}3,000 \\
(97,000)\end{array}$ \\
\hline $\begin{array}{l}\text { Royalties } \\
\text { Production value } \\
\text { Potash: }\end{array}$ & $\begin{array}{r}838 \\
(9,669)\end{array}$ & $\begin{array}{r}811 \\
(9,674)\end{array}$ & $\begin{array}{r}842 \\
(11,314)\end{array}$ & $\begin{array}{c}1,618 \\
(31,158)\end{array}$ & $\begin{array}{c}\cdot 1,538 \\
(28,383)\end{array}$ & $\begin{array}{c}1,868 \\
(25,769)\end{array}$ & $\begin{array}{c}500 \\
(6,000)\end{array}$ \\
\hline $\begin{array}{l}\text { Royalties } \\
\text { Production value } \\
\text { Sodium: }\end{array}$ & $\begin{array}{r}3,695 \\
(83,521)\end{array}$ & $\begin{array}{r}3,104 \\
(72,227)\end{array}$ & $\begin{array}{r}3,270 \\
(75,872)\end{array}$ & $\begin{array}{c}3,962 \\
(96,897)\end{array}$ & $\begin{array}{r}5,565 \\
(132,518)\end{array}$ & $\begin{array}{c}6,321 \\
(144,693)\end{array}$ & $\begin{array}{c}1,800 \\
(40,000)\end{array}$ \\
\hline $\begin{array}{l}\text { Royalties } \\
\text { Production value }- \\
\text { Copper: }\end{array}$ & $\begin{array}{c}1,960 \\
(47,680)\end{array}$ & $\begin{array}{r}2,531 \\
(59,728)\end{array}$ & $\begin{array}{c}2,547 \\
(58,179)\end{array}$ & $\begin{array}{c}2,439 \\
(56,240)\end{array}$ & $\begin{array}{c}5,046 \\
(109,590)\end{array}$ & $\begin{array}{c}7,364 \\
(155,612)\end{array}$ & $\begin{array}{c}2,600 \\
(51,000)\end{array}$ \\
\hline $\begin{array}{l}\text { Copper: } \\
\text { Royalties } \\
\text { Production value } \\
\text { Fluospar: }\end{array}$ & $\begin{array}{c}198 \\
(4,137)\end{array}$ & $\begin{array}{c}153 \\
(2,995)\end{array}$ & $\begin{array}{c}158 \\
(2,691)\end{array}$ & $\begin{array}{c}563 \\
(6,087)\end{array}$ & $\begin{array}{c}1,331 \\
(7,140)\end{array}$ & $\begin{array}{c}1,328 \\
(7,347)\end{array}$ & $\begin{array}{c}328 \\
(1,750)\end{array}$ \\
\hline $\begin{array}{l}\text { Royalties } \\
\text { Production value }\end{array}$ & $\begin{array}{c}40 \\
(485)\end{array}$ & $\begin{array}{c}70 \\
(698)\end{array}$ & $\begin{array}{c}86 \\
(865)\end{array}$ & $\begin{array}{c}31 \\
(322)\end{array}$ & ----- & $\begin{array}{c}11 \\
(180)\end{array}$ & $\begin{array}{c}5 \\
(100)\end{array}$ \\
\hline $\begin{array}{l}\text { Lead and zinc: } \\
\text { Royalties } \\
\text { Production value }\end{array}$ & $\begin{array}{c}1,765 \\
(44,017)\end{array}$ & $\begin{array}{r}1,695 \\
(42,195)\end{array}$ & $\begin{array}{r}2,192 \\
(54,640)\end{array}$ & $\begin{array}{c}3,241 \\
(75,319)\end{array}$ & $\begin{array}{r}5,109 \\
(115,340)\end{array}$ & $\begin{array}{c}3,677 \\
(81,564)\end{array}$ & $\begin{array}{r}950 \\
(22,000)\end{array}$ \\
\hline $\begin{array}{l}\text { Limestone: } \\
\quad \text { Royalties } \\
\quad \text { Production value }\end{array}$ & $\begin{array}{c}4 \\
(75)\end{array}$ & $\begin{array}{c}3 \\
(20)\end{array}$ & $\begin{array}{c}4 \\
(54)\end{array}$ & $\begin{array}{c}6 \\
(86)\end{array}$ & $\begin{array}{c}10 \\
(83)\end{array}$ & - & --- \\
\hline $\begin{array}{l}\text { Sand and gravel: } \\
\text { Royalties } \\
\text { Production value }\end{array}$ & $\begin{array}{r}614 \\
(6,879)\end{array}$ & $\begin{array}{r}886 \\
(9,713)\end{array}$ & $\begin{array}{c}623 \\
(6,846)\end{array}$ & $\begin{array}{c}633 \\
(7,430)\end{array}$ & $\begin{array}{c}842 \\
(18,774)\end{array}$ & $\begin{array}{c}505 \\
(12,431)\end{array}$ & $\begin{array}{c}125 \\
(3,200)\end{array}$ \\
\hline $\begin{array}{l}\text { Silica-pumice: } \\
\text { Royalties } \\
\text { Production value }\end{array}$ & ----- & ----- & $\begin{array}{c}1 \\
(14)\end{array}$ & ----- & ----- & ----- & ---- \\
\hline $\begin{array}{l}\text { Uranium: } \\
\quad \text { Royalties } \\
\quad \text { Production value }\end{array}$ & $\begin{array}{c}2,176 \\
(18,370)\end{array}$ & $\begin{array}{c}2,205 \\
(18,394)\end{array}$ & $\begin{array}{c}2,303 \\
(18,822)\end{array}$ & $\begin{array}{c}2,224 \\
(22,014)\end{array}$ & $\begin{array}{c}2,664 \\
(16,938)\end{array}$ & $\begin{array}{c}3,191 \\
(23,912)\end{array}$ & $\begin{array}{c}800 \\
(6,000)\end{array}$ \\
\hline $\begin{array}{l}\text { Zinc: } \\
\quad \text { Royalties } \\
\quad \text { Production value }-1.0\end{array}$ & $\begin{array}{c}206 \\
(5,119)\end{array}$ & $\begin{array}{c}214 \\
(5,219)\end{array}$ & $\begin{array}{c}336 \\
(8,207)\end{array}$ & $\begin{array}{c}936 \\
(22,806)\end{array}$ & $\begin{array}{c}1,006 \\
(24,413)\end{array}$ & $\begin{array}{r}1,001 \\
(22,240)\end{array}$ & $\begin{array}{r}350 \\
(8,000)\end{array}$ \\
\hline $\begin{array}{l}\text { Other: } \\
\quad \text { Royalties } \\
\text { Production value }\end{array}$ & $\begin{array}{c}75 \\
(3,478)\end{array}$ & $\begin{array}{c}50 \\
(2,546)\end{array}$ & $\begin{array}{r}42 \\
(4,490)\end{array}$ & $\begin{array}{c}84 \\
(5,146)\end{array}$ & $\begin{array}{r}56 \\
(3,155)\end{array}$ & $\begin{array}{c}214 \\
(2,161)\end{array}$ & $\begin{array}{c}542 \\
(4,950)\end{array}$ \\
\hline
\end{tabular}

1 Includes bonuses of $\$ 448,797,000$ from four competitive oil-shale

lease sales.
21976 estimated in part.

TABLE 54.- Information products ordered from the EROS Data Center, fiscal years 1974-76 and transition quarter [Dollars in thousands] ${ }^{1}$

\begin{tabular}{|c|c|c|c|c|c|c|c|c|c|}
\hline \multirow[b]{2}{*}{ Product } & \multicolumn{2}{|c|}{1974} & \multicolumn{2}{|c|}{1975} & \multicolumn{2}{|c|}{1976} & \multicolumn{3}{|c|}{ Transition quarter } \\
\hline & Images & Value & Images & Value & Images & Value & Images. & & Value \\
\hline Totals _..... & 284,097 & 837 & 414,084 & $\$ 1,610$ & 407,395 & $\$ 2,589$ & 104,414 & $\$$ & 718 \\
\hline Landsat images & $157, \overline{178}$ & 529 & 195,125 & 760 & 246,449 & 1,238 & 50,804 & & 274 \\
\hline Landsat computer-compatible data tapes & 228 & 36 & 879 & 169 & 2,289 & 404 & 1,010 & & 178 \\
\hline Gemini, Apollo, and Skylab images and photo- & & & & & & & & & \\
\hline graphs & 17,201 & 34 & 28,049 & 113 & 9,664 & 86 & 1,405 & & 15 \\
\hline Aerial photographs & 109,490 & 237 & 190,031 & 567 & 148,993 & 735 & 51,195 & & 221 \\
\hline Miscellaneous custom and special products _- & ------ & ---- & ------ & ----- & ----- & 125 &.---- & & 30 \\
\hline
\end{tabular}

1 Dollar amounts may not total due to rounding. 
TABLE 55.-U.S. Geological Survey Library Operating Statistics, fiscal years $1971-76^{1}$ and transition quarter [N.A., not applicable]

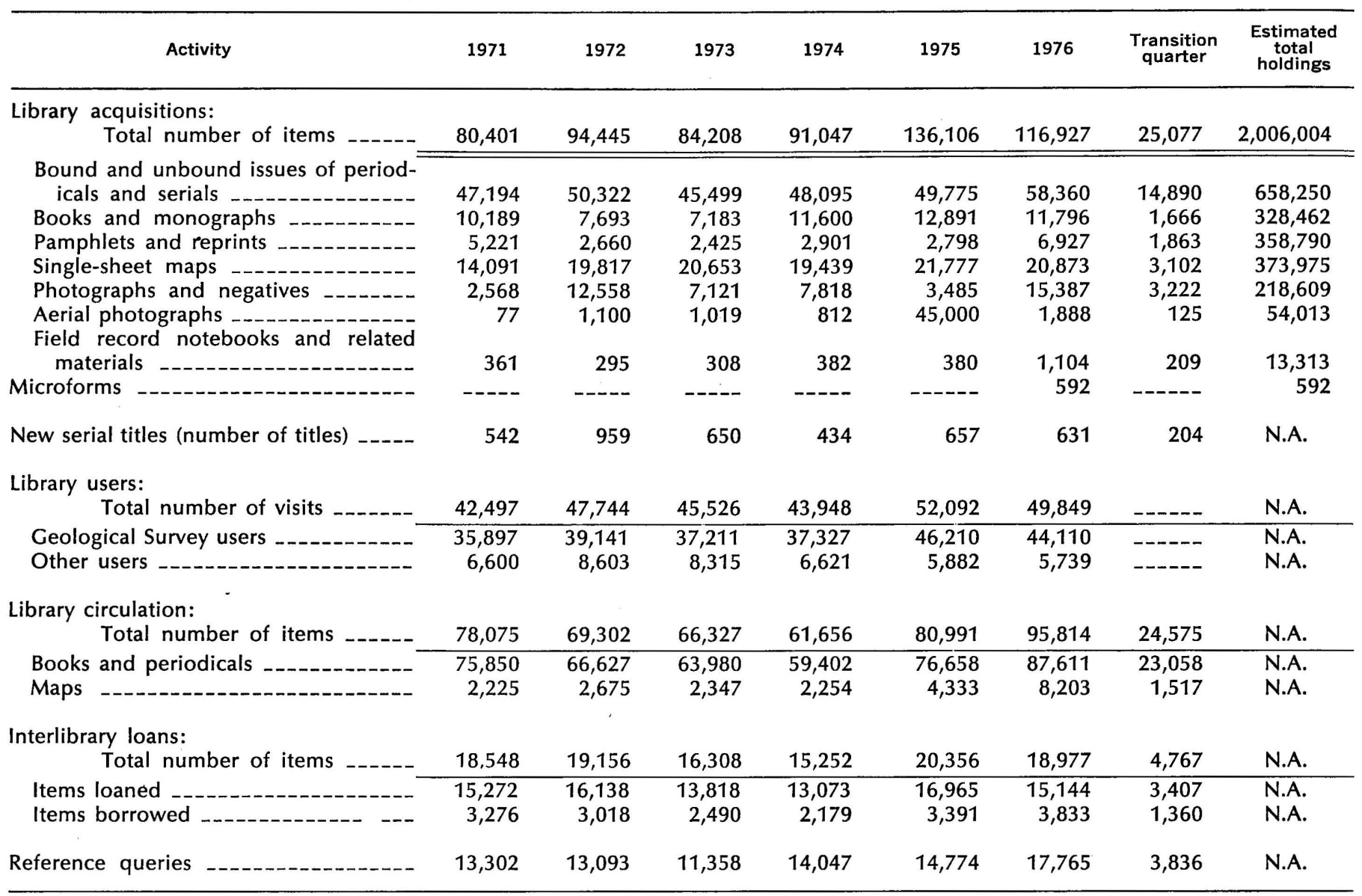

1 Statistics include the operations of the Survey's main library in Reston, Va., and branch libraries in Denver, Colo., Menlo Park, Calif., and Flagstaff, Ariz. 




\title{
UNITED STATES DEPARTMENT OF THE INTERIOR
}

\author{
Cecil D. Andrus, Secretary
}

\section{GEOLOGICAL SURVEY}

\section{E. McKelvey, Director}

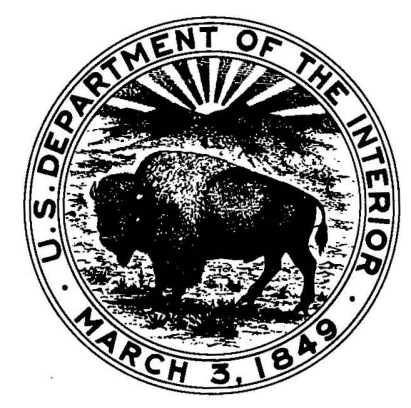

For sale by the Superintendent of Documents U.S. Government Printing Office

Washington, D.C. 20402

STOCK NUMBER 024-001-02952-9 


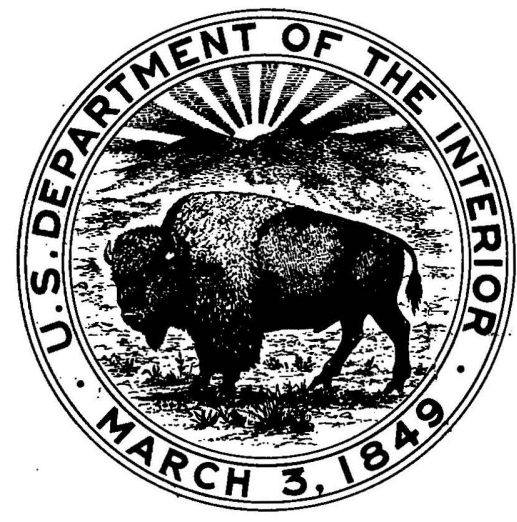

As the Nation's principal conservation agency, the Department of the Interior has responsibility for most of our nationally owned public lands and natural resources. This includes fostering the wisest use of our land and water resources, protecting our fish and wildlife, preserving the environmental and cultural values of our national parks and historical places, and providing for the enjoyment of life through outdoor recreation. The Department assesses our energy and mineral resources and works to assure that their development is in the best interest of all our people. The Department also has a major responsibility for American Indian reservation communities and for people who live in Island Territories under U.S. Administration.

On the cover: USGS Building I, housing offices of the Administrative and Geologic Divisions, in Menlo Park, California. 





